\begin{abstract}
SUMNER, JACLYN PATRICIA. Methods to Evaluate Normal Rainfall for Short-Term Wetland Hydrology Assessment (Under the direction of Dr. Michael J. Vepraskas).

It is assumed, but not proven, that wetland hydrology can be evaluated with single-season measurements of water table data, if antecedent rainfall is within a normal or drier than normal range. Four methods of rainfall analysis were compared to longterm records of water table levels to determine which method could be used to identify sites with wetland hydrology. Water tables were simulated by DRAINMOD for two sites in NC and collected manually for one site in MN. Single years from 40 to 45 years of long-term water table data records were evaluated and compared with results from longterm records. Plots with wetland hydrology had a water table within $30 \mathrm{~cm}$ of the surface, during the growing season, in at least half the years. Years meeting wetland hydrology were identified for each site.
\end{abstract}

Normal rainfall was determined by using the $30^{\text {th }}$ and $70^{\text {th }}$ percentiles obtained from a WETS data set for the nearest available weather stations. The first two methods computed a 30-day moving rainfall total that was compared with a normal range of rainfall values obtained from the WETS data. The remaining two methods used a 3month period of antecedent rainfall approach along with the WETS data to determine whether a given period had a normal range of rainfall.

Wetland hydrology was met in over $90 \%$ of the years in the long-term records at all sites. For single-year data, the moving total methods provided the correct conclusion in less than $45 \%$ of the years that met wetland hydrology. The direct antecedent rainfall 
evaluation method (DAREM) approaches, which used rainfall for the prior 3-month period, correctly identified plots with wetland hydrology in over $80 \%$ of the years. In the majority of cases when wetland hydrology was satisfied in $90 \%$ of the long-term data, single-season data can used to identify wetland hydrology and no more than two years of measurement will be needed to reach a correct conclusion. However, this is not the case for sites that only satisfy the wetland hydrology requirement in $60-75 \%$ of the years. These plots would have to be analyzed for longer periods. Also, there may be plots that have significant periods of drought or wetness and it is imperative to study surrounding plots at the research site to obtain the overall wetland hydrology for the site. 


\title{
METHODS TO EVALUATE NORMAL RAINFALL FOR SHORT- TERM WETLAND HYDROLOGY ASSESSMENT
}

By

\section{JACLYN PATRICIA SUMNER}

\author{
A thesis submitted to the Graduate Faculty of \\ North Carolina State University \\ In partial fulfillment of the \\ Requirements for the Degree of \\ Master of Science
}

SOIL SCIENCE

Raleigh, NC

2006

APPROVED BY:

Dr. Michael J. Vepraskas

Chair of Advisory Committee
Dr. Randall K. Kolka

Member of Advisory Committee
Dr. David L. Lindbo

Member of Advisory Committee
Dr. R. Wayne Skaggs

Minor Representative 


\section{BIOGRAPHY}

Jaclyn P. Sumner was born May 15, 1981 to Kenneth and Judith Sumner. Both parents grew up in the city of Waltham, MA. Her father received his B.S. in Accounting from Bentley College in 1965 and is currently working as a Certified Public Accountant in Waltham, MA. Her mother works in the Waltham school systems as a teaching assistant for special needs young adults. She has two older sisters and one older brother that all have obtained B.A. degrees in Communications. Along with her parents, her siblings all reside in Massachusetts with their families and all currently hold jobs in the communications field.

Jaclyn spent the first 18 years of her life in Waltham, MA. She graduated high school in 1999 and then moved to Selinsgrove, PA to enroll at Susquehanna University in the fall of 1999. She then began working towards her B.S. in Geology and Environmental Science with an emphasis in Hydrology. Through her time at Susquehanna University, she served as President of the Geology club and a member of Geology honor society, Sigma Gamma Epsilon. She also worked with Dr. Daniel E. Ressler on an undergraduate research thesis, in which she studied the use of soil microbial communities as wetland indicators.

After graduating with Departmental Honors in 2003, Jaclyn went on to pursue her M.S. degree in Soil Science at North Carolina State University under the direction of Dr. James A. Thompson. However, due to unforeseen circumstances, Dr. Thompson left the department and she pursued her M.S. under the direction of Dr. Michael J. Vepraskas. 
While there, she worked on determining most accurate methods to evaluate normal rainfall for short-term wetland hydrology assessment.

\section{ACKNOWLEDGEMENTS}

This work is a product of the United States Department of Agriculture Forest Service through N.C. State University, Raleigh.

I would like to thank first my committee chair, Dr. Michael J. Vepraskas. I had first contacted Dr. Vepraskas before entering the graduate program at NCSU because I was interested in his work with wetland soils. His wetland soils class was one of my favorites in the graduate program. Although he was not my initial committee chair, he stepped into the role nicely and has helped me achieve my goals in this program.

I would also like to thank Dr. Randy Kolka, who had so generously decided to fund my original project with Dr. Thompson as well as my work under Dr. Vepraskas. He has been a great resource and help throughout my time at NCSU. Without his continuous help and data contributions, this project would not be the same. Even though he is located in Minnesota, he has always been available through the phone or email, which has made him become like a second advisor to me.

I would also like to thank Dr. David Lindbo. His constant optimistic and friendly views have kept me motivated and excited about my research. He has been a good professor and a good friend. He has given me great advice, as well as posed questions about my research that have been very thought provoking. It is always good to see him and know that he is always going to be supportive, no matter what the situation is.

I would also like to thank Dr. R. Wayne Skaggs. Although I have not spent a lot of time with him, his work on DRAINMOD has greatly impacted my research and has 
also made me think about other options that are available to evaluate wetland hydrology. His dedication and passion to his field serves as inspiration for all of his students.

I would also like to thank fellow graduate students Dr. Xiaoxia He, Erik Severson and Heather Smith for contributing data and DRAINMOD simulations that helped make my project possible.

To my good friends Laura, Sheri and Scott, who have been here for me through a lot of hard times and good times through my time at NCSU. My strength as a graduate student and person is due in large part to the friendships that I have developed here in the Soil Science department. We have discussed our research projects on a number of occasions and I leave not only knowing a great deal about my own topic, but theirs as well.

Finally I would like to thank the staff of the Soil Science department for helping with all things related to the program, finances and other miscellaneous issues that arose during my time at NCSU. I would like to thank Roberta Miller-Haraway for all her help with formatting and hard work. I am extremely grateful to her for her help during a very stressful time. I especially want to thank them for being understanding and supportive through the transition of changing advisors. 


\section{TABLE OF CONTENTS}

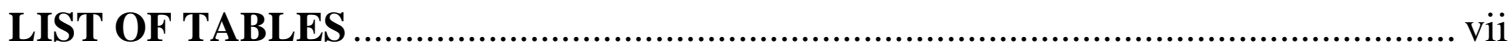

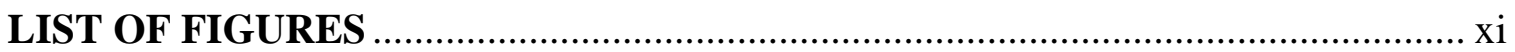

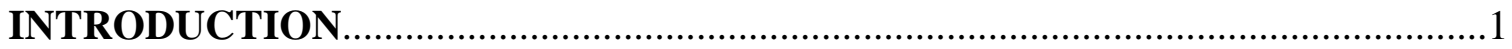

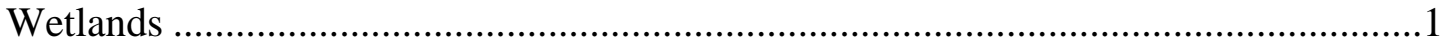

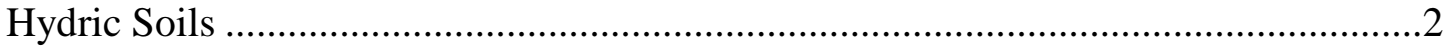

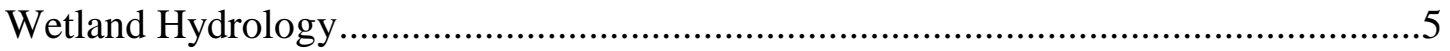

Wetland Hydrology Determination...........................................................................

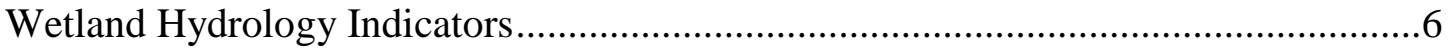

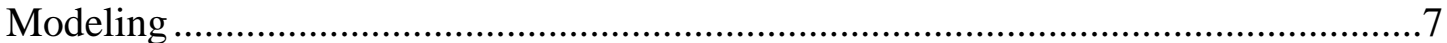

Army Corps of Engineers Technical Standard ........................................................

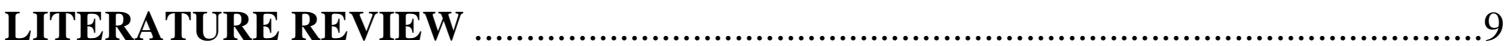

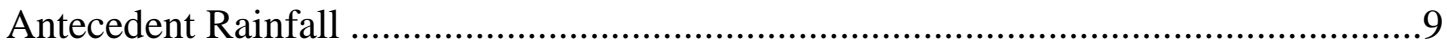

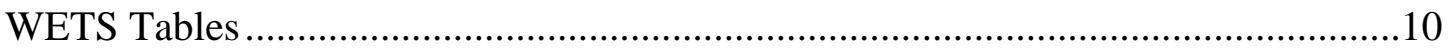

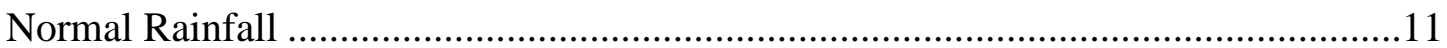

Palmer Drought Severity Index ………………………..................................12

Antecedent Rainfall Evaluation ...........................................................................13

Direct Antecedent Rainfall Evaluation Method (DAREM).........................................15

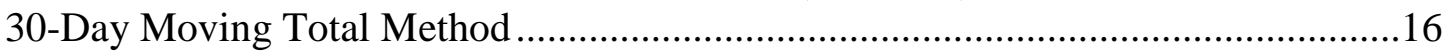

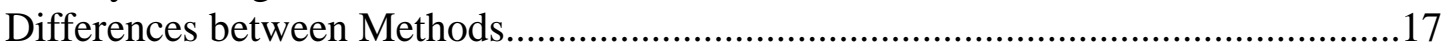

Prior Research ..........................................................................................

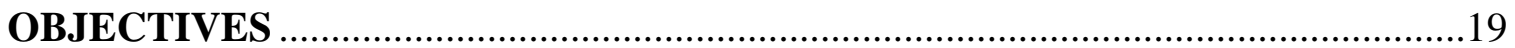

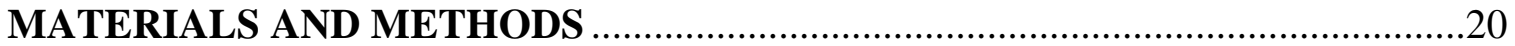

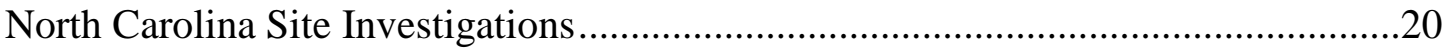

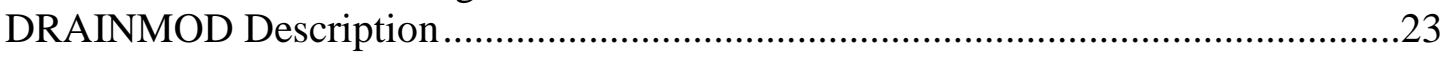

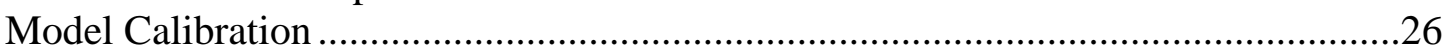

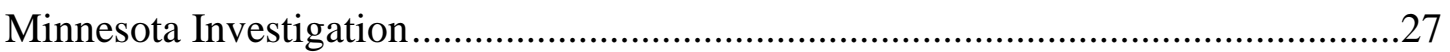

Assessment of the Hydrology Technical Standard ..................................................28

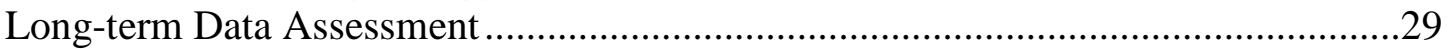




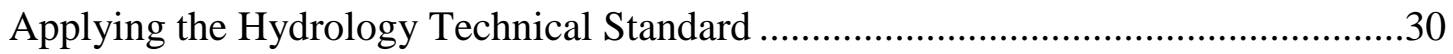

Direct Antecedent Rainfall Assessment Method (DAREM) .....................................

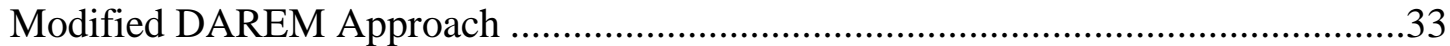

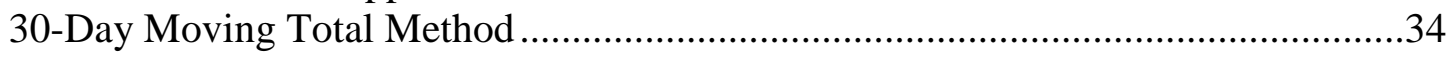

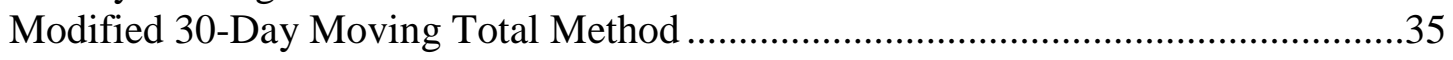

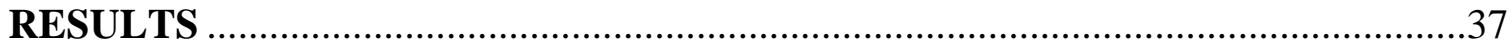

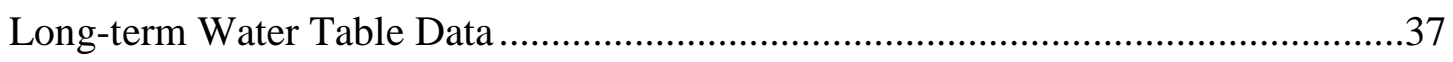

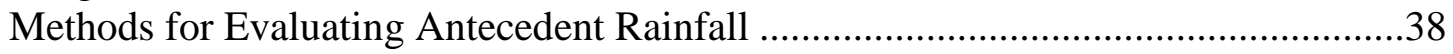

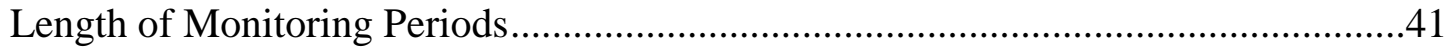

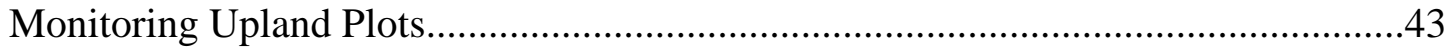

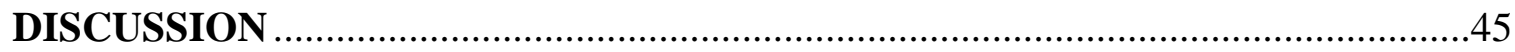

False Positives and False Negatives .............................................................46

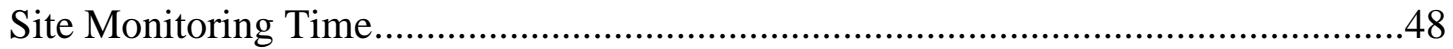

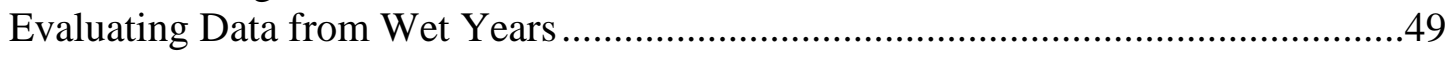

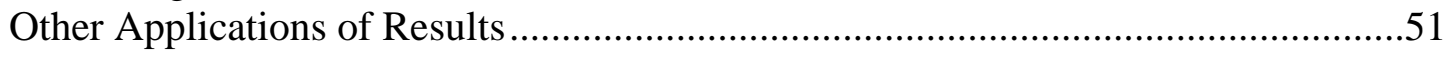

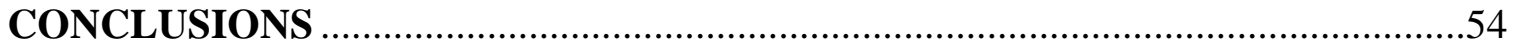

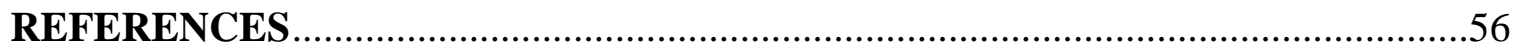

APPENDICES

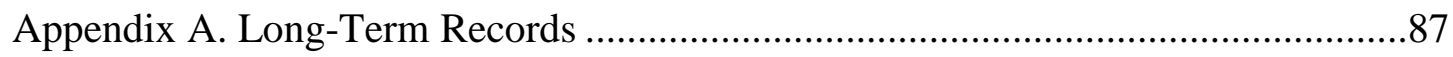

Appendix B. 40 to 45 Year Evaluation Records ..................................................100

Appendix C. DAREM and Modified DAREM calculations ..................................193

Appendix D. Moving Total Graphs .............................................................2. 


\section{LIST OF TABLES}

Table 1 WETS Table used for the Greenville site

Table 2 WETS Table used for the Bertie site

Table 3

WETS Table used for the Marcell Experimental Forest

Table 4 Hydric soil field indicators present for plots at each of the three study sites

Table 5 Growing season dates and length for each of the three sites. Data were obtained from the WETS weather stations shown

Table 6 DAREM calculation method to determine the condition of the rainfall period for May 1959 at plot $1 \mathrm{R}$ in Greenville. The month of June is being evaluated as the month of interest while the months May, April and March are taken into consideration. Once calculations have been completed, the 3-month period can be evaluated on whether it has acceptable rainfall amounts. In this case, this 3-month period is "normal" so the period for June is acceptable to use

Table 7 Modified DAREM calculation method to determine the condition of the rainfall period for May 1959 at plot $1 \mathrm{R}$ in Greenville. The water table rose to within $30 \mathrm{~cm}$ of the surface on June 16. With this method, the month of June is taken as the most recent prior month. Rainfall for the first half of June will be considered (days 1-15). Because only monthly data are reported, the measured rainfall amounts for June were multiplied by 0.5 , and the same was done with the WETS data values. With this approach the antecedent period is considered drier than normal. In contrast, the regular DAREM method (Table 6) concluded the antecedent rainfall was normal because June values were not considered.....

Table 8 The 30-Day Moving total calculation for Greenville plots during the year 1959. The moving total is the sum of the amount of rainfall over a 30 day period and is calculated by adding the daily precipitation values from the first 30 days and then subtracting out the first day from the count and adding in the $31^{\text {st }}$ day to have a continuous 30 day calculation total for precipitation throughout the year. The $70^{\text {th }}$ Percentile values are obtained directly from WETS Tables. The moving total for $1 / 30 / 1959$ is the sum of daily rainfall amounts from $1 / 1 / 1959$ to $1 / 30 / 1959$, which is 3.50 
$\mathrm{cm}$. The moving total for $1 / 31 / 1959$ is the sum of daily rainfall amounts from $1 / 2 / 1959$ to $1 / 31 / 1959$, which is 4.11 because it includes $0.61 \mathrm{~cm}$ from day 31 and excludes precipitation from day $1(0 \mathrm{~cm}$ not shown)

Table 9 Three study sites of Greenville, Bertie and Marcell each had 17 plots that met wetland hydrology and 6 plots that did not meet wetland hydrology. Plots that did meet wetland hydrology had a hydric soil field indicator present, while plots that did not meet wetland hydrology had no hydric soil field indicator present. Plots met wetland hydrology, met it an average of $83 \%$ or higher

Table 10 Average results from all plots at all sites from water table saturation criteria examinations. For a given year, the water table was examined during the growing season to see first if a period of saturation occurred within $30 \mathrm{~cm}$ of the surface for at least 14 days. If it did, then rainfall was examined next to determine if rainfall was normal, below normal, or wetter than normal using each of the four methods separately. For example, if the modified DAREM approach was being considered, then it was applied to the period prior to when the water table rose above a depth of 30 $\mathrm{cm}$. If the rainfall was found to be normal or drier than normal for the modified DAREM approach, then that year was considered to have met the wetland hydrology criteria and another method of rainfall evaluation was tested. On the other hand, if rainfall was found to be wetter than normal with the modified DAREM approach, then additional periods during that same year were examined to determine if the water table met the saturation criteria during normal or drier than normal rainfall. If a year was considered to be wetter than normal for the modified DAREM approach, that meant that there were no periods during that year when the water table met saturation criteria during a period of normal or drier than normal rainfall. Periods of normal rainfall were not considered if they did not meet water table saturation criteria. This was then used for the remaining methods of rainfall evaluation

Table 11 Evaluation results for all four methods from all study sites for hydric soils. Plots at each site have been averaged together to get the means for each method and the range is listed below the mean to get an idea of how wide the range between percent wetland hydrology was met among the individual plots. Both direct antecedent methods have closer percentage results compared with the long-term water table records and the moving total methods are significantly lower than the long-term records. 
Table 12 Partial 40 year record for plot Greenville plot 4R that displays results from the Corps Moving Total method and that has met wetland hydrology 12 out of 20 years $(60 \%)$ when the water table (WT) was within $30 \mathrm{~cm}$ for 14 days or longer during the period listed for each year shown .70

Table 13 Modified DAREM approach to determine the condition of the rainfall period for July 1965 at plot $4 \mathrm{R}$ in Greenville. The month of June is being evaluated as the month of interest while the months June, May and April are taken into consideration. Once calculations have been completed, the 3-month period can be evaluated on whether it has acceptable rainfall amounts.

Although the most recent month of June is Wet, this 3-month period is considered "normal" because the preceding two months of May and April were normal or dryer than normal so the period for July is acceptable to use

Table 14 Partial 40-year record for plot 4R at Greenville that displays results from modified DAREM and that has met wetland hydrology in 17 out of 20 years $(85 \%)$ when the water table (WT) was within $30 \mathrm{~cm}$ of the surface for 14 days or longer during the growing season

Table $15 \quad$ Partial 40-year record for Greenville plot 4R for all methods evaluated. Some methods did not meet wetland hydrology in some years when the other methods met wetland hydrology in the same years

Table 16 Number of times that wetland hydrology was not met for different lengths of years using Modified DAREM. For example, plot S3 did not meet wetland hydrology for 23 out of 45 years. There was a single year, two consecutive years, one period of 5 consecutive years and one period of 15 consecutive years that did not meet wetland hydrology because plot S3 was considered too dry and did not meet the water table criteria.

Table 17 Evaluation results from all methods for all adjacent non-hydric soil plots at Greenville (1L-4L) and Bertie (2S and $2 \mathrm{~N})$ represented in percentages compared with the long-term water table measurement for wetland hydrology. Both DAREM and Modified DAREM approaches are closer to the long-term water table measurement averages than either of the 30-day moving total methods. In the years that the long-term measurement met wetland hydrology, the four methods did not because they were considered to be "wet" and removed 
Table 18 Examples of how long adjacent non-hydric soil plots at Greenville (1L-4L) and Bertie ( $2 \mathrm{~S}$ and $2 \mathrm{~N}$ ) would have to be monitored to not meet wetland hydrology (or meet wetland hydrology) based on a single year worth of data or several

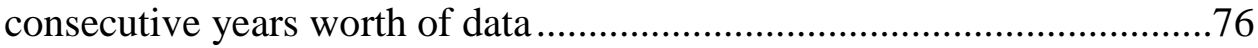

Table 19 Percentage of False Negatives for all plots at Greenville, Bertie and Marcell. False negatives occur when a plot does meet wetland hydrology according to long-term records, but do not meet wetland hydrology according to a short-term method because of above normal rainfall 


\section{LIST OF FIGURES}

Figure 1 State maps of North Carolina and Minnesota, which show

research locations in relationship to state and capitals

Figure 2 Greenville site map with plots of interest labeled as: 1L, 1R ... 4L, 4R and 4P to represent transect and series name (He et al., 2002). For example, plot $1 \mathrm{R}$ represents Rains soil series plot 1

Figure 3 Bertie site map with plots of interest labeled as: 1, 2N, 3N, 4N, $5 \mathrm{~N}, 2 \mathrm{~S}, 3 \mathrm{~S}, 4 \mathrm{~S}, 5 \mathrm{~S}$ to represent the soil series (1-Noboco, 2-

Goldsboro, 3-Lenoir, 4,5-Leaf) and transect (North and South)

(He et. al, 2002)

Figure $4 \quad$ Marcell site map with plots of interest labeled as: S1, S2, S3, S4, $\mathrm{S} 5$ and S6. S4 and S5 are located in the northern part of the Marcel Experimental Forest, while all other plots are located in the southern part. They also represent the soil series (S1, S2, S4, S5 - Loxy peat, S3 - Mooselake peat, S6 - Greenwood peat).

Figure 5 Example of partial output from DRAINMOD for plot 4P at Greenville which shows parameters and output to give the number of periods of 14 days or more with water table depth within $30 \mathrm{~cm}$ of the surface and the longest consecutive period in days of saturation for each year of record.

Figure 6 30-Day Moving Total graph for 1989 for Greenville Plot 4R, which is above the 70th Percentile through day 186. However, day 186 through day 276 is under the $70^{\text {th }}$ Percentile line and within the growing season and is therefore considered to be an acceptable period to meet wetland hydrology. This graph was then compared with water table data generated from DRAINMOD to determine if the water table was within $30 \mathrm{~cm}$ for 14 days or longer during the period between day 186 and 276.

Figure 7 30-Day Moving total graph for 1972 for Greenville plots. The highlighted period of interest would be excluded from the Adjusted 30-day moving total method because although it has a 31 day period of normal or drier than normal rainfall, the period that directly precedes the saturation at day 166 is above the $70^{\text {th }}$ percentile and therefore that above normal precipitation could have caused the saturation in the days highlighted. This graph met wetland hydrology for the 30-day moving total method because the 14-day saturation occurred within the 31 days of 
normal or drier than normal precipitation. However, this graph did not meet wetland hydrology within the 30-day modified moving total method due to prior above normal rainfall before

Figure 8 Number of consecutive days water table was within $30 \mathrm{~cm}$ of the surface during the growing season for a 40 year period (19591998) in plot 4R at Greenville. The dotted line represents the 14day saturation requirement for wetland hydrology to compare which years met wetland hydrology and which did not. All years but 1976 and 1985 met the 14-day saturation requirement.

Figure 9 Long-term water table data record for plot S3 at Marcell, which met wetland hydrology 24 out of 45 years. The longest consecutive period of saturation within $30 \mathrm{~cm}$ of the surface for each year from 1961 through 2005 was plotted with a line that represents 14-day saturation requirement for wetland hydrology to compare which years met wetland hydrology and which did not. There were only two periods within the first 20 years that met wetland hydrology because plots did not meet water table saturation criterion and considered dry 


\section{INTRODUCTION}

\section{Wetlands}

Wetlands were defined by Cowardin et al. (1979) as: "Lands transitional between terrestrial and aquatic systems where the water table is usually at or near the surface or the land is covered by shallow water." They also proposed that wetlands have one or more of the following attributes: (1) at least periodically, the land supports predominantly hydrophytes; (2) the substrate is predominantly undrained hydric soils; and (3) the substrate is nonsoil and is saturated with water or covered by shallow water at some time during the growing season of each year (Cowardin et al., 1979). This general definition can be applied to most wetlands.

The federal regulations that implement Section 404 of the Clean Water Act define wetlands as:

Those areas that are inundated or saturated by surface or ground water (hydrology) at a frequency and duration sufficient to support, and that under normal circumstances do support, a prevalence of vegetation (hydrophytes) typically adapted for life in saturated soil conditions (hydric soils). Wetlands generally include swamps, marshes, bogs, and similar areas $(40$ CFR 232.2(r)).

With passage of the Clean Water Act in 1974, a wetland protection program began in the U.S. that required specific and legally workable ways for wetlands to be identified such that specific boundaries of wetlands could be drawn on maps. The U.S. Army Corps of Engineers (Corps) became the lead federal agency defining jurisdictional wetlands. The Corps developed several manuals, all of which had different interpretations of Section 404 of the Clean Water Act, which were published throughout the 1970s and 1980s and described specific parameters that needed to be used to identify wetland boundaries. The 
problem with these manuals was that they all described wetlands differently and there was no uniform definition that was implemented in wetland boundary analysis. To date, the manual published in 1987 ('87 Manual) has become the standard by which wetlands are identified to conform to the requirements of the Clean Water Act (Environmental Laboratory, 1987). The Corps defined jurisdictional wetlands by three parameters: 1) wetland hydrology, 2) hydric soils, and 3) hydrophytic plants (US ACOE 1987). Hydrophytic plants are those that are specially adapted to survive in saturated and anaerobic soils. All three parameters must be present for an area to be considered a jurisdictional wetland (Mitsch and Gosselink 2000). This is also a federal law and wetlands have been defined within the Federal Register (Environmental Laboratory, 1987).

\section{Hydric Soils}

Hydric soils form under conditions of saturation, flooding, or ponding long enough during the growing season to develop anaerobic conditions in the upper part of the soil (Federal Register, 1994). The upper part has been left undefined, but has generally been considered to be the upper $30 \mathrm{~cm}$ for loamy and clayey soils, and the upper $15 \mathrm{~cm}$ for sandy soils (USDA NRCS, 2002). Hydric soils are identified using field indicators that develop in soils that were saturated and anaerobic during the growing season. The USDA-NRCS, published Field Indicators of Hydric Soils in the United States: A Guide for Identifying and Delineating Hydric Soils (1998), which was established by a number of soil scientists across the country and reflects indicators that are associated with hydric soils (USDA NRCS, 2002). Field indicators were specified for 
four soil categories: all soils, sandy soils, loamy and clayey soils, and test indicators. The field indicators include a main indicator, a brief profile description, and soil colors and features that are required to be present to meet the criteria for one of the hydric soil field indicators. Four hydric soil field indicators were found at sites specific to this study. They were used to distinguish soil plots that meet wetland hydrology in $50 \%$ of the years as well as to compare water tables of soil plots that did not meet hydric soil field indicators.

The Depleted Matrix field indicator (F3) is commonly used in wetland boundary determinations through the U.S. and is the most common within the eastern U.S. This field indicator requires a layer of soil at least $15 \mathrm{~cm}$ thick with a depleted matrix that has $60 \%$ or more chroma 2 or less starting within $25 \mathrm{~cm}$ of the surface (USDA NRCS, 2002). The depleted matrix is a soil horizon, or subhorizon, from which iron has been removed or transformed by processes such as reduction or translocation which creates colors of low chroma and high value (Richardson and Vepraskas, 2001). Some horizons, such as A, E, or any calcic horizons present may have low chromas and high values and might be mistaken for a depleted matrix. They are excluded except when common or many distinct or prominent redox concentrations as soft masses or pore linings are present. The depleted matrix can change colors due to air exposure. The following combinations of Munsell values and chroma identify a depleted matrix:

1. Matrix value of 5 or more and chroma 1 or less with or without redox concentrations as soft masses and/or pore linings; or 
2. Matrix value 6 or more and chroma 2 or less with or without redox concentrations as soft masses and/or pore linings; or

3. Matrix value 4 or 5 and chroma 2 and has $2 \%$ or more distinct or prominent redox concentrations as soft masses and/or pore linings; or

4. Matrix value 4 and chroma 1 and has $2 \%$ or more distinct or prominent redox concentrations as soft masses and/or pore linings. (Richardson and Vepraskas, 2001)

The Umbric Surface field indicator (F13) is also commonly used in wetland boundary determination in the U.S. It is defined as a layer of soil $15 \mathrm{~cm}$ or more thick starting within the upper $15 \mathrm{~cm}$ of the soil surface with the value 3 or less and chroma 1 or less immediately underlain by a layer of $10 \mathrm{~cm}$ or more thick with chroma 2 or less on concave positions of interstream divides and also within depressions (USDA, 2002). Thickness requirements are less than those required for an umbric epipedon, which requires a thickness of $18 \mathrm{~cm}$ (Buol et al., 2003). Umbric surfaces that are located on higher landscape positions, like Umbrepts, are excluded from the Umbric Surface field indicator (USDA, 2002).

The Histosol field indicator (A1) is used with organic soils, which are also commonly used in wetland identification in the U.S. This indicator is defined as a layer $40 \mathrm{~cm}$ or more of the upper $80 \mathrm{~cm}$ as organic soil material, which has an organic carbon content of 12 to 18 percent or more depending on clay content of the soil (USDA, 2002). USDA (1998) defines organic soil materials as muck (sapric soil material), mucky peat (hemic soil material), or peat (fibric soil material). 


\section{Wetland Hydrology}

Areas that have wetland hydrology are those where the existence of water has an overriding influence on vegetation and soils, which is due to anaerobic and reducing conditions. These vegetation and soil characteristics are usually present in areas that are inundated or have saturated soils for enough time to develop hydric soils and support hydrophytic vegetation. However, hydrology is usually the least exact of the three parameters for wetland identification and indicators of wetland hydrology are sometimes difficult to find in the field. It is essential to establish whether wetland hydrology occurs in a potential wetland location. (Environmental Laboratory, 1987)

Wetland hydrology is determined by a number of different site characteristics that include: precipitation amount, evapotranspiration, runoff, groundwater inflow, proximity to streams, topographic position, soil permeability, and plant cover (Environmental Laboratory, 1987). All of these factors determine the frequency and duration of soil saturation or inundation (Environmental Laboratory, 1987). For jurisdictional purposes, wetland hydrology occurs when a site saturates to the surface or inundates for a period lasting at least $5 \%$ of the growing season in at least $50 \%$ of the years studied. Growing season is generally determined from the duration of frost-free days that occur for an air temperature of $28^{\circ} \mathrm{F}\left(-2^{\circ} \mathrm{C}\right)$ that occur in of $50 \%$ of the years. While saturation to the surface would seem to require that a water table be at the surface, this is not the case. The Corps have ruled that a soil is saturated to the surface when the water table is within $30 \mathrm{~cm}$ of the surface, because the capillary fringe (saturated zone above the water table) will reach to the surface (National Research Council, 1995). 


\section{Wetland Hydrology Determination}

There are currently four ways to identify wetland hydrology: 1) long-term water table data records, 2) hydrologic field indicators, 3) use of hydrologic models to simulate long-term water levels, and 4) use of the U.S. Army Corps of Engineers Technical Standard. However, several problems occur with each method. When available, longterm (10 years or more) water table data records are an easy and reliable method for evaluating wetland hydrology. Long-term records should include both wet and dry years to account for climatic variation. Determining whether a site meets wetland hydrology from long-term data records simply requires that the water table be within $30 \mathrm{~cm}$ of the surface for periods lasting $5 \%$ of the growing season or longer, and these conditions must occur in $50 \%$ of the years or more. While this method is simple, it is not used often because long-term records of water table data are rare, as well as being costly and time consuming to obtain (Warne and Wakeley, 2000).

\section{Wetland Hydrology Field Indicators}

Wetland hydrology field indicators are features that can be observed in the landscape that show whether or not the site has been inundated or saturated. Indicators fall into two groups, primary and secondary. Primary indicators are direct evidence that a site has been flooding or saturated with groundwater (Environmental Laboratory, 1987). Only one primary indicator is required to show that a site experiences wetland hydrology. Observing inundation, water marks on trees, drift lines of debris, sediment deposits on leaves, or a water table within $30 \mathrm{~cm}$ of the surface are examples of primary indicators. Secondary indicators are less definitive of wetland hydrology than primary indicators, 
and as a result, two secondary indicators are required to show that a site has wetland hydrology. Examples of secondary indicators of wetland hydrology include oxidized rhizospheres (root channels coated with Fe oxides) in the upper $30 \mathrm{~cm}$ of the soil, waterstained leaves, and local soil survey data that suggest saturation (Environmental Laboratory, 1987).

\section{Modeling}

Hydrologic models can be used to estimate long-term water table data (Skaggs 1999). These models will compute water table levels from precipitation data when they are properly calibrated for the soil conditions at a site. Hydrologic modeling can be used to predict long-term historic water table fluctuations on a day-to-day basis once a model has been calibrated at a site using short-term (several months to years) measurements of precipitation and water table levels (Skaggs, 1999). The hydrologic model DRAINMOD was originally developed for poorly drained agricultural fields, and has since been widely used to analyze the long-term effects of drainage on water table fluctuations (Skaggs et al., 1994). The DRAINMOD model can calculate saturation frequency at a specified depth and duration during the year (He et al., 2002). DRAINMOD has proven reliable through extensive field experiments on a wide range of soils, crops, and climatological conditions (Skaggs, 1982; Gayle et al., 1985; Fouss et al., 1987). The model must be calibrated for individual plots/areas of study using a short-term record of observed weather data and water table measurements that have been recorded through a 1 to 3 year period (He et al., 2002). 


\section{Army Corps of Engineers Technical Standard}

Wetland hydrology can also be determined for a jurisdictional purpose by using the Army Corps of Engineers Technical Standard. The Wetland Hydrology Technical Standard is a short-term procedure that determines whether a site meets wetland hydrology by using water table measurements made over a single season (Sprecher and Warne, 2000). The Standard is met if a water table occurs within $30 \mathrm{~cm}$ of the soil surface for 14 days or more during a period of acceptable rainfall. Rainfall is evaluated by one of three methods that consider antecedent precipitation. These methods have been described by Sprecher and Warne (2000) as: 1) direct antecedent, 2) moving total, and 3) Palmer Drought Severity Index. These methods focus on the amounts of rainfall that have fallen prior to the time the water table rises to within $30 \mathrm{~cm}$ of the surface to determine whether the antecedent precipitation was within normal limits such that wetland hydrology could be expected in most years, rather than just during the wet years. These methods will be discussed in detail in the subsequent section.

The Wetland Hydrology Technical Standard has not been extensively tested, and it is not known how reliable the procedure is compared to long-term water table monitoring. In addition, it is not known whether the methods for evaluating rainfall proposed in the Technical Standard produce equivalent results. We hypothesized that short-term measurements can be used to reach the same wetland hydrology conclusions as long-term data if precipitation data are used properly during a time of normal or drier than normal precipitation. 


\section{LITERATURE REVIEW}

\section{Antecedent Rainfall}

Precipitation is the process that results from collection of water vapor and small droplets of water in the atmosphere. Precipitation, along with clouds and storm systems, are created by the cooling of a parcel of air in the atmosphere (Black, 1996). The parcel of air is lifted to atmospheric regions of significantly lower pressure and temperature to reach the dew point through several processes such as air mass weather, which is a function of the Coriolis Force and the pressure gradient force along with relative humidity to cause air movements based on molecular weight of moist and dry air, orographic lifting and convection (Black, 1996). Precipitation has many forms that include rain, snow, and ice and is most often measured with a device known as a rain gauge. Precipitation events have different durations, frequencies, intensities and amount of precipitation that falls, however, long-term precipitation over a specific area is thought to have received the same amount of precipitation over a 30 to 40 year span with different storm intensities throughout individual years (Hershfield, 1961). Different regions have different precipitation patterns. These regions can be broken down into smaller areas, or watersheds, where precipitation patterns could be drastically different than surrounding areas (Black, 1996).

The National Oceanic and Atmospheric Administration (NOAA) and the National Weather Service (NWS) have published technical papers and rainfall frequency atlases at specified frequencies and durations within different regions throughout the United States (Bonnin et al., 2002). These rainfall frequency atlases are used to design a wide range of structures from urban storm water drainage systems, dams and spillways, as well as to 
address issues in environmental management (Bonnin et al., 2002). Extreme flooding or droughts can occur at any time over a long-term record depending on the amount of precipitation a specific region receives. Borga et al. (2005) states that the objective of rainfall frequency analyses is to estimate the amount of rainfall, or precipitation, falling at a given point for a specified duration and return period. This is most commonly done by referencing the annual maximum series. The annual maximum series are the largest values of precipitation that fall within each year. There is an alternative data format for rainfall frequency studies that is based on the peak-over-threshold concept, which is all large precipitation amounts above certain thresholds selected for specific durations (Borga et al., 2005). However, Borga et al. (2005) states that the annual-maximum-seriesbased method has a simpler structure and is therefore the more widely used method.

\section{WETS Tables}

WETS Tables are a statistical summary of monthly precipitation and temperature that provide ranges of normal monthly precipitation that are available for over 8000 National Weather Service (NWS) weather stations that are published by the USDA National Weather Service and Climate Center (Sprecher and Warne, 2000). WETS Tables were conceived by Phil Pasteris, who created the word WETS, which wasn't derived from a series of words, but rather a word that was created. It was created during a meeting held in the middle 1990s and helped describe in one word the climate information needed to define a wetland (P. Pasteris, personal statement, 2006). The range of normal precipitation is reported using long-term precipitation data to determine the $30^{\text {th }}$ and $70^{\text {th }}$ percentiles of all the numbers in the precipitation record (Sprecher and 
Warne, 2000). WETS Tables help to determine whether precipitation is normal, drier than normal, or above normal at a specific NWS weather stations (Sprecher and Warne, 2000). Growing season dates can also be found on WETS Tables. The growing season is defined for wetland hydrology on the basis of soil temperatures, which have been estimated based on NRCS reports of 50 percent likelihood of last and first $28^{\circ} \mathrm{F}\left(-2^{\circ} \mathrm{C}\right)$ frost (Sprecher and Warne, 2000). WETS Tables can be obtained for any weather station via the World Wide Web at http://www.wcc.nrcs.usda.gov/climate/climate-map.html. WETS Tables for study sites can be found on Table 1 (Greenville), Table 2 (Bertie), and Table 3 (Marcell Experimental Forest).

\section{Normal Rainfall}

Normal rainfall can be defined as a range of precipitation amounts, which is useful for grouping precipitation values into broad classes (Sprecher and Warne, 2000). Boundaries of the classes depend on the number of classes needed, the purpose of the classification, and the tradition of the discipline (Sprecher and Warne, 2000). The range of normal rainfall can be defined using WETS Tables, in which the normal rainfall falls between the $30^{\text {th }}$ and $70^{\text {th }}$ percentiles. The range of normal precipitation for each month on the WETS Table is based on rainfall data from the preceding three decades. The $30^{\text {th }}$ and $70^{\text {th }}$ percentile numbers are calculated using all the precipitation values obtained from the previous three decades.

Above normal rainfall, or wet periods, occurs when measured precipitation values exceed the $70^{\text {th }}$ percentile on the WETS Table. Water table data that is within $30 \mathrm{~cm}$ from the surface for 14 days or longer during a period that exceeds the $70^{\text {th }}$ percentile is 
considered to be a wet period and cannot be used to judge that wetland hydrology is present at the site. These wet periods are usually caused by large precipitation events, such as hurricanes, large storm systems, or snow melt. These periods occur irregularly throughout a long-term record, but are extremely important to short-term evaluation. Water table data that are within $30 \mathrm{~cm}$ from the surface, during the growing season for 14 days or longer during a period that is less than the $70^{\text {th }}$ percentile indicate that wetland hydrology is present at the site. If a year has to be removed because it contains a wet period, then more monitoring of a site might be needed or a different method of evaluation must be used. However, wet periods may occur early in the growing season and have normal precipitation as the year progresses. Wetland hydrology is met at anytime during the growing season when water table criterion is met during a period "normal" or "drier than normal" precipitation.

\section{Palmer Drought Severity Index}

The Palmer Drought Severity Index (PDSI) is the most widely used definition for drought monitoring and analyses in the United States (McKee et al., 1993). It has been used over a long-term period (30+ years) to quantify drought conditions for a specific location and time. However, Wells and Goddard (2004) suggest that a common critique of the PDSI is that the behavior of the index at various locations is inconsistent, making spatial comparisons of PDSI values difficult, if not meaningless. Each PSDI reported represents excess precipitation as well as drought conditions and is calculated using a function of precipitation and temperature (Sprecher and Warne, 2000).

Evapotranspiration and soil moisture content are inferred from the measured precipitation 
and temperature over a period of weeks to months (Sprecher and Warne, 2000). Sprecher and Warne (2000) also suggest that the Palmer Indices compliment the WETS Tables because they integrate several different components of the hydrologic budget. McKee et al. (1993) and Sprecher and Warne (2000) both point out several weaknesses of the PDSI that include indices that are regional in nature and not site-specific. Some disadvantages to using the PDSI include: no distinguishing between snowfall and rainfall, conversion to percentiles is only approximate given the resolution of the graphs online, indices are not specified, most recent indices are provisional and subject to change, so should not be reported in legal documentation and some assumptions for calculation of soil moisture may not be valid for the site that is being evaluated (Sprecher and Warne, 2000). Some advantages to using the PDSI include: data are current, drought indices integrate precipitation, soil moisture and evapotranspiration all into one value, and that the information is easily obtainable and can be converted to percentile frequencies (Sprecher and Warne, 2000).

\section{Antecedent Rainfall Evaluation}

The direct antecedent rainfall evaluation method (DAREM), the 30-day moving totals method, and the combined method are the three methods by which antecedent rainfall can be evaluated. Onsite rain gauges are often used to obtain daily and monthly precipitation values. Precipitation is generally not distributed uniformly throughout the duration of the year or within an area of interest (Black, 1996). Precipitation events occur sporadically during a given year and individual events have different areas of heavier and lighter precipitation. The Natural Resources Conservation Service (NRCS) Engineering 
Field Handbook uses monthly precipitation values along with WETS Tables to evaluate prior two to three month periods of precipitation inputs. WETS Tables define the normal range for monthly precipitation and normal range for growing season required to assess the climatic characteristics for a geographic area over a representative time period (NRCS, 1997). Sprecher and Warne (2000) point out that the main weakness of using this method is that it does not evaluate daily changes in precipitation patterns, especially for the current month that is being analyzed.

The other short-term method for evaluating antecedent precipitation is the 30 -day moving total (rolling total) that is computed using precipitation for 30 days (Sprecher and Warne, 2000). Since precipitation patterns are reflected more on a daily basis rather than monthly basis, Sprecher and Warne (2000) suggest that the 30-day moving total approach is commonly the more desirable than DAREM because it evaluates higher frequency precipitation on a daily basis rather than monthly totals that are reset to zero at the beginning of each month. However, 30-day moving totals also artificially zeroes rainfall after 30 days and abruptly drops major rainfall events, from prior to the 30 days, out of the 30-day moving total (Sprecher and Warne, 2000).

Sprecher and Warne (2000) state that precipitation data fit a gamma distribution rather than a bell curve because a site cannot experience less than zero precipitation in any span of time (day, week or month), but a site can experience a large precipitation amount compared with the previous record high. Due to the new spike in large precipitation values, the frequency will then be skewed to the right.

Sprecher and Warne (2000) hypothesized the combined method for evaluating wetland hydrology using both the DAREM method and the 30-day moving total method. 
This method would allow a 30, 60 or possibly 90 day moving total using 30 day increments rather than only at the beginning of a calendar month (Sprecher and Warne, 2000). However, Sprecher and Warne (2000) also note that using the combined method will show how challenging it is to decide whether a particular period of rolling totals falls on one side of the threshold of normal or above the normal range. This method was not studied in this research.

\section{Direct Antecedent Rainfall Evaluation Method (DAREM)}

The Direct Antecedent Rainfall Evaluation Method (DAREM) is a procedure to systematically evaluate rainfall conditions for the three-month period prior to the site investigation (Sprecher and Warne, 2000). The procedure calculates a numerical rating of prior precipitation by weighting the data for both the amount of precipitation and the relative time between the time of interest and the time of a rainfall event. The two weighting factors are multiplied together to give a numerical rating that is used to describe whether the prior three month period of precipitation was within the range of normal, drier than normal or above normal (Sprecher and Warne, 2000). The DAREM approach processes the data in month format and does not include individual days.

Dr. Paul Rodrigue has recently proposed a modification to the DAREM approach (P. Rodrigue, USDA, personal statement, 2006). The modified DAREM is very similar to the DAREM approach; however instead of ignoring precipitation from the month of the site investigation, it is incorporated into the precipitation assessment. Precipitation up to the day of saturation is prorated and included in the 3 prior month calculation. There are several benefits of using this approach which include: all precipitation being accounted 
for within the calculation, large rainfall events within the month of the site investigation are not discounted because the precipitation from the month of interest is included in the calculation and it is a more accurate way to assess the precipitation at a specific site ( $\mathrm{P}$. Rodrigue, USDA, personal statement, 2006).

\section{0-Day Moving Total Method}

As stated previously, the 30-day moving total method is a method of evaluating short-term rainfall for wetland hydrology determination. Sprecher and Warne (2000) claim that the 30-day moving total is technically more sound than monthly totals in the DAREM approach because monthly totals do not accurately reflect antecedent rainfall in the middle of the month. The 30-day moving total is generated by summing the past 30 days worth of precipitation and continually updating a tally of the prior 30-day rainfall totals (Sprecher and Warne, 2000). These 30-day moving totals can be plotted against days of the year to get a continuous moving total graph for a particular site. These moving total graphs give a better idea of what is going on year round at a particular site instead of blocking it into months. A line representing the monthly values for $70^{\text {th }}$ percentile from the WETS Table can be added to the moving total graph to determine whether the collected precipitation from the moving total method is within normal range during the time of site investigation. To meet wetland hydrology criteria, a 30-day window of normal precipitation is required prior to when the water table is within $30 \mathrm{~cm}$ for 14 consecutive days or longer during the growing season.

However, the 30-day moving total method does allow the wetland hydrology criteria to be met if the period of normal precipitation occurs after a long wet period. 
Another way to analyze the moving total method is to evaluate soil saturation data based on when it occurs in the moving total. If soil saturation occurs directly after a long wet period (above the $70^{\text {th }}$ percentile), then it could be considered wet because the saturation is caused directly by the long period of above normal precipitation.

\section{Differences Between Methods}

There are several differences between the DAREM and the 30-day moving total method. The 30-day moving total method incorporates a more accurate assessment of daily antecedent moisture conditions at a site than the monthly averages used in DAREM (Sprecher and Warne, 2000). DAREM indicates when a period (prior 3 months included)

is drier than normal, normal, or above normal and doesn't account for the days/periods of the month when the wetness/dryness occurred, while the 30-day moving totals just looks at a 30 day summation of precipitation of normal rainfall and isn't concerned with data in monthly format (Sprecher and Warne, 2000). However, the moving total method only looks at 30 days of data. A 30-day window of normal rainfall could occur directly after a long, above normal precipitation period that directly affects the water table levels. The Modified DAREM corrects the monthly problems of DAREM because it just looks at the 3 months, or 90 days, prior to the date of saturation. Also, adjustments can be made to the moving total method to factor in prior precipitation, which includes long periods of above normal precipitation that proceed the 30-day period of normal precipitation. 


\section{Prior Research}

Wetland hydrologic status is usually determined directly from water table measurements only during a period when the rainfall is judged to be "normal" or "near average" (Hunt et al., 2001). Hunt et al. (2001) also stated that unusually high rainfall periods may cause water tables to be shallow on upland sites and may cause water tales on wetlands to be unusually deep during dry periods and therefore it is important to study these water tables when the rainfall is judged to be "normal" or "near average." Hunt et al. (2001) tested the hypothesis that sites that satisfy the wetland hydrologic criterion in one out of two years also satisfy the criterion under the "normal" or "near average" rainfall conditions. This study included DRAINMOD simulations for both upland and wetland sites for a 40-year period of climate data. Hunt et al. (2001) then analyzed generated water table records to determine whether the water table conditions that occurred during periods of "average" rainfall accurately reflected the wetland hydrologic status. In the Hunt et al. (2001) study, if the high water table was continuously above the $30 \mathrm{~cm}$ depth for the required duration during an average rainfall month during the growing season, then the site is judged to have wetland hydrology. However, high water table conditions that occurred in months with above average rainfall were not considered.

Through conducted research, Hunt et al. (2001) concluded that limiting the analysis for assessing wetland hydrologic status to months with near-average rainfall produced different results than basing the determination on long-term water table records under the rainfall conditions. Confining the analysis to periods of near-average rainfall often lead to the conclusion that wetland sites do not satisfy the wetland hydrology criterion and it was concluded that those sites had upland hydrology (Hunt et al., 2001). 
Hunt et al. (2001) also concluded that the field method was not a reliable method for prediction whether sites met the wetland hydrology criterion that is defined by the 1987 USACE manual. Hunt et al. (2001) also looked at a 30-day moving total method to analyze short-term data for wetland hydrology assessment. In this study, near-average rainfall typically did not cause the wetland hydrology criterion to be satisfied due to water table depths that occurred below $30 \mathrm{~cm}$. When the average rainfall interpretation was used in place of the Corps' actual definition, many sites which actually met the wetland hydrology criterion were wrongly predicted to have upland hydrology (Hunt et al., 2001). Hunt et al. (2001) concluded that indicated that the Corps' definition and the average rainfall interpretation are not the same and do not lead to similar results.

\section{Objectives}

The objectives of this study were: 1) to determine if short-term methods, DAREM, modified DAREM, 30-day Moving Total and modified 30-day Moving Total, of rainfall assessment can predict long-term wetland hydrology, and 2) to determine if there is a better way to incorporate wet periods in a wetland hydrology assessment. 


\section{MATERIALS AND METHODS}

Hydrologic data for this study came from three sites, two in North Carolina and one in Minnesota (Fig. 1). Simulated water table data were obtained from calibrated DRAINMOD models developed for soils in NC, while directly measured water table data were obtained from Minnesota.

\section{North Carolina Investigations}

Soil and hydrologic data were collected from previous studies of Hayes (2000) and $\mathrm{He}$ (2003). The following discussion summarizes the work done by these investigations. Studies were conducted at two sites in the North Carolina Coastal Plain. Both sites contained toposequences of soils that ranged from well drained to very poorly drained. The Greenville site was located in Pitt County, NC, approximately $5.1 \mathrm{~km}$ southwest of Greenville at $\mathrm{N} 35^{\circ} 34^{\prime} 10^{\prime \prime}$ and $\mathrm{W} 77^{\circ} 26^{\prime} 26^{\prime \prime}$ (He et al., 2002) with an average slope of $2 \%$. Dominant vegetation consisted of loblolly pine (Pinus taeda L.), red maple (Acer rubrum L.), and white oak (Quercus alba L.) that were between 10 and 50 years old (He et al., 2002). Additional data on soil morphology at the site was previously reported by Hayes and Vepraskas (2000).

Approximately one half of the study plots at the Greenville site contained hydric soils. For this investigation, only the plots in hydric soils and adjacent upland soils were selected for study because these were the soils most likely to meet wetland hydrology requirements (Fig. 2). The water table data at the Greenville site were collected from plots placed in the following soils: Lynchburg (fine-loamy, siliceous, thermic Aeric Paleaquults), Rains (fine-loamy, siliceous, thermic Typic Paleaquults), and Pantego (fineloamy, siliceous, thermic Umbric Paleaquult) (He et al., 2002). Previous work by Hayes 
(2000) showed that plots in the Rains and Pantego soils were hydric soils, while those in the Lynchburg soils were not. The field indicators identified are listed and defined in Table 4.

Wells in each soil were placed in plots along four transects which contained a total of nine plots (Fig. 2). The transects were established at increasing distances from a ditch. Each transect consisted of two or three plots that included Lynchburg (somewhat poorly drained) and Rains (poorly drained) soils. Transect 4 contained an additional plot in the (very poorly drained) Pantego soil.

Bertie, the second site, (Fig. 3), was located in Bertie County, NC at N 76 48'00", and $\mathrm{W} 36^{\circ} 5^{\prime} 30^{\prime \prime}$. The dominant vegetation at the site included a mixture of loblolly pine (Pinus taeda L.), red maple (Acer rubrum L.), sweet bay (Magnolia virginiana L.), white oak (Quercus alba L.), red oak (Quercus borealis L.), and black cherry (Prunus serotina L.) (He et al. (2002). The soil toposequence consisted of soils in the following series: Noboco (fine-loamy, siliceous, thermic Typic Paleudults), Goldsboro (fine-loamy, siliceous, thermic Aquic Paleudults), Lenoir (clayey, mixed, thermic Aeric Paleaquults), and Leaf (clayey, mixed, thermic Typic Albaquults) (He et al., 2002). The experiment was conducted along two transects, labeled North $(\mathrm{N})$ and South $(\mathrm{S})$, and each transect contained five plots (Fig. 3).

In each plot at the Bertie and Greenville sites, water table levels were monitored daily (12:00 AM, midnight) with recording wells (Remote Data Systems, Inc. P.O. Box 2522, Wilmington, NC 28402). Wells were installed by boring a 10-cm diameter hole bored to a depth of $2.25 \mathrm{~m}$, inserting the well, and then filling the space between the well screen and soil with sand. The well screen extended the length of the well beginning at 15 
$\mathrm{cm}$ below the surface. A 3-cm thick layer of dry, bentonite pellets was then placed on the top of the sand to seal the well from surface water inflow. A conical mound of soil was placed over the bentonite to direct surface water away from the well (He et al., 2002). The water table data were collected from November 1996 until March 1999 at the Greenville site and from December 1996 to October 2000 at the Bertie site (He et al., 2002).

To ensure that the recording wells were monitoring daily water levels accurately, a manual check well was installed at each plot to a depth of approximately $127 \mathrm{~cm}$ below the mineral soil surface. Every two to three weeks the check wells were measured to compare with the water table data from the recording wells. Rainfall was also measured daily at each site using recording gauges (Onset Computer Corp., 470 MacArthur Blvd., Bourne, MA 02532) (He et al., 2002).

Parameters obtained by He et al. (2002) were used to simulate water tables levels using DRAINMOD for plots at both Greenville and Bertie sites. Major soil horizons were identified and described from pits ( $1 \mathrm{~m}$ deep) that were dug at each plot. Undisturbed soil cores $(7.6 \mathrm{~cm}$ in diam. by $7.6 \mathrm{~cm}$ in height) were collected in each soil horizon except the O horizon (organic layer) by using an Uhland core sampler (Uhland, 1950). Soil water characteristics, which relate soil water contents to specific soil water potential, were determined for each undisturbed core using the standard pressure plate method (Klute, 1986; Richards and Weaver, 1943). Vertical saturated hydraulic conductivity was measured on each undisturbed core using the constant head method (Klute and Dirksen, 1986) after the measurements of soil water characteristic were completed for pressure levels $>-500 \mathrm{~cm}$. Lateral saturated hydraulic conductivity was measured in the 
field for each layer at each plot using the Compact Constant Head Permeameter (Amoozegar, 1992; Amoozegar and Wilson, 1999). Soil samples were collected from each plot in $15 \mathrm{~cm}$-depth increments to a depth of $225 \mathrm{~cm}$. The samples were air-dried, and ground to pass through a 2-mm-mesh sieve. Particle size distribution was determined using the hydrometer method (Gee and Bauder, 1986). The position and elevation of each plot in the two experimental sites was determined with a surveyor's transit. (He et al., 2002)

\section{DRAINMOD Description}

DRAINMOD is a hydrologic model that simulates water table levels in a soil plot over time from input data consisting of precipitation, evapotranspiration, infiltration, runoff, and subsurface drainage (Skaggs, 1999). DRAINMOD was developed specifically for shallow water table soils with parallel drains that occur on nearly level landscapes. The model computes a water balance on a soil pedon of unit cross-sectional area. A water balance is determined on a day-by-day, hour-by-hour basis and a water table depth is computed for each time step.

The water balance for a time increment $\Delta \mathrm{t}$ can be written as (Skaggs, 1999):

$$
\Delta \mathrm{Va}=\mathrm{D}+\mathrm{ET}+\mathrm{DS}-\mathrm{I}
$$

where $\Delta \mathrm{Va}$ is change of water free pore space or air volume $(\mathrm{cm}), \mathrm{D}$ is drainage (or subirrigation) from the soil profile $(\mathrm{cm})$, ET is evapotranspiration $(\mathrm{cm})$, DS is deep seepage $(\mathrm{cm})$, and I is infiltration entering the soil profile $(\mathrm{cm})$. A water balance is also computed at the soil surface for each time increment using:

$$
\mathrm{P}=\mathrm{I}+\Delta \mathrm{S}+\mathrm{RO}
$$


where $\mathrm{P}=$ precipitation $(\mathrm{cm}), \Delta \mathrm{S}=$ change in volume of water stored on the surface $(\mathrm{cm})$, $\mathrm{RO}=$ surface runoff $(\mathrm{cm})$ and $\mathrm{I}$, again is infiltration entering the soil profile $(\mathrm{cm})$.

The soil plot extends from the soil surface to the top of a restrictive layer.

Precipitation falling on the plot surface collects in shallow depressions and then infiltrates the soil. Once the storage capacity of the depressions is filled, remaining precipitation leaves the plot area by surface runoff. Water that infiltrates moves through an unsaturated zone to the water table. Below the water table the water drains from the plot by lateral movement or vertically downward through a restrictive layer. The volume of water-free pore space above the water table, VA $\left(\mathrm{cm}^{3} \mathrm{~cm}^{-2}\right.$ surface area), is related to water table depth (WTD) and is a function of the soil water characteristic and thickness of individual soil horizons (Skaggs, 1999). Each plot is considered separately, and water draining from a specific plot is assumed to be lost from the landscape and assumed to not directly affect another plot.

DRAINMOD computes the subsurface drainage rate of water that leaves the pedon below the water table in one of two ways depending on whether the surface is ponded with water or not. For the more typical non-ponded conditions, the subsurface drainage rate is computed using the steady-state Hooghoudt equation (Bouwer and van Schlifgaarde, 1963). It is assumed that the water table is elliptically shaped between parallel drains and that most drainage occurs below the water table by water moving laterally toward the drains. The Hooghoudt equation may be written as:

$$
\mathrm{q}=\underline{8 \mathrm{Kd}} \underline{\underline{\mathrm{m}}+4 \mathrm{Km}^{2}} \mathrm{~L}^{2}
$$


where $\mathrm{q}$ is drainage rate $(\mathrm{cm} / \mathrm{h}), \mathrm{d}_{\mathrm{e}}$ is the effective depth of the restrictive layer below the drain $(\mathrm{cm}), \mathrm{m}$ is the water table height above the drain $(\mathrm{cm})$ in the soil plot which is assumed to be located at a point midway between ditches, $\mathrm{K}$ is effective lateral saturated hydraulic conductivity $(\mathrm{cm} / \mathrm{h})$, and $\mathrm{L}$ is distance between drains $(\mathrm{cm})$.

During large storm events or long continuous wet periods the water table may rise to the surface. In such cases the water table does not have the elliptical shape assumed in Hooghoudt equation, and an equation developed by Kirkham (1957) is used in DRAINMOD to quantify drainage.

Climatic inputs for the model include hourly values for precipitation and daily potential evapotranspiration (PET). The Thornthwaite (1948) method was used to calculate PET in this study. Daily maximum and minimum temperature data were obtained from the nearest available weather station. The monthly correction factors of PET used in the model were obtained from Workman et al. (1994). Because the vegetation at the two experimental sites was forest, rooting depth was the only plant factor considered. Rooting depth was determined from soil pits dug in each plot.

Soil property inputs include soil water characteristics of the A horizon and saturated hydraulic conductivity of soil horizons from the surface to the top of the restrictive layer. Infiltration is calculated by the Green-Ampt equation (Green and Ampt, 1911):

$$
f=\mathrm{A} / \mathrm{F}+\mathrm{B}
$$

where $f$ is infiltration rate $(\mathrm{cm} / \mathrm{h}), \mathrm{F}$ is cumulative infiltration $(\mathrm{cm}), \mathrm{A}$ and $\mathrm{B}$ are parameters that depend on soil properties. The relationship of parameters A and B with 
water table depth was calculated in this application using the soil preparation program within DRAINMOD.

Surface storage capacity was characterized by the average depth of depression storage that must be satisfied before runoff can begin. Depressional storage parameters are usually estimated visually in the field according to the topography. In most cases it is assumed that depressional storage is evenly distributed over the field. Depressional storage parameters $<0.5 \mathrm{~cm}$ indicate little ponding of water occurs because the surface is relatively smooth. Areas with some depressions where water ponds after rains have depression storage values between 1 and $1.5 \mathrm{~cm}$, while areas with many depressions causing widespread ponding of water after heavy rains have depression storage values $>2$ $\mathrm{cm}$.

\section{Model Calibration}

The DRAINMOD model was calibrated separately for each experimental plot for the Greenville and Bertie sites using a short-term record of observed weather data and water table measurements recorded over a 1 to 3 yr period. Predicted and monitored water table fluctuations were compared and then model parameters were adjusted individually to better model measured values. The agreement between monitored and predicted daily water table depths was quantified by the absolute deviation $(\alpha)$ for the observed period defined as follows:

$$
\alpha=\underline{\Sigma \mid Y_{\underline{m}}}-\underline{Y_{p}} \mid
$$


where $\mathrm{n}$ was number of days in observed period, $\mathrm{Y}_{\mathrm{m}}$ was monitored water table depth at midnight of each day $(\mathrm{cm})$, and $\mathrm{Y}_{\mathrm{p}}$ was corresponding predicted water table depth $(\mathrm{cm})$. Average absolute deviations for calibrated models in all plots were generally $\leq 16 \mathrm{~cm}$ at the Greenville site, and $\leq 20 \mathrm{~cm}$ at the Bertie site as reported by He et al. (2002). DRAINMOD produced an output for the analysis of wetland hydrology criteria for each plot at Greenville and Bertie.

\section{Minnesota Investigation}

Research data from Minnesota were collected on the USDA Forest Service's Marcell Experimental Forest (MEF) located in the Chippewa National Forest near Grand Rapids, MN. Water table measurements were collected over a 45-year period. MEF (Fig. 4) has six calibrated watersheds that consist of a mineral soil upland and an organic soil peatland. The dominant vegetation in the sandy uplands consisted of red pine (Pinus resinosa L.), jack pine (Pinus banksiana L.), aspen (Populus tremuloides L.), white birch (Betula papyrifera L.), balsam fir (Abies balsamea L.) and white spruce (Picea glauca L.). Dominant overstory vegetation of the forested bogs are black spruce (Picea mariana L.) and eastern tamarack (Larix laricina L.). The dominant understory vegetation in the peatlands consists of sphagnum mosses and ericaceae shrubs. Dominant vegetation in the forested fen is similar to the forested but and also have northern white cedar (Thuja occidentalis L.) and occasionally black ash (Fraxinus nigra L.). MEF consisted of soils in the following series: Loxley peat (Dysic Typic Borosaprist), Mooselake peat (Euic Typic Borohemist), and Greenwood peat (Dysic Typic Borosaprist). Plots were labeled as $\mathrm{S} 1, \mathrm{~S} 2, \mathrm{~S} 3, \mathrm{~S} 4, \mathrm{~S} 5$ and S6 to represent the individual peatlands in the six experimental watersheds. The peatland soils present within each experimental watershed included 
Loxley (S1, S2, S4, and S5), Mooselake (S3) and Greenwood (S6). Wells were located near the center of each peatland.

\section{Assessment of the Hydrology Technical Standard}

The Corps Hydrology Technical Standard was developed by the Army Corps of Engineers to determine wetland hydrology using their definition of wetland hydrology along with a single season of data. The accuracy of the Technical Standard was assessed in this study by comparing its results to long-term data records. The same approach was used for all three-study sites. A set of daily water table measurements that spanned 40 to 45 years was obtained for each experimental plot. The number of years that the water table was within $30 \mathrm{~cm}$ of the surface for 14 or more continuous days during the growing season was then determined. Wetland hydrology was considered met where the water table was within $30 \mathrm{~cm}$ of the surface, 14 or more days in $50 \%$ of the years or more.

The Corps definition of wetland hydrology requires that the duration of saturation last at least 5\% of the growing season (Environmental Laboratory, 1987). Growing season start and stop dates, as well as duration was obtained from the WETS data tables

(Table 5). In all cases, the data for growing season was that for an air temperature of $-2^{\circ}$ $\mathrm{C}\left(28^{\circ} \mathrm{F}\right)$ and a probability of $5 \mathrm{yr}$ in 10 (Tables 1-3). To determine air temperature effects on plants, three main threshold temperature values are used in growing season date evaluation. These threshold temperature values are 32,28 and $24^{\circ} \mathrm{F} .32$ to $29^{\circ} \mathrm{F}$ is a light freeze and does not greatly affect plant tissue, while 28 to $25^{\circ} \mathrm{F}$ is a moderate freeze and creates significant tissue damage on most vegetation, while anything below $25^{\circ} \mathrm{F}$ creates a severe freeze (NRCS, 1995). For the sites used here, 5\% of the growing season was 12 days for the Greenville and Bertie sites, and 7 days for the Marcell site (Table 5). 
Thus, if a plot met wetland hydrology using a 14-day limit, then it would also meet it using a limit of $5 \%$ of the growing season. However, the 14 day limit might underestimate the number of years hydrology is met.

\section{Long-Term Data Assessment}

Long-term data records spanning 40 to 45 years of daily water table levels were obtained for all experimental plots. Data for the NC sites (Greenville and Bertie) were obtained through simulation using calibrated DRAINMOD models. Data for the MN sites were obtained through direct measurements of water table levels.

Historic water table levels for North Carolina sites were predicted using the calibrated DRAINMOD models for each plot and long-term rainfall and temperature data. A 40-yr record of daily rainfall data was available for the Greenville site from the period of January 1, 1959 through December 31, 1998 from a weather station located 9.2 $\mathrm{km}$ from the site (Pitt County Airport). A 45-year record of daily rainfall data was available for the Bertie site from the period of January 1, 1950 through December 31, 1994 from the Lewiston weather station located in Bertie County. The daily rainfall data from both sites were then disaggregated into hourly data and converted to a format compatible with DRAINMOD using a computer program developed by Robbins (1988). Daily maximum and minimum temperature data and geographic location were required for the PET (potential evapotranspiration) calculation in DRAINMOD (He et al., 2002). These data were also obtained from the weather station located at Pitt County Airport and Lewiston weather station (He et al., 2002).

Daily water table levels were computed for each of the 9 plots at the Greenville site for the previous 40 years and 8 plots at the Bertie site for the previous 45 years using 
the calibrated DRAINMOD models. Required inputs for the DRAINMOD model to calculate the number of years w hen the wetland hydrology criteria was met included the starting and ending day of the simulation, continuous days of saturation, and maximum depth to saturation. Hydrology "within the growing season" and "outside of the growing season" were parameters of interest. One depth, at $30 \mathrm{~cm}$, was simulated to analyze the hydrology. The DRAINMOD model computed the number of years that a site had a water table within $30 \mathrm{~cm}$ of the surface for 14 consecutive days or longer during the growing season (Fig. 5).

Plots at both Greenville and Bertie sites were divided into two groups, those meeting hydric soil field indicators, and those not meeting indicators. Five plots at the Greenville site met a field indicator and those plots were located in the Rains and Pantego soil series. Five plots at the Bertie site met a field indicator and those plots were located in the Lenoir and Leaf soil series. For each of these plots, the years when the water table was above a depth of $30 \mathrm{~cm}$ for 14 consecutive days or longer during the growing season were identified. . For both Minnesota and North Carolina plots, rainfall data were then examined for each saturation period to determine whether the antecedent moisture was normal, above normal, or below normal.

\section{Applying the Hydrology Technical Standard}

The second step of the procedure to assess the Hydrology Technical Standard was to apply it to each year of the long-term data for each plot at all sites, to determine the number of years in which a plot met wetland hydrology according to the Technical Standard. If a water table was within $30 \mathrm{~cm}$ of the surface, for 14 days or more during 
the growing season, when antecedent rainfall had been within a normal or drier than normal range, then wetland hydrology was judged to be met for that year.

Sprecher and Warne (2000) specified that at least two different methods could be used for assessing antecedent rainfall. One method used a 30-day moving total, while the second considered a 3-month period and weighted the rainfall differently for each month. In this study, two variations of each short-term method were computed to determine when the Hydrology Technical Standard was met. The short-term rainfall methods were named: 1) Direct Antecedent Rainfall Method (DAREM), 2) Modified DAREM, 3) 30Day Moving Total and 4) Modified 30-Day Moving Total.

For each evaluation method, water table level data was analyzed rather than periods of normal rainfall. For a given year, the water table record was examined during the growing season to see first if a period of saturation occurred where the water table rose to within $30 \mathrm{~cm}$ of the surface for at least 14 days. If such a period of saturation did not occur, the year was not considered further. If it did, then the rainfall was examined next to determine if rainfall was normal, below normal or wetter than normal using each of the four methods described below separately. For example, if the modified DAREM approach was being considered, then it was applied to the period prior to when the water table rose above a depth of $30 \mathrm{~cm}$. If the rainfall was found to be normal or drier than normal for the modified DAREM approach, then tat year was considered to have met the wetland hydrology criteria and another method of rainfall evaluation was tested. On the other hand, if rainfall was found to be wetter than normal with the modified DAREM approach, then additional periods during the same year were examined to determine if the water table was within $30 \mathrm{~cm}$ of the surface during a period of normal or drier than 
normal rainfall. If a year was considered to be wetter then normal for the modified DAREM approach, that meant that there was no period during that year when the water table was within $30 \mathrm{~cm}$ of the surface during a period of normal or drier than normal rainfall. Periods of normal rainfall were not considered if they did not have a water table within $30 \mathrm{~cm}$ of the surface for 14 days or longer. Once the analysis was finished with the modified DAREM approach, the DAREM approach was applied to determine if any period when the water table was within $30 \mathrm{~cm}$ met a normal or drier than normal condition. This approach was used for the raining methods of rainfall evaluation.

Direct Antecedent Rainfall Method (DAREM). The Direct Antecedent Rainfall Evaluation Method (DAREM) uses the previous 3 months of precipitation data to determine when saturation occurs during normal or below normal rainfall. To evaluate measured rainfall one compares it to the $30^{\text {th }}$ and $70^{\text {th }}$ percentiles found in a WETS data table (Example Table 6). The example shown in Table 6 evaluated precipitation data for plot $1 \mathrm{R}$ at the Greenville site for the year 1959 for the month of June. Assume that the water table rose on June 16 and remained within $30 \mathrm{~cm}$ of the surface for 20 days, falling below $30 \mathrm{~cm}$ on July 6 . For this method, rainfall coming during the month that the water table first rose above a depth of $30 \mathrm{~cm}$ (June) is not of interest, nor is any rainfall of interest that came after the water table had risen to the target depth $(30 \mathrm{~cm})$. Therefore, the antecedent rainfall is considered to be that falling in May, April, and March. As shown in Table 6, these three months are written in the table. The $30^{\text {th }}$ and $70^{\text {th }}$ percentile values from the WETS data table for Greenville are factored into the table. Also the rainfall data measured on-site is placed into the table. The measured rainfall values for each month can be classified as having a "dry", "wet", or "normal" condition 
by comparing the values to the WETS percentiles for the appropriate month. Rainfall for May was classified as having a "dry" condition because the measured value $(3.29 \mathrm{~cm})$ was less than that shown for the $30^{\text {th }}$ percentile in May $(7.09 \mathrm{~cm})$. Rainfall values for the months of April and March were classified as having a "wet" condition because they were higher than the values for the $70^{\text {th }}$ percentiles for each of these months. A condition value is then determined for each of the conditions were identified. A monthly weight value is automatically specified on the table. Values are then multiplied and the products are reported and summed. For the example in Table 6, the sum is 12 and this is considered to be "normal" antecedent rainfall. The overall conclusion is that plot $1 \mathrm{R}$ met the requirements for wetland hydrology in 1959 because the water table was within 30 $\mathrm{cm}$ of the surface for 14 days or more during the growing season during a period of normal antecedent rainfall.

The DAREM approach was completed for each year of the long-term water table data record (40 years for Greenville, 45 years for Bertie, 45 years for Marcell). Results from the DAREM calculations were summarized by computing the percentage of years that each plot met wetland hydrology. This percentage was then compared to percentages of years that met wetland hydrology obtained from the long-term data records.

Modified DAREM Approach. The modified-DAREM approach was developed following discussions with Dr. Paul Rodrigue of the USDA in 2005. This method uses the same calculations as DAREM, but it utilizes a different method for selecting the first or most recent "prior month" to incorporate the most recent precipitation. For example, if the water table rose to within $30 \mathrm{~cm}$ of the surface during the first 14 days of a month, then the calculation is similar to that used for DAREM — the first prior month is that of 
the preceding month as described earlier. However, if the water table rose to within 30 $\mathrm{cm}$ of the surface on days 15 to 27 of a given month, then the first 15 days of the month are prorated to determine if precipitation was categorized as of dry, normal, or wet rainfall. If the water table rose to within $30 \mathrm{~cm}$ of the surface on day 28 or later, then the entire month is used as the first prior month.

An example calculation using this method is shown in Table 7 for the same data that was illustrated previously in Table 6. Data are for site 1R at Greenville for 1959. The water table rose above a depth of $30 \mathrm{~cm}$ on day 16 of June. Therefore, June is the first prior month used in the calculations. Only rainfall coming in the first one-half of the month is considered (days 1 to 15 ) in this method. Because the $30^{\text {th }}$ and $70^{\text {th }}$ percentiles, as well as the measured monthly rainfall for June, were determined for the entire month, the values shown in Table 7 for June are prorated, that is the monthly WETS values and measured rainfall for June were multiplied by 0.5 before putting them into Table 7 . All other calculations are the same as described previously.

Prorated June data (Table 7) was classified as having a dry condition. Conditions for May and April rainfall remained the same as previously discussed. The overall conclusion is that the antecedent rainfall was drier than normal. Therefore, the plot analyses of these data indicate that wetland hydrology requirements for the Hydrology Technical Standard are satisfied.

30-Day Moving Total Method. Long-term precipitation records were placed in spreadsheets. The first 30 days of rainfall values (days 1 to 30 ) were summed to generate the first moving total value (Table 8). The second moving total value summed rainfall amounts for days 2 to 31 . This was done for all the days of each year. 
Moving total values that were generated for each day of the year after the first 30 days were then plotted against days of the year along with the yearly $70^{\text {th }}$ percentile (above normal precipitation values obtained from WETS Tables) values using graphs (Figure 6). Moving total graphs were computed for each year in each plot (Greenville: 1959 through 1998, Bertie: 1950 through 1994, and Marcel: 1961 through 2005). Moving total graphs were then compared with water table data from each plot at each site to determine when the water table was within $30 \mathrm{~cm}$ of the surface for 14 or more days during the growing season. This criterion was only met when the moving total was below the $70^{\text {th }}$ percentile line for a total of at least 30 days, which is considered to be a 30 -day period of normal or drier than normal rainfall. Plots met wetland hydrology when saturation, for at least 14 days, occurred during a time when the 30-day moving total was less than the $70^{\text {th }}$ percentile rainfall amount. Plots did not meet wetland hydrology if they met water table requirements during a period when the 30-day moving total was above the $70^{\text {th }}$ percentile rainfall threshold.

Modified 30-Day Moving Total Method. The moving total procedure previously described was altered slightly to incorporate prior precipitation, and used to evaluate all plots at the three sites on a 60 day basis. Moving total graphs generated in the regular 30-day moving total method were used again with water table levels. Like the previous method, plots that had a water table at or within $30 \mathrm{~cm}$ from the surface for 14 days or longer during the growing season, when rainfall was less than the $70^{\text {th }}$ percentile for 30 days or longer, met wetland hydrology. However, this method differs from the pervious method because an additional 30 days of rainfall prior to the 30-day normal or drier than normal precipitation period was considered. Consistent wet periods (when the 
moving total was above the $70^{\text {th }}$ percentile) and large above normal precipitation periods that occurred within 30 days before the moving total fell into "normal" or "drier than normal" precipitation, were taken into consideration. This was considered a 60-day moving total. These long wet periods or large precipitation events were considered in wetland hydrology evaluation to obtain the correct wetland hydrology condition. Plots that met the water table criteria after the moving total had fallen beneath the $70^{\text {th }}$ percentile line were considered "wet" because large precipitation events in prior 60 days affected saturation of the water tables. For example, water table saturation could be falsely represented as meeting wetland hydrology because it meets the saturation criterion, but only meets the criterion due to either long periods of above normal precipitation or a large precipitation event (such as a hurricane). Plots that had a moving total consistently under the $70^{\text {th }}$ percentile line, or had normal or drier than normal precipitation, when the water table was within $30 \mathrm{~cm}$ for 14 days or longer met wetland hydrology because saturation was not caused by a large precipitation event. Years were only excluded if there was a high spike in 30-day prior precipitation in the 60 -day moving total before the 14-day saturation occurred (Fig. 7). 


\section{RESULTS}

Wetland hydrology occurs in a soil when the water table is at the surface for 5$12 \%$ or more of the growing season in at least $50 \%$ of the years (Environmental Laboratory, 1987). The Corps of Engineers Technical Standard for Wetland Hydrology considers wetland hydrology met if a water table is within $30 \mathrm{~cm}$ of the surface for 14 days or more during the growing season, during a time when antecedent rainfall is normal or drier than normal. This study evaluated four methods for assessing antecedent rainfall with the Corps's Wetland Hydrology Technical Standard.

\section{Long-term Water Table Data}

Long-term (40 to $45 \mathrm{yr}$ ) water table levels were determined for each plot used in this study to identify those plots that met wetland hydrology as defined for the Technical Standard. There were 17 plots that met wetland hydrology across the three sites (Table 9). At the Greenville and Bertie sites, all plots meeting criterion for determination of wetland hydrology had a water table within $30 \mathrm{~cm}$ of the surface for 14 days or more during the growing season in over $80 \%$ of the years. All but one of these plots also met a hydric soil field indicator, usually either an Umbric Surface (F13) or a Depleted Matrix (F3) (USDA, NRCS, 2002). A typical summary of the annual durations for when the water table was within $30 \mathrm{~cm}$ of the surface is shown in Figure 8 for plot $4 \mathrm{R}$ at the Greenville site. For a given year, the water table was within $30 \mathrm{~cm}$ of the surface for periods ranging from 20 to nearly 80 days. Only 2 years had water tables within $30 \mathrm{~cm}$ of the surface for less than 14 days. These years were isolated cases in that the years before and after had water tables within $30 \mathrm{~cm}$ for more than 14 days. 
At the Marcell site in $\mathrm{MN}$, all six peatlands met criterion for determination of wetland hydrology, and these plots also met a hydric soil field indicator (Table 9). The number of years when the water table was within $30 \mathrm{~cm}$ of the surface for 14 days or more during the growing season ranged broadly from 53 to $100 \%$. As shown in Figure 6, plot S3, which was the fen, did not have a water table within $30 \mathrm{~cm}$ of the surface (dry) for the 19 out of 21 years from 1961 through 1982, but did have a water table within 30 $\mathrm{cm}$ in most years after 1982. A similar water table record was found in plot S6, which was a cross between a fen and a bog. The 1960's and 1970's were dry in the portion of Minnesota where these wetlands were found even though hydric soil field indicators were met.

Six plots did not meet saturation criterion for determining wetland hydrology at the Greenville and Bertie sites (Table 9). Proportions of time when water tables were within $30 \mathrm{~cm}$ of the surface for 14 days were very low $(\leq 11 \%)$. None of the soils in these plots met field indicators.

\section{Methods for Evaluating Antecedent Rainfall}

Long-term water table data indicated that the plots with hydric soils had a water table within $30 \mathrm{~cm}$ of the surface for at least 14 days on average in $90 \%$ of the years evaluated (Table 10 and Table 11). Using either of the two 30-day moving total approaches for evaluating antecedent rainfall with the Technical Standard resulted in a site being judged to have met criterion for determination of wetland hydrology in approximately 40 to $50 \%$ of the years. The "Corps's 30-day Moving Total Method" produced results closer to long-term data than the "Modified 30-day Moving Total" but 
the difference was small between the two methods. Neither moving total method seems suitable for evaluating antecedent rainfall for the Corps's Hydrology Technical Standard.

Better results were obtained with either the DAREM approach or modified DAREM approach for assessing antecedent rainfall when water table saturation criterion were analyzed (Table 11). The hydric soil plots satisfied the wetland hydrology requirement in approximately $80 \%$ of the years with either DAREM or Modified DAREM methods compared with long-term records that satisfied the wetland hydrology requirement in approximately $90 \%$ of the years. The poorest agreement for all antecedent precipitation methods were found for the Bertie sites in NC. The Bertie site had high amounts of precipitation throughout the long-term record, and this produced a relatively large number of wet years.

The 30-day moving total methods considered a 30-day period when evaluating antecedent precipitation. This approach tended to classify periods during the early part of the growing season as wetter than normal (Figure 6). This was a time when water tables were within $30 \mathrm{~cm}$ of the surface. However, if the 30-day moving total rose above the 70th percentile then the period was classified as "wet" then the water table data could not be used for evaluating wetland hydrology. Suitable rainfall periods tended to be found later in the growing season (Figure 6), but this coincided with the times when water tables tended to fall below a $30 \mathrm{~cm}$ depth. A partial summary of the results found in one plot using the 30-day moving total approach is shown in Table 12. For the 20-year record shown, the water table was within $30 \mathrm{~cm}$ of the surface for an appropriate length of time in 7 of the years, but the period was considered too wet because the moving total rainfall amount exceeded the $70^{\text {th }}$ percentile. 
One reason the DAREM and modified DAREM performed better is that they considered a longer period of antecedent rainfall (approximately 90 days) than did either 30-day moving total methods. With the modified DAREM (Table 13), if the most recent month, or the month preceding the time when the water table is within 30 of the surface, is classified as "wet", the period may still be acceptable if the $2^{\text {nd }}$ or $3^{\text {rd }}$ prior months have normal and drier than normal rainfall amounts. When the same rainfall data are analyzed by a moving total method, the 30 -day period prior to the time the water table is within 30 $\mathrm{cm}$, would be above the $70^{\text {th }}$ percentile and would be unusable. The manner in which the methods treat wet years can be illustrated by comparing the results from the modified DAREM (Table 14) to those found with the Corps 30-day moving total method (Table 12) for the same plot and time period. The Corps 30-day moving total method found the following seven years to be "wet" and unusable when the water table was within $30 \mathrm{~cm}$ of the surface for 14 days or more: 1961, 1962, 1964, 1968, 1973, 1975, and 1977. When the same water table data were evaluated with the modified DAREM, it was found that the periods were normal in terms of rainfall and only 2 years were too wet, 1960 and 1964 (Table 14). Evaluating rainfall with either moving total approach tended to exclude more years because they were too "wet" than did either method that considered rainfall during a prior 3-month period (Table 15). Again, results were obtained by analysis of water table saturation criteria rather than considering period of normal rainfall throughout the years studied at each plot. 


\section{Length of Monitoring Periods}

The Hydrology Technical Standard was developed to evaluate data collected in a single year. As shown previously, wet or dry years will be encountered that require measurements be made for more than a single year. Table 16 shows how long a site that meets criterion for wetland hydrology would have to be monitored if a single season of data was not sufficient to prove whether wetland hydrology existed at a site. For example, plot $1 \mathrm{R}$ at the Greenville site was $3 \mathrm{~m}$ from a ditch (Fig. 2) and did not meet wetland hydrology requirements in 10 years when rainfall was evaluated by the modified DAREM. Two of the 10 years were single years, where wetland hydrology was met in prior and following years, thus monitoring would have to be continued for at least 2 years to confirm wetland hydrology. Three sets of 2-consecutive years also occurred, resulting in monitoring for 3 consecutive years to evaluate wetland hydrology. At the Greenville site, the average values show that most plots did not meet wetland hydrology in single years rather than two consecutive years or more in short-term evaluation methods.

The Bertie site posed more challenges for monitoring than did the Greenville site because years removed from the record due to above normal rainfall (wetness) occurred in consecutive years, and not single years like the Greenville site. On average, plots in the Bertie site did not meet wetland hydrology in 11 years. Five of these years were single year events, where previous and following years met wetland hydrology requirements. However, two plots at the Bertie site (plots $3 \mathrm{~N}$ and $3 \mathrm{~S}$ ) experienced extensive periods of 4 to 5 consecutive years where wetland hydrology was not met due to above normal precipitation conditions. Monitoring would have to be done for 8 to 10 years in cases where long periods of dry or wet weather were encountered. As shown in Fig. 3, plots 
$3 \mathrm{~N}$ and $3 \mathrm{~S}$ were on the edge of the hydric soil area with the upland. These areas would be expected to meet wetland hydrology less often than plots further downslope.

The Marcell site in MN also had two problematic plots that did not meet wetland hydrology in consecutive periods of 5 or more years (Table 16). The two plots (fen plot S3 and plot S6) had periods of ranging from 5 to 15 consecutive years where wetland hydrology was not met. Both plots were supplied by groundwater in a much larger water source, while the other four plots at MEF were supplied with direct precipitation. During the first 20 years water table levels were not within $30 \mathrm{~cm}$ of the surface for 14 days or more within the growing season.

Long-term water table records for fen plot S3 (Fig. 9) indicate 19 dry years, 1 wet year, and 1 year that met wetland hydrology within the first half of the long-term record (1961-1981). It met wetland hydrology in 21 years, and had only one wet year and two dry years during the second half of the long-term record (1982-2005). This indicates that the fen did not reach the $30 \mathrm{~cm}$ saturation criteria for the first 20 years of measurement. However, the last 25 years of the record indicates that the fen's groundwater system may have risen just high enough to meet the saturation criteria.

Plot S6 had similar results; there were 10 dry years within the first 11 years of the long-term record while also having one wet year (1965-1976). However, S6 met wetland hydrology 26 times in the remaining 29 years of the record, while having one wet year and two dry years (1977-2005). Both plots S3 and S6 also had water tables that were saturated relatively close to $30 \mathrm{~cm}$ (within 35 to $40 \mathrm{~cm}$ ) but were considered dry because they did not reach the $30 \mathrm{~cm}$ saturation mark. Plot S6 also is part fen and fed through a groundwater system, which could have risen within 20 years to levels that satisfied the 30 
$\mathrm{cm}$ saturation criteria. However, with the exception of a few initial years in Plot S1, all other plots at Marcell did not have problems meeting water table saturation criterion during the first half of the long-term wetland hydrology record due to direct precipitation.

There was much variability among plots in a single site as shown in Table 16 where some plots did not meet wetland hydrology in 4 years, but other plots did not meet it for 15 years. To increase the chance that sites with wetland hydrology are found to meet the Technical Standard in single years, multiple plots need to be instrumented. Plots should be placed along transects, perpendicular to the contour, beginning in an upland area near the suspected wetland boundary and extending down into the lowest topographic position. Multiple transects are warranted for large sites, and where funds permit. Plots most likely requiring more than a single year of measurement will be near ditches and near wetland boundaries.

\section{Monitoring Upland Plots}

Upland plots, which did not meet wetland hydrology based on long-term measurements, were also examined to see if they met wetland hydrology with single season data. As shown in Table 17, long-term measurements showed that only three plots had a water table within $30 \mathrm{~cm}$ of the surface for 14 days or more. Rainfall assessment using either moving total method did not find any year acceptable for use with the Hydrology Technical Standard. However, either of the two methods considering a 3 -month period would have considered plot $2 \mathrm{~N}$ to have met wetland hydrology in $2 \%$ of the years. Using the modified DAREM, Plot $2 \mathrm{~N}$ was found to have met wetland hydrology in only one of the 45 years had the Hydrology Technical Standard been used 
in that single year to monitor water table levels and rainfall (Table 18). This finding shows that false positive results are possible with the Hydrology Technical Standard, but the chance of getting a false positive appears to be negligible as it would have occurred only once in 45 years in only one of six plots. 


\section{DISCUSSION}

Although long-term hydrologic records (>30 years) are the most reliable and best evidence to use to evaluate a site's long-term wetland hydrology, such records are time consuming and expensive to acquire, and may not be available for most sites. Four shortterm methods developed by the Army Corps were evaluated in this study. Two methods were found to be reliable ways to evaluate wetland hydrology over the period of one growing season. They are inexpensive and require less site monitoring time. The two methods, DAREM and Modified DAREM, had fewer wet years that were unusable than the moving total methods, and were more consistent with the findings from long-term records.

Long-term wetland hydrology records used in this research included wet years, with high amounts of precipitation, and dry years, with low amounts of precipitation, as well as normal years of precipitation that spanned 40 to 45 years. However, wet periods are removed from the short-term records so that the number of years that wetland hydrology is met is less with the short-term methods than with long-term methods. Data evaluated with the DAREM and Modified DAREM approaches met wetland hydrology in $80 \%$ of the years as compared to long-term records, which met criterion for determining wetland hydrology in $90 \%$ of the years (Table 11). Determinations using the moving total methods indicated the wetland hydrology criteria were satisfied in $45 \%$ of the years on average (Table 11). There are more years removed from records due to wetter than normal (>70\%) precipitation using both moving total methods than are removed in both DAREM methods. Most wet years excluded with moving total methods were included in DAREM and modified DAREM, because they fell within an acceptable 
period of rainfall as defined by the DAREM procedures. Three-month periods of precipitation were considered in the DAREM methods whereas only 1 month is considered in the moving total methods. Normal periods were found even when the most recent month was "wetter than normal", if the other two prior months were "normal" or "drier than normal".

Both 30-day moving total methods (Army Corps and the Corps-modified methods) did not include prior three month precipitation, but rather evaluated wetland hydrology based on a continuous 30-day total throughout the year. Plots did not satisfy the wetland hydrology requirement when the moving total rainfall was above the $70^{\text {th }}$ percentile. Similar results were also found by Hunt et al. (2001) for the 30-day moving total method. Hunt et al. (2001) concluded that periods of high water tables occurred during periods of above average rainfall. Because the moving total only consists of 30 days of precipitation throughout the year, large precipitation events impact the moving total drastically and increase the chance of a 30-day period being considered "wet" (Sprecher and Warne, 2000). For example a hurricane could sweep through the area and drop 8 to10 inches $(20-25 \mathrm{~cm})$ within one day. This precipitation will affect water table levels for several days, but it may not cause water tables to occur within $30 \mathrm{~cm}$ of the surface for 14 days. Yet the 30-day period that contains this single event will be considered wet and therefore the water table record will not be considered.

\section{False Positives and False Negatives}

One potential problem with these short-term evaluations of hydrology is the chance of falsely concluding that a site has wetland hydrology, even though long-term 
records show it does not. This is called a false positive. False positives only occurred in upland soils that not only did not meet wetland hydrology over the long-term, but were also not hydric soils. False positives occurred in only $3 \%$ of the years (1 year out of 40) for plots $2 \mathrm{~L}$ and $3 \mathrm{~L}$ at Greenville, and no years for the plots $1 \mathrm{~L}$ and $4 \mathrm{~L}$ at Greenville. The percentage of false positives was higher at the Bertie site for two plots, $11 \%$ of the years ( 5 out of 45 years) for plot $2 \mathrm{~N}$ and no years for plot $2 \mathrm{~S}$, which also were not hydric soils. False positives did not pose problems for determination of overall wetland hydrology for plots with hydric soils at Greenville and Bertie. No false positives occurred at the Marcell Experimental Forest because no upland soils were evaluated. Hunt et al. (2001) also found that the field method typically predicted upland sites to not meet the hydrologic criterion and that it was correctly predicted for $99 \%$ of the sites.

False negative conclusions are also the potential problem and these occurred when wet periods were excluded from being considered for wetland hydrology analysis in plots that met the criterion for determination of wetland hydrology according to longterm records. Although some of these years had normal periods of rainfall, water table saturation criterion only occurred during above normal rainfall and was then considered to be wet. On average, moving total methods had a $45 \%$ chance of a false negative (Table 19), which means that in all the years evaluated, an average of $45 \%$ had years that met criterion for determination wetland hydrology in the long-term records, but wetland hydrology could not be confirmed in a short-term study due to above normal rainfall. Both DAREM approaches had less of a chance (about 12\%) of identifying false negatives in the short-term records (Table 19). Hunt et al. (2001) also looked at 30-day moving totals, which failed to correctly assess hydrologic status on an even larger percentage of 
wetland sites than when "average" rainfall was evaluated on a monthly basis. Only $13 \%$ of marginal wetlands were predicted to have wetland hydrology in the Hunt et al. (2001) study, while the 30-day moving total method incorrectly predicted wet sites $87 \%$ of the time.

\section{Site Monitoring Time}

Most of the years that were removed from the record due to above normal precipitation occurred as single years. However, some plots did not meet the criterion for determining wetland hydrology in two consecutive years due to above normal rainfall. During these two years, water table saturation criterion was met during above normal rainfall and did not occur during any periods of normal or drier than normal rainfall. There were three periods of 4 and 5 consecutive years at plots $3 \mathrm{~N}$ and $3 \mathrm{~S}$ for Bertie as well as three periods of 5,10 and 15 consecutive years at Marcell that did not meet the criterion for determining wetland hydrology. These 4-5 year consecutive periods that occurred at Bertie were due to above normal rainfall. Long consecutive periods at Marcell that did not meet the criterion for determining wetland hydrology were due to different water sources that feed fens as opposed to bogs at the MEF. The water table was not saturated at $30 \mathrm{~cm}$ from the surface for at least 14 days during these periods.

Although most plots studied had single years that did not accurately predict wetland hydrology, 2 to 3 years of monitoring would be optimum to accurately predict wetland hydrology. Potential periods of above normal rainfall could provide false negatives at a site that does actually meet wetland hydrology. To avoid false negatives, more years would have to be monitored. The plots that had 2 or more consecutive years that did not 
meet the criterion for determining wetland hydrology occurred less frequently than plots where wetland hydrology saturation criterion was met in single years.

\section{Evaluating Data from Wet Years}

Results also indicated that adjacent upland soil plots without hydric indicators should be monitored for one year to obtain an accurate assessment of wetland hydrology at a site. Adjacent plots that do not meet hydric soil field indicators may be used to incorporate wet periods into short-term records. To do this, adjacent soil plots that do not meet a hydric soil field indicator would also have to be monitored to determine if their water table was within $30 \mathrm{~cm}$ of the surface during a wet period or wet year. If the adjacent soil plot did not meet the water table saturation criterion during the wet periods and wet years, then plots that do meet hydric soil field indicators could be incorporated into the short-term record having wetland hydrology. However, this would also depend on relative wetness at the site and how far up the landscape these adjacent upland soils occurred. As Table 9 indicates, the sites in NC (Greenville and Bertie) had soils that met hydric soil field indicators and adjacent soils that did not have any hydric soil field indicators present. If a plot within the Rains series did not meet wetland hydrology due to above normal rainfall, then a plot within the Lynchburg series could be analyzed to determine if it met wetland hydrology during the same period of above normal rainfall.

To lessen the chance of false positive or negative conclusions occurring, it is recommended that data be collected along transects that span hydric and non-hydric soils. Non-hydric soils should be located upslope from hydric soils. Water tables from transects should be monitored over the period of one growing season and evaluated using 
DAREM approaches. Comparison of water tables of non-hydric soils and hydric soils will indicate if non-hydric soils do not have water table saturation within $30 \mathrm{~cm}$ for 14 days or longer during wet periods when the hydric soils meet water table criterion. Hydric soil field indicators need to be used to separate hydric soils from non-hydric soils. Non-hydric or upland soils would not meet any hydric soil field indicators. This evaluation technique could be the way that wet years are used for short-term evaluations. If adjacent, non-hydric plots do meet wetland hydrology when precipitation is above normal, then hydric soils at the site would need further monitoring to evaluate the hydrologic condition at the site under normal or drier than normal precipitation. Another way to incorporate wet years into short-term evaluations is to raise the depth requirement for the water table. In wet years, the water table depth requirement for wetland hydrology could be changed from $30 \mathrm{~cm}$ to $20 \mathrm{~cm}$. However, to confirm a new depth requirement requires that more plots be monitored than was done in this study. A water table within $20 \mathrm{~cm}$ of the surface during wetter than normal periods is suggested but has not been confirmed. For example, water tables from a wetter than normal period for plot $1 \mathrm{R}$, that met a hydric soil field indicator, could be compared to the water tables from a wetter than normal period for plot 1L. This would help compare plots and determine if the non-hydric plot met the 14-day saturation criterion to meet wetland hydrology and if it did not, than plot $1 \mathrm{R}$ that did meet the saturation criterion could be considered to have met wetland hydrology and the wet period would not be a factor. 


\section{Other Applications of Results}

Soil evaluation for use of onsite wastewater systems is another area to which this research could be applied. By regulation in most states, septic system drain lines or trenches need to maintain a minimum separation between the infiltrative surface (trench bottom) and the seasonal high water table (soil wetness condition) to prevent contamination of groundwater (American Ground Water Trust, 2006). Furthermore, systems need to maintain this separation every day throughout the year. In NC, the required separation distance between trench bottom and soil wetness is 12 inches $(30 \mathrm{~cm})$ in loamy and clayey soils or 18 inches $(45 \mathrm{~cm})$ in sandy soils (NCGA, 2005). Soil wetness is a term used by Regulators and is equivalent to the water table. If the water table is below 24 inches $(60 \mathrm{~cm})$ even during above normal rainfall periods, the site generally will be suitable based on soil wetness for septic systems. If it is above 24 inches but below 12 inches an alternative system may be used or the system would have to be placed in another suitable location.

The depth to soil wetness is determined by the presence of $>2 \%$ chroma 2 mottles. This method is considered reliable in most situations. However, in altered sites the soil morphology may no longer be reliable and the hydrology must be evaluated. Currently, the state of North Carolina uses an intensive and expensive monitoring and modeling procedure to evaluate soil wetness in altered sites. DAREM approaches may help simplify evaluation of hydrology by helping to identify precipitation periods that fall within an acceptable range.

The most important rainfall conditions that need to be evaluated to determine potential septic system sites are those with normal and above normal rainfall. These 
conditions provide the worst-case scenario. Onsite wastewater systems require the water table to be within a certain depth for suitability. If soil wetness is at or below 24 inches $(60 \mathrm{~cm})$ during the 14-day period of saturation when precipitation is either normal or wetter than normal, then the site is considered suitable for an in ground (no fill) septic system. However, if the 14-day period of saturation occurs when the water table is between 12 inches $(30 \mathrm{~cm})$ and 24 inches $(60 \mathrm{~cm})$, then the site would require a more costly alternative system. When the water table is between 12 inches $(30 \mathrm{~cm})$ and the surface, than the site is considered unsuitable for an onsite wastewater system.

To determine onsite wastewater systems suitability, the WETS Table $30^{\text {th }}$ percentile would be used to determine periods that were normal or wetter than normal, rather than use the $70^{\text {th }}$ percentile, as in the wetland hydrology evaluation methods. Drier than normal periods are not considered, because sites that meet the drier than normal condition (water tables deeper when precipitation is drier than normal) will be considered suitable and therefore are not a concern. However, to study worst-case scenarios, the onsite monitoring must focus mainly on above (wetter than) normal to normal rainfall, which is precipitation above the WETS Table $30^{\text {th }}$ percentile boundary. The periods to be evaluated for water table depth are from January to April as these are generally the periods when water tables are nearest to the surface (NCGA, 2005).

Both DAREM approaches could potentially be used to evaluate water table data from sites where septic systems are being considered. Both procedures would compare water table levels at the potential site with the evaluated precipitation conditions. Since the most important periods to look at are January through April, the best approach might be DAREM, or using a 90-day or 120-day moving total. These methods would provide a 
precipitation condition such as drier than normal, normal or above normal. Water tables could then be evaluated for the 14-day period of saturation required by rule .1942 (NCGA, 2005) during the months of January through April. Research on the four evaluated precipitation methods could be applied here to determine hydrology for potential septic system's suitability. 


\section{CONCLUSIONS}

An analysis of long-term water table records is the best way to assess wetland hydrology where sites meet saturation criteria in $90 \%$ of the years. However, short-term methods such as DAREM and Modified DAREM correctly predicted long-term wetland hydrology in $80 \%$ of the years evaluated. Both the 30-day moving total method and the modified 30-day moving total method satisfied the wetland hydrology requirement in $45 \%$ of the years evaluated for the same sites. Although the Modified DAREM produced a slightly higher percentage (81\%) over the DAREM (78\%), both methods could be used to accurately assess wetland hydrology over one to two growing seasons to predict longterm wetland hydrology. However, this is not the case for sites that only satisfy the wetland hydrology requirement in $60-75 \%$ of the years. Sites that only satisfy the wetland hydrology requirement in $60-75 \%$ of the years would require more monitoring time to correctly assess the hydrology condition.

False positives rarely occur in upland soils and should not be a concern in shortterm site monitoring. However, false negatives occur more frequently with all four methods, but less frequently with DAREM approaches, and might need to be monitored for longer than one growing season. Sites should be monitored over one growing season along with adjacent upland soil plots and to obtain the correct wetland hydrology

assessment. To lessen the chance of finding false positives, wetland hydrology from water tables of adjacent upland soil plots could be determined and compared with plots that did not meet wetland hydrology due to above normal precipitation.

There is also a large amount of variability among plots at a specific research site. Several plots should be studied at a site to get an accurate assessment of wetland 
hydrology over a single season. Some plots might be located close to drainage ditches, development or other areas that may disrupt accurate wetland hydrology measurements and therefore multiple plots should be assessed at a research site. 


\section{REFERENCES}

American Ground Water Trust. 2006. Septic Systems for Waste Disposal. Concord, NH. Available at: http://www.agwt.org/SepticSystems.htm. Accessed 28 August 2006.

Amoozegar, A. 1992. Compact constant head Permeameter: A convenient device for measuring hydraulic conductivity. p. 31-42. In G. C. Topp et al. (ed.) Advances in measurement of soil physical properties: Bringing theory into practice. SSSA Spec. Publ. 30. SSSA, Madison, WI.

Amoozegar, A., and A.W. Wilson. 1999. Methods for measuring hydraulic conductivity and drainable porosity. P. 1149-1205. In R. W. Skaggs et al. (ed.) Agricultural Drainage. Agron. Monogr. 38. ASA, CSSA, and SSSA, Madison, WI.

Black, P.E. 1996. Watershed Hydrology. $2^{\text {nd }}$ Ed. Ann Arbor, Chelsea.

Bonnin, G.M., B. Lin, and T. Parzybok. 2003. Updating NOAA/NWS rainfall frequency atlases. NWS, NOAA. Silver Spring, MD.

Bouwer, H., and J. van Schlifgaarde. 1963. Simplified method of prediction fall of water table in drained land. Trans. ASAE 6: 288-291.

Borga, M., C. Vezzani, and G.D. Fontana. 2005. Regional rainfall depth-durationfrequency equations for an alpine region. Natural Hazards 36: 221-235.

Buol, S.W., R.J. Southard, R.C. Graham, and P.A. McDaniel. 2003. Soil Genesis and Classification. $5^{\text {th }}$ Ed. Iowa State Press, Ames.

Cowardin, L.M., V. Carter, F.C. Golet, and E.T. LaRoe. 1979. Classification of Wetlands and Deepwater Habitats of the United States. FWS/OBS-79-31. USDI Fish and Wildlife Service, Washington, DC. 103 pp.

Environmental Laboratory, 1987. Corps of Engineers Wetland Delineation Manual. Technical Report Y-87-1. US Army Engineers Waterways Experiment Station, Vicksburg, MS.

Federal Register. July 13, 1994. Changes in hydric soils of the United States. Vol. 59, no. 133, page 35,680. U.S. Gov. Print. Office, Washington, DC.

Fouss, J.L., R.W. Skaggs, and J.S. Roberts. 1987. Two-stage weir control for subsurface drainage in humid areas. Trans. ASAE 30: 1713-1719.

Gayle, G.A., R.W. Skaggs, and C.E. Carter. 1985. Evaluation of a water management model for a Louisiana sugar cane field. J. Am. Soc. Sugar Cane Tech. 4:18-28. 
Gee, G.W., and J.W. Bauder, 1986. Particle-size analysis. p. 383-411. In A. Klute (ed.) Methods of soil analysis. Part 1. $2^{\text {nd }}$ ed. ASA and SSSA, Madison, WI.

Green, W.H., and G. Ampt. 1911. Studies of soil physics, Part I: The flow of air and water through soil. J. Agric. Sci. 4:1-24.

Hayes, W.A. and M.J. Vepraskas. 2000. Morphological changes in soils produced when hydrology is altered by ditching. Soil Sci. Soc. Am. J. 64: 1893-1904.

He, X., M.J. Vepraskas, R.W. Skaggs, and D.L. Lindbo. 2002. Adapting a drainage model to simulate water table levels in coastal plain soils. Soil Sci. Soc. Am. J. 66: 17221731.

He, X., M.J. Vepraskas, D.L. Lindbo, and R.W. Skaggs. 2003. A method to predict soil saturation frequency and duration from soil color. Soil Sci. Soc. Am. J. 67: 961-969.

Hershfield, D.M. 1961. Rainfall Frequency Atlas of the United States for Durations from 30 Minutes to 24 Hours and Return Periods from 1 to 100 Years. Technical Paper No. 40. National Weather Bureau, Washington, DC.

Hunt, W.F., III, R.W. Skaggs, G.M. Chescheir, and D.M. Amatya. 2001. Examination of the wetland hydrologic criterion and its application in the determination of wetland hydrology status. UNC-WRRI-2001-333.

Kirkham, D. 1957. Theory of land drainage. In J.N. Luthin (ed.) Drainage of agricultural lands. Agron. Monogr. 7. ASA, Madison, WI.

Klute, A. 1986. Water retention: Laboratory methods. p. 635-662. In Methods of soil analysis, Part 1. 2nd ed. ASA and SSSA, Madison, WI.

Klute, A., and C. Dirksen. 1986. Hydraulic conductivity and diffusivity: Laboratory methods. p. 687-734. In Methods of soil analysis, Part 1. 2nd ed. ASA and SSSA, Madison, WI.

McKee, T.B., N.J. Doesken and J. Kleist. 1993. The relationship of drought frequency and duration to time scales. Eighth Con. On App. Climatology. Anaheim, CA.

Mitsch, W.J., and J.G. Gooselink. 2000. Wetlands. $3^{\text {rd }}$ Ed. Wiley and Sons, New York.

National Research Council. 1995. Wetlands: Characteristics and boundaries. National Research Council Committee on Characterization of Wetlands, National Academy Press, Washington, DC.

North Carolina General Assembly (NCGA). 2005. Laws and Rules for Sewage Treatment and Disposal Systems, North Carolina General Statute 130A-333,4, Rules. 
.1900 of Title 15A Subchapter 18A of the North Carolina Administrative Code. Raleigh, North Carolina.

Natural Resources Conservation Service. 1997. WETS Table Documentation. Portland, OR: Water and Climate Center. Available at:

http://www.wcc.nrcs.usda.gov/climate/wets_doc.html. Accessed 16 May 2006.

Richards, L.A., and L.R. Weaver. 1943. Fifteen atmosphere percentage as related to the permanent wilting percentage. Soil Sci. 56: 331-340.

Richardson, J.L. and M.J. Vepraskas. 2001. Wetland Soils. Lewis Publishers, New York.

Robbins, K.D. 1988. Simulated climate inputs for DRAINMOD. Ph.D. dissertation. North Carolina State University. Raleigh, NC.

Skaggs, R.W. 1982. Field evaluation of a water management model. Trans. ASAE 25: 666-674.

Skaggs, R.W. 1999. Drainage simulation models. P. 461-492. In R.W. Skaggs et al. (ed.) Agricultural drainage. Agron. Monogr. 38. ASA, CSSA, and SSSA, Madison, WI.

Skaggs, R.W., D. Amatya, R.O. Evans, and J.E. Parsons. 1994. Characterization and evaluation of proposed hydrologic criteria for wetlands. J. Soil Water Conserv. 49: 501510.

Sprecher, S. W., and A. G. Warne. 2000. "Accessing and Using Meteorogical Data to Evaluate Wetland Hydrology,” ERDC/EL TR-WRAP-00-01, U. S. Army Engineer Research and Development Center, Vicksburg, MS.

Thornthwaite, C.W. 1948. An approach toward a rational classification of climate. Geog. Rev. 38: 55-94.

United States Dep. Of Agriculture, Natural Resources Conservation Service. 2002. Field indicators of hydric soils in the United States. Version 5.0. G. W. Hurt, P. M. Whited, and R. F. Pringle (eds.) USDA, NRCS, Ft. Worth, TX.

Warne, A.G., and Wakeley, J.S. 2000. "Guidelines for conducting and reporting hydrologic assessments of potential wetland sites," WRAP Technical Notes Collection (ERDC TN-WRAP-00-01), U.S. Army Research and Development Center, Vicksburg, MS.

Wells, N., S. Goddard, and M.J. Hayes. 2004. A self-calibrating palmer drought severity index. J. of Climate Vol. 17. 12: 2335-2351.

Workman, S.R., J.E. Parsons, G.M. Chescheir, R.W. Skaggs, and J.F. Rice. 1994. DRAINMOD User's guide. USDA-NRCS, U.S. Gov. Print. Office, Washington, DC. 
Table 1: WETS Table used for the Greenville Site.

\begin{tabular}{|c|c|c|c|c|c|c|c|c|}
\hline $\begin{array}{l}\text { Latitude: } \\
\text { State FIPS/ } \\
\text { Start yr. }\end{array}$ & $\begin{array}{l}3537 \\
\text { County (1 } \\
-1971\end{array}$ & $\begin{array}{l}\text { Longit } \\
\text { IPS) : } \\
\text { End yr. }\end{array}$ & $\begin{array}{l}\text { Ede: } \\
37147 \\
-\quad 2000\end{array}$ & $\begin{array}{l}7723 \\
\text { County }\end{array}$ & $\begin{array}{c}\text { Elevat } \\
\text { Name: Pitt }\end{array}$ & on: 000 & 30 & \\
\hline Month & $\begin{array}{c}\text { avg } \\
\text { daily } \\
\max \end{array}$ & $\begin{array}{l}\text { Temperat } \\
\text { (Degrees }\end{array}$ & $\begin{array}{l}\text { are } \\
\text { F. ) }\end{array}$ & avg & $\begin{array}{c}30 \% \mathrm{ch} \\
\text { will } \\
----- \\
\text { less } \\
\text { than }\end{array}$ & $\begin{array}{l}\text { hance } \\
\text { have } \\
\text { more } \\
\text { than }\end{array}$ & $\left|\begin{array}{c}\text { avg } \\
\# \text { of } \\
\text { days } \\
\text { w/. } 1 \\
\text { or } \\
\text { more }\end{array}\right|$ & $\begin{array}{l}\text { avg } \\
\text { total } \\
\text { snow } \\
\text { fall }\end{array}$ \\
\hline January & 52.0 & 31.0 & 41.5 & 4.42 & 3.53 & 5.33 & 8 & 0.9 \\
\hline Eebruary & 55.8 & 33.2 & 44.5 & 3.45 & 2.34 & 4.16 & 6 & 1.4 \\
\hline March & 63.9 & 40.2 & 52.0 & 4.07 & 3.19 & 4.83 & 7 & 0.6 \\
\hline April & 73.0 & 47.9 & 60.5 & 3.19 & 2.18 & 4.31 & 5 & 0.0 \\
\hline May & 79.9 & 56.8 & 68.3 & 4.04 & 2.79 & 5.01 & 7 & 0.0 \\
\hline June & 86.2 & 64.7 & 75.5 & 4.46 & 3.00 & 5.25 & 7 & 0.0 \\
\hline July & 89.9 & 69.4 & 79.7 & 5.24 & 3.75 & 6.45 & 7 & 0.0 \\
\hline August & 88.1 & 67.8 & 77.9 & 5.89 & 3.65 & 7.03 & 7 & 0.0 \\
\hline September & 82.9 & 61.9 & 72.4 & 5.50 & 2.78 & 7.13 & 6 & 0.0 \\
\hline October & 73.5 & 48.9 & 61.2 & 3.27 & 2.00 & 4.34 & 4 & 0.0 \\
\hline November & 64.7 & 40.4 & 52.6 & 2.85 & 2.03 & 3.46 & 5 & 0.0 \\
\hline December & 55.6 & 33.6 & 44.6 & 3.23 & 2.10 & 4.02 & 6 & 0.4 \\
\hline -ー-ー-ー---- & ------- & ------- & --ー-ー--- & $\begin{array}{l}-------- \\
--------\end{array}$ & $\begin{array}{l}-------- \\
--------\end{array}$ & ----ー--- & ---- & ------ \\
\hline Annual & ------ & ----- & ----- & ------ & 44.45 & 52.35 & -- & ---- \\
\hline $\begin{array}{c}---------- \\
\text { Average }\end{array}$ & $\begin{array}{c}------- \\
72.1\end{array}$ & $\begin{array}{c}------ \\
49.7\end{array}$ & $\begin{array}{c}------- \\
60.9\end{array}$ & $\begin{array}{c}-------- \\
------\end{array}$ & $\begin{array}{c}-------- \\
-------\end{array}$ & $\begin{array}{c}-------- \\
-------\end{array}$ & $\begin{array}{c}---- \\
--\end{array}$ & $\begin{array}{c}------ \\
----\end{array}$ \\
\hline---------- & ------- & ------- & ------- & -------- & -------- & -------- & ---- & ------ \\
\hline Total & ----- & ----- & ----- & 49.61 & ------ & ------- & 75 & 3.4 \\
\hline
\end{tabular}

GROWING SEASON DATES

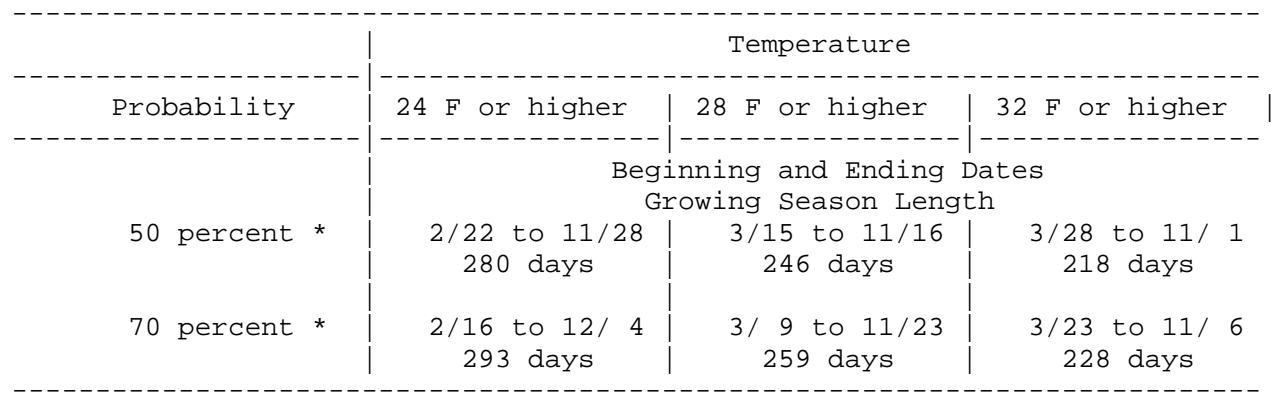

* Percent chance of the growing season occurring between the Beginning and Ending dates. 
Table 2: WETS Table used for the Bertie site.

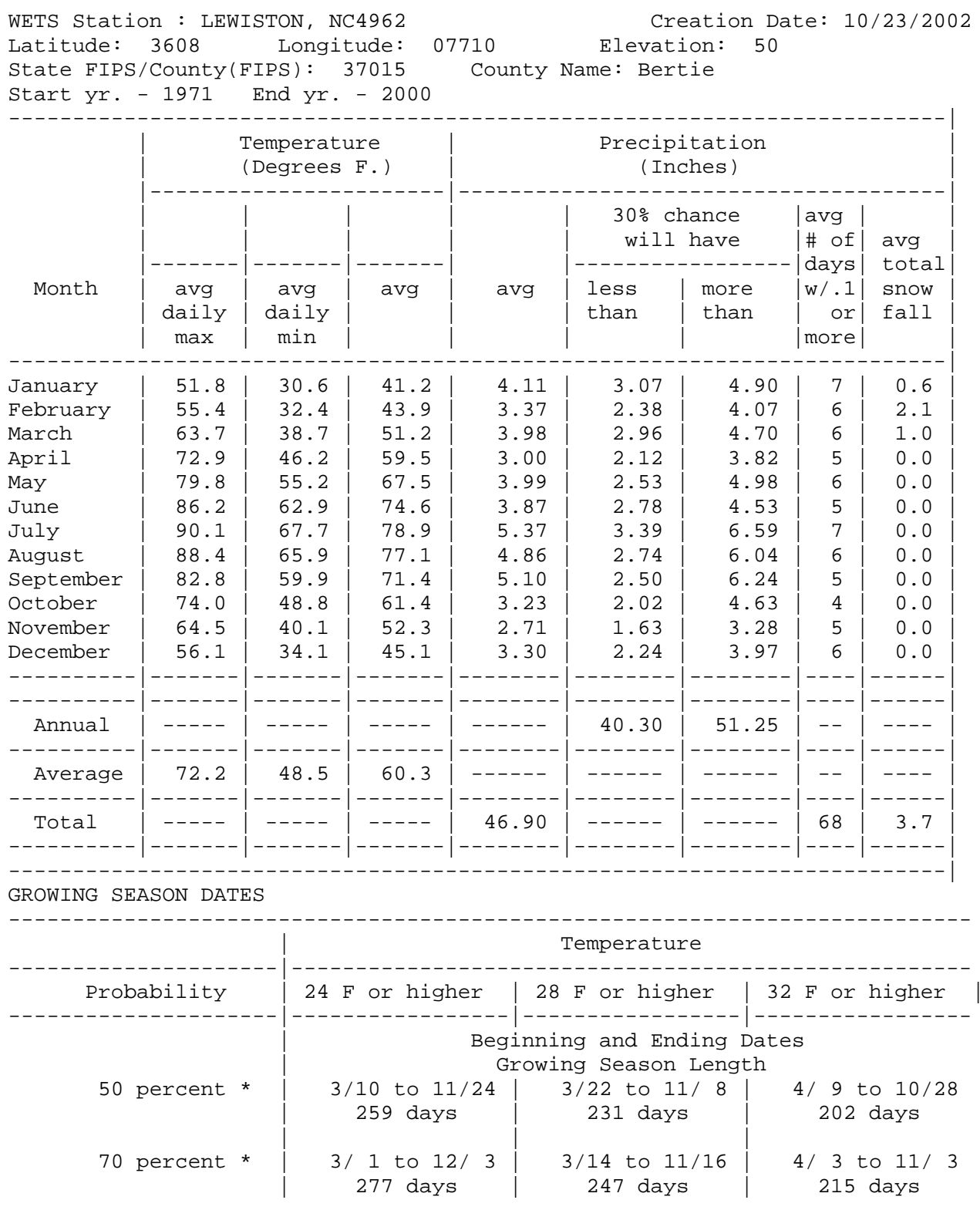

* Percent chance of the growing season occurring between the Beginning and Ending dates. 
Table 3: WETS Table used for the Marcell Experimental Forest.

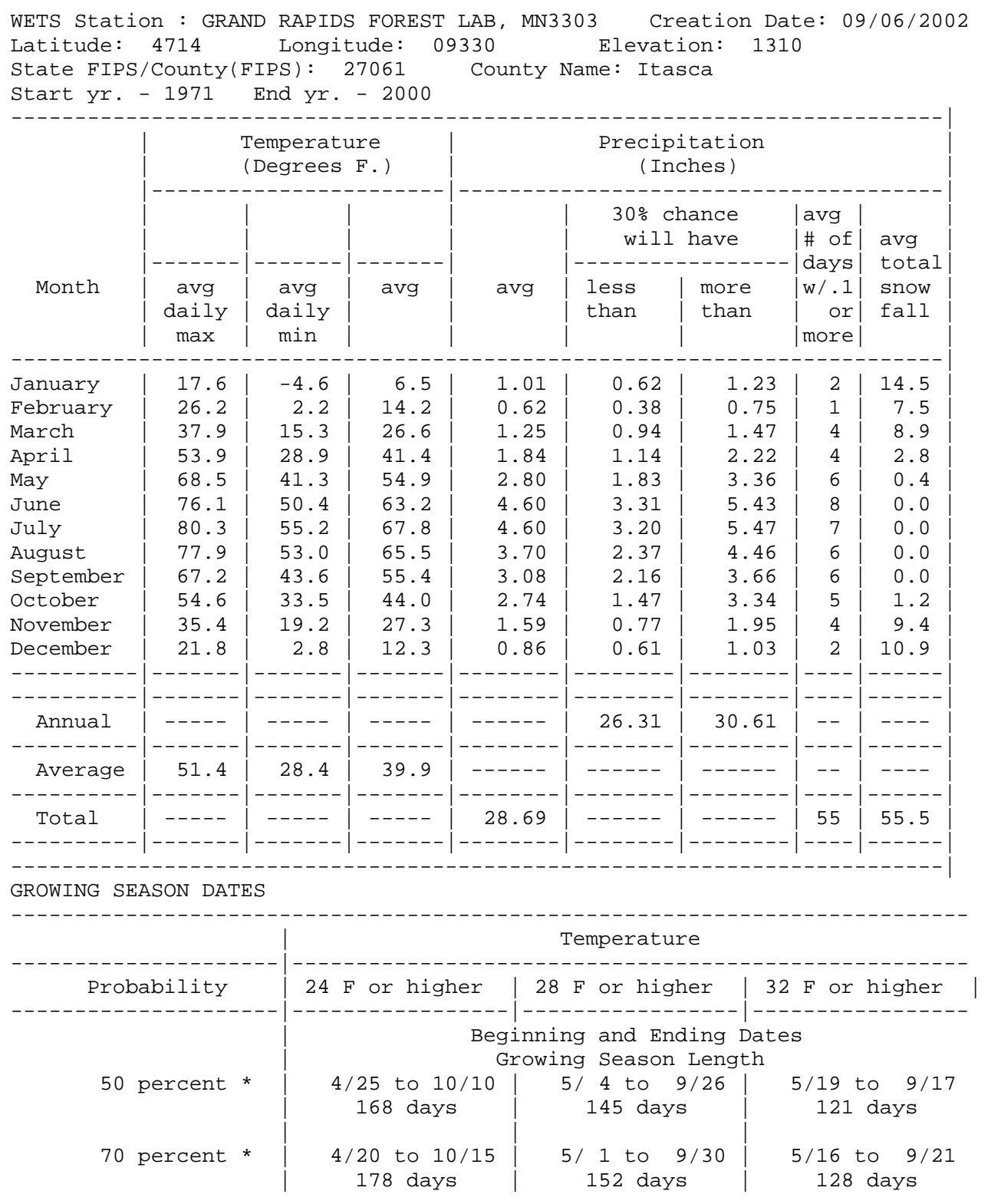

* Percent chance of the growing season occurring between the Beginning and Ending dates. 
Table 4: Hydric soil field indicators present for plots at each of the three study sites.

\begin{tabular}{|c|c|c|}
\hline Site & Plot & Hydric Soil Field Indicator \\
\hline Greenville & $1 \mathrm{R}, 2 \mathrm{R}, 3 \mathrm{R}, 4 \mathrm{R}, 4 \mathrm{P}$ & $\begin{array}{l}\text { F13- Umbric Surface - In depressions and other } \\
\text { concave landforms, a layer } 15 \mathrm{~cm} \text { ( } 6 \text { in.) or more } \\
\text { thick starting within the upper } 15 \mathrm{~cm}(6 \text { in.) of the } \\
\text { soil surface with value } 3 \text { or less and chroma } 1 \text { or } \\
\text { less immediately underlain by a layer } 10 \mathrm{~cm} \text { ( } 4 \\
\text { in.) or more thick with chroma } 2 \text { or less }\end{array}$ \\
\hline Bertie & $3 \mathrm{~N}, 4 \mathrm{~N}, 5 \mathrm{~N}, 3 \mathrm{~S}, 4 \mathrm{~S}, 5 \mathrm{~S}$ & $\begin{array}{l}\text { F3- Depleted Matrix - A layer at least } 15 \mathrm{~cm}(6 \\
\text { in.) thick with a depleted matrix that has } 60 \% \text { or } \\
\text { more chroma } 2 \text { or less starting within } 25 \mathrm{~cm}(10 \\
\text { in.) of the surface }\end{array}$ \\
\hline Marcell & $\mathrm{S} 1, \mathrm{~S} 2, \mathrm{~S} 3, \mathrm{~S} 4, \mathrm{~S} 5, \mathrm{~S} 6$ & $\begin{array}{l}\text { A1- Histosol (Organic Soils) - A Histosol has } 40 \\
\mathrm{~cm} \text { (16 in.) or more of the upper } 80 \mathrm{~cm} \text { ( } 32 \mathrm{in} .) \text { as } \\
\text { organic soil material. Organic soil material has an } \\
\text { organic carbon content (by weight) of } 12 \text { to } 18 \\
\text { percent, or more, depending on the clay content } \\
\text { of the soil. These materials include muck (sapric } \\
\text { soil material), mucky peat (hemic soil material), } \\
\text { or peat (fibric soil material) and organic soil } \\
\text { material. }\end{array}$ \\
\hline
\end{tabular}


Table 5: Growing season dates and length for each of the three sites. Data were obtained from the WETS weather stations shown.

\begin{tabular}{cccccc}
\hline \multirow{2}{*}{ Site } & \multirow{2}{*}{$\begin{array}{c}\text { Weather } \\
\text { station name } \\
\text { and location }\end{array}$} & Start Date & End Date & $\begin{array}{c}\text { Length } \\
\text { (days) }\end{array}$ & $5 \%$ \\
\cline { 3 - 5 } Greenville & $\begin{array}{c}\text { Greenville 2, } \\
\text { NC }\end{array}$ & 15-Mar & 16-Nov & 246 & 12 \\
\cline { 4 - 6 } Bertie & $\begin{array}{c}\text { Lewiston, NC } \\
\text { Marcell }\end{array}$ & 22-Mar & 8-Nov & 231 & 12 \\
& $\begin{array}{c}\text { Grand Rapids } \\
\text { Forest Lab., }\end{array}$ & 4-May & 26-Sep & 145 & 7 \\
\hline
\end{tabular}


Table 6: DAREM calculation method to determine the condition of the rainfall period for June 1959 at plot $1 \mathrm{R}$ in Greenville. The month of June is being evaluated as the month of interest while the months May, April and March are taken into consideration. Once calculations have been completed, the 3-month period can be evaluated on whether it has acceptable rainfall amounts. In this case, this 3-month period is "normal" so the period for June is acceptable to use.

\begin{tabular}{|c|c|c|c|c|c|c|c|c|}
\hline \multicolumn{2}{|c|}{ Prior Month } & \multicolumn{2}{|c|}{$\begin{array}{l}\text { WETS Rainfall } \\
\text { Percentile }\end{array}$} & \multirow[t]{2}{*}{$\begin{array}{l}\text { Measured } \\
\text { Rainfall }\end{array}$} & \multirow{2}{*}{$\begin{array}{l}\text { Condition: } \\
\text { Dry, Wet, } \\
\text { Normal }\end{array}$} & \multirow{3}{*}{$\begin{array}{c}\begin{array}{c}\text { Condition } \\
\text { Value }\end{array} \\
\begin{array}{c}\text { (1=dry, } \\
2=\text { normal, } \\
\text { or } 3=\text { wet })\end{array}\end{array}$} & \multirow[t]{2}{*}{$\begin{array}{l}\text { Month } \\
\text { weight }\end{array}$} & \multirow{2}{*}{$\begin{array}{c}\text { Multiply } \\
\text { Previous two } \\
\text { columns }\end{array}$} \\
\hline & Name & $30^{\text {th }}$ & 70th & & & & & \\
\hline & & \multicolumn{3}{|c|}{----------cm------------ } & & & & \\
\hline $1^{\text {st }}$ (most recent) & May & 7.09 & 12.73 & 3.29 & Dry & 1 & 3 & 3 \\
\hline 2 nd & April & 5.54 & 10.95 & 18.51 & Wet & 3 & 2 & 6 \\
\hline $3 \mathrm{rd}$ & March & 8.10 & 12.27 & 14.11 & Wet & 3 & 1 & 3 \\
\hline \multirow{2}{*}{\multicolumn{8}{|c|}{$\begin{array}{ll} & \text { Sum } \\
\text { Rainfall of prior period was: } & \end{array}$}} & 12 \\
\hline & & & & & & & & Normal \\
\hline
\end{tabular}


Table 7: Modified DAREM calculation method to determine the condition of the rainfall period for May 1959 at plot $1 \mathrm{R}$ in Greenville. The water table rose to within $30 \mathrm{~cm}$ of the surface on June 16. With this method, the month of June is taken as the most recent prior month. Rainfall for the first half of June will be considered (days 1-15). Because only monthly data are reported, the measured rainfall amounts for June were multiplied by 0.5 , and the same was done with the WETS data values. With this approach the antecedent period is considered drier than normal. In contrast, the regular DAREM method (Table 6) concluded the antecedent rainfall was normal because June values were not considered.

\begin{tabular}{|c|c|c|c|c|c|c|c|c|}
\hline \multicolumn{2}{|c|}{ Prior Month } & \multicolumn{2}{|c|}{$\begin{array}{l}\text { WETS Rainfall } \\
\text { Percentile }\end{array}$} & \multirow[t]{2}{*}{$\begin{array}{l}\text { Measured } \\
\text { Rainfall }\end{array}$} & \multirow{2}{*}{$\begin{array}{l}\text { Condition: } \\
\text { Dry, Wet, } \\
\text { Normal }\end{array}$} & \multirow{3}{*}{$\begin{array}{c}\begin{array}{c}\text { Condition } \\
\text { Value }\end{array} \\
\text { (1=dry, } \\
\begin{array}{c}\text { 2=normal, } \\
\text { or } 3=\text { wet })\end{array}\end{array}$} & \multirow[t]{2}{*}{$\begin{array}{l}\text { Month } \\
\text { weight }\end{array}$} & \multirow{2}{*}{$\begin{array}{c}\text { Multiply } \\
\text { Previous two } \\
\text { columns }\end{array}$} \\
\hline & Name & $30^{\text {th }}$ & 70th & & & & & \\
\hline & & \multicolumn{3}{|c|}{----------cm------------ } & & & & \\
\hline $1^{\text {st }}$ (most recent) & June & 3.81 & 6.67 & 1.84 & Dry & 1 & 3 & 3 \\
\hline 2nd & May & 7.09 & 12.73 & 3.29 & Dry & 1 & 2 & 2 \\
\hline $3 \mathrm{rd}$ & April & 5.54 & 10.95 & 18.51 & Wet & 3 & 1 & 3 \\
\hline \multirow{2}{*}{\multicolumn{8}{|c|}{$\begin{array}{l}\text { Rainfall of prior period was: } \\
\text { drier than normal (sum is 6-9), normal (sum is 10-14), wetter than normal (sum is 15-18) }\end{array}$}} & 8 \\
\hline & & & & & & & & $\begin{array}{l}\text { Drier than } \\
\text { normal }\end{array}$ \\
\hline
\end{tabular}


Table 8: The 30-day Moving total calculation for Greenville plots during the year 1959. The moving total is the sum of the amount of rainfall over a 30 day period and is calculated by adding the daily precipitation values from the first 30 days and then subtracting out the first day from the count and adding in the $31^{\text {st }}$ day to have a continuous 30 day calculation total for precipitation throughout the year. The $70^{\text {th }}$ Percentile values are obtained directly from WETS Tables. The moving total for $1 / 30 / 1959$ is the sum of daily rainfall amounts from $1 / 1 / 1959$ to $1 / 30 / 1959$, which is 3.50 $\mathrm{cm}$. The moving total for $1 / 31 / 1959$ is the sum of daily rainfall amounts from $1 / 2 / 1959$ to $1 / 31 / 1959$, which is 4.11 because it includes $0.61 \mathrm{~cm}$ from day 31 and excludes precipitation from day $1(0 \mathrm{~cm}$ not shown $)$.

\begin{tabular}{ccccc}
\hline Date & $\begin{array}{c}\text { 70th } \\
\text { Percentile } \\
(\mathbf{c m})\end{array}$ & Day & $\begin{array}{c}\text { Precipitation } \\
(\mathbf{c m})\end{array}$ & Moving Total $(\mathbf{c m})$ \\
\hline $1 / 30 / 1959$ & 13.54 & 30 & 0 & 3.50 \\
$1 / 31 / 1959$ & 13.54 & 31 & 0.61 & 4.11 \\
$2 / 1 / 1959$ & 10.57 & 32 & 0 & 3.02 \\
$2 / 2 / 1959$ & 10.57 & 33 & 0 & 3.02 \\
$2 / 3 / 1959$ & 10.57 & 34 & 0 & 3.02 \\
$2 / 4 / 1959$ & 10.57 & 35 & 2.01 & 5.03 \\
$2 / 5 / 1959$ & 10.57 & 36 & 5 & 10.03 \\
$2 / 6 / 1959$ & 10.57 & 37 & 0 & 10.03 \\
$2 / 7 / 1959$ & 10.57 & 38 & 0 & 10.03 \\
$2 / 8 / 1959$ & 10.57 & 39 & 0 & 9.93 \\
$2 / 9 / 1959$ & 10.57 & 40 & 0 & 9.93 \\
$2 / 10 / 1959$ & 10.57 & 41 & 0.3 & 10.23 \\
$2 / 11 / 1959$ & 10.57 & 42 & 0 & 10.23 \\
$2 / 12 / 1959$ & 10.57 & 43 & 0 & 10.23 \\
$2 / 13 / 1959$ & 10.57 & 44 & 0.99 & 11.22 \\
\hline
\end{tabular}


Table 9: Three study sites of Greenville, Bertie and Marcell each had 17 plots that met wetland hydrology and 6 plots that did not meet wetland hydrology. Plots that did meet wetland hydrology had a hydric soil field indicator present, while plots that did not meet wetland hydrology had no hydric soil field indicator present. Plots met wetland hydrology, met it an average of $83 \%$ or higher.

\begin{tabular}{|c|c|c|c|c|c|c|}
\hline Site & Plot & $\begin{array}{c}\text { Proportion } \\
\text { of years } \\
\text { water } \\
\text { table was } \\
\text { within } 30 \\
\text { cm for } \\
\geq 14 \mathrm{~d} \\
\end{array}$ & $\begin{array}{c}\text { Field } \\
\text { indicator } \\
\text { present }\end{array}$ & Plot & $\begin{array}{c}\text { Proportion } \\
\text { of years } \\
\text { wetland } \\
\text { hydrology } \\
\text { met }\end{array}$ & $\begin{array}{c}\text { Field } \\
\text { indicator } \\
\text { present }\end{array}$ \\
\hline Greenville & $\begin{array}{c}1 \mathrm{R} \\
2 \mathrm{R} \\
3 \mathrm{R} \\
4 \mathrm{R} \\
4 \mathrm{P} \\
\text { Average }\end{array}$ & $\begin{array}{c}\% \\
\\
88 \\
100 \\
98 \\
95 \\
98 \\
96 \\
\end{array}$ & $\begin{array}{c}\text { F13 } \\
\text { ““ } \\
\text { ““ } \\
\text { “ } \\
\end{array}$ & $\begin{array}{l}1 \mathrm{~L} \\
2 \mathrm{~L} \\
3 \mathrm{~L} \\
4 \mathrm{~L}\end{array}$ & $\begin{array}{l}\% \\
0 \\
3 \\
3 \\
0\end{array}$ & None \\
\hline Bertie & $\begin{array}{c}3 \mathrm{~S} \\
4 \mathrm{~S} \\
5 \mathrm{~S} \\
3 \mathrm{~N} \\
4 \mathrm{~N} \\
5 \mathrm{~N} \\
\text { Average }\end{array}$ & $\begin{array}{l}87 \\
91 \\
98 \\
83 \\
86 \\
98 \\
92\end{array}$ & $\begin{array}{c}\text { F3 } \\
\text { None } \\
\text { F3, A11 } \\
\text { F3 } \\
\text { F3 } \\
\text { F3, A11 }\end{array}$ & $\begin{array}{l}2 \mathrm{~N} \\
2 \mathrm{~S}\end{array}$ & $\begin{array}{c}0 \\
11\end{array}$ & None \\
\hline Marcell & $\begin{array}{c}\text { S1 } \\
\\
\text { S2 } \\
\text { S3 } \\
\text { S4 } \\
\text { S5 } \\
\text { S6 } \\
\text { Average }\end{array}$ & $\begin{array}{c}78 \\
\\
100 \\
53 \\
100 \\
98 \\
69 \\
83\end{array}$ & $\begin{array}{l}\text { A1 } \\
“ \\
“ \\
“ \\
“ \\
“\end{array}$ & $\begin{array}{c}\text { Not } \\
\text { Studied } \\
\text { “ } \\
“ \\
“ \\
“ \\
“ \\
\text { “ }\end{array}$ & $\begin{array}{l}-- \\
-- \\
-- \\
-- \\
-- \\
--\end{array}$ & $\begin{array}{l}-- \\
-- \\
-- \\
-- \\
-- \\
--\end{array}$ \\
\hline
\end{tabular}


Table 10: Average results from all plots at all sites from water table saturation criteria examinations. For a given year, the water table was examined during the growing season to see first if a period of saturation occurred within $30 \mathrm{~cm}$ of the surface for at least 14 days. If it did, then rainfall was examined next to determine if rainfall was normal, below normal, or wetter than normal using each of the four methods separately. For example, if the modified DAREM approach was being considered, then it was applied to the period prior to when the water table rose above a depth of $30 \mathrm{~cm}$. If the rainfall was found to be normal or drier than normal for the modified DAREM approach, then that year was considered to have met the wetland hydrology criteria and another method of rainfall evaluation was tested. On the other hand, if rainfall was found to be wetter than normal with the modified DAREM approach, then additional periods during that same year were examined to determine if the water table met the saturation criteria during normal or drier than normal rainfall. If a year was considered to be wetter than normal for the modified DAREM approach, that meant that there were no periods during that year when the water table met saturation criteria during a period of normal or drier than normal rainfall.

Periods of normal rainfall were not considered if they did not meet water table saturation criteria. This was then used for the remaining methods of rainfall evaluation.

\begin{tabular}{|c|c|c|c|c|c|c|}
\hline \multirow{3}{*}{ Site } & \multirow{3}{*}{ Plot } & \multicolumn{5}{|c|}{ Rainfall Evaluation Method } \\
\hline & & \multirow{2}{*}{$\begin{array}{c}\text { Long-term } \\
\text { Measurement }\end{array}$} & \multicolumn{2}{|c|}{ Moving Total } & \multicolumn{2}{|c|}{ DAREM } \\
\hline & & & Modified & Corps & Corps & Modified \\
\hline \multirow{7}{*}{ Greenville } & & & --- & --- & --O & -------. \\
\hline & $1 \mathrm{R}$ & 88 & 23 & 33 & 70 & 75 \\
\hline & $2 \mathrm{R}$ & 100 & 48 & 70 & 93 & 93 \\
\hline & $3 R$ & 98 & 45 & 68 & 90 & 93 \\
\hline & $4 \mathrm{R}$ & 95 & 40 & 63 & 85 & 85 \\
\hline & $4 \mathrm{P}$ & 98 & 58 & 78 & 93 & 93 \\
\hline & Average & 96 & 43 & 62 & 86 & 88 \\
\hline \multirow{7}{*}{ Bertie } & $3 \mathrm{~S}$ & 87 & 13 & 24 & 53 & 62 \\
\hline & $4 \mathrm{~S}$ & 91 & 18 & 20 & 71 & 78 \\
\hline & $5 \mathrm{~S}$ & 98 & 29 & 29 & 76 & 84 \\
\hline & $3 \mathrm{~N}$ & 83 & 7 & 11 & 60 & 62 \\
\hline & $4 \mathrm{~N}$ & 96 & 18 & 24 & 73 & 80 \\
\hline & $5 \mathrm{~N}$ & 98 & 22 & 27 & 78 & 84 \\
\hline & Average & 92 & 18 & 23 & 69 & 75 \\
\hline \multirow{7}{*}{ Marcell } & S1 & 78 & 49 & 53 & 76 & 76 \\
\hline & $\mathrm{S} 2$ & 100 & 82 & 89 & 100 & 100 \\
\hline & S3 & 53 & 40 & 40 & 49 & 49 \\
\hline & $\mathrm{S} 4$ & 100 & 91 & 91 & 93 & 95 \\
\hline & S5 & 98 & 78 & 80 & 84 & 84 \\
\hline & S6 & 69 & 35 & 38 & 65 & 65 \\
\hline & Average & 83 & 63 & 65 & 78 & 78 \\
\hline
\end{tabular}


Table 11: Evaluation results for all four methods from all study sites for hydric soils. Plots at each site have been averaged together to get the means for each method and the range is listed below the mean to get an idea of how wide the range between percent wetland hydrology was met among the individual plots. Both direct antecedent methods have closer percentage results compared with the long-term water table records and the moving total methods are significantly lower than the long-term records.

\begin{tabular}{ccccccc}
\hline Site & Statistic & $\begin{array}{c}\text { Long- } \\
\text { term } \\
\text { Record }\end{array}$ & $\begin{array}{c}\text { Modified } \\
\text { Moving } \\
\text { Total }\end{array}$ & $\begin{array}{c}\text { Corps } \\
\text { Moving } \\
\text { Total }\end{array}$ & DAREM & $\begin{array}{c}\text { Modified } \\
\text { DAREM }\end{array}$ \\
\hline \multirow{2}{*}{ Greenville } & Mean & 96 & 43 & 62 & 86 & 88 \\
& Range & $88-100$ & $23-58$ & $33-78$ & $70-93$ & $75-93$ \\
Bertie & Mean & 92 & 18 & 23 & 69 & 75 \\
& Range & $83-98$ & $7-29$ & $11-29$ & $53-78$ & $62-84$ \\
Marcell & Mean & 83 & 62 & 64 & 79 & 79 \\
& Range & $53-100$ & $35-93$ & $35-95$ & $49-100$ & $49-100$ \\
Overall & & & & & & \\
Mean & & 90 & 41 & 50 & 78 & 81 \\
\hline
\end{tabular}


Table 12: Partial 40 year record for plot Greenville plot $4 \mathrm{R}$ that displays results from the Corps Moving Total method and that has met wetland hydrology 12 out of 20 years $(60 \%)$ when the water table (WT) was within $30 \mathrm{~cm}$ for 14 days or longer during the period listed for each year shown.

\begin{tabular}{|c|c|c|}
\hline Year & $\begin{array}{c}\text { Water } \\
\text { Table } \\
\text { within } 30 \\
\text { cm of } \\
\text { surface } \\
\text { for } 14 \\
\text { days or } \\
\text { more } \\
\end{array}$ & Hydrology Technical Standard Result \\
\hline 1959 & yes & $\begin{array}{l}\text { WT is within } 30 \mathrm{~cm} \text { for } 14+\text { days and does not exceed the } 70 \text { th } \\
\text { percentile }\end{array}$ \\
\hline 1960 & yes & $\begin{array}{l}\text { WT is within } 30 \mathrm{~cm} \text { for } 14+\text { days and does not exceed the } 70 \text { th } \\
\text { percentile }\end{array}$ \\
\hline 1961 & no & Moving total exceeds 70th percentile \\
\hline 1962 & no & Moving total exceeds 70th percentile \\
\hline 1963 & yes & $\begin{array}{l}\text { WT is within } 30 \mathrm{~cm} \text { for } 14+\text { days and does not exceed the } 70 \text { th } \\
\text { percentile }\end{array}$ \\
\hline 1964 & no & Moving total exceeds 70th percentile \\
\hline 1965 & yes & $\begin{array}{l}\text { WT is within } 30 \mathrm{~cm} \text { for } 14+\text { days and does not exceed the } 70 \text { th } \\
\text { percentile }\end{array}$ \\
\hline 1966 & yes & $\begin{array}{l}\text { WT is within } 30 \mathrm{~cm} \text { for } 14+\text { days and does not exceed the } 70 \text { th } \\
\text { percentile }\end{array}$ \\
\hline 1967 & yes & $\begin{array}{l}\text { WT is within } 30 \mathrm{~cm} \text { for } 14+\text { days and does not exceed the } 70 \text { th } \\
\text { percentile }\end{array}$ \\
\hline 1968 & no & Moving total exceeds 70 th percentile \\
\hline 1969 & yes & $\begin{array}{l}\text { WT is within } 30 \mathrm{~cm} \text { for } 14+\text { days and does not exceed the } 70 \text { th } \\
\text { percentile }\end{array}$ \\
\hline 1970 & yes & $\begin{array}{l}\text { WT is within } 30 \mathrm{~cm} \text { for } 14+\text { days and does not exceed the } 70 \text { th } \\
\text { percentile }\end{array}$ \\
\hline 1971 & yes & $\begin{array}{l}\text { WT is within } 30 \mathrm{~cm} \text { for } 14+\text { days and does not exceed the } 70 \text { th } \\
\text { percentile }\end{array}$ \\
\hline 1972 & yes & $\begin{array}{l}\text { WT is within } 30 \mathrm{~cm} \text { for } 14+\text { days and does not exceed the } 70 \text { th } \\
\text { percentile }\end{array}$ \\
\hline 1973 & no & Moving total exceeds 70 th percentile \\
\hline 1974 & yes & $\begin{array}{l}\text { WT is within } 30 \mathrm{~cm} \text { for } 14+\text { days and does not exceed the } 70 \text { th } \\
\text { percentile }\end{array}$ \\
\hline 1975 & no & Moving total exceeds 70 th percentile \\
\hline 1976 & no & WT is not within $30 \mathrm{~cm}$ for $14+$ days \\
\hline 1977 & no & Moving total exceeds 70 th percentile \\
\hline 1978 & yes & $\begin{array}{l}\text { WT is within } 30 \mathrm{~cm} \text { for } 14+\text { days and does not exceed the } 70 \text { th } \\
\text { percentile }\end{array}$ \\
\hline
\end{tabular}


Table 13: Modified DAREM approach to determine the condition of the rainfall period for July 1965 at plot 4R in Greenville. The month of June is being evaluated as the month of interest while the months June, May and April are taken into consideration. Once calculations have been completed, the 3-month period can be evaluated on whether it has acceptable rainfall amounts. Although the most recent month of June is Wet, this 3-month period is considered "normal" because the preceding two months of May and April were normal or dryer than normal so the period for July is acceptable to use.

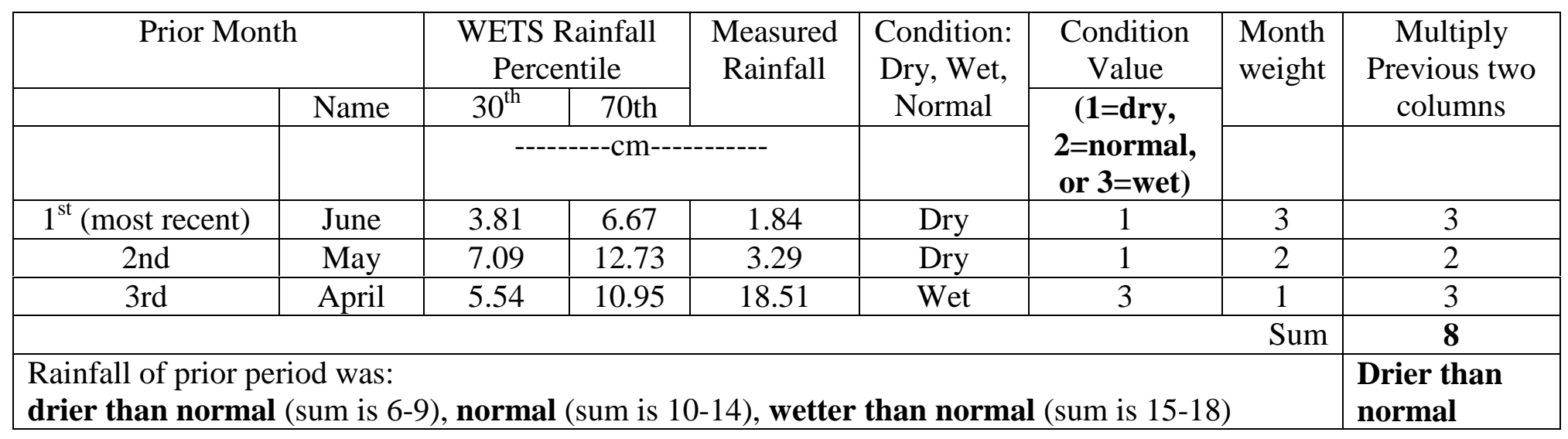


Table 14: Partial 40-year record for plot $4 \mathrm{R}$ at Greenville that displays results from modified DAREM and that has met wetland hydrology in 17 out of 20 years (85\%) when the water table (WT) was within $30 \mathrm{~cm}$ of the surface for 14 days or longer during the growing season.

\begin{tabular}{|c|c|c|}
\hline Year & $\begin{array}{c}\text { Water } \\
\text { Table } \\
\text { within } 30 \\
\text { cm for } 14 \\
\text { days or } \\
\text { more } \\
\end{array}$ & Modified DAREM Result \\
\hline 1959 & yes & $\begin{array}{l}\text { October - WT is within } 30 \mathrm{~cm} \text { for } 14+\text { days (starting October } \\
15 \text { th) }\end{array}$ \\
\hline 1960 & no & March/April/August - "wet" \\
\hline 1961 & yes & March - WT is within $30 \mathrm{~cm}$ for $14+$ days (starting March 15 th) \\
\hline 1962 & yes & March - WT is within $30 \mathrm{~cm}$ for $14+$ days (starting March 15 th) \\
\hline 1963 & yes & March - WT is within $30 \mathrm{~cm}$ for 14+ days (starting March 15th) \\
\hline 1964 & no & March/April/August/September - "wet" \\
\hline 1965 & yes & March - WT is within $30 \mathrm{~cm}$ for 14+ days (starting March 15th) \\
\hline 1966 & yes & March - WT is within $30 \mathrm{~cm}$ for 14+ days (starting March 15th) \\
\hline 1967 & yes & August - WT is within $30 \mathrm{~cm}$ for $14+$ days (starting August 12 th) \\
\hline 1968 & yes & March - WT is within $30 \mathrm{~cm}$ for 14+ days (starting March 15th) \\
\hline 1969 & yes & March - WT is within $30 \mathrm{~cm}$ for $14+$ days (starting March 15th) \\
\hline 1970 & yes & March - WT is within $30 \mathrm{~cm}$ for $14+$ days (starting March 15 th) \\
\hline 1971 & yes & March - WT is within $30 \mathrm{~cm}$ for $14+$ days (starting March 15 th) \\
\hline 1972 & yes & March - WT is within $30 \mathrm{~cm}$ for $14+$ days (starting March 15 th) \\
\hline 1973 & yes & March - WT is within $30 \mathrm{~cm}$ for $14+$ days (starting March 15th) \\
\hline 1974 & yes & March - WT is within $30 \mathrm{~cm}$ for $14+$ days (starting March 15th) \\
\hline 1975 & yes & $\begin{array}{l}\text { April - WT is within } 30 \mathrm{~cm} \text { for } 14+\text { days (starting April 1st) } \\
\text { water table is not within } 30 \mathrm{~cm} \text { for } 14+\end{array}$ \\
\hline 1976 & no & days \\
\hline 1977 & yes & March - WT is within $30 \mathrm{~cm}$ for $14+$ days (starting March 15th) \\
\hline 1978 & yes & March - WT is within $30 \mathrm{~cm}$ for 14+ days (starting March 15th) \\
\hline
\end{tabular}


Table 15: Partial 40-year record for Greenville plot $4 \mathrm{R}$ for all methods evaluated. Some methods did not meet wetland hydrology in some years when the other methods met wetland hydrology in the same years.

\begin{tabular}{|c|c|c|c|c|c|}
\hline \multirow{3}{*}{ Year } & \multirow{3}{*}{$\begin{array}{l}\text { Long-Term } \\
\text { Record }\end{array}$} & \multicolumn{4}{|c|}{ Years Wetland Hydrology Met } \\
\hline & & \multicolumn{2}{|c|}{ Moving Total } & \multicolumn{2}{|c|}{ DAREM } \\
\hline & & Corps & Adjusted & Corps & Modified \\
\hline 1959 & yes $\dagger$ & yes $\dagger$ & no $\ddagger$ & yest & yes $\dagger$ \\
\hline 1960 & yes $\dagger$ & no & not & no $\neq$ & no \\
\hline 1961 & yes $\dagger$ & no & no $\neq$ & yes $\dagger$ & yes $\dagger$ \\
\hline 1962 & yes $\dagger$ & no $\ddagger$ & no $\ddagger$ & yes $\dagger$ & yes $\dagger$ \\
\hline 1963 & yes $\dagger$ & yes $\dagger$ & yes $\dagger$ & yes $\dagger$ & yes $\dagger$ \\
\hline 1964 & yes $\dagger$ & no & no & no & not \\
\hline 1965 & yes $\dagger$ & yes $\dagger$ & yes $\dagger$ & yes $\dagger$ & yes $\dagger$ \\
\hline 1966 & yes $\dagger$ & no $\ddagger$ & no & yes $\dagger$ & yes $\dagger$ \\
\hline 1967 & yes $\dagger$ & yes $\dagger$ & yes $\dagger$ & yes $†$ & yes $\dagger$ \\
\hline 1968 & yes $\dagger$ & no & no & yes $\dagger$ & yes $\dagger$ \\
\hline 1969 & yes $\dagger$ & no & yes $\dagger$ & yes $\dagger$ & yes $\dagger$ \\
\hline 1970 & yes $\dagger$ & yes $\dagger$ & yes $\dagger$ & yes $\dagger$ & yes $\dagger$ \\
\hline 1971 & yes $\dagger$ & no & no $\neq$ & yes $\dagger$ & yes $\dagger$ \\
\hline 1972 & yes $\dagger$ & yes $\dagger$ & yest & yes $\dagger$ & yes $\dagger$ \\
\hline 1973 & yes $\dagger$ & yes $\dagger$ & no & yes $\dagger$ & yes $\dagger$ \\
\hline 1974 & yes $\dagger$ & yes $\dagger$ & yest & yes $\dagger$ & yes $\dagger$ \\
\hline 1975 & yes $\dagger$ & yes $\dagger$ & no & yes $\dagger$ & yes $\dagger$ \\
\hline 1976 & no* & no* & no* & no* & no* \\
\hline 1977 & yes $\dagger$ & no $\neq$ & no & yes $\dagger$ & yes $\dagger$ \\
\hline 1978 & yes $\dagger$ & no & yes $\dagger$ & yes $\dagger$ & yes $\dagger$ \\
\hline
\end{tabular}

$+\quad$ Plots that met wetland hydrology saturation requirement during a period of normal or drier than normal rainfall

* Plots that met the wetland hydrology saturation requirement, but met it during a period of above normal rainfall "wet"

* Plots that did not meet the wetland hydrology saturation requirement "dry" 
Table 16: Number of times that wetland hydrology was not met for different lengths of years using Modified DAREM. For example, plot S3 did not meet wetland hydrology for 23 out of 45 years. There was a single year, two consecutive years, one period of 5 consecutive years and one period of 15 consecutive years that did not meet wetland hydrology because plot S3 was considered too dry and did not meet the water table criteria.

\begin{tabular}{|c|c|c|c|c|c|c|}
\hline Site & Plot & $\begin{array}{l}\text { Total } \\
\text { Years }\end{array}$ & $\begin{array}{c}\text { No. Years Not } \\
\text { Met }\end{array}$ & $\begin{array}{l}\text { Single } \\
\text { Years }\end{array}$ & $\begin{array}{c}2 \\
\text { Consecutive } \\
\text { Years }\end{array}$ & $\begin{array}{c}>2 \text { Consecutive } \\
\text { Years }\end{array}$ \\
\hline \multirow{6}{*}{ Greenville } & $1 \mathrm{R}$ & 40 & 10 & 2 & 3 & 0 \\
\hline & $2 \mathrm{R}$ & 40 & 3 & 3 & 0 & 0 \\
\hline & $3 R$ & 40 & 3 & 3 & 0 & 0 \\
\hline & $4 \mathrm{R}$ & 40 & 6 & 6 & 0 & 0 \\
\hline & $4 \mathrm{P}$ & 40 & 3 & 3 & 0 & 0 \\
\hline & AVG & ----- & 5 & 3.4 & 0.6 & 0 \\
\hline \multirow{7}{*}{ Bertie } & $3 \mathrm{~N}$ & 45 & 17 & 4 & 2 & $\begin{array}{l}2 \text { periods ( } 4 \text { years } \\
\text { and } 5 \text { years) }\end{array}$ \\
\hline & $4 \mathrm{~N}$ & 45 & 9 & 5 & 2 & 0 \\
\hline & $5 \mathrm{~N}$ & 45 & 7 & 5 & 1 & 0 \\
\hline & $3 S$ & 45 & 17 & 6 & 3 & 1 period ( 5 years) \\
\hline & $4 \mathrm{~S}$ & 45 & 10 & 4 & 3 & 0 \\
\hline & $5 \mathrm{~S}$ & 45 & 7 & 5 & 1 & 0 \\
\hline & AVG & ------ & 11 & 5 & 2 & 3.8 \\
\hline \multirow{7}{*}{ Marcell } & S1 & 45 & 10 & 4 & 3 & 0 \\
\hline & S2 & 45 & 0 & 0 & 0 & 0 \\
\hline & S3 & 45 & 23 & 1 & 1 & $\begin{array}{l}2 \text { periods ( } 5 \text { years } \\
\text { and } 15 \text { years) }\end{array}$ \\
\hline & S4 & 44 & 1 & 1 & 0 & 0 \\
\hline & S5 & 44 & 6 & 6 & 0 & 0 \\
\hline & S6 & 40 & 14 & 2 & 1 & 1 period (10 years) \\
\hline & AVG & ------ & 9 & 2.3 & 0.8 & 7.5 \\
\hline
\end{tabular}


Table 17: Evaluation results from all methods for all adjacent non-hydric soil plots at Greenville (1L-4L) and Bertie ( $2 \mathrm{~S}$ and $2 \mathrm{~N}$ ) represented in percentages compared with the long-term water table measurement for wetland hydrology. Both DAREM and Modified DAREM approaches are closer to the long-term water table measurement averages than either of the 30-day moving total methods. In the years that the long-term measurement met wetland hydrology, the four methods did not because they were considered to be "wet" and removed.

\begin{tabular}{|c|c|c|c|c|c|}
\hline \multirow{3}{*}{ Plot } & \multirow{3}{*}{$\begin{array}{l}\text { Long-term } \\
\text { Measurement }\end{array}$} & \multicolumn{4}{|c|}{ Rainfall Evaluation Method } \\
\hline & & \multicolumn{2}{|c|}{ Moving Total } & \multicolumn{2}{|c|}{ DAREM } \\
\hline & & Modified & Corps & Corps & Modified \\
\hline & ----------------- & & $\%$ & ------- n n & ---------- \\
\hline & & & -- & & \\
\hline $1 \mathrm{~L}$ & 0 & 0 & 0 & 0 & 0 \\
\hline $2 \mathrm{~L}$ & 3 & 0 & 0 & 0 & 0 \\
\hline $3 \mathrm{~L}$ & 3 & 0 & 0 & 0 & 0 \\
\hline $4 \mathrm{~L}$ & 0 & 0 & 0 & 0 & 0 \\
\hline $2 \mathrm{~S}$ & 0 & 0 & 0 & 0 & 0 \\
\hline $2 \mathrm{~N}$ & 11 & 0 & 0 & 2 & 2 \\
\hline Average & 3 & 0 & 0 & 0.3 & 0.3 \\
\hline
\end{tabular}


Table 18: Examples of how long adjacent non-hydric soil plots at Greenville (1L-4L) and Bertie ( $2 \mathrm{~S}$ and $2 \mathrm{~N}$ ) would have to be monitored to not meet wetland hydrology (or meet wetland hydrology) based on a single year worth of data or several consecutive years worth of data.

\begin{tabular}{cccccc}
\hline Plot & $\begin{array}{c}\text { Total } \\
\text { Years }\end{array}$ & $\begin{array}{c}\text { No. Years } \\
\text { Wetland } \\
\text { Hydrology }\end{array}$ & $\begin{array}{c}\text { Single } \\
\text { Years }\end{array}$ & $\begin{array}{c}\text { 2 Consecutive } \\
\text { Years }\end{array}$ & Consecutive Years \\
\hline 1L & 40 & 0 & 0 & 0 & 0 \\
2L & 40 & 0 & 0 & 0 & 0 \\
3L & 40 & 0 & 0 & 0 & 0 \\
4L & 40 & 0 & 0 & 0 & 0 \\
2S & 45 & 0 & 0 & 0 & 0 \\
2N & 45 & 1 & 1 & 0 & 0 \\
\hline
\end{tabular}


Table 19: Percentage of False Positives (FP) and False Negatives for all plots at Greenville, Bertie and Marcell. False positives occur when an upland plot meets wetland hydrology but does not according to long-term records. False negatives occur when a plot does meet wetland hydrology according to long-term records, but do not meet wetland hydrology according to a short-term method because of above normal rainfall.

\begin{tabular}{|c|c|c|c|c|c|c|}
\hline \multirow[b]{2}{*}{ Site } & \multirow[b]{2}{*}{ Plot } & \multirow[b]{2}{*}{$\begin{array}{l}\text { Total } \\
\text { Years }\end{array}$} & \multicolumn{4}{|c|}{ False Negatives } \\
\hline & & & $\begin{array}{c}\text { Moving } \\
\text { Total }\end{array}$ & $\begin{array}{c}\text { Adjust Moving } \\
\text { Total } \\
\text { Percent of }\end{array}$ & $\begin{array}{l}\text { DAREM } \\
\text { otal Years }\end{array}$ & $\begin{array}{l}\text { Modified } \\
\text { DAREM }\end{array}$ \\
\hline \multirow{9}{*}{ Greenville } & $1 \mathrm{R}$ & 40 & 55 & 65 & 18 & 13 \\
\hline & $2 \mathrm{R}$ & 40 & 30 & 53 & 10 & 8 \\
\hline & $3 \mathrm{R}$ & 40 & 30 & 53 & 8 & 5 \\
\hline & $4 \mathrm{R}$ & 40 & 33 & 55 & 10 & 10 \\
\hline & $4 \mathrm{P}$ & 40 & 20 & 53 & 5 & 5 \\
\hline & $1 \mathrm{~L}$ & 40 & 0 & 0 & 0 & 0 \\
\hline & $2 \mathrm{~L}$ & 40 & $3(\mathrm{FP})$ & $3(\mathrm{FP})$ & $3(\mathrm{FP})$ & $3(\mathrm{FP})$ \\
\hline & $3 \mathrm{~L}$ & 40 & $3(\mathrm{FP})$ & $3(\mathrm{FP})$ & $3(\mathrm{FP})$ & $3(\mathrm{FP})$ \\
\hline & $4 \mathrm{~L}$ & 40 & 0 & 0 & 0 & 0 \\
\hline \multirow{8}{*}{ Bertie } & $2 \mathrm{~S}$ & 45 & 0 & 0 & 0 & 0 \\
\hline & $3 \mathrm{~S}$ & 45 & 76 & 80 & 27 & 24 \\
\hline & $4 \mathrm{~S}$ & 45 & 67 & 73 & 18 & 13 \\
\hline & $5 S$ & 45 & 71 & 76 & 20 & 13 \\
\hline & $2 \mathrm{~N}$ & 45 & $11(\mathrm{FP})$ & $11(\mathrm{FP})$ & $9(\mathrm{FP})$ & $9(\mathrm{FP})$ \\
\hline & $3 \mathrm{~N}$ & 45 & 58 & 69 & 29 & 20 \\
\hline & $4 \mathrm{~N}$ & 45 & 76 & 78 & 24 & 16 \\
\hline & $5 \mathrm{~N}$ & 45 & 69 & 69 & 22 & 13 \\
\hline \multirow{6}{*}{ Marcell } & S1 & 45 & 31 & 36 & 9 & 9 \\
\hline & $\mathrm{S} 2$ & 45 & 11 & 18 & 0 & 0 \\
\hline & S3 & 45 & 16 & 13 & 4 & 4 \\
\hline & $\mathrm{S} 4$ & 44 & 9 & 9 & 7 & 5 \\
\hline & S5 & 44 & 18 & 20 & 14 & 14 \\
\hline & S6 & 40 & 35 & 38 & 8 & 8 \\
\hline Average & & 43 & 36 & 44 & 12 & 12 \\
\hline
\end{tabular}




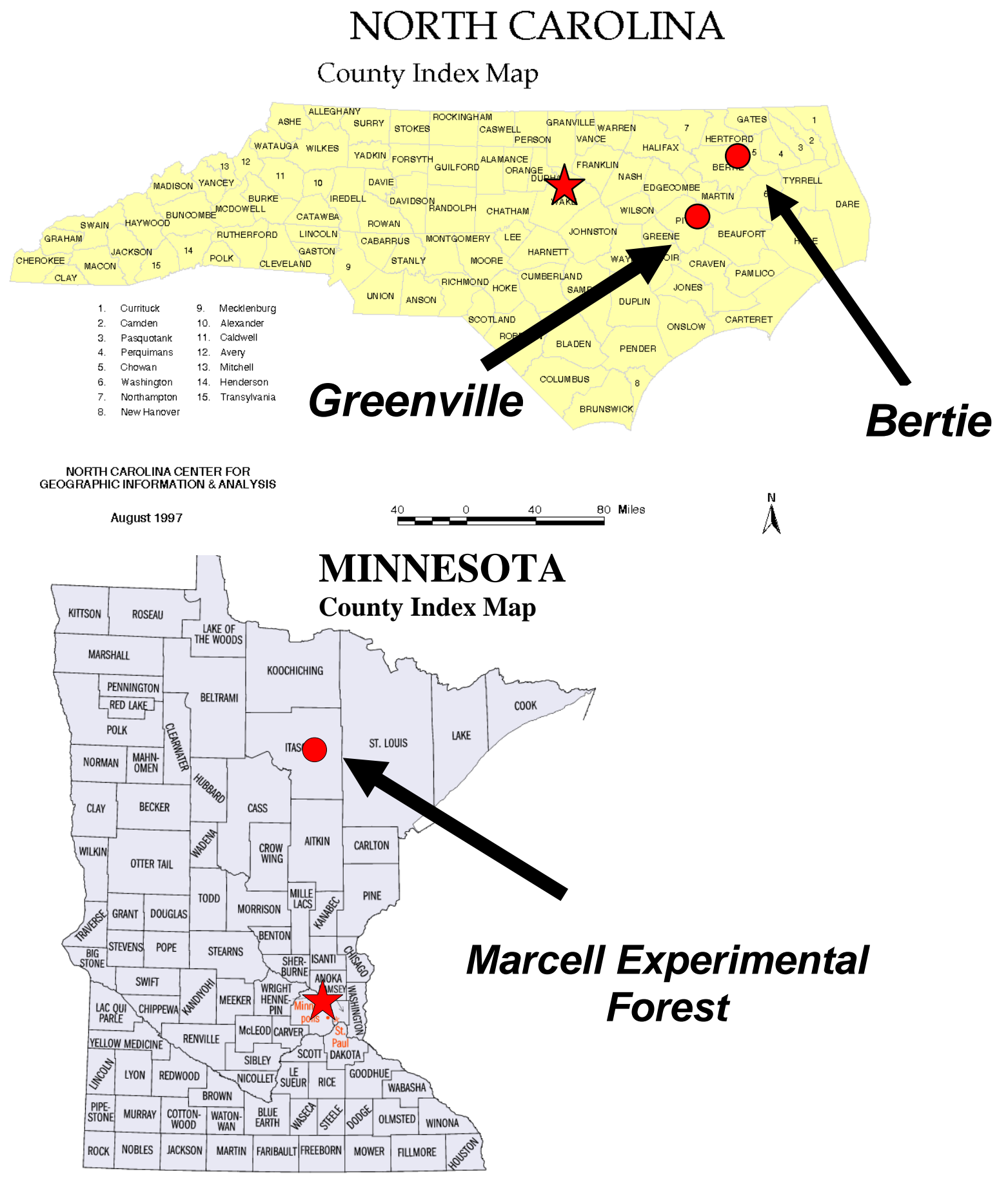

Figure 1: State maps of North Carolina and Minnesota, which show research locations in relationship to state and capitals. 


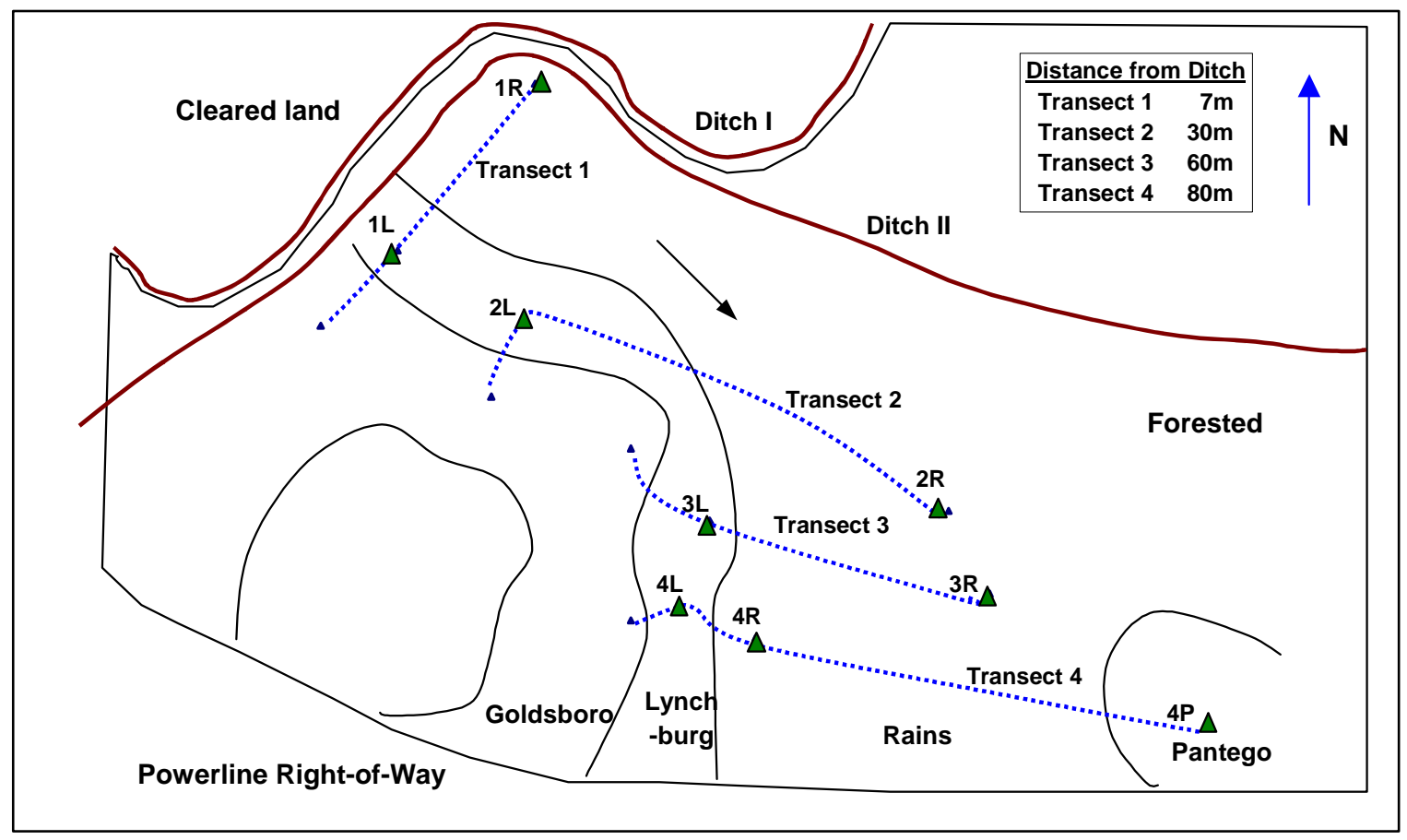

Figure 2: Greenville site map with plots of interest labeled as: 1L, 1R .. 4L, 4R and 4P to represent transect and series name (He et al., 2002). For example, plot 1R represents Rains soil series plot 1 . 


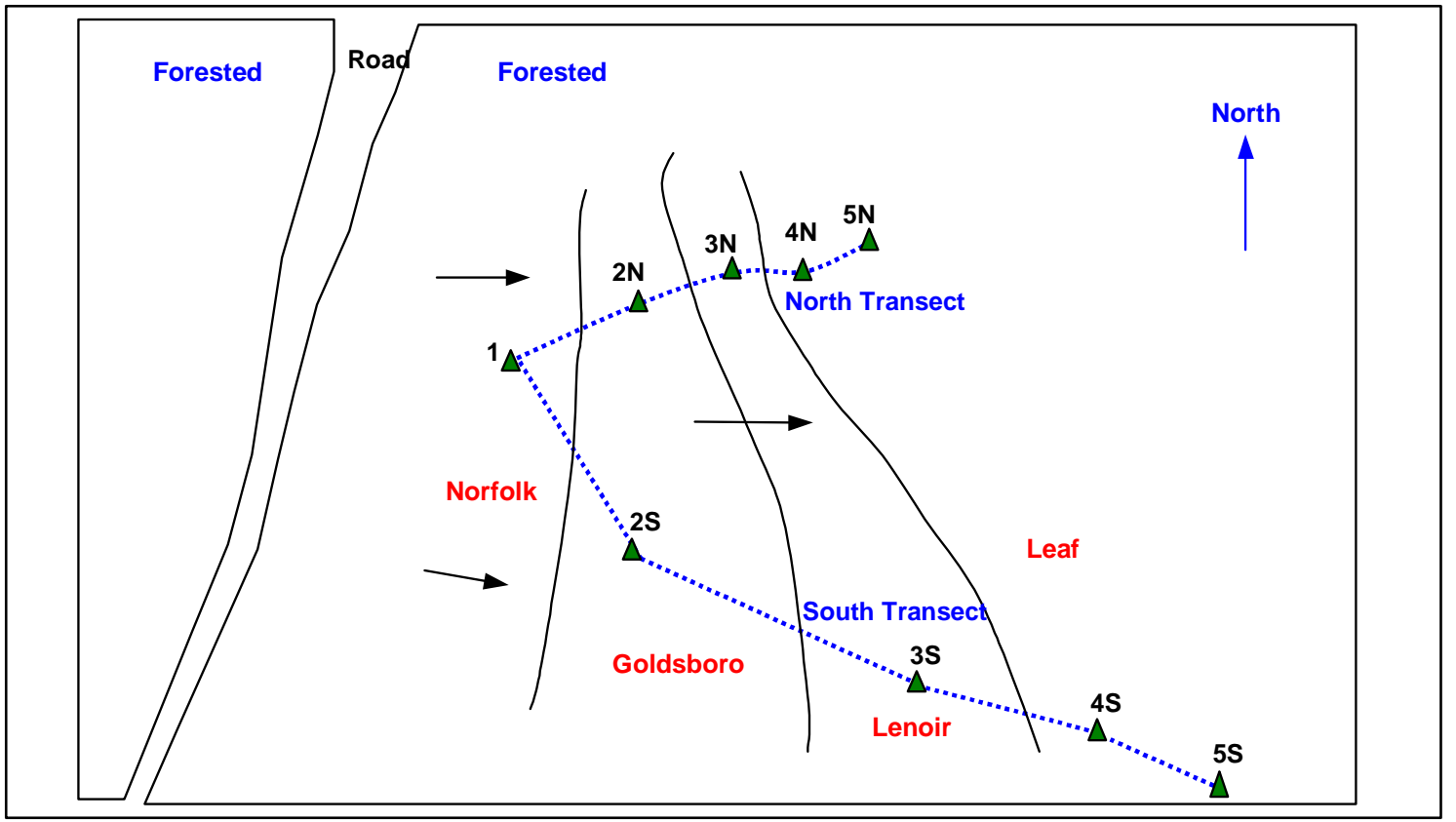

Figure 3: Bertie site map with plots of interest labeled as: 1, 2N, 3N, 4N, 5N, 2S, 3S, 4S, $5 \mathrm{~S}$ to represent the soil series (1-Noboco, 2-Goldsboro, 3-Lenoir, 4,5-Leaf) and transect (North and South) (He et. al, 2002). 


\section{Marcell Experimental Forest}
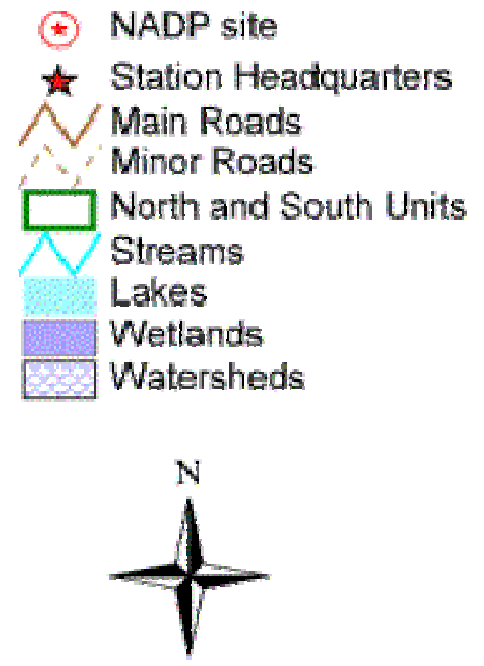

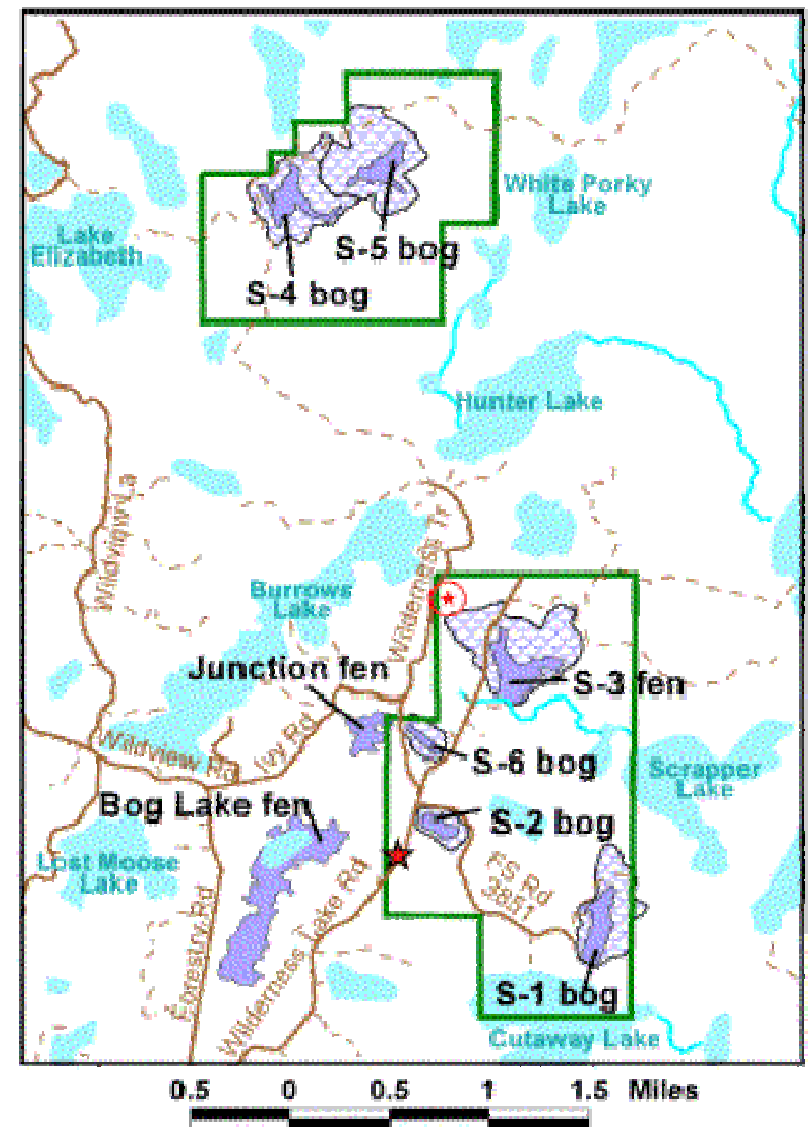

Figure 4: Marcell site map with watersheds of interest labeled as: S1, S2, S3, S4, S5 and S6. S4 and S5 are located in the northern part of the Marcel Experimental Forest, while all other watersheds are located in the southern part. They also represent the soil series found in the peatlands of each watershed (S1, S2, S4, S5 - Loxley peat, S3 - Mooselake peat, S6 - Greenwood peat). 


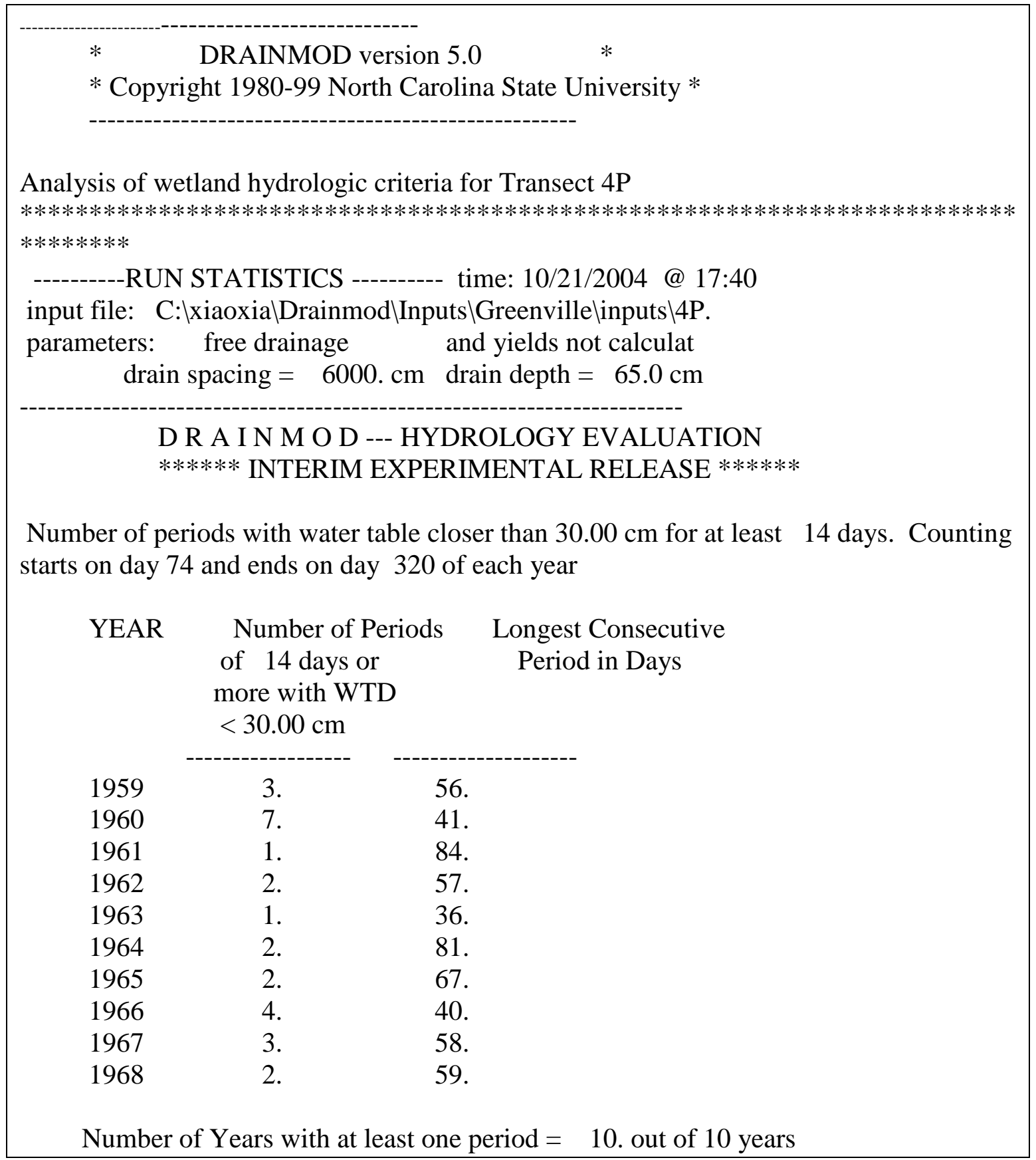

Figure 5: Example of partial output from DRAINMOD for plot 4P at Greenville which shows parameters and output to give the number of periods of 14 days or more with water table depth within $30 \mathrm{~cm}$ of the surface and the longest consecutive period in days of saturation for each year of record. 


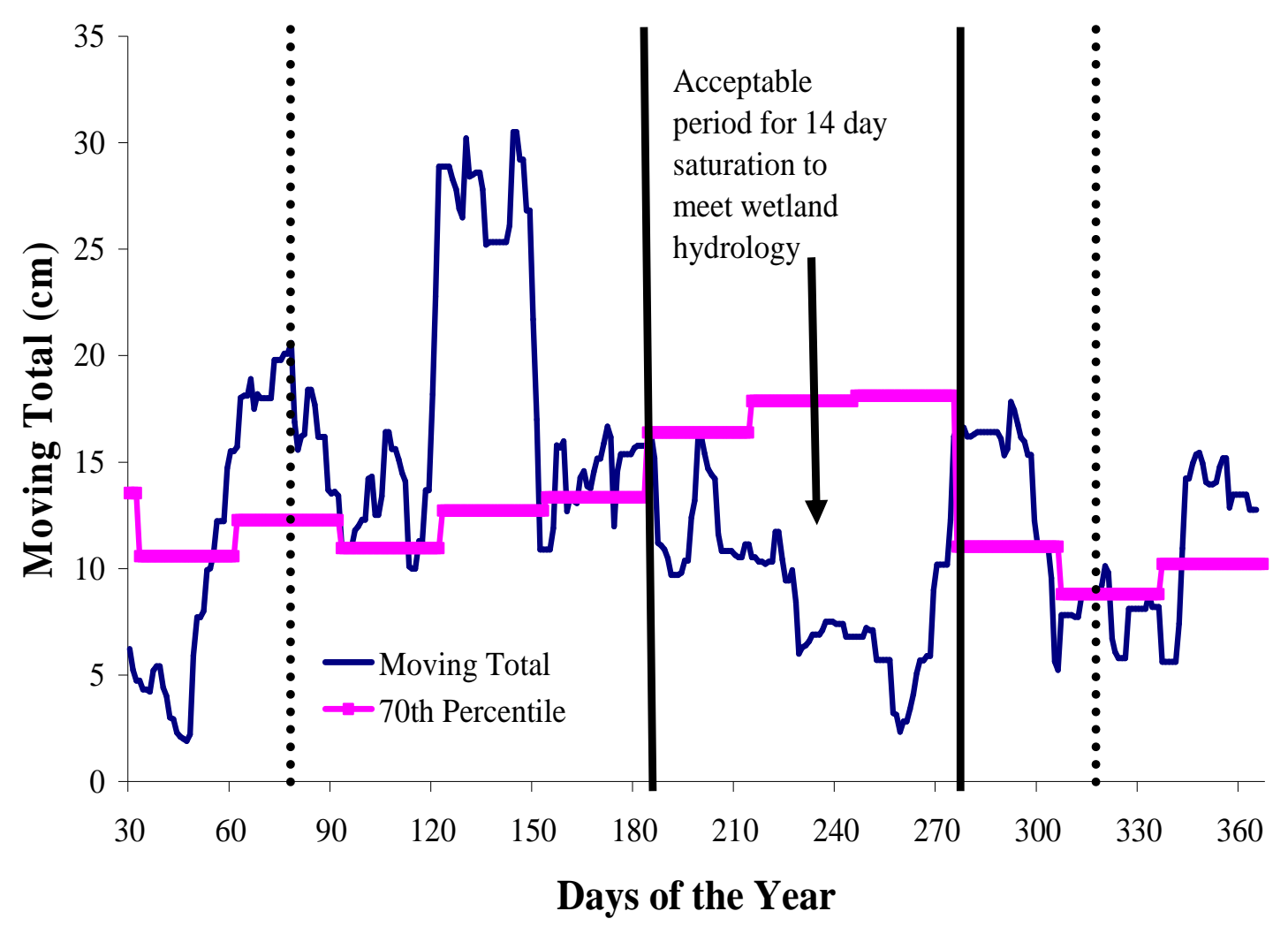

Figure 6: 30-Day Moving Total graph for 1989 for Greenville Plot 4R, which is above the 70th Percentile through day 186 . However, day 186 through day 276 is under the $70^{\text {th }}$ Percentile line and within the growing season and is therefore considered to be an acceptable period to meet wetland hydrology. This graph was then compared with water table data generated from DRAINMOD to determine if the water table was within $30 \mathrm{~cm}$ for 14 days or longer during the period between day 186 and 276. 


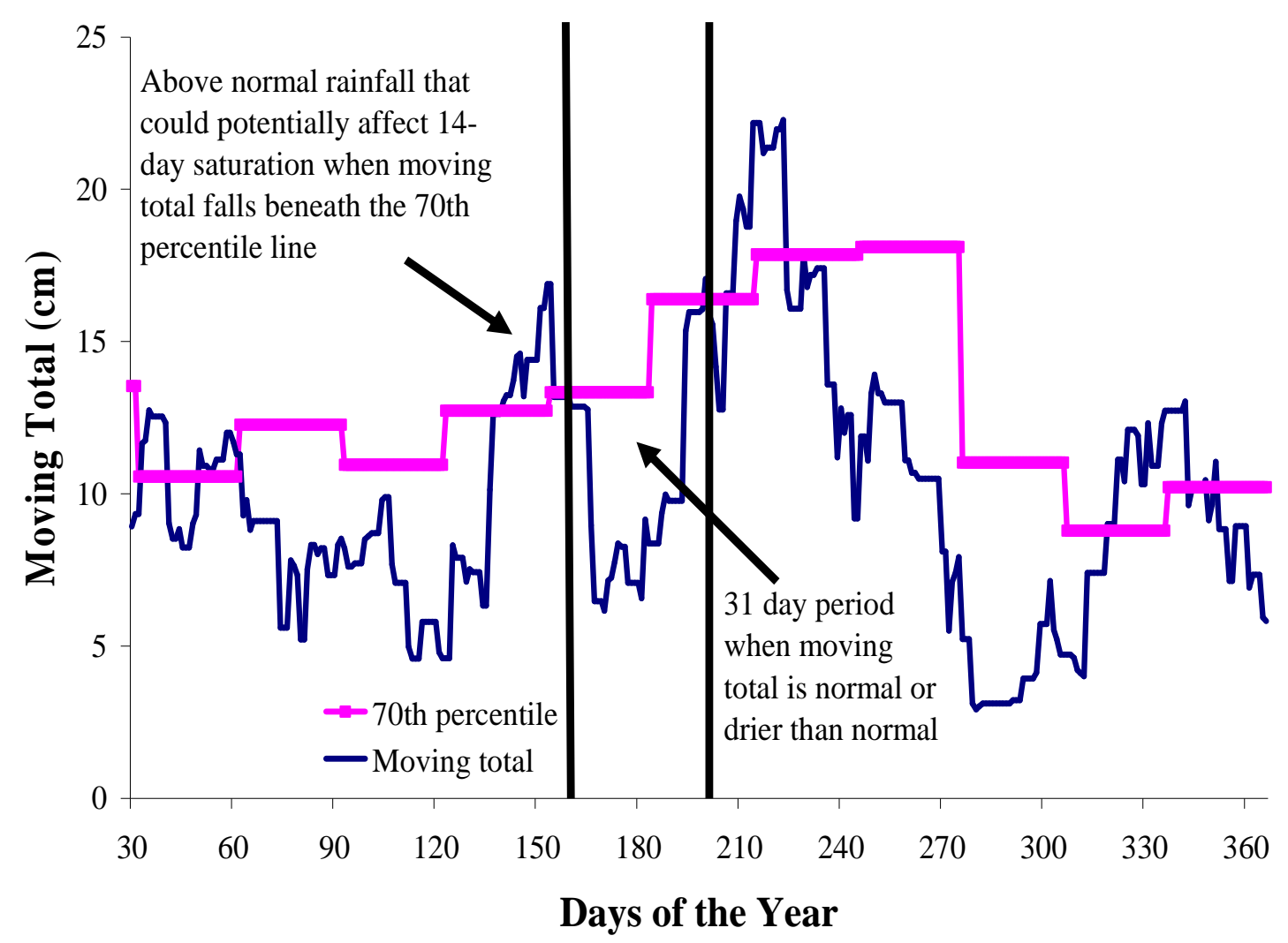

Figure 7: The 30-Day Moving total graph for 1972 for Greenville plots. The highlighted period of interest would be excluded from the 30-day modified moving total method because although it has a 31 day period of normal or drier than normal rainfall, the $30-$ day period that precedes the saturation at day 166 is above the $70^{\text {th }}$ percentile. Therefore that above normal precipitation could have caused the saturation in the days highlighted. This graph met the criterion for determining wetland hydrology for the 30-day moving total method because the 14-day saturation occurred within the 31 days of normal or drier than normal precipitation. However, this graph did not meet wetland hydrology within the 30-day modified moving total method due to prior above normal rainfall within 30 days before the 31 day period. 


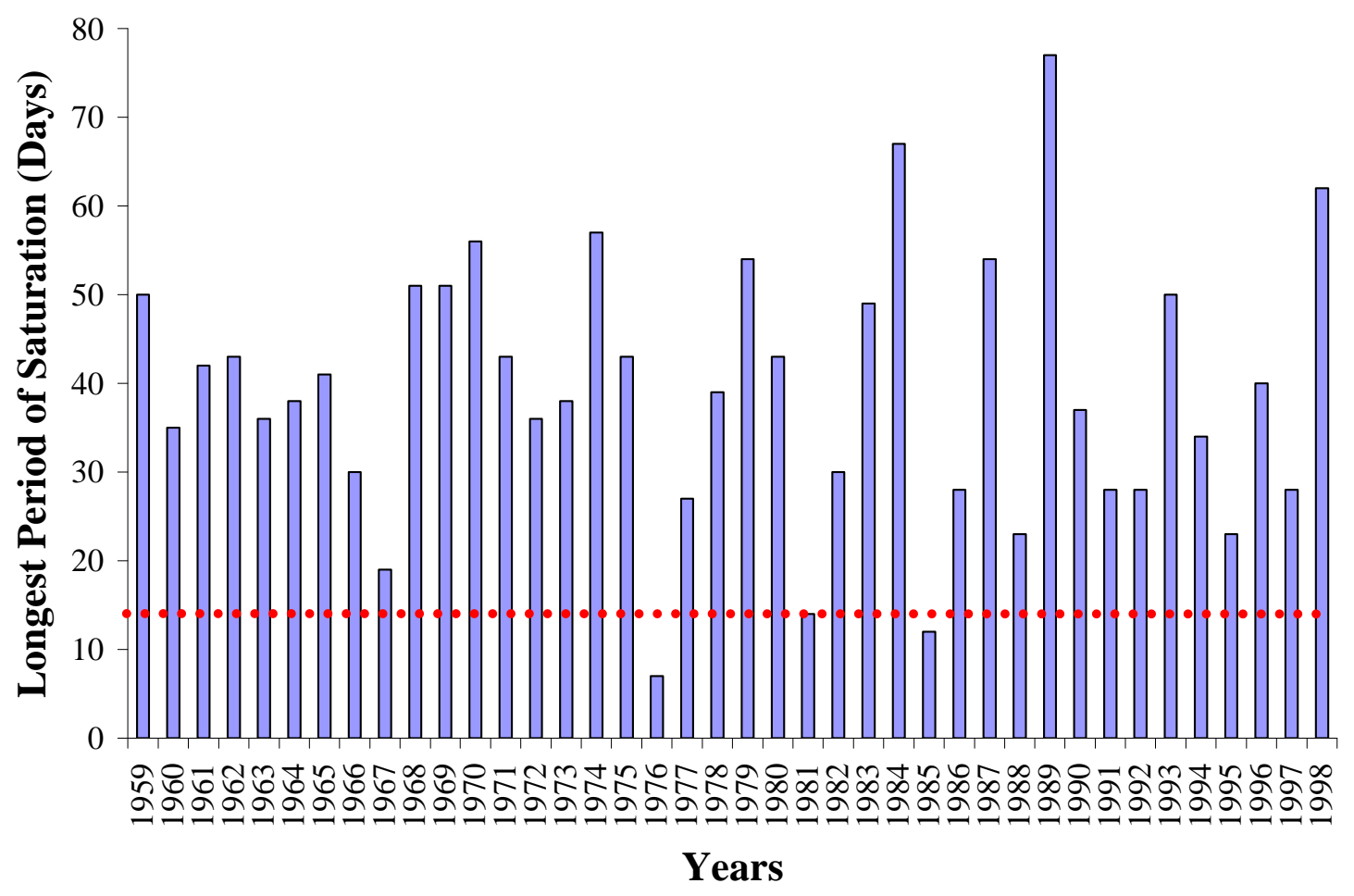

Figure 8: Number of consecutive days water table was within $30 \mathrm{~cm}$ of the surface during the growing season for a 40 year period (1959-1998) in plot 4R at Greenville. The dotted line represents the 14-day saturation requirement for wetland hydrology to compare which years met wetland hydrology and which did not. All years but 1976 and 1985 met the 14-day saturation requirement. 


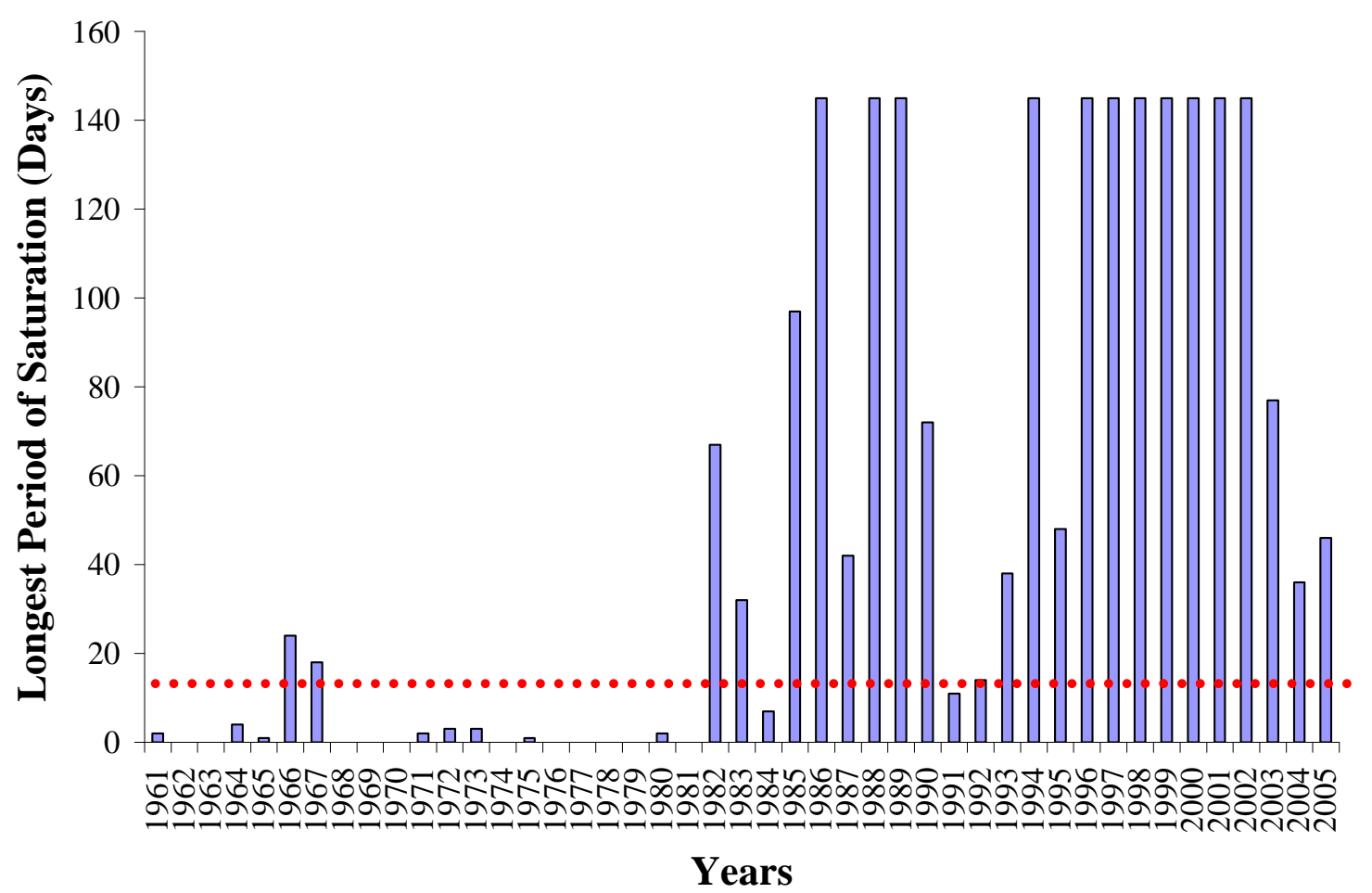

Figure 9: Long-term water table data record for plot $\mathrm{S} 3$ at Marcell, which met wetland hydrology 24 out of 45 years. The longest consecutive period of saturation within $30 \mathrm{~cm}$ of the surface for each year from 1961 through 2005 was plotted with a line that represents 14-day saturation requirement for wetland hydrology to compare which years met wetland hydrology and which did not. There were only two periods within the first 20 years that met wetland hydrology because plots did not meet water table saturation criterion and considered dry. 
APPENDIX A

Long-term Records 


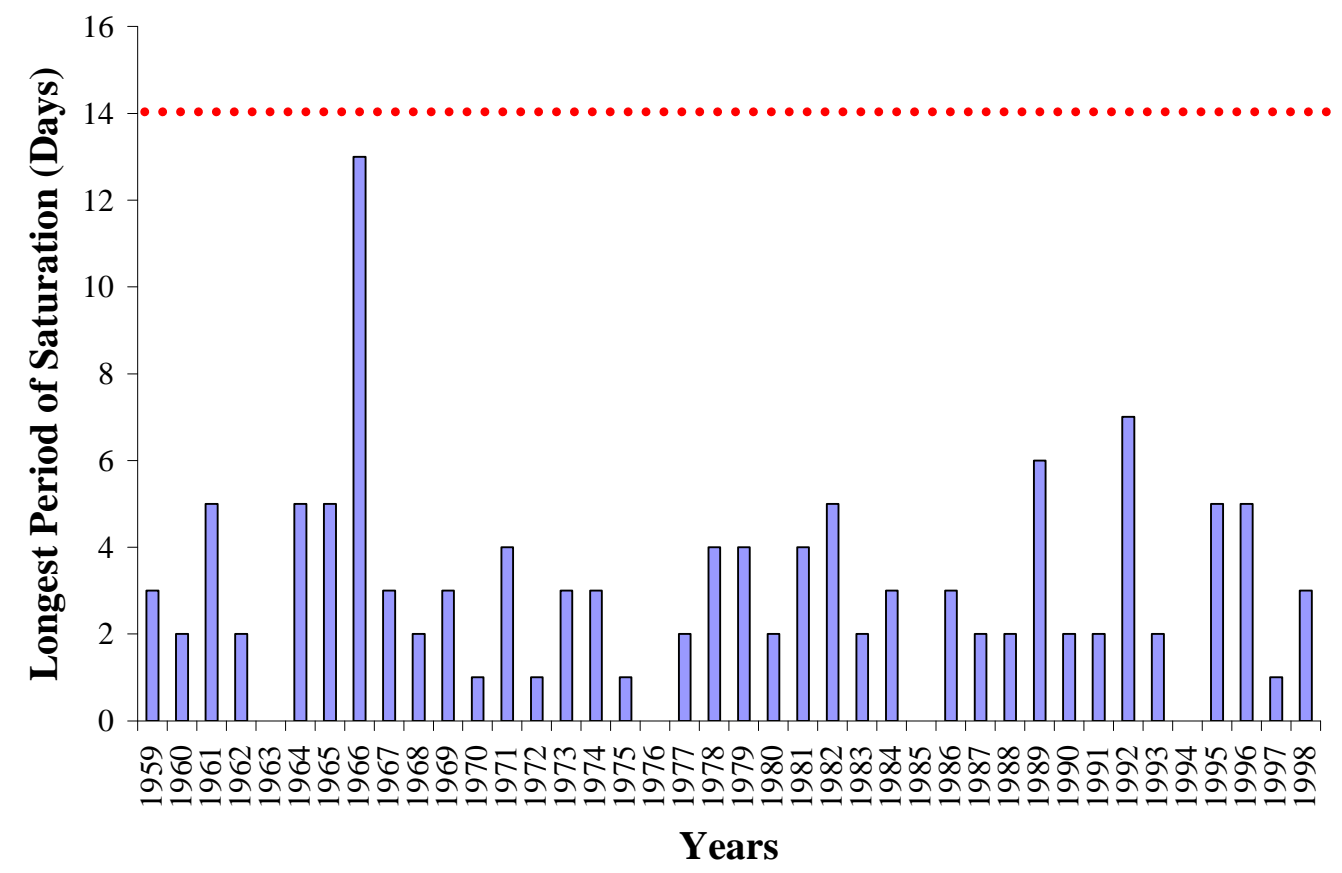

Figure A.1: Long-term continuous period of saturation during the growing season when water table was within $30 \mathrm{~cm}$ of the surface. Data are for plot $1 \mathrm{~L}$ at Greenville and met wetland hydrology in 0 out of 40 years. Dashed line shows 14 days.

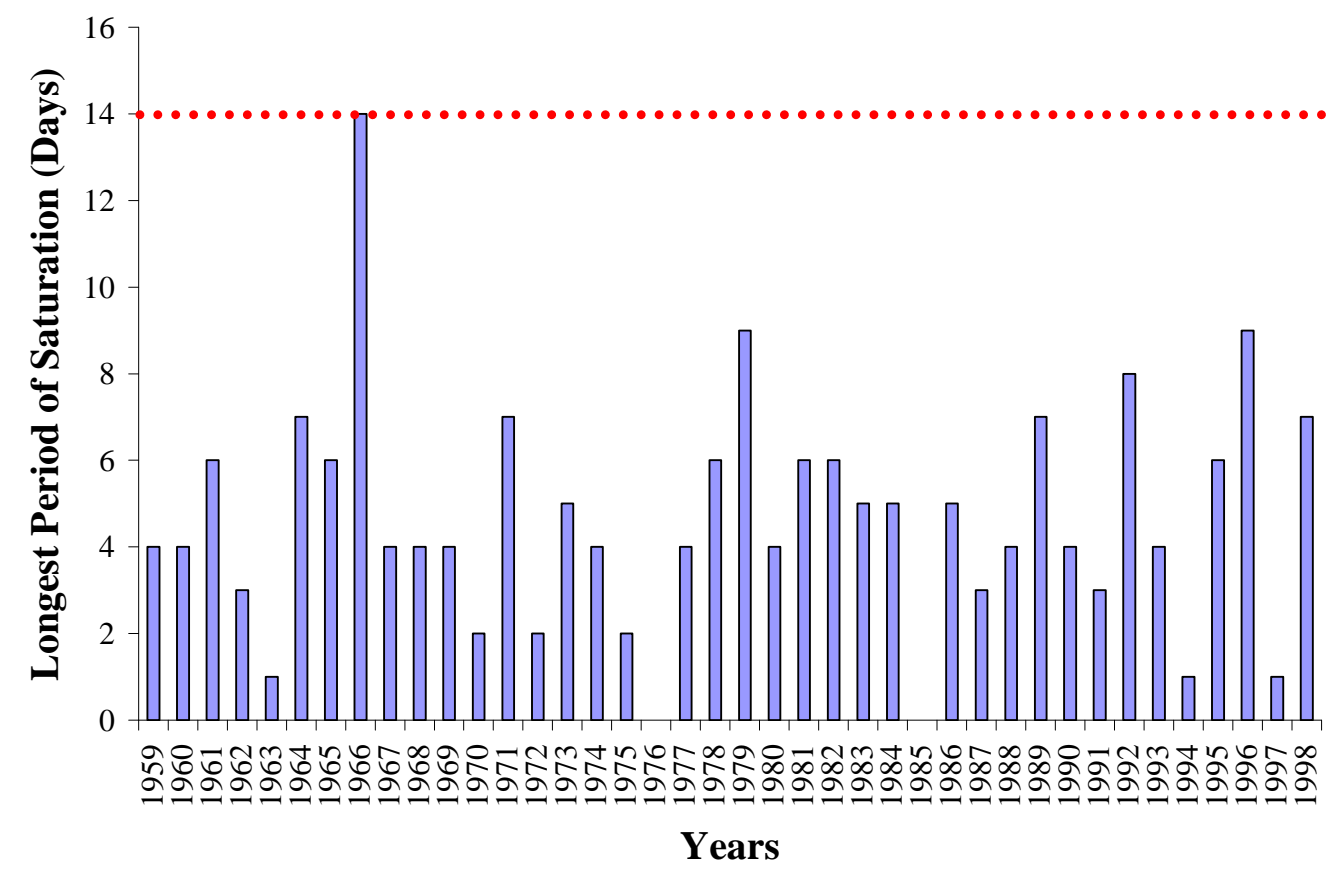

Figure A.2: Long-term continuous period of saturation during the growing season when water table was within $30 \mathrm{~cm}$ of the surface. Data are for plot $2 \mathrm{~L}$ at Greenville and met wetland hydrology in 1 out of 40 years. Dashed line shows 14 days. 


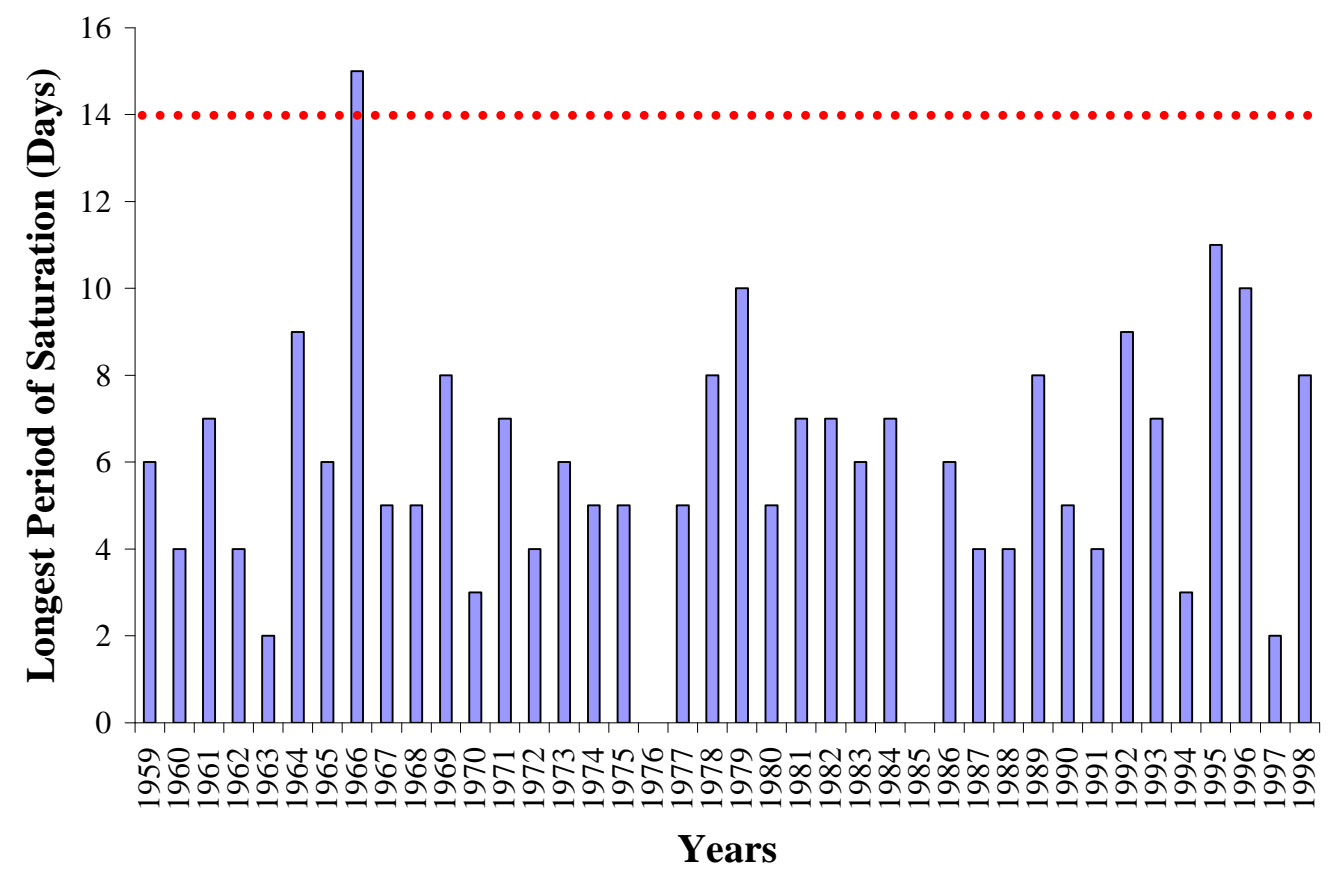

Figure A.3: Long-term continuous period of saturation during the growing season when water table was within $30 \mathrm{~cm}$ of the surface. Data are for plot $3 \mathrm{~L}$ at Greenville and met wetland hydrology in 1 out of 40 years. Dashed line shows 14 days.

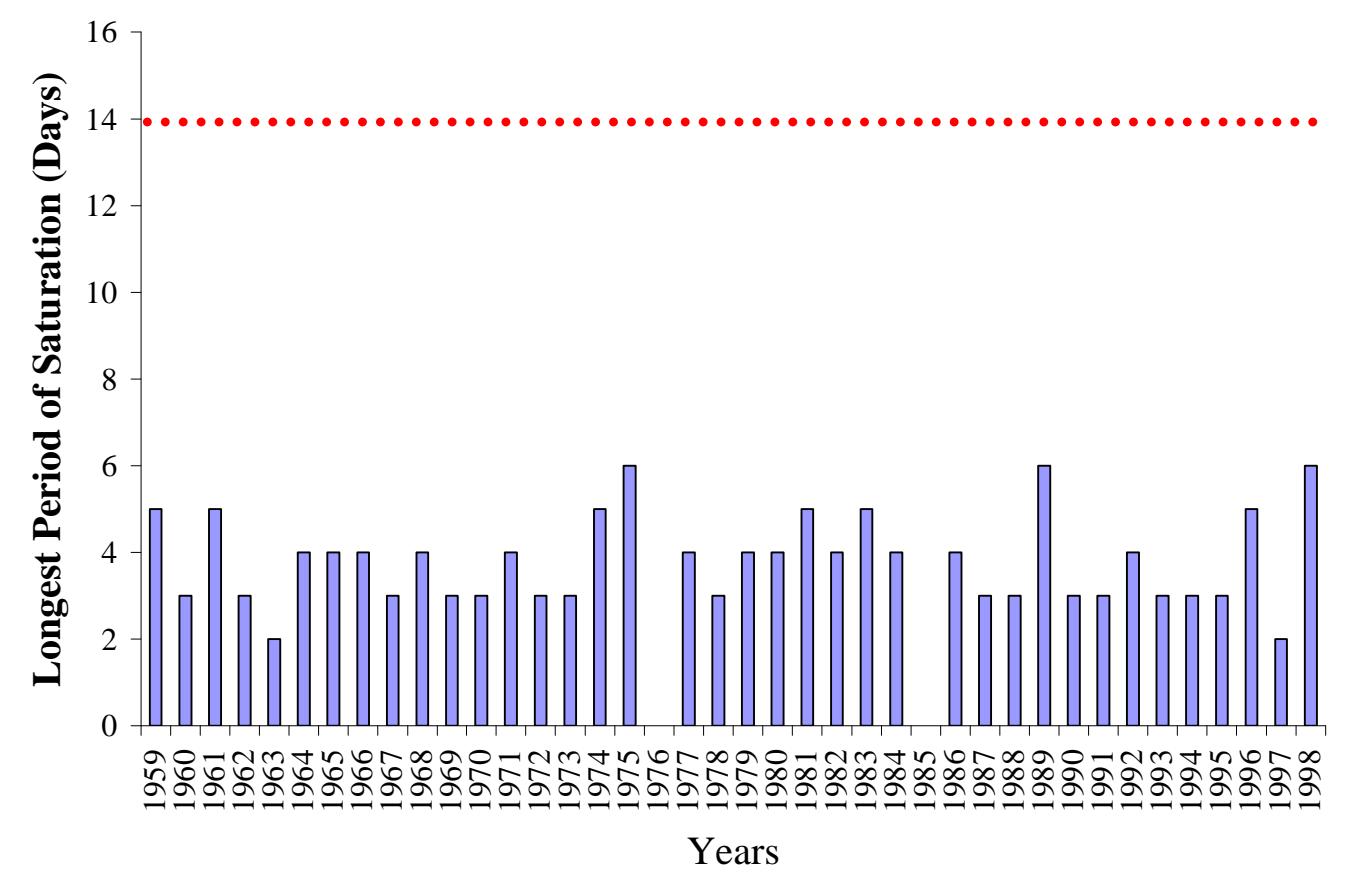

Figure A.4: Long-term continuous period of saturation during the growing season when water table was within $30 \mathrm{~cm}$ of the surface. Data are for plot $4 \mathrm{~L}$ at Greenville and met wetland hydrology in 0 out of 40 years. Dashed line shows 14 days. 


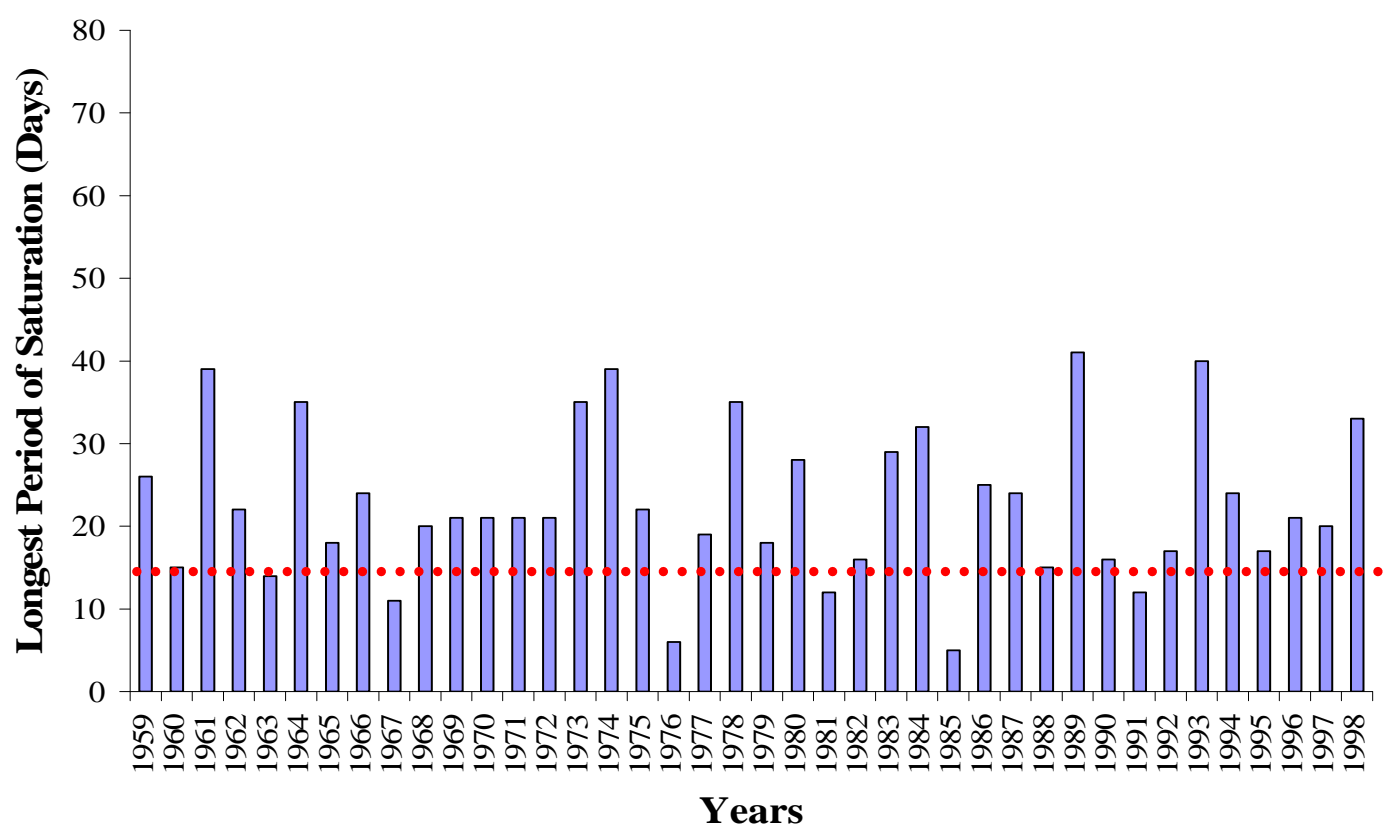

Figure A.5: Long-term continuous period of saturation during the growing season when water table was within $30 \mathrm{~cm}$ of the surface. Data are for plot $1 \mathrm{R}$ at Greenville and met wetland hydrology in 35 out of 40 years. Dashed line shows 14 days.

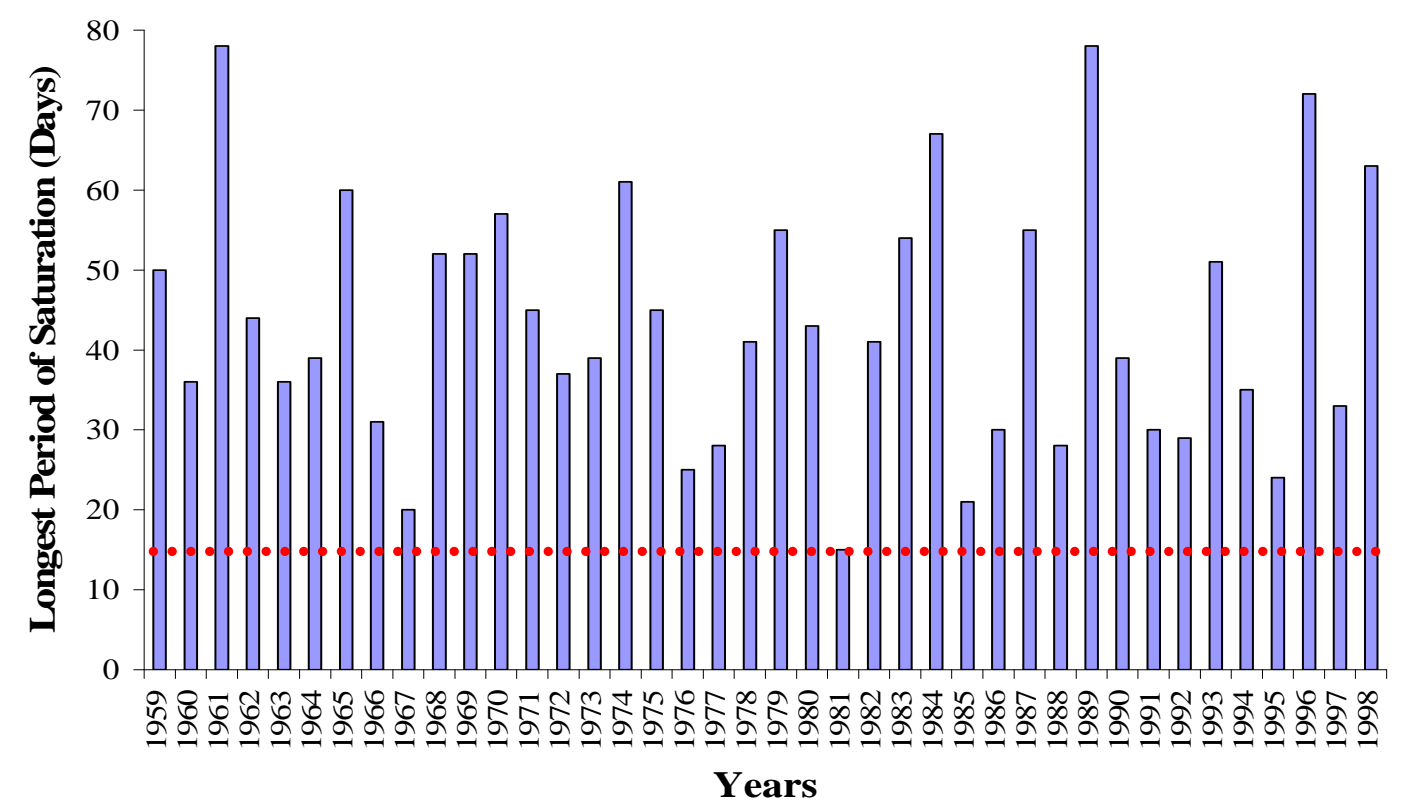

Figure A.6: Long-term continuous period of saturation during the growing season when water table was within $30 \mathrm{~cm}$ of the surface. Data are for plot $2 \mathrm{R}$ at Greenville and met wetland hydrology in 40 out of 40 years. Dashed line shows 14 days. 


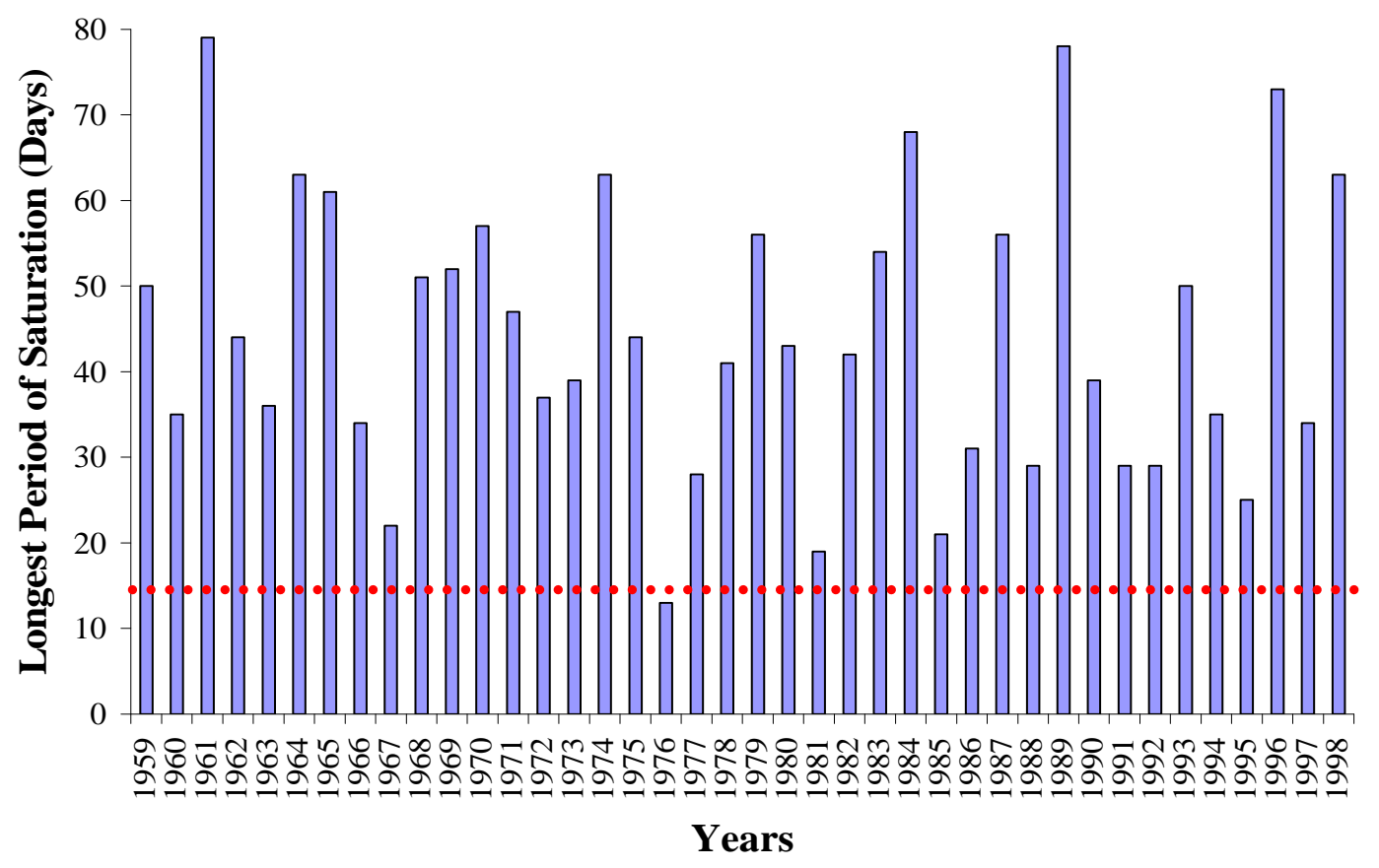

Figure A.7: Long-term continuous period of saturation during the growing season when water table was within $30 \mathrm{~cm}$ of the surface. Data are for plot $3 \mathrm{R}$ at Greenville and met wetland hydrology in 39 out of 40 years. Dashed line shows 14 days.

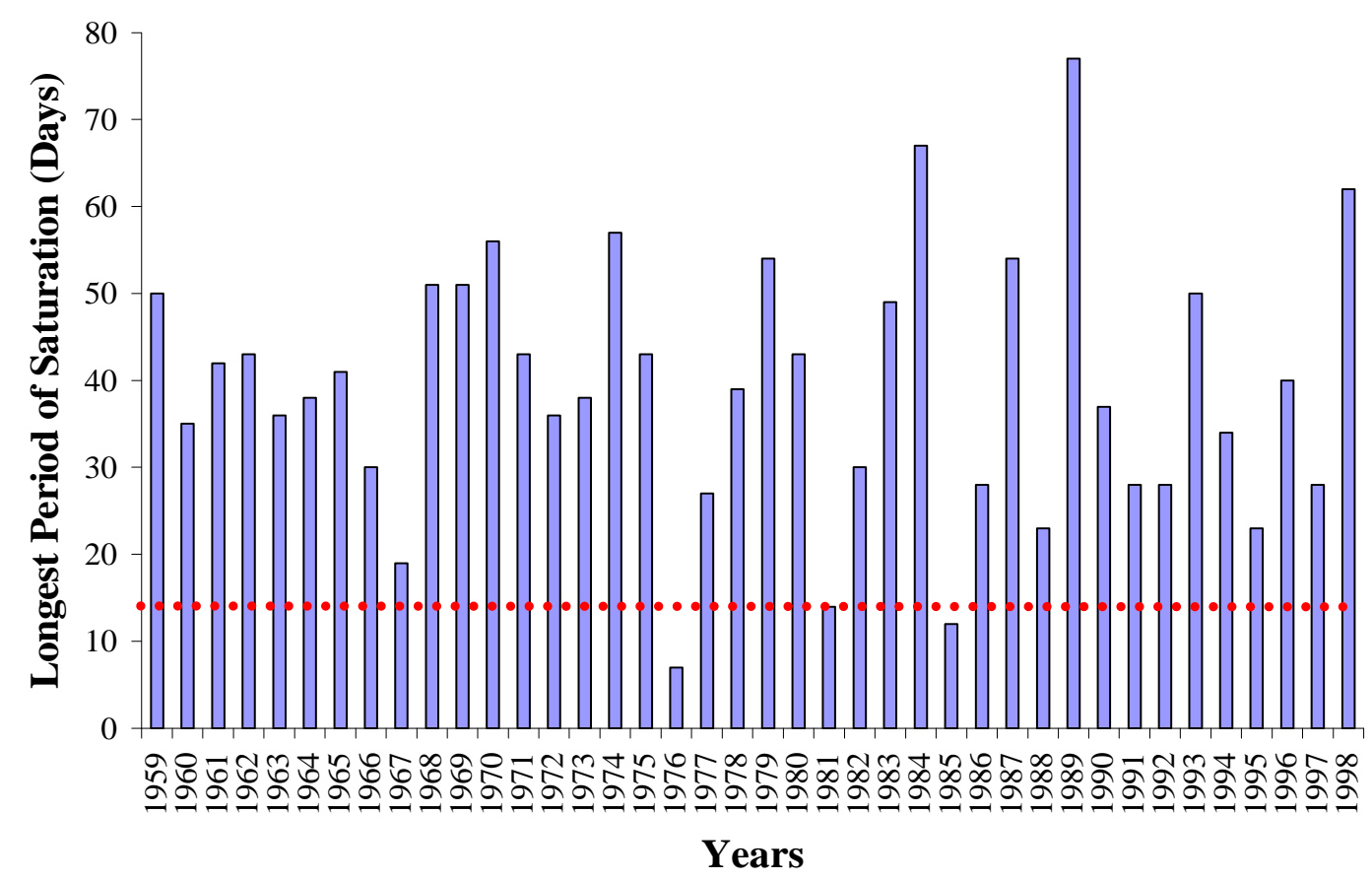

Figure A.8: Long-term continuous period of saturation during the growing season when water table was within $30 \mathrm{~cm}$ of the surface. Data are for plot $4 \mathrm{R}$ at Greenville and met wetland hydrology in 38 out of 40 years. Dashed line shows 14 days. 


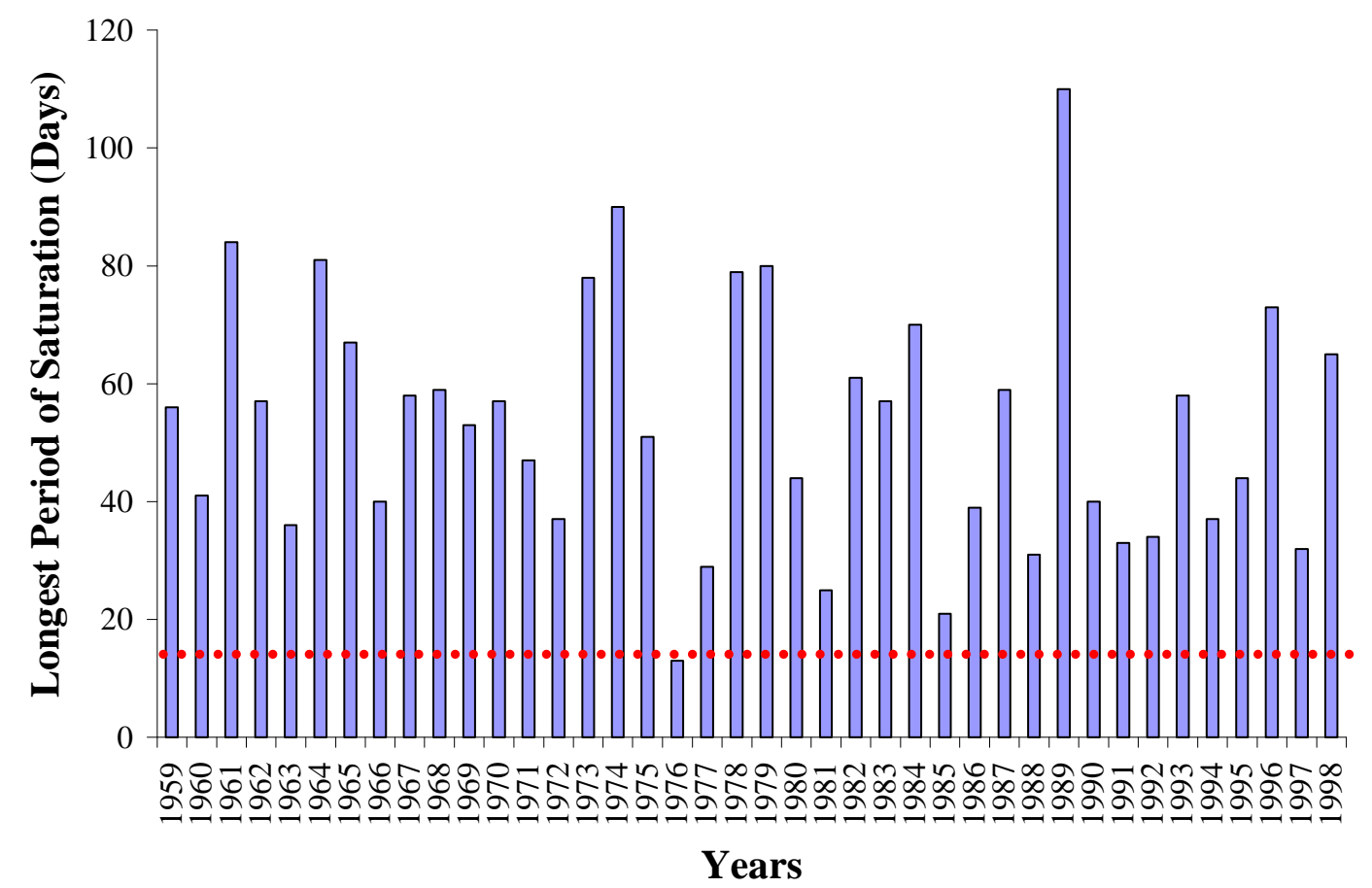

Figure A.9: Long-term continuous period of saturation during the growing season when water table was within $30 \mathrm{~cm}$ of the surface. Data are for plot $4 \mathrm{P}$ at Greenville and met wetland hydrology in 39 out of 40 years. Dashed line shows 14 days.

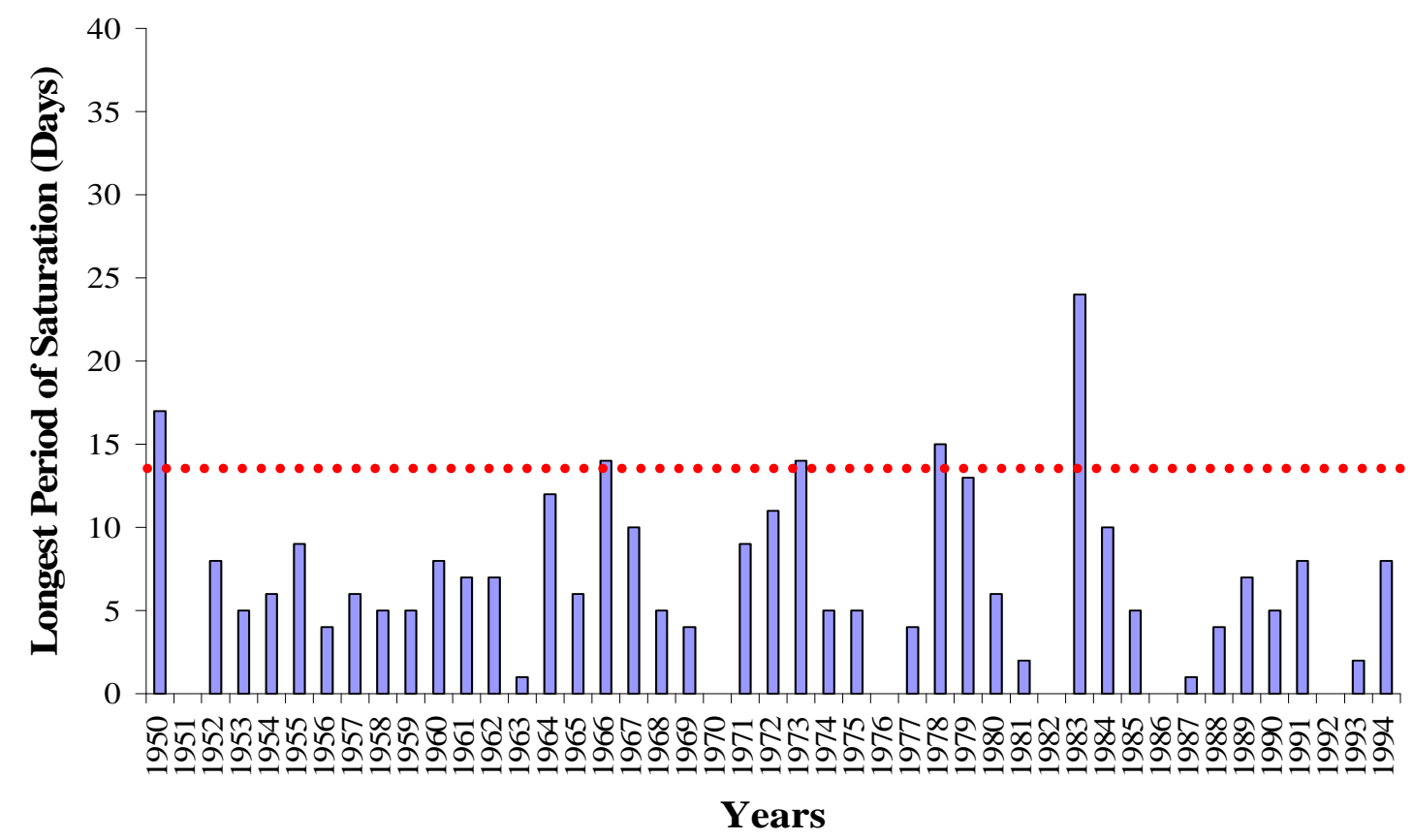

Figure A.10: Long-term continuous period of saturation during the growing season when water table was within $30 \mathrm{~cm}$ of the surface. Data are for plot $2 \mathrm{~N}$ at Bertie and met wetland hydrology in 5 out of 45 years. Dashed line shows 14 days. 


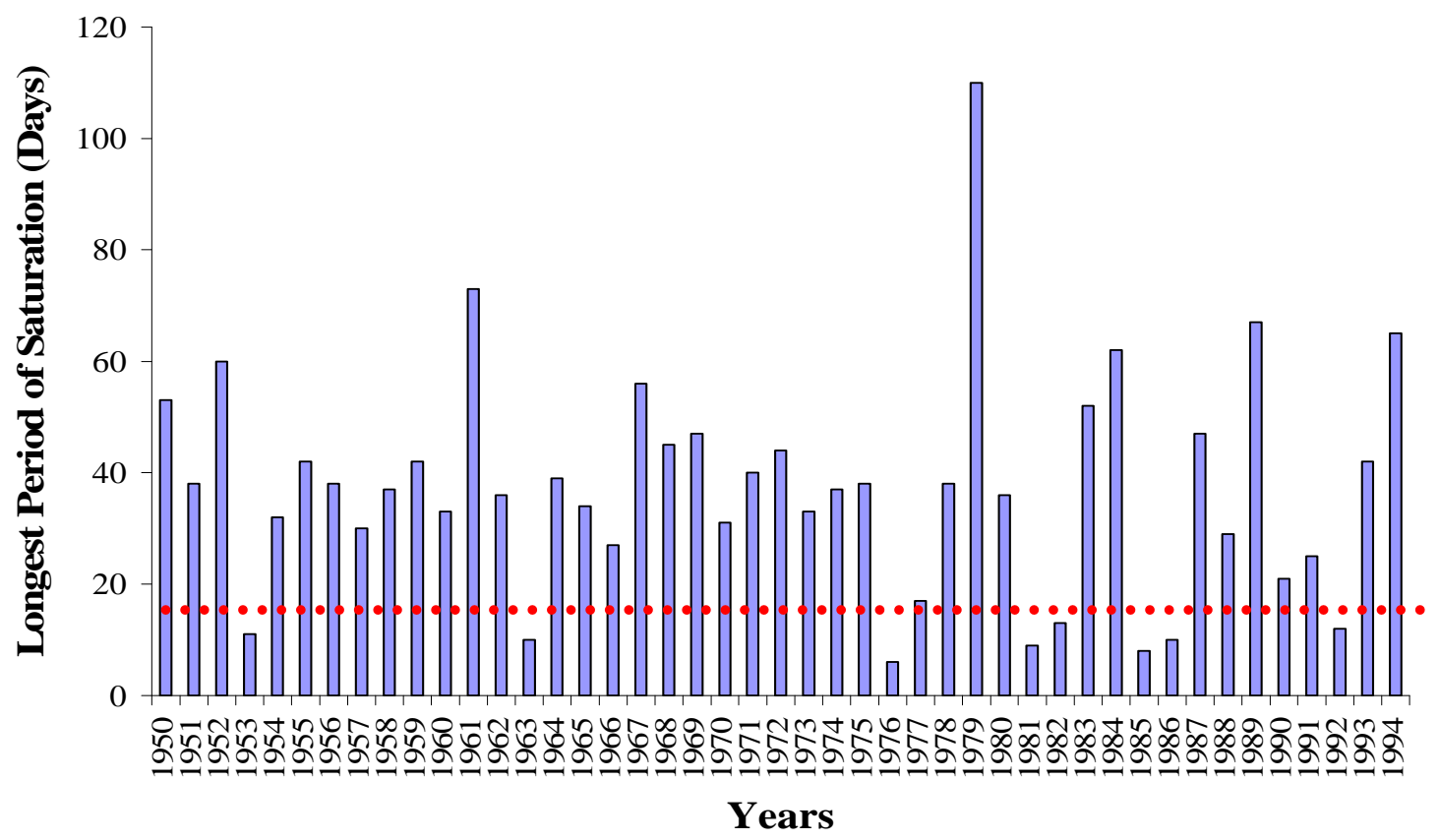

Figure A.11: Long-term continuous period of saturation during the growing season when water table was within $30 \mathrm{~cm}$ of the surface. Data are for plot $3 \mathrm{~N}$ at Bertie and met wetland hydrology in 37 out of 45 years. Dashed line shows 14 days.

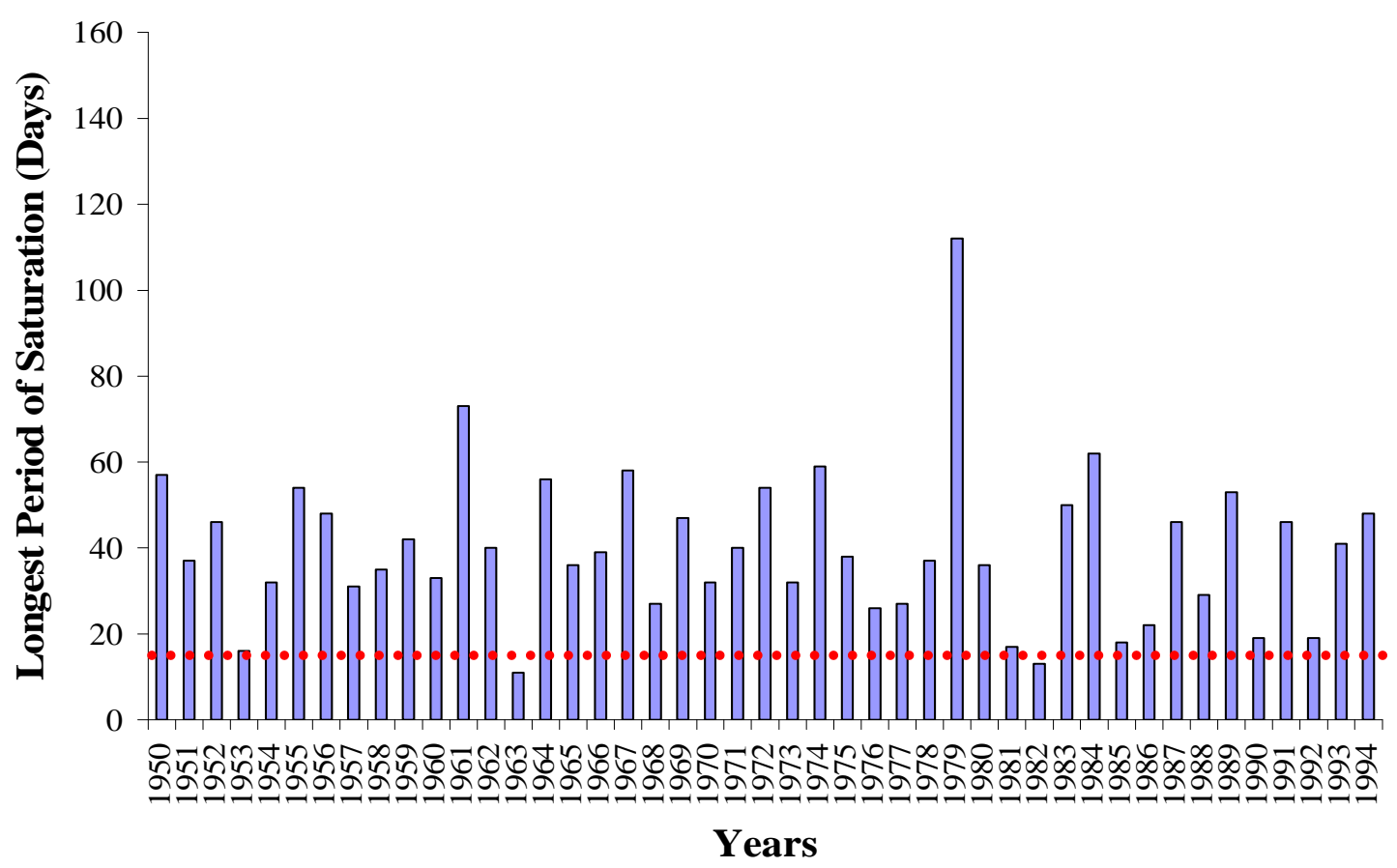

Figure A.12: Long-term continuous period of saturation during the growing season when water table was within $30 \mathrm{~cm}$ of the surface. Data are for plot $4 \mathrm{~N}$ at Bertie and met wetland hydrology in 43 out of 45 years. Dashed line shows 14 days. 


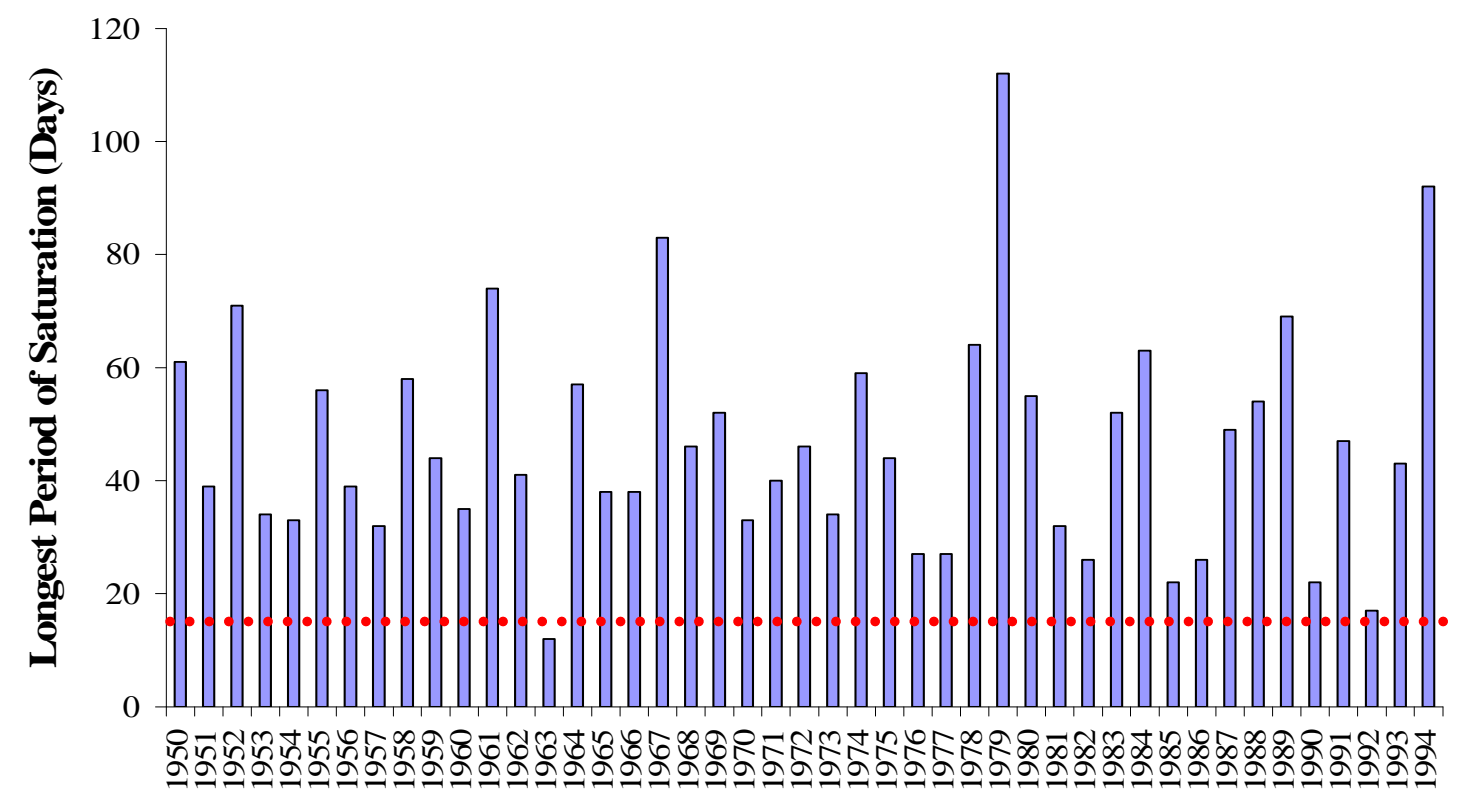

Years

Figure A.13: Long-term continuous period of saturation during the growing season when water table was within $30 \mathrm{~cm}$ of the surface. Data are for plot $5 \mathrm{~N}$ at Bertie and met wetland hydrology in 44 out of 45 years. Dashed line shows 14 days.

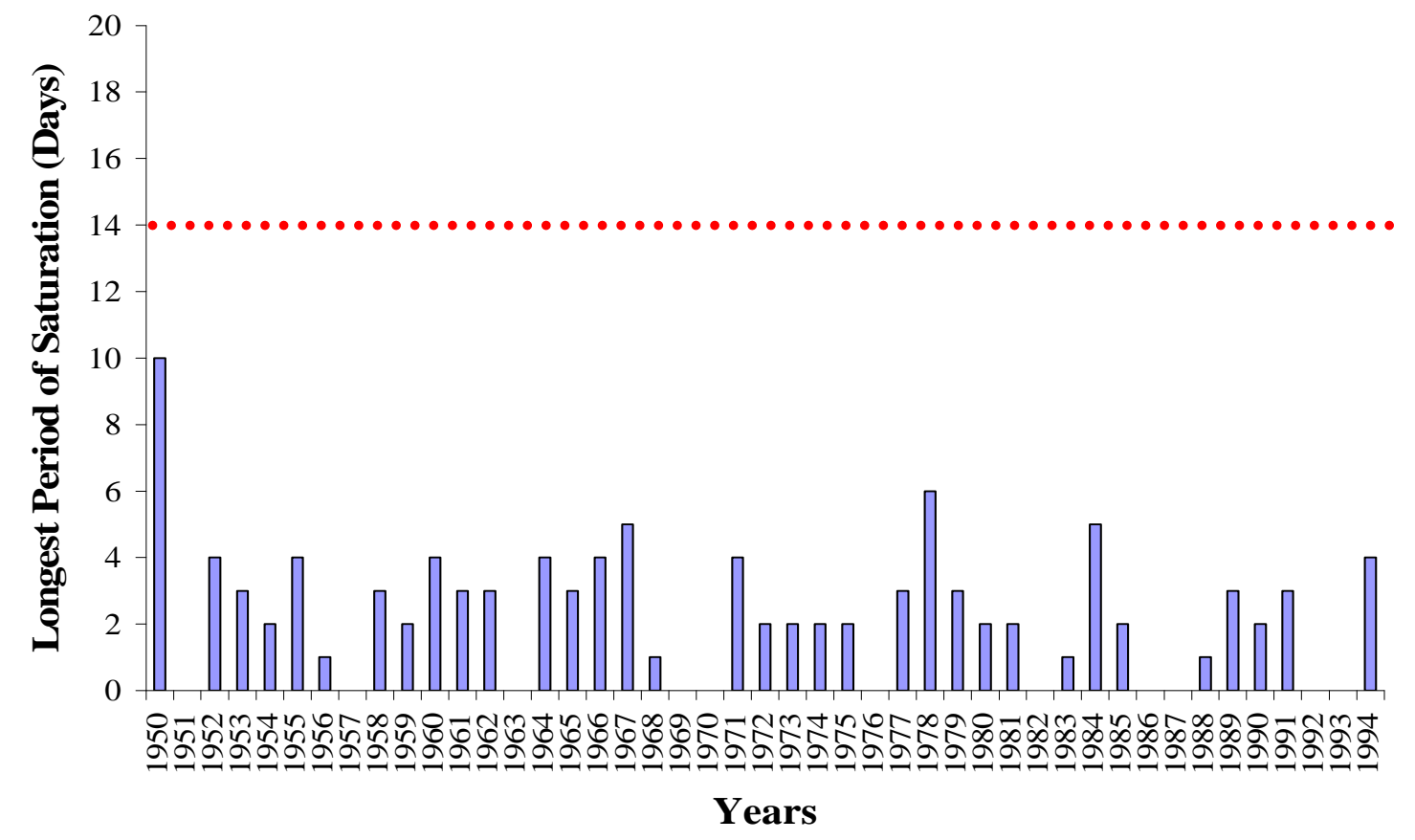

Figure A.14: Long-term continuous period of saturation during the growing season when water table was within $30 \mathrm{~cm}$ of the surface. Data are for plot $2 \mathrm{~S}$ at Bertie and met wetland hydrology in 0 out of 45 years. Dashed line shows 14 days. 


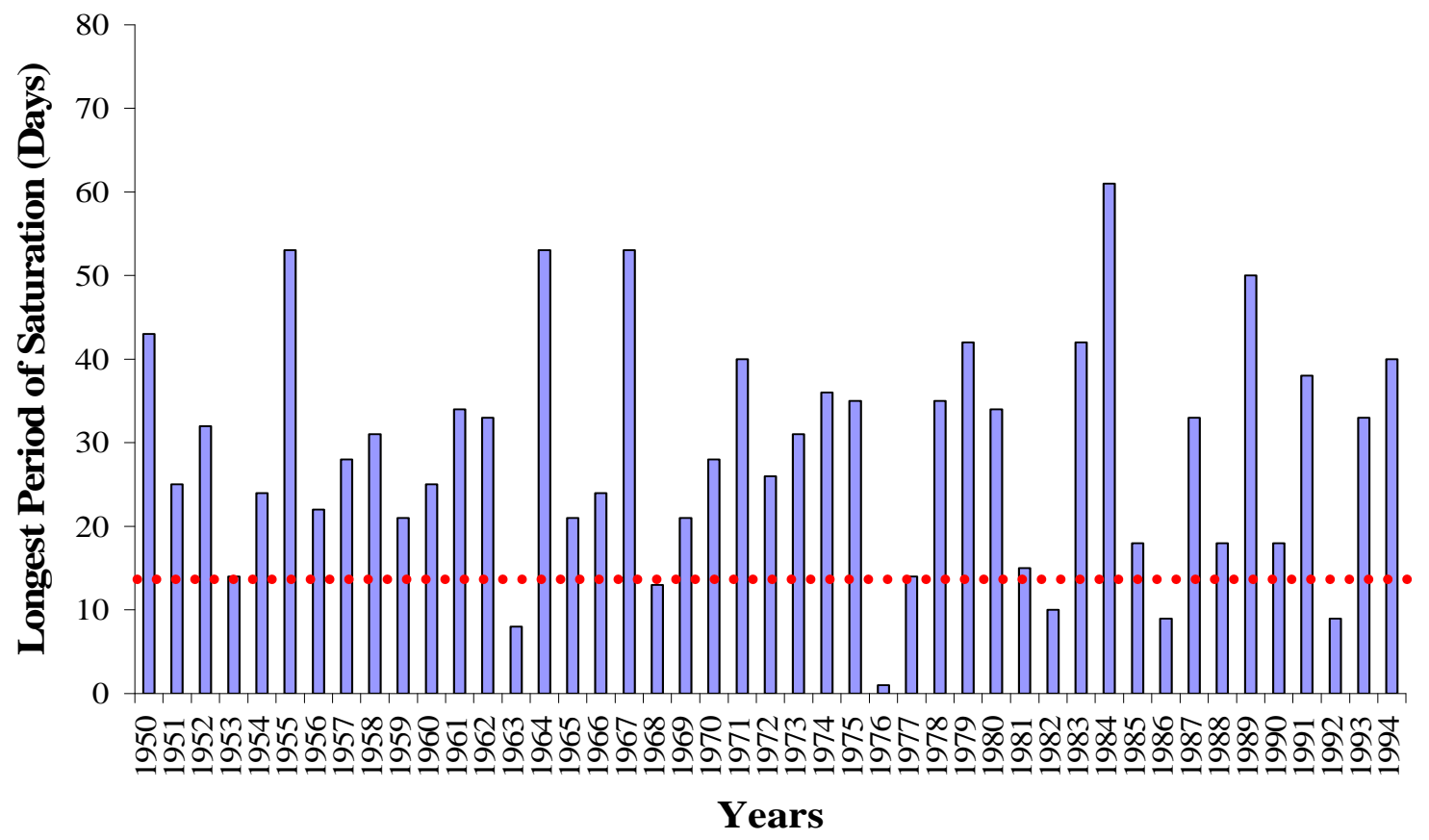

Figure A.15: Long-term continuous period of saturation during the growing season when water table was within $30 \mathrm{~cm}$ of the surface. Data are for plot $3 \mathrm{~S}$ at Bertie and met wetland hydrology in 39 out of 45 years. Dashed line shows 14 days.

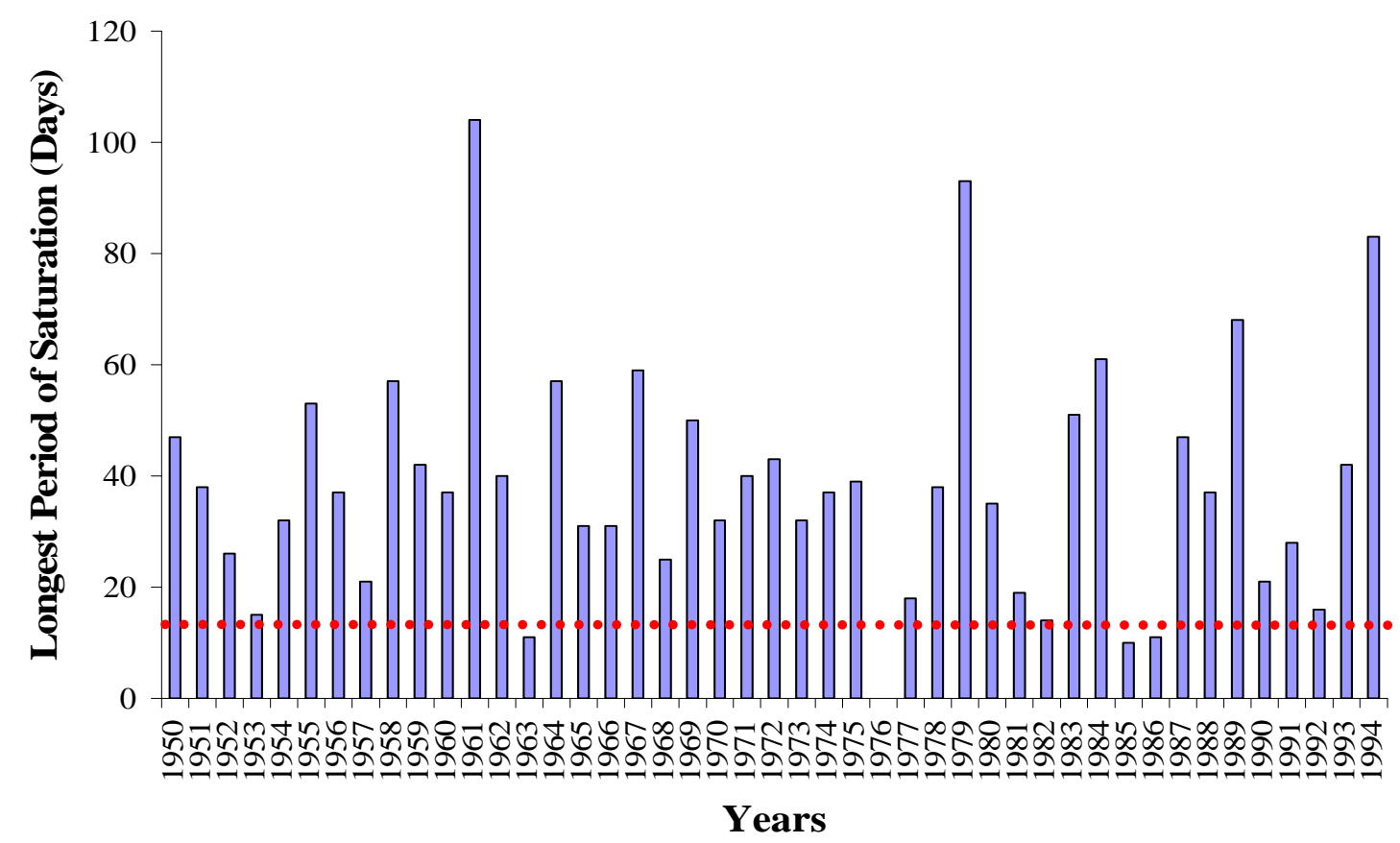

Figure A.16: Long-term continuous period of saturation during the growing season when water table was within $30 \mathrm{~cm}$ of the surface. Data are for plot $4 \mathrm{~S}$ at Bertie and met wetland hydrology in 41 out of 45 years. Dashed line shows 14 days. 


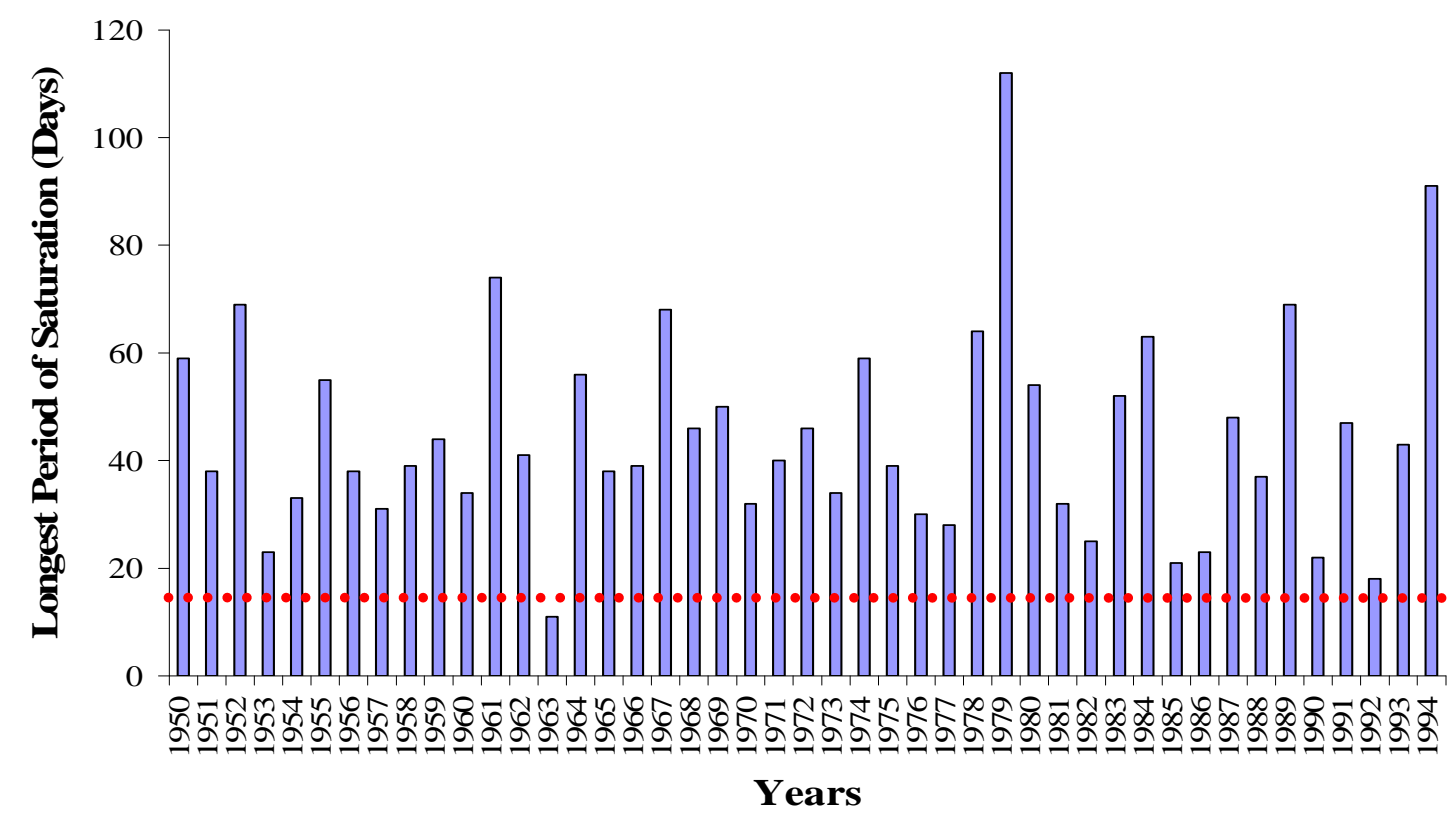

Figure A.17: Long-term continuous period of saturation during the growing season when water table was within $30 \mathrm{~cm}$ of the surface. Data are for plot $5 \mathrm{~S}$ at Bertie and met wetland hydrology in 44 out of 45 years. Dashed line shows 14 days.

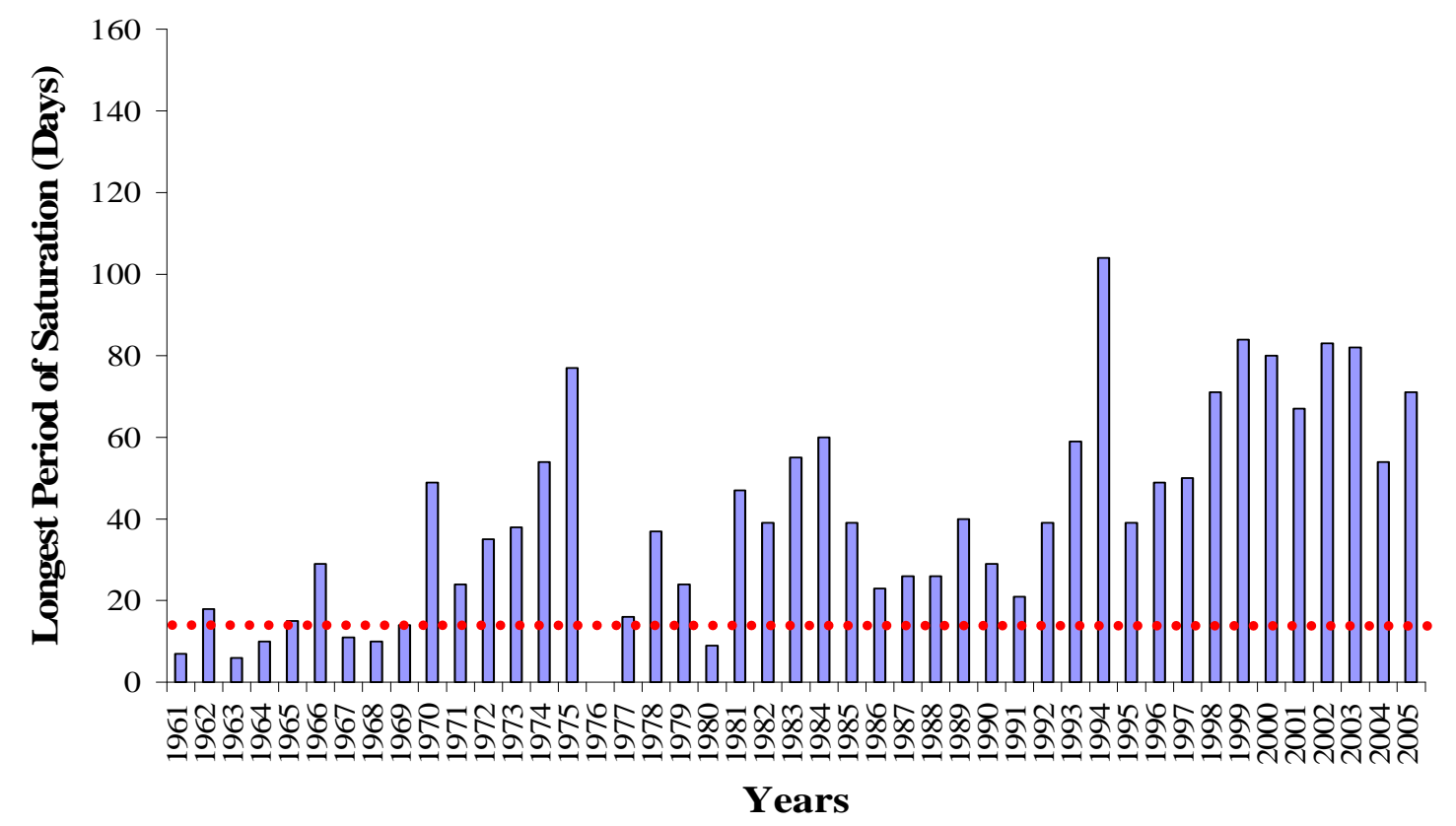

Figure A.18: Long-term continuous period of saturation during the growing season when water table was within $30 \mathrm{~cm}$ of the surface. Data are for bogwell plot S1 at the Marcell Experimental Forest and met wetland hydrology in 38 out of 45 years. Dashed line shows 14 days. 


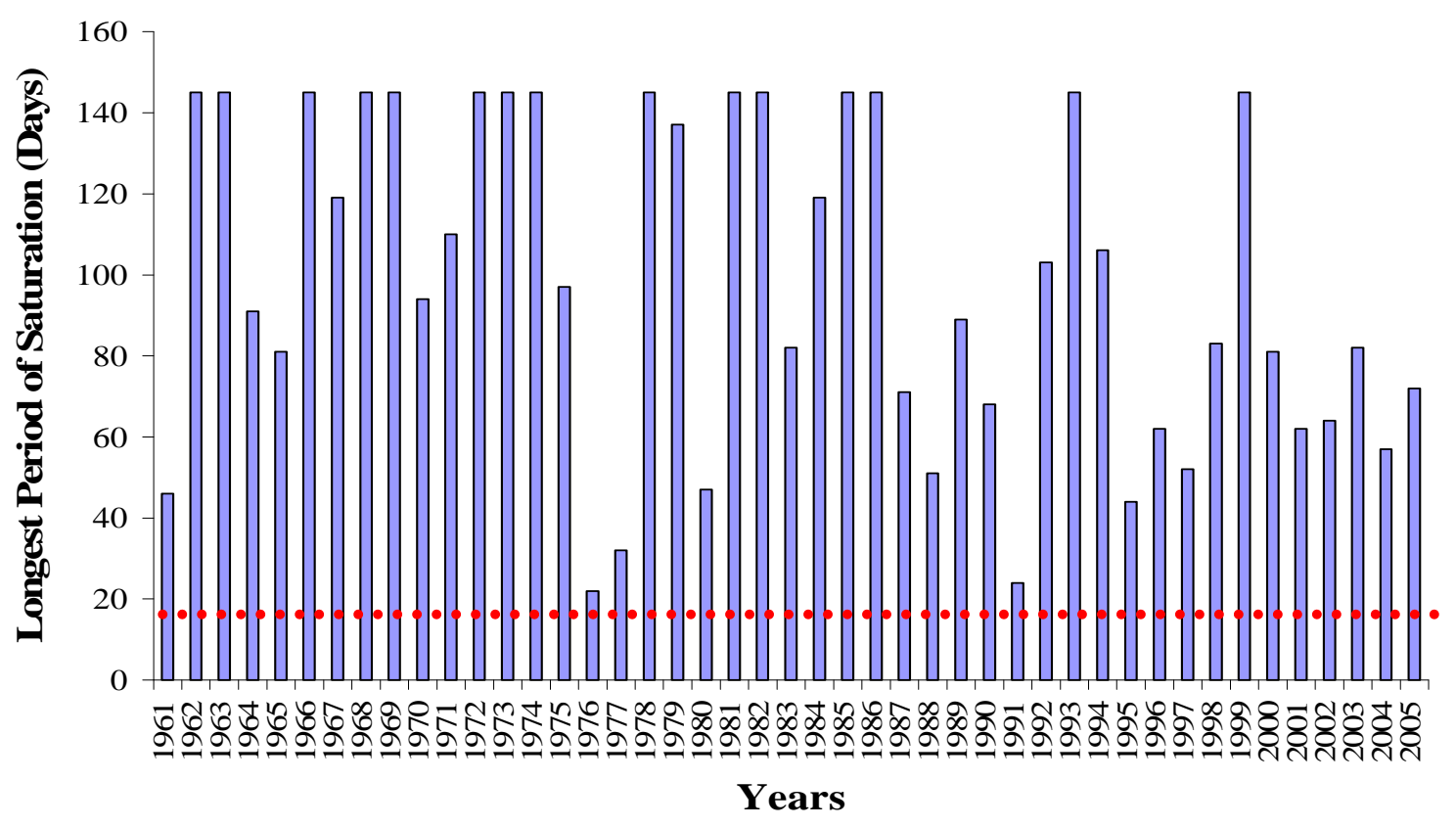

Figure A.19: Long-term continuous period of saturation during the growing season when water table was within $30 \mathrm{~cm}$ of the surface. Data are for bogwell plot S2 at the Marcell Experimental Forest and met wetland hydrology in 45 out of 45 years. Dashed line shows 14 days.

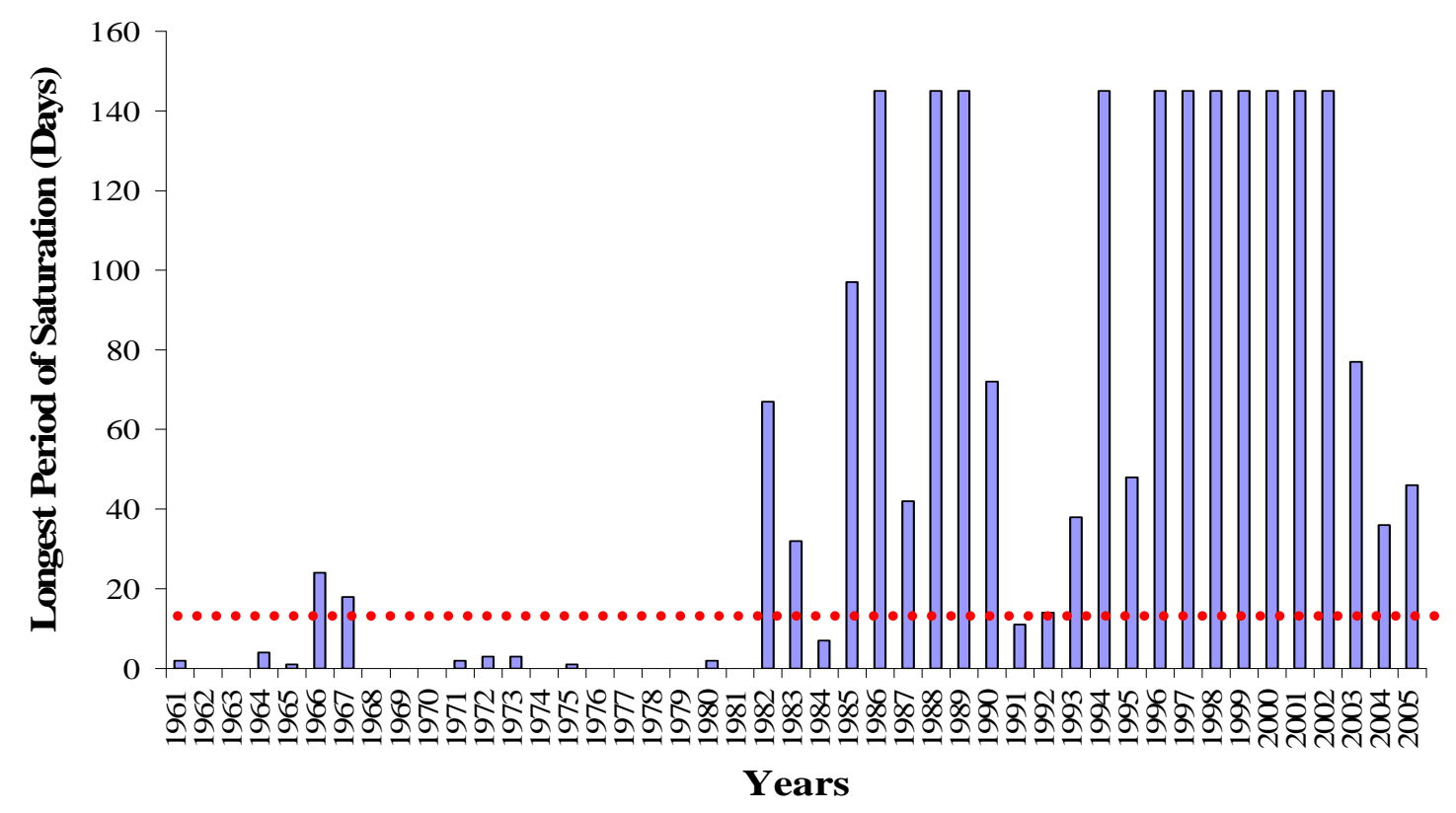

Figure A.20: Long-term continuous period of saturation during the growing season when water table was within $30 \mathrm{~cm}$ of the surface. Data are for bogwell plot S3 at the Marcell Experimental Forest and met wetland hydrology in 24 out of 45 years. Dashed line shows 14 days. 


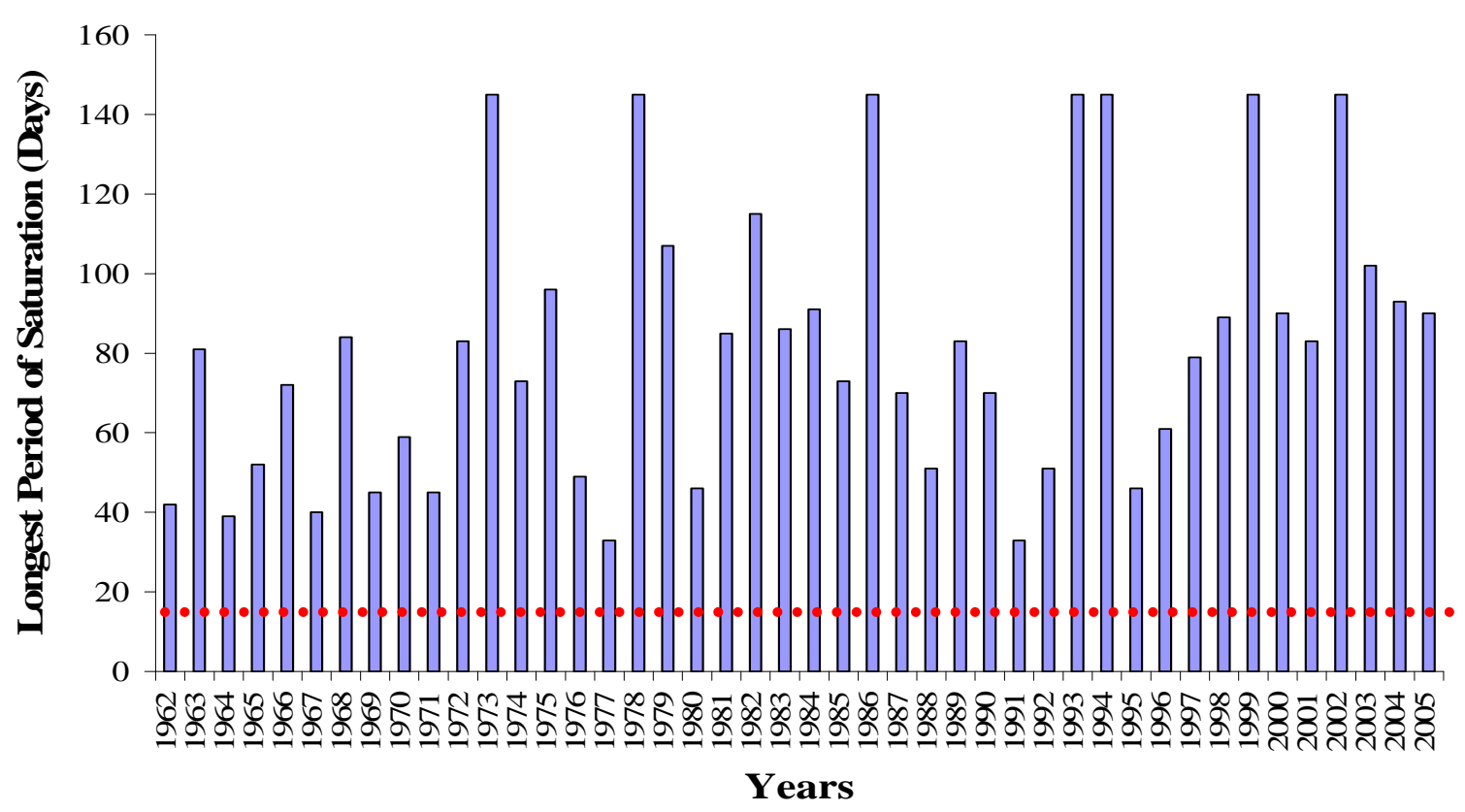

Figure A.21: Long-term continuous period of saturation during the growing season when water table was within $30 \mathrm{~cm}$ of the surface. Data are for bogwell plot S4 at the Marcell Experimental Forest and met wetland hydrology in 44 out of 44 years. Dashed line shows 14 days.

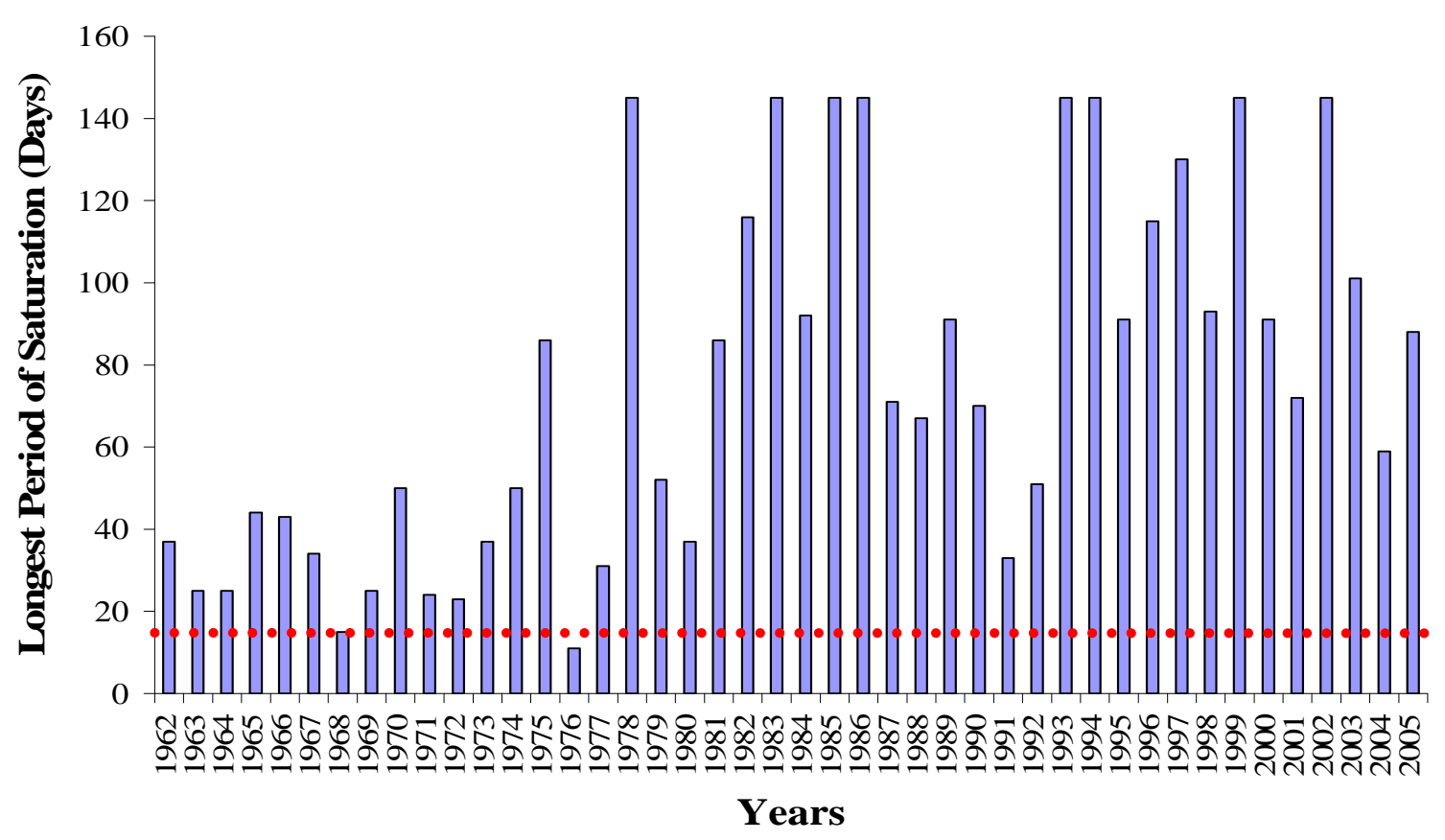

Figure A.22: Long-term continuous period of saturation during the growing season when water table was within $30 \mathrm{~cm}$ of the surface. Data are for bogwell plot S5 at the Marcell Experimental Forest and met wetland hydrology in 43 out of 44 years. Dashed line shows 14 days. 


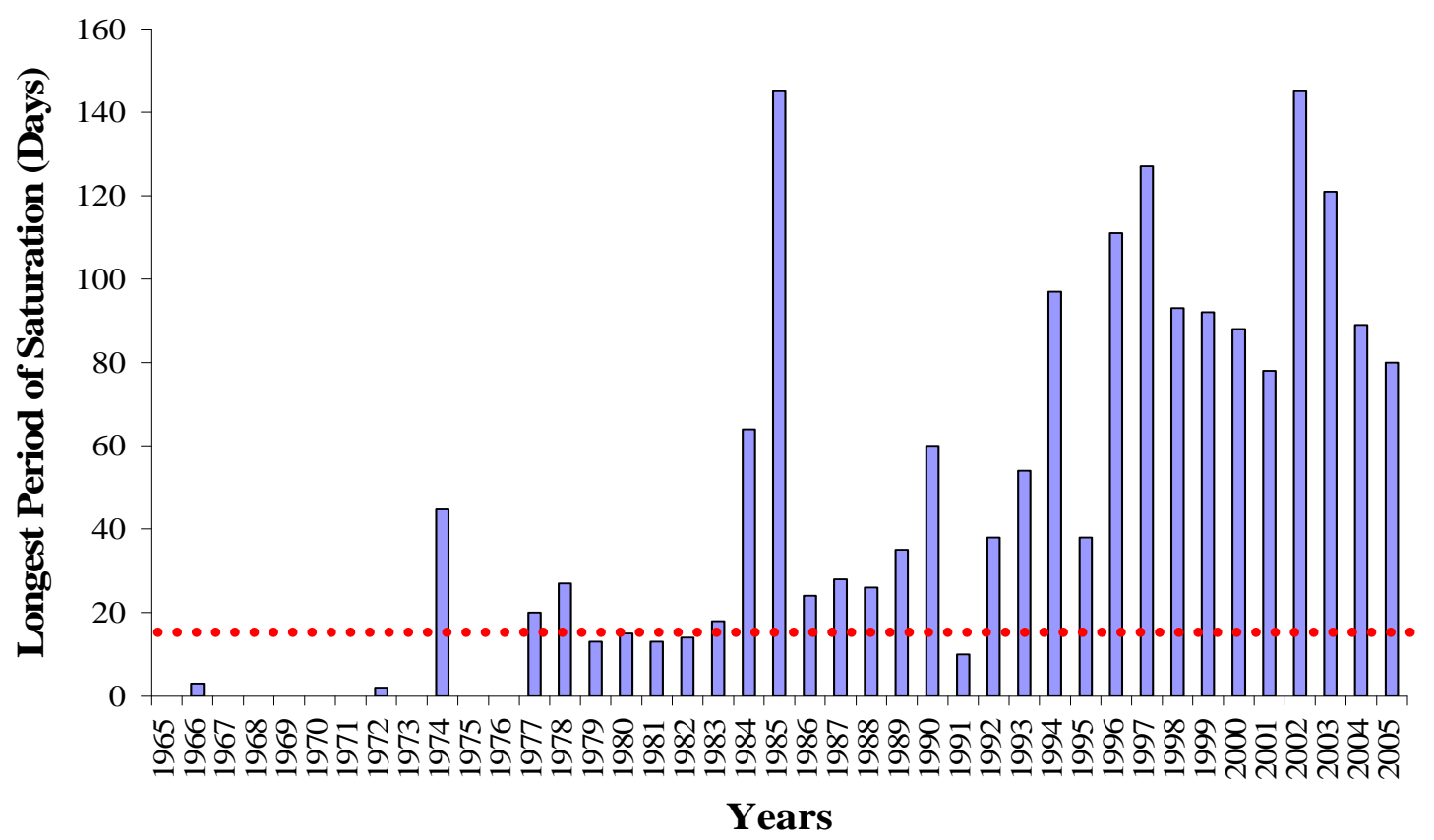

Figure A.23: Long-term continuous period of saturation during the growing season when water table was within $30 \mathrm{~cm}$ of the surface. Data are for bogwell plot S6 at the Marcell Experimental Forest and met wetland hydrology in 29 out of 40 years. Dashed line shows 14 days. 


\section{APPENDIX B}

40-45 Year Evaluation Record Results 
Table B.1: 40-year record for the DAREM approach for plot $1 \mathrm{~L}$ at Greenville. This plot met wetland hydrology in 0 out of 40 years. All years did not meet water table saturation criterion.

\begin{tabular}{|c|c|c|}
\hline Year & $\begin{array}{c}\text { Met/Not } \\
\text { Met }\end{array}$ & Reason Year did or did not meet Wetland Hydrology \\
\hline 1959 & no & water table not within $30 \mathrm{~cm}$ for 14+ days \\
\hline 1960 & no & water table not within $30 \mathrm{~cm}$ for $14+$ days \\
\hline 1961 & no & water table not within $30 \mathrm{~cm}$ for $14+$ days \\
\hline 1962 & no & water table not within $30 \mathrm{~cm}$ for $14+$ days \\
\hline 1963 & no & water table not within $30 \mathrm{~cm}$ for $14+$ days \\
\hline 1964 & no & water table not within $30 \mathrm{~cm}$ for $14+$ days \\
\hline 1965 & no & water table not within $30 \mathrm{~cm}$ for $14+$ days \\
\hline 1966 & no & water table not within $30 \mathrm{~cm}$ for $14+$ days \\
\hline 1967 & no & water table not within $30 \mathrm{~cm}$ for $14+$ days \\
\hline 1968 & no & water table not within $30 \mathrm{~cm}$ for $14+$ days \\
\hline 1969 & no & water table not within $30 \mathrm{~cm}$ for $14+$ days \\
\hline 1970 & no & water table not within $30 \mathrm{~cm}$ for $14+$ days \\
\hline 1971 & no & water table not within $30 \mathrm{~cm}$ for $14+$ days \\
\hline 1972 & no & water table not within $30 \mathrm{~cm}$ for $14+$ days \\
\hline 1973 & no & water table not within $30 \mathrm{~cm}$ for $14+$ days \\
\hline 1974 & no & water table not within $30 \mathrm{~cm}$ for $14+$ days \\
\hline 1975 & no & water table not within $30 \mathrm{~cm}$ for $14+$ days \\
\hline 1976 & no & water table not within $30 \mathrm{~cm}$ for $14+$ days \\
\hline 1977 & no & water table not within $30 \mathrm{~cm}$ for $14+$ days \\
\hline 1978 & no & water table not within $30 \mathrm{~cm}$ for $14+$ days \\
\hline 1979 & no & water table not within $30 \mathrm{~cm}$ for $14+$ days \\
\hline 1980 & no & water table not within $30 \mathrm{~cm}$ for $14+$ days \\
\hline 1981 & no & water table not within $30 \mathrm{~cm}$ for $14+$ days \\
\hline 1982 & no & water table not within $30 \mathrm{~cm}$ for $14+$ days \\
\hline 1983 & no & water table not within $30 \mathrm{~cm}$ for $14+$ days \\
\hline 1984 & no & water table not within $30 \mathrm{~cm}$ for $14+$ days \\
\hline 1985 & no & water table not within $30 \mathrm{~cm}$ for $14+$ days \\
\hline 1986 & no & water table not within $30 \mathrm{~cm}$ for $14+$ days \\
\hline 1987 & no & water table not within $30 \mathrm{~cm}$ for $14+$ days \\
\hline 1988 & no & water table not within $30 \mathrm{~cm}$ for $14+$ days \\
\hline 1989 & no & water table not within $30 \mathrm{~cm}$ for $14+$ days \\
\hline 1990 & no & water table not within $30 \mathrm{~cm}$ for $14+$ days \\
\hline 1991 & no & water table not within $30 \mathrm{~cm}$ for $14+$ days \\
\hline 1992 & no & water table not within $30 \mathrm{~cm}$ for $14+$ days \\
\hline 1993 & no & water table not within $30 \mathrm{~cm}$ for $14+$ days \\
\hline 1994 & no & water table not within $30 \mathrm{~cm}$ for $14+$ days \\
\hline 1995 & no & water table not within $30 \mathrm{~cm}$ for $14+$ days \\
\hline 1996 & no & water table not within $30 \mathrm{~cm}$ for $14+$ days \\
\hline 1997 & no & water table not within $30 \mathrm{~cm}$ for $14+$ days \\
\hline 1998 & no & water table not within $30 \mathrm{~cm}$ for $14+$ days \\
\hline
\end{tabular}


Table B.2: 40-year record for the DAREM approach for plot $2 \mathrm{~L}$ at Greenville. This plot met wetland hydrology in 0 out of 40 years. There was 1 year that did not meet wetland hydrology because water table saturation occurred during a "wet" period, while 39 years did not meet water table saturation criterion.

\begin{tabular}{|c|c|c|}
\hline Year & $\begin{array}{c}\text { Met/Not } \\
\text { Met }\end{array}$ & Reason Year did or did not meet Wetland Hydrology \\
\hline 1959 & no & water table not within $30 \mathrm{~cm}$ for 14+ days \\
\hline 1960 & no & water table not within $30 \mathrm{~cm}$ for $14+$ days \\
\hline 1961 & no & water table not within $30 \mathrm{~cm}$ for $14+$ days \\
\hline 1962 & no & water table not within $30 \mathrm{~cm}$ for $14+$ days \\
\hline 1963 & no & water table not within $30 \mathrm{~cm}$ for $14+$ days \\
\hline 1964 & no & water table not within $30 \mathrm{~cm}$ for $14+$ days \\
\hline 1965 & no & water table not within $30 \mathrm{~cm}$ for $14+$ days \\
\hline 1966 & no & August - "wet" \\
\hline 1967 & no & water table not within $30 \mathrm{~cm}$ for $14+$ days \\
\hline 1968 & no & water table not within $30 \mathrm{~cm}$ for $14+$ days \\
\hline 1969 & no & water table not within $30 \mathrm{~cm}$ for $14+$ days \\
\hline 1970 & no & water table not within $30 \mathrm{~cm}$ for $14+$ days \\
\hline 1971 & no & water table not within $30 \mathrm{~cm}$ for $14+$ days \\
\hline 1972 & no & water table not within $30 \mathrm{~cm}$ for $14+$ days \\
\hline 1973 & no & water table not within $30 \mathrm{~cm}$ for $14+$ days \\
\hline 1974 & no & water table not within $30 \mathrm{~cm}$ for $14+$ days \\
\hline 1975 & no & water table not within $30 \mathrm{~cm}$ for $14+$ days \\
\hline 1976 & no & water table not within $30 \mathrm{~cm}$ for $14+$ days \\
\hline 1977 & no & water table not within $30 \mathrm{~cm}$ for $14+$ days \\
\hline 1978 & no & water table not within $30 \mathrm{~cm}$ for $14+$ days \\
\hline 1979 & no & water table not within $30 \mathrm{~cm}$ for $14+$ days \\
\hline 1980 & no & water table not within $30 \mathrm{~cm}$ for $14+$ days \\
\hline 1981 & no & water table not within $30 \mathrm{~cm}$ for $14+$ days \\
\hline 1982 & no & water table not within $30 \mathrm{~cm}$ for $14+$ days \\
\hline 1983 & no & water table not within $30 \mathrm{~cm}$ for $14+$ days \\
\hline 1984 & no & water table not within $30 \mathrm{~cm}$ for $14+$ days \\
\hline 1985 & no & water table not within $30 \mathrm{~cm}$ for $14+$ days \\
\hline 1986 & no & water table not within $30 \mathrm{~cm}$ for $14+$ days \\
\hline 1987 & no & water table not within $30 \mathrm{~cm}$ for $14+$ days \\
\hline 1988 & no & water table not within $30 \mathrm{~cm}$ for $14+$ days \\
\hline 1989 & no & water table not within $30 \mathrm{~cm}$ for $14+$ days \\
\hline 1990 & no & water table not within $30 \mathrm{~cm}$ for $14+$ days \\
\hline 1991 & no & water table not within $30 \mathrm{~cm}$ for $14+$ days \\
\hline 1992 & no & water table not within $30 \mathrm{~cm}$ for $14+$ days \\
\hline 1993 & no & water table not within $30 \mathrm{~cm}$ for $14+$ days \\
\hline 1994 & no & water table not within $30 \mathrm{~cm}$ for $14+$ days \\
\hline 1995 & no & water table not within $30 \mathrm{~cm}$ for $14+$ days \\
\hline 1996 & no & water table not within $30 \mathrm{~cm}$ for $14+$ days \\
\hline 1997 & no & water table not within $30 \mathrm{~cm}$ for $14+$ days \\
\hline 1998 & no & water table not within $30 \mathrm{~cm}$ for $14+$ days \\
\hline
\end{tabular}


Table B.3: 40-year record for the DAREM approach for plot 3L at Greenville. This plot met wetland hydrology in 0 out of 40 years. There was 1 year that did not meet wetland hydrology because water table saturation occurred during a "wet" period, while 39 years did not meet water table saturation criterion.

\begin{tabular}{|c|c|c|}
\hline Year & $\begin{array}{c}\text { Met/Not } \\
\text { Met }\end{array}$ & Reason Year did or did not meet Wetland Hydrology \\
\hline 1959 & no & water table not within $30 \mathrm{~cm}$ for 14+ days \\
\hline 1960 & no & water table not within $30 \mathrm{~cm}$ for $14+$ days \\
\hline 1961 & no & water table not within $30 \mathrm{~cm}$ for $14+$ days \\
\hline 1962 & no & water table not within $30 \mathrm{~cm}$ for $14+$ days \\
\hline 1963 & no & water table not within $30 \mathrm{~cm}$ for $14+$ days \\
\hline 1964 & no & water table not within $30 \mathrm{~cm}$ for $14+$ days \\
\hline 1965 & no & water table not within $30 \mathrm{~cm}$ for $14+$ days \\
\hline 1966 & no & August - "wet" \\
\hline 1967 & no & water table not within $30 \mathrm{~cm}$ for $14+$ days \\
\hline 1968 & no & water table not within $30 \mathrm{~cm}$ for $14+$ days \\
\hline 1969 & no & water table not within $30 \mathrm{~cm}$ for $14+$ days \\
\hline 1970 & no & water table not within $30 \mathrm{~cm}$ for $14+$ days \\
\hline 1971 & no & water table not within $30 \mathrm{~cm}$ for $14+$ days \\
\hline 1972 & no & water table not within $30 \mathrm{~cm}$ for $14+$ days \\
\hline 1973 & no & water table not within $30 \mathrm{~cm}$ for $14+$ days \\
\hline 1974 & no & water table not within $30 \mathrm{~cm}$ for $14+$ days \\
\hline 1975 & no & water table not within $30 \mathrm{~cm}$ for $14+$ days \\
\hline 1976 & no & water table not within $30 \mathrm{~cm}$ for $14+$ days \\
\hline 1977 & no & water table not within $30 \mathrm{~cm}$ for $14+$ days \\
\hline 1978 & no & water table not within $30 \mathrm{~cm}$ for $14+$ days \\
\hline 1979 & no & water table not within $30 \mathrm{~cm}$ for $14+$ days \\
\hline 1980 & no & water table not within $30 \mathrm{~cm}$ for $14+$ days \\
\hline 1981 & no & water table not within $30 \mathrm{~cm}$ for $14+$ days \\
\hline 1982 & no & water table not within $30 \mathrm{~cm}$ for $14+$ days \\
\hline 1983 & no & water table not within $30 \mathrm{~cm}$ for $14+$ days \\
\hline 1984 & no & water table not within $30 \mathrm{~cm}$ for $14+$ days \\
\hline 1985 & no & water table not within $30 \mathrm{~cm}$ for $14+$ days \\
\hline 1986 & no & water table not within $30 \mathrm{~cm}$ for $14+$ days \\
\hline 1987 & no & water table not within $30 \mathrm{~cm}$ for $14+$ days \\
\hline 1988 & no & water table not within $30 \mathrm{~cm}$ for $14+$ days \\
\hline 1989 & no & water table not within $30 \mathrm{~cm}$ for $14+$ days \\
\hline 1990 & no & water table not within $30 \mathrm{~cm}$ for $14+$ days \\
\hline 1991 & no & water table not within $30 \mathrm{~cm}$ for $14+$ days \\
\hline 1992 & no & water table not within $30 \mathrm{~cm}$ for $14+$ days \\
\hline 1993 & no & water table not within $30 \mathrm{~cm}$ for $14+$ days \\
\hline 1994 & no & water table not within $30 \mathrm{~cm}$ for $14+$ days \\
\hline 1995 & no & water table not within $30 \mathrm{~cm}$ for $14+$ days \\
\hline 1996 & no & water table not within $30 \mathrm{~cm}$ for $14+$ days \\
\hline 1997 & no & water table not within $30 \mathrm{~cm}$ for $14+$ days \\
\hline 1998 & no & water table not within $30 \mathrm{~cm}$ for $14+$ days \\
\hline
\end{tabular}


Table B.4: 40-year record for the DAREM approach for plot $1 \mathrm{~L}$ at Greenville. This plot met wetland hydrology in 0 out of 40 years. All years did not meet water table saturation criterion.

\begin{tabular}{|c|c|c|}
\hline Year & $\begin{array}{c}\text { Met/Not } \\
\text { Met }\end{array}$ & Reason Year did or did not meet Wetland Hydrology \\
\hline 1959 & no & water table not within $30 \mathrm{~cm}$ for 14+ days \\
\hline 1960 & no & water table not within $30 \mathrm{~cm}$ for $14+$ days \\
\hline 1961 & no & water table not within $30 \mathrm{~cm}$ for $14+$ days \\
\hline 1962 & no & water table not within $30 \mathrm{~cm}$ for $14+$ days \\
\hline 1963 & no & water table not within $30 \mathrm{~cm}$ for $14+$ days \\
\hline 1964 & no & water table not within $30 \mathrm{~cm}$ for $14+$ days \\
\hline 1965 & no & water table not within $30 \mathrm{~cm}$ for $14+$ days \\
\hline 1966 & no & water table not within $30 \mathrm{~cm}$ for $14+$ days \\
\hline 1967 & no & water table not within $30 \mathrm{~cm}$ for $14+$ days \\
\hline 1968 & no & water table not within $30 \mathrm{~cm}$ for $14+$ days \\
\hline 1969 & no & water table not within $30 \mathrm{~cm}$ for $14+$ days \\
\hline 1970 & no & water table not within $30 \mathrm{~cm}$ for $14+$ days \\
\hline 1971 & no & water table not within $30 \mathrm{~cm}$ for $14+$ days \\
\hline 1972 & no & water table not within $30 \mathrm{~cm}$ for $14+$ days \\
\hline 1973 & no & water table not within $30 \mathrm{~cm}$ for $14+$ days \\
\hline 1974 & no & water table not within $30 \mathrm{~cm}$ for $14+$ days \\
\hline 1975 & no & water table not within $30 \mathrm{~cm}$ for $14+$ days \\
\hline 1976 & no & water table not within $30 \mathrm{~cm}$ for $14+$ days \\
\hline 1977 & no & water table not within $30 \mathrm{~cm}$ for $14+$ days \\
\hline 1978 & no & water table not within $30 \mathrm{~cm}$ for $14+$ days \\
\hline 1979 & no & water table not within $30 \mathrm{~cm}$ for $14+$ days \\
\hline 1980 & no & water table not within $30 \mathrm{~cm}$ for $14+$ days \\
\hline 1981 & no & water table not within $30 \mathrm{~cm}$ for $14+$ days \\
\hline 1982 & no & water table not within $30 \mathrm{~cm}$ for $14+$ days \\
\hline 1983 & no & water table not within $30 \mathrm{~cm}$ for $14+$ days \\
\hline 1984 & no & water table not within $30 \mathrm{~cm}$ for $14+$ days \\
\hline 1985 & no & water table not within $30 \mathrm{~cm}$ for $14+$ days \\
\hline 1986 & no & water table not within $30 \mathrm{~cm}$ for $14+$ days \\
\hline 1987 & no & water table not within $30 \mathrm{~cm}$ for $14+$ days \\
\hline 1988 & no & water table not within $30 \mathrm{~cm}$ for $14+$ days \\
\hline 1989 & no & water table not within $30 \mathrm{~cm}$ for $14+$ days \\
\hline 1990 & no & water table not within $30 \mathrm{~cm}$ for $14+$ days \\
\hline 1991 & no & water table not within $30 \mathrm{~cm}$ for $14+$ days \\
\hline 1992 & no & water table not within $30 \mathrm{~cm}$ for $14+$ days \\
\hline 1993 & no & water table not within $30 \mathrm{~cm}$ for $14+$ days \\
\hline 1994 & no & water table not within $30 \mathrm{~cm}$ for $14+$ days \\
\hline 1995 & no & water table not within $30 \mathrm{~cm}$ for $14+$ days \\
\hline 1996 & no & water table not within $30 \mathrm{~cm}$ for $14+$ days \\
\hline 1997 & no & water table not within $30 \mathrm{~cm}$ for $14+$ days \\
\hline 1998 & no & water table not within $30 \mathrm{~cm}$ for $14+$ days \\
\hline
\end{tabular}


Table B.5: 40-year record for the DAREM approach for plot $1 \mathrm{R}$ at Greenville. This plot met wetland hydrology in 28 out of 40 years. There were 7 years that did not meet wetland hydrology because water table saturation occurred during "wet" periods, while 5 years did not meet water table saturation criterion.

\begin{tabular}{|c|c|c|}
\hline Year & $\begin{array}{c}\text { Met/Not } \\
\text { Met }\end{array}$ & Reason Year did or did not meet Wetland Hydrology \\
\hline 1959 & no & April is "wet" \\
\hline 1960 & no & April is "wet" \\
\hline 1961 & yes & March, April within $30 \mathrm{~cm}$ for $14+$ days \\
\hline 1962 & yes & March within $30 \mathrm{~cm}$ for $14+$ days \\
\hline 1963 & yes & March within $30 \mathrm{~cm}$ for $14+$ days \\
\hline 1964 & no & March, April, October - "wet" \\
\hline 1965 & yes & March, July within $30 \mathrm{~cm}$ for $14+$ days \\
\hline 1966 & no & August - "wet" \\
\hline 1967 & no & water table not within $30 \mathrm{~cm}$ for $14+$ days \\
\hline 1968 & yes & March, April within $30 \mathrm{~cm}$ for 14+ days \\
\hline 1969 & yes & March, August within $30 \mathrm{~cm}$ for $14+$ days \\
\hline 1970 & yes & March/April is within $30 \mathrm{~cm}$ for $14+$ days \\
\hline 1971 & yes & October normal within $30 \mathrm{~cm}$ for $14+$ days \\
\hline 1972 & yes & March - normal within $30 \mathrm{~cm}$ for $14+$ days \\
\hline 1973 & yes & March, April within $30 \mathrm{~cm}$ for $14+$ days \\
\hline 1974 & yes & March, August within $30 \mathrm{~cm}$ for $14+$ days \\
\hline 1975 & no & March - "wet" \\
\hline 1976 & no & water table not within $30 \mathrm{~cm}$ for $14+$ days \\
\hline 1977 & yes & March within $30 \mathrm{~cm}$ for $14+$ days \\
\hline 1978 & yes & May within $30 \mathrm{~cm}$ for $14+$ days \\
\hline 1979 & yes & March, August within $30 \mathrm{~cm}$ for $14+$ days \\
\hline 1980 & yes & March within $30 \mathrm{~cm}$ for $14+$ days \\
\hline 1981 & no & water table not within $30 \mathrm{~cm}$ for $14+$ days \\
\hline 1982 & yes & March within $30 \mathrm{~cm}$ for $14+$ days \\
\hline 1983 & yes & March within $30 \mathrm{~cm}$ for $14+$ days \\
\hline 1984 & yes & July within $30 \mathrm{~cm}$ for $14+$ days \\
\hline 1985 & no & water table not within $30 \mathrm{~cm}$ for $14+$ days \\
\hline 1986 & yes & August within $30 \mathrm{~cm}$ for $14+$ days \\
\hline 1987 & no & March - "wet" \\
\hline 1988 & yes & April within $30 \mathrm{~cm}$ for $14+$ days \\
\hline 1989 & yes & March within $30 \mathrm{~cm}$ for $14+$ days \\
\hline 1990 & yes & March/April within $30 \mathrm{~cm}$ for $14+$ days \\
\hline 1991 & no & water table not within $30 \mathrm{~cm}$ for $14+$ days \\
\hline 1992 & yes & August within $30 \mathrm{~cm}$ for $14+$ days \\
\hline 1993 & yes & March, April within $30 \mathrm{~cm}$ for $14+$ days \\
\hline 1994 & yes & March within $30 \mathrm{~cm}$ for $14+$ days \\
\hline 1995 & yes & June within $30 \mathrm{~cm}$ for $14+$ days \\
\hline 1996 & yes & April, September, October within $30 \mathrm{~cm}$ for $14+$ days \\
\hline 1997 & yes & March within $30 \mathrm{~cm}$ for $14+$ days \\
\hline 1998 & no & March, April \& September - "wet" \\
\hline
\end{tabular}


Table B.6: 40-year record for the DAREM approach for plot $2 \mathrm{R}$ at Greenville. This plot met wetland hydrology in 37 out of 40 years. There were 3 years that did not meet wetland hydrology because water table saturation occurred during "wet" periods.

\begin{tabular}{|c|c|c|}
\hline Year & $\begin{array}{c}\text { Met/Not } \\
\text { Met }\end{array}$ & Reason Year did or did not meet Wetland Hydrology \\
\hline 1959 & yes & October within $30 \mathrm{~cm}$ for $14+$ days \\
\hline 1960 & no & March, April - "wet" \\
\hline 1961 & yes & March, April within $30 \mathrm{~cm}$ for $14+$ days \\
\hline 1962 & yes & March within $30 \mathrm{~cm}$ for $14+$ days \\
\hline 1963 & yes & March, April - within 30cm for 14+ days \\
\hline 1964 & no & March, April, September, October - "wet" \\
\hline 1965 & yes & March, June, July within $30 \mathrm{~cm}$ for $14+$ days \\
\hline 1966 & yes & March within $30 \mathrm{~cm}$ for $14+$ days \\
\hline 1967 & yes & August within $30 \mathrm{~cm}$ for $14+$ days \\
\hline 1968 & yes & March, April within $30 \mathrm{~cm}$ for $14+$ days \\
\hline 1969 & yes & March, August, November within $30 \mathrm{~cm}$ for $14+$ days \\
\hline 1970 & yes & March, April within $30 \mathrm{~cm}$ for $14+$ days \\
\hline 1971 & yes & March, October within $30 \mathrm{~cm}$ for $14+$ days \\
\hline 1972 & yes & March, April, May within $30 \mathrm{~cm}$ for $14+$ days \\
\hline 1973 & yes & March, April within $30 \mathrm{~cm}$ for $14+$ days \\
\hline 1974 & yes & March, August within $30 \mathrm{~cm}$ for $14+$ days \\
\hline 1975 & yes & April within $30 \mathrm{~cm}$ for $14+$ days \\
\hline 1976 & yes & March within $30 \mathrm{~cm}$ for $14+$ days \\
\hline 1977 & yes & March within $30 \mathrm{~cm}$ for $14+$ days \\
\hline 1978 & yes & March, May within $30 \mathrm{~cm}$ for $14+$ days \\
\hline 1979 & yes & March, April, May, June, September within $30 \mathrm{~cm}$ for $14+$ days \\
\hline 1980 & yes & March, April within $30 \mathrm{~cm}$ for $14+$ days \\
\hline 1981 & yes & March within $30 \mathrm{~cm}$ for $14+$ days \\
\hline 1982 & yes & March, June, November within $30 \mathrm{~cm}$ for $14+$ days \\
\hline 1983 & yes & March, April within $30 \mathrm{~cm}$ for $14+$ days \\
\hline 1984 & yes & July, September within $30 \mathrm{~cm}$ for $14+$ days \\
\hline 1985 & yes & March within $30 \mathrm{~cm}$ for $14+$ days \\
\hline 1986 & yes & March, July within $30 \mathrm{~cm}$ for $14+$ days \\
\hline 1987 & yes & April is within $30 \mathrm{~cm}$ for $14+$ days \\
\hline 1988 & yes & March, April within $30 \mathrm{~cm}$ for $14+$ days \\
\hline 1989 & yes & March within $30 \mathrm{~cm}$ for $14+$ days \\
\hline 1990 & yes & March, April within $30 \mathrm{~cm}$ for 14+ days \\
\hline 1991 & yes & March within $30 \mathrm{~cm}$ for $14+$ days \\
\hline 1992 & yes & April, August, November within $30 \mathrm{~cm}$ for $14+$ days \\
\hline 1993 & yes & March, April within $30 \mathrm{~cm}$ for 14+ days \\
\hline 1994 & yes & March within $30 \mathrm{~cm}$ for $14+$ days \\
\hline 1995 & yes & March, June within $30 \mathrm{~cm}$ for $14+$ days \\
\hline 1996 & yes & March, April, September, October within $30 \mathrm{~cm}$ for $14+$ days \\
\hline 1997 & yes & March, April, May within $30 \mathrm{~cm}$ for $14+$ days \\
\hline 1998 & no & March, April, May, August - "wet" \\
\hline
\end{tabular}


Table B.7: 40-year record for the DAREM approach for plot 3R at Greenville. This plot met wetland hydrology in 36 out of 40 years. There were 3 years that did not meet wetland hydrology because water table saturation occurred during "wet" periods, while 1 year did not meet water table saturation criterion.

\begin{tabular}{|c|c|c|}
\hline Year & $\begin{array}{c}\text { Met/Not } \\
\text { Met }\end{array}$ & Reason Year did or did not meet Wetland Hydrology \\
\hline 1959 & yes & October within $30 \mathrm{~cm}$ for $14+$ days \\
\hline 1960 & yes & August/September is within $30 \mathrm{~cm}$ for $14+$ days \\
\hline 1961 & yes & March, April within $30 \mathrm{~cm}$ for $14+$ days \\
\hline 1962 & yes & March within $30 \mathrm{~cm}$ for $14+$ days \\
\hline 1963 & yes & March, April within $30 \mathrm{~cm}$ for $14+$ days \\
\hline 1964 & no & March, April, September, October - "wet" \\
\hline 1965 & yes & March, June, July within $30 \mathrm{~cm}$ for $14+$ days \\
\hline 1966 & yes & March, April within $30 \mathrm{~cm}$ for $14+$ days \\
\hline 1967 & no & March, September - "wet" \\
\hline 1968 & yes & March, April, June within $30 \mathrm{~cm}$ for $14+$ days \\
\hline 1969 & yes & March, April, July, August, November within $30 \mathrm{~cm}$ for $14+$ days \\
\hline 1970 & yes & March, April within $30 \mathrm{~cm}$ for $14+$ days \\
\hline 1971 & yes & March, October, November within $30 \mathrm{~cm}$ for $14+$ days \\
\hline 1972 & yes & March, April, May, September within $30 \mathrm{~cm}$ for 14+ days \\
\hline 1973 & yes & March, April within $30 \mathrm{~cm}$ for $14+$ days \\
\hline 1974 & yes & March, August within $30 \mathrm{~cm}$ for 14+ days \\
\hline 1975 & yes & April within $30 \mathrm{~cm}$ for $14+$ days \\
\hline 1976 & no & water table not within $30 \mathrm{~cm}$ for $14+$ days \\
\hline 1977 & yes & March within $30 \mathrm{~cm}$ for $14+$ days \\
\hline 1978 & yes & March, April, May within $30 \mathrm{~cm}$ for $14+$ days \\
\hline 1979 & yes & March, April, May, September within $30 \mathrm{~cm}$ for $14+$ days \\
\hline 1980 & yes & March, April within $30 \mathrm{~cm}$ for $14+$ days \\
\hline 1981 & yes & March within $30 \mathrm{~cm}$ for $14+$ days \\
\hline 1982 & yes & March, April, June, July, November within $30 \mathrm{~cm}$ for $14+$ days \\
\hline 1983 & yes & March, April within $30 \mathrm{~cm}$ for $14+$ days \\
\hline 1984 & yes & July, September within $30 \mathrm{~cm}$ for $14+$ days \\
\hline 1985 & yes & March within $30 \mathrm{~cm}$ for $14+$ days \\
\hline 1986 & yes & March, August within $30 \mathrm{~cm}$ for $14+$ days \\
\hline 1987 & yes & April within $30 \mathrm{~cm}$ for $14+$ days \\
\hline 1988 & yes & March, April, June within $30 \mathrm{~cm}$ for $14+$ days \\
\hline 1989 & yes & March within $30 \mathrm{~cm}$ for $14+$ days \\
\hline 1990 & yes & March, April within $30 \mathrm{~cm}$ for 14+ days \\
\hline 1991 & yes & March within $30 \mathrm{~cm}$ for $14+$ days \\
\hline 1992 & yes & March, August within $30 \mathrm{~cm}$ for $14+$ days \\
\hline 1993 & yes & March, April within $30 \mathrm{~cm}$ for $14+$ days \\
\hline 1994 & yes & March within $30 \mathrm{~cm}$ for $14+$ days \\
\hline 1995 & yes & March, June within $30 \mathrm{~cm}$ for 14+ days \\
\hline 1996 & yes & March, April, July, August, September within $30 \mathrm{~cm}$ for $14+$ days \\
\hline 1997 & yes & March, April May within $30 \mathrm{~cm}$ for $14+$ days \\
\hline 1998 & no & March, April, May, September - "wet" \\
\hline
\end{tabular}


Table B.8: 40-year record for the DAREM approach for plot 4R at Greenville. This plot met wetland hydrology in 34 out of 40 years. There were 4 years that did not meet wetland hydrology because water table saturation occurred during "wet" periods, while 2 years did not meet water table saturation criterion.

\begin{tabular}{|c|c|c|}
\hline Year & $\begin{array}{c}\text { Met/Not } \\
\text { Met }\end{array}$ & Reason Year did or did not meet Wetland Hydrology \\
\hline 1959 & yes & October within $30 \mathrm{~cm}$ for $14+$ days \\
\hline 1960 & no & March, April - "wet" \\
\hline 1961 & yes & March, April, May within $30 \mathrm{~cm}$ for $14+$ days \\
\hline 1962 & yes & March within $30 \mathrm{~cm}$ for $14+$ days \\
\hline 1963 & yes & March, April within $30 \mathrm{~cm}$ for $14+$ days \\
\hline 1964 & no & March, April, September, October - "wet" \\
\hline 1965 & yes & March, June, July within $30 \mathrm{~cm}$ for 14+ days \\
\hline 1966 & yes & March within $30 \mathrm{~cm}$ for $14+$ days \\
\hline 1967 & yes & August within $30 \mathrm{~cm}$ for $14+$ days \\
\hline 1968 & yes & March, April within $30 \mathrm{~cm}$ for $14+$ days \\
\hline 1969 & yes & March, August, November within $30 \mathrm{~cm}$ for $14+$ days \\
\hline 1970 & yes & March, April within $30 \mathrm{~cm}$ for $14+$ days \\
\hline 1971 & yes & March, October within $30 \mathrm{~cm}$ for 14+ days \\
\hline 1972 & yes & March, April, May within $30 \mathrm{~cm}$ for $14+$ days \\
\hline 1973 & yes & March, April within $30 \mathrm{~cm}$ for $14+$ days \\
\hline 1974 & yes & August within $30 \mathrm{~cm}$ for $14+$ days \\
\hline 1975 & yes & April within $30 \mathrm{~cm}$ for $14+$ days \\
\hline 1976 & no & water table not within $30 \mathrm{~cm}$ for $14+$ days \\
\hline 1977 & yes & March within $30 \mathrm{~cm}$ for $14+$ days \\
\hline 1978 & yes & March, May within $30 \mathrm{~cm}$ for $14+$ days \\
\hline 1979 & yes & March, April, May, August within $30 \mathrm{~cm}$ for $14+$ days \\
\hline 1980 & yes & March, April within $30 \mathrm{~cm}$ for $14+$ days \\
\hline 1981 & no & September - "wet" \\
\hline 1982 & yes & March, June, November within $30 \mathrm{~cm}$ for $14+$ days \\
\hline 1983 & yes & March, April within $30 \mathrm{~cm}$ for $14+$ days \\
\hline 1984 & yes & July, September within $30 \mathrm{~cm}$ for $14+$ days \\
\hline 1985 & no & water table not within $30 \mathrm{~cm}$ for $14+$ days \\
\hline 1986 & yes & March, August within $30 \mathrm{~cm}$ for $14+$ days \\
\hline 1987 & yes & April within $30 \mathrm{~cm}$ for $14+$ days \\
\hline 1988 & yes & March, April within $30 \mathrm{~cm}$ for $14+$ days \\
\hline 1989 & yes & March within $30 \mathrm{~cm}$ for $14+$ days \\
\hline 1990 & yes & March, April within $30 \mathrm{~cm}$ for $14+$ days \\
\hline 1991 & yes & March within $30 \mathrm{~cm}$ for $14+$ days \\
\hline 1992 & yes & April, August, November within $30 \mathrm{~cm}$ for $14+$ days \\
\hline 1993 & yes & March, April within $30 \mathrm{~cm}$ for $14+$ days \\
\hline 1994 & yes & March within $30 \mathrm{~cm}$ for $14+$ days \\
\hline 1995 & yes & March, June within $30 \mathrm{~cm}$ for $14+$ days \\
\hline 1996 & yes & March, April, September within $30 \mathrm{~cm}$ for $14+$ days \\
\hline 1997 & yes & March, April, May within $30 \mathrm{~cm}$ for $14+$ days \\
\hline 1998 & no & March, April, May, September - "wet" \\
\hline
\end{tabular}


Table B.9: 40-year record for the DAREM approach for plot 4P at Greenville. This plot met wetland hydrology in 37 out of 40 years. There were 2 years that did not meet wetland hydrology because water table saturation occurred during "wet" periods, while 1 year did not meet water table saturation criterion.

\begin{tabular}{|c|c|c|}
\hline Year & $\begin{array}{c}\text { Met/Not } \\
\text { Met }\end{array}$ & Reason Year did or did not meet Wetland Hydrology \\
\hline 1959 & yes & June, July within $30 \mathrm{~cm}$ for $14+$ days \\
\hline 1960 & yes & May, August, September, October within $30 \mathrm{~cm}$ for $14+$ days \\
\hline 1961 & yes & March, April within $30 \mathrm{~cm}$ for $14+$ days \\
\hline 1962 & yes & March, July within $30 \mathrm{~cm}$ for $14+$ days \\
\hline 1963 & yes & March, April within $30 \mathrm{~cm}$ for $14+$ days \\
\hline 1964 & no & March, April, September, October, November - "wet" \\
\hline 1965 & yes & March, April, June, July within $30 \mathrm{~cm}$ for $14+$ days \\
\hline 1966 & yes & March, April within $30 \mathrm{~cm}$ for $14+$ days \\
\hline 1967 & yes & August within $30 \mathrm{~cm}$ for $14+$ days \\
\hline 1968 & yes & March, April, June within $30 \mathrm{~cm}$ for $14+$ days \\
\hline 1969 & yes & March, July, August, October, November within $30 \mathrm{~cm}$ for $14+$ days \\
\hline 1970 & yes & March, April within $30 \mathrm{~cm}$ for $14+$ days \\
\hline 1971 & yes & March, October, November within $30 \mathrm{~cm}$ for $14+$ days \\
\hline 1972 & yes & March, April, May, September within $30 \mathrm{~cm}$ for $14+$ days \\
\hline 1973 & yes & March, April, May within $30 \mathrm{~cm}$ for $14+$ days \\
\hline 1974 & yes & March, August, October within $30 \mathrm{~cm}$ for $14+$ days \\
\hline 1975 & yes & April within $30 \mathrm{~cm}$ for $14+$ days \\
\hline 1976 & no & water table not within $30 \mathrm{~cm}$ for $14+$ days \\
\hline 1977 & yes & March, April within $30 \mathrm{~cm}$ for 14+ days \\
\hline 1978 & yes & March, April, May within $30 \mathrm{~cm}$ for 14+ days \\
\hline 1979 & yes & March, April, May, September, November within $30 \mathrm{~cm}$ for $14+$ days \\
\hline 1980 & yes & March, April within $30 \mathrm{~cm}$ for $14+$ days \\
\hline 1981 & yes & March within $30 \mathrm{~cm}$ for $14+$ days \\
\hline 1982 & yes & March, April, June, July, September, October within $30 \mathrm{~cm}$ for $14+$ days \\
\hline 1983 & yes & March, April within $30 \mathrm{~cm}$ for $14+$ days \\
\hline 1984 & yes & July, September, October within $30 \mathrm{~cm}$ for $14+$ days \\
\hline 1985 & yes & March, November within $30 \mathrm{~cm}$ for $14+$ days \\
\hline 1986 & yes & March, August within $30 \mathrm{~cm}$ for $14+$ days \\
\hline 1987 & yes & April within $30 \mathrm{~cm}$ for $14+$ days \\
\hline 1988 & yes & March, April, May within $30 \mathrm{~cm}$ for $14+$ days \\
\hline 1989 & yes & March within $30 \mathrm{~cm}$ for $14+$ days \\
\hline 1990 & yes & March, April within $30 \mathrm{~cm}$ for $14+$ days \\
\hline 1991 & yes & March, April, October within $30 \mathrm{~cm}$ for $14+$ days \\
\hline 1992 & yes & March, April, August, November within $30 \mathrm{~cm}$ for $14+$ days \\
\hline 1993 & yes & March, April within $30 \mathrm{~cm}$ for $14+$ days \\
\hline 1994 & yes & March within $30 \mathrm{~cm}$ for $14+$ days \\
\hline 1995 & yes & $\begin{array}{l}\text { March, June, July within } 30 \mathrm{~cm} \text { for } 14+\text { days } \\
\text { March, April, June, September, October, November within } 30 \mathrm{~cm} \text { for }\end{array}$ \\
\hline 1996 & yes & $14+$ days \\
\hline 1997 & yes & March, April, May, November within $30 \mathrm{~cm}$ for $14+$ days \\
\hline 1998 & no & March, April, May, September - "wet" \\
\hline
\end{tabular}


Table B.10: 45 -year record for the DAREM approach for plot $2 \mathrm{~N}$ at Bertie. This plot met wetland hydrology in 1 out of 45 years. There were 4 years that did not meet wetland hydrology because water table saturation occurred during "wet" periods, while 40 years did not meet water table saturation criterion.

\begin{tabular}{|c|c|c|}
\hline Year & $\begin{array}{c}\text { Met/Not } \\
\text { Met }\end{array}$ & Reason Year did or did not meet Wetland Hydrology \\
\hline 1950 & no & July - "wet" \\
\hline 1951 & no & water table not within $30 \mathrm{~cm}$ for $14+$ days \\
\hline 1952 & no & water table not within $30 \mathrm{~cm}$ for $14+$ days \\
\hline 1953 & no & water table not within $30 \mathrm{~cm}$ for $14+$ days \\
\hline 1954 & no & water table not within $30 \mathrm{~cm}$ for $14+$ days \\
\hline 1955 & no & water table not within $30 \mathrm{~cm}$ for $14+$ days \\
\hline 1956 & no & water table not within $30 \mathrm{~cm}$ for $14+$ days \\
\hline 1957 & no & water table not within $30 \mathrm{~cm}$ for $14+$ days \\
\hline 1958 & no & water table not within $30 \mathrm{~cm}$ for $14+$ days \\
\hline 1959 & no & water table not within $30 \mathrm{~cm}$ for $14+$ days \\
\hline 1960 & no & water table not within $30 \mathrm{~cm}$ for $14+$ days \\
\hline 1961 & no & water table not within $30 \mathrm{~cm}$ for $14+$ days \\
\hline 1962 & no & water table not within $30 \mathrm{~cm}$ for $14+$ days \\
\hline 1963 & no & water table not within $30 \mathrm{~cm}$ for $14+$ days \\
\hline 1964 & no & water table not within $30 \mathrm{~cm}$ for $14+$ days \\
\hline 1965 & no & water table not within $30 \mathrm{~cm}$ for $14+$ days \\
\hline 1966 & yes & May/June within $30 \mathrm{~cm}$ for $14+$ days \\
\hline 1967 & no & water table not within $30 \mathrm{~cm}$ for $14+$ days \\
\hline 1968 & no & water table not within $30 \mathrm{~cm}$ for $14+$ days \\
\hline 1969 & no & water table not within $30 \mathrm{~cm}$ for $14+$ days \\
\hline 1970 & no & water table not within $30 \mathrm{~cm}$ for $14+$ days \\
\hline 1971 & no & water table not within $30 \mathrm{~cm}$ for $14+$ days \\
\hline 1972 & no & water table not within $30 \mathrm{~cm}$ for $14+$ days \\
\hline 1973 & no & April - "wet" \\
\hline 1974 & no & water table not within $30 \mathrm{~cm}$ for $14+$ days \\
\hline 1975 & no & water table not within $30 \mathrm{~cm}$ for $14+$ days \\
\hline 1976 & no & water table not within $30 \mathrm{~cm}$ for $14+$ days \\
\hline 1977 & no & water table not within $30 \mathrm{~cm}$ for $14+$ days \\
\hline 1978 & no & May - "wet" \\
\hline 1979 & no & water table not within $30 \mathrm{~cm}$ for $14+$ days \\
\hline 1980 & no & water table not within $30 \mathrm{~cm}$ for $14+$ days \\
\hline 1981 & no & water table not within $30 \mathrm{~cm}$ for $14+$ days \\
\hline 1982 & no & water table not within $30 \mathrm{~cm}$ for $14+$ days \\
\hline 1983 & no & March, April - "wet" \\
\hline 1984 & no & water table not within $30 \mathrm{~cm}$ for $14+$ days \\
\hline 1985 & no & water table not within $30 \mathrm{~cm}$ for $14+$ days \\
\hline 1986 & no & water table not within $30 \mathrm{~cm}$ for $14+$ days \\
\hline 1987 & no & water table not within $30 \mathrm{~cm}$ for $14+$ days \\
\hline 1988 & no & water table not within $30 \mathrm{~cm}$ for $14+$ days \\
\hline 1989 & no & water table not within $30 \mathrm{~cm}$ for $14+$ days \\
\hline 1990 & no & water table not within $30 \mathrm{~cm}$ for $14+$ days \\
\hline 1991 & no & water table not within $30 \mathrm{~cm}$ for $14+$ days \\
\hline 1992 & no & water table not within $30 \mathrm{~cm}$ for $14+$ days \\
\hline 1993 & no & water table not within $30 \mathrm{~cm}$ for $14+$ days \\
\hline 1994 & no & water table not within $30 \mathrm{~cm}$ for $14+$ days \\
\hline
\end{tabular}


Table B.11: 45-year record for the DAREM approach for plot 3N at Bertie. This plot met wetland hydrology in 24 out of 45 years. There were 13 years that did not meet wetland hydrology because water table saturation occurred during "wet" periods, while 8 years did not meet water table saturation criterion.

\begin{tabular}{|c|c|c|}
\hline Year & $\begin{array}{c}\text { Met/Not } \\
\text { Met }\end{array}$ & Reason Year did or did not meet Wetland Hydrology \\
\hline 1950 & yes & September is within $30 \mathrm{~cm}$ for $14+$ days \\
\hline 1951 & yes & April is within $30 \mathrm{~cm}$ for $14+$ days \\
\hline 1952 & no & August, September, October - "wet" \\
\hline 1953 & no & water table not within $30 \mathrm{~cm}$ for $14+$ days \\
\hline 1954 & yes & April is within $30 \mathrm{~cm}$ for $14+$ days \\
\hline 1955 & no & September - "wet" \\
\hline 1956 & yes & April is within $30 \mathrm{~cm}$ for $14+$ days \\
\hline 1957 & no & April - "wet" \\
\hline 1958 & yes & April, May and October within $30 \mathrm{~cm}$ for $14+$ days \\
\hline 1959 & yes & April is within $30 \mathrm{~cm}$ for $14+$ days \\
\hline 1960 & yes & August is within $30 \mathrm{~cm}$ for $14+$ days \\
\hline 1961 & yes & April is within $30 \mathrm{~cm}$ for $14+$ days \\
\hline 1962 & yes & April is within $30 \mathrm{~cm}$ for $14+$ days \\
\hline 1963 & no & water table not within $30 \mathrm{~cm}$ for $14+$ days \\
\hline 1964 & no & April, September - "wet" \\
\hline 1965 & no & July - "wet" \\
\hline 1966 & yes & June is within $30 \mathrm{~cm}$ for $14+$ days \\
\hline 1967 & yes & August is within $30 \mathrm{~cm}$ for $14+$ days \\
\hline 1968 & yes & April is within $30 \mathrm{~cm}$ for $14+$ days \\
\hline 1969 & yes & April is within $30 \mathrm{~cm}$ for $14+$ days \\
\hline 1970 & yes & April is within $30 \mathrm{~cm}$ for $14+$ days \\
\hline 1971 & yes & May is within $30 \mathrm{~cm}$ for $14+$ days \\
\hline 1972 & yes & May, June within $30 \mathrm{~cm}$ for $14+$ days \\
\hline 1973 & no & April, May - "wet" \\
\hline 1974 & no & April, September - "wet" \\
\hline 1975 & no & April - "wet" \\
\hline 1976 & no & water table not within $30 \mathrm{~cm}$ for $14+$ days \\
\hline 1977 & no & June - "wet" \\
\hline 1978 & no & May, June, July - "wet" \\
\hline 1979 & no & April, May, June - "wet" \\
\hline 1980 & no & April - "wet" \\
\hline 1981 & no & water table not within $30 \mathrm{~cm}$ for $14+$ days \\
\hline 1982 & no & water table not within $30 \mathrm{~cm}$ for $14+$ days \\
\hline 1983 & no & April - "wet" \\
\hline 1984 & yes & July, September is within $30 \mathrm{~cm}$ for $14+$ days \\
\hline 1985 & no & water table not within $30 \mathrm{~cm}$ for $14+$ days \\
\hline 1986 & no & water table not within $30 \mathrm{~cm}$ for $14+$ days \\
\hline 1987 & yes & April is within $30 \mathrm{~cm}$ for $14+$ days \\
\hline 1988 & yes & April is within $30 \mathrm{~cm}$ for $14+$ days \\
\hline 1989 & yes & April is within $30 \mathrm{~cm}$ for $14+$ days \\
\hline 1990 & yes & April is within $30 \mathrm{~cm}$ for $14+$ days \\
\hline 1991 & yes & October is within $30 \mathrm{~cm}$ for $14+$ days \\
\hline 1992 & no & water table not within $30 \mathrm{~cm}$ for $14+$ days \\
\hline 1993 & yes & April is within $30 \mathrm{~cm}$ for $14+$ days \\
\hline 1994 & yes & October is within $30 \mathrm{~cm}$ for $14+$ days \\
\hline
\end{tabular}


Table B.12: 45-year record for the DAREM approach for plot $4 \mathrm{~N}$ at Bertie. This plot met wetland hydrology in 32 out of 45 years. There were 11 years that did not meet wetland hydrology because water table saturation occurred during "wet" periods, while 2 years did not meet water table saturation criterion.

\begin{tabular}{|c|c|c|}
\hline Year & $\begin{array}{c}\text { Met/Not } \\
\text { Met }\end{array}$ & Reason Year did or did not meet Wetland Hydrology \\
\hline 1950 & yes & September is within $30 \mathrm{~cm}$ for $14+$ days \\
\hline 1951 & yes & April is within $30 \mathrm{~cm}$ for $14+$ days \\
\hline 1952 & no & September, August - "wet" \\
\hline 1953 & yes & August is within $30 \mathrm{~cm}$ for $14+$ days \\
\hline 1954 & yes & April is within $30 \mathrm{~cm}$ for $14+$ days \\
\hline 1955 & yes & August is within $30 \mathrm{~cm}$ for $14+$ days \\
\hline 1956 & yes & April is within $30 \mathrm{~cm}$ for $14+$ days \\
\hline 1957 & no & April - "wet" \\
\hline 1958 & yes & April, May, October within $30 \mathrm{~cm}$ for $14+$ days \\
\hline 1959 & yes & April, July, August within $30 \mathrm{~cm}$ for $14+$ days \\
\hline 1960 & yes & September is within $30 \mathrm{~cm}$ for $14+$ days \\
\hline 1961 & yes & April, October within $30 \mathrm{~cm}$ for $14+$ days \\
\hline 1962 & yes & April is within $30 \mathrm{~cm}$ for $14+$ days \\
\hline 1963 & no & water table is not within $30 \mathrm{~cm}$ for $14+$ days \\
\hline 1964 & yes & September is within $30 \mathrm{~cm}$ for $14+$ days \\
\hline 1965 & no & July - "wet" \\
\hline 1966 & yes & June, August within $30 \mathrm{~cm}$ for $14+$ days \\
\hline 1967 & yes & July, August within $30 \mathrm{~cm}$ for $14+$ days \\
\hline 1968 & no & May - "wet" \\
\hline 1969 & yes & April is within $30 \mathrm{~cm}$ for $14+$ days \\
\hline 1970 & yes & April is within $30 \mathrm{~cm}$ for $14+$ days \\
\hline 1971 & yes & May is within $30 \mathrm{~cm}$ for $14+$ days \\
\hline 1972 & yes & May, June, July within $30 \mathrm{~cm}$ for $14+$ days \\
\hline 1973 & yes & August is within $30 \mathrm{~cm}$ for $14+$ days \\
\hline 1974 & yes & August is within $30 \mathrm{~cm}$ for $14+$ days \\
\hline 1975 & yes & June is within $30 \mathrm{~cm}$ for $14+$ days \\
\hline 1976 & no & August - "wet" \\
\hline 1977 & yes & October is within $30 \mathrm{~cm}$ for $14+$ days \\
\hline 1978 & no & May, June, July, August - "wet" \\
\hline 1979 & no & April, May, June - "wet" \\
\hline 1980 & no & April - "wet" \\
\hline 1981 & yes & March/April is within $30 \mathrm{~cm}$ for $14+$ days \\
\hline 1982 & no & water table is not within $30 \mathrm{~cm}$ for $14+$ days \\
\hline 1983 & no & April, June - "wet" \\
\hline 1984 & yes & July, August, September within $30 \mathrm{~cm}$ for $14+$ days \\
\hline 1985 & no & October - "wet" \\
\hline 1986 & no & September - "wet" \\
\hline 1987 & yes & April is within $30 \mathrm{~cm}$ for $14+$ days \\
\hline 1988 & yes & April is within $30 \mathrm{~cm}$ for $14+$ days \\
\hline 1989 & yes & April is within $30 \mathrm{~cm}$ for $14+$ days \\
\hline 1990 & yes & April is within $30 \mathrm{~cm}$ for $14+$ days \\
\hline 1991 & yes & August, October within $30 \mathrm{~cm}$ for $14+$ days \\
\hline 1992 & yes & August is within $30 \mathrm{~cm}$ for $14+$ days \\
\hline 1993 & yes & April is within $30 \mathrm{~cm}$ for $14+$ days \\
\hline 1994 & yes & August, October within $30 \mathrm{~cm}$ for $14+$ days \\
\hline
\end{tabular}


Table B.13: 45-year record for the DAREM approach for plot $5 \mathrm{~N}$ at Bertie. This plot met wetland hydrology in 34 out of 45 years. There were 10 years that did not meet wetland hydrology because water table saturation occurred during "wet" periods, while 1 year did not meet water table saturation criterion.

\begin{tabular}{|c|c|c|}
\hline Year & $\begin{array}{c}\text { Met/Not } \\
\text { Met }\end{array}$ & Reason Year did or did not meet Wetland Hydrology \\
\hline 1950 & yes & September is within $30 \mathrm{~cm}$ for $14+$ \\
\hline 1951 & yes & April is within $30 \mathrm{~cm}$ for $14+$ days \\
\hline 1952 & no & June, August, September, October - "wet" \\
\hline 1953 & yes & April, August within $30 \mathrm{~cm}$ for $14+$ days \\
\hline 1954 & yes & April is within $30 \mathrm{~cm}$ for $14+$ days \\
\hline 1955 & yes & August within $30 \mathrm{~cm}$ for $14+$ days \\
\hline 1956 & yes & April is within $30 \mathrm{~cm}$ for $14+$ days \\
\hline 1957 & no & April - "wet" \\
\hline 1958 & yes & April, May, October within $30 \mathrm{~cm}$ for $14+$ days \\
\hline 1959 & yes & April, July, August within $30 \mathrm{~cm}$ for $14+$ days \\
\hline 1960 & yes & September is within $30 \mathrm{~cm}$ for $14+$ days \\
\hline 1961 & yes & April, October within $30 \mathrm{~cm}$ for $14+$ days \\
\hline 1962 & yes & April is within $30 \mathrm{~cm}$ for $14+$ days \\
\hline 1963 & no & water table is not within $30 \mathrm{~cm}$ for $14+$ days \\
\hline 1964 & yes & September is within $30 \mathrm{~cm}$ for $14+$ days \\
\hline 1965 & no & July - "wet" \\
\hline 1966 & yes & June, September, October within $30 \mathrm{~cm}$ for $14+$ days \\
\hline 1967 & yes & July, August within $30 \mathrm{~cm}$ for $14+$ days \\
\hline 1968 & yes & April is within $30 \mathrm{~cm}$ for $14+$ days \\
\hline 1969 & yes & April is within $30 \mathrm{~cm}$ for $14+$ days \\
\hline 1970 & yes & April is within $30 \mathrm{~cm}$ for $14+$ days \\
\hline 1971 & yes & May is within $30 \mathrm{~cm}$ for $14+$ days \\
\hline 1972 & yes & May, June within $30 \mathrm{~cm}$ for $14+$ days \\
\hline 1973 & yes & August within $30 \mathrm{~cm}$ for $14+$ days \\
\hline 1974 & yes & August within $30 \mathrm{~cm}$ for $14+$ days \\
\hline 1975 & yes & July is within $30 \mathrm{~cm}$ for $14+$ days \\
\hline 1976 & no & August - "wet" \\
\hline 1977 & yes & October is within $30 \mathrm{~cm}$ for $14+$ days \\
\hline 1978 & no & May, June, July, August - 'wet" \\
\hline 1979 & yes & September is within $30 \mathrm{~cm}$ for $14+$ days \\
\hline 1980 & no & April, May - "wet" \\
\hline 1981 & no & September - "wet" \\
\hline 1982 & yes & April is within $30 \mathrm{~cm}$ for $14+$ days \\
\hline 1983 & no & April - "wet" \\
\hline 1984 & yes & July, August, September within $30 \mathrm{~cm}$ for $14+$ days \\
\hline 1985 & no & October - "wet" \\
\hline 1986 & no & September - "wet" \\
\hline 1987 & yes & April, September within $30 \mathrm{~cm}$ for $14+$ days \\
\hline 1988 & yes & April within $30 \mathrm{~cm}$ for $14+$ days \\
\hline 1989 & yes & April is within $30 \mathrm{~cm}$ for $14+$ days \\
\hline 1990 & yes & April is within $30 \mathrm{~cm}$ for $14+$ days \\
\hline 1991 & yes & August, October within $30 \mathrm{~cm}$ for $14+$ days \\
\hline 1992 & yes & August within $30 \mathrm{~cm}$ for $14+$ days \\
\hline 1993 & yes & April is within $30 \mathrm{~cm}$ for $14+$ days \\
\hline 1994 & yes & August within $30 \mathrm{~cm}$ for $14+$ days \\
\hline
\end{tabular}


Table B.14: 45-year record for the DAREM approach for plot $2 \mathrm{~S}$ at Bertie. This plot met wetland hydrology in 0 out of 45 years. There were 45 years did not meet water table saturation criterion.

\begin{tabular}{|c|c|c|}
\hline Year & $\begin{array}{c}\text { Met/Not } \\
\text { Met }\end{array}$ & Reason Year did or did not meet Wetland Hydrology \\
\hline 1950 & no & water table is not within $30 \mathrm{~cm}$ for $14+$ days \\
\hline 1951 & no & water table is not within $30 \mathrm{~cm}$ for $14+$ days \\
\hline 1952 & no & water table is not within $30 \mathrm{~cm}$ for $14+$ days \\
\hline 1953 & no & water table is not within $30 \mathrm{~cm}$ for $14+$ days \\
\hline 1954 & no & water table is not within $30 \mathrm{~cm}$ for $14+$ days \\
\hline 1955 & no & water table is not within $30 \mathrm{~cm}$ for $14+$ days \\
\hline 1956 & no & water table is not within $30 \mathrm{~cm}$ for $14+$ days \\
\hline 1957 & no & water table is not within $30 \mathrm{~cm}$ for $14+$ days \\
\hline 1958 & no & water table is not within $30 \mathrm{~cm}$ for $14+$ days \\
\hline 1959 & no & water table is not within $30 \mathrm{~cm}$ for $14+$ days \\
\hline 1960 & no & water table is not within $30 \mathrm{~cm}$ for $14+$ days \\
\hline 1961 & no & water table is not within $30 \mathrm{~cm}$ for $14+$ days \\
\hline 1962 & no & water table is not within $30 \mathrm{~cm}$ for $14+$ days \\
\hline 1963 & no & water table is not within $30 \mathrm{~cm}$ for $14+$ days \\
\hline 1964 & no & water table is not within $30 \mathrm{~cm}$ for $14+$ days \\
\hline 1965 & no & water table is not within $30 \mathrm{~cm}$ for $14+$ days \\
\hline 1966 & no & water table is not within $30 \mathrm{~cm}$ for $14+$ days \\
\hline 1967 & no & water table is not within $30 \mathrm{~cm}$ for $14+$ days \\
\hline 1968 & no & water table is not within $30 \mathrm{~cm}$ for $14+$ days \\
\hline 1969 & no & water table is not within $30 \mathrm{~cm}$ for $14+$ days \\
\hline 1970 & no & water table is not within $30 \mathrm{~cm}$ for $14+$ days \\
\hline 1971 & no & water table is not within $30 \mathrm{~cm}$ for $14+$ days \\
\hline 1972 & no & water table is not within $30 \mathrm{~cm}$ for $14+$ days \\
\hline 1973 & no & water table is not within $30 \mathrm{~cm}$ for $14+$ days \\
\hline 1974 & no & water table is not within $30 \mathrm{~cm}$ for $14+$ days \\
\hline 1975 & no & water table is not within $30 \mathrm{~cm}$ for $14+$ days \\
\hline 1976 & no & water table is not within $30 \mathrm{~cm}$ for $14+$ days \\
\hline 1977 & no & water table is not within $30 \mathrm{~cm}$ for $14+$ days \\
\hline 1978 & no & water table is not within $30 \mathrm{~cm}$ for $14+$ days \\
\hline 1979 & no & water table is not within $30 \mathrm{~cm}$ for $14+$ days \\
\hline 1980 & no & water table is not within $30 \mathrm{~cm}$ for $14+$ days \\
\hline 1981 & no & water table is not within $30 \mathrm{~cm}$ for $14+$ days \\
\hline 1982 & no & water table is not within $30 \mathrm{~cm}$ for $14+$ days \\
\hline 1983 & no & water table is not within $30 \mathrm{~cm}$ for $14+$ days \\
\hline 1984 & no & water table is not within $30 \mathrm{~cm}$ for $14+$ days \\
\hline 1985 & no & water table is not within $30 \mathrm{~cm}$ for $14+$ days \\
\hline 1986 & no & water table is not within $30 \mathrm{~cm}$ for $14+$ days \\
\hline 1987 & no & water table is not within $30 \mathrm{~cm}$ for $14+$ days \\
\hline 1988 & no & water table is not within $30 \mathrm{~cm}$ for $14+$ days \\
\hline 1989 & no & water table is not within $30 \mathrm{~cm}$ for $14+$ days \\
\hline 1990 & no & water table is not within $30 \mathrm{~cm}$ for $14+$ days \\
\hline 1991 & no & water table is not within $30 \mathrm{~cm}$ for $14+$ days \\
\hline 1992 & no & water table is not within $30 \mathrm{~cm}$ for $14+$ days \\
\hline 1993 & no & water table is not within $30 \mathrm{~cm}$ for $14+$ days \\
\hline 1994 & no & water table is not within $30 \mathrm{~cm}$ for $14+$ days \\
\hline
\end{tabular}


Table B.15: 45-year record for the DAREM approach for plot 3S at Bertie. This plot met wetland hydrology in 27 out of 45 years. There were 12 years that did not meet wetland hydrology because water table saturation occurred during "wet" periods, while 6 years did not meet water table saturation criterion.

\begin{tabular}{|c|c|c|}
\hline Year & $\begin{array}{c}\text { Met/Not } \\
\text { Met }\end{array}$ & Reason Year did or did not meet Wetland Hydrology \\
\hline 1950 & yes & September is within $30 \mathrm{~cm}$ for $14+$ days \\
\hline 1951 & yes & April is within $30 \mathrm{~cm}$ for $14+$ days \\
\hline 1952 & no & August, September - "wet" \\
\hline 1953 & yes & August is within $30 \mathrm{~cm}$ for $14+$ days \\
\hline 1954 & yes & April is within $30 \mathrm{~cm}$ for $14+$ days \\
\hline 1955 & yes & August is within $30 \mathrm{~cm}$ for $14+$ days \\
\hline 1956 & yes & April is within $30 \mathrm{~cm}$ for $14+$ days \\
\hline 1957 & no & April - "wet" \\
\hline 1958 & yes & April, October within $30 \mathrm{~cm}$ for $14+$ days \\
\hline 1959 & yes & April is within $30 \mathrm{~cm}$ for $14+$ days \\
\hline 1960 & yes & September is within $30 \mathrm{~cm}$ for $14+$ days \\
\hline 1961 & yes & April, October within $30 \mathrm{~cm}$ for $14+$ days \\
\hline 1962 & yes & April is within $30 \mathrm{~cm}$ for $14+$ days \\
\hline 1963 & no & water table is not within $30 \mathrm{~cm}$ for $14+$ days \\
\hline 1964 & yes & September is within $30 \mathrm{~cm}$ for $14+$ days \\
\hline 1965 & no & July - "wet" \\
\hline 1966 & yes & September is within $30 \mathrm{~cm}$ for $14+$ days \\
\hline 1967 & yes & August is within $30 \mathrm{~cm}$ for $14+$ days \\
\hline 1968 & no & water table is not within $30 \mathrm{~cm}$ for $14+$ days \\
\hline 1969 & yes & March/April within $30 \mathrm{~cm}$ for $14+$ days \\
\hline 1970 & yes & April is within $30 \mathrm{~cm}$ for $14+$ days \\
\hline 1971 & no & April, October - "wet" \\
\hline 1972 & no & April - "wet" \\
\hline 1973 & no & April, May - "wet" \\
\hline 1974 & no & April - "wet" \\
\hline 1975 & yes & July is within $30 \mathrm{~cm}$ for $14+$ days \\
\hline 1976 & no & water table is not within $30 \mathrm{~cm}$ for $14+$ days \\
\hline 1977 & yes & March/April within $30 \mathrm{~cm}$ for $14+$ days \\
\hline 1978 & no & May, June, July - "wet" \\
\hline 1979 & no & May - "wet" \\
\hline 1980 & no & April - "wet" \\
\hline 1981 & yes & March/April within $30 \mathrm{~cm}$ for $14+$ days \\
\hline 1982 & no & water table is not within $30 \mathrm{~cm}$ for $14+$ days \\
\hline 1983 & no & April - "wet" \\
\hline 1984 & yes & July, September is within $30 \mathrm{~cm}$ for $14+$ days \\
\hline 1985 & no & October - "wet" \\
\hline 1986 & no & water table is not within $30 \mathrm{~cm}$ for $14+$ days \\
\hline 1987 & yes & April is within $30 \mathrm{~cm}$ for $14+$ days \\
\hline 1988 & yes & April is within $30 \mathrm{~cm}$ for $14+$ days \\
\hline 1989 & yes & April is within $30 \mathrm{~cm}$ for $14+$ days \\
\hline 1990 & yes & April is within $30 \mathrm{~cm}$ for $14+$ days \\
\hline 1991 & yes & August, October within $30 \mathrm{~cm}$ for $14+$ days \\
\hline 1992 & no & water table is not within $30 \mathrm{~cm}$ for $14+$ days \\
\hline 1993 & yes & April is within $30 \mathrm{~cm}$ for $14+$ days \\
\hline 1994 & yes & August is within $30 \mathrm{~cm}$ for $14+$ days \\
\hline
\end{tabular}


Table B.16: 45-year record for the DAREM approach for plot $4 \mathrm{~S}$ at Bertie. This plot met wetland hydrology in 33 out of 45 years. There were 8 years that did not meet wetland hydrology because water table saturation occurred during "wet" periods, while 4 years did not meet water table saturation criterion.

\begin{tabular}{|c|c|c|}
\hline Year & $\begin{array}{c}\text { Met/Not } \\
\text { Met }\end{array}$ & Reason Year did or did not meet Wetland Hydrology \\
\hline 1950 & yes & September is within $30 \mathrm{~cm}$ for $14+$ days \\
\hline 1951 & yes & April is within $30 \mathrm{~cm}$ for $14+$ days \\
\hline 1952 & no & September - "wet" \\
\hline 1953 & yes & August is within $30 \mathrm{~cm}$ for $14+$ days \\
\hline 1954 & yes & April is within $30 \mathrm{~cm}$ for $14+$ days \\
\hline 1955 & yes & August is within $30 \mathrm{~cm}$ for $14+$ days \\
\hline 1956 & yes & April is within $30 \mathrm{~cm}$ for $14+$ days \\
\hline 1957 & no & April - "wet" \\
\hline 1958 & yes & April, May, October within $30 \mathrm{~cm}$ for $14+$ days \\
\hline 1959 & yes & April, July, August within $30 \mathrm{~cm}$ for 14+ days \\
\hline 1960 & yes & September is within $30 \mathrm{~cm}$ for $14+$ days \\
\hline 1961 & yes & April, October within $30 \mathrm{~cm}$ for $14+$ days \\
\hline 1962 & yes & April is within $30 \mathrm{~cm}$ for $14+$ days \\
\hline 1963 & no & water table is not within $30 \mathrm{~cm}$ for $14+$ days \\
\hline 1964 & yes & September is within $30 \mathrm{~cm}$ for $14+$ days \\
\hline 1965 & no & July - "wet" \\
\hline 1966 & yes & September, October within $30 \mathrm{~cm}$ for $14+$ days \\
\hline 1967 & yes & July, August within $30 \mathrm{~cm}$ for $14+$ days \\
\hline 1968 & yes & April is within $30 \mathrm{~cm}$ for $14+$ days \\
\hline 1969 & yes & April is within $30 \mathrm{~cm}$ for $14+$ days \\
\hline 1970 & yes & April is within $30 \mathrm{~cm}$ for $14+$ days \\
\hline 1971 & yes & May is within $30 \mathrm{~cm}$ for $14+$ days \\
\hline 1972 & yes & May, June within $30 \mathrm{~cm}$ for $14+$ days \\
\hline 1973 & no & April, May - "wet" \\
\hline 1974 & yes & August is within $30 \mathrm{~cm}$ for $14+$ days \\
\hline 1975 & yes & July is within $30 \mathrm{~cm}$ for $14+$ days \\
\hline 1976 & no & water table is not within $30 \mathrm{~cm}$ for $14+$ days \\
\hline 1977 & yes & March/April is within $30 \mathrm{~cm}$ for $14+$ days \\
\hline 1978 & no & May, June, July, August - "wet" \\
\hline 1979 & no & April, May, June - "wet" \\
\hline 1980 & no & April, May - "wet" \\
\hline 1981 & yes & March/April is within $30 \mathrm{~cm}$ for $14+$ days \\
\hline 1982 & yes & April is within $30 \mathrm{~cm}$ for $14+$ days \\
\hline 1983 & no & April - "wet" \\
\hline 1984 & yes & July, August, September within $30 \mathrm{~cm}$ for $14+$ days \\
\hline 1985 & no & water table is not within $30 \mathrm{~cm}$ for $14+$ days \\
\hline 1986 & no & water table is not within $30 \mathrm{~cm}$ for $14+$ days \\
\hline 1987 & yes & April is within $30 \mathrm{~cm}$ for $14+$ days \\
\hline 1988 & yes & April, May within $30 \mathrm{~cm}$ for $14+$ days \\
\hline 1989 & yes & April is within $30 \mathrm{~cm}$ for $14+$ days \\
\hline 1990 & yes & April is within $30 \mathrm{~cm}$ for $14+$ days \\
\hline 1991 & yes & October is within $30 \mathrm{~cm}$ for $14+$ days \\
\hline 1992 & yes & August is within $30 \mathrm{~cm}$ for $14+$ days \\
\hline 1993 & yes & April is within $30 \mathrm{~cm}$ for $14+$ days \\
\hline 1994 & yes & August, October within $30 \mathrm{~cm}$ for $14+$ days \\
\hline
\end{tabular}


Table B.17: 45-year record for the DAREM approach for plot 5S at Bertie. This plot met wetland hydrology in 35 out of 45 years. There were 9 years that did not meet wetland hydrology because water table saturation occurred during "wet" periods, while 1 year did not meet water table saturation criterion.

\begin{tabular}{|c|c|c|}
\hline Year & $\begin{array}{c}\text { Met/Not } \\
\text { Met }\end{array}$ & Reason Year did or did not meet Wetland Hydrology \\
\hline 1950 & yes & August is within $30 \mathrm{~cm}$ for $14+$ days \\
\hline 1951 & yes & April is within $30 \mathrm{~cm}$ for $14+$ days \\
\hline 1952 & no & June, August, September, October - "wet" \\
\hline 1953 & yes & April, August within $30 \mathrm{~cm}$ for $14+$ days \\
\hline 1954 & yes & April, May within $30 \mathrm{~cm}$ for $14+$ days \\
\hline 1955 & yes & August is within $30 \mathrm{~cm}$ for $14+$ days \\
\hline 1956 & yes & April is within $30 \mathrm{~cm}$ for $14+$ days \\
\hline 1957 & no & April - "wet" \\
\hline 1958 & yes & April, May, October within $30 \mathrm{~cm}$ for $14+$ days \\
\hline 1959 & yes & April, July, August within $30 \mathrm{~cm}$ for 14+ days \\
\hline 1960 & yes & September within $30 \mathrm{~cm}$ for $14+$ days \\
\hline 1961 & yes & April, October within $30 \mathrm{~cm}$ for $14+$ days \\
\hline 1962 & yes & April is within $30 \mathrm{~cm}$ for $14+$ days \\
\hline 1963 & no & water table is not within $30 \mathrm{~cm}$ for $14+$ days \\
\hline 1964 & yes & September within $30 \mathrm{~cm}$ for $14+$ days \\
\hline 1965 & no & July - "wet" \\
\hline 1966 & yes & June, September, October within $30 \mathrm{~cm}$ for $14+$ days \\
\hline 1967 & yes & June, July within $30 \mathrm{~cm}$ for $14+$ days \\
\hline 1968 & yes & April is within $30 \mathrm{~cm}$ for $14+$ days \\
\hline 1969 & yes & April is within $30 \mathrm{~cm}$ for $14+$ days \\
\hline 1970 & yes & April is within $30 \mathrm{~cm}$ for $14+$ days \\
\hline 1971 & yes & May is within $30 \mathrm{~cm}$ for $14+$ days \\
\hline 1972 & yes & May, June within $30 \mathrm{~cm}$ for $14+$ days \\
\hline 1973 & yes & August is within $30 \mathrm{~cm}$ for $14+$ days \\
\hline 1974 & yes & August is within $30 \mathrm{~cm}$ for $14+$ days \\
\hline 1975 & yes & July is within $30 \mathrm{~cm}$ for $14+$ days \\
\hline 1976 & no & August - "Wet" \\
\hline 1977 & yes & October is within $30 \mathrm{~cm}$ for $14+$ days \\
\hline 1978 & yes & April is within $30 \mathrm{~cm}$ for $14+$ days \\
\hline 1979 & yes & September within $30 \mathrm{~cm}$ for $14+$ days \\
\hline 1980 & no & April - "wet" \\
\hline 1981 & no & September - "wet" \\
\hline 1982 & yes & April is within $30 \mathrm{~cm}$ for $14+$ days \\
\hline 1983 & no & April, June - "wet" \\
\hline 1984 & yes & July, August, September within $30 \mathrm{~cm}$ for $14+$ days \\
\hline 1985 & no & October - "wet" \\
\hline 1986 & no & September - "Wet" \\
\hline 1987 & yes & April, September within $30 \mathrm{~cm}$ for $14+$ days \\
\hline 1988 & yes & April is within $30 \mathrm{~cm}$ for $14+$ days \\
\hline 1989 & yes & April is within $30 \mathrm{~cm}$ for $14+$ days \\
\hline 1990 & yes & April is within $30 \mathrm{~cm}$ for $14+$ days \\
\hline 1991 & yes & August, October within $30 \mathrm{~cm}$ for $14+$ days \\
\hline 1992 & yes & August, October within $30 \mathrm{~cm}$ for $14+$ days \\
\hline 1993 & yes & April is within $30 \mathrm{~cm}$ for $14+$ days \\
\hline 1994 & yes & August is within $30 \mathrm{~cm}$ for $14+$ days \\
\hline
\end{tabular}


Table B.18: 45-year record for the DAREM approach for bogwell plot S1 at Marcell. This plot met wetland hydrology in 34 out of 45 years. There were 4 years that did not meet wetland hydrology because water table saturation occurred during "wet" periods, while 7 years did not meet water table saturation criterion.

\begin{tabular}{|c|c|c|}
\hline Year & $\begin{array}{c}\text { Met/Not } \\
\text { Met }\end{array}$ & Reason Year did or did not meet Wetland Hydrology \\
\hline 1961 & no & water table not within $30 \mathrm{~cm}$ for $14+$ days \\
\hline 1962 & yes & May is within $30 \mathrm{~cm}$ for $14+$ days \\
\hline 1963 & no & water table not within $30 \mathrm{~cm}$ for $14+$ days \\
\hline 1964 & no & water table not within $30 \mathrm{~cm}$ for $14+$ days \\
\hline 1965 & yes & May is within $30 \mathrm{~cm}$ for $14+$ days \\
\hline 1966 & yes & August is within $30 \mathrm{~cm}$ for $14+$ days \\
\hline 1967 & no & water table not within $30 \mathrm{~cm}$ for $14+$ days \\
\hline 1968 & no & water table not within $30 \mathrm{~cm}$ for $14+$ days \\
\hline 1969 & yes & May/June is within $30 \mathrm{~cm}$ for $14+$ days \\
\hline 1970 & yes & June is within $30 \mathrm{~cm}$ for $14+$ days \\
\hline 1971 & yes & May/June is within $30 \mathrm{~cm}$ for $14+$ days \\
\hline 1972 & yes & July is within $30 \mathrm{~cm}$ for $14+$ days \\
\hline 1973 & yes & May is within $30 \mathrm{~cm}$ for $14+$ days \\
\hline 1974 & no & May/June - "wet" \\
\hline 1975 & yes & July is within $30 \mathrm{~cm}$ for $14+$ days \\
\hline 1976 & no & water table not within $30 \mathrm{~cm}$ for $14+$ days \\
\hline 1977 & yes & August/September is within $30 \mathrm{~cm}$ for $14+$ days \\
\hline 1978 & yes & July is within $30 \mathrm{~cm}$ for $14+$ days \\
\hline 1979 & no & May - "wet" \\
\hline 1980 & no & water table not within $30 \mathrm{~cm}$ for $14+$ days \\
\hline 1981 & yes & May is within $30 \mathrm{~cm}$ for $14+$ days \\
\hline 1982 & yes & May is within $30 \mathrm{~cm}$ for $14+$ days \\
\hline 1983 & yes & May is within $30 \mathrm{~cm}$ for $14+$ days \\
\hline 1984 & yes & May is within $30 \mathrm{~cm}$ for $14+$ days \\
\hline 1985 & yes & September is within $30 \mathrm{~cm}$ for $14+$ days \\
\hline 1986 & yes & May is within $30 \mathrm{~cm}$ for $14+$ days \\
\hline 1987 & yes & May/June within $30 \mathrm{~cm}$ for $14+$ days \\
\hline 1988 & yes & May is within $30 \mathrm{~cm}$ for $14+$ days \\
\hline 1989 & yes & May/June is within $30 \mathrm{~cm}$ for $14+$ days \\
\hline 1990 & yes & June is within $30 \mathrm{~cm}$ for $14+$ days \\
\hline 1991 & no & May - "wet" \\
\hline 1992 & no & July/August - "wet" \\
\hline 1993 & yes & June/July is within $30 \mathrm{~cm}$ for $14+$ days \\
\hline 1994 & yes & June is within $30 \mathrm{~cm}$ for $14+$ days \\
\hline 1995 & yes & May is within $30 \mathrm{~cm}$ for $14+$ days \\
\hline 1996 & yes & May is within $30 \mathrm{~cm}$ for $14+$ days \\
\hline 1997 & yes & May is within $30 \mathrm{~cm}$ for $14+$ days \\
\hline 1998 & yes & May is within $30 \mathrm{~cm}$ for $14+$ days \\
\hline 1999 & yes & July is within $30 \mathrm{~cm}$ for $14+$ days \\
\hline 2000 & yes & June is within $30 \mathrm{~cm}$ for $14+$ days \\
\hline 2001 & yes & May is within $30 \mathrm{~cm}$ for $14+$ days \\
\hline 2002 & yes & May is within $30 \mathrm{~cm}$ for $14+$ days \\
\hline 2003 & yes & May is within $30 \mathrm{~cm}$ for $14+$ days \\
\hline 2004 & yes & May is within $30 \mathrm{~cm}$ for $14+$ days \\
\hline 2005 & yes & May is within $30 \mathrm{~cm}$ for $14+$ days \\
\hline
\end{tabular}


Table B.19: 45-year record for the DAREM approach for bogwell plot S2 at Marcell. This plot met wetland hydrology in 45 out of 45 years.

\begin{tabular}{|c|c|c|}
\hline Year & $\begin{array}{c}\text { Met/Not } \\
\text { Met }\end{array}$ & Reason Year did or did not meet Wetland Hydrology \\
\hline 1961 & yes & May is within $30 \mathrm{~cm}$ for $14+$ days \\
\hline 1962 & yes & May is within $30 \mathrm{~cm}$ for $14+$ days \\
\hline 1963 & yes & September is within $30 \mathrm{~cm}$ for $14+$ days \\
\hline 1964 & yes & May is within $30 \mathrm{~cm}$ for $14+$ days \\
\hline 1965 & yes & May is within $30 \mathrm{~cm}$ for $14+$ days \\
\hline 1966 & yes & July is within $30 \mathrm{~cm}$ for $14+$ days \\
\hline 1967 & yes & June is within $30 \mathrm{~cm}$ for $14+$ days \\
\hline 1968 & yes & August is within $30 \mathrm{~cm}$ for $14+$ days \\
\hline 1969 & yes & May is within $30 \mathrm{~cm}$ for $14+$ days \\
\hline 1970 & yes & June is within $30 \mathrm{~cm}$ for $14+$ days \\
\hline 1971 & yes & May is within $30 \mathrm{~cm}$ for $14+$ days \\
\hline 1972 & yes & July is within $30 \mathrm{~cm}$ for $14+$ days \\
\hline 1973 & yes & May is within $30 \mathrm{~cm}$ for $14+$ days \\
\hline 1974 & yes & July is within $30 \mathrm{~cm}$ for $14+$ days \\
\hline 1975 & yes & July is within $30 \mathrm{~cm}$ for $14+$ days \\
\hline 1976 & yes & May is within $30 \mathrm{~cm}$ for $14+$ days \\
\hline 1977 & yes & July is within $30 \mathrm{~cm}$ for $14+$ days \\
\hline 1978 & yes & May is within $30 \mathrm{~cm}$ for $14+$ days \\
\hline 1979 & yes & June is within $30 \mathrm{~cm}$ for $14+$ days \\
\hline 1980 & yes & May is within $30 \mathrm{~cm}$ for $14+$ days \\
\hline 1981 & yes & June is within $30 \mathrm{~cm}$ for $14+$ days \\
\hline 1982 & yes & May is within $30 \mathrm{~cm}$ for $14+$ days \\
\hline 1983 & yes & May is within $30 \mathrm{~cm}$ for $14+$ days \\
\hline 1984 & yes & May is within $30 \mathrm{~cm}$ for $14+$ days \\
\hline 1985 & yes & September is within $30 \mathrm{~cm}$ for $14+$ days \\
\hline 1986 & yes & May is within $30 \mathrm{~cm}$ for $14+$ days \\
\hline 1987 & yes & May/June within $30 \mathrm{~cm}$ for $14+$ days \\
\hline 1988 & yes & May is within $30 \mathrm{~cm}$ for $14+$ days \\
\hline 1989 & yes & May is within $30 \mathrm{~cm}$ for $14+$ days \\
\hline 1990 & yes & June is within $30 \mathrm{~cm}$ for $14+$ days \\
\hline 1991 & yes & June is within $30 \mathrm{~cm}$ for $14+$ days \\
\hline 1992 & yes & May is within $30 \mathrm{~cm}$ for $14+$ days \\
\hline 1993 & yes & May is within $30 \mathrm{~cm}$ for $14+$ days \\
\hline 1994 & yes & June is within $30 \mathrm{~cm}$ for $14+$ days \\
\hline 1995 & yes & May is within $30 \mathrm{~cm}$ for $14+$ days \\
\hline 1996 & yes & May is within $30 \mathrm{~cm}$ for $14+$ days \\
\hline 1997 & yes & May is within $30 \mathrm{~cm}$ for $14+$ days \\
\hline 1998 & yes & May is within $30 \mathrm{~cm}$ for $14+$ days \\
\hline 1999 & yes & July is within $30 \mathrm{~cm}$ for $14+$ days \\
\hline 2000 & yes & June is within $30 \mathrm{~cm}$ for $14+$ days \\
\hline 2001 & yes & May is within $30 \mathrm{~cm}$ for $14+$ days \\
\hline 2002 & yes & May is within $30 \mathrm{~cm}$ for $14+$ days \\
\hline 2003 & yes & May is within $30 \mathrm{~cm}$ for $14+$ days \\
\hline 2004 & yes & May is within $30 \mathrm{~cm}$ for $14+$ days \\
\hline 2005 & yes & May is within $30 \mathrm{~cm}$ for $14+$ days \\
\hline
\end{tabular}


Table B.20: 45-year record for the DAREM approach for bogwell plot S3 at Marcell. This plot met wetland hydrology in 22 out of 45 years. There were 2 years that did not meet wetland hydrology because water table saturation occurred during "wet" periods, while 21 years did not meet water table saturation criterion.

\begin{tabular}{|c|c|c|}
\hline Year & $\begin{array}{c}\text { Met/Not } \\
\text { Met }\end{array}$ & Reason Year did or did not meet Wetland Hydrology \\
\hline 1961 & no & water table is not within $30 \mathrm{~cm}$ for $14+$ days \\
\hline 1962 & no & water table is not within $30 \mathrm{~cm}$ for $14+$ days \\
\hline 1963 & no & water table is not within $30 \mathrm{~cm}$ for $14+$ days \\
\hline 1964 & no & water table is not within $30 \mathrm{~cm}$ for $14+$ days \\
\hline 1965 & no & water table is not within $30 \mathrm{~cm}$ for $14+$ days \\
\hline 1966 & yes & August is within $30 \mathrm{~cm}$ for $14+$ days \\
\hline 1967 & no & May - "wet" \\
\hline 1968 & no & water table is not within $30 \mathrm{~cm}$ for $14+$ days \\
\hline 1969 & no & water table is not within $30 \mathrm{~cm}$ for $14+$ days \\
\hline 1970 & no & water table is not within $30 \mathrm{~cm}$ for $14+$ days \\
\hline 1971 & no & water table is not within $30 \mathrm{~cm}$ for $14+$ days \\
\hline 1972 & no & water table is not within $30 \mathrm{~cm}$ for $14+$ days \\
\hline 1973 & no & water table is not within $30 \mathrm{~cm}$ for $14+$ days \\
\hline 1974 & no & water table is not within $30 \mathrm{~cm}$ for $14+$ days \\
\hline 1975 & no & water table is not within $30 \mathrm{~cm}$ for $14+$ days \\
\hline 1976 & no & water table is not within $30 \mathrm{~cm}$ for $14+$ days \\
\hline 1977 & no & water table is not within $30 \mathrm{~cm}$ for $14+$ days \\
\hline 1978 & no & water table is not within $30 \mathrm{~cm}$ for $14+$ days \\
\hline 1979 & no & water table is not within $30 \mathrm{~cm}$ for $14+$ days \\
\hline 1980 & no & water table is not within $30 \mathrm{~cm}$ for $14+$ days \\
\hline 1981 & no & water table is not within $30 \mathrm{~cm}$ for $14+$ days \\
\hline 1982 & yes & May is within $30 \mathrm{~cm}$ for $14+$ days \\
\hline 1983 & yes & May is within $30 \mathrm{~cm}$ for $14+$ days \\
\hline 1984 & no & water table is not within $30 \mathrm{~cm}$ for $14+$ days \\
\hline 1985 & yes & September is within $30 \mathrm{~cm}$ for $14+$ days \\
\hline 1986 & yes & May is within $30 \mathrm{~cm}$ for $14+$ days \\
\hline 1987 & yes & May/June within $30 \mathrm{~cm}$ for $14+$ days \\
\hline 1988 & yes & May is within $30 \mathrm{~cm}$ for $14+$ days \\
\hline 1989 & yes & May is within $30 \mathrm{~cm}$ for $14+$ days \\
\hline 1990 & yes & June is within $30 \mathrm{~cm}$ for $14+$ days \\
\hline 1991 & no & water table is not within $30 \mathrm{~cm}$ for $14+$ days \\
\hline 1992 & no & August - "wet" \\
\hline 1993 & yes & August/September is within $30 \mathrm{~cm}$ for $14+$ days \\
\hline 1994 & yes & June is within $30 \mathrm{~cm}$ for $14+$ days \\
\hline 1995 & yes & May is within $30 \mathrm{~cm}$ for $14+$ days \\
\hline 1996 & yes & May is within $30 \mathrm{~cm}$ for $14+$ days \\
\hline 1997 & yes & May is within $30 \mathrm{~cm}$ for $14+$ days \\
\hline 1998 & yes & May is within $30 \mathrm{~cm}$ for $14+$ days \\
\hline 1999 & yes & July is within $30 \mathrm{~cm}$ for $14+$ days \\
\hline 2000 & yes & June is within $30 \mathrm{~cm}$ for $14+$ days \\
\hline 2001 & yes & May is within $30 \mathrm{~cm}$ for $14+$ days \\
\hline 2002 & yes & May is within $30 \mathrm{~cm}$ for $14+$ days \\
\hline 2003 & yes & May is within $30 \mathrm{~cm}$ for $14+$ days \\
\hline 2004 & yes & May is within $30 \mathrm{~cm}$ for $14+$ days \\
\hline 2005 & yes & May is within $30 \mathrm{~cm}$ for $14+$ days \\
\hline
\end{tabular}


Table B.21: 45-year record for the DAREM approach for bogwell plot S4 at Marcell. This plot met wetland hydrology in 41 out of 44 years. There were 3 years that did not meet wetland hydrology because water table saturation occurred during "wet" periods.

\begin{tabular}{|c|c|c|}
\hline Year & $\begin{array}{c}\text { Met/Not } \\
\text { Met }\end{array}$ & Reason Year did or did not meet Wetland Hydrology \\
\hline 1962 & yes & May is within $30 \mathrm{~cm}$ for $14+$ days \\
\hline 1963 & no & May/June/July/August/Sept - "wet" \\
\hline 1964 & yes & August is within $30 \mathrm{~cm}$ for $14+$ days \\
\hline 1965 & yes & May is within $30 \mathrm{~cm}$ for $14+$ days \\
\hline 1966 & yes & July is within $30 \mathrm{~cm}$ for $14+$ days \\
\hline 1967 & yes & June is within $30 \mathrm{~cm}$ for $14+$ days \\
\hline 1968 & yes & August is within $30 \mathrm{~cm}$ for $14+$ days \\
\hline 1969 & yes & May is within $30 \mathrm{~cm}$ for $14+$ days \\
\hline 1970 & no & May, June - "wet" \\
\hline 1971 & yes & May is within $30 \mathrm{~cm}$ for $14+$ days \\
\hline 1972 & yes & July is within $30 \mathrm{~cm}$ for $14+$ days \\
\hline 1973 & yes & May is within $30 \mathrm{~cm}$ for $14+$ days \\
\hline 1974 & yes & July is within $30 \mathrm{~cm}$ for $14+$ days \\
\hline 1975 & yes & July is within $30 \mathrm{~cm}$ for $14+$ days \\
\hline 1976 & yes & May is within $30 \mathrm{~cm}$ for $14+$ days \\
\hline 1977 & yes & July is within $30 \mathrm{~cm}$ for $14+$ days \\
\hline 1978 & yes & May is within $30 \mathrm{~cm}$ for $14+$ days \\
\hline 1979 & yes & June is within $30 \mathrm{~cm}$ for $14+$ days \\
\hline 1980 & yes & May is within $30 \mathrm{~cm}$ for $14+$ days \\
\hline 1981 & yes & June is within $30 \mathrm{~cm}$ for $14+$ days \\
\hline 1982 & yes & May is within $30 \mathrm{~cm}$ for $14+$ days \\
\hline 1983 & yes & May is within $30 \mathrm{~cm}$ for $14+$ days \\
\hline 1984 & yes & May is within $30 \mathrm{~cm}$ for $14+$ days \\
\hline 1985 & yes & September is within $30 \mathrm{~cm}$ for $14+$ days \\
\hline 1986 & yes & May is within $30 \mathrm{~cm}$ for $14+$ days \\
\hline 1987 & yes & May is within $30 \mathrm{~cm}$ for $14+$ days \\
\hline 1988 & yes & May is within $30 \mathrm{~cm}$ for $14+$ days \\
\hline 1989 & yes & May is within $30 \mathrm{~cm}$ for $14+$ days \\
\hline 1990 & yes & June is within $30 \mathrm{~cm}$ for $14+$ days \\
\hline 1991 & no & May/June/July - "wet" \\
\hline 1992 & yes & May is within $30 \mathrm{~cm}$ for $14+$ days \\
\hline 1993 & yes & May is within $30 \mathrm{~cm}$ for $14+$ days \\
\hline 1994 & yes & June is within $30 \mathrm{~cm}$ for $14+$ days \\
\hline 1995 & yes & May is within $30 \mathrm{~cm}$ for $14+$ days \\
\hline 1996 & yes & May is within $30 \mathrm{~cm}$ for $14+$ days \\
\hline 1997 & yes & May is within $30 \mathrm{~cm}$ for $14+$ days \\
\hline 1998 & yes & May is within $30 \mathrm{~cm}$ for $14+$ days \\
\hline 1999 & yes & July is within $30 \mathrm{~cm}$ for $14+$ days \\
\hline 2000 & yes & May is within $30 \mathrm{~cm}$ for $14+$ days \\
\hline 2001 & yes & May is within $30 \mathrm{~cm}$ for $14+$ days \\
\hline 2002 & yes & May is within $30 \mathrm{~cm}$ for $14+$ days \\
\hline 2003 & yes & May is within $30 \mathrm{~cm}$ for $14+$ days \\
\hline 2004 & yes & May is within $30 \mathrm{~cm}$ for $14+$ days \\
\hline 2005 & yes & May is within $30 \mathrm{~cm}$ for $14+$ days \\
\hline
\end{tabular}


Table B.22: 45-year record for the DAREM approach for bogwell plot S5 at Marcell. This plot met wetland hydrology in 37 out of 44 years. There were 6 years that did not meet wetland hydrology because water table saturation occurred during "wet" periods, while 1 year did not meet water table saturation criterion.

\begin{tabular}{|c|c|c|}
\hline Year & $\begin{array}{c}\text { Met/Not } \\
\text { Met }\end{array}$ & Reason Year did or did not meet Wetland Hydrology \\
\hline 1962 & yes & May is within $30 \mathrm{~cm}$ for $14+$ days \\
\hline 1963 & no & May - "wet" \\
\hline 1964 & no & May/June - "wet" \\
\hline 1965 & yes & May is within $30 \mathrm{~cm}$ for $14+$ days \\
\hline 1966 & yes & August is within $30 \mathrm{~cm}$ for $14+$ days \\
\hline 1967 & yes & June is within $30 \mathrm{~cm}$ for $14+$ days \\
\hline 1968 & no & June - "wet" \\
\hline 1969 & yes & May is within $30 \mathrm{~cm}$ for $14+$ days \\
\hline 1970 & no & May/June - "wet" \\
\hline 1971 & yes & June/July is within $30 \mathrm{~cm}$ for $14+$ days \\
\hline 1972 & yes & July is within $30 \mathrm{~cm}$ for $14+$ days \\
\hline 1973 & yes & May is within $30 \mathrm{~cm}$ for $14+$ days \\
\hline 1974 & no & May/June - "wet" \\
\hline 1975 & yes & July is within $30 \mathrm{~cm}$ for $14+$ days \\
\hline 1976 & no & water table is not within $30 \mathrm{~cm}$ for $14+$ days \\
\hline 1977 & yes & August is within $30 \mathrm{~cm}$ for $14+$ days \\
\hline 1978 & yes & May is within $30 \mathrm{~cm}$ for $14+$ days \\
\hline 1979 & yes & June is within $30 \mathrm{~cm}$ for $14+$ days \\
\hline 1980 & yes & May is within $30 \mathrm{~cm}$ for $14+$ days \\
\hline 1981 & yes & June is within $30 \mathrm{~cm}$ for $14+$ days \\
\hline 1982 & yes & May is within $30 \mathrm{~cm}$ for $14+$ days \\
\hline 1983 & yes & May is within $30 \mathrm{~cm}$ for $14+$ days \\
\hline 1984 & yes & May is within $30 \mathrm{~cm}$ for $14+$ days \\
\hline 1985 & yes & September is within $30 \mathrm{~cm}$ for $14+$ days \\
\hline 1986 & yes & May is within $30 \mathrm{~cm}$ for $14+$ days \\
\hline 1987 & yes & May is within $30 \mathrm{~cm}$ for $14+$ days \\
\hline 1988 & yes & May is within $30 \mathrm{~cm}$ for $14+$ days \\
\hline 1989 & yes & May is within $30 \mathrm{~cm}$ for $14+$ days \\
\hline 1990 & yes & June is within $30 \mathrm{~cm}$ for $14+$ days \\
\hline 1991 & no & May/June - "wet" \\
\hline 1992 & yes & May is within $30 \mathrm{~cm}$ for $14+$ days \\
\hline 1993 & yes & May is within $30 \mathrm{~cm}$ for $14+$ days \\
\hline 1994 & yes & June is within $30 \mathrm{~cm}$ for $14+$ days \\
\hline 1995 & yes & May is within $30 \mathrm{~cm}$ for $14+$ days \\
\hline 1996 & yes & May is within $30 \mathrm{~cm}$ for $14+$ days \\
\hline 1997 & yes & May is within $30 \mathrm{~cm}$ for $14+$ days \\
\hline 1998 & yes & May is within $30 \mathrm{~cm}$ for $14+$ days \\
\hline 1999 & yes & July is within $30 \mathrm{~cm}$ for $14+$ days \\
\hline 2000 & yes & May is within $30 \mathrm{~cm}$ for $14+$ days \\
\hline 2001 & yes & May is within $30 \mathrm{~cm}$ for $14+$ days \\
\hline 2002 & yes & May is within $30 \mathrm{~cm}$ for $14+$ days \\
\hline 2003 & yes & May is within $30 \mathrm{~cm}$ for $14+$ days \\
\hline 2004 & yes & May is within $30 \mathrm{~cm}$ for $14+$ days \\
\hline 2005 & yes & May is within $30 \mathrm{~cm}$ for $14+$ days \\
\hline
\end{tabular}


Table B.23: 45-year record for the DAREM approach for bogwell plot S6 at Marcell. This plot met wetland hydrology in 26 out of 40 years. There were 3 years that did not meet wetland hydrology because water table saturation occurred during "wet" periods, while 11 years did not meet water table saturation criterion.

\begin{tabular}{|c|c|c|}
\hline Year & $\begin{array}{c}\text { Met/Not } \\
\text { Met }\end{array}$ & Reason Year did or did not meet Wetland Hydrology \\
\hline 1961 & no data & \\
\hline 1962 & no data & \\
\hline 1963 & no data & \\
\hline 1964 & no data & \\
\hline 1965 & no & water table not within $30 \mathrm{~cm}$ for $14+$ days \\
\hline 1966 & no & water table not within $30 \mathrm{~cm}$ for $14+$ days \\
\hline 1967 & no & water table not within $30 \mathrm{~cm}$ for $14+$ days \\
\hline 1968 & no & water table not within $30 \mathrm{~cm}$ for $14+$ days \\
\hline 1969 & no & water table not within $30 \mathrm{~cm}$ for $14+$ days \\
\hline 1970 & no & water table not within $30 \mathrm{~cm}$ for $14+$ days \\
\hline 1971 & no & water table not within $30 \mathrm{~cm}$ for $14+$ days \\
\hline 1972 & no & water table not within $30 \mathrm{~cm}$ for $14+$ days \\
\hline 1973 & no & water table not within $30 \mathrm{~cm}$ for $14+$ days \\
\hline 1974 & no & May/June - "wet" \\
\hline 1975 & no data & \\
\hline 1976 & no & water table not within $30 \mathrm{~cm}$ for $14+$ days \\
\hline 1977 & yes & July is within $30 \mathrm{~cm}$ for $14+$ days \\
\hline 1978 & yes & July is within $30 \mathrm{~cm}$ for $14+$ days \\
\hline 1979 & yes & July is within $30 \mathrm{~cm}$ for $14+$ days \\
\hline 1980 & yes & September is within $30 \mathrm{~cm}$ for $14+$ days \\
\hline 1981 & no & May - "wet" \\
\hline 1982 & yes & May is within $30 \mathrm{~cm}$ for $14+$ days \\
\hline 1983 & yes & May is within $30 \mathrm{~cm}$ for $14+$ days \\
\hline 1984 & yes & May is within $30 \mathrm{~cm}$ for $14+$ days \\
\hline 1985 & yes & September is within $30 \mathrm{~cm}$ for $14+$ days \\
\hline 1986 & yes & May is within $30 \mathrm{~cm}$ for $14+$ days \\
\hline 1987 & yes & May/June within $30 \mathrm{~cm}$ for $14+$ days \\
\hline 1988 & yes & May is within $30 \mathrm{~cm}$ for $14+$ days \\
\hline 1989 & yes & June is within $30 \mathrm{~cm}$ for $14+$ days \\
\hline 1990 & yes & June is within $30 \mathrm{~cm}$ for $14+$ days \\
\hline 1991 & no & water table not within $30 \mathrm{~cm}$ for $14+$ days \\
\hline 1992 & no & June/July/August - "wet" \\
\hline 1993 & yes & June is within $30 \mathrm{~cm}$ for $14+$ days \\
\hline 1994 & yes & June is within $30 \mathrm{~cm}$ for $14+$ days \\
\hline 1995 & yes & May is within $30 \mathrm{~cm}$ for $14+$ days \\
\hline 1996 & yes & May is within $30 \mathrm{~cm}$ for $14+$ days \\
\hline 1997 & yes & May is within $30 \mathrm{~cm}$ for $14+$ days \\
\hline 1998 & yes & May is within $30 \mathrm{~cm}$ for $14+$ days \\
\hline 1999 & yes & July is within $30 \mathrm{~cm}$ for $14+$ days \\
\hline 2000 & yes & June is within $30 \mathrm{~cm}$ for $14+$ days \\
\hline 2001 & yes & May is within $30 \mathrm{~cm}$ for $14+$ days \\
\hline 2002 & yes & May is within $30 \mathrm{~cm}$ for $14+$ days \\
\hline 2003 & yes & May is within $30 \mathrm{~cm}$ for $14+$ days \\
\hline 2004 & yes & May is within $30 \mathrm{~cm}$ for $14+$ days \\
\hline 2005 & yes & May is within $30 \mathrm{~cm}$ for $14+$ days \\
\hline
\end{tabular}


Table B.24: 40-year record for modified DAREM approach for plot $1 \mathrm{~L}$ at Greenville. 0 out of 40 years met wetland hydrology, with all years that did not meet water table criterion.

\begin{tabular}{|c|c|c|}
\hline Year & $\begin{array}{c}\text { Met/Not } \\
\text { Met }\end{array}$ & Reason Year did or did not meet Wetland Hydrology \\
\hline 1959 & no & water table not within $30 \mathrm{~cm}$ for $14+$ days \\
\hline 1960 & no & water table not within $30 \mathrm{~cm}$ for $14+$ days \\
\hline 1961 & no & water table not within $30 \mathrm{~cm}$ for $14+$ days \\
\hline 1962 & no & water table not within $30 \mathrm{~cm}$ for $14+$ days \\
\hline 1963 & no & water table not within $30 \mathrm{~cm}$ for $14+$ days \\
\hline 1964 & no & water table not within $30 \mathrm{~cm}$ for $14+$ days \\
\hline 1965 & no & water table not within $30 \mathrm{~cm}$ for $14+$ days \\
\hline 1966 & no & water table not within $30 \mathrm{~cm}$ for $14+$ days \\
\hline 1967 & no & water table not within $30 \mathrm{~cm}$ for $14+$ days \\
\hline 1968 & no & water table not within $30 \mathrm{~cm}$ for $14+$ days \\
\hline 1969 & no & water table not within $30 \mathrm{~cm}$ for $14+$ days \\
\hline 1970 & no & water table not within $30 \mathrm{~cm}$ for $14+$ days \\
\hline 1971 & no & water table not within $30 \mathrm{~cm}$ for $14+$ days \\
\hline 1972 & no & water table not within $30 \mathrm{~cm}$ for $14+$ days \\
\hline 1973 & no & water table not within $30 \mathrm{~cm}$ for $14+$ days \\
\hline 1974 & no & water table not within $30 \mathrm{~cm}$ for $14+$ days \\
\hline 1975 & no & water table not within $30 \mathrm{~cm}$ for $14+$ days \\
\hline 1976 & no & water table not within $30 \mathrm{~cm}$ for $14+$ days \\
\hline 1977 & no & water table not within $30 \mathrm{~cm}$ for $14+$ days \\
\hline 1978 & no & water table not within $30 \mathrm{~cm}$ for $14+$ days \\
\hline 1979 & no & water table not within $30 \mathrm{~cm}$ for $14+$ days \\
\hline 1980 & no & water table not within $30 \mathrm{~cm}$ for $14+$ days \\
\hline 1981 & no & water table not within $30 \mathrm{~cm}$ for $14+$ days \\
\hline 1982 & no & water table not within $30 \mathrm{~cm}$ for $14+$ days \\
\hline 1983 & no & water table not within $30 \mathrm{~cm}$ for $14+$ days \\
\hline 1984 & no & water table not within $30 \mathrm{~cm}$ for $14+$ days \\
\hline 1985 & no & water table not within $30 \mathrm{~cm}$ for $14+$ days \\
\hline 1986 & no & water table not within $30 \mathrm{~cm}$ for $14+$ days \\
\hline 1987 & no & water table not within $30 \mathrm{~cm}$ for $14+$ days \\
\hline 1988 & no & water table not within $30 \mathrm{~cm}$ for $14+$ days \\
\hline 1989 & no & water table not within $30 \mathrm{~cm}$ for $14+$ days \\
\hline 1990 & no & water table not within $30 \mathrm{~cm}$ for $14+$ days \\
\hline 1991 & no & water table not within $30 \mathrm{~cm}$ for $14+$ days \\
\hline 1992 & no & water table not within $30 \mathrm{~cm}$ for $14+$ days \\
\hline 1993 & no & water table not within $30 \mathrm{~cm}$ for $14+$ days \\
\hline 1994 & no & water table not within $30 \mathrm{~cm}$ for $14+$ days \\
\hline 1995 & no & water table not within $30 \mathrm{~cm}$ for $14+$ days \\
\hline 1996 & no & water table not within $30 \mathrm{~cm}$ for $14+$ days \\
\hline 1997 & no & water table not within $30 \mathrm{~cm}$ for $14+$ days \\
\hline 1998 & no & water table not within $30 \mathrm{~cm}$ for $14+$ days \\
\hline
\end{tabular}


Table B.25: 40-year record for modified DAREM approach for plot 2L at Greenville. 0 out of 40 years met wetland hydrology, with 1 year that met water table saturation criterion during a "wet" period and 39 years that did not meet water table criterion.

\begin{tabular}{|c|c|}
\hline $\begin{array}{c}\text { Met/Not } \\
\text { Met }\end{array}$ & Reason Year did or did not meet Wetland Hydrology \\
\hline 1959 no & water table is not within $30 \mathrm{~cm}$ for $14+$ days \\
\hline 1960 no & water table is not within $30 \mathrm{~cm}$ for $14+$ days \\
\hline 1961 no & water table is not within $30 \mathrm{~cm}$ for $14+$ days \\
\hline 1962 no & water table is not within $30 \mathrm{~cm}$ for $14+$ days \\
\hline 1963 no & water table is not within $30 \mathrm{~cm}$ for $14+$ days \\
\hline 1964 no & water table is not within $30 \mathrm{~cm}$ for $14+$ days \\
\hline 1965 no & water table is not within $30 \mathrm{~cm}$ for $14+$ days \\
\hline 1966 no & August - "above normal" \\
\hline 1967 no & water table is not within $30 \mathrm{~cm}$ for $14+$ days \\
\hline 1968 no & water table is not within $30 \mathrm{~cm}$ for $14+$ days \\
\hline 1969 no & water table is not within $30 \mathrm{~cm}$ for $14+$ days \\
\hline 1970 no & water table is not within $30 \mathrm{~cm}$ for $14+$ days \\
\hline 1971 no & water table is not within $30 \mathrm{~cm}$ for $14+$ days \\
\hline 1972 no & water table is not within $30 \mathrm{~cm}$ for $14+$ days \\
\hline 1973 no & water table is not within $30 \mathrm{~cm}$ for $14+$ days \\
\hline 1974 no & water table is not within $30 \mathrm{~cm}$ for $14+$ days \\
\hline 1975 no & water table is not within $30 \mathrm{~cm}$ for $14+$ days \\
\hline 1976 no & water table is not within $30 \mathrm{~cm}$ for $14+$ days \\
\hline 1977 no & water table is not within $30 \mathrm{~cm}$ for $14+$ days \\
\hline 1978 no & water table is not within $30 \mathrm{~cm}$ for $14+$ days \\
\hline 1979 no & water table is not within $30 \mathrm{~cm}$ for $14+$ days \\
\hline 1980 no & water table is not within $30 \mathrm{~cm}$ for $14+$ days \\
\hline 1981 no & water table is not within $30 \mathrm{~cm}$ for $14+$ days \\
\hline 1982 no & water table is not within $30 \mathrm{~cm}$ for $14+$ days \\
\hline 1983 no & water table is not within $30 \mathrm{~cm}$ for $14+$ days \\
\hline 1984 no & water table is not within $30 \mathrm{~cm}$ for $14+$ days \\
\hline 1985 no & water table is not within $30 \mathrm{~cm}$ for $14+$ days \\
\hline 1986 no & water table is not within $30 \mathrm{~cm}$ for $14+$ days \\
\hline 1987 no & water table is not within $30 \mathrm{~cm}$ for $14+$ days \\
\hline 1988 no & water table is not within $30 \mathrm{~cm}$ for $14+$ days \\
\hline 1989 no & water table is not within $30 \mathrm{~cm}$ for $14+$ days \\
\hline 1990 no & water table is not within $30 \mathrm{~cm}$ for $14+$ days \\
\hline 1991 no & water table is not within $30 \mathrm{~cm}$ for $14+$ days \\
\hline 1992 no & water table is not within $30 \mathrm{~cm}$ for $14+$ days \\
\hline 1993 no & water table is not within $30 \mathrm{~cm}$ for $14+$ days \\
\hline 1994 no & water table is not within $30 \mathrm{~cm}$ for $14+$ days \\
\hline 1995 no & water table is not within $30 \mathrm{~cm}$ for $14+$ days \\
\hline 1996 no & water table is not within $30 \mathrm{~cm}$ for $14+$ days \\
\hline 1997 no & water table is not within $30 \mathrm{~cm}$ for $14+$ days \\
\hline 1998 no & water table is not within $30 \mathrm{~cm}$ for $14+$ days \\
\hline
\end{tabular}


Table B.26: 40-year record for modified DAREM approach for plot 3L at Greenville. 0 out of 40 years met wetland hydrology, with 1 year that met water table saturation criterion during a "wet" period and 39 years that did not meet water table criterion.

\begin{tabular}{|c|c|c|}
\hline Year & $\begin{array}{l}\text { Met/Not } \\
\text { Met }\end{array}$ & $\begin{array}{l}\text { Reason Year did or did not meet Wetland } \\
\text { Hydrology }\end{array}$ \\
\hline 1959 & no & water table is not within $30 \mathrm{~cm}$ for $14+$ days \\
\hline 1960 & no & water table is not within $30 \mathrm{~cm}$ for $14+$ days \\
\hline 1961 & no & water table is not within $30 \mathrm{~cm}$ for $14+$ days \\
\hline 1962 & no & water table is not within $30 \mathrm{~cm}$ for $14+$ days \\
\hline 1963 & no & water table is not within $30 \mathrm{~cm}$ for $14+$ days \\
\hline 1964 & no & water table is not within $30 \mathrm{~cm}$ for $14+$ days \\
\hline 1965 & no & water table is not within $30 \mathrm{~cm}$ for $14+$ days \\
\hline 1966 & no & August - "above normal" \\
\hline 1967 & no & water table is not within $30 \mathrm{~cm}$ for $14+$ days \\
\hline 1968 & no & water table is not within $30 \mathrm{~cm}$ for $14+$ days \\
\hline 1969 & no & water table is not within $30 \mathrm{~cm}$ for $14+$ days \\
\hline 1970 & no & water table is not within $30 \mathrm{~cm}$ for $14+$ days \\
\hline 1971 & no & water table is not within $30 \mathrm{~cm}$ for $14+$ days \\
\hline 1972 & no & water table is not within $30 \mathrm{~cm}$ for $14+$ days \\
\hline 1973 & no & water table is not within $30 \mathrm{~cm}$ for $14+$ days \\
\hline 1974 & no & water table is not within $30 \mathrm{~cm}$ for $14+$ days \\
\hline 1975 & no & water table is not within $30 \mathrm{~cm}$ for $14+$ days \\
\hline 1976 & no & water table is not within $30 \mathrm{~cm}$ for $14+$ days \\
\hline 1977 & no & water table is not within $30 \mathrm{~cm}$ for $14+$ days \\
\hline 1978 & no & water table is not within $30 \mathrm{~cm}$ for $14+$ days \\
\hline 1979 & no & water table is not within $30 \mathrm{~cm}$ for $14+$ days \\
\hline 1980 & no & water table is not within $30 \mathrm{~cm}$ for $14+$ days \\
\hline 1981 & no & water table is not within $30 \mathrm{~cm}$ for $14+$ days \\
\hline 1982 & no & water table is not within $30 \mathrm{~cm}$ for $14+$ days \\
\hline 1983 & no & water table is not within $30 \mathrm{~cm}$ for $14+$ days \\
\hline 1984 & no & water table is not within $30 \mathrm{~cm}$ for $14+$ days \\
\hline 1985 & no & water table is not within $30 \mathrm{~cm}$ for $14+$ days \\
\hline 1986 & no & water table is not within $30 \mathrm{~cm}$ for $14+$ days \\
\hline 1987 & no & water table is not within $30 \mathrm{~cm}$ for $14+$ days \\
\hline 1988 & no & water table is not within $30 \mathrm{~cm}$ for $14+$ days \\
\hline 1989 & no & water table is not within $30 \mathrm{~cm}$ for $14+$ days \\
\hline 1990 & no & water table is not within $30 \mathrm{~cm}$ for $14+$ days \\
\hline 1991 & no & water table is not within $30 \mathrm{~cm}$ for $14+$ days \\
\hline 1992 & no & water table is not within $30 \mathrm{~cm}$ for $14+$ days \\
\hline 1993 & no & water table is not within $30 \mathrm{~cm}$ for $14+$ days \\
\hline 1994 & no & water table is not within $30 \mathrm{~cm}$ for $14+$ days \\
\hline 1995 & no & water table is not within $30 \mathrm{~cm}$ for $14+$ days \\
\hline 1996 & no & water table is not within $30 \mathrm{~cm}$ for $14+$ days \\
\hline 1997 & no & water table is not within $30 \mathrm{~cm}$ for $14+$ days \\
\hline 1998 & no & water table is not within $30 \mathrm{~cm}$ for $14+$ days \\
\hline
\end{tabular}


Table B.27: 40-year record for modified DAREM approach for plot $1 \mathrm{~L}$ at Greenville. 0 out of 40 years met wetland hydrology, with all years that did not meet water table criterion.

\begin{tabular}{|c|c|c|}
\hline Year & $\begin{array}{c}\text { Met/Not } \\
\text { Met }\end{array}$ & Reason Year did or did not meet Wetland Hydrology \\
\hline 1959 & no & water table not within $30 \mathrm{~cm}$ for 14+ days \\
\hline 1960 & no & water table not within $30 \mathrm{~cm}$ for $14+$ days \\
\hline 1961 & no & water table not within $30 \mathrm{~cm}$ for $14+$ days \\
\hline 1962 & no & water table not within $30 \mathrm{~cm}$ for $14+$ days \\
\hline 1963 & no & water table not within $30 \mathrm{~cm}$ for $14+$ days \\
\hline 1964 & no & water table not within $30 \mathrm{~cm}$ for $14+$ days \\
\hline 1965 & no & water table not within $30 \mathrm{~cm}$ for $14+$ days \\
\hline 1966 & no & water table not within $30 \mathrm{~cm}$ for $14+$ days \\
\hline 1967 & no & water table not within $30 \mathrm{~cm}$ for $14+$ days \\
\hline 1968 & no & water table not within $30 \mathrm{~cm}$ for $14+$ days \\
\hline 1969 & no & water table not within $30 \mathrm{~cm}$ for $14+$ days \\
\hline 1970 & no & water table not within $30 \mathrm{~cm}$ for $14+$ days \\
\hline 1971 & no & water table not within $30 \mathrm{~cm}$ for $14+$ days \\
\hline 1972 & no & water table not within $30 \mathrm{~cm}$ for $14+$ days \\
\hline 1973 & no & water table not within $30 \mathrm{~cm}$ for $14+$ days \\
\hline 1974 & no & water table not within $30 \mathrm{~cm}$ for $14+$ days \\
\hline 1975 & no & water table not within $30 \mathrm{~cm}$ for $14+$ days \\
\hline 1976 & no & water table not within $30 \mathrm{~cm}$ for $14+$ days \\
\hline 1977 & no & water table not within $30 \mathrm{~cm}$ for $14+$ days \\
\hline 1978 & no & water table not within $30 \mathrm{~cm}$ for $14+$ days \\
\hline 1979 & no & water table not within $30 \mathrm{~cm}$ for $14+$ days \\
\hline 1980 & no & water table not within $30 \mathrm{~cm}$ for $14+$ days \\
\hline 1981 & no & water table not within $30 \mathrm{~cm}$ for $14+$ days \\
\hline 1982 & no & water table not within $30 \mathrm{~cm}$ for $14+$ days \\
\hline 1983 & no & water table not within $30 \mathrm{~cm}$ for $14+$ days \\
\hline 1984 & no & water table not within $30 \mathrm{~cm}$ for $14+$ days \\
\hline 1985 & no & water table not within $30 \mathrm{~cm}$ for $14+$ days \\
\hline 1986 & no & water table not within $30 \mathrm{~cm}$ for $14+$ days \\
\hline 1987 & no & water table not within $30 \mathrm{~cm}$ for $14+$ days \\
\hline 1988 & no & water table not within $30 \mathrm{~cm}$ for $14+$ days \\
\hline 1989 & no & water table not within $30 \mathrm{~cm}$ for $14+$ days \\
\hline 1990 & no & water table not within $30 \mathrm{~cm}$ for $14+$ days \\
\hline 1991 & no & water table not within $30 \mathrm{~cm}$ for $14+$ days \\
\hline 1992 & no & water table not within $30 \mathrm{~cm}$ for $14+$ days \\
\hline 1993 & no & water table not within $30 \mathrm{~cm}$ for $14+$ days \\
\hline 1994 & no & water table not within $30 \mathrm{~cm}$ for $14+$ days \\
\hline 1995 & no & water table not within $30 \mathrm{~cm}$ for $14+$ days \\
\hline 1996 & no & water table not within $30 \mathrm{~cm}$ for $14+$ days \\
\hline 1997 & no & water table not within $30 \mathrm{~cm}$ for $14+$ days \\
\hline 1998 & no & water table not within $30 \mathrm{~cm}$ for $14+$ days \\
\hline
\end{tabular}


Table B.28: 40-year record for modified DAREM for plot $1 \mathrm{R}$ at Greenville. 30 years met wetland hydrology, 5 years met water table saturation criterion during "wet" periods, while 5 years did not meet water table saturation criterion.

\begin{tabular}{|c|c|c|}
\hline Year & $\begin{array}{c}\text { Met/Not } \\
\text { Met }\end{array}$ & Reason Year did or did not meet Wetland Hydrology \\
\hline 1959 & no & March/April - "wet" \\
\hline 1960 & no & April - "wet" \\
\hline 1961 & yes & March - WT is within $30 \mathrm{~cm}$ for 14+ days (starting March 15th) \\
\hline 1962 & yes & March - WT is within $30 \mathrm{~cm}$ for 14+ days (starting March 15th) \\
\hline 1963 & yes & March - WT is within $30 \mathrm{~cm}$ for 14+ days (starting March 15th) \\
\hline 1964 & no & March/April - "wet" \\
\hline 1965 & yes & March - WT is within $30 \mathrm{~cm}$ for 14+ days (starting March 18th - prorated) \\
\hline 1966 & no & August - "wet" \\
\hline 1967 & no & water table is not within $30 \mathrm{~cm}$ for $14+$ days \\
\hline 1968 & yes & March - WT is within $30 \mathrm{~cm}$ for 14+ days (starting March 15th) \\
\hline 1969 & yes & March - WT is within $30 \mathrm{~cm}$ for 14+ days (starting March 15th) \\
\hline 1970 & yes & $\begin{array}{l}\text { March/April - WT is within } 30 \mathrm{~cm} \text { for } 14+\text { days (starting March 20th - } \\
\text { prorated) }\end{array}$ \\
\hline 1971 & yes & October - WT is within $30 \mathrm{~cm}$ for 14+ days (starting October $1 \mathrm{st}$ ) \\
\hline 1972 & yes & March - WT is within $30 \mathrm{~cm}$ for $14+$ days (starting March 17th - prorated) \\
\hline 1973 & yes & March - WT is within $30 \mathrm{~cm}$ for $14+$ days (starting March $15 \mathrm{th}$ ) \\
\hline 1974 & yes & August - WT is within $30 \mathrm{~cm}$ for $14+$ days (starting August 6th) \\
\hline 1975 & yes & March - WT is within $30 \mathrm{~cm}$ for 14+ days (starting March 23rd - prorated) \\
\hline 1976 & no & water table is not within $30 \mathrm{~cm}$ for $14+$ days \\
\hline 1977 & yes & March - WT is within $30 \mathrm{~cm}$ for 14+ days (starting March 15th) \\
\hline 1978 & yes & May - WT is within $30 \mathrm{~cm}$ for $14+$ days (starting May $1 \mathrm{st}$ ) \\
\hline 1979 & yes & March - WT is within $30 \mathrm{~cm}$ for $14+$ days (starting March 15th) \\
\hline 1980 & yes & March - WT is within $30 \mathrm{~cm}$ for 14+ days (starting March 15th) \\
\hline 1981 & no & water table is not within $30 \mathrm{~cm}$ for $14+$ days \\
\hline 1982 & yes & March - WT is within $30 \mathrm{~cm}$ for 14+ days (starting March 15th) \\
\hline 1983 & yes & March - WT is within $30 \mathrm{~cm}$ for $14+$ days (starting March 15th) \\
\hline 1984 & yes & July - WT is within $30 \mathrm{~cm}$ for $14+$ days (starting July 18 th - prorated) \\
\hline 1985 & no & water table is not within $30 \mathrm{~cm}$ for $14+$ days \\
\hline 1986 & yes & August - WT is within $30 \mathrm{~cm}$ for $14+$ days (starting August 12th) \\
\hline 1987 & yes & March - WT is within $30 \mathrm{~cm}$ for $14+$ days (starting March 25th - prorated) \\
\hline 1988 & yes & April - WT is within $30 \mathrm{~cm}$ for $14+$ days (starting April $1 \mathrm{st}$ ) \\
\hline 1989 & yes & March - WT is within $30 \mathrm{~cm}$ for $14+$ days (starting March $15 \mathrm{th}$ ) \\
\hline 1990 & yes & March - WT is within $30 \mathrm{~cm}$ for $14+$ days (starting March 19th - prorated) \\
\hline 1991 & no & water table is not within $30 \mathrm{~cm}$ for $14+$ days \\
\hline 1992 & yes & March - WT is within $30 \mathrm{~cm}$ for $14+$ days (starting March 23rd - prorated) \\
\hline 1993 & yes & March - WT is within $30 \mathrm{~cm}$ for $14+$ days (starting March $15 \mathrm{th}$ ) \\
\hline 1994 & yes & March - WT is within $30 \mathrm{~cm}$ for 14+ days (starting March 15th) \\
\hline 1995 & yes & June - WT is within $30 \mathrm{~cm}$ for $14+$ days (starting June 6 th) \\
\hline 1996 & yes & April - WT is within $30 \mathrm{~cm}$ for $14+$ days (starting April 1st) \\
\hline 1997 & yes & March - WT is within $30 \mathrm{~cm}$ for 14+ days (starting March 15th) \\
\hline 1998 & no & March/April - "wet" \\
\hline
\end{tabular}


Table B.29: 40-year record for modified DAREM approach for plot $2 \mathrm{R}$ at Greenville. 37 out of 40 years met wetland hydrology, 3 years met water table saturation criterion during "wet" periods.

\begin{tabular}{|c|c|c|}
\hline Year & $\begin{array}{c}\text { Met/Not } \\
\text { Met }\end{array}$ & Reason Year did or did not meet Wetland Hydrology \\
\hline 1959 & yes & October - WT is within $30 \mathrm{~cm}$ for $14+$ days (starting October $15 \mathrm{th}$ ) \\
\hline 1960 & no & March/April/May/August - "wet" \\
\hline 1961 & yes & March - WT is within $30 \mathrm{~cm}$ for $14+$ days (starting March 15 th) \\
\hline 1962 & yes & March - WT is within $30 \mathrm{~cm}$ for $14+$ days (starting March $15 \mathrm{th}$ ) \\
\hline 1963 & yes & March - WT is within $30 \mathrm{~cm}$ for $14+$ days (starting March $15 \mathrm{th}$ ) \\
\hline 1964 & no & March/April/May/September/October - "wet" \\
\hline 1965 & yes & March - WT is within $30 \mathrm{~cm}$ for $14+$ days (starting March 15th) \\
\hline 1966 & yes & March - WT is within $30 \mathrm{~cm}$ for 14+ days (starting March 15th) \\
\hline 1967 & yes & March - WT is within $30 \mathrm{~cm}$ for 14+ days (starting March 21st - prorated) \\
\hline 1968 & yes & March - WT is within $30 \mathrm{~cm}$ for $14+$ days (starting March $15 \mathrm{th}$ ) \\
\hline 1969 & yes & March - WT is within $30 \mathrm{~cm}$ for $14+$ days (starting March $15 \mathrm{th}$ ) \\
\hline 1970 & yes & March - WT is within $30 \mathrm{~cm}$ for $14+$ days (starting March 15th) \\
\hline 1971 & yes & March - WT is within $30 \mathrm{~cm}$ for $14+$ days (starting March $15 \mathrm{th}$ ) \\
\hline 1972 & yes & March - WT is within $30 \mathrm{~cm}$ for $14+$ days (starting March $15 \mathrm{th}$ ) \\
\hline 1973 & yes & March - WT is within $30 \mathrm{~cm}$ for $14+$ days (starting March 15th) \\
\hline 1974 & yes & March - WT is within $30 \mathrm{~cm}$ for $14+$ days (starting March $15 \mathrm{th}$ ) \\
\hline 1975 & yes & April - WT is within $30 \mathrm{~cm}$ for $14+$ days (starting April $1 \mathrm{st}$ ) \\
\hline 1976 & yes & March - WT is within $30 \mathrm{~cm}$ for $14+$ days (starting March $15 \mathrm{th}$ ) \\
\hline 1977 & yes & March - WT is within $30 \mathrm{~cm}$ for $14+$ days (starting March 15th) \\
\hline 1978 & yes & March - WT is within $30 \mathrm{~cm}$ for $14+$ days (starting March 15th) \\
\hline 1979 & yes & March - WT is within $30 \mathrm{~cm}$ for $14+$ days (starting March $15 \mathrm{th}$ ) \\
\hline 1980 & yes & March - WT is within $30 \mathrm{~cm}$ for $14+$ days (starting March 15 th) \\
\hline 1981 & yes & March - WT is within $30 \mathrm{~cm}$ for $14+$ days (starting March 15th) \\
\hline 1982 & yes & March - WT is within $30 \mathrm{~cm}$ for $14+$ days (starting March 15 th) \\
\hline 1983 & yes & July - WT is within $30 \mathrm{~cm}$ for $14+$ days (starting July 17 th - prorated) \\
\hline 1984 & yes & March - WT is within $30 \mathrm{~cm}$ for $14+$ days (starting March 15 th) \\
\hline 1985 & yes & March - WT is within $30 \mathrm{~cm}$ for $14+$ days (starting March $15 \mathrm{th}$ ) \\
\hline 1986 & yes & March - WT is within $30 \mathrm{~cm}$ for $14+$ days (starting March 15 th) \\
\hline 1987 & yes & April - WT is within $30 \mathrm{~cm}$ for $14+$ days (starting April 1st) \\
\hline 1988 & yes & March - WT is within $30 \mathrm{~cm}$ for $14+$ days (starting March 15th) \\
\hline 1989 & yes & March - WT is within $30 \mathrm{~cm}$ for $14+$ days (starting March 15th) \\
\hline 1990 & yes & March - WT is within $30 \mathrm{~cm}$ for $14+$ days (starting March $15 \mathrm{th}$ ) \\
\hline 1991 & yes & March - WT is within $30 \mathrm{~cm}$ for $14+$ days (starting March $15 \mathrm{th}$ ) \\
\hline 1992 & yes & March - WT is within $30 \mathrm{~cm}$ for $14+$ days (starting March $15 \mathrm{th}$ ) \\
\hline 1993 & yes & March - WT is within $30 \mathrm{~cm}$ for $14+$ days (starting March 15 th) \\
\hline 1994 & yes & March - WT is within $30 \mathrm{~cm}$ for $14+$ days (starting March $15 \mathrm{th}$ ) \\
\hline 1995 & yes & March - WT is within $30 \mathrm{~cm}$ for $14+$ days (starting March $15 \mathrm{th}$ ) \\
\hline 1996 & yes & March - WT is within $30 \mathrm{~cm}$ for $14+$ days (starting March 15th) \\
\hline 1997 & yes & March - WT is within $30 \mathrm{~cm}$ for $14+$ days (starting March 15th) \\
\hline 1998 & no & March/April/May/September - "wet \\
\hline
\end{tabular}


Table B.30: 40-year record for modified DAREM approach for plot 3R at Greenville. 37 out of 40 years met wetland hydrology, 2 years met water table saturation criterion during "wet" periods and 1 year did not meet water table saturation criterion.

\begin{tabular}{|c|c|c|}
\hline Year & $\begin{array}{c}\text { Met/Not } \\
\text { Met }\end{array}$ & Reason Year did or did not meet Wetland Hydrology \\
\hline 1959 & yes & October - WT is within $30 \mathrm{~cm}$ for $14+$ days (starting October 15th) \\
\hline 1960 & yes & Aug/Sept - WT is within $30 \mathrm{~cm}$ for $14+$ days (starting August $24 \mathrm{th}-$ prorated) \\
\hline 1961 & yes & March - WT is within $30 \mathrm{~cm}$ for $14+$ days (starting March 15 th) \\
\hline 1962 & yes & March - WT is within $30 \mathrm{~cm}$ for 14+ days (starting March 15th) \\
\hline 1963 & yes & March - WT is within $30 \mathrm{~cm}$ for 14+ days (starting March 15th) \\
\hline 1964 & no & March/April/September/October - "wet" \\
\hline 1965 & yes & March - WT is within $30 \mathrm{~cm}$ for $14+$ days (starting March 15 th) \\
\hline 1966 & yes & March - WT is within $30 \mathrm{~cm}$ for $14+$ days (starting March 15th) \\
\hline 1967 & yes & March - WT is within $30 \mathrm{~cm}$ for $14+$ days (starting March $23 \mathrm{rd}-$ prorated) \\
\hline 1968 & yes & March - WT is within $30 \mathrm{~cm}$ for $14+$ days (starting March 15 th) \\
\hline 1969 & yes & March - WT is within $30 \mathrm{~cm}$ for 14+ days (starting March 15th) \\
\hline 1970 & yes & March - WT is within $30 \mathrm{~cm}$ for $14+$ days (starting March 15th) \\
\hline 1971 & yes & March - WT is within $30 \mathrm{~cm}$ for 14+ days (starting March 15th) \\
\hline 1972 & yes & March - WT is within $30 \mathrm{~cm}$ for $14+$ days (starting March $15 \mathrm{th}$ ) \\
\hline 1973 & yes & March - WT is within $30 \mathrm{~cm}$ for 14+ days (starting March 15th) \\
\hline 1974 & yes & March - WT is within $30 \mathrm{~cm}$ for 14+ days (starting March 15th) \\
\hline 1975 & yes & March - WT is within $30 \mathrm{~cm}$ for 14+ days (starting March 15th) \\
\hline 1976 & no & water table is not within $30 \mathrm{~cm}$ for $14+$ days \\
\hline 1977 & yes & March - WT is within $30 \mathrm{~cm}$ for $14+$ days (starting March 15th) \\
\hline 1978 & yes & March - WT is within $30 \mathrm{~cm}$ for $14+$ days (starting March $15 \mathrm{th}$ ) \\
\hline 1979 & yes & March - WT is within $30 \mathrm{~cm}$ for 14+ days (starting March 15th) \\
\hline 1980 & yes & March - WT is within $30 \mathrm{~cm}$ for $14+$ days (starting March $15 \mathrm{th}$ ) \\
\hline 1981 & yes & March - WT is within $30 \mathrm{~cm}$ for $14+$ days (starting March 15th) \\
\hline 1982 & yes & March - WT is within $30 \mathrm{~cm}$ for 14+ days (starting March 15th) \\
\hline 1983 & yes & March - WT is within $30 \mathrm{~cm}$ for $14+$ days (starting March 15 th) \\
\hline 1984 & yes & July - WT is within $30 \mathrm{~cm}$ for $14+$ days (starting July 17 th - prorated) \\
\hline 1985 & yes & March - WT is within $30 \mathrm{~cm}$ for $14+$ days (starting March 15 th) \\
\hline 1986 & yes & March - WT is within $30 \mathrm{~cm}$ for 14+ days (starting March 15th) \\
\hline 1987 & yes & April - WT is within $30 \mathrm{~cm}$ for $14+$ days (starting April 1st) \\
\hline 1988 & yes & March - WT is within $30 \mathrm{~cm}$ for $14+$ days (starting March 15th) \\
\hline 1989 & yes & March - WT is within $30 \mathrm{~cm}$ for 14+ days (starting March 15th) \\
\hline 1990 & yes & March - WT is within $30 \mathrm{~cm}$ for $14+$ days (starting March 15 th) \\
\hline 1991 & yes & March - WT is within $30 \mathrm{~cm}$ for $14+$ days (starting March $15 \mathrm{th}$ ) \\
\hline 1992 & yes & March - WT is within $30 \mathrm{~cm}$ for $14+$ days (starting March 19th - prorated) \\
\hline 1993 & yes & March - WT is within $30 \mathrm{~cm}$ for $14+$ days (starting March $15 \mathrm{th}$ ) \\
\hline 1994 & yes & March - WT is within $30 \mathrm{~cm}$ for 14+ days (starting March 15th) \\
\hline 1995 & yes & March - WT is within $30 \mathrm{~cm}$ for 14+ days (starting March 15th) \\
\hline 1996 & yes & March - WT is within $30 \mathrm{~cm}$ for 14+ days (starting March 15th) \\
\hline 1997 & yes & March - WT is within $30 \mathrm{~cm}$ for $14+$ days (starting March 15 th) \\
\hline 1998 & no & March/April/September - "wet" \\
\hline
\end{tabular}


Table B.31: 40-year record for modified DAREM method for plot 4R at Greenville. 34 out of 40 years met wetland hydrology, with 4 years that met water table saturation criterion during "wet" period and 2 years that did not meet the water table saturation criterion.

\begin{tabular}{|c|c|c|}
\hline Year & $\begin{array}{l}\text { Met/Not } \\
\text { Met }\end{array}$ & Reason Year did or did not meet Wetland Hydrology \\
\hline 1959 & yes & October - WT is within $30 \mathrm{~cm}$ for $14+$ days (starting October $15 \mathrm{th}$ ) \\
\hline 1960 & no & March/April/August - "wet" \\
\hline 1961 & yes & March - WT is within $30 \mathrm{~cm}$ for $14+$ days (starting March $15 \mathrm{th}$ ) \\
\hline 1962 & yes & March - WT is within $30 \mathrm{~cm}$ for $14+$ days (starting March 15th) \\
\hline 1963 & yes & March - WT is within $30 \mathrm{~cm}$ for $14+$ days (starting March 15th) \\
\hline 1964 & no & March/April/August/September - "wet" \\
\hline 1965 & yes & March - WT is within $30 \mathrm{~cm}$ for $14+$ days (starting March $15 \mathrm{th}$ ) \\
\hline 1966 & yes & March - WT is within $30 \mathrm{~cm}$ for $14+$ days (starting March 15th) \\
\hline 1967 & yes & August - WT is within $30 \mathrm{~cm}$ for $14+$ days (starting August 12th) \\
\hline 1968 & yes & March - WT is within $30 \mathrm{~cm}$ for $14+$ days (starting March 15th) \\
\hline 1969 & yes & March - WT is within $30 \mathrm{~cm}$ for $14+$ days (starting March 15th) \\
\hline 1970 & yes & March - WT is within $30 \mathrm{~cm}$ for $14+$ days (starting March 15th) \\
\hline 1971 & yes & March - WT is within $30 \mathrm{~cm}$ for $14+$ days (starting March 15th) \\
\hline 1972 & yes & March - WT is within $30 \mathrm{~cm}$ for $14+$ days (starting March 15th) \\
\hline 1973 & yes & March - WT is within $30 \mathrm{~cm}$ for $14+$ days (starting March 15th) \\
\hline 1974 & yes & March - WT is within $30 \mathrm{~cm}$ for $14+$ days (starting March 15th) \\
\hline 1975 & yes & April - WT is within $30 \mathrm{~cm}$ for $14+$ days (starting April 1st) \\
\hline 1976 & no & water table is not within $30 \mathrm{~cm}$ for $14+$ days \\
\hline 1977 & yes & March - WT is within $30 \mathrm{~cm}$ for $14+$ days (starting March 15th) \\
\hline 1978 & yes & March - WT is within $30 \mathrm{~cm}$ for $14+$ days (starting March $15 \mathrm{th}$ ) \\
\hline 1979 & yes & March - WT is within $30 \mathrm{~cm}$ for $14+$ days (starting March 15th) \\
\hline 1980 & yes & March - WT is within $30 \mathrm{~cm}$ for $14+$ days (starting March 15th) \\
\hline 1981 & no & August - "wet" \\
\hline 1982 & yes & March - WT is within $30 \mathrm{~cm}$ for $14+$ days (starting March 15th) \\
\hline 1983 & yes & March - WT is within $30 \mathrm{~cm}$ for $14+$ days (starting March 15th) \\
\hline 1984 & yes & July - WT is within $30 \mathrm{~cm}$ for $14+$ days (starting July 17 th - prorated) \\
\hline 1985 & no & water table is not within $30 \mathrm{~cm}$ for $14+$ days \\
\hline 1986 & yes & March - WT is within $30 \mathrm{~cm}$ for $14+$ days (starting March $15 \mathrm{th}$ ) \\
\hline 1987 & yes & April - WT is within $30 \mathrm{~cm}$ for $14+$ days (starting April 1st) \\
\hline 1988 & yes & March - WT is within $30 \mathrm{~cm}$ for $14+$ days (starting March $15 \mathrm{th}$ ) \\
\hline 1989 & yes & March - WT is within $30 \mathrm{~cm}$ for $14+$ days (starting March 15th) \\
\hline 1990 & yes & March - WT is within $30 \mathrm{~cm}$ for $14+$ days (starting March 15th) \\
\hline 1991 & yes & March - WT is within $30 \mathrm{~cm}$ for $14+$ days (starting March $15 \mathrm{th}$ ) \\
\hline 1992 & yes & $\begin{array}{l}\text { March - WT is within } 30 \mathrm{~cm} \text { for 14+ days (starting March 19th - } \\
\text { prorated) }\end{array}$ \\
\hline 1993 & yes & March - WT is within $30 \mathrm{~cm}$ for $14+$ days (starting March $15 \mathrm{th}$ ) \\
\hline 1994 & yes & March - WT is within $30 \mathrm{~cm}$ for $14+$ days (starting March 15th) \\
\hline 1995 & yes & March - WT is within $30 \mathrm{~cm}$ for $14+$ days (starting March 15th) \\
\hline 1996 & yes & March - WT is within $30 \mathrm{~cm}$ for $14+$ days (starting March 15th) \\
\hline 1997 & yes & March - WT is within $30 \mathrm{~cm}$ for $14+$ days (starting March $15 \mathrm{th}$ ) \\
\hline 1998 & no & March/April/May/August/September - "wet" \\
\hline
\end{tabular}


Table B.32: 40-year record for modified DAREM approach for plot 4P at Greenville. 37 out of 40 years met wetland hydrology, with 2 years that met water table saturation criterion during "wet" periods and 1 year that did not meet the water table saturation criteria.

\begin{tabular}{|c|c|c|}
\hline Year & Met/Not Met & Reason Year did or did not meet Wetland Hydrology \\
\hline 1959 & yes & July - WT is within $30 \mathrm{~cm}$ for 14+ days (starting July 15th) \\
\hline 1960 & yes & May - WT is within $30 \mathrm{~cm}$ for 14+ days (starting May 1st) \\
\hline 1961 & yes & March - WT is within $30 \mathrm{~cm}$ for $14+$ days (starting March 15th) \\
\hline 1962 & yes & March - WT is within $30 \mathrm{~cm}$ for $14+$ days (starting March 15th) \\
\hline 1963 & yes & March - WT is within $30 \mathrm{~cm}$ for $14+$ days (starting March $15 \mathrm{th}$ ) \\
\hline 1964 & no & March, April, August/September - "wet" \\
\hline 1965 & yes & March - WT is within $30 \mathrm{~cm}$ for $14+$ days (starting March $15 \mathrm{th}$ ) \\
\hline 1966 & yes & March - WT is within $30 \mathrm{~cm}$ for $14+$ days (starting March 15 th) \\
\hline 1967 & yes & $\begin{array}{l}\text { March/August - WT is within } 30 \mathrm{~cm} \text { for } 14+\text { days (starting March } \\
\text { 23rd - prorated) (August 11th) }\end{array}$ \\
\hline 1968 & yes & March - WT is within $30 \mathrm{~cm}$ for $14+$ days (starting March 15th) \\
\hline 1969 & yes & March - WT is within $30 \mathrm{~cm}$ for $14+$ days (starting March 15 th) \\
\hline 1970 & yes & March - WT is within $30 \mathrm{~cm}$ for $14+$ days (starting March 15 th) \\
\hline 1971 & yes & March - WT is within $30 \mathrm{~cm}$ for $14+$ days (starting March 15 th) \\
\hline 1972 & yes & March - WT is within $30 \mathrm{~cm}$ for 14+ days (starting March 15th) \\
\hline 1973 & yes & March - WT is within $30 \mathrm{~cm}$ for $14+$ days (starting March 15th) \\
\hline 1974 & yes & March - WT is within $30 \mathrm{~cm}$ for $14+$ days (starting March 15 th) \\
\hline 1975 & yes & April - WT is within $30 \mathrm{~cm}$ for 14+ days (starting April 1st) \\
\hline 1976 & no & water table is not within $30 \mathrm{~cm}$ for $14+$ days \\
\hline 1977 & yes & March - WT is within $30 \mathrm{~cm}$ for 14+ days (starting March 15th) \\
\hline 1978 & yes & March - WT is within $30 \mathrm{~cm}$ for 14+ days (starting March 15th) \\
\hline 1979 & yes & March - WT is within $30 \mathrm{~cm}$ for $14+$ days (starting March 15 th) \\
\hline 1980 & yes & March - WT is within $30 \mathrm{~cm}$ for 14+ days (starting March 15th) \\
\hline 1981 & yes & March - WT is within $30 \mathrm{~cm}$ for $14+$ days (starting March 15 th) \\
\hline 1982 & yes & March - WT is within $30 \mathrm{~cm}$ for 14+ days (starting March 15th) \\
\hline 1983 & yes & March - WT is within $30 \mathrm{~cm}$ for 14+ days (starting March 15th) \\
\hline 1984 & yes & $\begin{array}{l}\text { September - WT is within } 30 \mathrm{~cm} \text { for } 14+\text { days (starting September } \\
\text { 13th) }\end{array}$ \\
\hline 1985 & yes & March - WT is within $30 \mathrm{~cm}$ for $14+$ days (starting March 15th) \\
\hline 1986 & yes & March - WT is within $30 \mathrm{~cm}$ for $14+$ days (starting March 15 th) \\
\hline 1987 & yes & April - WT is within $30 \mathrm{~cm}$ for $14+$ days (starting April 1st) \\
\hline 1988 & yes & March - WT is within $30 \mathrm{~cm}$ for 14+ days (starting March 15th) \\
\hline 1989 & yes & March - WT is within $30 \mathrm{~cm}$ for 14+ days (starting March 15th) \\
\hline 1990 & yes & March - WT is within $30 \mathrm{~cm}$ for 14+ days (starting March 15th) \\
\hline 1991 & yes & March - WT is within $30 \mathrm{~cm}$ for $14+$ days (starting March 15 th) \\
\hline 1992 & yes & March - WT is within $30 \mathrm{~cm}$ for 14+ days (starting March 15th) \\
\hline 1993 & yes & March - WT is within $30 \mathrm{~cm}$ for 14+ days (starting March 15th) \\
\hline 1994 & yes & March - WT is within $30 \mathrm{~cm}$ for $14+$ days (starting March $15 \mathrm{th}$ ) \\
\hline 1995 & yes & March - WT is within $30 \mathrm{~cm}$ for 14+ days (starting March 15th) \\
\hline 1996 & yes & March - WT is within $30 \mathrm{~cm}$ for 14+ days (starting March 15th) \\
\hline 1997 & yes & March - WT is within $30 \mathrm{~cm}$ for $14+$ days (starting March 15 th) \\
\hline 1998 & no & March, April, August/September - "wet" \\
\hline
\end{tabular}


Table B.33: 45-year record for modified DAREM approach for plot $2 \mathrm{~N}$ at Bertie. 1 out of 45 years met wetland hydrology, 4 years met water table criterion during "wet" periods while 40 years did not meet water table

\begin{tabular}{|c|c|c|}
\hline Year & Met/Not Met & Reason Year did or did not meet Wetland Hydrology \\
\hline 1950 & no & July - "wet" \\
\hline 1951 & no & water table not within $30 \mathrm{~cm}$ for $14+$ days \\
\hline 1952 & no & water table not within $30 \mathrm{~cm}$ for $14+$ days \\
\hline 1953 & no & water table not within $30 \mathrm{~cm}$ for $14+$ days \\
\hline 1954 & no & water table not within $30 \mathrm{~cm}$ for $14+$ days \\
\hline 1955 & no & water table not within $30 \mathrm{~cm}$ for $14+$ days \\
\hline 1956 & no & water table not within $30 \mathrm{~cm}$ for $14+$ days \\
\hline 1957 & no & water table not within $30 \mathrm{~cm}$ for $14+$ days \\
\hline 1958 & no & water table not within $30 \mathrm{~cm}$ for $14+$ days \\
\hline 1959 & no & water table not within $30 \mathrm{~cm}$ for $14+$ days \\
\hline 1960 & no & water table not within $30 \mathrm{~cm}$ for $14+$ days \\
\hline 1961 & no & water table not within $30 \mathrm{~cm}$ for $14+$ days \\
\hline 1962 & no & water table not within $30 \mathrm{~cm}$ for $14+$ days \\
\hline 1963 & no & water table not within $30 \mathrm{~cm}$ for $14+$ days \\
\hline 1964 & no & water table not within $30 \mathrm{~cm}$ for $14+$ days \\
\hline 1965 & no & water table not within $30 \mathrm{~cm}$ for $14+$ days \\
\hline 1966 & yes & May - WT is within $30 \mathrm{~cm}$ for $14+$ days (starting May 22nd - prorated) \\
\hline 1967 & no & water table not within $30 \mathrm{~cm}$ for $14+$ days \\
\hline 1968 & no & water table not within $30 \mathrm{~cm}$ for $14+$ days \\
\hline 1969 & no & water table not within $30 \mathrm{~cm}$ for $14+$ days \\
\hline 1970 & no & water table not within $30 \mathrm{~cm}$ for $14+$ days \\
\hline 1971 & no & water table not within $30 \mathrm{~cm}$ for $14+$ days \\
\hline 1972 & no & water table not within $30 \mathrm{~cm}$ for $14+$ days \\
\hline 1973 & no & April - "wet" \\
\hline 1974 & no & water table not within $30 \mathrm{~cm}$ for $14+$ days \\
\hline 1975 & no & water table not within $30 \mathrm{~cm}$ for $14+$ days \\
\hline 1976 & no & water table not within $30 \mathrm{~cm}$ for $14+$ days \\
\hline 1977 & no & water table not within $30 \mathrm{~cm}$ for $14+$ days \\
\hline 1978 & no & May - "wet" \\
\hline 1979 & no & water table not within $30 \mathrm{~cm}$ for $14+$ days \\
\hline 1980 & no & water table not within $30 \mathrm{~cm}$ for $14+$ days \\
\hline 1981 & no & water table not within $30 \mathrm{~cm}$ for $14+$ days \\
\hline 1982 & no & water table not within $30 \mathrm{~cm}$ for $14+$ days \\
\hline 1983 & no & March, April - "wet" \\
\hline 1984 & no & water table not within $30 \mathrm{~cm}$ for $14+$ days \\
\hline 1985 & no & water table not within $30 \mathrm{~cm}$ for $14+$ days \\
\hline 1986 & no & water table not within $30 \mathrm{~cm}$ for $14+$ days \\
\hline 1987 & no & water table not within $30 \mathrm{~cm}$ for $14+$ days \\
\hline 1988 & no & water table not within $30 \mathrm{~cm}$ for $14+$ days \\
\hline 1989 & no & water table not within $30 \mathrm{~cm}$ for $14+$ days \\
\hline 1990 & no & water table not within $30 \mathrm{~cm}$ for $14+$ days \\
\hline 1991 & no & water table not within $30 \mathrm{~cm}$ for $14+$ days \\
\hline 1992 & no & water table not within $30 \mathrm{~cm}$ for $14+$ days \\
\hline 1993 & no & water table not within $30 \mathrm{~cm}$ for $14+$ days \\
\hline 1994 & no & water table not within $30 \mathrm{~cm}$ for $14+$ days \\
\hline
\end{tabular}


Table B.34: 45-year record for modified DAREM approach for plot $3 \mathrm{~N}$ at Bertie. 28 out of 45 years met wetland hydrology, 9 years met water table criterion during "wet" periods while 8 years did not meet water table criterion.

\begin{tabular}{|c|c|c|}
\hline Year & Met/Not Met & Reason Year did or did not meet Wetland Hydrology \\
\hline 1950 & yes & September - WT within $30 \mathrm{~cm}$ for 14+ days (starting September 10th) \\
\hline 1951 & yes & March - WT within $30 \mathrm{~cm}$ for $14+$ days (starting March 22nd - prorated) \\
\hline 1952 & yes & March - WT within $30 \mathrm{~cm}$ for $14+$ days (starting March 22nd - prorated) \\
\hline 1953 & no & water table is not within $30 \mathrm{~cm}$ for $14+$ days \\
\hline 1954 & yes & March - WT within $30 \mathrm{~cm}$ for 14+ days (starting March 22nd - prorated) \\
\hline 1955 & no & August/September - "wet" \\
\hline 1956 & yes & March - WT within $30 \mathrm{~cm}$ for $14+$ days (starting March 22nd - prorated) \\
\hline 1957 & no & March/April - "wet" \\
\hline 1958 & yes & March - WT within $30 \mathrm{~cm}$ for 14+ days (starting March 22nd - prorated) \\
\hline 1959 & yes & March - WT within $30 \mathrm{~cm}$ for $14+$ days (starting March 22nd - prorated) \\
\hline 1960 & yes & September - WT within $30 \mathrm{~cm}$ for 14+ days (starting September 12th) \\
\hline 1961 & yes & March - WT within $30 \mathrm{~cm}$ for $14+$ days (starting March 22nd - prorated) \\
\hline 1962 & yes & March - WT within $30 \mathrm{~cm}$ for $14+$ days (starting March 22nd - prorated) \\
\hline 1963 & no & water table is not within $30 \mathrm{~cm}$ for $14+$ days \\
\hline 1964 & yes & September - WT is within $30 \mathrm{~cm}$ for $14+$ days (starting Sept $13^{\text {th }}$ ) \\
\hline 1965 & yes & March - WT within $30 \mathrm{~cm}$ for 14+ days (starting March 22nd - prorated) \\
\hline 1966 & yes & May - WT is within $30 \mathrm{~cm}$ for $14+$ days (starting May 20th - prorated) \\
\hline 1967 & yes & August - WT is within $30 \mathrm{~cm}$ for $14+$ days (starting August 11th) \\
\hline 1968 & yes & April - WT is within $30 \mathrm{~cm}$ for $14+$ days (starting April 6th) \\
\hline 1969 & yes & March - WT within $30 \mathrm{~cm}$ for $14+$ days (starting March 22nd - prorated) \\
\hline 1970 & yes & March - WT within $30 \mathrm{~cm}$ for $14+$ days (starting March 22nd - prorated) \\
\hline 1971 & yes & May - WT is within $30 \mathrm{~cm}$ for 14+ days (starting May 13th) \\
\hline 1972 & yes & May - WT is within $30 \mathrm{~cm}$ for $14+$ days (starting May 4th) \\
\hline 1973 & no & March/April/May - "wet" \\
\hline 1974 & no & March/April/May/September - "wet" \\
\hline 1975 & no & March/April - "wet" \\
\hline 1976 & no & water table is not within $30 \mathrm{~cm}$ for $14+$ days \\
\hline 1977 & yes & March - WT within $30 \mathrm{~cm}$ for 14+ days (starting March 22nd - prorated) \\
\hline 1978 & yes & March - WT within $30 \mathrm{~cm}$ for $14+$ days (starting March 22nd - prorated) \\
\hline 1979 & no & March/April/May - "wet" \\
\hline 1980 & no & March/April/May - "wet" \\
\hline 1981 & no & water table is not within $30 \mathrm{~cm}$ for $14+$ days \\
\hline 1982 & no & water table is not within $30 \mathrm{~cm}$ for $14+$ days \\
\hline 1983 & no & March/April/May - "wet" \\
\hline 1984 & yes & July - WT is within $30 \mathrm{~cm}$ for $14+$ days (starting July 18 th - prorated) \\
\hline 1985 & no & water table is not within $30 \mathrm{~cm}$ for $14+$ days \\
\hline 1986 & no & water table is not within $30 \mathrm{~cm}$ for $14+$ days \\
\hline 1987 & yes & March - WT within $30 \mathrm{~cm}$ for $14+$ days (starting March 22nd - prorated) \\
\hline 1988 & yes & April - WT is within $30 \mathrm{~cm}$ for 14+ days (starting April 12th) \\
\hline 1989 & yes & March - WT within $30 \mathrm{~cm}$ for $14+$ days (starting March 22nd - prorated) \\
\hline 1990 & yes & March - WT within $30 \mathrm{~cm}$ for 14+ days (starting March 29th - prorated) \\
\hline 1991 & yes & July - WT is within $30 \mathrm{~cm}$ for $14+$ days (starting July 26 th - prorated) \\
\hline 1992 & no & water table is not within $30 \mathrm{~cm}$ for $14+$ days \\
\hline 1993 & yes & March - WT within $30 \mathrm{~cm}$ for $14+$ days (starting March 22nd - prorated) \\
\hline 1994 & yes & October - WT is within $30 \mathrm{~cm}$ for $14+$ days (starting October $1 \mathrm{st}$ ) \\
\hline
\end{tabular}


Table B.35: 45-year record for modified DAREM approach for plot $4 \mathrm{~N}$ at Bertie. 36 out of 45 years met wetland hydrology, 7 years met water table criterion during "wet" periods while 2 years did not meet water table criterion.

\begin{tabular}{|c|c|c|}
\hline Year & $\begin{array}{c}\text { Met/Not } \\
\text { Met }\end{array}$ & Reason Year did or did not meet Wetland Hydrology \\
\hline 1950 & yes & September - WT is within $30 \mathrm{~cm}$ for $14+$ days (starting September 10th) \\
\hline 1951 & yes & March - WT is within $30 \mathrm{~cm}$ for $14+$ days (starting March 22nd - prorated) \\
\hline 1952 & yes & March - WT is within $30 \mathrm{~cm}$ for 14+ days (starting March 22nd - prorated) \\
\hline 1953 & yes & August - WT is within $30 \mathrm{~cm}$ for $14+$ days (starting August 14th) \\
\hline 1954 & yes & March - WT is within $30 \mathrm{~cm}$ for $14+$ days (starting March 22nd - prorated) \\
\hline 1955 & yes & August - WT is within $30 \mathrm{~cm}$ for $14+$ days (starting August 12th) \\
\hline 1956 & yes & March - WT is within $30 \mathrm{~cm}$ for $14+$ days (starting March 22nd - prorated) \\
\hline 1957 & no & March/April - "wet" \\
\hline 1958 & yes & March - WT is within $30 \mathrm{~cm}$ for $14+$ days (starting March 22nd - prorated) \\
\hline 1959 & yes & March - WT is within $30 \mathrm{~cm}$ for $14+$ days (starting March 22nd - prorated) \\
\hline 1960 & yes & September - WT is within $30 \mathrm{~cm}$ for 14+ days (starting September 11th) \\
\hline 1961 & yes & March - WT is within $30 \mathrm{~cm}$ for $14+$ days (starting March 22nd - prorated) \\
\hline 1962 & yes & March - WT is within $30 \mathrm{~cm}$ for $14+$ days (starting March 22nd - prorated) \\
\hline 1963 & yes & water table is not within $30 \mathrm{~cm}$ for $14+$ days \\
\hline 1964 & yes & September - WT is within $30 \mathrm{~cm}$ for 14+ days (starting September 13th) \\
\hline 1965 & yes & March - WT is within $30 \mathrm{~cm}$ for $14+$ days (starting March 22nd - prorated) \\
\hline 1966 & yes & May - WT is within $30 \mathrm{~cm}$ for $14+$ days (starting May 20th - prorated) \\
\hline 1967 & yes & July - WT is within $30 \mathrm{~cm}$ for $14+$ days (starting July 16 th - prorated) \\
\hline 1968 & no & March/April/May - "wet" \\
\hline 1969 & yes & March - WT is within $30 \mathrm{~cm}$ for 14+ days (starting March 22nd - prorated) \\
\hline 1970 & yes & March - WT is within $30 \mathrm{~cm}$ for $14+$ days (starting March 22nd - prorated) \\
\hline 1971 & yes & May - WT is within $30 \mathrm{~cm}$ for $14+$ days (starting May $13 \mathrm{th}$ ) \\
\hline 1972 & yes & May - WT is within $30 \mathrm{~cm}$ for $14+$ days (starting May 4th) \\
\hline 1973 & yes & August - WT is within $30 \mathrm{~cm}$ for $14+$ days (starting August 12th) \\
\hline 1974 & yes & August - WT is within $30 \mathrm{~cm}$ for 14+ days (starting August 2nd) \\
\hline 1975 & yes & July - WT is within $30 \mathrm{~cm}$ for $14+$ days (starting July 16 th - prorated) \\
\hline 1976 & no & July - "wet" \\
\hline 1977 & yes & March - WT is within $30 \mathrm{~cm}$ for $14+$ days (starting March 22nd - prorated) \\
\hline 1978 & yes & March - WT is within $30 \mathrm{~cm}$ for $14+$ days (starting March 22nd - prorated) \\
\hline 1979 & yes & September - WT is within $30 \mathrm{~cm}$ for $14+$ days (starting September 25 th - prorated) \\
\hline 1980 & no & March/April/May - "wet" \\
\hline 1981 & yes & March - WT is within $30 \mathrm{~cm}$ for 14+ days (starting March 22nd - prorated) \\
\hline 1982 & no & water table is not within $30 \mathrm{~cm}$ for $14+$ days \\
\hline 1983 & no & March/April/May - "wet" \\
\hline 1984 & yes & July - WT is within $30 \mathrm{~cm}$ for $14+$ days (starting July 14 th) \\
\hline 1985 & no & October - "wet" \\
\hline 1986 & no & August - "wet" \\
\hline 1987 & yes & March - WT is within $30 \mathrm{~cm}$ for $14+$ days (starting March 22nd - prorated) \\
\hline 1988 & yes & April - WT is within $30 \mathrm{~cm}$ for $14+$ days (starting April 12th) \\
\hline 1989 & yes & March - WT is within $30 \mathrm{~cm}$ for $14+$ days (starting March 22nd - prorated) \\
\hline 1990 & yes & April - WT is within $30 \mathrm{~cm}$ for $14+$ days (starting April 1st) \\
\hline 1991 & yes & August - WT is within $30 \mathrm{~cm}$ for 14+ days (starting August 1st) \\
\hline 1992 & yes & August - WT is within $30 \mathrm{~cm}$ for $14+$ days (starting August $15 \mathrm{th}$ ) \\
\hline 1993 & yes & March - WT is within $30 \mathrm{~cm}$ for $14+$ days (starting March $22^{\text {nd }}-$ prorated) \\
\hline 1994 & yes & August - WT is within $30 \mathrm{~cm}$ for $14+$ days (starting August $1^{\text {st }}$ ) \\
\hline
\end{tabular}


Table B.36: 45 -year record for modified DAREM approach for plot $5 \mathrm{~N}$ at Bertie. 38 out of 45 years met wetland hydrology, 6 years met water table criterion during "wet" periods while 1 year did not meet water table criterion.

\begin{tabular}{|c|c|c|}
\hline Year & $\begin{array}{c}\text { Met/Not } \\
\text { Met }\end{array}$ & Reason Year did or did not meet Wetland Hydrology \\
\hline 1950 & yes & September - WT is within $30 \mathrm{~cm}$ for $14+$ days (starting September $10^{\text {th }}$ ) \\
\hline 1951 & yes & March - WT is within $30 \mathrm{~cm}$ for $14+$ days (starting March $22^{\text {nd }}-$ prorated) \\
\hline 1952 & yes & March - WT is within $30 \mathrm{~cm}$ for $14+$ days (starting March $22^{\text {nd }}-$ prorated) \\
\hline 1953 & yes & August $-\mathrm{WT}$ is within $30 \mathrm{~cm}$ for $14+$ days (starting August $14^{\text {th }}$ ) \\
\hline 1954 & yes & March - WT is within $30 \mathrm{~cm}$ for $14+$ days (starting March $22^{\text {nd }}-$ prorated) \\
\hline 1955 & yes & August $-\mathrm{WT}$ is within $30 \mathrm{~cm}$ for $14+$ days (starting August $12^{\text {th }}$ ) \\
\hline 1956 & yes & March - WT is within $30 \mathrm{~cm}$ for $14+$ days (starting March $22^{\text {nd }}-$ prorated) \\
\hline 1957 & no & March/April - "wet" \\
\hline 1958 & yes & March - WT is within $30 \mathrm{~cm}$ for $14+$ days (starting March $22^{\text {nd }}-$ prorated) \\
\hline 1959 & yes & March - WT is within $30 \mathrm{~cm}$ for $14+$ days (starting March $22^{\text {nd }}-$ prorated) \\
\hline 1960 & yes & September - WT is within $30 \mathrm{~cm}$ for $14+$ days (starting September $11^{\text {th }}$ ) \\
\hline 1961 & yes & March - WT is within $30 \mathrm{~cm}$ for $14+$ days (starting March $22^{\text {nd }}-$ prorated) \\
\hline 1962 & yes & March - WT is within $30 \mathrm{~cm}$ for $14+$ days (starting March $22^{\text {nd }}-$ prorated) \\
\hline 1963 & no & water table is not within $30 \mathrm{~cm}$ for $14+$ days \\
\hline 1964 & yes & September - WT is within $30 \mathrm{~cm}$ for $14+$ days (starting September $13^{\text {th }}$ ) \\
\hline 1965 & yes & March - WT is within $30 \mathrm{~cm}$ for $14+$ days (starting March $22^{\text {nd }}-$ prorated) \\
\hline 1966 & yes & May $-\mathrm{WT}$ is within $30 \mathrm{~cm}$ for $14+$ days (starting May $20^{\text {th }}-$ prorated) \\
\hline 1967 & yes & July - WT is within $30 \mathrm{~cm}$ for $14+$ days (starting July $16^{\text {th }}-$ prorated) \\
\hline 1968 & no & March/April/May - "wet" \\
\hline 1969 & yes & March - WT is within $30 \mathrm{~cm}$ for $14+$ days (starting March $22^{\text {nd }}-$ prorated) \\
\hline 1970 & yes & March - WT is within $30 \mathrm{~cm}$ for $14+$ days (starting March $22^{\text {nd }}-$ prorated) \\
\hline 1971 & yes & May - WT is within $30 \mathrm{~cm}$ for $14+$ days (starting May $13^{\text {th }}$ ) \\
\hline 1972 & yes & May - WT is within $30 \mathrm{~cm}$ for $14+$ days (starting May $4^{\text {th }}$ ) \\
\hline 1973 & yes & August $-\mathrm{WT}$ is within $30 \mathrm{~cm}$ for $14+$ days (starting August $12^{\text {th }}$ ) \\
\hline 1974 & yes & August $-\mathrm{WT}$ is within $30 \mathrm{~cm}$ for $14+$ days (starting August $2^{\text {nd }}$ ) \\
\hline 1975 & yes & July - WT is within $30 \mathrm{~cm}$ for $14+$ days (starting July $16^{\text {th }}-$ prorated) \\
\hline 1976 & no & July - "wet" \\
\hline 1977 & yes & March - WT is within $30 \mathrm{~cm}$ for $14+$ days (starting March $22^{\text {nd }}-$ prorated) \\
\hline 1978 & yes & March - WT is within $30 \mathrm{~cm}$ for $14+$ days (starting March $22^{\text {nd }}-$ prorated) \\
\hline 1979 & yes & September - WT is within $30 \mathrm{~cm}$ for $14+$ days (starting September $25^{\text {th }}-$ prorated) \\
\hline 1980 & no & March/April/May - "wet" \\
\hline 1981 & yes & March - WT is within $30 \mathrm{~cm}$ for $14+$ days (starting March $22^{\text {nd }}-$ prorated) \\
\hline 1982 & no & water table is not within $30 \mathrm{~cm}$ for $14+$ days \\
\hline 1983 & no & March/April/May - "wet" \\
\hline 1984 & yes & July - WT is within $30 \mathrm{~cm}$ for $14+$ days (starting July $14^{\text {th }}$ ) \\
\hline 1985 & no & October - "wet" \\
\hline 1986 & no & August - "wet" \\
\hline 1987 & yes & March - WT is within $30 \mathrm{~cm}$ for $14+$ days (starting March $22^{\text {nd }}-$ prorated) \\
\hline 1988 & yes & April - WT is within $30 \mathrm{~cm}$ for $14+$ days (starting April $12^{\text {th }}$ ) \\
\hline 1989 & yes & March - WT is within $30 \mathrm{~cm}$ for $14+$ days (starting March $22^{\text {nd }}-$ prorated) \\
\hline 1990 & yes & April - WT is within $30 \mathrm{~cm}$ for $14+$ days (starting April $1^{\text {st }}$ ) \\
\hline 1991 & yes & August $-\mathrm{WT}$ is within $30 \mathrm{~cm}$ for $14+$ days (starting August $1^{\mathrm{st}}$ ) \\
\hline 1992 & yes & August $-\mathrm{WT}$ is within $30 \mathrm{~cm}$ for $14+$ days (starting August $15^{\text {th }}$ ) \\
\hline 1993 & yes & March - WT is within $30 \mathrm{~cm}$ for $14+$ days (starting March $22^{\text {nd }}-$ prorated) \\
\hline 1994 & yes & August $-\mathrm{WT}$ is within $30 \mathrm{~cm}$ for $14+$ days (starting August $1^{\mathrm{st}}$ ) \\
\hline
\end{tabular}


Table B.37: 45-year record for modified DAREM approach for plot $2 \mathrm{~S}$ at Bertie. 0 out of 45 years met wetland hydrology, 45 years did not meet water table criterion.

\begin{tabular}{|c|c|c|}
\hline Year & $\begin{array}{c}\text { Met/Not } \\
\text { Met }\end{array}$ & Reason Year did or did not meet Wetland Hydrology \\
\hline 1950 & no & water table is not within $30 \mathrm{~cm}$ for $14+$ days \\
\hline 1951 & no & water table is not within $30 \mathrm{~cm}$ for $14+$ days \\
\hline 1952 & no & water table is not within $30 \mathrm{~cm}$ for $14+$ days \\
\hline 1953 & no & water table is not within $30 \mathrm{~cm}$ for $14+$ days \\
\hline 1954 & no & water table is not within $30 \mathrm{~cm}$ for $14+$ days \\
\hline 1955 & no & water table is not within $30 \mathrm{~cm}$ for $14+$ days \\
\hline 1956 & no & water table is not within $30 \mathrm{~cm}$ for $14+$ days \\
\hline 1957 & no & water table is not within $30 \mathrm{~cm}$ for $14+$ days \\
\hline 1958 & no & water table is not within $30 \mathrm{~cm}$ for $14+$ days \\
\hline 1959 & no & water table is not within $30 \mathrm{~cm}$ for $14+$ days \\
\hline 1960 & no & water table is not within $30 \mathrm{~cm}$ for $14+$ days \\
\hline 1961 & no & water table is not within $30 \mathrm{~cm}$ for $14+$ days \\
\hline 1962 & no & water table is not within $30 \mathrm{~cm}$ for $14+$ days \\
\hline 1963 & no & water table is not within $30 \mathrm{~cm}$ for $14+$ days \\
\hline 1964 & no & water table is not within $30 \mathrm{~cm}$ for $14+$ days \\
\hline 1965 & no & water table is not within $30 \mathrm{~cm}$ for $14+$ days \\
\hline 1966 & no & water table is not within $30 \mathrm{~cm}$ for $14+$ days \\
\hline 1967 & no & water table is not within $30 \mathrm{~cm}$ for $14+$ days \\
\hline 1968 & no & water table is not within $30 \mathrm{~cm}$ for $14+$ days \\
\hline 1969 & no & water table is not within $30 \mathrm{~cm}$ for $14+$ days \\
\hline 1970 & no & water table is not within $30 \mathrm{~cm}$ for $14+$ days \\
\hline 1971 & no & water table is not within $30 \mathrm{~cm}$ for $14+$ days \\
\hline 1972 & no & water table is not within $30 \mathrm{~cm}$ for $14+$ days \\
\hline 1973 & no & water table is not within $30 \mathrm{~cm}$ for $14+$ days \\
\hline 1974 & no & water table is not within $30 \mathrm{~cm}$ for $14+$ days \\
\hline 1975 & no & water table is not within $30 \mathrm{~cm}$ for $14+$ days \\
\hline 1976 & no & water table is not within $30 \mathrm{~cm}$ for $14+$ days \\
\hline 1977 & no & water table is not within $30 \mathrm{~cm}$ for $14+$ days \\
\hline 1978 & no & water table is not within $30 \mathrm{~cm}$ for $14+$ days \\
\hline 1979 & no & water table is not within $30 \mathrm{~cm}$ for $14+$ days \\
\hline 1980 & no & water table is not within $30 \mathrm{~cm}$ for $14+$ days \\
\hline 1981 & no & water table is not within $30 \mathrm{~cm}$ for $14+$ days \\
\hline 1982 & no & water table is not within $30 \mathrm{~cm}$ for $14+$ days \\
\hline 1983 & no & water table is not within $30 \mathrm{~cm}$ for $14+$ days \\
\hline 1984 & no & water table is not within $30 \mathrm{~cm}$ for $14+$ days \\
\hline 1985 & no & water table is not within $30 \mathrm{~cm}$ for $14+$ days \\
\hline 1986 & no & water table is not within $30 \mathrm{~cm}$ for $14+$ days \\
\hline 1987 & no & water table is not within $30 \mathrm{~cm}$ for $14+$ days \\
\hline 1988 & no & water table is not within $30 \mathrm{~cm}$ for $14+$ days \\
\hline 1989 & no & water table is not within $30 \mathrm{~cm}$ for $14+$ days \\
\hline 1990 & no & water table is not within $30 \mathrm{~cm}$ for $14+$ days \\
\hline 1991 & no & water table is not within $30 \mathrm{~cm}$ for $14+$ days \\
\hline 1992 & no & water table is not within $30 \mathrm{~cm}$ for $14+$ days \\
\hline 1993 & no & water table is not within $30 \mathrm{~cm}$ for $14+$ days \\
\hline 1994 & no & water table is not within $30 \mathrm{~cm}$ for $14+$ days \\
\hline
\end{tabular}


Table B.38: 45-year record for modified DAREM approach for plot 3S at Bertie. 28 out of 45 years met wetland hydrology, 11 years met water table criterion during "wet" periods while 6 years did not meet water table criterion.

\begin{tabular}{|c|c|c|}
\hline Year & Met/Not Met & Reason Year did or did not meet Wetland Hydrology \\
\hline 1950 & yes & September - WT is within $30 \mathrm{~cm}$ for $14+$ days (starting September $10^{\text {th }}$ ) \\
\hline 1951 & yes & March - WT is within $30 \mathrm{~cm}$ for $14+$ days (starting March $22^{\text {nd }}-$ prorated) \\
\hline 1952 & no & July/August - "wet" \\
\hline 1953 & yes & August $-\mathrm{WT}$ is within $30 \mathrm{~cm}$ for $14+$ days (starting August $14^{\text {th }}$ ) \\
\hline 1954 & yes & March - WT is within $30 \mathrm{~cm}$ for $14+$ days (starting March 28th - prorated) \\
\hline 1955 & yes & August $-\mathrm{WT}$ is within $30 \mathrm{~cm}$ for $14+$ days (starting August $12^{\text {th }}$ ) \\
\hline 1956 & yes & March - WT is within $30 \mathrm{~cm}$ for $14+$ days (starting March $22^{\text {nd }}-$ prorated) \\
\hline 1957 & no & March/April - "wet" \\
\hline 1958 & yes & March - WT is within $30 \mathrm{~cm}$ for $14+$ days (starting March $22^{\text {nd }}-$ prorated) \\
\hline 1959 & yes & March - WT is within $30 \mathrm{~cm}$ for $14+$ days (starting March $22^{\text {nd }}-$ prorated) \\
\hline 1960 & yes & September - WT is within $30 \mathrm{~cm}$ for $14+$ days (starting September $11^{\text {th }}$ ) \\
\hline 1961 & yes & March - WT is within $30 \mathrm{~cm}$ for $14+$ days (starting March $22^{\text {nd }}-$ prorated) \\
\hline 1962 & yes & March - WT is within $30 \mathrm{~cm}$ for $14+$ days (starting March $22^{\text {nd }}-$ prorated) \\
\hline 1963 & no & water table not within $30 \mathrm{~cm}$ for $14+$ days \\
\hline 1964 & yes & September - WT is within $30 \mathrm{~cm}$ for $14+$ days (starting September $13^{\text {th }}$ ) \\
\hline 1965 & yes & March - WT is within $30 \mathrm{~cm}$ for $14+$ days (starting March $22^{\text {nd }}-$ prorated) \\
\hline 1966 & yes & May - WT is within $30 \mathrm{~cm}$ for $14+$ days (starting May $20^{\text {th }}-$ prorated) \\
\hline 1967 & yes & August $-\mathrm{WT}$ is within $30 \mathrm{~cm}$ for $14+$ days (starting August $11^{\text {th }}$ ) \\
\hline 1968 & no & water table not within $30 \mathrm{~cm}$ for 14+ days \\
\hline 1969 & yes & March - WT is within $30 \mathrm{~cm}$ for $14+$ days (starting March $22^{\text {nd }}-$ prorated) \\
\hline 1970 & yes & March - WT is within $30 \mathrm{~cm}$ for $14+$ days (starting March $22^{\text {nd }}-$ prorated) \\
\hline 1971 & no & March/April/October - "wet” \\
\hline 1972 & yes & May $-\mathrm{WT}$ is within $30 \mathrm{~cm}$ for $14+$ days (starting May $23^{\text {rd }}-$ prorated) \\
\hline 1973 & no & March/April - "wet" \\
\hline 1974 & no & March/April - "wet" \\
\hline 1975 & yes & July - WT is within $30 \mathrm{~cm}$ for $14+$ days (starting July $16^{\text {th }}-$ prorated) \\
\hline 1976 & no & water table not within $30 \mathrm{~cm}$ for $14+$ days \\
\hline 1977 & no & October - "wet" \\
\hline 1978 & yes & March - WT is within $30 \mathrm{~cm}$ for $14+$ days (starting March $22^{\text {nd }}-$ prorated) \\
\hline 1979 & no & April/May - "wet" \\
\hline 1980 & no & March/April - "wet" \\
\hline 1981 & no & August - "wet" \\
\hline 1982 & no & water table not within $30 \mathrm{~cm}$ for $14+$ days \\
\hline 1983 & no & March/April - "wet" \\
\hline 1984 & yes & July - WT is within $30 \mathrm{~cm}$ for $14+$ days (starting July $18^{\text {th }}-$ prorated) \\
\hline 1985 & no & September - "wet" \\
\hline 1986 & no & water table not within $30 \mathrm{~cm}$ for $14+$ days \\
\hline 1987 & yes & March - WT is within $30 \mathrm{~cm}$ for $14+$ days (starting March $22^{\text {nd }}-$ prorated) \\
\hline 1988 & yes & April - WT is within $30 \mathrm{~cm}$ for $14+$ days (starting April $13^{\text {th }}$ ) \\
\hline 1989 & yes & March - WT is within $30 \mathrm{~cm}$ for $14+$ days (starting March 29nd - prorated) \\
\hline 1990 & yes & March - WT is within $30 \mathrm{~cm}$ for $14+$ days (starting March $22^{\text {nd }}-$ prorated) \\
\hline 1991 & yes & August $-\mathrm{WT}$ is within $30 \mathrm{~cm}$ for $14+$ days (starting August $7^{\text {th }}$ ) \\
\hline 1992 & no & water table not within $30 \mathrm{~cm}$ for $14+$ days \\
\hline 1993 & yes & March - WT is within $30 \mathrm{~cm}$ for $14+$ days (starting March $22^{\text {nd }}-$ prorated) \\
\hline 1994 & yes & August $-\mathrm{WT}$ is within $30 \mathrm{~cm}$ for $14+$ days (starting August $7^{\text {th }}$ ) \\
\hline
\end{tabular}


Table B.39: 45-year record for modified DAREM approach for plot $4 \mathrm{~S}$ at Bertie. 35 out of 45 years met wetland hydrology, 6 years met water table criterion during "wet" periods while 4 years did not meet water table criterion.

\begin{tabular}{|c|c|c|}
\hline Year & Met TS & Reason Year did or did not meet Wetland Hydrology \\
\hline 1950 & yes & September - WT is within $30 \mathrm{~cm}$ for $14+$ days (starting September $10^{\text {th }}$ ) \\
\hline 1951 & yes & March - WT is within $30 \mathrm{~cm}$ for $14+$ days (starting March $22^{\text {nd }}-$ prorated) \\
\hline 1952 & yes & March - WT is within $30 \mathrm{~cm}$ for $14+$ days (starting March $22^{\text {nd }}-$ prorated) \\
\hline 1953 & yes & August $-\mathrm{WT}$ is within $30 \mathrm{~cm}$ for $14+$ days (starting August $14^{\text {th }}$ ) \\
\hline 1954 & yes & March - WT is within $30 \mathrm{~cm}$ for $14+$ days (starting March $22^{\text {nd }}-$ prorated) \\
\hline 1955 & yes & August $-\mathrm{WT}$ is within $30 \mathrm{~cm}$ for $14+$ days (starting August $14^{\text {th }}$ ) \\
\hline 1956 & yes & March - WT is within $30 \mathrm{~cm}$ for $14+$ days (starting March $22^{\text {nd }}-$ prorated) \\
\hline 1957 & no & March/April - "wet" \\
\hline 1958 & yes & March - WT is within $30 \mathrm{~cm}$ for $14+$ days (starting March $22^{\text {nd }}-$ prorated) \\
\hline 1959 & yes & March - WT is within $30 \mathrm{~cm}$ for $14+$ days (starting March $22^{\text {nd }}-$ prorated) \\
\hline 1960 & yes & September - WT is within $30 \mathrm{~cm}$ for $14+$ days (starting September $11^{\text {th }}$ ) \\
\hline 1961 & yes & March - WT is within $30 \mathrm{~cm}$ for $14+$ days (starting March $22^{\text {nd }}-$ prorated) \\
\hline 1962 & yes & March - WT is within $30 \mathrm{~cm}$ for $14+$ days (starting March $22^{\text {nd }}-$ prorated) \\
\hline 1963 & no & water table is not within $30 \mathrm{~cm}$ for $14+$ days \\
\hline 1964 & yes & September - WT is within $30 \mathrm{~cm}$ for $14+$ days (starting September $13^{\text {th }}$ ) \\
\hline 1965 & yes & March - WT is within $30 \mathrm{~cm}$ for $14+$ days (starting March $22^{\text {nd }}-$ prorated) \\
\hline 1966 & yes & May - WT is within $30 \mathrm{~cm}$ for $14+$ days (starting May $20^{\text {th }}-$ prorated) \\
\hline 1967 & yes & July - WT is within $30 \mathrm{~cm}$ for $14+$ days (starting July $16^{\text {th }}-$ prorated) \\
\hline 1968 & yes & April $-\mathrm{WT}$ is within $30 \mathrm{~cm}$ for $14+$ days (starting April $6^{\text {th }}$ ) \\
\hline 1969 & yes & March - WT is within $30 \mathrm{~cm}$ for $14+$ days (starting March $22^{\text {nd }}-$ prorated) \\
\hline 1970 & yes & March - WT is within $30 \mathrm{~cm}$ for $14+$ days (starting March $22^{\text {nd }}-$ prorated) \\
\hline 1971 & yes & May - WT is within $30 \mathrm{~cm}$ for $14+$ days (starting May $13^{\text {th }}$ ) \\
\hline 1972 & yes & May - WT is within $30 \mathrm{~cm}$ for $14+$ days (starting May $4^{\text {th }}$ ) \\
\hline 1973 & no & March/April/May - "wet” \\
\hline 1974 & no & March/April/August/September - "Wet" \\
\hline 1975 & yes & July - WT is within $30 \mathrm{~cm}$ for $14+$ days (starting July $16^{\text {th }}-$ prorated) \\
\hline 1976 & no & water table is not within $30 \mathrm{~cm}$ for $14+$ days \\
\hline 1977 & yes & March - WT is within $30 \mathrm{~cm}$ for $14+$ days (starting March $22^{\text {nd }}-$ prorated) \\
\hline 1978 & yes & March - WT is within $30 \mathrm{~cm}$ for $14+$ days (starting March $22^{\text {nd }}-$ prorated) \\
\hline 1979 & no & March/April/May/June - "wet” \\
\hline 1980 & no & March/April - "wet" \\
\hline 1981 & yes & March - WT is within $30 \mathrm{~cm}$ for $14+$ days (starting March $22^{\text {nd }}-$ prorated) \\
\hline 1982 & yes & March - WT is within $30 \mathrm{~cm}$ for $14+$ days (starting March $22^{\text {nd }}-$ prorated) \\
\hline 1983 & no & March/April - "wet" \\
\hline 1984 & yes & July - WT is within $30 \mathrm{~cm}$ for $14+$ days (starting July $18^{\text {th }}-$ prorated) \\
\hline 1985 & no & water table is not within $30 \mathrm{~cm}$ for $14+$ days \\
\hline 1986 & no & water table is not within $30 \mathrm{~cm}$ for $14+$ days \\
\hline 1987 & yes & March - WT is within $30 \mathrm{~cm}$ for $14+$ days (starting March $22^{\text {nd }}-$ prorated) \\
\hline 1988 & yes & April $-\mathrm{WT}$ is within $30 \mathrm{~cm}$ for $14+$ days (starting April $7^{\text {th }}$ ) \\
\hline 1989 & yes & March - WT is within $30 \mathrm{~cm}$ for $14+$ days (starting March $22^{\text {nd }}-$ prorated) \\
\hline 1990 & yes & March - WT is within $30 \mathrm{~cm}$ for $14+$ days (starting March $29^{\text {th }}-$ prorated) \\
\hline 1991 & yes & October - WT is within $30 \mathrm{~cm}$ for $14+$ days (starting October $3^{\text {rd }}$ ) \\
\hline 1992 & yes & August $-\mathrm{WT}$ is within $30 \mathrm{~cm}$ for $14+$ days (starting August $15^{\text {th }}$ ) \\
\hline 1993 & yes & March - WT is within $30 \mathrm{~cm}$ for $14+$ days (starting March $22^{\text {nd }}-$ prorated) \\
\hline 1994 & yes & August $-\mathrm{WT}$ is within $30 \mathrm{~cm}$ for $14+$ days (starting August $7^{\text {th }}$ ) \\
\hline
\end{tabular}


Table B.40: 45-year record for modified DAREM approach for plot $5 \mathrm{~S}$ at Bertie. 38 out of 45 years met wetland hydrology, 6 years met water table criterion during "wet" periods while 1 years did not meet water table criterion.

\begin{tabular}{|c|c|c|}
\hline Year & $\begin{array}{c}\text { Met/Not } \\
\text { Met }\end{array}$ & Reason Year did or did not meet Wetland Hydrology \\
\hline 1950 & yes & September - WT is within $30 \mathrm{~cm}$ for $14+$ days (starting September $10^{\text {th }}$ ) \\
\hline 1951 & yes & March - WT is within $30 \mathrm{~cm}$ for $14+$ days (starting March $22^{\text {nd }}-$ prorated) \\
\hline 1952 & yes & March - WT is within $30 \mathrm{~cm}$ for $14+$ days (starting March $22^{\text {nd }}-$ prorated) \\
\hline 1953 & yes & April - WT is within $30 \mathrm{~cm}$ for $14+$ days (starting April $2^{\text {nd }}$ ) \\
\hline 1954 & yes & March - WT is within $30 \mathrm{~cm}$ for $14+$ days (starting March $22^{\text {nd }}-$ prorated) \\
\hline 1955 & yes & August $-\mathrm{WT}$ is within $30 \mathrm{~cm}$ for $14+$ days (starting August $12^{\text {th }}$ ) \\
\hline 1956 & yes & March - WT is within $30 \mathrm{~cm}$ for $14+$ days (starting March $22^{\text {nd }}-$ prorated) \\
\hline 1957 & no & March/April - "wet" \\
\hline 1958 & yes & March - WT is within $30 \mathrm{~cm}$ for $14+$ days (starting March $22^{\text {nd }}-$ prorated) \\
\hline 1959 & yes & March - WT is within $30 \mathrm{~cm}$ for $14+$ days (starting March $22^{\text {nd }}-$ prorated) \\
\hline 1960 & yes & September - WT is within $30 \mathrm{~cm}$ for $14+$ days (starting September $11^{\text {th }}$ ) \\
\hline 1961 & yes & March - WT is within $30 \mathrm{~cm}$ for $14+$ days (starting March $22^{\text {nd }}-$ prorated) \\
\hline 1962 & yes & March - WT is within $30 \mathrm{~cm}$ for $14+$ days (starting March $22^{\text {nd }}-$ prorated) \\
\hline 1963 & no & water table is not within $30 \mathrm{~cm}$ for $14+$ days \\
\hline 1964 & yes & September - WT is within $30 \mathrm{~cm}$ for $14+$ days (starting September $13^{\text {th }}$ ) \\
\hline 1965 & yes & March - WT is within $30 \mathrm{~cm}$ for $14+$ days (starting March $22^{\text {nd }}-$ prorated) \\
\hline 1966 & yes & May - WT is within $30 \mathrm{~cm}$ for $14+$ days (starting May $19^{\text {th }}-$ prorated) \\
\hline 1967 & yes & July - WT is within $30 \mathrm{~cm}$ for $14+$ days (starting July $16^{\text {th }}-$ prorated) \\
\hline 1968 & yes & April - WT is within $30 \mathrm{~cm}$ for $14+$ days (starting April $6^{\text {th }}$ ) \\
\hline 1969 & yes & March - WT is within $30 \mathrm{~cm}$ for $14+$ days (starting March $22^{\text {nd }}-$ prorated) \\
\hline 1970 & yes & March - WT is within $30 \mathrm{~cm}$ for $14+$ days (starting March $22^{\text {nd }}-$ prorated) \\
\hline 1971 & yes & May - WT is within $30 \mathrm{~cm}$ for $14+$ days (starting May $13^{\text {th }}-$ prorated) \\
\hline 1972 & yes & May - WT is within $30 \mathrm{~cm}$ for $14+$ days (starting May $4^{\text {th }}-$ prorated) \\
\hline 1973 & yes & August $-\mathrm{WT}$ is within $30 \mathrm{~cm}$ for $14+$ days (starting August $12^{\text {th }}$ ) \\
\hline 1974 & yes & August $-\mathrm{WT}$ is within $30 \mathrm{~cm}$ for $14+$ days (starting August $4^{\text {th }}$ ) \\
\hline 1975 & yes & July - WT is within $30 \mathrm{~cm}$ for $14+$ days (starting July $16^{\text {th }}-$ prorated) \\
\hline 1976 & no & July/August - "Wet" \\
\hline 1977 & yes & March - WT is within $30 \mathrm{~cm}$ for $14+$ days (starting March $22^{\text {nd }}-$ prorated) \\
\hline 1978 & yes & March - WT is within $30 \mathrm{~cm}$ for $14+$ days (starting March $22^{\text {nd }}-$ prorated) \\
\hline 1979 & yes & September - WT is within $30 \mathrm{~cm}$ for $14+$ days (starting September $5^{\text {th }}$ ) \\
\hline 1980 & no & March/April - "wet" \\
\hline 1981 & yes & March - WT is within $30 \mathrm{~cm}$ for $14+$ days (starting March $22^{\text {nd }}-$ prorated) \\
\hline 1982 & yes & March - WT is within $30 \mathrm{~cm}$ for $14+$ days (starting March $22^{\text {nd }}-$ prorated) \\
\hline 1983 & no & March/April/May - "Wet" \\
\hline 1984 & yes & July - WT is within $30 \mathrm{~cm}$ for $14+$ days (starting July $18^{\text {th }}-$ prorated) \\
\hline 1985 & no & September- "wet" \\
\hline 1986 & no & August - "wet" \\
\hline 1987 & yes & March - WT is within $30 \mathrm{~cm}$ for $14+$ days (starting March $22^{\text {nd }}-$ prorated) \\
\hline 1988 & yes & April - WT is within $30 \mathrm{~cm}$ for $14+$ days (starting April $7^{\text {th }}$ ) \\
\hline 1989 & yes & March - WT is within $30 \mathrm{~cm}$ for $14+$ days (starting March $22^{\text {nd }}-$ prorated) \\
\hline 1990 & yes & March - WT is within $30 \mathrm{~cm}$ for $14+$ days (starting March $29^{\text {th }}-$ prorated) \\
\hline 1991 & yes & August $-\mathrm{WT}$ is within $30 \mathrm{~cm}$ for $14+$ days (starting August $12^{\text {th }}$ ) \\
\hline 1992 & yes & August $-\mathrm{WT}$ is within $30 \mathrm{~cm}$ for $14+$ days (starting August $15^{\text {th }}$ ) \\
\hline 1993 & yes & March - WT is within $30 \mathrm{~cm}$ for $14+$ days (starting March $22^{\text {nd }}-$ prorated) \\
\hline 1994 & yes & August $-\mathrm{WT}$ is within $30 \mathrm{~cm}$ for $14+$ days (starting August $1^{\text {st }}$ ) \\
\hline
\end{tabular}


Table B.41: 45-year record for modified DAREM approach for plot S1 at Marcell. 34 out of 45 years met wetland hydrology, 4 years met water table criterion during "wet" periods while 7 years did not meet water table criterion.

\begin{tabular}{|c|c|c|}
\hline Year & Met/Not Met & Reason Year did or did not meet Wetland Hydrology \\
\hline 1961 & no & water table not within $30 \mathrm{~cm}$ for $14+$ days \\
\hline 1962 & yes & WT is within $30 \mathrm{~cm}$ for $14+$ days (starting May $12^{\text {th }}$ ) \\
\hline 1963 & no & water table not within $30 \mathrm{~cm}$ for $14+$ days \\
\hline 1964 & no & water table not within $30 \mathrm{~cm}$ for $14+$ days \\
\hline 1965 & yes & WT is within $30 \mathrm{~cm}$ for $14+$ days (starting May $14^{\text {th }}$ ) \\
\hline 1966 & yes & August is within $30 \mathrm{~cm}$ for $14+$ days (starting August $7^{\text {th }}$ ) \\
\hline 1967 & no & water table not within $30 \mathrm{~cm}$ for $14+$ days \\
\hline 1968 & no & water table not within $30 \mathrm{~cm}$ for $14+$ days \\
\hline 1969 & yes & May is within $30 \mathrm{~cm}$ for $14+$ days (starting May $31^{\mathrm{st}}$ ) \\
\hline 1970 & yes & June is within $30 \mathrm{~cm}$ for $14+$ days (starting June $1^{\text {st }}$ ) \\
\hline 1971 & yes & May is within $30 \mathrm{~cm}$ for $14+$ days (starting May $20^{\text {th }}-$ prorated) \\
\hline 1972 & yes & July is within $30 \mathrm{~cm}$ for $14+$ days (July $9^{\text {th }}$ ) \\
\hline 1973 & yes & May is within $30 \mathrm{~cm}$ for $14+$ days (starting May $4^{\text {th }}$ ) \\
\hline 1974 & no & May/June - "wet" \\
\hline 1975 & yes & July is within $30 \mathrm{~cm}$ for $14+$ days (July $1^{\text {st }}$ ) \\
\hline 1976 & no & water table not within $30 \mathrm{~cm}$ for $14+$ days \\
\hline 1977 & yes & August is within $30 \mathrm{~cm}$ for $14+$ days (starting August $27^{\text {th }}-$ prorated) \\
\hline 1978 & yes & July is within $30 \mathrm{~cm}$ for $14+$ days (starting July $1^{\text {st }}$ ) \\
\hline 1979 & no & May - "wet" \\
\hline 1980 & no & water table not within $30 \mathrm{~cm}$ for $14+$ days \\
\hline 1981 & yes & May is within $30 \mathrm{~cm}$ for $14+$ days (starting May $22^{\text {nd }}-$ prorated) \\
\hline 1982 & yes & May is within $30 \mathrm{~cm}$ for $14+$ days (starting May $4^{\text {th }}$ ) \\
\hline 1983 & yes & May is within $30 \mathrm{~cm}$ for $14+$ days (starting May $4^{\text {th }}$ ) \\
\hline 1984 & yes & May is within $30 \mathrm{~cm}$ for $14+$ days (starting May $4^{\text {th }}$ ) \\
\hline 1985 & yes & August is within $\mathrm{cm}$ for $14+$ days (starting August $31^{\text {st }}-$ prorated) \\
\hline 1986 & yes & May is within $30 \mathrm{~cm}$ for $14+$ days (starting May $4^{\text {th }}$ ) \\
\hline 1987 & yes & May is within $30 \mathrm{~cm}$ for $14+$ days (starting May $17^{\text {th }}-$ prorated) \\
\hline 1988 & yes & May is within $30 \mathrm{~cm}$ for $14+$ days (starting May $7^{\text {th }}$ ) \\
\hline 1989 & yes & May is within $30 \mathrm{~cm}$ for $14+$ days (starting May $24^{\text {th }}-$ prorated) \\
\hline 1990 & yes & June is within $30 \mathrm{~cm}$ for $14+$ days (starting June $2^{\text {nd }}$ ) \\
\hline 1991 & no & May - "wet" \\
\hline 1992 & no & July/August - "wet" \\
\hline 1993 & yes & June is within $30 \mathrm{~cm}$ for $14+$ days (starting June $23^{\text {rd }}-$ prorated) \\
\hline 1994 & yes & June is within $30 \mathrm{~cm}$ for $14+$ days (starting June $1^{\text {st }}$ ) \\
\hline 1995 & yes & May is within $30 \mathrm{~cm}$ for $14+$ days (starting May $4^{\text {th }}$ ) \\
\hline 1996 & yes & May is within $30 \mathrm{~cm}$ for $14+$ days (starting May $4^{\text {th }}$ ) \\
\hline 1997 & yes & May is within $30 \mathrm{~cm}$ for $14+$ days (starting May $4^{\text {th }}$ ) \\
\hline 1998 & yes & May is within $30 \mathrm{~cm}$ for $14+$ days (starting May $11^{\text {th }}$ ) \\
\hline 1999 & yes & July is within $30 \mathrm{~cm}$ for $14+$ days (starting July $4^{\text {th }}$ ) \\
\hline 2000 & yes & June is within $30 \mathrm{~cm}$ for $14+$ days (starting June $1^{\text {st }}$ ) \\
\hline 2001 & yes & May is within $30 \mathrm{~cm}$ for $14+$ days (starting May $4^{\text {th }}$ ) \\
\hline 2002 & yes & May is within $30 \mathrm{~cm}$ for $14+$ days (starting May $4^{\text {th }}$ ) \\
\hline 2003 & yes & May is within $30 \mathrm{~cm}$ for $14+$ days ( $\operatorname{starting}$ May $4^{\text {th }}$ ) \\
\hline 2004 & yes & May is within $30 \mathrm{~cm}$ for $14+$ days ( $\operatorname{starting}$ May $4^{\text {th }}$ ) \\
\hline 2005 & yes & May is within $30 \mathrm{~cm}$ for $14+$ days ( $\operatorname{starting}$ May $4^{\text {th }}$ ) \\
\hline
\end{tabular}


Table B.42: 45-year record for modified DAREM approach for plot S2 at Marcell. 45 out of 45 years met wetland hydrology.

\begin{tabular}{|c|c|c|}
\hline Year & Met/Not Met & Reason Year did or did not meet Wetland Hydrology \\
\hline 1961 & yes & May is within $30 \mathrm{~cm}$ for $14+$ days (starting May $4^{\text {th }}$ ) \\
\hline 1962 & yes & May is within $30 \mathrm{~cm}$ for $14+$ days (starting May $4^{\text {th }}$ ) \\
\hline 1963 & yes & August is within $30 \mathrm{~cm}$ for $14+$ days (starting September $1^{\text {st }}$ ) \\
\hline 1964 & yes & May is within $30 \mathrm{~cm}$ for $14+$ days (starting May $4^{\text {th }}$ ) \\
\hline 1965 & yes & May is within $30 \mathrm{~cm}$ for $14+$ days (starting May $4^{\text {th }}$ ) \\
\hline 1966 & yes & July is within $30 \mathrm{~cm}$ for $14+$ days (starting July $1^{\text {st }}$ ) \\
\hline 1967 & yes & June is within $30 \mathrm{~cm}$ for $14+$ days (starting June $1^{\text {st }}$ ) \\
\hline 1968 & yes & August is within $30 \mathrm{~cm}$ for $14+$ days (starting August $1^{\text {st }}$ ) \\
\hline 1969 & yes & May is within $30 \mathrm{~cm}$ for $14+$ days (starting May $4^{\text {th }}$ ) \\
\hline 1970 & yes & June is within $30 \mathrm{~cm}$ for $14+$ days (starting June $1^{\text {st }}$ ) \\
\hline 1971 & yes & May is within $30 \mathrm{~cm}$ for $14+$ days (starting May $4^{\text {th }}$ ) \\
\hline 1972 & yes & July is within $30 \mathrm{~cm}$ for $14+$ days (starting July $1^{\text {st }}$ ) \\
\hline 1973 & yes & May is within $30 \mathrm{~cm}$ for $14+$ days (starting May $4^{\text {th }}$ ) \\
\hline 1974 & yes & July is within $30 \mathrm{~cm}$ for $14+$ days (starting July $1^{\text {st }}$ ) \\
\hline 1975 & yes & July is within $30 \mathrm{~cm}$ for $14+$ days (starting July $1^{\text {st }}$ ) \\
\hline 1976 & yes & May is within $30 \mathrm{~cm}$ for $14+$ days (starting May $4^{\text {th }}$ ) \\
\hline 1977 & yes & June is within $30 \mathrm{~cm}$ for $14+$ days (starting June $16^{\text {th }}-$ prorated) \\
\hline 1978 & yes & May is within $30 \mathrm{~cm}$ for $14+$ days (starting May $4^{\text {th }}$ ) \\
\hline 1979 & yes & June is within $30 \mathrm{~cm}$ for $14+$ days (starting June $1^{\text {st }}$ ) \\
\hline 1980 & yes & May is within $30 \mathrm{~cm}$ for $14+$ days (starting May $4^{\text {th }}$ ) \\
\hline 1981 & yes & May is within $30 \mathrm{~cm}$ for $14+$ days (starting May $16^{\text {th }}-$ prorated) \\
\hline 1982 & yes & May is within $30 \mathrm{~cm}$ for $14+$ days (starting May $4^{\text {th }}$ ) \\
\hline 1983 & yes & May is within $30 \mathrm{~cm}$ for $14+$ days (starting May $4^{\text {th }}$ ) \\
\hline 1984 & yes & May is within $30 \mathrm{~cm}$ for $14+$ days (starting May $4^{\text {th }}$ ) \\
\hline 1985 & yes & August is within $30 \mathrm{~cm}$ for $14+$ days (starting August $1^{\text {st }}$ ) \\
\hline 1986 & yes & May is within $30 \mathrm{~cm}$ for $14+$ days (starting May $4^{\text {th }}$ ) \\
\hline 1987 & yes & May is within $30 \mathrm{~cm}$ for $14+$ days (starting May $15^{\text {th }}-$ prorated) \\
\hline 1988 & yes & May is within $30 \mathrm{~cm}$ for $14+$ days (starting May $4^{\text {th }}$ ) \\
\hline 1989 & yes & May is within $30 \mathrm{~cm}$ for $14+$ days (starting May $4^{\text {th }}$ ) \\
\hline 1990 & yes & June is within $30 \mathrm{~cm}$ for $14+$ days (starting June $1^{\text {st }}$ ) \\
\hline 1991 & yes & July is within $30 \mathrm{~cm}$ for $14+$ days (starting July $1^{\text {st }}$ ) \\
\hline 1992 & yes & May is within $30 \mathrm{~cm}$ for $14+$ days (starting May $4^{\text {th }}$ ) \\
\hline 1993 & yes & May is within $30 \mathrm{~cm}$ for $14+$ days (starting May $4^{\text {th }}$ ) \\
\hline 1994 & yes & June is within $30 \mathrm{~cm}$ for $14+$ days (starting June $1^{\text {st }}$ ) \\
\hline 1995 & yes & May is within $30 \mathrm{~cm}$ for $14+$ days (starting May $4^{\text {th }}$ ) \\
\hline 1996 & yes & May is within $30 \mathrm{~cm}$ for $14+$ days (starting May $4^{\text {th }}$ ) \\
\hline 1997 & yes & May is within $30 \mathrm{~cm}$ for $14+$ days (starting May $4^{\text {th }}$ ) \\
\hline 1998 & yes & May is within $30 \mathrm{~cm}$ for $14+$ days (starting May $11^{\text {th }}$ ) \\
\hline 1999 & yes & July is within $30 \mathrm{~cm}$ for $14+$ days (starting July $1^{\text {st }}$ ) \\
\hline 2000 & yes & June is within $30 \mathrm{~cm}$ for $14+$ days (starting June $1^{\text {st }}$ ) \\
\hline 2001 & yes & May is within $30 \mathrm{~cm}$ for $14+$ days (starting May $4^{\text {th }}$ ) \\
\hline 2002 & yes & May is within $30 \mathrm{~cm}$ for $14+$ days (starting May $4^{\text {th }}$ ) \\
\hline 2003 & yes & May is within $30 \mathrm{~cm}$ for $14+$ days (starting May $4^{\text {th }}$ ) \\
\hline 2004 & yes & May is within $30 \mathrm{~cm}$ for $14+$ days (starting May $4^{\text {th }}$ ) \\
\hline 2005 & yes & May is within $30 \mathrm{~cm}$ for $14+$ days (starting May $4^{\text {th }}$ ) \\
\hline
\end{tabular}


Table B.43: 45-year record for modified DAREM approach for plot S3 at Marcell. 22 out of 45 years met wetland hydrology, 2 years met water table criterion during "wet" periods while 21 years did not meet water table criterion.

\begin{tabular}{|c|c|c|}
\hline Year & Met/Not Met & Reason Year did or did not meet Wetland Hydrology \\
\hline 1961 & no & water table is not within $30 \mathrm{~cm}$ for $14+$ days \\
\hline 1962 & no & water table is not within $30 \mathrm{~cm}$ for $14+$ days \\
\hline 1963 & no & water table is not within $30 \mathrm{~cm}$ for $14+$ days \\
\hline 1964 & no & water table is not within $30 \mathrm{~cm}$ for $14+$ days \\
\hline 1965 & no & water table is not within $30 \mathrm{~cm}$ for $14+$ days \\
\hline 1966 & yes & August is within $30 \mathrm{~cm}$ for $14+$ days (starting August $6^{\text {th }}$ ) \\
\hline 1967 & no & May - "wet" \\
\hline 1968 & no & water table is not within $30 \mathrm{~cm}$ for $14+$ days \\
\hline 1969 & no & water table is not within $30 \mathrm{~cm}$ for $14+$ days \\
\hline 1970 & no & water table is not within $30 \mathrm{~cm}$ for $14+$ days \\
\hline 1971 & no & water table is not within $30 \mathrm{~cm}$ for $14+$ days \\
\hline 1972 & no & water table is not within $30 \mathrm{~cm}$ for $14+$ days \\
\hline 1973 & no & water table is not within $30 \mathrm{~cm}$ for $14+$ days \\
\hline 1974 & no & water table is not within $30 \mathrm{~cm}$ for $14+$ days \\
\hline 1975 & no & water table is not within $30 \mathrm{~cm}$ for $14+$ days \\
\hline 1976 & no & water table is not within $30 \mathrm{~cm}$ for $14+$ days \\
\hline 1977 & no & water table is not within $30 \mathrm{~cm}$ for $14+$ days \\
\hline 1978 & no & water table is not within $30 \mathrm{~cm}$ for $14+$ days \\
\hline 1979 & no & water table is not within $30 \mathrm{~cm}$ for $14+$ days \\
\hline 1980 & no & water table is not within $30 \mathrm{~cm}$ for $14+$ days \\
\hline 1981 & no & water table is not within $30 \mathrm{~cm}$ for $14+$ days \\
\hline 1982 & yes & May is within $30 \mathrm{~cm}$ for $14+$ days (starting May $4^{\text {th }}$ ) \\
\hline 1983 & yes & May is within $30 \mathrm{~cm}$ for $14+$ days (starting May $4^{\text {th }}$ ) \\
\hline 1984 & no & water table is not within $30 \mathrm{~cm}$ for $14+$ days \\
\hline 1985 & yes & August is within $30 \mathrm{~cm}$ for $14+$ days (starting August $1^{\text {st }}$ ) \\
\hline 1986 & yes & May is within $30 \mathrm{~cm}$ for $14+$ days (starting May $4^{\text {th }}$ ) \\
\hline 1987 & yes & May is within $30 \mathrm{~cm}$ for $14+$ days (starting May $15^{\text {th }}-$ prorated) \\
\hline 1988 & yes & May is within $30 \mathrm{~cm}$ for $14+$ days (starting May $4^{\text {th }}$ ) \\
\hline 1989 & yes & May is within $30 \mathrm{~cm}$ for $14+$ days (starting May $4^{\text {th }}$ ) \\
\hline 1990 & yes & June is within $30 \mathrm{~cm}$ for $14+$ days (starting June $1^{\text {st }}$ ) \\
\hline 1991 & no & water table is not within $30 \mathrm{~cm}$ for $14+$ days \\
\hline 1992 & no & August - "wet" \\
\hline 1993 & yes & August is within $30 \mathrm{~cm}$ for $14+$ days (starting August $22^{\text {nd }}-$ prorated) \\
\hline 1994 & yes & June is within $30 \mathrm{~cm}$ for $14+$ days (starting June $1^{\text {st }}$ ) \\
\hline 1995 & yes & May is within $30 \mathrm{~cm}$ for $14+$ days (starting May $4^{\text {th }}$ ) \\
\hline 1996 & yes & May is within $30 \mathrm{~cm}$ for $14+$ days (starting May $4^{\text {th }}$ ) \\
\hline 1997 & yes & May is within $30 \mathrm{~cm}$ for $14+$ days (starting May $4^{\text {th }}$ ) \\
\hline 1998 & yes & May is within $30 \mathrm{~cm}$ for $14+$ days (starting May $4^{\text {th }}$ ) \\
\hline 1999 & yes & July is within $30 \mathrm{~cm}$ for $14+$ days (starting July $1^{\text {st }}$ ) \\
\hline 2000 & yes & June is within $30 \mathrm{~cm}$ for $14+$ days (starting June $1^{\text {st }}$ ) \\
\hline 2001 & yes & May is within $30 \mathrm{~cm}$ for $14+$ days (starting May $4^{\text {th }}$ ) \\
\hline 2002 & yes & May is within $30 \mathrm{~cm}$ for $14+$ days (starting May $4^{\text {th }}$ ) \\
\hline 2003 & yes & May is within $30 \mathrm{~cm}$ for $14+$ days (starting May $4^{\text {th }}$ ) \\
\hline 2004 & yes & May is within $30 \mathrm{~cm}$ for $14+$ days (starting May $12^{\text {th }}$ ) \\
\hline 2005 & yes & May is within $30 \mathrm{~cm}$ for $14+$ days (starting May $9^{\text {th }}$ ) \\
\hline
\end{tabular}


Table B.44: 45-year record for modified DAREM approach for plot S4 at Marcell. 42 out of 44 years met wetland hydrology, 2 years met water table criterion during "wet" periods.

\begin{tabular}{|c|c|c|}
\hline Year & Met/Not Met & Reason Year did or did not meet Wetland Hydrology \\
\hline 1962 & yes & May is within $30 \mathrm{~cm}$ for $14+$ days (starting May 4th) \\
\hline 1963 & no & Growing season is "wet" \\
\hline 1964 & yes & August is within $30 \mathrm{~cm}$ for $14+$ days (starting August 20th - prorated) \\
\hline 1965 & yes & May is within $30 \mathrm{~cm}$ for $14+$ days (starting May 4 th) \\
\hline 1966 & yes & July is within $30 \mathrm{~cm}$ for $14+$ days (starting July 17 th - prorated) \\
\hline 1967 & yes & June is within $30 \mathrm{~cm}$ for $14+$ days (starting June $6 \mathrm{th}$ ) \\
\hline 1968 & yes & July is within $30 \mathrm{~cm}$ for $14+$ days (starting July $1 \mathrm{st}$ ) \\
\hline 1969 & yes & May is within $30 \mathrm{~cm}$ for $14+$ days (starting May 4th) \\
\hline 1970 & yes & June is within $30 \mathrm{~cm}$ for $14+$ days (starting June 15 th - prorated) \\
\hline 1971 & yes & May is within $30 \mathrm{~cm}$ for $14+$ days (starting May 19 th - prorated) \\
\hline 1972 & yes & July is within $30 \mathrm{~cm}$ for $14+$ days (starting July 6 th) \\
\hline 1973 & yes & May is within $30 \mathrm{~cm}$ for 14+ days (starting May 4th) \\
\hline 1974 & yes & June is within $30 \mathrm{~cm}$ for $14+$ days (starting July $22 \mathrm{nd}$ - prorated) \\
\hline 1975 & yes & July is within $30 \mathrm{~cm}$ for $14+$ days (starting July $1 \mathrm{st}$ ) \\
\hline 1976 & yes & May is within $30 \mathrm{~cm}$ for $14+$ days (starting May 4th) \\
\hline 1977 & yes & June is within $30 \mathrm{~cm}$ for $14+$ days (starting June 16th - prorated) \\
\hline 1978 & yes & May is within $30 \mathrm{~cm}$ for $14+$ days (starting May 4th) \\
\hline 1979 & yes & June is within $30 \mathrm{~cm}$ for $14+$ days (starting June $1 \mathrm{st}$ ) \\
\hline 1980 & yes & May is within $30 \mathrm{~cm}$ for $14+$ days (starting May 4th) \\
\hline 1981 & yes & June is within $30 \mathrm{~cm}$ for $14+$ days (starting June $1 \mathrm{st}$ ) \\
\hline 1982 & yes & May is within $30 \mathrm{~cm}$ for $14+$ days (starting May 4th) \\
\hline 1983 & yes & May is within $30 \mathrm{~cm}$ for $14+$ days (starting May 4th) \\
\hline 1984 & yes & May is within $30 \mathrm{~cm}$ for $14+$ days (starting May 4 th) \\
\hline 1985 & yes & August is within $30 \mathrm{~cm}$ for $14+$ days (starting August 16th - prorated) \\
\hline 1986 & yes & May is within $30 \mathrm{~cm}$ for $14+$ days (starting May 4 th) \\
\hline 1987 & yes & May is within $30 \mathrm{~cm}$ for $14+$ days (starting May 4th) \\
\hline 1988 & yes & May is within $30 \mathrm{~cm}$ for $14+$ days (starting May 4th) \\
\hline 1989 & yes & May is within $30 \mathrm{~cm}$ for $14+$ days (starting May 4th) \\
\hline 1990 & yes & June is within $30 \mathrm{~cm}$ for $14+$ days (starting June $1 \mathrm{st}$ ) \\
\hline 1991 & no & May/June/July - "wet" \\
\hline 1992 & yes & May is within $30 \mathrm{~cm}$ for $14+$ days (starting May 4th) \\
\hline 1993 & yes & May is within $30 \mathrm{~cm}$ for $14+$ days (starting May 4th) \\
\hline 1994 & yes & June is within $30 \mathrm{~cm}$ for $14+$ days (starting June $1 \mathrm{st}$ ) \\
\hline 1995 & yes & May is within $30 \mathrm{~cm}$ for $14+$ days (starting May 4th) \\
\hline 1996 & yes & May is within $30 \mathrm{~cm}$ for $14+$ days (starting May 4th) \\
\hline 1997 & yes & May is within $30 \mathrm{~cm}$ for $14+$ days (starting May 4th) \\
\hline 1998 & yes & May is within $30 \mathrm{~cm}$ for $14+$ days (starting May 4th) \\
\hline 1999 & yes & July is within $30 \mathrm{~cm}$ for $14+$ days (starting July 1st) \\
\hline 2000 & yes & May is within $30 \mathrm{~cm}$ for $14+$ days (starting May 4th) \\
\hline 2001 & yes & May is within $30 \mathrm{~cm}$ for $14+$ days (starting May 4th) \\
\hline 2002 & yes & May is within $30 \mathrm{~cm}$ for $14+$ days (starting May 4th) \\
\hline 2003 & yes & May is within $30 \mathrm{~cm}$ for $14+$ days (starting May 4th) \\
\hline 2004 & yes & May is within $30 \mathrm{~cm}$ for $14+$ days (starting May 4th) \\
\hline 2005 & yes & May is within $30 \mathrm{~cm}$ for $14+$ days (starting May 4th) \\
\hline
\end{tabular}


Table B.45: 45-year record for modified DAREM approach for plot S5 at Marcell. 37 out of 45 years met wetland hydrology, 6 years met water table criterion during "wet" periods while 1 years did not meet water table criterion.

\begin{tabular}{|c|c|c|}
\hline Year & Met/Not Met & Reason Year did or did not meet Wetland Hydrology \\
\hline 1962 & yes & May is within $30 \mathrm{~cm}$ for $14+$ days (starting May 4th) \\
\hline 1963 & no & all growing season is "wet" \\
\hline 1964 & no & May/June - "wet" \\
\hline 1965 & yes & May is within $30 \mathrm{~cm}$ for $14+$ days (starting May 4 th) \\
\hline 1966 & yes & August is within $30 \mathrm{~cm}$ for $14+$ days (starting August 5 th) \\
\hline 1967 & yes & June is within $30 \mathrm{~cm}$ for $14+$ days (starting June 8 th) \\
\hline 1968 & no & June - "wet" \\
\hline 1969 & yes & May is within $30 \mathrm{~cm}$ for $14+$ days (starting May 4 th) \\
\hline 1970 & no & May/June - "wet" \\
\hline 1971 & yes & June is within $30 \mathrm{~cm}$ for $14+$ days (starting June 17 th - prorated) \\
\hline 1972 & yes & July is within $30 \mathrm{~cm}$ for $14+$ days (starting July 10 th) \\
\hline 1973 & yes & May is within $30 \mathrm{~cm}$ for $14+$ days (starting May 4th) \\
\hline 1974 & no & May/June - "wet" \\
\hline 1975 & yes & July is within $30 \mathrm{~cm}$ for $14+$ days (starting July $1 \mathrm{st}$ ) \\
\hline 1976 & no & water table is not within $30 \mathrm{~cm}$ for $14+$ days \\
\hline 1977 & yes & August is within $30 \mathrm{~cm}$ for $14+$ days (starting August 27th - prorated) \\
\hline 1978 & yes & May is within $30 \mathrm{~cm}$ for $14+$ days (starting May 4 th) \\
\hline 1979 & yes & June is within $30 \mathrm{~cm}$ for $14+$ days (starting June $1 \mathrm{st}$ ) \\
\hline 1980 & yes & May is within $30 \mathrm{~cm}$ for $14+$ days (starting May 4th) \\
\hline 1981 & yes & June is within $30 \mathrm{~cm}$ for $14+$ days (starting June $1 \mathrm{st}$ ) \\
\hline 1982 & yes & May is within $30 \mathrm{~cm}$ for $14+$ days (starting May $4 \mathrm{th}$ ) \\
\hline 1983 & yes & May is within $30 \mathrm{~cm}$ for $14+$ days (starting May 4 th) \\
\hline 1984 & yes & May is within $30 \mathrm{~cm}$ for $14+$ days (starting May 4th) \\
\hline 1985 & yes & August is within $30 \mathrm{~cm}$ for $14+$ days (starting August 16 th - prorated) \\
\hline 1986 & yes & May is within $30 \mathrm{~cm}$ for $14+$ days (starting May 4 th) \\
\hline 1987 & yes & May is within $30 \mathrm{~cm}$ for $14+$ days (starting May 4th) \\
\hline 1988 & yes & May is within $30 \mathrm{~cm}$ for $14+$ days (starting May 4th) \\
\hline 1989 & yes & May is within $30 \mathrm{~cm}$ for $14+$ days (starting May 4th) \\
\hline 1990 & yes & June is within $30 \mathrm{~cm}$ for $14+$ days (starting June $1 \mathrm{st}$ ) \\
\hline 1991 & no & May/June - "wet" \\
\hline 1992 & yes & May is within $30 \mathrm{~cm}$ for $14+$ days (starting May 4th) \\
\hline 1993 & yes & May is within $30 \mathrm{~cm}$ for $14+$ days (starting May 4th) \\
\hline 1994 & yes & June is within $30 \mathrm{~cm}$ for $14+$ days (starting June $1 \mathrm{st}$ ) \\
\hline 1995 & yes & May is within $30 \mathrm{~cm}$ for $14+$ days (starting May 4th) \\
\hline 1996 & yes & May is within $30 \mathrm{~cm}$ for $14+$ days (starting May 4 th) \\
\hline 1997 & yes & May is within $30 \mathrm{~cm}$ for $14+$ days (starting May 4th) \\
\hline 1998 & yes & May is within $30 \mathrm{~cm}$ for $14+$ days (starting May 4th) \\
\hline 1999 & yes & July is within $30 \mathrm{~cm}$ for $14+$ days (starting July $1 \mathrm{st}$ ) \\
\hline 2000 & yes & May is within $30 \mathrm{~cm}$ for $14+$ days (starting May 4th) \\
\hline 2001 & yes & May is within $30 \mathrm{~cm}$ for $14+$ days (starting May 4th) \\
\hline 2002 & yes & May is within $30 \mathrm{~cm}$ for $14+$ days (starting May 4th) \\
\hline 2003 & yes & May is within $30 \mathrm{~cm}$ for $14+$ days (starting May 4th) \\
\hline 2004 & yes & May is within $30 \mathrm{~cm}$ for $14+$ days (starting May 4th) \\
\hline 2005 & yes & May is within $30 \mathrm{~cm}$ for $14+$ days (starting May 4th) \\
\hline
\end{tabular}


Table B.46: 45-year record for modified DAREM approach for plot S6 at Marcell. 26 out of 40 years met wetland hydrology, 3 years met water table criterion during "wet" periods while 11 years did not meet water table criterion.

\begin{tabular}{|c|c|c|}
\hline Year & Met/Not Met & Reason Year did or did not meet Wetland Hydrology \\
\hline 1961 & no data & \\
\hline 1962 & no data & \\
\hline 1963 & no data & \\
\hline 1964 & no data & \\
\hline 1965 & no & water table not within $30 \mathrm{~cm}$ for $14+$ days \\
\hline 1966 & no & water table not within $30 \mathrm{~cm}$ for $14+$ days \\
\hline 1967 & no & water table not within $30 \mathrm{~cm}$ for $14+$ days \\
\hline 1968 & no & water table not within $30 \mathrm{~cm}$ for $14+$ days \\
\hline 1969 & no & water table not within $30 \mathrm{~cm}$ for $14+$ days \\
\hline 1970 & no & water table not within $30 \mathrm{~cm}$ for $14+$ days \\
\hline 1971 & no & water table not within $30 \mathrm{~cm}$ for $14+$ days \\
\hline 1972 & no & water table not within $30 \mathrm{~cm}$ for $14+$ days \\
\hline 1973 & no & water table not within $30 \mathrm{~cm}$ for $14+$ days \\
\hline 1974 & no & May/June - "wet" \\
\hline 1975 & no data & \\
\hline 1976 & no & water table not within $30 \mathrm{~cm}$ for $14+$ days \\
\hline 1977 & yes & June is within $30 \mathrm{~cm}$ for $14+$ days (starting June 17 th - prorated) \\
\hline 1978 & yes & July is within $30 \mathrm{~cm}$ for $14+$ days (starting July $1 \mathrm{st}$ ) \\
\hline 1979 & yes & July is within $30 \mathrm{~cm}$ for $14+$ days (starting July $1 \mathrm{st}$ ) \\
\hline 1980 & yes & September is within $30 \mathrm{~cm}$ for $14+$ days (starting September 11 th) \\
\hline 1981 & no & May - "wet" \\
\hline 1982 & yes & May is within $30 \mathrm{~cm}$ for $14+$ days (starting May 11 th) \\
\hline 1983 & yes & May is within $30 \mathrm{~cm}$ for $14+$ days (starting May 4th) \\
\hline 1984 & yes & May is within $30 \mathrm{~cm}$ for $14+$ days (starting May 4th) \\
\hline 1985 & yes & August is within $30 \mathrm{~cm}$ for $14+$ days (starting August $1 \mathrm{st}$ ) \\
\hline 1986 & yes & May is within $30 \mathrm{~cm}$ for $14+$ days (starting May 4th) \\
\hline 1987 & yes & May is within $30 \mathrm{~cm}$ for $14+$ days (starting May 16 th - prorated) \\
\hline 1988 & yes & May is within $30 \mathrm{~cm}$ for $14+$ days (starting May $4 \mathrm{th}$ ) \\
\hline 1989 & yes & June is within $30 \mathrm{~cm}$ for $14+$ days (starting June 12 th) \\
\hline 1990 & yes & June is within $30 \mathrm{~cm}$ for $14+$ days (starting June $1 \mathrm{st}$ ) \\
\hline 1991 & no & water table not within $30 \mathrm{~cm}$ for $14+$ days \\
\hline 1992 & no & June/July/August - "wet" \\
\hline 1993 & yes & June is within $30 \mathrm{~cm}$ for $14+$ days (starting June 24th - prorated) \\
\hline 1994 & yes & June is within $30 \mathrm{~cm}$ for $14+$ days (starting June $1 \mathrm{st}$ ) \\
\hline 1995 & yes & May is within $30 \mathrm{~cm}$ for $14+$ days (starting May 4th) \\
\hline 1996 & yes & May is within $30 \mathrm{~cm}$ for $14+$ days (starting May 4th) \\
\hline 1997 & yes & May is within $30 \mathrm{~cm}$ for $14+$ days (starting May 4th) \\
\hline 1998 & yes & May is within $30 \mathrm{~cm}$ for $14+$ days (starting May 4 th) \\
\hline 1999 & yes & July is within $30 \mathrm{~cm}$ for $14+$ days (starting July $1 \mathrm{st}$ ) \\
\hline 2000 & yes & June is within $30 \mathrm{~cm}$ for $14+$ days (starting June $1 \mathrm{st}$ ) \\
\hline 2001 & yes & May is within $30 \mathrm{~cm}$ for $14+$ days (starting May 4th) \\
\hline 2002 & yes & May is within $30 \mathrm{~cm}$ for $14+$ days (starting May 4 th) \\
\hline 2003 & yes & May is within $30 \mathrm{~cm}$ for $14+$ days (starting May 4th) \\
\hline 2004 & yes & May is within $30 \mathrm{~cm}$ for $14+$ days (starting May 4th) \\
\hline 2005 & yes & May is within $30 \mathrm{~cm}$ for $14+$ days (starting May 4th) \\
\hline
\end{tabular}


Table B.47: 40-year record for the Army Corps 30-day Moving Total approach for plot $1 \mathrm{~L}$ at Greenville. This plot met wetland hydrology in 0 out of 40 years. All years did not meet water table saturation criterion.

\begin{tabular}{|c|c|c|}
\hline Year & $\begin{array}{c}\text { Met/Not } \\
\text { Met }\end{array}$ & Reason Year did or did not meet Wetland Hydrology \\
\hline 1959 & no & water table not within $30 \mathrm{~cm}$ for $14+$ days \\
\hline 1960 & no & water table not within $30 \mathrm{~cm}$ for $14+$ days \\
\hline 1961 & no & water table not within $30 \mathrm{~cm}$ for $14+$ days \\
\hline 1962 & no & water table not within $30 \mathrm{~cm}$ for $14+$ days \\
\hline 1963 & no & water table not within $30 \mathrm{~cm}$ for $14+$ days \\
\hline 1964 & no & water table not within $30 \mathrm{~cm}$ for $14+$ days \\
\hline 1965 & no & water table not within $30 \mathrm{~cm}$ for $14+$ days \\
\hline 1966 & no & water table not within $30 \mathrm{~cm}$ for $14+$ days \\
\hline 1967 & no & water table not within $30 \mathrm{~cm}$ for $14+$ days \\
\hline 1968 & no & water table not within $30 \mathrm{~cm}$ for $14+$ days \\
\hline 1969 & no & water table not within $30 \mathrm{~cm}$ for $14+$ days \\
\hline 1970 & no & water table not within $30 \mathrm{~cm}$ for $14+$ days \\
\hline 1971 & no & water table not within $30 \mathrm{~cm}$ for $14+$ days \\
\hline 1972 & no & water table not within $30 \mathrm{~cm}$ for $14+$ days \\
\hline 1973 & no & water table not within $30 \mathrm{~cm}$ for $14+$ days \\
\hline 1974 & no & water table not within $30 \mathrm{~cm}$ for $14+$ days \\
\hline 1975 & no & water table not within $30 \mathrm{~cm}$ for $14+$ days \\
\hline 1976 & no & water table not within $30 \mathrm{~cm}$ for $14+$ days \\
\hline 1977 & no & water table not within $30 \mathrm{~cm}$ for $14+$ days \\
\hline 1978 & no & water table not within $30 \mathrm{~cm}$ for $14+$ days \\
\hline 1979 & no & water table not within $30 \mathrm{~cm}$ for $14+$ days \\
\hline 1980 & no & water table not within $30 \mathrm{~cm}$ for $14+$ days \\
\hline 1981 & no & water table not within $30 \mathrm{~cm}$ for $14+$ days \\
\hline 1982 & no & water table not within $30 \mathrm{~cm}$ for $14+$ days \\
\hline 1983 & no & water table not within $30 \mathrm{~cm}$ for $14+$ days \\
\hline 1984 & no & water table not within $30 \mathrm{~cm}$ for $14+$ days \\
\hline 1985 & no & water table not within $30 \mathrm{~cm}$ for $14+$ days \\
\hline 1986 & no & water table not within $30 \mathrm{~cm}$ for $14+$ days \\
\hline 1987 & no & water table not within $30 \mathrm{~cm}$ for $14+$ days \\
\hline 1988 & no & water table not within $30 \mathrm{~cm}$ for $14+$ days \\
\hline 1989 & no & water table not within $30 \mathrm{~cm}$ for $14+$ days \\
\hline 1990 & no & water table not within $30 \mathrm{~cm}$ for $14+$ days \\
\hline 1991 & no & water table not within $30 \mathrm{~cm}$ for $14+$ days \\
\hline 1992 & no & water table not within $30 \mathrm{~cm}$ for $14+$ days \\
\hline 1993 & no & water table not within $30 \mathrm{~cm}$ for $14+$ days \\
\hline 1994 & no & water table not within $30 \mathrm{~cm}$ for $14+$ days \\
\hline 1995 & no & water table not within $30 \mathrm{~cm}$ for $14+$ days \\
\hline 1996 & no & water table not within $30 \mathrm{~cm}$ for $14+$ days \\
\hline 1997 & no & water table not within $30 \mathrm{~cm}$ for $14+$ days \\
\hline 1998 & no & water table not within $30 \mathrm{~cm}$ for $14+$ days \\
\hline
\end{tabular}


Table B.48: 40-year record for the Army Corps 30-day Moving Total approach for plot $2 \mathrm{~L}$ at Greenville. This plot met wetland hydrology in 0 out of 40 years. There was 1 year that did not meet wetland hydrology because water table saturation occurred during a "wet" period, while 39 years did not meet water table saturation criterion.

\begin{tabular}{|c|c|c|}
\hline Year & $\begin{array}{c}\text { Met/Not } \\
\text { Met }\end{array}$ & Reason Year did or did not meet Wetland Hydrology \\
\hline 1959 & no & water table not within $30 \mathrm{~cm}$ for 14+ days \\
\hline 1960 & no & water table not within $30 \mathrm{~cm}$ for $14+$ days \\
\hline 1961 & no & water table not within $30 \mathrm{~cm}$ for $14+$ days \\
\hline 1962 & no & water table not within $30 \mathrm{~cm}$ for $14+$ days \\
\hline 1963 & no & water table not within $30 \mathrm{~cm}$ for $14+$ days \\
\hline 1964 & no & water table not within $30 \mathrm{~cm}$ for $14+$ days \\
\hline 1965 & no & water table not within $30 \mathrm{~cm}$ for $14+$ days \\
\hline 1966 & no & August - "wet" \\
\hline 1967 & no & water table not within $30 \mathrm{~cm}$ for $14+$ days \\
\hline 1968 & no & water table not within $30 \mathrm{~cm}$ for $14+$ days \\
\hline 1969 & no & water table not within $30 \mathrm{~cm}$ for $14+$ days \\
\hline 1970 & no & water table not within $30 \mathrm{~cm}$ for $14+$ days \\
\hline 1971 & no & water table not within $30 \mathrm{~cm}$ for $14+$ days \\
\hline 1972 & no & water table not within $30 \mathrm{~cm}$ for $14+$ days \\
\hline 1973 & no & water table not within $30 \mathrm{~cm}$ for $14+$ days \\
\hline 1974 & no & water table not within $30 \mathrm{~cm}$ for $14+$ days \\
\hline 1975 & no & water table not within $30 \mathrm{~cm}$ for $14+$ days \\
\hline 1976 & no & water table not within $30 \mathrm{~cm}$ for $14+$ days \\
\hline 1977 & no & water table not within $30 \mathrm{~cm}$ for $14+$ days \\
\hline 1978 & no & water table not within $30 \mathrm{~cm}$ for $14+$ days \\
\hline 1979 & no & water table not within $30 \mathrm{~cm}$ for $14+$ days \\
\hline 1980 & no & water table not within $30 \mathrm{~cm}$ for $14+$ days \\
\hline 1981 & no & water table not within $30 \mathrm{~cm}$ for $14+$ days \\
\hline 1982 & no & water table not within $30 \mathrm{~cm}$ for $14+$ days \\
\hline 1983 & no & water table not within $30 \mathrm{~cm}$ for $14+$ days \\
\hline 1984 & no & water table not within $30 \mathrm{~cm}$ for $14+$ days \\
\hline 1985 & no & water table not within $30 \mathrm{~cm}$ for $14+$ days \\
\hline 1986 & no & water table not within $30 \mathrm{~cm}$ for $14+$ days \\
\hline 1987 & no & water table not within $30 \mathrm{~cm}$ for $14+$ days \\
\hline 1988 & no & water table not within $30 \mathrm{~cm}$ for $14+$ days \\
\hline 1989 & no & water table not within $30 \mathrm{~cm}$ for $14+$ days \\
\hline 1990 & no & water table not within $30 \mathrm{~cm}$ for $14+$ days \\
\hline 1991 & no & water table not within $30 \mathrm{~cm}$ for $14+$ days \\
\hline 1992 & no & water table not within $30 \mathrm{~cm}$ for $14+$ days \\
\hline 1993 & no & water table not within $30 \mathrm{~cm}$ for $14+$ days \\
\hline 1994 & no & water table not within $30 \mathrm{~cm}$ for $14+$ days \\
\hline 1995 & no & water table not within $30 \mathrm{~cm}$ for $14+$ days \\
\hline 1996 & no & water table not within $30 \mathrm{~cm}$ for $14+$ days \\
\hline 1997 & no & water table not within $30 \mathrm{~cm}$ for $14+$ days \\
\hline 1998 & no & water table not within $30 \mathrm{~cm}$ for $14+$ days \\
\hline
\end{tabular}


Table B.49: 40-year record for the Army Corps 30-day Moving Total approach for plot $3 \mathrm{~L}$ at Greenville. This plot met wetland hydrology in 0 out of 40 years. There was 1 year that did not meet wetland hydrology because water table saturation occurred during a "wet" period, while 39 years did not meet water table saturation criterion.

\begin{tabular}{|c|c|c|}
\hline Year & $\begin{array}{c}\text { Met/Not } \\
\text { Met }\end{array}$ & Reason Year did or did not meet Wetland Hydrology \\
\hline 1959 & no & water table not within $30 \mathrm{~cm}$ for 14+ days \\
\hline 1960 & no & water table not within $30 \mathrm{~cm}$ for $14+$ days \\
\hline 1961 & no & water table not within $30 \mathrm{~cm}$ for $14+$ days \\
\hline 1962 & no & water table not within $30 \mathrm{~cm}$ for $14+$ days \\
\hline 1963 & no & water table not within $30 \mathrm{~cm}$ for $14+$ days \\
\hline 1964 & no & water table not within $30 \mathrm{~cm}$ for $14+$ days \\
\hline 1965 & no & water table not within $30 \mathrm{~cm}$ for $14+$ days \\
\hline 1966 & no & August - "wet" \\
\hline 1967 & no & water table not within $30 \mathrm{~cm}$ for $14+$ days \\
\hline 1968 & no & water table not within $30 \mathrm{~cm}$ for $14+$ days \\
\hline 1969 & no & water table not within $30 \mathrm{~cm}$ for $14+$ days \\
\hline 1970 & no & water table not within $30 \mathrm{~cm}$ for $14+$ days \\
\hline 1971 & no & water table not within $30 \mathrm{~cm}$ for $14+$ days \\
\hline 1972 & no & water table not within $30 \mathrm{~cm}$ for $14+$ days \\
\hline 1973 & no & water table not within $30 \mathrm{~cm}$ for $14+$ days \\
\hline 1974 & no & water table not within $30 \mathrm{~cm}$ for $14+$ days \\
\hline 1975 & no & water table not within $30 \mathrm{~cm}$ for $14+$ days \\
\hline 1976 & no & water table not within $30 \mathrm{~cm}$ for $14+$ days \\
\hline 1977 & no & water table not within $30 \mathrm{~cm}$ for $14+$ days \\
\hline 1978 & no & water table not within $30 \mathrm{~cm}$ for $14+$ days \\
\hline 1979 & no & water table not within $30 \mathrm{~cm}$ for $14+$ days \\
\hline 1980 & no & water table not within $30 \mathrm{~cm}$ for $14+$ days \\
\hline 1981 & no & water table not within $30 \mathrm{~cm}$ for $14+$ days \\
\hline 1982 & no & water table not within $30 \mathrm{~cm}$ for $14+$ days \\
\hline 1983 & no & water table not within $30 \mathrm{~cm}$ for $14+$ days \\
\hline 1984 & no & water table not within $30 \mathrm{~cm}$ for $14+$ days \\
\hline 1985 & no & water table not within $30 \mathrm{~cm}$ for $14+$ days \\
\hline 1986 & no & water table not within $30 \mathrm{~cm}$ for $14+$ days \\
\hline 1987 & no & water table not within $30 \mathrm{~cm}$ for $14+$ days \\
\hline 1988 & no & water table not within $30 \mathrm{~cm}$ for $14+$ days \\
\hline 1989 & no & water table not within $30 \mathrm{~cm}$ for $14+$ days \\
\hline 1990 & no & water table not within $30 \mathrm{~cm}$ for $14+$ days \\
\hline 1991 & no & water table not within $30 \mathrm{~cm}$ for $14+$ days \\
\hline 1992 & no & water table not within $30 \mathrm{~cm}$ for $14+$ days \\
\hline 1993 & no & water table not within $30 \mathrm{~cm}$ for $14+$ days \\
\hline 1994 & no & water table not within $30 \mathrm{~cm}$ for $14+$ days \\
\hline 1995 & no & water table not within $30 \mathrm{~cm}$ for $14+$ days \\
\hline 1996 & no & water table not within $30 \mathrm{~cm}$ for $14+$ days \\
\hline 1997 & no & water table not within $30 \mathrm{~cm}$ for $14+$ days \\
\hline 1998 & no & water table not within $30 \mathrm{~cm}$ for $14+$ days \\
\hline
\end{tabular}


Table B.50: 40-year record for the Army Corps 30-day Moving Total approach for plot $1 \mathrm{~L}$ at Greenville. This plot met wetland hydrology in 0 out of 40 years. All years did not meet water table saturation criterion.

\begin{tabular}{|c|c|c|}
\hline Year & $\begin{array}{c}\text { Met/Not } \\
\text { Met }\end{array}$ & Reason Year did or did not meet Wetland Hydrology \\
\hline 1959 & no & water table not within $30 \mathrm{~cm}$ for $14+$ days \\
\hline 1960 & no & water table not within $30 \mathrm{~cm}$ for $14+$ days \\
\hline 1961 & no & water table not within $30 \mathrm{~cm}$ for $14+$ days \\
\hline 1962 & no & water table not within $30 \mathrm{~cm}$ for $14+$ days \\
\hline 1963 & no & water table not within $30 \mathrm{~cm}$ for $14+$ days \\
\hline 1964 & no & water table not within $30 \mathrm{~cm}$ for $14+$ days \\
\hline 1965 & no & water table not within $30 \mathrm{~cm}$ for $14+$ days \\
\hline 1966 & no & water table not within $30 \mathrm{~cm}$ for $14+$ days \\
\hline 1967 & no & water table not within $30 \mathrm{~cm}$ for $14+$ days \\
\hline 1968 & no & water table not within $30 \mathrm{~cm}$ for $14+$ days \\
\hline 1969 & no & water table not within $30 \mathrm{~cm}$ for $14+$ days \\
\hline 1970 & no & water table not within $30 \mathrm{~cm}$ for $14+$ days \\
\hline 1971 & no & water table not within $30 \mathrm{~cm}$ for $14+$ days \\
\hline 1972 & no & water table not within $30 \mathrm{~cm}$ for $14+$ days \\
\hline 1973 & no & water table not within $30 \mathrm{~cm}$ for $14+$ days \\
\hline 1974 & no & water table not within $30 \mathrm{~cm}$ for $14+$ days \\
\hline 1975 & no & water table not within $30 \mathrm{~cm}$ for $14+$ days \\
\hline 1976 & no & water table not within $30 \mathrm{~cm}$ for $14+$ days \\
\hline 1977 & no & water table not within $30 \mathrm{~cm}$ for $14+$ days \\
\hline 1978 & no & water table not within $30 \mathrm{~cm}$ for $14+$ days \\
\hline 1979 & no & water table not within $30 \mathrm{~cm}$ for $14+$ days \\
\hline 1980 & no & water table not within $30 \mathrm{~cm}$ for $14+$ days \\
\hline 1981 & no & water table not within $30 \mathrm{~cm}$ for $14+$ days \\
\hline 1982 & no & water table not within $30 \mathrm{~cm}$ for $14+$ days \\
\hline 1983 & no & water table not within $30 \mathrm{~cm}$ for $14+$ days \\
\hline 1984 & no & water table not within $30 \mathrm{~cm}$ for $14+$ days \\
\hline 1985 & no & water table not within $30 \mathrm{~cm}$ for $14+$ days \\
\hline 1986 & no & water table not within $30 \mathrm{~cm}$ for $14+$ days \\
\hline 1987 & no & water table not within $30 \mathrm{~cm}$ for $14+$ days \\
\hline 1988 & no & water table not within $30 \mathrm{~cm}$ for $14+$ days \\
\hline 1989 & no & water table not within $30 \mathrm{~cm}$ for $14+$ days \\
\hline 1990 & no & water table not within $30 \mathrm{~cm}$ for $14+$ days \\
\hline 1991 & no & water table not within $30 \mathrm{~cm}$ for $14+$ days \\
\hline 1992 & no & water table not within $30 \mathrm{~cm}$ for $14+$ days \\
\hline 1993 & no & water table not within $30 \mathrm{~cm}$ for $14+$ days \\
\hline 1994 & no & water table not within $30 \mathrm{~cm}$ for $14+$ days \\
\hline 1995 & no & water table not within $30 \mathrm{~cm}$ for $14+$ days \\
\hline 1996 & no & water table not within $30 \mathrm{~cm}$ for $14+$ days \\
\hline 1997 & no & water table not within $30 \mathrm{~cm}$ for $14+$ days \\
\hline 1998 & no & water table not within $30 \mathrm{~cm}$ for $14+$ days \\
\hline
\end{tabular}


Table B.51: 40-year record for the Army Corps 30-day Moving Total approach for plot 1R at Greenville. This plot met wetland hydrology in 13 out of 40 years. There were 22 year that did not meet wetland hydrology because water table (WT) saturation occurred during "wet" periods, while 5 years did not meet water table saturation criterion.

\begin{tabular}{|c|c|c|}
\hline Year & $\begin{array}{c}\text { Met/Not } \\
\text { Met }\end{array}$ & Reason Year did or did not meet Wetland Hydrology \\
\hline 1959 & yes & WT is within $30 \mathrm{~cm}$ for $14+$ days and rainfall is under 70 th percentile \\
\hline 1960 & no & Moving total exceeds 70 th percentile \\
\hline 1961 & no & Moving total exceeds 70th percentile \\
\hline 1962 & no & Moving total exceeds 70th percentile \\
\hline 1963 & yes & WT is within $30 \mathrm{~cm}$ for $14+$ days and rainfall is under 70 th percentile \\
\hline 1964 & no & Moving total exceeds 70 th percentile \\
\hline 1965 & yes & WT is within $30 \mathrm{~cm}$ for $14+$ days and rainfall is under 70 th percentile \\
\hline 1966 & no & Moving total exceeds 70 th percentile \\
\hline 1967 & no & WT is not within $30 \mathrm{~cm}$ for $14+$ days \\
\hline 1968 & no & Moving total exceeds 70 th percentile \\
\hline 1969 & no & Moving total exceeds 70 th percentile \\
\hline 1970 & yes & WT is within $30 \mathrm{~cm}$ for $14+$ days and rainfall is under 70 th percentile \\
\hline 1971 & no & Moving total exceeds 70 th percentile \\
\hline 1972 & yes & WT is within $30 \mathrm{~cm}$ for $14+$ days and rainfall is under 70 th percentile \\
\hline 1973 & yes & WT is within $30 \mathrm{~cm}$ for $14+$ days and rainfall is under 70 th percentile \\
\hline 1974 & yes & WT is within $30 \mathrm{~cm}$ for $14+$ days and rainfall is under 70 th percentile \\
\hline 1975 & yes & WT is within $30 \mathrm{~cm}$ for $14+$ days and rainfall is under 70 th percentile \\
\hline 1976 & no & WT is not within $30 \mathrm{~cm}$ for $14+$ days \\
\hline 1977 & no & Moving total exceeds 70 th percentile \\
\hline 1978 & no & Moving total exceeds 70 th percentile \\
\hline 1979 & no & Moving total exceeds 70th percentile \\
\hline 1980 & no & Moving total exceeds 70 th percentile \\
\hline 1981 & yes & WT is within $30 \mathrm{~cm}$ for $14+$ days and rainfall is under 70 th percentile \\
\hline 1982 & yes & WT is within $30 \mathrm{~cm}$ for $14+$ days and rainfall is under 70 th percentile \\
\hline 1983 & no & Moving total exceeds 70 th percentile \\
\hline 1984 & no & Moving total exceeds 70 th percentile \\
\hline 1985 & no & WT is not within $30 \mathrm{~cm}$ for $14+$ days \\
\hline 1986 & no & WT is not within $30 \mathrm{~cm}$ for $14+$ days \\
\hline 1987 & no & Moving total exceeds 70 th percentile \\
\hline 1988 & no & Moving total exceeds 70 th percentile \\
\hline 1989 & no & Moving total exceeds 70th percentile \\
\hline 1990 & no & Moving total exceeds 70 th percentile \\
\hline 1991 & no & WT is not within $30 \mathrm{~cm}$ for $14+$ days \\
\hline 1992 & yes & WT is within $30 \mathrm{~cm}$ for $14+$ days and rainfall is under 70 th percentile \\
\hline 1993 & no & Moving total exceeds 70 th percentile \\
\hline 1994 & no & Moving total exceeds 70th percentile \\
\hline 1995 & no & Moving total exceeds 70 th percentile \\
\hline 1996 & yes & WT is within $30 \mathrm{~cm}$ for $14+$ days and rainfall is under 70 th percentile \\
\hline 1997 & yes & WT is within $30 \mathrm{~cm}$ for $14+$ days and rainfall is under 70 th percentile \\
\hline 1998 & no & Moving total exceeds 70 th percentile \\
\hline
\end{tabular}


Table B.52: 40-year record for the Army Corps 30-day Moving Total approach for plot 2R at Greenville. This plot met wetland hydrology in 28 out of 40 years. There were 12 years that did not meet wetland hydrology because water table (WT) saturation occurred during "wet" periods.

\begin{tabular}{|c|c|c|}
\hline Year & $\begin{array}{c}\text { Met/Not } \\
\text { Met }\end{array}$ & Reason Year did or did not meet Wetland Hydrology \\
\hline 1959 & yes & WT is within $30 \mathrm{~cm}$ for $14+$ days and rainfall is under 70 th percentile \\
\hline 1960 & yes & WT is within $30 \mathrm{~cm}$ for $14+$ days and rainfall is under 70 th percentile \\
\hline 1961 & no & Moving Total exceeds 70th Percentile \\
\hline 1962 & no & Moving Total exceeds 70th Percentile \\
\hline 1963 & yes & WT is within $30 \mathrm{~cm}$ for $14+$ days and rainfall is under 70 th percentile \\
\hline 1964 & no & Moving Total exceeds 70th Percentile \\
\hline 1965 & yes & WT is within $30 \mathrm{~cm}$ for $14+$ days and rainfall is under 70 th percentile \\
\hline 1966 & yes & WT is within $30 \mathrm{~cm}$ for $14+$ days and rainfall is under 70 th percentile \\
\hline 1967 & yes & WT is within $30 \mathrm{~cm}$ for $14+$ days and rainfall is under 70 th percentile \\
\hline 1968 & no & Moving Total exceeds 70th Percentile \\
\hline 1969 & yes & WT is within $30 \mathrm{~cm}$ for $14+$ days and rainfall is under 70 th percentile \\
\hline 1970 & yes & WT is within $30 \mathrm{~cm}$ for $14+$ days and rainfall is under 70 th percentile \\
\hline 1971 & yes & WT is within $30 \mathrm{~cm}$ for $14+$ days and rainfall is under 70 th percentile \\
\hline 1972 & yes & WT is within $30 \mathrm{~cm}$ for $14+$ days and rainfall is under 70 th percentile \\
\hline 1973 & no & Moving Total exceeds 70th Percentile \\
\hline 1974 & yes & WT is within $30 \mathrm{~cm}$ for $14+$ days and rainfall is under 70 th percentile \\
\hline 1975 & no & Moving Total exceeds 70th Percentile \\
\hline 1976 & yes & WT is within $30 \mathrm{~cm}$ for $14+$ days and rainfall is under 70 th percentile \\
\hline 1977 & no & Moving Total exceeds 70th Percentile \\
\hline 1978 & yes & WT is within $30 \mathrm{~cm}$ for $14+$ days and rainfall is under 70 th percentile \\
\hline 1979 & yes & WT is within $30 \mathrm{~cm}$ for $14+$ days and rainfall is under 70 th percentile \\
\hline 1980 & no & Moving Total exceeds 70th Percentile \\
\hline 1981 & yes & WT is within $30 \mathrm{~cm}$ for $14+$ days and rainfall is under 70 th percentile \\
\hline 1982 & yes & WT is within $30 \mathrm{~cm}$ for $14+$ days and rainfall is under 70 th percentile \\
\hline 1983 & yes & WT is within $30 \mathrm{~cm}$ for $14+$ days and rainfall is under 70 th percentile \\
\hline 1984 & no & Moving Total exceeds 70th Percentile \\
\hline 1985 & yes & WT is within $30 \mathrm{~cm}$ for $14+$ days and rainfall is under 70 th percentile \\
\hline 1986 & yes & WT is within $30 \mathrm{~cm}$ for $14+$ days and rainfall is under 70 th percentile \\
\hline 1987 & no & Moving Total exceeds 70th Percentile \\
\hline 1988 & yes & WT is within $30 \mathrm{~cm}$ for $14+$ days and rainfall is under 70 th percentile \\
\hline 1989 & no & Moving Total exceeds 70th Percentile \\
\hline 1990 & yes & WT is within $30 \mathrm{~cm}$ for $14+$ days and rainfall is under 70 th percentile \\
\hline 1991 & yes & WT is within $30 \mathrm{~cm}$ for $14+$ days and rainfall is under 70 th percentile \\
\hline 1992 & yes & WT is within $30 \mathrm{~cm}$ for $14+$ days and rainfall is under 70 th percentile \\
\hline 1993 & no & Moving Total exceeds 70th Percentile \\
\hline 1994 & yes & WT is within $30 \mathrm{~cm}$ for $14+$ days and rainfall is under 70 th percentile \\
\hline 1995 & yes & WT is within $30 \mathrm{~cm}$ for $14+$ days and rainfall is under 70 th percentile \\
\hline 1996 & yes & WT is within $30 \mathrm{~cm}$ for $14+$ days and rainfall is under 70 th percentile \\
\hline 1997 & yes & WT is within $30 \mathrm{~cm}$ for $14+$ days and rainfall is under 70 th percentile \\
\hline 1998 & yes & WT is within $30 \mathrm{~cm}$ for $14+$ days and rainfall is under 70 th percentile \\
\hline
\end{tabular}


Table B.53: 40-year record for the Army Corps 30-day Moving Total approach for plot 3R at Greenville. This plot met wetland hydrology in 27 out of 40 years. There were 12 years that did not meet wetland hydrology because water table (WT) saturation occurred during "wet" periods, while 1 year did not meet water table saturation criterion.

\begin{tabular}{|c|c|c|}
\hline Year & $\begin{array}{c}\text { Met/Not } \\
\text { Met }\end{array}$ & Reason Year did or did not meet Wetland Hydrology \\
\hline 1959 & yes & WT is within $30 \mathrm{~cm}$ for $14+$ days and under the 70 th percentile \\
\hline 1960 & yes & WT is within $30 \mathrm{~cm}$ for $14+$ days and under the 70 th percentile \\
\hline 1961 & no & Moving total exceeds 70th Percentile \\
\hline 1962 & no & Moving total exceeds 70th Percentile \\
\hline 1963 & yes & WT is within $30 \mathrm{~cm}$ for $14+$ days and under the 70 th percentile \\
\hline 1964 & no & Moving total exceeds 70th Percentile \\
\hline 1965 & yes & WT is within $30 \mathrm{~cm}$ for $14+$ days and under the 70 th percentile \\
\hline 1966 & yes & WT is within $30 \mathrm{~cm}$ for $14+$ days and under the 70 th percentile \\
\hline 1967 & yes & WT is within $30 \mathrm{~cm}$ for $14+$ days and under the 70 th percentile \\
\hline 1968 & no & Moving total exceeds 70th Percentile \\
\hline 1969 & yes & WT is within $30 \mathrm{~cm}$ for $14+$ days and under the 70 th percentile \\
\hline 1970 & yes & WT is within $30 \mathrm{~cm}$ for $14+$ days and under the 70 th percentile \\
\hline 1971 & yes & WT is within $30 \mathrm{~cm}$ for $14+$ days and under the 70 th percentile \\
\hline 1972 & yes & WT is within $30 \mathrm{~cm}$ for $14+$ days and under the 70 th percentile \\
\hline 1973 & no & Moving total exceeds 70th Percentile \\
\hline 1974 & yes & WT is within $30 \mathrm{~cm}$ for $14+$ days and under the 70 th percentile \\
\hline 1975 & no & Moving total exceeds 70th Percentile \\
\hline 1976 & no & WT is not within $30 \mathrm{~cm}$ for $14+$ days \\
\hline 1977 & no & Moving total exceeds 70th Percentile \\
\hline 1978 & yes & WT is within $30 \mathrm{~cm}$ for $14+$ days and under the 70 th percentile \\
\hline 1979 & yes & WT is within $30 \mathrm{~cm}$ for $14+$ days and under the 70 th percentile \\
\hline 1980 & no & Moving total exceeds 70 th Percentile \\
\hline 1981 & yes & WT is within $30 \mathrm{~cm}$ for $14+$ days and under the 70 th percentile \\
\hline 1982 & yes & WT is within $30 \mathrm{~cm}$ for $14+$ days and under the 70 th percentile \\
\hline 1983 & yes & WT is within $30 \mathrm{~cm}$ for $14+$ days and under the 70 th percentile \\
\hline 1984 & no & Moving total exceeds 70th Percentile \\
\hline 1985 & yes & WT is within $30 \mathrm{~cm}$ for $14+$ days and under the 70 th percentile \\
\hline 1986 & yes & WT is within $30 \mathrm{~cm}$ for $14+$ days and under the 70 th percentile \\
\hline 1987 & no & Moving total exceeds 70th Percentile \\
\hline 1988 & yes & WT is within $30 \mathrm{~cm}$ for $14+$ days and under the 70 th percentile \\
\hline 1989 & no & Moving total exceeds 70th Percentile \\
\hline 1990 & yes & WT is within $30 \mathrm{~cm}$ for $14+$ days and under the 70 th percentile \\
\hline 1991 & yes & WT is within $30 \mathrm{~cm}$ for $14+$ days and under the 70 th percentile \\
\hline 1992 & yes & WT is within $30 \mathrm{~cm}$ for $14+$ days and under the 70 th percentile \\
\hline 1993 & no & Moving total exceeds 70th Percentile \\
\hline 1994 & yes & WT is within $30 \mathrm{~cm}$ for $14+$ days and under the 70 th percentile \\
\hline 1995 & yes & WT is within $30 \mathrm{~cm}$ for $14+$ days and under the 70 th percentile \\
\hline 1996 & yes & WT is within $30 \mathrm{~cm}$ for $14+$ days and under the 70 th percentile \\
\hline 1997 & yes & WT is within $30 \mathrm{~cm}$ for $14+$ days and under the 70 th percentile \\
\hline 1998 & yes & WT is within $30 \mathrm{~cm}$ for $14+$ days and under the 70 th percentile \\
\hline
\end{tabular}


Table B.54: 40-year record for the Army Corps 30-day Moving Total approach for plot 4R at Greenville. This plot met wetland hydrology in 25 out of 40 years. There were 13 years that did not meet wetland hydrology because water table (WT) saturation occurred during "wet" periods, while 2 years did not meet water table saturation criterion.

\begin{tabular}{|c|c|c|}
\hline Year & $\begin{array}{c}\text { Met/Not } \\
\text { Met }\end{array}$ & Reason Year did or did not meet Wetland Hydrology \\
\hline 1959 & yes & WT is within $30 \mathrm{~cm}$ for $14+$ days and does not exceed the 70 th percentile \\
\hline 1960 & yes & WT is within $30 \mathrm{~cm}$ for $14+$ days and does not exceed the 70 th percentile \\
\hline 1961 & no & Moving total exceeds 70 th percentile \\
\hline 1962 & no & Moving total exceeds 70th percentile \\
\hline 1963 & yes & WT is within $30 \mathrm{~cm}$ for $14+$ days and does not exceed the 70 th percentile \\
\hline 1964 & no & Moving total exceeds 70 th percentile \\
\hline 1965 & yes & WT is within $30 \mathrm{~cm}$ for $14+$ days and does not exceed the 70 th percentile \\
\hline 1966 & yes & WT is within $30 \mathrm{~cm}$ for $14+$ days and does not exceed the 70 th percentile \\
\hline 1967 & yes & WT is within $30 \mathrm{~cm}$ for $14+$ days and does not exceed the 70 th percentile \\
\hline 1968 & no & Moving total exceeds 70th percentile \\
\hline 1969 & yes & WT is within $30 \mathrm{~cm}$ for $14+$ days and does not exceed the 70 th percentile \\
\hline 1970 & yes & WT is within $30 \mathrm{~cm}$ for $14+$ days and does not exceed the 70 th percentile \\
\hline 1971 & yes & WT is within $30 \mathrm{~cm}$ for $14+$ days and does not exceed the 70 th percentile \\
\hline 1972 & yes & WT is within $30 \mathrm{~cm}$ for $14+$ days and does not exceed the 70 th percentile \\
\hline 1973 & no & Moving total exceeds 70th percentile \\
\hline 1974 & yes & WT is within $30 \mathrm{~cm}$ for $14+$ days and does not exceed the 70 th percentile \\
\hline 1975 & no & Moving total exceeds 70 th percentile \\
\hline 1976 & no & WT is not within $30 \mathrm{~cm}$ for $14+$ days \\
\hline 1977 & no & Moving total exceeds 70th percentile \\
\hline 1978 & yes & WT is within $30 \mathrm{~cm}$ for $14+$ days and does not exceed the 70 th percentile \\
\hline 1979 & yes & WT is within $30 \mathrm{~cm}$ for $14+$ days and does not exceed the 70 th percentile \\
\hline 1980 & no & Moving total exceeds 70th percentile \\
\hline 1981 & no & Moving total exceeds 70 th percentile \\
\hline 1982 & yes & WT is within $30 \mathrm{~cm}$ for $14+$ days and does not exceed the 70 th percentile \\
\hline 1983 & yes & WT is within $30 \mathrm{~cm}$ for $14+$ days and does not exceed the 70 th percentile \\
\hline 1984 & no & Moving total exceeds 70th percentile \\
\hline 1985 & no & WT is not within $30 \mathrm{~cm}$ for $14+$ days \\
\hline 1986 & yes & WT is within $30 \mathrm{~cm}$ for $14+$ days and does not exceed the 70 th percentile \\
\hline 1987 & no & Moving total exceeds 70 th percentile \\
\hline 1988 & yes & WT is within $30 \mathrm{~cm}$ for $14+$ days and does not exceed the 70 th percentile \\
\hline 1989 & no & Moving total exceeds 70 th percentile \\
\hline 1990 & yes & WT is within $30 \mathrm{~cm}$ for $14+$ days and does not exceed the 70 th percentile \\
\hline 1991 & yes & WT is within $30 \mathrm{~cm}$ for $14+$ days and does not exceed the 70 th percentile \\
\hline 1992 & yes & WT is within $30 \mathrm{~cm}$ for $14+$ days and does not exceed the 70 th percentile \\
\hline 1993 & no & Moving total exceeds 70 th percentile \\
\hline 1994 & yes & WT is within $30 \mathrm{~cm}$ for $14+$ days and does not exceed the 70 th percentile \\
\hline 1995 & yes & WT is within $30 \mathrm{~cm}$ for $14+$ days and does not exceed the 70 th percentile \\
\hline 1996 & yes & WT is within $30 \mathrm{~cm}$ for $14+$ days and does not exceed the 70 th percentile \\
\hline 1997 & yes & WT is within $30 \mathrm{~cm}$ for $14+$ days and does not exceed the 70 th percentile \\
\hline 1998 & yes & WT is within $30 \mathrm{~cm}$ for $14+$ days and does not exceed the 70 th percentile \\
\hline
\end{tabular}


Table B.55: 40-year record for the Army Corps 30-day Moving Total approach for plot 4P at Greenville. This plot met wetland hydrology in 31 out of 40 years. There were 8 years that did not meet wetland hydrology because water table (WT) saturation occurred during "wet" periods, while 1 year did not meet water table saturation criterion.

\begin{tabular}{|c|c|c|}
\hline Year & $\begin{array}{c}\text { Met/Not } \\
\text { Met }\end{array}$ & Reason Year did or did not meet Wetland Hydrology \\
\hline 1959 & yes & WT is within $30 \mathrm{~cm}$ for $14+$ days and does not exceed 70 th Percentile \\
\hline 1960 & yes & WT is within $30 \mathrm{~cm}$ for $14+$ days and does not exceed 70 th Percentile \\
\hline 1961 & no & Moving total exceeds 70th Percentile \\
\hline 1962 & no & Moving total exceeds 70th Percentile \\
\hline 1963 & yes & WT is within $30 \mathrm{~cm}$ for $14+$ days and does not exceed 70th Percentile \\
\hline 1964 & yes & WT is within $30 \mathrm{~cm}$ for $14+$ days and does not exceed 70th Percentile \\
\hline 1965 & yes & WT is within $30 \mathrm{~cm}$ for $14+$ days and does not exceed 70th Percentile \\
\hline 1966 & yes & WT is within $30 \mathrm{~cm}$ for $14+$ days and does not exceed 70th Percentile \\
\hline 1967 & yes & WT is within $30 \mathrm{~cm}$ for $14+$ days and does not exceed 70th Percentile \\
\hline 1968 & no & Moving total exceeds 70th Percentile \\
\hline 1969 & yes & WT is within $30 \mathrm{~cm}$ for $14+$ days and does not exceed 70th Percentile \\
\hline 1970 & yes & WT is within $30 \mathrm{~cm}$ for $14+$ days and does not exceed 70th Percentile \\
\hline 1971 & yes & WT is within $30 \mathrm{~cm}$ for $14+$ days and does not exceed 70th Percentile \\
\hline 1972 & yes & WT is within $30 \mathrm{~cm}$ for $14+$ days and does not exceed 70th Percentile \\
\hline 1973 & no & Moving total exceeds 70th Percentile \\
\hline 1974 & yes & WT is within $30 \mathrm{~cm}$ for $14+$ days and does not exceed 70th Percentile \\
\hline 1975 & yes & WT is within $30 \mathrm{~cm}$ for $14+$ days and does not exceed 70 th Percentile \\
\hline 1976 & no & WT is not within $30 \mathrm{~cm}$ for $14+$ days \\
\hline 1977 & yes & WT is within $30 \mathrm{~cm}$ for $14+$ days and does not exceed 70 th Percentile \\
\hline 1978 & yes & WT is within $30 \mathrm{~cm}$ for $14+$ days and does not exceed 70th Percentile \\
\hline 1979 & yes & WT is within $30 \mathrm{~cm}$ for $14+$ days and does not exceed 70th Percentile \\
\hline 1980 & no & Moving total exceeds 70th Percentile \\
\hline 1981 & yes & WT is within $30 \mathrm{~cm}$ for $14+$ days and does not exceed 70th Percentile \\
\hline 1982 & yes & WT is within $30 \mathrm{~cm}$ for $14+$ days and does not exceed 70th Percentile \\
\hline 1983 & yes & WT is within $30 \mathrm{~cm}$ for $14+$ days and does not exceed 70th Percentile \\
\hline 1984 & no & Moving total exceeds 70th Percentile \\
\hline 1985 & yes & WT is within $30 \mathrm{~cm}$ for $14+$ days and does not exceed 70th Percentile \\
\hline 1986 & yes & WT is within $30 \mathrm{~cm}$ for $14+$ days and does not exceed 70th Percentile \\
\hline 1987 & no & Moving total exceeds 70th Percentile \\
\hline 1988 & yes & WT is within $30 \mathrm{~cm}$ for $14+$ days and does not exceed 70 th Percentile \\
\hline 1989 & no & Moving total exceeds 70th Percentile \\
\hline 1990 & yes & WT is within $30 \mathrm{~cm}$ for $14+$ days and does not exceed 70th Percentile \\
\hline 1991 & yes & WT is within $30 \mathrm{~cm}$ for $14+$ days and does not exceed 70 th Percentile \\
\hline 1992 & yes & WT is within $30 \mathrm{~cm}$ for $14+$ days and does not exceed 70th Percentile \\
\hline 1993 & yes & WT is within $30 \mathrm{~cm}$ for $14+$ days and does not exceed 70 th Percentile \\
\hline 1994 & yes & WT is within $30 \mathrm{~cm}$ for $14+$ days and does not exceed 70th Percentile \\
\hline 1995 & yes & WT is within $30 \mathrm{~cm}$ for $14+$ days and does not exceed 70th Percentile \\
\hline 1996 & yes & WT is within $30 \mathrm{~cm}$ for $14+$ days and does not exceed 70th Percentile \\
\hline 1997 & yes & WT is within $30 \mathrm{~cm}$ for $14+$ days and does not exceed 70th Percentile \\
\hline 1998 & yes & WT is within $30 \mathrm{~cm}$ for $14+$ days and does not exceed 70th Percentile \\
\hline
\end{tabular}


Table B.56: 45-year record for the Army Corps 30-day Moving Total approach for plot $2 \mathrm{~N}$ at Bertie. This plot met wetland hydrology in 0 out of 45 years. There were 5 years that did not meet wetland hydrology because water table (WT) saturation occurred during "wet" periods, while 40 years did not meet water table saturation criterion.

\begin{tabular}{|c|c|c|}
\hline Year & $\begin{array}{c}\text { Met/Not } \\
\text { Met }\end{array}$ & Reason Year did or did not meet Wetland Hydrology \\
\hline 1950 & no & WT is within $30 \mathrm{~cm}$ for $14+$ days above 70 th percentile \\
\hline 1951 & no & water table is not within $30 \mathrm{~cm}$ for $14+$ days \\
\hline 1952 & no & water table is not within $30 \mathrm{~cm}$ for $14+$ days \\
\hline 1953 & no & water table is not within $30 \mathrm{~cm}$ for $14+$ days \\
\hline 1954 & no & water table is not within $30 \mathrm{~cm}$ for $14+$ days \\
\hline 1955 & no & water table is not within $30 \mathrm{~cm}$ for $14+$ days \\
\hline 1956 & no & water table is not within $30 \mathrm{~cm}$ for $14+$ days \\
\hline 1957 & no & water table is not within $30 \mathrm{~cm}$ for $14+$ days \\
\hline 1958 & no & water table is not within $30 \mathrm{~cm}$ for $14+$ days \\
\hline 1959 & no & water table is not within $30 \mathrm{~cm}$ for $14+$ days \\
\hline 1960 & no & water table is not within $30 \mathrm{~cm}$ for $14+$ days \\
\hline 1961 & no & water table is not within $30 \mathrm{~cm}$ for $14+$ days \\
\hline 1962 & no & water table is not within $30 \mathrm{~cm}$ for $14+$ days \\
\hline 1963 & no & water table is not within $30 \mathrm{~cm}$ for $14+$ days \\
\hline 1964 & no & water table is not within $30 \mathrm{~cm}$ for $14+$ days \\
\hline 1965 & no & water table is not within $30 \mathrm{~cm}$ for $14+$ days \\
\hline 1966 & no & WT is within $30 \mathrm{~cm}$ for $14+$ days above 70 th percentile \\
\hline 1967 & no & water table is not within $30 \mathrm{~cm}$ for $14+$ days \\
\hline 1968 & no & water table is not within $30 \mathrm{~cm}$ for $14+$ days \\
\hline 1969 & no & water table is not within $30 \mathrm{~cm}$ for $14+$ days \\
\hline 1970 & no & water table is not within $30 \mathrm{~cm}$ for $14+$ days \\
\hline 1971 & no & water table is not within $30 \mathrm{~cm}$ for $14+$ days \\
\hline 1972 & no & water table is not within $30 \mathrm{~cm}$ for $14+$ days \\
\hline 1973 & no & WT is within $30 \mathrm{~cm}$ for $14+$ days above 70 th percentile \\
\hline 1974 & no & water table is not within $30 \mathrm{~cm}$ for $14+$ days \\
\hline 1975 & no & water table is not within $30 \mathrm{~cm}$ for $14+$ days \\
\hline 1976 & no & water table is not within $30 \mathrm{~cm}$ for $14+$ days \\
\hline 1977 & no & water table is not within $30 \mathrm{~cm}$ for $14+$ days \\
\hline 1978 & no & WT is within $30 \mathrm{~cm}$ for $14+$ days above 70 th percentile \\
\hline 1979 & no & water table is not within $30 \mathrm{~cm}$ for $14+$ days \\
\hline 1980 & no & water table is not within $30 \mathrm{~cm}$ for $14+$ days \\
\hline 1981 & no & water table is not within $30 \mathrm{~cm}$ for $14+$ days \\
\hline 1982 & no & water table is not within $30 \mathrm{~cm}$ for $14+$ days \\
\hline 1983 & no & WT is within $30 \mathrm{~cm}$ for $14+$ days above 70 th percentile \\
\hline 1984 & no & water table is not within $30 \mathrm{~cm}$ for $14+$ days \\
\hline 1985 & no & water table is not within $30 \mathrm{~cm}$ for $14+$ days \\
\hline 1986 & no & water table is not within $30 \mathrm{~cm}$ for $14+$ days \\
\hline 1987 & no & water table is not within $30 \mathrm{~cm}$ for $14+$ days \\
\hline 1988 & no & water table is not within $30 \mathrm{~cm}$ for $14+$ days \\
\hline 1989 & no & water table is not within $30 \mathrm{~cm}$ for $14+$ days \\
\hline 1990 & no & water table is not within $30 \mathrm{~cm}$ for $14+$ days \\
\hline 1991 & no & water table is not within $30 \mathrm{~cm}$ for $14+$ days \\
\hline 1992 & no & water table is not within $30 \mathrm{~cm}$ for $14+$ days \\
\hline 1993 & no & water table is not within $30 \mathrm{~cm}$ for $14+$ days \\
\hline 1994 & no & water table is not within $30 \mathrm{~cm}$ for $14+$ days \\
\hline
\end{tabular}


Table B.57: 45-year record for the Army Corps 30-day Moving Total approach for plot $3 \mathrm{~N}$ at Bertie. This plot met wetland hydrology in 11 out of 45 years. There were 26 years that did not meet wetland hydrology because water table (WT) saturation occurred during "wet" periods, while 8 years did not meet water table saturation criterion.

\begin{tabular}{|c|c|c|}
\hline Year & $\begin{array}{c}\text { Met/Not } \\
\text { Met }\end{array}$ & Reason Year did or did not meet Wetland Hydrology \\
\hline 1950 & no & WT is within $30 \mathrm{~cm}$ for $14+$ days while rainfall is above 70 th percentile \\
\hline 1951 & yes & water table within $30 \mathrm{~cm}$ for $14+$ days \\
\hline 1952 & no & WT is within $30 \mathrm{~cm}$ for $14+$ days while rainfall is above 70 th percentile \\
\hline 1953 & no & water table is not within $30 \mathrm{~cm}$ for $14+$ days \\
\hline 1954 & no & WT is within $30 \mathrm{~cm}$ for $14+$ days while rainfall is above 70 th percentile \\
\hline 1955 & no & WT is within $30 \mathrm{~cm}$ for $14+$ days while rainfall is above 70 th percentile \\
\hline 1956 & yes & water table within $30 \mathrm{~cm}$ for $14+$ days \\
\hline 1957 & no & WT is within $30 \mathrm{~cm}$ for $14+$ days while rainfall is above 70 th percentile \\
\hline 1958 & yes & water table is within $30 \mathrm{~cm}$ for $14+$ days \\
\hline 1959 & no & WT is within $30 \mathrm{~cm}$ for $14+$ days while rainfall is above 70 th percentile \\
\hline 1960 & yes & water table is within $30 \mathrm{~cm}$ for $14+$ days \\
\hline 1961 & no & WT is within $30 \mathrm{~cm}$ for $14+$ days while rainfall is above 70 th percentile \\
\hline 1962 & no & WT is within $30 \mathrm{~cm}$ for $14+$ days while rainfall is above 70 th percentile \\
\hline 1963 & no & water table is not within $30 \mathrm{~cm}$ for $14+$ days \\
\hline 1964 & no & WT is within $30 \mathrm{~cm}$ for $14+$ days while rainfall is above 70 th percentile \\
\hline 1965 & yes & water table is within $30 \mathrm{~cm}$ for $14+$ days \\
\hline 1966 & no & WT is within $30 \mathrm{~cm}$ for $14+$ days while rainfall is above 70 th percentile \\
\hline 1967 & no & WT is within $30 \mathrm{~cm}$ for $14+$ days while rainfall is above 70 th percentile \\
\hline 1968 & no & WT is within $30 \mathrm{~cm}$ for $14+$ days while rainfall is above 70 th percentile \\
\hline 1969 & no & WT is within $30 \mathrm{~cm}$ for $14+$ days while rainfall is above 70 th percentile \\
\hline 1970 & yes & water table is within $30 \mathrm{~cm}$ for $14+$ days \\
\hline 1971 & yes & water table is within $30 \mathrm{~cm}$ for $14+$ days \\
\hline 1972 & yes & water table is within $30 \mathrm{~cm}$ for $14+$ days \\
\hline 1973 & no & WT is within $30 \mathrm{~cm}$ for $14+$ days while rainfall is above 70 th percentile \\
\hline 1974 & yes & water table is within $30 \mathrm{~cm}$ for $14+$ days \\
\hline 1975 & no & WT is within $30 \mathrm{~cm}$ for $14+$ days while rainfall is above 70 th percentile \\
\hline 1976 & no & water table is not within $30 \mathrm{~cm}$ for $14+$ days \\
\hline 1977 & no & WT is within $30 \mathrm{~cm}$ for $14+$ days while rainfall is above 70 th percentile \\
\hline 1978 & no & WT is within $30 \mathrm{~cm}$ for $14+$ days while rainfall is above 70 th percentile \\
\hline 1979 & no & WT is within $30 \mathrm{~cm}$ for $14+$ days while rainfall is above 70 th percentile \\
\hline 1980 & no & WT is within $30 \mathrm{~cm}$ for $14+$ days while rainfall is above 70 th percentile \\
\hline 1981 & no & water table is not within $30 \mathrm{~cm}$ for $14+$ days \\
\hline 1982 & no & water table is not within $30 \mathrm{~cm}$ for $14+$ days \\
\hline 1983 & yes & water table is within $30 \mathrm{~cm}$ for $14+$ days \\
\hline 1984 & no & WT is within $30 \mathrm{~cm}$ for $14+$ days while rainfall is above 70 th percentile \\
\hline 1985 & no & water table is not within $30 \mathrm{~cm}$ for $14+$ days \\
\hline 1986 & no & water table is not within $30 \mathrm{~cm}$ for $14+$ days \\
\hline 1987 & yes & water table is within $30 \mathrm{~cm}$ for $14+$ days \\
\hline 1988 & no & WT is within $30 \mathrm{~cm}$ for $14+$ days while rainfall is above 70 th percentile \\
\hline 1989 & no & WT is within $30 \mathrm{~cm}$ for $14+$ days while rainfall is above 70 th percentile \\
\hline 1990 & no & WT is within $30 \mathrm{~cm}$ for $14+$ days while rainfall is above 70 th percentile \\
\hline 1991 & no & WT is within $30 \mathrm{~cm}$ for $14+$ days while rainfall is above 70 th percentile \\
\hline 1992 & no & water table is not within $30 \mathrm{~cm}$ for $14+$ days \\
\hline 1993 & no & WT is within $30 \mathrm{~cm}$ for $14+$ days while rainfall is above 70 th percentile \\
\hline 1994 & no & WT is within $30 \mathrm{~cm}$ for $14+$ days while rainfall is above 70 th percentile \\
\hline
\end{tabular}


Table B.58: 45-year record for the Army Corps 30-day Moving Total approach for plot $4 \mathrm{~N}$ at Bertie. This plot met wetland hydrology in 9 out of 45 years. There were 34 years that did not meet wetland hydrology because water table (WT) saturation occurred during "wet" periods, while 2 years did not meet water table saturation criterion.

\begin{tabular}{|c|c|c|}
\hline Year & $\begin{array}{c}\text { Met/Not } \\
\text { Met }\end{array}$ & Reason Year did or did not meet Wetland Hydrology \\
\hline 1950 & no & WT is within $30 \mathrm{~cm}$ for $14+$ days while rainfall is above 70 th percentile \\
\hline 1951 & yes & water table is within $30 \mathrm{~cm}$ for $14+$ days \\
\hline 1952 & no & WT is within $30 \mathrm{~cm}$ for $14+$ days while rainfall is above 70 th percentile \\
\hline 1953 & no & WT is within $30 \mathrm{~cm}$ for $14+$ days while rainfall is above 70 th percentile \\
\hline 1954 & no & WT is within $30 \mathrm{~cm}$ for $14+$ days while rainfall is above 70 th percentile \\
\hline 1955 & no & WT is within $30 \mathrm{~cm}$ for $14+$ days while rainfall is above 70 th percentile \\
\hline 1956 & no & WT is within $30 \mathrm{~cm}$ for $14+$ days while rainfall is above 70 th percentile \\
\hline 1957 & no & WT is within $30 \mathrm{~cm}$ for $14+$ days while rainfall is above 70 th percentile \\
\hline 1958 & no & WT is within $30 \mathrm{~cm}$ for $14+$ days while rainfall is above 70 th percentile \\
\hline 1959 & no & WT is within $30 \mathrm{~cm}$ for $14+$ days while rainfall is above 70 th percentile \\
\hline 1960 & yes & water table is within $30 \mathrm{~cm}$ for $14+$ days \\
\hline 1961 & no & WT is within $30 \mathrm{~cm}$ for $14+$ days while rainfall is above 70 th percentile \\
\hline 1962 & no & WT is within $30 \mathrm{~cm}$ for $14+$ days while rainfall is above 70 th percentile \\
\hline 1963 & no & water table is not within $30 \mathrm{~cm}$ for $14+$ days \\
\hline 1964 & no & WT is within $30 \mathrm{~cm}$ for $14+$ days while rainfall is above 70 th percentile \\
\hline 1965 & yes & water table is within $30 \mathrm{~cm}$ for $14+$ days \\
\hline 1966 & no & WT is within $30 \mathrm{~cm}$ for $14+$ days while rainfall is above 70 th percentile \\
\hline 1967 & no & WT is within $30 \mathrm{~cm}$ for $14+$ days while rainfall is above 70 th percentile \\
\hline 1968 & no & WT is within $30 \mathrm{~cm}$ for $14+$ days while rainfall is above 70 th percentile \\
\hline 1969 & no & WT is within $30 \mathrm{~cm}$ for $14+$ days while rainfall is above 70 th percentile \\
\hline 1970 & yes & water table is within $30 \mathrm{~cm}$ for $14+$ days \\
\hline 1971 & yes & water table is within $30 \mathrm{~cm}$ for $14+$ days \\
\hline 1972 & yes & water table is within $30 \mathrm{~cm}$ for $14+$ days \\
\hline 1973 & no & WT is within $30 \mathrm{~cm}$ for $14+$ days while rainfall is above 70 th percentile \\
\hline 1974 & yes & water table is within $30 \mathrm{~cm}$ for $14+$ days \\
\hline 1975 & no & WT is within $30 \mathrm{~cm}$ for $14+$ days while rainfall is above 70 th percentile \\
\hline 1976 & no & WT is within $30 \mathrm{~cm}$ for $14+$ days while rainfall is above 70 th percentile \\
\hline 1977 & no & WT is within $30 \mathrm{~cm}$ for $14+$ days while rainfall is above 70 th percentile \\
\hline 1978 & no & WT is within $30 \mathrm{~cm}$ for $14+$ days while rainfall is above 70 th percentile \\
\hline 1979 & no & WT is within $30 \mathrm{~cm}$ for $14+$ days while rainfall is above 70 th percentile \\
\hline 1980 & no & WT is within $30 \mathrm{~cm}$ for $14+$ days while rainfall is above 70 th percentile \\
\hline 1981 & yes & water table is within $30 \mathrm{~cm}$ for $14+$ days \\
\hline 1982 & no & water table is not within $30 \mathrm{~cm}$ for $14+$ days \\
\hline 1983 & no & WT is within $30 \mathrm{~cm}$ for $14+$ days while rainfall is above 70 th percentile \\
\hline 1984 & no & WT is within $30 \mathrm{~cm}$ for $14+$ days while rainfall is above 70 th percentile \\
\hline 1985 & no & WT is within $30 \mathrm{~cm}$ for $14+$ days while rainfall is above 70 th percentile \\
\hline 1986 & no & WT is within $30 \mathrm{~cm}$ for $14+$ days while rainfall is above 70 th percentile \\
\hline 1987 & yes & water table is within $30 \mathrm{~cm}$ for $14+$ days \\
\hline 1988 & no & WT is within $30 \mathrm{~cm}$ for $14+$ days while rainfall is above 70 th percentile \\
\hline 1989 & no & WT is within $30 \mathrm{~cm}$ for $14+$ days while rainfall is above 70 th percentile \\
\hline 1990 & no & WT is within $30 \mathrm{~cm}$ for $14+$ days while rainfall is above 70 th percentile \\
\hline 1991 & no & WT is within $30 \mathrm{~cm}$ for $14+$ days while rainfall is above 70 th percentile \\
\hline 1992 & no & WT is within $30 \mathrm{~cm}$ for $14+$ days while rainfall is above 70 th percentile \\
\hline 1993 & no & WT is within $30 \mathrm{~cm}$ for $14+$ days while rainfall is above 70 th percentile \\
\hline 1994 & no & WT is within $30 \mathrm{~cm}$ for $14+$ days while rainfall is above 70 th percentile \\
\hline
\end{tabular}


Table B.59: 45-year record for the Army Corps 30-day Moving Total approach for plot $5 \mathrm{~N}$ at Bertie. This plot met wetland hydrology in 13 out of 45 years. There were 31 years that did not meet wetland hydrology because water table (WT) saturation occurred during "wet" periods, while 1 year did not meet water table saturation criterion.

\begin{tabular}{|c|c|c|}
\hline Year & $\begin{array}{c}\text { Met/Not } \\
\text { Met }\end{array}$ & Reason Year did or did not meet Wetland Hydrology \\
\hline 1950 & no & WT is within $30 \mathrm{~cm}$ for $14+$ days and above the 70 th percentile \\
\hline 1951 & yes & water table is within $30 \mathrm{~cm}$ for $14+$ days \\
\hline 1952 & no & WT is within $30 \mathrm{~cm}$ for $14+$ days and above the 70 th percentile \\
\hline 1953 & yes & water table is within $30 \mathrm{~cm}$ for $14+$ days \\
\hline 1954 & no & WT is within $30 \mathrm{~cm}$ for $14+$ days and above the 70 th percentile \\
\hline 1955 & no & WT is within $30 \mathrm{~cm}$ for $14+$ days and above the 70 th percentile \\
\hline 1956 & no & WT is within $30 \mathrm{~cm}$ for $14+$ days and above the 70 th percentile \\
\hline 1957 & no & WT is within $30 \mathrm{~cm}$ for $14+$ days and above the 70 th percentile \\
\hline 1958 & no & WT is within $30 \mathrm{~cm}$ for $14+$ days and above the 70 th percentile \\
\hline 1959 & no & WT is within $30 \mathrm{~cm}$ for $14+$ days and above the 70 th percentile \\
\hline 1960 & yes & water table is within $30 \mathrm{~cm}$ for $14+$ days \\
\hline 1961 & no & WT is within $30 \mathrm{~cm}$ for $14+$ days and above the 70 th percentile \\
\hline 1962 & no & WT is within $30 \mathrm{~cm}$ for $14+$ days and above the 70 th percentile \\
\hline 1963 & no & water table is not within $30 \mathrm{~cm}$ for $14+$ days \\
\hline 1964 & no & WT is within $30 \mathrm{~cm}$ for $14+$ days and above the 70 th percentile \\
\hline 1965 & yes & water table is within $30 \mathrm{~cm}$ for $14+$ days \\
\hline 1966 & no & WT is within $30 \mathrm{~cm}$ for $14+$ days and above the 70th percentile \\
\hline 1967 & no & WT is within $30 \mathrm{~cm}$ for $14+$ days and above the 70th percentile \\
\hline 1968 & no & WT is within $30 \mathrm{~cm}$ for $14+$ days and above the 70 th percentile \\
\hline 1969 & no & WT is within $30 \mathrm{~cm}$ for $14+$ days and above the 70th percentile \\
\hline 1970 & yes & water table is within $30 \mathrm{~cm}$ for $14+$ days \\
\hline 1971 & yes & water table is within $30 \mathrm{~cm}$ for $14+$ days \\
\hline 1972 & yes & water table is within $30 \mathrm{~cm}$ for $14+$ days \\
\hline 1973 & no & WT is within $30 \mathrm{~cm}$ for $14+$ days and above the 70 th percentile \\
\hline 1974 & yes & water table is within $30 \mathrm{~cm}$ for $14+$ days \\
\hline 1975 & no & WT is within $30 \mathrm{~cm}$ for $14+$ days and above the 70 th percentile \\
\hline 1976 & no & WT is within $30 \mathrm{~cm}$ for $14+$ days and above the 70 th percentile \\
\hline 1977 & no & WT is within $30 \mathrm{~cm}$ for $14+$ days and above the 70 th percentile \\
\hline 1978 & no & WT is within $30 \mathrm{~cm}$ for $14+$ days and above the 70 th percentile \\
\hline 1979 & no & WT is within $30 \mathrm{~cm}$ for $14+$ days and above the 70 th percentile \\
\hline 1980 & no & WT is within $30 \mathrm{~cm}$ for $14+$ days and above the 70 th percentile \\
\hline 1981 & yes & water table is within $30 \mathrm{~cm}$ for $14+$ days \\
\hline 1982 & yes & water table is within $30 \mathrm{~cm}$ for $14+$ days \\
\hline 1983 & no & WT is within $30 \mathrm{~cm}$ for $14+$ days and above the 70 th percentile \\
\hline 1984 & no & WT is within $30 \mathrm{~cm}$ for $14+$ days and above the 70 th percentile \\
\hline 1985 & no & WT is within $30 \mathrm{~cm}$ for $14+$ days and above the 70 th percentile \\
\hline 1986 & no & WT is within $30 \mathrm{~cm}$ for $14+$ days and above the 70 th percentile \\
\hline 1987 & yes & water table is within $30 \mathrm{~cm}$ for $14+$ days \\
\hline 1988 & yes & water table is within $30 \mathrm{~cm}$ for $14+$ days \\
\hline 1989 & no & WT is within $30 \mathrm{~cm}$ for $14+$ days and above the 70 th percentile \\
\hline 1990 & no & WT is within $30 \mathrm{~cm}$ for $14+$ days and above the 70 th percentile \\
\hline 1991 & no & WT is within $30 \mathrm{~cm}$ for $14+$ days and above the 70 th percentile \\
\hline 1992 & yes & water table is within $30 \mathrm{~cm}$ for $14+$ days \\
\hline 1993 & no & WT is within $30 \mathrm{~cm}$ for $14+$ days and above the 70 th percentile \\
\hline 1994 & no & WT is within $30 \mathrm{~cm}$ for $14+$ days and above the 70 th percentile \\
\hline
\end{tabular}


Table B.60: 45-year record for the Army Corps 30-day Moving Total approach for plot $2 \mathrm{~S}$ at Bertie. This plot met wetland hydrology in 0 out of 45 years. There were 45 years did not meet water table saturation criterion.

\begin{tabular}{|c|c|c|}
\hline Year & $\begin{array}{c}\text { Met/Not } \\
\text { Met }\end{array}$ & Reason Year did or did not meet Wetland Hydrology \\
\hline 1950 & no & water table is not within $30 \mathrm{~cm}$ for $14+$ days \\
\hline 1951 & no & water table is not within $30 \mathrm{~cm}$ for $14+$ days \\
\hline 1952 & no & water table is not within $30 \mathrm{~cm}$ for $14+$ days \\
\hline 1953 & no & water table is not within $30 \mathrm{~cm}$ for $14+$ days \\
\hline 1954 & no & water table is not within $30 \mathrm{~cm}$ for $14+$ days \\
\hline 1955 & no & water table is not within $30 \mathrm{~cm}$ for $14+$ days \\
\hline 1956 & no & water table is not within $30 \mathrm{~cm}$ for $14+$ days \\
\hline 1957 & no & water table is not within $30 \mathrm{~cm}$ for $14+$ days \\
\hline 1958 & no & water table is not within $30 \mathrm{~cm}$ for $14+$ days \\
\hline 1959 & no & water table is not within $30 \mathrm{~cm}$ for $14+$ days \\
\hline 1960 & no & water table is not within $30 \mathrm{~cm}$ for $14+$ days \\
\hline 1961 & no & water table is not within $30 \mathrm{~cm}$ for $14+$ days \\
\hline 1962 & no & water table is not within $30 \mathrm{~cm}$ for $14+$ days \\
\hline 1963 & no & water table is not within $30 \mathrm{~cm}$ for $14+$ days \\
\hline 1964 & no & water table is not within $30 \mathrm{~cm}$ for $14+$ days \\
\hline 1965 & no & water table is not within $30 \mathrm{~cm}$ for $14+$ days \\
\hline 1966 & no & water table is not within $30 \mathrm{~cm}$ for $14+$ days \\
\hline 1967 & no & water table is not within $30 \mathrm{~cm}$ for $14+$ days \\
\hline 1968 & no & water table is not within $30 \mathrm{~cm}$ for $14+$ days \\
\hline 1969 & no & water table is not within $30 \mathrm{~cm}$ for $14+$ days \\
\hline 1970 & no & water table is not within $30 \mathrm{~cm}$ for $14+$ days \\
\hline 1971 & no & water table is not within $30 \mathrm{~cm}$ for $14+$ days \\
\hline 1972 & no & water table is not within $30 \mathrm{~cm}$ for $14+$ days \\
\hline 1973 & no & water table is not within $30 \mathrm{~cm}$ for $14+$ days \\
\hline 1974 & no & water table is not within $30 \mathrm{~cm}$ for $14+$ days \\
\hline 1975 & no & water table is not within $30 \mathrm{~cm}$ for $14+$ days \\
\hline 1976 & no & water table is not within $30 \mathrm{~cm}$ for $14+$ days \\
\hline 1977 & no & water table is not within $30 \mathrm{~cm}$ for $14+$ days \\
\hline 1978 & no & water table is not within $30 \mathrm{~cm}$ for $14+$ days \\
\hline 1979 & no & water table is not within $30 \mathrm{~cm}$ for $14+$ days \\
\hline 1980 & no & water table is not within $30 \mathrm{~cm}$ for $14+$ days \\
\hline 1981 & no & water table is not within $30 \mathrm{~cm}$ for $14+$ days \\
\hline 1982 & no & water table is not within $30 \mathrm{~cm}$ for $14+$ days \\
\hline 1983 & no & water table is not within $30 \mathrm{~cm}$ for $14+$ days \\
\hline 1984 & no & water table is not within $30 \mathrm{~cm}$ for $14+$ days \\
\hline 1985 & no & water table is not within $30 \mathrm{~cm}$ for $14+$ days \\
\hline 1986 & no & water table is not within $30 \mathrm{~cm}$ for $14+$ days \\
\hline 1987 & no & water table is not within $30 \mathrm{~cm}$ for $14+$ days \\
\hline 1988 & no & water table is not within $30 \mathrm{~cm}$ for $14+$ days \\
\hline 1989 & no & water table is not within $30 \mathrm{~cm}$ for $14+$ days \\
\hline 1990 & no & water table is not within $30 \mathrm{~cm}$ for $14+$ days \\
\hline 1991 & no & water table is not within $30 \mathrm{~cm}$ for $14+$ days \\
\hline 1992 & no & water table is not within $30 \mathrm{~cm}$ for $14+$ days \\
\hline 1993 & no & water table is not within $30 \mathrm{~cm}$ for $14+$ days \\
\hline 1994 & no & water table is not within $30 \mathrm{~cm}$ for $14+$ days \\
\hline
\end{tabular}


Table B.61: 45-year record for the Army Corps 30-day Moving Total approach for plot $3 \mathrm{~S}$ at Bertie. This plot met wetland hydrology in 5 out of 45 years. There were 34 years that did not meet wetland hydrology because water table (WT) saturation occurred during "wet" periods, while 6 years did not meet water table saturation criterion.

\begin{tabular}{|c|c|c|}
\hline Year & $\begin{array}{c}\text { Met/Not } \\
\text { Met }\end{array}$ & Reason Year did or did not meet Wetland Hydrology \\
\hline 1950 & no & WT is within $30 \mathrm{~cm}$ for $14+$ days during a period above 70 th percentile \\
\hline 1951 & no & WT is within $30 \mathrm{~cm}$ for $14+$ days during a period above 70 th percentile \\
\hline 1952 & no & WT is within $30 \mathrm{~cm}$ for $14+$ days during a period above 70 th percentile \\
\hline 1953 & no & WT is within $30 \mathrm{~cm}$ for $14+$ days during a period above 70 th percentile \\
\hline 1954 & no & WT is within $30 \mathrm{~cm}$ for $14+$ days during a period above 70 th percentile \\
\hline 1955 & no & WT is within $30 \mathrm{~cm}$ for $14+$ days during a period above 70 th percentile \\
\hline 1956 & no & WT is within $30 \mathrm{~cm}$ for $14+$ days during a period above 70 th percentile \\
\hline 1957 & no & WT is within $30 \mathrm{~cm}$ for $14+$ days during a period above 70 th percentile \\
\hline 1958 & no & WT is within $30 \mathrm{~cm}$ for $14+$ days during a period above 70 th percentile \\
\hline 1959 & no & WT is within $30 \mathrm{~cm}$ for $14+$ days during a period above 70 th percentile \\
\hline 1960 & yes & water table is within $30 \mathrm{~cm}$ for $14+$ days \\
\hline 1961 & no & WT is within $30 \mathrm{~cm}$ for $14+$ days during a period above 70 th percentile \\
\hline 1962 & no & WT is within $30 \mathrm{~cm}$ for $14+$ days during a period above 70 th percentile \\
\hline 1963 & no & water table is not within $30 \mathrm{~cm}$ for $14+$ days \\
\hline 1964 & no & WT is within $30 \mathrm{~cm}$ for $14+$ days during a period above 70 th percentile \\
\hline 1965 & yes & water table is within $30 \mathrm{~cm}$ for $14+$ days \\
\hline 1966 & no & WT is within $30 \mathrm{~cm}$ for $14+$ days during a period above 70 th percentile \\
\hline 1967 & no & WT is within $30 \mathrm{~cm}$ for $14+$ days during a period above 70 th percentile \\
\hline 1968 & no & water table is not within $30 \mathrm{~cm}$ for $14+$ days \\
\hline 1969 & no & WT is within $30 \mathrm{~cm}$ for $14+$ days during a period above 70 th percentile \\
\hline 1970 & yes & water table is within $30 \mathrm{~cm}$ for $14+$ days \\
\hline 1971 & yes & water table is within $30 \mathrm{~cm}$ for $14+$ days \\
\hline 1972 & no & WT is within $30 \mathrm{~cm}$ for $14+$ days during a period above 70 th percentile \\
\hline 1973 & no & WT is within $30 \mathrm{~cm}$ for $14+$ days during a period above 70 th percentile \\
\hline 1974 & no & WT is within $30 \mathrm{~cm}$ for $14+$ days during a period above 70 th percentile \\
\hline 1975 & no & WT is within $30 \mathrm{~cm}$ for $14+$ days during a period above 70 th percentile \\
\hline 1976 & no & water table is not within $30 \mathrm{~cm}$ for $14+$ days \\
\hline 1977 & no & WT is within $30 \mathrm{~cm}$ for $14+$ days during a period above 70 th percentile \\
\hline 1978 & no & WT is within $30 \mathrm{~cm}$ for $14+$ days during a period above 70 th percentile \\
\hline 1979 & no & WT is within $30 \mathrm{~cm}$ for $14+$ days during a period above 70 th percentile \\
\hline 1980 & no & WT is within $30 \mathrm{~cm}$ for $14+$ days during a period above 70 th percentile \\
\hline 1981 & no & WT is within $30 \mathrm{~cm}$ for $14+$ days during a period above 70 th percentile \\
\hline 1982 & no & water table is not within $30 \mathrm{~cm}$ for $14+$ days \\
\hline 1983 & no & WT is within $30 \mathrm{~cm}$ for $14+$ days during a period above 70 th percentile \\
\hline 1984 & no & WT is within $30 \mathrm{~cm}$ for $14+$ days during a period above 70 th percentile \\
\hline 1985 & no & WT is within $30 \mathrm{~cm}$ for $14+$ days during a period above 70 th percentile \\
\hline 1986 & no & water table is not within $30 \mathrm{~cm}$ for $14+$ days \\
\hline 1987 & yes & water table is within $30 \mathrm{~cm}$ for $14+$ days \\
\hline 1988 & no & WT is within $30 \mathrm{~cm}$ for $14+$ days during a period above 70 th percentile \\
\hline 1989 & no & WT is within $30 \mathrm{~cm}$ for $14+$ days during a period above 70 th percentile \\
\hline 1990 & no & WT is within $30 \mathrm{~cm}$ for $14+$ days during a period above 70 th percentile \\
\hline 1991 & no & WT is within $30 \mathrm{~cm}$ for $14+$ days during a period above 70 th percentile \\
\hline 1992 & no & water table is not within $30 \mathrm{~cm}$ for $14+$ days \\
\hline 1993 & no & WT is within $30 \mathrm{~cm}$ for $14+$ days during a period above 70 th percentile \\
\hline 1994 & no & WT is within $30 \mathrm{~cm}$ for $14+$ days during a period above 70 th percentile \\
\hline
\end{tabular}


Table B.62: 45-year record for the Army Corps 30-day Moving Total approach for plot 4S at Bertie. This plot met wetland hydrology in 11 out of 45 years. There were 30 years that did not meet wetland hydrology because water table (WT) saturation occurred during "wet" periods, while 4 years did not meet water table saturation criterion.

\begin{tabular}{|c|c|c|}
\hline Year & $\begin{array}{c}\text { Met/Not } \\
\text { Met }\end{array}$ & Reason Year did or did not meet Wetland Hydrology \\
\hline 1950 & no & WT is within $30 \mathrm{~cm}$ for $14+$ but is above the 70 th percentile \\
\hline 1951 & yes & water table is within $30 \mathrm{~cm}$ for $14+$ days \\
\hline 1952 & no & WT is within $30 \mathrm{~cm}$ for $14+$ but is above the 70 th percentile \\
\hline 1953 & no & WT is within $30 \mathrm{~cm}$ for $14+$ but is above the 70 th percentile \\
\hline 1954 & no & WT is within $30 \mathrm{~cm}$ for $14+$ but is above the 70 th percentile \\
\hline 1955 & no & WT is within $30 \mathrm{~cm}$ for $14+$ but is above the 70 th percentile \\
\hline 1956 & no & WT is within $30 \mathrm{~cm}$ for $14+$ but is above the 70 th percentile \\
\hline 1957 & no & WT is within $30 \mathrm{~cm}$ for $14+$ but is above the 70 th percentile \\
\hline 1958 & no & WT is within $30 \mathrm{~cm}$ for $14+$ but is above the 70 th percentile \\
\hline 1959 & no & WT is within $30 \mathrm{~cm}$ for $14+$ but is above the 70 th percentile \\
\hline 1960 & yes & water table is within $30 \mathrm{~cm}$ for $14+$ days \\
\hline 1961 & no & WT is within $30 \mathrm{~cm}$ for $14+$ but is above the 70 th percentile \\
\hline 1962 & no & WT is within $30 \mathrm{~cm}$ for $14+$ but is above the 70 th percentile \\
\hline 1963 & no & water table is not within $30 \mathrm{~cm}$ for $14+$ days \\
\hline 1964 & no & WT is within $30 \mathrm{~cm}$ for $14+$ but is above the 70 th percentile \\
\hline 1965 & yes & water table is within $30 \mathrm{~cm}$ for $14+$ days \\
\hline 1966 & no & WT is within $30 \mathrm{~cm}$ for $14+$ but is above the 70 th percentile \\
\hline 1967 & no & WT is within $30 \mathrm{~cm}$ for $14+$ but is above the 70 th percentile \\
\hline 1968 & no & WT is within $30 \mathrm{~cm}$ for $14+$ but is above the 70 th percentile \\
\hline 1969 & no & WT is within $30 \mathrm{~cm}$ for $14+$ but is above the 70 th percentile \\
\hline 1970 & yes & water table is within $30 \mathrm{~cm}$ for $14+$ days \\
\hline 1971 & yes & water table is within $30 \mathrm{~cm}$ for $14+$ days \\
\hline 1972 & yes & water table is within $30 \mathrm{~cm}$ for $14+$ days \\
\hline 1973 & no & WT is within $30 \mathrm{~cm}$ for $14+$ but is above the 70 th percentile \\
\hline 1974 & yes & water table is within $30 \mathrm{~cm}$ for $14+$ days \\
\hline 1975 & no & WT is within $30 \mathrm{~cm}$ for $14+$ but is above the 70 th percentile \\
\hline 1976 & no & water table is not within $30 \mathrm{~cm}$ for $14+$ days \\
\hline 1977 & no & WT is within $30 \mathrm{~cm}$ for $14+$ but is above the 70 th percentile \\
\hline 1978 & no & WT is within $30 \mathrm{~cm}$ for $14+$ but is above the 70 th percentile \\
\hline 1979 & no & WT is within $30 \mathrm{~cm}$ for $14+$ but is above the 70 th percentile \\
\hline 1980 & no & WT is within $30 \mathrm{~cm}$ for $14+$ but is above the 70 th percentile \\
\hline 1981 & yes & water table is within $30 \mathrm{~cm}$ for $14+$ days \\
\hline 1982 & yes & water table is within $30 \mathrm{~cm}$ for $14+$ days \\
\hline 1983 & no & WT is within $30 \mathrm{~cm}$ for $14+$ but is above the 70 th percentile \\
\hline 1984 & no & WT is within $30 \mathrm{~cm}$ for $14+$ but is above the 70 th percentile \\
\hline 1985 & no & water table is not within $30 \mathrm{~cm}$ for $14+$ days \\
\hline 1986 & no & water table is not within $30 \mathrm{~cm}$ for $14+$ days \\
\hline 1987 & yes & water table is within $30 \mathrm{~cm}$ for $14+$ days \\
\hline 1988 & yes & water table is within $30 \mathrm{~cm}$ for $14+$ days \\
\hline 1989 & no & WT is within $30 \mathrm{~cm}$ for $14+$ but is above the 70 th percentile \\
\hline 1990 & no & WT is within $30 \mathrm{~cm}$ for $14+$ but is above the 70 th percentile \\
\hline 1991 & no & WT is within $30 \mathrm{~cm}$ for $14+$ but is above the 70 th percentile \\
\hline 1992 & no & WT is within $30 \mathrm{~cm}$ for $14+$ but is above the 70 th percentile \\
\hline 1993 & no & WT is within $30 \mathrm{~cm}$ for $14+$ but is above the 70 th percentile \\
\hline 1994 & no & WT is within $30 \mathrm{~cm}$ for $14+$ but is above the 70 th percentile \\
\hline
\end{tabular}


Table B.63: 45-year record for the Army Corps 30-day Moving Total approach for plot 5S at Bertie. This plot met wetland hydrology in 12 out of 45 years. There were 32 years that did not meet wetland hydrology because water table (WT) saturation occurred during "wet" periods, while 1 year did not meet water table saturation criterion.

\begin{tabular}{|c|c|c|}
\hline Year & $\begin{array}{c}\text { Met/Not } \\
\text { Met }\end{array}$ & Reason Year did or did not meet Wetland Hydrology \\
\hline 1950 & no & WT is within $30 \mathrm{~cm}$ for $14+$ days but above 70 th percentile \\
\hline 1951 & yes & water table is within $30 \mathrm{~cm}$ for $14+$ days \\
\hline 1952 & no & WT is within $30 \mathrm{~cm}$ for $14+$ days but above 70 th percentile \\
\hline 1953 & yes & water table is within $30 \mathrm{~cm}$ for $14+$ days \\
\hline 1954 & no & WT is within $30 \mathrm{~cm}$ for $14+$ days but above 70 th percentile \\
\hline 1955 & no & WT is within $30 \mathrm{~cm}$ for $14+$ days but above 70 th percentile \\
\hline 1956 & no & WT is within $30 \mathrm{~cm}$ for $14+$ days but above 70 th percentile \\
\hline 1957 & no & WT is within $30 \mathrm{~cm}$ for $14+$ days but above 70 th percentile \\
\hline 1958 & no & WT is within $30 \mathrm{~cm}$ for $14+$ days but above 70 th percentile \\
\hline 1959 & no & WT is within $30 \mathrm{~cm}$ for $14+$ days but above 70 th percentile \\
\hline 1960 & yes & water table is within $30 \mathrm{~cm}$ for $14+$ days \\
\hline 1961 & no & WT is within $30 \mathrm{~cm}$ for $14+$ days but above 70 th percentile \\
\hline 1962 & no & WT is within $30 \mathrm{~cm}$ for $14+$ days but above 70 th percentile \\
\hline 1963 & no & water table is not within $30 \mathrm{~cm}$ for $14+$ days \\
\hline 1964 & no & WT is within $30 \mathrm{~cm}$ for $14+$ days but above 70 th percentile \\
\hline 1965 & yes & water table is within $30 \mathrm{~cm}$ for $14+$ days \\
\hline 1966 & no & WT is within $30 \mathrm{~cm}$ for $14+$ days but above 70 th percentile \\
\hline 1967 & no & WT is within $30 \mathrm{~cm}$ for $14+$ days but above 70 th percentile \\
\hline 1968 & no & WT is within $30 \mathrm{~cm}$ for $14+$ days but above 70 th percentile \\
\hline 1969 & no & WT is within $30 \mathrm{~cm}$ for $14+$ days but above 70 th percentile \\
\hline 1970 & yes & water table is within $30 \mathrm{~cm}$ for $14+$ days \\
\hline 1971 & yes & water table is within $30 \mathrm{~cm}$ for $14+$ days \\
\hline 1972 & yes & water table is within $30 \mathrm{~cm}$ for $14+$ days \\
\hline 1973 & no & WT is within $30 \mathrm{~cm}$ for $14+$ days but above 70 th percentile \\
\hline 1974 & yes & water table is within $30 \mathrm{~cm}$ for $14+$ days \\
\hline 1975 & no & WT is within $30 \mathrm{~cm}$ for $14+$ days but above 70 th percentile \\
\hline 1976 & no & WT is within $30 \mathrm{~cm}$ for $14+$ days but above 70 th percentile \\
\hline 1977 & no & WT is within $30 \mathrm{~cm}$ for $14+$ days but above 70 th percentile \\
\hline 1978 & no & WT is within $30 \mathrm{~cm}$ for $14+$ days but above 70 th percentile \\
\hline 1979 & no & WT is within $30 \mathrm{~cm}$ for $14+$ days but above 70 th percentile \\
\hline 1980 & no & WT is within $30 \mathrm{~cm}$ for $14+$ days but above 70 th percentile \\
\hline 1981 & yes & water table is within $30 \mathrm{~cm}$ for $14+$ days \\
\hline 1982 & yes & water table is within $30 \mathrm{~cm}$ for $14+$ days \\
\hline 1983 & no & WT is within $30 \mathrm{~cm}$ for $14+$ days but above 70 th percentile \\
\hline 1984 & no & WT is within $30 \mathrm{~cm}$ for $14+$ days but above 70 th percentile \\
\hline 1985 & no & WT is within $30 \mathrm{~cm}$ for $14+$ days but above 70 th percentile \\
\hline 1986 & no & WT is within $30 \mathrm{~cm}$ for $14+$ days but above 70 th percentile \\
\hline 1987 & yes & water table is within $30 \mathrm{~cm}$ for $14+$ days \\
\hline 1988 & yes & water table is within $30 \mathrm{~cm}$ for $14+$ days \\
\hline 1989 & no & WT is within $30 \mathrm{~cm}$ for $14+$ days but above 70 th percentile \\
\hline 1990 & no & WT is within $30 \mathrm{~cm}$ for $14+$ days but above 70 th percentile \\
\hline 1991 & no & WT is within $30 \mathrm{~cm}$ for $14+$ days but above 70 th percentile \\
\hline 1992 & no & WT is within $30 \mathrm{~cm}$ for $14+$ days but above 70 th percentile \\
\hline 1993 & no & WT is within $30 \mathrm{~cm}$ for $14+$ days but above 70 th percentile \\
\hline 1994 & no & WT is within $30 \mathrm{~cm}$ for $14+$ days but above 70 th percentile \\
\hline
\end{tabular}


Table B.64: 45-year record for the Army Corps 30-day Moving Total approach for bogwell plot S1 at Marcell. This plot met wetland hydrology in 12 out of 45 years. There were 14 years that did not meet wetland hydrology because water table (WT) saturation occurred during "wet" periods, while 7 years did not meet water table saturation criterion.

\begin{tabular}{|c|c|c|}
\hline Year & $\begin{array}{c}\text { Met/Not } \\
\text { Met }\end{array}$ & Reason Year did or did not meet Wetland Hydrology \\
\hline 1961 & no & water table not within $30 \mathrm{~cm}$ for $14+$ days \\
\hline 1962 & no & WT is within $30 \mathrm{~cm}$ for $14+$ days when above 70 th Percentile \\
\hline 1963 & no & water table not within $30 \mathrm{~cm}$ for $14+$ days \\
\hline 1964 & no & water table not within $30 \mathrm{~cm}$ for $14+$ days \\
\hline 1965 & no & WT is within $30 \mathrm{~cm}$ for $14+$ days when above 70 th Percentile \\
\hline 1966 & no & WT is within $30 \mathrm{~cm}$ for $14+$ days when above 70 th Percentile \\
\hline 1967 & no & water table not within $30 \mathrm{~cm}$ for $14+$ days \\
\hline 1968 & no & water table not within $30 \mathrm{~cm}$ for $14+$ days \\
\hline 1969 & yes & water table is within $30 \mathrm{~cm}$ for $14+$ days \\
\hline 1970 & yes & water table is within $30 \mathrm{~cm}$ for $14+$ days \\
\hline 1971 & yes & water table is within $30 \mathrm{~cm}$ for $14+$ days \\
\hline 1972 & no & WT is within $30 \mathrm{~cm}$ for $14+$ days when above 70 th Percentile \\
\hline 1973 & yes & water table is within $30 \mathrm{~cm}$ for $14+$ days \\
\hline 1974 & yes & water table is within $30 \mathrm{~cm}$ for $14+$ days \\
\hline 1975 & yes & water table is within $30 \mathrm{~cm}$ for $14+$ days \\
\hline 1976 & no & water table is not within $30 \mathrm{~cm}$ for $14+$ days \\
\hline 1977 & no & WT is within $30 \mathrm{~cm}$ for $14+$ days when above 70 th Percentile \\
\hline 1978 & no & WT is within $30 \mathrm{~cm}$ for $14+$ days when above 70 th Percentile \\
\hline 1979 & yes & water table is within $30 \mathrm{~cm}$ for $14+$ days \\
\hline 1980 & no & water table is not within $30 \mathrm{~cm}$ for $14+$ days \\
\hline 1981 & yes & water table is within $30 \mathrm{~cm}$ for $14+$ days \\
\hline 1982 & yes & water table is within $30 \mathrm{~cm}$ for $14+$ days \\
\hline 1983 & yes & water table is within $30 \mathrm{~cm}$ for $14+$ days \\
\hline 1984 & no & WT is within $30 \mathrm{~cm}$ for $14+$ days when above 70 th Percentile \\
\hline 1985 & no & WT is within $30 \mathrm{~cm}$ for $14+$ days when above 70 th Percentile \\
\hline 1986 & no & WT is within $30 \mathrm{~cm}$ for $14+$ days when above 70 th Percentile \\
\hline 1987 & no & WT is within $30 \mathrm{~cm}$ for $14+$ days when above 70 th Percentile \\
\hline 1988 & yes & water table is within $30 \mathrm{~cm}$ for $14+$ days \\
\hline 1989 & yes & water table is within $30 \mathrm{~cm}$ for $14+$ days \\
\hline 1990 & yes & water table is within $30 \mathrm{~cm}$ for $14+$ days \\
\hline 1991 & no & WT is within $30 \mathrm{~cm}$ for $14+$ days when above 70 th Percentile \\
\hline 1992 & no & WT is within $30 \mathrm{~cm}$ for $14+$ days when above 70 th Percentile \\
\hline 1993 & no & WT is within $30 \mathrm{~cm}$ for $14+$ days when above 70 th Percentile \\
\hline 1994 & yes & water table is within $30 \mathrm{~cm}$ for $14+$ days \\
\hline 1995 & yes & water table is within $30 \mathrm{~cm}$ for $14+$ days \\
\hline 1996 & yes & water table is within $30 \mathrm{~cm}$ for $14+$ days \\
\hline 1997 & yes & water table is within $30 \mathrm{~cm}$ for $14+$ days \\
\hline 1998 & yes & water table is within $30 \mathrm{~cm}$ for $14+$ days \\
\hline 1999 & yes & water table is within $30 \mathrm{~cm}$ for $14+$ days \\
\hline 2000 & yes & water table is within $30 \mathrm{~cm}$ for $14+$ days \\
\hline 2001 & no & WT is within $30 \mathrm{~cm}$ for $14+$ days when above 70 th Percentile \\
\hline 2002 & yes & water table is within $30 \mathrm{~cm}$ for $14+$ days \\
\hline 2003 & yes & water table is within $30 \mathrm{~cm}$ for $14+$ days \\
\hline 2004 & yes & water table is within $30 \mathrm{~cm}$ for $14+$ days \\
\hline 2005 & yes & water table is within $30 \mathrm{~cm}$ for $14+$ days \\
\hline
\end{tabular}


Table B.65: 45-year record for the Army Corps 30-day Moving Total approach for bogwell plot S2 at Marcell. This plot met wetland hydrology in 40 out of 45 years. There were 5 years that did not meet wetland hydrology because water table (WT) saturation occurred during "wet" periods.

\begin{tabular}{|c|c|c|}
\hline Year & $\begin{array}{c}\text { Met/Not } \\
\text { Met }\end{array}$ & Reason Year did or did not meet Wetland Hydrology \\
\hline 1961 & yes & water table is within $30 \mathrm{~cm}$ for $14+$ days \\
\hline 1962 & yes & water table is within $30 \mathrm{~cm}$ for $14+$ days \\
\hline 1963 & yes & water table is within $30 \mathrm{~cm}$ for $14+$ days \\
\hline 1964 & yes & water table is within $30 \mathrm{~cm}$ for $14+$ days \\
\hline 1965 & yes & water table is within $30 \mathrm{~cm}$ for $14+$ days \\
\hline 1966 & yes & water table is within $30 \mathrm{~cm}$ for $14+$ days \\
\hline 1967 & yes & water table is within $30 \mathrm{~cm}$ for $14+$ days \\
\hline 1968 & yes & water table is within $30 \mathrm{~cm}$ for $14+$ days \\
\hline 1969 & yes & water table is within $30 \mathrm{~cm}$ for $14+$ days \\
\hline 1970 & yes & water table is within $30 \mathrm{~cm}$ for $14+$ days \\
\hline 1971 & yes & water table is within $30 \mathrm{~cm}$ for $14+$ days \\
\hline 1972 & yes & water table is within $30 \mathrm{~cm}$ for $14+$ days \\
\hline 1973 & yes & water table is within $30 \mathrm{~cm}$ for $14+$ days \\
\hline 1974 & yes & water table is within $30 \mathrm{~cm}$ for $14+$ days \\
\hline 1975 & yes & water table is within $30 \mathrm{~cm}$ for $14+$ days \\
\hline 1976 & yes & water table is within $30 \mathrm{~cm}$ for $14+$ days \\
\hline 1977 & no & WT is within $30 \mathrm{~cm}$ for $14+$ days when above 70 th percentile \\
\hline 1978 & yes & water table is within $30 \mathrm{~cm}$ for $14+$ days \\
\hline 1979 & yes & water table is within $30 \mathrm{~cm}$ for $14+$ days \\
\hline 1980 & yes & water table is within $30 \mathrm{~cm}$ for $14+$ days \\
\hline 1981 & yes & water table is within $30 \mathrm{~cm}$ for $14+$ days \\
\hline 1982 & yes & water table is within $30 \mathrm{~cm}$ for $14+$ days \\
\hline 1983 & yes & water table is within $30 \mathrm{~cm}$ for $14+$ days \\
\hline 1984 & yes & water table is within $30 \mathrm{~cm}$ for $14+$ days \\
\hline 1985 & no & WT is within $30 \mathrm{~cm}$ for $14+$ days when above 70 th percentile \\
\hline 1986 & yes & water table is within $30 \mathrm{~cm}$ for $14+$ days \\
\hline 1987 & no & WT is within $30 \mathrm{~cm}$ for $14+$ days when above 70 th percentile \\
\hline 1988 & yes & water table is within $30 \mathrm{~cm}$ for $14+$ days \\
\hline 1989 & yes & water table is within $30 \mathrm{~cm}$ for $14+$ days \\
\hline 1990 & yes & water table is within $30 \mathrm{~cm}$ for $14+$ days \\
\hline 1991 & no & WT is within $30 \mathrm{~cm}$ for $14+$ days when above 70 th percentile \\
\hline 1992 & yes & water table is within $30 \mathrm{~cm}$ for $14+$ days \\
\hline 1993 & yes & water table is within $30 \mathrm{~cm}$ for $14+$ days \\
\hline 1994 & yes & water table is within $30 \mathrm{~cm}$ for $14+$ days \\
\hline 1995 & yes & water table is within $30 \mathrm{~cm}$ for $14+$ days \\
\hline 1996 & yes & water table is within $30 \mathrm{~cm}$ for $14+$ days \\
\hline 1997 & yes & water table is within $30 \mathrm{~cm}$ for $14+$ days \\
\hline 1998 & yes & water table is within $30 \mathrm{~cm}$ for $14+$ days \\
\hline 1999 & yes & water table is within $30 \mathrm{~cm}$ for $14+$ days \\
\hline 2000 & yes & water table is within $30 \mathrm{~cm}$ for $14+$ days \\
\hline 2001 & no & WT is within $30 \mathrm{~cm}$ for $14+$ days when above 70 th percentile \\
\hline 2002 & yes & water table is within $30 \mathrm{~cm}$ for $14+$ days \\
\hline 2003 & yes & water table is within $30 \mathrm{~cm}$ for $14+$ days \\
\hline 2004 & yes & water table is within $30 \mathrm{~cm}$ for $14+$ days \\
\hline 2005 & yes & water table is within $30 \mathrm{~cm}$ for $14+$ days \\
\hline
\end{tabular}


Table B.66: 45-year record for the Army Corps 30-day Moving Total approach for bogwell plot S3 at Marcell. This plot met wetland hydrology in 18 out of 45 years. There were 7 years that did not meet wetland hydrology because water table (WT) saturation occurred during "wet" periods, while 21 years did not meet water table saturation criterion.

\begin{tabular}{|c|c|c|}
\hline Year & $\begin{array}{c}\text { Met/Not } \\
\text { Met }\end{array}$ & Reason Year did or did not meet Wetland Hydrology \\
\hline 1961 & no & water table is not within $30 \mathrm{~cm}$ for $14+$ days \\
\hline 1962 & no & water table is not within $30 \mathrm{~cm}$ for $14+$ days \\
\hline 1963 & no & water table is not within $30 \mathrm{~cm}$ for $14+$ days \\
\hline 1964 & no & water table is not within $30 \mathrm{~cm}$ for $14+$ days \\
\hline 1965 & no & water table is not within $30 \mathrm{~cm}$ for $14+$ days \\
\hline 1966 & no & WT is within $30 \mathrm{~cm}$ for $14+$ days when above 70 th percentile \\
\hline 1967 & no & WT is within $30 \mathrm{~cm}$ for $14+$ days when above 70 th percentile \\
\hline 1968 & no & water table is not within $30 \mathrm{~cm}$ for $14+$ days \\
\hline 1969 & no & water table is not within $30 \mathrm{~cm}$ for $14+$ days \\
\hline 1970 & no & water table is not within $30 \mathrm{~cm}$ for $14+$ days \\
\hline 1971 & no & water table is not within $30 \mathrm{~cm}$ for $14+$ days \\
\hline 1972 & no & water table is not within $30 \mathrm{~cm}$ for $14+$ days \\
\hline 1973 & no & water table is not within $30 \mathrm{~cm}$ for $14+$ days \\
\hline 1974 & no & water table is not within $30 \mathrm{~cm}$ for $14+$ days \\
\hline 1975 & no & water table is not within $30 \mathrm{~cm}$ for $14+$ days \\
\hline 1976 & no & water table is not within $30 \mathrm{~cm}$ for $14+$ days \\
\hline 1977 & no & water table is not within $30 \mathrm{~cm}$ for $14+$ days \\
\hline 1978 & no & water table is not within $30 \mathrm{~cm}$ for $14+$ days \\
\hline 1979 & no & water table is not within $30 \mathrm{~cm}$ for $14+$ days \\
\hline 1980 & no & water table is not within $30 \mathrm{~cm}$ for $14+$ days \\
\hline 1981 & no & water table is not within $30 \mathrm{~cm}$ for $14+$ days \\
\hline 1982 & yes & water table is within $30 \mathrm{~cm}$ for $14+$ days \\
\hline 1983 & yes & water table is within $30 \mathrm{~cm}$ for $14+$ days \\
\hline 1984 & no & water table is not within $30 \mathrm{~cm}$ for $14+$ days \\
\hline 1985 & no & WT is within $30 \mathrm{~cm}$ for $14+$ days when above 70 th percentile \\
\hline 1986 & yes & water table is within $30 \mathrm{~cm}$ for $14+$ days \\
\hline 1987 & no & WT is within $30 \mathrm{~cm}$ for $14+$ days when above 70 th percentile \\
\hline 1988 & yes & water table is within $30 \mathrm{~cm}$ for $14+$ days \\
\hline 1989 & yes & water table is within $30 \mathrm{~cm}$ for $14+$ days \\
\hline 1990 & yes & water table is within $30 \mathrm{~cm}$ for $14+$ days \\
\hline 1991 & no & water table is not within $30 \mathrm{~cm}$ for $14+$ days \\
\hline 1992 & no & WT is within $30 \mathrm{~cm}$ for $14+$ days when above 70 th percentile \\
\hline 1993 & no & WT is within $30 \mathrm{~cm}$ for $14+$ days when above 70 th percentile \\
\hline 1994 & yes & water table is within $30 \mathrm{~cm}$ for $14+$ days \\
\hline 1995 & yes & water table is within $30 \mathrm{~cm}$ for $14+$ days \\
\hline 1996 & yes & water table is within $30 \mathrm{~cm}$ for $14+$ days \\
\hline 1997 & yes & water table is within $30 \mathrm{~cm}$ for $14+$ days \\
\hline 1998 & yes & water table is within $30 \mathrm{~cm}$ for $14+$ days \\
\hline 1999 & yes & water table is within $30 \mathrm{~cm}$ for $14+$ days \\
\hline 2000 & yes & water table is within $30 \mathrm{~cm}$ for $14+$ days \\
\hline 2001 & yes & water table is within $30 \mathrm{~cm}$ for $14+$ days \\
\hline 2002 & yes & water table is within $30 \mathrm{~cm}$ for $14+$ days \\
\hline 2003 & yes & water table is within $30 \mathrm{~cm}$ for $14+$ days \\
\hline 2004 & yes & water table is within $30 \mathrm{~cm}$ for $14+$ days \\
\hline 2005 & yes & water table is within $30 \mathrm{~cm}$ for $14+$ days \\
\hline
\end{tabular}


Table B.67: 45-year record for the Army Corps 30-day Moving Total approach for bogwell plot S4 at Marcell. This plot met wetland hydrology in 40 out of 44 years. There were 4 years that did not meet wetland hydrology because water table (WT) saturation occurred during "wet" periods.

\begin{tabular}{|c|c|c|}
\hline Year & $\begin{array}{l}\text { Met/Not } \\
\text { Met }\end{array}$ & Reason Year did or did not meet Wetland Hydrology \\
\hline 1962 & no & WT is within $30 \mathrm{~cm}$ for $14+$ days when above 70 th Percentile \\
\hline 1963 & yes & water table is within $30 \mathrm{~cm}$ for $14+$ days \\
\hline 1964 & no & WT is within $30 \mathrm{~cm}$ for $14+$ days when above 70 th Percentile \\
\hline 1965 & yes & water table is within $30 \mathrm{~cm}$ for $14+$ days \\
\hline 1966 & yes & water table is within $30 \mathrm{~cm}$ for $14+$ days \\
\hline 1967 & yes & water table is within $30 \mathrm{~cm}$ for $14+$ days \\
\hline 1968 & yes & water table is within $30 \mathrm{~cm}$ for $14+$ days \\
\hline 1969 & yes & water table is within $30 \mathrm{~cm}$ for $14+$ days \\
\hline 1970 & yes & water table is within $30 \mathrm{~cm}$ for $14+$ days \\
\hline 1971 & yes & water table is within $30 \mathrm{~cm}$ for $14+$ days \\
\hline 1972 & yes & water table is within $30 \mathrm{~cm}$ for $14+$ days \\
\hline 1973 & yes & water table is within $30 \mathrm{~cm}$ for $14+$ days \\
\hline 1974 & yes & water table is within $30 \mathrm{~cm}$ for $14+$ days \\
\hline 1975 & yes & water table is within $30 \mathrm{~cm}$ for $14+$ days \\
\hline 1976 & yes & water table is within $30 \mathrm{~cm}$ for $14+$ days \\
\hline 1977 & no & WT is within $30 \mathrm{~cm}$ for $14+$ days when above 70 th Percentile \\
\hline 1978 & yes & water table is within $30 \mathrm{~cm}$ for $14+$ days \\
\hline 1979 & yes & water table is within $30 \mathrm{~cm}$ for $14+$ days \\
\hline 1980 & yes & water table is within $30 \mathrm{~cm}$ for $14+$ days \\
\hline 1981 & yes & water table is within $30 \mathrm{~cm}$ for $14+$ days \\
\hline 1982 & yes & water table is within $30 \mathrm{~cm}$ for $14+$ days \\
\hline 1983 & yes & water table is within $30 \mathrm{~cm}$ for $14+$ days \\
\hline 1984 & yes & water table is within $30 \mathrm{~cm}$ for $14+$ days \\
\hline 1985 & yes & water table is within $30 \mathrm{~cm}$ for $14+$ days \\
\hline 1986 & yes & water table is within $30 \mathrm{~cm}$ for $14+$ days \\
\hline 1987 & yes & water table is within $30 \mathrm{~cm}$ for $14+$ days \\
\hline 1988 & yes & water table is within $30 \mathrm{~cm}$ for $14+$ days \\
\hline 1989 & yes & water table is within $30 \mathrm{~cm}$ for $14+$ days \\
\hline 1990 & yes & water table is within $30 \mathrm{~cm}$ for $14+$ days \\
\hline 1991 & yes & water table is within $30 \mathrm{~cm}$ for $14+$ days \\
\hline 1992 & yes & water table is within $30 \mathrm{~cm}$ for $14+$ days \\
\hline 1993 & yes & water table is within $30 \mathrm{~cm}$ for $14+$ days \\
\hline 1994 & yes & water table is within $30 \mathrm{~cm}$ for $14+$ days \\
\hline 1995 & yes & water table is within $30 \mathrm{~cm}$ for $14+$ days \\
\hline 1996 & yes & water table is within $30 \mathrm{~cm}$ for $14+$ days \\
\hline 1997 & yes & water table is within $30 \mathrm{~cm}$ for $14+$ days \\
\hline 1998 & yes & water table is within $30 \mathrm{~cm}$ for $14+$ days \\
\hline 1999 & no & WT is within $30 \mathrm{~cm}$ for $14+$ days when above 70 th Percentile \\
\hline 2000 & yes & water table is within $30 \mathrm{~cm}$ for $14+$ days \\
\hline 2001 & yes & water table is within $30 \mathrm{~cm}$ for $14+$ days \\
\hline 2002 & yes & water table is within $30 \mathrm{~cm}$ for $14+$ days \\
\hline 2003 & yes & water table is within $30 \mathrm{~cm}$ for $14+$ days \\
\hline 2004 & yes & water table is within $30 \mathrm{~cm}$ for $14+$ days \\
\hline 2005 & yes & water table is within $30 \mathrm{~cm}$ for $14+$ days \\
\hline
\end{tabular}


Table B.68: 45-year record for the Army Corps 30-day Moving Total approach for bogwell plot S5 at Marcell. This plot met wetland hydrology in 35 out of 44 years. There were 8 years that did not meet wetland hydrology because water table (WT) saturation occurred during "wet" periods, while 1 year did not meet water table saturation criterion.

\begin{tabular}{|c|c|c|}
\hline Year & $\begin{array}{c}\text { Met/Not } \\
\text { Met }\end{array}$ & Reason Year did or did not meet Wetland Hydrology \\
\hline 1962 & no & WT is within $30 \mathrm{~cm}$ for $14+$ days when above 70 th Percentile \\
\hline 1963 & no & WT is within $30 \mathrm{~cm}$ for $14+$ days when above 70 th Percentile \\
\hline 1964 & no & WT is within $30 \mathrm{~cm}$ for $14+$ days when above 70 th Percentile \\
\hline 1965 & yes & water table is within $30 \mathrm{~cm}$ for $14+$ days \\
\hline 1966 & yes & water table is within $30 \mathrm{~cm}$ for $14+$ days \\
\hline 1967 & yes & water table is within $30 \mathrm{~cm}$ for $14+$ days \\
\hline 1968 & yes & water table is within $30 \mathrm{~cm}$ for $14+$ days \\
\hline 1969 & yes & water table is within $30 \mathrm{~cm}$ for $14+$ days \\
\hline 1970 & yes & water table is within $30 \mathrm{~cm}$ for $14+$ days \\
\hline 1971 & no & WT is within $30 \mathrm{~cm}$ for $14+$ days when above 70th Percentile \\
\hline 1972 & no & WT is within $30 \mathrm{~cm}$ for $14+$ days when above 70 th Percentile \\
\hline 1973 & yes & water table is within $30 \mathrm{~cm}$ for $14+$ days \\
\hline 1974 & no & WT is within $30 \mathrm{~cm}$ for $14+$ days when above 70 th Percentile \\
\hline 1975 & yes & water table is within $30 \mathrm{~cm}$ for $14+$ days \\
\hline 1976 & no & water table is not within $30 \mathrm{~cm}$ for $14+$ days \\
\hline 1977 & no & WT is within $30 \mathrm{~cm}$ for $14+$ days when above 70 th Percentile \\
\hline 1978 & yes & water table is within $30 \mathrm{~cm}$ for $14+$ days \\
\hline 1979 & yes & water table is within $30 \mathrm{~cm}$ for $14+$ days \\
\hline 1980 & yes & water table is within $30 \mathrm{~cm}$ for $14+$ days \\
\hline 1981 & yes & water table is within $30 \mathrm{~cm}$ for $14+$ days \\
\hline 1982 & yes & water table is within $30 \mathrm{~cm}$ for $14+$ days \\
\hline 1983 & yes & water table is within $30 \mathrm{~cm}$ for $14+$ days \\
\hline 1984 & yes & water table is within $30 \mathrm{~cm}$ for $14+$ days \\
\hline 1985 & yes & water table is within $30 \mathrm{~cm}$ for $14+$ days \\
\hline 1986 & yes & water table is within $30 \mathrm{~cm}$ for $14+$ days \\
\hline 1987 & yes & water table is within $30 \mathrm{~cm}$ for $14+$ days \\
\hline 1988 & yes & water table is within $30 \mathrm{~cm}$ for $14+$ days \\
\hline 1989 & yes & water table is within $30 \mathrm{~cm}$ for $14+$ days \\
\hline 1990 & yes & water table is within $30 \mathrm{~cm}$ for $14+$ days \\
\hline 1991 & yes & water table is within $30 \mathrm{~cm}$ for $14+$ days \\
\hline 1992 & yes & water table is within $30 \mathrm{~cm}$ for $14+$ days \\
\hline 1993 & yes & water table is within $30 \mathrm{~cm}$ for $14+$ days \\
\hline 1994 & yes & water table is within $30 \mathrm{~cm}$ for $14+$ days \\
\hline 1995 & yes & water table is within $30 \mathrm{~cm}$ for $14+$ days \\
\hline 1996 & yes & water table is within $30 \mathrm{~cm}$ for $14+$ days \\
\hline 1997 & yes & water table is within $30 \mathrm{~cm}$ for $14+$ days \\
\hline 1998 & yes & water table is within $30 \mathrm{~cm}$ for $14+$ days \\
\hline 1999 & no & WT is within $30 \mathrm{~cm}$ for $14+$ days when above 70 th Percentile \\
\hline 2000 & yes & water table is within $30 \mathrm{~cm}$ for $14+$ days \\
\hline 2001 & yes & water table is within $30 \mathrm{~cm}$ for $14+$ days \\
\hline 2002 & yes & water table is within $30 \mathrm{~cm}$ for $14+$ days \\
\hline 2003 & yes & water table is within $30 \mathrm{~cm}$ for $14+$ days \\
\hline 2004 & yes & water table is within $30 \mathrm{~cm}$ for $14+$ days \\
\hline 2005 & yes & water table is within $30 \mathrm{~cm}$ for $14+$ days \\
\hline
\end{tabular}


Table B.69: 45-year record for the Army Corps 30-day Moving Total approach for bogwell plot S6 at Marcell. This plot met wetland hydrology in 15 out of 40 years. There were 14 years that did not meet wetland hydrology because water table (WT) saturation occurred during "wet" periods, while 11 years did not meet water table saturation criterion.

\begin{tabular}{|c|c|c|}
\hline Year & $\begin{array}{c}\text { Met/Not } \\
\text { Met }\end{array}$ & Reason Year did or did not meet Wetland Hydrology \\
\hline 1961 & no data & \\
\hline 1962 & no data & \\
\hline 1963 & no data & \\
\hline 1964 & no data & \\
\hline 1965 & no & water table not within $30 \mathrm{~cm}$ for $14+$ days \\
\hline 1966 & no & water table not within $30 \mathrm{~cm}$ for $14+$ days \\
\hline 1967 & no & water table not within $30 \mathrm{~cm}$ for $14+$ days \\
\hline 1968 & no & water table not within $30 \mathrm{~cm}$ for $14+$ days \\
\hline 1969 & no & water table not within $30 \mathrm{~cm}$ for $14+$ days \\
\hline 1970 & no & water table not within $30 \mathrm{~cm}$ for $14+$ days \\
\hline 1971 & no & water table not within $30 \mathrm{~cm}$ for $14+$ days \\
\hline 1972 & no & water table not within $30 \mathrm{~cm}$ for $14+$ days \\
\hline 1973 & no & water table not within $30 \mathrm{~cm}$ for $14+$ days \\
\hline 1974 & no & WT is within $30 \mathrm{~cm}$ for $14+$ days when above 70 th Percentile \\
\hline 1975 & no data & \\
\hline 1976 & no & water table not within $30 \mathrm{~cm}$ for $14+$ days \\
\hline 1977 & no & WT is within $30 \mathrm{~cm}$ for $14+$ days when above 70 th Percentile \\
\hline 1978 & no & WT is within $30 \mathrm{~cm}$ for $14+$ days when above 70 th Percentile \\
\hline 1979 & no & WT is within $30 \mathrm{~cm}$ for $14+$ days when above 70 th Percentile \\
\hline 1980 & no & WT is within $30 \mathrm{~cm}$ for $14+$ days when above 70 th Percentile \\
\hline 1981 & no & WT is within $30 \mathrm{~cm}$ for $14+$ days when above 70 th Percentile \\
\hline 1982 & no & WT is within $30 \mathrm{~cm}$ for $14+$ days when above 70 th Percentile \\
\hline 1983 & yes & water table is within $30 \mathrm{~cm}$ for $14+$ days \\
\hline 1984 & no & WT is within $30 \mathrm{~cm}$ for $14+$ days when above 70 th Percentile \\
\hline 1985 & no & WT is within $30 \mathrm{~cm}$ for $14+$ days when above 70 th Percentile \\
\hline 1986 & no & WT is within $30 \mathrm{~cm}$ for $14+$ days when above 70 th Percentile \\
\hline 1987 & no & WT is within $30 \mathrm{~cm}$ for $14+$ days when above 70 th Percentile \\
\hline 1988 & yes & water table is within $30 \mathrm{~cm}$ for $14+$ days \\
\hline 1989 & no & water table is $30 \mathrm{~cm}$ for $14+$ days when above the 70 th Percentile \\
\hline 1990 & yes & water table is within $30 \mathrm{~cm}$ for $14+$ days \\
\hline 1991 & no & water table not within $30 \mathrm{~cm}$ for $14+$ days \\
\hline 1992 & no & WT is within $30 \mathrm{~cm}$ for $14+$ days when above 70 th Percentile \\
\hline 1993 & no & WT is within $30 \mathrm{~cm}$ for $14+$ days when above 70 th Percentile \\
\hline 1994 & yes & water table is within $30 \mathrm{~cm}$ for $14+$ days \\
\hline 1995 & yes & water table is within $30 \mathrm{~cm}$ for $14+$ days \\
\hline 1996 & yes & water table is within $30 \mathrm{~cm}$ for $14+$ days \\
\hline 1997 & yes & water table is within $30 \mathrm{~cm}$ for $14+$ days \\
\hline 1998 & yes & water table is within $30 \mathrm{~cm}$ for $14+$ days \\
\hline 1999 & yes & water table is within $30 \mathrm{~cm}$ for $14+$ days \\
\hline 2000 & yes & water table is within $30 \mathrm{~cm}$ for $14+$ days \\
\hline 2001 & yes & water table is within $30 \mathrm{~cm}$ for $14+$ days \\
\hline 2002 & yes & water table is within $30 \mathrm{~cm}$ for $14+$ days \\
\hline 2003 & yes & water table is within $30 \mathrm{~cm}$ for $14+$ days \\
\hline 2004 & yes & water table is within $30 \mathrm{~cm}$ for $14+$ days \\
\hline 2005 & yes & water table is within $30 \mathrm{~cm}$ for $14+$ days \\
\hline
\end{tabular}


Table B.70: 40-year record for the modified 30-day Moving Total approach for plot $1 \mathrm{~L}$ at Greenville. This plot met wetland hydrology in 0 out of 40 years. All years did not meet water table saturation criterion.

\begin{tabular}{|c|c|c|}
\hline Year & $\begin{array}{c}\text { Met/Not } \\
\text { Met }\end{array}$ & Reason Year did or did not meet Wetland Hydrology \\
\hline 1959 & no & water table not within $30 \mathrm{~cm}$ for $14+$ days \\
\hline 1960 & no & water table not within $30 \mathrm{~cm}$ for $14+$ days \\
\hline 1961 & no & water table not within $30 \mathrm{~cm}$ for $14+$ days \\
\hline 1962 & no & water table not within $30 \mathrm{~cm}$ for $14+$ days \\
\hline 1963 & no & water table not within $30 \mathrm{~cm}$ for $14+$ days \\
\hline 1964 & no & water table not within $30 \mathrm{~cm}$ for $14+$ days \\
\hline 1965 & no & water table not within $30 \mathrm{~cm}$ for $14+$ days \\
\hline 1966 & no & water table not within $30 \mathrm{~cm}$ for $14+$ days \\
\hline 1967 & no & water table not within $30 \mathrm{~cm}$ for $14+$ days \\
\hline 1968 & no & water table not within $30 \mathrm{~cm}$ for $14+$ days \\
\hline 1969 & no & water table not within $30 \mathrm{~cm}$ for $14+$ days \\
\hline 1970 & no & water table not within $30 \mathrm{~cm}$ for $14+$ days \\
\hline 1971 & no & water table not within $30 \mathrm{~cm}$ for $14+$ days \\
\hline 1972 & no & water table not within $30 \mathrm{~cm}$ for $14+$ days \\
\hline 1973 & no & water table not within $30 \mathrm{~cm}$ for $14+$ days \\
\hline 1974 & no & water table not within $30 \mathrm{~cm}$ for $14+$ days \\
\hline 1975 & no & water table not within $30 \mathrm{~cm}$ for $14+$ days \\
\hline 1976 & no & water table not within $30 \mathrm{~cm}$ for $14+$ days \\
\hline 1977 & no & water table not within $30 \mathrm{~cm}$ for $14+$ days \\
\hline 1978 & no & water table not within $30 \mathrm{~cm}$ for $14+$ days \\
\hline 1979 & no & water table not within $30 \mathrm{~cm}$ for $14+$ days \\
\hline 1980 & no & water table not within $30 \mathrm{~cm}$ for $14+$ days \\
\hline 1981 & no & water table not within $30 \mathrm{~cm}$ for $14+$ days \\
\hline 1982 & no & water table not within $30 \mathrm{~cm}$ for $14+$ days \\
\hline 1983 & no & water table not within $30 \mathrm{~cm}$ for $14+$ days \\
\hline 1984 & no & water table not within $30 \mathrm{~cm}$ for $14+$ days \\
\hline 1985 & no & water table not within $30 \mathrm{~cm}$ for $14+$ days \\
\hline 1986 & no & water table not within $30 \mathrm{~cm}$ for $14+$ days \\
\hline 1987 & no & water table not within $30 \mathrm{~cm}$ for $14+$ days \\
\hline 1988 & no & water table not within $30 \mathrm{~cm}$ for $14+$ days \\
\hline 1989 & no & water table not within $30 \mathrm{~cm}$ for $14+$ days \\
\hline 1990 & no & water table not within $30 \mathrm{~cm}$ for $14+$ days \\
\hline 1991 & no & water table not within $30 \mathrm{~cm}$ for $14+$ days \\
\hline 1992 & no & water table not within $30 \mathrm{~cm}$ for $14+$ days \\
\hline 1993 & no & water table not within $30 \mathrm{~cm}$ for $14+$ days \\
\hline 1994 & no & water table not within $30 \mathrm{~cm}$ for $14+$ days \\
\hline 1995 & no & water table not within $30 \mathrm{~cm}$ for $14+$ days \\
\hline 1996 & no & water table not within $30 \mathrm{~cm}$ for $14+$ days \\
\hline 1997 & no & water table not within $30 \mathrm{~cm}$ for $14+$ days \\
\hline 1998 & no & water table not within $30 \mathrm{~cm}$ for $14+$ days \\
\hline
\end{tabular}


Table B.71: 40-year record for the modified 30-day Moving Total approach for plot $2 \mathrm{~L}$ at Greenville. This plot met wetland hydrology in 0 out of 40 years. There was 1 year that did not meet wetland hydrology because water table saturation occurred during a "wet" period, while 39 years did not meet water table saturation criterion.

\begin{tabular}{|c|c|c|}
\hline Year & $\begin{array}{c}\text { Met/Not } \\
\text { Met }\end{array}$ & Reason Year did or did not meet Wetland Hydrology \\
\hline 1959 & no & water table not within $30 \mathrm{~cm}$ for $14+$ days \\
\hline 1960 & no & water table not within $30 \mathrm{~cm}$ for $14+$ days \\
\hline 1961 & no & water table not within $30 \mathrm{~cm}$ for $14+$ days \\
\hline 1962 & no & water table not within $30 \mathrm{~cm}$ for $14+$ days \\
\hline 1963 & no & water table not within $30 \mathrm{~cm}$ for $14+$ days \\
\hline 1964 & no & water table not within $30 \mathrm{~cm}$ for $14+$ days \\
\hline 1965 & no & water table not within $30 \mathrm{~cm}$ for $14+$ days \\
\hline 1966 & no & WT is within $30 \mathrm{~cm}$ for $14+$ days when rainfall is above 70 th Percentile \\
\hline 1967 & no & water table not within $30 \mathrm{~cm}$ for $14+$ days \\
\hline 1968 & no & water table not within $30 \mathrm{~cm}$ for $14+$ days \\
\hline 1969 & no & water table not within $30 \mathrm{~cm}$ for $14+$ days \\
\hline 1970 & no & water table not within $30 \mathrm{~cm}$ for $14+$ days \\
\hline 1971 & no & water table not within $30 \mathrm{~cm}$ for $14+$ days \\
\hline 1972 & no & water table not within $30 \mathrm{~cm}$ for $14+$ days \\
\hline 1973 & no & water table not within $30 \mathrm{~cm}$ for $14+$ days \\
\hline 1974 & no & water table not within $30 \mathrm{~cm}$ for $14+$ days \\
\hline 1975 & no & water table not within $30 \mathrm{~cm}$ for $14+$ days \\
\hline 1976 & no & water table not within $30 \mathrm{~cm}$ for $14+$ days \\
\hline 1977 & no & water table not within $30 \mathrm{~cm}$ for $14+$ days \\
\hline 1978 & no & water table not within $30 \mathrm{~cm}$ for $14+$ days \\
\hline 1979 & no & water table not within $30 \mathrm{~cm}$ for $14+$ days \\
\hline 1980 & no & water table not within $30 \mathrm{~cm}$ for $14+$ days \\
\hline 1981 & no & water table not within $30 \mathrm{~cm}$ for $14+$ days \\
\hline 1982 & no & water table not within $30 \mathrm{~cm}$ for $14+$ days \\
\hline 1983 & no & water table not within $30 \mathrm{~cm}$ for $14+$ days \\
\hline 1984 & no & water table not within $30 \mathrm{~cm}$ for $14+$ days \\
\hline 1985 & no & water table not within $30 \mathrm{~cm}$ for $14+$ days \\
\hline 1986 & no & water table not within $30 \mathrm{~cm}$ for $14+$ days \\
\hline 1987 & no & water table not within $30 \mathrm{~cm}$ for $14+$ days \\
\hline 1988 & no & water table not within $30 \mathrm{~cm}$ for $14+$ days \\
\hline 1989 & no & water table not within $30 \mathrm{~cm}$ for $14+$ days \\
\hline 1990 & no & water table not within $30 \mathrm{~cm}$ for $14+$ days \\
\hline 1991 & no & water table not within $30 \mathrm{~cm}$ for $14+$ days \\
\hline 1992 & no & water table not within $30 \mathrm{~cm}$ for $14+$ days \\
\hline 1993 & no & water table not within $30 \mathrm{~cm}$ for $14+$ days \\
\hline 1994 & no & water table not within $30 \mathrm{~cm}$ for $14+$ days \\
\hline 1995 & no & water table not within $30 \mathrm{~cm}$ for $14+$ days \\
\hline 1996 & no & water table not within $30 \mathrm{~cm}$ for $14+$ days \\
\hline 1997 & no & water table not within $30 \mathrm{~cm}$ for $14+$ days \\
\hline 1998 & no & water table not within $30 \mathrm{~cm}$ for $14+$ days \\
\hline
\end{tabular}


Table B.72: 40-year record for the modified 30-day Moving Total approach for plot 3L at Greenville. This plot met wetland hydrology in 0 out of 40 years. There was 1 year that did not meet wetland hydrology because water table saturation occurred during a "wet" period, while 39 years did not meet water table saturation criterion.

\begin{tabular}{|c|c|c|}
\hline Year & $\begin{array}{c}\text { Met/Not } \\
\text { Met }\end{array}$ & Reason Year did or did not meet Wetland Hydrology \\
\hline 1959 & no & water table not within $30 \mathrm{~cm}$ for $14+$ days \\
\hline 1960 & no & water table not within $30 \mathrm{~cm}$ for $14+$ days \\
\hline 1961 & no & water table not within $30 \mathrm{~cm}$ for $14+$ days \\
\hline 1962 & no & water table not within $30 \mathrm{~cm}$ for $14+$ days \\
\hline 1963 & no & water table not within $30 \mathrm{~cm}$ for $14+$ days \\
\hline 1964 & no & water table not within $30 \mathrm{~cm}$ for $14+$ days \\
\hline 1965 & no & water table not within $30 \mathrm{~cm}$ for $14+$ days \\
\hline 1966 & no & WT is within $30 \mathrm{~cm}$ for $14+$ days when rainfall is above 70 th Percentile \\
\hline 1967 & no & water table not within $30 \mathrm{~cm}$ for $14+$ days \\
\hline 1968 & no & water table not within $30 \mathrm{~cm}$ for $14+$ days \\
\hline 1969 & no & water table not within $30 \mathrm{~cm}$ for $14+$ days \\
\hline 1970 & no & water table not within $30 \mathrm{~cm}$ for $14+$ days \\
\hline 1971 & no & water table not within $30 \mathrm{~cm}$ for $14+$ days \\
\hline 1972 & no & water table not within $30 \mathrm{~cm}$ for $14+$ days \\
\hline 1973 & no & water table not within $30 \mathrm{~cm}$ for $14+$ days \\
\hline 1974 & no & water table not within $30 \mathrm{~cm}$ for $14+$ days \\
\hline 1975 & no & water table not within $30 \mathrm{~cm}$ for $14+$ days \\
\hline 1976 & no & water table not within $30 \mathrm{~cm}$ for $14+$ days \\
\hline 1977 & no & water table not within $30 \mathrm{~cm}$ for $14+$ days \\
\hline 1978 & no & water table not within $30 \mathrm{~cm}$ for $14+$ days \\
\hline 1979 & no & water table not within $30 \mathrm{~cm}$ for $14+$ days \\
\hline 1980 & no & water table not within $30 \mathrm{~cm}$ for $14+$ days \\
\hline 1981 & no & water table not within $30 \mathrm{~cm}$ for $14+$ days \\
\hline 1982 & no & water table not within $30 \mathrm{~cm}$ for $14+$ days \\
\hline 1983 & no & water table not within $30 \mathrm{~cm}$ for $14+$ days \\
\hline 1984 & no & water table not within $30 \mathrm{~cm}$ for $14+$ days \\
\hline 1985 & no & water table not within $30 \mathrm{~cm}$ for $14+$ days \\
\hline 1986 & no & water table not within $30 \mathrm{~cm}$ for $14+$ days \\
\hline 1987 & no & water table not within $30 \mathrm{~cm}$ for $14+$ days \\
\hline 1988 & no & water table not within $30 \mathrm{~cm}$ for $14+$ days \\
\hline 1989 & no & water table not within $30 \mathrm{~cm}$ for $14+$ days \\
\hline 1990 & no & water table not within $30 \mathrm{~cm}$ for $14+$ days \\
\hline 1991 & no & water table not within $30 \mathrm{~cm}$ for $14+$ days \\
\hline 1992 & no & water table not within $30 \mathrm{~cm}$ for $14+$ days \\
\hline 1993 & no & water table not within $30 \mathrm{~cm}$ for $14+$ days \\
\hline 1994 & no & water table not within $30 \mathrm{~cm}$ for $14+$ days \\
\hline 1995 & no & water table not within $30 \mathrm{~cm}$ for $14+$ days \\
\hline 1996 & no & water table not within $30 \mathrm{~cm}$ for $14+$ days \\
\hline 1997 & no & water table not within $30 \mathrm{~cm}$ for $14+$ days \\
\hline 1998 & no & water table not within $30 \mathrm{~cm}$ for $14+$ days \\
\hline
\end{tabular}


Table B.73: 40-year record for the modified 30-day Moving Total approach for plot $1 \mathrm{~L}$ at Greenville. This plot met wetland hydrology in 0 out of 40 years. All years did not meet water table saturation criterion.

\begin{tabular}{|c|c|c|}
\hline Year & $\begin{array}{c}\text { Met/Not } \\
\text { Met }\end{array}$ & Reason Year did or did not meet Wetland Hydrology \\
\hline 1959 & no & water table not within $30 \mathrm{~cm}$ for $14+$ days \\
\hline 1960 & no & water table not within $30 \mathrm{~cm}$ for $14+$ days \\
\hline 1961 & no & water table not within $30 \mathrm{~cm}$ for $14+$ days \\
\hline 1962 & no & water table not within $30 \mathrm{~cm}$ for $14+$ days \\
\hline 1963 & no & water table not within $30 \mathrm{~cm}$ for $14+$ days \\
\hline 1964 & no & water table not within $30 \mathrm{~cm}$ for $14+$ days \\
\hline 1965 & no & water table not within $30 \mathrm{~cm}$ for $14+$ days \\
\hline 1966 & no & water table not within $30 \mathrm{~cm}$ for $14+$ days \\
\hline 1967 & no & water table not within $30 \mathrm{~cm}$ for $14+$ days \\
\hline 1968 & no & water table not within $30 \mathrm{~cm}$ for $14+$ days \\
\hline 1969 & no & water table not within $30 \mathrm{~cm}$ for $14+$ days \\
\hline 1970 & no & water table not within $30 \mathrm{~cm}$ for $14+$ days \\
\hline 1971 & no & water table not within $30 \mathrm{~cm}$ for $14+$ days \\
\hline 1972 & no & water table not within $30 \mathrm{~cm}$ for $14+$ days \\
\hline 1973 & no & water table not within $30 \mathrm{~cm}$ for $14+$ days \\
\hline 1974 & no & water table not within $30 \mathrm{~cm}$ for $14+$ days \\
\hline 1975 & no & water table not within $30 \mathrm{~cm}$ for $14+$ days \\
\hline 1976 & no & water table not within $30 \mathrm{~cm}$ for $14+$ days \\
\hline 1977 & no & water table not within $30 \mathrm{~cm}$ for $14+$ days \\
\hline 1978 & no & water table not within $30 \mathrm{~cm}$ for $14+$ days \\
\hline 1979 & no & water table not within $30 \mathrm{~cm}$ for $14+$ days \\
\hline 1980 & no & water table not within $30 \mathrm{~cm}$ for $14+$ days \\
\hline 1981 & no & water table not within $30 \mathrm{~cm}$ for $14+$ days \\
\hline 1982 & no & water table not within $30 \mathrm{~cm}$ for $14+$ days \\
\hline 1983 & no & water table not within $30 \mathrm{~cm}$ for $14+$ days \\
\hline 1984 & no & water table not within $30 \mathrm{~cm}$ for $14+$ days \\
\hline 1985 & no & water table not within $30 \mathrm{~cm}$ for $14+$ days \\
\hline 1986 & no & water table not within $30 \mathrm{~cm}$ for $14+$ days \\
\hline 1987 & no & water table not within $30 \mathrm{~cm}$ for $14+$ days \\
\hline 1988 & no & water table not within $30 \mathrm{~cm}$ for $14+$ days \\
\hline 1989 & no & water table not within $30 \mathrm{~cm}$ for $14+$ days \\
\hline 1990 & no & water table not within $30 \mathrm{~cm}$ for $14+$ days \\
\hline 1991 & no & water table not within $30 \mathrm{~cm}$ for $14+$ days \\
\hline 1992 & no & water table not within $30 \mathrm{~cm}$ for $14+$ days \\
\hline 1993 & no & water table not within $30 \mathrm{~cm}$ for $14+$ days \\
\hline 1994 & no & water table not within $30 \mathrm{~cm}$ for $14+$ days \\
\hline 1995 & no & water table not within $30 \mathrm{~cm}$ for $14+$ days \\
\hline 1996 & no & water table not within $30 \mathrm{~cm}$ for $14+$ days \\
\hline 1997 & no & water table not within $30 \mathrm{~cm}$ for $14+$ days \\
\hline 1998 & no & water table not within $30 \mathrm{~cm}$ for $14+$ days \\
\hline
\end{tabular}


Table B.74: 40-year record for the modified 30-day Moving Total approach for plot 1R at Greenville. This plot met wetland hydrology in 9 out of 40 years. There were 26 years that did not meet wetland hydrology because water table (WT) saturation occurred during "wet" periods, while 5 years did not meet water table saturation criterion.

\begin{tabular}{|c|c|c|}
\hline Year & $\begin{array}{c}\text { Met/Not } \\
\text { Met }\end{array}$ & Reason Year did or did not meet Wetland Hydrology \\
\hline 1959 & no & WT is within $30 \mathrm{~cm}$ for $14+$ days when rainfall is above 70 th Percentile \\
\hline 1960 & no & WT is within $30 \mathrm{~cm}$ for $14+$ days when rainfall is above 70 th Percentile \\
\hline 1961 & no & WT is within $30 \mathrm{~cm}$ for $14+$ days when rainfall is above 70 th Percentile \\
\hline 1962 & no & WT is within $30 \mathrm{~cm}$ for $14+$ days when rainfall is above 70 th Percentile \\
\hline 1963 & yes & water table is within $30 \mathrm{~cm}$ for $14+$ days \\
\hline 1964 & no & WT is within $30 \mathrm{~cm}$ for $14+$ days when rainfall is above 70 th Percentile \\
\hline 1965 & yes & water table is within $30 \mathrm{~cm}$ for $14+$ days \\
\hline 1966 & no & WT is within $30 \mathrm{~cm}$ for $14+$ days when rainfall is above 70 th Percentile \\
\hline 1967 & no & water table is not within $30 \mathrm{~cm}$ for $14+$ days \\
\hline 1968 & no & WT is within $30 \mathrm{~cm}$ for $14+$ days when rainfall is above 70 th Percentile \\
\hline 1969 & no & WT is within $30 \mathrm{~cm}$ for $14+$ days when rainfall is above 70 th Percentile \\
\hline 1970 & yes & water table is within $30 \mathrm{~cm}$ for $14+$ days \\
\hline 1971 & no & WT is within $30 \mathrm{~cm}$ for $14+$ days when rainfall is above 70 th Percentile \\
\hline 1972 & yes & water table is within $30 \mathrm{~cm}$ for $14+$ days \\
\hline 1973 & no & WT is within $30 \mathrm{~cm}$ for $14+$ days when rainfall is above 70 th Percentile \\
\hline 1974 & yes & water table is within $30 \mathrm{~cm}$ for $14+$ days \\
\hline 1975 & no & WT is within $30 \mathrm{~cm}$ for $14+$ days when rainfall is above 70 th Percentile \\
\hline 1976 & no & water table is not within $30 \mathrm{~cm}$ for $14+$ days \\
\hline 1977 & no & WT is within $30 \mathrm{~cm}$ for $14+$ days when rainfall is above 70 th Percentile \\
\hline 1978 & no & WT is within $30 \mathrm{~cm}$ for $14+$ days when rainfall is above 70 th Percentile \\
\hline 1979 & no & WT is within $30 \mathrm{~cm}$ for $14+$ days when rainfall is above 70 th Percentile \\
\hline 1980 & no & WT is within $30 \mathrm{~cm}$ for $14+$ days when rainfall is above 70 th Percentile \\
\hline 1981 & no & water table is not within $30 \mathrm{~cm}$ for $14+$ days \\
\hline 1982 & yes & water table is within $30 \mathrm{~cm}$ for $14+$ days \\
\hline 1983 & no & WT is within $30 \mathrm{~cm}$ for $14+$ days when rainfall is above 70 th Percentile \\
\hline 1984 & no & WT is within $30 \mathrm{~cm}$ for $14+$ days when rainfall is above 70 th Percentile \\
\hline 1985 & no & water table is not within $30 \mathrm{~cm}$ for $14+$ days \\
\hline 1986 & no & WT is within $30 \mathrm{~cm}$ for $14+$ days when rainfall is above 70 th Percentile \\
\hline 1987 & no & WT is within $30 \mathrm{~cm}$ for $14+$ days when rainfall is above 70 th Percentile \\
\hline 1988 & no & WT is within $30 \mathrm{~cm}$ for $14+$ days when rainfall is above 70 th Percentile \\
\hline 1989 & no & WT is within $30 \mathrm{~cm}$ for $14+$ days when rainfall is above 70 th Percentile \\
\hline 1990 & no & WT is within $30 \mathrm{~cm}$ for $14+$ days when rainfall is above 70 th Percentile \\
\hline 1991 & yes & water table is within $30 \mathrm{~cm}$ for $14+$ days \\
\hline 1992 & yes & water table is within $30 \mathrm{~cm}$ for $14+$ days \\
\hline 1993 & no & WT is within $30 \mathrm{~cm}$ for $14+$ days when rainfall is above 70 th Percentile \\
\hline 1994 & no & WT is within $30 \mathrm{~cm}$ for $14+$ days when rainfall is above 70 th Percentile \\
\hline 1995 & no & WT is within $30 \mathrm{~cm}$ for $14+$ days when rainfall is above 70 th Percentile \\
\hline 1996 & yes & water table is within $30 \mathrm{~cm}$ for $14+$ days \\
\hline 1997 & yes & water table is within $30 \mathrm{~cm}$ for $14+$ days \\
\hline 1998 & no & WT is within $30 \mathrm{~cm}$ for $14+$ days when rainfall is above 70 th Percentile \\
\hline
\end{tabular}


Table B.75: 40-year record for the modified 30-day Moving Total approach for plot 2R at Greenville. This plot met wetland hydrology in 19 out of 40 years. There were 21 years that did not meet wetland hydrology because water table (WT) saturation occurred during "wet" periods.

\begin{tabular}{|c|c|c|}
\hline Year & $\begin{array}{c}\text { Met/Not } \\
\text { Met }\end{array}$ & Reason Year did or did not meet Wetland Hydrology \\
\hline 1959 & no & WT is within $30 \mathrm{~cm}$ for $14+$ days when rainfall exceeds 70 th percentile \\
\hline 1960 & no & WT is within $30 \mathrm{~cm}$ for $14+$ days when rainfall exceeds 70 th percentile \\
\hline 1961 & no & WT is within $30 \mathrm{~cm}$ for $14+$ days when rainfall exceeds 70 th percentile \\
\hline 1962 & no & WT is within $30 \mathrm{~cm}$ for $14+$ days when rainfall exceeds 70 th percentile \\
\hline 1963 & yes & water table is within $30 \mathrm{~cm}$ for $14+$ days \\
\hline 1964 & no & WT is within $30 \mathrm{~cm}$ for $14+$ days when rainfall exceeds 70 th percentile \\
\hline 1965 & yes & water table is within $30 \mathrm{~cm}$ for $14+$ days \\
\hline 1966 & no & WT is within $30 \mathrm{~cm}$ for $14+$ days when rainfall exceeds 70 th percentile \\
\hline 1967 & yes & water table is within $30 \mathrm{~cm}$ for $14+$ days \\
\hline 1968 & no & WT is within $30 \mathrm{~cm}$ for $14+$ days when rainfall exceeds 70 th percentile \\
\hline 1969 & yes & water table is within $30 \mathrm{~cm}$ for $14+$ days \\
\hline 1970 & yes & water table is within $30 \mathrm{~cm}$ for $14+$ days \\
\hline 1971 & no & WT is within $30 \mathrm{~cm}$ for $14+$ days when rainfall exceeds 70 th percentile \\
\hline 1972 & yes & water table is within $30 \mathrm{~cm}$ for $14+$ days \\
\hline 1973 & no & WT is within $30 \mathrm{~cm}$ for $14+$ days when rainfall exceeds 70 th percentile \\
\hline 1974 & yes & water table is within $30 \mathrm{~cm}$ for $14+$ days \\
\hline 1975 & no & WT is within $30 \mathrm{~cm}$ for $14+$ days when rainfall exceeds 70 th percentile \\
\hline 1976 & yes & water table is within $30 \mathrm{~cm}$ for $14+$ days \\
\hline 1977 & no & WT is within $30 \mathrm{~cm}$ for $14+$ days when rainfall exceeds 70 th percentile \\
\hline 1978 & yes & water table is within $30 \mathrm{~cm}$ for $14+$ days \\
\hline 1979 & no & WT is within $30 \mathrm{~cm}$ for $14+$ days when rainfall exceeds 70 th percentile \\
\hline 1980 & no & WT is within $30 \mathrm{~cm}$ for $14+$ days when rainfall exceeds 70 th percentile \\
\hline 1981 & yes & water table is within $30 \mathrm{~cm}$ for $14+$ days \\
\hline 1982 & yes & water table is within $30 \mathrm{~cm}$ for $14+$ days \\
\hline 1983 & no & WT is within $30 \mathrm{~cm}$ for $14+$ days when rainfall exceeds 70 th percentile \\
\hline 1984 & no & WT is within $30 \mathrm{~cm}$ for $14+$ days when rainfall exceeds 70 th percentile \\
\hline 1985 & yes & water table is within $30 \mathrm{~cm}$ for $14+$ days \\
\hline 1986 & yes & water table is within $30 \mathrm{~cm}$ for $14+$ days \\
\hline 1987 & no & WT is within $30 \mathrm{~cm}$ for $14+$ days when rainfall exceeds 70 th percentile \\
\hline 1988 & yes & water table is within $30 \mathrm{~cm}$ for $14+$ days \\
\hline 1989 & no & WT is within $30 \mathrm{~cm}$ for $14+$ days when rainfall exceeds 70 th percentile \\
\hline 1990 & yes & water table is within $30 \mathrm{~cm}$ for $14+$ days \\
\hline 1991 & yes & water table is within $30 \mathrm{~cm}$ for $14+$ days \\
\hline 1992 & yes & water table is within $30 \mathrm{~cm}$ for $14+$ days \\
\hline 1993 & no & WT is within $30 \mathrm{~cm}$ for $14+$ days when rainfall exceeds 70 th percentile \\
\hline 1994 & no & WT is within $30 \mathrm{~cm}$ for $14+$ days when rainfall exceeds 70 th percentile \\
\hline 1995 & no & WT is within $30 \mathrm{~cm}$ for $14+$ days when rainfall exceeds 70 th percentile \\
\hline 1996 & yes & water table is within $30 \mathrm{~cm}$ for $14+$ days \\
\hline 1997 & yes & water table is within $30 \mathrm{~cm}$ for $14+$ days \\
\hline 1998 & no & WT is within $30 \mathrm{~cm}$ for $14+$ days when rainfall exceeds 70 th percentile \\
\hline
\end{tabular}


Table B.76: 40-year record for the modified 30-day Moving Total approach for plot 3R at Greenville. This plot met wetland hydrology in 18 out of 40 years. There were 21 years that did not meet wetland hydrology because water table saturation (WT) occurred during "wet" periods, while 1 year did not meet water table saturation criterion.

\begin{tabular}{|c|c|c|}
\hline Year & $\begin{array}{c}\text { Met/Not } \\
\text { Met }\end{array}$ & Reason Year did or did not meet Wetland Hydrology \\
\hline 1959 & no & WT is within $30 \mathrm{~cm}$ for $14+$ days when rainfall exceeds 70 th percentile \\
\hline 1960 & no & WT is within $30 \mathrm{~cm}$ for $14+$ days when rainfall exceeds 70 th percentile \\
\hline 1961 & no & WT is within $30 \mathrm{~cm}$ for $14+$ days when rainfall exceeds 70 th percentile \\
\hline 1962 & no & WT is within $30 \mathrm{~cm}$ for $14+$ days when rainfall exceeds 70 th percentile \\
\hline 1963 & yes & water table is within $30 \mathrm{~cm}$ for $14+$ days \\
\hline 1964 & no & WT is within $30 \mathrm{~cm}$ for $14+$ days when rainfall exceeds 70 th percentile \\
\hline 1965 & yes & water table is within $30 \mathrm{~cm}$ for $14+$ days \\
\hline 1966 & no & WT is within $30 \mathrm{~cm}$ for $14+$ days when rainfall exceeds 70 th percentile \\
\hline 1967 & yes & water table is within $30 \mathrm{~cm}$ for $14+$ days \\
\hline 1968 & no & WT is within $30 \mathrm{~cm}$ for $14+$ days when rainfall exceeds 70 th percentile \\
\hline 1969 & yes & water table is within $30 \mathrm{~cm}$ for $14+$ days \\
\hline 1970 & yes & water table is within $30 \mathrm{~cm}$ for $14+$ days \\
\hline 1971 & no & WT is within $30 \mathrm{~cm}$ for $14+$ days when rainfall exceeds 70 th percentile \\
\hline 1972 & yes & water table is within $30 \mathrm{~cm}$ for $14+$ days \\
\hline 1973 & no & WT is within $30 \mathrm{~cm}$ for $14+$ days when rainfall exceeds 70 th percentile \\
\hline 1974 & yes & water table is within $30 \mathrm{~cm}$ for $14+$ days \\
\hline 1975 & no & WT is within $30 \mathrm{~cm}$ for $14+$ days when rainfall exceeds 70 th percentile \\
\hline 1976 & no & water table is not within $30 \mathrm{~cm}$ for $14+$ days \\
\hline 1977 & no & WT is within $30 \mathrm{~cm}$ for $14+$ days when rainfall exceeds 70 th percentile \\
\hline 1978 & yes & water table is within $30 \mathrm{~cm}$ for $14+$ days \\
\hline 1979 & no & WT is within $30 \mathrm{~cm}$ for $14+$ days when rainfall exceeds 70 th percentile \\
\hline 1980 & no & WT is within $30 \mathrm{~cm}$ for $14+$ days when rainfall exceeds 70 th percentile \\
\hline 1981 & yes & water table is within $30 \mathrm{~cm}$ for $14+$ days \\
\hline 1982 & yes & water table is within $30 \mathrm{~cm}$ for $14+$ days \\
\hline 1983 & no & WT is within $30 \mathrm{~cm}$ for $14+$ days when rainfall exceeds 70 th percentile \\
\hline 1984 & no & WT is within $30 \mathrm{~cm}$ for $14+$ days when rainfall exceeds 70 th percentile \\
\hline 1985 & yes & water table is within $30 \mathrm{~cm}$ for $14+$ days \\
\hline 1986 & yes & water table is within $30 \mathrm{~cm}$ for $14+$ days \\
\hline 1987 & no & WT is within $30 \mathrm{~cm}$ for $14+$ days when rainfall exceeds 70 th percentile \\
\hline 1988 & yes & water table is within $30 \mathrm{~cm}$ for $14+$ days \\
\hline 1989 & no & WT is within $30 \mathrm{~cm}$ for $14+$ days when rainfall exceeds 70 th percentile \\
\hline 1990 & yes & water table is within $30 \mathrm{~cm}$ for $14+$ days \\
\hline 1991 & yes & water table is within $30 \mathrm{~cm}$ for $14+$ days \\
\hline 1992 & yes & water table is within $30 \mathrm{~cm}$ for $14+$ days \\
\hline 1993 & no & WT is within $30 \mathrm{~cm}$ for $14+$ days when rainfall exceeds 70 th percentile \\
\hline 1994 & no & WT is within $30 \mathrm{~cm}$ for $14+$ days when rainfall exceeds 70 th percentile \\
\hline 1995 & no & WT is within $30 \mathrm{~cm}$ for $14+$ days when rainfall exceeds 70 th percentile \\
\hline 1996 & yes & water table is within $30 \mathrm{~cm}$ for $14+$ days \\
\hline 1997 & yes & water table is within $30 \mathrm{~cm}$ for $14+$ days \\
\hline 1998 & no & WT is within $30 \mathrm{~cm}$ for $14+$ days when rainfall exceeds 70 th percentile \\
\hline
\end{tabular}


Table B.77: 40-year record for the modified 30-day Moving Total approach for plot 4R at Greenville. This plot met wetland hydrology in 16 out of 40 years. There were 22 years that did not meet wetland hydrology because water table saturation (WT) occurred during "wet" periods, while 2 years did not meet water table saturation criterion.

\begin{tabular}{|c|c|c|}
\hline Year & $\begin{array}{c}\text { Met/Not } \\
\text { Met }\end{array}$ & Reason Year did or did not meet Wetland Hydrology \\
\hline 1959 & no & WT is within $30 \mathrm{~cm}$ for $14+$ days when rainfall exceeds 70 th percentile \\
\hline 1960 & no & WT is within $30 \mathrm{~cm}$ for $14+$ days when rainfall exceeds 70 th percentile \\
\hline 1961 & no & WT is within $30 \mathrm{~cm}$ for $14+$ days when rainfall exceeds 70 th percentile \\
\hline 1962 & no & WT is within $30 \mathrm{~cm}$ for $14+$ days when rainfall exceeds 70 th percentile \\
\hline 1963 & yes & water table is within $30 \mathrm{~cm}$ for $14+$ days \\
\hline 1964 & no & WT is within $30 \mathrm{~cm}$ for $14+$ days when rainfall exceeds 70 th percentile \\
\hline 1965 & yes & water table is within $30 \mathrm{~cm}$ for $14+$ days \\
\hline 1966 & no & WT is within $30 \mathrm{~cm}$ for $14+$ days when rainfall exceeds 70 th percentile \\
\hline 1967 & yes & water table is within $30 \mathrm{~cm}$ for $14+$ days \\
\hline 1968 & no & WT is within $30 \mathrm{~cm}$ for $14+$ days when rainfall exceeds 70 th percentile \\
\hline 1969 & yes & water table is within $30 \mathrm{~cm}$ for $14+$ days \\
\hline 1970 & yes & water table is within $30 \mathrm{~cm}$ for $14+$ days \\
\hline 1971 & no & WT is within $30 \mathrm{~cm}$ for $14+$ days when rainfall exceeds 70 th percentile \\
\hline 1972 & yes & water table is within $30 \mathrm{~cm}$ for $14+$ days \\
\hline 1973 & no & WT is within $30 \mathrm{~cm}$ for $14+$ days when rainfall exceeds 70 th percentile \\
\hline 1974 & yes & water table is within $30 \mathrm{~cm}$ for $14+$ days \\
\hline 1975 & no & WT is within $30 \mathrm{~cm}$ for $14+$ days when rainfall exceeds 70 th percentile \\
\hline 1976 & no & water table is not within $30 \mathrm{~cm}$ for $14+$ days \\
\hline 1977 & no & WT is within $30 \mathrm{~cm}$ for $14+$ days when rainfall exceeds 70 th percentile \\
\hline 1978 & yes & water table is within $30 \mathrm{~cm}$ for $14+$ days \\
\hline 1979 & no & WT is within $30 \mathrm{~cm}$ for $14+$ days when rainfall exceeds 70 th percentile \\
\hline 1980 & no & WT is within $30 \mathrm{~cm}$ for $14+$ days when rainfall exceeds 70 th percentile \\
\hline 1981 & no & WT is within $30 \mathrm{~cm}$ for $14+$ days when rainfall exceeds 70 th percentile \\
\hline 1982 & yes & water table is within $30 \mathrm{~cm}$ for $14+$ days \\
\hline 1983 & no & WT is within $30 \mathrm{~cm}$ for $14+$ days when rainfall exceeds 70 th percentile \\
\hline 1984 & no & WT is within $30 \mathrm{~cm}$ for $14+$ days when rainfall exceeds 70 th percentile \\
\hline 1985 & no & water table is not within $30 \mathrm{~cm}$ for $14+$ days \\
\hline 1986 & yes & water table is within $30 \mathrm{~cm}$ for $14+$ days \\
\hline 1987 & no & WT is within $30 \mathrm{~cm}$ for $14+$ days when rainfall exceeds 70 th percentile \\
\hline 1988 & yes & water table is within $30 \mathrm{~cm}$ for $14+$ days \\
\hline 1989 & no & WT is within $30 \mathrm{~cm}$ for $14+$ days when rainfall exceeds 70 th percentile \\
\hline 1990 & yes & water table is within $30 \mathrm{~cm}$ for $14+$ days \\
\hline 1991 & yes & water table is within $30 \mathrm{~cm}$ for $14+$ days \\
\hline 1992 & yes & water table is within $30 \mathrm{~cm}$ for $14+$ days \\
\hline 1993 & no & WT is within $30 \mathrm{~cm}$ for $14+$ days when rainfall exceeds 70 th percentile \\
\hline 1994 & no & WT is within $30 \mathrm{~cm}$ for $14+$ days when rainfall exceeds 70 th percentile \\
\hline 1995 & no & WT is within $30 \mathrm{~cm}$ for $14+$ days when rainfall exceeds 70 th percentile \\
\hline 1996 & yes & water table is within $30 \mathrm{~cm}$ for $14+$ days \\
\hline 1997 & yes & water table is within $30 \mathrm{~cm}$ for $14+$ days \\
\hline 1998 & no & WT is within $30 \mathrm{~cm}$ for $14+$ days when rainfall exceeds 70 th percentile \\
\hline
\end{tabular}


Table B.78: 40-year record for the DAREM approach for plot 4P at Greenville. This plot met wetland hydrology in 23 out of 40 years. There were 21 years that did not meet wetland hydrology because water table (WT) saturation occurred during "wet" periods, while 1 year did not meet water table saturation criterion.

\begin{tabular}{|c|c|c|}
\hline Year & $\begin{array}{c}\text { Met/Not } \\
\text { Met }\end{array}$ & Reason Year did or did not meet Wetland Hydrology \\
\hline 1959 & no & WT is within $30 \mathrm{~cm}$ for $14+$ days when rainfall exceeds 70 th percentile \\
\hline 1960 & no & WT is within $30 \mathrm{~cm}$ for $14+$ days when rainfall exceeds 70 th percentile \\
\hline 1961 & no & WT is within $30 \mathrm{~cm}$ for $14+$ days when rainfall exceeds 70 th percentile \\
\hline 1962 & no & WT is within $30 \mathrm{~cm}$ for $14+$ days when rainfall exceeds 70 th percentile \\
\hline 1963 & yes & water table is within $30 \mathrm{~cm}$ for $14+$ days \\
\hline 1964 & no & WT is within $30 \mathrm{~cm}$ for $14+$ days when rainfall exceeds 70 th percentile \\
\hline 1965 & yes & water table is within $30 \mathrm{~cm}$ for $14+$ days \\
\hline 1966 & no & WT is within $30 \mathrm{~cm}$ for $14+$ days when rainfall exceeds 70 th percentile \\
\hline 1967 & yes & water table is within $30 \mathrm{~cm}$ for $14+$ days \\
\hline 1968 & no & WT is within $30 \mathrm{~cm}$ for $14+$ days when rainfall exceeds 70 th percentile \\
\hline 1969 & yes & water table is within $30 \mathrm{~cm}$ for $14+$ days \\
\hline 1970 & yes & water table is within $30 \mathrm{~cm}$ for $14+$ days \\
\hline 1971 & no & WT is within $30 \mathrm{~cm}$ for $14+$ days when rainfall exceeds 70 th percentile \\
\hline 1972 & yes & water table is within $30 \mathrm{~cm}$ for $14+$ days \\
\hline 1973 & no & WT is within $30 \mathrm{~cm}$ for $14+$ days when rainfall exceeds 70 th percentile \\
\hline 1974 & yes & water table is within $30 \mathrm{~cm}$ for $14+$ days \\
\hline 1975 & no & WT is within $30 \mathrm{~cm}$ for $14+$ days when rainfall exceeds 70 th percentile \\
\hline 1976 & no & water table is not within $30 \mathrm{~cm}$ for $14+$ days \\
\hline 1977 & no & WT is within $30 \mathrm{~cm}$ for $14+$ days when rainfall exceeds 70 th percentile \\
\hline 1978 & yes & water table is within $30 \mathrm{~cm}$ for $14+$ days \\
\hline 1979 & no & WT is within $30 \mathrm{~cm}$ for $14+$ days when rainfall exceeds 70 th percentile \\
\hline 1980 & no & WT is within $30 \mathrm{~cm}$ for $14+$ days when rainfall exceeds 70 th percentile \\
\hline 1981 & yes & water table is within $30 \mathrm{~cm}$ for $14+$ days \\
\hline 1982 & yes & water table is within $30 \mathrm{~cm}$ for $14+$ days \\
\hline 1983 & no & WT is within $30 \mathrm{~cm}$ for $14+$ days when rainfall exceeds 70 th percentile \\
\hline 1984 & no & WT is within $30 \mathrm{~cm}$ for $14+$ days when rainfall exceeds 70 th percentile \\
\hline 1985 & yes & water table is within $30 \mathrm{~cm}$ for $14+$ days \\
\hline 1986 & yes & water table is within $30 \mathrm{~cm}$ for $14+$ days \\
\hline 1987 & no & WT is within $30 \mathrm{~cm}$ for $14+$ days when rainfall exceeds 70 th percentile \\
\hline 1988 & yes & water table is within $30 \mathrm{~cm}$ for $14+$ days \\
\hline 1989 & no & WT is within $30 \mathrm{~cm}$ for $14+$ days when rainfall exceeds 70 th percentile \\
\hline 1990 & yes & water table is within $30 \mathrm{~cm}$ for $14+$ days \\
\hline 1991 & yes & water table is within $30 \mathrm{~cm}$ for $14+$ days \\
\hline 1992 & yes & water table is within $30 \mathrm{~cm}$ for $14+$ days \\
\hline 1993 & no & WT is within $30 \mathrm{~cm}$ for $14+$ days when rainfall exceeds 70 th percentile \\
\hline 1994 & no & WT is within $30 \mathrm{~cm}$ for $14+$ days when rainfall exceeds 70 th percentile \\
\hline 1995 & no & WT is within $30 \mathrm{~cm}$ for $14+$ days when rainfall exceeds 70 th percentile \\
\hline 1996 & yes & water table is within $30 \mathrm{~cm}$ for $14+$ days \\
\hline 1997 & yes & water table is within $30 \mathrm{~cm}$ for $14+$ days \\
\hline 1998 & no & WT is within $30 \mathrm{~cm}$ for $14+$ days when rainfall exceeds 70 th percentile \\
\hline
\end{tabular}


Table B.79: 45-year record for the modified 30-day Moving Total approach for plot $2 \mathrm{~N}$ at Bertie. This plot met wetland hydrology in 0 out of 45 years. There were 5 years that did not meet wetland hydrology because water table (WT) saturation occurred during "wet" periods, while 40 years did not meet water table saturation criterion.

\begin{tabular}{|c|c|c|}
\hline Year & $\begin{array}{c}\text { Met/Not } \\
\text { Met }\end{array}$ & Reason Year did or did not meet Wetland Hydrology \\
\hline 1950 & no & WT is within $30 \mathrm{~cm}$ for $14+$ days above 70 th percentile \\
\hline 1951 & no & water table is not within $30 \mathrm{~cm}$ for $14+$ days \\
\hline 1952 & no & water table is not within $30 \mathrm{~cm}$ for $14+$ days \\
\hline 1953 & no & water table is not within $30 \mathrm{~cm}$ for $14+$ days \\
\hline 1954 & no & water table is not within $30 \mathrm{~cm}$ for $14+$ days \\
\hline 1955 & no & water table is not within $30 \mathrm{~cm}$ for $14+$ days \\
\hline 1956 & no & water table is not within $30 \mathrm{~cm}$ for $14+$ days \\
\hline 1957 & no & water table is not within $30 \mathrm{~cm}$ for $14+$ days \\
\hline 1958 & no & water table is not within $30 \mathrm{~cm}$ for $14+$ days \\
\hline 1959 & no & water table is not within $30 \mathrm{~cm}$ for $14+$ days \\
\hline 1960 & no & water table is not within $30 \mathrm{~cm}$ for $14+$ days \\
\hline 1961 & no & water table is not within $30 \mathrm{~cm}$ for $14+$ days \\
\hline 1962 & no & water table is not within $30 \mathrm{~cm}$ for $14+$ days \\
\hline 1963 & no & water table is not within $30 \mathrm{~cm}$ for $14+$ days \\
\hline 1964 & no & water table is not within $30 \mathrm{~cm}$ for $14+$ days \\
\hline 1965 & no & water table is not within $30 \mathrm{~cm}$ for $14+$ days \\
\hline 1966 & no & WT is within $30 \mathrm{~cm}$ for $14+$ days above 70 th percentile \\
\hline 1967 & no & water table is not within $30 \mathrm{~cm}$ for $14+$ days \\
\hline 1968 & no & water table is not within $30 \mathrm{~cm}$ for $14+$ days \\
\hline 1969 & no & water table is not within $30 \mathrm{~cm}$ for $14+$ days \\
\hline 1970 & no & water table is not within $30 \mathrm{~cm}$ for $14+$ days \\
\hline 1971 & no & water table is not within $30 \mathrm{~cm}$ for $14+$ days \\
\hline 1972 & no & water table is not within $30 \mathrm{~cm}$ for $14+$ days \\
\hline 1973 & no & WT is within $30 \mathrm{~cm}$ for $14+$ days above 70 th percentile \\
\hline 1974 & no & water table is not within $30 \mathrm{~cm}$ for $14+$ days \\
\hline 1975 & no & water table is not within $30 \mathrm{~cm}$ for $14+$ days \\
\hline 1976 & no & water table is not within $30 \mathrm{~cm}$ for $14+$ days \\
\hline 1977 & no & water table is not within $30 \mathrm{~cm}$ for $14+$ days \\
\hline 1978 & no & WT is within $30 \mathrm{~cm}$ for $14+$ days above 70 th percentile \\
\hline 1979 & no & water table is not within $30 \mathrm{~cm}$ for $14+$ days \\
\hline 1980 & no & water table is not within $30 \mathrm{~cm}$ for $14+$ days \\
\hline 1981 & no & water table is not within $30 \mathrm{~cm}$ for $14+$ days \\
\hline 1982 & no & water table is not within $30 \mathrm{~cm}$ for $14+$ days \\
\hline 1983 & no & WT is within $30 \mathrm{~cm}$ for $14+$ days above 70 th percentile \\
\hline 1984 & no & water table is not within $30 \mathrm{~cm}$ for $14+$ days \\
\hline 1985 & no & water table is not within $30 \mathrm{~cm}$ for $14+$ days \\
\hline 1986 & no & water table is not within $30 \mathrm{~cm}$ for $14+$ days \\
\hline 1987 & no & water table is not within $30 \mathrm{~cm}$ for $14+$ days \\
\hline 1988 & no & water table is not within $30 \mathrm{~cm}$ for $14+$ days \\
\hline 1989 & no & water table is not within $30 \mathrm{~cm}$ for $14+$ days \\
\hline 1990 & no & water table is not within $30 \mathrm{~cm}$ for $14+$ days \\
\hline 1991 & no & water table is not within $30 \mathrm{~cm}$ for $14+$ days \\
\hline 1992 & no & water table is not within $30 \mathrm{~cm}$ for $14+$ days \\
\hline 1993 & no & water table is not within $30 \mathrm{~cm}$ for $14+$ days \\
\hline 1994 & no & water table is not within $30 \mathrm{~cm}$ for $14+$ days \\
\hline
\end{tabular}


Table B.80: 45 -year record for the modified 30-day Moving Total approach for plot $3 \mathrm{~N}$ at Bertie. This plot met wetland hydrology in 6 out of 45 years. There were 31 years that did not meet wetland hydrology because water table (WT) saturation occurred during "wet" periods, while 8 years did not meet water table saturation criterion.

\begin{tabular}{|c|c|c|}
\hline Year & $\begin{array}{c}\text { Met/Not } \\
\text { Met }\end{array}$ & Reason Year did or did not meet Wetland Hydrology \\
\hline 1950 & no & WT is within $30 \mathrm{~cm}$ for $14+$ days while rainfall is above 70 th percentile \\
\hline 1951 & yes & water table within $30 \mathrm{~cm}$ for $14+$ days \\
\hline 1952 & no & WT is within $30 \mathrm{~cm}$ for $14+$ days while rainfall is above 70th percentile \\
\hline 1953 & no & water table is not within $30 \mathrm{~cm}$ for $14+$ days \\
\hline 1954 & no & WT is within $30 \mathrm{~cm}$ for $14+$ days while rainfall is above 70th percentile \\
\hline 1955 & no & WT is within $30 \mathrm{~cm}$ for $14+$ days while rainfall is above 70 th percentile \\
\hline 1956 & no & WT is within $30 \mathrm{~cm}$ for $14+$ days while rainfall is above 70 th percentile \\
\hline 1957 & no & WT is within $30 \mathrm{~cm}$ for $14+$ days while rainfall is above 70 th percentile \\
\hline 1958 & no & WT is within $30 \mathrm{~cm}$ for $14+$ days while rainfall is above 70 th percentile \\
\hline 1959 & no & WT is within $30 \mathrm{~cm}$ for $14+$ days while rainfall is above 70 th percentile \\
\hline 1960 & yes & water table is within $30 \mathrm{~cm}$ for $14+$ days \\
\hline 1961 & no & WT is within $30 \mathrm{~cm}$ for $14+$ days while rainfall is above 70 th percentile \\
\hline 1962 & no & WT is within $30 \mathrm{~cm}$ for $14+$ days while rainfall is above 70 th percentile \\
\hline 1963 & no & water table is not within $30 \mathrm{~cm}$ for $14+$ days \\
\hline 1964 & no & WT is within $30 \mathrm{~cm}$ for $14+$ days while rainfall is above 70 th percentile \\
\hline 1965 & yes & water table is within $30 \mathrm{~cm}$ for $14+$ days \\
\hline 1966 & no & WT is within $30 \mathrm{~cm}$ for $14+$ days while rainfall is above 70 th percentile \\
\hline 1967 & no & WT is within $30 \mathrm{~cm}$ for $14+$ days while rainfall is above 70 th percentile \\
\hline 1968 & no & WT is within $30 \mathrm{~cm}$ for $14+$ days while rainfall is above 70 th percentile \\
\hline 1969 & no & WT is within $30 \mathrm{~cm}$ for $14+$ days while rainfall is above 70 th percentile \\
\hline 1970 & yes & water table is within $30 \mathrm{~cm}$ for $14+$ days \\
\hline 1971 & no & WT is within $30 \mathrm{~cm}$ for $14+$ days while rainfall is above 70 th percentile \\
\hline 1972 & yes & water table is within $30 \mathrm{~cm}$ for $14+$ days \\
\hline 1973 & no & WT is within $30 \mathrm{~cm}$ for $14+$ days while rainfall is above 70th percentile \\
\hline 1974 & no & WT is within $30 \mathrm{~cm}$ for $14+$ days while rainfall is above 70 th percentile \\
\hline 1975 & no & WT is within $30 \mathrm{~cm}$ for $14+$ days while rainfall is above 70 th percentile \\
\hline 1976 & no & water table is not within $30 \mathrm{~cm}$ for $14+$ days \\
\hline 1977 & no & WT is within $30 \mathrm{~cm}$ for $14+$ days while rainfall is above 70 th percentile \\
\hline 1978 & no & WT is within $30 \mathrm{~cm}$ for $14+$ days while rainfall is above 70 th percentile \\
\hline 1979 & no & WT is within $30 \mathrm{~cm}$ for $14+$ days while rainfall is above 70th percentile \\
\hline 1980 & no & WT is within $30 \mathrm{~cm}$ for $14+$ days while rainfall is above 70 th percentile \\
\hline 1981 & no & water table is not within $30 \mathrm{~cm}$ for $14+$ days \\
\hline 1982 & no & water table is not within $30 \mathrm{~cm}$ for $14+$ days \\
\hline 1983 & no & WT is within $30 \mathrm{~cm}$ for $14+$ days while rainfall is above 70 th percentile \\
\hline 1984 & no & WT is within $30 \mathrm{~cm}$ for $14+$ days while rainfall is above 70 th percentile \\
\hline 1985 & no & water table is not within $30 \mathrm{~cm}$ for $14+$ days \\
\hline 1986 & no & water table is not within $30 \mathrm{~cm}$ for $14+$ days \\
\hline 1987 & yes & water table is within $30 \mathrm{~cm}$ for $14+$ days \\
\hline 1988 & no & WT is within $30 \mathrm{~cm}$ for $14+$ days while rainfall is above 70 th percentile \\
\hline 1989 & no & WT is within $30 \mathrm{~cm}$ for $14+$ days while rainfall is above 70th percentile \\
\hline 1990 & no & WT is within $30 \mathrm{~cm}$ for $14+$ days while rainfall is above 70 th percentile \\
\hline 1991 & no & WT is within $30 \mathrm{~cm}$ for $14+$ days while rainfall is above 70th percentile \\
\hline 1992 & no & water table is not within $30 \mathrm{~cm}$ for $14+$ days \\
\hline 1993 & no & WT is within $30 \mathrm{~cm}$ for $14+$ days while rainfall is above 70 th percentile \\
\hline 1994 & no & WT is within $30 \mathrm{~cm}$ for $14+$ days while rainfall is above 70 th percentile \\
\hline
\end{tabular}


Table B.81: 45-year record for the modified 30-day moving total approach for plot $4 \mathrm{~N}$ at Bertie. This plot met wetland hydrology in 8 out of 45 years. There were 35 years that did not meet wetland hydrology because water table (WT) saturation occurred during "wet" periods, while 2 years did not meet water table saturation criterion.

\begin{tabular}{|c|c|c|}
\hline Year & $\begin{array}{c}\text { Met/Not } \\
\text { Met }\end{array}$ & Reason Year did or did not meet Wetland Hydrology \\
\hline 1950 & no & WT is within $30 \mathrm{~cm}$ for $14+$ days while rainfall is above 70 th percentile \\
\hline 1951 & yes & water table is within $30 \mathrm{~cm}$ for $14+$ days \\
\hline 1952 & no & WT is within $30 \mathrm{~cm}$ for $14+$ days while rainfall is above 70th percentile \\
\hline 1953 & no & WT is within $30 \mathrm{~cm}$ for $14+$ days while rainfall is above 70th percentile \\
\hline 1954 & no & WT is within $30 \mathrm{~cm}$ for $14+$ days while rainfall is above 70 th percentile \\
\hline 1955 & no & WT is within $30 \mathrm{~cm}$ for $14+$ days while rainfall is above 70 th percentile \\
\hline 1956 & no & WT is within $30 \mathrm{~cm}$ for $14+$ days while rainfall is above 70 th percentile \\
\hline 1957 & no & WT is within $30 \mathrm{~cm}$ for $14+$ days while rainfall is above 70th percentile \\
\hline 1958 & no & WT is within $30 \mathrm{~cm}$ for $14+$ days while rainfall is above 70th percentile \\
\hline 1959 & no & WT is within $30 \mathrm{~cm}$ for $14+$ days while rainfall is above 70th percentile \\
\hline 1960 & yes & water table is within $30 \mathrm{~cm}$ for $14+$ days \\
\hline 1961 & no & WT is within $30 \mathrm{~cm}$ for $14+$ days while rainfall is above 70 th percentile \\
\hline 1962 & no & WT is within $30 \mathrm{~cm}$ for $14+$ days while rainfall is above 70 th percentile \\
\hline 1963 & no & water table is not within $30 \mathrm{~cm}$ for $14+$ days \\
\hline 1964 & no & WT is within $30 \mathrm{~cm}$ for $14+$ days while rainfall is above 70th percentile \\
\hline 1965 & yes & water table is within $30 \mathrm{~cm}$ for $14+$ days \\
\hline 1966 & no & WT is within $30 \mathrm{~cm}$ for $14+$ days while rainfall is above 70 th percentile \\
\hline 1967 & no & WT is within $30 \mathrm{~cm}$ for $14+$ days while rainfall is above 70th percentile \\
\hline 1968 & no & WT is within $30 \mathrm{~cm}$ for $14+$ days while rainfall is above 70th percentile \\
\hline 1969 & no & WT is within $30 \mathrm{~cm}$ for $14+$ days while rainfall is above 70th percentile \\
\hline 1970 & yes & water table is within $30 \mathrm{~cm}$ for $14+$ days \\
\hline 1971 & yes & water table is within $30 \mathrm{~cm}$ for $14+$ days \\
\hline 1972 & yes & water table is within $30 \mathrm{~cm}$ for $14+$ days \\
\hline 1973 & no & WT is within $30 \mathrm{~cm}$ for $14+$ days while rainfall is above 70th percentile \\
\hline 1974 & no & WT is within $30 \mathrm{~cm}$ for $14+$ days while rainfall is above 70th percentile \\
\hline 1975 & no & WT is within $30 \mathrm{~cm}$ for $14+$ days while rainfall is above 70th percentile \\
\hline 1976 & no & WT is within $30 \mathrm{~cm}$ for $14+$ days while rainfall is above 70 th percentile \\
\hline 1977 & no & WT is within $30 \mathrm{~cm}$ for $14+$ days while rainfall is above 70 th percentile \\
\hline 1978 & no & WT is within $30 \mathrm{~cm}$ for $14+$ days while rainfall is above 70th percentile \\
\hline 1979 & no & WT is within $30 \mathrm{~cm}$ for $14+$ days while rainfall is above 70th percentile \\
\hline 1980 & no & WT is within $30 \mathrm{~cm}$ for $14+$ days while rainfall is above 70th percentile \\
\hline 1981 & yes & water table is within $30 \mathrm{~cm}$ for $14+$ days \\
\hline 1982 & no & water table is not within $30 \mathrm{~cm}$ for $14+$ days \\
\hline 1983 & no & WT is within $30 \mathrm{~cm}$ for $14+$ days while rainfall is above 70 th percentile \\
\hline 1984 & no & WT is within $30 \mathrm{~cm}$ for $14+$ days while rainfall is above 70 th percentile \\
\hline 1985 & no & WT is within $30 \mathrm{~cm}$ for $14+$ days while rainfall is above 70 th percentile \\
\hline 1986 & no & WT is within $30 \mathrm{~cm}$ for $14+$ days while rainfall is above 70 th percentile \\
\hline 1987 & yes & water table is within $30 \mathrm{~cm}$ for $14+$ days \\
\hline 1988 & no & WT is within $30 \mathrm{~cm}$ for $14+$ days while rainfall is above 70th percentile \\
\hline 1989 & no & WT is within $30 \mathrm{~cm}$ for $14+$ days while rainfall is above 70 th percentile \\
\hline 1990 & no & WT is within $30 \mathrm{~cm}$ for $14+$ days while rainfall is above 70 th percentile \\
\hline 1991 & no & WT is within $30 \mathrm{~cm}$ for $14+$ days while rainfall is above 70 th percentile \\
\hline 1992 & no & WT is within $30 \mathrm{~cm}$ for $14+$ days while rainfall is above 70th percentile \\
\hline 1993 & no & WT is within $30 \mathrm{~cm}$ for $14+$ days while rainfall is above 70 th percentile \\
\hline 1994 & no & WT is within $30 \mathrm{~cm}$ for $14+$ days while rainfall is above 70 th percentile \\
\hline
\end{tabular}


Table B.82: 45-year record for the modified 30-day Moving Total approach for plot $5 \mathrm{~N}$ at Bertie. This plot met wetland hydrology in 13 out of 45 years. There were 31 years that did not meet wetland hydrology because water table (WT) saturation occurred during "wet" periods, while 1 year did not meet water table saturation criterion.

\begin{tabular}{|c|c|c|}
\hline Year & $\begin{array}{c}\text { Met/Not } \\
\text { Met }\end{array}$ & Reason Year did or did not meet Wetland Hydrology \\
\hline 1950 & no & WT is within $30 \mathrm{~cm}$ for $14+$ days and above the 70 th percentile \\
\hline 1951 & yes & water table is within $30 \mathrm{~cm}$ for $14+$ days \\
\hline 1952 & no & WT is within $30 \mathrm{~cm}$ for $14+$ days and above the 70 th percentile \\
\hline 1953 & yes & water table is within $30 \mathrm{~cm}$ for $14+$ days \\
\hline 1954 & no & WT is within $30 \mathrm{~cm}$ for $14+$ days and above the 70 th percentile \\
\hline 1955 & no & WT is within $30 \mathrm{~cm}$ for $14+$ days and above the 70 th percentile \\
\hline 1956 & no & WT is within $30 \mathrm{~cm}$ for $14+$ days and above the 70 th percentile \\
\hline 1957 & no & WT is within $30 \mathrm{~cm}$ for $14+$ days and above the 70 th percentile \\
\hline 1958 & yes & water table is within $30 \mathrm{~cm}$ for $14+$ days \\
\hline 1959 & yes & water table is within $30 \mathrm{~cm}$ for $14+$ days \\
\hline 1960 & yes & water table is within $30 \mathrm{~cm}$ for $14+$ days \\
\hline 1961 & no & WT is within $30 \mathrm{~cm}$ for $14+$ days and above the 70 th percentile \\
\hline 1962 & no & WT is within $30 \mathrm{~cm}$ for $14+$ days and above the 70 th percentile \\
\hline 1963 & no & water table is not within $30 \mathrm{~cm}$ for $14+$ days \\
\hline 1964 & no & WT is within $30 \mathrm{~cm}$ for $14+$ days and above the 70 th percentile \\
\hline 1965 & yes & water table is within $30 \mathrm{~cm}$ for $14+$ days \\
\hline 1966 & no & WT is within $30 \mathrm{~cm}$ for $14+$ days and above the 70 th percentile \\
\hline 1967 & no & WT is within $30 \mathrm{~cm}$ for $14+$ days and above the 70 th percentile \\
\hline 1968 & no & WT is within $30 \mathrm{~cm}$ for $14+$ days and above the 70 th percentile \\
\hline 1969 & no & WT is within $30 \mathrm{~cm}$ for $14+$ days and above the 70 th percentile \\
\hline 1970 & yes & water table is within $30 \mathrm{~cm}$ for $14+$ days \\
\hline 1971 & yes & water table is within $30 \mathrm{~cm}$ for $14+$ days \\
\hline 1972 & yes & water table is within $30 \mathrm{~cm}$ for $14+$ days \\
\hline 1973 & no & WT is within $30 \mathrm{~cm}$ for $14+$ days and above the 70 th percentile \\
\hline 1974 & no & WT is within $30 \mathrm{~cm}$ for $14+$ days and above the 70 th percentile \\
\hline 1975 & no & WT is within $30 \mathrm{~cm}$ for $14+$ days and above the 70 th percentile \\
\hline 1976 & no & WT is within $30 \mathrm{~cm}$ for $14+$ days and above the 70 th percentile \\
\hline 1977 & no & WT is within $30 \mathrm{~cm}$ for $14+$ days and above the 70 th percentile \\
\hline 1978 & no & WT is within $30 \mathrm{~cm}$ for $14+$ days and above the 70 th percentile \\
\hline 1979 & no & WT is within $30 \mathrm{~cm}$ for $14+$ days and above the 70 th percentile \\
\hline 1980 & no & WT is within $30 \mathrm{~cm}$ for $14+$ days and above the 70 th percentile \\
\hline 1981 & yes & water table is within $30 \mathrm{~cm}$ for $14+$ days \\
\hline 1982 & yes & water table is within $30 \mathrm{~cm}$ for $14+$ days \\
\hline 1983 & no & WT is within $30 \mathrm{~cm}$ for $14+$ days and above the 70 th percentile \\
\hline 1984 & no & WT is within $30 \mathrm{~cm}$ for $14+$ days and above the 70 th percentile \\
\hline 1985 & no & WT is within $30 \mathrm{~cm}$ for $14+$ days and above the 70 th percentile \\
\hline 1986 & no & WT is within $30 \mathrm{~cm}$ for $14+$ days and above the 70 th percentile \\
\hline 1987 & no & WT is within $30 \mathrm{~cm}$ for $14+$ days and above the 70 th percentile \\
\hline 1988 & yes & water table is within $30 \mathrm{~cm}$ for $14+$ days \\
\hline 1989 & no & WT is within $30 \mathrm{~cm}$ for $14+$ days and above the 70 th percentile \\
\hline 1990 & no & WT is within $30 \mathrm{~cm}$ for $14+$ days and above the 70 th percentile \\
\hline 1991 & no & WT is within $30 \mathrm{~cm}$ for $14+$ days and above the 70 th percentile \\
\hline 1992 & yes & water table is within $30 \mathrm{~cm}$ for $14+$ days \\
\hline 1993 & no & WT is within $30 \mathrm{~cm}$ for $14+$ days and above the 70 th percentile \\
\hline 1994 & no & WT is within $30 \mathrm{~cm}$ for $14+$ days and above the 70 th percentile \\
\hline
\end{tabular}


Table B.83: 45-year record for the modified 30-day Moving Total approach for plot $2 \mathrm{~S}$ at Bertie. This plot met wetland hydrology in 0 out of 45 years. There were 45 years did not meet water table saturation criterion.

\begin{tabular}{|c|c|c|}
\hline Year & $\begin{array}{c}\text { Met/Not } \\
\text { Met }\end{array}$ & Reason Year did or did not meet Wetland Hydrology \\
\hline 1950 & no & water table is not within $30 \mathrm{~cm}$ for $14+$ days \\
\hline 1951 & no & water table is not within $30 \mathrm{~cm}$ for $14+$ days \\
\hline 1952 & no & water table is not within $30 \mathrm{~cm}$ for $14+$ days \\
\hline 1953 & no & water table is not within $30 \mathrm{~cm}$ for $14+$ days \\
\hline 1954 & no & water table is not within $30 \mathrm{~cm}$ for $14+$ days \\
\hline 1955 & no & water table is not within $30 \mathrm{~cm}$ for $14+$ days \\
\hline 1956 & no & water table is not within $30 \mathrm{~cm}$ for $14+$ days \\
\hline 1957 & no & water table is not within $30 \mathrm{~cm}$ for $14+$ days \\
\hline 1958 & no & water table is not within $30 \mathrm{~cm}$ for $14+$ days \\
\hline 1959 & no & water table is not within $30 \mathrm{~cm}$ for $14+$ days \\
\hline 1960 & no & water table is not within $30 \mathrm{~cm}$ for $14+$ days \\
\hline 1961 & no & water table is not within $30 \mathrm{~cm}$ for $14+$ days \\
\hline 1962 & no & water table is not within $30 \mathrm{~cm}$ for $14+$ days \\
\hline 1963 & no & water table is not within $30 \mathrm{~cm}$ for $14+$ days \\
\hline 1964 & no & water table is not within $30 \mathrm{~cm}$ for $14+$ days \\
\hline 1965 & no & water table is not within $30 \mathrm{~cm}$ for $14+$ days \\
\hline 1966 & no & water table is not within $30 \mathrm{~cm}$ for $14+$ days \\
\hline 1967 & no & water table is not within $30 \mathrm{~cm}$ for $14+$ days \\
\hline 1968 & no & water table is not within $30 \mathrm{~cm}$ for $14+$ days \\
\hline 1969 & no & water table is not within $30 \mathrm{~cm}$ for $14+$ days \\
\hline 1970 & no & water table is not within $30 \mathrm{~cm}$ for $14+$ days \\
\hline 1971 & no & water table is not within $30 \mathrm{~cm}$ for $14+$ days \\
\hline 1972 & no & water table is not within $30 \mathrm{~cm}$ for $14+$ days \\
\hline 1973 & no & water table is not within $30 \mathrm{~cm}$ for $14+$ days \\
\hline 1974 & no & water table is not within $30 \mathrm{~cm}$ for $14+$ days \\
\hline 1975 & no & water table is not within $30 \mathrm{~cm}$ for $14+$ days \\
\hline 1976 & no & water table is not within $30 \mathrm{~cm}$ for $14+$ days \\
\hline 1977 & no & water table is not within $30 \mathrm{~cm}$ for $14+$ days \\
\hline 1978 & no & water table is not within $30 \mathrm{~cm}$ for $14+$ days \\
\hline 1979 & no & water table is not within $30 \mathrm{~cm}$ for $14+$ days \\
\hline 1980 & no & water table is not within $30 \mathrm{~cm}$ for $14+$ days \\
\hline 1981 & no & water table is not within $30 \mathrm{~cm}$ for $14+$ days \\
\hline 1982 & no & water table is not within $30 \mathrm{~cm}$ for $14+$ days \\
\hline 1983 & no & water table is not within $30 \mathrm{~cm}$ for $14+$ days \\
\hline 1984 & no & water table is not within $30 \mathrm{~cm}$ for $14+$ days \\
\hline 1985 & no & water table is not within $30 \mathrm{~cm}$ for $14+$ days \\
\hline 1986 & no & water table is not within $30 \mathrm{~cm}$ for $14+$ days \\
\hline 1987 & no & water table is not within $30 \mathrm{~cm}$ for $14+$ days \\
\hline 1988 & no & water table is not within $30 \mathrm{~cm}$ for $14+$ days \\
\hline 1989 & no & water table is not within $30 \mathrm{~cm}$ for $14+$ days \\
\hline 1990 & no & water table is not within $30 \mathrm{~cm}$ for $14+$ days \\
\hline 1991 & no & water table is not within $30 \mathrm{~cm}$ for $14+$ days \\
\hline 1992 & no & water table is not within $30 \mathrm{~cm}$ for $14+$ days \\
\hline 1993 & no & water table is not within $30 \mathrm{~cm}$ for $14+$ days \\
\hline 1994 & no & water table is not within $30 \mathrm{~cm}$ for $14+$ days \\
\hline
\end{tabular}


Table B.84: 45-year record for the modified 30-day Moving Total approach for plot 3S at Bertie. This plot met wetland hydrology in 3 out of 45 years. There were 36 years that did not meet wetland hydrology because water table (WT) saturation occurred during "wet" periods, while 6 years did not meet water table saturation criterion.

\begin{tabular}{|c|c|c|}
\hline Year & $\begin{array}{c}\text { Met/Not } \\
\text { Met }\end{array}$ & Reason Year did or did not meet Wetland Hydrology \\
\hline 1950 & no & WT is within $30 \mathrm{~cm}$ for $14+$ days during a period above 70 th percentile \\
\hline 1951 & no & WT is within $30 \mathrm{~cm}$ for $14+$ days during a period above 70 th percentile \\
\hline 1952 & no & WT is within $30 \mathrm{~cm}$ for $14+$ days during a period above 70 th percentile \\
\hline 1953 & no & WT is within $30 \mathrm{~cm}$ for $14+$ days during a period above 70 th percentile \\
\hline 1954 & no & WT is within $30 \mathrm{~cm}$ for $14+$ days during a period above 70 th percentile \\
\hline 1955 & no & WT is within $30 \mathrm{~cm}$ for $14+$ days during a period above 70 th percentile \\
\hline 1956 & no & WT is within $30 \mathrm{~cm}$ for $14+$ days during a period above 70 th percentile \\
\hline 1957 & no & WT is within $30 \mathrm{~cm}$ for $14+$ days during a period above 70 th percentile \\
\hline 1958 & no & WT is within $30 \mathrm{~cm}$ for $14+$ days during a period above 70 th percentile \\
\hline 1959 & no & WT is within $30 \mathrm{~cm}$ for $14+$ days during a period above 70 th percentile \\
\hline 1960 & yes & water table is within $30 \mathrm{~cm}$ for $14+$ days \\
\hline 1961 & no & WT is within $30 \mathrm{~cm}$ for $14+$ days during a period above 70 th percentile \\
\hline 1962 & no & WT is within $30 \mathrm{~cm}$ for $14+$ days during a period above 70 th percentile \\
\hline 1963 & no & water table is not within $30 \mathrm{~cm}$ for $14+$ days \\
\hline 1964 & no & WT is within $30 \mathrm{~cm}$ for $14+$ days during a period above 70 th percentile \\
\hline 1965 & yes & water table is within $30 \mathrm{~cm}$ for $14+$ days \\
\hline 1966 & no & WT is within $30 \mathrm{~cm}$ for $14+$ days during a period above 70 th percentile \\
\hline 1967 & no & WT is within $30 \mathrm{~cm}$ for $14+$ days during a period above 70 th percentile \\
\hline 1968 & no & water table is not within $30 \mathrm{~cm}$ for $14+$ days \\
\hline 1969 & no & WT is within $30 \mathrm{~cm}$ for $14+$ days during a period above 70 th percentile \\
\hline 1970 & yes & water table is within $30 \mathrm{~cm}$ for $14+$ days \\
\hline 1971 & no & WT is within $30 \mathrm{~cm}$ for $14+$ days during a period above 70 th percentile \\
\hline 1972 & no & WT is within $30 \mathrm{~cm}$ for $14+$ days during a period above 70 th percentile \\
\hline 1973 & no & WT is within $30 \mathrm{~cm}$ for $14+$ days during a period above 70 th percentile \\
\hline 1974 & no & WT is within $30 \mathrm{~cm}$ for $14+$ days during a period above 70 th percentile \\
\hline 1975 & no & WT is within $30 \mathrm{~cm}$ for $14+$ days during a period above 70 th percentile \\
\hline 1976 & no & water table is not within $30 \mathrm{~cm}$ for $14+$ days \\
\hline 1977 & no & WT is within $30 \mathrm{~cm}$ for $14+$ days during a period above 70 th percentile \\
\hline 1978 & no & WT is within $30 \mathrm{~cm}$ for $14+$ days during a period above 70 th percentile \\
\hline 1979 & no & WT is within $30 \mathrm{~cm}$ for $14+$ days during a period above 70 th percentile \\
\hline 1980 & no & WT is within $30 \mathrm{~cm}$ for $14+$ days during a period above 70 th percentile \\
\hline 1981 & no & WT is within $30 \mathrm{~cm}$ for $14+$ days during a period above 70 th percentile \\
\hline 1982 & no & water table is not within $30 \mathrm{~cm}$ for $14+$ days \\
\hline 1983 & no & WT is within $30 \mathrm{~cm}$ for $14+$ days during a period above 70 th percentile \\
\hline 1984 & no & WT is within $30 \mathrm{~cm}$ for $14+$ days during a period above 70 th percentile \\
\hline 1985 & no & WT is within $30 \mathrm{~cm}$ for $14+$ days during a period above 70 th percentile \\
\hline 1986 & no & water table is not within $30 \mathrm{~cm}$ for $14+$ days \\
\hline 1987 & no & WT is within $30 \mathrm{~cm}$ for $14+$ days during a period above 70 th percentile \\
\hline 1988 & no & WT is within $30 \mathrm{~cm}$ for $14+$ days during a period above 70 th percentile \\
\hline 1989 & no & WT is within $30 \mathrm{~cm}$ for $14+$ days during a period above 70 th percentile \\
\hline 1990 & no & WT is within $30 \mathrm{~cm}$ for $14+$ days during a period above 70 th percentile \\
\hline 1991 & no & WT is within $30 \mathrm{~cm}$ for $14+$ days during a period above 70 th percentile \\
\hline 1992 & no & water table is not within $30 \mathrm{~cm}$ for $14+$ days \\
\hline 1993 & no & WT is within $30 \mathrm{~cm}$ for $14+$ days during a period above 70 th percentile \\
\hline 1994 & no & WT is within $30 \mathrm{~cm}$ for $14+$ days during a period above 70 th percentile \\
\hline
\end{tabular}


Table B.85: 45-year record for the modified 30-day Moving Total approach for plot 4S at Bertie. This plot met wetland hydrology in 8 out of 45 years. There were 33 years that did not meet wetland hydrology because water table (WT) saturation occurred during "wet" periods, while 4 years did not meet water table saturation criterion.

\begin{tabular}{|c|c|c|}
\hline Year & $\begin{array}{c}\text { Met/Not } \\
\text { Met }\end{array}$ & Reason Year did or did not meet Wetland Hydrology \\
\hline 1950 & no & WT is within $30 \mathrm{~cm}$ for $14+$ but is above the 70 th percentile \\
\hline 1951 & yes & water table is within $30 \mathrm{~cm}$ for $14+$ days \\
\hline 1952 & no & WT is within $30 \mathrm{~cm}$ for $14+$ but is above the 70 th percentile \\
\hline 1953 & no & WT is within $30 \mathrm{~cm}$ for $14+$ but is above the 70 th percentile \\
\hline 1954 & no & WT is within $30 \mathrm{~cm}$ for $14+$ but is above the 70 th percentile \\
\hline 1955 & no & WT is within $30 \mathrm{~cm}$ for $14+$ but is above the 70 th percentile \\
\hline 1956 & no & WT is within $30 \mathrm{~cm}$ for $14+$ but is above the 70 th percentile \\
\hline 1957 & no & WT is within $30 \mathrm{~cm}$ for $14+$ but is above the 70 th percentile \\
\hline 1958 & no & WT is within $30 \mathrm{~cm}$ for $14+$ but is above the 70 th percentile \\
\hline 1959 & no & WT is within $30 \mathrm{~cm}$ for $14+$ but is above the 70 th percentile \\
\hline 1960 & yes & water table is within $30 \mathrm{~cm}$ for $14+$ days \\
\hline 1961 & no & WT is within $30 \mathrm{~cm}$ for $14+$ but is above the 70 th percentile \\
\hline 1962 & no & WT is within $30 \mathrm{~cm}$ for $14+$ but is above the 70 th percentile \\
\hline 1963 & no & water table is not within $30 \mathrm{~cm}$ for $14+$ days \\
\hline 1964 & no & WT is within $30 \mathrm{~cm}$ for $14+$ but is above the 70 th percentile \\
\hline 1965 & yes & water table is within $30 \mathrm{~cm}$ for $14+$ days \\
\hline 1966 & no & WT is within $30 \mathrm{~cm}$ for $14+$ but is above the 70 th percentile \\
\hline 1967 & no & WT is within $30 \mathrm{~cm}$ for $14+$ but is above the 70 th percentile \\
\hline 1968 & no & WT is within $30 \mathrm{~cm}$ for $14+$ but is above the 70 th percentile \\
\hline 1969 & no & WT is within $30 \mathrm{~cm}$ for $14+$ but is above the 70 th percentile \\
\hline 1970 & yes & water table is within $30 \mathrm{~cm}$ for $14+$ days \\
\hline 1971 & yes & water table is within $30 \mathrm{~cm}$ for $14+$ days \\
\hline 1972 & yes & water table is within $30 \mathrm{~cm}$ for $14+$ days \\
\hline 1973 & no & WT is within $30 \mathrm{~cm}$ for $14+$ but is above the 70 th percentile \\
\hline 1974 & no & WT is within $30 \mathrm{~cm}$ for $14+$ but is above the 70 th percentile \\
\hline 1975 & no & WT is within $30 \mathrm{~cm}$ for $14+$ but is above the 70 th percentile \\
\hline 1976 & no & water table is not within $30 \mathrm{~cm}$ for $14+$ days \\
\hline 1977 & no & WT is within $30 \mathrm{~cm}$ for $14+$ but is above the 70 th percentile \\
\hline 1978 & no & WT is within $30 \mathrm{~cm}$ for $14+$ but is above the 70 th percentile \\
\hline 1979 & no & WT is within $30 \mathrm{~cm}$ for $14+$ but is above the 70 th percentile \\
\hline 1980 & no & WT is within $30 \mathrm{~cm}$ for $14+$ but is above the 70 th percentile \\
\hline 1981 & yes & water table is within $30 \mathrm{~cm}$ for $14+$ days \\
\hline 1982 & no & WT is within $30 \mathrm{~cm}$ for $14+$ but is above the 70 th percentile \\
\hline 1983 & no & WT is within $30 \mathrm{~cm}$ for $14+$ but is above the 70 th percentile \\
\hline 1984 & no & WT is within $30 \mathrm{~cm}$ for $14+$ but is above the 70 th percentile \\
\hline 1985 & no & water table is not within $30 \mathrm{~cm}$ for $14+$ days \\
\hline 1986 & no & water table is not within $30 \mathrm{~cm}$ for $14+$ days \\
\hline 1987 & no & WT is within $30 \mathrm{~cm}$ for $14+$ but is above the 70 th percentile \\
\hline 1988 & yes & water table is within $30 \mathrm{~cm}$ for $14+$ days \\
\hline 1989 & no & WT is within $30 \mathrm{~cm}$ for $14+$ but is above the 70 th percentile \\
\hline 1990 & no & WT is within $30 \mathrm{~cm}$ for $14+$ but is above the 70 th percentile \\
\hline 1991 & no & WT is within $30 \mathrm{~cm}$ for $14+$ but is above the 70 th percentile \\
\hline 1992 & no & WT is within $30 \mathrm{~cm}$ for $14+$ but is above the 70 th percentile \\
\hline 1993 & no & WT is within $30 \mathrm{~cm}$ for $14+$ but is above the 70 th percentile \\
\hline 1994 & no & WT is within $30 \mathrm{~cm}$ for $14+$ but is above the 70 th percentile \\
\hline
\end{tabular}


Table B.86: 45-year record for the modified 30-day Moving Total approach for plot $5 \mathrm{~S}$ at Bertie. This plot met wetland hydrology in 10 out of 45 years. There were 34 years that did not meet wetland hydrology because water table saturation occurred during "wet" periods, while 1 year did not meet water table (WT) saturation criterion.

\begin{tabular}{|c|c|c|}
\hline Year & $\begin{array}{c}\text { Met/Not } \\
\text { Met }\end{array}$ & Reason Year did or did not meet Wetland Hydrology \\
\hline 1950 & no & WT is within $30 \mathrm{~cm}$ for $14+$ days but above 70 th percentile \\
\hline 1951 & yes & water table is within $30 \mathrm{~cm}$ for $14+$ days \\
\hline 1952 & no & WT is within $30 \mathrm{~cm}$ for $14+$ days but above 70 th percentile \\
\hline 1953 & yes & water table is within $30 \mathrm{~cm}$ for $14+$ days \\
\hline 1954 & no & WT is within $30 \mathrm{~cm}$ for $14+$ days but above 70 th percentile \\
\hline 1955 & no & WT is within $30 \mathrm{~cm}$ for $14+$ days but above 70 th percentile \\
\hline 1956 & no & WT is within $30 \mathrm{~cm}$ for $14+$ days but above 70 th percentile \\
\hline 1957 & no & WT is within $30 \mathrm{~cm}$ for $14+$ days but above 70 th percentile \\
\hline 1958 & no & WT is within $30 \mathrm{~cm}$ for $14+$ days but above 70 th percentile \\
\hline 1959 & no & WT is within $30 \mathrm{~cm}$ for $14+$ days but above 70 th percentile \\
\hline 1960 & yes & water table is within $30 \mathrm{~cm}$ for $14+$ days \\
\hline 1961 & no & WT is within $30 \mathrm{~cm}$ for $14+$ days but above 70 th percentile \\
\hline 1962 & no & WT is within $30 \mathrm{~cm}$ for $14+$ days but above 70 th percentile \\
\hline 1963 & no & water table is not within $30 \mathrm{~cm}$ for $14+$ days \\
\hline 1964 & no & WT is within $30 \mathrm{~cm}$ for $14+$ days but above 70 th percentile \\
\hline 1965 & yes & water table is within $30 \mathrm{~cm}$ for $14+$ days \\
\hline 1966 & no & WT is within $30 \mathrm{~cm}$ for $14+$ days but above 70 th percentile \\
\hline 1967 & no & WT is within $30 \mathrm{~cm}$ for $14+$ days but above 70 th percentile \\
\hline 1968 & no & WT is within $30 \mathrm{~cm}$ for $14+$ days but above 70 th percentile \\
\hline 1969 & no & WT is within $30 \mathrm{~cm}$ for $14+$ days but above 70 th percentile \\
\hline 1970 & yes & water table is within $30 \mathrm{~cm}$ for $14+$ days \\
\hline 1971 & yes & water table is within $30 \mathrm{~cm}$ for $14+$ days \\
\hline 1972 & yes & water table is within $30 \mathrm{~cm}$ for $14+$ days \\
\hline 1973 & no & WT is within $30 \mathrm{~cm}$ for $14+$ days but above 70 th percentile \\
\hline 1974 & no & WT is within $30 \mathrm{~cm}$ for $14+$ days but above 70 th percentile \\
\hline 1975 & no & WT is within $30 \mathrm{~cm}$ for $14+$ days but above 70 th percentile \\
\hline 1976 & no & WT is within $30 \mathrm{~cm}$ for $14+$ days but above 70 th percentile \\
\hline 1977 & no & WT is within $30 \mathrm{~cm}$ for $14+$ days but above 70 th percentile \\
\hline 1978 & no & WT is within $30 \mathrm{~cm}$ for $14+$ days but above 70 th percentile \\
\hline 1979 & no & WT is within $30 \mathrm{~cm}$ for $14+$ days but above 70 th percentile \\
\hline 1980 & no & WT is within $30 \mathrm{~cm}$ for $14+$ days but above 70 th percentile \\
\hline 1981 & yes & water table is within $30 \mathrm{~cm}$ for $14+$ days \\
\hline 1982 & yes & water table is within $30 \mathrm{~cm}$ for $14+$ days \\
\hline 1983 & no & WT is within $30 \mathrm{~cm}$ for $14+$ days but above 70 th percentile \\
\hline 1984 & no & WT is within $30 \mathrm{~cm}$ for $14+$ days but above 70 th percentile \\
\hline 1985 & no & WT is within $30 \mathrm{~cm}$ for $14+$ days but above 70 th percentile \\
\hline 1986 & no & WT is within $30 \mathrm{~cm}$ for $14+$ days but above 70 th percentile \\
\hline 1987 & no & WT is within $30 \mathrm{~cm}$ for $14+$ days but above 70 th percentile \\
\hline 1988 & no & WT is within $30 \mathrm{~cm}$ for $14+$ days but above 70 th percentile \\
\hline 1989 & yes & water table is within $30 \mathrm{~cm}$ for $14+$ days \\
\hline 1990 & no & WT is within $30 \mathrm{~cm}$ for $14+$ days but above 70 th percentile \\
\hline 1991 & no & WT is within $30 \mathrm{~cm}$ for $14+$ days but above 70 th percentile \\
\hline 1992 & no & WT is within $30 \mathrm{~cm}$ for $14+$ days but above 70 th percentile \\
\hline 1993 & no & WT is within $30 \mathrm{~cm}$ for $14+$ days but above 70 th percentile \\
\hline 1994 & no & WT is within $30 \mathrm{~cm}$ for $14+$ days but above 70 th percentile \\
\hline
\end{tabular}


Table B.87: 45-year record for the modified 30-day Moving Total approach for bogwell plot S1 at Marcell. This plot met wetland hydrology in 22 out of 45 years. There were 16 years that did not meet wetland hydrology because water table (WT) saturation occurred during "wet" periods, while 7 years did not meet water table saturation criterion.

\begin{tabular}{|c|c|c|}
\hline Year & $\begin{array}{c}\text { Met/Not } \\
\text { Met }\end{array}$ & Reason Year did or did not meet Wetland Hydrology \\
\hline 1961 & no & water table not within $30 \mathrm{~cm}$ for $14+$ days \\
\hline 1962 & no & WT is within $30 \mathrm{~cm}$ for $14+$ days when above 70 th Percentile \\
\hline 1963 & no & water table not within $30 \mathrm{~cm}$ for $14+$ days \\
\hline 1964 & no & water table not within $30 \mathrm{~cm}$ for $14+$ days \\
\hline 1965 & no & WT is within $30 \mathrm{~cm}$ for $14+$ days when above 70 th Percentile \\
\hline 1966 & no & WT is within $30 \mathrm{~cm}$ for $14+$ days when above 70 th Percentile \\
\hline 1967 & no & water table not within $30 \mathrm{~cm}$ for $14+$ days \\
\hline 1968 & no & water table not within $30 \mathrm{~cm}$ for $14+$ days \\
\hline 1969 & yes & water table is within $30 \mathrm{~cm}$ for $14+$ days \\
\hline 1970 & yes & water table is within $30 \mathrm{~cm}$ for $14+$ days \\
\hline 1971 & yes & water table is within $30 \mathrm{~cm}$ for $14+$ days \\
\hline 1972 & no & WT is within $30 \mathrm{~cm}$ for $14+$ days when above 70 th Percentile \\
\hline 1973 & yes & water table is within $30 \mathrm{~cm}$ for $14+$ days \\
\hline 1974 & no & WT is within $30 \mathrm{~cm}$ for $14+$ days when above 70 th Percentile \\
\hline 1975 & yes & water table is within $30 \mathrm{~cm}$ for $14+$ days \\
\hline 1976 & no & water table is not within $30 \mathrm{~cm}$ for $14+$ days \\
\hline 1977 & no & WT is within $30 \mathrm{~cm}$ for $14+$ days when above 70 th Percentile \\
\hline 1978 & no & WT is within $30 \mathrm{~cm}$ for $14+$ days when above 70 th Percentile \\
\hline 1979 & yes & water table is within $30 \mathrm{~cm}$ for $14+$ days \\
\hline 1980 & no & water table is not within $30 \mathrm{~cm}$ for $14+$ days \\
\hline 1981 & yes & water table is within $30 \mathrm{~cm}$ for $14+$ days \\
\hline 1982 & yes & water table is within $30 \mathrm{~cm}$ for $14+$ days \\
\hline 1983 & yes & water table is within $30 \mathrm{~cm}$ for $14+$ days \\
\hline 1984 & no & WT is within $30 \mathrm{~cm}$ for $14+$ days when above 70 th Percentile \\
\hline 1985 & no & WT is within $30 \mathrm{~cm}$ for $14+$ days when above 70 th Percentile \\
\hline 1986 & no & WT is within $30 \mathrm{~cm}$ for $14+$ days when above 70 th Percentile \\
\hline 1987 & no & WT is within $30 \mathrm{~cm}$ for $14+$ days when above 70 th Percentile \\
\hline 1988 & yes & water table is within $30 \mathrm{~cm}$ for $14+$ days \\
\hline 1989 & yes & water table is within $30 \mathrm{~cm}$ for $14+$ days \\
\hline 1990 & yes & water table is within $30 \mathrm{~cm}$ for $14+$ days \\
\hline 1991 & no & WT is within $30 \mathrm{~cm}$ for $14+$ days when above 70 th Percentile \\
\hline 1992 & no & WT is within $30 \mathrm{~cm}$ for $14+$ days when above 70 th Percentile \\
\hline 1993 & no & WT is within $30 \mathrm{~cm}$ for $14+$ days when above 70 th Percentile \\
\hline 1994 & no & WT is within $30 \mathrm{~cm}$ for $14+$ days when above 70 th Percentile \\
\hline 1995 & yes & water table is within $30 \mathrm{~cm}$ for $14+$ days \\
\hline 1996 & yes & water table is within $30 \mathrm{~cm}$ for $14+$ days \\
\hline 1997 & yes & water table is within $30 \mathrm{~cm}$ for $14+$ days \\
\hline 1998 & yes & water table is within $30 \mathrm{~cm}$ for $14+$ days \\
\hline 1999 & yes & water table is within $30 \mathrm{~cm}$ for $14+$ days \\
\hline 2000 & yes & water table is within $30 \mathrm{~cm}$ for $14+$ days \\
\hline 2001 & no & WT is within $30 \mathrm{~cm}$ for $14+$ days when above 70 th Percentile \\
\hline 2002 & yes & water table is within $30 \mathrm{~cm}$ for $14+$ days \\
\hline 2003 & yes & water table is within $30 \mathrm{~cm}$ for $14+$ days \\
\hline 2004 & yes & water table is within $30 \mathrm{~cm}$ for $14+$ days \\
\hline 2005 & yes & water table is within $30 \mathrm{~cm}$ for $14+$ days \\
\hline
\end{tabular}


Table B.88: 45-year record for the modified 30-day Moving Total approach for bogwell plot S2 at Marcell. This plot met wetland hydrology in 38 out of 45 years. There were 8 years that did not meet wetland hydrology because water table (WT) saturation occurred during "wet" periods.

\begin{tabular}{|c|c|c|}
\hline Year & $\begin{array}{c}\text { Met/Not } \\
\text { Met }\end{array}$ & Reason Year did or did not meet Wetland Hydrology \\
\hline 1961 & yes & water table is within $30 \mathrm{~cm}$ for $14+$ days \\
\hline 1962 & no & WT is within $30 \mathrm{~cm}$ for $14+$ days when above 70 th Percentile \\
\hline 1963 & yes & water table is within $30 \mathrm{~cm}$ for $14+$ days \\
\hline 1964 & yes & water table is within $30 \mathrm{~cm}$ for $14+$ days \\
\hline 1965 & yes & water table is within $30 \mathrm{~cm}$ for $14+$ days \\
\hline 1966 & yes & water table is within $30 \mathrm{~cm}$ for $14+$ days \\
\hline 1967 & yes & water table is within $30 \mathrm{~cm}$ for $14+$ days \\
\hline 1968 & yes & water table is within $30 \mathrm{~cm}$ for $14+$ days \\
\hline 1969 & yes & water table is within $30 \mathrm{~cm}$ for $14+$ days \\
\hline 1970 & yes & water table is within $30 \mathrm{~cm}$ for $14+$ days \\
\hline 1971 & yes & water table is within $30 \mathrm{~cm}$ for $14+$ days \\
\hline 1972 & yes & water table is within $30 \mathrm{~cm}$ for $14+$ days \\
\hline 1973 & yes & water table is within $30 \mathrm{~cm}$ for $14+$ days \\
\hline 1974 & yes & water table is within $30 \mathrm{~cm}$ for $14+$ days \\
\hline 1975 & yes & water table is within $30 \mathrm{~cm}$ for $14+$ days \\
\hline 1976 & yes & water table is within $30 \mathrm{~cm}$ for $14+$ days \\
\hline 1977 & no & WT is within $30 \mathrm{~cm}$ for $14+$ days when above 70 th Percentile \\
\hline 1978 & yes & water table is within $30 \mathrm{~cm}$ for $14+$ days \\
\hline 1979 & yes & water table is within $30 \mathrm{~cm}$ for $14+$ days \\
\hline 1980 & yes & water table is within $30 \mathrm{~cm}$ for $14+$ days \\
\hline 1981 & yes & water table is within $30 \mathrm{~cm}$ for $14+$ days \\
\hline 1982 & yes & water table is within $30 \mathrm{~cm}$ for $14+$ days \\
\hline 1983 & yes & water table is within $30 \mathrm{~cm}$ for $14+$ days \\
\hline 1984 & yes & water table is within $30 \mathrm{~cm}$ for $14+$ days \\
\hline 1985 & no & WT is within $30 \mathrm{~cm}$ for $14+$ days when above 70 th Percentile \\
\hline 1986 & yes & water table is within $30 \mathrm{~cm}$ for $14+$ days \\
\hline 1987 & no & WT is within $30 \mathrm{~cm}$ for $14+$ days when above 70 th Percentile \\
\hline 1988 & yes & water table is within $30 \mathrm{~cm}$ for $14+$ days \\
\hline 1989 & yes & water table is within $30 \mathrm{~cm}$ for $14+$ days \\
\hline 1990 & yes & water table is within $30 \mathrm{~cm}$ for $14+$ days \\
\hline 1991 & no & WT is within $30 \mathrm{~cm}$ for $14+$ days when above 70 th Percentile \\
\hline 1992 & yes & water table is within $30 \mathrm{~cm}$ for $14+$ days \\
\hline 1993 & yes & water table is within $30 \mathrm{~cm}$ for $14+$ days \\
\hline 1994 & no & WT is within $30 \mathrm{~cm}$ for $14+$ days when above 70 th Percentile \\
\hline 1995 & yes & water table is within $30 \mathrm{~cm}$ for $14+$ days \\
\hline 1996 & yes & water table is within $30 \mathrm{~cm}$ for $14+$ days \\
\hline 1997 & yes & water table is within $30 \mathrm{~cm}$ for $14+$ days \\
\hline 1998 & no & WT is within $30 \mathrm{~cm}$ for $14+$ days when above 70 th Percentile \\
\hline 1999 & yes & water table is within $30 \mathrm{~cm}$ for $14+$ days \\
\hline 2000 & yes & water table is within $30 \mathrm{~cm}$ for $14+$ days \\
\hline 2001 & no & WT is within $30 \mathrm{~cm}$ for $14+$ days when above 70 th Percentile \\
\hline 2002 & yes & water table is within $30 \mathrm{~cm}$ for $14+$ days \\
\hline 2003 & yes & water table is within $30 \mathrm{~cm}$ for $14+$ days \\
\hline 2004 & yes & water table is within $30 \mathrm{~cm}$ for $14+$ days \\
\hline 2005 & yes & water table is within $30 \mathrm{~cm}$ for $14+$ days \\
\hline
\end{tabular}


Table B.89: 45-year record for the modified 30-day Moving Total approach for bogwell plot S3 at Marcell. This plot met wetland hydrology in 18 out of 45 years. There were 6 years that did not meet wetland hydrology because water table (WT) saturation occurred during "wet" periods, while 21 years did not meet water table saturation criterion.

\begin{tabular}{|c|c|c|}
\hline Year & $\begin{array}{c}\text { Met/Not } \\
\text { Met }\end{array}$ & Reason Year did or did not meet Wetland Hydrology \\
\hline 1961 & no & water table is not within $30 \mathrm{~cm}$ for $14+$ days \\
\hline 1962 & no & water table is not within $30 \mathrm{~cm}$ for $14+$ days \\
\hline 1963 & no & water table is not within $30 \mathrm{~cm}$ for $14+$ days \\
\hline 1964 & no & water table is not within $30 \mathrm{~cm}$ for $14+$ days \\
\hline 1965 & no & water table is not within $30 \mathrm{~cm}$ for $14+$ days \\
\hline 1966 & no & WT is within $30 \mathrm{~cm}$ for $14+$ days when above 70 th percentile \\
\hline 1967 & no & WT is within $30 \mathrm{~cm}$ for $14+$ days when above 70 th percentile \\
\hline 1968 & no & water table is not within $30 \mathrm{~cm}$ for $14+$ days \\
\hline 1969 & no & water table is not within $30 \mathrm{~cm}$ for $14+$ days \\
\hline 1970 & no & water table is not within $30 \mathrm{~cm}$ for $14+$ days \\
\hline 1971 & no & water table is not within $30 \mathrm{~cm}$ for $14+$ days \\
\hline 1972 & no & water table is not within $30 \mathrm{~cm}$ for $14+$ days \\
\hline 1973 & no & water table is not within $30 \mathrm{~cm}$ for $14+$ days \\
\hline 1974 & no & water table is not within $30 \mathrm{~cm}$ for $14+$ days \\
\hline 1975 & no & water table is not within $30 \mathrm{~cm}$ for $14+$ days \\
\hline 1976 & no & water table is not within $30 \mathrm{~cm}$ for $14+$ days \\
\hline 1977 & no & water table is not within $30 \mathrm{~cm}$ for $14+$ days \\
\hline 1978 & no & water table is not within $30 \mathrm{~cm}$ for $14+$ days \\
\hline 1979 & no & water table is not within $30 \mathrm{~cm}$ for $14+$ days \\
\hline 1980 & no & water table is not within $30 \mathrm{~cm}$ for $14+$ days \\
\hline 1981 & no & water table is not within $30 \mathrm{~cm}$ for $14+$ days \\
\hline 1982 & yes & water table is within $30 \mathrm{~cm}$ for $14+$ days \\
\hline 1983 & yes & water table is within $30 \mathrm{~cm}$ for $14+$ days \\
\hline 1984 & no & water table is not within $30 \mathrm{~cm}$ for $14+$ days \\
\hline 1985 & no & WT is within $30 \mathrm{~cm}$ for $14+$ days when above 70 th percentile \\
\hline 1986 & yes & water table is within $30 \mathrm{~cm}$ for $14+$ days \\
\hline 1987 & no & WT is within $30 \mathrm{~cm}$ for $14+$ days when above 70 th percentile \\
\hline 1988 & yes & water table is within $30 \mathrm{~cm}$ for $14+$ days \\
\hline 1989 & yes & water table is within $30 \mathrm{~cm}$ for $14+$ days \\
\hline 1990 & yes & water table is within $30 \mathrm{~cm}$ for $14+$ days \\
\hline 1991 & no & water table is not within $30 \mathrm{~cm}$ for $14+$ days \\
\hline 1992 & no & WT is within $30 \mathrm{~cm}$ for $14+$ days when above 70 th percentile \\
\hline 1993 & no & WT is within $30 \mathrm{~cm}$ for $14+$ days when above 70 th percentile \\
\hline 1994 & yes & water table is within $30 \mathrm{~cm}$ for $14+$ days \\
\hline 1995 & yes & water table is within $30 \mathrm{~cm}$ for $14+$ days \\
\hline 1996 & yes & water table is within $30 \mathrm{~cm}$ for $14+$ days \\
\hline 1997 & yes & water table is within $30 \mathrm{~cm}$ for $14+$ days \\
\hline 1998 & yes & water table is within $30 \mathrm{~cm}$ for $14+$ days \\
\hline 1999 & yes & water table is within $30 \mathrm{~cm}$ for $14+$ days \\
\hline 2000 & yes & water table is within $30 \mathrm{~cm}$ for $14+$ days \\
\hline 2001 & yes & water table is within $30 \mathrm{~cm}$ for $14+$ days \\
\hline 2002 & yes & water table is within $30 \mathrm{~cm}$ for $14+$ days \\
\hline 2003 & yes & water table is within $30 \mathrm{~cm}$ for $14+$ days \\
\hline 2004 & yes & water table is within $30 \mathrm{~cm}$ for $14+$ days \\
\hline 2005 & yes & water table is within $30 \mathrm{~cm}$ for $14+$ days \\
\hline
\end{tabular}


Table B.90: 45-year record for the modified 30-day Moving Total approach for bogwell plot S4 at Marcell. This plot met wetland hydrology in 40 out of 44 years. There was 4 years that did not meet wetland hydrology because water table (WT) saturation occurred during "wet" periods.

\begin{tabular}{|c|c|c|}
\hline Year & $\begin{array}{c}\text { Met/Not } \\
\text { Met }\end{array}$ & Reason Year did or did not meet Wetland Hydrology \\
\hline 1962 & no & WT is within $30 \mathrm{~cm}$ for $14+$ days when above 70 th Percentile \\
\hline 1963 & yes & water table is within $30 \mathrm{~cm}$ for $14+$ days \\
\hline 1964 & no & WT is within $30 \mathrm{~cm}$ for $14+$ days when above 70 th Percentile \\
\hline 1965 & yes & water table is within $30 \mathrm{~cm}$ for $14+$ days \\
\hline 1966 & yes & water table is within $30 \mathrm{~cm}$ for $14+$ days \\
\hline 1967 & yes & water table is within $30 \mathrm{~cm}$ for $14+$ days \\
\hline 1968 & yes & water table is within $30 \mathrm{~cm}$ for $14+$ days \\
\hline 1969 & yes & water table is within $30 \mathrm{~cm}$ for $14+$ days \\
\hline 1970 & yes & water table is within $30 \mathrm{~cm}$ for $14+$ days \\
\hline 1971 & yes & water table is within $30 \mathrm{~cm}$ for $14+$ days \\
\hline 1972 & yes & water table is within $30 \mathrm{~cm}$ for $14+$ days \\
\hline 1973 & yes & water table is within $30 \mathrm{~cm}$ for $14+$ days \\
\hline 1974 & yes & water table is within $30 \mathrm{~cm}$ for $14+$ days \\
\hline 1975 & yes & water table is within $30 \mathrm{~cm}$ for $14+$ days \\
\hline 1976 & yes & water table is within $30 \mathrm{~cm}$ for $14+$ days \\
\hline 1977 & no & WT is within $30 \mathrm{~cm}$ for $14+$ days when above 70 th Percentile \\
\hline 1978 & yes & water table is within $30 \mathrm{~cm}$ for $14+$ days \\
\hline 1979 & yes & water table is within $30 \mathrm{~cm}$ for $14+$ days \\
\hline 1980 & yes & water table is within $30 \mathrm{~cm}$ for $14+$ days \\
\hline 1981 & yes & water table is within $30 \mathrm{~cm}$ for $14+$ days \\
\hline 1982 & yes & water table is within $30 \mathrm{~cm}$ for $14+$ days \\
\hline 1983 & yes & water table is within $30 \mathrm{~cm}$ for $14+$ days \\
\hline 1984 & yes & water table is within $30 \mathrm{~cm}$ for $14+$ days \\
\hline 1985 & yes & water table is within $30 \mathrm{~cm}$ for $14+$ days \\
\hline 1986 & yes & water table is within $30 \mathrm{~cm}$ for $14+$ days \\
\hline 1987 & yes & water table is within $30 \mathrm{~cm}$ for $14+$ days \\
\hline 1988 & yes & water table is within $30 \mathrm{~cm}$ for $14+$ days \\
\hline 1989 & yes & water table is within $30 \mathrm{~cm}$ for $14+$ days \\
\hline 1990 & yes & water table is within $30 \mathrm{~cm}$ for $14+$ days \\
\hline 1991 & yes & water table is within $30 \mathrm{~cm}$ for $14+$ days \\
\hline 1992 & yes & water table is within $30 \mathrm{~cm}$ for $14+$ days \\
\hline 1993 & yes & water table is within $30 \mathrm{~cm}$ for $14+$ days \\
\hline 1994 & yes & water table is within $30 \mathrm{~cm}$ for $14+$ days \\
\hline 1995 & yes & water table is within $30 \mathrm{~cm}$ for $14+$ days \\
\hline 1996 & yes & water table is within $30 \mathrm{~cm}$ for $14+$ days \\
\hline 1997 & yes & water table is within $30 \mathrm{~cm}$ for $14+$ days \\
\hline 1998 & yes & water table is within $30 \mathrm{~cm}$ for $14+$ days \\
\hline 1999 & no & WT is within $30 \mathrm{~cm}$ for $14+$ days when above 70 th Percentile \\
\hline 2000 & yes & water table is within $30 \mathrm{~cm}$ for $14+$ days \\
\hline 2001 & yes & water table is within $30 \mathrm{~cm}$ for $14+$ days \\
\hline 2002 & yes & water table is within $30 \mathrm{~cm}$ for $14+$ days \\
\hline 2003 & yes & water table is within $30 \mathrm{~cm}$ for $14+$ days \\
\hline 2004 & yes & water table is within $30 \mathrm{~cm}$ for $14+$ days \\
\hline 2005 & yes & water table is within $30 \mathrm{~cm}$ for $14+$ days \\
\hline
\end{tabular}


Table B.91: 45-year record for the modified 30-day Moving Total approach for bogwell plot S5 at Marcell. This plot met wetland hydrology in 34 out of 44 years. There were 9 years that did not meet wetland hydrology because water table (WT) saturation occurred during "wet" periods, while 1 year did not meet water table saturation criterion.

\begin{tabular}{|c|c|c|}
\hline Year & $\begin{array}{c}\text { Met/Not } \\
\text { Met }\end{array}$ & Reason Year did or did not meet Wetland Hydrology \\
\hline 1962 & no & WT is within $30 \mathrm{~cm}$ for $14+$ days when above 70 th Percentile \\
\hline 1963 & no & WT is within $30 \mathrm{~cm}$ for $14+$ days when above 70 th Percentile \\
\hline 1964 & no & WT is within $30 \mathrm{~cm}$ for $14+$ days when above 70 th Percentile \\
\hline 1965 & yes & water table is within $30 \mathrm{~cm}$ for $14+$ days \\
\hline 1966 & no & WT is within $30 \mathrm{~cm}$ for $14+$ days when above 70 th Percentile \\
\hline 1967 & yes & water table is within $30 \mathrm{~cm}$ for $14+$ days \\
\hline 1968 & yes & water table is within $30 \mathrm{~cm}$ for $14+$ days \\
\hline 1969 & yes & water table is within $30 \mathrm{~cm}$ for $14+$ days \\
\hline 1970 & yes & water table is within $30 \mathrm{~cm}$ for $14+$ days \\
\hline 1971 & no & WT is within $30 \mathrm{~cm}$ for $14+$ days when above 70 th Percentile \\
\hline 1972 & no & WT is within $30 \mathrm{~cm}$ for $14+$ days when above 70 th Percentile \\
\hline 1973 & yes & water table is within $30 \mathrm{~cm}$ for $14+$ days \\
\hline 1974 & no & WT is within $30 \mathrm{~cm}$ for $14+$ days when above 70 th Percentile \\
\hline 1975 & yes & water table is within $30 \mathrm{~cm}$ for $14+$ days \\
\hline 1976 & no & water table is not within $30 \mathrm{~cm}$ for $14+$ days \\
\hline 1977 & no & WT is within $30 \mathrm{~cm}$ for $14+$ days when above 70 th Percentile \\
\hline 1978 & yes & water table is within $30 \mathrm{~cm}$ for $14+$ days \\
\hline 1979 & yes & water table is within $30 \mathrm{~cm}$ for $14+$ days \\
\hline 1980 & yes & water table is within $30 \mathrm{~cm}$ for $14+$ days \\
\hline 1981 & yes & water table is within $30 \mathrm{~cm}$ for $14+$ days \\
\hline 1982 & yes & water table is within $30 \mathrm{~cm}$ for $14+$ days \\
\hline 1983 & yes & water table is within $30 \mathrm{~cm}$ for $14+$ days \\
\hline 1984 & yes & water table is within $30 \mathrm{~cm}$ for $14+$ days \\
\hline 1985 & yes & water table is within $30 \mathrm{~cm}$ for $14+$ days \\
\hline 1986 & yes & water table is within $30 \mathrm{~cm}$ for $14+$ days \\
\hline 1987 & yes & water table is within $30 \mathrm{~cm}$ for $14+$ days \\
\hline 1988 & yes & water table is within $30 \mathrm{~cm}$ for $14+$ days \\
\hline 1989 & yes & water table is within $30 \mathrm{~cm}$ for $14+$ days \\
\hline 1990 & yes & water table is within $30 \mathrm{~cm}$ for $14+$ days \\
\hline 1991 & yes & water table is within $30 \mathrm{~cm}$ for $14+$ days \\
\hline 1992 & yes & water table is within $30 \mathrm{~cm}$ for $14+$ days \\
\hline 1993 & yes & water table is within $30 \mathrm{~cm}$ for $14+$ days \\
\hline 1994 & yes & water table is within $30 \mathrm{~cm}$ for $14+$ days \\
\hline 1995 & yes & water table is within $30 \mathrm{~cm}$ for $14+$ days \\
\hline 1996 & yes & water table is within $30 \mathrm{~cm}$ for $14+$ days \\
\hline 1997 & yes & water table is within $30 \mathrm{~cm}$ for $14+$ days \\
\hline 1998 & yes & water table is within $30 \mathrm{~cm}$ for $14+$ days \\
\hline 1999 & no & WT is within $30 \mathrm{~cm}$ for $14+$ days when above 70 th Percentile \\
\hline 2000 & yes & water table is within $30 \mathrm{~cm}$ for $14+$ days \\
\hline 2001 & yes & water table is within $30 \mathrm{~cm}$ for $14+$ days \\
\hline 2002 & yes & water table is within $30 \mathrm{~cm}$ for $14+$ days \\
\hline 2003 & yes & water table is within $30 \mathrm{~cm}$ for $14+$ days \\
\hline 2004 & yes & water table is within $30 \mathrm{~cm}$ for $14+$ days \\
\hline 2005 & yes & water table is within $30 \mathrm{~cm}$ for $14+$ days \\
\hline
\end{tabular}


Table B.92: 45-year record for the modified 30-day Moving Total approach for bogwell plot S6 at Marcell. This plot met wetland hydrology in 14 out of 40 years. There were 15 years that did not meet wetland hydrology because water table (WT) saturation occurred during "wet" periods, while 11 years did not meet water table saturation criterion.

\begin{tabular}{|c|c|c|}
\hline Year & $\begin{array}{c}\text { Met/Not } \\
\text { Met }\end{array}$ & Reason Year did or did not meet Wetland Hydrology \\
\hline 1961 & no data & \\
\hline 1962 & no data & \\
\hline 1963 & no data & \\
\hline 1964 & no data & \\
\hline 1965 & no & water table not within $30 \mathrm{~cm}$ for $14+$ days \\
\hline 1966 & no & water table not within $30 \mathrm{~cm}$ for $14+$ days \\
\hline 1967 & no & water table not within $30 \mathrm{~cm}$ for $14+$ days \\
\hline 1968 & no & water table not within $30 \mathrm{~cm}$ for $14+$ days \\
\hline 1969 & no & water table not within $30 \mathrm{~cm}$ for $14+$ days \\
\hline 1970 & no & water table not within $30 \mathrm{~cm}$ for $14+$ days \\
\hline 1971 & no & water table not within $30 \mathrm{~cm}$ for $14+$ days \\
\hline 1972 & no & water table not within $30 \mathrm{~cm}$ for $14+$ days \\
\hline 1973 & no & water table not within $30 \mathrm{~cm}$ for $14+$ days \\
\hline 1974 & no & WT is $30 \mathrm{~cm}$ for $14+$ days when above 70 th Percentile \\
\hline 1975 & no data & \\
\hline 1976 & no & water table is not within $30 \mathrm{~cm}$ for $14+$ days \\
\hline 1977 & no & WT is $30 \mathrm{~cm}$ for $14+$ days when above 70 th Percentile \\
\hline 1978 & no & WT is $30 \mathrm{~cm}$ for $14+$ days when above 70 th Percentile \\
\hline 1979 & no & WT is $30 \mathrm{~cm}$ for $14+$ days when above 70 th Percentile \\
\hline 1980 & no & WT is $30 \mathrm{~cm}$ for $14+$ days when above 70 th Percentile \\
\hline 1981 & no & WT is $30 \mathrm{~cm}$ for $14+$ days when above 70 th Percentile \\
\hline 1982 & no & WT is $30 \mathrm{~cm}$ for $14+$ days when above 70 th Percentile \\
\hline 1983 & yes & water table is within $30 \mathrm{~cm}$ for $14+$ days \\
\hline 1984 & no & WT is $30 \mathrm{~cm}$ for $14+$ days when above 70 th Percentile \\
\hline 1985 & no & WT is $30 \mathrm{~cm}$ for $14+$ days when above 70 th Percentile \\
\hline 1986 & no & WT is $30 \mathrm{~cm}$ for $14+$ days when above 70 th Percentile \\
\hline 1987 & no & WT is $30 \mathrm{~cm}$ for $14+$ days when above 70 th Percentile \\
\hline 1988 & yes & water table is within $30 \mathrm{~cm}$ for $14+$ days \\
\hline 1989 & no & WT is $30 \mathrm{~cm}$ for $14+$ days when above 70 th Percentile \\
\hline 1990 & yes & water table is within $30 \mathrm{~cm}$ for $14+$ days \\
\hline 1991 & no & water table is not within $30 \mathrm{~cm}$ for $14+$ days \\
\hline 1992 & no & WT is $30 \mathrm{~cm}$ for $14+$ days when above 70 th Percentile \\
\hline 1993 & no & WT is $30 \mathrm{~cm}$ for $14+$ days when above 70 th Percentile \\
\hline 1994 & no & WT is $30 \mathrm{~cm}$ for $14+$ days when above 70 th Percentile \\
\hline 1995 & yes & water table is within $30 \mathrm{~cm}$ for $14+$ days \\
\hline 1996 & yes & water table is within $30 \mathrm{~cm}$ for $14+$ days \\
\hline 1997 & yes & water table is within $30 \mathrm{~cm}$ for $14+$ days \\
\hline 1998 & yes & water table is within $30 \mathrm{~cm}$ for $14+$ days \\
\hline 1999 & yes & water table is within $30 \mathrm{~cm}$ for $14+$ days \\
\hline 2000 & yes & water table is within $30 \mathrm{~cm}$ for $14+$ days \\
\hline 2001 & yes & water table is within $30 \mathrm{~cm}$ for $14+$ days \\
\hline 2002 & yes & water table is within $30 \mathrm{~cm}$ for $14+$ days \\
\hline 2003 & yes & water table is within $30 \mathrm{~cm}$ for $14+$ days \\
\hline 2004 & yes & water table is within $30 \mathrm{~cm}$ for $14+$ days \\
\hline 2005 & yes & water table is within $30 \mathrm{~cm}$ for $14+$ days \\
\hline
\end{tabular}




\section{APPENDIX C \\ DAREM and Modified DAREM Calculation Tables}

This Appendix includes 3-Month prior calculations used for both DAREM and Modified DAREM approaches and that were generated from precipitation data at each research site. These calculations show the period of interest that met wetland hydrology from the Modified DAREM results in Appendix B. The $30^{\text {th }}$ and $70^{\text {th }}$ percentile values were obtained from WETS Tables. A period of interested that had a sum with a value between 6 to 9 was considered Dry, a sum with a value between 10 and 14 was considered Normal, and a sum between 15 to 18 was considered Wet. Wetland hydrology was met during dry or normal periods and tables specific to results in Appendix B are listed within this Appendix. Refer to Appendix 2 to see which years met wetland hydrology. 
Table C.1: DAREM and Modified DAREM calculations for period that met wetland hydrology for plots $2 \mathrm{R}, 3 \mathrm{R}$, 4R, and 4P at Greenville within the year 1959.

\begin{tabular}{|c|c|c|c|c|c|c|c|c|}
\hline \multicolumn{2}{|c|}{ Prior Month } & \multicolumn{2}{|c|}{$\begin{array}{l}\text { WETS Rainfall } \\
\text { Percentile }\end{array}$} & \multirow[t]{2}{*}{$\begin{array}{c}\text { Measured } \\
\text { Rainfall }\end{array}$} & \multirow{2}{*}{$\begin{array}{l}\text { Condition: } \\
\text { Dry, Wet, } \\
\text { Normal }\end{array}$} & \multirow{3}{*}{$\begin{array}{c}\text { Condition } \\
\text { Value } \\
(\mathbf{1 = d r y ,}, \\
2=\text { normal, } \\
\text { or } 3=\text { wet })\end{array}$} & \multirow[t]{2}{*}{$\begin{array}{l}\text { Month } \\
\text { weight }\end{array}$} & \multirow{2}{*}{$\begin{array}{l}\text { Multiply } \\
\text { Previous two } \\
\text { columns }\end{array}$} \\
\hline & Name & $30^{\text {th }}$ & 70th & & & & & \\
\hline & & \multicolumn{3}{|c|}{----------cm------------ } & & & & \\
\hline $1^{\text {st }}($ most recent $)$ & Sept & 7.06 & 18.11 & 11.61 & Normal & 2 & 3 & 6 \\
\hline 2nd & August & 9.27 & 17.86 & 10.54 & Normal & 2 & 2 & 4 \\
\hline $3 \mathrm{rd}$ & July & 7.53 & 16.83 & 30.78 & Wet & 3 & 1 & 3 \\
\hline \multirow{2}{*}{\multicolumn{8}{|c|}{$\begin{array}{ll} & \text { Sum } \\
\text { Rainfall of prior period was: } & \text { drier than normal (sum is 6-9), normal (sum is 10-14), wetter than normal (sum is 15-18) }\end{array}$}} & 13 \\
\hline & & & & & & & & Normal \\
\hline
\end{tabular}

Table C.2: DAREM and Modified DAREM calculations for period that met wetland hydrology for plot 4P at Greenville within the year 1960.

\begin{tabular}{|c|c|c|c|c|c|c|c|c|}
\hline \multicolumn{2}{|c|}{ Prior Month } & \multicolumn{2}{|c|}{$\begin{array}{l}\text { WETS Rainfall } \\
\text { Percentile }\end{array}$} & \multirow[t]{2}{*}{$\begin{array}{c}\text { Measured } \\
\text { Rainfall }\end{array}$} & \multirow{2}{*}{$\begin{array}{c}\text { Condition: } \\
\text { Dry, Wet, } \\
\text { Normal } \\
\end{array}$} & \multirow{3}{*}{ 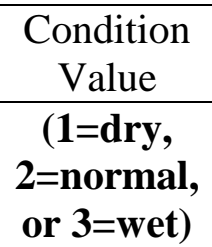 } & \multirow[t]{2}{*}{$\begin{array}{l}\text { Month } \\
\text { weight }\end{array}$} & \multirow{2}{*}{$\begin{array}{c}\text { Multiply } \\
\text { Previous two } \\
\text { columns } \\
\end{array}$} \\
\hline & Name & $30^{\text {th }}$ & 70th & & & & & \\
\hline & & \multicolumn{3}{|c|}{----------cm------------ } & & & & \\
\hline $1^{\text {st }}$ (most recent) & April & 5.54 & 10.95 & 10.91 & Normal & 2 & 3 & 6 \\
\hline 2nd & March & 8.10 & 12.27 & 8.11 & Normal & 2 & 2 & 4 \\
\hline $3 \mathrm{rd}$ & Feb & 5.94 & 10.57 & 14.25 & Wet & 3 & 1 & 3 \\
\hline & & & & & & & Sum & 13 \\
\hline & Normal \\
\hline
\end{tabular}


Table C.3: DAREM and Modified DAREM calculations for period that met wetland hydrology for plots $1 \mathrm{R}, 2 \mathrm{R}, 3 \mathrm{R}$, 4R, and 4P at Greenville within the year the year 1961.

\begin{tabular}{|c|c|c|c|c|c|c|c|c|}
\hline \multicolumn{2}{|c|}{ Prior Month } & \multicolumn{2}{|c|}{$\begin{array}{l}\text { WETS Rainfall } \\
\text { Percentile }\end{array}$} & \multirow[t]{2}{*}{$\begin{array}{c}\text { Measured } \\
\text { Rainfall }\end{array}$} & \multirow{2}{*}{$\begin{array}{l}\text { Condition: } \\
\text { Dry, Wet, } \\
\text { Normal }\end{array}$} & \multirow{3}{*}{$\begin{array}{c}\begin{array}{c}\text { Condition } \\
\text { Value }\end{array} \\
\text { (1=dry, } \\
2=\text { normal, } \\
\text { or } 3=\text { wet })\end{array}$} & \multirow[t]{2}{*}{$\begin{array}{l}\text { Month } \\
\text { weight }\end{array}$} & \multirow{2}{*}{$\begin{array}{l}\text { Multiply } \\
\text { Previous two } \\
\text { columns }\end{array}$} \\
\hline & Name & $30^{\text {th }}$ & 70th & & & & & \\
\hline & & \multicolumn{3}{|c|}{---------cm----------- } & & & & \\
\hline $1^{\text {st }}$ (most recent) & Feb & 5.94 & 10.57 & 16.65 & Wet & 3 & 3 & 9 \\
\hline 2nd & Jan & 8.97 & 13.54 & 7.11 & Dry & 1 & 2 & 2 \\
\hline $3 \mathrm{rd}$ & Dec & 5.33 & 10.21 & 6.00 & Normal & 2 & 1 & 2 \\
\hline \multirow{2}{*}{\multicolumn{8}{|c|}{$\begin{array}{ll} & \text { Sum } \\
\text { Rainfall of prior period was: } & \\
\text { drier than normal (sum is 6-9), normal (sum is } 10-14), \text { wetter than normal (sum is 15-18) }\end{array}$}} & 13 \\
\hline & & & & & & & & Normal \\
\hline
\end{tabular}

Table C.4: DAREM and Modified DAREM calculations for period that met wetland hydrology for plots 1R, 2R, 3R, 4R and 4P at Greenville within the year 1962.

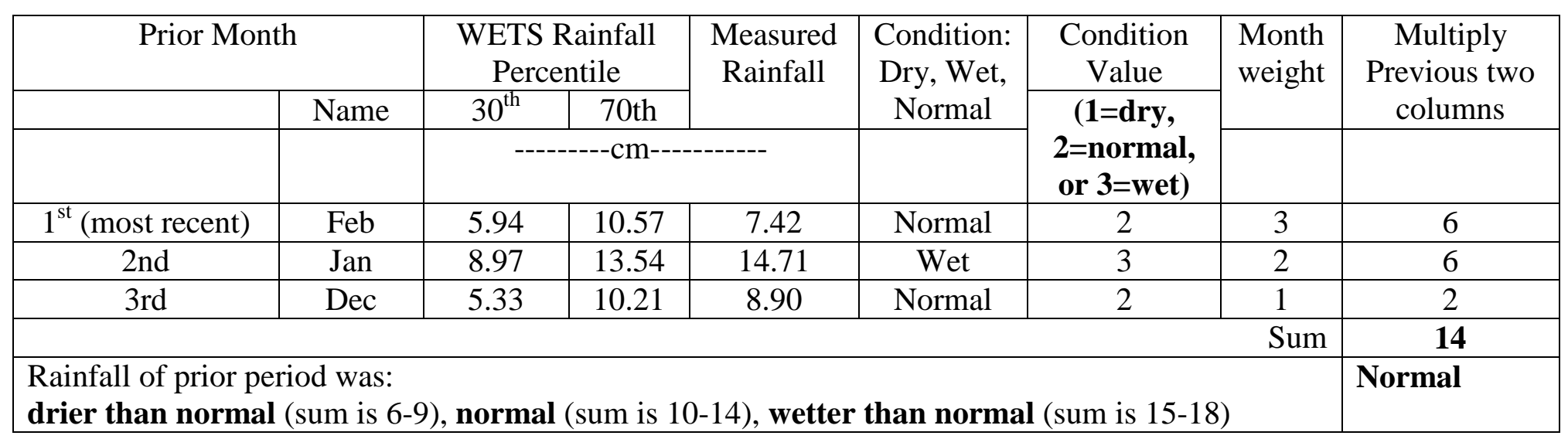


Table C.5: DAREM and Modified DAREM calculations for period that met wetland hydrology for plots $1 \mathrm{R}, 2 \mathrm{R}, 3 \mathrm{R}$, 4R and 4P at Greenville the year 1963.

\begin{tabular}{|c|c|c|c|c|c|c|c|c|}
\hline \multicolumn{2}{|c|}{ Prior Month } & \multicolumn{2}{|c|}{$\begin{array}{l}\text { WETS Rainfall } \\
\text { Percentile }\end{array}$} & \multirow[t]{2}{*}{$\begin{array}{c}\text { Measured } \\
\text { Rainfall }\end{array}$} & \multirow{2}{*}{$\begin{array}{l}\text { Condition: } \\
\text { Dry, Wet, } \\
\text { Normal }\end{array}$} & \multirow{3}{*}{$\begin{array}{c}\text { Condition } \\
\text { Value }\end{array}$} & \multirow[t]{2}{*}{$\begin{array}{l}\text { Month } \\
\text { weight }\end{array}$} & \multirow{2}{*}{$\begin{array}{c}\text { Multiply } \\
\text { Previous two } \\
\text { columns }\end{array}$} \\
\hline & Name & $30^{\text {th }}$ & 70th & & & & & \\
\hline & & \multicolumn{3}{|c|}{----------cm------------ } & & & & \\
\hline $1^{\text {st }}($ most recent $)$ & Feb & 5.94 & 10.57 & 8.78 & Normal & 2 & 3 & 6 \\
\hline 2nd & Jan & 8.97 & 13.54 & 18.03 & Wet & 3 & 2 & 6 \\
\hline 3rd & Dec & 5.33 & 10.21 & 8.41 & Normal & 2 & 1 & 2 \\
\hline \multirow{2}{*}{\multicolumn{8}{|c|}{$\begin{array}{l}\text { Rainfall of prior period was: } \\
\text { drier than normal (sum is 6-9), normal (sum is } 10-14 \text { ), wetter than normal (sum is } 15-18 \text { ) }\end{array}$}} & 14 \\
\hline & & & & & & & & Normal \\
\hline
\end{tabular}

Table C.6: DAREM and Modified DAREM calculations for period that met wetland hydrology for plots 1R, 2R, 3R, 4R and 4P at Greenville within the year 1965.

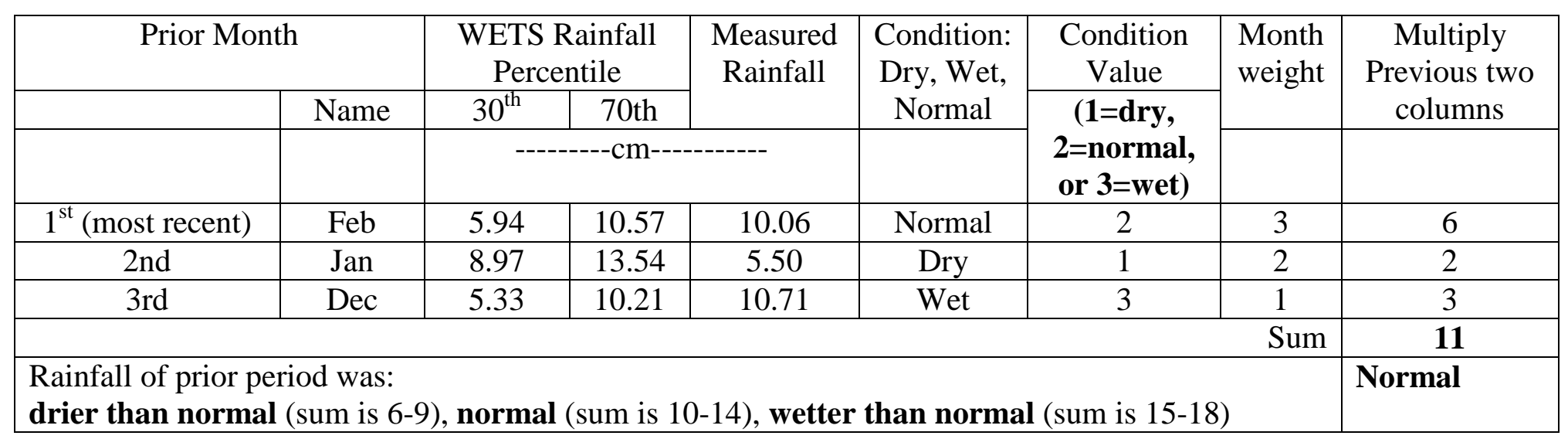


Table C.7: DAREM and Modified DAREM calculations for period that met wetland hydrology for plots $2 \mathrm{R}, 3 \mathrm{R}, 4 \mathrm{R}$ and 4P at Greenville within the year 1966.

\begin{tabular}{|c|c|c|c|c|c|c|c|c|}
\hline \multicolumn{2}{|c|}{ Prior Month } & \multicolumn{2}{|c|}{$\begin{array}{l}\text { WETS Rainfall } \\
\text { Percentile }\end{array}$} & \multirow[t]{2}{*}{$\begin{array}{l}\text { Measured } \\
\text { Rainfall }\end{array}$} & \multirow{2}{*}{$\begin{array}{l}\text { Condition: } \\
\text { Dry, Wet, } \\
\text { Normal }\end{array}$} & \multirow{3}{*}{$\begin{array}{c}\text { Condition } \\
\text { Value } \\
\text { (1=dry, } \\
2=\text { normal, } \\
\text { or } 3=\text { wet) }\end{array}$} & \multirow[t]{2}{*}{$\begin{array}{l}\text { Month } \\
\text { weight }\end{array}$} & \multirow{2}{*}{$\begin{array}{c}\text { Multiply } \\
\text { Previous two } \\
\text { columns }\end{array}$} \\
\hline & Name & $30^{\text {th }}$ & 70th & & & & & \\
\hline & & \multicolumn{3}{|c|}{----------cm------------ } & & & & \\
\hline $1^{\text {st }}$ (most recent) & Feb & 5.94 & 10.57 & 8.10 & Normal & 2 & 3 & 6 \\
\hline 2nd & Jan & 8.97 & 13.54 & 16.61 & Wet & 3 & 2 & 6 \\
\hline $3 \mathrm{rd}$ & Dec & 5.33 & 10.21 & 1.52 & Dry & 1 & 1 & 1 \\
\hline \multirow{2}{*}{\multicolumn{8}{|c|}{$\begin{array}{l}\text { Rainfall of prior period was: } \\
\text { drier than normal (sum is 6-9), normal (sum is 10-14), wetter than normal (sum is 15-18) }\end{array}$}} & 13 \\
\hline & & & & & & & & Normal \\
\hline
\end{tabular}

Table C.8: DAREM and Modified DAREM calculations for period that met wetland hydrology for plots $2 \mathrm{R}, 3 \mathrm{R}$, and 4P at Greenville within the year 1967.

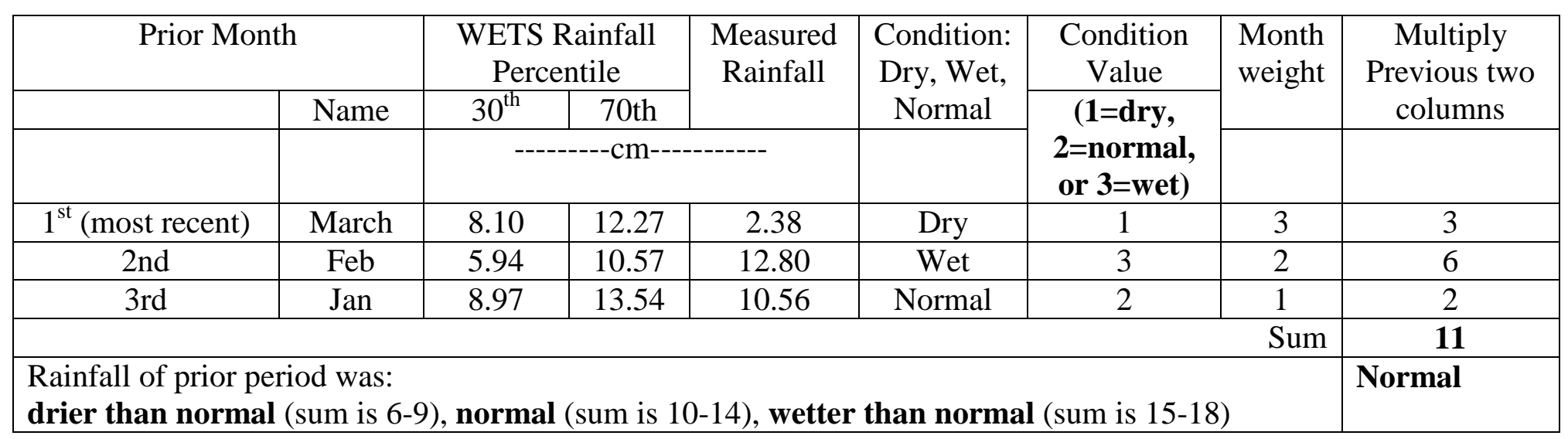


Table C.9: DAREM and Modified DAREM calculations for period that met wetland hydrology for plots $1 \mathrm{R}, 2 \mathrm{R}, 3 \mathrm{R}$, 4R and 4P at Greenville within the year 1968.

\begin{tabular}{|c|c|c|c|c|c|c|c|c|}
\hline \multicolumn{2}{|c|}{ Prior Month } & \multicolumn{2}{|c|}{$\begin{array}{l}\text { WETS Rainfall } \\
\text { Percentile }\end{array}$} & \multirow[t]{2}{*}{$\begin{array}{l}\text { Measured } \\
\text { Rainfall }\end{array}$} & \multirow{2}{*}{$\begin{array}{c}\text { Condition: } \\
\text { Dry, Wet, } \\
\text { Normal }\end{array}$} & \multirow{3}{*}{$\begin{array}{c}\text { Condition } \\
\text { Value } \\
(\mathbf{1 = d r y ,}, \\
2=\text { normal, } \\
\text { or } 3=\text { wet })\end{array}$} & \multirow[t]{2}{*}{$\begin{array}{l}\text { Month } \\
\text { weight }\end{array}$} & \multirow{2}{*}{$\begin{array}{c}\text { Multiply } \\
\text { Previous two } \\
\text { columns } \\
\end{array}$} \\
\hline & Name & $30^{\text {th }}$ & 70th & & & & & \\
\hline & & \multicolumn{3}{|c|}{----------cm----------- } & & & & \\
\hline $1^{\mathrm{st}}$ (most recent) & Feb & 5.94 & 10.57 & 2.90 & Dry & 1 & 3 & 3 \\
\hline 2nd & Jan & 8.97 & 13.54 & 12.01 & Normal & 2 & 2 & 4 \\
\hline 3rd & Dec & 5.33 & 10.21 & 11.91 & Wet & 3 & 1 & 3 \\
\hline \multirow{2}{*}{\multicolumn{8}{|c|}{$\begin{array}{l}\text { Rainfall of prior period was: } \\
\text { drier than normal (sum is 6-9), normal (sum is } 10-14 \text { ), wetter than normal (sum is 15-18) }\end{array}$}} & 10 \\
\hline & & & & & & & & Normal \\
\hline
\end{tabular}

Table C.10: DAREM and Modified DAREM calculations for period that met wetland hydrology for plots $1 R, 2 R, 3 R$, 4R and 4P at Greenville within the year 1969.

\begin{tabular}{|c|c|c|c|c|c|c|c|c|}
\hline \multicolumn{2}{|c|}{ Prior Month } & \multicolumn{2}{|c|}{$\begin{array}{l}\text { WETS Rainfall } \\
\text { Percentile }\end{array}$} & \multirow[t]{2}{*}{$\begin{array}{l}\text { Measured } \\
\text { Rainfall }\end{array}$} & \multirow{2}{*}{$\begin{array}{l}\text { Condition: } \\
\text { Dry, Wet, } \\
\text { Normal }\end{array}$} & \multirow{3}{*}{ 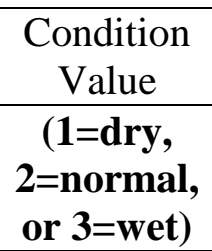 } & \multirow[t]{3}{*}{$\begin{array}{l}\text { Month } \\
\text { weight }\end{array}$} & \multirow{2}{*}{$\begin{array}{c}\text { Multiply } \\
\text { Previous two } \\
\text { columns } \\
\end{array}$} \\
\hline & Name & $30^{\text {th }}$ & 70th & & & & & \\
\hline & & \multicolumn{3}{|c|}{----------cm------------ } & & & & \\
\hline $1^{\mathrm{st}}$ (most recent) & Feb & 5.94 & 10.57 & 8.09 & Normal & 2 & 3 & 6 \\
\hline 2 nd & Jan & 8.97 & 13.54 & 9.90 & Normal & 2 & 2 & 4 \\
\hline $3 \mathrm{rd}$ & Dec & 5.33 & 10.21 & 5.41 & Normal & 2 & 1 & 2 \\
\hline \multirow{2}{*}{\multicolumn{8}{|c|}{$\begin{array}{ll} & \text { Sum } \\
\text { Rainfall of prior period was: } & \\
\text { drier than normal (sum is } 6-9), \text { normal (sum is } 10-14), \text { wetter than normal (sum is } 15-18)\end{array}$}} & 12 \\
\hline & & & & & & & & Normal \\
\hline
\end{tabular}


Table C.11: DAREM and Modified DAREM calculations for period that met wetland hydrology for plots 1R, 2R, 3R, 4R and 4P at Greenville within the year 1970.

\begin{tabular}{|c|c|c|c|c|c|c|c|c|}
\hline \multicolumn{2}{|c|}{ Prior Month } & \multicolumn{2}{|c|}{$\begin{array}{l}\text { WETS Rainfall } \\
\text { Percentile }\end{array}$} & \multirow[t]{2}{*}{$\begin{array}{l}\text { Measured } \\
\text { Rainfall }\end{array}$} & \multirow{2}{*}{$\begin{array}{c}\text { Condition: } \\
\text { Dry, Wet, } \\
\text { Normal }\end{array}$} & \multirow{3}{*}{$\begin{array}{c}\text { Condition } \\
\text { Value } \\
(\mathbf{1 = d r y ,}, \\
2=\text { normal, } \\
\text { or } 3=\text { wet })\end{array}$} & \multirow[t]{2}{*}{$\begin{array}{l}\text { Month } \\
\text { weight }\end{array}$} & \multirow{2}{*}{$\begin{array}{c}\text { Multiply } \\
\text { Previous two } \\
\text { columns } \\
\end{array}$} \\
\hline & Name & $30^{\text {th }}$ & 70th & & & & & \\
\hline & & \multicolumn{3}{|c|}{----------cm----------- } & & & & \\
\hline $1^{\mathrm{st}}$ (most recent) & Feb & 5.94 & 10.57 & 10.79 & Wet & 3 & 3 & 9 \\
\hline 2nd & Jan & 8.97 & 13.54 & 5.78 & Dry & 2 & 2 & 4 \\
\hline $3 \mathrm{rd}$ & Dec & 5.33 & 10.21 & 9.97 & Normal & 1 & 1 & 1 \\
\hline \multirow{2}{*}{\multicolumn{8}{|c|}{$\begin{array}{l}\text { Rainfall of prior period was: } \\
\text { drier than normal (sum is 6-9), normal (sum is } 10-14 \text { ), wetter than normal (sum is 15-18) }\end{array}$}} & 14 \\
\hline & & & & & & & & Normal \\
\hline
\end{tabular}

Table C.12: DAREM and Modified DAREM calculations for period that met wetland hydrology for plots $2 \mathrm{R}, 3 \mathrm{R}, 4 \mathrm{R}$ and 4P at Greenville within the year 1971.

\begin{tabular}{|c|c|c|c|c|c|c|c|c|}
\hline \multicolumn{2}{|c|}{ Prior Month } & \multicolumn{2}{|c|}{$\begin{array}{l}\text { WETS Rainfall } \\
\text { Percentile }\end{array}$} & \multirow[t]{2}{*}{$\begin{array}{l}\text { Measured } \\
\text { Rainfall }\end{array}$} & \multirow{2}{*}{$\begin{array}{l}\text { Condition: } \\
\text { Dry, Wet, } \\
\text { Normal }\end{array}$} & \multirow{3}{*}{ 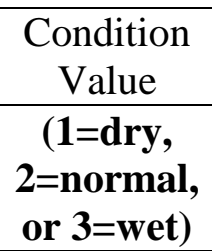 } & \multirow[t]{3}{*}{$\begin{array}{l}\text { Month } \\
\text { weight }\end{array}$} & \multirow{2}{*}{$\begin{array}{c}\text { Multiply } \\
\text { Previous two } \\
\text { columns } \\
\end{array}$} \\
\hline & Name & $30^{\text {th }}$ & 70th & & & & & \\
\hline & & \multicolumn{3}{|c|}{----------cm------------ } & & & & \\
\hline $1^{\mathrm{st}}$ (most recent) & Feb & 5.94 & 10.57 & 15.08 & Wet & 3 & 3 & 9 \\
\hline 2 nd & Jan & 8.97 & 13.54 & 7.60 & Dry & 1 & 2 & 2 \\
\hline $3 \mathrm{rd}$ & Dec & 5.33 & 10.21 & 5.79 & Normal & 2 & 1 & 2 \\
\hline \multirow{2}{*}{\multicolumn{8}{|c|}{$\begin{array}{ll} & \text { Sum } \\
\text { Rainfall of prior period was: } & \end{array}$}} & 13 \\
\hline & & & & & & & & Normal \\
\hline
\end{tabular}


Table C.13: DAREM and Modified DAREM calculations for period that met wetland hydrology for plots $1 \mathrm{R}, 2 \mathrm{R}, 3 \mathrm{R}$, 4R and 4P at Greenville within the year 1972.

\begin{tabular}{|c|c|c|c|c|c|c|c|c|}
\hline \multicolumn{2}{|c|}{ Prior Month } & \multicolumn{2}{|c|}{$\begin{array}{l}\text { WETS Rainfall } \\
\text { Percentile }\end{array}$} & \multirow[t]{2}{*}{$\begin{array}{l}\text { Measured } \\
\text { Rainfall }\end{array}$} & \multirow{2}{*}{$\begin{array}{c}\text { Condition: } \\
\text { Dry, Wet, } \\
\text { Normal }\end{array}$} & \multirow{3}{*}{$\begin{array}{c}\text { Condition } \\
\text { Value } \\
(\mathbf{1 = d r y ,}, \\
2=\text { normal, } \\
\text { or } 3=\text { wet })\end{array}$} & \multirow[t]{2}{*}{$\begin{array}{l}\text { Month } \\
\text { weight }\end{array}$} & \multirow{2}{*}{$\begin{array}{c}\text { Multiply } \\
\text { Previous two } \\
\text { columns } \\
\end{array}$} \\
\hline & Name & $30^{\text {th }}$ & 70th & & & & & \\
\hline & & \multicolumn{3}{|c|}{----------cm----------- } & & & & \\
\hline $1^{\mathrm{st}}$ (most recent) & Feb & 5.94 & 10.57 & 11.30 & Wet & 3 & 3 & 9 \\
\hline 2nd & Jan & 8.97 & 13.54 & 9.34 & Normal & 2 & 2 & 4 \\
\hline $3 \mathrm{rd}$ & Dec & 5.33 & 10.21 & 2.30 & Dry & 1 & 1 & 1 \\
\hline \multirow{2}{*}{\multicolumn{8}{|c|}{$\begin{array}{l}\text { Rainfall of prior period was: } \\
\text { drier than normal (sum is 6-9), normal (sum is 10-14), wetter than normal (sum is 15-18) }\end{array}$}} & 14 \\
\hline & & & & & & & & Normal \\
\hline
\end{tabular}

Table C.14: DAREM and Modified DAREM calculations for period that met wetland hydrology for plots $1 \mathrm{R}, 2 \mathrm{R}, 3 \mathrm{R}$, 4R and 4P at Greenville within the year 1973.

\begin{tabular}{|c|c|c|c|c|c|c|c|c|}
\hline \multicolumn{2}{|c|}{ Prior Month } & \multicolumn{2}{|c|}{$\begin{array}{l}\text { WETS Rainfall } \\
\text { Percentile }\end{array}$} & \multirow[t]{2}{*}{$\begin{array}{l}\text { Measured } \\
\text { Rainfall }\end{array}$} & \multirow{2}{*}{$\begin{array}{l}\text { Condition: } \\
\text { Dry, Wet, } \\
\text { Normal }\end{array}$} & \multirow{3}{*}{ 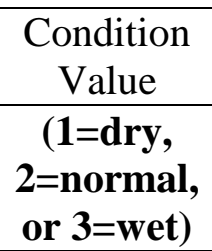 } & \multirow[t]{3}{*}{$\begin{array}{l}\text { Month } \\
\text { weight }\end{array}$} & \multirow{2}{*}{$\begin{array}{c}\text { Multiply } \\
\text { Previous two } \\
\text { columns } \\
\end{array}$} \\
\hline & Name & $30^{\text {th }}$ & 70th & & & & & \\
\hline & & \multicolumn{3}{|c|}{----------cm------------ } & & & & \\
\hline $1^{\mathrm{st}}$ (most recent) & Feb & 5.94 & 10.57 & 14.53 & Wet & 3 & 3 & 9 \\
\hline 2 nd & Jan & 8.97 & 13.54 & 8.81 & Dry & 1 & 2 & 2 \\
\hline $3 \mathrm{rd}$ & Dec & 5.33 & 10.21 & 6.24 & Normal & 2 & 1 & 2 \\
\hline \multirow{2}{*}{\multicolumn{8}{|c|}{$\begin{array}{ll} & \text { Sum } \\
\text { Rainfall of prior period was: } & \end{array}$}} & 13 \\
\hline & & & & & & & & Normal \\
\hline
\end{tabular}


Table C.15: DAREM and Modified DAREM calculations for period that met wetland hydrology for plots $2 \mathrm{R}, 3 \mathrm{R}, 4 \mathrm{R}$ and 4P at Greenville within the year 1974.

\begin{tabular}{|c|c|c|c|c|c|c|c|c|}
\hline \multicolumn{2}{|c|}{ Prior Month } & \multicolumn{2}{|c|}{$\begin{array}{l}\text { WETS Rainfall } \\
\text { Percentile }\end{array}$} & \multirow[t]{2}{*}{$\begin{array}{l}\text { Measured } \\
\text { Rainfall }\end{array}$} & \multirow{2}{*}{$\begin{array}{c}\text { Condition: } \\
\text { Dry, Wet, } \\
\text { Normal }\end{array}$} & \multirow{3}{*}{$\begin{array}{c}\text { Condition } \\
\text { Value } \\
(\mathbf{1 = d r y ,}, \\
2=\text { normal, } \\
\text { or } 3=\text { wet })\end{array}$} & \multirow[t]{2}{*}{$\begin{array}{l}\text { Month } \\
\text { weight }\end{array}$} & \multirow{2}{*}{$\begin{array}{c}\text { Multiply } \\
\text { Previous two } \\
\text { columns } \\
\end{array}$} \\
\hline & Name & $30^{\text {th }}$ & 70th & & & & & \\
\hline & & \multicolumn{3}{|c|}{----------cm----------- } & & & & \\
\hline $1^{\mathrm{st}}$ (most recent) & Feb & 5.94 & 10.57 & 9.72 & Normal & 2 & 3 & 6 \\
\hline 2nd & Jan & 8.97 & 13.54 & 8.99 & Normal & 2 & 2 & 4 \\
\hline $3 \mathrm{rd}$ & Dec & 5.33 & 10.21 & 19.88 & Wet & 3 & 1 & 3 \\
\hline \multirow{2}{*}{\multicolumn{8}{|c|}{$\begin{array}{l}\text { Rainfall of prior period was: } \\
\text { drier than normal (sum is 6-9), normal (sum is 10-14), wetter than normal (sum is 15-18) }\end{array}$}} & 13 \\
\hline & & & & & & & & Normal \\
\hline
\end{tabular}

Table C.16: DAREM and Modified DAREM calculations for period that met wetland hydrology for plots $1 \mathrm{R}, 3 \mathrm{R}, 4 \mathrm{R}$ and $4 \mathrm{P}$ at Greenville within the year 1975.

\begin{tabular}{|c|c|c|c|c|c|c|c|c|}
\hline \multicolumn{2}{|c|}{ Prior Month } & \multicolumn{2}{|c|}{$\begin{array}{l}\text { WETS Rainfall } \\
\text { Percentile }\end{array}$} & \multirow[t]{2}{*}{$\begin{array}{l}\text { Measured } \\
\text { Rainfall }\end{array}$} & \multirow{2}{*}{$\begin{array}{l}\text { Condition: } \\
\text { Dry, Wet, } \\
\text { Normal }\end{array}$} & \multirow{3}{*}{ 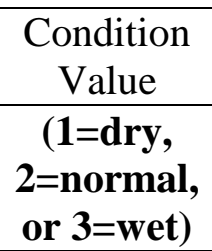 } & \multirow[t]{3}{*}{$\begin{array}{l}\text { Month } \\
\text { weight }\end{array}$} & \multirow{2}{*}{$\begin{array}{c}\text { Multiply } \\
\text { Previous two } \\
\text { columns } \\
\end{array}$} \\
\hline & Name & $30^{\text {th }}$ & 70th & & & & & \\
\hline & & \multicolumn{3}{|c|}{----------cm------------ } & & & & \\
\hline $1^{\mathrm{st}}$ (most recent) & March & 8.10 & 12.27 & 8.81 & Normal & 2 & 3 & 6 \\
\hline 2 nd & Feb & 5.94 & 10.57 & 10.78 & Wet & 3 & 2 & 6 \\
\hline $3 \mathrm{rd}$ & Jan & 8.97 & 13.54 & 12.59 & Normal & 2 & 1 & 2 \\
\hline \multirow{2}{*}{\multicolumn{8}{|c|}{$\begin{array}{ll} & \text { Sum } \\
\text { Rainfall of prior period was: } & \\
\text { drier than normal (sum is } 6-9), \text { normal (sum is } 10-14), \text { wetter than normal (sum is } 15-18)\end{array}$}} & 14 \\
\hline & & & & & & & & Normal \\
\hline
\end{tabular}


Table C.17: DAREM and Modified DAREM calculations for period that met wetland hydrology for plot $2 \mathrm{R}$ at Greenville within the year 1976.

\begin{tabular}{|c|c|c|c|c|c|c|c|c|}
\hline \multicolumn{2}{|c|}{ Prior Month } & \multicolumn{2}{|c|}{$\begin{array}{l}\text { WETS Rainfall } \\
\text { Percentile }\end{array}$} & \multirow[t]{2}{*}{$\begin{array}{l}\text { Measured } \\
\text { Rainfall }\end{array}$} & \multirow{2}{*}{$\begin{array}{c}\text { Condition: } \\
\text { Dry, Wet, } \\
\text { Normal }\end{array}$} & \multirow{3}{*}{$\begin{array}{c}\text { Condition } \\
\text { Value } \\
(\mathbf{1 = d r y ,}, \\
2=\text { normal, } \\
\text { or } 3=\text { wet })\end{array}$} & \multirow[t]{2}{*}{$\begin{array}{l}\text { Month } \\
\text { weight }\end{array}$} & \multirow{2}{*}{$\begin{array}{c}\text { Multiply } \\
\text { Previous two } \\
\text { columns } \\
\end{array}$} \\
\hline & Name & $30^{\text {th }}$ & 70th & & & & & \\
\hline & & \multicolumn{3}{|c|}{----------cm----------- } & & & & \\
\hline $1^{\mathrm{st}}$ (most recent) & Feb & 5.94 & 10.57 & 3.43 & Dry & 1 & 3 & 3 \\
\hline 2nd & Jan & 8.97 & 13.54 & 13.10 & Normal & 2 & 2 & 4 \\
\hline $3 \mathrm{rd}$ & Dec & 5.33 & 10.21 & 11.04 & Wet & 3 & 1 & 3 \\
\hline \multirow{2}{*}{\multicolumn{8}{|c|}{$\begin{array}{l}\text { Rainfall of prior period was: } \\
\text { drier than normal (sum is 6-9), normal (sum is 10-14), wetter than normal (sum is 15-18) }\end{array}$}} & 10 \\
\hline & & & & & & & & Normal \\
\hline
\end{tabular}

Table C.18: DAREM and Modified DAREM calculations for period that met wetland hydrology for plots $1 R, 2 R, 3 R$, 4R and 4P at Greenville within the year 1977.

\begin{tabular}{|c|c|c|c|c|c|c|c|c|}
\hline \multicolumn{2}{|c|}{ Prior Month } & \multicolumn{2}{|c|}{$\begin{array}{l}\text { WETS Rainfall } \\
\text { Percentile }\end{array}$} & \multirow[t]{2}{*}{$\begin{array}{l}\text { Measured } \\
\text { Rainfall }\end{array}$} & \multirow{2}{*}{$\begin{array}{l}\text { Condition: } \\
\text { Dry, Wet, } \\
\text { Normal }\end{array}$} & \multirow{3}{*}{ 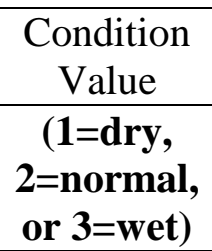 } & \multirow[t]{3}{*}{$\begin{array}{l}\text { Month } \\
\text { weight }\end{array}$} & \multirow{2}{*}{$\begin{array}{c}\text { Multiply } \\
\text { Previous two } \\
\text { columns } \\
\end{array}$} \\
\hline & Name & $30^{\text {th }}$ & 70th & & & & & \\
\hline & & \multicolumn{3}{|c|}{----------cm------------ } & & & & \\
\hline $1^{\mathrm{st}}$ (most recent) & Feb & 5.94 & 10.57 & 6.42 & Normal & 2 & 3 & 6 \\
\hline 2 nd & Jan & 8.97 & 13.54 & 10.79 & Normal & 2 & 2 & 4 \\
\hline $3 \mathrm{rd}$ & Dec & 5.33 & 10.21 & 10.93 & Wet & 3 & 1 & 3 \\
\hline \multirow{2}{*}{\multicolumn{8}{|c|}{$\begin{array}{l}\text { Rainfall of prior period was: } \\
\text { drier than normal (sum is } 6-9) \text {, normal (sum is } 10-14) \text {, wetter than normal (sum is } 15-18 \text { ) }\end{array}$}} & 13 \\
\hline & & & & & & & & Normal \\
\hline
\end{tabular}


Table C.19: DAREM and Modified DAREM calculations for period that met wetland hydrology for plots $2 \mathrm{R}, 3 \mathrm{R}, 4 \mathrm{R}$ and 4P at Greenville within the year 1978.

\begin{tabular}{|c|c|c|c|c|c|c|c|c|}
\hline \multicolumn{2}{|c|}{ Prior Month } & \multicolumn{2}{|c|}{$\begin{array}{l}\text { WETS Rainfall } \\
\text { Percentile }\end{array}$} & \multirow[t]{2}{*}{$\begin{array}{l}\text { Measured } \\
\text { Rainfall }\end{array}$} & \multirow{2}{*}{$\begin{array}{l}\text { Condition: } \\
\text { Dry, Wet, } \\
\text { Normal }\end{array}$} & \multirow{3}{*}{$\begin{array}{c}\text { Condition } \\
\text { Value }\end{array}$} & \multirow[t]{2}{*}{$\begin{array}{l}\text { Month } \\
\text { weight }\end{array}$} & \multirow{2}{*}{$\begin{array}{c}\text { Multiply } \\
\text { Previous two } \\
\text { columns }\end{array}$} \\
\hline & Name & $30^{\text {th }}$ & 70th & & & & & \\
\hline & & \multicolumn{3}{|c|}{----------cm------------ } & & & & \\
\hline $1^{\text {st }}$ (most recent) & Feb & 5.94 & 10.57 & 3.32 & Dry & 1 & 3 & 3 \\
\hline 2nd & Jan & 8.97 & 13.54 & 15.09 & Wet & 3 & 2 & 6 \\
\hline $3 \mathrm{rd}$ & Dec & 5.33 & 10.21 & 12.57 & Wet & 3 & 1 & 3 \\
\hline \multirow{2}{*}{\multicolumn{8}{|c|}{$\begin{array}{l}\text { Rainfall of prior period was: } \\
\text { drier than normal (sum is 6-9), normal (sum is } 10-14 \text { ), wetter than normal (sum is } 15-18 \text { ) }\end{array}$}} & 12 \\
\hline & & & & & & & & Normal \\
\hline
\end{tabular}

Table C.20: DAREM and Modified DAREM calculations for period that met wetland hydrology for plots $1 \mathrm{R}, 2 \mathrm{R}, 3 \mathrm{R}$, 4R and 4P at Greenville within the year 1979.

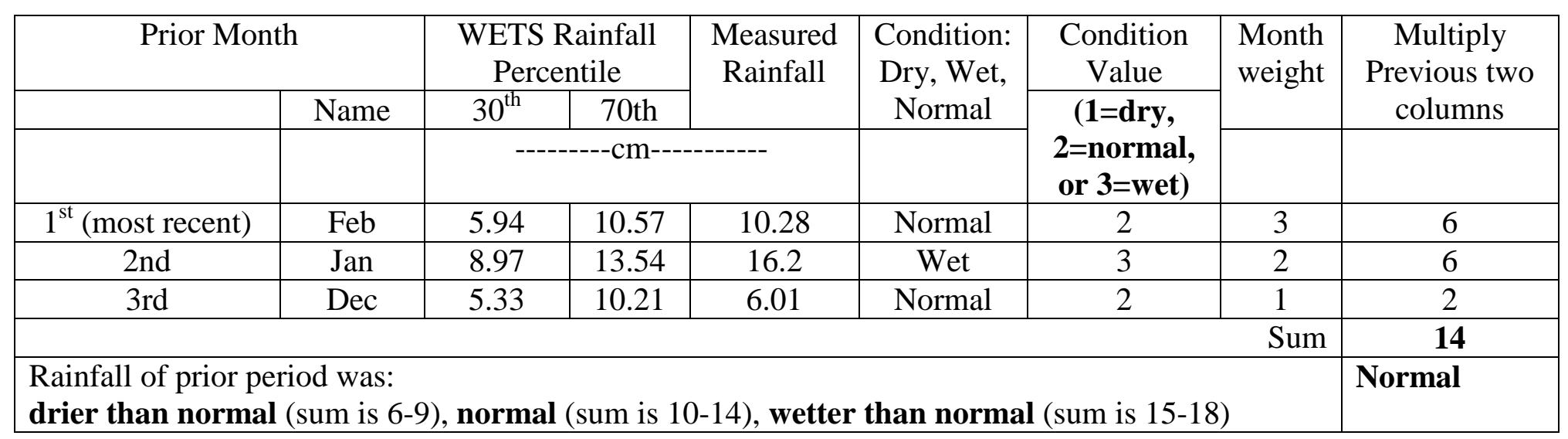


Table C.21: DAREM and Modified DAREM calculations for period that met wetland hydrology for plots $1 \mathrm{R}, 2 \mathrm{R}, 3 \mathrm{R}$, 4R and 4P at Greenville within the year 1980.

\begin{tabular}{|c|c|c|c|c|c|c|c|c|}
\hline \multicolumn{2}{|c|}{ Prior Month } & \multicolumn{2}{|c|}{$\begin{array}{l}\text { WETS Rainfall } \\
\text { Percentile }\end{array}$} & \multirow[t]{2}{*}{$\begin{array}{c}\text { Measured } \\
\text { Rainfall }\end{array}$} & \multirow{2}{*}{$\begin{array}{c}\text { Condition: } \\
\text { Dry, Wet, } \\
\text { Normal }\end{array}$} & \multirow{3}{*}{$\begin{array}{c}\text { Condition } \\
\text { Value } \\
\text { (1=dry, } \\
2=\text { normal, } \\
\text { or } 3=\text { wet })\end{array}$} & \multirow[t]{2}{*}{$\begin{array}{l}\text { Month } \\
\text { weight }\end{array}$} & \multirow{2}{*}{$\begin{array}{c}\text { Multiply } \\
\text { Previous two } \\
\text { columns }\end{array}$} \\
\hline & Name & $30^{\text {th }}$ & 70th & & & & & \\
\hline & & \multicolumn{3}{|c|}{---------cm---------- } & & & & \\
\hline $1^{\text {st }}$ (most recent) & Feb & 5.94 & 10.57 & 4.63 & Dry & 1 & 3 & 3 \\
\hline $2 \mathrm{nd}$ & Jan & 8.97 & 13.54 & 11.52 & Normal & 2 & 2 & 4 \\
\hline 3rd & Dec & 5.33 & 10.21 & 4.32 & Dry & 1 & 1 & 1 \\
\hline \multirow{2}{*}{\multicolumn{8}{|c|}{$\begin{array}{l}\text { Rainfall of prior period was: } \\
\text { drier than normal (sum is 6-9), normal (sum is } 10-14 \text { ), wetter than normal (sum is } 15-18 \text { ) }\end{array}$}} & 8 \\
\hline & & & & & & & & Dry \\
\hline
\end{tabular}

Table C.22: DAREM and Modified DAREM calculations for period that met wetland hydrology for plots $2 \mathrm{R}, 3 \mathrm{R}$, and 4P at Greenville within the year 1981 .

\begin{tabular}{|c|c|c|c|c|c|c|c|c|}
\hline \multicolumn{2}{|c|}{ Prior Month } & \multicolumn{2}{|c|}{$\begin{array}{l}\text { WETS Rainfall } \\
\text { Percentile }\end{array}$} & \multirow[t]{2}{*}{$\begin{array}{l}\text { Measured } \\
\text { Rainfall }\end{array}$} & \multirow{2}{*}{$\begin{array}{l}\text { Condition: } \\
\text { Dry, Wet, } \\
\text { Normal }\end{array}$} & \multirow{3}{*}{$\begin{array}{c}\begin{array}{c}\text { Condition } \\
\text { Value }\end{array} \\
\text { (1=dry, } \\
2=\text { normal, } \\
\text { or } 3=\text { wet) }\end{array}$} & \multirow[t]{2}{*}{$\begin{array}{l}\text { Month } \\
\text { weight }\end{array}$} & \multirow{2}{*}{$\begin{array}{c}\text { Multiply } \\
\text { Previous two } \\
\text { columns }\end{array}$} \\
\hline & Name & $30^{\text {th }}$ & 70th & & & & & \\
\hline & & \multicolumn{3}{|c|}{---------cm----------- } & & & & \\
\hline $1^{\text {st }}$ (most recent) & Feb & 5.94 & 10.57 & 6.09 & Normal & 2 & 3 & 6 \\
\hline 2nd & Jan & 8.97 & 13.54 & 2.81 & Dry & 1 & 2 & 2 \\
\hline $3 \mathrm{rd}$ & Dec & 5.33 & 10.21 & 5.41 & Normal & 2 & 1 & 2 \\
\hline \multicolumn{8}{|c|}{$\begin{array}{ll} & \text { Sum } \\
\text { Rainfall of nrior neriod was. } & 1\end{array}$} & 10 \\
\hline \multicolumn{8}{|c|}{$\begin{array}{l}\text { Rainfall of prior period was: } \\
\text { drier than normal (sum is } 6-9 \text { ), normal (sum is } 10-14 \text { ), wetter than normal (sum is } 15-18 \text { ) }\end{array}$} & Normal \\
\hline
\end{tabular}


Table C.23: DAREM and Modified DAREM calculations for period that met wetland hydrology for plots $1 \mathrm{R}, 2 \mathrm{R}, 3 \mathrm{R}$, 4R and 4P at Greenville within the year 1982.

\begin{tabular}{|c|c|c|c|c|c|c|c|c|}
\hline \multicolumn{2}{|c|}{ Prior Month } & \multicolumn{2}{|c|}{$\begin{array}{l}\text { WETS Rainfall } \\
\text { Percentile }\end{array}$} & \multirow[t]{2}{*}{$\begin{array}{l}\text { Measured } \\
\text { Rainfall }\end{array}$} & \multirow{2}{*}{$\begin{array}{c}\text { Condition: } \\
\text { Dry, Wet, } \\
\text { Normal }\end{array}$} & \multirow{3}{*}{$\begin{array}{c}\text { Condition } \\
\text { Value } \\
(\mathbf{1 = d r y ,}, \\
2=\text { normal, } \\
\text { or } 3=\text { wet })\end{array}$} & \multirow[t]{2}{*}{$\begin{array}{l}\text { Month } \\
\text { weight }\end{array}$} & \multirow{2}{*}{$\begin{array}{c}\text { Multiply } \\
\text { Previous two } \\
\text { columns } \\
\end{array}$} \\
\hline & Name & $30^{\text {th }}$ & 70th & & & & & \\
\hline & & \multicolumn{3}{|c|}{----------cm----------- } & & & & \\
\hline $1^{\mathrm{st}}$ (most recent) & Feb & 5.94 & 10.57 & 9.66 & Normal & 2 & 3 & 6 \\
\hline 2nd & Jan & 8.97 & 13.54 & 12.03 & Normal & 2 & 2 & 4 \\
\hline $3 \mathrm{rd}$ & Dec & 5.33 & 10.21 & 10.21 & Normal & 2 & 1 & 2 \\
\hline \multirow{2}{*}{\multicolumn{8}{|c|}{$\begin{array}{l}\text { Rainfall of prior period was: } \\
\text { drier than normal (sum is 6-9), normal (sum is 10-14), wetter than normal (sum is 15-18) }\end{array}$}} & 12 \\
\hline & & & & & & & & Normal \\
\hline
\end{tabular}

Table C.24: DAREM and Modified DAREM calculations for period that met wetland hydrology for plots $1 \mathrm{R}, 3 \mathrm{R}, 4 \mathrm{R}$ and $4 \mathrm{P}$ at Greenville within the year 1983.

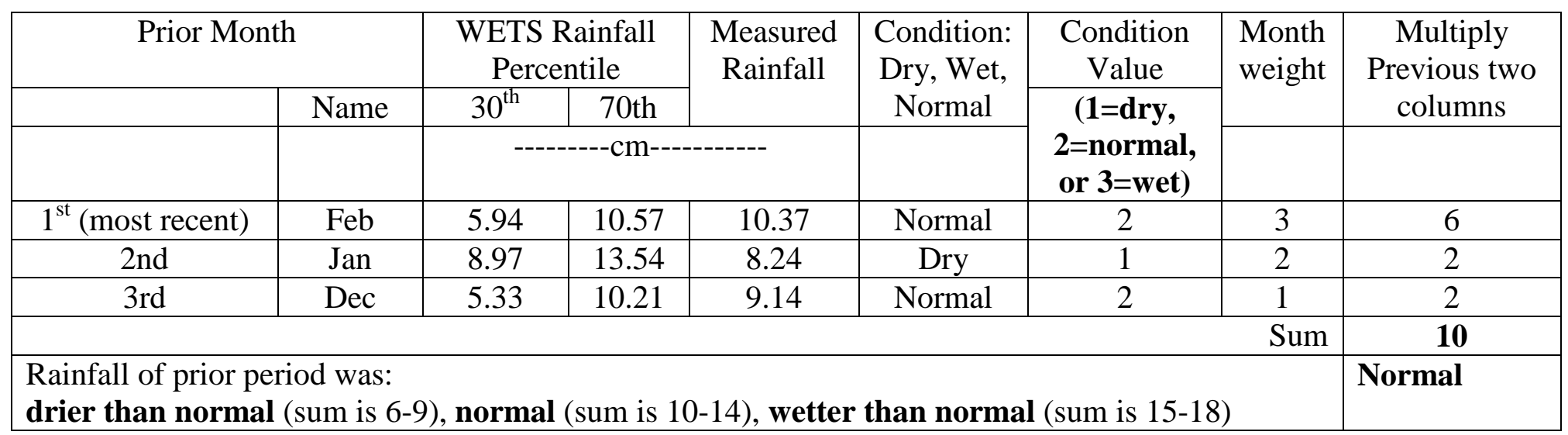


Table C.25: DAREM and Modified DAREM calculations for period that met wetland hydrology for plot 3R, 4R and 4P at Greenville within the year 1984.

\begin{tabular}{|c|c|c|c|c|c|c|c|c|}
\hline \multicolumn{2}{|c|}{ Prior Month } & \multicolumn{2}{|c|}{$\begin{array}{l}\text { WETS Rainfall } \\
\text { Percentile }\end{array}$} & \multirow[t]{2}{*}{$\begin{array}{l}\text { Measured } \\
\text { Rainfall }\end{array}$} & \multirow{2}{*}{$\begin{array}{c}\text { Condition: } \\
\text { Dry, Wet, } \\
\text { Normal }\end{array}$} & \multirow{3}{*}{$\begin{array}{c}\text { Condition } \\
\text { Value }\end{array}$} & \multirow[t]{2}{*}{$\begin{array}{l}\text { Month } \\
\text { weight }\end{array}$} & \multirow{2}{*}{$\begin{array}{c}\text { Multiply } \\
\text { Previous two } \\
\text { columns } \\
\end{array}$} \\
\hline & Name & $30^{\text {th }}$ & 70th & & & & & \\
\hline & & \multicolumn{3}{|c|}{----------cm----------- } & & & & \\
\hline $1^{\text {st }}($ most recent $)$ & July & 9.53 & 16.38 & 29.45 & Wet & 3 & 3 & 9 \\
\hline 2nd & June & 7.62 & 13.34 & 5.63 & Dry & 1 & 2 & 2 \\
\hline $3 \mathrm{rd}$ & May & 7.09 & 12.73 & 20.42 & Wet & 3 & 1 & 3 \\
\hline \multirow{2}{*}{\multicolumn{8}{|c|}{$\begin{array}{l}\text { Rainfall of prior period was: } \\
\text { drier than normal (sum is 6-9), normal (sum is 10-14), wetter than normal (sum is 15-18) }\end{array}$}} & 14 \\
\hline & & & & & & & & Normal \\
\hline
\end{tabular}

Table C.26: DAREM and Modified DAREM calculations for period that met wetland hydrology for plots $2 \mathrm{R}, 3 \mathrm{R}$, and 4P at Greenville within the year 1985.

\begin{tabular}{|c|c|c|c|c|c|c|c|c|}
\hline \multicolumn{2}{|c|}{ Prior Month } & \multicolumn{2}{|c|}{$\begin{array}{l}\text { WETS Rainfall } \\
\text { Percentile }\end{array}$} & \multirow[t]{2}{*}{$\begin{array}{l}\text { Measured } \\
\text { Rainfall }\end{array}$} & \multirow{2}{*}{$\begin{array}{l}\text { Condition: } \\
\text { Dry, Wet, } \\
\text { Normal }\end{array}$} & \multirow{3}{*}{$\begin{array}{c}\begin{array}{c}\text { Condition } \\
\text { Value }\end{array} \\
\text { (1=dry, } \\
2=\text { normal, } \\
\text { or } 3=\text { wet) }\end{array}$} & \multirow[t]{2}{*}{$\begin{array}{l}\text { Month } \\
\text { weight }\end{array}$} & \multirow{2}{*}{$\begin{array}{c}\text { Multiply } \\
\text { Previous two } \\
\text { columns }\end{array}$} \\
\hline & Name & $30^{\text {th }}$ & 70th & & & & & \\
\hline & & \multicolumn{3}{|c|}{---------cm----------- } & & & & \\
\hline $1^{\text {st }}$ (most recent) & Feb & 5.94 & 10.57 & 13.43 & Wet & 3 & 3 & 9 \\
\hline 2nd & Jan & 8.97 & 13.54 & 10.07 & Normal & 2 & 2 & 4 \\
\hline $3 \mathrm{rd}$ & Dec & 5.33 & 10.21 & 3.49 & Dry & 1 & 1 & 1 \\
\hline \multicolumn{8}{|c|}{$\begin{array}{ll} & \text { Sum } \\
\text { Rainfall of nrior neriod was. } & 1\end{array}$} & 14 \\
\hline \multicolumn{8}{|c|}{$\begin{array}{l}\text { Rainfall of prior period was: } \\
\text { drier than normal (sum is } 6-9 \text { ), normal (sum is } 10-14 \text { ), wetter than normal (sum is } 15-18 \text { ) }\end{array}$} & Normal \\
\hline
\end{tabular}


Table C.27: DAREM and Modified DAREM calculations for period that met wetland hydrology for plots $2 \mathrm{R}, 3 \mathrm{R}, 4 \mathrm{R}$ and 4P at Greenville within the year 1986.

\begin{tabular}{|c|c|c|c|c|c|c|c|c|}
\hline \multicolumn{2}{|c|}{ Prior Month } & \multicolumn{2}{|c|}{$\begin{array}{l}\text { WETS Rainfall } \\
\text { Percentile }\end{array}$} & \multirow[t]{2}{*}{$\begin{array}{l}\text { Measured } \\
\text { Rainfall }\end{array}$} & \multirow{2}{*}{$\begin{array}{l}\text { Condition: } \\
\text { Dry, Wet, } \\
\text { Normal }\end{array}$} & \multirow{3}{*}{$\begin{array}{c}\text { Condition } \\
\text { Value }\end{array}$} & \multirow[t]{2}{*}{$\begin{array}{l}\text { Month } \\
\text { weight }\end{array}$} & \multirow{2}{*}{$\begin{array}{c}\text { Multiply } \\
\text { Previous two } \\
\text { columns }\end{array}$} \\
\hline & Name & $30^{\text {th }}$ & 70th & & & & & \\
\hline & & \multicolumn{3}{|c|}{----------cm------------ } & & & & \\
\hline $1^{\text {st }}$ (most recent) & Feb & 5.94 & 10.57 & 6.22 & Normal & 2 & 3 & 6 \\
\hline 2nd & Jan & 8.97 & 13.54 & 5.30 & Dry & 1 & 2 & 2 \\
\hline $3 \mathrm{rd}$ & Dec & 5.33 & 10.21 & 4.19 & Dry & 1 & 1 & 1 \\
\hline \multirow{2}{*}{\multicolumn{8}{|c|}{$\begin{array}{l}\text { Rainfall of prior period was: } \\
\text { drier than normal (sum is 6-9), normal (sum is } 10-14 \text { ), wetter than normal (sum is } 15-18 \text { ) }\end{array}$}} & 9 \\
\hline & & & & & & & & Dry \\
\hline
\end{tabular}

Table C.28: DAREM and Modified DAREM calculations for period that met wetland hydrology for plots $1 \mathrm{R}, 2 \mathrm{R}, 3 \mathrm{R}$, 4R and 4P at Greenville within the year 1987.

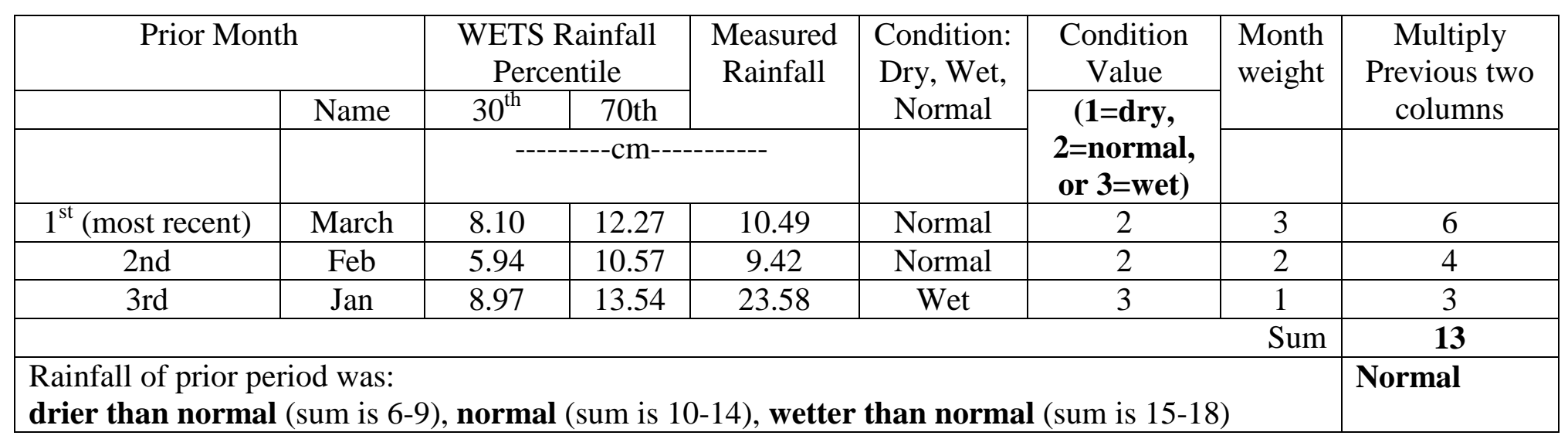


Table C.29: DAREM and Modified DAREM calculations for period that met wetland hydrology for plots $1 \mathrm{R}, 2 \mathrm{R}, 3 \mathrm{R}$, 4R and 4P at Greenville within the year 1988.

\begin{tabular}{|c|c|c|c|c|c|c|c|c|}
\hline \multicolumn{2}{|c|}{ Prior Month } & \multicolumn{2}{|c|}{$\begin{array}{l}\text { WETS Rainfall } \\
\text { Percentile }\end{array}$} & \multirow[t]{2}{*}{$\begin{array}{c}\text { Measured } \\
\text { Rainfall }\end{array}$} & \multirow{2}{*}{$\begin{array}{c}\text { Condition: } \\
\text { Dry, Wet, } \\
\text { Normal }\end{array}$} & \multirow{3}{*}{$\begin{array}{c}\text { Condition } \\
\text { Value } \\
\text { (1=dry, } \\
2=\text { normal, } \\
\text { or } 3=\text { wet })\end{array}$} & \multirow[t]{2}{*}{$\begin{array}{l}\text { Month } \\
\text { weight }\end{array}$} & \multirow{2}{*}{$\begin{array}{c}\text { Multiply } \\
\text { Previous two } \\
\text { columns }\end{array}$} \\
\hline & Name & $30^{\text {th }}$ & 70th & & & & & \\
\hline & & \multicolumn{3}{|c|}{---------cm---------- } & & & & \\
\hline $1^{\text {st }}$ (most recent) & Feb & 5.94 & 10.57 & 5.61 & Dry & 1 & 3 & 3 \\
\hline $2 \mathrm{nd}$ & Jan & 8.97 & 13.54 & 9.38 & Normal & 2 & 2 & 4 \\
\hline 3rd & Dec & 5.33 & 10.21 & 8.99 & Normal & 2 & 1 & 2 \\
\hline \multirow{2}{*}{\multicolumn{8}{|c|}{$\begin{array}{l}\text { Rainfall of prior period was: } \\
\text { drier than normal (sum is 6-9), normal (sum is } 10-14 \text { ), wetter than normal (sum is } 15-18 \text { ) }\end{array}$}} & 9 \\
\hline & & & & & & & & Dry \\
\hline
\end{tabular}

Table C.30: DAREM and Modified DAREM calculations for period that met wetland hydrology for plots $1 \mathrm{R}, 2 \mathrm{R}, 3 \mathrm{R}$, 4R and 4P at Greenville within the year 1989.

\begin{tabular}{|c|c|c|c|c|c|c|c|c|}
\hline \multicolumn{2}{|c|}{ Prior Month } & \multicolumn{2}{|c|}{$\begin{array}{l}\text { WETS Rainfall } \\
\text { Percentile }\end{array}$} & \multirow[t]{2}{*}{$\begin{array}{l}\text { Measured } \\
\text { Rainfall }\end{array}$} & \multirow{2}{*}{$\begin{array}{l}\text { Condition: } \\
\text { Dry, Wet, } \\
\text { Normal }\end{array}$} & \multirow{3}{*}{$\begin{array}{c}\begin{array}{c}\text { Condition } \\
\text { Value }\end{array} \\
\text { (1=dry, } \\
2=\text { normal, } \\
\text { or } 3=\text { wet) }\end{array}$} & \multirow[t]{2}{*}{$\begin{array}{l}\text { Month } \\
\text { weight }\end{array}$} & \multirow{2}{*}{$\begin{array}{c}\text { Multiply } \\
\text { Previous two } \\
\text { columns }\end{array}$} \\
\hline & Name & $30^{\text {th }}$ & 70th & & & & & \\
\hline & & \multicolumn{3}{|c|}{---------cm----------- } & & & & \\
\hline $1^{\text {st }}$ (most recent) & Feb & 5.94 & 10.57 & 14.71 & Wet & 3 & 3 & 9 \\
\hline 2nd & Jan & 8.97 & 13.54 & 6.22 & Dry & 1 & 2 & 2 \\
\hline $3 \mathrm{rd}$ & Dec & 5.33 & 10.21 & 1.12 & Dry & 1 & 1 & 1 \\
\hline \multicolumn{8}{|c|}{$\begin{array}{ll} & \text { Sum } \\
\text { Rainfall of nrior neriod was. } & 1\end{array}$} & 12 \\
\hline \multicolumn{8}{|c|}{$\begin{array}{l}\text { Rainfall of prior period was: } \\
\text { drier than normal (sum is } 6-9 \text { ), normal (sum is } 10-14 \text { ), wetter than normal (sum is } 15-18 \text { ) }\end{array}$} & Normal \\
\hline
\end{tabular}


Table C.31: DAREM and Modified DAREM calculations for period that met wetland hydrology for plots $1 \mathrm{R}, 2 \mathrm{R}, 3 \mathrm{R}$, 4R and 4P at Greenville within the year 1990.

\begin{tabular}{|c|c|c|c|c|c|c|c|c|}
\hline \multicolumn{2}{|c|}{ Prior Month } & \multicolumn{2}{|c|}{$\begin{array}{l}\text { WETS Rainfall } \\
\text { Percentile }\end{array}$} & \multirow[t]{2}{*}{$\begin{array}{c}\text { Measured } \\
\text { Rainfall }\end{array}$} & \multirow{2}{*}{$\begin{array}{c}\text { Condition: } \\
\text { Dry, Wet, } \\
\text { Normal }\end{array}$} & \multirow{3}{*}{$\begin{array}{c}\text { Condition } \\
\text { Value } \\
\text { (1=dry, } \\
2=\text { normal, } \\
\text { or } 3=\text { wet })\end{array}$} & \multirow[t]{2}{*}{$\begin{array}{l}\text { Month } \\
\text { weight }\end{array}$} & \multirow{2}{*}{$\begin{array}{c}\text { Multiply } \\
\text { Previous two } \\
\text { columns } \\
\end{array}$} \\
\hline & Name & $30^{\text {th }}$ & 70th & & & & & \\
\hline & & \multicolumn{3}{|c|}{---------cm---------- } & & & & \\
\hline $1^{\text {st }}$ (most recent) & Feb & 5.94 & 10.57 & 9.10 & Normal & 2 & 3 & 6 \\
\hline $2 \mathrm{nd}$ & Jan & 8.97 & 13.54 & 6.92 & Dry & 1 & 2 & 2 \\
\hline 3rd & Dec & 5.33 & 10.21 & 12.76 & Wet & 3 & 1 & 3 \\
\hline \multirow{2}{*}{\multicolumn{8}{|c|}{$\begin{array}{l}\text { Rainfall of prior period was: } \\
\text { drier than normal (sum is 6-9), normal (sum is } 10-14 \text { ), wetter than normal (sum is } 15-18 \text { ) }\end{array}$}} & 11 \\
\hline & & & & & & & & Normal \\
\hline
\end{tabular}

Table C.32: DAREM and Modified DAREM calculations for period that met wetland hydrology for plots $2 \mathrm{R}, 3 \mathrm{R}$, 4R and 4P at Greenville within the year 1991.

\begin{tabular}{|c|c|c|c|c|c|c|c|c|}
\hline \multicolumn{2}{|c|}{ Prior Month } & \multicolumn{2}{|c|}{$\begin{array}{l}\text { WETS Rainfall } \\
\text { Percentile }\end{array}$} & \multirow[t]{2}{*}{$\begin{array}{l}\text { Measured } \\
\text { Rainfall }\end{array}$} & \multirow{2}{*}{$\begin{array}{l}\text { Condition: } \\
\text { Dry, Wet, } \\
\text { Normal }\end{array}$} & \multirow{3}{*}{ 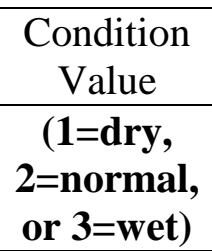 } & \multirow[t]{3}{*}{$\begin{array}{l}\text { Month } \\
\text { weight }\end{array}$} & \multirow{2}{*}{$\begin{array}{c}\text { Multiply } \\
\text { Previous two } \\
\text { columns } \\
\end{array}$} \\
\hline & Name & $30^{\text {th }}$ & 70th & & & & & \\
\hline & & \multicolumn{3}{|c|}{---------cm----------- } & & & & \\
\hline $1^{\mathrm{st}}$ (most recent) & Feb & 5.94 & 10.57 & 2.12 & Dry & 1 & 3 & 3 \\
\hline $2 \mathrm{nd}$ & Jan & 8.97 & 13.54 & 11.53 & Normal & 2 & 2 & 4 \\
\hline $3 \mathrm{rd}$ & Dec & 5.33 & 10.21 & 5.22 & Dry & 1 & 1 & 1 \\
\hline \multirow{2}{*}{\multicolumn{8}{|c|}{$\begin{array}{ll} & \text { Sum } \\
\text { Rainfall of prior period was: } & \end{array}$}} & 8 \\
\hline & & & & & & & & Dry \\
\hline
\end{tabular}


Table C.35: DAREM and Modified DAREM calculations for period that met wetland hydrology for plots $1 \mathrm{R}, 2 \mathrm{R}, 3 \mathrm{R}$, 4R and 4P at Greenville within the year 1994.

\begin{tabular}{|c|c|c|c|c|c|c|c|c|}
\hline \multicolumn{2}{|c|}{ Prior Month } & \multicolumn{2}{|c|}{$\begin{array}{l}\text { WETS Rainfall } \\
\text { Percentile }\end{array}$} & \multirow[t]{2}{*}{$\begin{array}{l}\text { Measured } \\
\text { Rainfall }\end{array}$} & \multirow{2}{*}{$\begin{array}{c}\text { Condition: } \\
\text { Dry, Wet, } \\
\text { Normal }\end{array}$} & \multirow{3}{*}{$\begin{array}{c}\text { Condition } \\
\text { Value } \\
(\mathbf{1 = d r y ,}, \\
2=\text { normal, } \\
\text { or } 3=\text { wet })\end{array}$} & \multirow[t]{2}{*}{$\begin{array}{l}\text { Month } \\
\text { weight }\end{array}$} & \multirow{2}{*}{$\begin{array}{c}\text { Multiply } \\
\text { Previous two } \\
\text { columns } \\
\end{array}$} \\
\hline & Name & $30^{\text {th }}$ & 70th & & & & & \\
\hline & & \multicolumn{3}{|c|}{----------cm----------- } & & & & \\
\hline $1^{\mathrm{st}}$ (most recent) & Feb & 5.94 & 10.57 & 8.12 & Normal & 2 & 3 & 6 \\
\hline 2nd & Jan & 8.97 & 13.54 & 11.59 & Normal & 2 & 2 & 4 \\
\hline $3 \mathrm{rd}$ & Dec & 5.33 & 10.21 & 8.09 & Normal & 2 & 1 & 2 \\
\hline \multirow{2}{*}{\multicolumn{8}{|c|}{$\begin{array}{l}\text { Rainfall of prior period was: } \\
\text { drier than normal (sum is 6-9), normal (sum is 10-14), wetter than normal (sum is 15-18) }\end{array}$}} & 12 \\
\hline & & & & & & & & Normal \\
\hline
\end{tabular}

Table C.36: DAREM and Modified DAREM calculations for period that met wetland hydrology for plots $2 \mathrm{R}, 3 \mathrm{R}, 4 \mathrm{R}$ and 4P at Greenville within the year 1995.

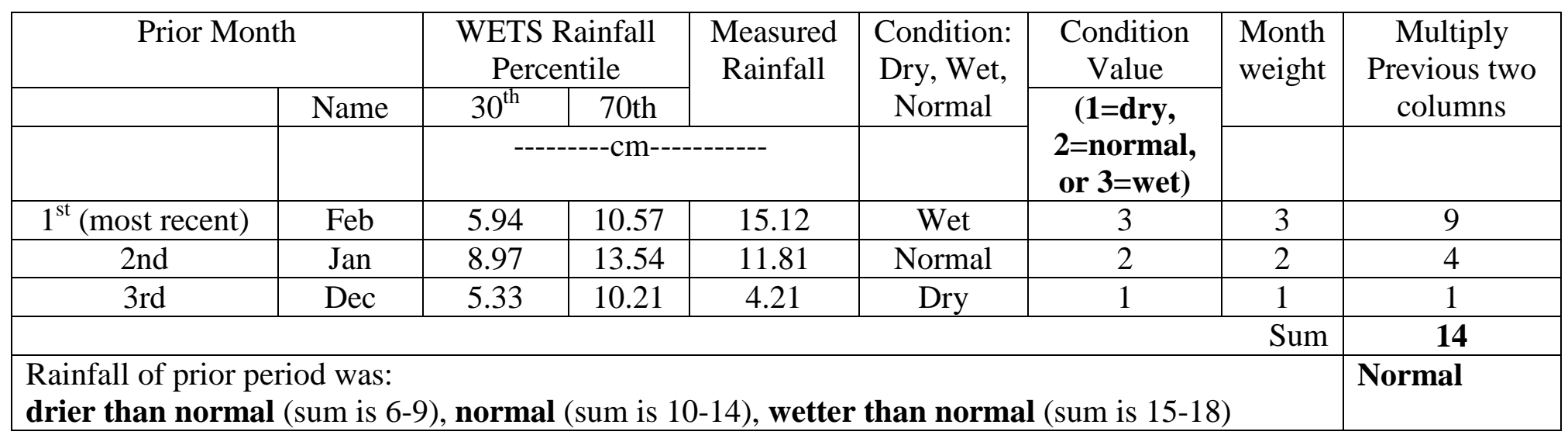


Table C.37: DAREM and Modified DAREM calculations for period that met wetland hydrology for plots $1 \mathrm{R}, 2 \mathrm{R}, 3 \mathrm{R}$, 4R and 4P at Greenville within the year 1996.

\begin{tabular}{|c|c|c|c|c|c|c|c|c|}
\hline \multicolumn{2}{|c|}{ Prior Month } & \multicolumn{2}{|c|}{$\begin{array}{l}\text { WETS Rainfall } \\
\text { Percentile }\end{array}$} & \multirow[t]{2}{*}{$\begin{array}{l}\text { Measured } \\
\text { Rainfall }\end{array}$} & \multirow{2}{*}{$\begin{array}{c}\text { Condition: } \\
\text { Dry, Wet, } \\
\text { Normal }\end{array}$} & \multirow{3}{*}{$\begin{array}{c}\text { Condition } \\
\text { Value } \\
(\mathbf{1 = d r y ,}, \\
2=\text { normal, } \\
\text { or } 3=\text { wet })\end{array}$} & \multirow[t]{2}{*}{$\begin{array}{l}\text { Month } \\
\text { weight }\end{array}$} & \multirow{2}{*}{$\begin{array}{c}\text { Multiply } \\
\text { Previous two } \\
\text { columns } \\
\end{array}$} \\
\hline & Name & $30^{\text {th }}$ & 70th & & & & & \\
\hline & & \multicolumn{3}{|c|}{----------cm----------- } & & & & \\
\hline $1^{\mathrm{st}}$ (most recent) & Feb & 5.94 & 10.57 & 6.71 & Normal & 2 & 3 & 6 \\
\hline 2nd & Jan & 8.97 & 13.54 & 11.93 & Normal & 2 & 2 & 4 \\
\hline $3 \mathrm{rd}$ & Dec & 5.33 & 10.21 & 4.62 & Dry & 1 & 1 & 1 \\
\hline \multirow{2}{*}{\multicolumn{8}{|c|}{$\begin{array}{l}\text { Rainfall of prior period was: } \\
\text { drier than normal (sum is 6-9), normal (sum is 10-14), wetter than normal (sum is 15-18) }\end{array}$}} & 11 \\
\hline & & & & & & & & Normal \\
\hline
\end{tabular}

Table C.38: DAREM and Modified DAREM calculations for period that met wetland hydrology for plots $1 \mathrm{R}, 2 \mathrm{R}, 3 \mathrm{R}$, 4R and 4P at Greenville within the year 1997.

\begin{tabular}{|c|c|c|c|c|c|c|c|c|}
\hline \multicolumn{2}{|c|}{ Prior Month } & \multicolumn{2}{|c|}{$\begin{array}{l}\text { WETS Rainfall } \\
\text { Percentile }\end{array}$} & \multirow[t]{2}{*}{$\begin{array}{l}\text { Measured } \\
\text { Rainfall }\end{array}$} & \multirow{2}{*}{$\begin{array}{l}\text { Condition: } \\
\text { Dry, Wet, } \\
\text { Normal }\end{array}$} & \multirow{3}{*}{$\begin{array}{c}\text { Condition } \\
\text { Value } \\
(\mathbf{1 = d r y ,}, \\
\begin{array}{c}2=\text { normal, } \\
\text { or } 3=\text { wet })\end{array}\end{array}$} & \multirow[t]{2}{*}{$\begin{array}{l}\text { Month } \\
\text { weight }\end{array}$} & \multirow{2}{*}{$\begin{array}{l}\text { Multiply } \\
\text { Previous two } \\
\text { columns }\end{array}$} \\
\hline & Name & $30^{\text {th }}$ & 70th & & & & & \\
\hline & & \multicolumn{3}{|c|}{---------cm----------- } & & & & \\
\hline $1^{\text {st }}($ most recent $)$ & Feb & 5.94 & 10.57 & 7.99 & Normal & 2 & 3 & 6 \\
\hline 2nd & Jan & 8.97 & 13.54 & 8.01 & Dry & 1 & 2 & 2 \\
\hline $3 \mathrm{rd}$ & Dec & 5.33 & 10.21 & 9.51 & Normal & 2 & 1 & 2 \\
\hline \multirow{2}{*}{\multicolumn{8}{|c|}{$\begin{array}{ll}\text { Rainfall of prior period was: } & \text { Sum } \\
\text { drier than normal (sum is 6-9), normal (sum is 10-14), wetter than normal (sum is 15-18) }\end{array}$}} & 10 \\
\hline & & & & & & & & Normal \\
\hline
\end{tabular}


Table C.39: DAREM and Modified DAREM calculations for period that met wetland hydrology for plots $3 \mathrm{~N}, 4 \mathrm{~N}$, $5 \mathrm{~N}, 3 \mathrm{~S}, 4 \mathrm{~S}$ and $5 \mathrm{~S}$ at Bertie within the year 1950.

\begin{tabular}{|c|c|c|c|c|c|c|c|c|}
\hline \multicolumn{2}{|c|}{ Prior Month } & \multicolumn{2}{|c|}{$\begin{array}{l}\text { WETS Rainfall } \\
\text { Percentile }\end{array}$} & \multirow[t]{2}{*}{$\begin{array}{c}\text { Measured } \\
\text { Rainfall }\end{array}$} & \multirow{2}{*}{$\begin{array}{c}\text { Condition: } \\
\text { Dry, Wet, } \\
\text { Normal }\end{array}$} & \multirow{3}{*}{$\begin{array}{c}\text { Condition } \\
\text { Value } \\
\text { (1=dry, } \\
2=\text { normal, } \\
\text { or } 3=\text { wet })\end{array}$} & \multirow[t]{2}{*}{$\begin{array}{l}\text { Month } \\
\text { weight }\end{array}$} & \multirow{2}{*}{$\begin{array}{c}\text { Multiply } \\
\text { Previous two } \\
\text { columns } \\
\end{array}$} \\
\hline & Name & $30^{\text {th }}$ & 70th & & & & & \\
\hline & & \multicolumn{3}{|c|}{---------cm---------- } & & & & \\
\hline $1^{\text {st }}$ (most recent) & Aug & 6.96 & 15.34 & 4.19 & Dry & 1 & 3 & 3 \\
\hline 2nd & July & 8.61 & 16.74 & 32.14 & Wet & 3 & 2 & 6 \\
\hline 3rd & June & 7.06 & 11.51 & 26.74 & Wet & 3 & 1 & 3 \\
\hline \multirow{2}{*}{\multicolumn{8}{|c|}{$\begin{array}{l}\text { Rainfall of prior period was: } \\
\text { drier than normal (sum is 6-9), normal (sum is } 10-14 \text { ), wetter than normal (sum is } 15-18 \text { ) }\end{array}$}} & 12 \\
\hline & & & & & & & & Normal \\
\hline
\end{tabular}

Table C.40: DAREM and Modified DAREM calculations for period that met wetland hydrology for plots $3 \mathrm{~N}, 4 \mathrm{~N}, 5 \mathrm{~N}$, 3S, 4S and 5S at Bertie within the year 1951.

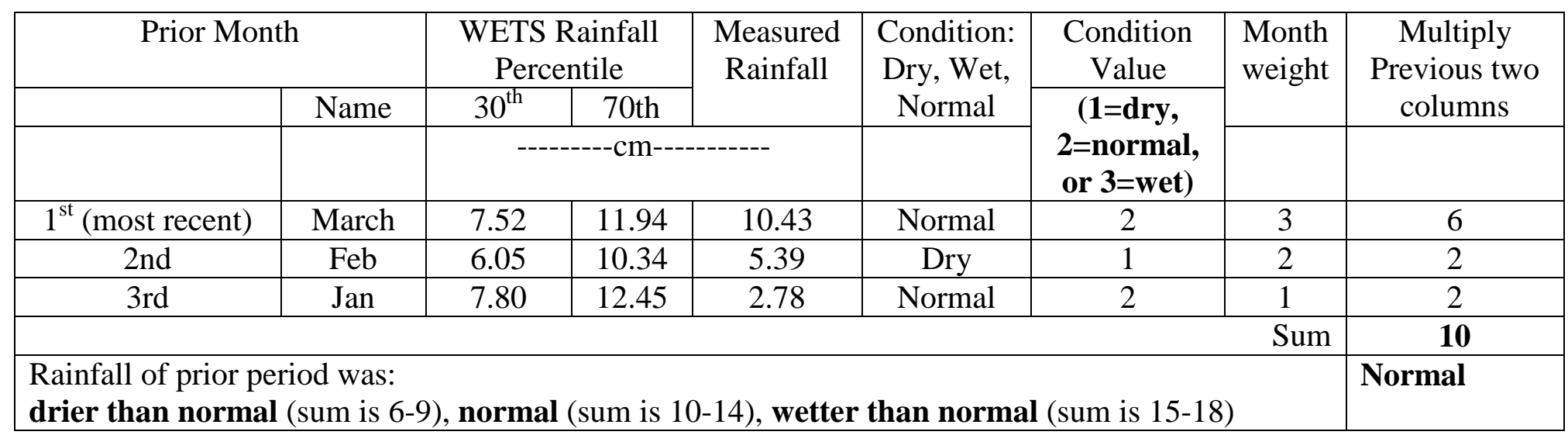


Table C.41: DAREM and Modified DAREM calculations for period that met wetland hydrology for plots $3 \mathrm{~N}, 4 \mathrm{~N}, 5 \mathrm{~N}$, $4 \mathrm{~S}$ and $5 \mathrm{~S}$ at Bertie within the year 1952.

\begin{tabular}{|c|c|c|c|c|c|c|c|c|}
\hline \multicolumn{2}{|c|}{ Prior Month } & \multicolumn{2}{|c|}{$\begin{array}{l}\text { WETS Rainfall } \\
\text { Percentile }\end{array}$} & \multirow[t]{2}{*}{$\begin{array}{l}\text { Measured } \\
\text { Rainfall }\end{array}$} & \multirow{2}{*}{$\begin{array}{c}\text { Condition: } \\
\text { Dry, Wet, } \\
\text { Normal }\end{array}$} & \multirow{3}{*}{$\begin{array}{c}\text { Condition } \\
\text { Value } \\
(\mathbf{1 = d r y ,}, \\
2=\text { normal, } \\
\text { or } 3=\text { wet })\end{array}$} & \multirow[t]{2}{*}{$\begin{array}{l}\text { Month } \\
\text { weight }\end{array}$} & \multirow{2}{*}{$\begin{array}{c}\text { Multiply } \\
\text { Previous two } \\
\text { columns } \\
\end{array}$} \\
\hline & Name & $30^{\text {th }}$ & 70th & & & & & \\
\hline & & \multicolumn{3}{|c|}{----------cm----------- } & & & & \\
\hline $1^{\mathrm{st}}$ (most recent) & March & 7.52 & 11.94 & 11.28 & Normal & 2 & 3 & 6 \\
\hline 2nd & Feb & 6.05 & 10.34 & 14.28 & Wet & 3 & 2 & 6 \\
\hline $3 \mathrm{rd}$ & Jan & 7.80 & 12.45 & 5.68 & Dry & 1 & 1 & 1 \\
\hline \multirow{2}{*}{\multicolumn{8}{|c|}{$\begin{array}{l}\text { Rainfall of prior period was: } \\
\text { drier than normal (sum is 6-9), normal (sum is 10-14), wetter than normal (sum is 15-18) }\end{array}$}} & 13 \\
\hline & & & & & & & & Normal \\
\hline
\end{tabular}

Table C.42: DAREM and Modified DAREM calculations for period that met wetland hydrology for plots 4N, 3S, 4S and at Bertie within the year 1953.

\begin{tabular}{|c|c|c|c|c|c|c|c|c|}
\hline \multicolumn{2}{|c|}{ Prior Month } & \multicolumn{2}{|c|}{$\begin{array}{l}\text { WETS Rainfall } \\
\text { Percentile }\end{array}$} & \multirow[t]{2}{*}{$\begin{array}{l}\text { Measured } \\
\text { Rainfall }\end{array}$} & \multirow{2}{*}{$\begin{array}{l}\text { Condition: } \\
\text { Dry, Wet, } \\
\text { Normal }\end{array}$} & \multirow{3}{*}{$\begin{array}{c}\text { Condition } \\
\text { Value } \\
(\mathbf{1 = d r y ,}, \\
\begin{array}{c}2=\text { normal, } \\
\text { or } 3=\text { wet })\end{array}\end{array}$} & \multirow[t]{3}{*}{$\begin{array}{l}\text { Month } \\
\text { weight }\end{array}$} & \multirow{2}{*}{$\begin{array}{c}\text { Multiply } \\
\text { Previous two } \\
\text { columns } \\
\end{array}$} \\
\hline & Name & $30^{\text {th }}$ & 70th & & & & & \\
\hline & & \multicolumn{3}{|c|}{----------cm------------ } & & & & \\
\hline $1^{\mathrm{st}}$ (most recent) & July & 8.61 & 16.74 & 6.25 & Dry & 1 & 3 & 3 \\
\hline 2 nd & June & 7.06 & 11.51 & 13.60 & Wet & 3 & 2 & 6 \\
\hline $3 \mathrm{rd}$ & May & 6.43 & 12.65 & 5.33 & Dry & 1 & 1 & 1 \\
\hline \multirow{2}{*}{\multicolumn{8}{|c|}{$\begin{array}{l}\text { Rainfall of prior period was: } \\
\text { drier than normal (sum is } 6-9) \text {, normal (sum is } 10-14) \text {, wetter than normal (sum is } 15-18 \text { ) }\end{array}$}} & 10 \\
\hline & & & & & & & & Normal \\
\hline
\end{tabular}


Table C.43: DAREM and Modified DAREM calculations for period that met wetland hydrology for plots $3 \mathrm{~N}, 4 \mathrm{~N}, 5 \mathrm{~N}$, $3 \mathrm{~S}, 4 \mathrm{~S}$ and $5 \mathrm{~S}$ at Bertie within the year 1954.

\begin{tabular}{|c|c|c|c|c|c|c|c|c|}
\hline \multicolumn{2}{|c|}{ Prior Month } & \multicolumn{2}{|c|}{$\begin{array}{l}\text { WETS Rainfall } \\
\text { Percentile }\end{array}$} & \multirow[t]{2}{*}{$\begin{array}{c}\text { Measured } \\
\text { Rainfall }\end{array}$} & \multirow{2}{*}{$\begin{array}{c}\text { Condition: } \\
\text { Dry, Wet, } \\
\text { Normal } \\
\end{array}$} & \multirow{3}{*}{$\begin{array}{c}\text { Condition } \\
\text { Value } \\
\text { (1=dry, } \\
2=\text { normal, } \\
\text { or } 3=\text { wet })\end{array}$} & \multirow[t]{2}{*}{$\begin{array}{l}\text { Month } \\
\text { weight }\end{array}$} & \multirow{2}{*}{$\begin{array}{c}\text { Multiply } \\
\text { Previous two } \\
\text { columns } \\
\end{array}$} \\
\hline & Name & $30^{\text {th }}$ & 70th & & & & & \\
\hline & & \multicolumn{3}{|c|}{---------cm---------- } & & & & \\
\hline $1^{\text {st }}$ (most recent) & March & 7.52 & 11.94 & 13.52 & Wet & 3 & 3 & 9 \\
\hline $2 \mathrm{nd}$ & Feb & 6.05 & 10.34 & 3.52 & Dry & 1 & 2 & 2 \\
\hline 3rd & Jan & 7.80 & 12.45 & 13.00 & Wet & 3 & 1 & 3 \\
\hline \multirow{2}{*}{\multicolumn{8}{|c|}{$\begin{array}{l}\text { Rainfall of prior period was: } \\
\text { drier than normal (sum is 6-9), normal (sum is } 10-14 \text { ), wetter than normal (sum is } 15-18 \text { ) }\end{array}$}} & 14 \\
\hline & & & & & & & & Normal \\
\hline
\end{tabular}

Table C.44: DAREM and Modified DAREM calculations for period that met wetland hydrology for plots $3 \mathrm{~N}$, $4 \mathrm{~N}$, and $5 \mathrm{~N}$ at Bertie within the year 1955 .

\begin{tabular}{|c|c|c|c|c|c|c|c|c|}
\hline \multicolumn{2}{|c|}{ Prior Month } & \multicolumn{2}{|c|}{$\begin{array}{l}\text { WETS Rainfall } \\
\text { Percentile }\end{array}$} & \multirow[t]{2}{*}{$\begin{array}{l}\text { Measured } \\
\text { Rainfall }\end{array}$} & \multirow{2}{*}{$\begin{array}{l}\text { Condition: } \\
\text { Dry, Wet, } \\
\text { Normal }\end{array}$} & \multirow{3}{*}{$\begin{array}{c}\text { Condition } \\
\text { Value } \\
(1=\text { dry, } \\
2=\text { normal, } \\
\text { or } 3=\text { wet })\end{array}$} & \multirow[t]{3}{*}{$\begin{array}{l}\text { Month } \\
\text { weight }\end{array}$} & \multirow{2}{*}{$\begin{array}{c}\text { Multiply } \\
\text { Previous two } \\
\text { columns } \\
\end{array}$} \\
\hline & Name & $30^{\text {th }}$ & 70th & & & & & \\
\hline & & \multicolumn{3}{|c|}{----------cm------------ } & & & & \\
\hline $1^{\mathrm{st}}$ (most recent) & March & 7.52 & 11.94 & 8.91 & Normal & 2 & 3 & 6 \\
\hline 2 nd & Feb & 6.05 & 10.34 & 5.90 & Dry & 1 & 2 & 2 \\
\hline $3 \mathrm{rd}$ & Jan & 7.80 & 12.45 & 7.69 & Dry & 1 & 1 & 1 \\
\hline & & & & & & & Sum & 9 \\
\hline $\begin{array}{l}\text { Rainfall of prior } p \\
\text { drier than norma }\end{array}$ & od was: & +2 & . & +2 & 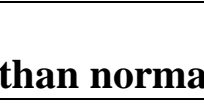 & 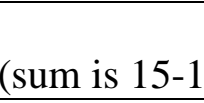 & +2 & Dry \\
\hline
\end{tabular}


Table C.45: DAREM and Modified DAREM calculations for period that met wetland hydrology for plots $3 \mathrm{~N}, 4 \mathrm{~N}, 5 \mathrm{~N}$, 3S, $4 \mathrm{~S}$ and $5 \mathrm{~S}$ at Bertie within the year 1956.

\begin{tabular}{|c|c|c|c|c|c|c|c|c|}
\hline \multicolumn{2}{|c|}{ Prior Month } & \multicolumn{2}{|c|}{$\begin{array}{l}\text { WETS Rainfall } \\
\text { Percentile }\end{array}$} & \multirow[t]{2}{*}{$\begin{array}{c}\text { Measured } \\
\text { Rainfall }\end{array}$} & \multirow{2}{*}{$\begin{array}{l}\text { Condition: } \\
\text { Dry, Wet, } \\
\text { Normal }\end{array}$} & \multirow{3}{*}{$\begin{array}{c}\text { Condition } \\
\text { Value } \\
\text { (1=dry, } \\
2=\text { normal, } \\
\text { or } 3=\text { wet) }\end{array}$} & \multirow[t]{2}{*}{$\begin{array}{l}\text { Month } \\
\text { weight }\end{array}$} & \multirow{2}{*}{$\begin{array}{l}\text { Multiply } \\
\text { Previous two } \\
\text { columns }\end{array}$} \\
\hline & Name & $30^{\text {th }}$ & 70th & & & & & \\
\hline & & \multicolumn{3}{|c|}{---------cm----------- } & & & & \\
\hline $1^{\text {st }}$ (most recent) & March & 7.52 & 11.94 & 8.15 & Normal & 2 & 3 & 6 \\
\hline 2nd & Feb & 6.05 & 10.34 & 12.39 & Wet & 3 & 2 & 6 \\
\hline $3 \mathrm{rd}$ & Jan & 7.80 & 12.45 & 8.09 & Normal & 2 & 1 & 2 \\
\hline \multirow{2}{*}{\multicolumn{8}{|c|}{$\begin{array}{ll} & \text { Sum } \\
\text { Rainfall of prior period was: } & \\
\text { drier than normal (sum is 6-9), normal (sum is } 10-14), \text { wetter than normal (sum is 15-18) }\end{array}$}} & 14 \\
\hline & & & & & & & & Normal \\
\hline
\end{tabular}

Table C.46: DAREM and Modified DAREM calculations for period that met wetland hydrology for plots $3 \mathrm{~N}, 4 \mathrm{~N}, 5 \mathrm{~N}$, 3S, 4S and 5S at Bertie within the year 1958.

\begin{tabular}{|c|c|c|c|c|c|c|c|c|}
\hline \multicolumn{2}{|c|}{ Prior Month } & \multicolumn{2}{|c|}{$\begin{array}{l}\text { WETS Rainfall } \\
\text { Percentile }\end{array}$} & \multirow[t]{2}{*}{$\begin{array}{l}\text { Measured } \\
\text { Rainfall }\end{array}$} & \multirow{2}{*}{$\begin{array}{l}\text { Condition: } \\
\text { Dry, Wet, } \\
\text { Normal }\end{array}$} & \multirow{3}{*}{$\begin{array}{c}\begin{array}{c}\text { Condition } \\
\text { Value }\end{array} \\
\text { (1=dry, } \\
2=\text { normal, } \\
\text { or } 3=\text { wet) }\end{array}$} & \multirow[t]{2}{*}{$\begin{array}{l}\text { Month } \\
\text { weight }\end{array}$} & \multirow{2}{*}{$\begin{array}{c}\text { Multiply } \\
\text { Previous two } \\
\text { columns }\end{array}$} \\
\hline & Name & $30^{\text {th }}$ & 70th & & & & & \\
\hline & & \multicolumn{3}{|c|}{---------cm----------- } & & & & \\
\hline $1^{\text {st }}$ (most recent) & March & 7.52 & 11.94 & 11.30 & Normal & 2 & 3 & 6 \\
\hline 2nd & Feb & 6.05 & 10.34 & 10.06 & Normal & 2 & 2 & 4 \\
\hline $3 \mathrm{rd}$ & Jan & 7.80 & 12.45 & 13.05 & Wet & 3 & 1 & 3 \\
\hline \multicolumn{8}{|c|}{$\begin{array}{ll} & \text { Sum } \\
\text { Rainfall of nrior neriod was. } & 1\end{array}$} & 13 \\
\hline \multicolumn{8}{|c|}{$\begin{array}{l}\text { Rainfall of prior period was: } \\
\text { drier than normal (sum is } 6-9 \text { ), normal (sum is } 10-14 \text { ), wetter than normal (sum is } 15-18 \text { ) }\end{array}$} & Normal \\
\hline
\end{tabular}


Table C.47: DAREM and Modified DAREM calculations for period that met wetland hydrology for plots $3 \mathrm{~N}, 4 \mathrm{~N}, 5 \mathrm{~N}$, 3S, 4S and 5S at Bertie within the year 1959.

\begin{tabular}{|c|c|c|c|c|c|c|c|c|}
\hline \multicolumn{2}{|c|}{ Prior Month } & \multicolumn{2}{|c|}{$\begin{array}{l}\text { WETS Rainfall } \\
\text { Percentile }\end{array}$} & \multirow[t]{2}{*}{$\begin{array}{l}\text { Measured } \\
\text { Rainfall }\end{array}$} & \multirow{2}{*}{$\begin{array}{l}\text { Condition: } \\
\text { Dry, Wet, } \\
\text { Normal }\end{array}$} & \multirow{3}{*}{$\begin{array}{c}\text { Condition } \\
\text { Value }\end{array}$} & \multirow[t]{2}{*}{$\begin{array}{l}\text { Month } \\
\text { weight }\end{array}$} & \multirow{2}{*}{$\begin{array}{c}\text { Multiply } \\
\text { Previous two } \\
\text { columns }\end{array}$} \\
\hline & Name & $30^{\text {th }}$ & 70th & & & & & \\
\hline & & \multicolumn{3}{|c|}{---------cm----------- } & & & & \\
\hline $1^{\text {st }}$ (most recent) & March & 7.52 & 11.94 & 13.07 & Wet & 3 & 3 & 9 \\
\hline 2nd & Feb & 6.05 & 10.34 & 9.53 & Normal & 2 & 2 & 4 \\
\hline $3 \mathrm{rd}$ & Jan & 7.80 & 12.45 & 3.67 & Dry & 1 & 1 & 1 \\
\hline \multirow{2}{*}{\multicolumn{8}{|c|}{$\begin{array}{l}\text { Rainfall of prior period was: } \\
\text { drier than normal (sum is 6-9), normal (sum is 10-14), wetter than normal (sum is 15-18) }\end{array}$}} & 14 \\
\hline & & & & & & & & Normal \\
\hline
\end{tabular}

Table C.48: DAREM and Modified DAREM calculations for period that met wetland hydrology for plots $3 \mathrm{~N}, 4 \mathrm{~N}, 5 \mathrm{~N}$, 3S, 4S and 5S at Bertie within the year 1960.

\begin{tabular}{|c|c|c|c|c|c|c|c|c|}
\hline \multicolumn{2}{|c|}{ Prior Month } & \multicolumn{2}{|c|}{$\begin{array}{l}\text { WETS Rainfall } \\
\text { Percentile }\end{array}$} & \multirow[t]{2}{*}{$\begin{array}{l}\text { Measured } \\
\text { Rainfall }\end{array}$} & \multirow{2}{*}{$\begin{array}{l}\text { Condition: } \\
\text { Dry, Wet, } \\
\text { Normal }\end{array}$} & \multirow{3}{*}{$\begin{array}{c}\begin{array}{c}\text { Condition } \\
\text { Value }\end{array} \\
\text { (1=dry, } \\
2=\text { normal, } \\
\text { or } 3=\text { wet) }\end{array}$} & \multirow[t]{2}{*}{$\begin{array}{l}\text { Month } \\
\text { weight }\end{array}$} & \multirow{2}{*}{$\begin{array}{c}\text { Multiply } \\
\text { Previous two } \\
\text { columns }\end{array}$} \\
\hline & Name & $30^{\text {th }}$ & 70th & & & & & \\
\hline & & \multicolumn{3}{|c|}{---------cm----------- } & & & & \\
\hline $1^{\text {st }}$ (most recent) & Aug & 6.96 & 15.34 & 8.20 & Normal & 2 & 3 & 6 \\
\hline 2nd & July & 8.61 & 16.74 & 16.25 & Normal & 2 & 2 & 4 \\
\hline $3 \mathrm{rd}$ & June & 7.06 & 11.51 & 22.91 & Wet & 3 & 1 & 3 \\
\hline \multicolumn{8}{|c|}{$\begin{array}{ll} & \text { Sum } \\
\text { Rainfall of nrior neriod was. } & 1\end{array}$} & 13 \\
\hline \multicolumn{8}{|c|}{$\begin{array}{l}\text { Rainfall of prior period was: } \\
\text { drier than normal (sum is } 6-9 \text { ), normal (sum is } 10-14 \text { ), wetter than normal (sum is } 15-18 \text { ) }\end{array}$} & Normal \\
\hline
\end{tabular}


Table C.49: DAREM and Modified DAREM calculations for period that met wetland hydrology for plots $3 \mathrm{~N}, 4 \mathrm{~N}, 5 \mathrm{~N}$, 3S, 4S and 5S at Bertie within the year 1961.

\begin{tabular}{|c|c|c|c|c|c|c|c|c|}
\hline \multicolumn{2}{|c|}{ Prior Month } & \multicolumn{2}{|c|}{$\begin{array}{l}\text { WETS Rainfall } \\
\text { Percentile }\end{array}$} & \multirow[t]{2}{*}{$\begin{array}{c}\text { Measured } \\
\text { Rainfall }\end{array}$} & \multirow{2}{*}{$\begin{array}{l}\text { Condition: } \\
\text { Dry, Wet, } \\
\text { Normal }\end{array}$} & \multirow{3}{*}{$\begin{array}{c}\text { Condition } \\
\text { Value } \\
(\mathbf{1 = d r y ,}, \\
2=\text { normal, } \\
\text { or } 3=\text { wet })\end{array}$} & \multirow[t]{2}{*}{$\begin{array}{l}\text { Month } \\
\text { weight }\end{array}$} & \multirow{2}{*}{$\begin{array}{l}\text { Multiply } \\
\text { Previous two } \\
\text { columns }\end{array}$} \\
\hline & Name & $30^{\text {th }}$ & 70th & & & & & \\
\hline & & \multicolumn{3}{|c|}{---------cm----------- } & & & & \\
\hline $1^{\text {st }}$ (most recent) & March & 7.52 & 11.94 & 9.34 & Normal & 2 & 3 & 6 \\
\hline 2nd & Feb & 6.05 & 10.34 & 17.28 & Wet & 3 & 2 & 6 \\
\hline $3 \mathrm{rd}$ & Jan & 7.80 & 12.45 & 7.24 & Dry & 1 & 1 & 1 \\
\hline \multirow{2}{*}{\multicolumn{8}{|c|}{$\begin{array}{ll} & \text { Sum } \\
\text { Rainfall of prior period was: } & \\
\text { drier than normal (sum is 6-9), normal (sum is } 10-14), \text { wetter than normal (sum is 15-18) }\end{array}$}} & 13 \\
\hline & & & & & & & & Normal \\
\hline
\end{tabular}

Table C.50: DAREM and Modified DAREM calculations for period that met wetland hydrology for plots $3 \mathrm{~N}, 4 \mathrm{~N}, 5 \mathrm{~N}$, 3S, 4S and 5S at Bertie within the year 1962.

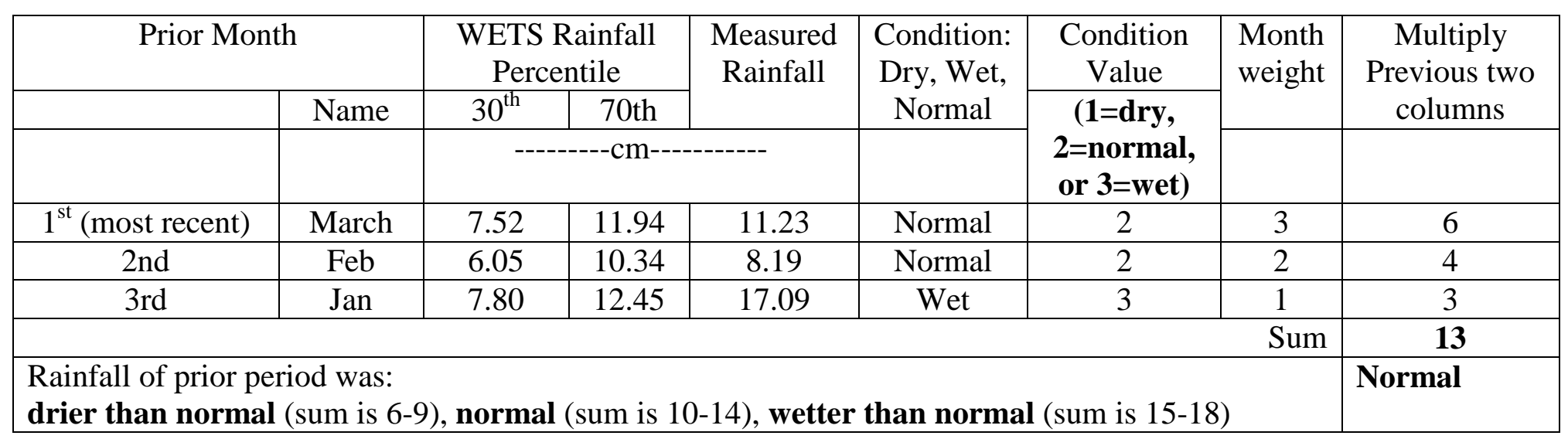


Table C.51: DAREM and Modified DAREM calculations for period that met wetland hydrology for plots $3 \mathrm{~N}, 4 \mathrm{~N}, 5 \mathrm{~N}$, 3S, 4S and 5S at Bertie within the year 1964.

\begin{tabular}{|c|c|c|c|c|c|c|c|c|}
\hline \multicolumn{2}{|c|}{ Prior Month } & \multicolumn{2}{|c|}{$\begin{array}{l}\text { WETS Rainfall } \\
\text { Percentile }\end{array}$} & \multirow[t]{2}{*}{$\begin{array}{c}\text { Measured } \\
\text { Rainfall }\end{array}$} & \multirow{2}{*}{$\begin{array}{l}\text { Condition: } \\
\text { Dry, Wet, } \\
\text { Normal }\end{array}$} & \multirow{3}{*}{$\begin{array}{c}\begin{array}{c}\text { Condition } \\
\text { Value }\end{array} \\
\text { (1=dry, } \\
2=\text { normal, } \\
\text { or } 3=\text { wet })\end{array}$} & \multirow[t]{2}{*}{$\begin{array}{l}\text { Month } \\
\text { weight }\end{array}$} & \multirow{2}{*}{$\begin{array}{l}\text { Multiply } \\
\text { Previous two } \\
\text { columns }\end{array}$} \\
\hline & Name & $30^{\text {th }}$ & 70th & & & & & \\
\hline & & \multicolumn{3}{|c|}{---------cm----------- } & & & & \\
\hline $1^{\text {st }}$ (most recent) & Aug & 6.96 & 15.34 & 19.75 & Wet & 3 & 3 & 9 \\
\hline 2nd & July & 8.61 & 16.74 & 12.51 & Normal & 2 & 2 & 4 \\
\hline $3 \mathrm{rd}$ & June & 7.06 & 11.51 & 6.12 & Dry & 1 & 1 & 1 \\
\hline \multirow{2}{*}{\multicolumn{8}{|c|}{$\begin{array}{ll} & \text { Sum } \\
\text { Rainfall of prior period was: } & \\
\text { drier than normal (sum is 6-9), normal (sum is } 10-14), \text { wetter than normal (sum is 15-18) }\end{array}$}} & 14 \\
\hline & & & & & & & & Normal \\
\hline
\end{tabular}

Table C.52: DAREM and Modified DAREM calculations for period that met wetland hydrology for plots $3 \mathrm{~N}, 4 \mathrm{~N}, 5 \mathrm{~N}$, 3S, 4S and 5S at Bertie within the year 1965.

\begin{tabular}{|c|c|c|c|c|c|c|c|c|}
\hline \multicolumn{2}{|c|}{ Prior Month } & \multicolumn{2}{|c|}{$\begin{array}{l}\text { WETS Rainfall } \\
\text { Percentile }\end{array}$} & \multirow[t]{2}{*}{$\begin{array}{l}\text { Measured } \\
\text { Rainfall }\end{array}$} & \multirow{2}{*}{$\begin{array}{l}\text { Condition: } \\
\text { Dry, Wet, } \\
\text { Normal }\end{array}$} & \multirow{3}{*}{ 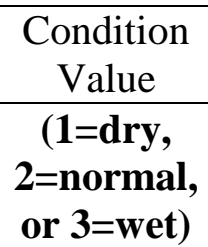 } & \multirow[t]{2}{*}{$\begin{array}{l}\text { Month } \\
\text { weight }\end{array}$} & \multirow{2}{*}{$\begin{array}{l}\text { Multiply } \\
\text { Previous two } \\
\text { columns }\end{array}$} \\
\hline & Name & $30^{\text {th }}$ & 70th & & & & & \\
\hline & & \multicolumn{3}{|c|}{---------cm----------- } & & & & \\
\hline $1^{\text {st }}($ most recent $)$ & March & 7.52 & 11.94 & 10.03 & Normal & 2 & 3 & 6 \\
\hline 2nd & Feb & 6.05 & 10.34 & 9.86 & Normal & 2 & 2 & 4 \\
\hline $3 \mathrm{rd}$ & Jan & 7.80 & 12.45 & 3.95 & Dry & 1 & 1 & 1 \\
\hline \multirow{2}{*}{\multicolumn{8}{|c|}{$\begin{array}{ll}\text { Rainfall of prior period was: } & \text { Sum } \\
\text { drier than normal (sum is 6-9), normal (sum is 10-14), wetter than normal (sum is 15-18) }\end{array}$}} & 11 \\
\hline & & & & & & & & Normal \\
\hline
\end{tabular}


Table C.53: DAREM and Modified DAREM calculations for period that met wetland hydrology for plots $3 \mathrm{~N}, 4 \mathrm{~N}, 5 \mathrm{~N}$, 3S, 4S and 5S at Bertie within the year 1966.

\begin{tabular}{|c|c|c|c|c|c|c|c|c|}
\hline \multicolumn{2}{|c|}{ Prior Month } & \multicolumn{2}{|c|}{$\begin{array}{l}\text { WETS Rainfall } \\
\text { Percentile }\end{array}$} & \multirow[t]{2}{*}{$\begin{array}{c}\text { Measured } \\
\text { Rainfall }\end{array}$} & \multirow{2}{*}{$\begin{array}{l}\text { Condition: } \\
\text { Dry, Wet, } \\
\text { Normal }\end{array}$} & \multirow{3}{*}{$\begin{array}{c}\text { Condition } \\
\text { Value } \\
(\mathbf{1 = d r y ,}, \\
2=\text { normal, } \\
\text { or } 3=\text { wet })\end{array}$} & \multirow[t]{2}{*}{$\begin{array}{l}\text { Month } \\
\text { weight }\end{array}$} & \multirow{2}{*}{$\begin{array}{l}\text { Multiply } \\
\text { Previous two } \\
\text { columns }\end{array}$} \\
\hline & Name & $30^{\text {th }}$ & 70th & & & & & \\
\hline & & \multicolumn{3}{|c|}{---------cm----------- } & & & & \\
\hline $1^{\text {st }}$ (most recent) & May & 6.43 & 12.65 & 28.26 & Wet & 3 & 3 & 9 \\
\hline 2nd & April & 5.39 & 9.70 & 4.33 & Dry & 1 & 2 & 2 \\
\hline $3 \mathrm{rd}$ & March & 7.52 & 11.94 & 4.58 & Dry & 1 & 1 & 1 \\
\hline \multirow{2}{*}{\multicolumn{8}{|c|}{$\begin{array}{ll} & \text { Sum } \\
\text { Rainfall of prior period was: } & \\
\text { drier than normal (sum is 6-9), normal (sum is } 10-14), \text { wetter than normal (sum is 15-18) }\end{array}$}} & 12 \\
\hline & & & & & & & & Normal \\
\hline
\end{tabular}

Table C.54: DAREM and Modified DAREM calculations for period that met wetland hydrology for plots $3 \mathrm{~N}, 4 \mathrm{~N}, 5 \mathrm{~N}$, 3S, 4S and 5S at Bertie within the year 1967.

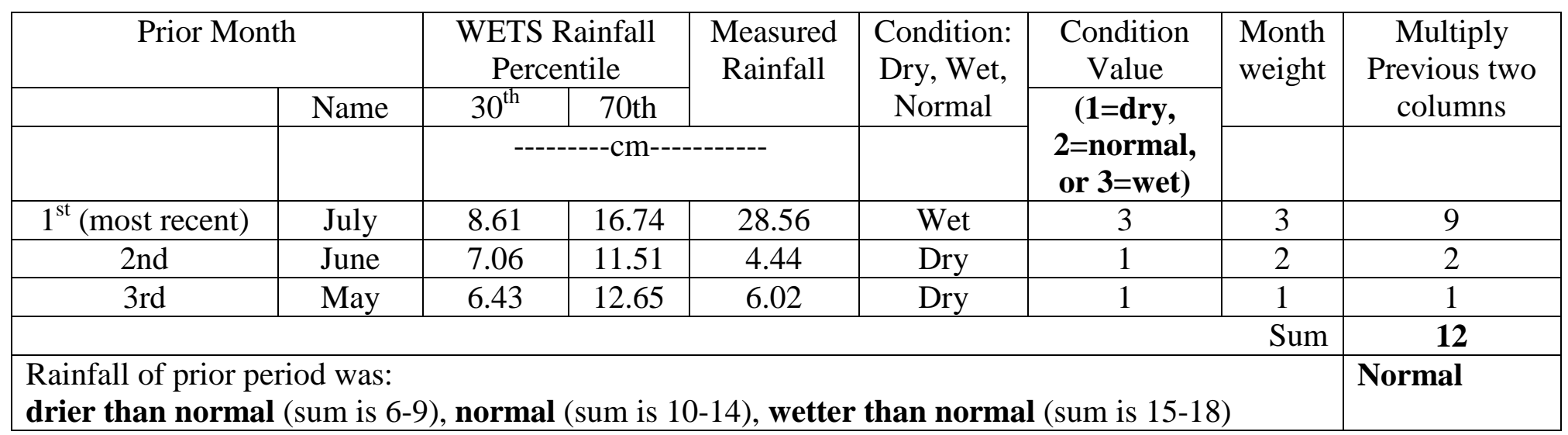


Table C.55: DAREM and Modified DAREM calculations for period that met wetland hydrology for plots $3 \mathrm{~N}, 5 \mathrm{~N}, 3 \mathrm{~S}$, and 5S at Bertie within the year 1968.

\begin{tabular}{|c|c|c|c|c|c|c|c|c|}
\hline \multicolumn{2}{|c|}{ Prior Month } & \multicolumn{2}{|c|}{$\begin{array}{l}\text { WETS Rainfall } \\
\text { Percentile }\end{array}$} & \multirow[t]{2}{*}{$\begin{array}{l}\text { Measured } \\
\text { Rainfall }\end{array}$} & \multirow{2}{*}{$\begin{array}{l}\text { Condition: } \\
\text { Dry, Wet, } \\
\text { Normal }\end{array}$} & \multirow{3}{*}{$\begin{array}{c}\text { Condition } \\
\text { Value }\end{array}$} & \multirow[t]{2}{*}{$\begin{array}{l}\text { Month } \\
\text { weight }\end{array}$} & \multirow{2}{*}{$\begin{array}{c}\text { Multiply } \\
\text { Previous two } \\
\text { columns }\end{array}$} \\
\hline & Name & $30^{\text {th }}$ & 70th & & & & & \\
\hline & & \multicolumn{3}{|c|}{----------cm------------ } & & & & \\
\hline $1^{\text {st }}$ (most recent) & March & 7.52 & 11.94 & 14.25 & Wet & 3 & 3 & 9 \\
\hline 2nd & Feb & 6.05 & 10.34 & 2.77 & Dry & 1 & 2 & 2 \\
\hline $3 \mathrm{rd}$ & Jan & 7.80 & 12.45 & 9.75 & Normal & 2 & 1 & 2 \\
\hline \multirow{2}{*}{\multicolumn{8}{|c|}{$\begin{array}{l}\text { Rainfall of prior period was: } \\
\text { drier than normal (sum is 6-9), normal (sum is } 10-14 \text { ), wetter than normal (sum is } 15-18 \text { ) }\end{array}$}} & 13 \\
\hline & & & & & & & & Normal \\
\hline
\end{tabular}

Table C.56: DAREM and Modified DAREM calculations for period that met wetland hydrology for plots $3 \mathrm{~N}, 4 \mathrm{~N}, 5 \mathrm{~N}$, 3S, 4S and 5S at Bertie within the year 1969.

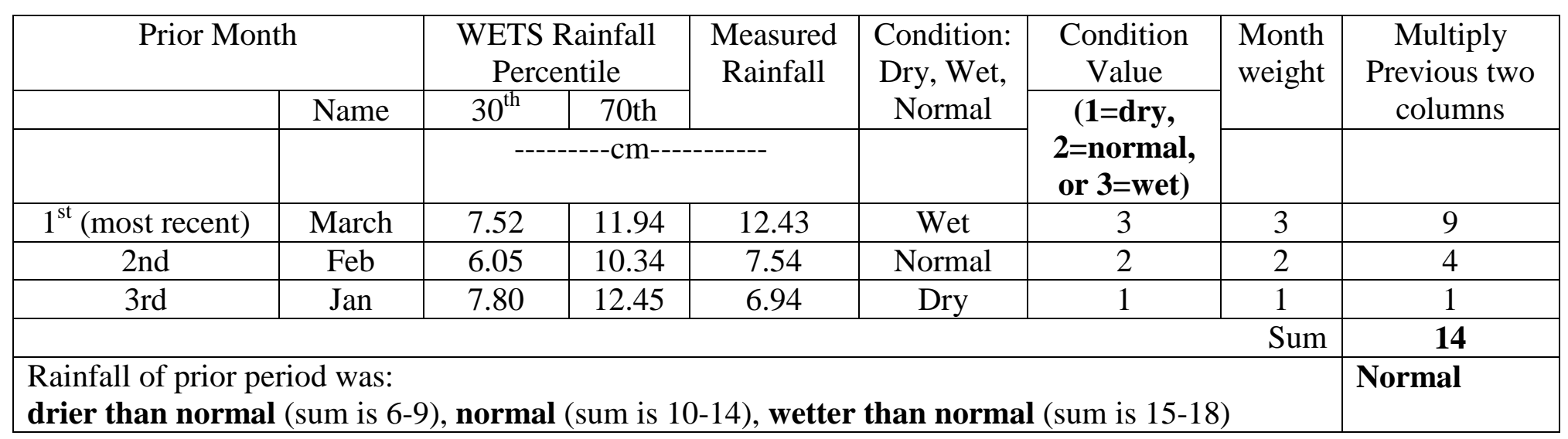


Table C.57: DAREM and Modified DAREM calculations for period that met wetland hydrology for plots $3 \mathrm{~N}, 4 \mathrm{~N}, 5 \mathrm{~N}$, 3S, 4S and 5S at Bertie within the year 1970.

\begin{tabular}{|c|c|c|c|c|c|c|c|c|}
\hline \multicolumn{2}{|c|}{ Prior Month } & \multicolumn{2}{|c|}{$\begin{array}{l}\text { WETS Rainfall } \\
\text { Percentile }\end{array}$} & \multirow[t]{2}{*}{$\begin{array}{c}\text { Measured } \\
\text { Rainfall }\end{array}$} & \multirow{2}{*}{$\begin{array}{l}\text { Condition: } \\
\text { Dry, Wet, } \\
\text { Normal }\end{array}$} & \multirow{3}{*}{$\begin{array}{c}\text { Condition } \\
\text { Value } \\
(\mathbf{1 = d r y ,}, \\
2=\text { normal, } \\
\text { or } 3=\text { wet })\end{array}$} & \multirow[t]{2}{*}{$\begin{array}{l}\text { Month } \\
\text { weight }\end{array}$} & \multirow{2}{*}{$\begin{array}{l}\text { Multiply } \\
\text { Previous two } \\
\text { columns }\end{array}$} \\
\hline & Name & $30^{\text {th }}$ & 70th & & & & & \\
\hline & & \multicolumn{3}{|c|}{---------cm----------- } & & & & \\
\hline $1^{\text {st }}$ (most recent) & March & 7.52 & 11.94 & 8.10 & Normal & 2 & 3 & 6 \\
\hline 2nd & Feb & 6.05 & 10.34 & 10.42 & Wet & 3 & 2 & 6 \\
\hline $3 \mathrm{rd}$ & Jan & 7.80 & 12.45 & 3.94 & Dry & 1 & 1 & 1 \\
\hline \multirow{2}{*}{\multicolumn{8}{|c|}{$\begin{array}{ll} & \text { Sum } \\
\text { Rainfall of prior period was: } & \\
\text { drier than normal (sum is 6-9), normal (sum is } 10-14), \text { wetter than normal (sum is 15-18) }\end{array}$}} & 13 \\
\hline & & & & & & & & Normal \\
\hline
\end{tabular}

Table C.58: DAREM and Modified DAREM calculations for period that met wetland hydrology for plots $3 \mathrm{~N}, 4 \mathrm{~N}, 5 \mathrm{~N}$, 4S and 5S at Bertie within the year 1971.

\begin{tabular}{|c|c|c|c|c|c|c|c|c|}
\hline \multicolumn{2}{|c|}{ Prior Month } & \multicolumn{2}{|c|}{$\begin{array}{l}\text { WETS Rainfall } \\
\text { Percentile }\end{array}$} & \multirow[t]{2}{*}{$\begin{array}{c}\text { Measured } \\
\text { Rainfall }\end{array}$} & \multirow{2}{*}{$\begin{array}{l}\text { Condition: } \\
\text { Dry, Wet, } \\
\text { Normal }\end{array}$} & \multirow{3}{*}{ 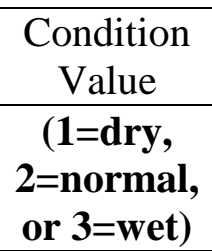 } & \multirow[t]{3}{*}{$\begin{array}{l}\text { Month } \\
\text { weight }\end{array}$} & \multirow{2}{*}{$\begin{array}{c}\text { Multiply } \\
\text { Previous two } \\
\text { columns } \\
\end{array}$} \\
\hline & Name & $30^{\text {th }}$ & 70th & & & & & \\
\hline & & \multicolumn{3}{|c|}{---------cm----------- } & & & & \\
\hline $1^{\mathrm{st}}$ (most recent) & April & 5.39 & 9.70 & 5.08 & Dry & 1 & 3 & 3 \\
\hline $2 \mathrm{nd}$ & March & 7.52 & 11.94 & 14.96 & Wet & 3 & 2 & 6 \\
\hline $3 \mathrm{rd}$ & Feb & 6.05 & 10.34 & 15.34 & Wet & 3 & 1 & 3 \\
\hline \multirow{2}{*}{\multicolumn{8}{|c|}{$\begin{array}{ll} & \text { Sum } \\
\text { Rainfall of prior period was: } & \end{array}$}} & 12 \\
\hline & & & & & & & & Normal \\
\hline
\end{tabular}


Table C.59: DAREM and Modified DAREM calculations for period that met wetland hydrology for plots $3 \mathrm{~N}, 4 \mathrm{~N}, 5 \mathrm{~N}$, 3S, 4S and 5S at Bertie within the year 1972.

\begin{tabular}{|c|c|c|c|c|c|c|c|c|}
\hline \multicolumn{2}{|c|}{ Prior Month } & \multicolumn{2}{|c|}{$\begin{array}{l}\text { WETS Rainfall } \\
\text { Percentile }\end{array}$} & \multirow[t]{2}{*}{$\begin{array}{c}\text { Measured } \\
\text { Rainfall }\end{array}$} & \multirow{2}{*}{$\begin{array}{l}\text { Condition: } \\
\text { Dry, Wet, } \\
\text { Normal }\end{array}$} & \multirow{3}{*}{$\begin{array}{c}\text { Condition } \\
\text { Value } \\
\text { (1=dry, } \\
2=\text { normal, } \\
\text { or } 3=\text { wet) }\end{array}$} & \multirow[t]{2}{*}{$\begin{array}{l}\text { Month } \\
\text { weight }\end{array}$} & \multirow{2}{*}{$\begin{array}{l}\text { Multiply } \\
\text { Previous two } \\
\text { columns }\end{array}$} \\
\hline & Name & $30^{\text {th }}$ & 70th & & & & & \\
\hline & & \multicolumn{3}{|c|}{---------cm----------- } & & & & \\
\hline $1^{\text {st }}$ (most recent) & April & 5.39 & 9.70 & 5.00 & Dry & 1 & 3 & 3 \\
\hline 2nd & March & 7.52 & 11.94 & 13.33 & Wet & 3 & 2 & 6 \\
\hline $3 \mathrm{rd}$ & Feb & 6.05 & 10.34 & 10.33 & Normal & 2 & 1 & 2 \\
\hline \multirow{2}{*}{\multicolumn{8}{|c|}{$\begin{array}{ll} & \text { Sum } \\
\text { Rainfall of prior period was: } & \\
\text { drier than normal (sum is 6-9), normal (sum is } 10-14), \text { wetter than normal (sum is 15-18) }\end{array}$}} & 11 \\
\hline & & & & & & & & Normal \\
\hline
\end{tabular}

Table C.60: DAREM and Modified DAREM calculations for period that met wetland hydrology for plots $4 \mathrm{~N}, 5 \mathrm{~N}$, and $5 S$ at Bertie within the year 1973.

\begin{tabular}{|c|c|c|c|c|c|c|c|c|}
\hline \multicolumn{2}{|c|}{ Prior Month } & \multicolumn{2}{|c|}{$\begin{array}{l}\text { WETS Rainfall } \\
\text { Percentile }\end{array}$} & \multirow[t]{2}{*}{$\begin{array}{l}\text { Measured } \\
\text { Rainfall }\end{array}$} & \multirow{2}{*}{$\begin{array}{l}\text { Condition: } \\
\text { Dry, Wet, } \\
\text { Normal }\end{array}$} & \multirow{3}{*}{$\begin{array}{c}\begin{array}{c}\text { Condition } \\
\text { Value }\end{array} \\
\text { (1=dry, } \\
2=\text { normal, } \\
\text { or } 3=\text { wet) }\end{array}$} & \multirow[t]{2}{*}{$\begin{array}{l}\text { Month } \\
\text { weight }\end{array}$} & \multirow{2}{*}{$\begin{array}{c}\text { Multiply } \\
\text { Previous two } \\
\text { columns }\end{array}$} \\
\hline & Name & $30^{\text {th }}$ & 70th & & & & & \\
\hline & & \multicolumn{3}{|c|}{---------cm----------- } & & & & \\
\hline $1^{\text {st }}$ (most recent) & July & 8.61 & 16.74 & 12.82 & Normal & 2 & 3 & 6 \\
\hline 2nd & June & 7.06 & 11.51 & 16.91 & Wet & 3 & 2 & 6 \\
\hline $3 \mathrm{rd}$ & May & 6.43 & 12.65 & 10.47 & Normal & 2 & 1 & 2 \\
\hline \multicolumn{8}{|c|}{$\begin{array}{ll} & \text { Sum } \\
\text { Rainfall of nrior neriod was. } & 1\end{array}$} & 14 \\
\hline \multicolumn{8}{|c|}{$\begin{array}{l}\text { Rainfall of prior period was: } \\
\text { drier than normal (sum is } 6-9 \text { ), normal (sum is } 10-14 \text { ), wetter than normal (sum is } 15-18 \text { ) }\end{array}$} & Normal \\
\hline
\end{tabular}


Table C.61: DAREM and Modified DAREM calculations for period that met wetland hydrology for plots $4 \mathrm{~N}, 5 \mathrm{~N}$, and 5S at Bertie within the year 1974.

\begin{tabular}{|c|c|c|c|c|c|c|c|c|}
\hline \multicolumn{2}{|c|}{ Prior Month } & \multicolumn{2}{|c|}{$\begin{array}{l}\text { WETS Rainfall } \\
\text { Percentile }\end{array}$} & \multirow[t]{2}{*}{$\begin{array}{l}\text { Measured } \\
\text { Rainfall }\end{array}$} & \multirow{2}{*}{$\begin{array}{l}\text { Condition: } \\
\text { Dry, Wet, } \\
\text { Normal }\end{array}$} & \multirow{3}{*}{$\begin{array}{c}\text { Condition } \\
\text { Value }\end{array}$} & \multirow[t]{2}{*}{$\begin{array}{l}\text { Month } \\
\text { weight }\end{array}$} & \multirow{2}{*}{$\begin{array}{c}\text { Multiply } \\
\text { Previous two } \\
\text { columns }\end{array}$} \\
\hline & Name & $30^{\text {th }}$ & 70th & & & & & \\
\hline & & \multicolumn{3}{|c|}{----------cm------------ } & & & & \\
\hline $1^{\text {st }}($ most recent $)$ & July & 8.61 & 16.74 & 14.33 & Normal & 2 & 3 & 6 \\
\hline 2nd & June & 7.06 & 11.51 & 8.74 & Normal & 2 & 2 & 4 \\
\hline 3rd & May & 6.43 & 12.65 & 15.54 & Wet & 3 & 1 & 3 \\
\hline \multirow{2}{*}{\multicolumn{8}{|c|}{$\begin{array}{l}\text { Rainfall of prior period was: } \\
\text { drier than normal (sum is 6-9), normal (sum is } 10-14 \text { ), wetter than normal (sum is } 15-18 \text { ) }\end{array}$}} & 13 \\
\hline & & & & & & & & Normal \\
\hline
\end{tabular}

Table C.62: DAREM and Modified DAREM calculations for period that met wetland hydrology for plots 4N, 5N, 3S, 4S and 5S at Bertie within the year 1975.

\begin{tabular}{|c|c|c|c|c|c|c|c|c|}
\hline \multicolumn{2}{|c|}{ Prior Month } & \multicolumn{2}{|c|}{$\begin{array}{l}\text { WETS Rainfall } \\
\text { Percentile }\end{array}$} & \multirow[t]{2}{*}{$\begin{array}{l}\text { Measured } \\
\text { Rainfall }\end{array}$} & \multirow{2}{*}{$\begin{array}{l}\text { Condition: } \\
\text { Dry, Wet, } \\
\text { Normal }\end{array}$} & \multirow{3}{*}{$\begin{array}{c}\text { Condition } \\
\text { Value } \\
(\mathbf{1 = d r y ,}, \\
\begin{array}{c}2=\text { normal, } \\
\text { or } 3=\text { wet })\end{array}\end{array}$} & \multirow[t]{3}{*}{$\begin{array}{l}\text { Month } \\
\text { weight }\end{array}$} & \multirow{2}{*}{$\begin{array}{c}\text { Multiply } \\
\text { Previous two } \\
\text { columns } \\
\end{array}$} \\
\hline & Name & $30^{\text {th }}$ & 70th & & & & & \\
\hline & & \multicolumn{3}{|c|}{----------cm------------ } & & & & \\
\hline $1^{\mathrm{st}}$ (most recent) & June & 7.06 & 11.51 & 5.99 & Dry & 1 & 3 & 3 \\
\hline 2 nd & May & 6.43 & 12.65 & 6.90 & Normal & 2 & 2 & 4 \\
\hline $3 \mathrm{rd}$ & April & 5.39 & 9.70 & 11.01 & Wet & 3 & 1 & 3 \\
\hline \multirow{2}{*}{\multicolumn{8}{|c|}{$\begin{array}{l}\text { Sumfall of prior period was: } \\
\text { drier than normal (sum is 6-9), normal (sum is } 10-14) \text {, wetter than normal (sum is } 15-18 \text { ) }\end{array}$}} & 10 \\
\hline & & & & & & & & Normal \\
\hline
\end{tabular}


Table C.63: DAREM and Modified DAREM calculations for period that met wetland hydrology for plots $3 \mathrm{~N}, 4 \mathrm{~N}, 5 \mathrm{~N}$, 4S and 5S at Bertie within the year 1977.

\begin{tabular}{|c|c|c|c|c|c|c|c|c|}
\hline \multicolumn{2}{|c|}{ Prior Month } & \multicolumn{2}{|c|}{$\begin{array}{l}\text { WETS Rainfall } \\
\text { Percentile }\end{array}$} & \multirow[t]{2}{*}{$\begin{array}{l}\text { Measured } \\
\text { Rainfall }\end{array}$} & \multirow{2}{*}{$\begin{array}{l}\text { Condition: } \\
\text { Dry, Wet, } \\
\text { Normal }\end{array}$} & \multirow{3}{*}{$\begin{array}{c}\text { Condition } \\
\text { Value }\end{array}$} & \multirow[t]{2}{*}{$\begin{array}{l}\text { Month } \\
\text { weight }\end{array}$} & \multirow{2}{*}{$\begin{array}{c}\text { Multiply } \\
\text { Previous two } \\
\text { columns }\end{array}$} \\
\hline & Name & $30^{\text {th }}$ & 70th & & & & & \\
\hline & & \multicolumn{3}{|c|}{----------cm------------ } & & & & \\
\hline $1^{\text {st }}$ (most recent) & March & 7.52 & 11.94 & 10.51 & Normal & 2 & 3 & 6 \\
\hline 2nd & Feb & 6.05 & 10.34 & 4.62 & Dry & 1 & 2 & 2 \\
\hline $3 \mathrm{rd}$ & Jan & 7.80 & 12.45 & 8.95 & Normal & 2 & 1 & 2 \\
\hline \multirow{2}{*}{\multicolumn{8}{|c|}{$\begin{array}{l}\text { Rainfall of prior period was: } \\
\text { drier than normal (sum is 6-9), normal (sum is } 10-14 \text { ), wetter than normal (sum is } 15-18 \text { ) }\end{array}$}} & $\mathbf{1 0}$ \\
\hline & & & & & & & & Normal \\
\hline
\end{tabular}

Table C.64: DAREM and Modified DAREM calculations for period that met wetland hydrology for plots $3 \mathrm{~N}, 4 \mathrm{~N}, 5 \mathrm{~N}$, 3S, 4S and 5S at Bertie within the year 1978.

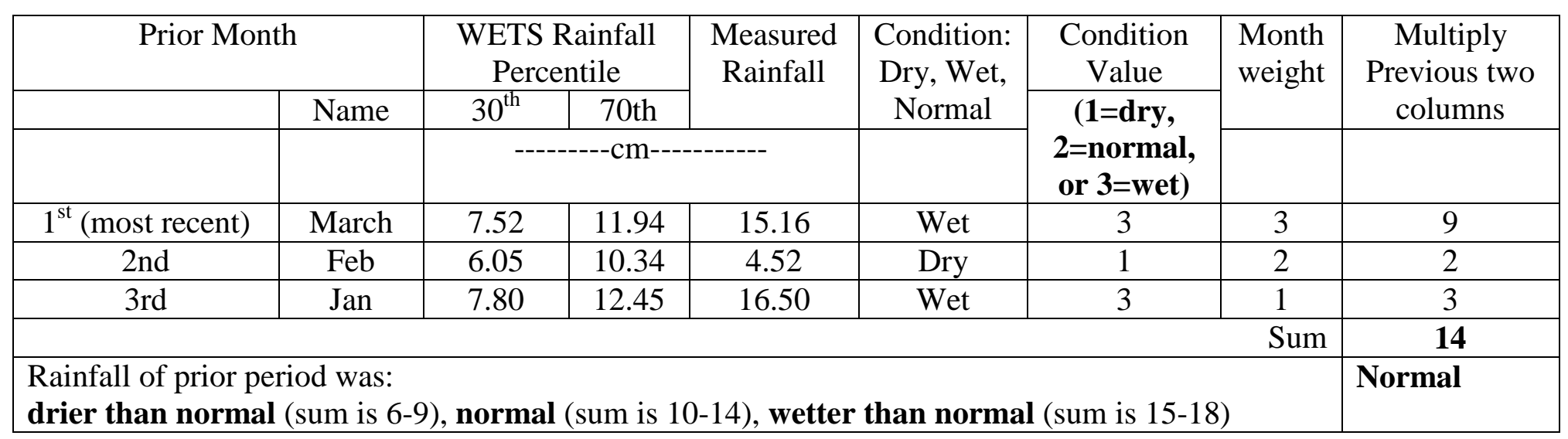


Table C.65: DAREM and Modified DAREM calculations for period that met wetland hydrology for plots 5N and 5S at Bertie within the year 1979.

\begin{tabular}{|c|c|c|c|c|c|c|c|c|}
\hline \multicolumn{2}{|c|}{ Prior Month } & \multicolumn{2}{|c|}{$\begin{array}{l}\text { WETS Rainfall } \\
\text { Percentile }\end{array}$} & \multirow[t]{2}{*}{$\begin{array}{l}\text { Measured } \\
\text { Rainfall }\end{array}$} & \multirow{2}{*}{$\begin{array}{c}\text { Condition: } \\
\text { Dry, Wet, } \\
\text { Normal }\end{array}$} & \multirow{3}{*}{$\begin{array}{c}\text { Condition } \\
\text { Value } \\
(\mathbf{1 = d r y ,}, \\
2=\text { normal, } \\
\text { or } 3=\text { wet })\end{array}$} & \multirow[t]{2}{*}{$\begin{array}{l}\text { Month } \\
\text { weight }\end{array}$} & \multirow{2}{*}{$\begin{array}{c}\text { Multiply } \\
\text { Previous two } \\
\text { columns } \\
\end{array}$} \\
\hline & Name & $30^{\text {th }}$ & 70th & & & & & \\
\hline & & \multicolumn{3}{|c|}{----------cm----------- } & & & & \\
\hline $1^{\mathrm{st}}$ (most recent) & Aug & 6.96 & 15.34 & 6.69 & Dry & 1 & 3 & 3 \\
\hline 2nd & July & 8.61 & 16.74 & 9.51 & Normal & 2 & 2 & 4 \\
\hline $3 \mathrm{rd}$ & June & 7.06 & 11.51 & 19.68 & Wet & 3 & 1 & 3 \\
\hline \multirow{2}{*}{\multicolumn{8}{|c|}{$\begin{array}{l}\text { Rainfall of prior period was: } \\
\text { drier than normal (sum is 6-9), normal (sum is } 10-14 \text { ), wetter than normal (sum is 15-18) }\end{array}$}} & 10 \\
\hline & & & & & & & & Normal \\
\hline
\end{tabular}

Table C.66: DAREM and Modified DAREM calculations for period that met wetland hydrology for plots $4 \mathrm{~N}, 5 \mathrm{~N}, 4 \mathrm{~S}$ and $5 \mathrm{~S}$ at Bertie within the year 1981.

\begin{tabular}{|c|c|c|c|c|c|c|c|c|}
\hline \multicolumn{2}{|c|}{ Prior Month } & \multicolumn{2}{|c|}{$\begin{array}{l}\text { WETS Rainfall } \\
\text { Percentile }\end{array}$} & \multirow[t]{2}{*}{$\begin{array}{l}\text { Measured } \\
\text { Rainfall }\end{array}$} & \multirow{2}{*}{$\begin{array}{l}\text { Condition: } \\
\text { Dry, Wet, } \\
\text { Normal }\end{array}$} & \multirow{3}{*}{$\begin{array}{c}\text { Condition } \\
\text { Value } \\
(\mathbf{1 = d r y ,}, \\
\begin{array}{c}2=\text { normal, } \\
\text { or } 3=\text { wet })\end{array}\end{array}$} & \multirow[t]{3}{*}{$\begin{array}{l}\text { Month } \\
\text { weight }\end{array}$} & \multirow{2}{*}{$\begin{array}{c}\text { Multiply } \\
\text { Previous two } \\
\text { columns } \\
\end{array}$} \\
\hline & Name & $30^{\text {th }}$ & 70th & & & & & \\
\hline & & \multicolumn{3}{|c|}{----------cm------------ } & & & & \\
\hline $1^{\mathrm{st}}$ (most recent) & March & 7.52 & 11.94 & 5.56 & Dry & 1 & 3 & 3 \\
\hline 2 nd & Feb & 6.05 & 10.34 & 7.67 & Normal & 2 & 2 & 4 \\
\hline $3 \mathrm{rd}$ & Jan & 7.80 & 12.45 & 3.97 & Dry & 1 & 1 & 1 \\
\hline \multirow{2}{*}{\multicolumn{8}{|c|}{$\begin{array}{l}\text { Rainfall of prior period was: } \\
\text { drier than normal (sum is } 6-9) \text {, normal (sum is } 10-14) \text {, wetter than normal (sum is } 15-18 \text { ) }\end{array}$}} & 8 \\
\hline & & & & & & & & Dry \\
\hline
\end{tabular}


Table C.67: DAREM and Modified DAREM calculations for period that met wetland hydrology for plots $5 \mathrm{~N}, 4 \mathrm{~S}$ and $5 \mathrm{~S}$ at Bertie within the year 1982.

\begin{tabular}{|c|c|c|c|c|c|c|c|c|}
\hline \multicolumn{2}{|c|}{ Prior Month } & \multicolumn{2}{|c|}{$\begin{array}{l}\text { WETS Rainfall } \\
\text { Percentile }\end{array}$} & \multirow[t]{2}{*}{$\begin{array}{l}\text { Measured } \\
\text { Rainfall }\end{array}$} & \multirow{2}{*}{$\begin{array}{l}\text { Condition: } \\
\text { Dry, Wet, } \\
\text { Normal }\end{array}$} & \multirow{3}{*}{$\begin{array}{c}\text { Condition } \\
\text { Value }\end{array}$} & \multirow[t]{2}{*}{$\begin{array}{l}\text { Month } \\
\text { weight }\end{array}$} & \multirow{2}{*}{$\begin{array}{c}\text { Multiply } \\
\text { Previous two } \\
\text { columns }\end{array}$} \\
\hline & Name & $30^{\text {th }}$ & 70th & & & & & \\
\hline & & \multicolumn{3}{|c|}{----------cm------------ } & & & & \\
\hline $1^{\text {st }}$ (most recent) & March & 7.52 & 11.94 & 8.47 & Normal & 2 & 3 & 6 \\
\hline 2nd & Feb & 6.05 & 10.34 & 12.08 & Wet & 3 & 2 & 6 \\
\hline $3 \mathrm{rd}$ & Jan & 7.80 & 12.45 & 11.80 & Normal & 2 & 1 & 2 \\
\hline \multirow{2}{*}{\multicolumn{8}{|c|}{$\begin{array}{l}\text { Rainfall of prior period was: } \\
\text { drier than normal (sum is 6-9), normal (sum is } 10-14 \text { ), wetter than normal (sum is } 15-18 \text { ) }\end{array}$}} & 14 \\
\hline & & & & & & & & Normal \\
\hline
\end{tabular}

Table C.68: DAREM and Modified DAREM calculations for period that met wetland hydrology for plots $3 \mathrm{~N}, 4 \mathrm{~N}, 5 \mathrm{~N}$, 3S, 4S and 5S at Bertie within the year 1984.

\begin{tabular}{|c|c|c|c|c|c|c|c|c|}
\hline \multicolumn{2}{|c|}{ Prior Month } & \multicolumn{2}{|c|}{$\begin{array}{l}\text { WETS Rainfall } \\
\text { Percentile }\end{array}$} & \multirow[t]{2}{*}{$\begin{array}{c}\text { Measured } \\
\text { Rainfall }\end{array}$} & \multirow{2}{*}{$\begin{array}{l}\text { Condition: } \\
\text { Dry, Wet, } \\
\text { Normal }\end{array}$} & \multirow{3}{*}{ 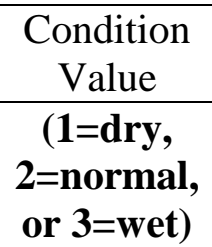 } & \multirow[t]{2}{*}{$\begin{array}{l}\text { Month } \\
\text { weight }\end{array}$} & \multirow{2}{*}{$\begin{array}{l}\text { Multiply } \\
\text { Previous two } \\
\text { columns }\end{array}$} \\
\hline & Name & $30^{\text {th }}$ & 70th & & & & & \\
\hline & & \multicolumn{3}{|c|}{----------cm------------ } & & & & \\
\hline $1^{\text {st }}$ (most recent) & July & 8.61 & 16.74 & 35.76 & Wet & 3 & 3 & 9 \\
\hline 2nd & June & 7.06 & 11.51 & 3.82 & Dry & 1 & 2 & 2 \\
\hline $3 \mathrm{rd}$ & May & 6.43 & 12.65 & 17.32 & Wet & 3 & 1 & 3 \\
\hline \multirow{2}{*}{\multicolumn{8}{|c|}{$\begin{array}{ll} & \text { Sum } \\
\text { Rainfall of prior period was: } & \\
\text { drier than normal (sum is 6-9), normal (sum is 10-14), wetter than normal (sum is } 15-18)\end{array}$}} & 14 \\
\hline & & & & & & & & Normal \\
\hline
\end{tabular}


Table C.69: DAREM and Modified DAREM calculations for period that met wetland hydrology for plots $3 \mathrm{~N}, 4 \mathrm{~N}, 5 \mathrm{~N}$, 3S, 4S and 5S at Bertie within the year 1987.

\begin{tabular}{|c|c|c|c|c|c|c|c|c|}
\hline \multicolumn{2}{|c|}{ Prior Month } & \multicolumn{2}{|c|}{$\begin{array}{l}\text { WETS Rainfall } \\
\text { Percentile }\end{array}$} & \multirow[t]{2}{*}{$\begin{array}{c}\text { Measured } \\
\text { Rainfall }\end{array}$} & \multirow{2}{*}{$\begin{array}{l}\text { Condition: } \\
\text { Dry, Wet, } \\
\text { Normal }\end{array}$} & \multirow{3}{*}{$\begin{array}{c}\text { Condition } \\
\text { Value } \\
(\mathbf{1 = d r y ,}, \\
2=\text { normal, } \\
\text { or } 3=\text { wet })\end{array}$} & \multirow[t]{2}{*}{$\begin{array}{l}\text { Month } \\
\text { weight }\end{array}$} & \multirow{2}{*}{$\begin{array}{l}\text { Multiply } \\
\text { Previous two } \\
\text { columns }\end{array}$} \\
\hline & Name & $30^{\text {th }}$ & 70th & & & & & \\
\hline & & \multicolumn{3}{|c|}{---------cm----------- } & & & & \\
\hline $1^{\text {st }}$ (most recent) & March & 7.52 & 11.94 & 11.35 & Normal & 2 & 3 & 6 \\
\hline 2nd & Feb & 6.05 & 10.34 & 7.08 & Normal & 2 & 2 & 4 \\
\hline $3 \mathrm{rd}$ & Jan & 7.80 & 12.45 & 21.70 & Wet & 3 & 1 & 3 \\
\hline \multirow{2}{*}{\multicolumn{8}{|c|}{$\begin{array}{ll} & \text { Sum } \\
\text { Rainfall of prior period was: } & \\
\text { drier than normal (sum is 6-9), normal (sum is } 10-14), \text { wetter than normal (sum is 15-18) }\end{array}$}} & 13 \\
\hline & & & & & & & & Normal \\
\hline
\end{tabular}

Table C.70: DAREM and Modified DAREM calculations for period that met wetland hydrology for plots $3 \mathrm{~N}, 4 \mathrm{~N}, 5 \mathrm{~N}$, 3S, 4S and 5S at Bertie within the year 1988.

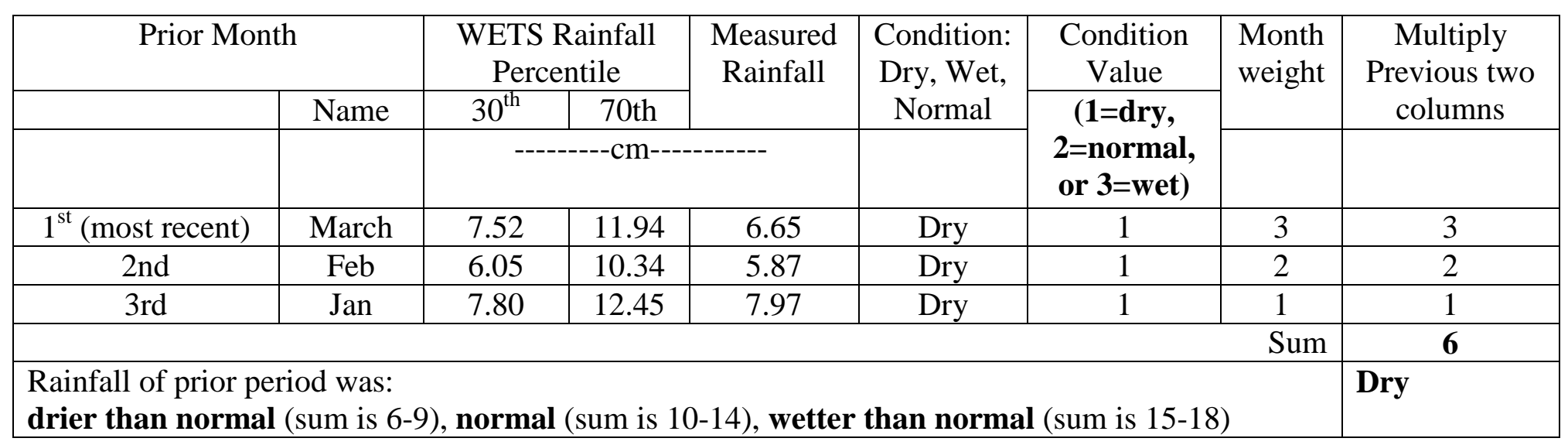


Table C.71: DAREM and Modified DAREM calculations for period that met wetland hydrology for plots $3 \mathrm{~N}, 4 \mathrm{~N}, 5 \mathrm{~N}$, 3S, 4S and 5S at Bertie within the year 1989.

\begin{tabular}{|c|c|c|c|c|c|c|c|c|}
\hline \multicolumn{2}{|c|}{ Prior Month } & \multicolumn{2}{|c|}{$\begin{array}{l}\text { WETS Rainfall } \\
\text { Percentile }\end{array}$} & \multirow[t]{2}{*}{$\begin{array}{c}\text { Measured } \\
\text { Rainfall }\end{array}$} & \multirow{2}{*}{$\begin{array}{c}\text { Condition: } \\
\text { Dry, Wet, } \\
\text { Normal }\end{array}$} & \multirow{3}{*}{$\begin{array}{c}\text { Condition } \\
\text { Value } \\
\text { (1=dry, } \\
2=\text { normal, } \\
\text { or } 3=\text { wet })\end{array}$} & \multirow[t]{2}{*}{$\begin{array}{l}\text { Month } \\
\text { weight }\end{array}$} & \multirow{2}{*}{$\begin{array}{c}\text { Multiply } \\
\text { Previous two } \\
\text { columns }\end{array}$} \\
\hline & Name & $30^{\text {th }}$ & 70th & & & & & \\
\hline & & \multicolumn{3}{|c|}{---------cm---------- } & & & & \\
\hline $1^{\text {st }}$ (most recent) & March & 7.52 & 11.94 & 19.66 & Wet & 3 & 3 & 9 \\
\hline 2nd & Feb & 6.05 & 10.34 & 9.13 & Normal & 2 & 2 & 4 \\
\hline 3rd & Jan & 7.80 & 12.45 & 6.03 & Dry & 1 & 1 & 1 \\
\hline \multirow{2}{*}{\multicolumn{8}{|c|}{$\begin{array}{l}\text { Rainfall of prior period was: } \\
\text { drier than normal (sum is 6-9), normal (sum is } 10-14 \text { ), wetter than normal (sum is } 15-18 \text { ) }\end{array}$}} & 14 \\
\hline & & & & & & & & Normal \\
\hline
\end{tabular}

Table C.72: DAREM and Modified DAREM calculations for period that met wetland hydrology for plots $3 \mathrm{~N}, 4 \mathrm{~N}, 5 \mathrm{~N}$, 3S, 4S and 5S at Bertie within the year 1990.

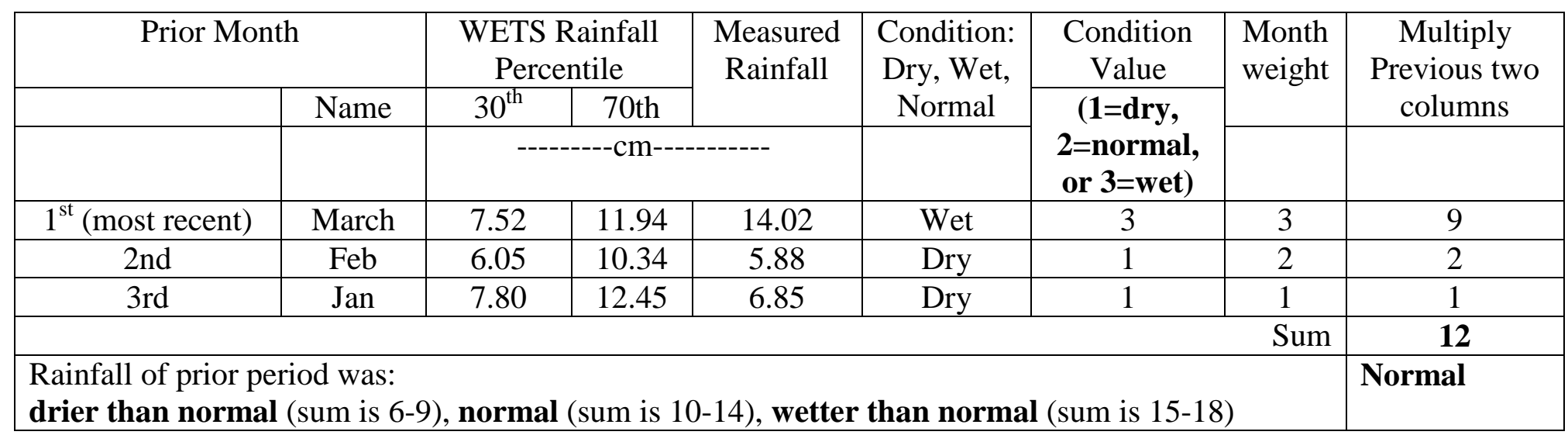


Table C.73: DAREM and Modified DAREM calculations for period that met wetland hydrology for plots $3 \mathrm{~N}, 4 \mathrm{~N}, 5 \mathrm{~N}$, 3S, and 5S at Bertie within the year 1991.

\begin{tabular}{|c|c|c|c|c|c|c|c|c|}
\hline \multicolumn{2}{|c|}{ Prior Month } & \multicolumn{2}{|c|}{$\begin{array}{l}\text { WETS Rainfall } \\
\text { Percentile }\end{array}$} & \multirow[t]{2}{*}{$\begin{array}{l}\text { Measured } \\
\text { Rainfall }\end{array}$} & \multirow{2}{*}{$\begin{array}{c}\text { Condition: } \\
\text { Dry, Wet, } \\
\text { Normal }\end{array}$} & \multirow{3}{*}{$\begin{array}{c}\text { Condition } \\
\text { Value } \\
(\mathbf{1 = d r y ,}, \\
2=\text { normal, } \\
\text { or } 3=\text { wet })\end{array}$} & \multirow[t]{2}{*}{$\begin{array}{l}\text { Month } \\
\text { weight }\end{array}$} & \multirow{2}{*}{$\begin{array}{c}\text { Multiply } \\
\text { Previous two } \\
\text { columns } \\
\end{array}$} \\
\hline & Name & $30^{\text {th }}$ & 70 th & & & & & \\
\hline & & \multicolumn{3}{|c|}{----------cm----------- } & & & & \\
\hline $1^{\mathrm{st}}$ (most recent) & July & 8.61 & 16.74 & 16.30 & Normal & 2 & 3 & 6 \\
\hline 2nd & June & 7.06 & 11.51 & 10.83 & Normal & 2 & 2 & 4 \\
\hline 3rd & May & 6.43 & 12.65 & 1.41 & Dry & 1 & 1 & 1 \\
\hline \multirow{2}{*}{\multicolumn{8}{|c|}{$\begin{array}{l}\text { Rainfall of prior period was: } \\
\text { drier than normal (sum is 6-9), normal (sum is } 10-14 \text { ), wetter than normal (sum is 15-18) }\end{array}$}} & 11 \\
\hline & & & & & & & & Normal \\
\hline
\end{tabular}

Table C.74: DAREM and Modified DAREM calculations for period that met wetland hydrology for plots $3 \mathrm{~N}, 4 \mathrm{~N}, 4 \mathrm{~S}$ and 5S at Bertie within the year 1992.

\begin{tabular}{|c|c|c|c|c|c|c|c|c|}
\hline \multicolumn{2}{|c|}{ Prior Month } & \multicolumn{2}{|c|}{$\begin{array}{l}\text { WETS Rainfall } \\
\text { Percentile }\end{array}$} & \multirow[t]{2}{*}{$\begin{array}{l}\text { Measured } \\
\text { Rainfall }\end{array}$} & \multirow{2}{*}{$\begin{array}{l}\text { Condition: } \\
\text { Dry, Wet, } \\
\text { Normal }\end{array}$} & \multirow{3}{*}{ 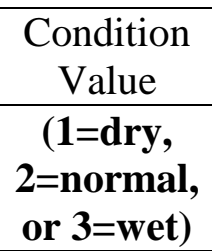 } & \multirow[t]{3}{*}{$\begin{array}{l}\text { Month } \\
\text { weight }\end{array}$} & \multirow{2}{*}{$\begin{array}{c}\text { Multiply } \\
\text { Previous two } \\
\text { columns } \\
\end{array}$} \\
\hline & Name & $30^{\text {th }}$ & 70th & & & & & \\
\hline & & \multicolumn{3}{|c|}{----------cm------------ } & & & & \\
\hline $1^{\mathrm{st}}$ (most recent) & July & 8.61 & 16.74 & 13.25 & Normal & 2 & 3 & 6 \\
\hline 2 nd & June & 7.06 & 11.51 & 12.16 & Wet & 3 & 2 & 6 \\
\hline $3 \mathrm{rd}$ & May & 6.43 & 12.65 & 11.80 & Normal & 2 & 1 & 2 \\
\hline \multirow{2}{*}{\multicolumn{8}{|c|}{$\begin{array}{l}\text { Rainfall of prior period was: } \\
\text { drier than normal (sum is } 6-9 \text { ), normal (sum is } 10-14 \text { ), wetter than normal (sum is } 15-18 \text { ) }\end{array}$}} & 14 \\
\hline & & & & & & & & Normal \\
\hline
\end{tabular}


Table C.75: DAREM and Modified DAREM calculations for period that met wetland hydrology for plots $3 \mathrm{~N}, 4 \mathrm{~N}, 5 \mathrm{~N}$, 3S, 4S and 5S at Bertie within the year 1993.

\begin{tabular}{|c|c|c|c|c|c|c|c|c|}
\hline \multicolumn{2}{|c|}{ Prior Month } & \multicolumn{2}{|c|}{$\begin{array}{l}\text { WETS Rainfall } \\
\text { Percentile }\end{array}$} & \multirow[t]{2}{*}{$\begin{array}{c}\text { Measured } \\
\text { Rainfall }\end{array}$} & \multirow{2}{*}{$\begin{array}{l}\text { Condition: } \\
\text { Dry, Wet, } \\
\text { Normal }\end{array}$} & \multirow{3}{*}{$\begin{array}{c}\text { Condition } \\
\text { Value } \\
(\mathbf{1 = d r y ,}, \\
2=\text { normal, } \\
\text { or } 3=\text { wet })\end{array}$} & \multirow[t]{2}{*}{$\begin{array}{l}\text { Month } \\
\text { weight }\end{array}$} & \multirow{2}{*}{$\begin{array}{l}\text { Multiply } \\
\text { Previous two } \\
\text { columns }\end{array}$} \\
\hline & Name & $30^{\text {th }}$ & 70th & & & & & \\
\hline & & \multicolumn{3}{|c|}{---------cm----------- } & & & & \\
\hline $1^{\text {st }}$ (most recent) & March & 7.52 & 11.94 & 13.21 & Wet & 3 & 3 & 9 \\
\hline 2nd & Feb & 6.05 & 10.34 & 5.48 & Dry & 1 & 2 & 2 \\
\hline $3 \mathrm{rd}$ & Jan & 7.80 & 12.45 & 17.79 & Wet & 3 & 1 & 3 \\
\hline \multirow{2}{*}{\multicolumn{8}{|c|}{$\begin{array}{ll} & \text { Sum } \\
\text { Rainfall of prior period was: } & \\
\text { drier than normal (sum is 6-9), normal (sum is } 10-14), \text { wetter than normal (sum is 15-18) }\end{array}$}} & 14 \\
\hline & & & & & & & & Normal \\
\hline
\end{tabular}

Table C.76: DAREM and Modified DAREM calculations for period that met wetland hydrology for plots 4N, 5N, 3S, 4S and 5S at Bertie within the year 1994.

\begin{tabular}{|c|c|c|c|c|c|c|c|c|}
\hline \multicolumn{2}{|c|}{ Prior Month } & \multicolumn{2}{|c|}{$\begin{array}{l}\text { WETS Rainfall } \\
\text { Percentile }\end{array}$} & \multirow[t]{2}{*}{$\begin{array}{l}\text { Measured } \\
\text { Rainfall }\end{array}$} & \multirow{2}{*}{$\begin{array}{l}\text { Condition: } \\
\text { Dry, Wet, } \\
\text { Normal }\end{array}$} & \multirow{3}{*}{$\begin{array}{c}\text { Condition } \\
\text { Value } \\
(1=\text { dry, } \\
2=\text { normal, } \\
\text { or } 3=\text { wet })\end{array}$} & \multirow[t]{3}{*}{$\begin{array}{l}\text { Month } \\
\text { weight }\end{array}$} & \multirow{2}{*}{$\begin{array}{c}\text { Multiply } \\
\text { Previous two } \\
\text { columns } \\
\end{array}$} \\
\hline & Name & $30^{\text {th }}$ & 70th & & & & & \\
\hline & & \multicolumn{3}{|c|}{----------cm------------ } & & & & \\
\hline $1^{\mathrm{st}}$ (most recent) & July & 8.61 & 16.74 & 16.3 & Normal & 2 & 3 & 6 \\
\hline 2 nd & June & 7.06 & 11.51 & 10.83 & Normal & 2 & 2 & 4 \\
\hline $3 \mathrm{rd}$ & May & 6.43 & 12.65 & 1.41 & Dry & 1 & 1 & 1 \\
\hline \multirow{2}{*}{\multicolumn{8}{|c|}{$\begin{array}{l}\text { Rainfall of prior period was: } \\
\text { drier than normal (sum is } 6-9) \text {, normal (sum is } 10-14) \text {, wetter than normal (sum is } 15-18 \text { ) }\end{array}$}} & 11 \\
\hline & & & & & & & & Normal \\
\hline
\end{tabular}


Table C.77: DAREM and Modified DAREM calculations for period that met wetland hydrology for plot S2 at the Marcell Experimental Forest within the year 1961.

\begin{tabular}{|c|c|c|c|c|c|c|c|c|}
\hline \multicolumn{2}{|c|}{ Prior Month } & \multicolumn{2}{|c|}{$\begin{array}{c}\text { WETS Rainfall } \\
\text { Percentile }\end{array}$} & \multirow[t]{2}{*}{$\begin{array}{l}\text { Measured } \\
\text { Rainfall }\end{array}$} & \multirow{2}{*}{$\begin{array}{c}\text { Condition: } \\
\text { Dry, Wet, } \\
\text { Normal }\end{array}$} & \multirow{3}{*}{$\begin{array}{c}\text { Condition } \\
\text { Value } \\
(\mathbf{1 = d r y ,}, \\
2=\text { normal, } \\
\text { or } 3=\text { wet })\end{array}$} & \multirow[t]{2}{*}{$\begin{array}{l}\text { Month } \\
\text { weight }\end{array}$} & \multirow{2}{*}{$\begin{array}{c}\text { Multiply } \\
\text { Previous two } \\
\text { columns } \\
\end{array}$} \\
\hline & Name & $30^{\text {th }}$ & 70th & & & & & \\
\hline & & \multicolumn{3}{|c|}{----------cm----------- } & & & & \\
\hline $1^{\mathrm{st}}$ (most recent) & April & 2.90 & 5.64 & 10.98 & Wet & 3 & 3 & 9 \\
\hline 2nd & March & 2.39 & 3.73 & 1.70 & Dry & 1 & 2 & 2 \\
\hline $3 \mathrm{rd}$ & Feb & 0.97 & 1.91 & 1.44 & Normal & 3 & 1 & 3 \\
\hline \multirow{2}{*}{\multicolumn{8}{|c|}{$\begin{array}{l}\text { Rainfall of prior period was: } \\
\text { drier than normal (sum is 6-9), normal (sum is 10-14), wetter than normal (sum is 15-18) }\end{array}$}} & 14 \\
\hline & & & & & & & & Normal \\
\hline
\end{tabular}

Table C.78: DAREM and Modified DAREM calculations for period that met wetland hydrology for plots S1 and S2 at the Marcell Experimental Forest within the year 1962.

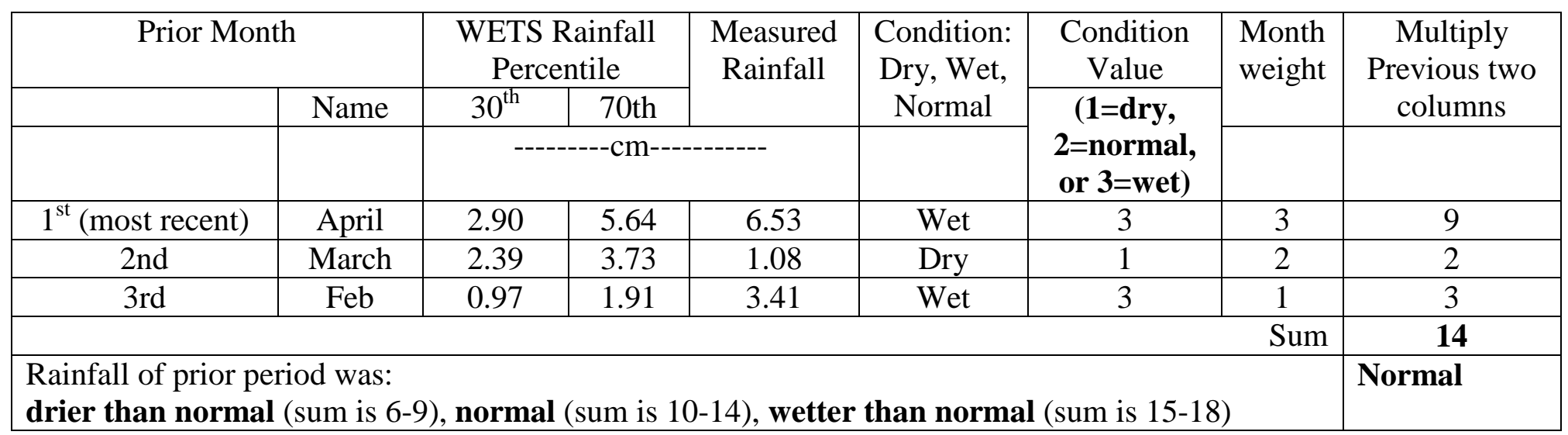


Table C.79: DAREM and Modified DAREM calculations for period that met wetland hydrology for plot S2 at the Marcell Experimental Forest within the year 1963.

\begin{tabular}{|c|c|c|c|c|c|c|c|c|}
\hline \multicolumn{2}{|c|}{ Prior Month } & \multicolumn{2}{|c|}{$\begin{array}{l}\text { WETS Rainfall } \\
\text { Percentile }\end{array}$} & \multirow[t]{2}{*}{$\begin{array}{l}\text { Measured } \\
\text { Rainfall }\end{array}$} & \multirow{2}{*}{$\begin{array}{c}\text { Condition: } \\
\text { Dry, Wet, } \\
\text { Normal }\end{array}$} & \multirow{3}{*}{$\begin{array}{c}\text { Condition } \\
\text { Value } \\
(\mathbf{1 = d r y ,}, \\
2=\text { normal, } \\
\text { or } 3=\text { wet })\end{array}$} & \multirow[t]{2}{*}{$\begin{array}{l}\text { Month } \\
\text { weight }\end{array}$} & \multirow{2}{*}{$\begin{array}{c}\text { Multiply } \\
\text { Previous two } \\
\text { columns } \\
\end{array}$} \\
\hline & Name & $30^{\text {th }}$ & 70th & & & & & \\
\hline & & \multicolumn{3}{|c|}{----------cm----------- } & & & & \\
\hline $1^{\mathrm{st}}$ (most recent) & Aug & 6.02 & 11.33 & 6.65 & Normal & 2 & 3 & 6 \\
\hline 2nd & July & 8.13 & 13.89 & 15.64 & Wet & 3 & 2 & 6 \\
\hline $3 \mathrm{rd}$ & June & 8.41 & 13.79 & 11.51 & Normal & 2 & 1 & 2 \\
\hline \multirow{2}{*}{\multicolumn{8}{|c|}{$\begin{array}{l}\text { Rainfall of prior period was: } \\
\text { drier than normal (sum is 6-9), normal (sum is 10-14), wetter than normal (sum is 15-18) }\end{array}$}} & 14 \\
\hline & & & & & & & & Normal \\
\hline
\end{tabular}

Table C.80: DAREM and Modified DAREM calculations for period that met wetland hydrology for plot S2 at the Marcell Experimental Forest within the year 1964.

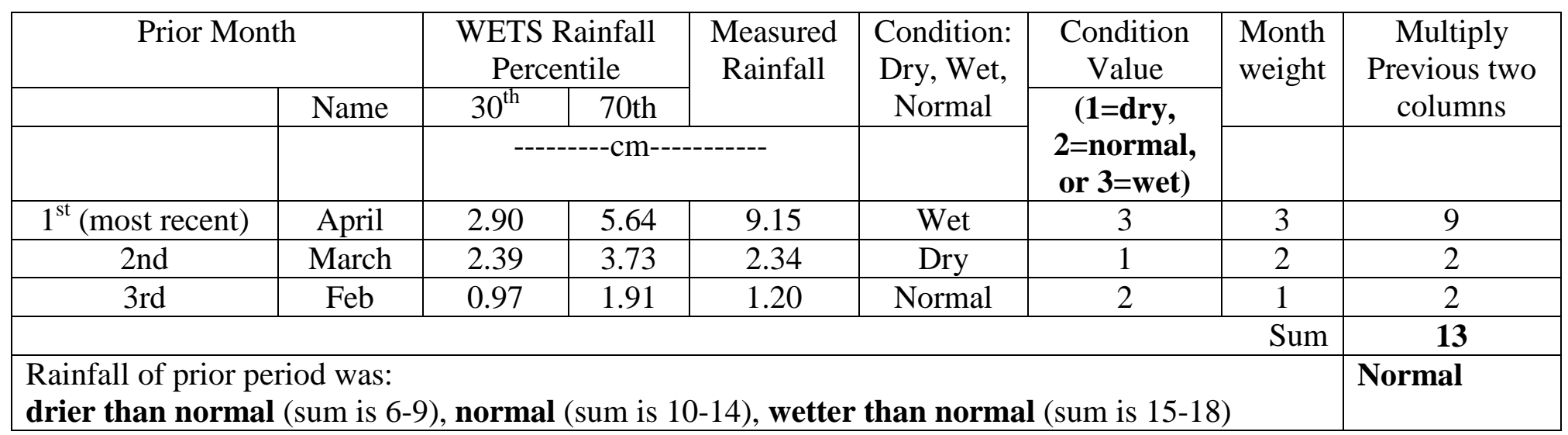


Table C.81: DAREM and Modified DAREM calculations for period that met wetland hydrology for plots S1 and S2 at the Marcell Experimental Forest within the year 1965.

\begin{tabular}{|c|c|c|c|c|c|c|c|c|}
\hline \multicolumn{2}{|c|}{ Prior Month } & \multicolumn{2}{|c|}{$\begin{array}{l}\text { WETS Rainfall } \\
\text { Percentile }\end{array}$} & \multirow[t]{2}{*}{$\begin{array}{l}\text { Measured } \\
\text { Rainfall }\end{array}$} & \multirow{2}{*}{$\begin{array}{l}\text { Condition: } \\
\text { Dry, Wet, } \\
\text { Normal }\end{array}$} & \multirow{3}{*}{ 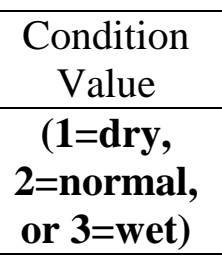 } & \multirow[t]{2}{*}{$\begin{array}{l}\text { Month } \\
\text { weight }\end{array}$} & \multirow{2}{*}{$\begin{array}{c}\text { Multiply } \\
\text { Previous two } \\
\text { columns }\end{array}$} \\
\hline & Name & $30^{\text {th }}$ & 70th & & & & & \\
\hline & & \multicolumn{3}{|c|}{----------cm------------ } & & & & \\
\hline $1^{\text {st }}($ most recent $)$ & April & 2.90 & 5.64 & 3.11 & Normal & 2 & 3 & 6 \\
\hline 2nd & March & 2.39 & 3.73 & 7.46 & Wet & 3 & 2 & 6 \\
\hline $3 \mathrm{rd}$ & Feb & 0.97 & 1.91 & 1.22 & Normal & 2 & 1 & 2 \\
\hline \multirow{2}{*}{\multicolumn{8}{|c|}{$\begin{array}{l}\text { Rainfall of prior period was: } \\
\text { drier than normal (sum is 6-9), normal (sum is 10-14), wetter than normal (sum is 15-18) }\end{array}$}} & 14 \\
\hline & & & & & & & & Normal \\
\hline
\end{tabular}

Table C.82: DAREM and Modified DAREM calculations for period that met wetland hydrology for plots S1, S2 and S3 at the Marcell Experimental Forest within the year 1966.

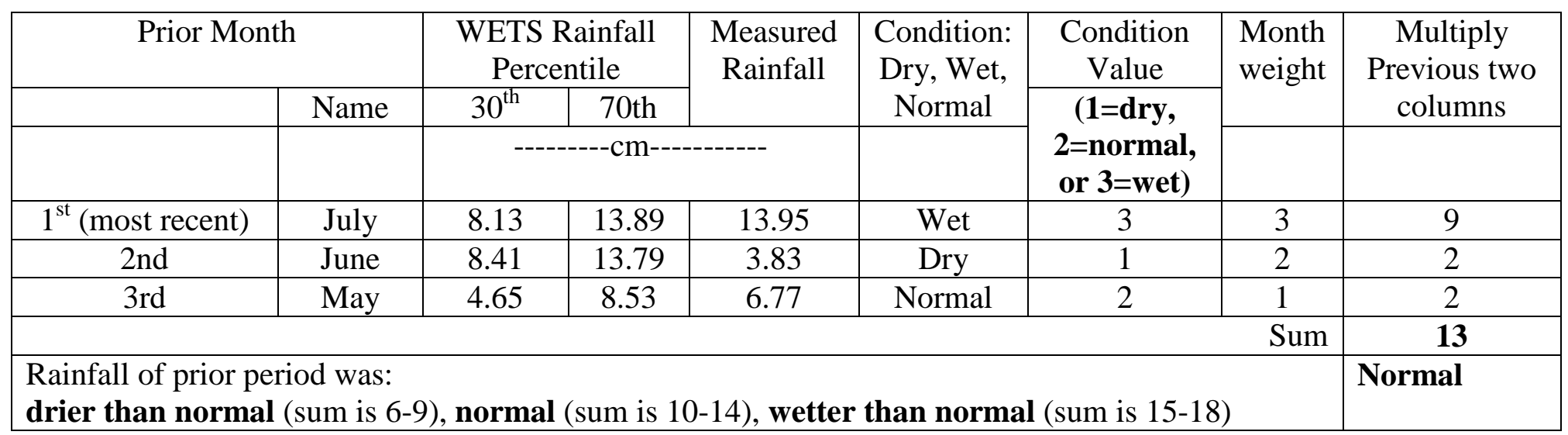


Table C.83: DAREM and Modified DAREM calculations for period that met wetland hydrology for plot S2 at the Marcell Experimental Forest within the year 1967.

\begin{tabular}{|c|c|c|c|c|c|c|c|c|}
\hline \multicolumn{2}{|c|}{ Prior Month } & \multicolumn{2}{|c|}{$\begin{array}{c}\text { WETS Rainfall } \\
\text { Percentile }\end{array}$} & \multirow[t]{2}{*}{$\begin{array}{l}\text { Measured } \\
\text { Rainfall }\end{array}$} & \multirow{2}{*}{$\begin{array}{c}\text { Condition: } \\
\text { Dry, Wet, } \\
\text { Normal }\end{array}$} & \multirow{3}{*}{$\begin{array}{c}\text { Condition } \\
\text { Value } \\
(\mathbf{1 = d r y ,}, \\
2=\text { normal, } \\
\text { or } 3=\text { wet })\end{array}$} & \multirow[t]{2}{*}{$\begin{array}{l}\text { Month } \\
\text { weight }\end{array}$} & \multirow{2}{*}{$\begin{array}{c}\text { Multiply } \\
\text { Previous two } \\
\text { columns } \\
\end{array}$} \\
\hline & Name & $30^{\text {th }}$ & 70th & & & & & \\
\hline & & \multicolumn{3}{|c|}{----------cm----------- } & & & & \\
\hline $1^{\mathrm{st}}$ (most recent) & May & 4.65 & 8.53 & 3.44 & Dry & 1 & 3 & 3 \\
\hline 2nd & April & 2.90 & 5.64 & 10.40 & Wet & 3 & 2 & 6 \\
\hline $3 \mathrm{rd}$ & March & 2.39 & 3.73 & 4.03 & Wet & 3 & 1 & 3 \\
\hline \multirow{2}{*}{\multicolumn{8}{|c|}{$\begin{array}{l}\text { Rainfall of prior period was: } \\
\text { drier than normal (sum is 6-9), normal (sum is 10-14), wetter than normal (sum is 15-18) }\end{array}$}} & 12 \\
\hline & & & & & & & & Normal \\
\hline
\end{tabular}

Table C.84: DAREM and Modified DAREM calculations for period that met wetland hydrology for plots S2 at the Marcell Experimental Forest within the year 1968.

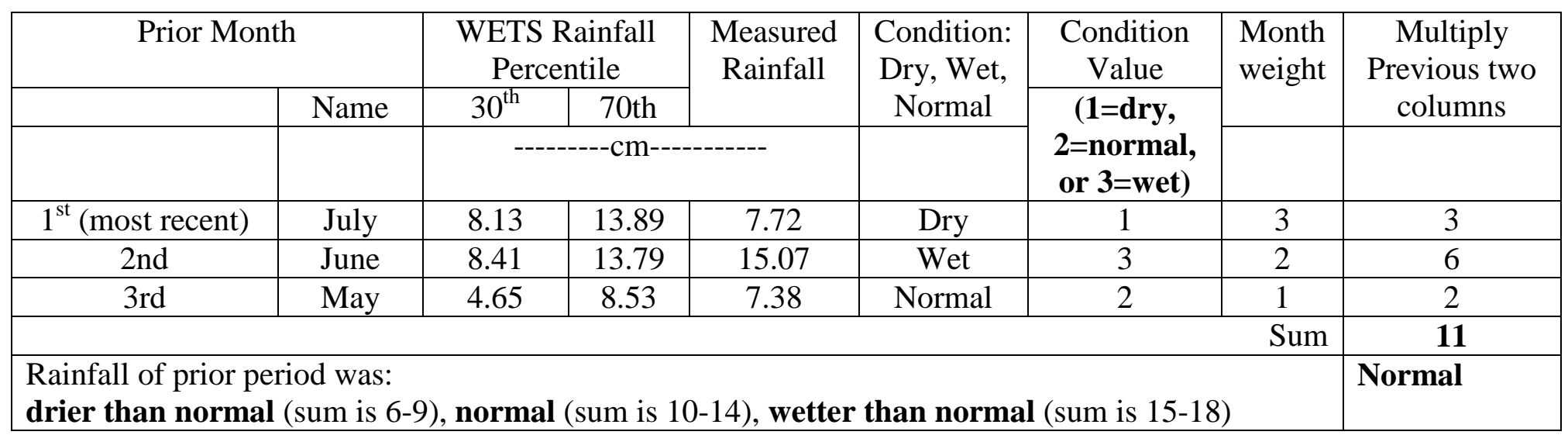


Table C.85: DAREM and Modified DAREM calculations for period that met wetland hydrology for plots S1 and S2 at the Marcell Experimental Forest within the year 1969.

\begin{tabular}{|c|c|c|c|c|c|c|c|c|}
\hline \multicolumn{2}{|c|}{ Prior Month } & \multicolumn{2}{|c|}{$\begin{array}{l}\text { WETS Rainfall } \\
\text { Percentile }\end{array}$} & \multirow[t]{2}{*}{$\begin{array}{c}\text { Measured } \\
\text { Rainfall }\end{array}$} & \multirow{2}{*}{$\begin{array}{l}\text { Condition: } \\
\text { Dry, Wet, } \\
\text { Normal }\end{array}$} & \multirow{3}{*}{$\begin{array}{c}\text { Condition } \\
\text { Value } \\
\text { (1=dry, } \\
2=\text { normal, } \\
\text { or } 3=\text { wet) }\end{array}$} & \multirow[t]{2}{*}{$\begin{array}{l}\text { Month } \\
\text { weight }\end{array}$} & \multirow{2}{*}{$\begin{array}{l}\text { Multiply } \\
\text { Previous two } \\
\text { columns }\end{array}$} \\
\hline & Name & $30^{\text {th }}$ & 70th & & & & & \\
\hline & & \multicolumn{3}{|c|}{---------cm----------- } & & & & \\
\hline $1^{\text {st }}$ (most recent) & April & 2.90 & 5.64 & 4.22 & Normal & 2 & 3 & 6 \\
\hline 2nd & March & 2.39 & 3.73 & 0.85 & Dry & 1 & 2 & 2 \\
\hline $3 \mathrm{rd}$ & Feb & 0.97 & 1.91 & 1.41 & Normal & 2 & 1 & 2 \\
\hline \multirow{2}{*}{\multicolumn{8}{|c|}{$\begin{array}{ll} & \text { Sum } \\
\text { Rainfall of prior period was: } & \\
\text { drier than normal (sum is 6-9), normal (sum is } 10-14), \text { wetter than normal (sum is 15-18) }\end{array}$}} & 10 \\
\hline & & & & & & & & Normal \\
\hline
\end{tabular}

Table C.86: DAREM and Modified DAREM calculations for period that met wetland hydrology for plots S1 and S2 at the Marcell Experimental Forest within the year 1970.

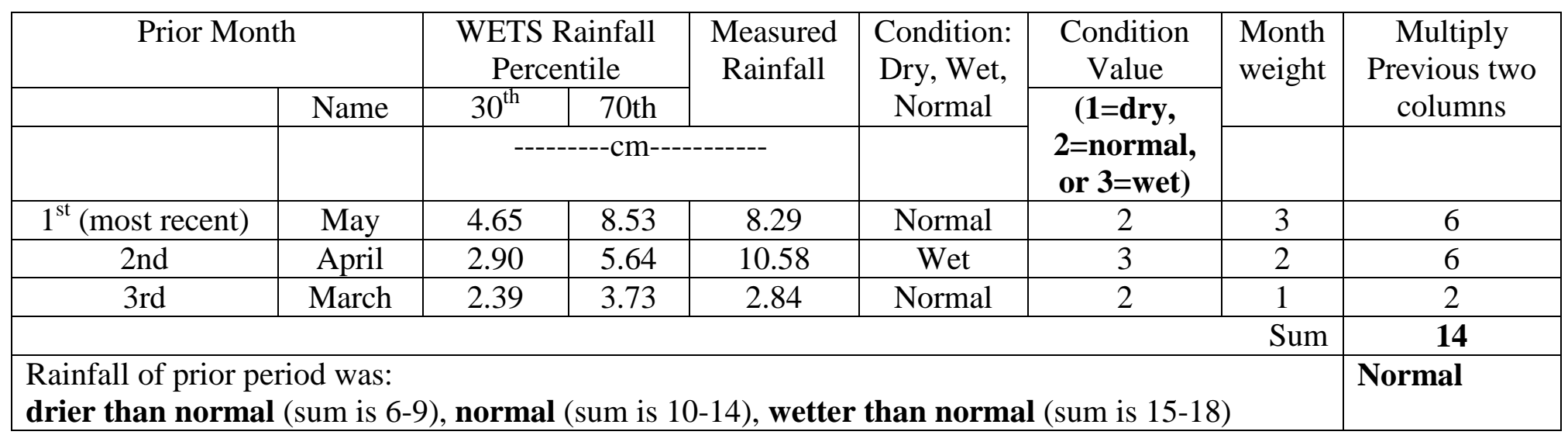


Table C.87: DAREM and Modified DAREM calculations for period that met wetland hydrology for plots S1 and S2 at the Marcell Experimental Forest within the year 1971.

\begin{tabular}{|c|c|c|c|c|c|c|c|c|}
\hline \multicolumn{2}{|c|}{ Prior Month } & \multicolumn{2}{|c|}{$\begin{array}{l}\text { WETS Rainfall } \\
\text { Percentile }\end{array}$} & \multirow[t]{2}{*}{$\begin{array}{c}\text { Measured } \\
\text { Rainfall }\end{array}$} & \multirow{2}{*}{$\begin{array}{l}\text { Condition: } \\
\text { Dry, Wet, } \\
\text { Normal }\end{array}$} & \multirow{3}{*}{$\begin{array}{c}\text { Condition } \\
\text { Value } \\
\text { (1=dry, } \\
2=\text { normal, } \\
\text { or } 3=\text { wet) }\end{array}$} & \multirow[t]{2}{*}{$\begin{array}{l}\text { Month } \\
\text { weight }\end{array}$} & \multirow{2}{*}{$\begin{array}{l}\text { Multiply } \\
\text { Previous two } \\
\text { columns }\end{array}$} \\
\hline & Name & $30^{\text {th }}$ & 70th & & & & & \\
\hline & & \multicolumn{3}{|c|}{---------cm----------- } & & & & \\
\hline $1^{\text {st }}$ (most recent) & April & 2.90 & 5.64 & 3.45 & Normal & 2 & 3 & 6 \\
\hline 2nd & March & 2.39 & 3.73 & 3.42 & Normal & 2 & 2 & 4 \\
\hline $3 \mathrm{rd}$ & Feb & 0.97 & 1.91 & 4.94 & Wet & 3 & 1 & 3 \\
\hline \multirow{2}{*}{\multicolumn{8}{|c|}{$\begin{array}{ll} & \text { Sum } \\
\text { Rainfall of prior period was: } & \\
\text { drier than normal (sum is 6-9), normal (sum is } 10-14), \text { wetter than normal (sum is 15-18) }\end{array}$}} & 13 \\
\hline & & & & & & & & Normal \\
\hline
\end{tabular}

Table C.88: DAREM and Modified DAREM calculations for period that met wetland hydrology for plots S1 and S2 at the Marcell Experimental Forest within the year 1972.

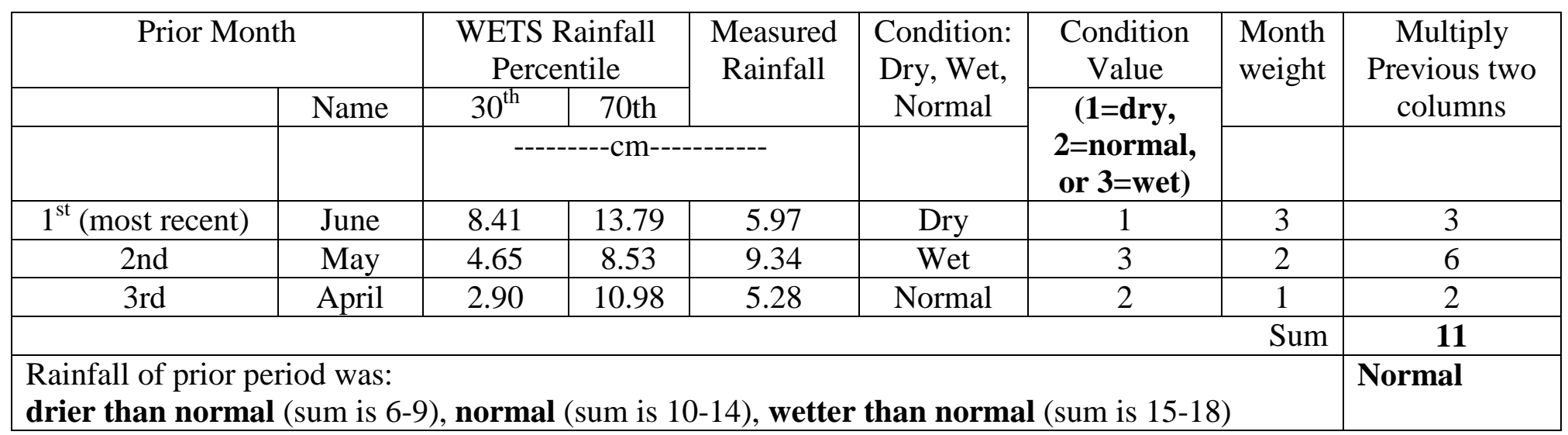


Table C.89: DAREM and Modified DAREM calculations for period that met wetland hydrology for plots S1 and S2 at the Marcell Experimental Forest within the year 1973.

\begin{tabular}{|c|c|c|c|c|c|c|c|c|}
\hline \multicolumn{2}{|c|}{ Prior Month } & \multicolumn{2}{|c|}{$\begin{array}{l}\text { WETS Rainfall } \\
\text { Percentile }\end{array}$} & \multirow[t]{2}{*}{$\begin{array}{c}\text { Measured } \\
\text { Rainfall }\end{array}$} & \multirow{2}{*}{$\begin{array}{l}\text { Condition: } \\
\text { Dry, Wet, } \\
\text { Normal }\end{array}$} & \multirow{3}{*}{$\begin{array}{c}\begin{array}{c}\text { Condition } \\
\text { Value }\end{array} \\
\text { (1=dry, } \\
2=\text { normal, } \\
\text { or } 3=\text { wet })\end{array}$} & \multirow[t]{2}{*}{$\begin{array}{l}\text { Month } \\
\text { weight }\end{array}$} & \multirow{2}{*}{$\begin{array}{l}\text { Multiply } \\
\text { Previous two } \\
\text { columns }\end{array}$} \\
\hline & Name & $30^{\text {th }}$ & 70th & & & & & \\
\hline & & \multicolumn{3}{|c|}{---------cm----------- } & & & & \\
\hline $1^{\text {st }}$ (most recent) & April & 2.90 & 5.64 & 1.86 & Dry & 1 & 3 & 3 \\
\hline 2nd & March & 2.39 & 3.73 & 3.72 & Normal & 2 & 2 & 4 \\
\hline $3 \mathrm{rd}$ & Feb & 0.97 & 1.91 & 0.19 & Dry & 1 & 1 & 1 \\
\hline \multirow{2}{*}{\multicolumn{8}{|c|}{$\begin{array}{ll} & \text { Sum } \\
\text { Rainfall of prior period was: } & \\
\text { drier than normal (sum is 6-9), normal (sum is } 10-14), \text { wetter than normal (sum is 15-18) }\end{array}$}} & 8 \\
\hline & & & & & & & & Dry \\
\hline
\end{tabular}

Table C.90: DAREM and Modified DAREM calculations for period that met wetland hydrology for plot S2 at the Marcell Experimental Forest within the year 1974.

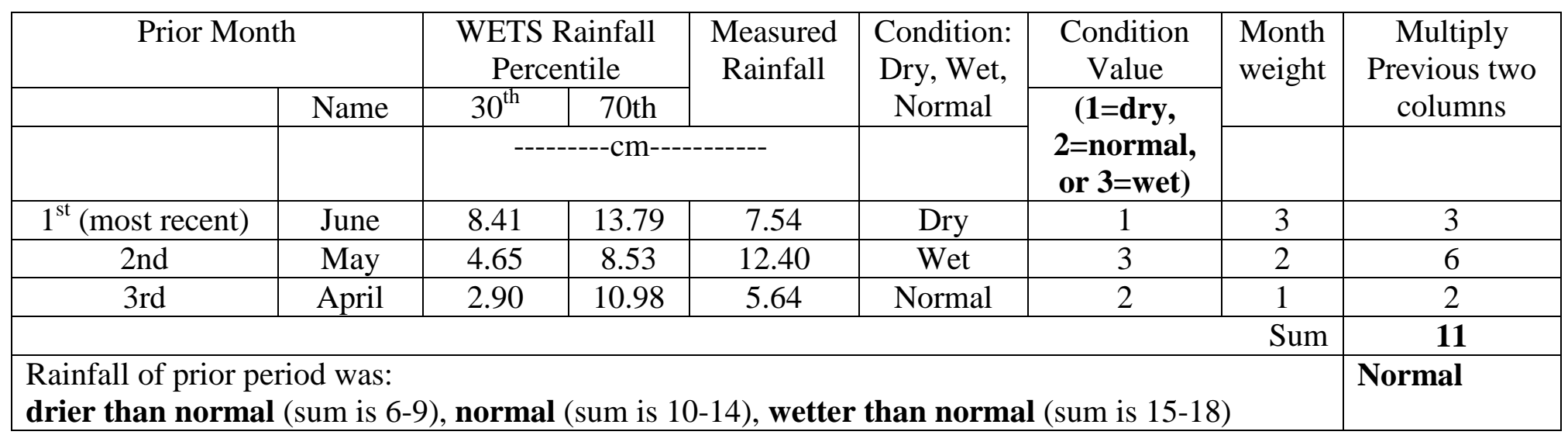


Table C.91: DAREM and Modified DAREM calculations for period that met wetland hydrology for plots S1 and S2 at the Marcell Experimental Forest within the year 1975.

\begin{tabular}{|c|c|c|c|c|c|c|c|c|}
\hline \multicolumn{2}{|c|}{ Prior Month } & \multicolumn{2}{|c|}{$\begin{array}{l}\text { WETS Rainfall } \\
\text { Percentile }\end{array}$} & \multirow[t]{2}{*}{$\begin{array}{c}\text { Measured } \\
\text { Rainfall }\end{array}$} & \multirow{2}{*}{$\begin{array}{c}\text { Condition: } \\
\text { Dry, Wet, } \\
\text { Normal }\end{array}$} & \multirow{3}{*}{$\begin{array}{c}\text { Condition } \\
\text { Value } \\
\text { (1=dry, } \\
2=\text { normal, } \\
\text { or } 3=\text { wet })\end{array}$} & \multirow[t]{2}{*}{$\begin{array}{l}\text { Month } \\
\text { weight }\end{array}$} & \multirow{2}{*}{$\begin{array}{c}\text { Multiply } \\
\text { Previous two } \\
\text { columns } \\
\end{array}$} \\
\hline & Name & $30^{\text {th }}$ & 70th & & & & & \\
\hline & & \multicolumn{3}{|c|}{---------cm---------- } & & & & \\
\hline $1^{\text {st }}$ (most recent) & June & 8.41 & 13.79 & 10.72 & Normal & 2 & 3 & 6 \\
\hline $2 \mathrm{nd}$ & May & 4.65 & 8.53 & 6.97 & Normal & 2 & 2 & 4 \\
\hline 3rd & April & 2.90 & 10.98 & 6.30 & Normal & 2 & 1 & 2 \\
\hline \multirow{2}{*}{\multicolumn{8}{|c|}{$\begin{array}{l}\text { Rainfall of prior period was: } \\
\text { drier than normal (sum is 6-9), normal (sum is } 10-14 \text { ), wetter than normal (sum is } 15-18 \text { ) }\end{array}$}} & 12 \\
\hline & & & & & & & & Normal \\
\hline
\end{tabular}

Table C.92: DAREM and Modified DAREM calculations for period that met wetland hydrology for plot S2 at the Marcell Experimental Forest within the year 1976.

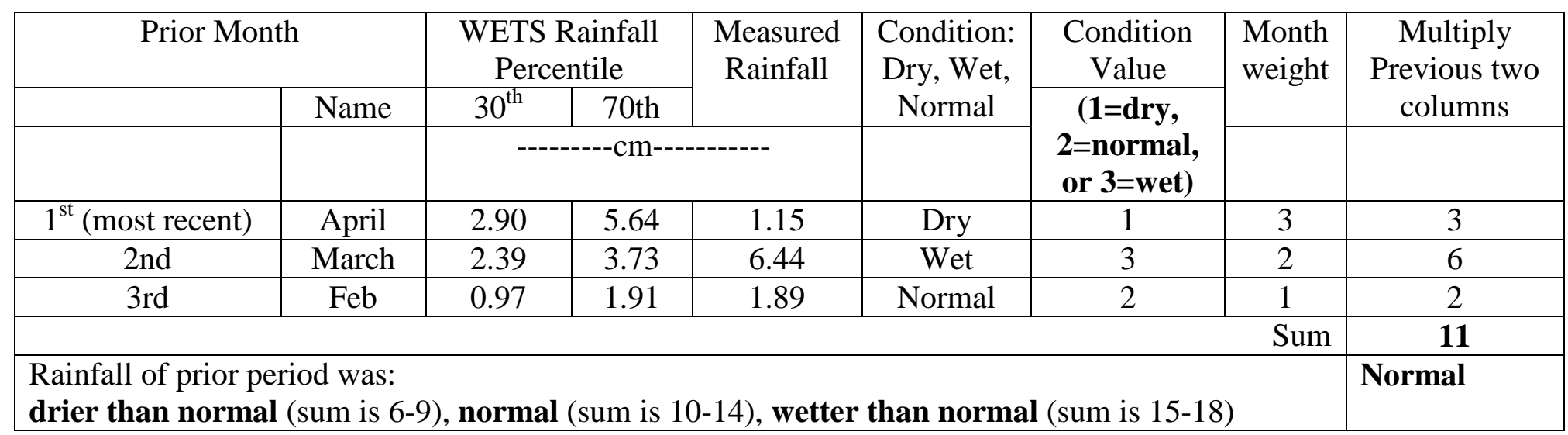


Table C.93: DAREM and Modified DAREM calculations for period that met wetland hydrology for plots S2 and S6 at the Marcell Experimental Forest within the year 1977.

\begin{tabular}{|c|c|c|c|c|c|c|c|c|}
\hline \multicolumn{2}{|c|}{ Prior Month } & \multicolumn{2}{|c|}{$\begin{array}{l}\text { WETS Rainfall } \\
\text { Percentile }\end{array}$} & \multirow[t]{2}{*}{$\begin{array}{c}\text { Measured } \\
\text { Rainfall }\end{array}$} & \multirow{2}{*}{$\begin{array}{c}\text { Condition: } \\
\text { Dry, Wet, } \\
\text { Normal }\end{array}$} & \multirow{3}{*}{$\begin{array}{c}\text { Condition } \\
\text { Value } \\
\text { (1=dry, } \\
2=\text { normal, } \\
\text { or } 3=\text { wet })\end{array}$} & \multirow[t]{2}{*}{$\begin{array}{l}\text { Month } \\
\text { weight }\end{array}$} & \multirow{2}{*}{$\begin{array}{c}\text { Multiply } \\
\text { Previous two } \\
\text { columns } \\
\end{array}$} \\
\hline & Name & $30^{\text {th }}$ & 70th & & & & & \\
\hline & & \multicolumn{3}{|c|}{---------cm---------- } & & & & \\
\hline $1^{\text {st }}$ (most recent) & June & 8.41 & 13.79 & 12.28 & Normal & 2 & 3 & 6 \\
\hline $2 \mathrm{nd}$ & May & 4.65 & 8.53 & 11.70 & Wet & 3 & 2 & 6 \\
\hline 3rd & April & 2.90 & 10.98 & 3.43 & Normal & 2 & 1 & 2 \\
\hline \multirow{2}{*}{\multicolumn{8}{|c|}{$\begin{array}{l}\text { Rainfall of prior period was: } \\
\text { drier than normal (sum is 6-9), normal (sum is } 10-14 \text { ), wetter than normal (sum is } 15-18 \text { ) }\end{array}$}} & 14 \\
\hline & & & & & & & & Normal \\
\hline
\end{tabular}

Table C.94: DAREM and Modified DAREM calculations for period that met wetland hydrology for plots S1 and S6 at the Marcell Experimental Forest within the year 1978.

\begin{tabular}{|c|c|c|c|c|c|c|c|c|}
\hline \multicolumn{2}{|c|}{ Prior Month } & \multicolumn{2}{|c|}{$\begin{array}{l}\text { WETS Rainfall } \\
\text { Percentile }\end{array}$} & \multirow[t]{2}{*}{$\begin{array}{l}\text { Measured } \\
\text { Rainfall }\end{array}$} & \multirow{2}{*}{$\begin{array}{l}\text { Condition: } \\
\text { Dry, Wet, } \\
\text { Normal }\end{array}$} & \multirow{3}{*}{$\begin{array}{c}\text { Condition } \\
\text { Value } \\
(\mathbf{1 = d r y ,}, \\
\begin{array}{c}2=\text { normal, } \\
\text { or } 3=\text { wet })\end{array}\end{array}$} & \multirow[t]{3}{*}{$\begin{array}{l}\text { Month } \\
\text { weight }\end{array}$} & \multirow{2}{*}{$\begin{array}{c}\text { Multiply } \\
\text { Previous two } \\
\text { columns } \\
\end{array}$} \\
\hline & Name & $30^{\text {th }}$ & 70th & & & & & \\
\hline & & \multicolumn{3}{|c|}{----------cm------------ } & & & & \\
\hline $1^{\mathrm{st}}$ (most recent) & June & 8.41 & 13.79 & 6.59 & Dry & 1 & 3 & 3 \\
\hline 2 nd & May & 4.65 & 8.53 & 9.97 & Wet & 3 & 2 & 6 \\
\hline $3 \mathrm{rd}$ & April & 2.90 & 10.98 & 4.02 & Normal & 2 & 1 & 2 \\
\hline \multirow{2}{*}{\multicolumn{8}{|c|}{$\begin{array}{l}\text { Rainfall of prior period was: } \\
\text { drier than normal (sum is } 6-9 \text { ), normal (sum is } 10-14 \text { ), wetter than normal (sum is } 15-18 \text { ) }\end{array}$}} & 11 \\
\hline & & & & & & & & Normal \\
\hline
\end{tabular}


Table C.95: DAREM and Modified DAREM calculations for period that met wetland hydrology for plot S2 at the Marcell Experimental Forest within the year 1979.

\begin{tabular}{|c|c|c|c|c|c|c|c|c|}
\hline \multicolumn{2}{|c|}{ Prior Month } & \multicolumn{2}{|c|}{$\begin{array}{c}\text { WETS Rainfall } \\
\text { Percentile }\end{array}$} & \multirow[t]{2}{*}{$\begin{array}{l}\text { Measured } \\
\text { Rainfall }\end{array}$} & \multirow{2}{*}{$\begin{array}{c}\text { Condition: } \\
\text { Dry, Wet, } \\
\text { Normal }\end{array}$} & \multirow{3}{*}{$\begin{array}{c}\text { Condition } \\
\text { Value } \\
(\mathbf{1 = d r y ,}, \\
2=\text { normal, } \\
\text { or } 3=\text { wet })\end{array}$} & \multirow[t]{2}{*}{$\begin{array}{l}\text { Month } \\
\text { weight }\end{array}$} & \multirow{2}{*}{$\begin{array}{c}\text { Multiply } \\
\text { Previous two } \\
\text { columns } \\
\end{array}$} \\
\hline & Name & $30^{\text {th }}$ & 70th & & & & & \\
\hline & & \multicolumn{3}{|c|}{----------cm----------- } & & & & \\
\hline $1^{\mathrm{st}}$ (most recent) & May & 4.65 & 8.53 & 6.52 & Normal & 2 & 3 & 6 \\
\hline 2nd & April & 2.90 & 5.64 & 3.59 & Normal & 2 & 2 & 4 \\
\hline 3rd & March & 2.39 & 3.73 & 8.94 & Wet & 3 & 1 & 3 \\
\hline \multirow{2}{*}{\multicolumn{8}{|c|}{$\begin{array}{l}\text { Rainfall of prior period was: } \\
\text { drier than normal (sum is 6-9), normal (sum is 10-14), wetter than normal (sum is 15-18) }\end{array}$}} & 13 \\
\hline & & & & & & & & Normal \\
\hline
\end{tabular}

Table C.96: DAREM and Modified DAREM calculations for period that met wetland hydrology for plot S2 at the Marcell Experimental Forest within the year 1980.

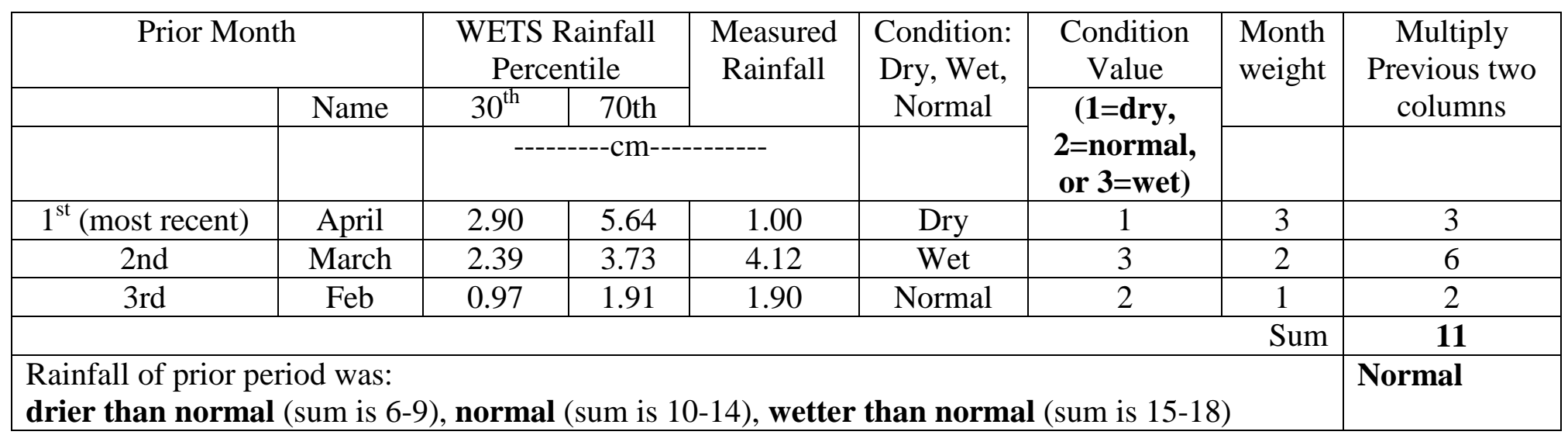


Table C.97: DAREM and Modified DAREM calculations for period that met wetland hydrology for plots S1 and S2 at the Marcell Experimental Forest within the year 1981.

\begin{tabular}{|c|c|c|c|c|c|c|c|c|}
\hline \multicolumn{2}{|c|}{ Prior Month } & \multicolumn{2}{|c|}{$\begin{array}{l}\text { WETS Rainfall } \\
\text { Percentile }\end{array}$} & \multirow[t]{2}{*}{$\begin{array}{c}\text { Measured } \\
\text { Rainfall }\end{array}$} & \multirow{2}{*}{$\begin{array}{l}\text { Condition: } \\
\text { Dry, Wet, } \\
\text { Normal }\end{array}$} & \multirow{3}{*}{$\begin{array}{c}\text { Condition } \\
\text { Value }\end{array}$} & \multirow[t]{2}{*}{$\begin{array}{l}\text { Month } \\
\text { weight }\end{array}$} & \multirow{2}{*}{$\begin{array}{l}\text { Multiply } \\
\text { Previous two } \\
\text { columns }\end{array}$} \\
\hline & Name & $30^{\text {th }}$ & 70th & & & & & \\
\hline & & \multicolumn{3}{|c|}{----------cm------------ } & & & & \\
\hline $1^{\text {st }}($ most recent $)$ & May & 4.65 & 8.53 & 3.03 & Dry & 1 & 3 & 3 \\
\hline 2nd & April & 2.90 & 5.64 & 10.20 & Wet & 3 & 2 & 6 \\
\hline $3 \mathrm{rd}$ & March & 2.39 & 3.73 & 3.65 & Normal & 2 & 1 & 2 \\
\hline \multirow{2}{*}{\multicolumn{8}{|c|}{$\begin{array}{ll} & \text { Sum } \\
\text { Rainfall of prior period was: } & \\
\text { drier than normal (sum is 6-9), normal (sum is 10-14), wetter than normal (sum is 15-18) }\end{array}$}} & 11 \\
\hline & & & & & & & & Normal \\
\hline
\end{tabular}

Table C.98: DAREM and Modified DAREM calculations for period that met wetland hydrology for plots S1, S2, S3 and S6 at the Marcell Experimental Forest within the year 1982.

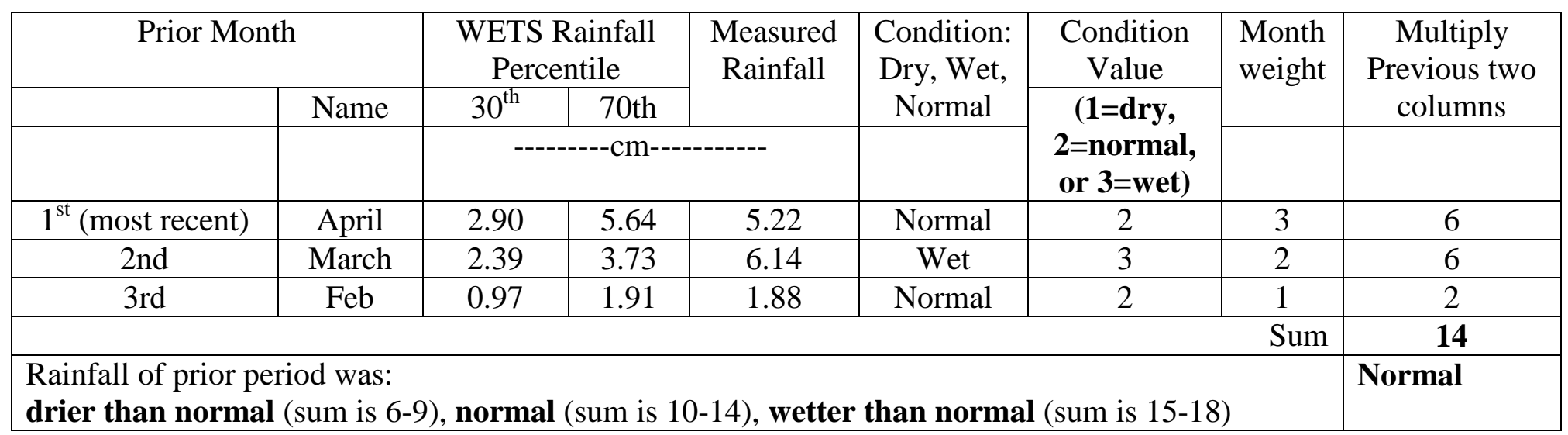


Table C.99: DAREM and Modified DAREM calculations for period that met wetland hydrology for plots S1, S2, S3 and S6 at the Marcell Experimental Forest within the year 1983.

\begin{tabular}{|c|c|c|c|c|c|c|c|c|}
\hline \multicolumn{2}{|c|}{ Prior Month } & \multicolumn{2}{|c|}{$\begin{array}{l}\text { WETS Rainfall } \\
\text { Percentile }\end{array}$} & \multirow[t]{2}{*}{$\begin{array}{c}\text { Measured } \\
\text { Rainfall }\end{array}$} & \multirow{2}{*}{$\begin{array}{c}\text { Condition: } \\
\text { Dry, Wet, } \\
\text { Normal } \\
\end{array}$} & \multirow{3}{*}{$\begin{array}{c}\text { Condition } \\
\text { Value }\end{array}$} & \multirow[t]{2}{*}{$\begin{array}{l}\text { Month } \\
\text { weight }\end{array}$} & \multirow{2}{*}{$\begin{array}{c}\text { Multiply } \\
\text { Previous two } \\
\text { columns }\end{array}$} \\
\hline & Name & $30^{\text {th }}$ & 70th & & & & & \\
\hline & & \multicolumn{3}{|c|}{----------cm------------ } & & & & \\
\hline $1^{\text {st }}$ (most recent) & April & 2.90 & 5.64 & 2.70 & Dry & 1 & 3 & 3 \\
\hline 2nd & March & 2.39 & 3.73 & 3.56 & Normal & 2 & 2 & 4 \\
\hline 3rd & Feb & 0.97 & 1.91 & 1.42 & Normal & 2 & 1 & 2 \\
\hline \multirow{2}{*}{\multicolumn{8}{|c|}{$\begin{array}{ll} & \text { Sum } \\
\text { Rainfall of prior period was: } & \end{array}$}} & 9 \\
\hline & & & & & & & & Dry \\
\hline
\end{tabular}

Table C.100: DAREM and Modified DAREM calculations for period that met wetland hydrology for plots S1, S2, and S6 at the Marcell Experimental Forest within the year 1984.

\begin{tabular}{|c|c|c|c|c|c|c|c|c|}
\hline \multicolumn{2}{|c|}{ Prior Month } & \multicolumn{2}{|c|}{$\begin{array}{l}\text { WETS Rainfall } \\
\text { Percentile }\end{array}$} & \multirow[t]{2}{*}{$\begin{array}{c}\text { Measured } \\
\text { Rainfall }\end{array}$} & \multirow{2}{*}{$\begin{array}{l}\text { Condition: } \\
\text { Dry, Wet, } \\
\text { Normal }\end{array}$} & \multirow{3}{*}{ 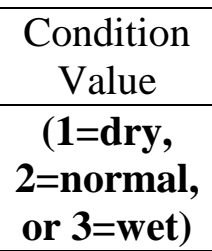 } & \multirow[t]{3}{*}{$\begin{array}{l}\text { Month } \\
\text { weight }\end{array}$} & \multirow{2}{*}{$\begin{array}{c}\text { Multiply } \\
\text { Previous two } \\
\text { columns } \\
\end{array}$} \\
\hline & Name & $30^{\text {th }}$ & 70th & & & & & \\
\hline & & \multicolumn{3}{|c|}{---------cm----------- } & & & & \\
\hline $1^{\mathrm{st}}$ (most recent) & April & 2.90 & 5.64 & 4.47 & Normal & 2 & 3 & 6 \\
\hline $2 \mathrm{nd}$ & March & 2.39 & 3.73 & 1.28 & Dry & 1 & 2 & 2 \\
\hline $3 \mathrm{rd}$ & Feb & 0.97 & 1.91 & 2.14 & Wet & 3 & 1 & 3 \\
\hline \multirow{2}{*}{\multicolumn{8}{|c|}{$\begin{array}{ll} & \text { Sum } \\
\text { Rainfall of prior period was: } & \end{array}$}} & 11 \\
\hline & & & & & & & & Normal \\
\hline
\end{tabular}


Table C.101: DAREM and Modified DAREM calculations for period that met wetland hydrology for plots S1, S2, S3 and S6 at the Marcell Experimental Forest within the year 1985.

\begin{tabular}{|c|c|c|c|c|c|c|c|c|}
\hline \multicolumn{2}{|c|}{ Prior Month } & \multicolumn{2}{|c|}{$\begin{array}{l}\text { WETS Rainfall } \\
\text { Percentile }\end{array}$} & \multirow[t]{2}{*}{$\begin{array}{l}\text { Measured } \\
\text { Rainfall }\end{array}$} & \multirow{2}{*}{$\begin{array}{c}\text { Condition: } \\
\text { Dry, Wet, } \\
\text { Normal }\end{array}$} & \multirow{3}{*}{$\begin{array}{c}\text { Condition } \\
\text { Value } \\
(\mathbf{1 = d r y ,}, \\
2=\text { normal, } \\
\text { or } 3=\text { wet })\end{array}$} & \multirow[t]{2}{*}{$\begin{array}{l}\text { Month } \\
\text { weight }\end{array}$} & \multirow{2}{*}{$\begin{array}{c}\text { Multiply } \\
\text { Previous two } \\
\text { columns } \\
\end{array}$} \\
\hline & Name & $30^{\text {th }}$ & 70th & & & & & \\
\hline & & \multicolumn{3}{|c|}{----------cm----------- } & & & & \\
\hline $1^{\mathrm{st}}$ (most recent) & Aug & 6.02 & 11.33 & 10.49 & Normal & 2 & 3 & 6 \\
\hline 2nd & July & 8.13 & 13.89 & 9.41 & Normal & 2 & 2 & 4 \\
\hline 3rd & June & 8.41 & 13.79 & 12.05 & Normal & 2 & 1 & 2 \\
\hline \multirow{2}{*}{\multicolumn{8}{|c|}{$\begin{array}{l}\text { Rainfall of prior period was: } \\
\text { drier than normal (sum is 6-9), normal (sum is 10-14), wetter than normal (sum is 15-18) }\end{array}$}} & 12 \\
\hline & & & & & & & & Normal \\
\hline
\end{tabular}

Table C.102: DAREM and Modified DAREM calculations for period that met wetland hydrology for plots S1, S2, S3 and S6 at the Marcell Experimental Forest within the year 1986.

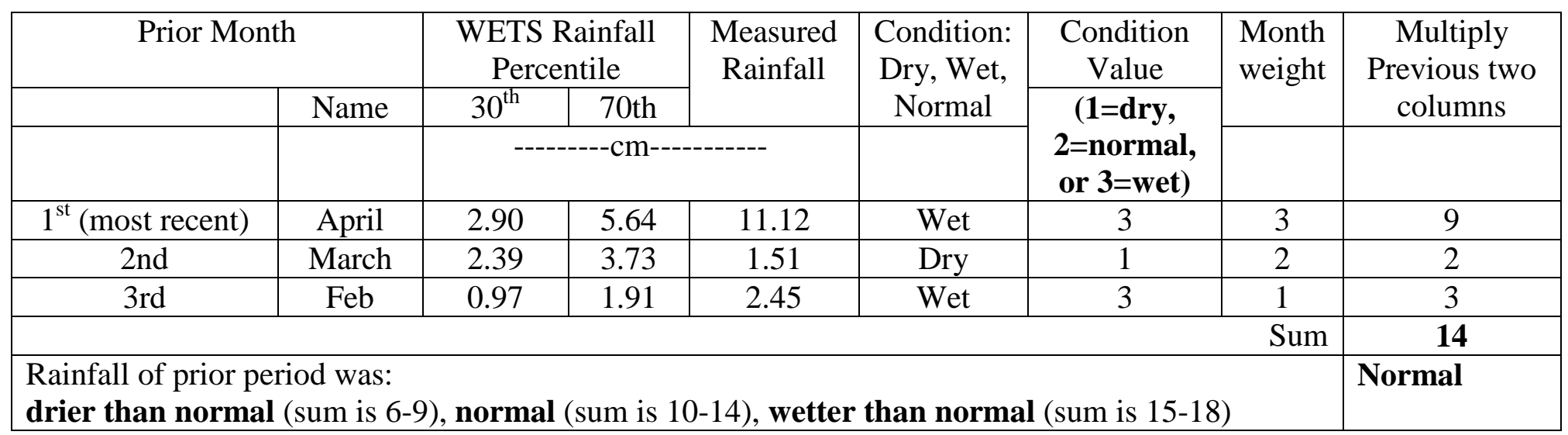


Table C.103: DAREM and Modified DAREM calculations for period that met wetland hydrology for plots S1, S2, S3 and S6 at the Marcell Experimental Forest within the year 1987.

\begin{tabular}{|c|c|c|c|c|c|c|c|c|}
\hline \multicolumn{2}{|c|}{ Prior Month } & \multicolumn{2}{|c|}{$\begin{array}{l}\text { WETS Rainfall } \\
\text { Percentile }\end{array}$} & \multirow[t]{2}{*}{$\begin{array}{c}\text { Measured } \\
\text { Rainfall }\end{array}$} & \multirow{2}{*}{$\begin{array}{c}\text { Condition: } \\
\text { Dry, Wet, } \\
\text { Normal } \\
\end{array}$} & \multirow{3}{*}{$\begin{array}{c}\text { Condition } \\
\text { Value } \\
\text { (1=dry, } \\
2=\text { normal, } \\
\text { or } 3=\text { wet })\end{array}$} & \multirow[t]{2}{*}{$\begin{array}{l}\text { Month } \\
\text { weight }\end{array}$} & \multirow{2}{*}{$\begin{array}{c}\text { Multiply } \\
\text { Previous two } \\
\text { columns }\end{array}$} \\
\hline & Name & $30^{\text {th }}$ & 70th & & & & & \\
\hline & & \multicolumn{3}{|c|}{--------cm-------- } & & & & \\
\hline $1^{\text {st }}$ (most recent) & April & 2.90 & 5.64 & 0.67 & Dry & 1 & 3 & 3 \\
\hline $2 \mathrm{nd}$ & March & 2.39 & 3.73 & 3.32 & Normal & 2 & 2 & 4 \\
\hline 3rd & Feb & 0.97 & 1.91 & 1.28 & Normal & 2 & 1 & 2 \\
\hline \multirow{2}{*}{\multicolumn{8}{|c|}{$\begin{array}{l}\text { Rainfall of prior period was: } \\
\text { drier than normal (sum is 6-9), normal (sum is } 10-14 \text { ), wetter than normal (sum is } 15-18 \text { ) }\end{array}$}} & 9 \\
\hline & & & & & & & & Dry \\
\hline
\end{tabular}

Table C.104: DAREM and Modified DAREM calculations for period that met wetland hydrology for plots S1, S2, S3 and S6 at the Marcell Experimental Forest within the year 1988.

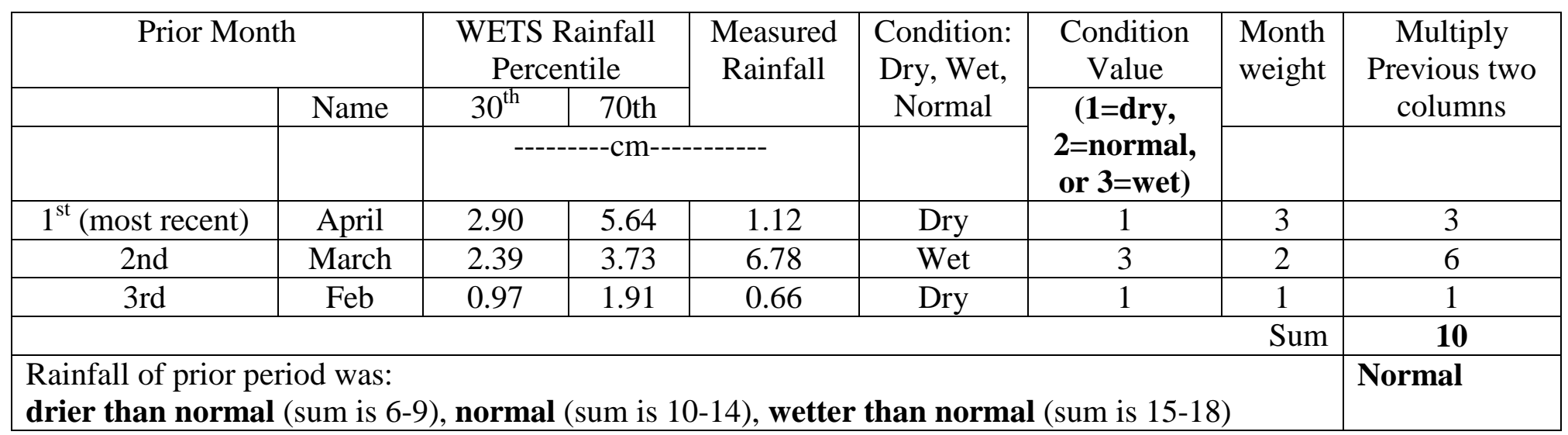


Table C.105: DAREM and Modified DAREM calculations for period that met wetland hydrology for plots S1, S2, and S3 at the Marcell Experimental Forest within the year 1989.

\begin{tabular}{|c|c|c|c|c|c|c|c|c|}
\hline \multicolumn{2}{|c|}{ Prior Month } & \multicolumn{2}{|c|}{$\begin{array}{c}\text { WETS Rainfall } \\
\text { Percentile }\end{array}$} & \multirow[t]{2}{*}{$\begin{array}{l}\text { Measured } \\
\text { Rainfall }\end{array}$} & \multirow{2}{*}{$\begin{array}{c}\text { Condition: } \\
\text { Dry, Wet, } \\
\text { Normal }\end{array}$} & \multirow{3}{*}{$\begin{array}{c}\text { Condition } \\
\text { Value } \\
(\mathbf{1 = d r y ,}, \\
2=\text { normal, } \\
\text { or } 3=\text { wet })\end{array}$} & \multirow[t]{2}{*}{$\begin{array}{l}\text { Month } \\
\text { weight }\end{array}$} & \multirow{2}{*}{$\begin{array}{c}\text { Multiply } \\
\text { Previous two } \\
\text { columns } \\
\end{array}$} \\
\hline & Name & $30^{\text {th }}$ & 70th & & & & & \\
\hline & & \multicolumn{3}{|c|}{----------cm----------- } & & & & \\
\hline $1^{\mathrm{st}}$ (most recent) & April & 2.90 & 5.64 & 4.39 & Normal & 2 & 3 & 6 \\
\hline 2nd & March & 2.39 & 3.73 & 2.76 & Normal & 2 & 2 & 4 \\
\hline 3rd & Feb & 0.97 & 1.91 & 1.40 & Normal & 2 & 1 & 2 \\
\hline \multirow{2}{*}{\multicolumn{8}{|c|}{$\begin{array}{l}\text { Rainfall of prior period was: } \\
\text { drier than normal (sum is 6-9), normal (sum is 10-14), wetter than normal (sum is 15-18) }\end{array}$}} & 12 \\
\hline & & & & & & & & Normal \\
\hline
\end{tabular}

Table C.106: DAREM and Modified DAREM calculations for period that met wetland hydrology for plots S1, S2, S3 and S6 at the Marcell Experimental Forest within the year 1990.

\begin{tabular}{|c|c|c|c|c|c|c|c|c|}
\hline \multicolumn{2}{|c|}{ Prior Month } & \multicolumn{2}{|c|}{$\begin{array}{l}\text { WETS Rainfall } \\
\text { Percentile }\end{array}$} & \multirow[t]{2}{*}{$\begin{array}{c}\text { Measured } \\
\text { Rainfall }\end{array}$} & \multirow{2}{*}{$\begin{array}{l}\text { Condition: } \\
\text { Dry, Wet, } \\
\text { Normal }\end{array}$} & \multirow{3}{*}{ 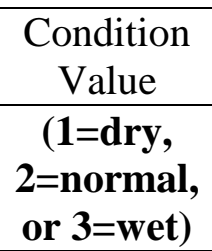 } & \multirow[t]{2}{*}{$\begin{array}{l}\text { Month } \\
\text { weight }\end{array}$} & \multirow{2}{*}{$\begin{array}{c}\text { Multiply } \\
\text { Previous two } \\
\text { columns } \\
\end{array}$} \\
\hline & Name & $30^{\text {th }}$ & 70th & & & & & \\
\hline & & \multicolumn{3}{|c|}{---------cm----------- } & & & & \\
\hline $1^{\mathrm{st}}$ (most recent) & May & 4.65 & 8.53 & 2.42 & Dry & 1 & 3 & 3 \\
\hline $2 \mathrm{nd}$ & April & 2.90 & 5.64 & 5.32 & Normal & 2 & 2 & 4 \\
\hline $3 \mathrm{rd}$ & March & 2.39 & 3.73 & 5.24 & Wet & 3 & 1 & 3 \\
\hline \multirow{2}{*}{\multicolumn{8}{|c|}{$\begin{array}{ll} & \text { Sum } \\
\text { Rainfall of prior period was: } & \end{array}$}} & 10 \\
\hline & & & & & & & & Normal \\
\hline
\end{tabular}


Table C.107: DAREM and Modified DAREM calculations for period that met wetland hydrology for plot S2 at the Marcell Experimental Forest within the year 1991.

\begin{tabular}{|c|c|c|c|c|c|c|c|c|}
\hline \multicolumn{2}{|c|}{ Prior Month } & \multicolumn{2}{|c|}{$\begin{array}{l}\text { WETS Rainfall } \\
\text { Percentile }\end{array}$} & \multirow[t]{2}{*}{$\begin{array}{l}\text { Measured } \\
\text { Rainfall }\end{array}$} & \multirow{2}{*}{$\begin{array}{l}\text { Condition: } \\
\text { Dry, Wet, } \\
\text { Normal }\end{array}$} & \multirow{3}{*}{$\begin{array}{c}\text { Condition } \\
\text { Value }\end{array}$} & \multirow[t]{2}{*}{$\begin{array}{l}\text { Month } \\
\text { weight }\end{array}$} & \multirow{2}{*}{$\begin{array}{l}\text { Multiply } \\
\text { Previous two } \\
\text { columns }\end{array}$} \\
\hline & Name & $30^{\text {th }}$ & 70th & & & & & \\
\hline & & \multicolumn{3}{|c|}{----------cm------------ } & & & & \\
\hline $1^{\text {st }}$ (most recent) & June & 8.41 & 13.79 & 10.49 & Normal & 2 & 3 & 6 \\
\hline 2nd & May & 4.65 & 8.53 & 7.64 & Normal & 2 & 2 & 4 \\
\hline $3 \mathrm{rd}$ & April & 2.90 & 10.98 & 7.03 & Normal & 2 & 1 & 2 \\
\hline \multirow{2}{*}{\multicolumn{8}{|c|}{$\begin{array}{ll} & \text { Sum } \\
\text { Rainfall of prior period was: } & \\
\text { drier than normal (sum is 6-9), normal (sum is } 10-14), \text { wetter than normal (sum is } 15-18)\end{array}$}} & 12 \\
\hline & & & & & & & & Normal \\
\hline
\end{tabular}

Table C.108: DAREM and Modified DAREM calculations for period that met wetland hydrology for plot S2 at the Marcell Experimental Forest within the year 1992.

\begin{tabular}{|c|c|c|c|c|c|c|c|c|}
\hline \multicolumn{2}{|c|}{ Prior Month } & \multicolumn{2}{|c|}{$\begin{array}{l}\text { WETS Rainfall } \\
\text { Percentile }\end{array}$} & \multirow[t]{2}{*}{$\begin{array}{l}\text { Measured } \\
\text { Rainfall }\end{array}$} & \multirow{2}{*}{$\begin{array}{c}\text { Condition: } \\
\text { Dry, Wet, } \\
\text { Normal } \\
\end{array}$} & \multirow{3}{*}{$\begin{array}{c}\begin{array}{c}\text { Condition } \\
\text { Value }\end{array} \\
\begin{array}{c}\text { (1=dry, } \\
2=\text { normal, } \\
\text { or } 3=\text { wet })\end{array}\end{array}$} & \multirow[t]{2}{*}{$\begin{array}{l}\text { Month } \\
\text { weight }\end{array}$} & \multirow{2}{*}{$\begin{array}{c}\text { Multiply } \\
\text { Previous two } \\
\text { columns }\end{array}$} \\
\hline & Name & $30^{\text {th }}$ & 70th & & & & & \\
\hline & & \multicolumn{3}{|c|}{----------cm------------ } & & & & \\
\hline $1^{\text {st }}$ (most recent) & April & 2.90 & 5.64 & 4.22 & Normal & 2 & 3 & 6 \\
\hline 2nd & March & 2.39 & 3.73 & 2.67 & Normal & 2 & 2 & 4 \\
\hline $3 \mathrm{rd}$ & Feb & 0.97 & 1.91 & 2.78 & Wet & 3 & 1 & 3 \\
\hline \multirow{2}{*}{\multicolumn{8}{|c|}{$\begin{array}{ll} & \text { Sum } \\
\text { Rainfall of prior period was: } & \end{array}$}} & 13 \\
\hline & & & & & & & & Normal \\
\hline
\end{tabular}


Table C.109: DAREM and Modified DAREM calculations for period that met wetland hydrology for plots S1, S2, and S6 at the Marcell Experimental Forest within the year 1993.

\begin{tabular}{|c|c|c|c|c|c|c|c|c|}
\hline \multicolumn{2}{|c|}{ Prior Month } & \multicolumn{2}{|c|}{$\begin{array}{c}\text { WETS Rainfall } \\
\text { Percentile }\end{array}$} & \multirow[t]{2}{*}{$\begin{array}{l}\text { Measured } \\
\text { Rainfall }\end{array}$} & \multirow{2}{*}{$\begin{array}{c}\text { Condition: } \\
\text { Dry, Wet, } \\
\text { Normal }\end{array}$} & \multirow{3}{*}{$\begin{array}{c}\text { Condition } \\
\text { Value } \\
(\mathbf{1 = d r y ,}, \\
2=\text { normal, } \\
\text { or } 3=\text { wet })\end{array}$} & \multirow[t]{2}{*}{$\begin{array}{l}\text { Month } \\
\text { weight }\end{array}$} & \multirow{2}{*}{$\begin{array}{c}\text { Multiply } \\
\text { Previous two } \\
\text { columns } \\
\end{array}$} \\
\hline & Name & $30^{\text {th }}$ & 70th & & & & & \\
\hline & & \multicolumn{3}{|c|}{----------cm----------- } & & & & \\
\hline $1^{\mathrm{st}}$ (most recent) & May & 4.65 & 8.53 & 6.78 & Normal & 2 & 3 & 6 \\
\hline 2nd & April & 2.90 & 5.64 & 7.25 & Wet & 3 & 2 & 6 \\
\hline 3rd & March & 2.39 & 3.73 & 3.07 & Normal & 2 & 1 & 2 \\
\hline \multirow{2}{*}{\multicolumn{8}{|c|}{$\begin{array}{l}\text { Rainfall of prior period was: } \\
\text { drier than normal (sum is 6-9), normal (sum is 10-14), wetter than normal (sum is 15-18) }\end{array}$}} & 14 \\
\hline & & & & & & & & Normal \\
\hline
\end{tabular}

Table C.110: DAREM and Modified DAREM calculations for period that met wetland hydrology for plots S1, S2, S3 and S6 at the Marcell Experimental Forest within the year 1994.

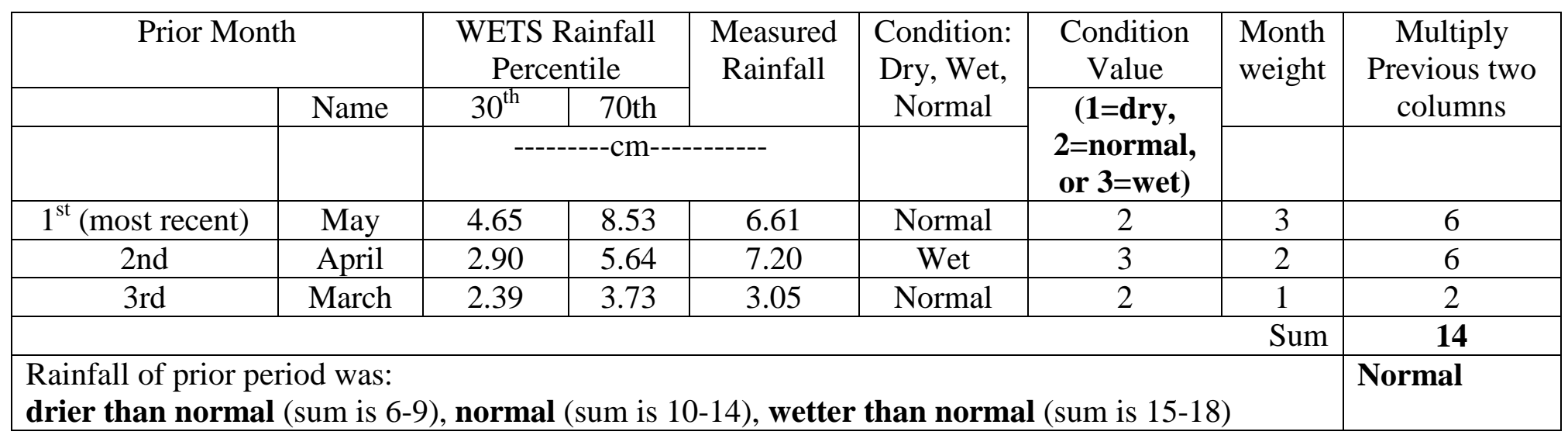


Table C.111: DAREM and Modified DAREM calculations for period that met wetland hydrology for plots S1, S2, S3 and S6 at the Marcell Experimental Forest within the year 1995.

\begin{tabular}{|c|c|c|c|c|c|c|c|c|}
\hline \multicolumn{2}{|c|}{ Prior Month } & \multicolumn{2}{|c|}{$\begin{array}{c}\text { WETS Rainfall } \\
\text { Percentile }\end{array}$} & \multirow[t]{2}{*}{$\begin{array}{l}\text { Measured } \\
\text { Rainfall }\end{array}$} & \multirow{2}{*}{$\begin{array}{c}\text { Condition: } \\
\text { Dry, Wet, } \\
\text { Normal }\end{array}$} & \multirow{3}{*}{$\begin{array}{c}\text { Condition } \\
\text { Value } \\
(\mathbf{1 = d r y ,}, \\
2=\text { normal, } \\
\text { or } 3=\text { wet })\end{array}$} & \multirow[t]{2}{*}{$\begin{array}{l}\text { Month } \\
\text { weight }\end{array}$} & \multirow{2}{*}{$\begin{array}{c}\text { Multiply } \\
\text { Previous two } \\
\text { columns } \\
\end{array}$} \\
\hline & Name & $30^{\text {th }}$ & 70th & & & & & \\
\hline & & \multicolumn{3}{|c|}{----------cm----------- } & & & & \\
\hline $1^{\mathrm{st}}$ (most recent) & April & 2.90 & 5.64 & 4.14 & Normal & 2 & 3 & 6 \\
\hline 2nd & March & 2.39 & 3.73 & 2.42 & Normal & 2 & 2 & 4 \\
\hline $3 \mathrm{rd}$ & Feb & 0.97 & 1.91 & 2.34 & Wet & 3 & 1 & 3 \\
\hline \multirow{2}{*}{\multicolumn{8}{|c|}{$\begin{array}{l}\text { Rainfall of prior period was: } \\
\text { drier than normal (sum is 6-9), normal (sum is 10-14), wetter than normal (sum is 15-18) }\end{array}$}} & 13 \\
\hline & & & & & & & & Normal \\
\hline
\end{tabular}

Table C.112: DAREM and Modified DAREM calculations for period that met wetland hydrology for plots S1, S2, S3 and S6 at the Marcell Experimental Forest within the year 1996.

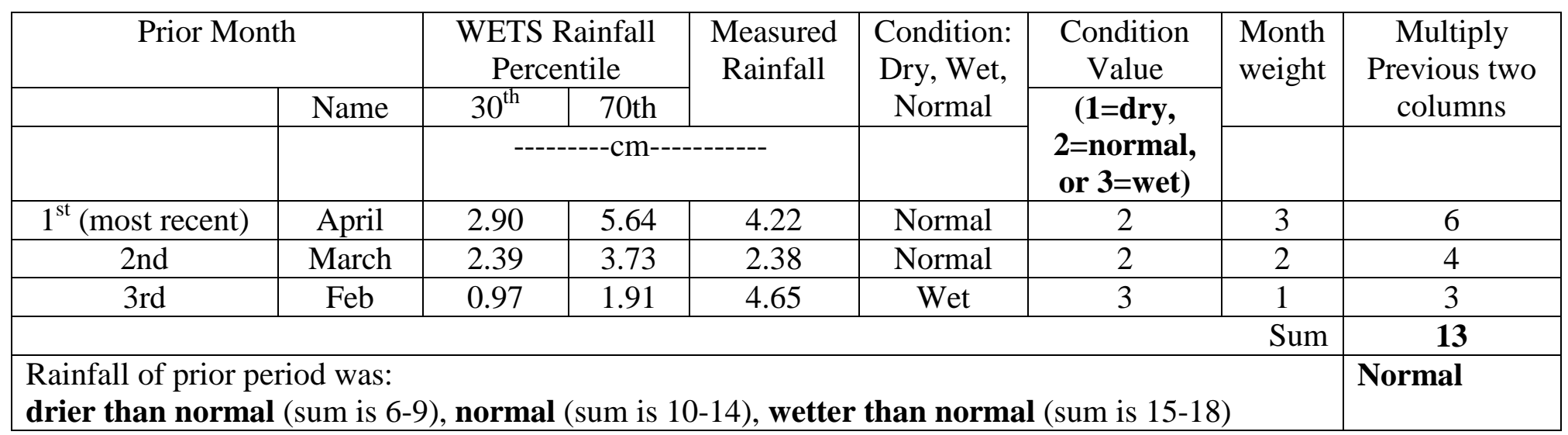


Table C.113: DAREM and Modified DAREM calculations for period that met wetland hydrology for plots S1, S2, S3 and S6 at the Marcell Experimental Forest within the year 1997.

\begin{tabular}{|c|c|c|c|c|c|c|c|c|}
\hline \multicolumn{2}{|c|}{ Prior Month } & \multicolumn{2}{|c|}{$\begin{array}{c}\text { WETS Rainfall } \\
\text { Percentile }\end{array}$} & \multirow[t]{2}{*}{$\begin{array}{l}\text { Measured } \\
\text { Rainfall }\end{array}$} & \multirow{2}{*}{$\begin{array}{c}\text { Condition: } \\
\text { Dry, Wet, } \\
\text { Normal }\end{array}$} & \multirow{3}{*}{$\begin{array}{c}\text { Condition } \\
\text { Value } \\
(\mathbf{1 = d r y ,}, \\
2=\text { normal, } \\
\text { or } 3=\text { wet })\end{array}$} & \multirow[t]{2}{*}{$\begin{array}{l}\text { Month } \\
\text { weight }\end{array}$} & \multirow{2}{*}{$\begin{array}{c}\text { Multiply } \\
\text { Previous two } \\
\text { columns } \\
\end{array}$} \\
\hline & Name & $30^{\text {th }}$ & 70th & & & & & \\
\hline & & \multicolumn{3}{|c|}{----------cm----------- } & & & & \\
\hline $1^{\mathrm{st}}$ (most recent) & April & 2.90 & 5.64 & 2.42 & Dry & 1 & 3 & 3 \\
\hline 2nd & March & 2.39 & 3.73 & 4.94 & Wet & 3 & 2 & 6 \\
\hline 3rd & Feb & 0.97 & 1.91 & 1.37 & Normal & 2 & 1 & 2 \\
\hline \multirow{2}{*}{\multicolumn{8}{|c|}{$\begin{array}{l}\text { Rainfall of prior period was: } \\
\text { drier than normal (sum is 6-9), normal (sum is 10-14), wetter than normal (sum is 15-18) }\end{array}$}} & 11 \\
\hline & & & & & & & & Normal \\
\hline
\end{tabular}

Table C.114: DAREM and Modified DAREM calculations for period that met wetland hydrology for plots S1, S2, S3 and S6 at the Marcell Experimental Forest within the year 1998.

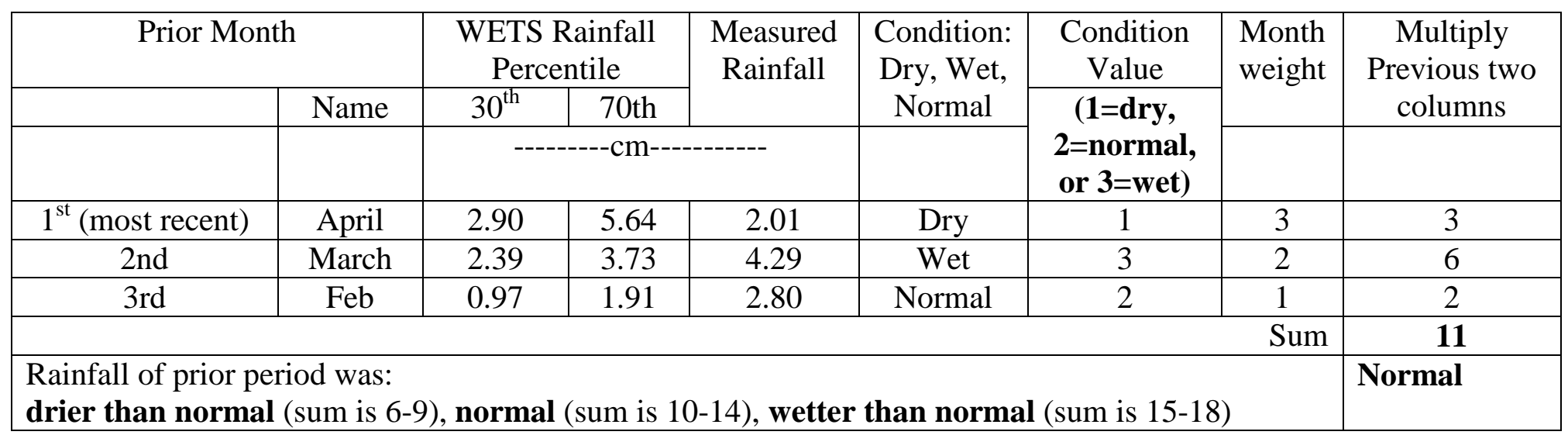


Table C.115: DAREM and Modified DAREM calculations for period that met wetland hydrology for plots S1, S2, S3 and S6 at the Marcell Experimental Forest within the year 1999.

\begin{tabular}{|c|c|c|c|c|c|c|c|c|}
\hline \multicolumn{2}{|c|}{ Prior Month } & \multicolumn{2}{|c|}{$\begin{array}{l}\text { WETS Rainfall } \\
\text { Percentile }\end{array}$} & \multirow[t]{2}{*}{$\begin{array}{l}\text { Measured } \\
\text { Rainfall }\end{array}$} & \multirow{2}{*}{$\begin{array}{c}\text { Condition: } \\
\text { Dry, Wet, } \\
\text { Normal }\end{array}$} & \multirow{3}{*}{$\begin{array}{c}\text { Condition } \\
\text { Value } \\
(\mathbf{1 = d r y ,}, \\
2=\text { normal, } \\
\text { or } 3=\text { wet })\end{array}$} & \multirow[t]{2}{*}{$\begin{array}{l}\text { Month } \\
\text { weight }\end{array}$} & \multirow{2}{*}{$\begin{array}{c}\text { Multiply } \\
\text { Previous two } \\
\text { columns } \\
\end{array}$} \\
\hline & Name & $30^{\text {th }}$ & 70th & & & & & \\
\hline & & \multicolumn{3}{|c|}{----------cm----------- } & & & & \\
\hline $1^{\mathrm{st}}$ (most recent) & June & 8.41 & 13.79 & 8.29 & Dry & 1 & 3 & 3 \\
\hline 2nd & May & 4.65 & 8.53 & 12.31 & Wet & 3 & 2 & 6 \\
\hline $3 \mathrm{rd}$ & April & 2.90 & 10.98 & 4.70 & Normal & 2 & 1 & 2 \\
\hline \multirow{2}{*}{\multicolumn{8}{|c|}{$\begin{array}{l}\text { Rainfall of prior period was: } \\
\text { drier than normal (sum is 6-9), normal (sum is 10-14), wetter than normal (sum is 15-18) }\end{array}$}} & 11 \\
\hline & & & & & & & & Normal \\
\hline
\end{tabular}

Table C.116: DAREM and Modified DAREM calculations for period that met wetland hydrology for plots S1, S2, S3 and S6 at the Marcell Experimental Forest within the year 2000.

\begin{tabular}{|c|c|c|c|c|c|c|c|c|}
\hline \multicolumn{2}{|c|}{ Prior Month } & \multicolumn{2}{|c|}{$\begin{array}{l}\text { WETS Rainfall } \\
\text { Percentile }\end{array}$} & \multirow[t]{2}{*}{$\begin{array}{c}\text { Measured } \\
\text { Rainfall }\end{array}$} & \multirow{2}{*}{$\begin{array}{l}\text { Condition: } \\
\text { Dry, Wet, } \\
\text { Normal }\end{array}$} & \multirow{3}{*}{ 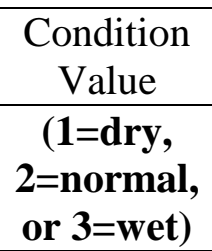 } & \multirow[t]{3}{*}{$\begin{array}{l}\text { Month } \\
\text { weight }\end{array}$} & \multirow{2}{*}{$\begin{array}{c}\text { Multiply } \\
\text { Previous two } \\
\text { columns } \\
\end{array}$} \\
\hline & Name & $30^{\text {th }}$ & 70th & & & & & \\
\hline & & \multicolumn{3}{|c|}{---------cm----------- } & & & & \\
\hline $1^{\mathrm{st}}$ (most recent) & May & 4.65 & 8.53 & 5.91 & Normal & 2 & 3 & 6 \\
\hline $2 \mathrm{nd}$ & April & 2.90 & 5.64 & 3.96 & Normal & 2 & 2 & 4 \\
\hline $3 \mathrm{rd}$ & March & 2.39 & 3.73 & 3.92 & Wet & 3 & 1 & 3 \\
\hline \multirow{2}{*}{\multicolumn{8}{|c|}{$\begin{array}{ll} & \text { Sum } \\
\text { Rainfall of prior period was: } & \end{array}$}} & 13 \\
\hline & & & & & & & & Normal \\
\hline
\end{tabular}


Table C.117: DAREM and Modified DAREM calculations for period that met wetland hydrology for plots S1, S2, S3 and S6 at the Marcell Experimental Forest within the year 2001.

\begin{tabular}{|c|c|c|c|c|c|c|c|c|}
\hline \multicolumn{2}{|c|}{ Prior Month } & \multicolumn{2}{|c|}{$\begin{array}{c}\text { WETS Rainfall } \\
\text { Percentile }\end{array}$} & \multirow[t]{2}{*}{$\begin{array}{l}\text { Measured } \\
\text { Rainfall }\end{array}$} & \multirow{2}{*}{$\begin{array}{c}\text { Condition: } \\
\text { Dry, Wet, } \\
\text { Normal }\end{array}$} & \multirow{3}{*}{$\begin{array}{c}\text { Condition } \\
\text { Value } \\
(\mathbf{1 = d r y ,}, \\
2=\text { normal, } \\
\text { or } 3=\text { wet })\end{array}$} & \multirow[t]{2}{*}{$\begin{array}{l}\text { Month } \\
\text { weight }\end{array}$} & \multirow{2}{*}{$\begin{array}{c}\text { Multiply } \\
\text { Previous two } \\
\text { columns } \\
\end{array}$} \\
\hline & Name & $30^{\text {th }}$ & 70th & & & & & \\
\hline & & \multicolumn{3}{|c|}{----------cm----------- } & & & & \\
\hline $1^{\mathrm{st}}$ (most recent) & April & 2.90 & 5.64 & 12.22 & Wet & 3 & 3 & 9 \\
\hline 2nd & March & 2.39 & 3.73 & 1.28 & Dry & 1 & 2 & 2 \\
\hline $3 \mathrm{rd}$ & Feb & 0.97 & 1.91 & 5.11 & Wet & 3 & 1 & 3 \\
\hline \multirow{2}{*}{\multicolumn{8}{|c|}{$\begin{array}{l}\text { Rainfall of prior period was: } \\
\text { drier than normal (sum is 6-9), normal (sum is 10-14), wetter than normal (sum is 15-18) }\end{array}$}} & 14 \\
\hline & & & & & & & & Normal \\
\hline
\end{tabular}

Table C.118: DAREM and Modified DAREM calculations for period that met wetland hydrology for plots S1, S2, S3 and S6 at the Marcell Experimental Forest within the year 2002.

\begin{tabular}{|c|c|c|c|c|c|c|c|c|}
\hline \multicolumn{2}{|c|}{ Prior Month } & \multicolumn{2}{|c|}{$\begin{array}{l}\text { WETS Rainfall } \\
\text { Percentile }\end{array}$} & \multirow[t]{2}{*}{$\begin{array}{l}\text { Measured } \\
\text { Rainfall }\end{array}$} & \multirow{2}{*}{$\begin{array}{l}\text { Condition: } \\
\text { Dry, Wet, } \\
\text { Normal }\end{array}$} & \multirow{3}{*}{ 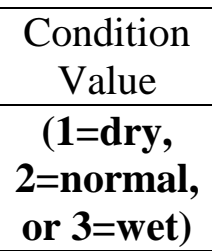 } & \multirow[t]{3}{*}{$\begin{array}{l}\text { Month } \\
\text { weight }\end{array}$} & \multirow{2}{*}{$\begin{array}{c}\text { Multiply } \\
\text { Previous two } \\
\text { columns } \\
\end{array}$} \\
\hline & Name & $30^{\text {th }}$ & 70th & & & & & \\
\hline & & \multicolumn{3}{|c|}{---------cm----------- } & & & & \\
\hline $1^{\mathrm{st}}$ (most recent) & April & 2.90 & 5.64 & 2.64 & Dry & 1 & 3 & 3 \\
\hline $2 \mathrm{nd}$ & March & 2.39 & 3.73 & 3.56 & Normal & 2 & 2 & 4 \\
\hline $3 \mathrm{rd}$ & Feb & 0.97 & 1.91 & 0.66 & Dry & 1 & 1 & 1 \\
\hline \multirow{2}{*}{\multicolumn{8}{|c|}{$\begin{array}{ll} & \text { Sum } \\
\text { Rainfall of prior period was: } & \end{array}$}} & 8 \\
\hline & & & & & & & & Dry \\
\hline
\end{tabular}


Table C.119: DAREM and Modified DAREM calculations for period that met wetland hydrology for plots S1, S2, S3 and S6 at the Marcell Experimental Forest within the year 2003.

\begin{tabular}{|c|c|c|c|c|c|c|c|c|}
\hline \multicolumn{2}{|c|}{ Prior Month } & \multicolumn{2}{|c|}{$\begin{array}{l}\text { WETS Rainfall } \\
\text { Percentile }\end{array}$} & \multirow[t]{2}{*}{$\begin{array}{c}\text { Measured } \\
\text { Rainfall }\end{array}$} & \multirow{2}{*}{$\begin{array}{c}\text { Condition: } \\
\text { Dry, Wet, } \\
\text { Normal } \\
\end{array}$} & \multirow{3}{*}{$\begin{array}{c}\text { Condition } \\
\text { Value } \\
\text { (1=dry, } \\
2=\text { normal, } \\
\text { or } 3=\text { wet })\end{array}$} & \multirow[t]{2}{*}{$\begin{array}{l}\text { Month } \\
\text { weight }\end{array}$} & \multirow{2}{*}{$\begin{array}{c}\text { Multiply } \\
\text { Previous two } \\
\text { columns }\end{array}$} \\
\hline & Name & $30^{\text {th }}$ & 70th & & & & & \\
\hline & & \multicolumn{3}{|c|}{---------cm---------- } & & & & \\
\hline $1^{\text {st }}$ (most recent) & April & 2.90 & 5.64 & 4.47 & Normal & 2 & 3 & 6 \\
\hline $2 \mathrm{nd}$ & March & 2.39 & 3.73 & 1.50 & Dry & 1 & 2 & 2 \\
\hline 3rd & Feb & 0.97 & 1.91 & 0.79 & Dry & 1 & 1 & 1 \\
\hline \multirow{2}{*}{\multicolumn{8}{|c|}{$\begin{array}{l}\text { Rainfall of prior period was: } \\
\text { drier than normal (sum is 6-9), normal (sum is } 10-14 \text { ), wetter than normal (sum is } 15-18 \text { ) }\end{array}$}} & 9 \\
\hline & & & & & & & & Dry \\
\hline
\end{tabular}

Table C.120: DAREM and Modified DAREM calculations for period that met wetland hydrology for plots S1, S2, S3 and S6 at the Marcell Experimental Forest within the year 2004.

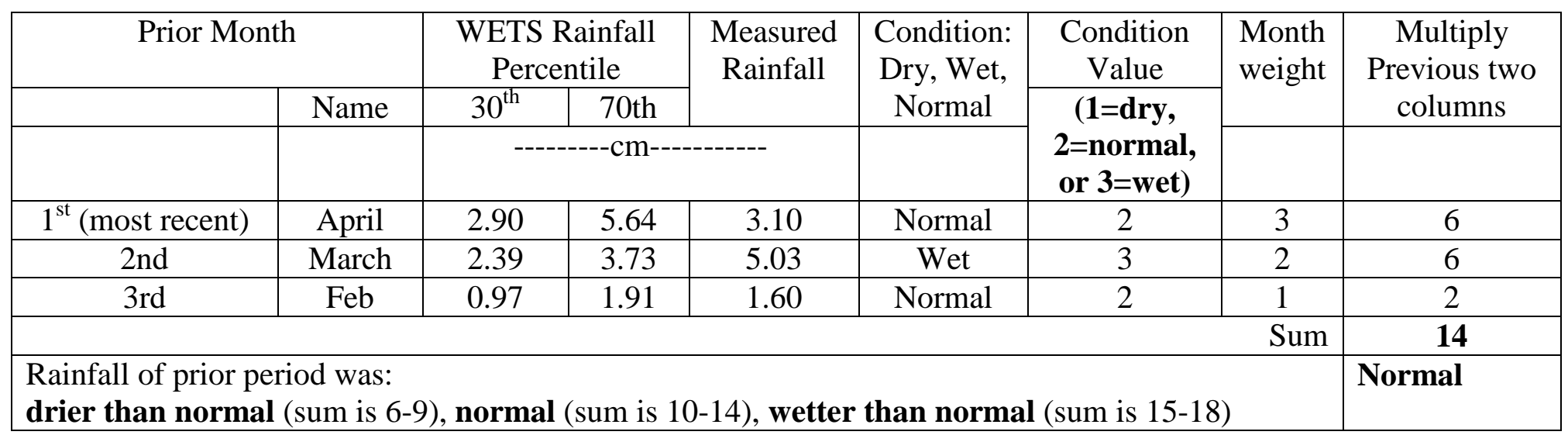


Table C.121: DAREM and Modified DAREM calculations for period that met wetland hydrology for plots S1, S2, S3 and S6 at the Marcell Experimental Forest within the year 2005.

\begin{tabular}{|c|c|c|c|c|c|c|c|c|}
\hline \multicolumn{2}{|c|}{ Prior Month } & \multicolumn{2}{|c|}{$\begin{array}{c}\text { WETS Rainfall } \\
\text { Percentile }\end{array}$} & \multirow[t]{2}{*}{$\begin{array}{l}\text { Measured } \\
\text { Rainfall }\end{array}$} & \multirow{2}{*}{$\begin{array}{c}\text { Condition: } \\
\text { Dry, Wet, } \\
\text { Normal }\end{array}$} & \multirow{3}{*}{$\begin{array}{c}\text { Condition } \\
\text { Value } \\
(\mathbf{1 = d r y ,}, \\
2=\text { normal, } \\
\text { or } 3=\text { wet })\end{array}$} & \multirow[t]{2}{*}{$\begin{array}{l}\text { Month } \\
\text { weight }\end{array}$} & \multirow{2}{*}{$\begin{array}{c}\text { Multiply } \\
\text { Previous two } \\
\text { columns } \\
\end{array}$} \\
\hline & Name & $30^{\text {th }}$ & 70th & & & & & \\
\hline & & \multicolumn{3}{|c|}{----------cm----------- } & & & & \\
\hline $1^{\mathrm{st}}$ (most recent) & April & 2.90 & 5.64 & 1.85 & Dry & 1 & 3 & 3 \\
\hline 2nd & March & 2.39 & 3.73 & 2.29 & Dry & 1 & 2 & 2 \\
\hline $3 \mathrm{rd}$ & Feb & 0.97 & 1.91 & 1.47 & Normal & 2 & 1 & 2 \\
\hline \multirow{2}{*}{\multicolumn{8}{|c|}{$\begin{array}{l}\text { Rainfall of prior period was: } \\
\text { drier than normal (sum is 6-9), normal (sum is 10-14), wetter than normal (sum is 15-18) }\end{array}$}} & 7 \\
\hline & & & & & & & & Dry \\
\hline
\end{tabular}

Table C.122: DAREM and Modified DAREM calculations for period that met wetland hydrology for plots S4 and S5 at the Marcell Experimental Forest within the year 1962.

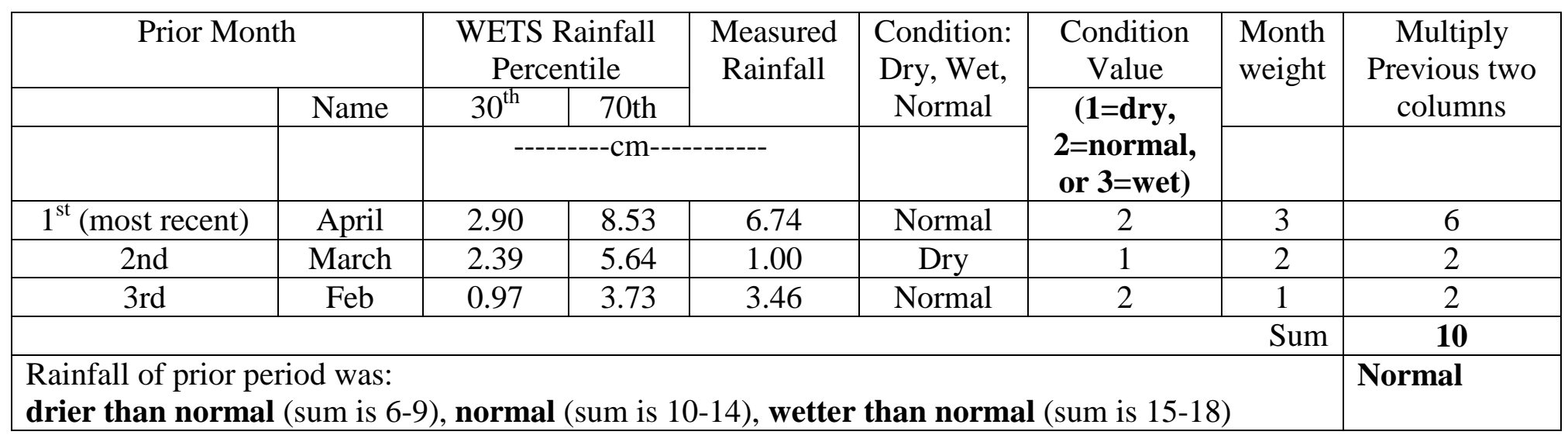


Table C.123: DAREM and Modified DAREM calculations for period that met wetland hydrology for plot S4 at the Marcell Experimental Forest within the year 1964.

\begin{tabular}{|c|c|c|c|c|c|c|c|c|}
\hline \multicolumn{2}{|c|}{ Prior Month } & \multicolumn{2}{|c|}{$\begin{array}{l}\text { WETS Rainfall } \\
\text { Percentile }\end{array}$} & \multirow[t]{2}{*}{$\begin{array}{c}\text { Measured } \\
\text { Rainfall }\end{array}$} & \multirow{2}{*}{$\begin{array}{l}\text { Condition: } \\
\text { Dry, Wet, } \\
\text { Normal }\end{array}$} & \multirow{3}{*}{$\begin{array}{c}\begin{array}{c}\text { Condition } \\
\text { Value }\end{array} \\
\text { (1=dry, } \\
2=\text { normal, } \\
\text { or } 3=\text { wet })\end{array}$} & \multirow[t]{2}{*}{$\begin{array}{l}\text { Month } \\
\text { weight }\end{array}$} & \multirow{2}{*}{$\begin{array}{l}\text { Multiply } \\
\text { Previous two } \\
\text { columns }\end{array}$} \\
\hline & Name & $30^{\text {th }}$ & 70th & & & & & \\
\hline & & \multicolumn{3}{|c|}{---------cm----------- } & & & & \\
\hline $1^{\text {st }}$ (most recent) & Aug & 6.02 & 11.33 & 16.62 & Wet & 3 & 3 & 9 \\
\hline 2nd & July & 8.13 & 13.89 & 5.68 & Dry & 1 & 2 & 2 \\
\hline $3 \mathrm{rd}$ & June & 8.41 & 13.79 & 15.19 & Wet & 3 & 1 & 3 \\
\hline \multirow{2}{*}{\multicolumn{8}{|c|}{$\begin{array}{ll} & \text { Sum } \\
\text { Rainfall of prior period was: } & \\
\text { drier than normal (sum is 6-9), normal (sum is } 10-14), \text { wetter than normal (sum is 15-18) }\end{array}$}} & 14 \\
\hline & & & & & & & & Normal \\
\hline
\end{tabular}

Table C.124: DAREM and Modified DAREM calculations for period that met wetland hydrology for plots S4 and S5 at the Marcell Experimental Forest within the year 1965.

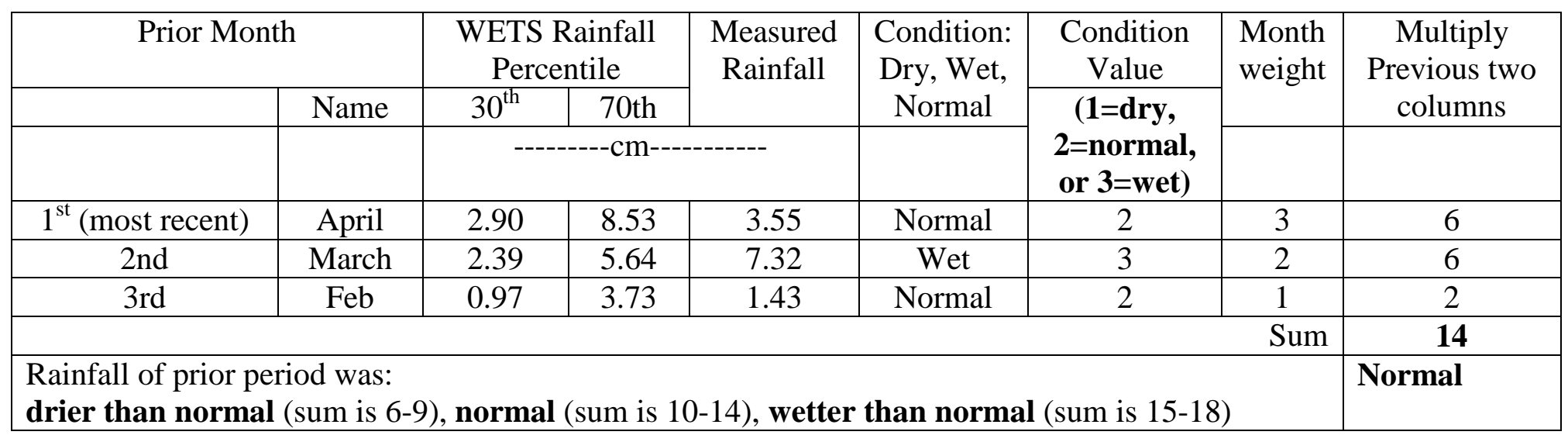


Table C. 125: DAREM and Modified DAREM calculations for period that met wetland hydrology for plots S4 and S5 at the Marcell Experimental Forest within the year 1966.

\begin{tabular}{|c|c|c|c|c|c|c|c|c|}
\hline \multicolumn{2}{|c|}{ Prior Month } & \multicolumn{2}{|c|}{$\begin{array}{l}\text { WETS Rainfall } \\
\text { Percentile }\end{array}$} & \multirow[t]{2}{*}{$\begin{array}{l}\text { Measured } \\
\text { Rainfall }\end{array}$} & \multirow{2}{*}{$\begin{array}{c}\text { Condition: } \\
\text { Dry, Wet, } \\
\text { Normal }\end{array}$} & \multirow{3}{*}{$\begin{array}{c}\text { Condition } \\
\text { Value } \\
(\mathbf{1 = d r y ,}, \\
2=\text { normal, } \\
\text { or } 3=\text { wet })\end{array}$} & \multirow[t]{2}{*}{$\begin{array}{l}\text { Month } \\
\text { weight }\end{array}$} & \multirow{2}{*}{$\begin{array}{c}\text { Multiply } \\
\text { Previous two } \\
\text { columns } \\
\end{array}$} \\
\hline & Name & $30^{\text {th }}$ & 70th & & & & & \\
\hline & & \multicolumn{3}{|c|}{----------cm----------- } & & & & \\
\hline $1^{\mathrm{st}}$ (most recent) & Aug & 6.02 & 11.33 & 23.59 & Wet & 3 & 3 & 9 \\
\hline 2nd & July & 8.13 & 13.89 & 11.29 & Normal & 2 & 2 & 4 \\
\hline 3rd & June & 8.41 & 13.79 & 4.77 & Dry & 1 & 1 & 1 \\
\hline \multirow{2}{*}{\multicolumn{8}{|c|}{$\begin{array}{l}\text { Rainfall of prior period was: } \\
\text { drier than normal (sum is 6-9), normal (sum is } 10-14 \text { ), wetter than normal (sum is 15-18) }\end{array}$}} & 14 \\
\hline & & & & & & & & Normal \\
\hline
\end{tabular}

Table C.126: DAREM and Modified DAREM calculations for period that met wetland hydrology for plots S4 and S5 at the Marcell Experimental Forest within the year 1967.

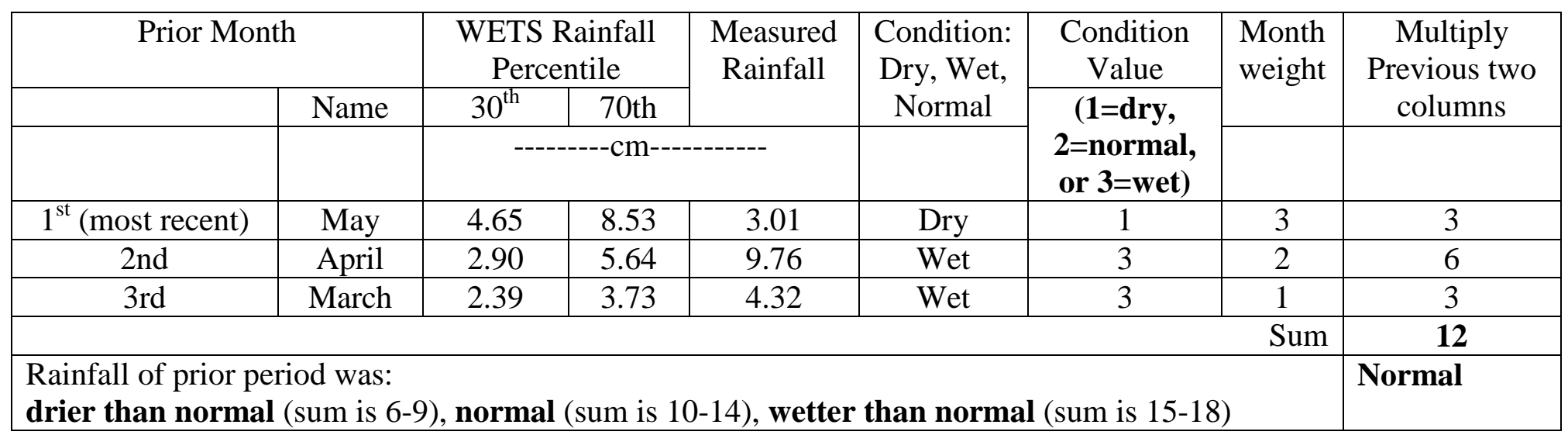


Table C.127: DAREM and Modified DAREM calculations for period that met wetland hydrology for plots S4 at the Marcell Experimental Forest within the year 1968.

\begin{tabular}{|c|c|c|c|c|c|c|c|c|}
\hline \multicolumn{2}{|c|}{ Prior Month } & \multicolumn{2}{|c|}{$\begin{array}{l}\text { WETS Rainfall } \\
\text { Percentile }\end{array}$} & \multirow[t]{2}{*}{$\begin{array}{c}\text { Measured } \\
\text { Rainfall }\end{array}$} & \multirow{2}{*}{$\begin{array}{l}\text { Condition: } \\
\text { Dry, Wet, } \\
\text { Normal }\end{array}$} & \multirow{3}{*}{$\begin{array}{c}\text { Condition } \\
\text { Value } \\
(\mathbf{1 = d r y ,}, \\
2=\text { normal, } \\
\text { or } 3=\text { wet })\end{array}$} & \multirow[t]{2}{*}{$\begin{array}{l}\text { Month } \\
\text { weight }\end{array}$} & \multirow{2}{*}{$\begin{array}{l}\text { Multiply } \\
\text { Previous two } \\
\text { columns }\end{array}$} \\
\hline & Name & $30^{\text {th }}$ & 70th & & & & & \\
\hline & & \multicolumn{3}{|c|}{---------cm----------- } & & & & \\
\hline $1^{\text {st }}$ (most recent) & June & 8.41 & 13.79 & 13.79 & Normal & 2 & 3 & 6 \\
\hline 2nd & May & 4.65 & 8.53 & 7.16 & Normal & 2 & 2 & 4 \\
\hline $3 \mathrm{rd}$ & April & 2.90 & 10.98 & 11.20 & Wet & 3 & 1 & 3 \\
\hline \multirow{2}{*}{\multicolumn{8}{|c|}{$\begin{array}{ll} & \text { Sum } \\
\text { Rainfall of prior period was: } & \\
\text { drier than normal (sum is 6-9), normal (sum is } 10-14), \text { wetter than normal (sum is 15-18) }\end{array}$}} & 13 \\
\hline & & & & & & & & Normal \\
\hline
\end{tabular}

Table C.128: DAREM and Modified DAREM calculations for period that met wetland hydrology for plots S4 and S5 at the Marcell Experimental Forest within the year 1969.

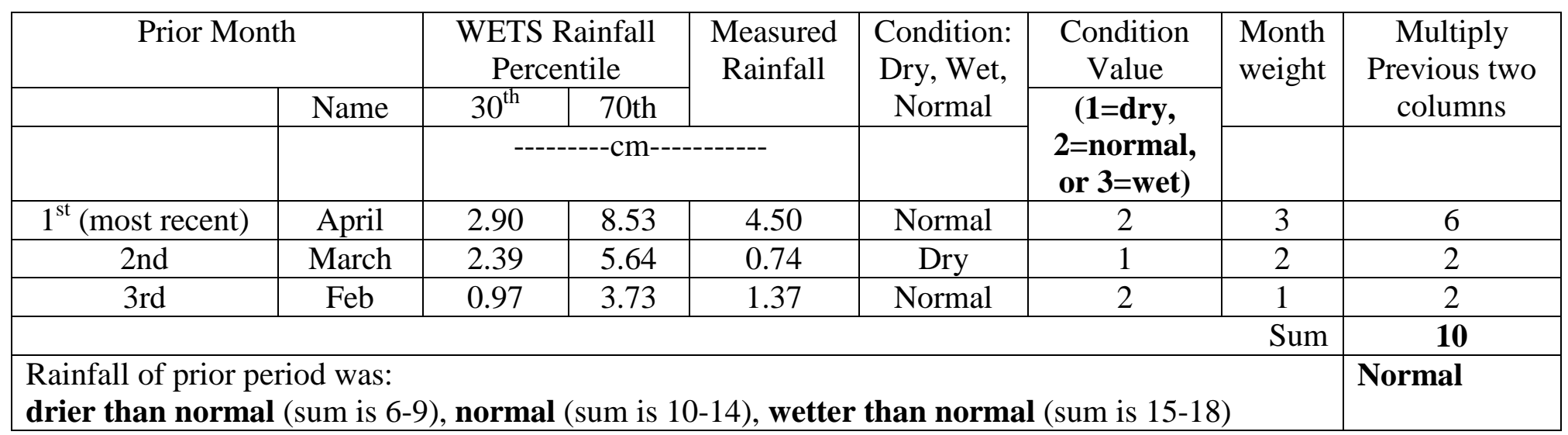


Table C.129: DAREM and Modified DAREM calculations for period that met wetland hydrology for plots S4 and S5 at the Marcell Experimental Forest within the year 1970.

\begin{tabular}{|c|c|c|c|c|c|c|c|c|}
\hline \multicolumn{2}{|c|}{ Prior Month } & \multicolumn{2}{|c|}{$\begin{array}{l}\text { WETS Rainfall } \\
\text { Percentile }\end{array}$} & \multirow[t]{2}{*}{$\begin{array}{c}\text { Measured } \\
\text { Rainfall }\end{array}$} & \multirow{2}{*}{$\begin{array}{l}\text { Condition: } \\
\text { Dry, Wet, } \\
\text { Normal }\end{array}$} & \multirow{3}{*}{$\begin{array}{c}\text { Condition } \\
\text { Value }\end{array}$} & \multirow[t]{2}{*}{$\begin{array}{l}\text { Month } \\
\text { weight }\end{array}$} & \multirow{2}{*}{$\begin{array}{c}\text { Multiply } \\
\text { Previous two } \\
\text { columns }\end{array}$} \\
\hline & Name & $30^{\text {th }}$ & 70th & & & & & \\
\hline & & \multicolumn{3}{|c|}{----------cm------------ } & & & & \\
\hline $1^{\text {st }}($ most recent $)$ & June & 8.41 & 13.79 & 5.23 & Dry & 1 & 3 & 3 \\
\hline 2nd & May & 4.65 & 8.53 & 8.57 & Wet & 3 & 2 & 6 \\
\hline 3rd & April & 2.90 & 5.64 & 10.88 & Wet & 3 & 1 & 3 \\
\hline \multirow{2}{*}{\multicolumn{8}{|c|}{$\begin{array}{l}\text { Rainfall of prior period was: } \\
\text { drier than normal (sum is 6-9), normal (sum is } 10-14 \text { ), wetter than normal (sum is } 15-18 \text { ) }\end{array}$}} & 12 \\
\hline & & & & & & & & Normal \\
\hline
\end{tabular}

Table C.130: DAREM and Modified DAREM calculations for period that met wetland hydrology for plot S4 at the Marcell Experimental Forest within the year 1971.

\begin{tabular}{|c|c|c|c|c|c|c|c|c|}
\hline \multicolumn{2}{|c|}{ Prior Month } & \multicolumn{2}{|c|}{$\begin{array}{l}\text { WETS Rainfall } \\
\text { Percentile }\end{array}$} & \multirow[t]{2}{*}{$\begin{array}{l}\text { Measured } \\
\text { Rainfall }\end{array}$} & \multirow{2}{*}{$\begin{array}{l}\text { Condition: } \\
\text { Dry, Wet, } \\
\text { Normal }\end{array}$} & \multirow{3}{*}{ 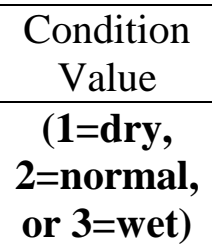 } & \multirow[t]{2}{*}{$\begin{array}{l}\text { Month } \\
\text { weight }\end{array}$} & \multirow{2}{*}{$\begin{array}{l}\text { Multiply } \\
\text { Previous two } \\
\text { columns }\end{array}$} \\
\hline & Name & $30^{\text {th }}$ & 70th & & & & & \\
\hline & & \multicolumn{3}{|c|}{----------cm------------ } & & & & \\
\hline $1^{\text {st }}$ (most recent) & April & 2.90 & 8.53 & 2.89 & Dry & 1 & 3 & 3 \\
\hline 2nd & March & 2.39 & 5.64 & 3.80 & Normal & 2 & 2 & 4 \\
\hline $3 \mathrm{rd}$ & Feb & 0.97 & 3.73 & 5.97 & Wet & 3 & 1 & 3 \\
\hline \multirow{2}{*}{\multicolumn{8}{|c|}{$\begin{array}{l}\text { Rainfall of prior period was: } \\
\text { drier than normal (sum is 6-9), normal (sum is 10-14), wetter than normal (sum is 15-18) }\end{array}$}} & 10 \\
\hline & & & & & & & & Normal \\
\hline
\end{tabular}


Table C.131: DAREM and Modified DAREM calculations for period that met wetland hydrology for plots S4 and S5 at the Marcell Experimental Forest within the year 1972.

\begin{tabular}{|c|c|c|c|c|c|c|c|c|}
\hline \multicolumn{2}{|c|}{ Prior Month } & \multicolumn{2}{|c|}{$\begin{array}{l}\text { WETS Rainfall } \\
\text { Percentile }\end{array}$} & \multirow[t]{2}{*}{$\begin{array}{c}\text { Measured } \\
\text { Rainfall }\end{array}$} & \multirow{2}{*}{$\begin{array}{l}\text { Condition: } \\
\text { Dry, Wet, } \\
\text { Normal }\end{array}$} & \multirow{3}{*}{$\begin{array}{c}\text { Condition } \\
\text { Value }\end{array}$} & \multirow[t]{2}{*}{$\begin{array}{l}\text { Month } \\
\text { weight }\end{array}$} & \multirow{2}{*}{$\begin{array}{l}\text { Multiply } \\
\text { Previous two } \\
\text { columns }\end{array}$} \\
\hline & Name & $30^{\text {th }}$ & 70th & & & & & \\
\hline & & \multicolumn{3}{|c|}{---------cm----------- } & & & & \\
\hline $1^{\text {st }}$ (most recent) & June & 8.41 & 13.79 & 5.48 & Dry & 1 & 3 & 3 \\
\hline 2nd & May & 4.65 & 8.53 & 11.33 & Wet & 3 & 2 & 6 \\
\hline $3 \mathrm{rd}$ & April & 2.90 & 10.98 & 5.87 & Normal & 2 & 1 & 2 \\
\hline \multirow{2}{*}{\multicolumn{8}{|c|}{$\begin{array}{ll} & \text { Sum } \\
\text { Rainfall of prior period was: } & \\
\text { drier than normal (sum is 6-9), normal (sum is } 10-14), \text { wetter than normal (sum is 15-18) }\end{array}$}} & 11 \\
\hline & & & & & & & & Normal \\
\hline
\end{tabular}

Table C.132: DAREM and Modified DAREM calculations for period that met wetland hydrology for plots S4 and S5 at the Marcell Experimental Forest within the year 1973.

\begin{tabular}{|c|c|c|c|c|c|c|c|c|}
\hline \multicolumn{2}{|c|}{ Prior Month } & \multicolumn{2}{|c|}{$\begin{array}{l}\text { WETS Rainfall } \\
\text { Percentile }\end{array}$} & \multirow[t]{2}{*}{$\begin{array}{l}\text { Measured } \\
\text { Rainfall }\end{array}$} & \multirow{2}{*}{$\begin{array}{l}\text { Condition: } \\
\text { Dry, Wet, } \\
\text { Normal }\end{array}$} & \multirow{3}{*}{ 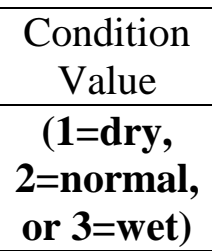 } & \multirow[t]{3}{*}{$\begin{array}{l}\text { Month } \\
\text { weight }\end{array}$} & \multirow{2}{*}{$\begin{array}{c}\text { Multiply } \\
\text { Previous two } \\
\text { columns } \\
\end{array}$} \\
\hline & Name & $30^{\text {th }}$ & 70th & & & & & \\
\hline & & \multicolumn{3}{|c|}{----------cm------------- } & & & & \\
\hline $1^{\text {st }}$ (most recent) & April & 2.90 & 8.53 & 2.20 & Dry & 1 & 3 & 3 \\
\hline $2 \mathrm{nd}$ & March & 2.39 & 5.64 & 3.83 & Normal & 2 & 2 & 4 \\
\hline $3 \mathrm{rd}$ & Feb & 0.97 & 3.73 & 0.48 & Dry & 1 & 1 & 1 \\
\hline \multirow{2}{*}{\multicolumn{8}{|c|}{$\begin{array}{ll} & \text { Sum } \\
\text { Rainfall of prior period was: } & \end{array}$}} & 8 \\
\hline & & & & & & & & Dry \\
\hline
\end{tabular}


Table C.133: DAREM and Modified DAREM calculations for period that met wetland hydrology for plot S4 at the Marcell Experimental Forest within the year 1974.

\begin{tabular}{|c|c|c|c|c|c|c|c|c|}
\hline \multicolumn{2}{|c|}{ Prior Month } & \multicolumn{2}{|c|}{$\begin{array}{c}\text { WETS Rainfall } \\
\text { Percentile }\end{array}$} & \multirow[t]{2}{*}{$\begin{array}{l}\text { Measured } \\
\text { Rainfall }\end{array}$} & \multirow{2}{*}{$\begin{array}{c}\text { Condition: } \\
\text { Dry, Wet, } \\
\text { Normal } \\
\end{array}$} & \multirow{3}{*}{ 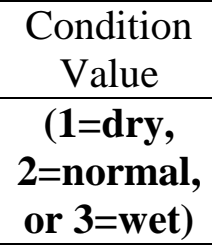 } & \multirow[t]{2}{*}{$\begin{array}{l}\text { Month } \\
\text { weight }\end{array}$} & \multirow{2}{*}{$\begin{array}{c}\text { Multiply } \\
\text { Previous two } \\
\text { columns }\end{array}$} \\
\hline & Name & $30^{\text {th }}$ & 70th & & & & & \\
\hline & & \multicolumn{3}{|c|}{----------cm------------ } & & & & \\
\hline $1^{\text {st }}$ (most recent) & June & 8.41 & 13.79 & 7.69 & & & 3 & \\
\hline 2nd & May & 4.65 & 8.53 & 11.84 & & & 2 & \\
\hline 3rd & April & 2.90 & 10.98 & 8.11 & & & 1 & \\
\hline \multicolumn{8}{|c|}{$\begin{array}{ll} & \text { Sum } \\
\end{array}$} & \\
\hline \multicolumn{8}{|c|}{$\begin{array}{l}\text { Rainfall of prior period was: } \\
\text { drier than normal (sum is 6-9), normal (sum is 10-14), wetter than normal (sum is 15-18) }\end{array}$} & \\
\hline
\end{tabular}

Table C.134: DAREM and Modified DAREM calculations for period that met wetland hydrology for plots S4 and S5 at the Marcell Experimental Forest within the year 1975.

\begin{tabular}{|c|c|c|c|c|c|c|c|c|}
\hline \multicolumn{2}{|c|}{ Prior Month } & \multicolumn{2}{|c|}{$\begin{array}{l}\text { WETS Rainfall } \\
\text { Percentile }\end{array}$} & \multirow[t]{2}{*}{$\begin{array}{l}\text { Measured } \\
\text { Rainfall }\end{array}$} & \multirow{2}{*}{$\begin{array}{l}\text { Condition: } \\
\text { Dry, Wet, } \\
\text { Normal }\end{array}$} & \multirow{3}{*}{ 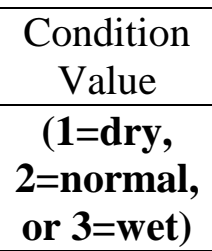 } & \multirow[t]{3}{*}{$\begin{array}{l}\text { Month } \\
\text { weight }\end{array}$} & \multirow{2}{*}{$\begin{array}{c}\text { Multiply } \\
\text { Previous two } \\
\text { columns } \\
\end{array}$} \\
\hline & Name & $30^{\text {th }}$ & 70th & & & & & \\
\hline & & \multicolumn{3}{|c|}{----------cm------------ } & & & & \\
\hline $1^{\mathrm{st}}$ (most recent) & June & 8.41 & 13.79 & 13.42 & Normal & 2 & 3 & 6 \\
\hline 2 nd & May & 4.65 & 8.53 & 6.00 & Normal & 2 & 2 & 4 \\
\hline $3 \mathrm{rd}$ & April & 2.90 & 10.98 & 6.52 & Normal & 2 & 1 & 2 \\
\hline \multirow{2}{*}{\multicolumn{8}{|c|}{$\begin{array}{l}\text { Rainfall of prior period was: } \\
\text { drier than normal (sum is } 6-9 \text { ), normal (sum is } 10-14 \text { ), wetter than normal (sum is } 15-18 \text { ) }\end{array}$}} & 12 \\
\hline & & & & & & & & Normal \\
\hline
\end{tabular}


Table C.135: DAREM and Modified DAREM calculations for period that met wetland hydrology for plot S4 at the Marcell Experimental Forest within the year 1976.

\begin{tabular}{|c|c|c|c|c|c|c|c|c|}
\hline \multicolumn{2}{|c|}{ Prior Month } & \multicolumn{2}{|c|}{$\begin{array}{l}\text { WETS Rainfall } \\
\text { Percentile }\end{array}$} & \multirow[t]{2}{*}{$\begin{array}{l}\text { Measured } \\
\text { Rainfall }\end{array}$} & \multirow{2}{*}{$\begin{array}{l}\text { Condition: } \\
\text { Dry, Wet, } \\
\text { Normal }\end{array}$} & \multirow{3}{*}{$\begin{array}{c}\text { Condition } \\
\text { Value }\end{array}$} & \multirow[t]{2}{*}{$\begin{array}{l}\text { Month } \\
\text { weight }\end{array}$} & \multirow{2}{*}{$\begin{array}{c}\text { Multiply } \\
\text { Previous two } \\
\text { columns }\end{array}$} \\
\hline & Name & $30^{\text {th }}$ & 70th & & & & & \\
\hline & & \multicolumn{3}{|c|}{----------cm------------ } & & & & \\
\hline $1^{\text {st }}($ most recent $)$ & April & 2.90 & 8.53 & 1.67 & Dry & 1 & 3 & 3 \\
\hline 2nd & March & 2.39 & 5.64 & 6.50 & Wet & 3 & 2 & 6 \\
\hline 3rd & Feb & 0.97 & 3.73 & 2.01 & Normal & 2 & 1 & 2 \\
\hline \multirow{2}{*}{\multicolumn{8}{|c|}{$\begin{array}{l}\text { Rainfall of prior period was: } \\
\text { drier than normal (sum is 6-9), normal (sum is } 10-14 \text { ), wetter than normal (sum is } 15-18 \text { ) }\end{array}$}} & 11 \\
\hline & & & & & & & & Normal \\
\hline
\end{tabular}

Table C.136: DAREM and Modified DAREM calculations for period that met wetland hydrology for plot S4 at the Marcell Experimental Forest within the year 1977.

\begin{tabular}{|c|c|c|c|c|c|c|c|c|}
\hline \multicolumn{2}{|c|}{ Prior Month } & \multicolumn{2}{|c|}{$\begin{array}{l}\text { WETS Rainfall } \\
\text { Percentile }\end{array}$} & \multirow[t]{2}{*}{$\begin{array}{l}\text { Measured } \\
\text { Rainfall }\end{array}$} & \multirow{2}{*}{$\begin{array}{l}\text { Condition: } \\
\text { Dry, Wet, } \\
\text { Normal }\end{array}$} & \multirow{3}{*}{$\begin{array}{c}\begin{array}{c}\text { Condition } \\
\text { Value }\end{array} \\
(1=\text { dry, } \\
2=\text { normal, } \\
\text { or } 3=\text { wet })\end{array}$} & \multirow[t]{3}{*}{$\begin{array}{l}\text { Month } \\
\text { weight }\end{array}$} & \multirow{2}{*}{$\begin{array}{l}\text { Multiply } \\
\text { Previous two } \\
\text { columns }\end{array}$} \\
\hline & Name & $30^{\text {th }}$ & 70th & & & & & \\
\hline & & \multicolumn{3}{|c|}{----------cm------------ } & & & & \\
\hline $1^{\text {st }}$ (most recent) & June & 8.41 & 13.79 & 11.66 & Normal & 2 & 3 & 6 \\
\hline 2nd & May & 4.65 & 8.53 & 11.08 & Wet & 3 & 2 & 6 \\
\hline $3 \mathrm{rd}$ & April & 2.90 & 5.64 & 4.23 & Normal & 2 & 1 & 2 \\
\hline \multirow{2}{*}{\multicolumn{8}{|c|}{$\begin{array}{ll} & \text { Sum } \\
\text { Rainfall of prior period was: } & \\
\text { drier than normal (sum is 6-9), normal (sum is 10-14), wetter than normal (sum is 15-18) }\end{array}$}} & 14 \\
\hline & & & & & & & & Normal \\
\hline
\end{tabular}


Table C.137: DAREM and Modified DAREM calculations for period that met wetland hydrology for plots S4 and S5 at the Marcell Experimental Forest within the year 1978.

\begin{tabular}{|c|c|c|c|c|c|c|c|c|}
\hline \multicolumn{2}{|c|}{ Prior Month } & \multicolumn{2}{|c|}{$\begin{array}{l}\text { WETS Rainfall } \\
\text { Percentile }\end{array}$} & \multirow[t]{2}{*}{$\begin{array}{c}\text { Measured } \\
\text { Rainfall }\end{array}$} & \multirow{2}{*}{$\begin{array}{l}\text { Condition: } \\
\text { Dry, Wet, } \\
\text { Normal }\end{array}$} & \multirow{3}{*}{$\begin{array}{c}\text { Condition } \\
\text { Value } \\
\text { (1=dry, } \\
2=\text { normal, } \\
\text { or } 3=\text { wet) }\end{array}$} & \multirow[t]{2}{*}{$\begin{array}{l}\text { Month } \\
\text { weight }\end{array}$} & \multirow{2}{*}{$\begin{array}{l}\text { Multiply } \\
\text { Previous two } \\
\text { columns }\end{array}$} \\
\hline & Name & $30^{\text {th }}$ & 70th & & & & & \\
\hline & & \multicolumn{3}{|c|}{---------cm----------- } & & & & \\
\hline $1^{\text {st }}$ (most recent) & April & 2.90 & 8.53 & 3.91 & Normal & 2 & 3 & 6 \\
\hline 2nd & March & 2.39 & 5.64 & 1.98 & Dry & 1 & 2 & 2 \\
\hline $3 \mathrm{rd}$ & Feb & 0.97 & 3.73 & 1.46 & Normal & 2 & 1 & 2 \\
\hline \multirow{2}{*}{\multicolumn{8}{|c|}{$\begin{array}{ll} & \text { Sum } \\
\text { Rainfall of prior period was: } & \\
\text { drier than normal (sum is 6-9), normal (sum is } 10-14), \text { wetter than normal (sum is 15-18) }\end{array}$}} & 10 \\
\hline & & & & & & & & Normal \\
\hline
\end{tabular}

Table C.138: DAREM and Modified DAREM calculations for period that met wetland hydrology for plots S4 and S5 at the Marcell Experimental Forest within the year 1979.

\begin{tabular}{|c|c|c|c|c|c|c|c|c|}
\hline \multicolumn{2}{|c|}{ Prior Month } & \multicolumn{2}{|c|}{$\begin{array}{l}\text { WETS Rainfall } \\
\text { Percentile }\end{array}$} & \multirow[t]{2}{*}{$\begin{array}{c}\text { Measured } \\
\text { Rainfall }\end{array}$} & \multirow{2}{*}{$\begin{array}{l}\text { Condition: } \\
\text { Dry, Wet, } \\
\text { Normal }\end{array}$} & \multirow{3}{*}{ 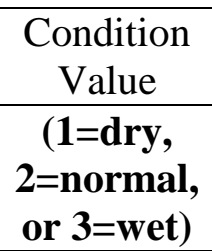 } & \multirow[t]{2}{*}{$\begin{array}{l}\text { Month } \\
\text { weight }\end{array}$} & \multirow{2}{*}{$\begin{array}{c}\text { Multiply } \\
\text { Previous two } \\
\text { columns } \\
\end{array}$} \\
\hline & Name & $30^{\text {th }}$ & 70th & & & & & \\
\hline & & \multicolumn{3}{|c|}{---------cm----------- } & & & & \\
\hline $1^{\mathrm{st}}$ (most recent) & May & 4.65 & 8.53 & 6.39 & Normal & 2 & 3 & 6 \\
\hline $2 \mathrm{nd}$ & April & 2.90 & 5.64 & 3.87 & Normal & 2 & 2 & 4 \\
\hline $3 \mathrm{rd}$ & March & 2.39 & 3.73 & 8.94 & Wet & 3 & 1 & 3 \\
\hline \multirow{2}{*}{\multicolumn{8}{|c|}{$\begin{array}{ll} & \text { Sum } \\
\text { Rainfall of prior period was: } & \end{array}$}} & 13 \\
\hline & & & & & & & & Normal \\
\hline
\end{tabular}


Table C.139: DAREM and Modified DAREM calculations for period that met wetland hydrology for plots S4 and S5 at the Marcell Experimental Forest within the year 1980.

\begin{tabular}{|c|c|c|c|c|c|c|c|c|}
\hline \multicolumn{2}{|c|}{ Prior Month } & \multicolumn{2}{|c|}{$\begin{array}{l}\text { WETS Rainfall } \\
\text { Percentile }\end{array}$} & \multirow[t]{2}{*}{$\begin{array}{c}\text { Measured } \\
\text { Rainfall }\end{array}$} & \multirow{2}{*}{$\begin{array}{l}\text { Condition: } \\
\text { Dry, Wet, } \\
\text { Normal }\end{array}$} & \multirow{3}{*}{$\begin{array}{c}\begin{array}{c}\text { Condition } \\
\text { Value }\end{array} \\
\text { (1=dry, } \\
2=\text { normal, } \\
\text { or } 3=\text { wet })\end{array}$} & \multirow[t]{2}{*}{$\begin{array}{l}\text { Month } \\
\text { weight }\end{array}$} & \multirow{2}{*}{$\begin{array}{l}\text { Multiply } \\
\text { Previous two } \\
\text { columns }\end{array}$} \\
\hline & Name & $30^{\text {th }}$ & 70th & & & & & \\
\hline & & \multicolumn{3}{|c|}{---------cm----------- } & & & & \\
\hline $1^{\text {st }}$ (most recent) & April & 2.90 & 8.53 & 0.85 & Dry & 1 & 3 & 3 \\
\hline 2nd & March & 2.39 & 5.64 & 4.35 & Normal & 2 & 2 & 4 \\
\hline $3 \mathrm{rd}$ & Feb & 0.97 & 3.73 & 2.07 & Normal & 2 & 1 & 2 \\
\hline \multirow{2}{*}{\multicolumn{8}{|c|}{$\begin{array}{ll} & \text { Sum } \\
\text { Rainfall of prior period was: } & \\
\text { drier than normal (sum is 6-9), normal (sum is } 10-14), \text { wetter than normal (sum is 15-18) }\end{array}$}} & 9 \\
\hline & & & & & & & & Dry \\
\hline
\end{tabular}

Table C.140: DAREM and Modified DAREM calculations for period that met wetland hydrology for plots S4 and S5 at the Marcell Experimental Forest within the year 1981.

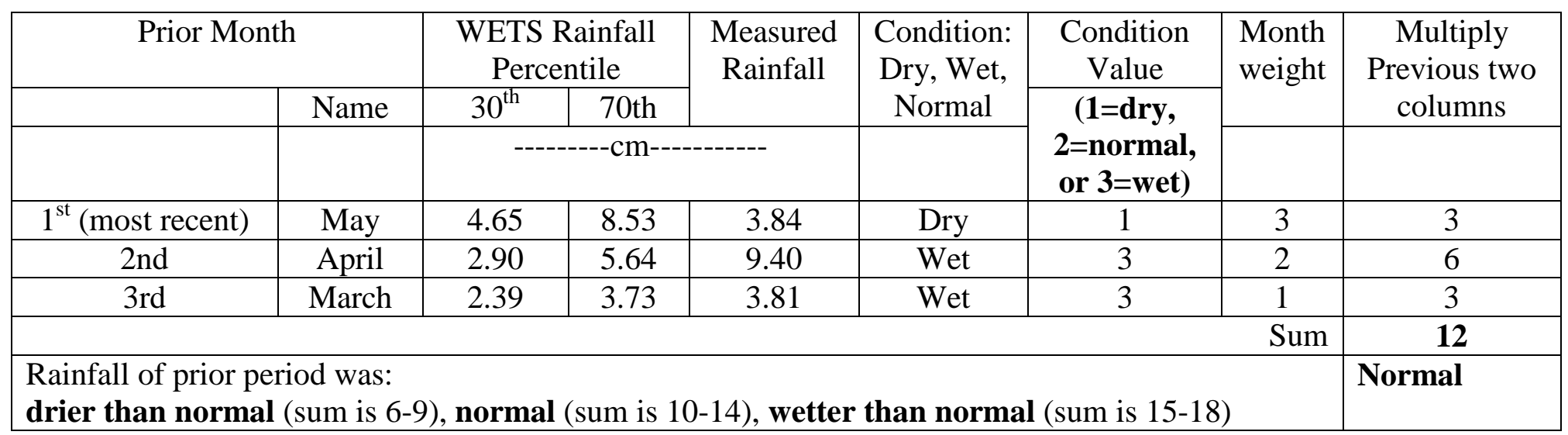


Table C.141: DAREM and Modified DAREM calculations for period that met wetland hydrology for plots S4 and S5 at the Marcell Experimental Forest within the year 1982.

\begin{tabular}{|c|c|c|c|c|c|c|c|c|}
\hline \multicolumn{2}{|c|}{ Prior Month } & \multicolumn{2}{|c|}{$\begin{array}{l}\text { WETS Rainfall } \\
\text { Percentile }\end{array}$} & \multirow[t]{2}{*}{$\begin{array}{c}\text { Measured } \\
\text { Rainfall }\end{array}$} & \multirow{2}{*}{$\begin{array}{l}\text { Condition: } \\
\text { Dry, Wet, } \\
\text { Normal }\end{array}$} & \multirow{3}{*}{$\begin{array}{c}\text { Condition } \\
\text { Value } \\
\text { (1=dry, } \\
2=\text { normal, } \\
\text { or } 3=\text { wet) }\end{array}$} & \multirow[t]{2}{*}{$\begin{array}{l}\text { Month } \\
\text { weight }\end{array}$} & \multirow{2}{*}{$\begin{array}{l}\text { Multiply } \\
\text { Previous two } \\
\text { columns }\end{array}$} \\
\hline & Name & $30^{\text {th }}$ & 70th & & & & & \\
\hline & & \multicolumn{3}{|c|}{---------cm----------- } & & & & \\
\hline $1^{\text {st }}$ (most recent) & April & 2.90 & 8.53 & 5.20 & Normal & 2 & 3 & 6 \\
\hline 2nd & March & 2.39 & 5.64 & 6.48 & Wet & 3 & 2 & 6 \\
\hline $3 \mathrm{rd}$ & Feb & 0.97 & 3.73 & 1.82 & Normal & 2 & 1 & 2 \\
\hline \multirow{2}{*}{\multicolumn{8}{|c|}{$\begin{array}{ll} & \text { Sum } \\
\text { Rainfall of prior period was: } & \\
\text { drier than normal (sum is 6-9), normal (sum is } 10-14), \text { wetter than normal (sum is 15-18) }\end{array}$}} & 14 \\
\hline & & & & & & & & Normal \\
\hline
\end{tabular}

Table C.142: DAREM and Modified DAREM calculations for period that met wetland hydrology for plots S4 and S5 at the Marcell Experimental Forest within the year 1983.

\begin{tabular}{|c|c|c|c|c|c|c|c|c|}
\hline \multicolumn{2}{|c|}{ Prior Month } & \multicolumn{2}{|c|}{$\begin{array}{l}\text { WETS Rainfall } \\
\text { Percentile }\end{array}$} & \multirow[t]{2}{*}{$\begin{array}{l}\text { Measured } \\
\text { Rainfall }\end{array}$} & \multirow{2}{*}{$\begin{array}{l}\text { Condition: } \\
\text { Dry, Wet, } \\
\text { Normal }\end{array}$} & \multirow{3}{*}{ 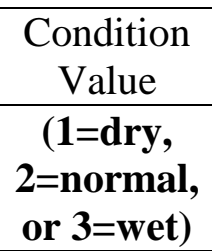 } & \multirow[t]{3}{*}{$\begin{array}{l}\text { Month } \\
\text { weight }\end{array}$} & \multirow{2}{*}{$\begin{array}{c}\text { Multiply } \\
\text { Previous two } \\
\text { columns } \\
\end{array}$} \\
\hline & Name & $30^{\text {th }}$ & 70th & & & & & \\
\hline & & \multicolumn{3}{|c|}{---------cm----------- } & & & & \\
\hline $1^{\text {st }}$ (most recent) & April & 2.90 & 8.53 & 2.55 & Dry & 1 & 3 & 3 \\
\hline $2 \mathrm{nd}$ & March & 2.39 & 5.64 & 3.67 & Normal & 2 & 2 & 4 \\
\hline $3 \mathrm{rd}$ & Feb & 0.97 & 3.73 & 1.71 & Normal & 2 & 1 & 2 \\
\hline \multirow{2}{*}{\multicolumn{8}{|c|}{$\begin{array}{ll} & \text { Sum } \\
\text { Rainfall of prior period was: } & \end{array}$}} & 9 \\
\hline & & & & & & & & Dry \\
\hline
\end{tabular}


Table C.143: DAREM and Modified DAREM calculations for period that met wetland hydrology for plots S4 and S5 at the Marcell Experimental Forest within the year 1984.

\begin{tabular}{|c|c|c|c|c|c|c|c|c|}
\hline \multicolumn{2}{|c|}{ Prior Month } & \multicolumn{2}{|c|}{$\begin{array}{l}\text { WETS Rainfall } \\
\text { Percentile }\end{array}$} & \multirow[t]{2}{*}{$\begin{array}{c}\text { Measured } \\
\text { Rainfall }\end{array}$} & \multirow{2}{*}{$\begin{array}{l}\text { Condition: } \\
\text { Dry, Wet, } \\
\text { Normal }\end{array}$} & \multirow{3}{*}{$\begin{array}{c}\text { Condition } \\
\text { Value } \\
(\mathbf{1 = d r y ,}, \\
2=\text { normal, } \\
\text { or } 3=\text { wet })\end{array}$} & \multirow[t]{2}{*}{$\begin{array}{l}\text { Month } \\
\text { weight }\end{array}$} & \multirow{2}{*}{$\begin{array}{l}\text { Multiply } \\
\text { Previous two } \\
\text { columns }\end{array}$} \\
\hline & Name & $30^{\text {th }}$ & 70th & & & & & \\
\hline & & \multicolumn{3}{|c|}{---------cm----------- } & & & & \\
\hline $1^{\text {st }}$ (most recent) & April & 2.90 & 8.53 & 4.23 & Normal & 2 & 3 & 6 \\
\hline 2nd & March & 2.39 & 5.64 & 1.30 & Dry & 1 & 2 & 2 \\
\hline $3 \mathrm{rd}$ & Feb & 0.97 & 3.73 & 2.44 & Normal & 2 & 1 & 2 \\
\hline \multirow{2}{*}{\multicolumn{8}{|c|}{$\begin{array}{ll} & \text { Sum } \\
\text { Rainfall of prior period was: } & \\
\text { drier than normal (sum is 6-9), normal (sum is } 10-14), \text { wetter than normal (sum is 15-18) }\end{array}$}} & 10 \\
\hline & & & & & & & & Normal \\
\hline
\end{tabular}

Table C.144: DAREM and Modified DAREM calculations for period that met wetland hydrology for plots S4 and S5 at the Marcell Experimental Forest within the year 1985.

\begin{tabular}{|c|c|c|c|c|c|c|c|c|}
\hline \multicolumn{2}{|c|}{ Prior Month } & \multicolumn{2}{|c|}{$\begin{array}{l}\text { WETS Rainfall } \\
\text { Percentile }\end{array}$} & \multirow[t]{2}{*}{$\begin{array}{c}\text { Measured } \\
\text { Rainfall }\end{array}$} & \multirow{2}{*}{$\begin{array}{l}\text { Condition: } \\
\text { Dry, Wet, } \\
\text { Normal }\end{array}$} & \multirow{3}{*}{ 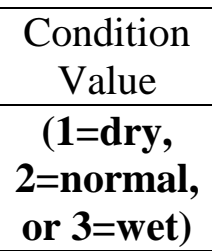 } & \multirow[t]{3}{*}{$\begin{array}{l}\text { Month } \\
\text { weight }\end{array}$} & \multirow{2}{*}{$\begin{array}{c}\text { Multiply } \\
\text { Previous two } \\
\text { columns } \\
\end{array}$} \\
\hline & Name & $30^{\text {th }}$ & 70th & & & & & \\
\hline & & \multicolumn{3}{|c|}{----------cm------------ } & & & & \\
\hline $1^{\mathrm{st}}$ (most recent) & Aug & 6.02 & 11.33 & 10.59 & Normal & 2 & 3 & 6 \\
\hline 2 nd & July & 8.13 & 13.89 & 8.65 & Normal & 2 & 2 & 4 \\
\hline $3 \mathrm{rd}$ & June & 8.41 & 13.79 & 9.55 & Normal & 2 & 1 & 2 \\
\hline \multirow{2}{*}{\multicolumn{8}{|c|}{$\begin{array}{ll} & \text { Sum } \\
\text { Rainfall of prior period was: } & \end{array}$}} & 12 \\
\hline & & & & & & & & Normal \\
\hline
\end{tabular}


Table C.145: DAREM and Modified DAREM calculations for period that met wetland hydrology for plots S4 and S5 at the Marcell Experimental Forest within the year 1986.

\begin{tabular}{|c|c|c|c|c|c|c|c|c|}
\hline \multicolumn{2}{|c|}{ Prior Month } & \multicolumn{2}{|c|}{$\begin{array}{l}\text { WETS Rainfall } \\
\text { Percentile }\end{array}$} & \multirow[t]{2}{*}{$\begin{array}{c}\text { Measured } \\
\text { Rainfall }\end{array}$} & \multirow{2}{*}{$\begin{array}{l}\text { Condition: } \\
\text { Dry, Wet, } \\
\text { Normal }\end{array}$} & \multirow{3}{*}{$\begin{array}{c}\begin{array}{c}\text { Condition } \\
\text { Value }\end{array} \\
\text { (1=dry, } \\
2=\text { normal, } \\
\text { or } 3=\text { wet })\end{array}$} & \multirow[t]{2}{*}{$\begin{array}{l}\text { Month } \\
\text { weight }\end{array}$} & \multirow{2}{*}{$\begin{array}{l}\text { Multiply } \\
\text { Previous two } \\
\text { columns }\end{array}$} \\
\hline & Name & $30^{\text {th }}$ & 70th & & & & & \\
\hline & & \multicolumn{3}{|c|}{----------cm------------ } & & & & \\
\hline $1^{\text {st }}$ (most recent) & April & 2.90 & 8.53 & 10.67 & Wet & 3 & 3 & 9 \\
\hline 2nd & March & 2.39 & 5.64 & 1.21 & Dry & 1 & 2 & 2 \\
\hline $3 \mathrm{rd}$ & Feb & 0.97 & 3.73 & 2.44 & Normal & 2 & 1 & 2 \\
\hline \multirow{2}{*}{\multicolumn{8}{|c|}{$\begin{array}{ll} & \text { Sum } \\
\text { Rainfall of prior period was: } & \\
\text { drier than normal (sum is 6-9), normal (sum is } 10-14), \text { wetter than normal (sum is 15-18) }\end{array}$}} & 13 \\
\hline & & & & & & & & Normal \\
\hline
\end{tabular}

Table C.146: DAREM and Modified DAREM calculations for period that met wetland hydrology for plots S4 and S5 at the Marcell Experimental Forest within the year 1987.

\begin{tabular}{|c|c|c|c|c|c|c|c|c|}
\hline \multicolumn{2}{|c|}{ Prior Month } & \multicolumn{2}{|c|}{$\begin{array}{l}\text { WETS Rainfall } \\
\text { Percentile }\end{array}$} & \multirow[t]{2}{*}{$\begin{array}{l}\text { Measured } \\
\text { Rainfall }\end{array}$} & \multirow{2}{*}{$\begin{array}{l}\text { Condition: } \\
\text { Dry, Wet, } \\
\text { Normal }\end{array}$} & \multirow{3}{*}{ 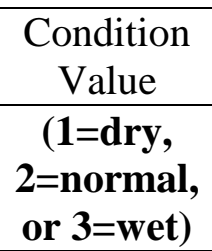 } & \multirow[t]{3}{*}{$\begin{array}{l}\text { Month } \\
\text { weight }\end{array}$} & \multirow{2}{*}{$\begin{array}{c}\text { Multiply } \\
\text { Previous two } \\
\text { columns } \\
\end{array}$} \\
\hline & Name & $30^{\text {th }}$ & 70th & & & & & \\
\hline & & \multicolumn{3}{|c|}{---------cm----------- } & & & & \\
\hline $1^{\mathrm{st}}$ (most recent) & April & 2.90 & 8.53 & 0.62 & Dry & 1 & 3 & 3 \\
\hline $2 \mathrm{nd}$ & March & 2.39 & 5.64 & 3.64 & Normal & 2 & 2 & 4 \\
\hline $3 \mathrm{rd}$ & Feb & 0.97 & 3.73 & 1.31 & Normal & 2 & 1 & 2 \\
\hline \multirow{2}{*}{\multicolumn{8}{|c|}{$\begin{array}{ll} & \text { Sum } \\
\text { Rainfall of prior period was: } & \end{array}$}} & 9 \\
\hline & & & & & & & & Dry \\
\hline
\end{tabular}


Table C.147: DAREM and Modified DAREM calculations for period that met wetland hydrology for plots S4 and S5 at the Marcell Experimental Forest within the year 1988.

\begin{tabular}{|c|c|c|c|c|c|c|c|c|}
\hline \multicolumn{2}{|c|}{ Prior Month } & \multicolumn{2}{|c|}{$\begin{array}{l}\text { WETS Rainfall } \\
\text { Percentile }\end{array}$} & \multirow[t]{2}{*}{$\begin{array}{c}\text { Measured } \\
\text { Rainfall }\end{array}$} & \multirow{2}{*}{$\begin{array}{l}\text { Condition: } \\
\text { Dry, Wet, } \\
\text { Normal }\end{array}$} & \multirow{3}{*}{$\begin{array}{c}\text { Condition } \\
\text { Value }\end{array}$} & \multirow[t]{2}{*}{$\begin{array}{l}\text { Month } \\
\text { weight }\end{array}$} & \multirow{2}{*}{$\begin{array}{l}\text { Multiply } \\
\text { Previous two } \\
\text { columns }\end{array}$} \\
\hline & Name & $30^{\text {th }}$ & 70th & & & & & \\
\hline & & \multicolumn{3}{|c|}{----------cm------------ } & & & & \\
\hline $1^{\text {st }}$ (most recent) & April & 2.90 & 8.53 & 1.22 & Dry & 1 & 3 & 3 \\
\hline 2nd & March & 2.39 & 5.64 & 7.15 & Wet & 3 & 2 & 6 \\
\hline $3 \mathrm{rd}$ & Feb & 0.97 & 3.73 & 0.79 & Dry & 1 & 1 & 1 \\
\hline \multirow{2}{*}{\multicolumn{8}{|c|}{$\begin{array}{ll} & \text { Sum } \\
\text { Rainfall of prior period was: } & \\
\text { drier than normal (sum is 6-9), normal (sum is } 10-14), \text { wetter than normal (sum is 15-18) }\end{array}$}} & 10 \\
\hline & & & & & & & & Normal \\
\hline
\end{tabular}

Table C.148: DAREM and Modified DAREM calculations for period that met wetland hydrology for plots S4 and S5 at the Marcell Experimental Forest within the year 1989.

\begin{tabular}{|c|c|c|c|c|c|c|c|c|}
\hline \multicolumn{2}{|c|}{ Prior Month } & \multicolumn{2}{|c|}{$\begin{array}{l}\text { WETS Rainfall } \\
\text { Percentile }\end{array}$} & \multirow[t]{2}{*}{$\begin{array}{c}\text { Measured } \\
\text { Rainfall }\end{array}$} & \multirow{2}{*}{$\begin{array}{l}\text { Condition: } \\
\text { Dry, Wet, } \\
\text { Normal }\end{array}$} & \multirow{3}{*}{ 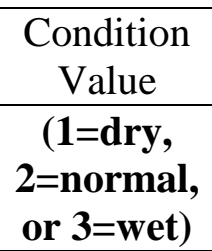 } & \multirow[t]{3}{*}{$\begin{array}{l}\text { Month } \\
\text { weight }\end{array}$} & \multirow{2}{*}{$\begin{array}{c}\text { Multiply } \\
\text { Previous two } \\
\text { columns } \\
\end{array}$} \\
\hline & Name & $30^{\text {th }}$ & 70th & & & & & \\
\hline & & \multicolumn{3}{|c|}{---------cm----------- } & & & & \\
\hline $1^{\mathrm{st}}$ (most recent) & April & 2.90 & 8.53 & 4.92 & Normal & 2 & 3 & 6 \\
\hline $2 \mathrm{nd}$ & March & 2.39 & 5.64 & 2.84 & Normal & 2 & 2 & 4 \\
\hline $3 \mathrm{rd}$ & Feb & 0.97 & 3.73 & 1.56 & Normal & 2 & 1 & 2 \\
\hline \multirow{2}{*}{\multicolumn{8}{|c|}{$\begin{array}{ll} & \text { Sum } \\
\text { Rainfall of prior period was: } & \end{array}$}} & 12 \\
\hline & & & & & & & & Normal \\
\hline
\end{tabular}


Table C.149: DAREM and Modified DAREM calculations for period that met wetland hydrology for plots S4 and S5 at the Marcell Experimental Forest within the year 1990.

\begin{tabular}{|c|c|c|c|c|c|c|c|c|}
\hline \multicolumn{2}{|c|}{ Prior Month } & \multicolumn{2}{|c|}{$\begin{array}{c}\text { WETS Rainfall } \\
\text { Percentile }\end{array}$} & \multirow[t]{2}{*}{$\begin{array}{l}\text { Measured } \\
\text { Rainfall }\end{array}$} & \multirow{2}{*}{$\begin{array}{c}\text { Condition: } \\
\text { Dry, Wet, } \\
\text { Normal }\end{array}$} & \multirow{3}{*}{$\begin{array}{c}\text { Condition } \\
\text { Value } \\
(\mathbf{1 = d r y ,}, \\
2=\text { normal, } \\
\text { or } 3=\text { wet })\end{array}$} & \multirow[t]{2}{*}{$\begin{array}{l}\text { Month } \\
\text { weight }\end{array}$} & \multirow{2}{*}{$\begin{array}{c}\text { Multiply } \\
\text { Previous two } \\
\text { columns } \\
\end{array}$} \\
\hline & Name & $30^{\text {th }}$ & 70th & & & & & \\
\hline & & \multicolumn{3}{|c|}{----------cm----------- } & & & & \\
\hline $1^{\mathrm{st}}$ (most recent) & May & 4.65 & 8.53 & 1.83 & Dry & 1 & 3 & 3 \\
\hline 2nd & April & 2.90 & 5.64 & 6.70 & Wet & 3 & 2 & 6 \\
\hline $3 \mathrm{rd}$ & March & 2.39 & 3.73 & 4.93 & Wet & 3 & 1 & 3 \\
\hline \multirow{2}{*}{\multicolumn{8}{|c|}{$\begin{array}{l}\text { Rainfall of prior period was: } \\
\text { drier than normal (sum is 6-9), normal (sum is 10-14), wetter than normal (sum is 15-18) }\end{array}$}} & 12 \\
\hline & & & & & & & & Normal \\
\hline
\end{tabular}

Table C.150: DAREM and Modified DAREM calculations for period that met wetland hydrology for plots S4 and S5 at the Marcell Experimental Forest within the year 1992.

\begin{tabular}{|c|c|c|c|c|c|c|c|c|}
\hline \multicolumn{2}{|c|}{ Prior Month } & \multicolumn{2}{|c|}{$\begin{array}{l}\text { WETS Rainfall } \\
\text { Percentile }\end{array}$} & \multirow[t]{2}{*}{$\begin{array}{c}\text { Measured } \\
\text { Rainfall }\end{array}$} & \multirow{2}{*}{$\begin{array}{l}\text { Condition: } \\
\text { Dry, Wet, } \\
\text { Normal }\end{array}$} & \multirow{3}{*}{ 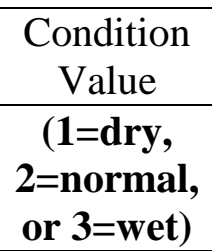 } & \multirow[t]{3}{*}{$\begin{array}{l}\text { Month } \\
\text { weight }\end{array}$} & \multirow{2}{*}{$\begin{array}{c}\text { Multiply } \\
\text { Previous two } \\
\text { columns } \\
\end{array}$} \\
\hline & Name & $30^{\text {th }}$ & 70th & & & & & \\
\hline & & \multicolumn{3}{|c|}{---------cm----------- } & & & & \\
\hline $1^{\mathrm{st}}$ (most recent) & April & 2.90 & 8.53 & 4.40 & Normal & 2 & 3 & 6 \\
\hline $2 \mathrm{nd}$ & March & 2.39 & 5.64 & 2.55 & Normal & 2 & 2 & 4 \\
\hline $3 \mathrm{rd}$ & Feb & 0.97 & 3.73 & 2.84 & Normal & 2 & 1 & 2 \\
\hline \multirow{2}{*}{\multicolumn{8}{|c|}{$\begin{array}{l}\text { Rainfall of prior period was: } \\
\text { drier than normal (sum is } 6-9 \text { ), normal (sum is } 10-14 \text { ), wetter than normal (sum is } 15-18 \text { ) }\end{array}$}} & 12 \\
\hline & & & & & & & & Normal \\
\hline
\end{tabular}


Table C.151: DAREM and Modified DAREM calculations for period that met wetland hydrology for plots S4 and S5 at the Marcell Experimental Forest within the year 1993.

\begin{tabular}{|c|c|c|c|c|c|c|c|c|}
\hline \multicolumn{2}{|c|}{ Prior Month } & \multicolumn{2}{|c|}{$\begin{array}{l}\text { WETS Rainfall } \\
\text { Percentile }\end{array}$} & \multirow[t]{2}{*}{$\begin{array}{c}\text { Measured } \\
\text { Rainfall }\end{array}$} & \multirow{2}{*}{$\begin{array}{l}\text { Condition: } \\
\text { Dry, Wet, } \\
\text { Normal }\end{array}$} & \multirow{3}{*}{$\begin{array}{c}\text { Condition } \\
\text { Value } \\
(\mathbf{1 = d r y ,}, \\
2=\text { normal, } \\
\text { or } 3=\text { wet })\end{array}$} & \multirow[t]{2}{*}{$\begin{array}{l}\text { Month } \\
\text { weight }\end{array}$} & \multirow{2}{*}{$\begin{array}{l}\text { Multiply } \\
\text { Previous two } \\
\text { columns }\end{array}$} \\
\hline & Name & $30^{\text {th }}$ & 70th & & & & & \\
\hline & & \multicolumn{3}{|c|}{---------cm----------- } & & & & \\
\hline $1^{\text {st }}$ (most recent) & April & 2.90 & 8.53 & 6.92 & Normal & 2 & 3 & 6 \\
\hline 2nd & March & 2.39 & 5.64 & 2.58 & Normal & 2 & 2 & 4 \\
\hline $3 \mathrm{rd}$ & Feb & 0.97 & 3.73 & 0.44 & Dry & 1 & 1 & 1 \\
\hline \multirow{2}{*}{\multicolumn{8}{|c|}{$\begin{array}{ll} & \text { Sum } \\
\text { Rainfall of prior period was: } & \\
\text { drier than normal (sum is 6-9), normal (sum is } 10-14), \text { wetter than normal (sum is 15-18) }\end{array}$}} & 11 \\
\hline & & & & & & & & Normal \\
\hline
\end{tabular}

Table C.152: DAREM and Modified DAREM calculations for period that met wetland hydrology for plots S4 and S5 at the Marcell Experimental Forest within the year 1994.

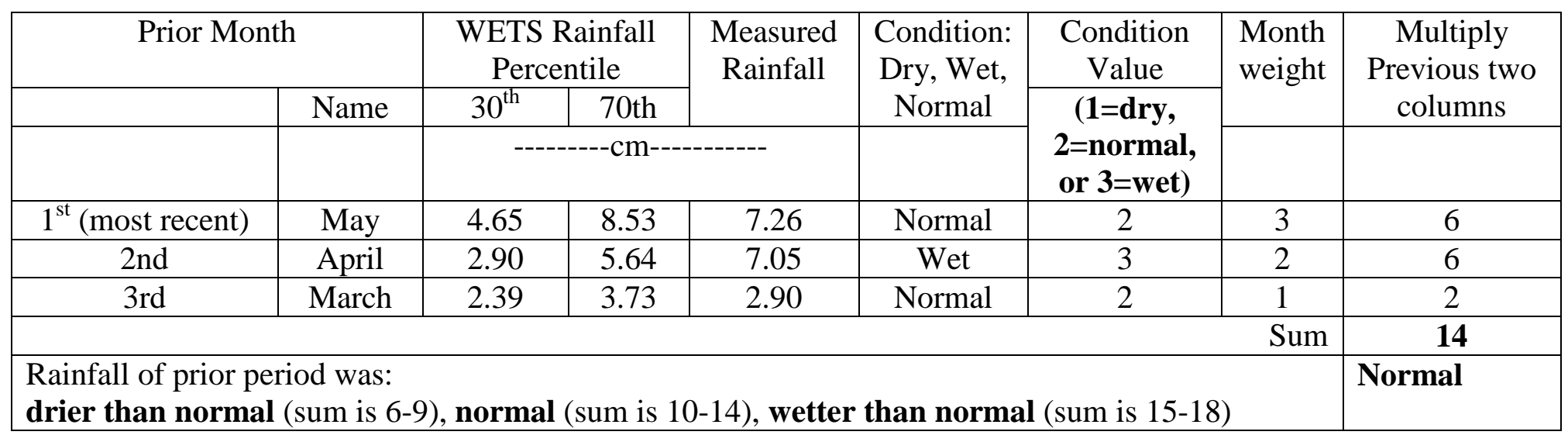


Table C.153: DAREM and Modified DAREM calculations for period that met wetland hydrology for plots S4 and S5 at the Marcell Experimental Forest within the year 1995.

\begin{tabular}{|c|c|c|c|c|c|c|c|c|}
\hline \multicolumn{2}{|c|}{ Prior Month } & \multicolumn{2}{|c|}{$\begin{array}{l}\text { WETS Rainfall } \\
\text { Percentile }\end{array}$} & \multirow[t]{2}{*}{$\begin{array}{c}\text { Measured } \\
\text { Rainfall }\end{array}$} & \multirow{2}{*}{$\begin{array}{l}\text { Condition: } \\
\text { Dry, Wet, } \\
\text { Normal }\end{array}$} & \multirow{3}{*}{$\begin{array}{c}\text { Condition } \\
\text { Value } \\
\text { (1=dry, } \\
2=\text { normal, } \\
\text { or } 3=\text { wet) }\end{array}$} & \multirow[t]{2}{*}{$\begin{array}{l}\text { Month } \\
\text { weight }\end{array}$} & \multirow{2}{*}{$\begin{array}{l}\text { Multiply } \\
\text { Previous two } \\
\text { columns }\end{array}$} \\
\hline & Name & $30^{\text {th }}$ & 70th & & & & & \\
\hline & & \multicolumn{3}{|c|}{----------cm------------ } & & & & \\
\hline $1^{\text {st }}$ (most recent) & April & 2.90 & 8.53 & 4.08 & Normal & 2 & 3 & 6 \\
\hline 2nd & March & 2.39 & 5.64 & 2.61 & Normal & 2 & 2 & 4 \\
\hline $3 \mathrm{rd}$ & Feb & 0.97 & 3.73 & 2.58 & Normal & 2 & 1 & 2 \\
\hline \multirow{2}{*}{\multicolumn{8}{|c|}{$\begin{array}{ll} & \text { Sum } \\
\text { Rainfall of prior period was: } & \\
\text { drier than normal (sum is 6-9), normal (sum is } 10-14), \text { wetter than normal (sum is 15-18) }\end{array}$}} & 12 \\
\hline & & & & & & & & Normal \\
\hline
\end{tabular}

Table C.154: DAREM and Modified DAREM calculations for period that met wetland hydrology for plots S4 and S5 at the Marcell Experimental Forest within the year 1996.

\begin{tabular}{|c|c|c|c|c|c|c|c|c|}
\hline \multicolumn{2}{|c|}{ Prior Month } & \multicolumn{2}{|c|}{$\begin{array}{l}\text { WETS Rainfall } \\
\text { Percentile }\end{array}$} & \multirow[t]{2}{*}{$\begin{array}{c}\text { Measured } \\
\text { Rainfall }\end{array}$} & \multirow{2}{*}{$\begin{array}{l}\text { Condition: } \\
\text { Dry, Wet, } \\
\text { Normal }\end{array}$} & \multirow{3}{*}{ 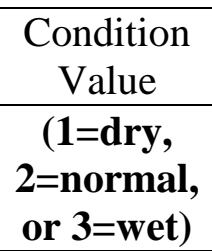 } & \multirow[t]{2}{*}{$\begin{array}{l}\text { Month } \\
\text { weight }\end{array}$} & \multirow{2}{*}{$\begin{array}{c}\text { Multiply } \\
\text { Previous two } \\
\text { columns } \\
\end{array}$} \\
\hline & Name & $30^{\text {th }}$ & 70th & & & & & \\
\hline & & \multicolumn{3}{|c|}{---------cm----------- } & & & & \\
\hline $1^{\mathrm{st}}$ (most recent) & April & 2.90 & 8.53 & 4.33 & Normal & 2 & 3 & 6 \\
\hline $2 \mathrm{nd}$ & March & 2.39 & 5.64 & 2.39 & Normal & 2 & 2 & 4 \\
\hline $3 \mathrm{rd}$ & Feb & 0.97 & 3.73 & 4.93 & Wet & 3 & 1 & 3 \\
\hline \multirow{2}{*}{\multicolumn{8}{|c|}{$\begin{array}{ll} & \text { Sum } \\
\text { Rainfall of prior period was: } & \end{array}$}} & 13 \\
\hline & & & & & & & & Normal \\
\hline
\end{tabular}


Table C.155: DAREM and Modified DAREM calculations for period that met wetland hydrology for plots S4 and S5 at the Marcell Experimental Forest within the year 1997.

\begin{tabular}{|c|c|c|c|c|c|c|c|c|}
\hline \multicolumn{2}{|c|}{ Prior Month } & \multicolumn{2}{|c|}{$\begin{array}{l}\text { WETS Rainfall } \\
\text { Percentile }\end{array}$} & \multirow[t]{2}{*}{$\begin{array}{c}\text { Measured } \\
\text { Rainfall }\end{array}$} & \multirow{2}{*}{$\begin{array}{l}\text { Condition: } \\
\text { Dry, Wet, } \\
\text { Normal }\end{array}$} & \multirow{3}{*}{$\begin{array}{c}\text { Condition } \\
\text { Value } \\
(\mathbf{1 = d r y ,}, \\
2=\text { normal, } \\
\text { or } 3=\text { wet })\end{array}$} & \multirow[t]{2}{*}{$\begin{array}{l}\text { Month } \\
\text { weight }\end{array}$} & \multirow{2}{*}{$\begin{array}{l}\text { Multiply } \\
\text { Previous two } \\
\text { columns }\end{array}$} \\
\hline & Name & $30^{\text {th }}$ & 70th & & & & & \\
\hline & & \multicolumn{3}{|c|}{---------cm----------- } & & & & \\
\hline $1^{\text {st }}$ (most recent) & April & 2.90 & 8.53 & 2.95 & Normal & 2 & 3 & 6 \\
\hline 2nd & March & 2.39 & 5.64 & 1.34 & Dry & 1 & 2 & 2 \\
\hline $3 \mathrm{rd}$ & Feb & 0.97 & 3.73 & 6.04 & Wet & 3 & 1 & 3 \\
\hline \multirow{2}{*}{\multicolumn{8}{|c|}{$\begin{array}{ll} & \text { Sum } \\
\text { Rainfall of prior period was: } & \\
\text { drier than normal (sum is 6-9), normal (sum is } 10-14), \text { wetter than normal (sum is 15-18) }\end{array}$}} & 11 \\
\hline & & & & & & & & Normal \\
\hline
\end{tabular}

Table C.156: DAREM and Modified DAREM calculations for period that met wetland hydrology for plots S4 and S5 at the Marcell Experimental Forest within the year 1998.

\begin{tabular}{|c|c|c|c|c|c|c|c|c|}
\hline \multicolumn{2}{|c|}{ Prior Month } & \multicolumn{2}{|c|}{$\begin{array}{l}\text { WETS Rainfall } \\
\text { Percentile }\end{array}$} & \multirow[t]{2}{*}{$\begin{array}{l}\text { Measured } \\
\text { Rainfall }\end{array}$} & \multirow{2}{*}{$\begin{array}{l}\text { Condition: } \\
\text { Dry, Wet, } \\
\text { Normal }\end{array}$} & \multirow{3}{*}{ 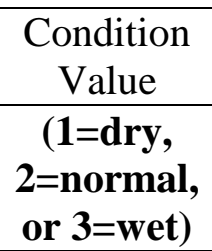 } & \multirow[t]{3}{*}{$\begin{array}{l}\text { Month } \\
\text { weight }\end{array}$} & \multirow{2}{*}{$\begin{array}{c}\text { Multiply } \\
\text { Previous two } \\
\text { columns } \\
\end{array}$} \\
\hline & Name & $30^{\text {th }}$ & 70th & & & & & \\
\hline & & \multicolumn{3}{|c|}{---------cm----------- } & & & & \\
\hline $1^{\text {st }}$ (most recent) & April & 2.90 & 8.53 & 2.24 & Dry & 1 & 3 & 3 \\
\hline $2 \mathrm{nd}$ & March & 2.39 & 5.64 & 4.51 & Normal & 2 & 2 & 4 \\
\hline $3 \mathrm{rd}$ & Feb & 0.97 & 3.73 & 2.86 & Normal & 2 & 1 & 2 \\
\hline \multirow{2}{*}{\multicolumn{8}{|c|}{$\begin{array}{ll} & \text { Sum } \\
\text { Rainfall of prior period was: } & \end{array}$}} & 9 \\
\hline & & & & & & & & Dry \\
\hline
\end{tabular}


Table C.157: DAREM and Modified DAREM calculations for period that met wetland hydrology for plots S4 and S5 at the Marcell Experimental Forest within the year 1999.

\begin{tabular}{|c|c|c|c|c|c|c|c|c|}
\hline \multicolumn{2}{|c|}{ Prior Month } & \multicolumn{2}{|c|}{$\begin{array}{l}\text { WETS Rainfall } \\
\text { Percentile }\end{array}$} & \multirow[t]{2}{*}{$\begin{array}{c}\text { Measured } \\
\text { Rainfall }\end{array}$} & \multirow{2}{*}{$\begin{array}{l}\text { Condition: } \\
\text { Dry, Wet, } \\
\text { Normal }\end{array}$} & \multirow{3}{*}{$\begin{array}{c}\text { Condition } \\
\text { Value } \\
(\mathbf{1 = d r y ,}, \\
2=\text { normal, } \\
\text { or } 3=\text { wet })\end{array}$} & \multirow[t]{2}{*}{$\begin{array}{l}\text { Month } \\
\text { weight }\end{array}$} & \multirow{2}{*}{$\begin{array}{l}\text { Multiply } \\
\text { Previous two } \\
\text { columns }\end{array}$} \\
\hline & Name & $30^{\text {th }}$ & 70th & & & & & \\
\hline & & \multicolumn{3}{|c|}{---------cm----------- } & & & & \\
\hline $1^{\text {st }}$ (most recent) & June & 8.41 & 13.79 & 11.30 & Normal & 2 & 3 & 6 \\
\hline 2nd & May & 4.65 & 8.53 & 13.89 & Wet & 3 & 2 & 6 \\
\hline $3 \mathrm{rd}$ & April & 2.90 & 10.98 & 4.77 & Normal & 2 & 1 & 2 \\
\hline \multirow{2}{*}{\multicolumn{8}{|c|}{$\begin{array}{ll} & \text { Sum } \\
\text { Rainfall of prior period was: } & \\
\text { drier than normal (sum is 6-9), normal (sum is } 10-14), \text { wetter than normal (sum is 15-18) }\end{array}$}} & 14 \\
\hline & & & & & & & & Normal \\
\hline
\end{tabular}

Table C.158: DAREM and Modified DAREM calculations for period that met wetland hydrology for plots S4 and S5 at the Marcell Experimental Forest within the year 2000.

\begin{tabular}{|c|c|c|c|c|c|c|c|c|}
\hline \multicolumn{2}{|c|}{ Prior Month } & \multicolumn{2}{|c|}{$\begin{array}{l}\text { WETS Rainfall } \\
\text { Percentile }\end{array}$} & \multirow[t]{2}{*}{$\begin{array}{c}\text { Measured } \\
\text { Rainfall }\end{array}$} & \multirow{2}{*}{$\begin{array}{l}\text { Condition: } \\
\text { Dry, Wet, } \\
\text { Normal }\end{array}$} & \multirow{3}{*}{ 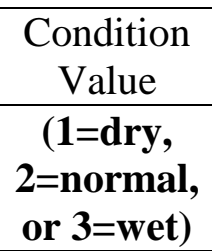 } & \multirow[t]{3}{*}{$\begin{array}{l}\text { Month } \\
\text { weight }\end{array}$} & \multirow{2}{*}{$\begin{array}{c}\text { Multiply } \\
\text { Previous two } \\
\text { columns } \\
\end{array}$} \\
\hline & Name & $30^{\text {th }}$ & 70th & & & & & \\
\hline & & \multicolumn{3}{|c|}{---------cm----------- } & & & & \\
\hline $1^{\mathrm{st}}$ (most recent) & April & 2.90 & 8.53 & 4.38 & Normal & 2 & 3 & 6 \\
\hline $2 \mathrm{nd}$ & March & 2.39 & 5.64 & 3.69 & Normal & 2 & 2 & 4 \\
\hline $3 \mathrm{rd}$ & Feb & 0.97 & 3.73 & 2.09 & Normal & 2 & 1 & 2 \\
\hline \multirow{2}{*}{\multicolumn{8}{|c|}{$\begin{array}{ll} & \text { Sum } \\
\text { Rainfall of prior period was: } & \end{array}$}} & 12 \\
\hline & & & & & & & & Normal \\
\hline
\end{tabular}


Table C.159: DAREM and Modified DAREM calculations for period that met wetland hydrology for plots S4 and S5 at the Marcell Experimental Forest within the year 2001.

\begin{tabular}{|c|c|c|c|c|c|c|c|c|}
\hline \multicolumn{2}{|c|}{ Prior Month } & \multicolumn{2}{|c|}{$\begin{array}{l}\text { WETS Rainfall } \\
\text { Percentile }\end{array}$} & \multirow[t]{2}{*}{$\begin{array}{c}\text { Measured } \\
\text { Rainfall }\end{array}$} & \multirow{2}{*}{$\begin{array}{l}\text { Condition: } \\
\text { Dry, Wet, } \\
\text { Normal }\end{array}$} & \multirow{3}{*}{$\begin{array}{c}\text { Condition } \\
\text { Value } \\
\text { (1=dry, } \\
2=\text { normal, } \\
\text { or } 3=\text { wet) }\end{array}$} & \multirow[t]{2}{*}{$\begin{array}{l}\text { Month } \\
\text { weight }\end{array}$} & \multirow{2}{*}{$\begin{array}{l}\text { Multiply } \\
\text { Previous two } \\
\text { columns }\end{array}$} \\
\hline & Name & $30^{\text {th }}$ & 70th & & & & & \\
\hline & & \multicolumn{3}{|c|}{---------cm----------- } & & & & \\
\hline $1^{\text {st }}$ (most recent) & April & 2.90 & 8.53 & 12.31 & Wet & 3 & 3 & 9 \\
\hline 2nd & March & 2.39 & 5.64 & 1.28 & Dry & 1 & 2 & 2 \\
\hline $3 \mathrm{rd}$ & Feb & 0.97 & 3.73 & 5.20 & Wet & 3 & 1 & 3 \\
\hline \multirow{2}{*}{\multicolumn{8}{|c|}{$\begin{array}{ll} & \text { Sum } \\
\text { Rainfall of prior period was: } & \\
\text { drier than normal (sum is 6-9), normal (sum is } 10-14), \text { wetter than normal (sum is 15-18) }\end{array}$}} & 14 \\
\hline & & & & & & & & Normal \\
\hline
\end{tabular}

Table C.160: DAREM and Modified DAREM calculations for period that met wetland hydrology for plots S4 and S5 at the Marcell Experimental Forest within the year 2002.

\begin{tabular}{|c|c|c|c|c|c|c|c|c|}
\hline \multicolumn{2}{|c|}{ Prior Month } & \multicolumn{2}{|c|}{$\begin{array}{l}\text { WETS Rainfall } \\
\text { Percentile }\end{array}$} & \multirow[t]{2}{*}{$\begin{array}{c}\text { Measured } \\
\text { Rainfall }\end{array}$} & \multirow{2}{*}{$\begin{array}{l}\text { Condition: } \\
\text { Dry, Wet, } \\
\text { Normal }\end{array}$} & \multirow{3}{*}{ 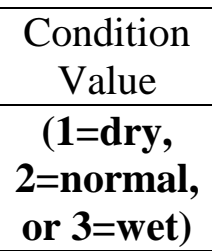 } & \multirow[t]{3}{*}{$\begin{array}{l}\text { Month } \\
\text { weight }\end{array}$} & \multirow{2}{*}{$\begin{array}{c}\text { Multiply } \\
\text { Previous two } \\
\text { columns } \\
\end{array}$} \\
\hline & Name & $30^{\text {th }}$ & 70th & & & & & \\
\hline & & \multicolumn{3}{|c|}{---------cm----------- } & & & & \\
\hline $1^{\mathrm{st}}$ (most recent) & April & 2.90 & 8.53 & 2.92 & Normal & 2 & 3 & 6 \\
\hline $2 \mathrm{nd}$ & March & 2.39 & 5.64 & 3.46 & Normal & 2 & 2 & 4 \\
\hline $3 \mathrm{rd}$ & Feb & 0.97 & 3.73 & 0.64 & Dry & 1 & 1 & 1 \\
\hline \multirow{2}{*}{\multicolumn{8}{|c|}{$\begin{array}{ll} & \text { Sum } \\
\text { Rainfall of prior period was: } & \end{array}$}} & 11 \\
\hline & & & & & & & & Normal \\
\hline
\end{tabular}


Table C.161: DAREM and Modified DAREM calculations for period that met wetland hydrology for plots S4 and S5 at the Marcell Experimental Forest within the year 2003.

\begin{tabular}{|c|c|c|c|c|c|c|c|c|}
\hline \multicolumn{2}{|c|}{ Prior Month } & \multicolumn{2}{|c|}{$\begin{array}{l}\text { WETS Rainfall } \\
\text { Percentile }\end{array}$} & \multirow[t]{2}{*}{$\begin{array}{c}\text { Measured } \\
\text { Rainfall }\end{array}$} & \multirow{2}{*}{$\begin{array}{l}\text { Condition: } \\
\text { Dry, Wet, } \\
\text { Normal }\end{array}$} & \multirow{3}{*}{$\begin{array}{c}\text { Condition } \\
\text { Value } \\
(\mathbf{1 = d r y ,}, \\
2=\text { normal, } \\
\text { or } 3=\text { wet })\end{array}$} & \multirow[t]{2}{*}{$\begin{array}{l}\text { Month } \\
\text { weight }\end{array}$} & \multirow{2}{*}{$\begin{array}{l}\text { Multiply } \\
\text { Previous two } \\
\text { columns }\end{array}$} \\
\hline & Name & $30^{\text {th }}$ & 70th & & & & & \\
\hline & & \multicolumn{3}{|c|}{---------cm----------- } & & & & \\
\hline $1^{\text {st }}$ (most recent) & April & 2.90 & 8.53 & 4.88 & Normal & 2 & 3 & 6 \\
\hline 2nd & March & 2.39 & 5.64 & 1.73 & Dry & 1 & 2 & 2 \\
\hline $3 \mathrm{rd}$ & Feb & 0.97 & 3.73 & 0.84 & Dry & 1 & 1 & 1 \\
\hline \multirow{2}{*}{\multicolumn{8}{|c|}{$\begin{array}{ll} & \text { Sum } \\
\text { Rainfall of prior period was: } & \\
\text { drier than normal (sum is 6-9), normal (sum is } 10-14), \text { wetter than normal (sum is 15-18) }\end{array}$}} & 9 \\
\hline & & & & & & & & Dry \\
\hline
\end{tabular}

Table C.162: DAREM and Modified DAREM calculations for period that met wetland hydrology for plots S4 and S5 at the Marcell Experimental Forest within the year 2004.

\begin{tabular}{|c|c|c|c|c|c|c|c|c|}
\hline \multicolumn{2}{|c|}{ Prior Month } & \multicolumn{2}{|c|}{$\begin{array}{l}\text { WETS Rainfall } \\
\text { Percentile }\end{array}$} & \multirow[t]{2}{*}{$\begin{array}{c}\text { Measured } \\
\text { Rainfall }\end{array}$} & \multirow{2}{*}{$\begin{array}{l}\text { Condition: } \\
\text { Dry, Wet, } \\
\text { Normal }\end{array}$} & \multirow{3}{*}{ 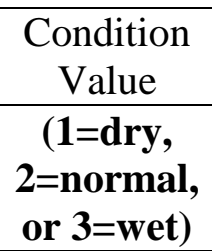 } & \multirow[t]{3}{*}{$\begin{array}{l}\text { Month } \\
\text { weight }\end{array}$} & \multirow{2}{*}{$\begin{array}{c}\text { Multiply } \\
\text { Previous two } \\
\text { columns } \\
\end{array}$} \\
\hline & Name & $30^{\text {th }}$ & 70th & & & & & \\
\hline & & \multicolumn{3}{|c|}{---------cm----------- } & & & & \\
\hline $1^{\mathrm{st}}$ (most recent) & April & 2.90 & 8.53 & 2.90 & Normal & 2 & 3 & 6 \\
\hline $2 \mathrm{nd}$ & March & 2.39 & 5.64 & 4.17 & Normal & 2 & 2 & 4 \\
\hline $3 \mathrm{rd}$ & Feb & 0.97 & 3.73 & 1.60 & Normal & 2 & 1 & 2 \\
\hline \multirow{2}{*}{\multicolumn{8}{|c|}{$\begin{array}{ll} & \text { Sum } \\
\text { Rainfall of prior period was: } & \end{array}$}} & 12 \\
\hline & & & & & & & & Normal \\
\hline
\end{tabular}


Table C.163: DAREM and Modified DAREM calculations for period that met wetland hydrology for plots S4 and S5 at the Marcell Experimental Forest within the year 2005.

\begin{tabular}{|c|c|c|c|c|c|c|c|c|}
\hline \multicolumn{2}{|c|}{ Prior Month } & \multicolumn{2}{|c|}{$\begin{array}{l}\text { WETS Rainfall } \\
\text { Percentile }\end{array}$} & \multirow[t]{2}{*}{$\begin{array}{l}\text { Measured } \\
\text { Rainfall }\end{array}$} & \multirow{2}{*}{$\begin{array}{l}\text { Condition: } \\
\text { Dry, Wet, } \\
\text { Normal }\end{array}$} & \multirow{3}{*}{$\begin{array}{c}\text { Condition } \\
\text { Value }\end{array}$} & \multirow[t]{2}{*}{$\begin{array}{l}\text { Month } \\
\text { weight }\end{array}$} & \multirow{2}{*}{$\begin{array}{c}\text { Multiply } \\
\text { Previous two } \\
\text { columns }\end{array}$} \\
\hline & Name & $30^{\text {th }}$ & 70th & & & & & \\
\hline & & \multicolumn{3}{|c|}{----------cm------------ } & & & & \\
\hline $1^{\text {st }}$ (most recent) & April & 2.90 & 8.53 & 1.91 & Dry & 1 & 3 & 3 \\
\hline 2nd & March & 2.39 & 5.64 & 2.26 & Dry & 1 & 2 & 2 \\
\hline $3 \mathrm{rd}$ & Feb & 0.97 & 3.73 & 1.55 & Normal & 2 & 1 & 2 \\
\hline \multirow{2}{*}{\multicolumn{8}{|c|}{$\begin{array}{l}\text { Rainfall of prior period was: } \\
\text { drier than normal (sum is 6-9), normal (sum is } 10-14 \text { ), wetter than normal (sum is } 15-18 \text { ) }\end{array}$}} & 7 \\
\hline & & & & & & & & Dry \\
\hline
\end{tabular}




\section{APPENDIX D}

\section{Moving Total Graphs}

This Appendix includes Moving Total graphs that were generated from precipitation data at each research site. These graphs show the calculated 30-day moving total throughout the year stated, and also show where the moving total graph lies in relation to the $70^{\text {th }}$ percentile values that were obtained from WETS Tabless. Rainfall amounts greater than the $70^{\text {th }}$ percentile are considered to be wetter than normal. Dashed vertical lines represent the growing season. Wetland hydrology conditions are met when the water table is within $30 \mathrm{~cm}$ of the surface for 14 days or more when: 1) the moving total is within the growing season, 2) is less than the $70^{\text {th }}$ percentile for 30 consecutive days or longer. However, if the water table saturation criterion is met when the moving total is above the $70^{\text {th }}$ percentile, then the study plot did not meet wetland hydrology. These graphs were used to determine which plots did or did not meet wetland hydrology. Refer to Appendix 2 to see which years met wetland hydrology. 


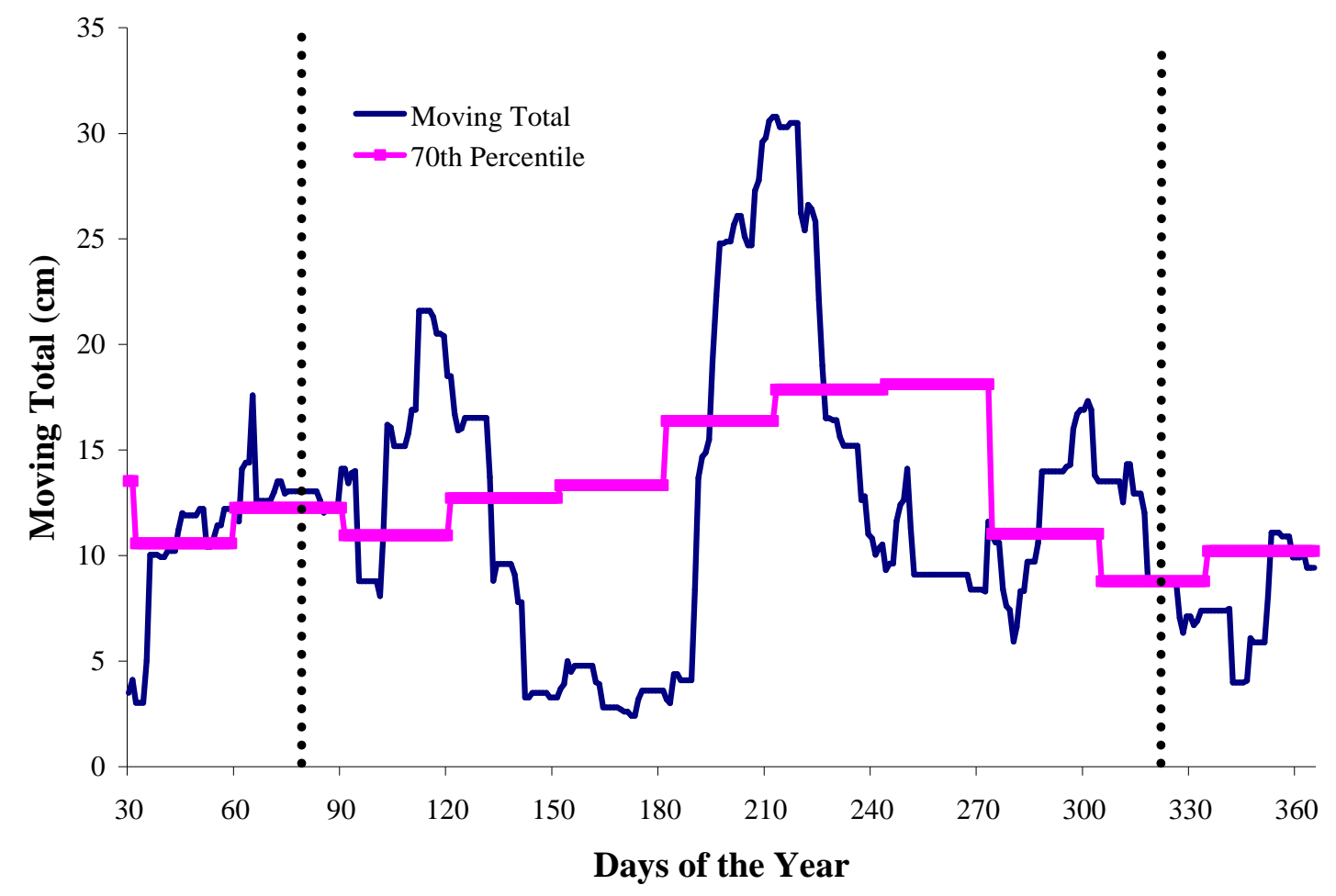

Figure D.1: Moving total graph for all Greenville plots for the year 1959.

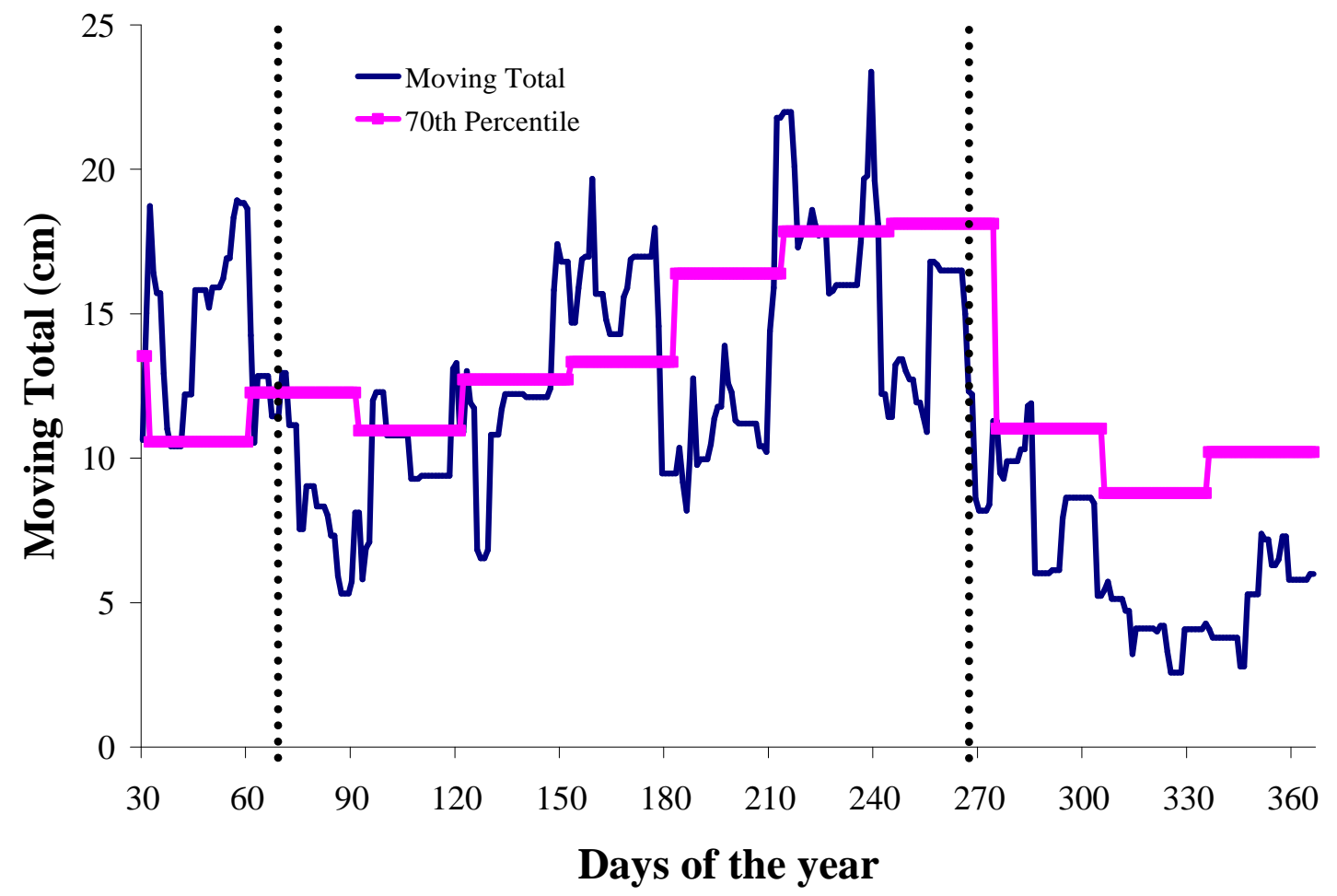

Figure D.2: Moving total graph for all Greenville plots for the year 1960. 


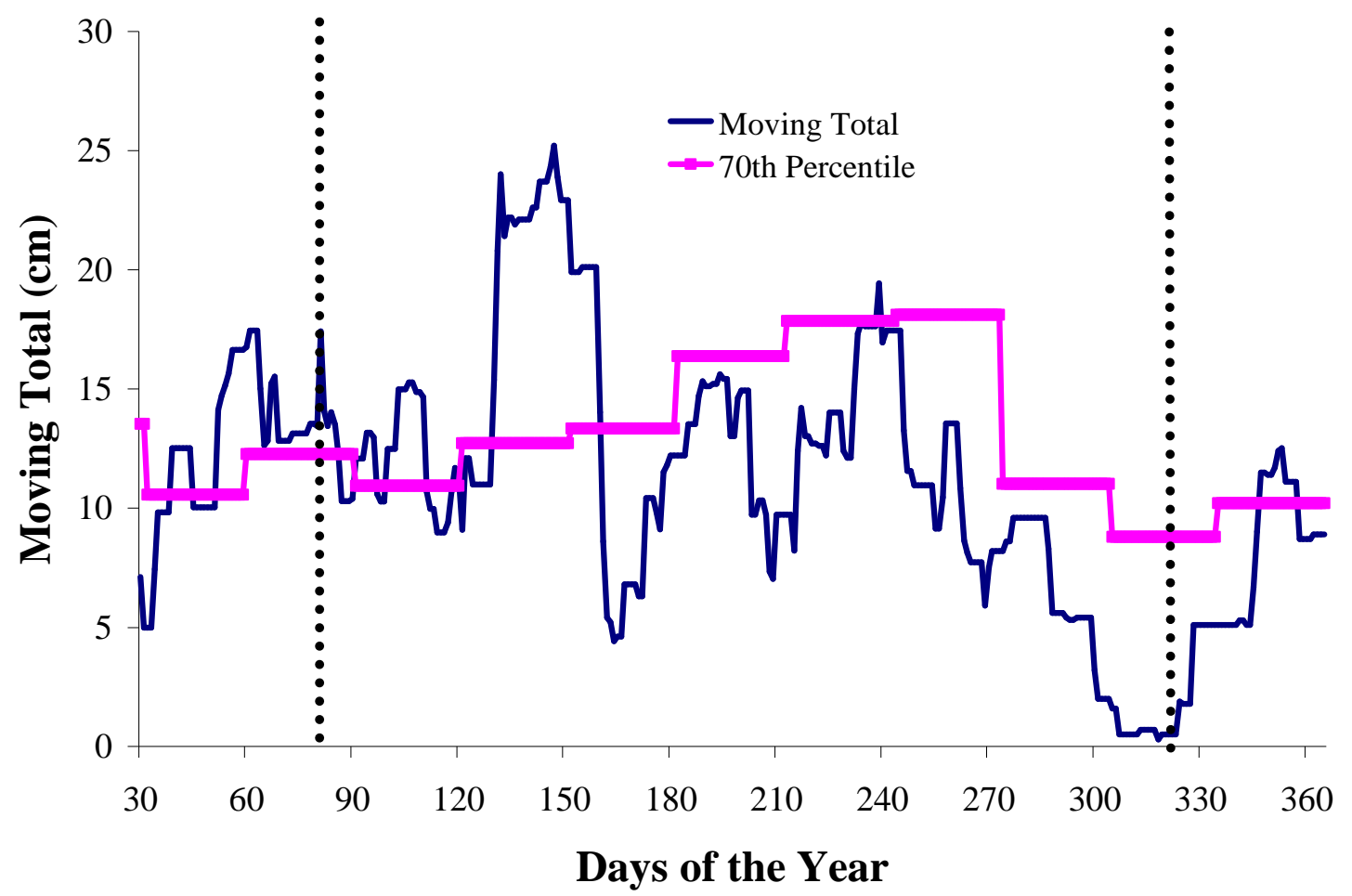

Figure D.3: Moving total graph for all plots at Greenville for the year 1961.

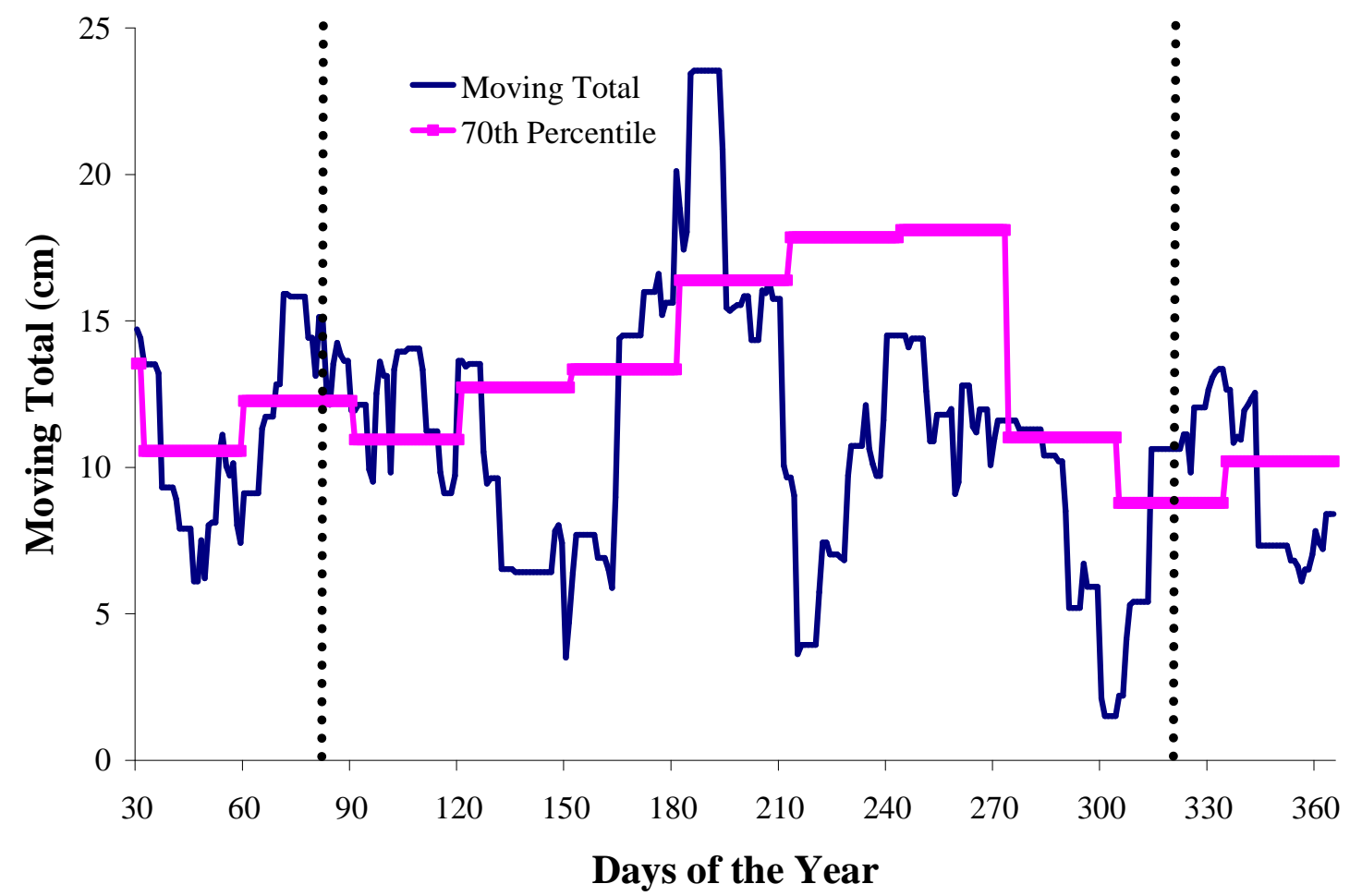

Figure D.4: Moving total graph for all plots at Greenville for the year 1962. 


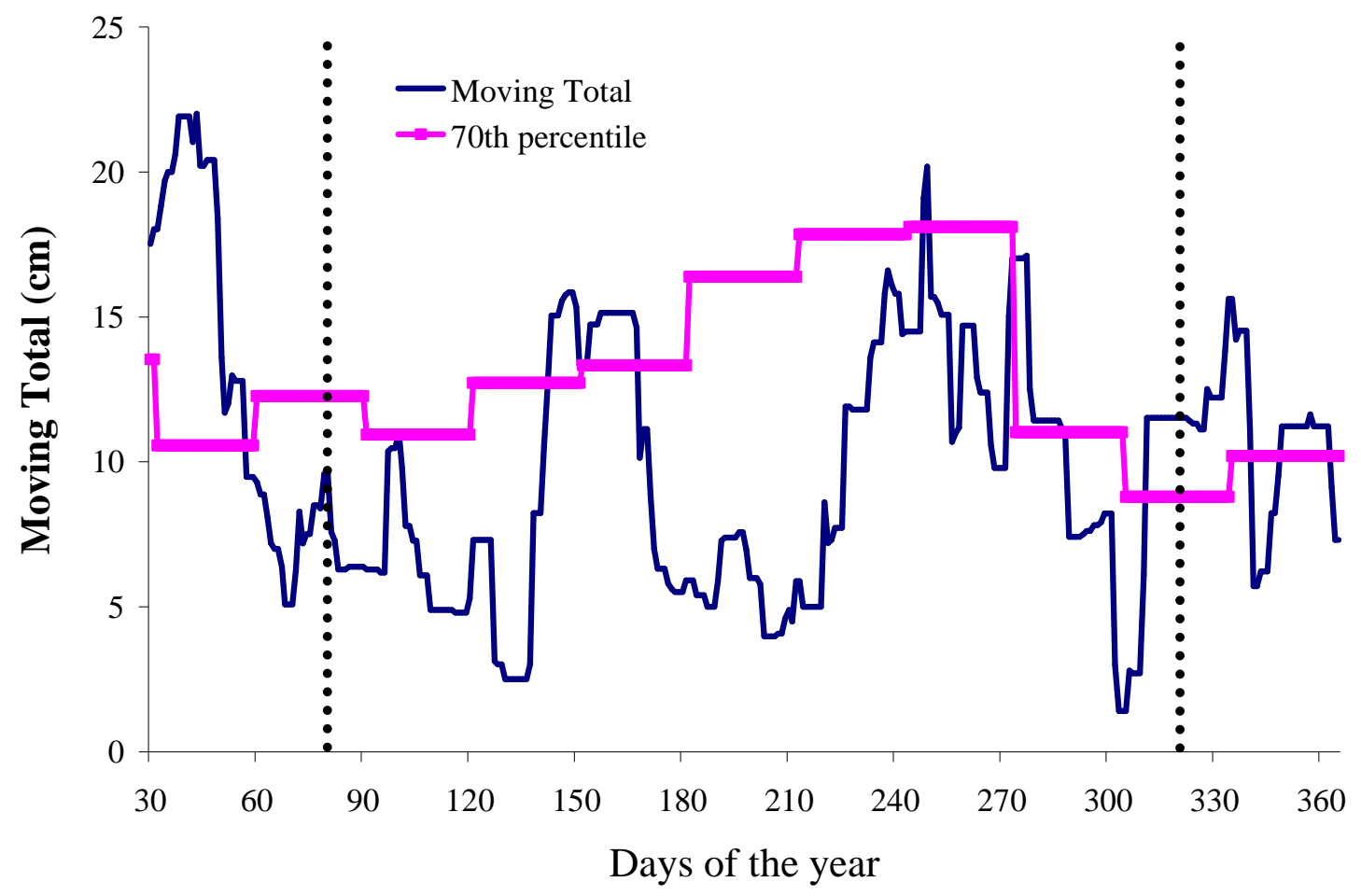

Figure D.5: Moving total graph for all plots at Greenville for year 1963.

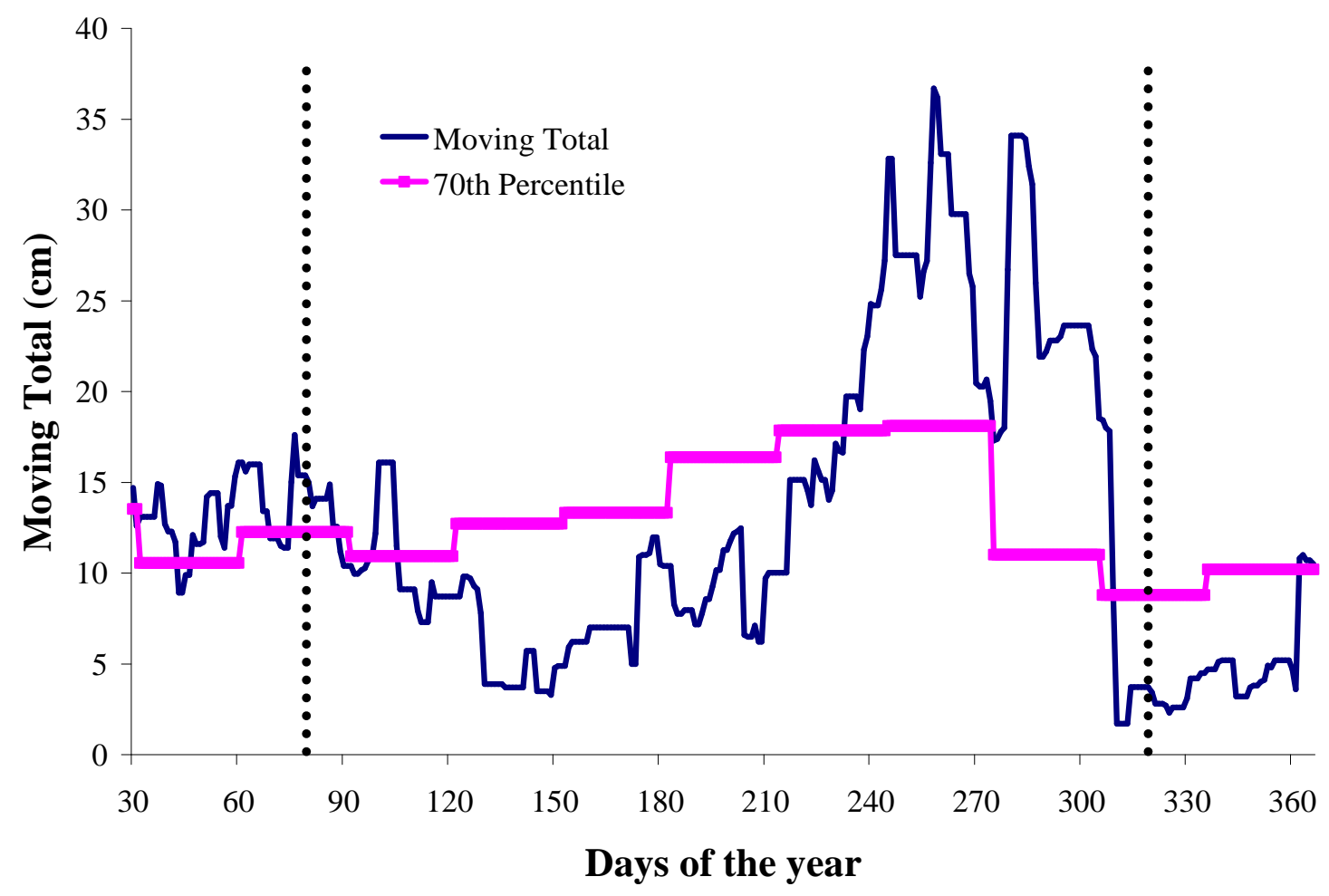

Figure D.6: Moving total graph for all plots at Greenville for year 1964 . 


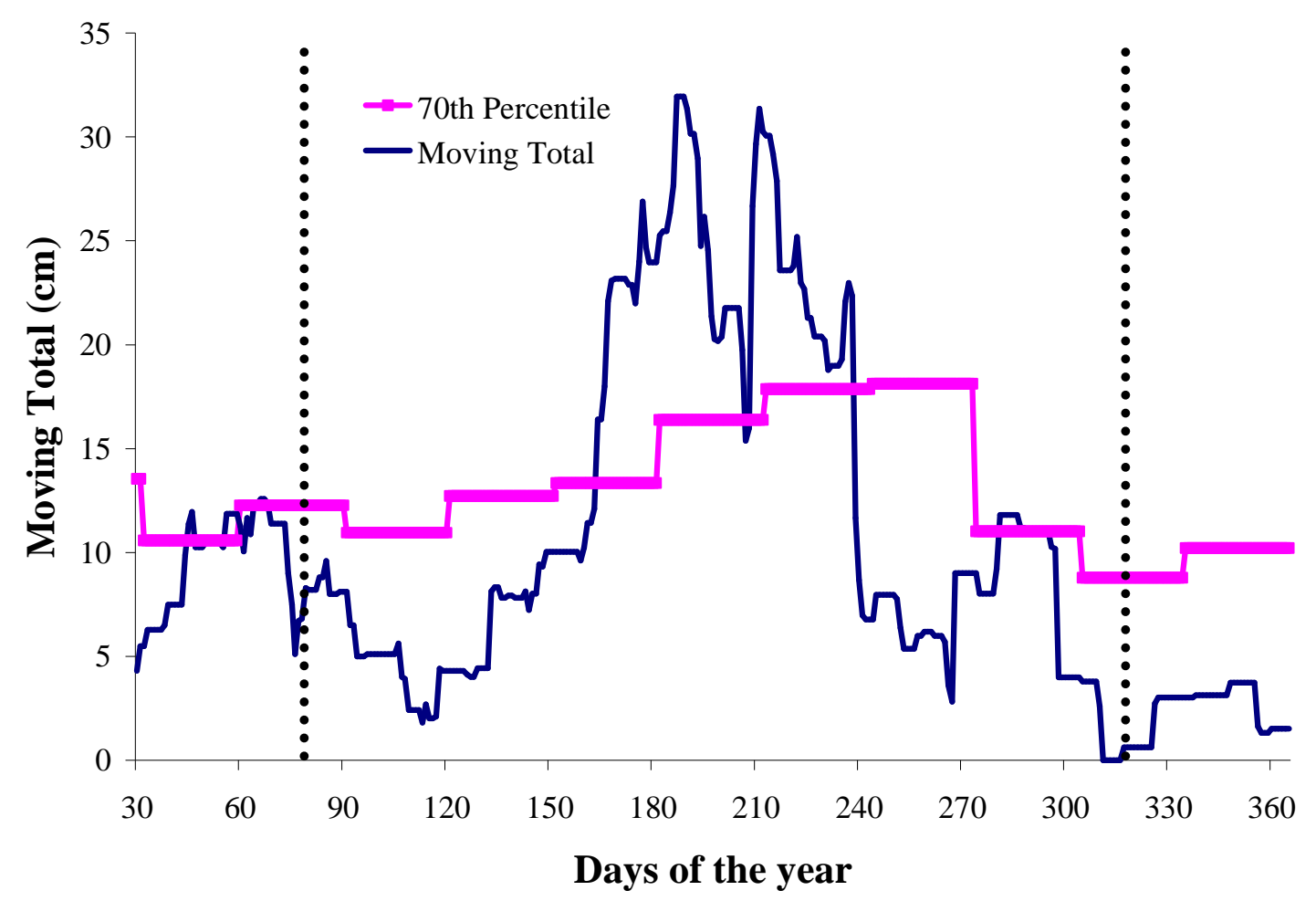

Figure D.7: Moving total graph for all plots at Greenville for year 1965.

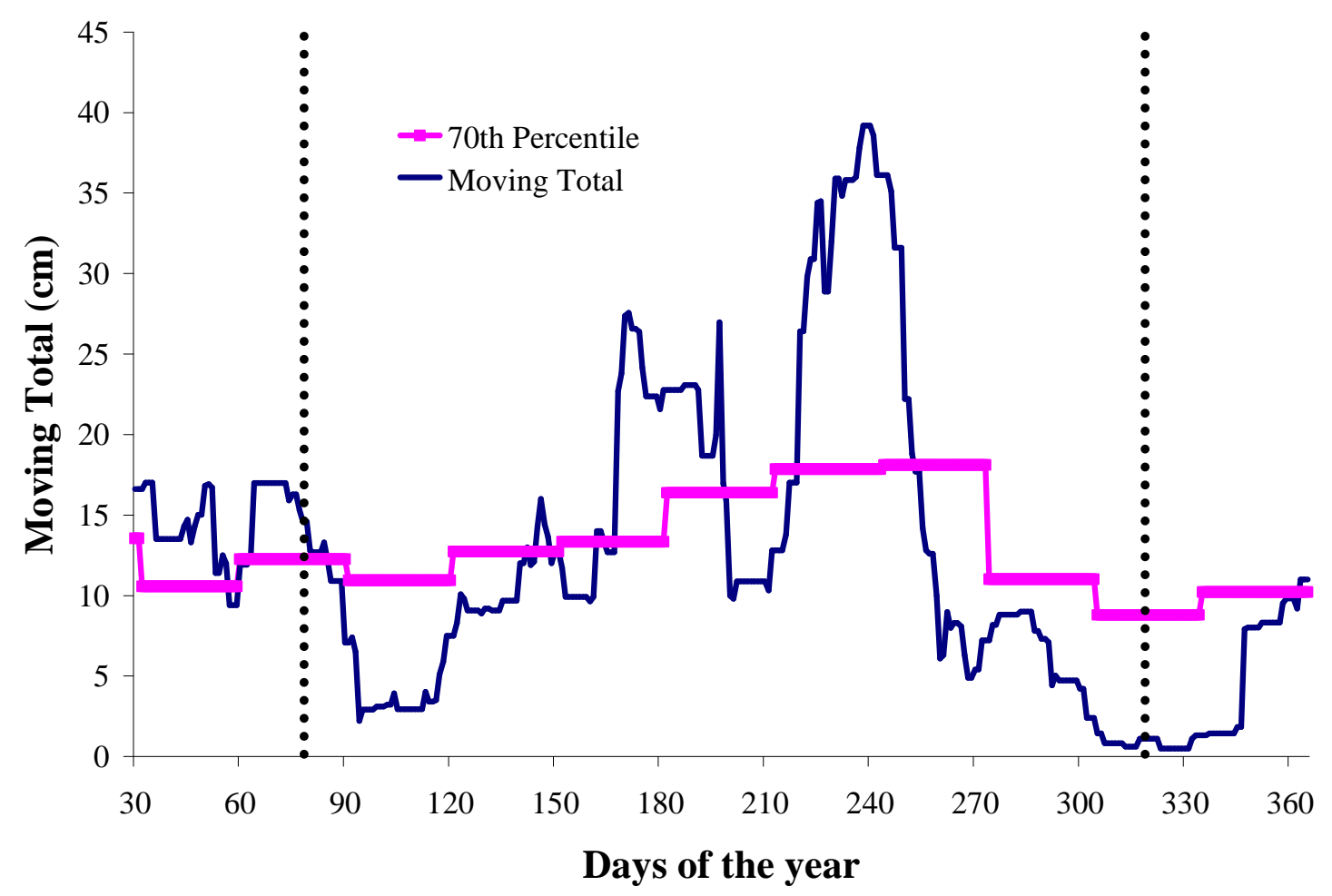

Figure D.8: Moving total graph for all plots at Greenville for year 1966. 


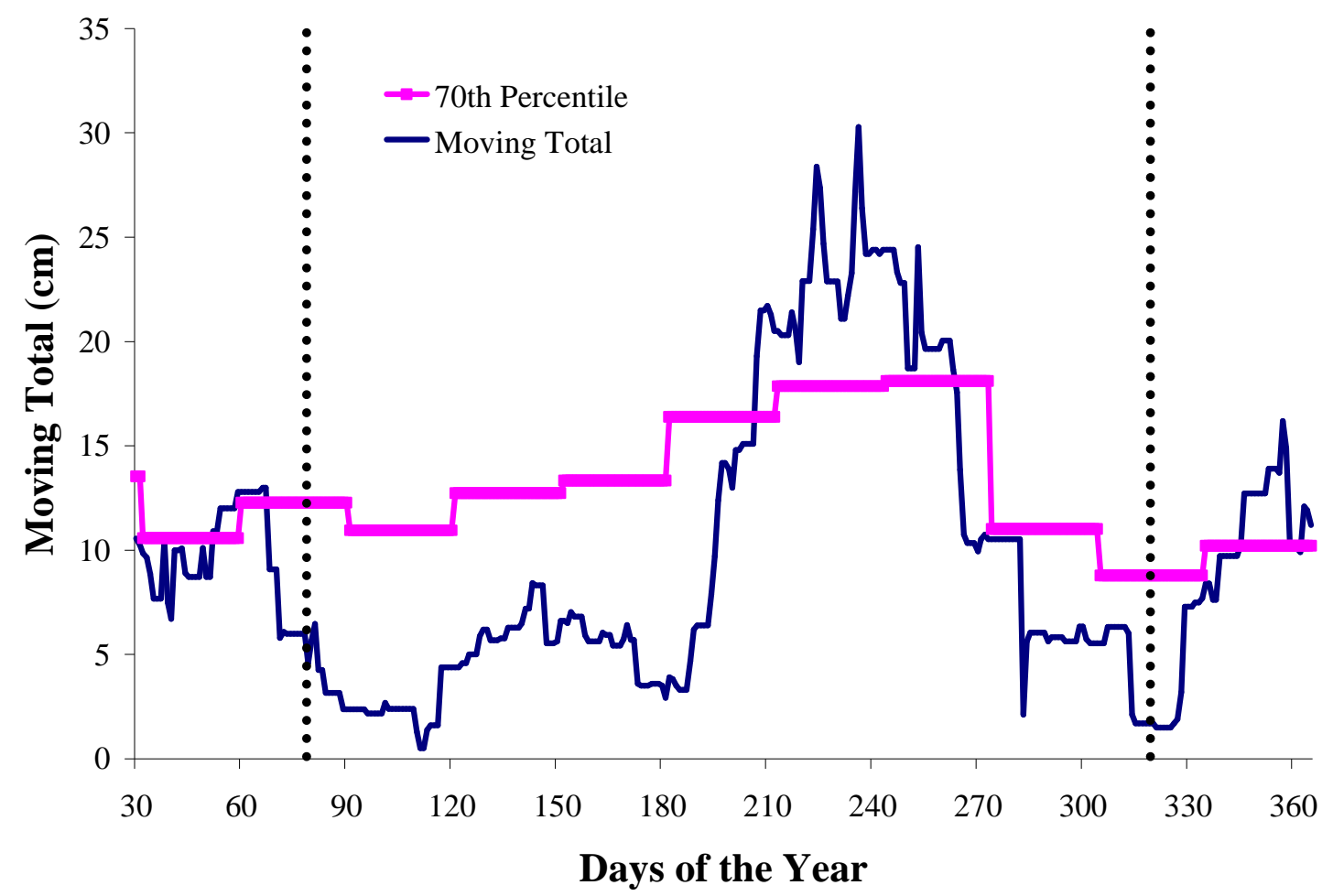

Figure D.9: Moving total graph for all plots at Greenville for year 1967.

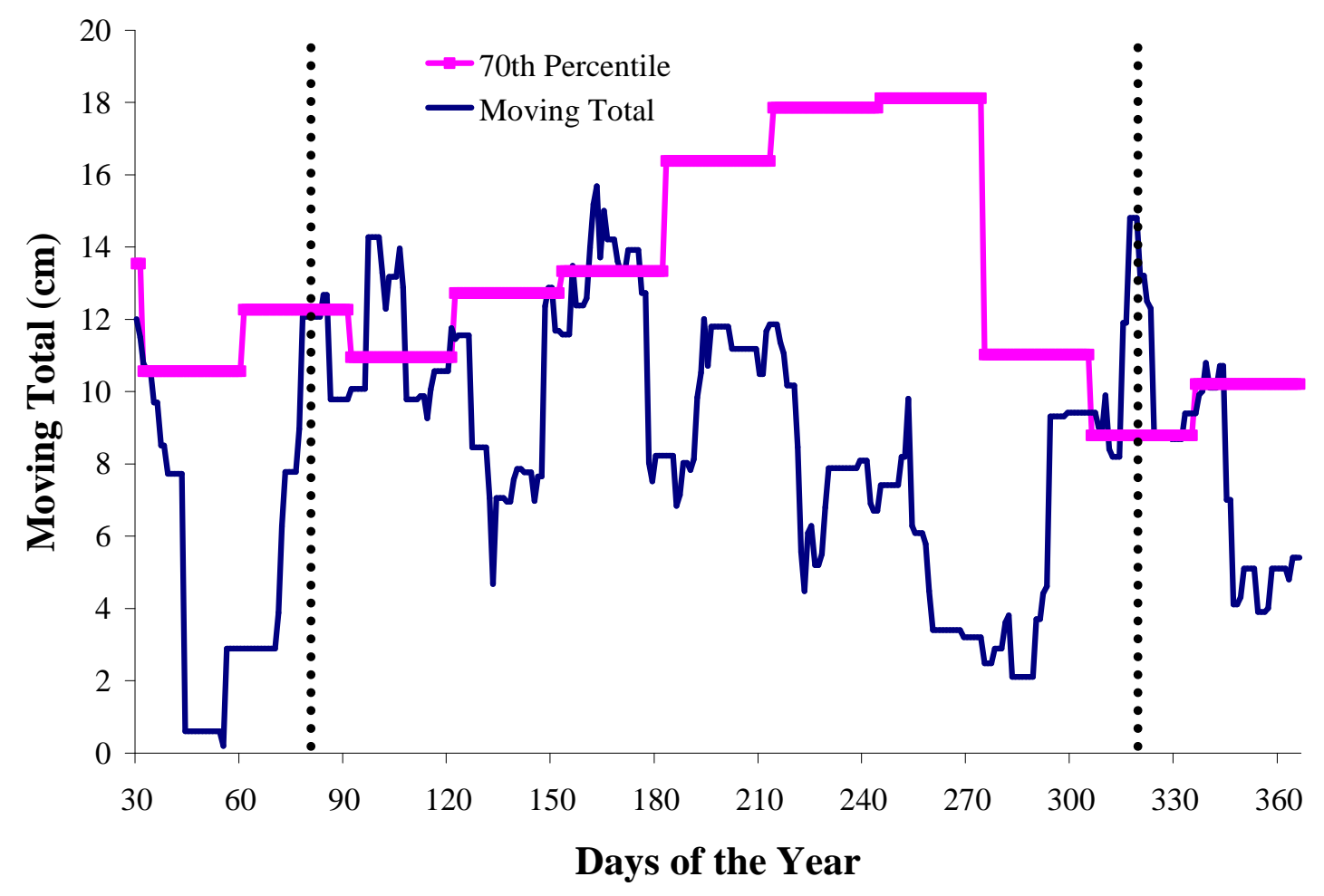

Figure D.10: Moving total graph for all plots at Greenville for year 1968. 


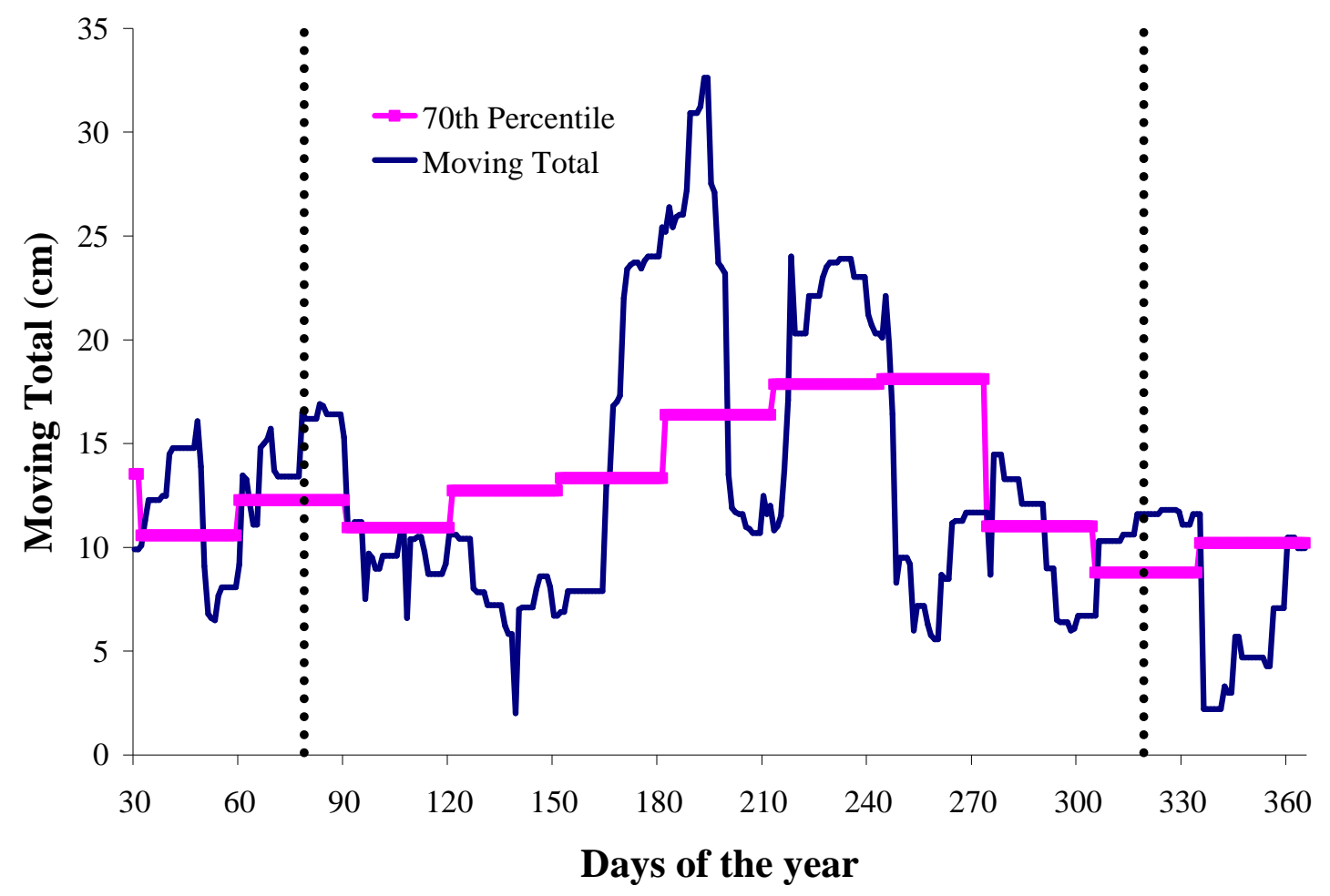

Figure D.11: Moving total graph for all plots at Greenville for year 1969.

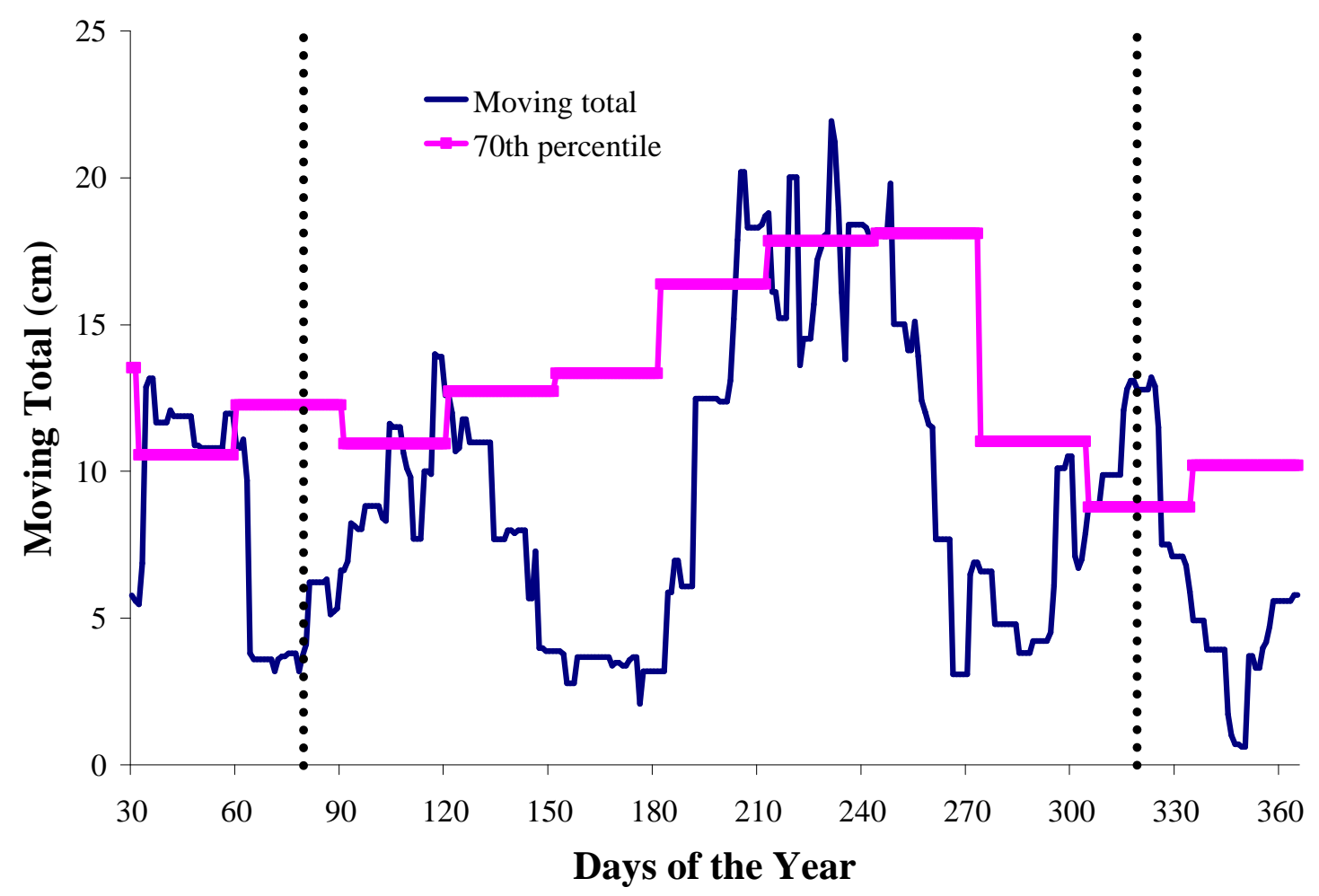

Figure D.12: Moving total graph for all plots at Greenville for year 1970. 


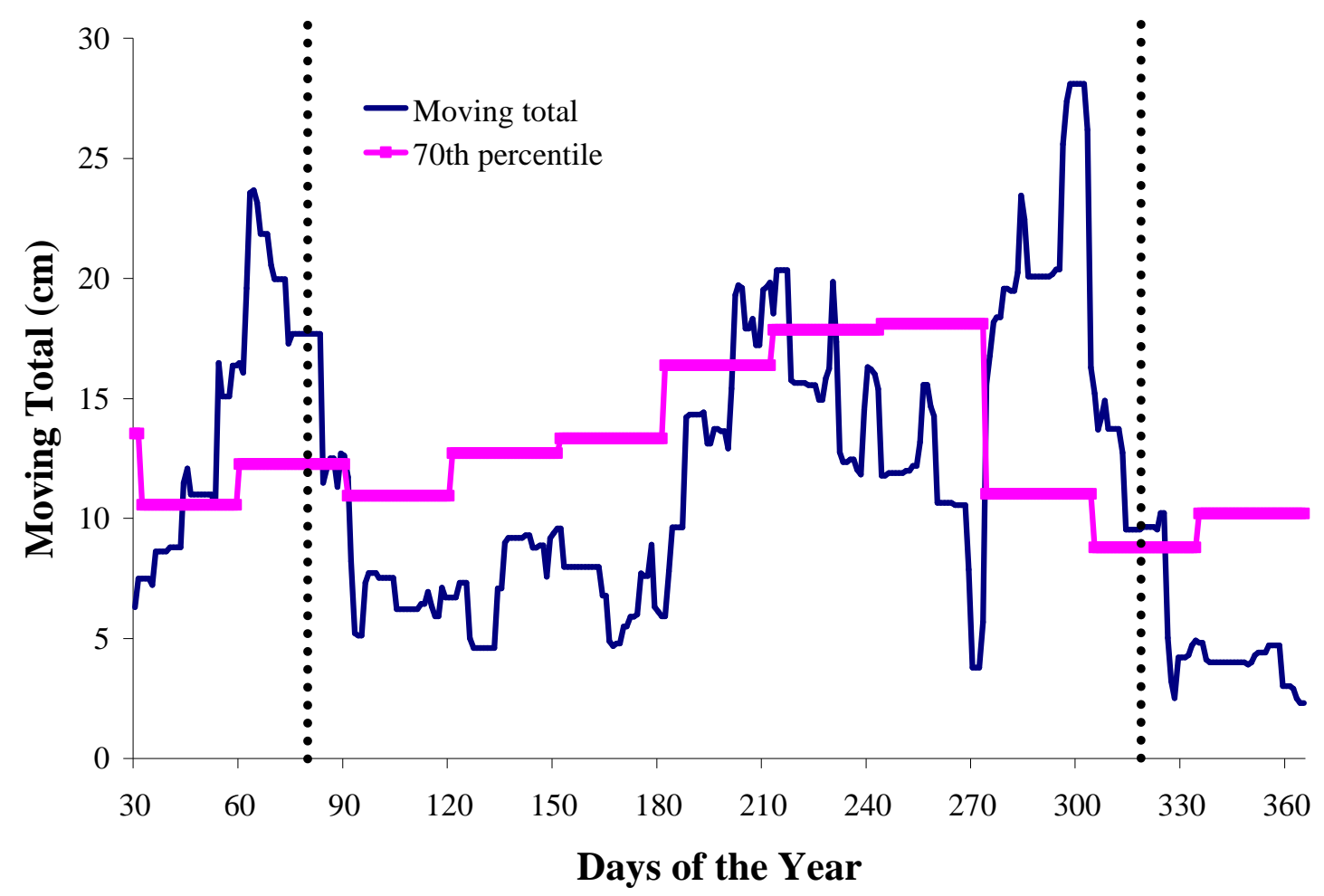

Figure D.13: Moving total graph for all plots at Greenville for year 1971.

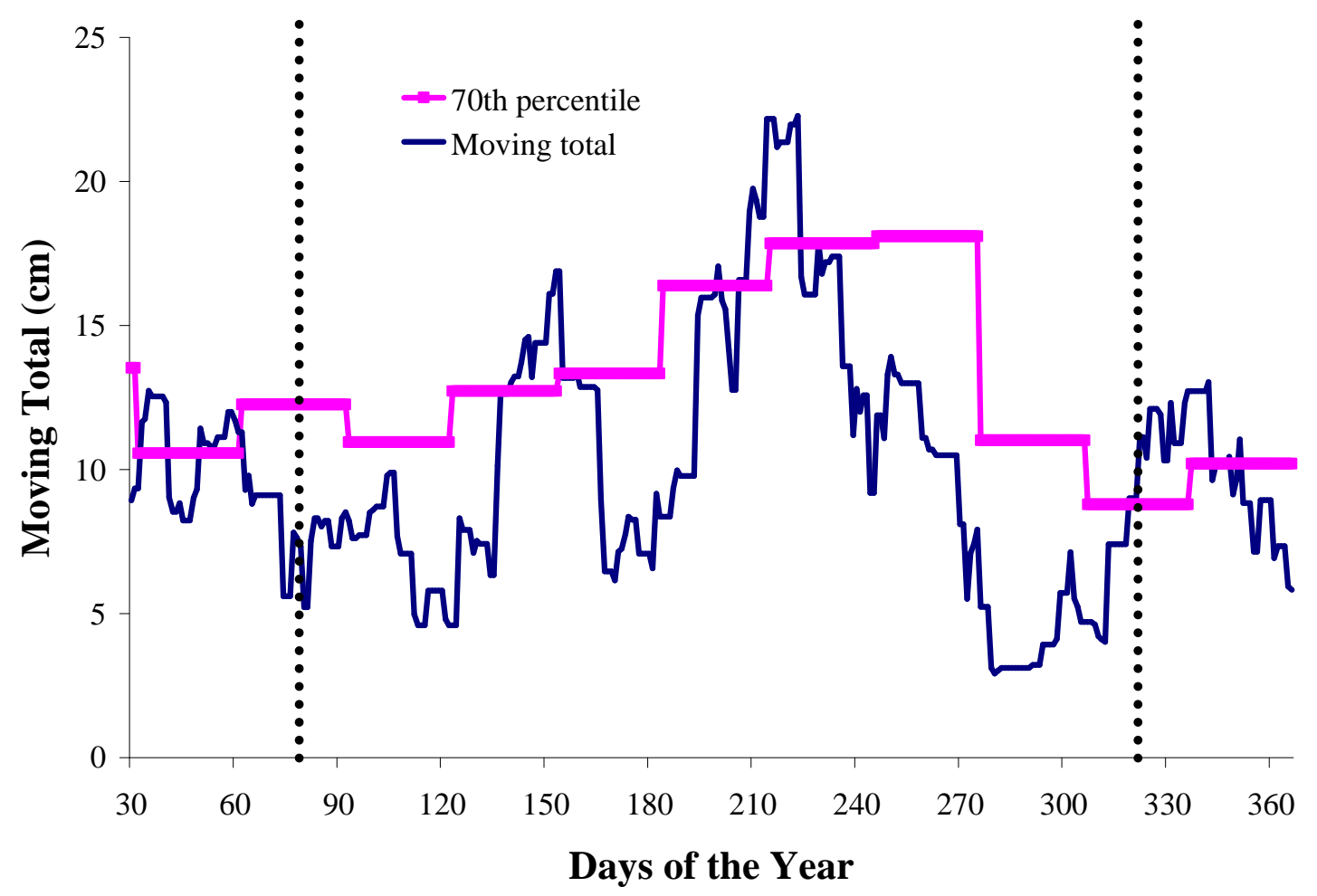

Figure D.14: Moving total graph for all plots at Greenville for year 1972. 


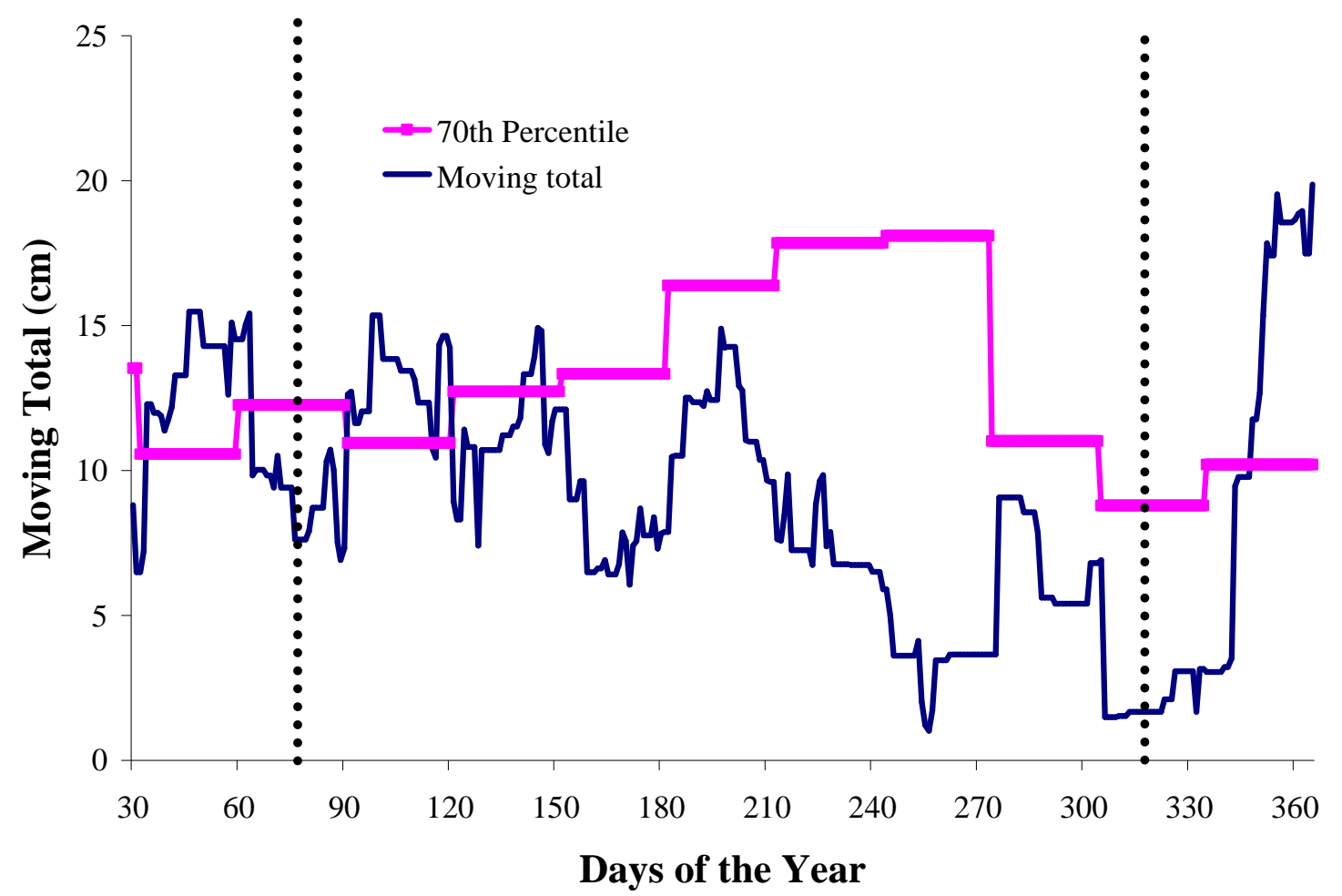

Figure D.15: Moving total graph for all plots at Greenville for year 1973.

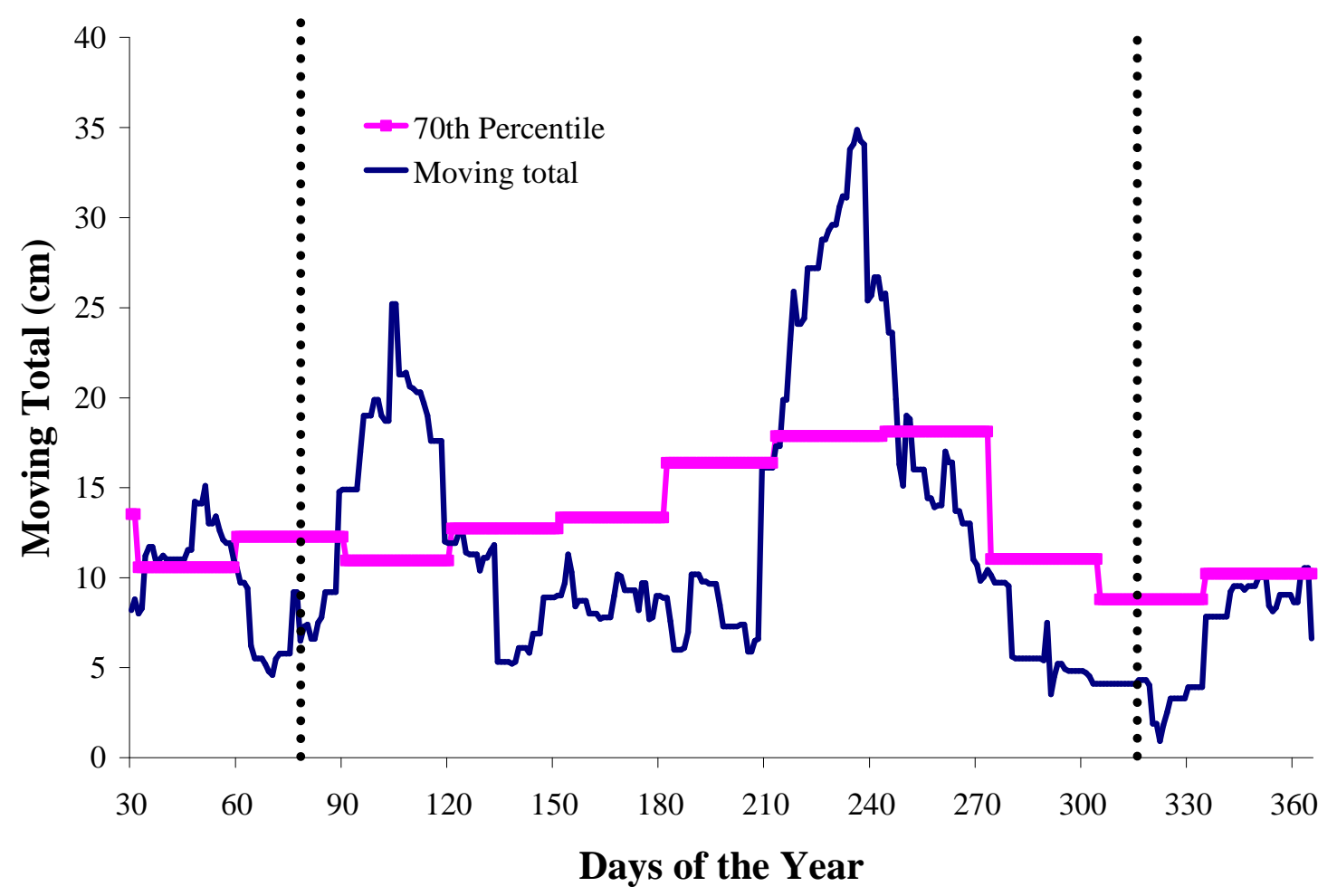

Figure D.16: Moving total graph for all plots at Greenville for year 1974. 


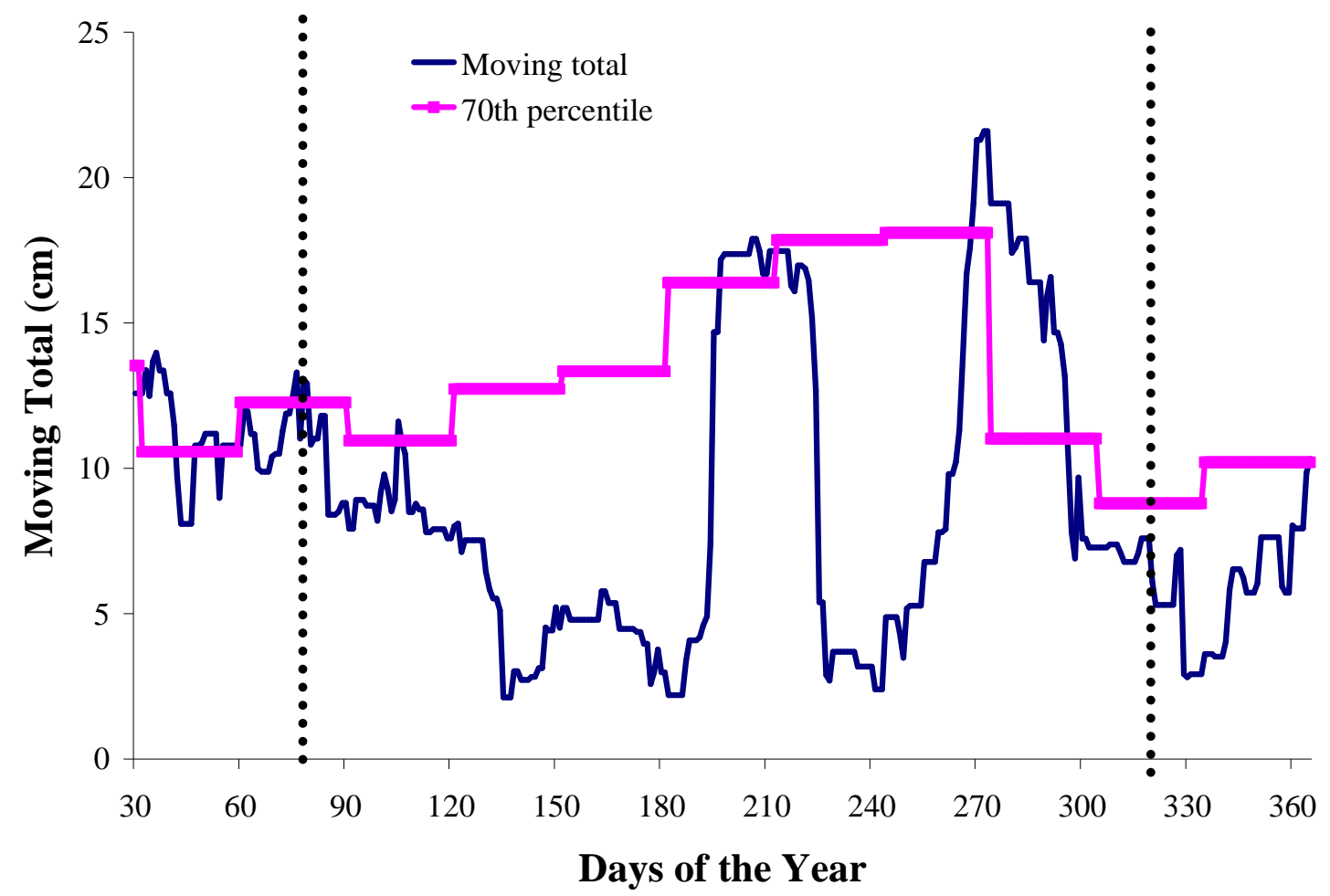

Figure D.17: Moving total graph for all plots at Greenville for year 1975.

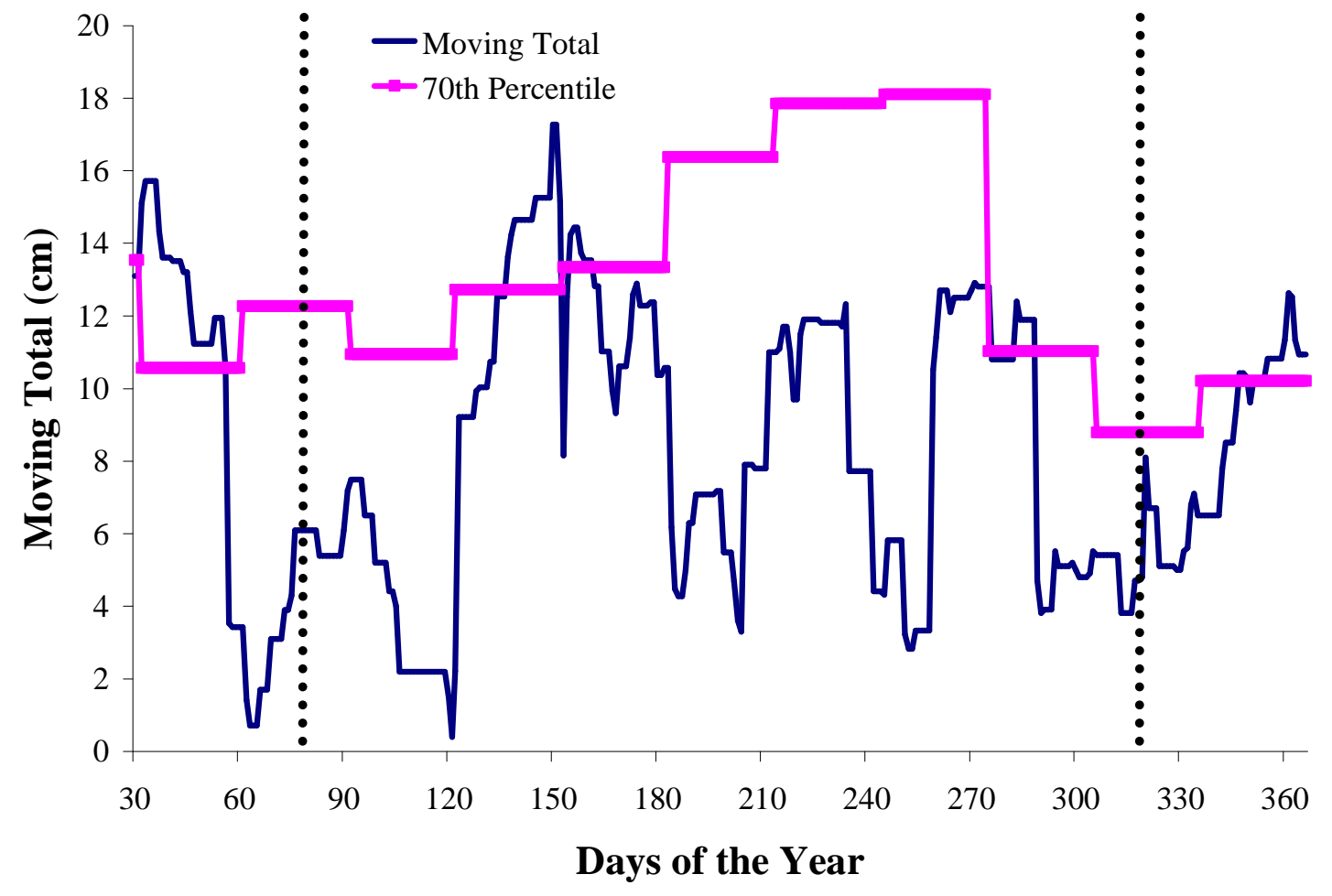

Figure D.18: Moving total graph for all plots at Greenville for year 1976. 


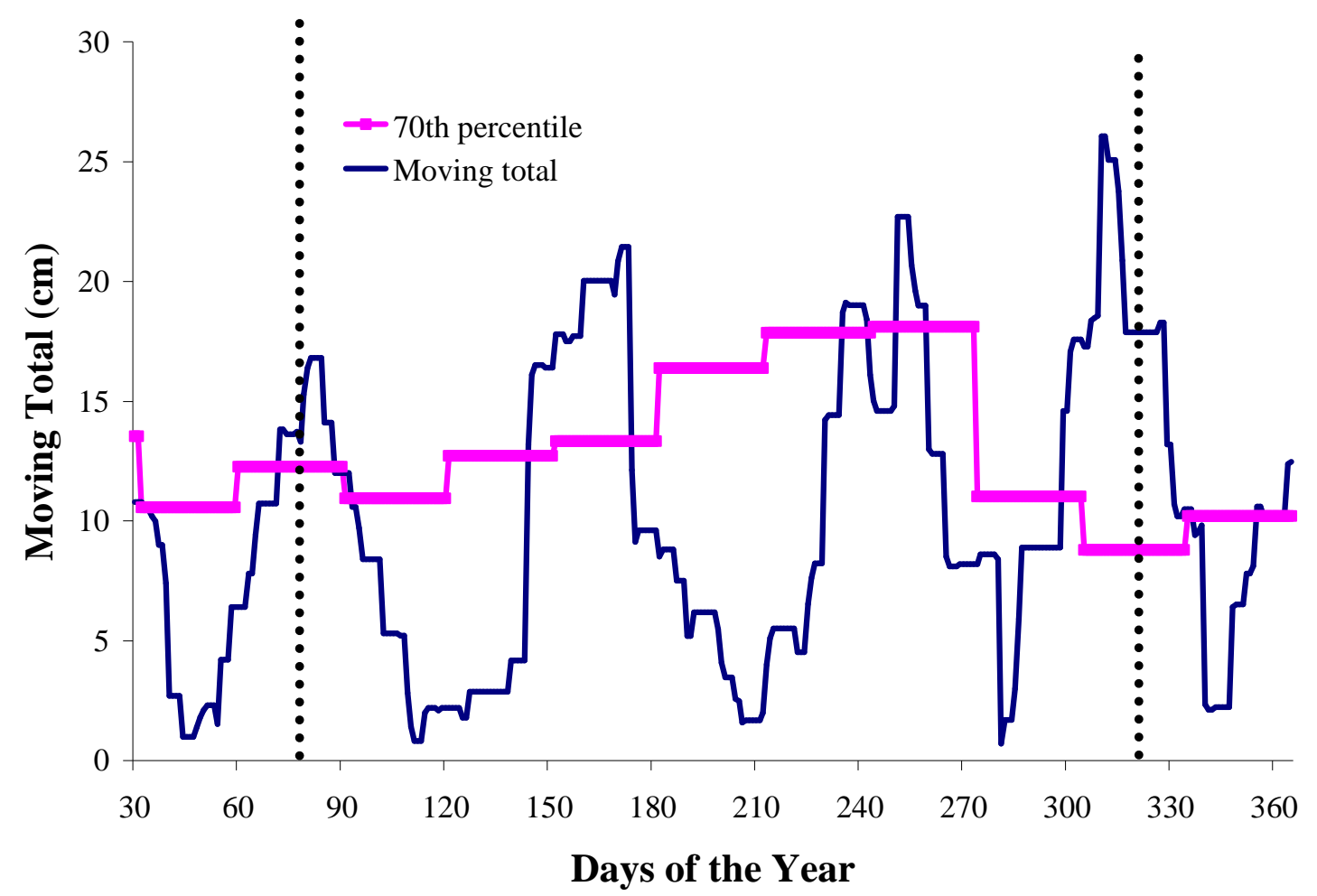

Figure D.19: Moving total graph for all plots at Greenville for year 1977.

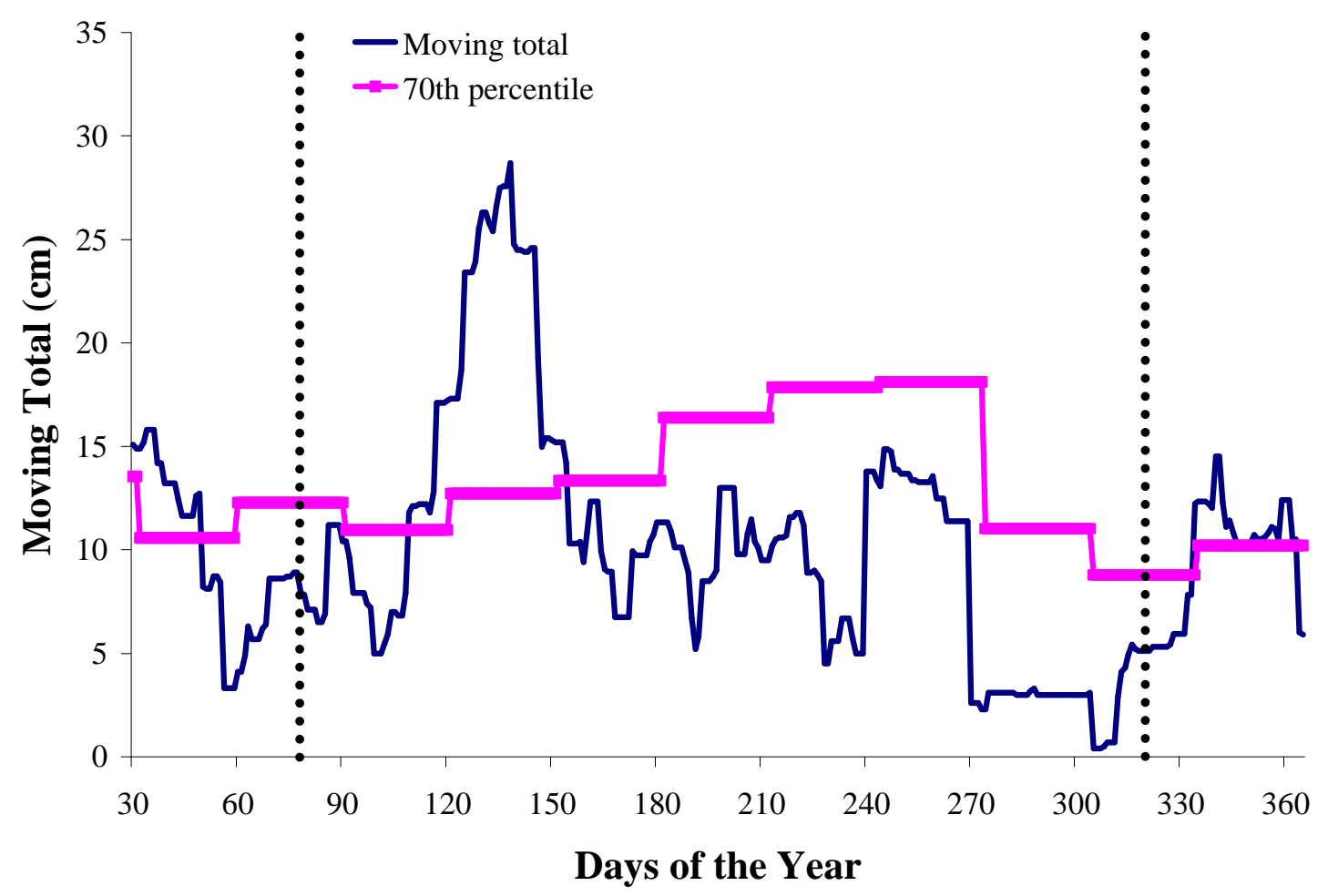

Figure D.20: Moving total graph for all plots at Greenville for year 1978. 


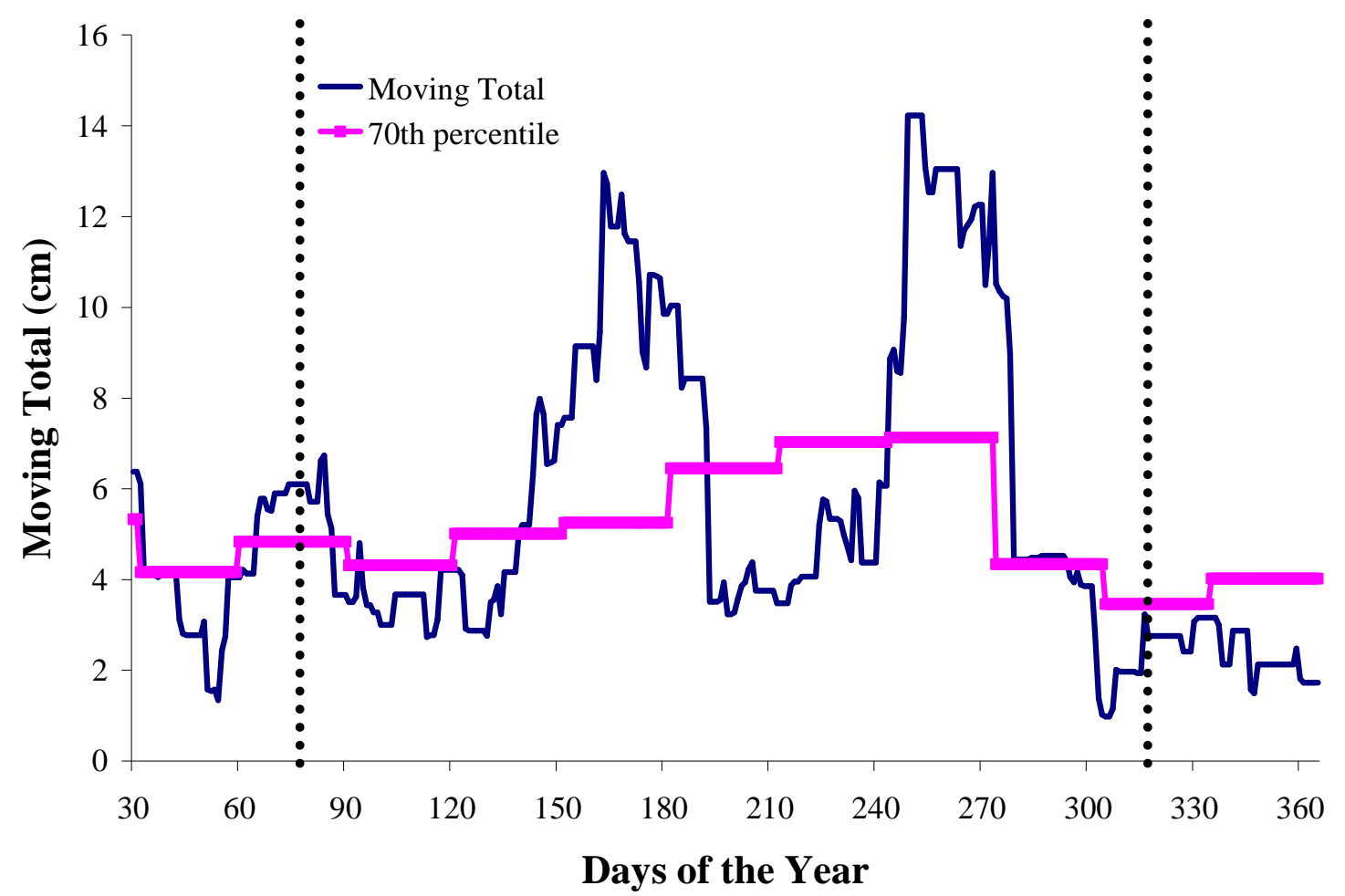

Figure D.21: Moving total graph for all plots at Greenville for year 1979.

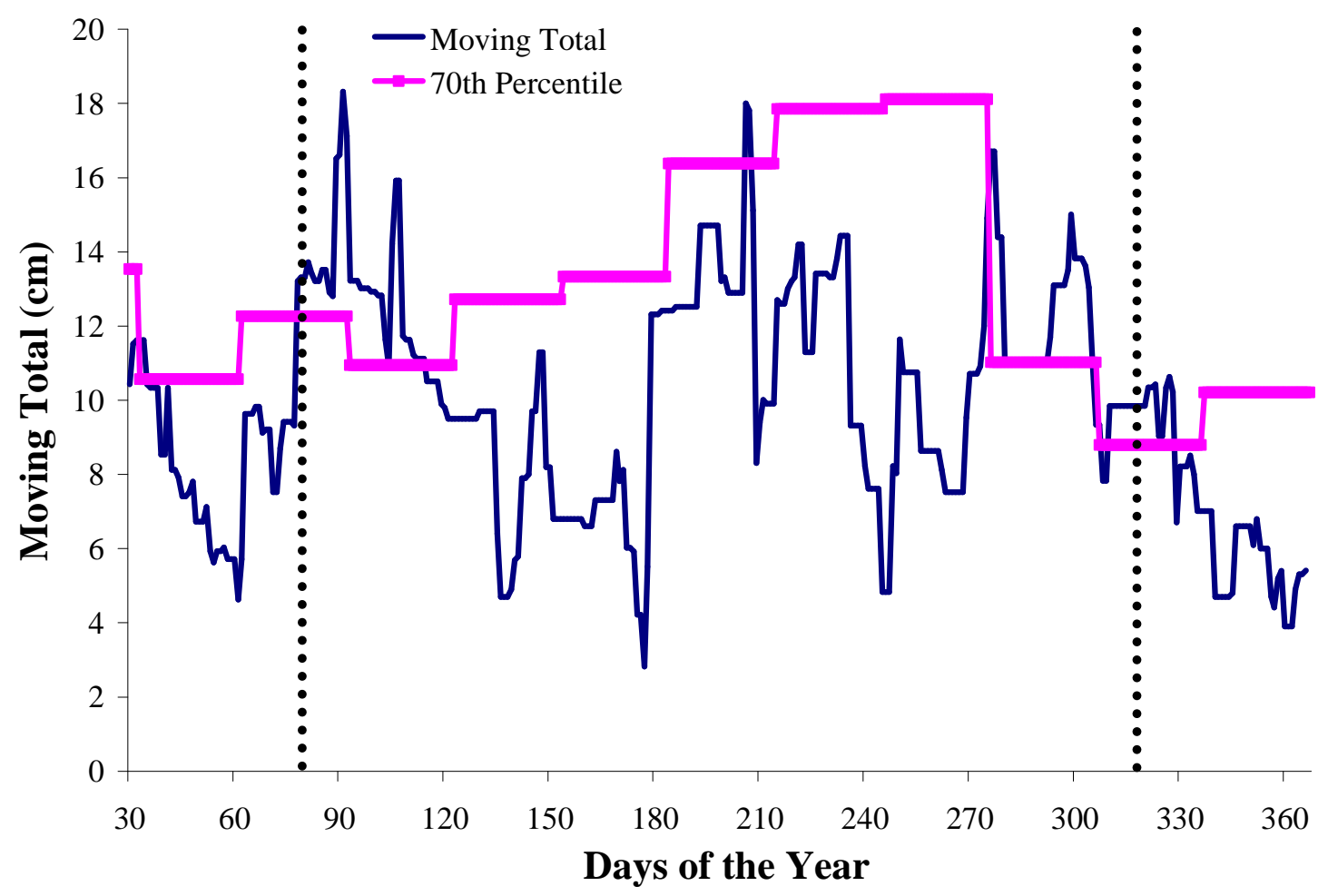

Figure D.22: Moving total graph for all plots at Greenville for year 1980. 


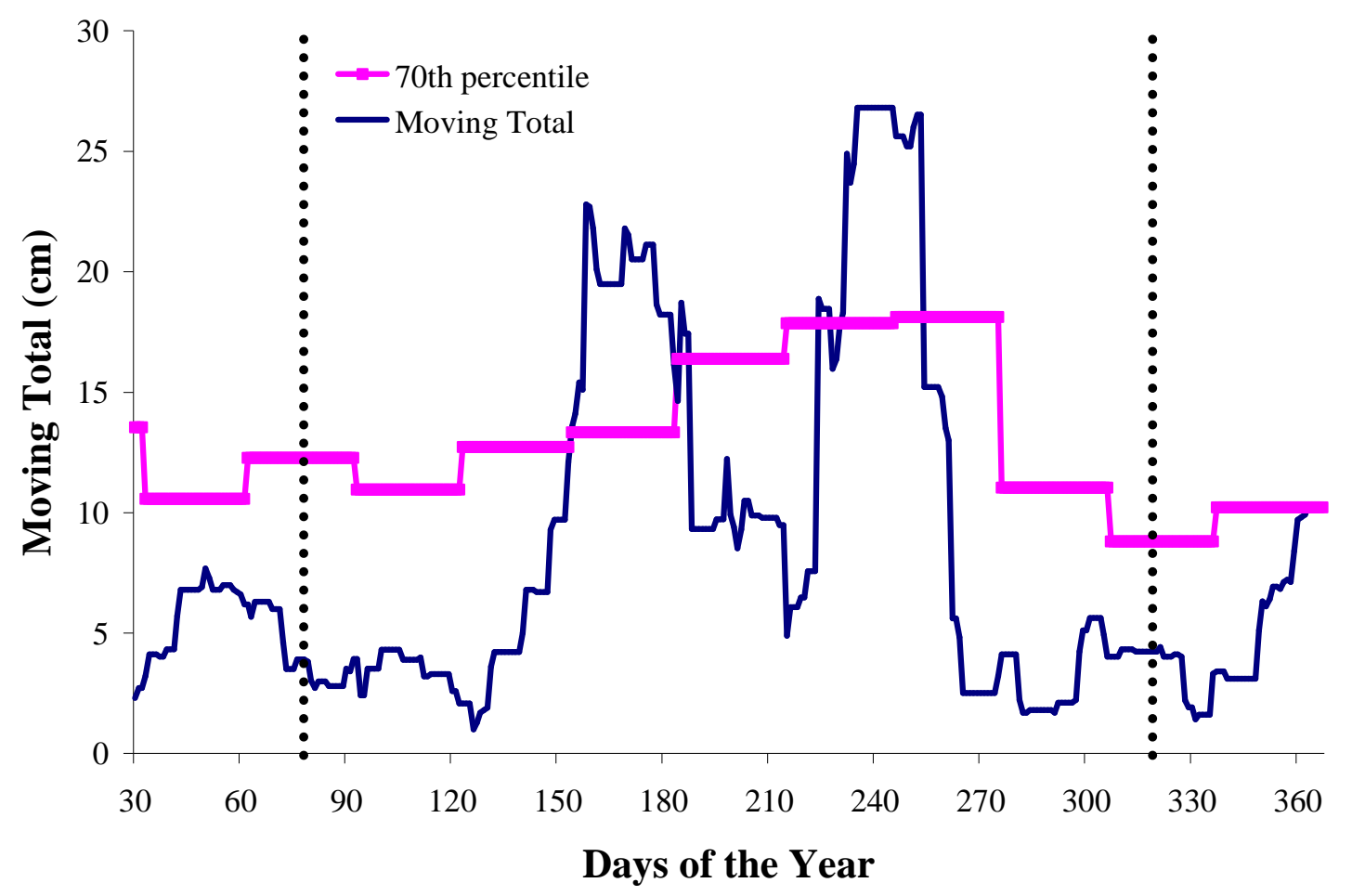

Figure D.23: Moving total graph for all plots at Greenville for year 1981.

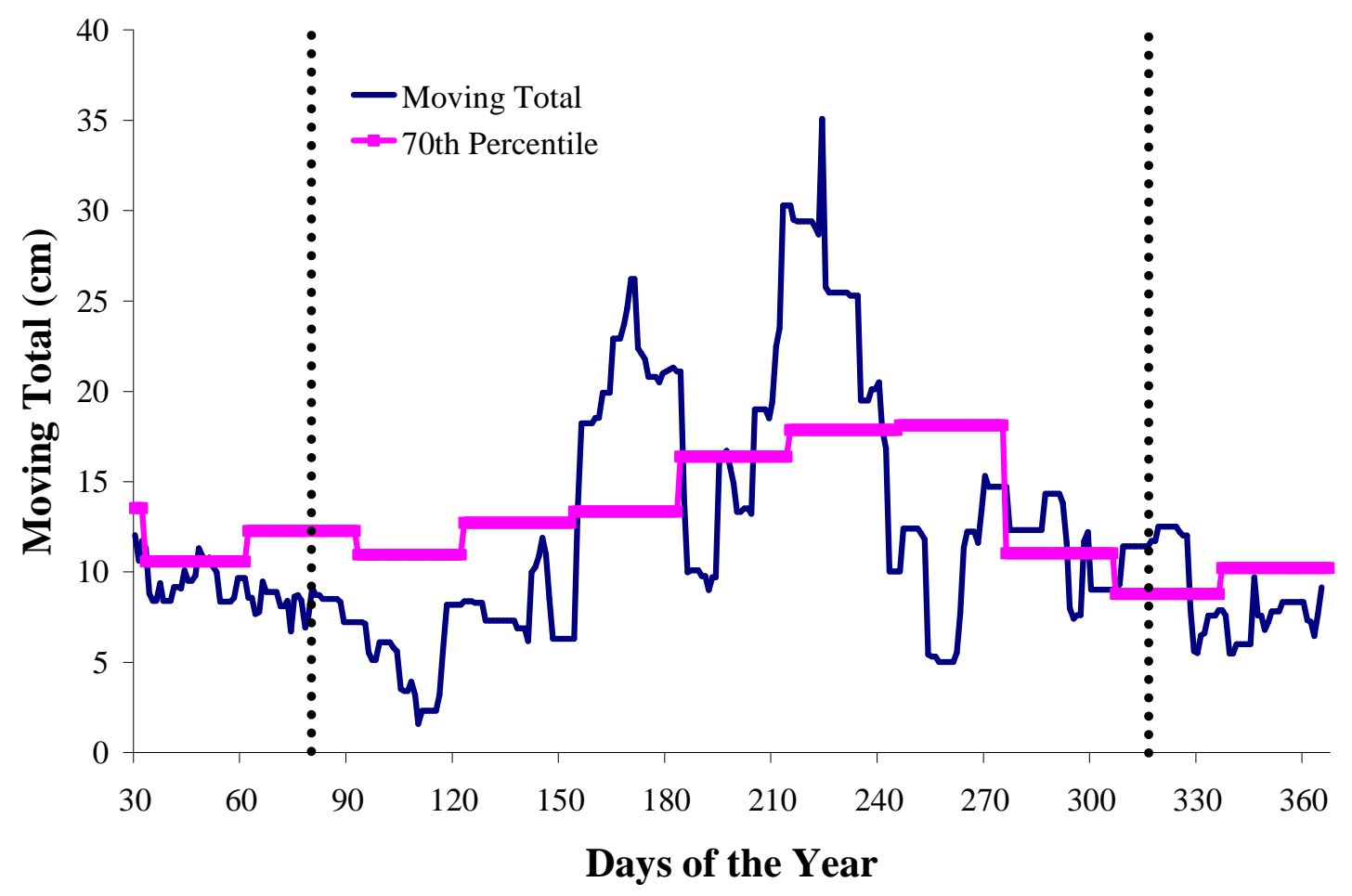

Figure D.24: Moving total graph for all plots at Greenville for year 1982. 


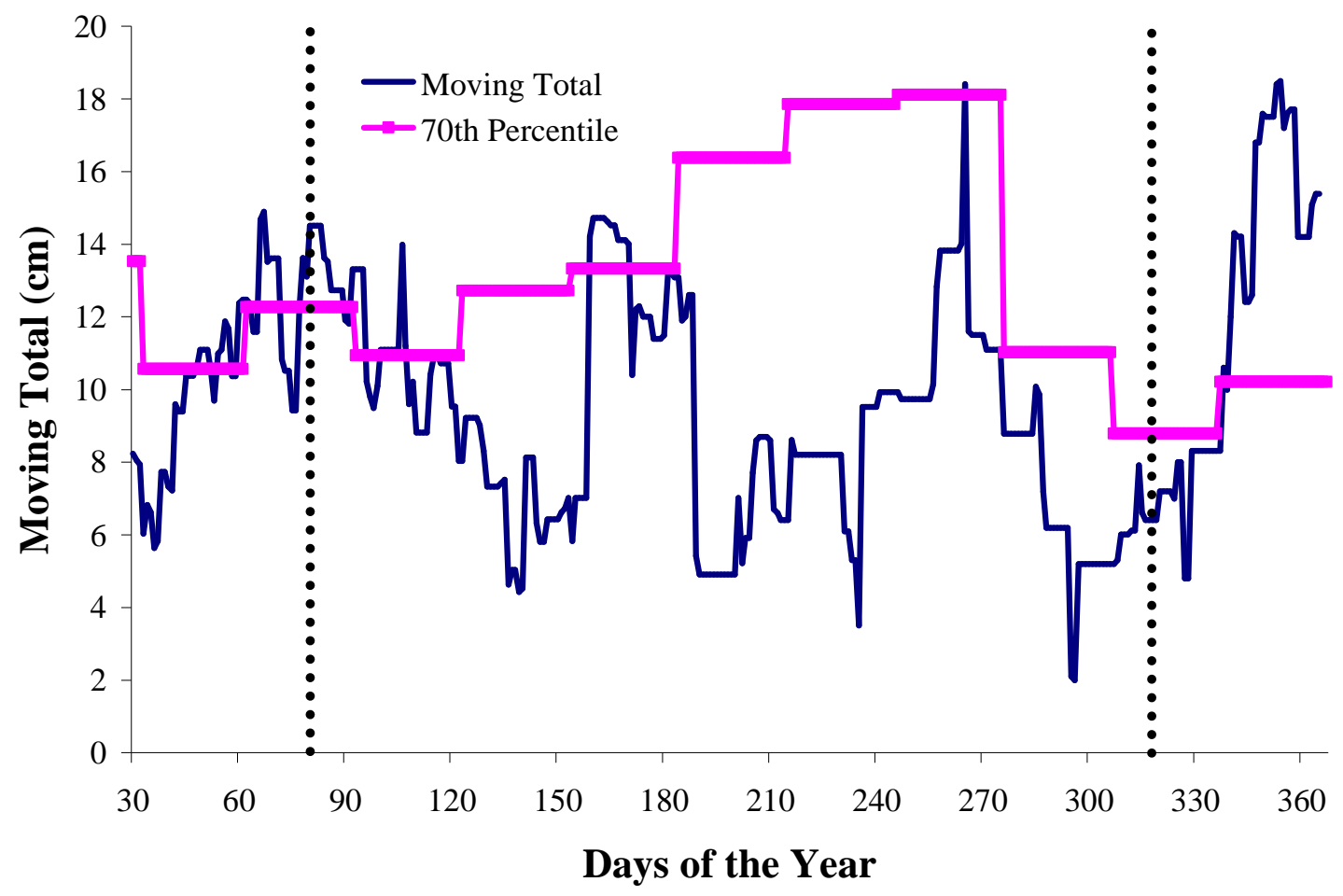

Figure D.25: Moving total graph for all plots at Greenville for year 1983.

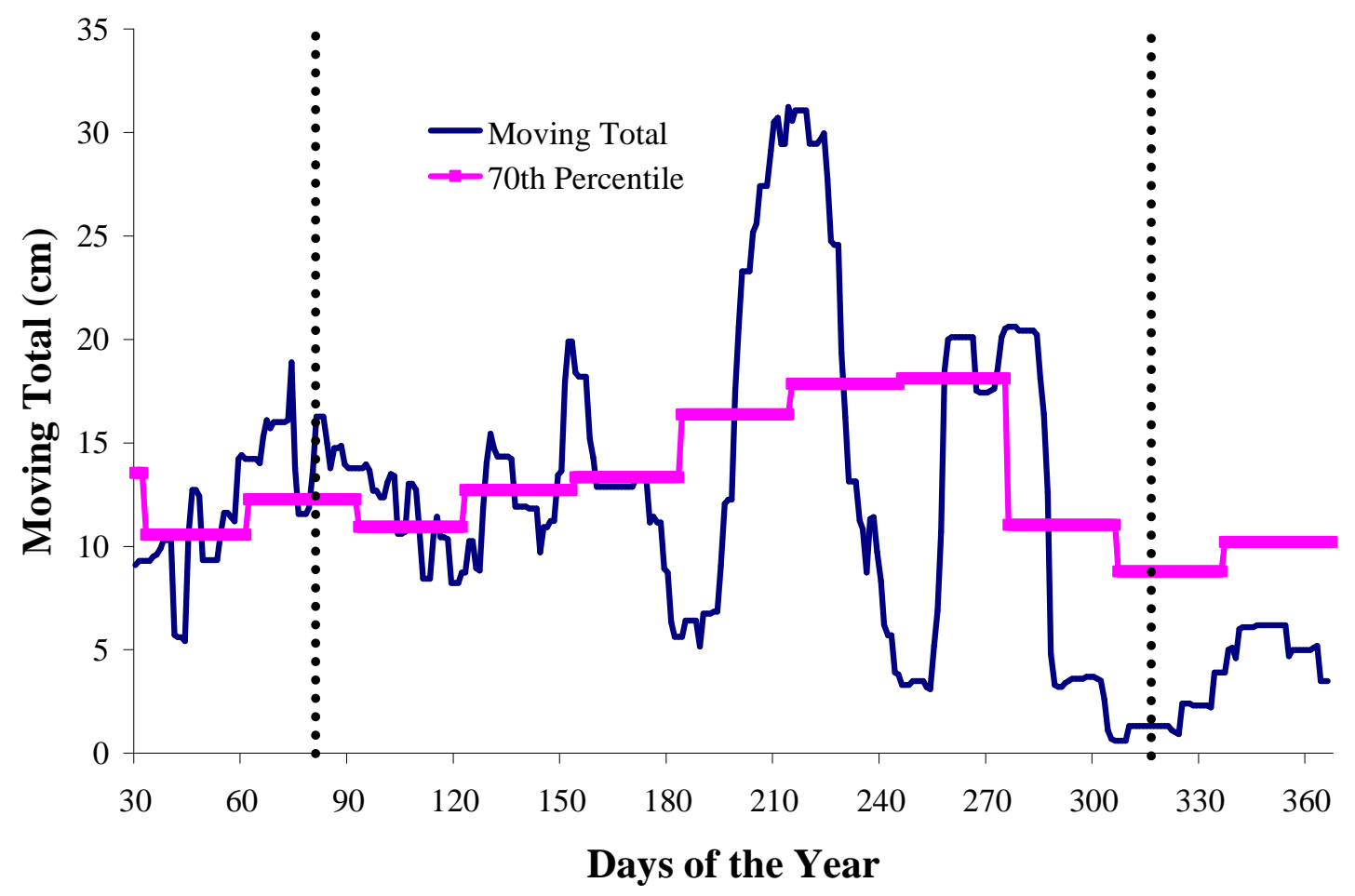

Figure D.26: Moving total graph for all plots at Greenville for year 1984. 


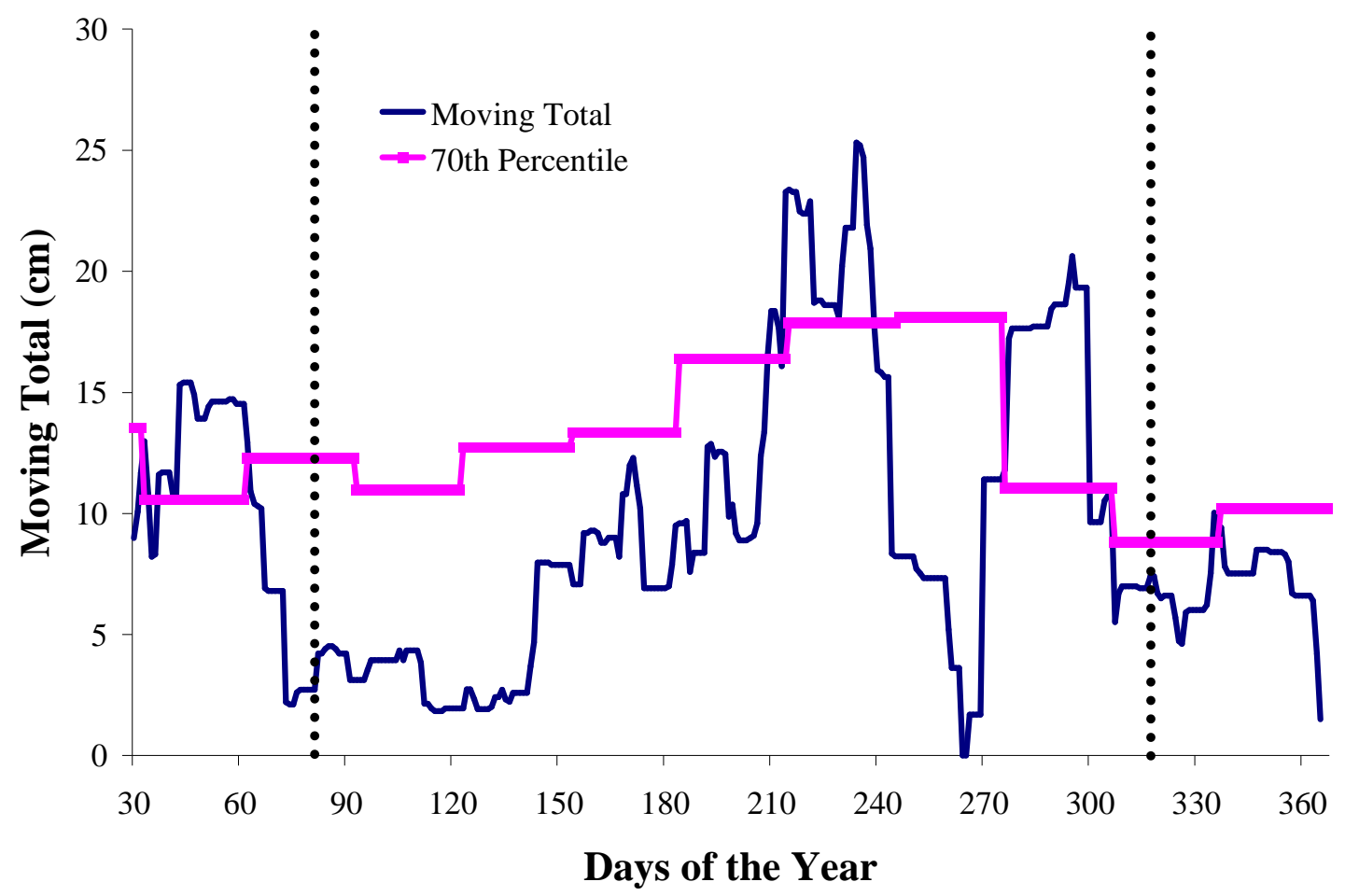

Figure D.27: Moving total graph for all plots at Greenville for year 1985.

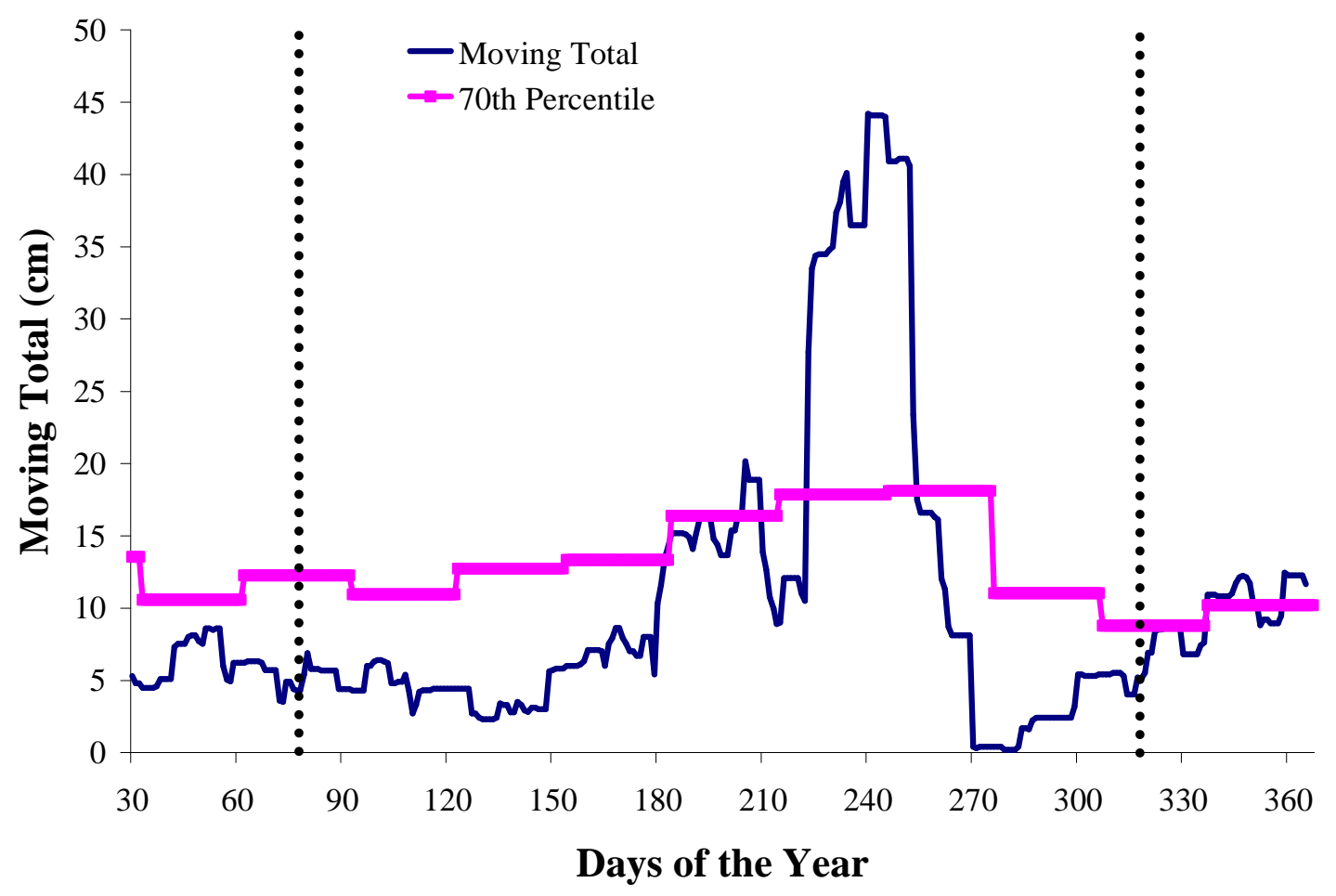

Figure D.28: Moving total graph for all plots at Greenville for year 1986. 


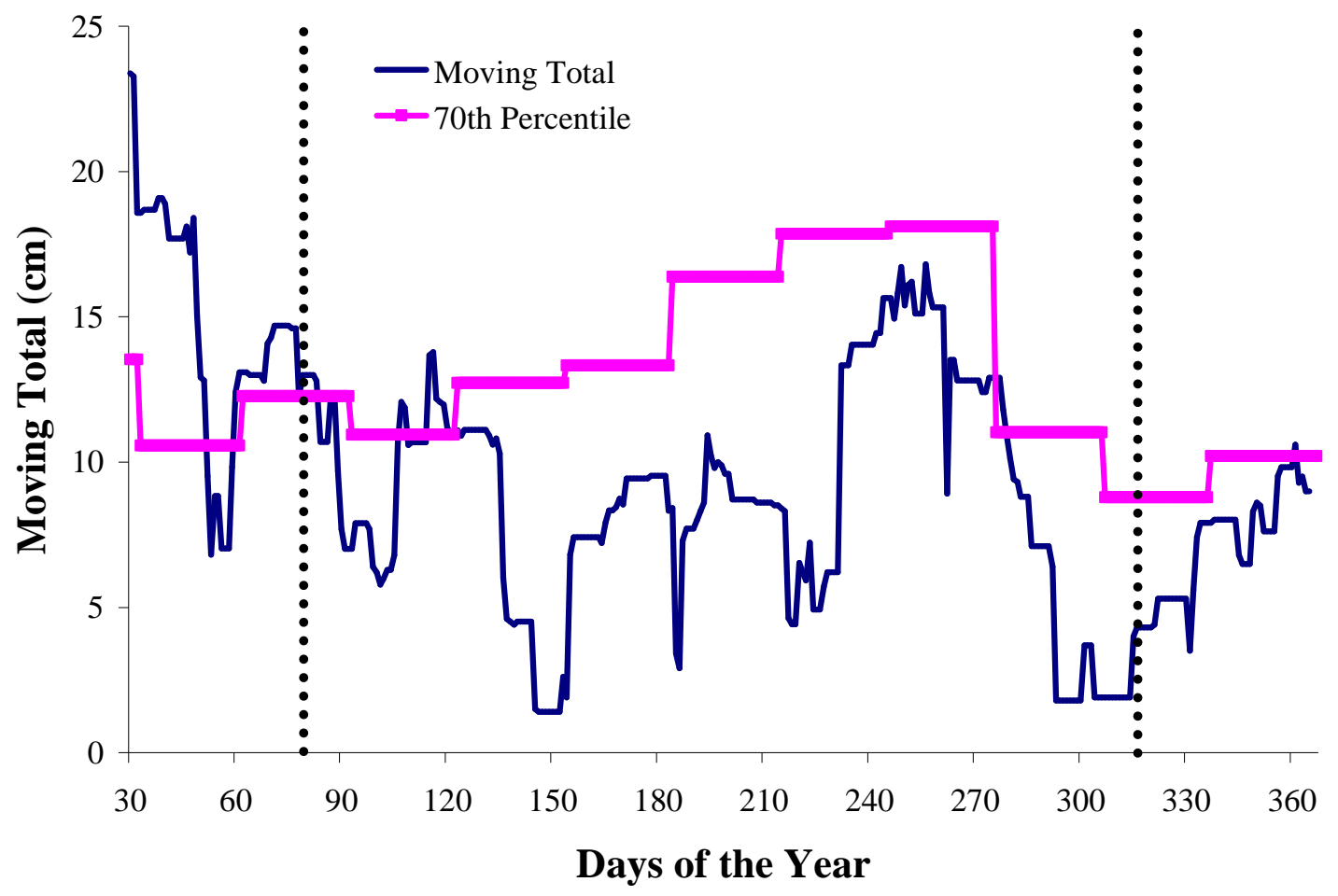

Figure D.29: Moving total graph for all plots at Greenville for year 1987.

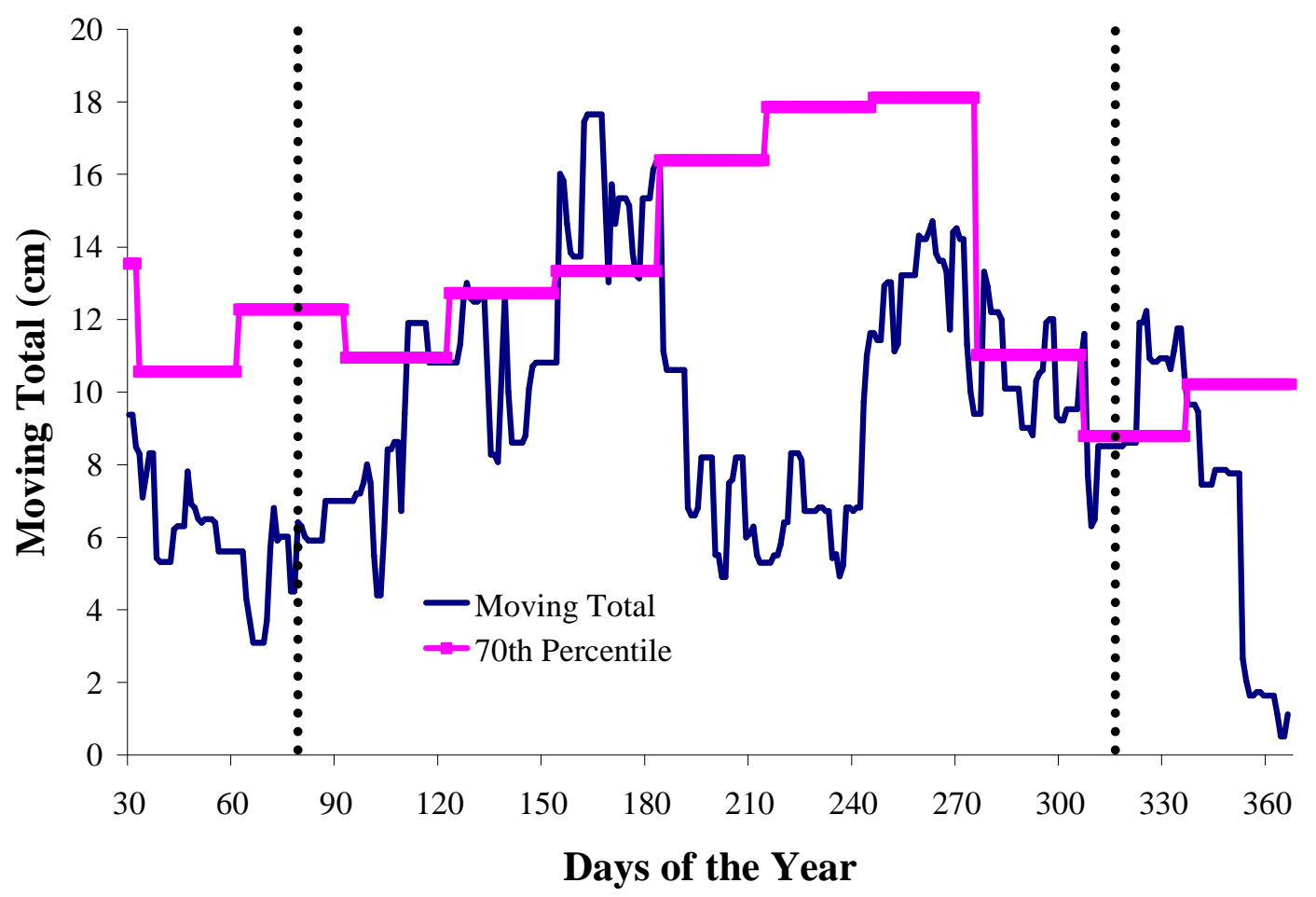

Figure D.30: Moving total graph for all plots at Greenville for year 1988. 


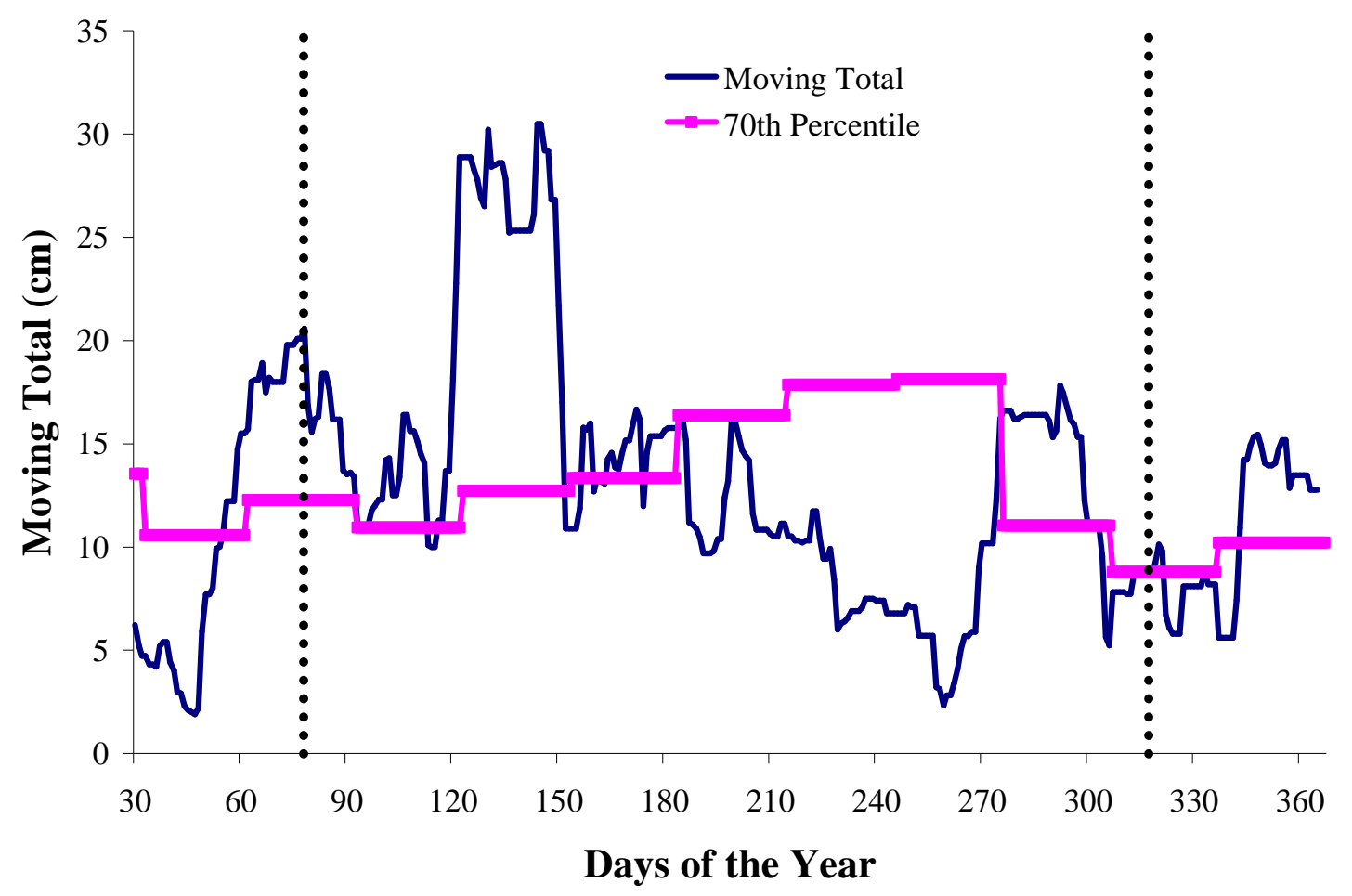

Figure D.31: Moving total graph for all plots at Greenville for year 1989.

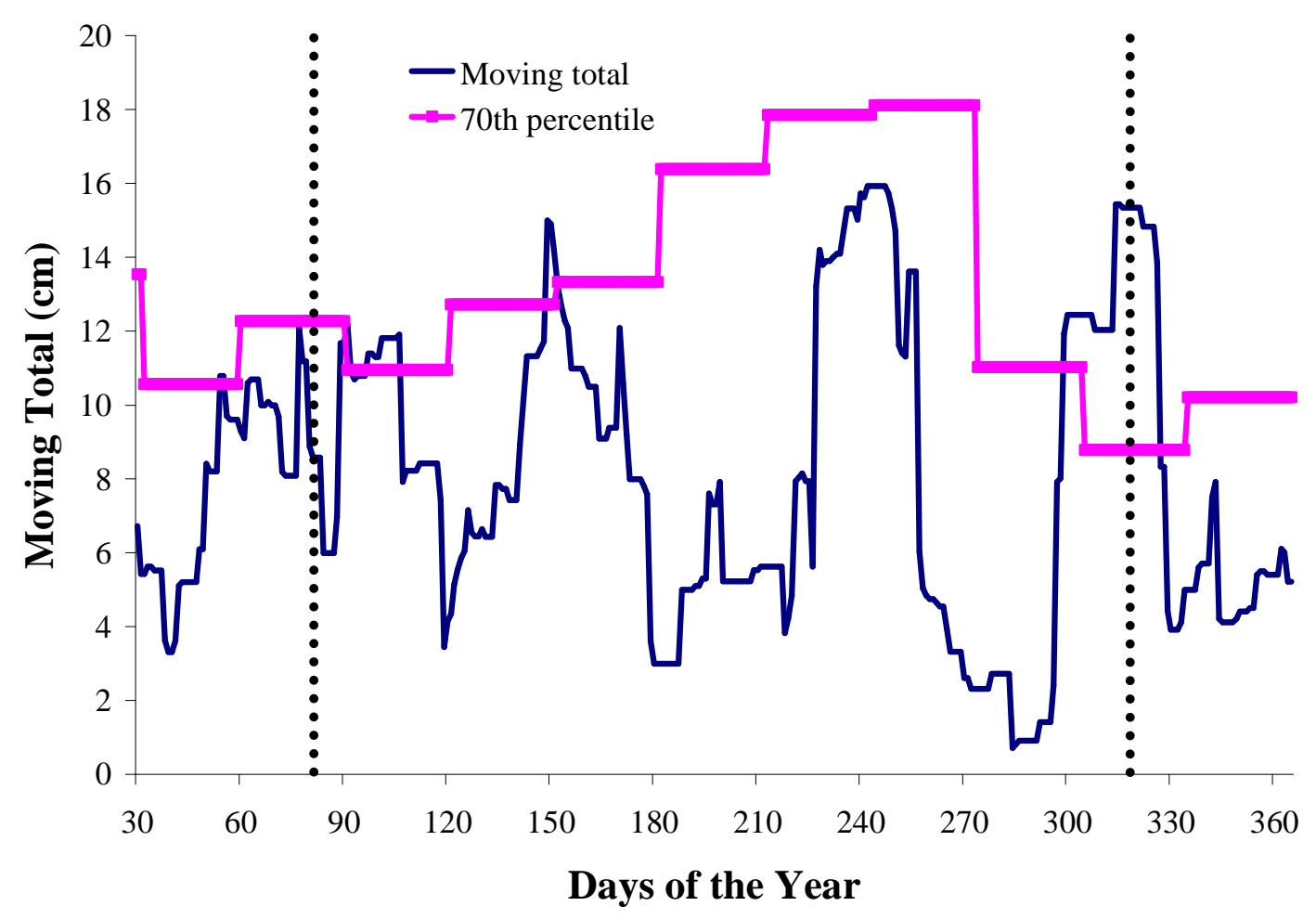

Figure D.32: Moving total graph for all plots at Greenville for year 1990. 


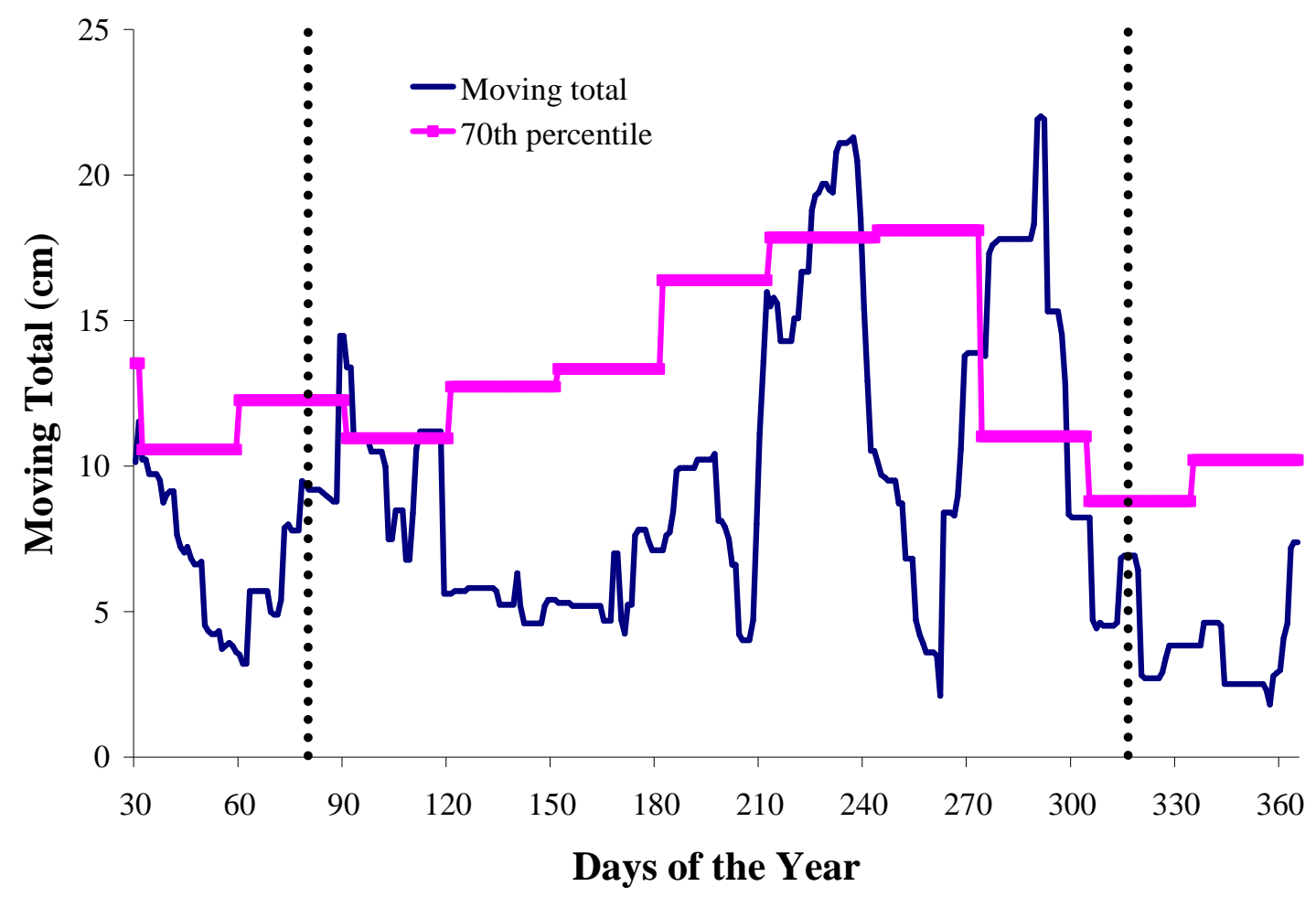

Figure D.33: Moving total graph for all plots at Greenville for year 1991.

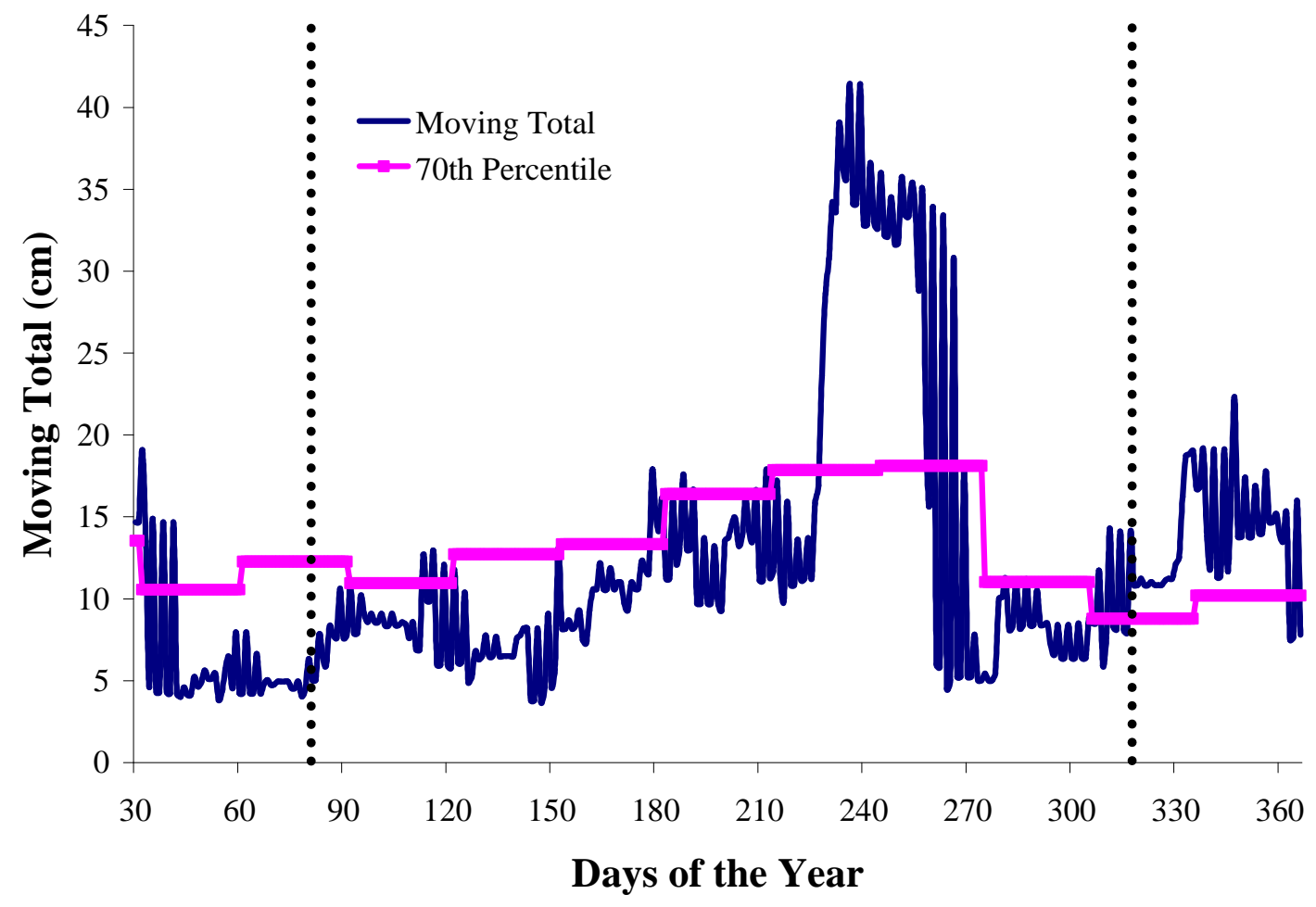

Figure D.34: Moving total graph for all plots at Greenville for year 1992. 


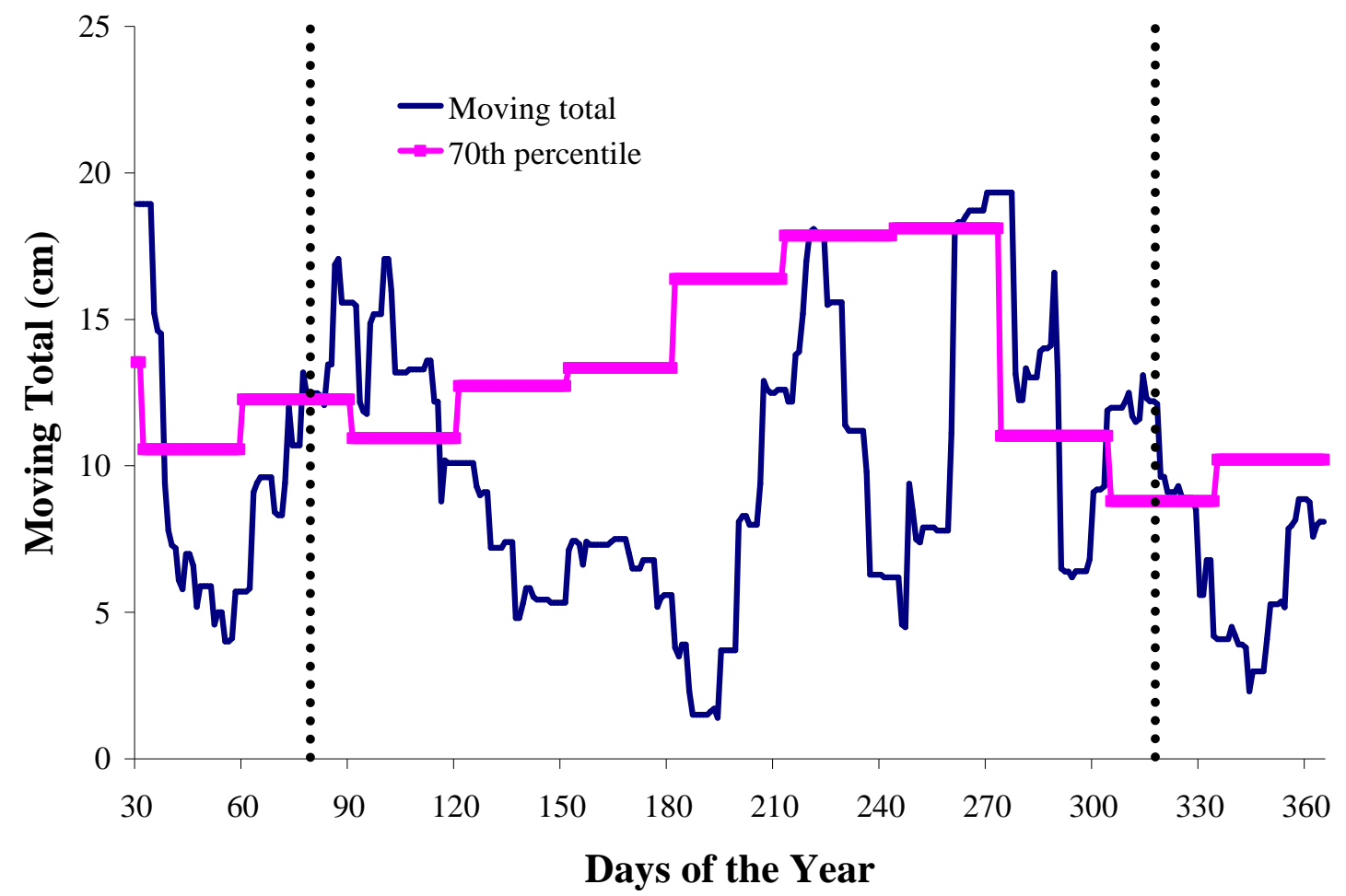

Figure D.35: Moving total graph for all plots at Greenville for year 1993.

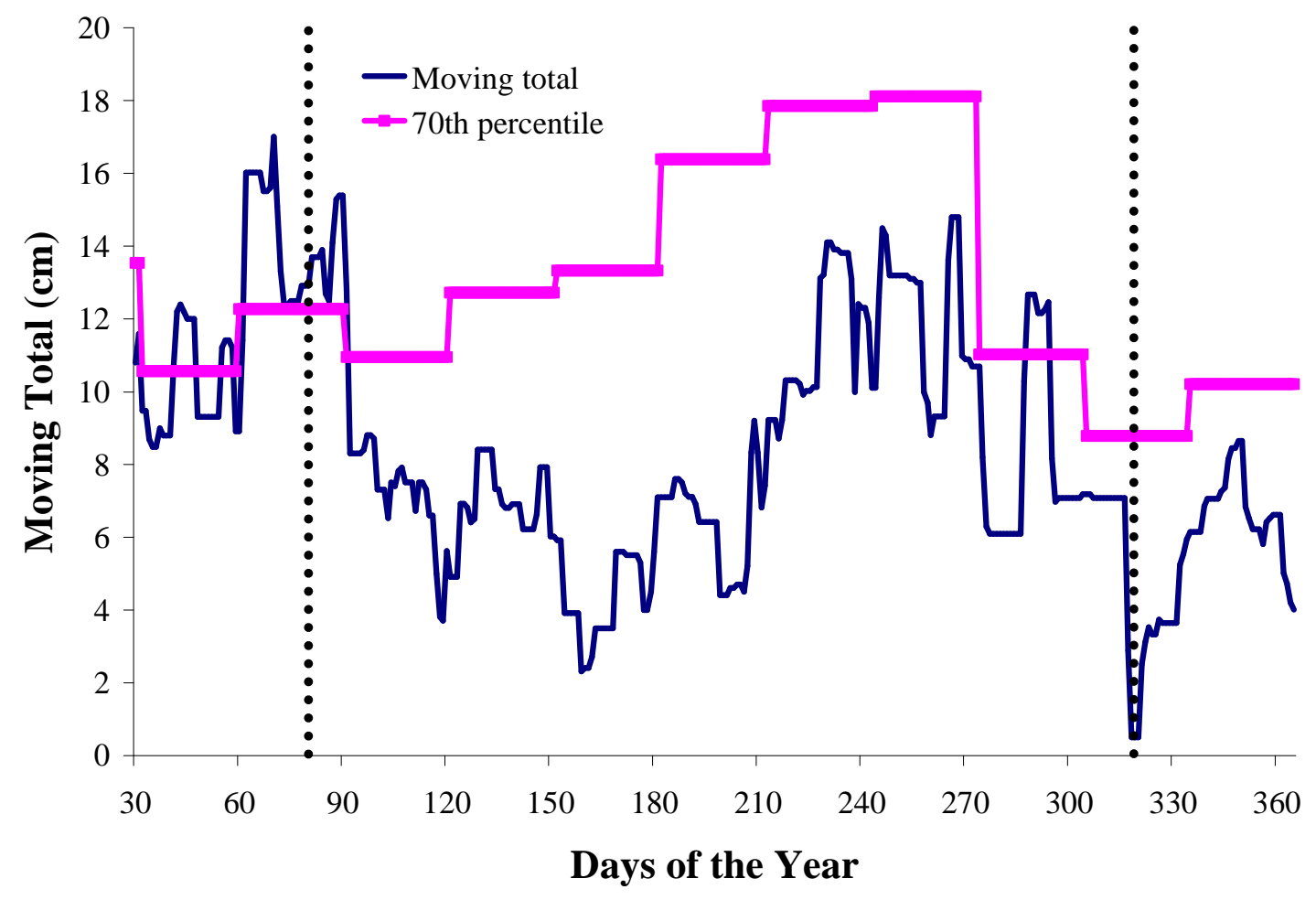

Figure D.36: Moving total graph for all plots at Greenville for year 1994. 


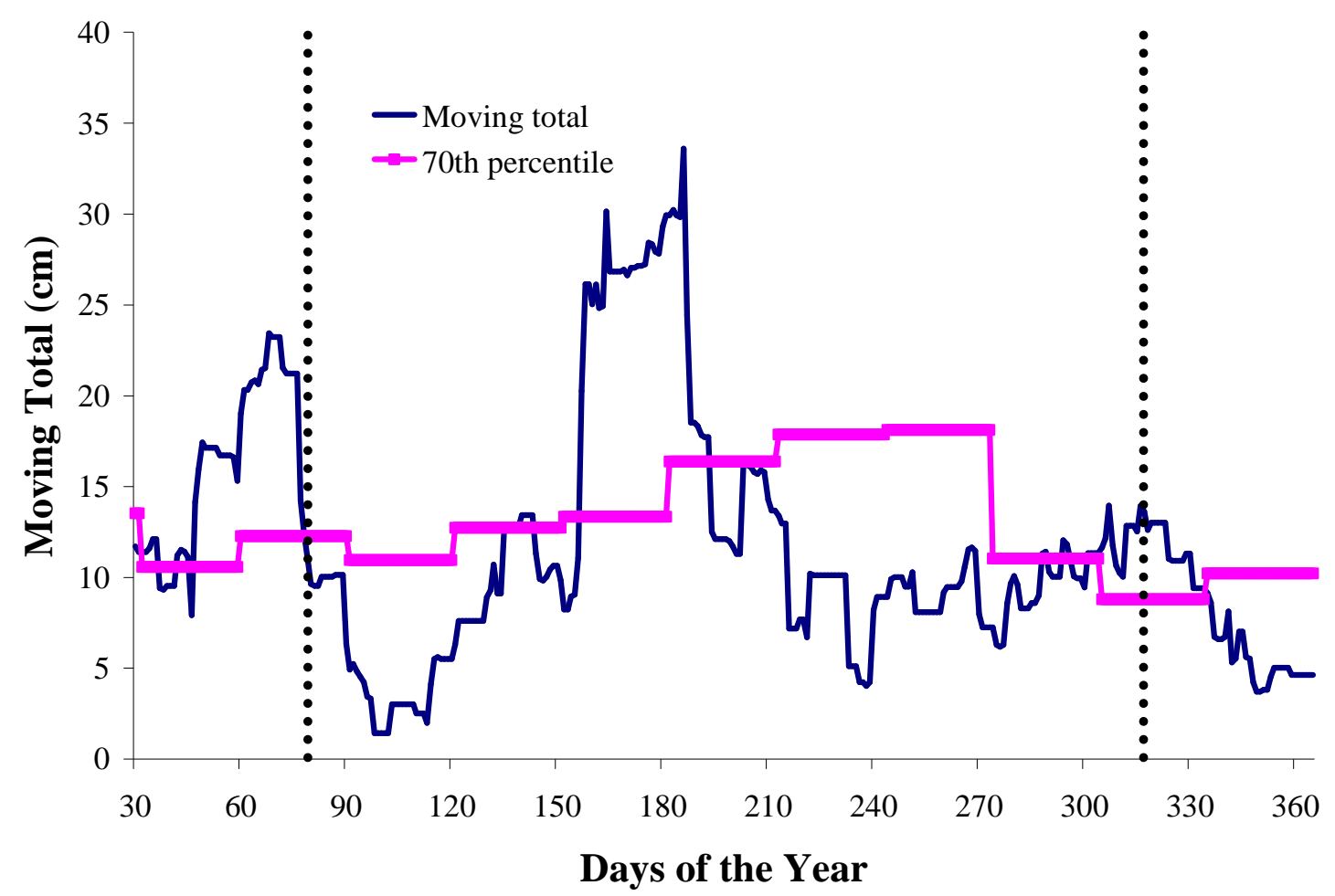

Figure D.37: Moving total graph for all plots at Greenville for year 1995.

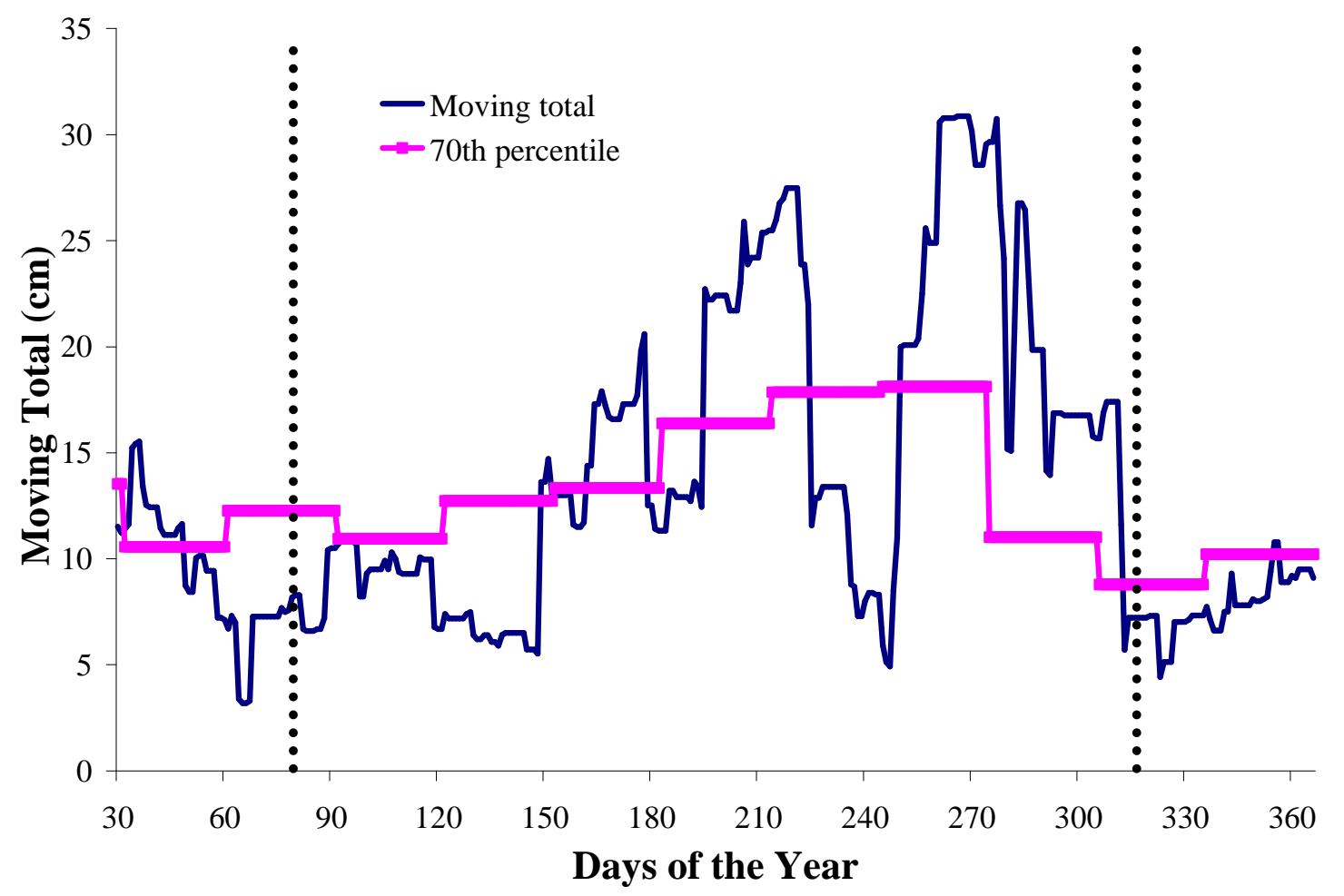

Figure D.38: Moving total graph for all plots at Greenville for year 1996. 


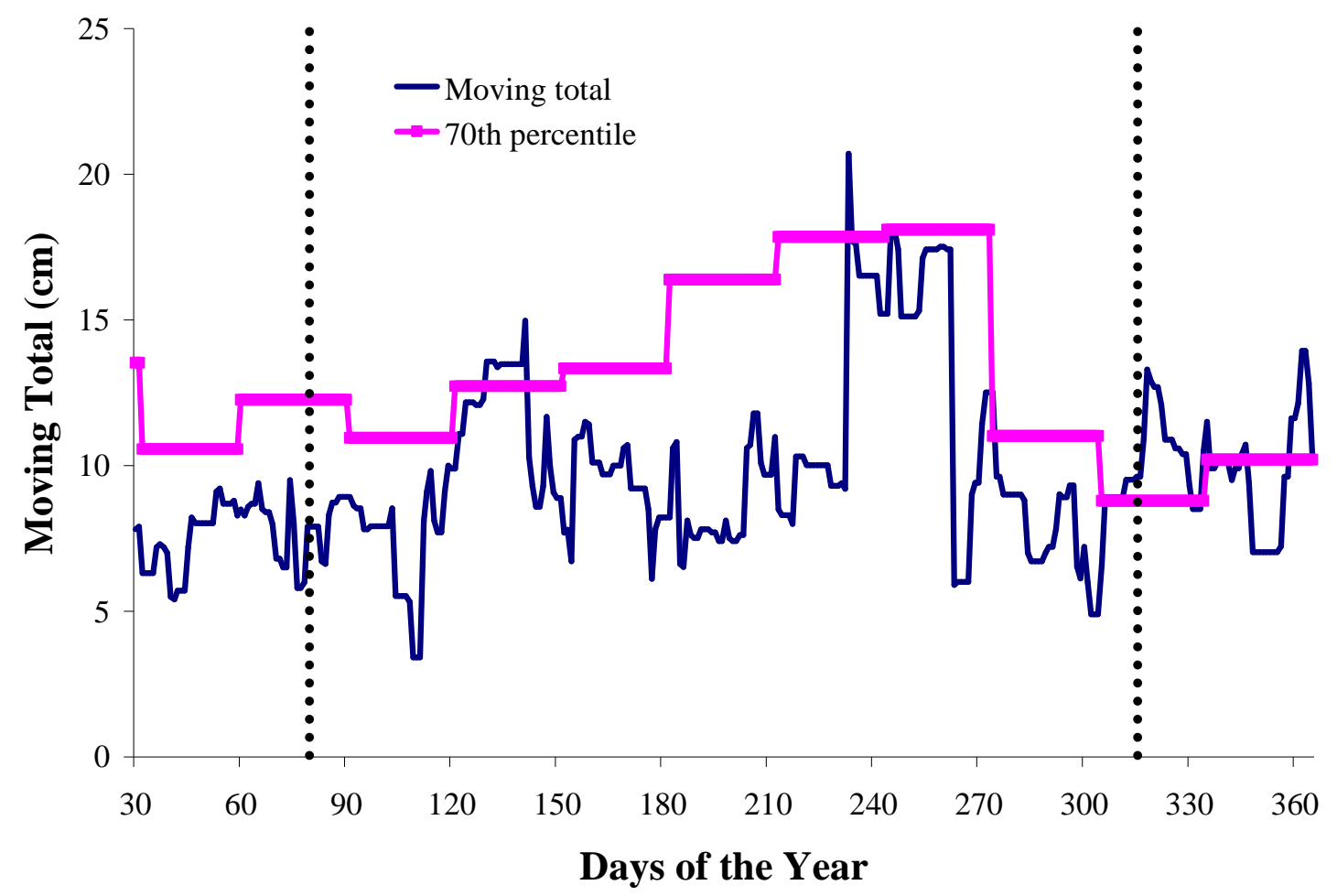

Figure D.39: Moving total graph for all plots at Greenville for year 1997.

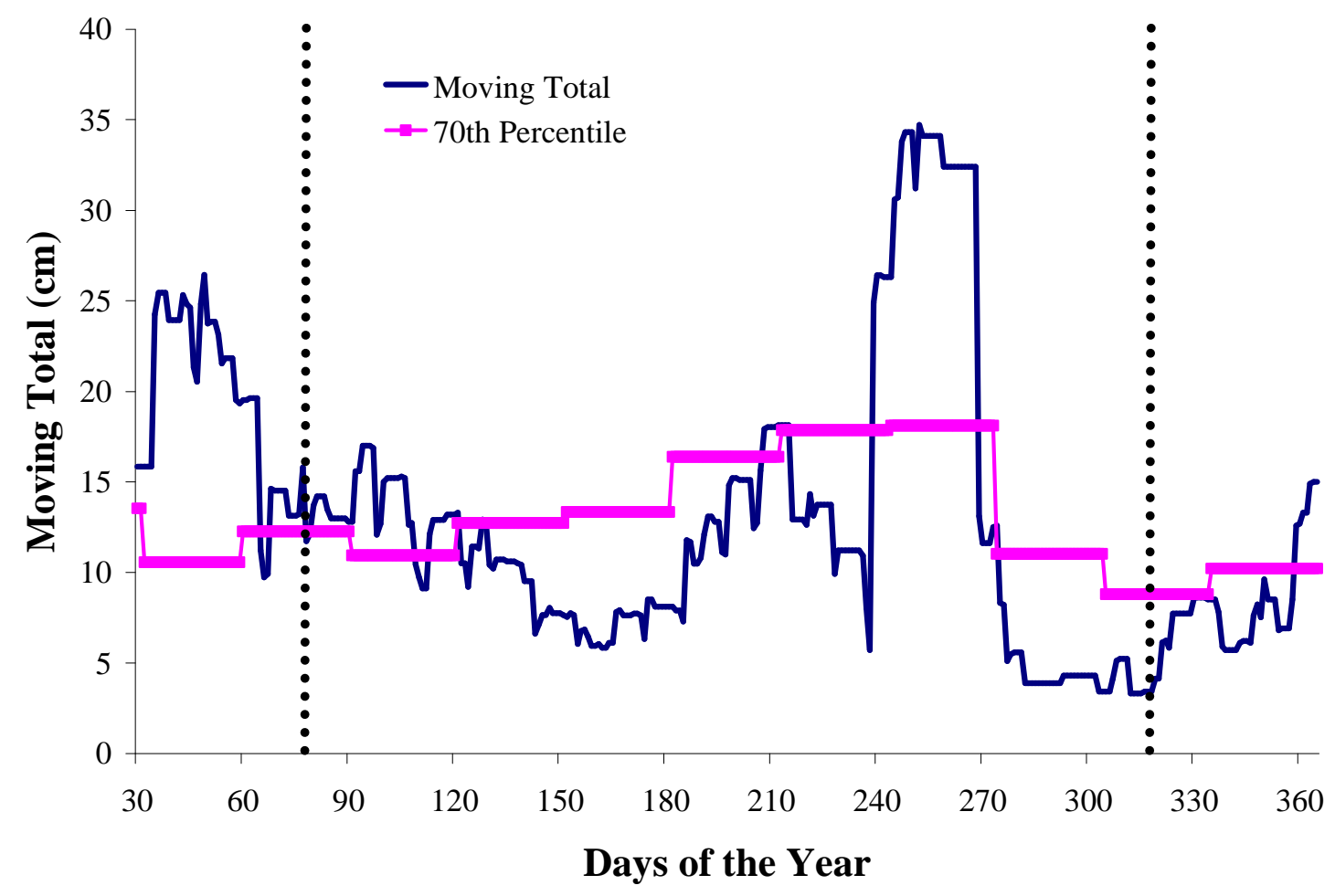

Figure D.40: Moving total graph for all plots at Greenville for year 1998. 


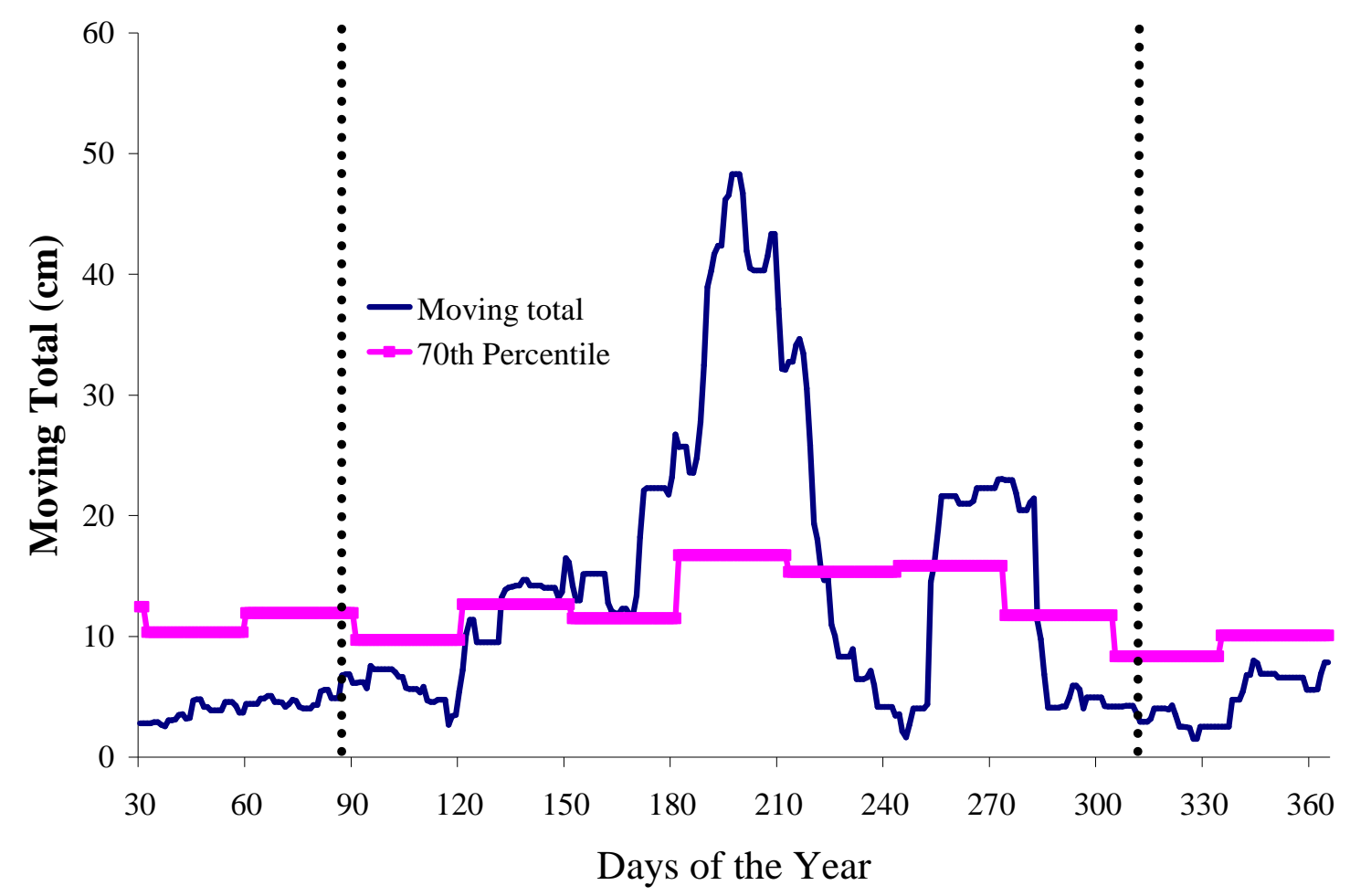

Figure D.41: Moving total graph for all plots at Bertie for year 1950.

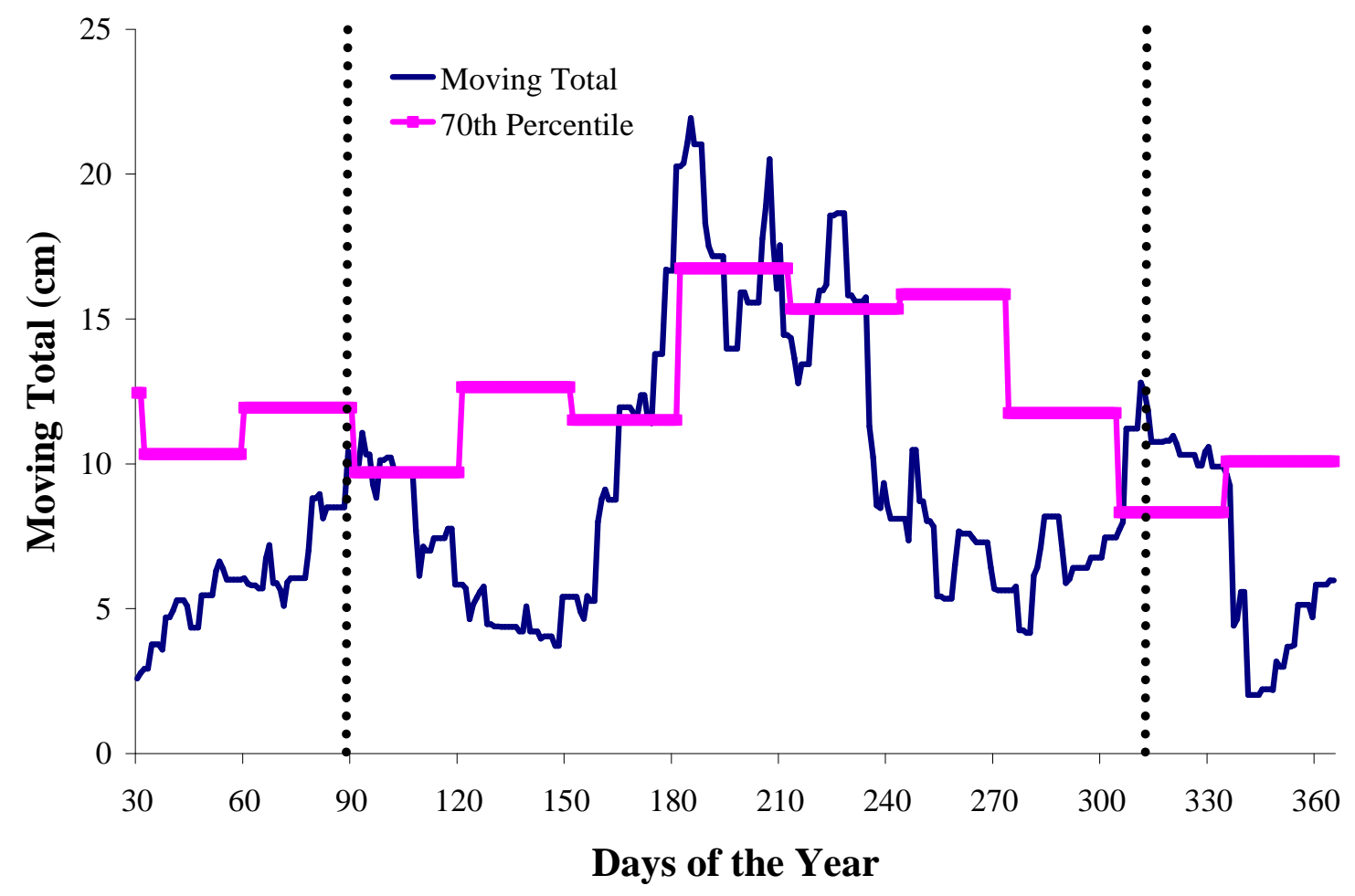

Figure D.42: Moving total graph for all plots at Bertie for year 1951. 


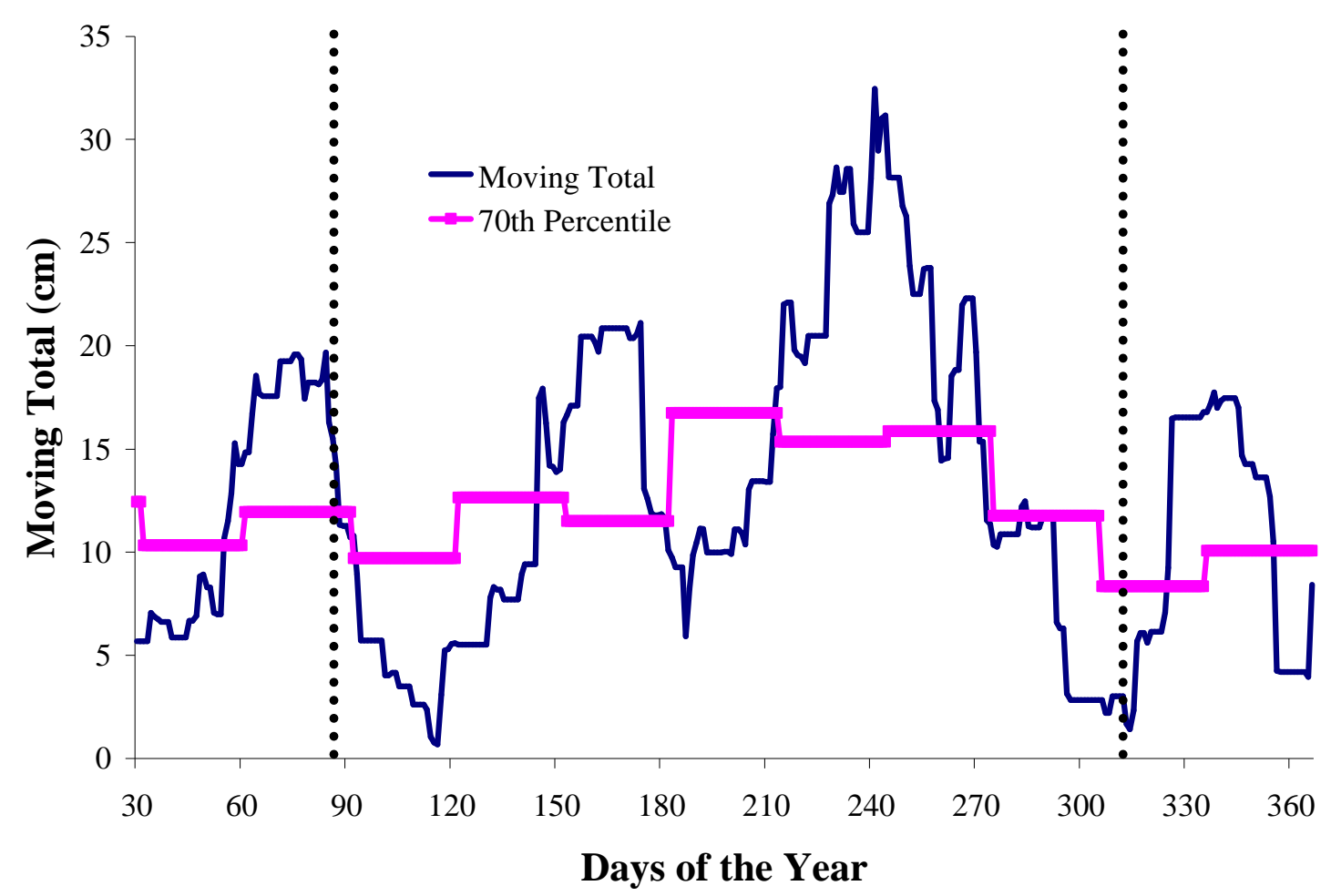

Figure D.43: Moving total graph for all plots at Bertie for year 1952.

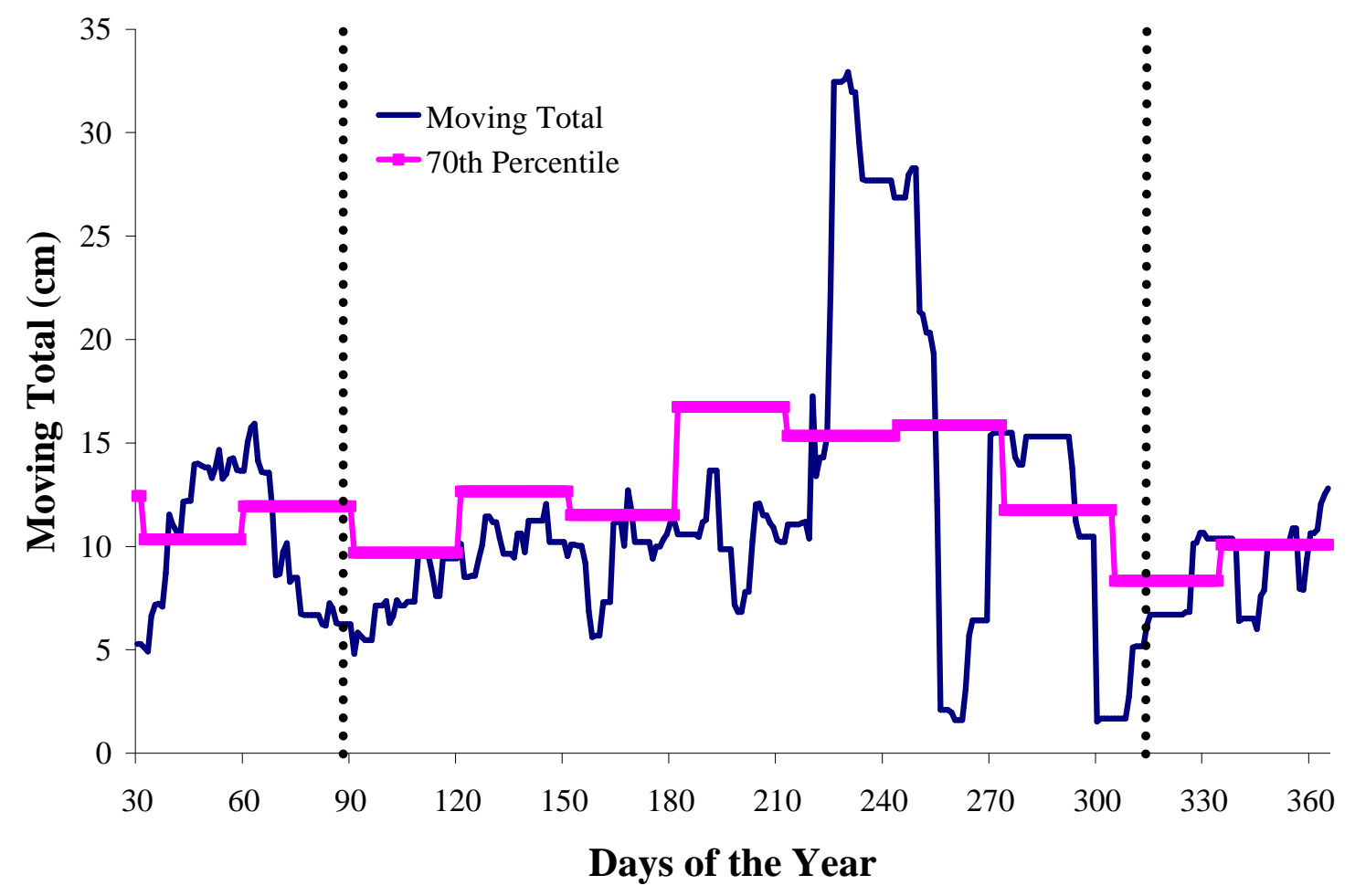

Figure D.44: Moving total graph for all plots at Bertie for year 1953. 


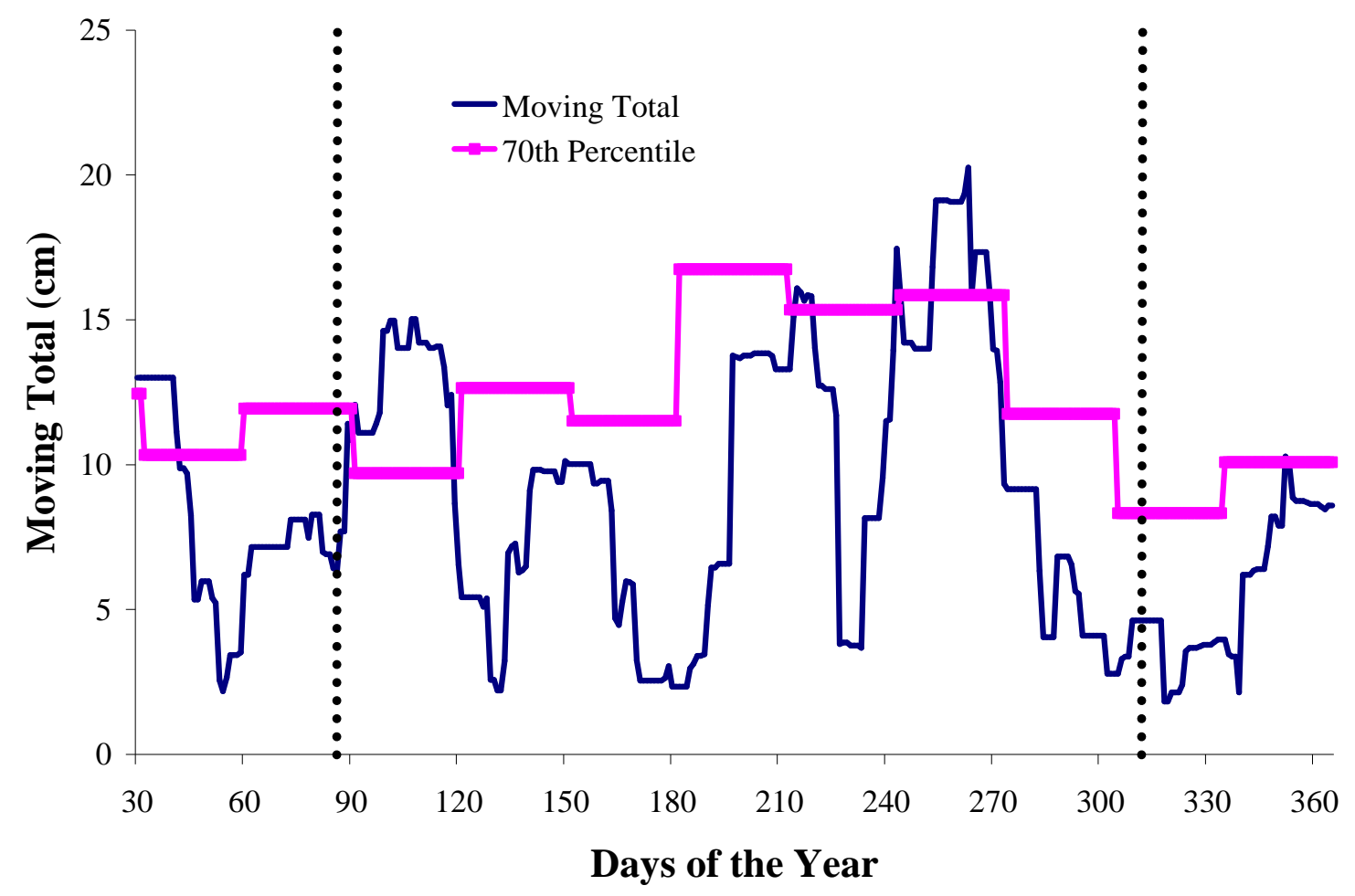

Figure D.45: Moving total graph for all plots at Bertie for year 1954 .

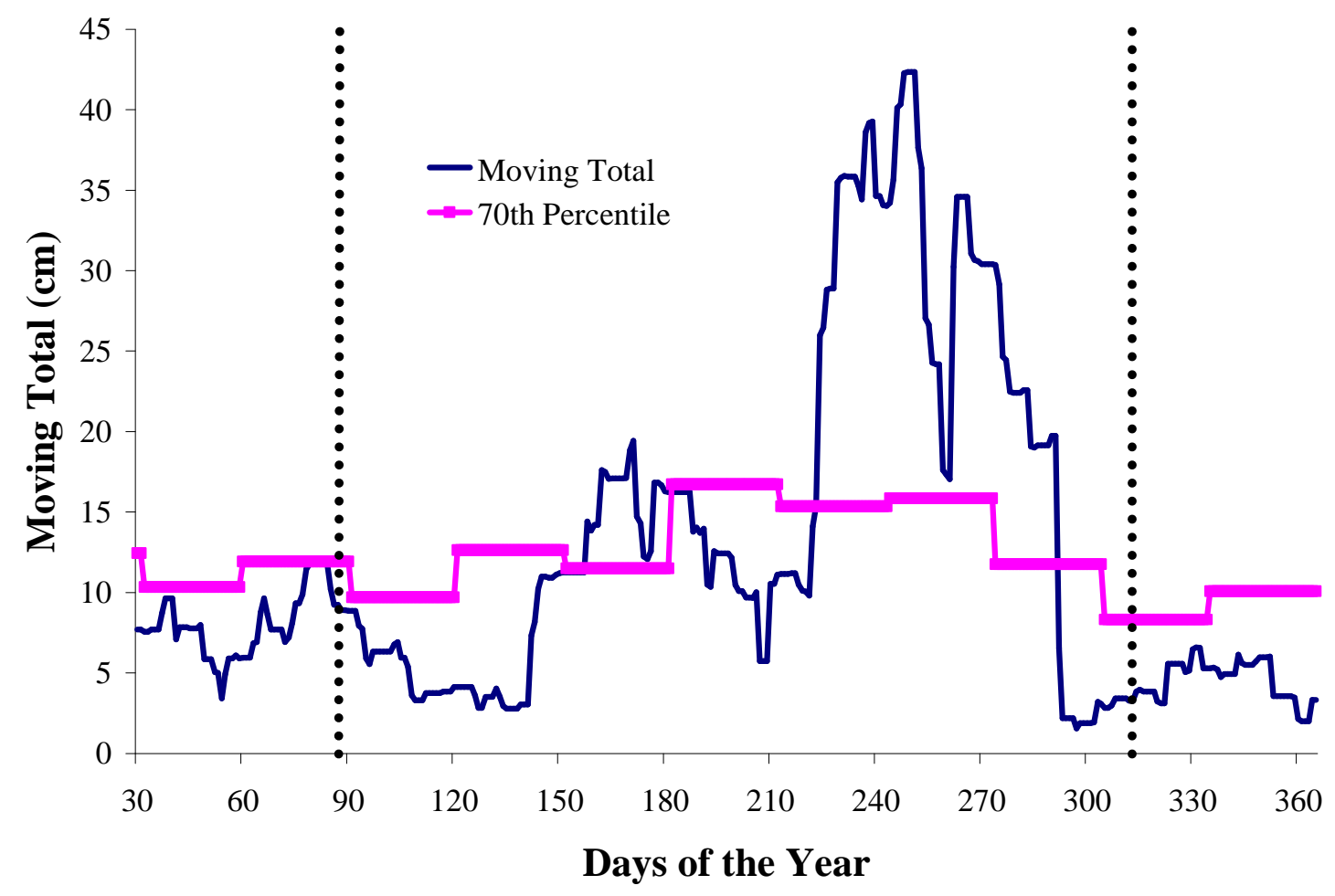

Figure D.46: Moving total graph for all plots at Bertie for year 1955. 


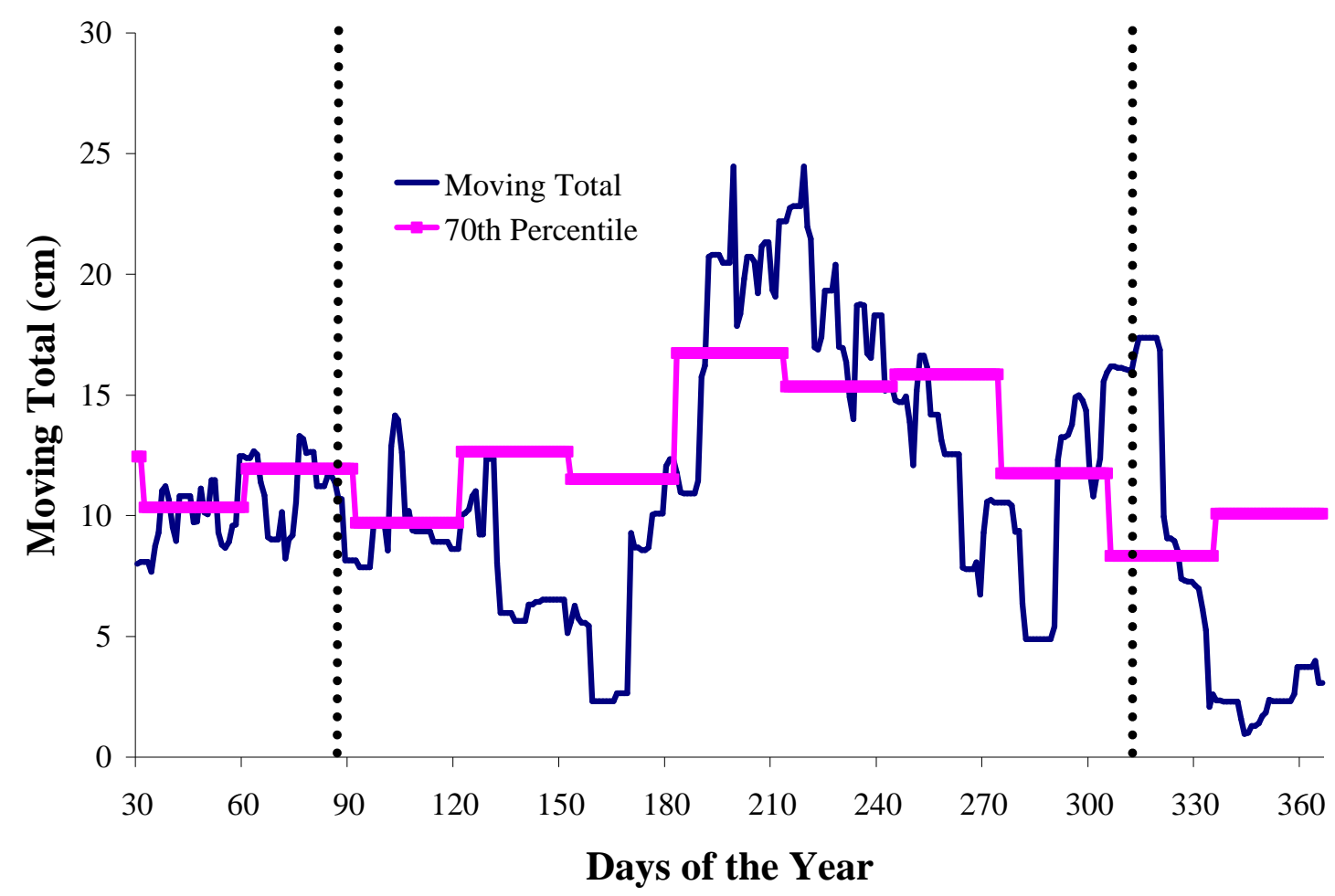

Figure D.47: Moving total graph for all plots at Bertie for year 1956.

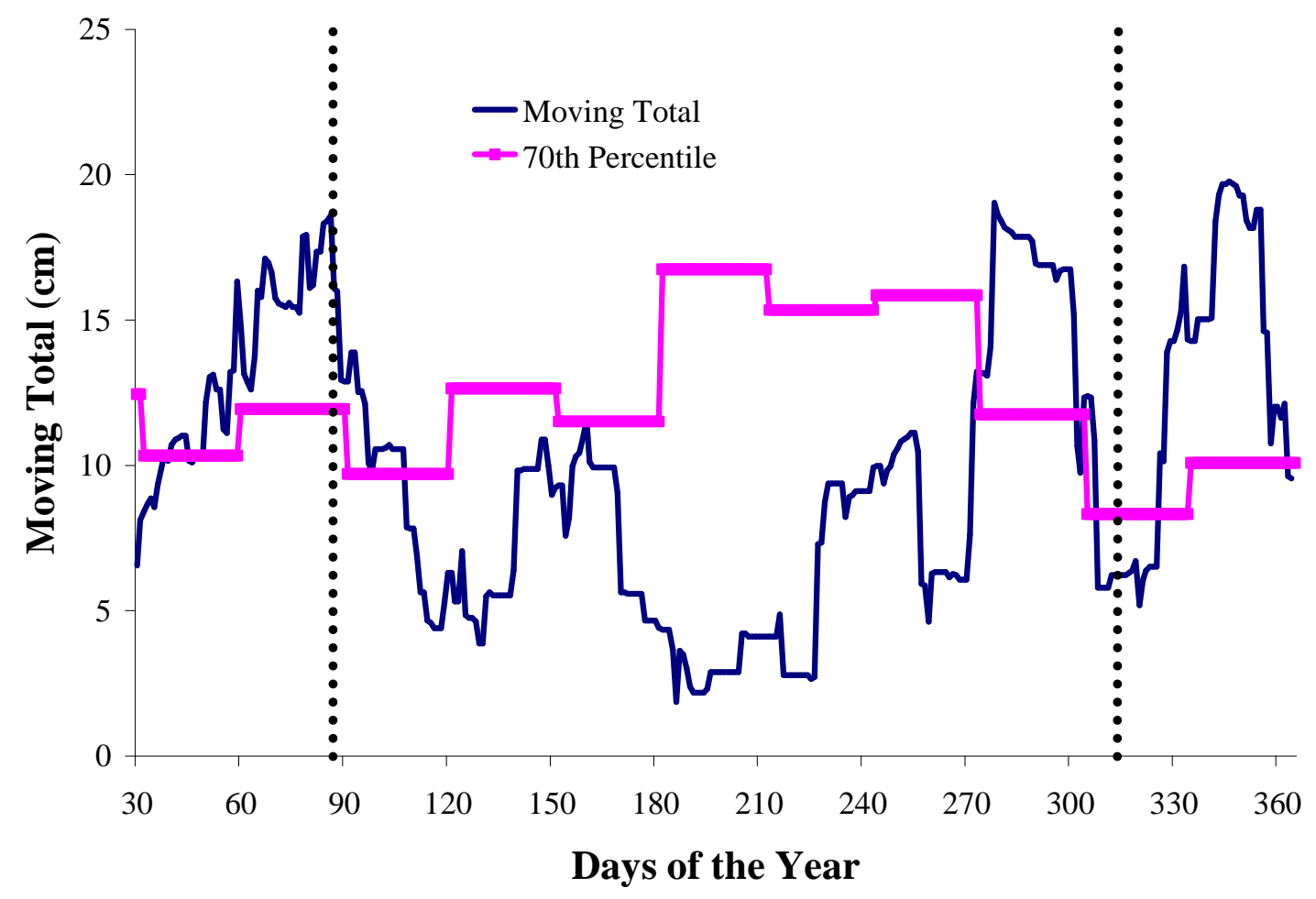

Figure D.48: Moving total graph for all plots at Bertie for year 1957. 


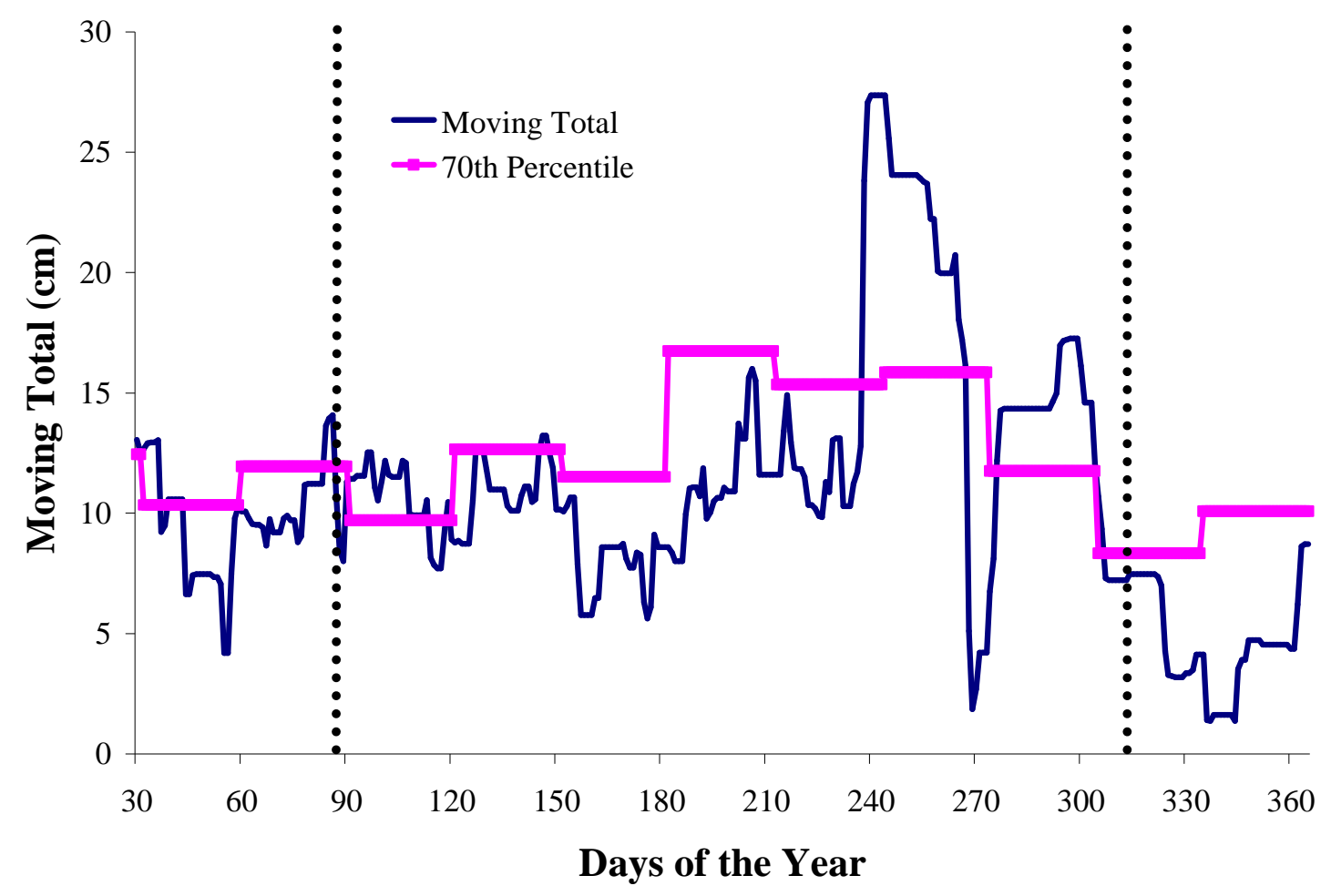

Figure D.49: Moving total graph for all plots at Bertie for year 1958.

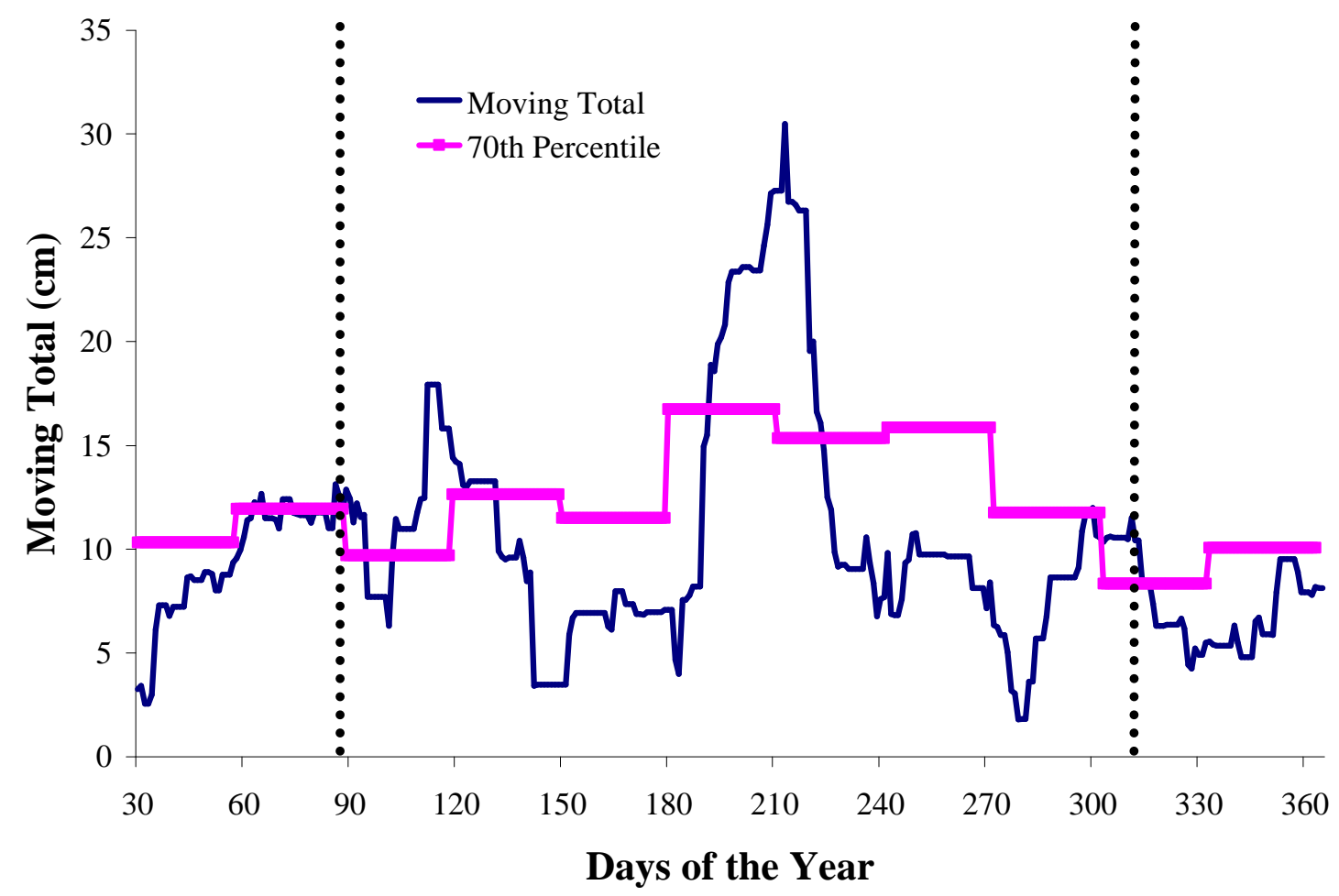

Figure D.50: Moving total graph for all plots at Bertie for year 1959. 


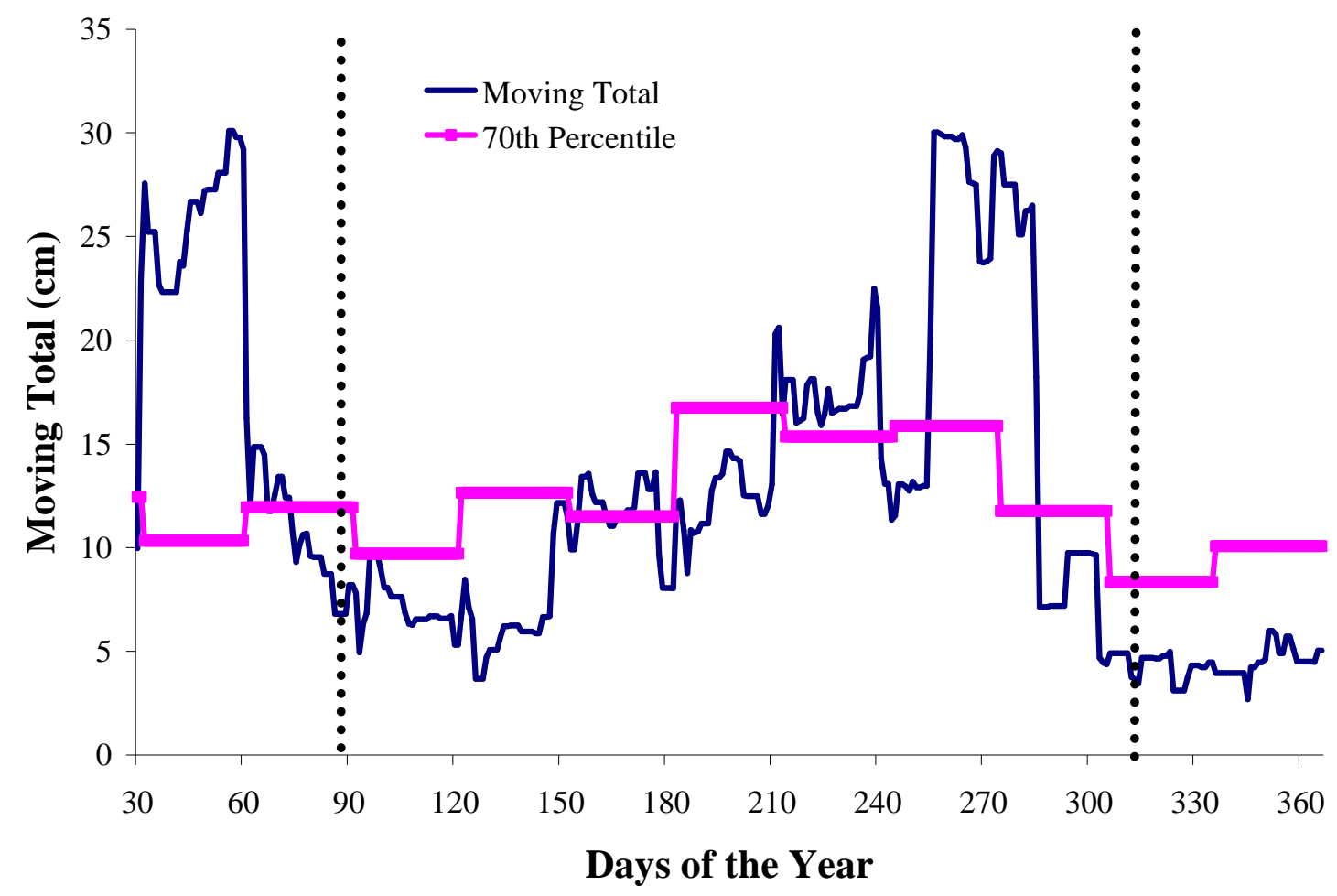

Figure D.51: Moving total graph for all plots at Bertie for year 1960 .

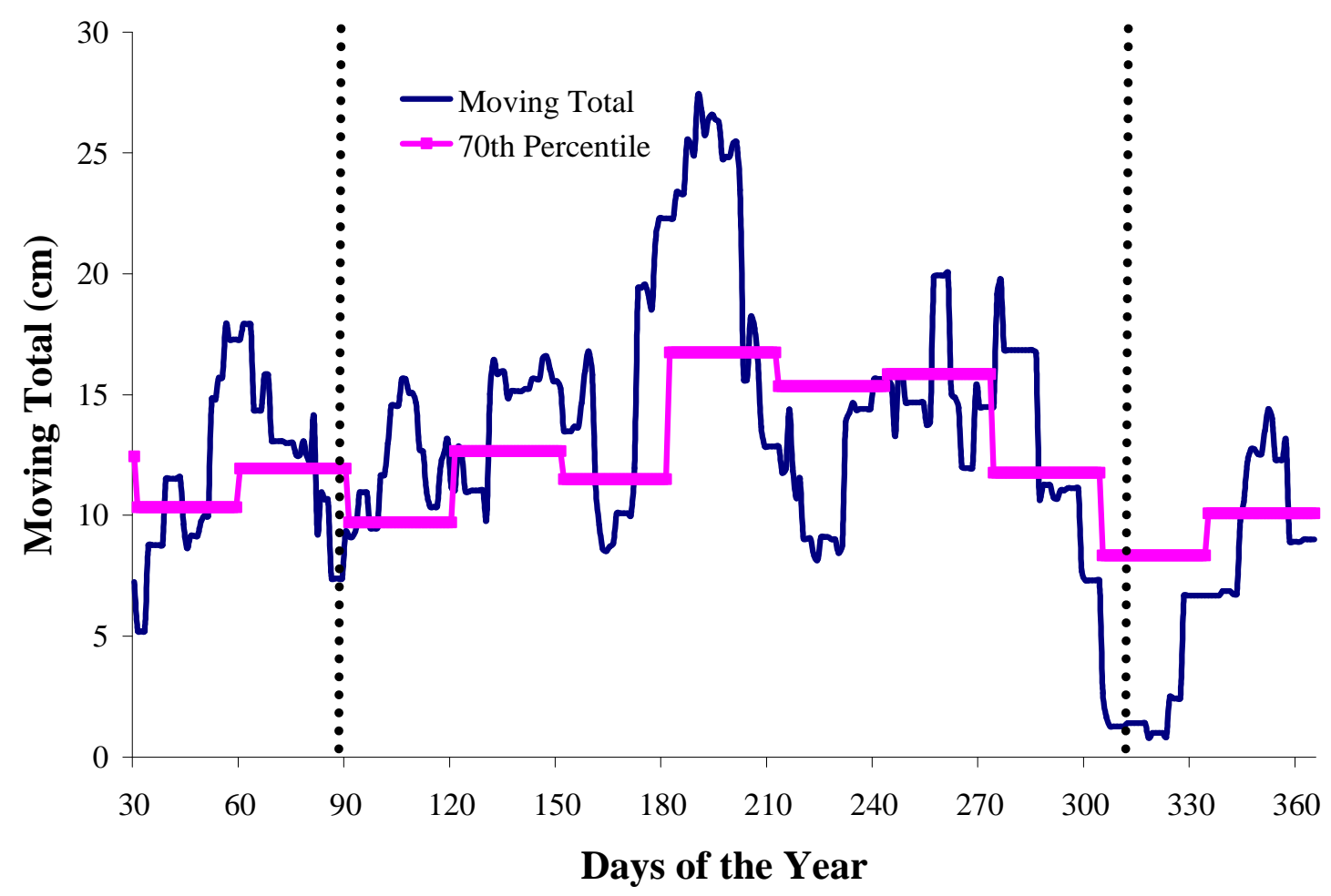

Figure D.52: Moving total graph for all plots at Bertie for year 1961. 


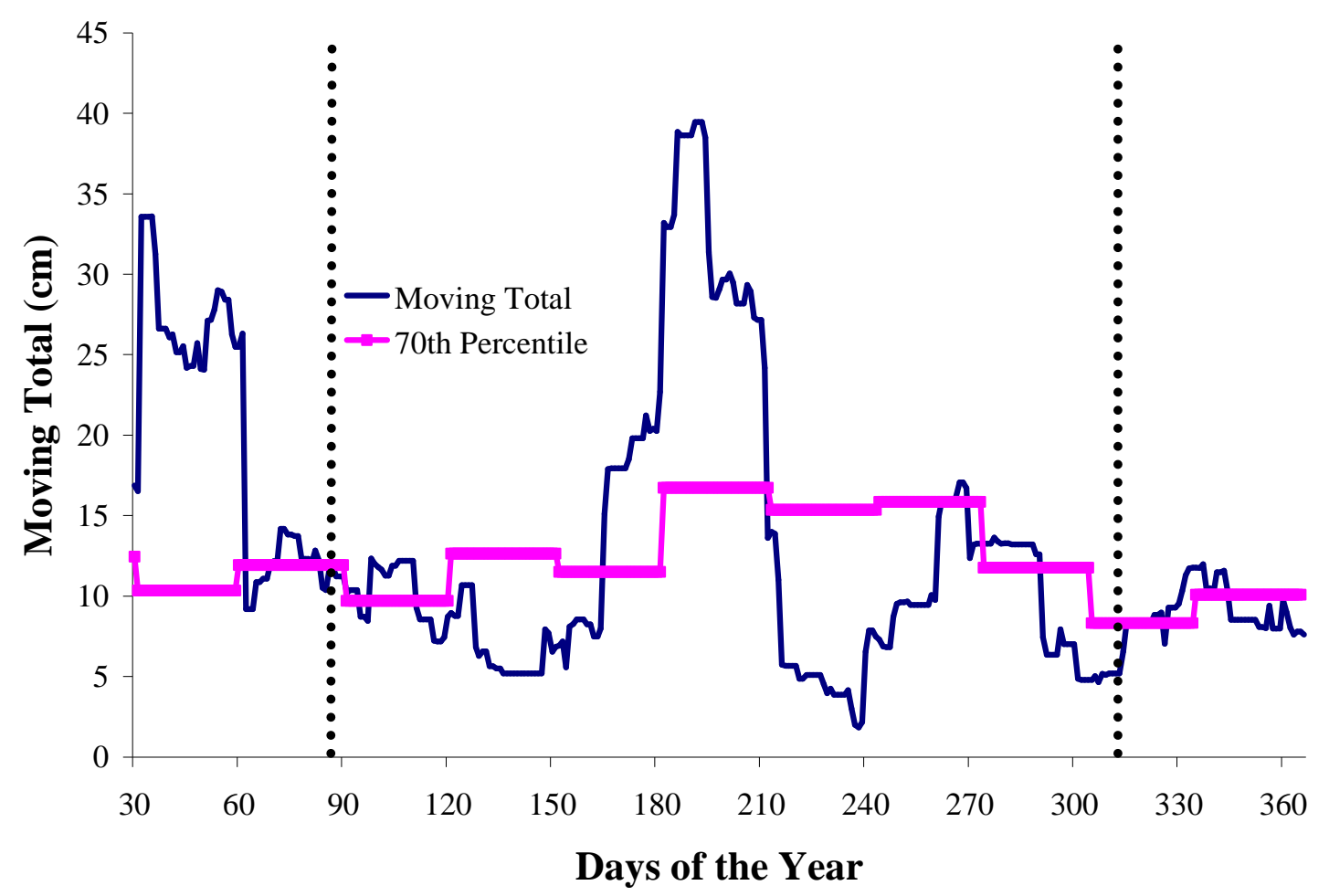

Figure D.53: Moving total graph for all plots at Bertie for year 1962 .

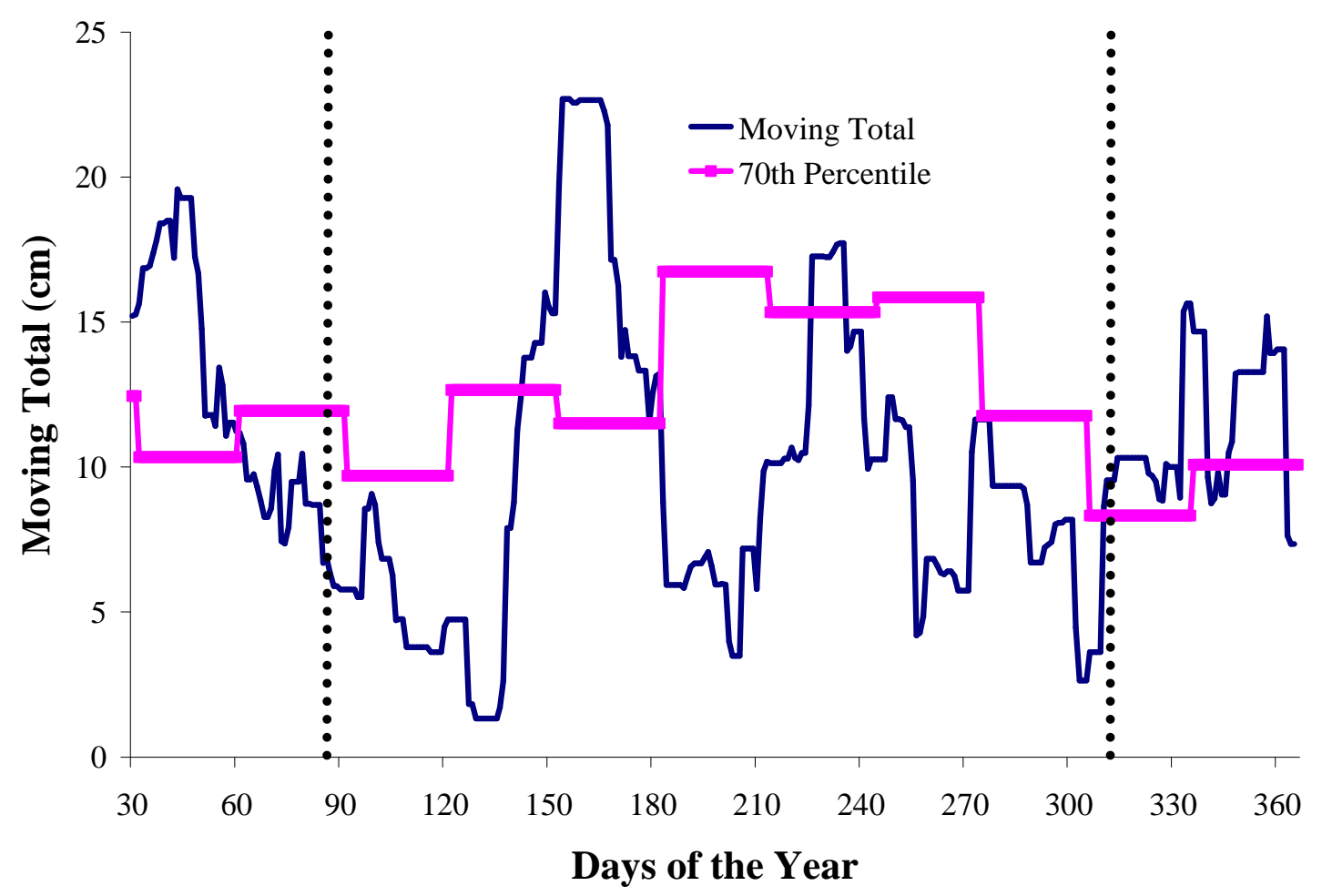

Figure D.54: Moving total graph for all plots at Bertie for year 1963. 


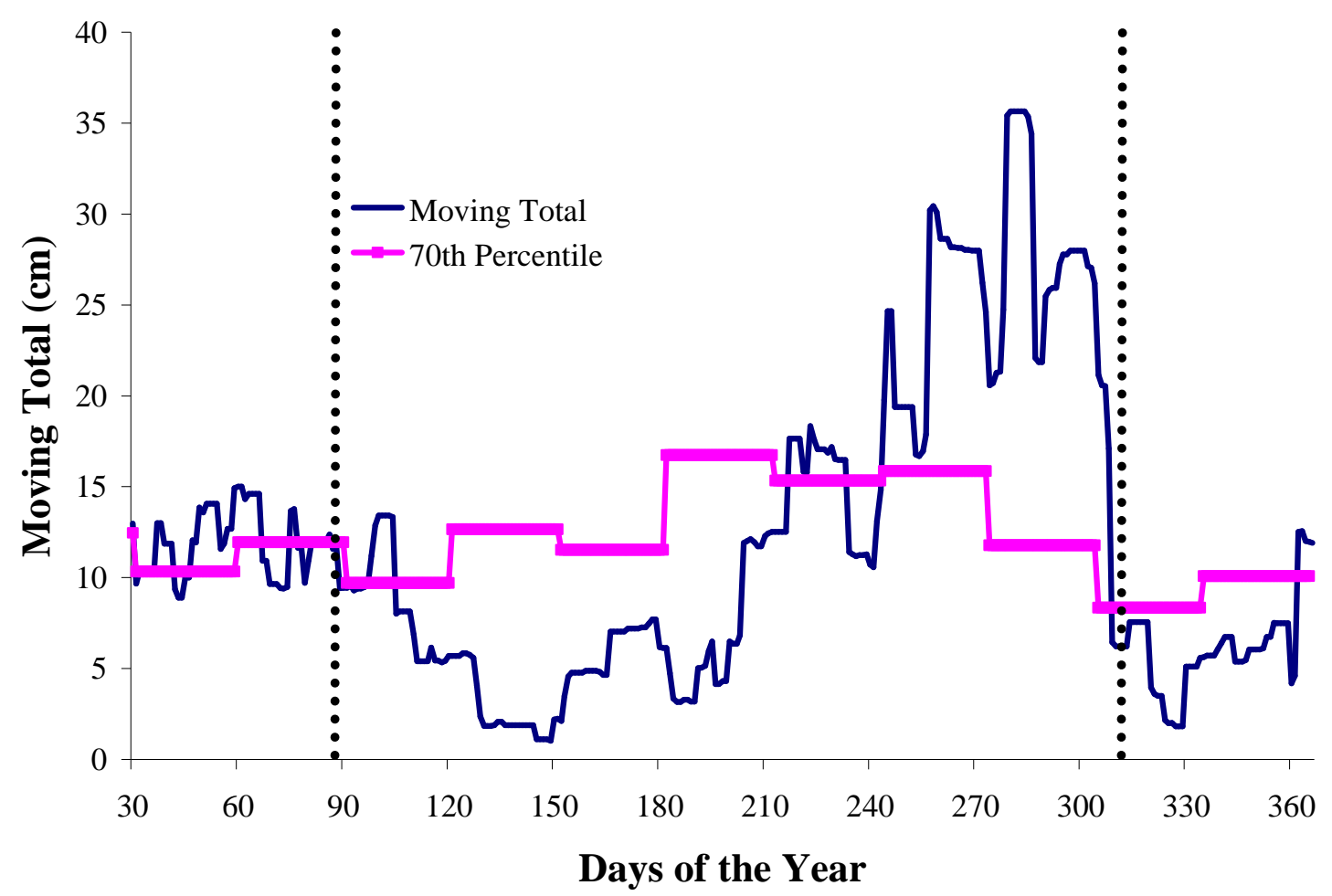

Figure D.55: Moving total graph for all plots at Bertie for year 1964 .

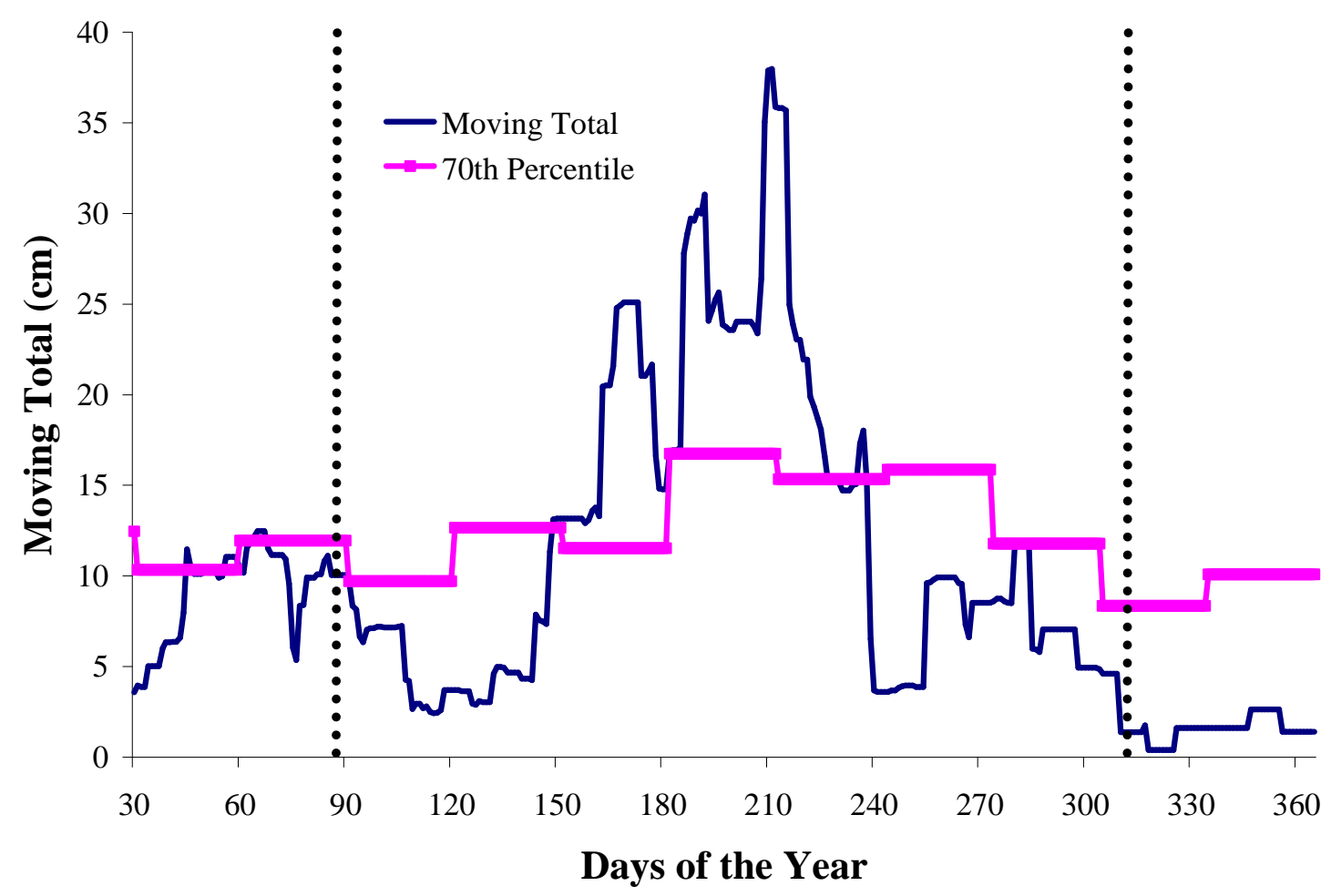

Figure D.56: Moving total graph for all plots at Bertie for year 1965 . 


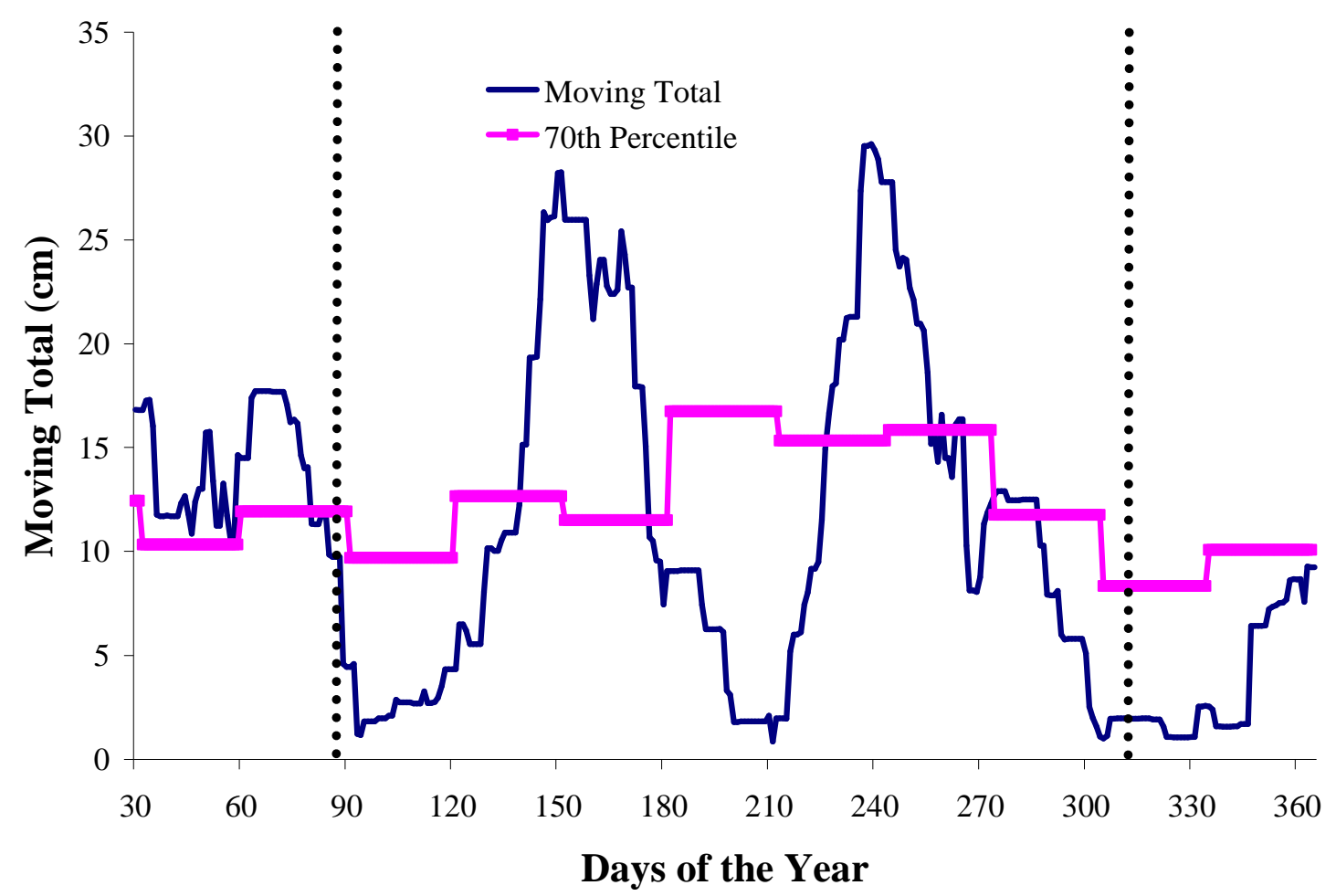

Figure D.57: Moving total graph for all plots at Bertie for year 1966 .

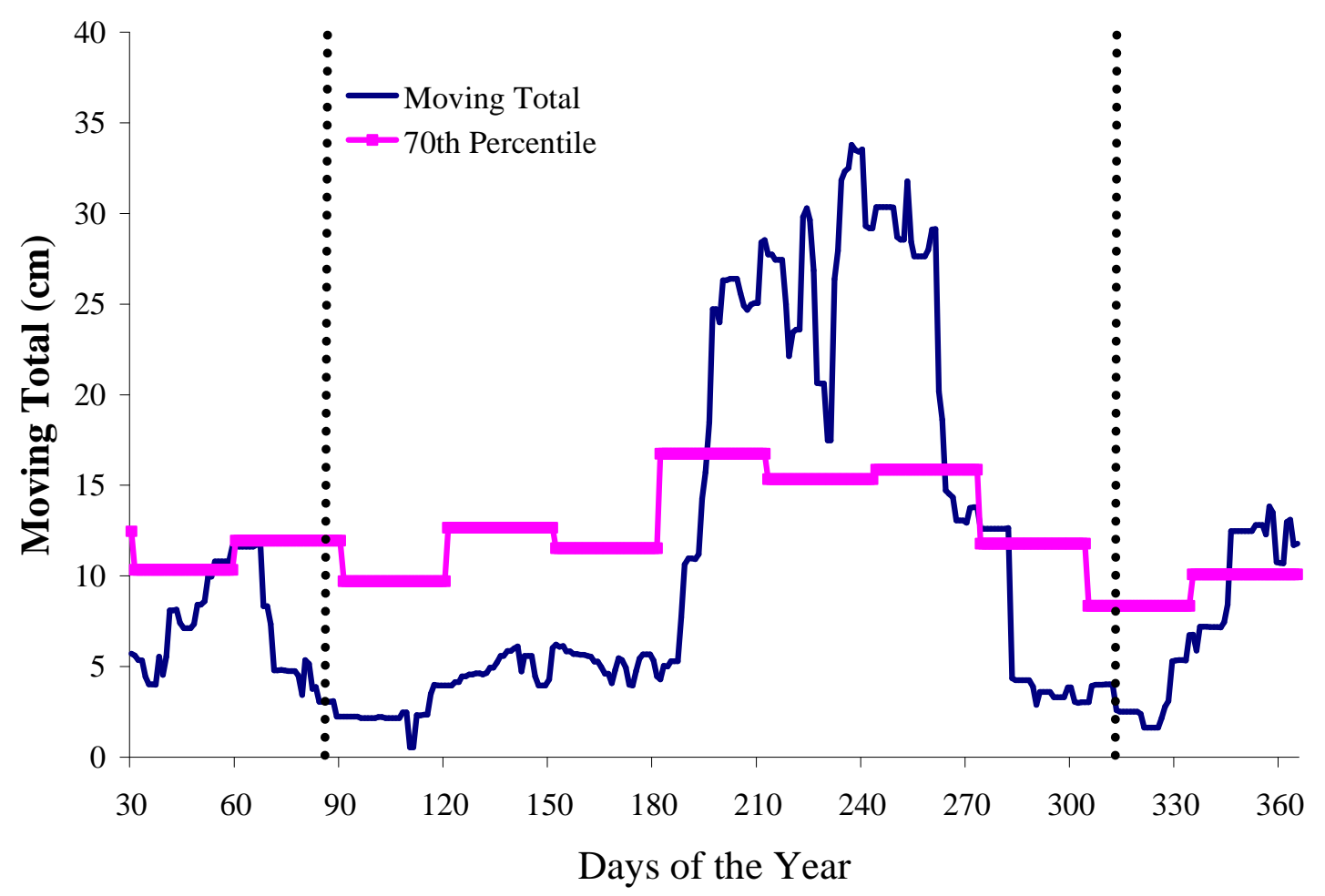

Figure D.58: Moving total graph for all plots at Bertie for year 1967. 


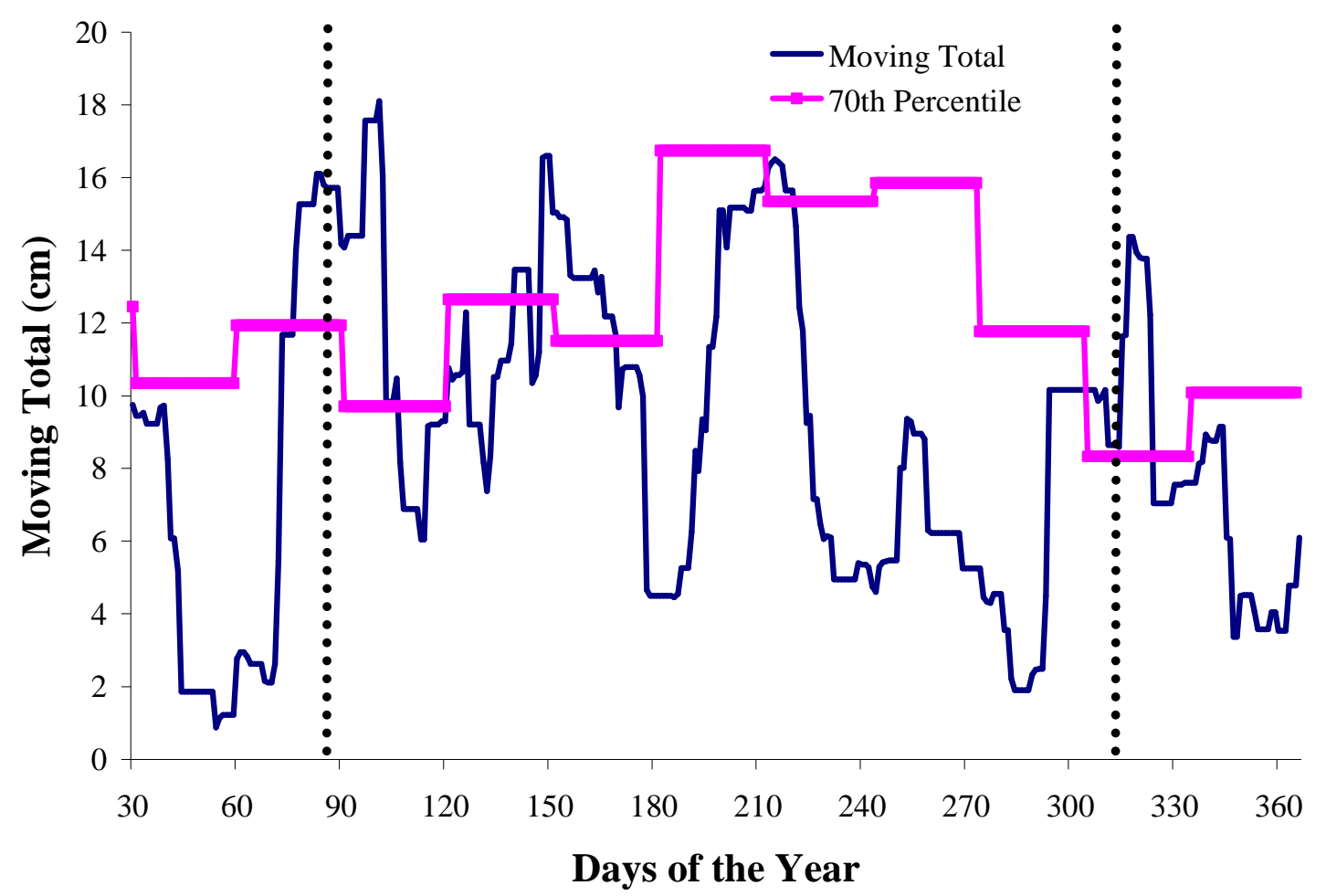

Figure D.59: Moving total graph for all plots at Bertie for year 1968 .

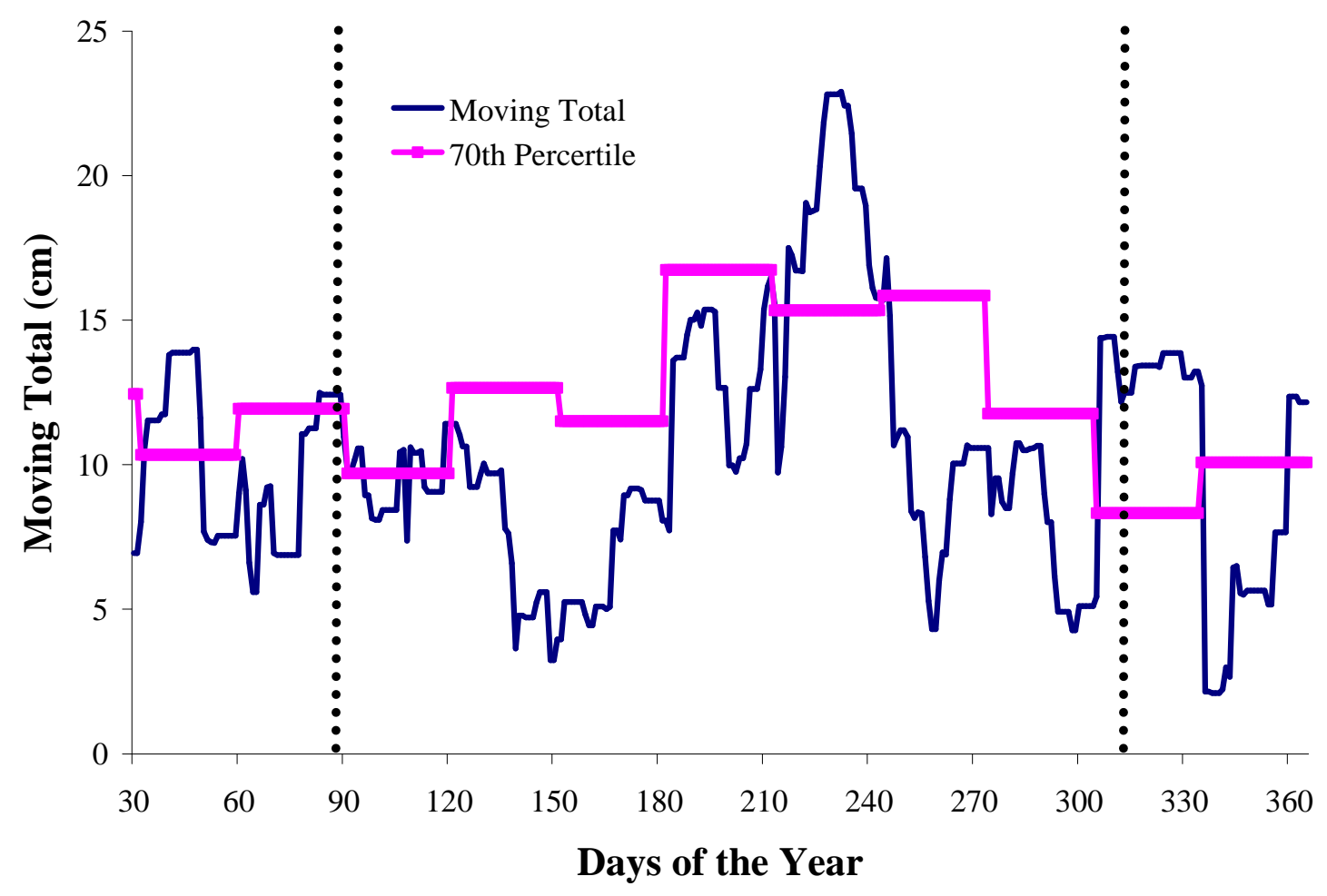

Figure D.60: Moving total graph for all plots at Bertie for year 1969. 


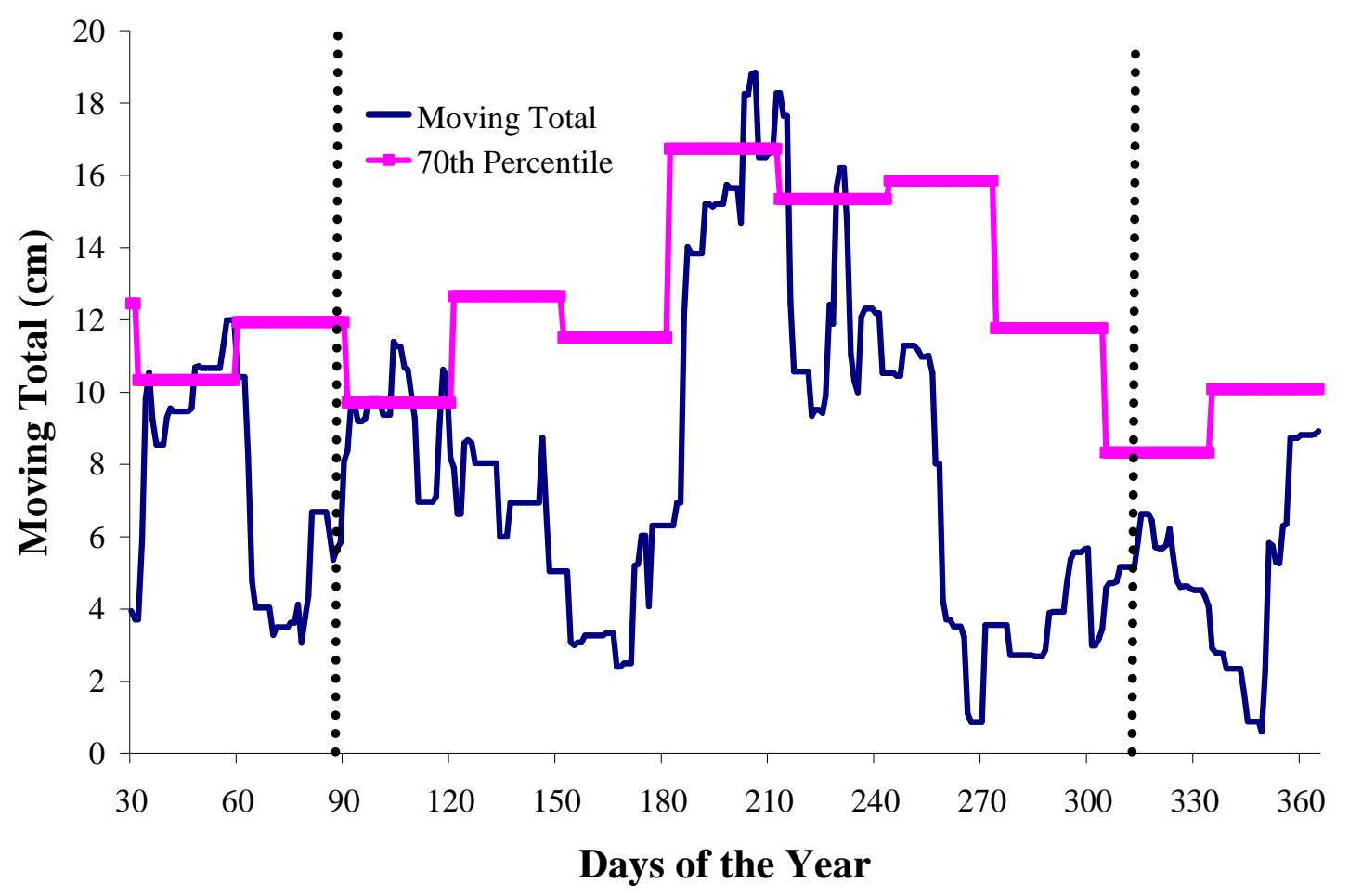

Figure D.61: Moving total graph for all plots at Bertie for year 1970.

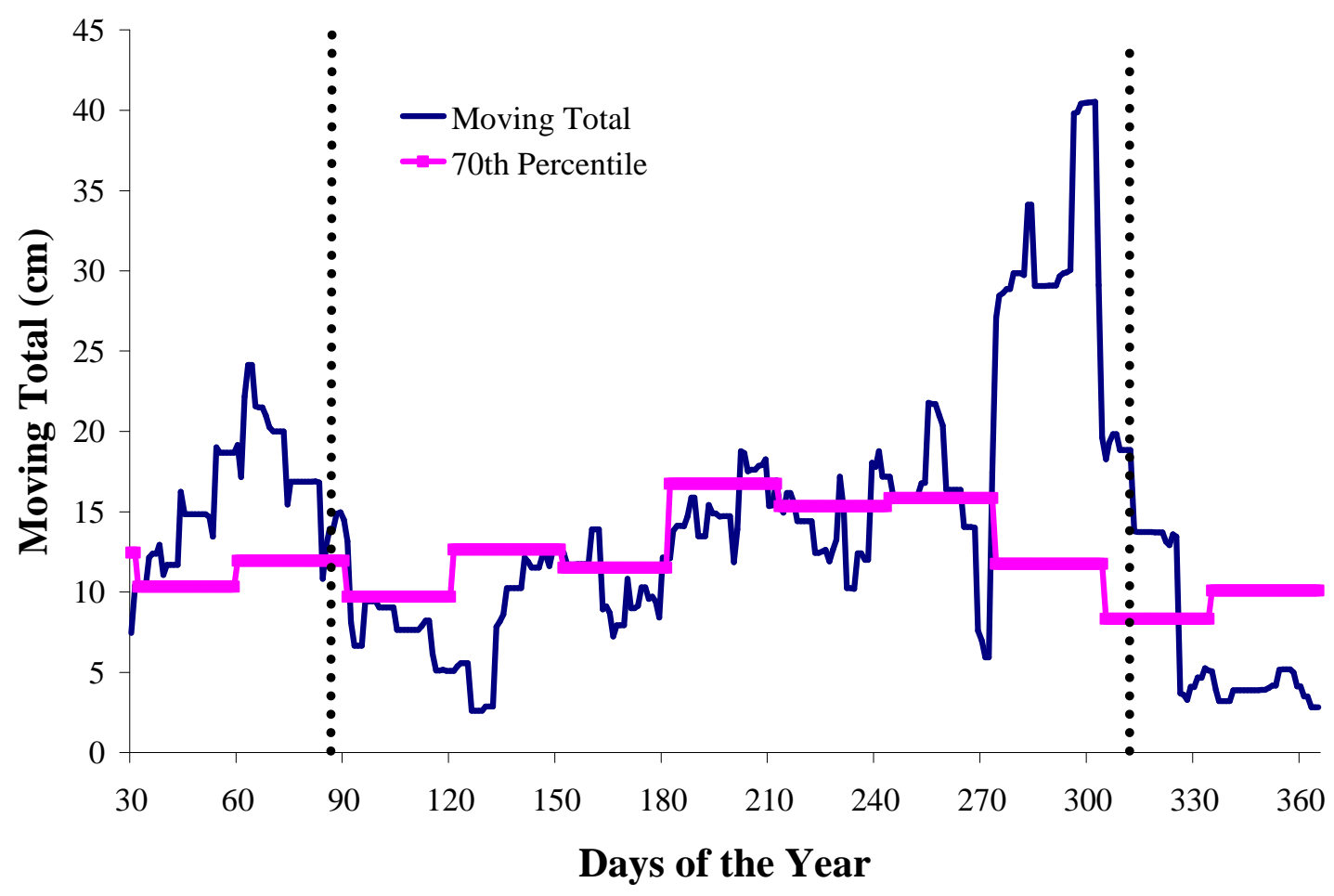

Figure D.62: Moving total graph for all plots at Bertie for year 1971. 


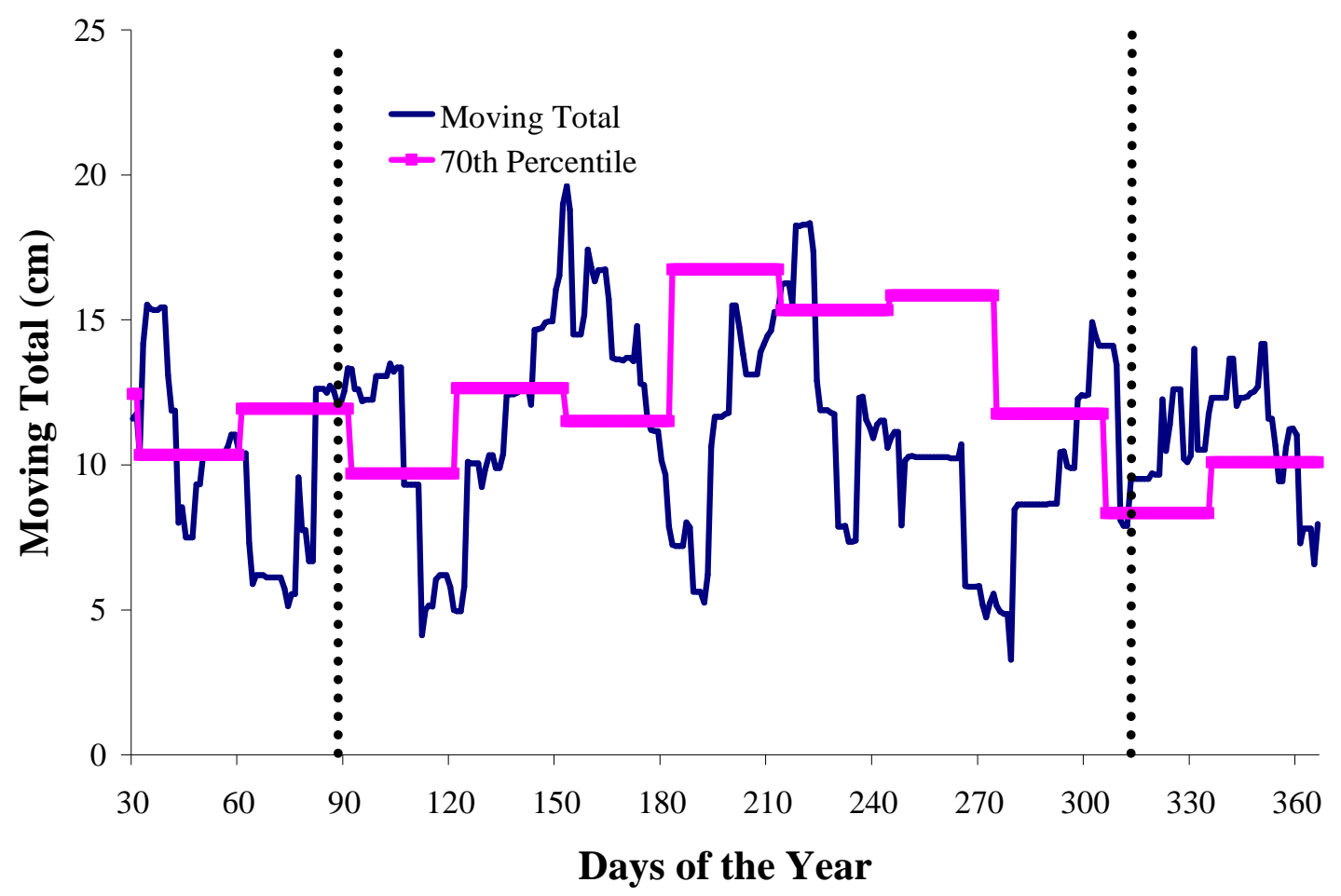

Figure D.63: Moving total graph for all plots at Bertie for year 1972.

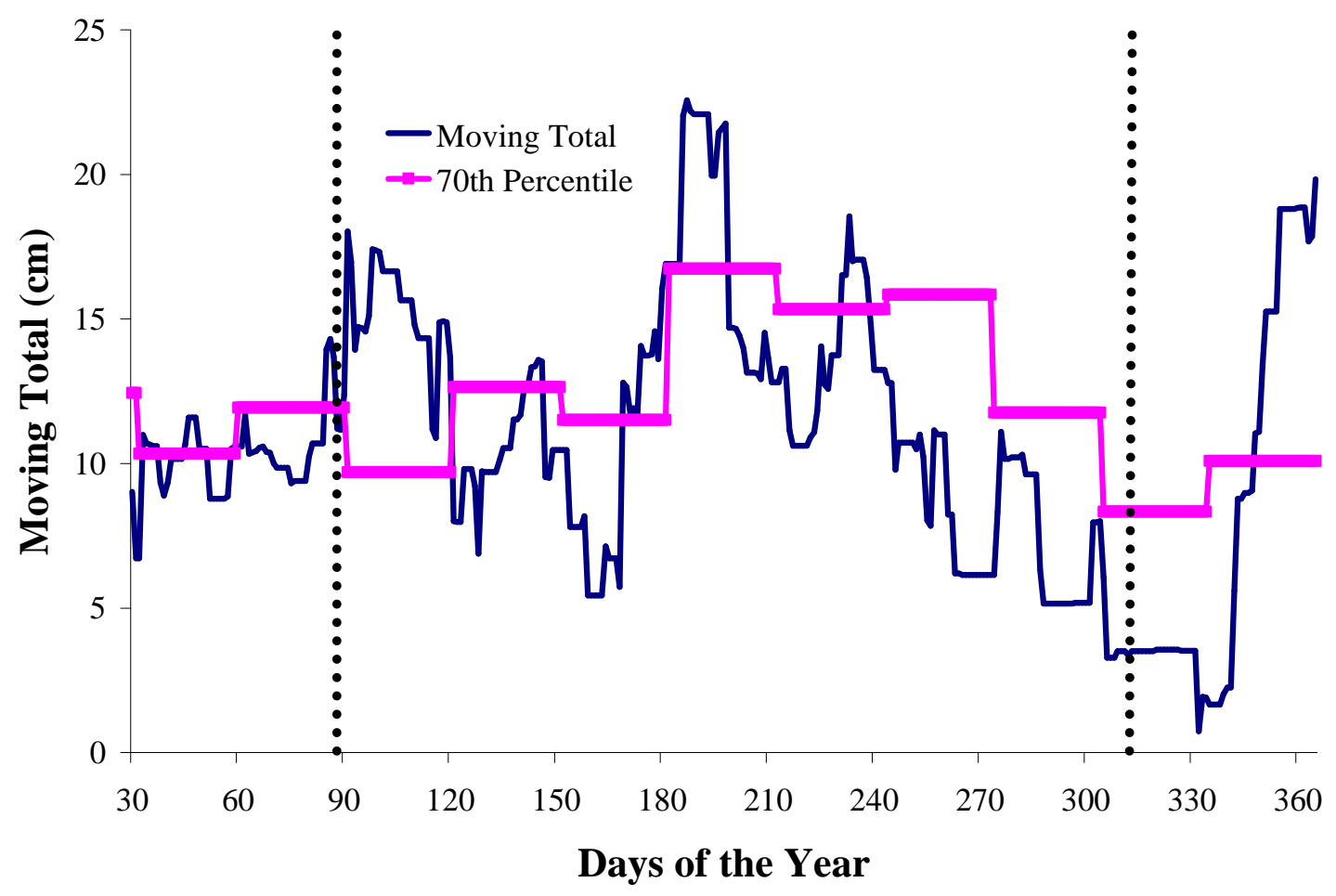

Figure D.64: Moving total graph for all plots at Bertie for year 1973. 


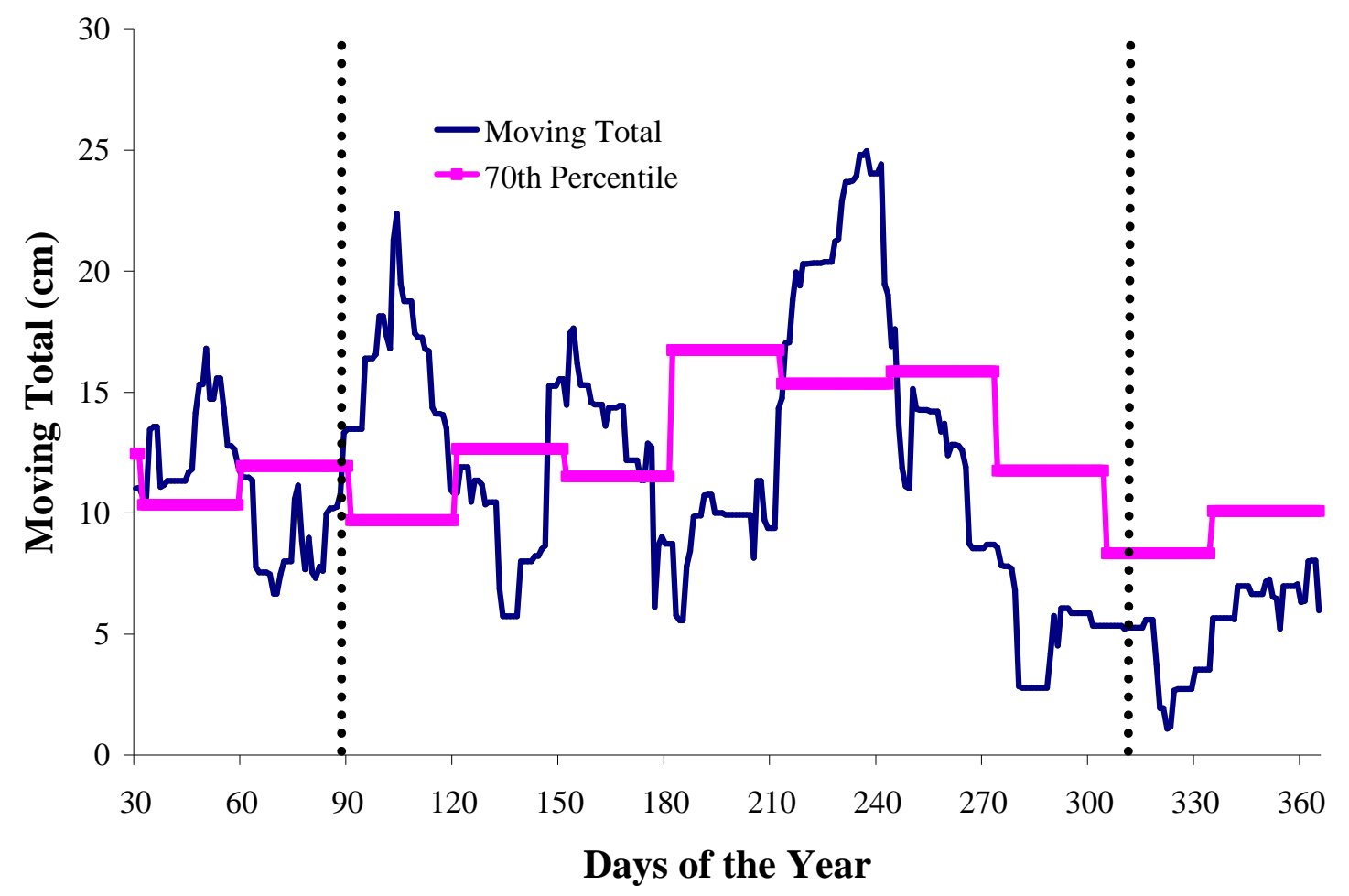

Figure D.65: Moving total graph for all plots at Bertie for year 1974 .

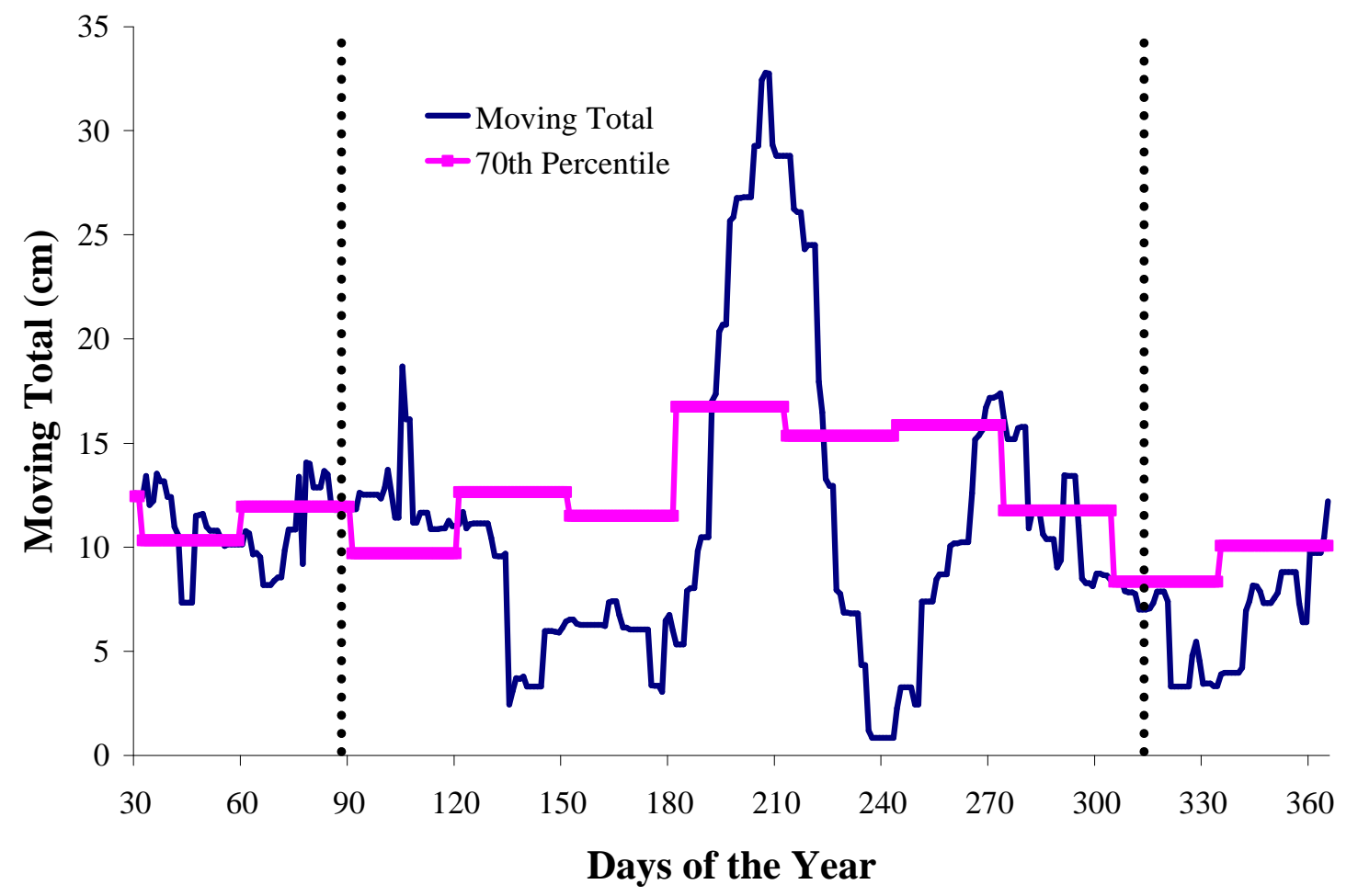

Figure D.66: Moving total graph for all plots at Bertie for year 1975. 


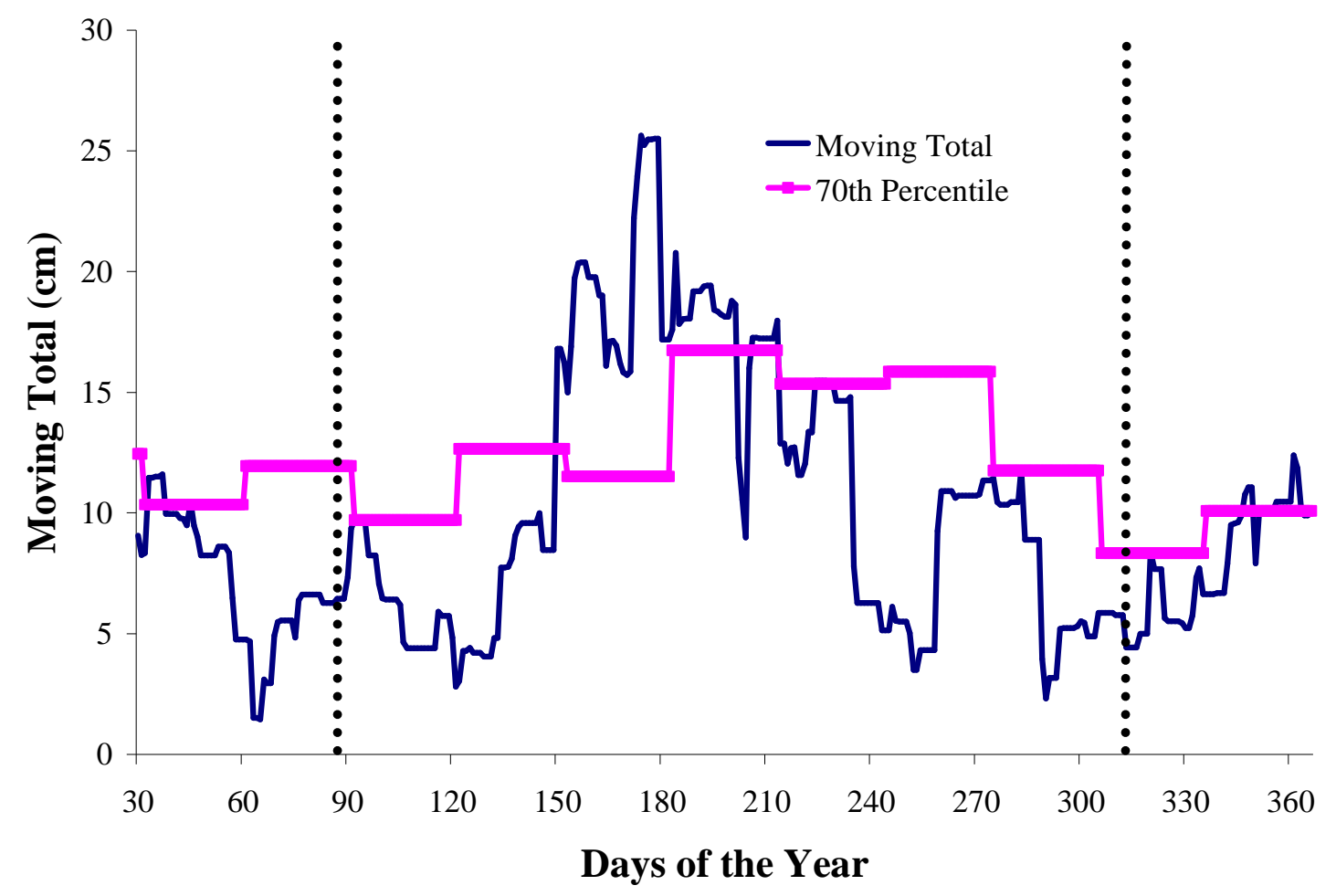

Figure D.67: Moving total graph for all plots at Bertie for year 1976.

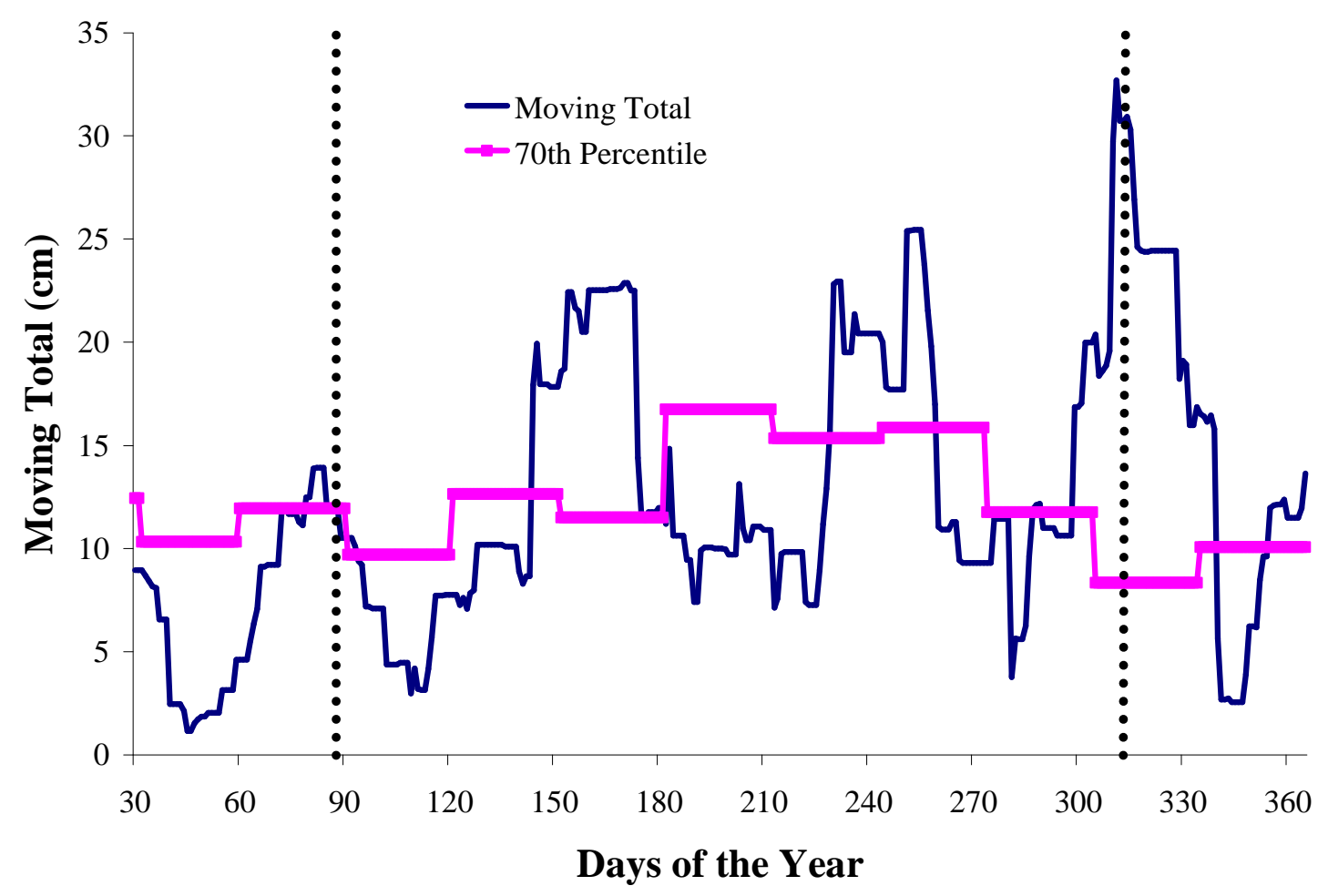

Figure D.68: Moving total graph for all plots at Bertie for year 1977. 


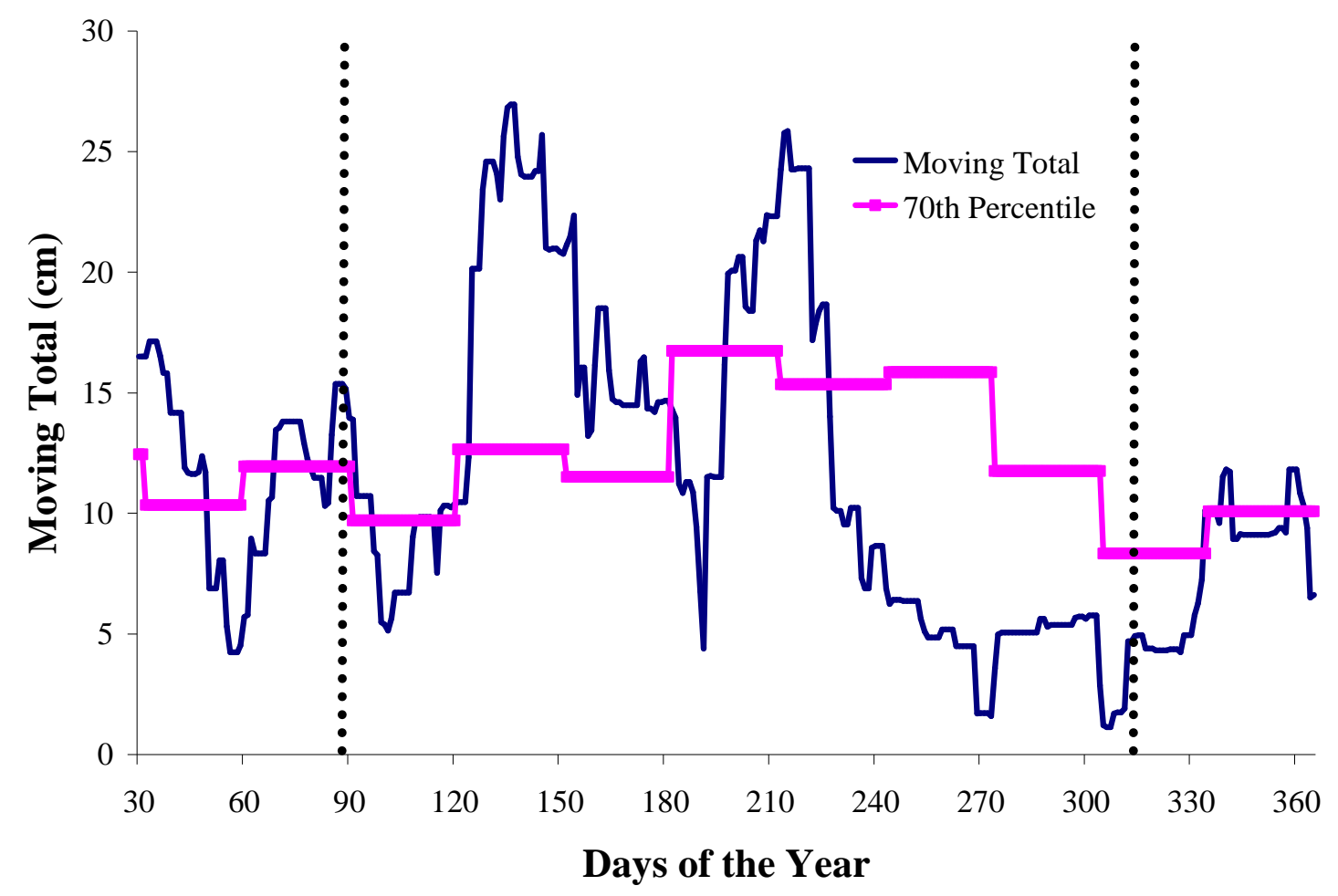

Figure D.69: Moving total graph for all plots at Bertie for year 1978.

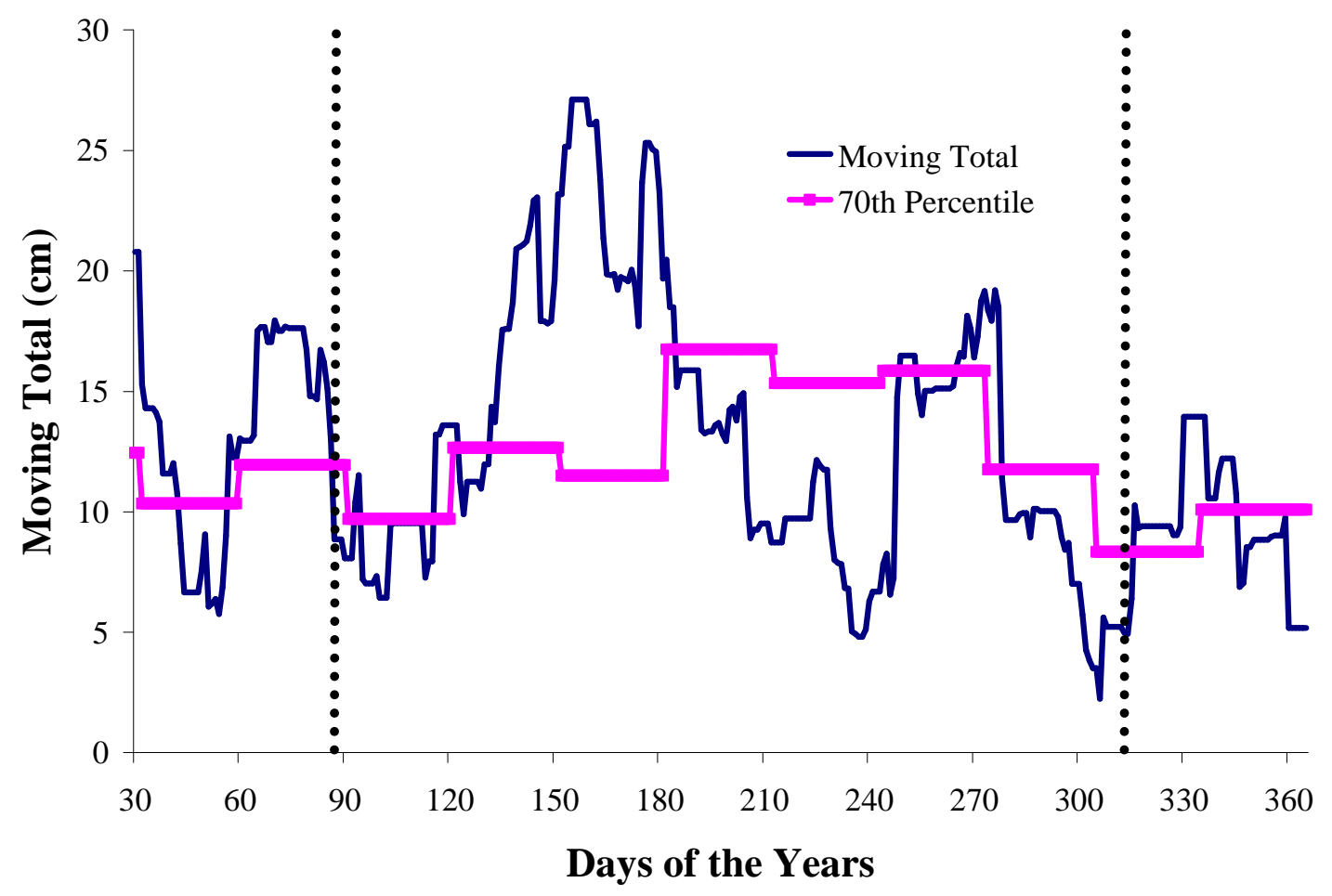

Figure D.70: Moving total graph for all plots at Bertie for year 1979. 


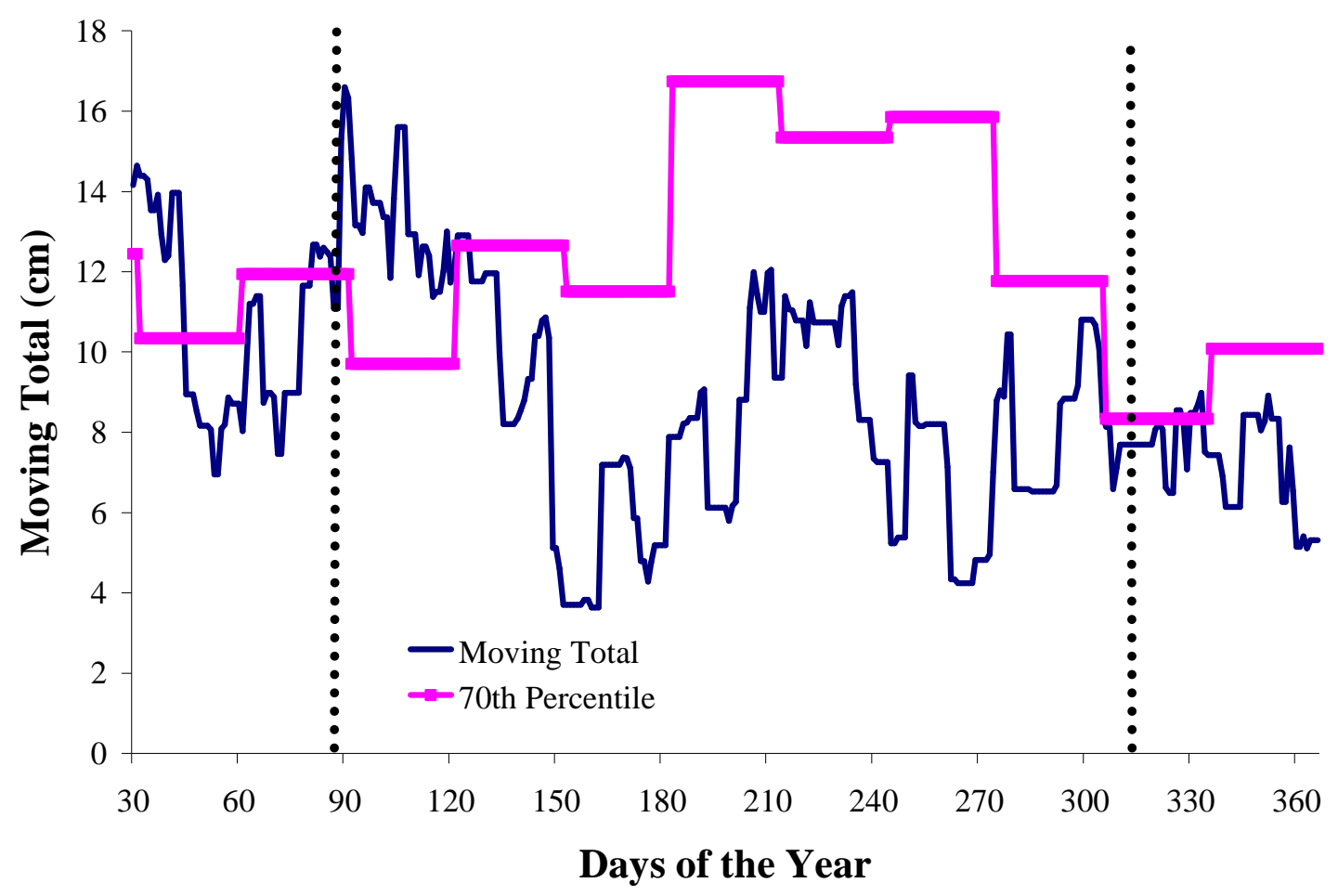

Figure D.71: Moving total graph for all plots at Bertie for year 1980.

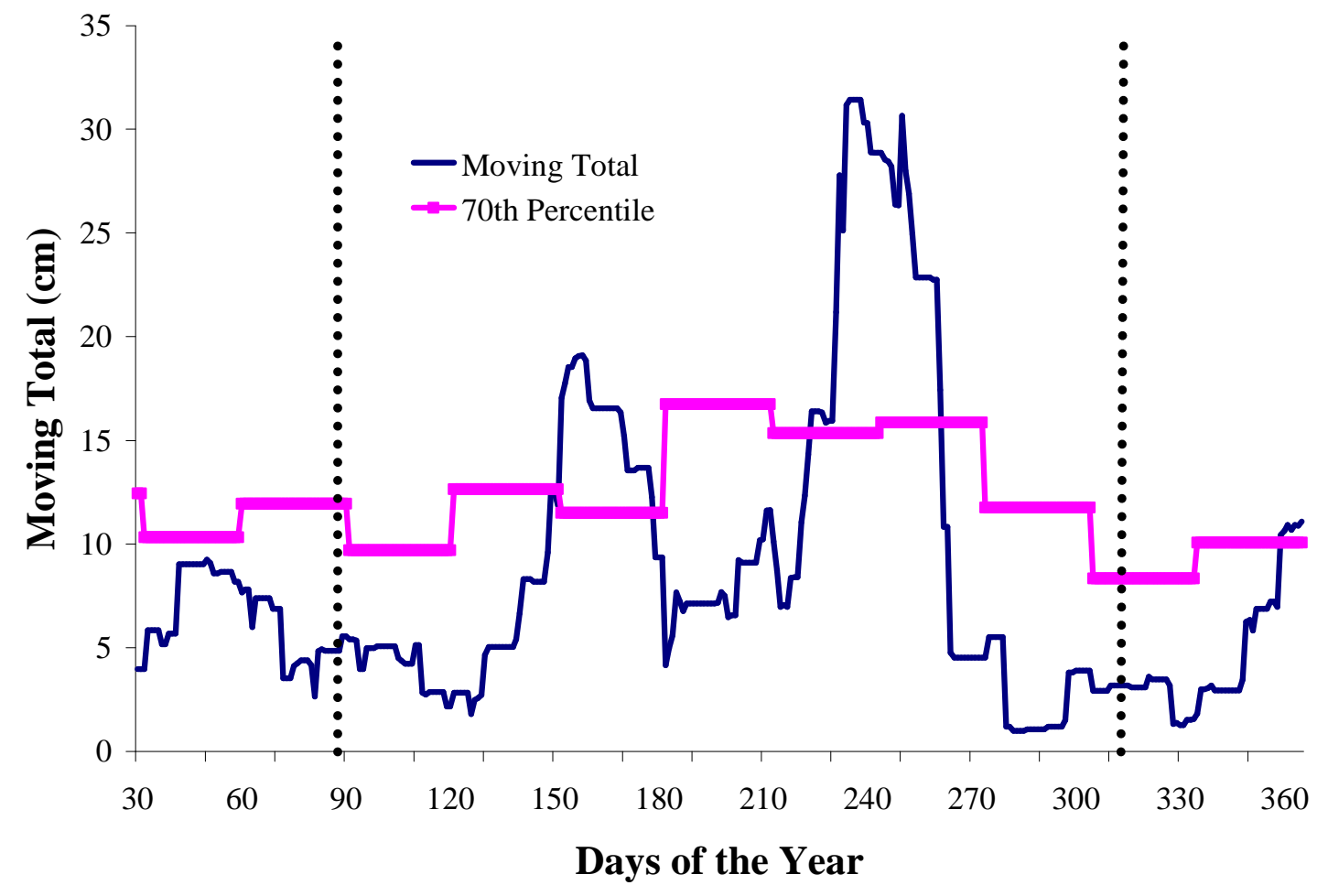

Figure D.72: Moving total graph for all plots at Bertie for year 1981. 


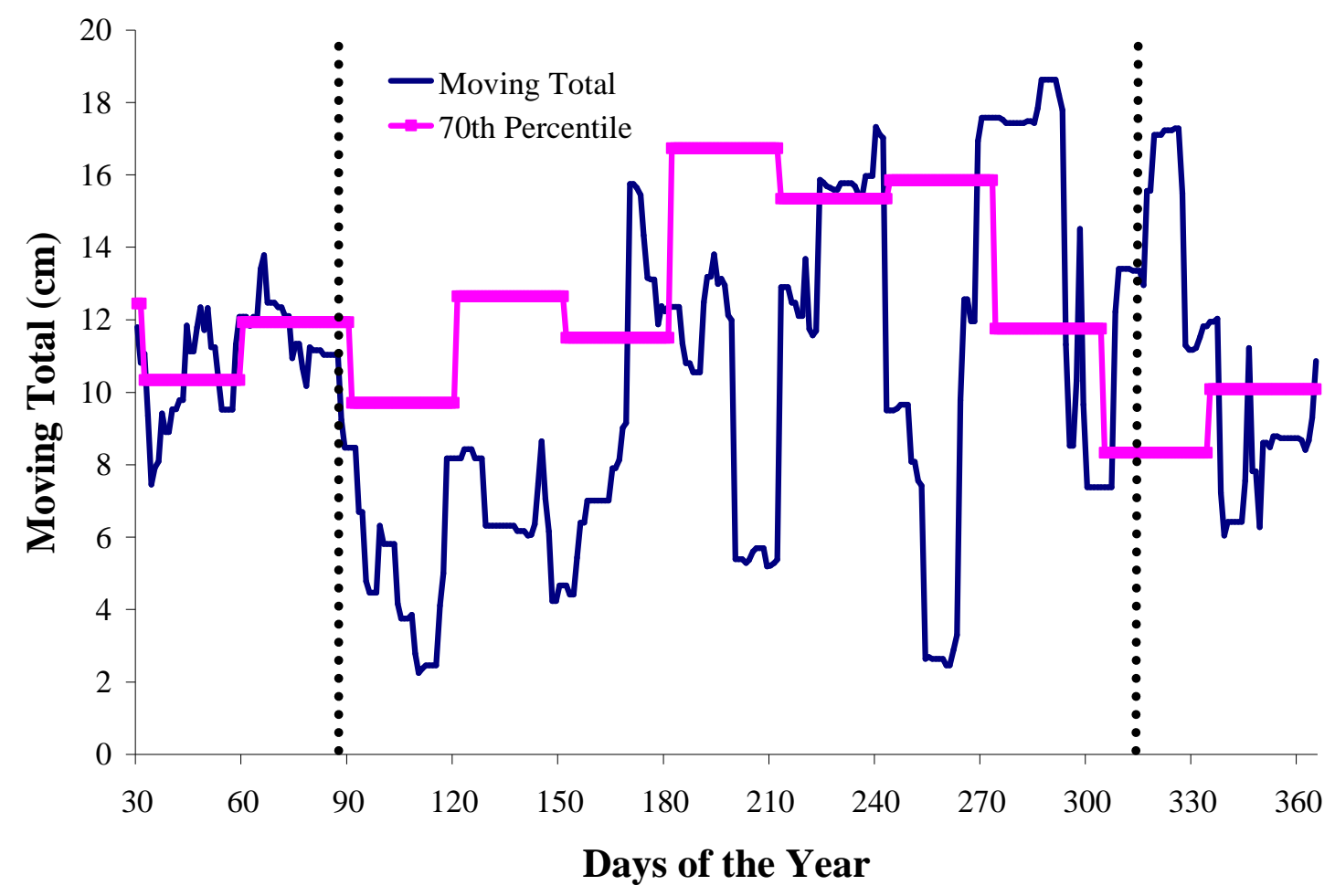

Figure D.73: Moving total graph for all plots at Bertie for year 1982.

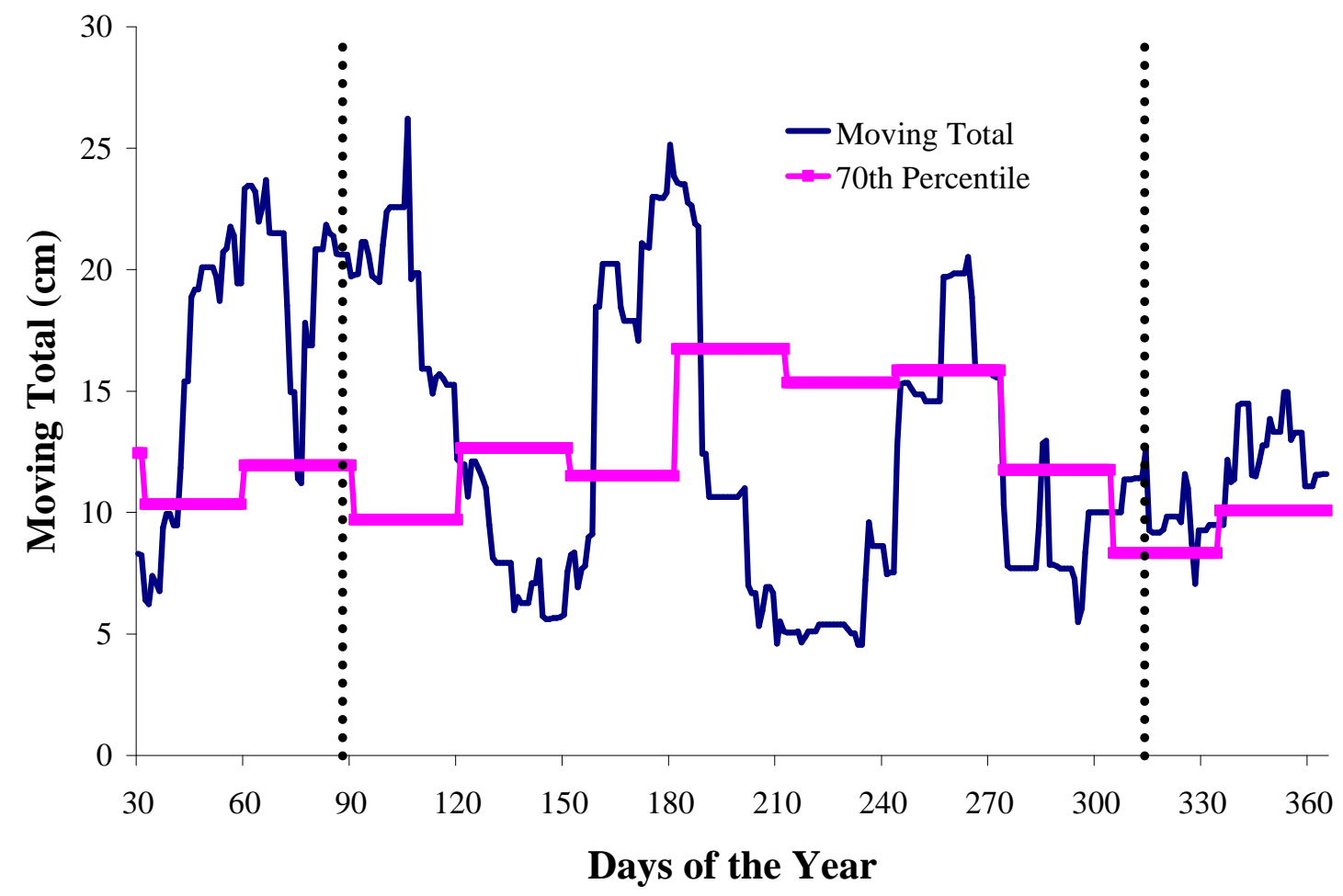

Figure D.74: Moving total graph for all plots at Bertie for year 1983. 


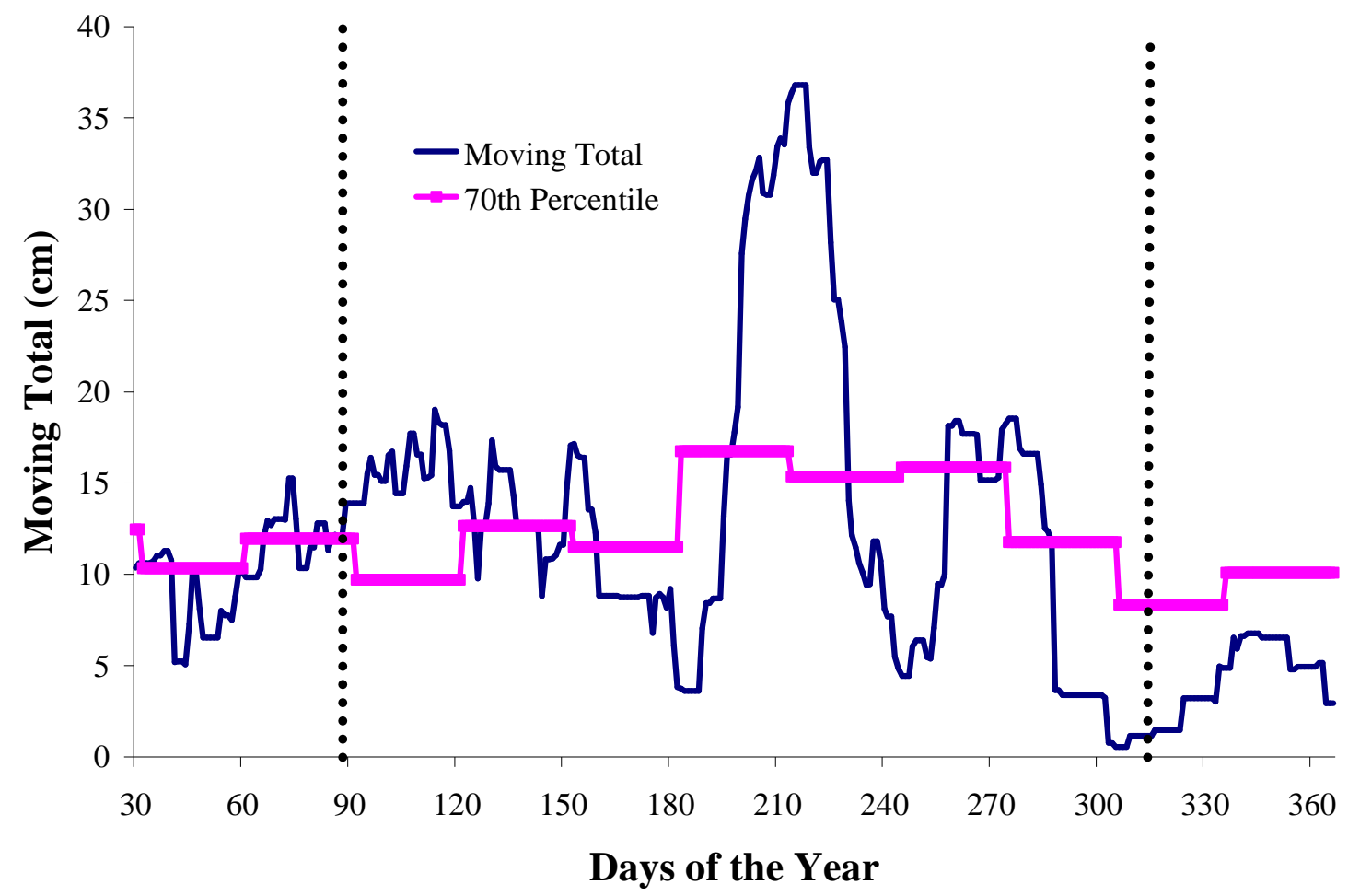

Figure D.75: Moving total graph for all plots at Bertie for year 1984 .

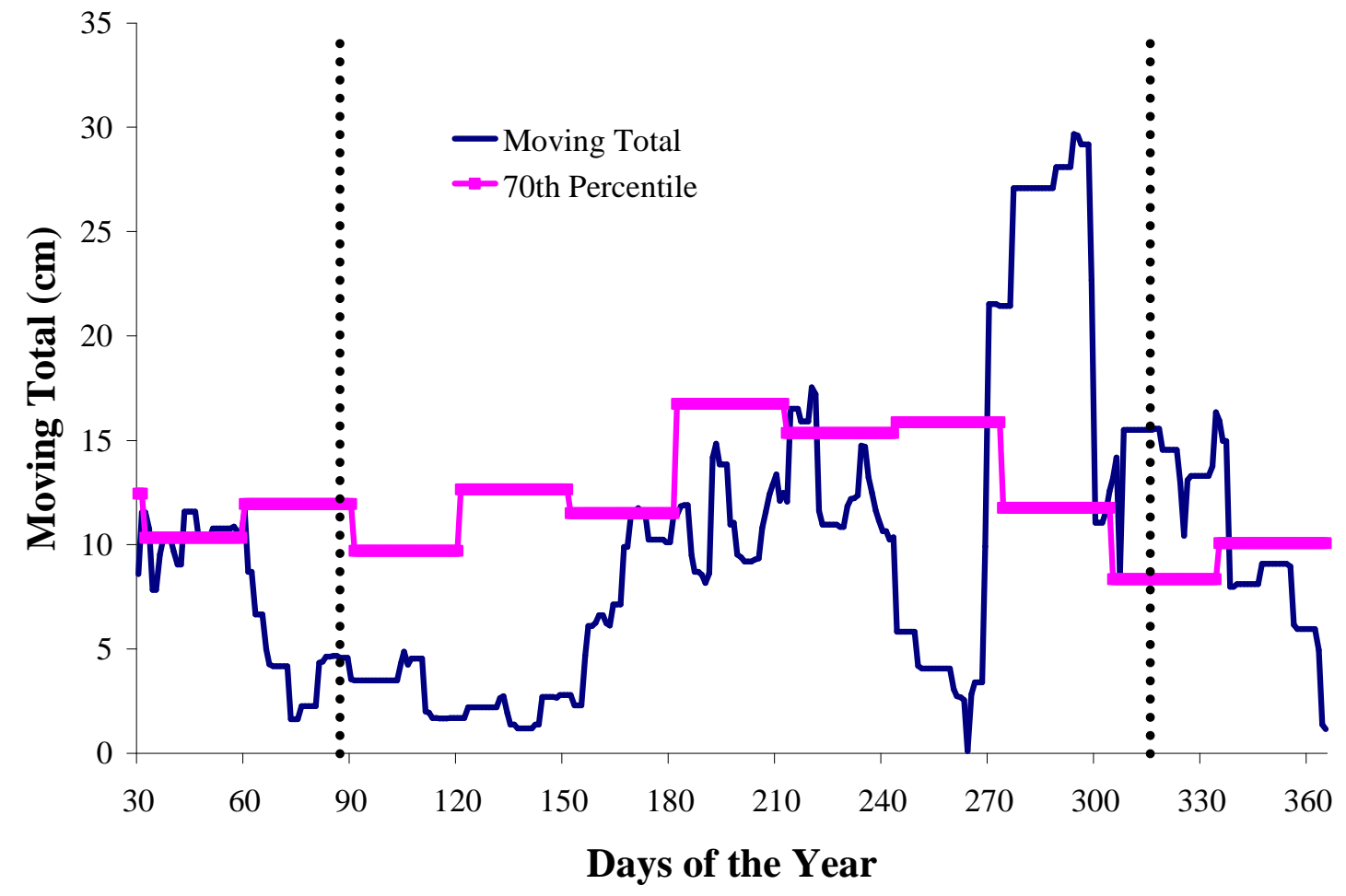

Figure D.76: Moving total graph for all plots at Bertie for year 1985. 


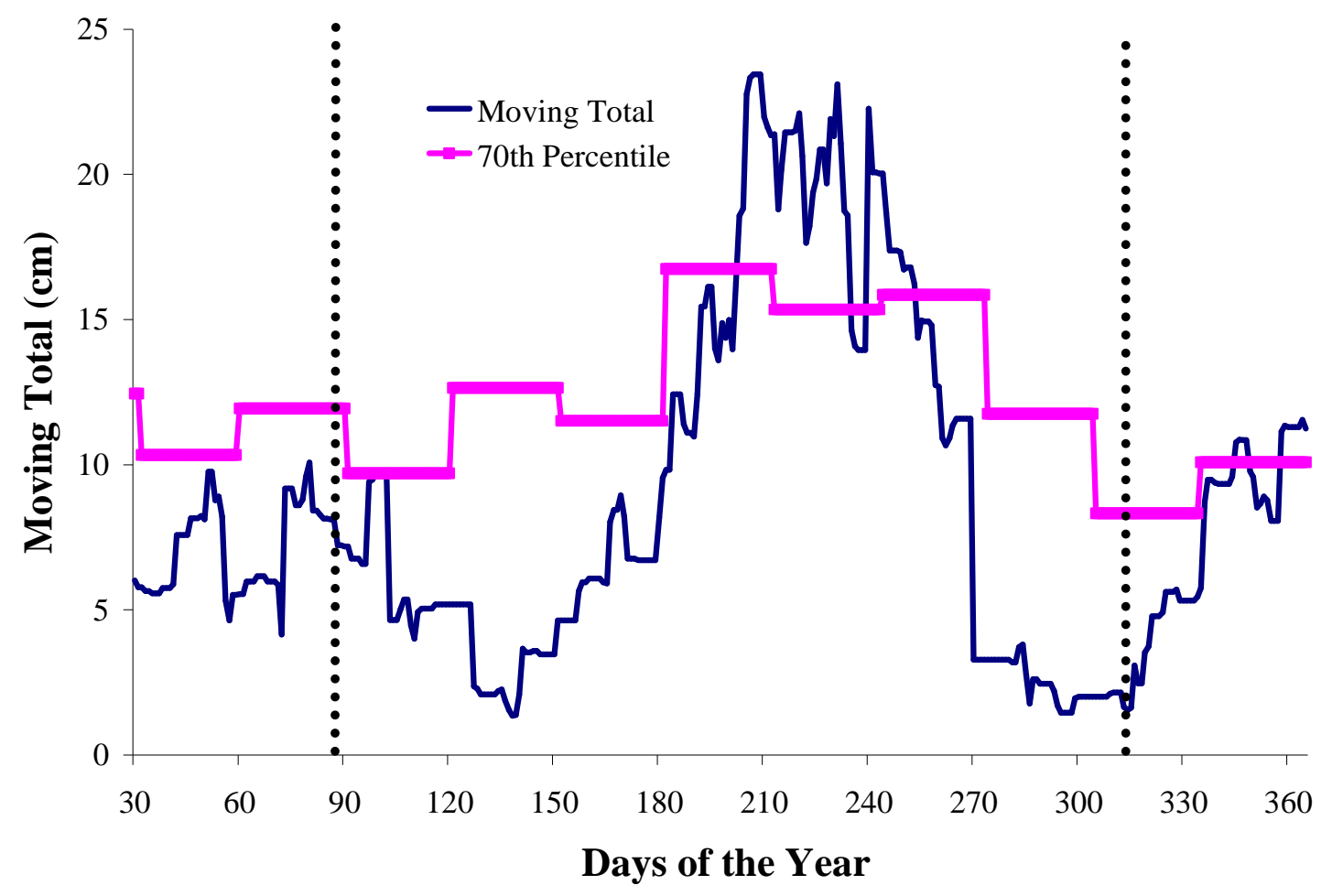

Figure D.77: Moving total graph for all plots at Bertie for year 1986.

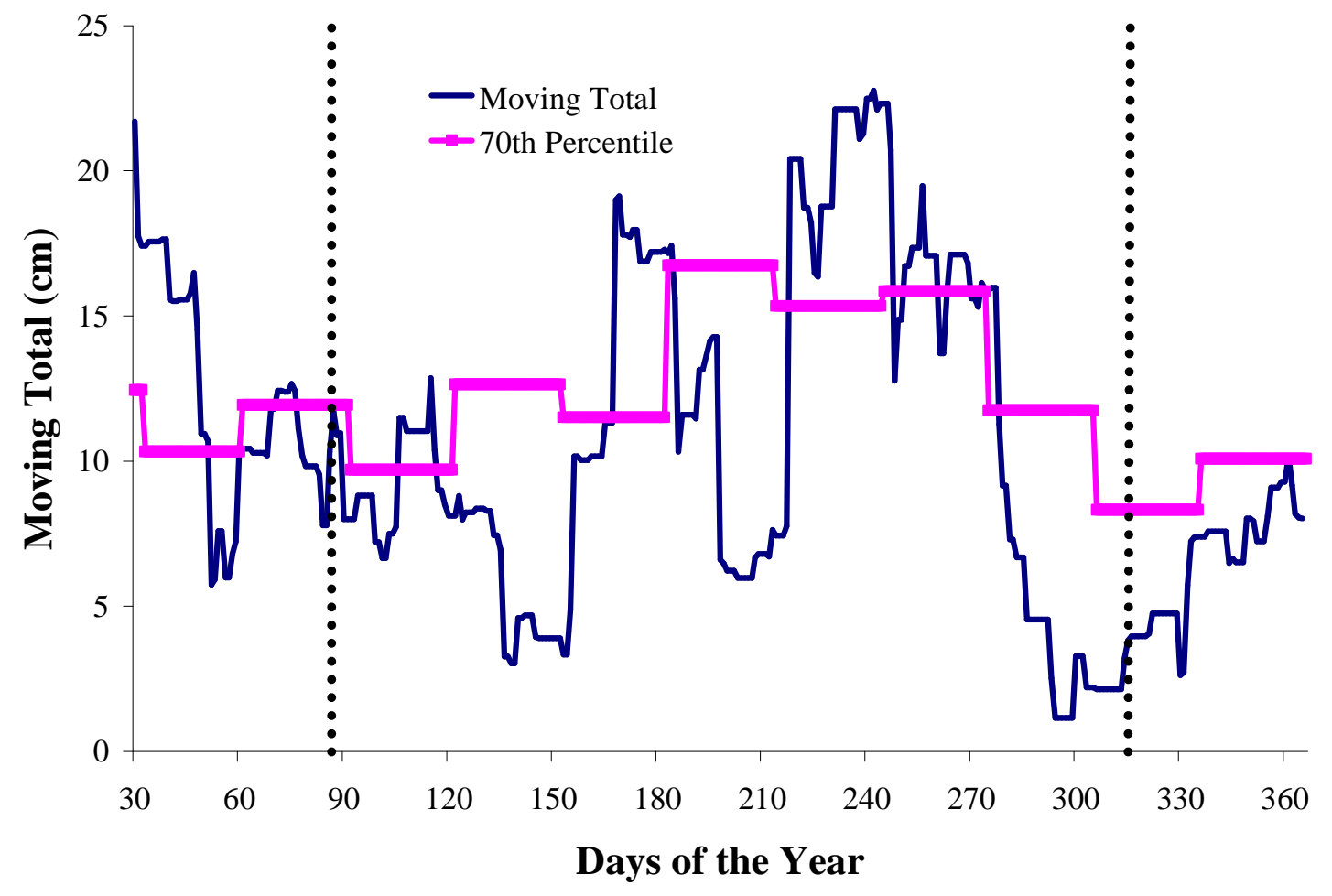

Figure D.78: Moving total graph for all plots at Bertie for year 1987. 


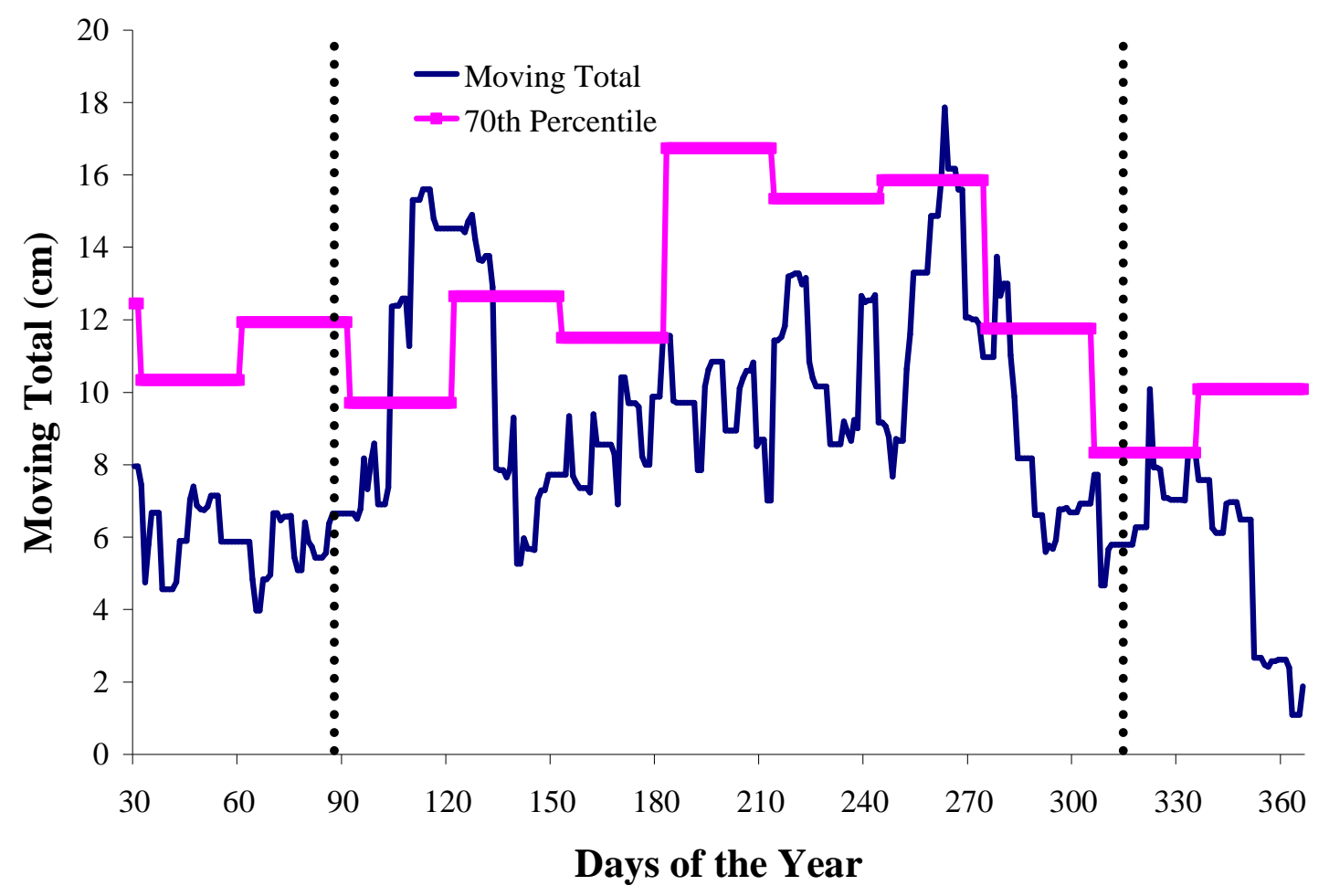

Figure D.79: Moving total graph for all plots at Bertie for year 1988.

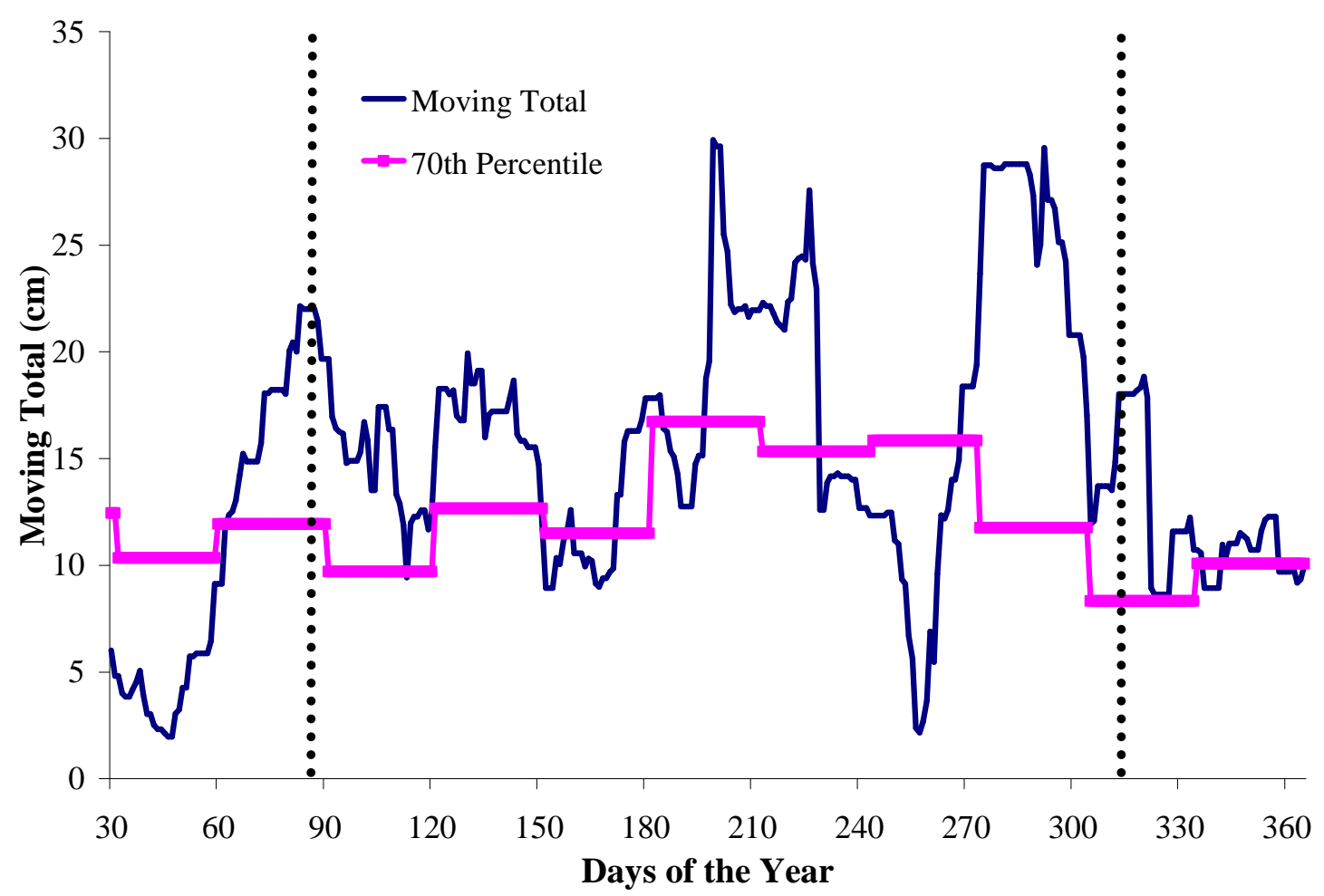

Figure D.80: Moving total graph for all plots at Bertie for year 1989. 


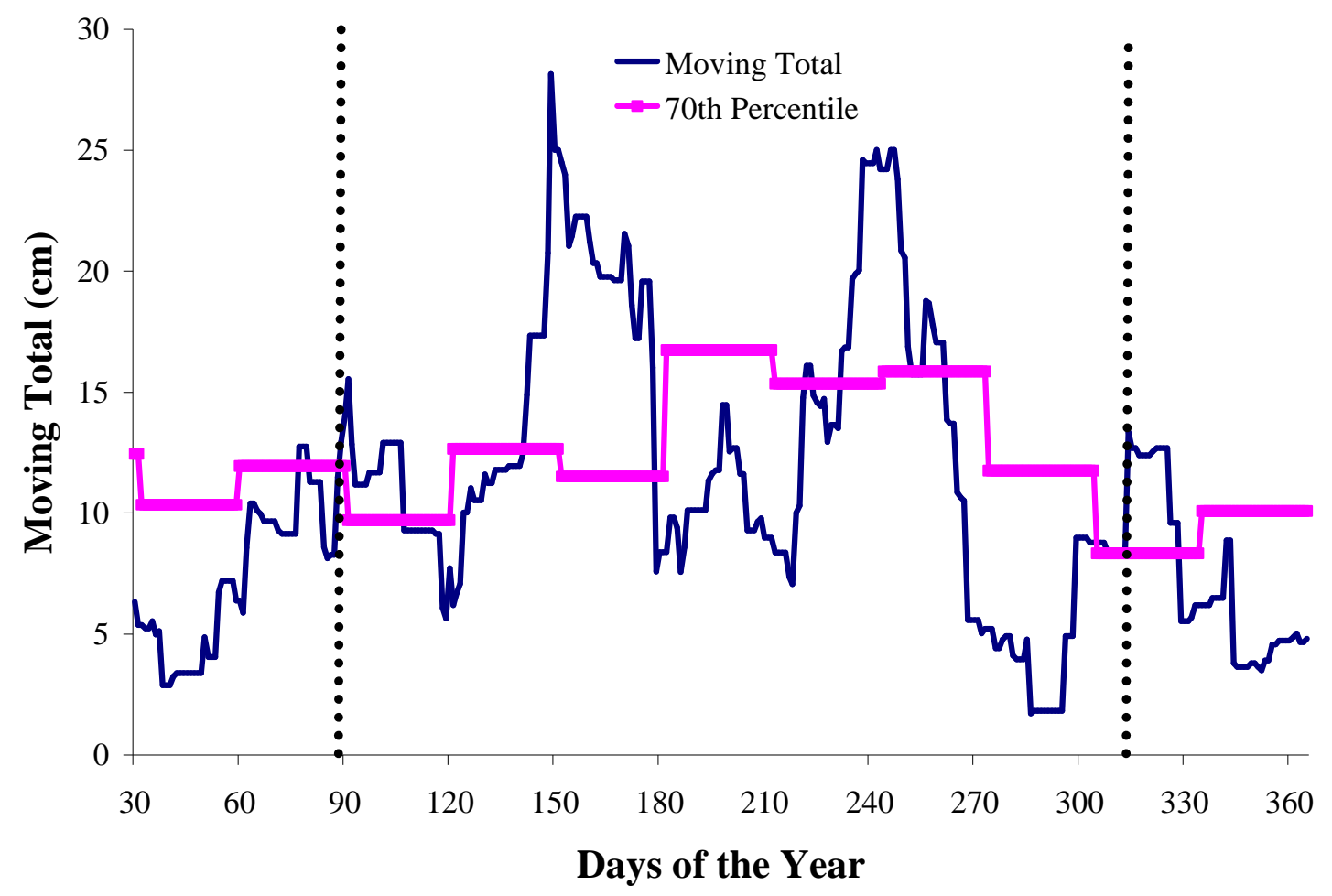

Figure D.81: Moving total graph for all plots at Bertie for year 1990.

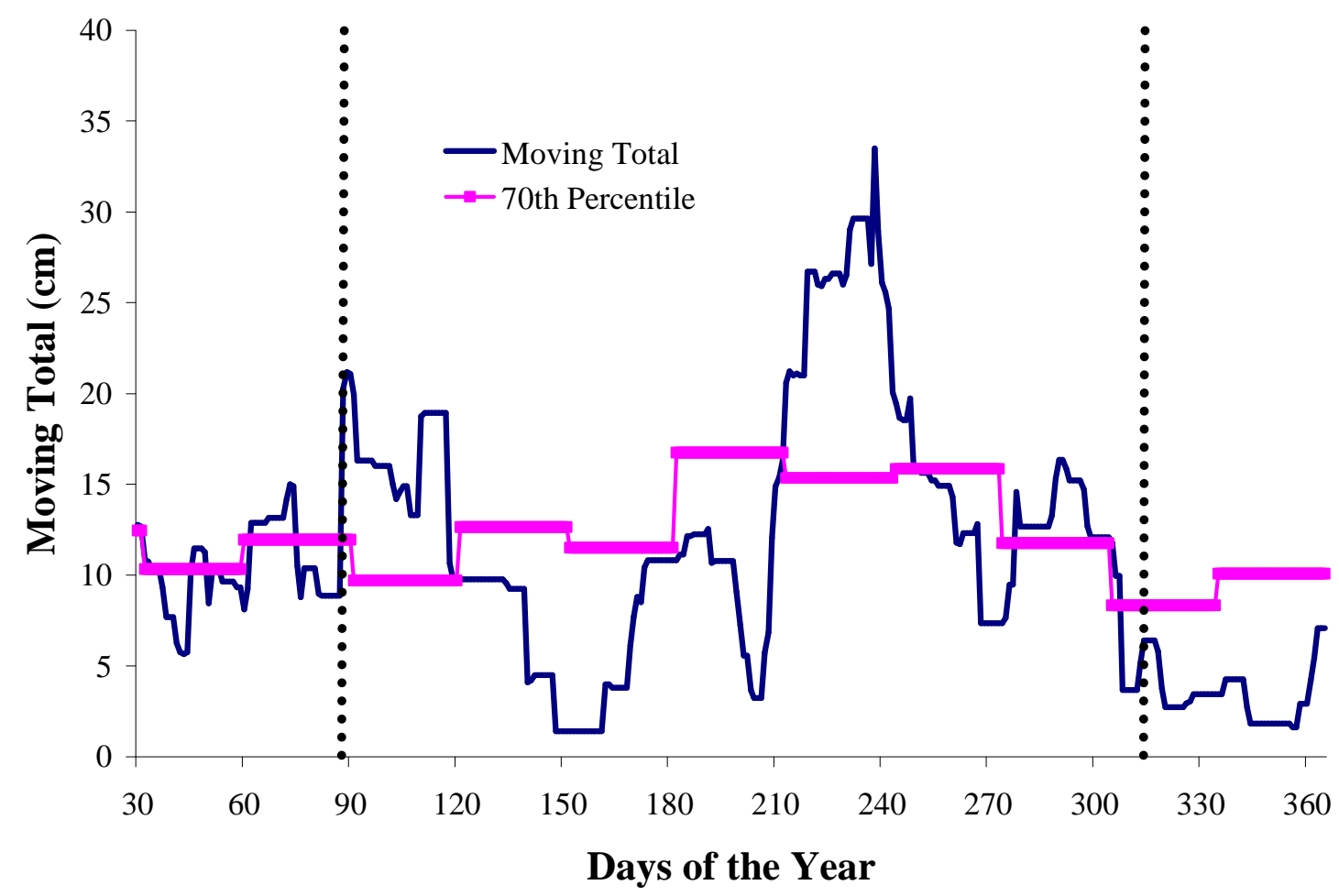

Figure D.82: Moving total graph for all plots at Bertie for year 1991. 


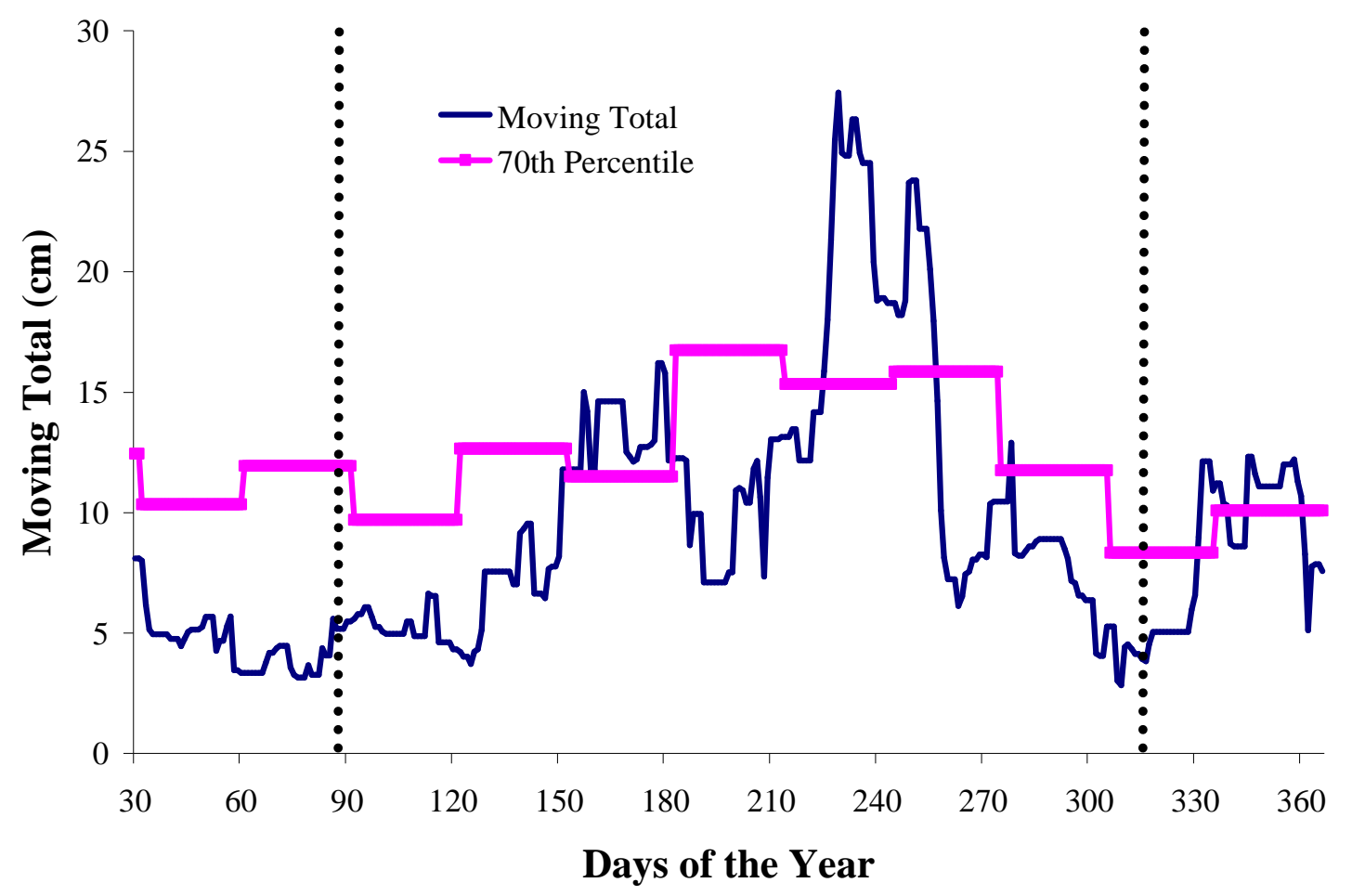

Figure D.83: Moving total graph for all plots at Bertie for year 1992.

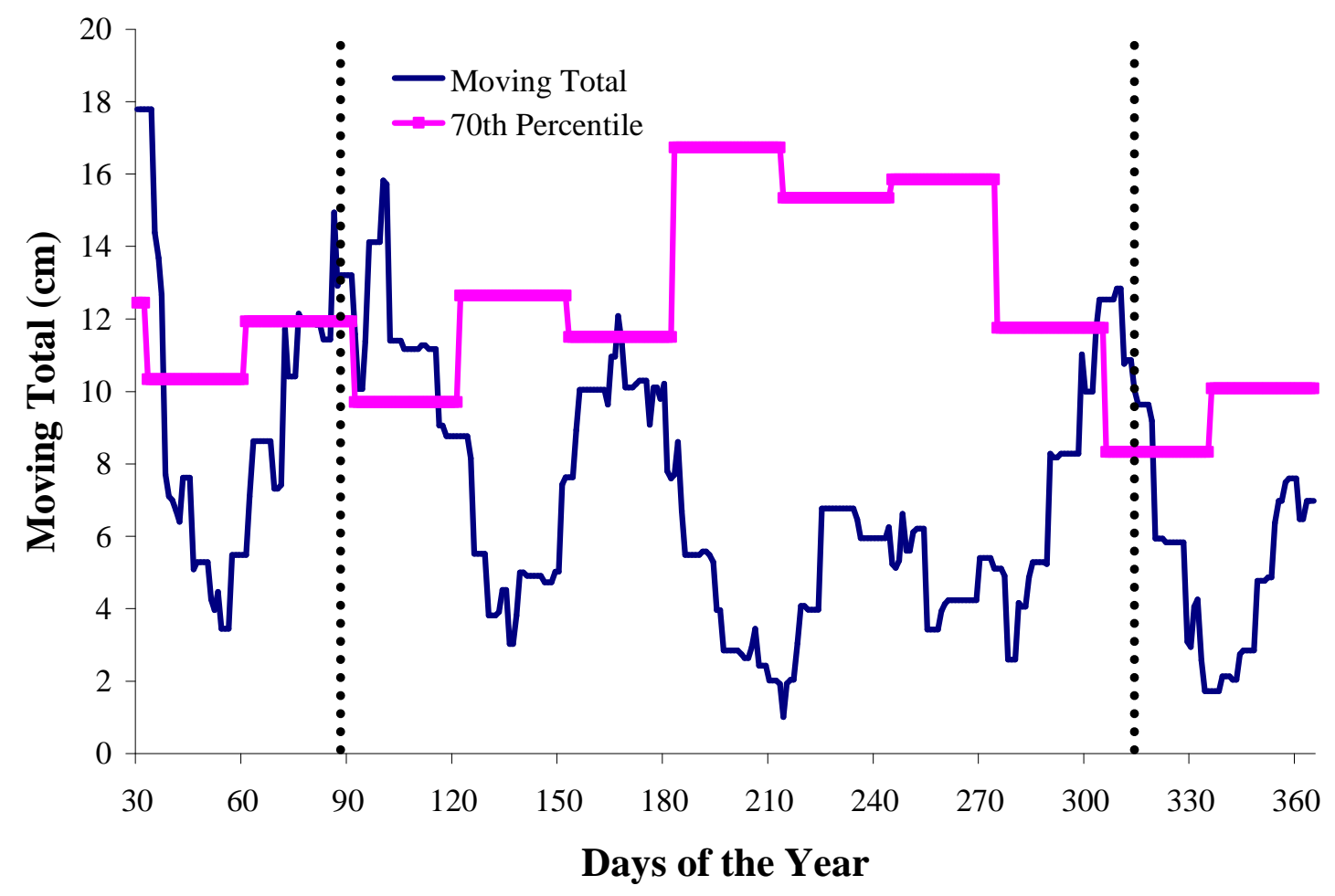

Figure D.84: Moving total graph for all plots at Bertie for year 1993. 


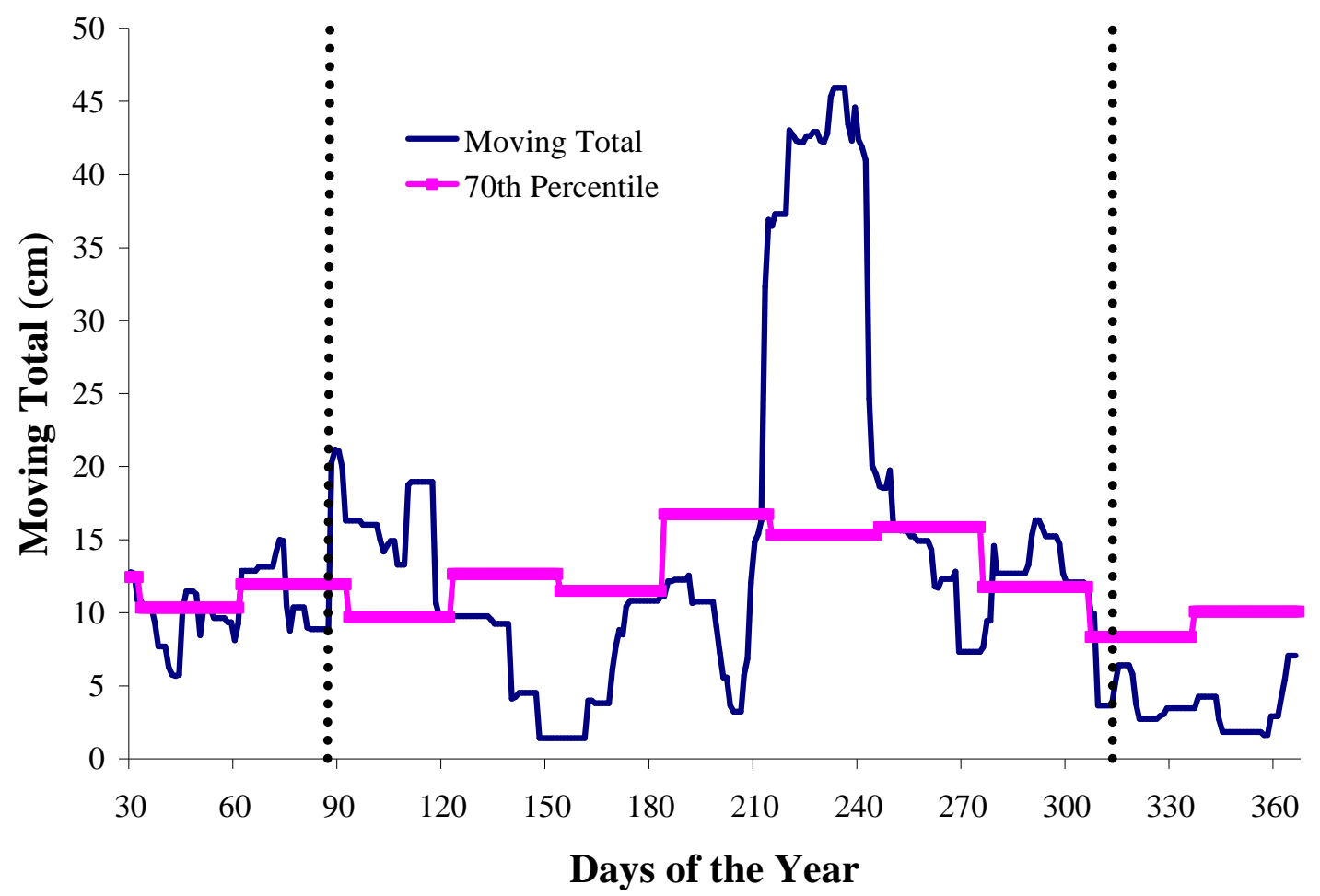

Figure D.85: Moving total graph for all plots at Bertie for year 1994.

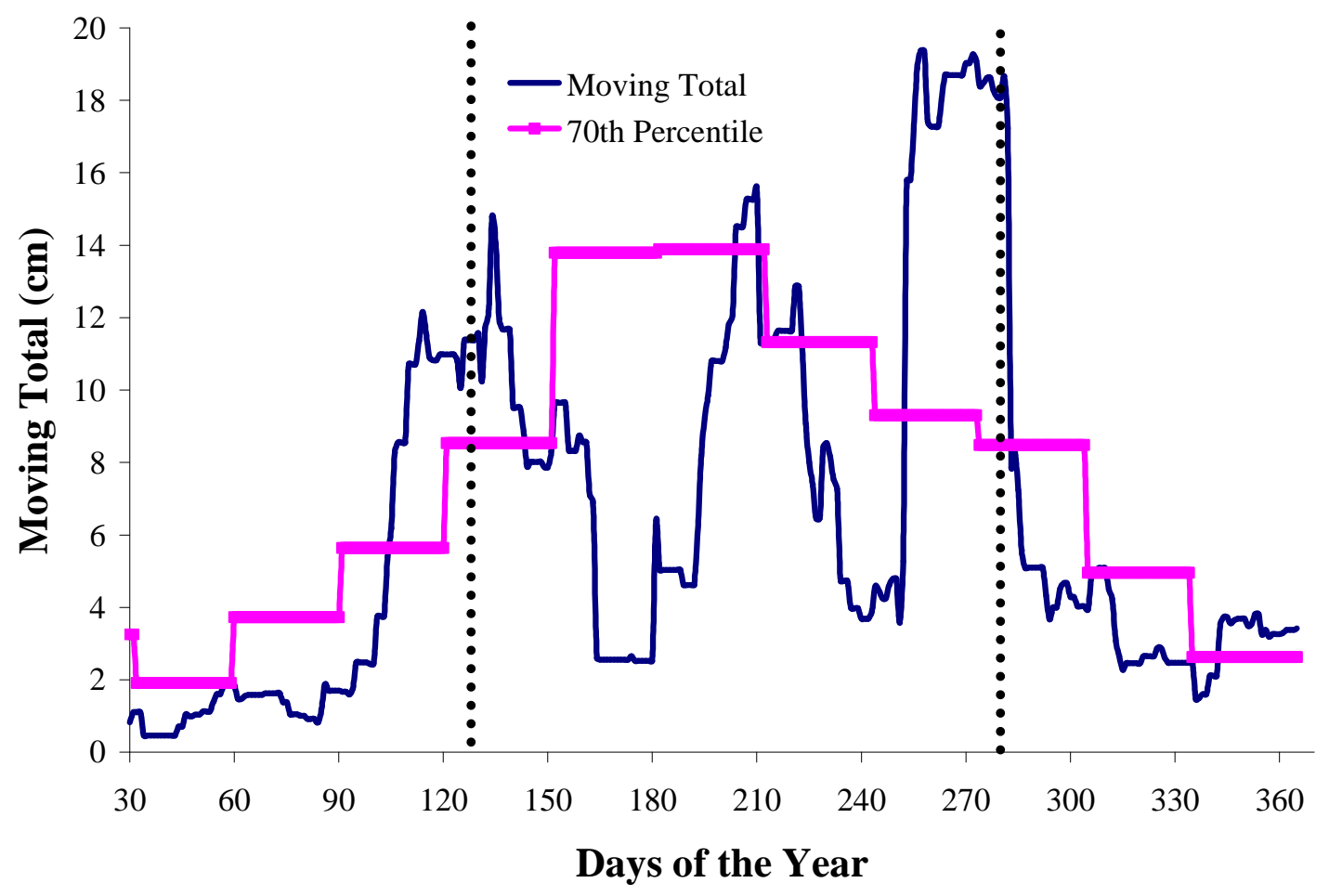

Figure D.86: Moving total graph for plots S1, S2, S3, and S6 at Marcell for year 1961. 


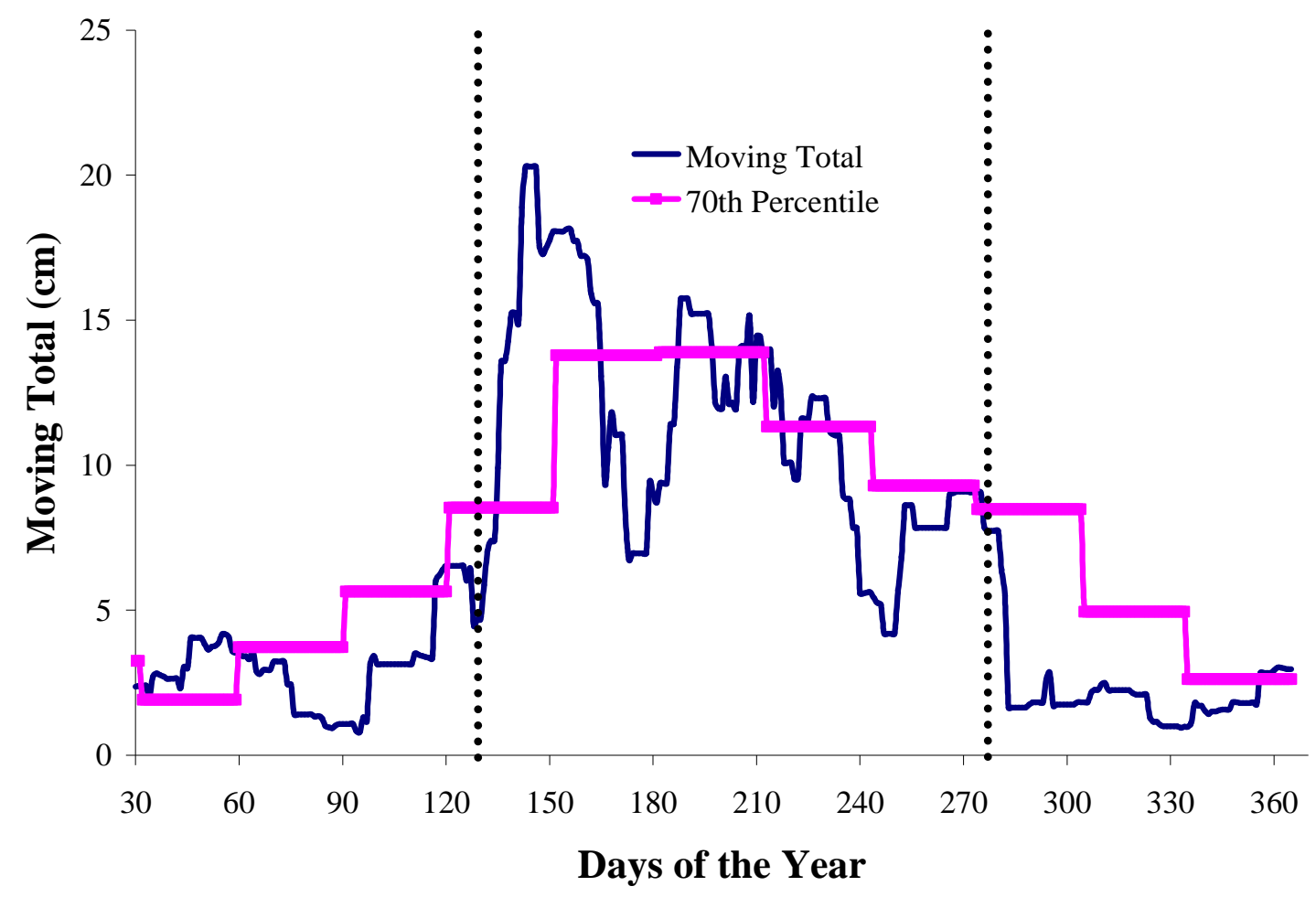

Figure D.87: Moving total graph for plots S1, S2, S3, and S6 at Marcell for year 1962.

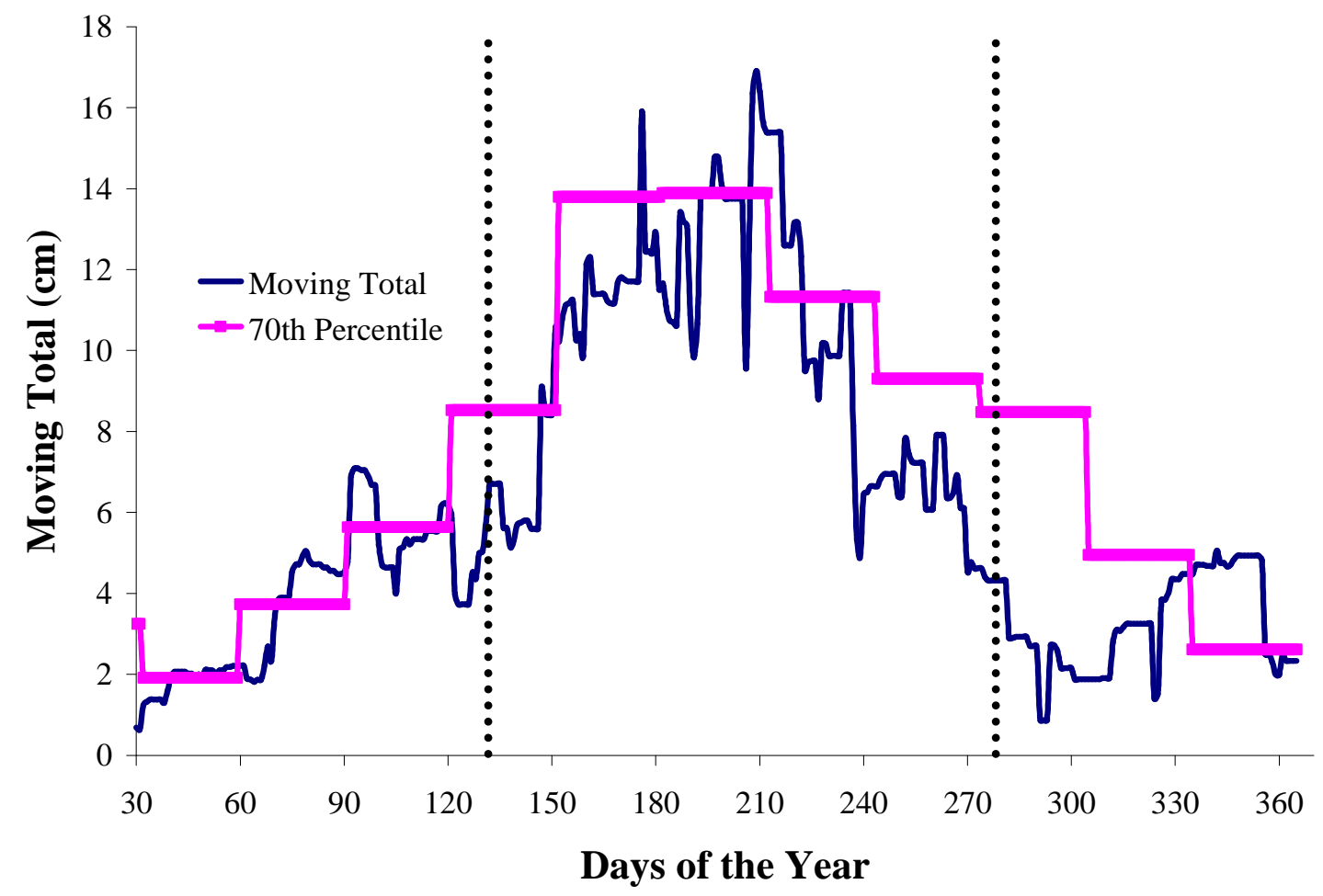

Figure D.88: Moving total graph for plots S1, S2, S3, and S6 at Marcell for year 1963. 


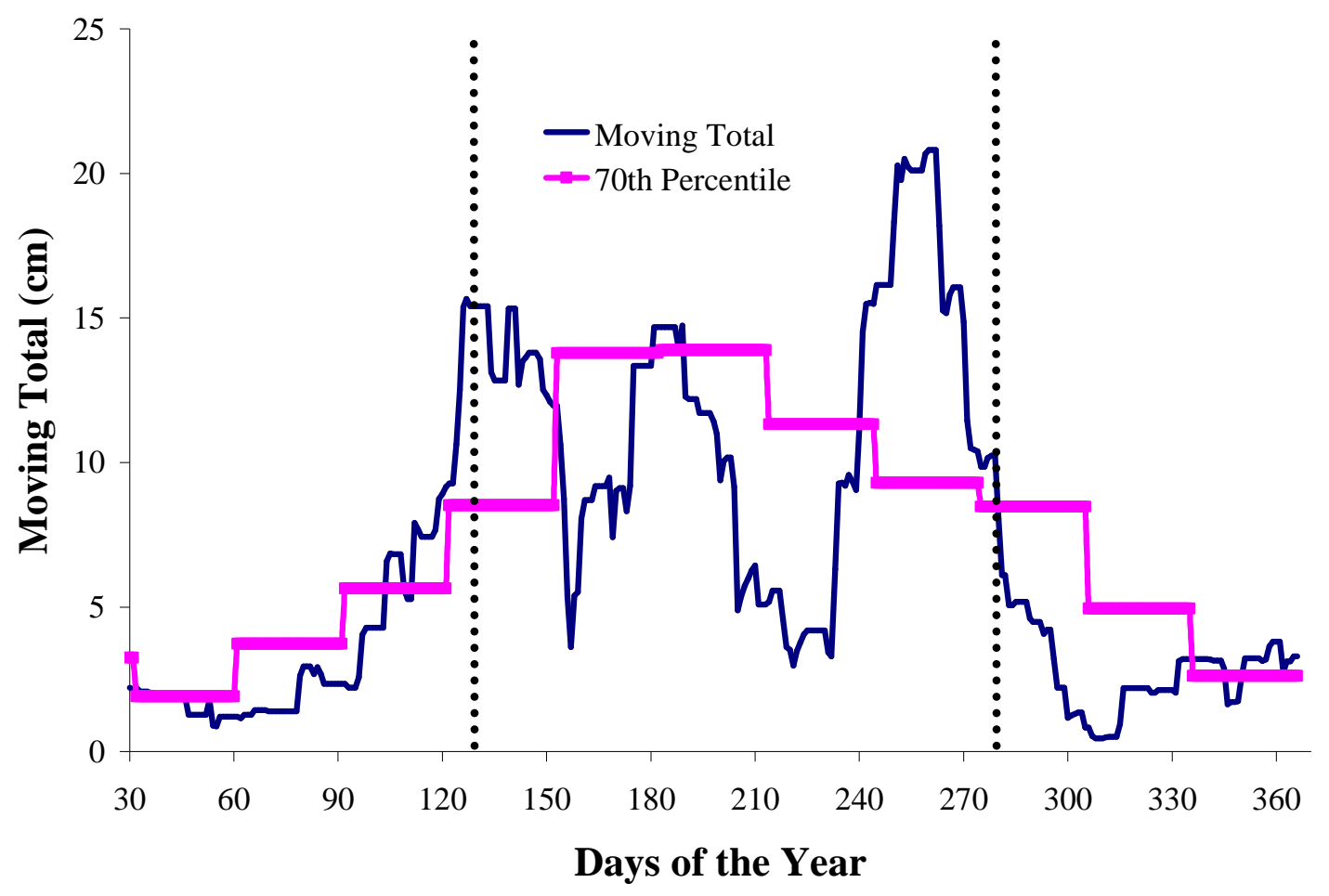

Figure D.89: Moving total graph for plots S1, S2, S3, and S6 at Marcell for year 1964.

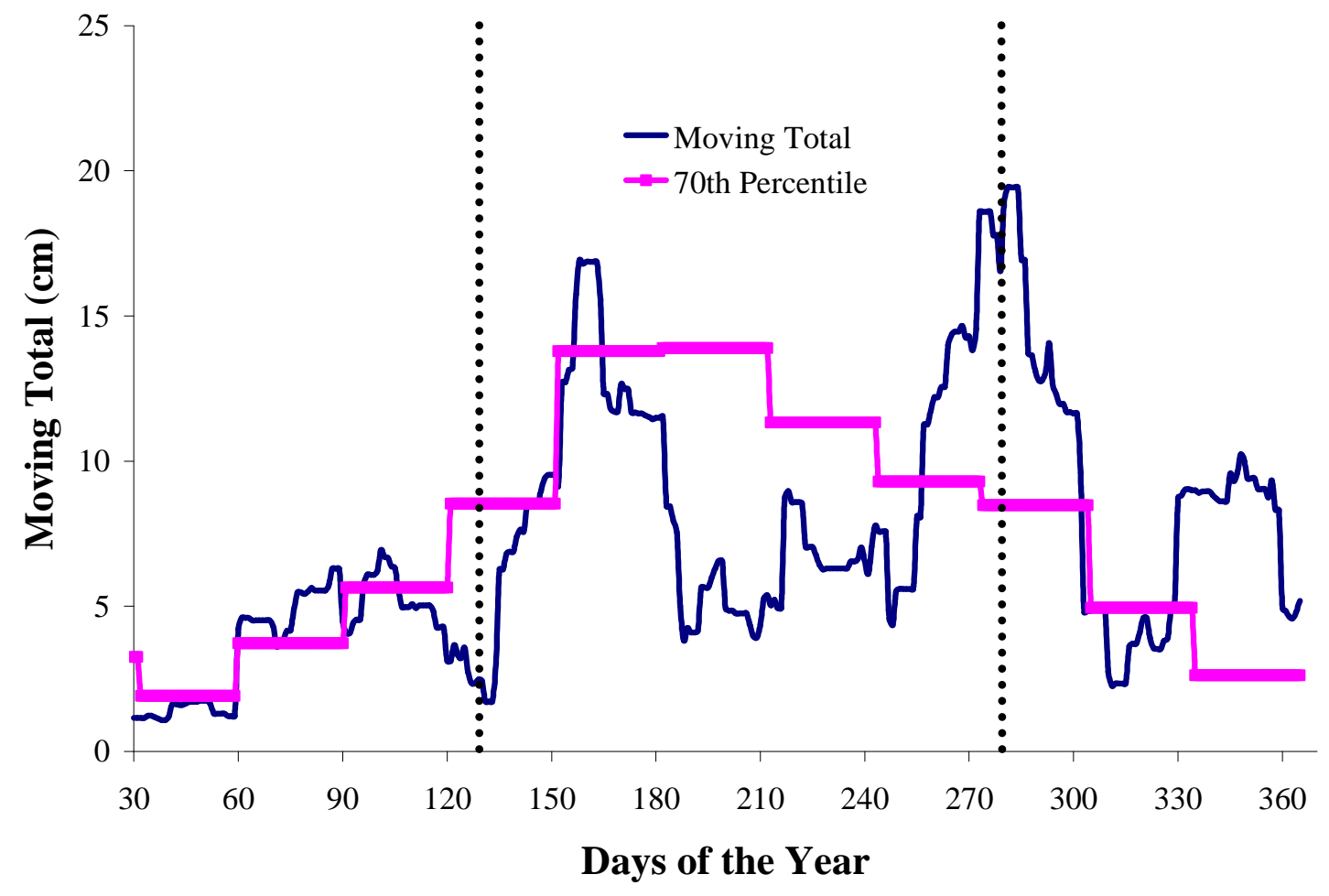

Figure D.90: Moving total graph for plots S1, S2, S3, and S6 at Marcell for year 1965. 


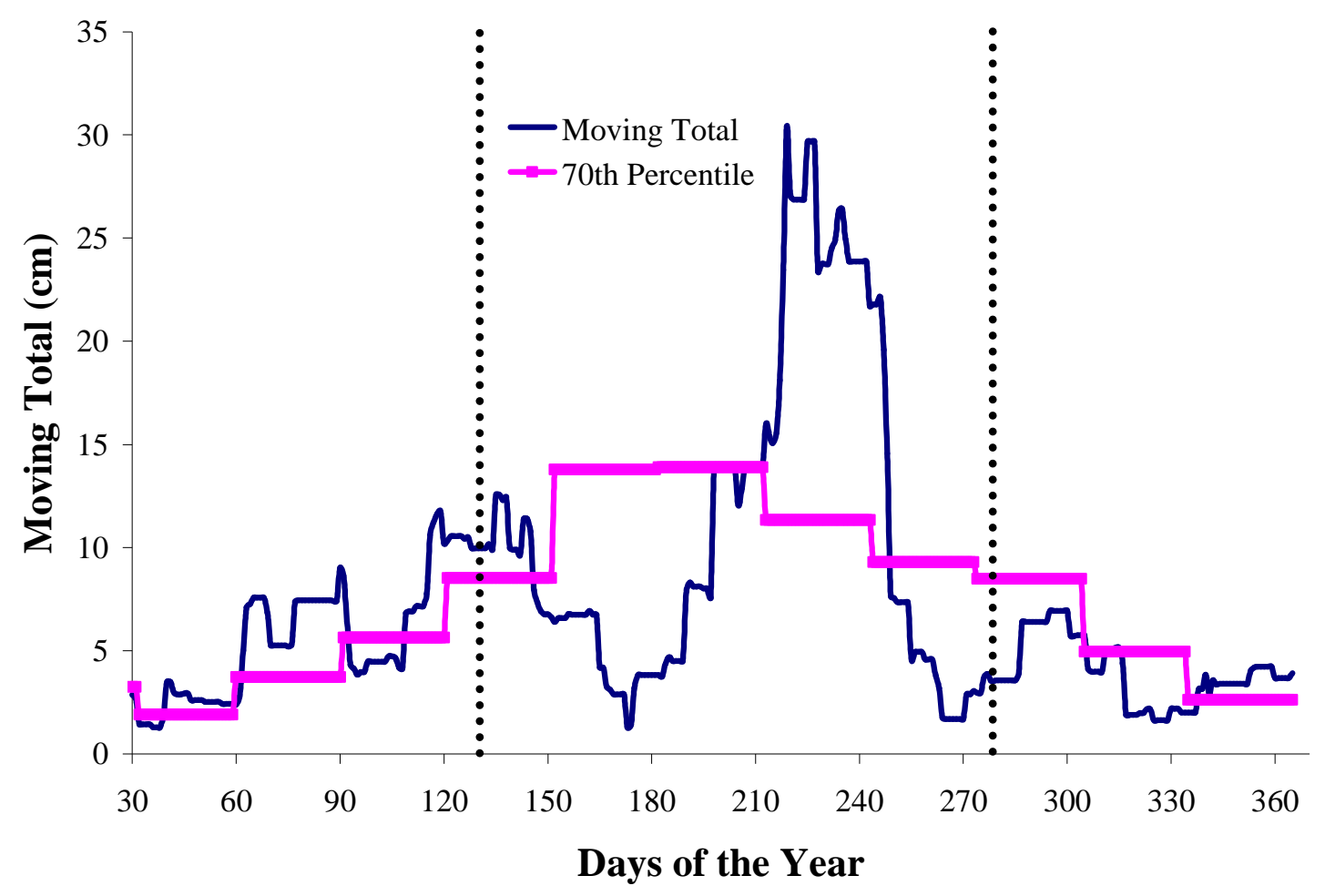

Figure D.91: Moving total graph for plots S1, S2, S3, and S6 at Marcell for year 1966.

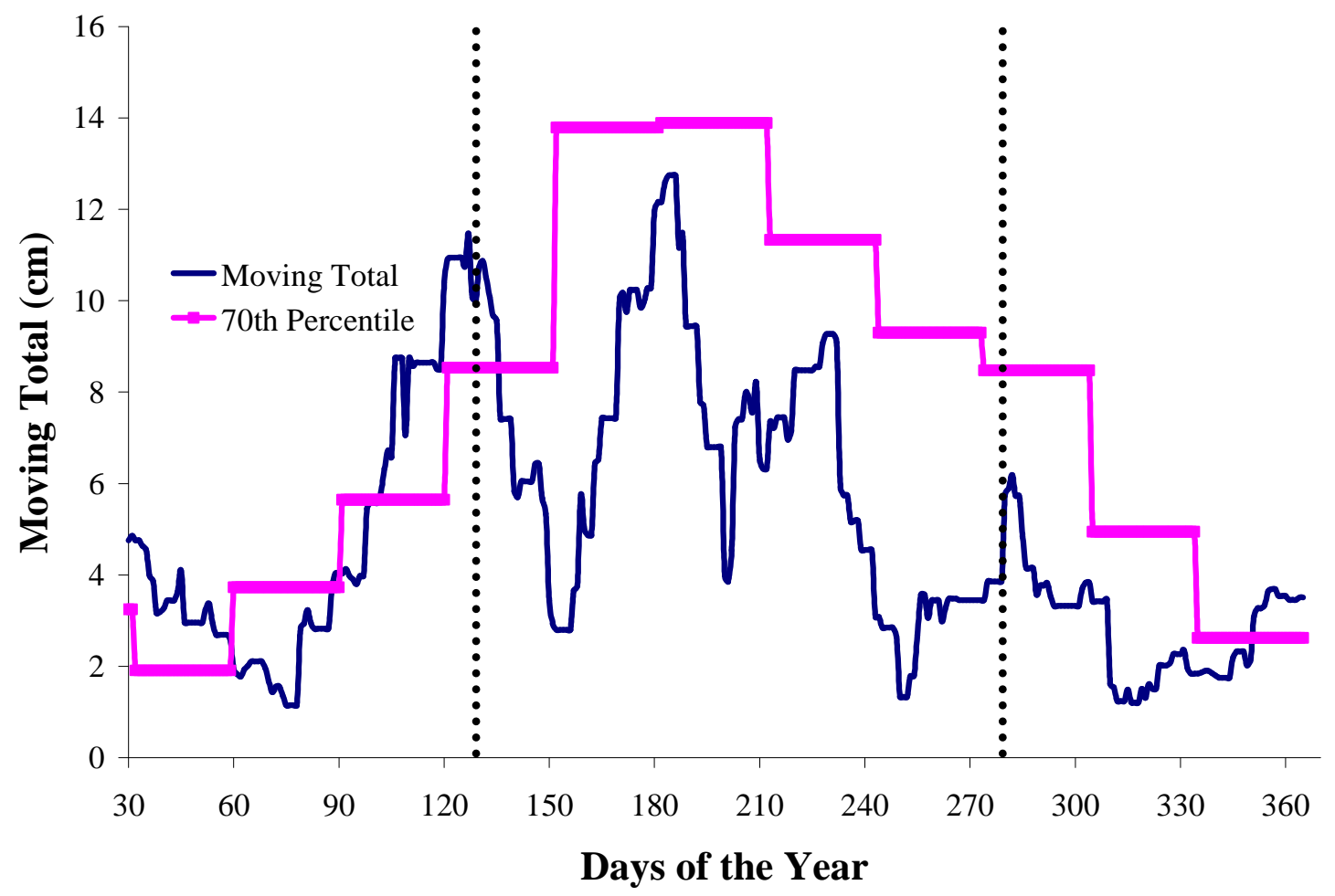

Figure D.92: Moving total graph for plots S1, S2, S3, and S6 at Marcell for year 1967. 


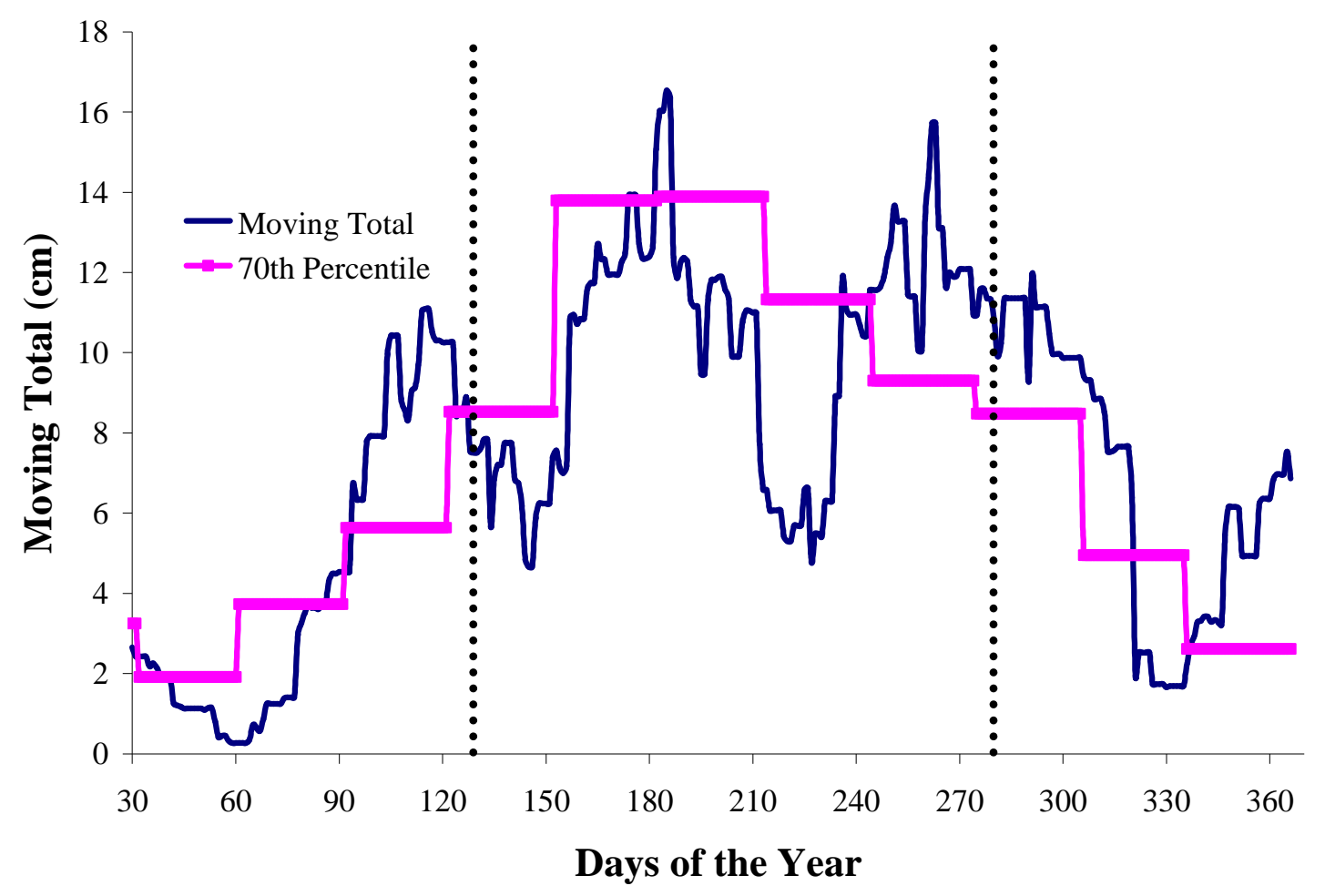

Figure D.93: Moving total graph for plots S1, S2, S3, and S6 at Marcell for year 1968.

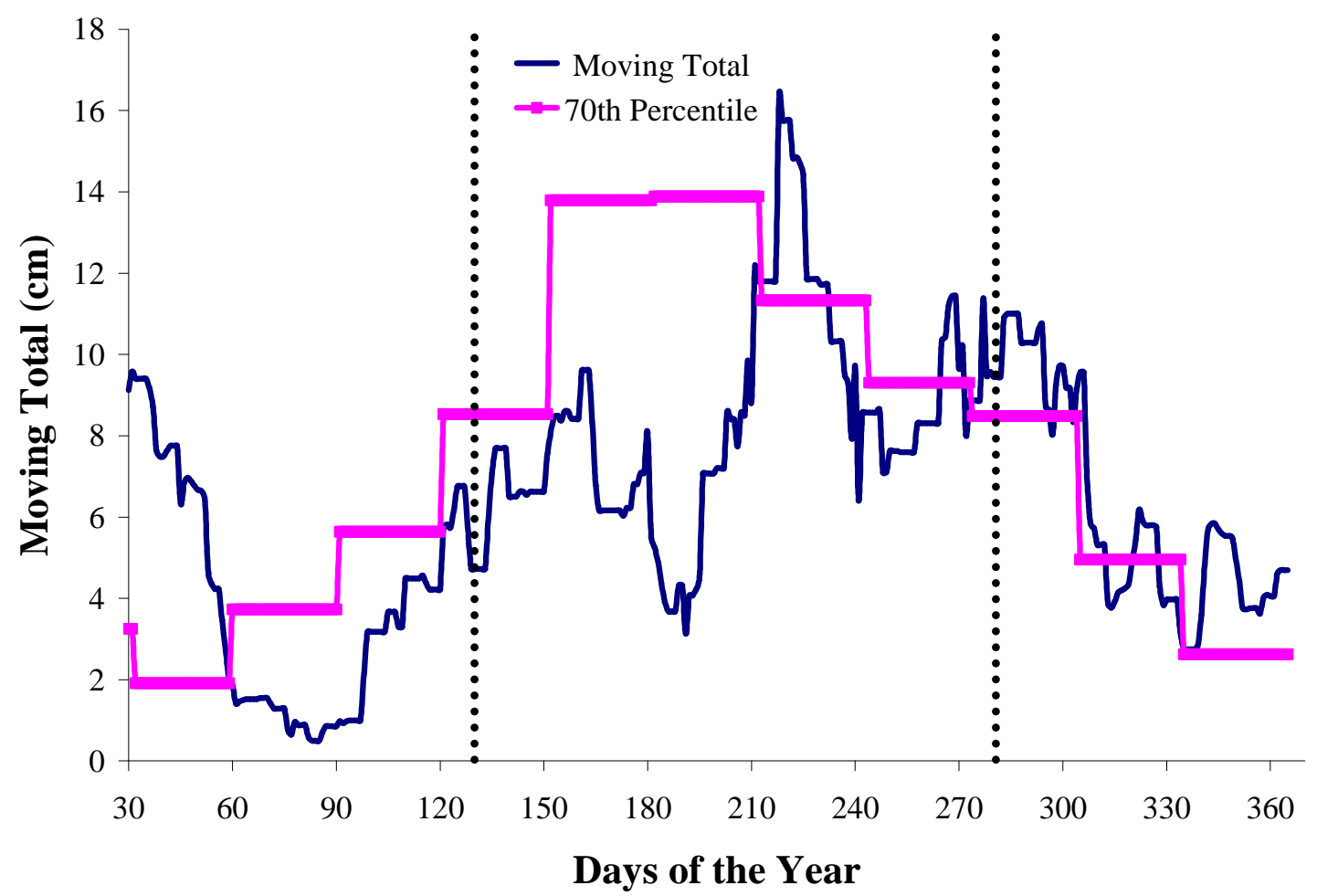

Figure D.94: Moving total graph for plots S1, S2, S3, and S6 at Marcell for year 1969. 


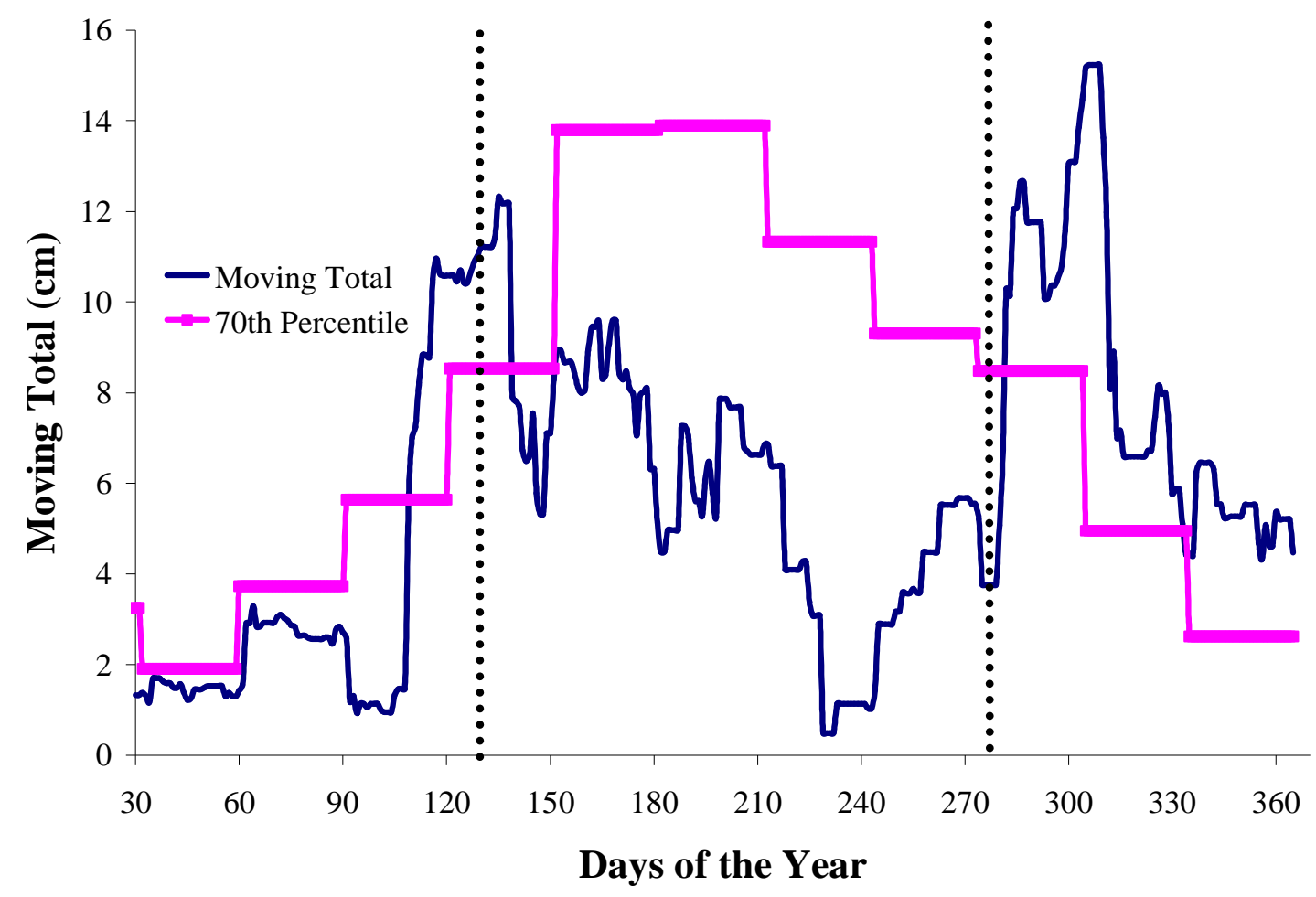

Figure D.95: Moving total graph for plots S1, S2, S3, and S6 at Marcell for year 1970.

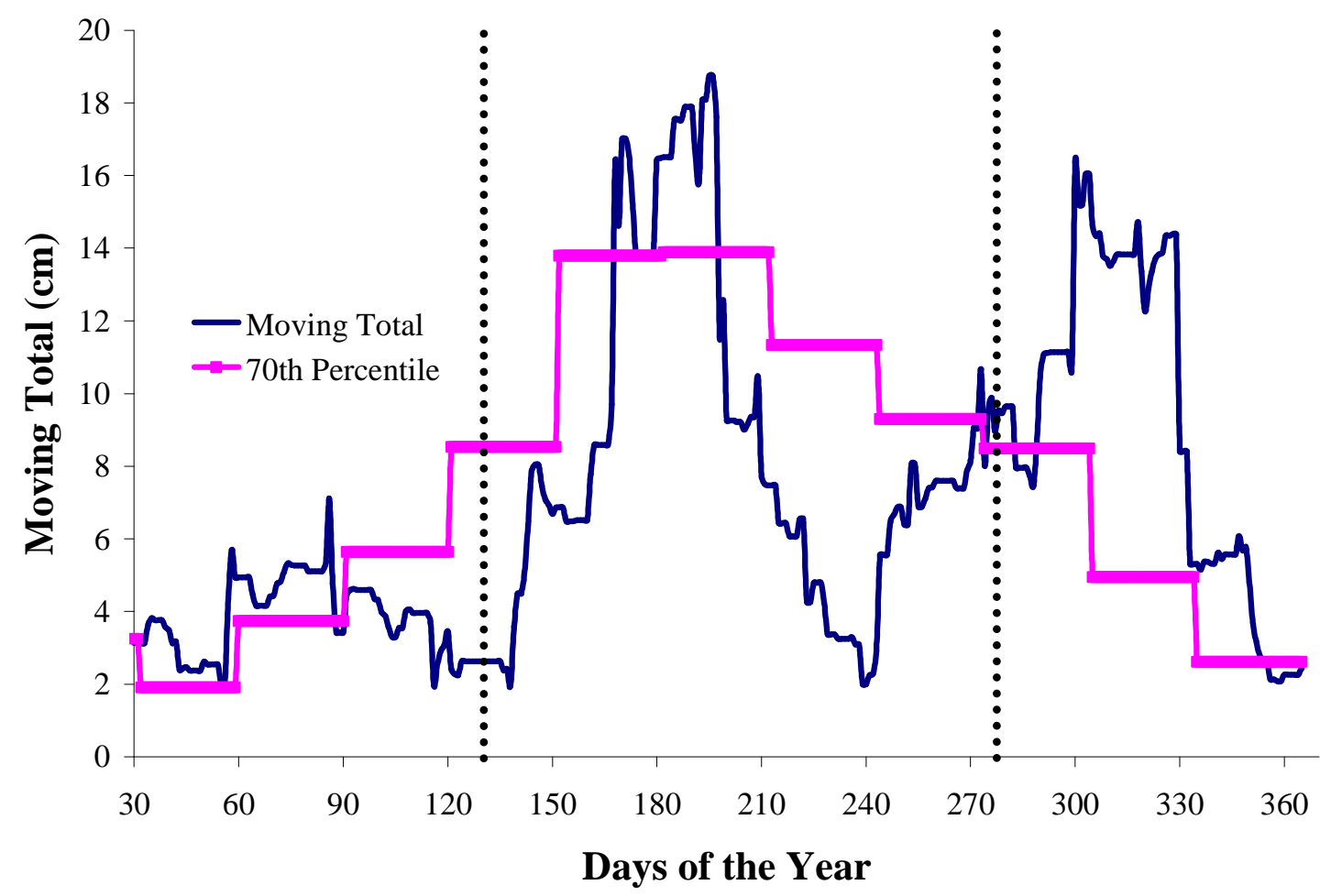

Figure D.96: Moving total graph for plots S1, S2, S3, and S6 at Marcell for year 1971. 


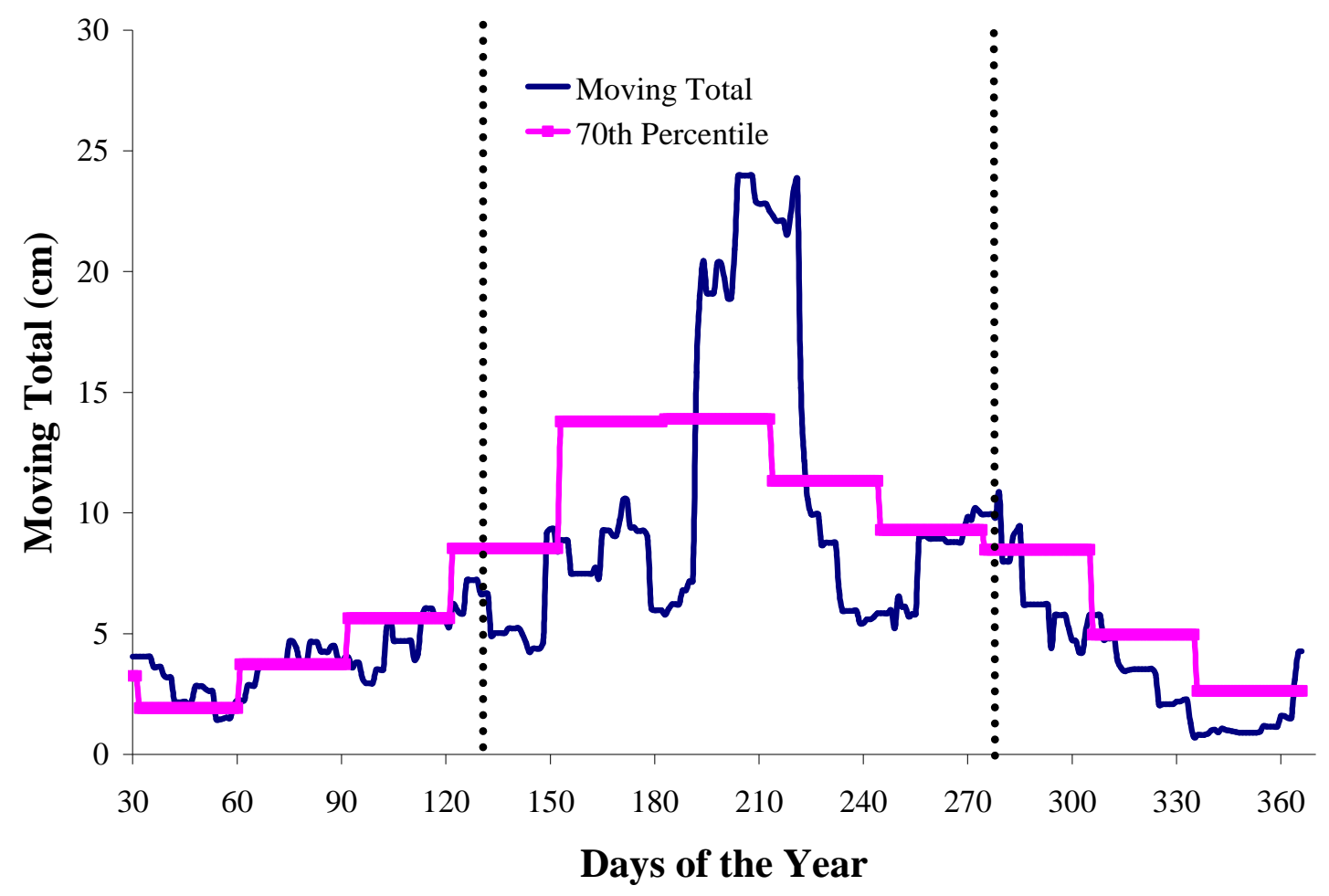

Figure D.97: Moving total graph for plots S1, S2, S3, and S6 at Marcell for year 1972.

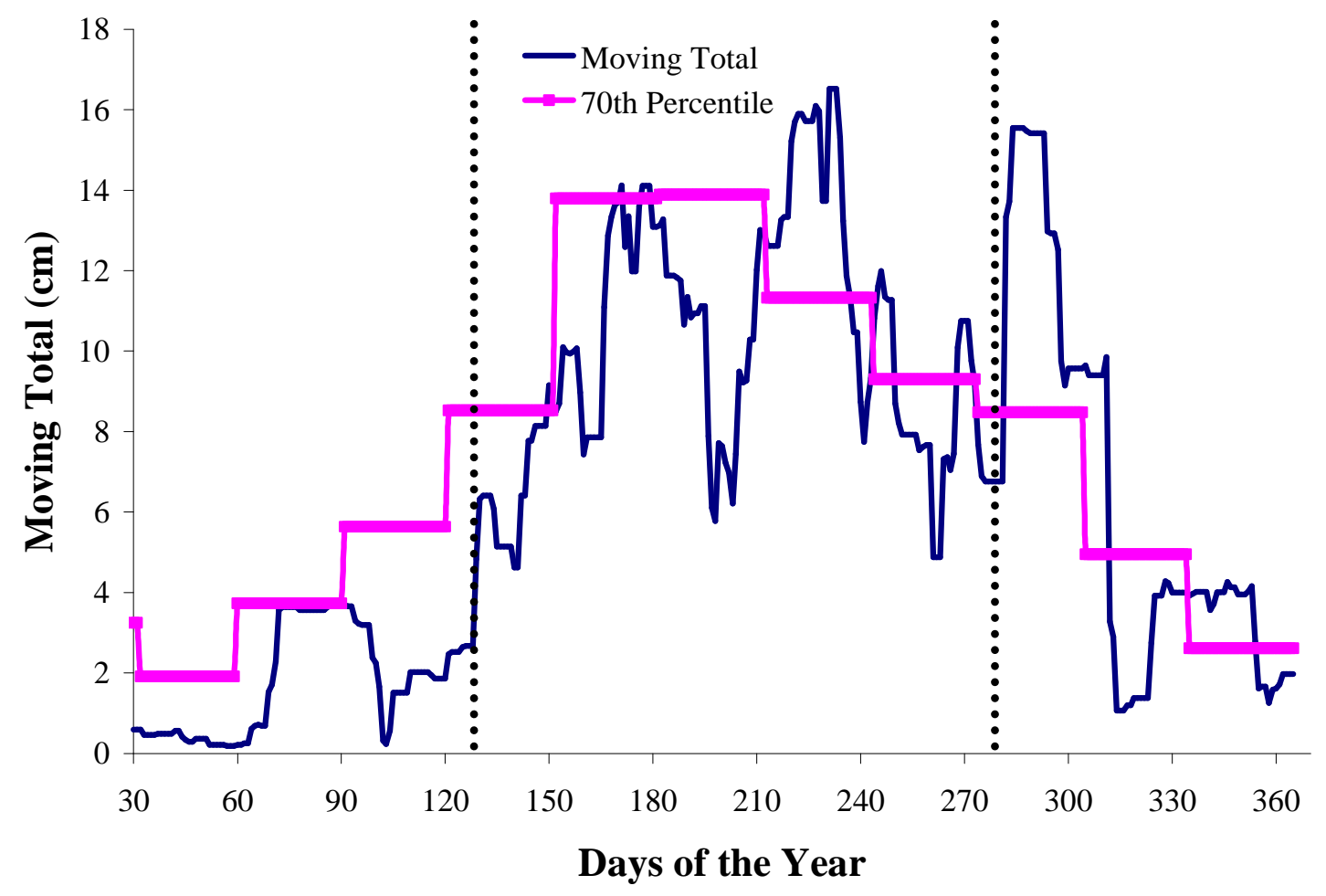

Figure D.98: Moving total graph for plots S1, S2, S3, and S6 at Marcell for year 1973. 


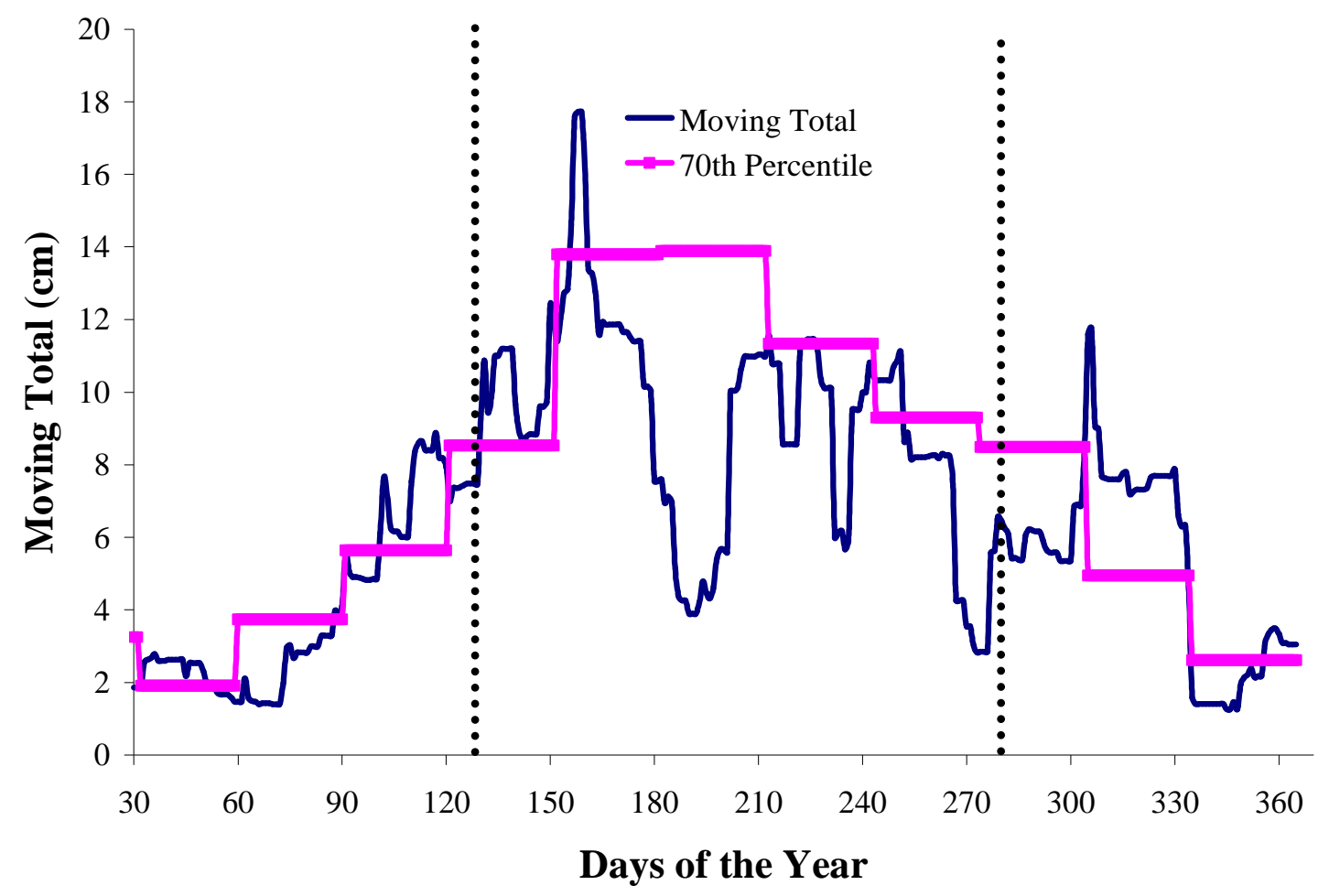

Figure D.99: Moving total graph for plots S1, S2, S3, and S6 at Marcell for year 1974.

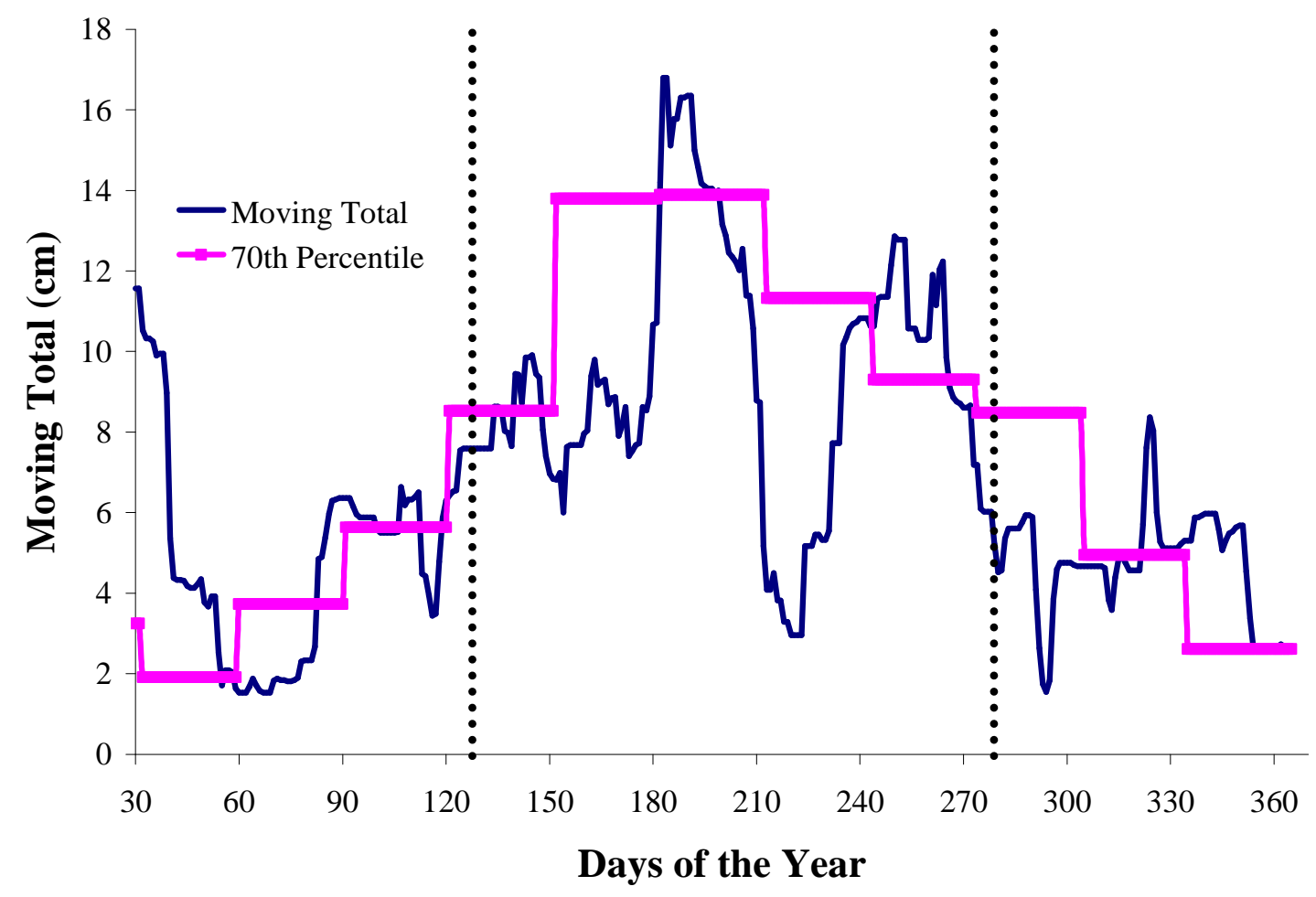

Figure D.100: Moving total graph for plots S1, S2, S3, and S6 at Marcell for year 1975. 


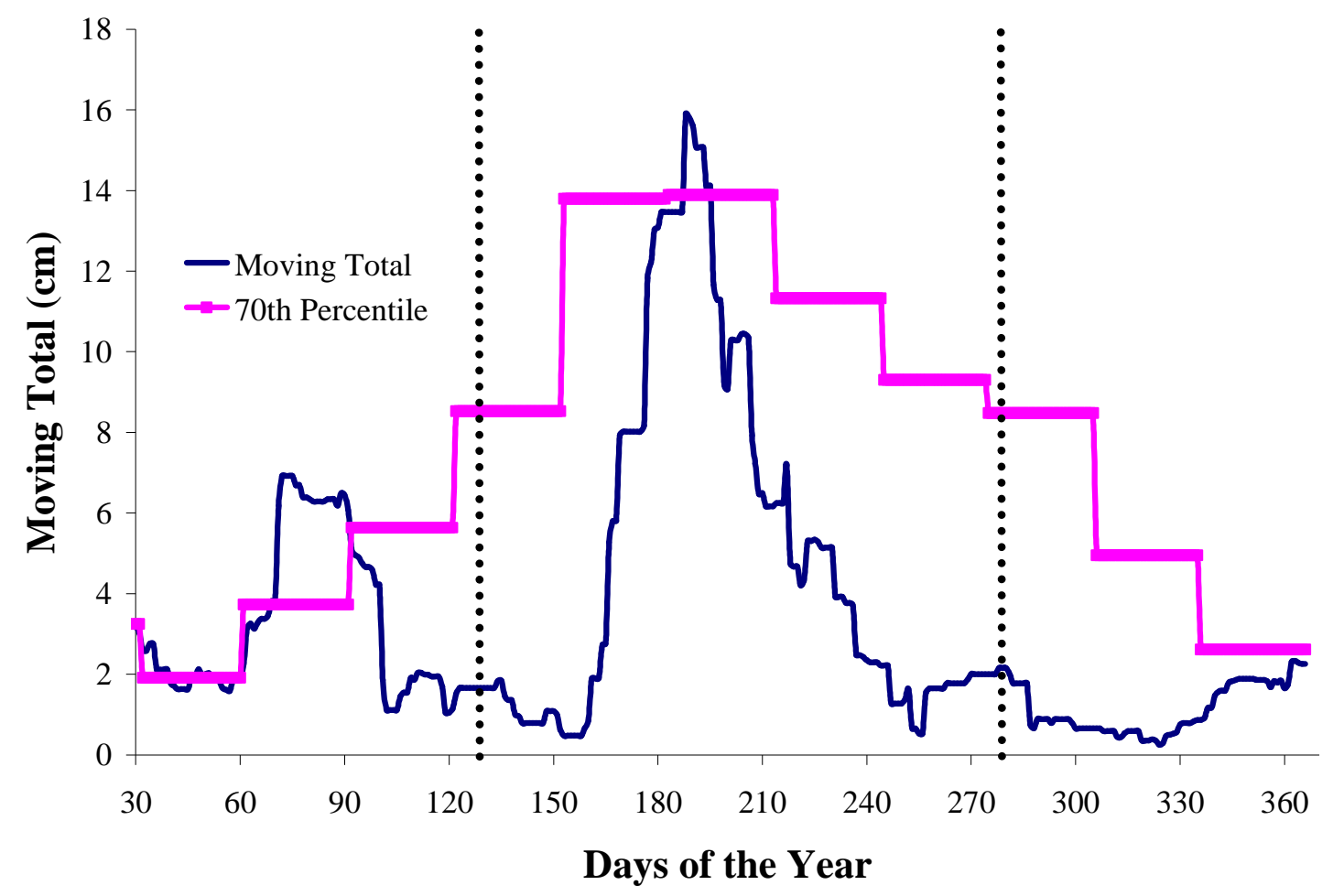

Figure D.101: Moving total graph for plots S1, S2, S3, and S6 at Marcell for year 1976.

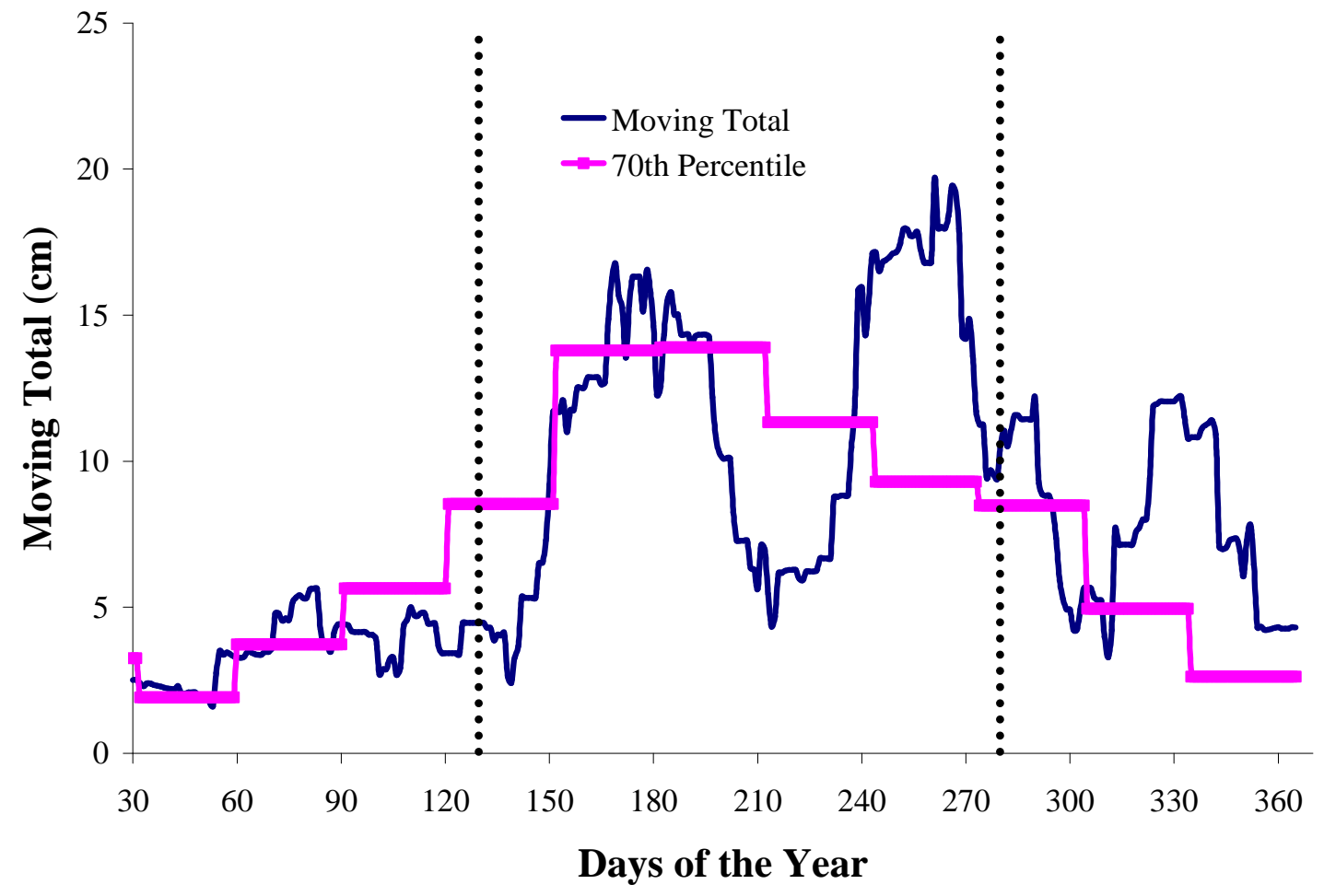

Figure D.102: Moving total graph for plots S1, S2, S3, and S6 at Marcell for year 1977. 


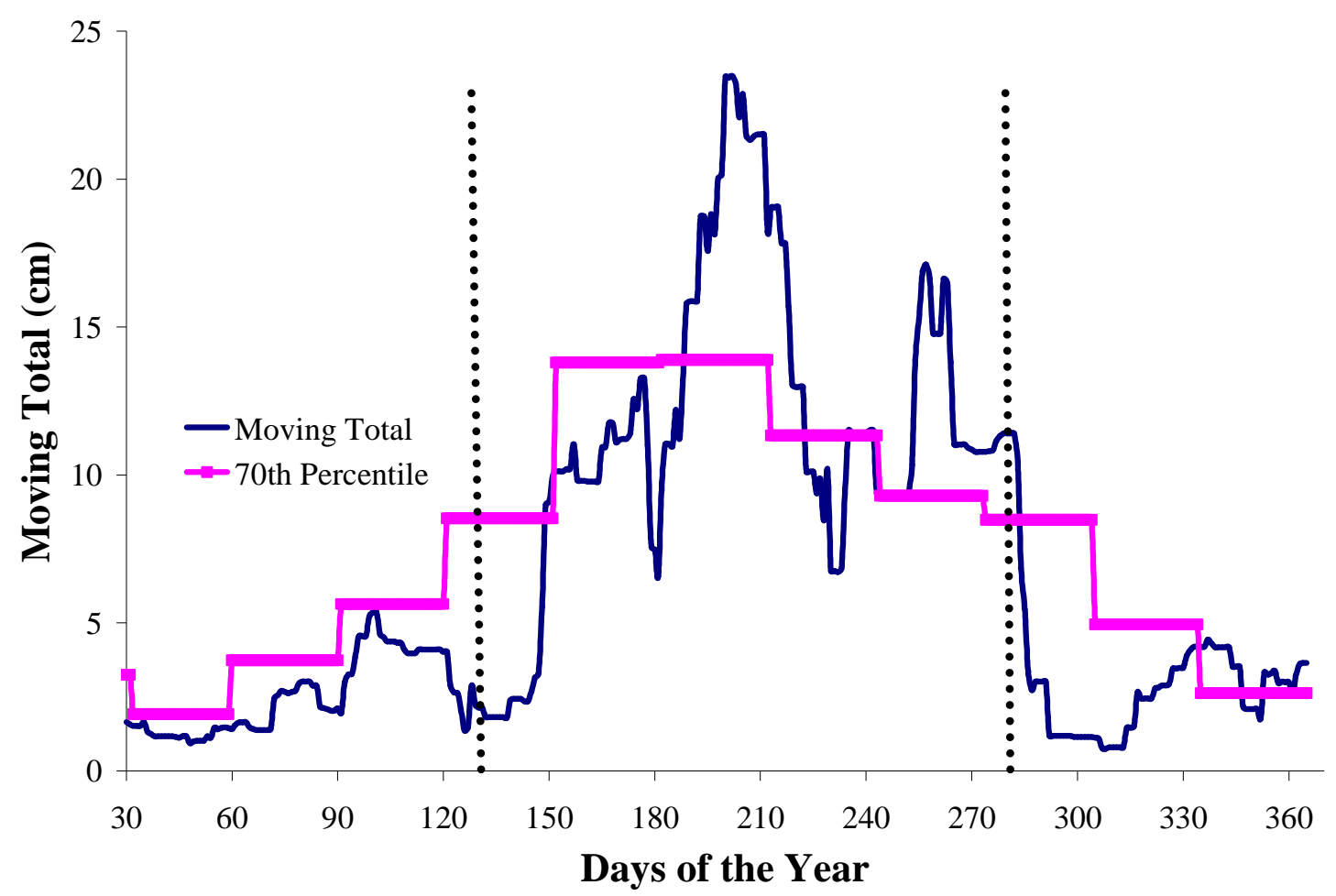

Figure D.103: Moving total graph for plots S1, S2, S3, and S6 at Marcell for year 1978.

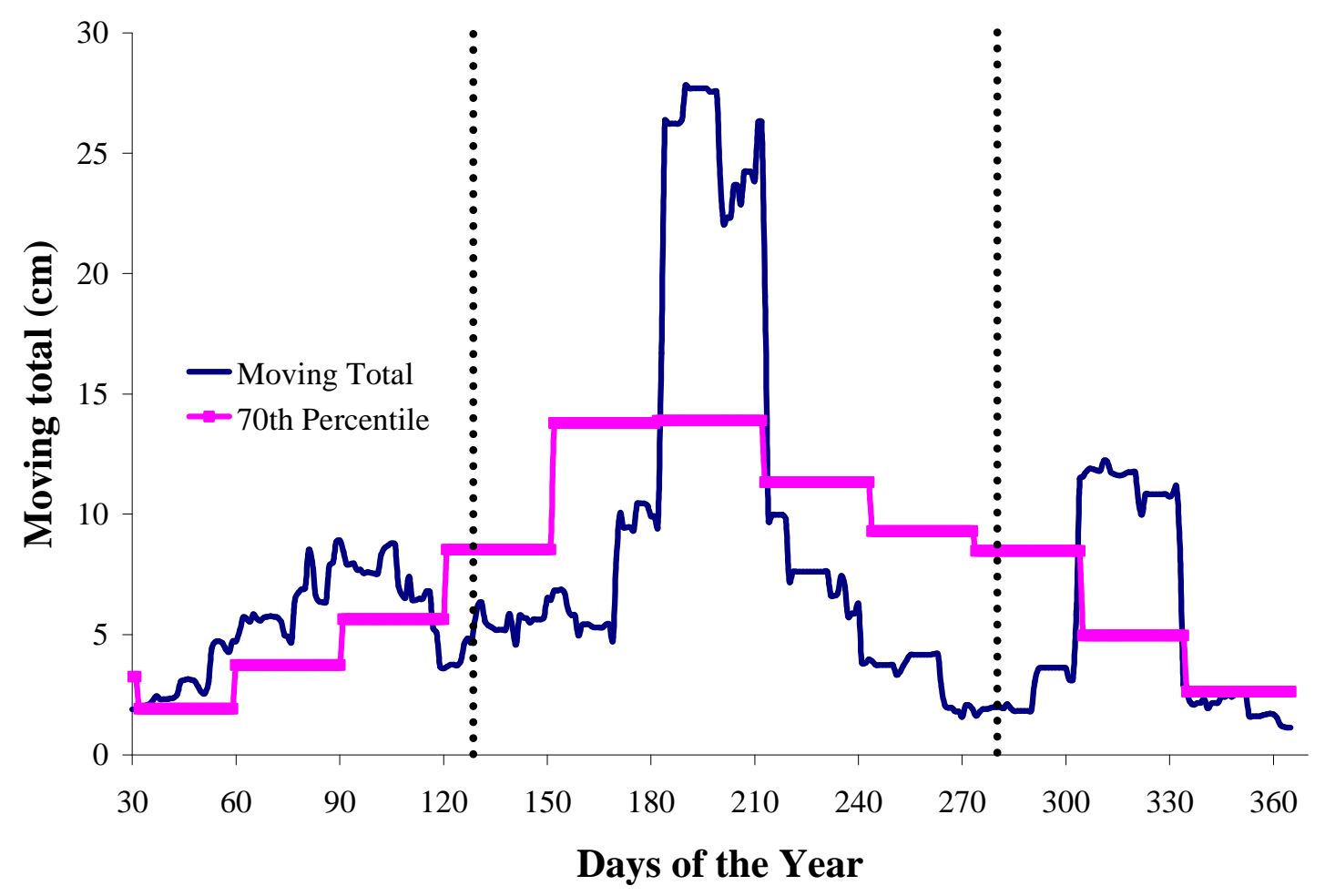

Figure D.104: Moving total graph for plots S1, S2, S3, and S6 at Marcell for year 1979. 


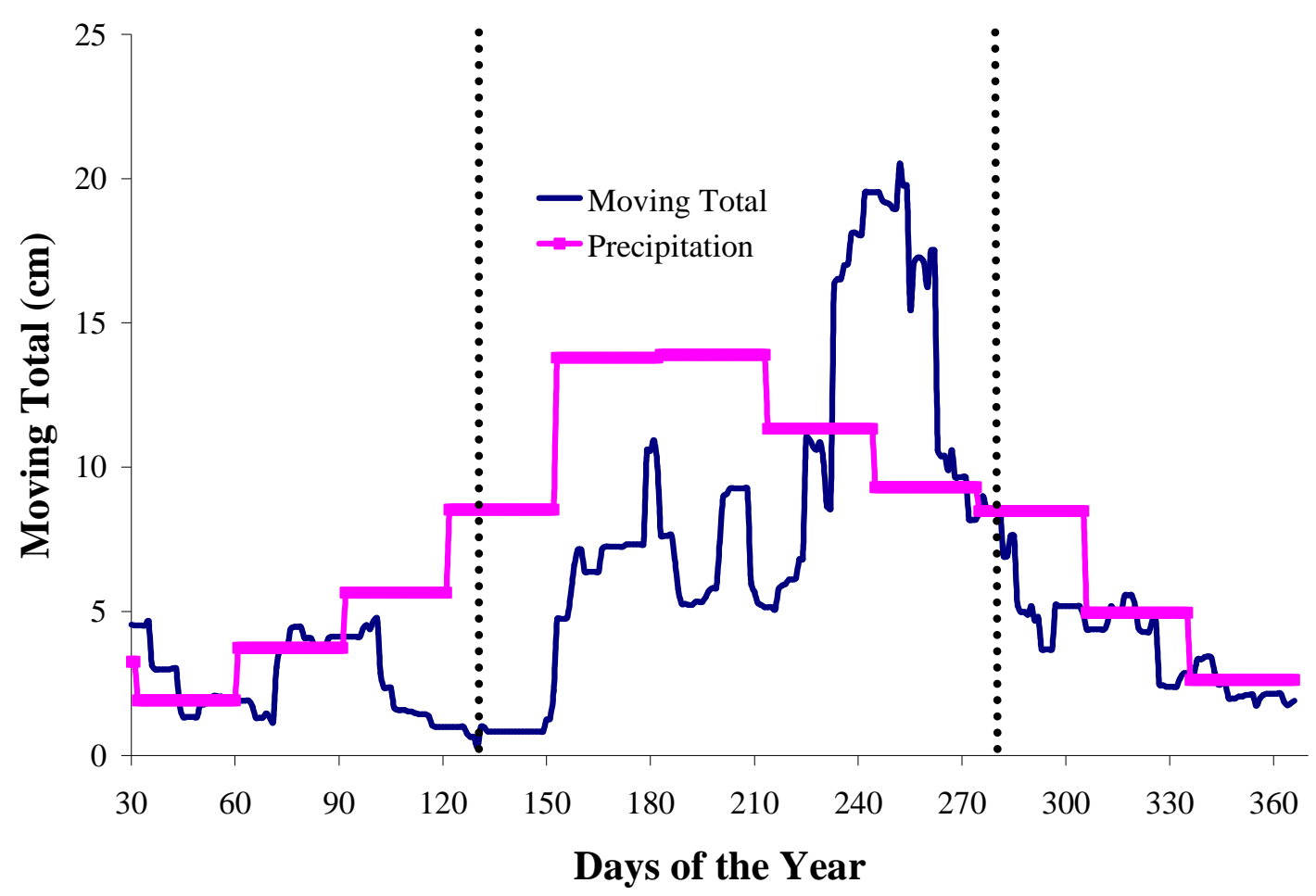

Figure D.105: Moving total graph for plots S1, S2, S3, and S6 at Marcell for year 1980.

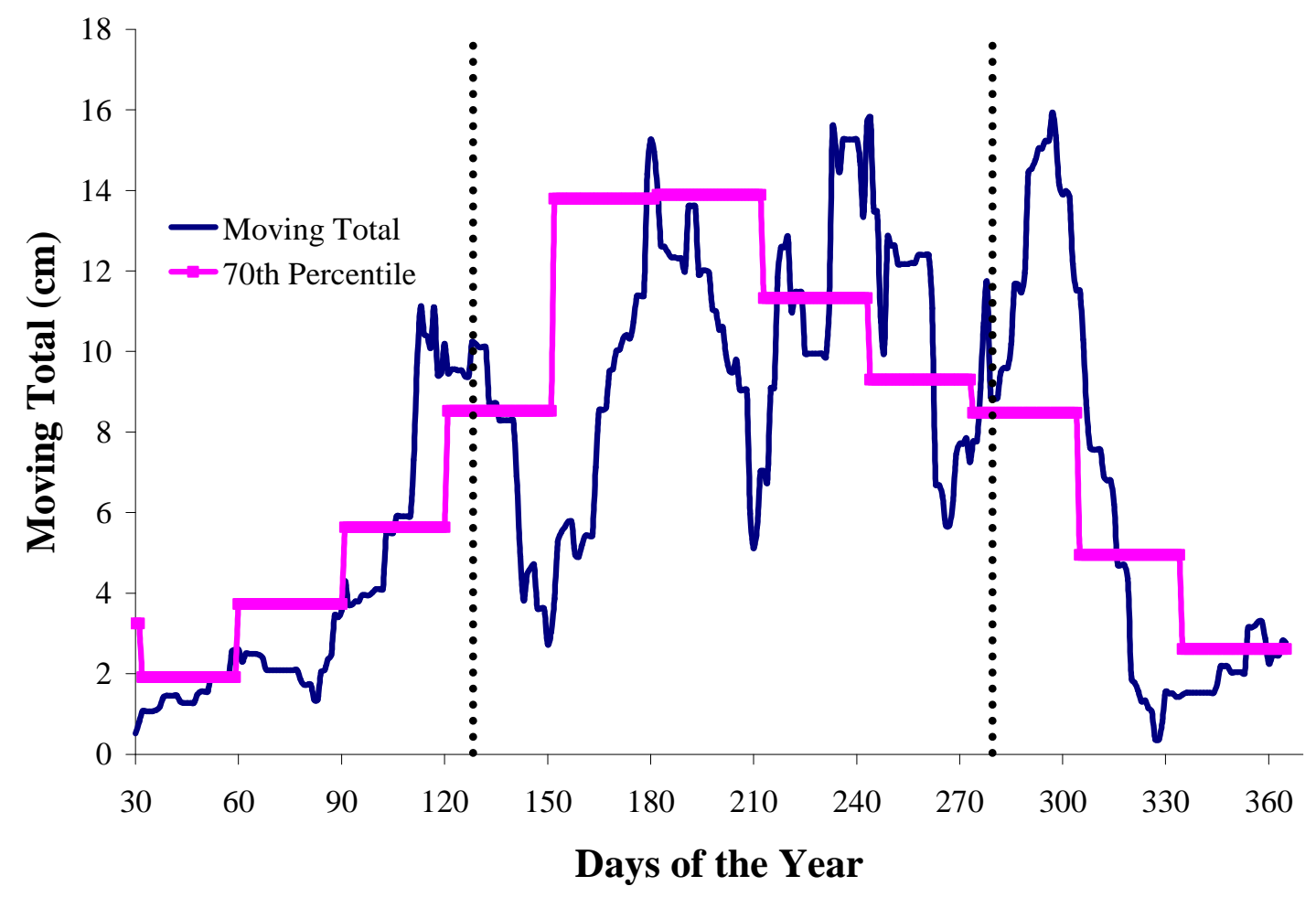

Figure D.106: Moving total graph for plots S1, S2, S3, and S6 at Marcell for year 1981. 


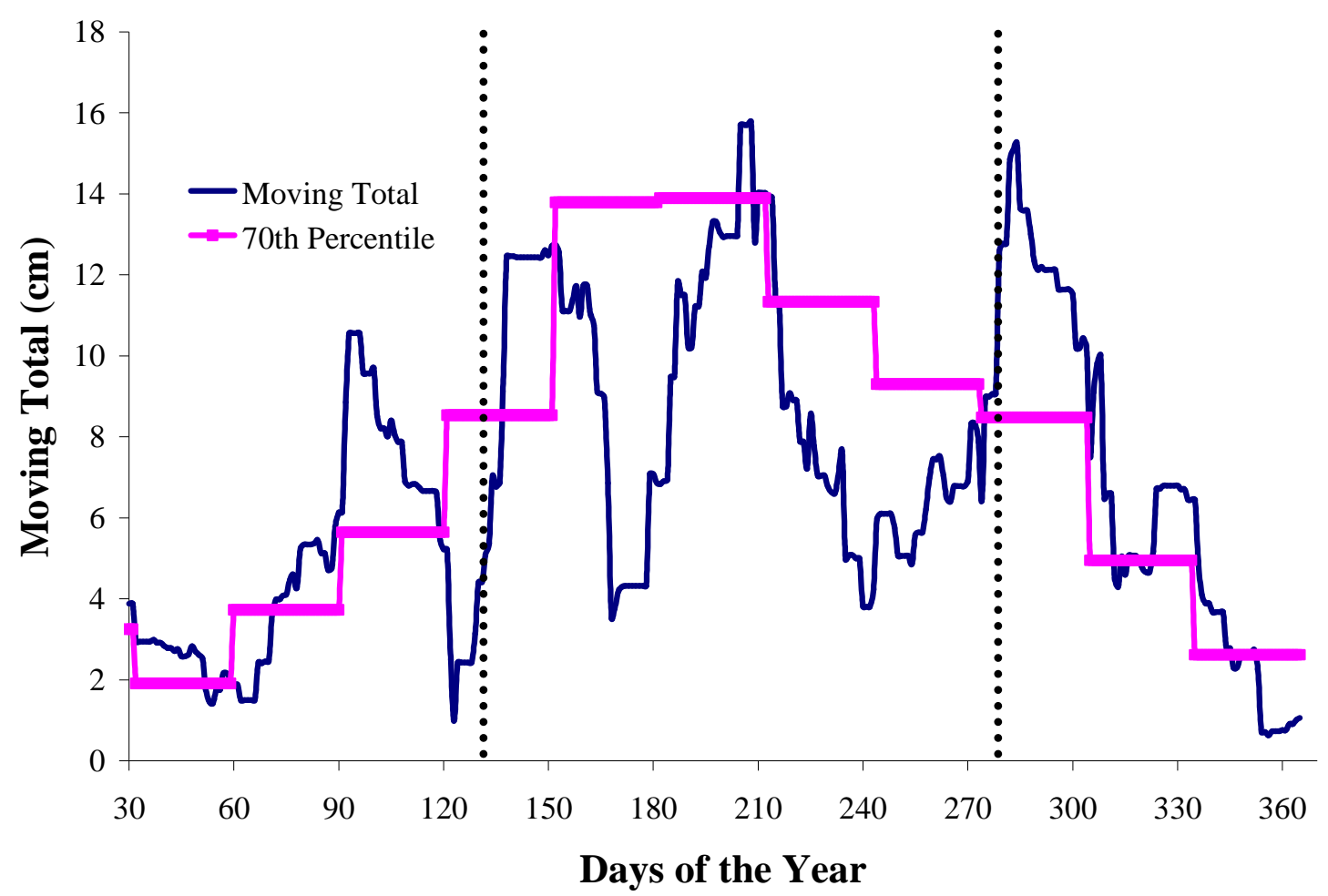

Figure D.107: Moving total graph for plots S1, S2, S3, and S6 at Marcell for year 1982.

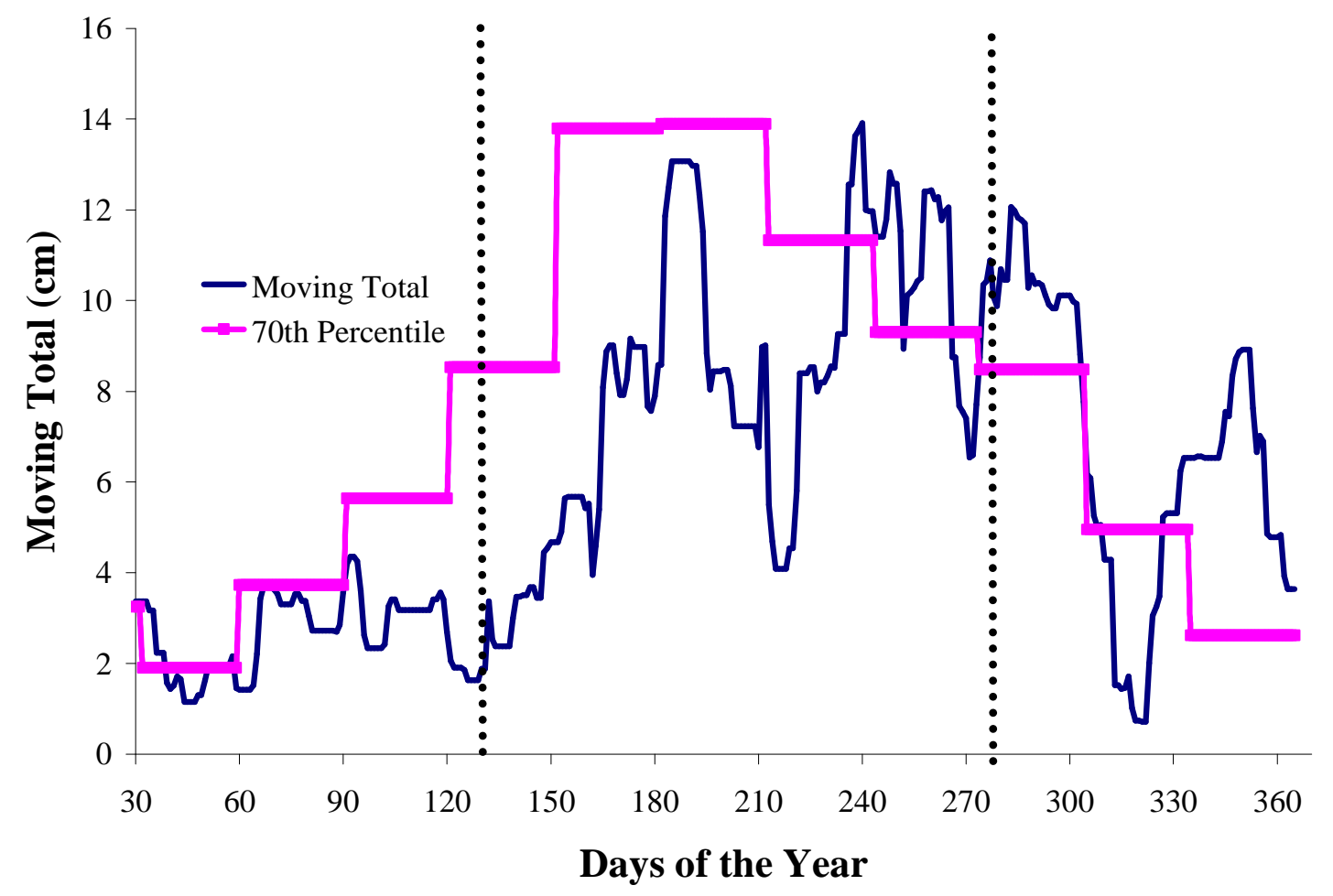

Figure D.108: Moving total graph for plots S1, S2, S3, and S6 at Marcell for year 1983. 


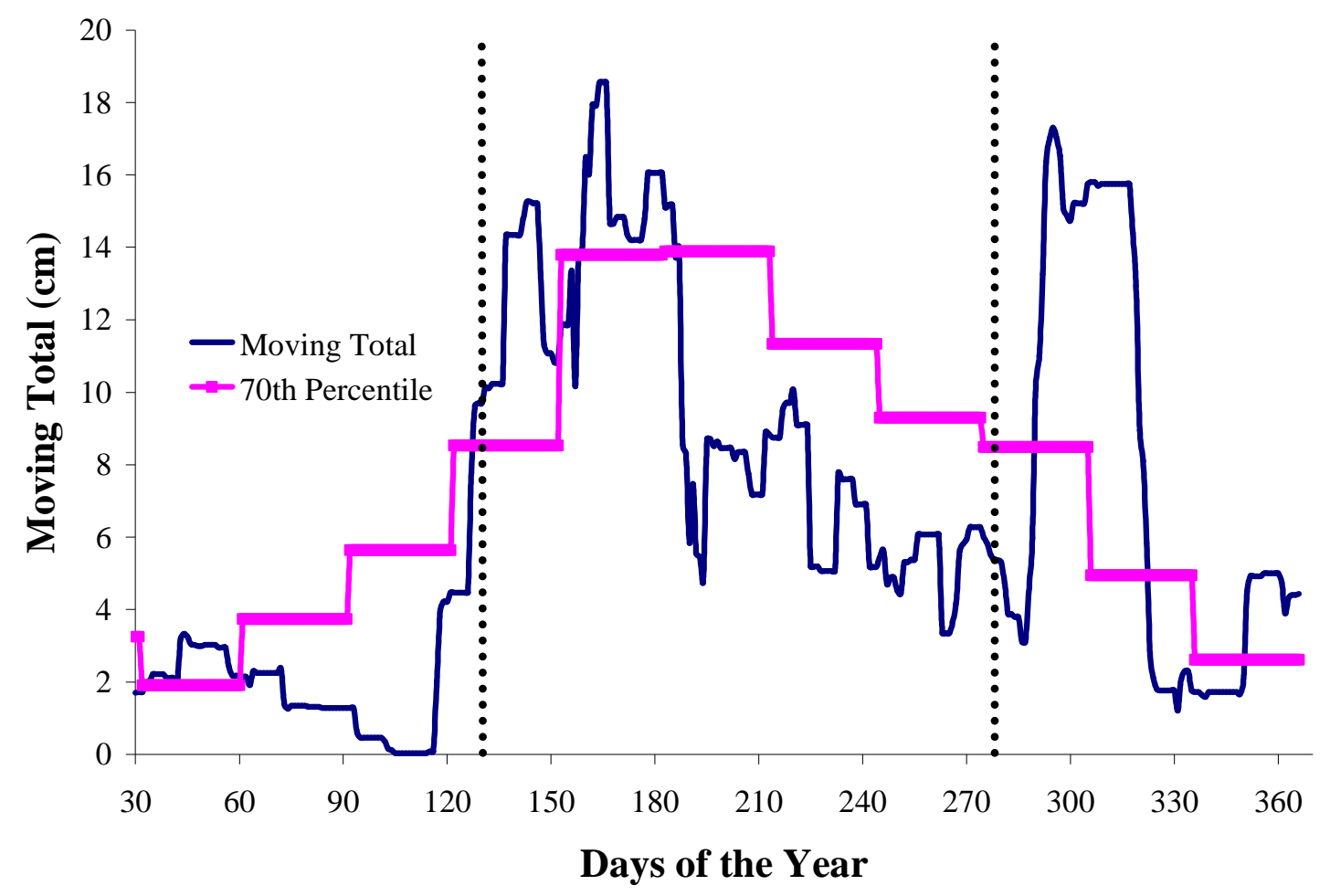

Figure D.109: Moving total graph for plots S1, S2, S3, and S6 at Marcell for year 1984.

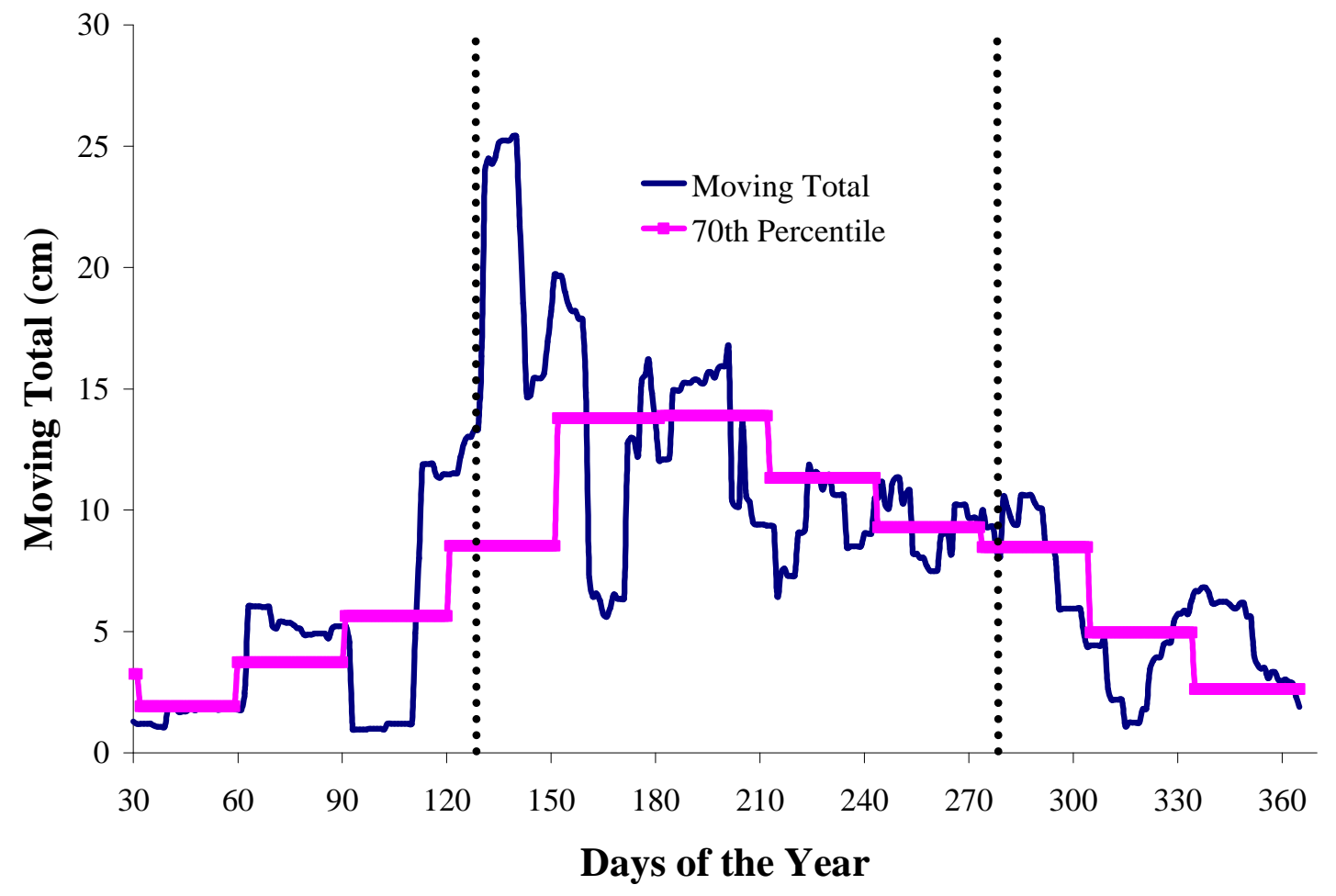

Figure D.110: Moving total graph for plots S1, S2, S3, and S6 at Marcell for year 1985. 


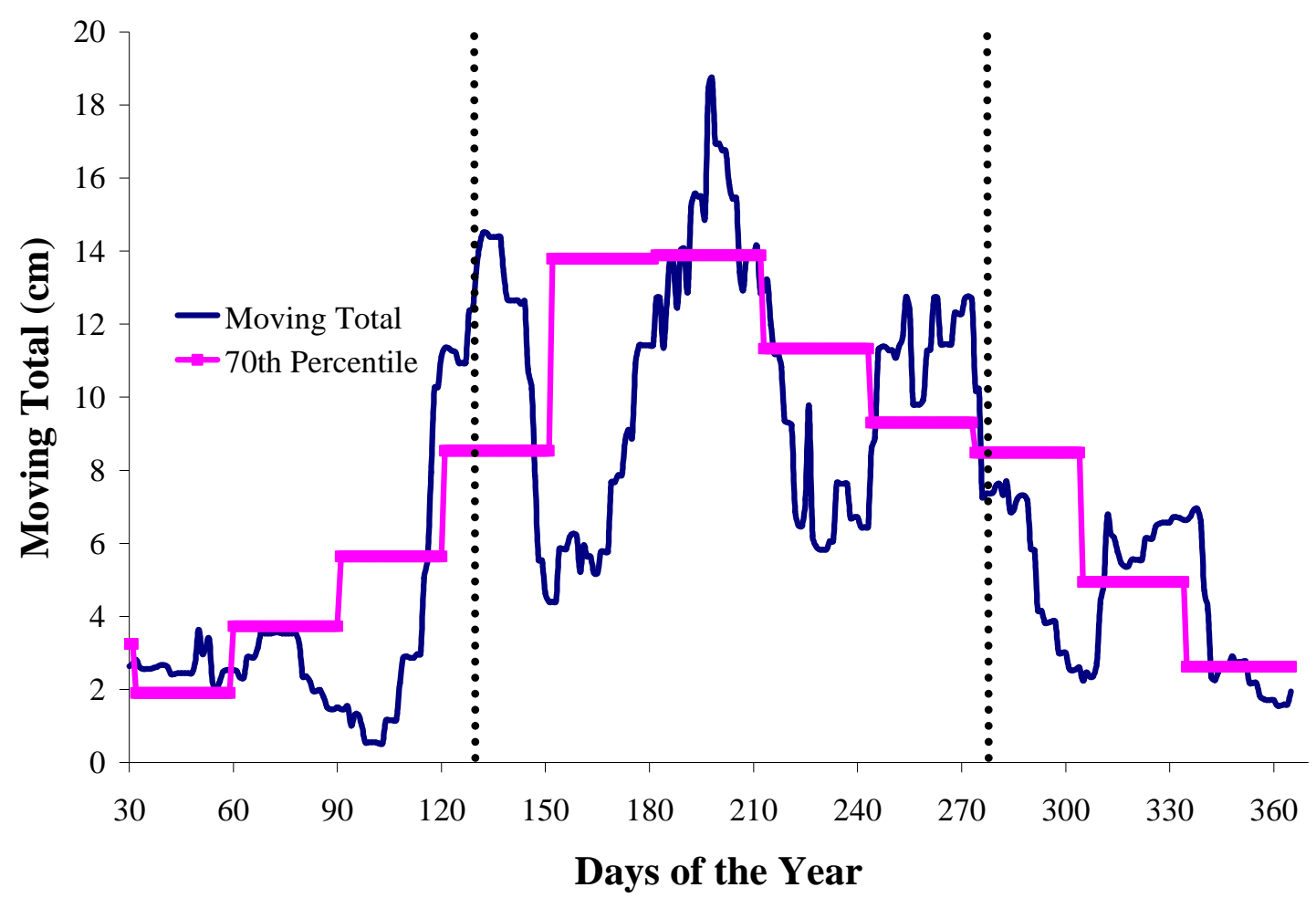

Figure D.111: Moving total graph for plots S1, S2, S3, and S6 at Marcell for year 1986.

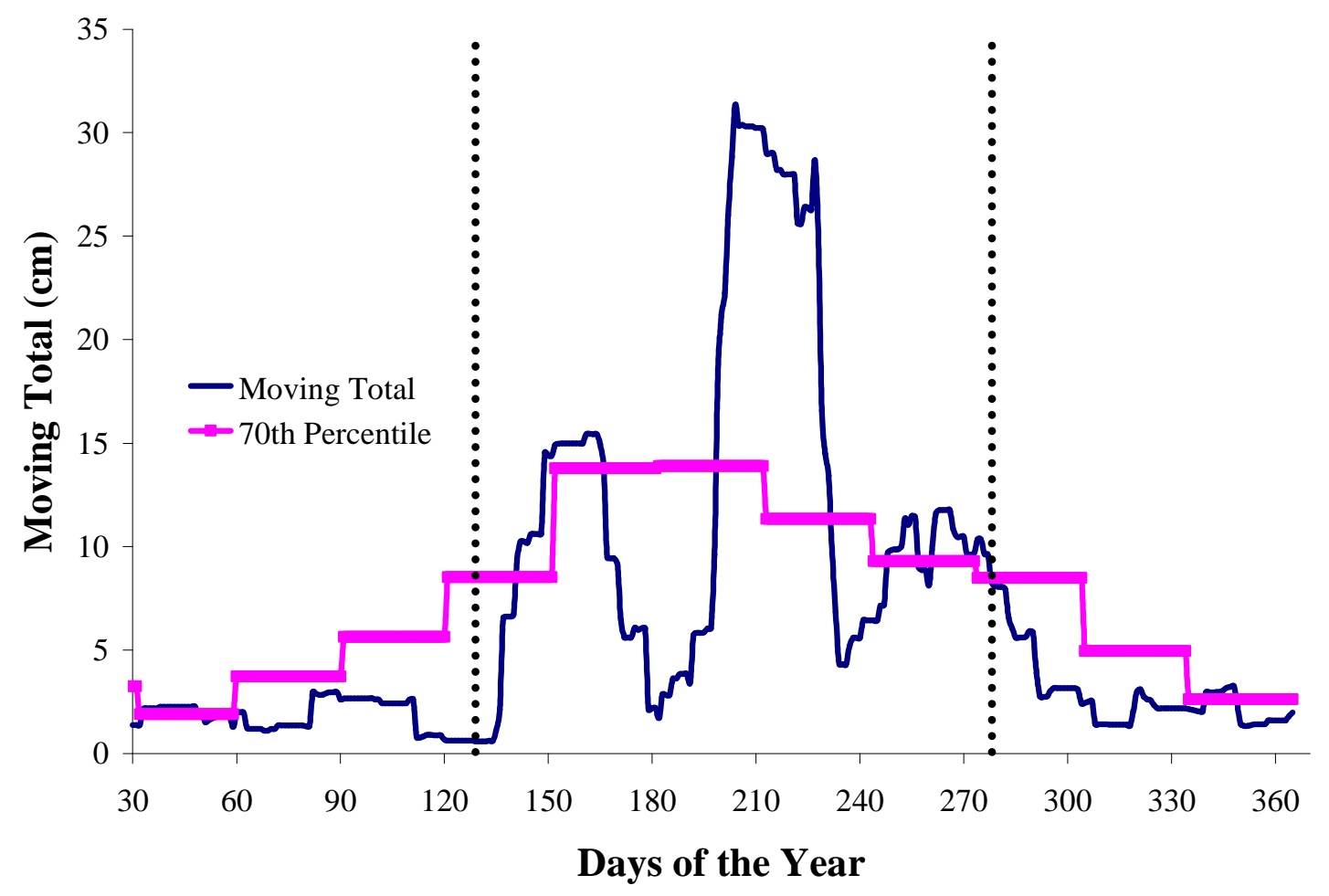

Figure D.112: Moving total graph for plots S1, S2, S3, and S6 at Marcell for year 1987. 


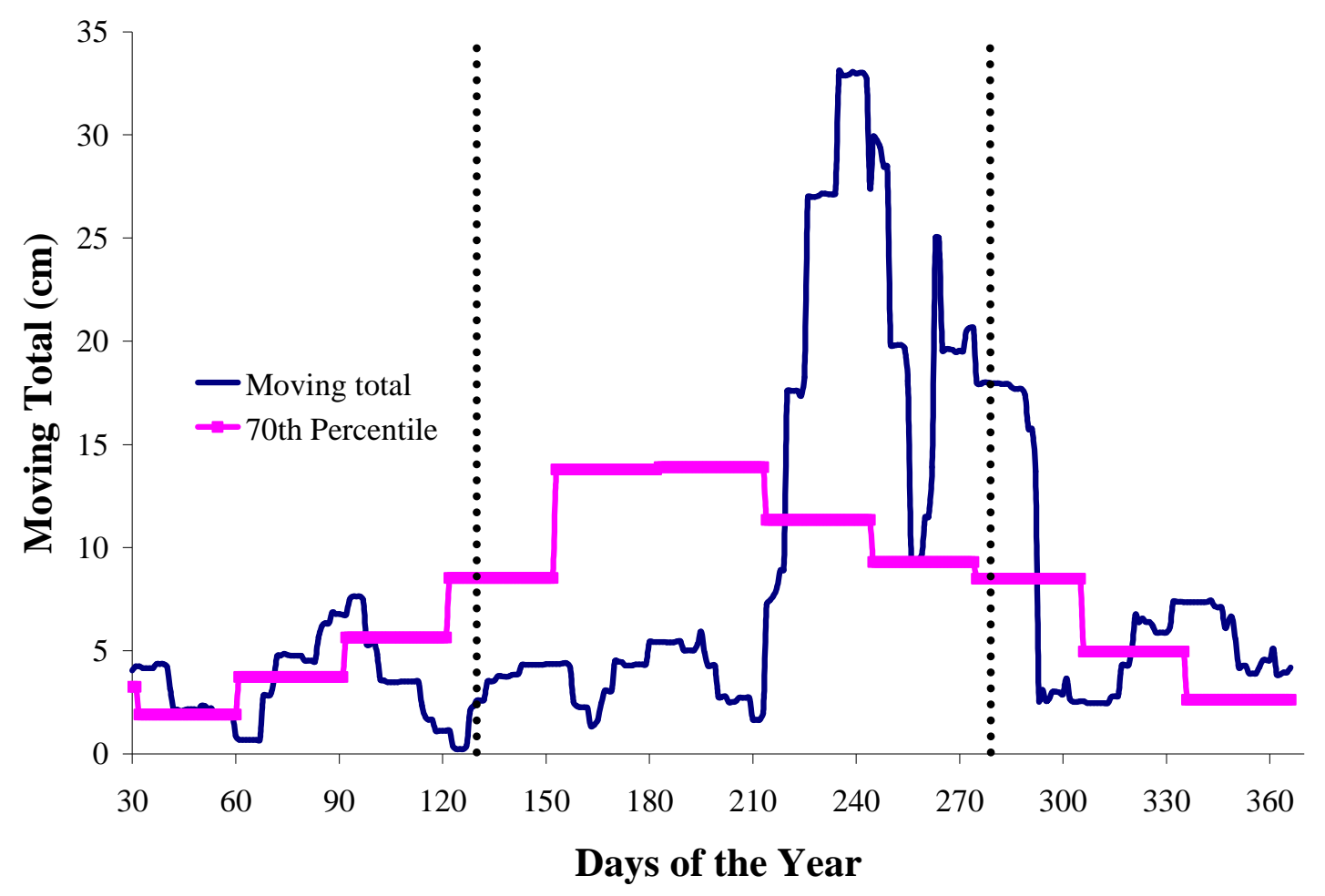

Figure D.113: Moving total graph for plots S1, S2, S3, and S6 at Marcell for year 1988.

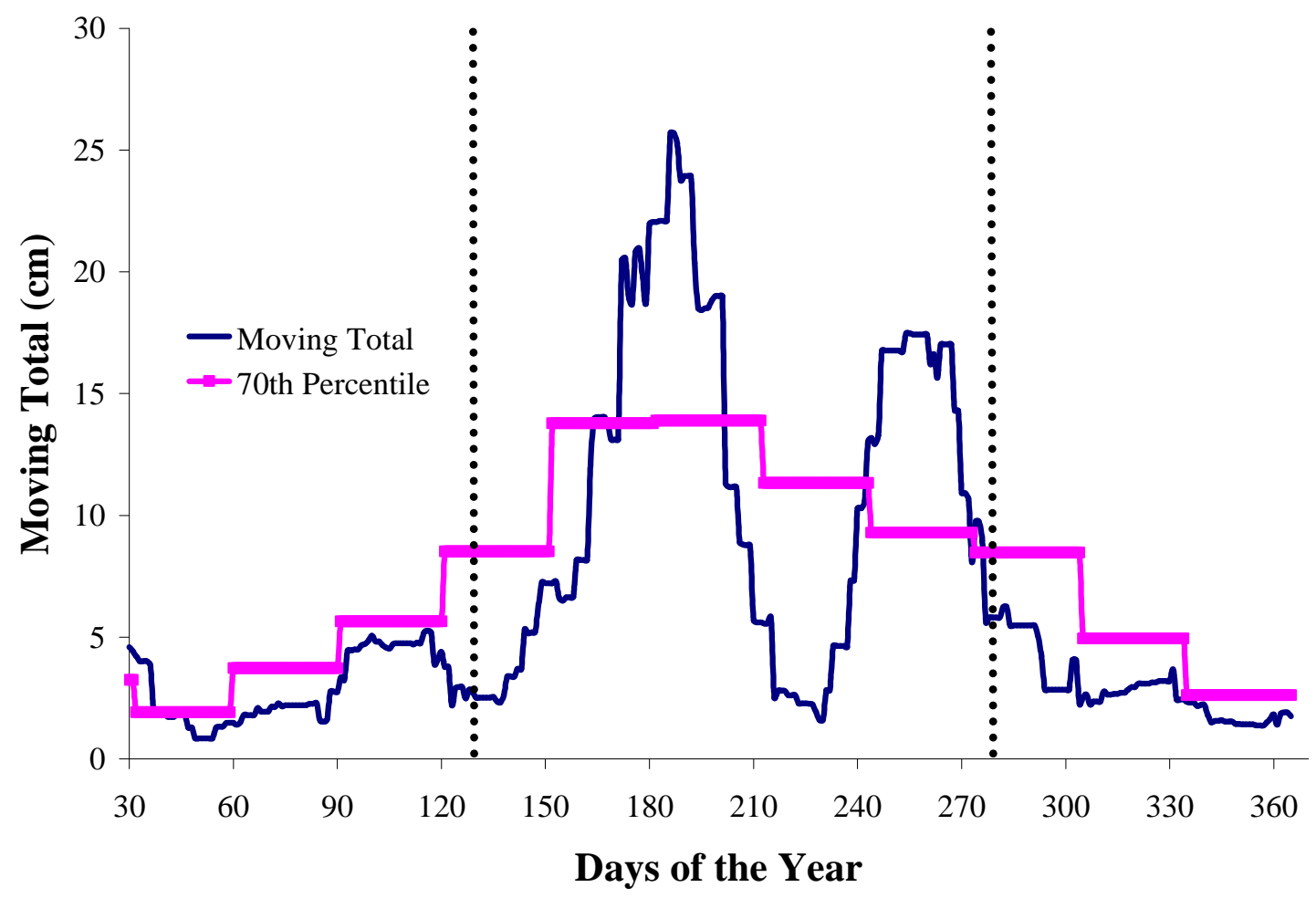

Figure D.114: Moving total graph for plots S1, S2, S3, and S6 at Marcell for year 1989. 


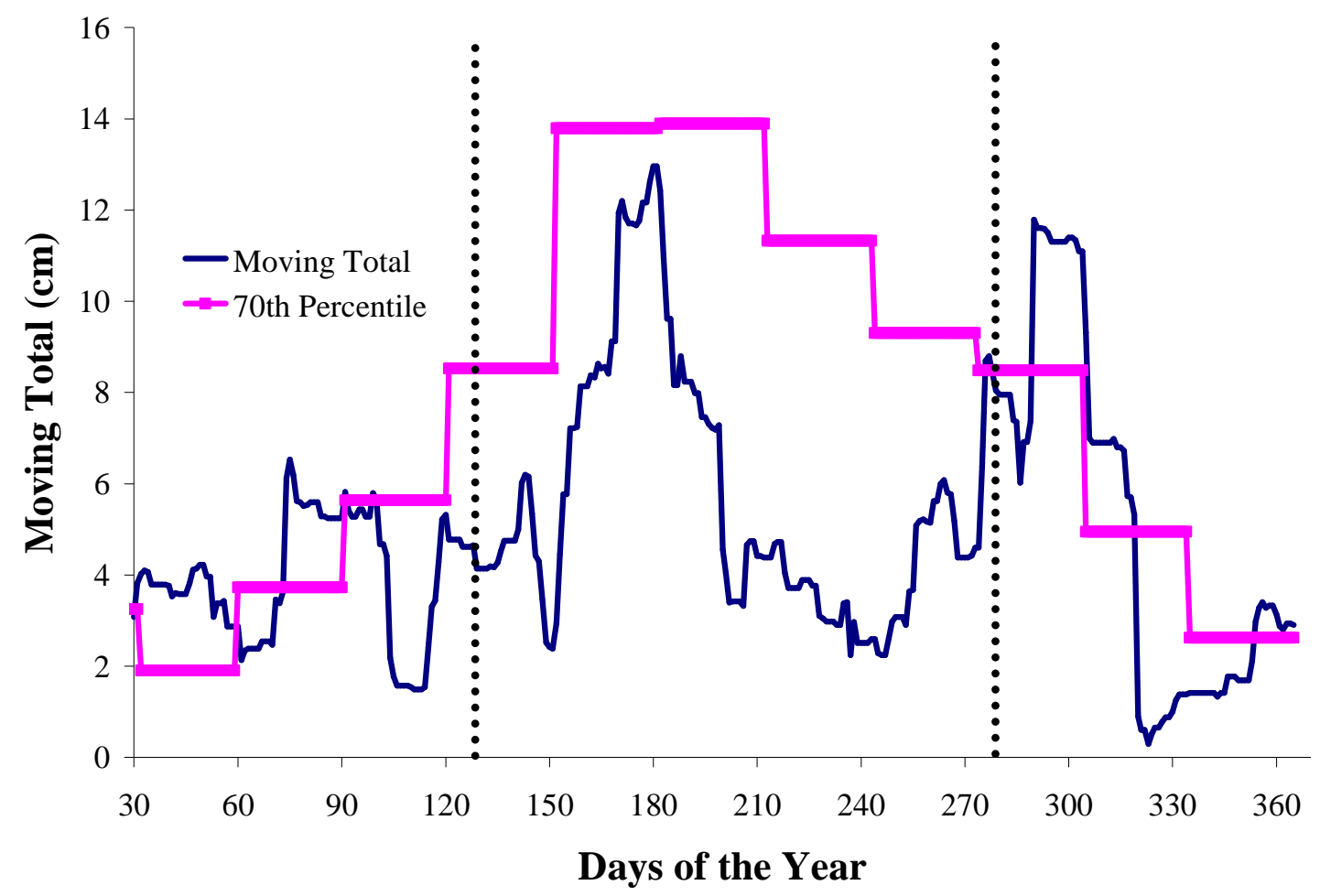

Figure D.115: Moving total graph for plots S1, S2, S3, and S6 at Marcell for year 1990.

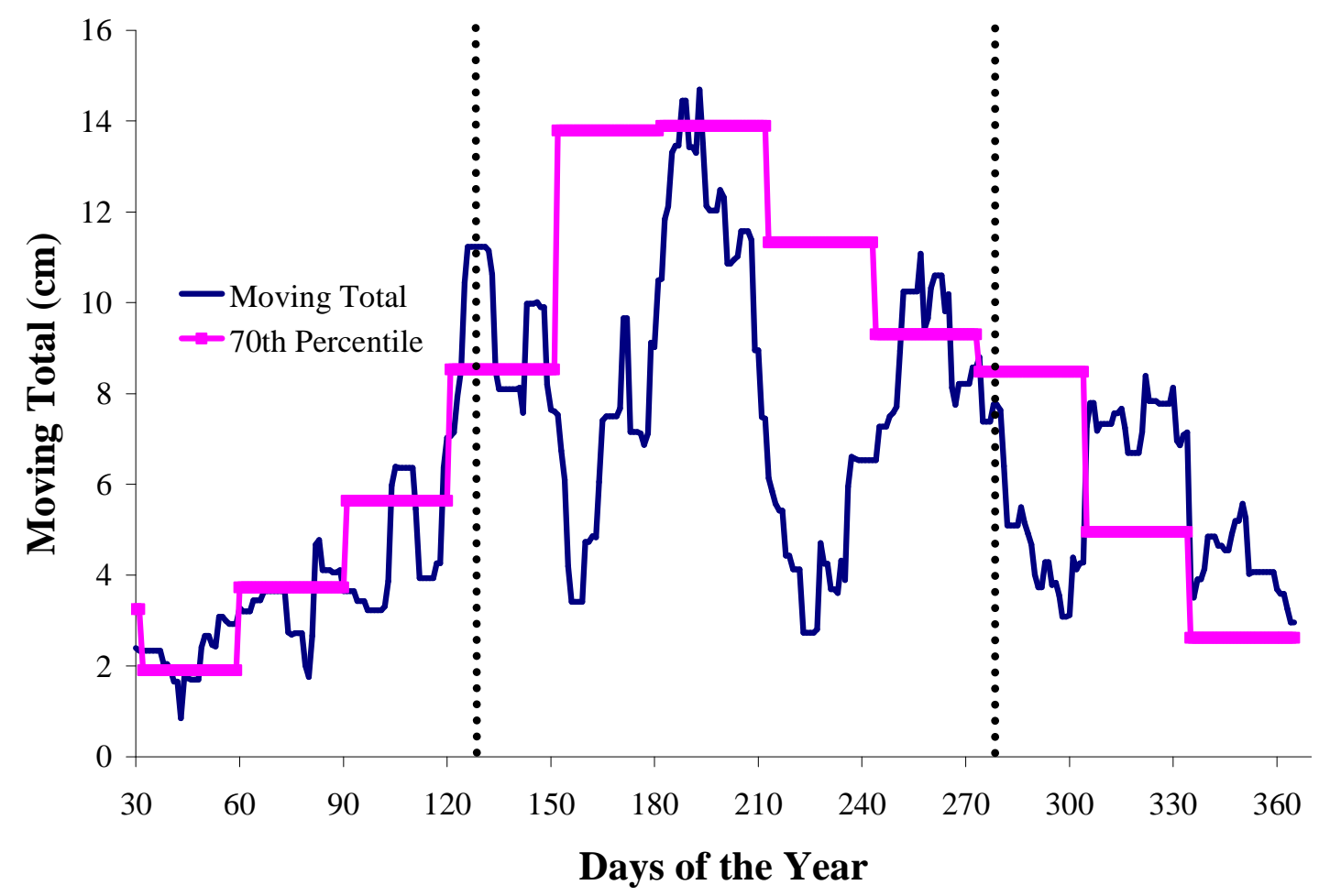

Figure D.116: Moving total graph for plots S1, S2, S3, and S6 at Marcell for year 1991. 


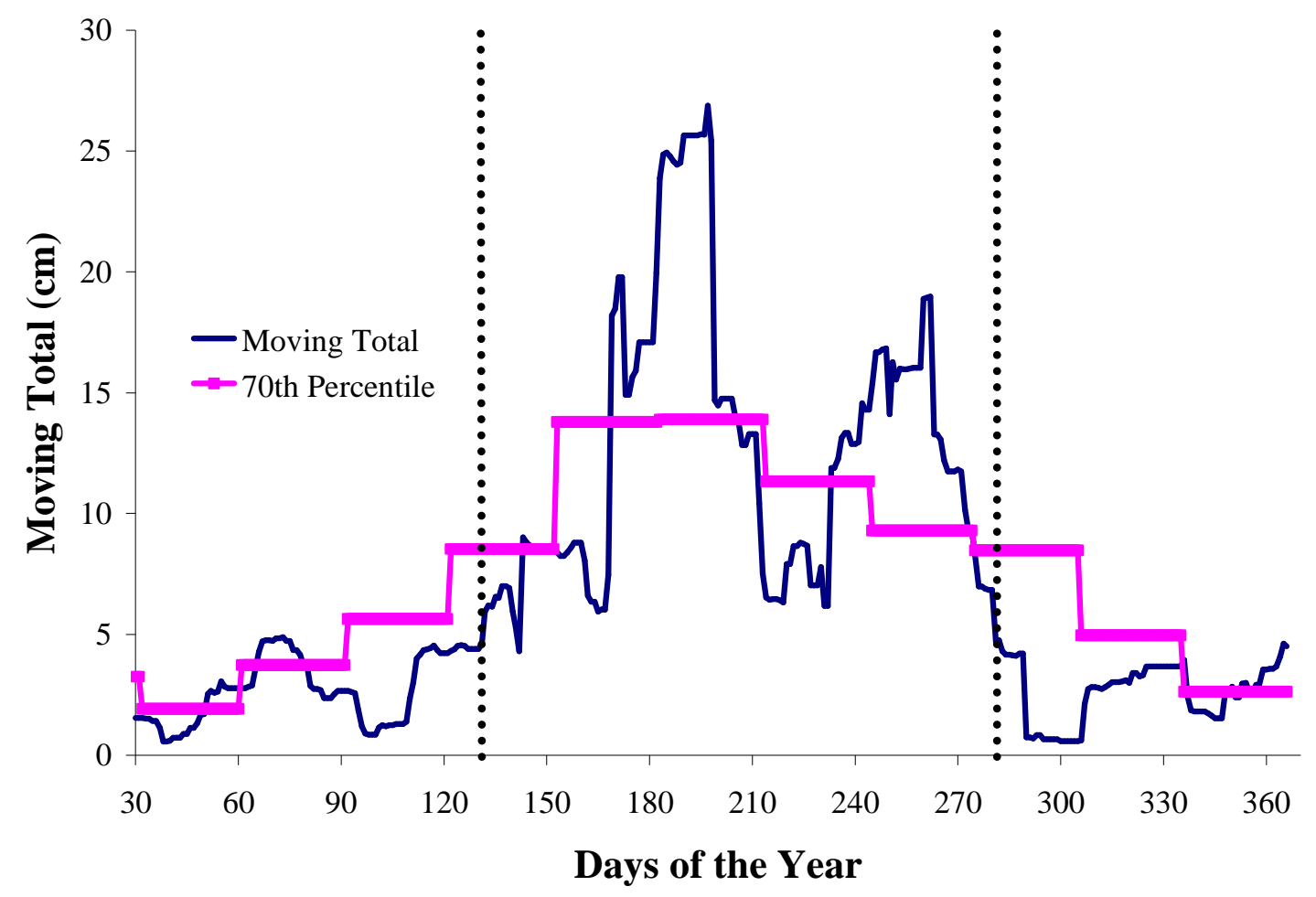

Figure D.117: Moving total graph for plots S1, S2, S3, and S6 at Marcell for year 1992.

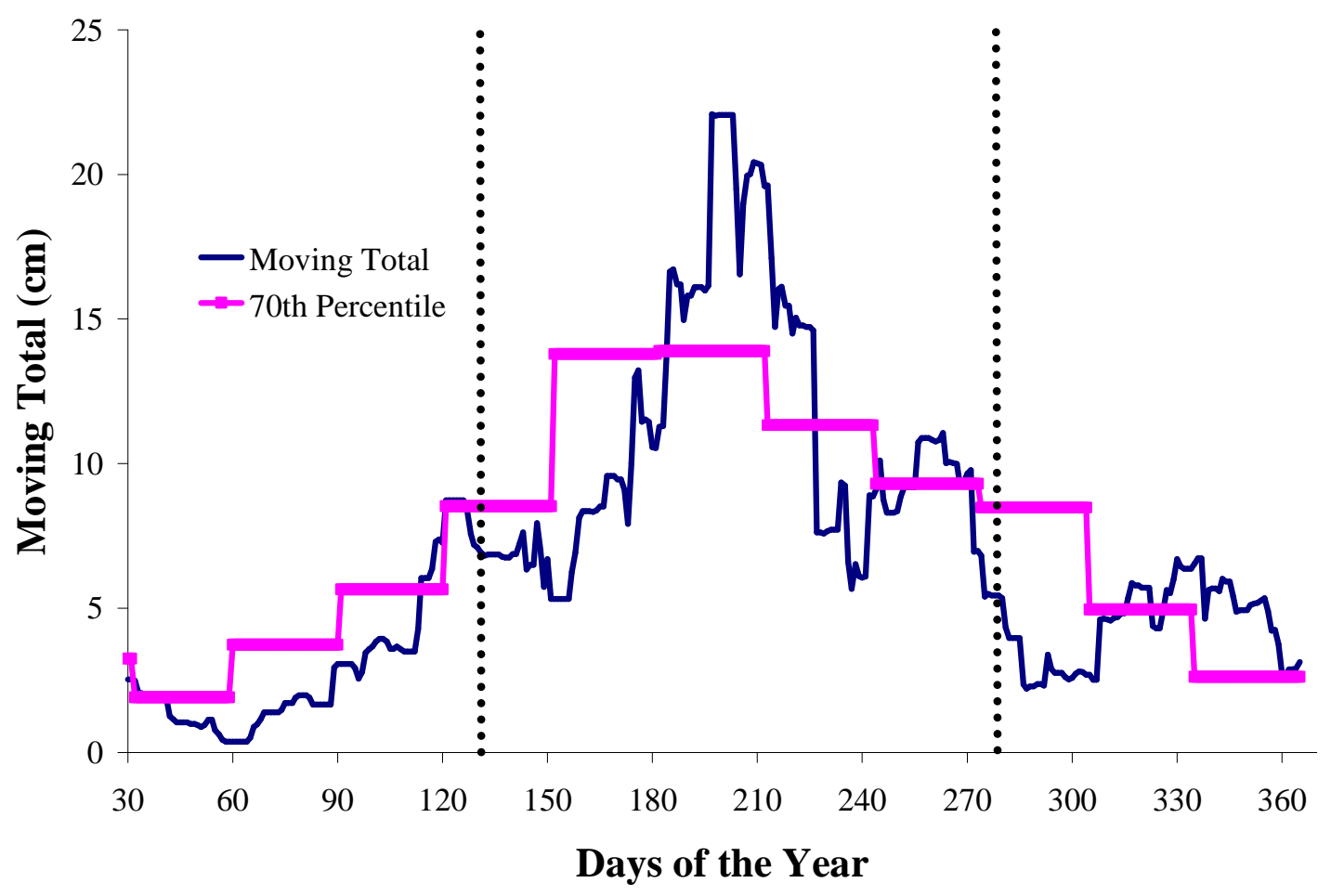

Figure D.118: Moving total graph for plots S1, S2, S3, and S6 at Marcell for year 1993. 


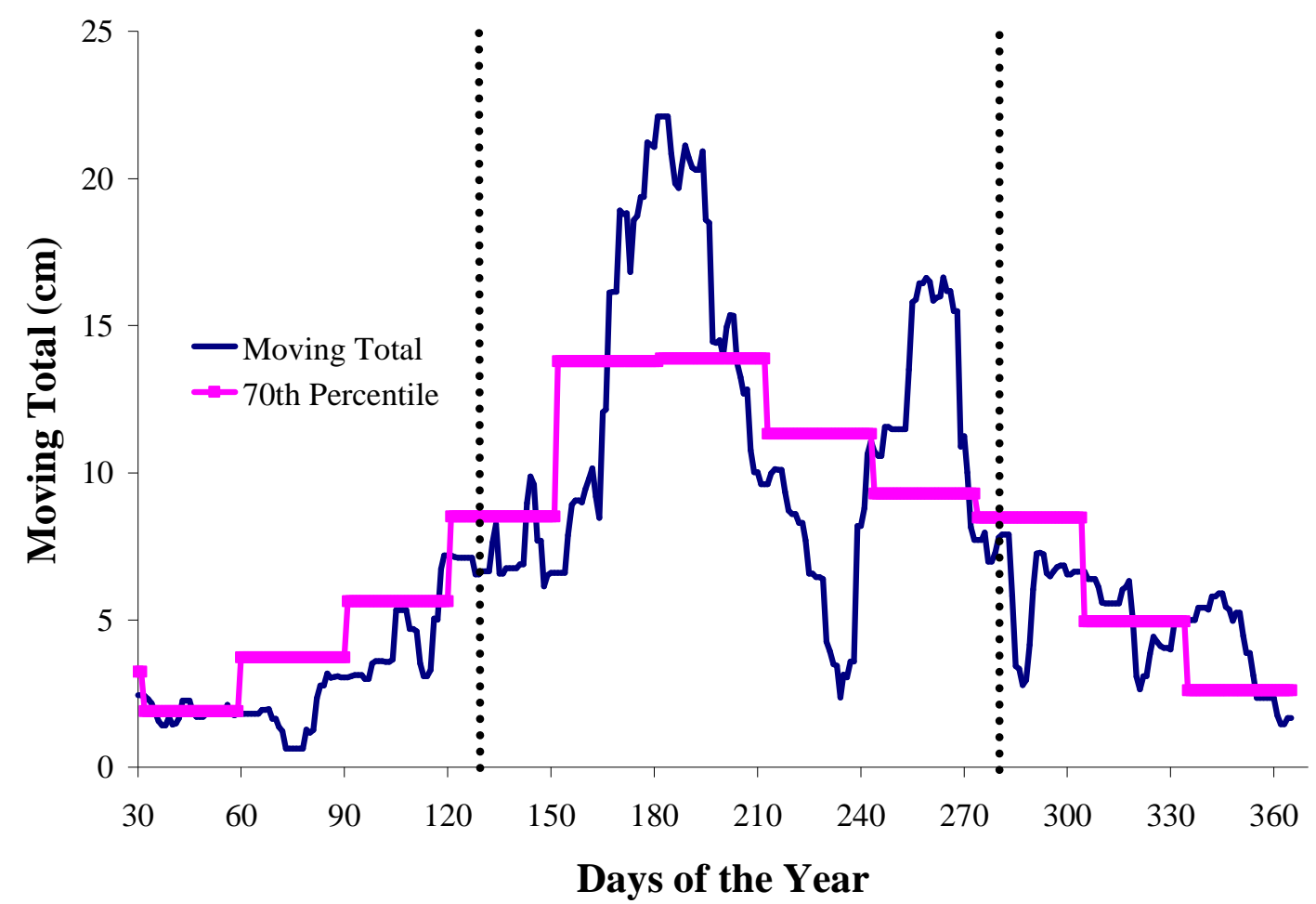

Figure D.119: Moving total graph for plots S1, S2, S3, and S6 at Marcell for year 1994.

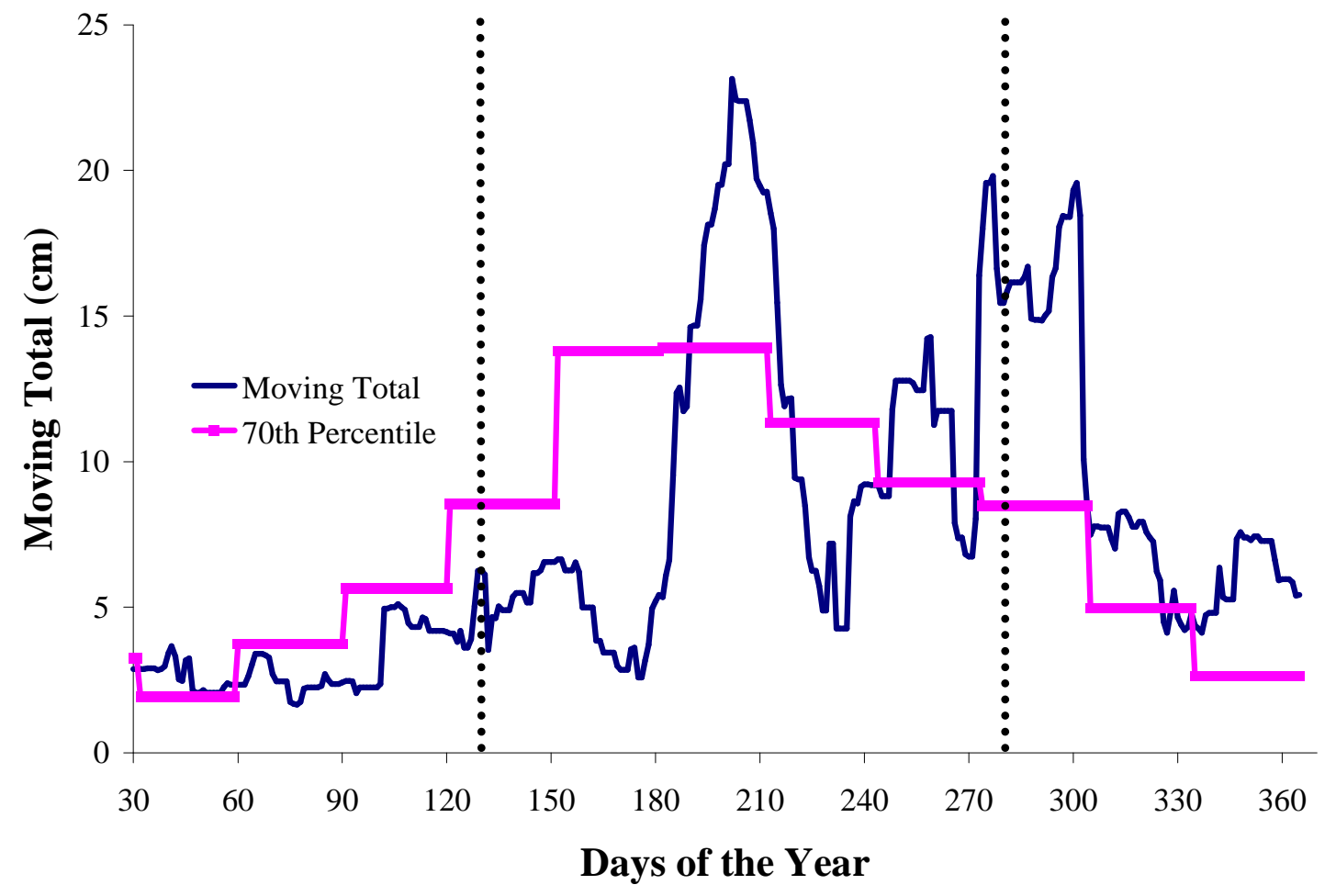

Figure D.120: Moving total graph for plots S1, S2, S3, and S6 at Marcell for year 1995. 


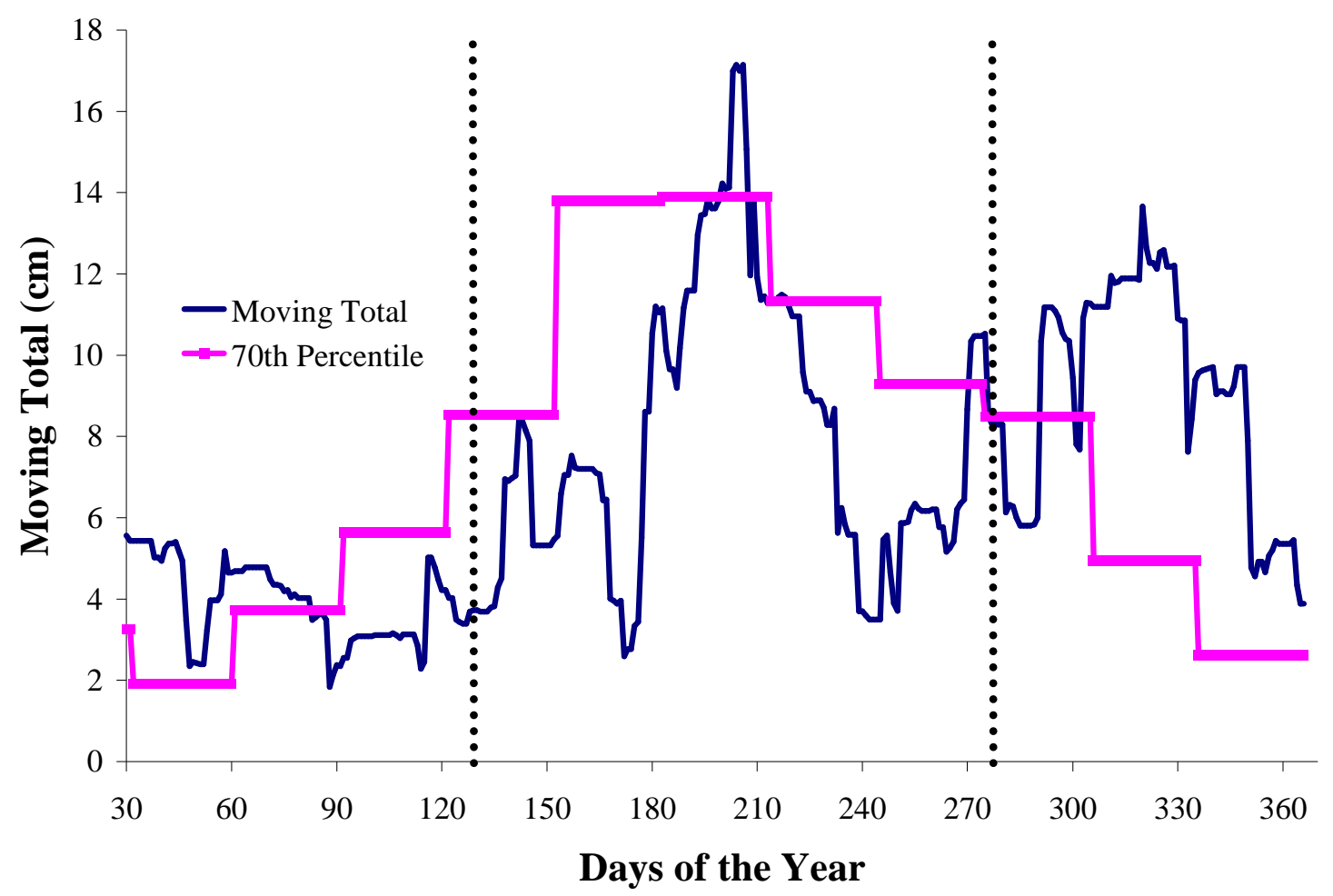

Figure D.121: Moving total graph for plots S1, S2, S3, and S6 at Marcell for year 1996.

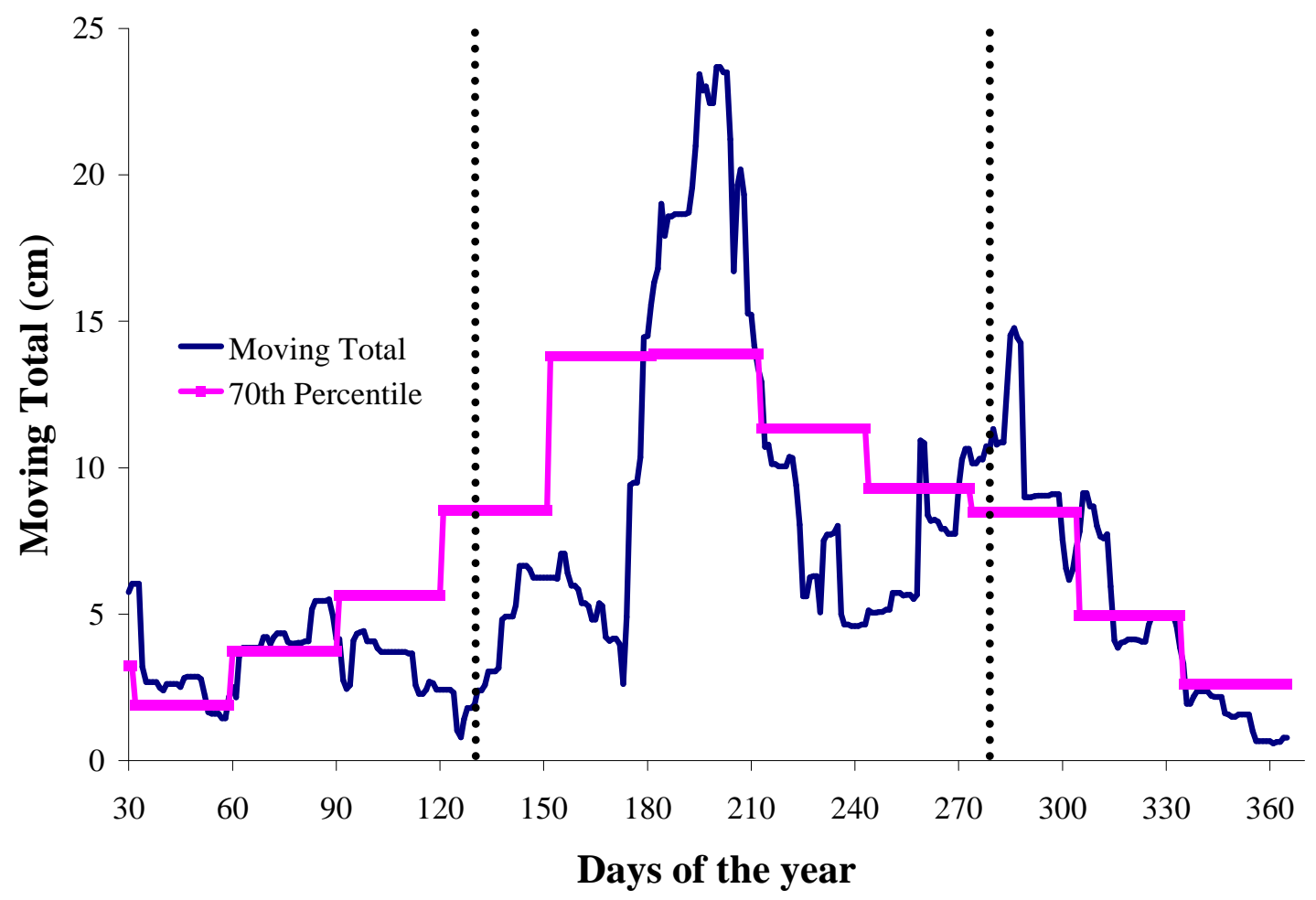

Figure D.122: Moving total graph for plots S1, S2, S3, and S6 at Marcell for year 1997. 


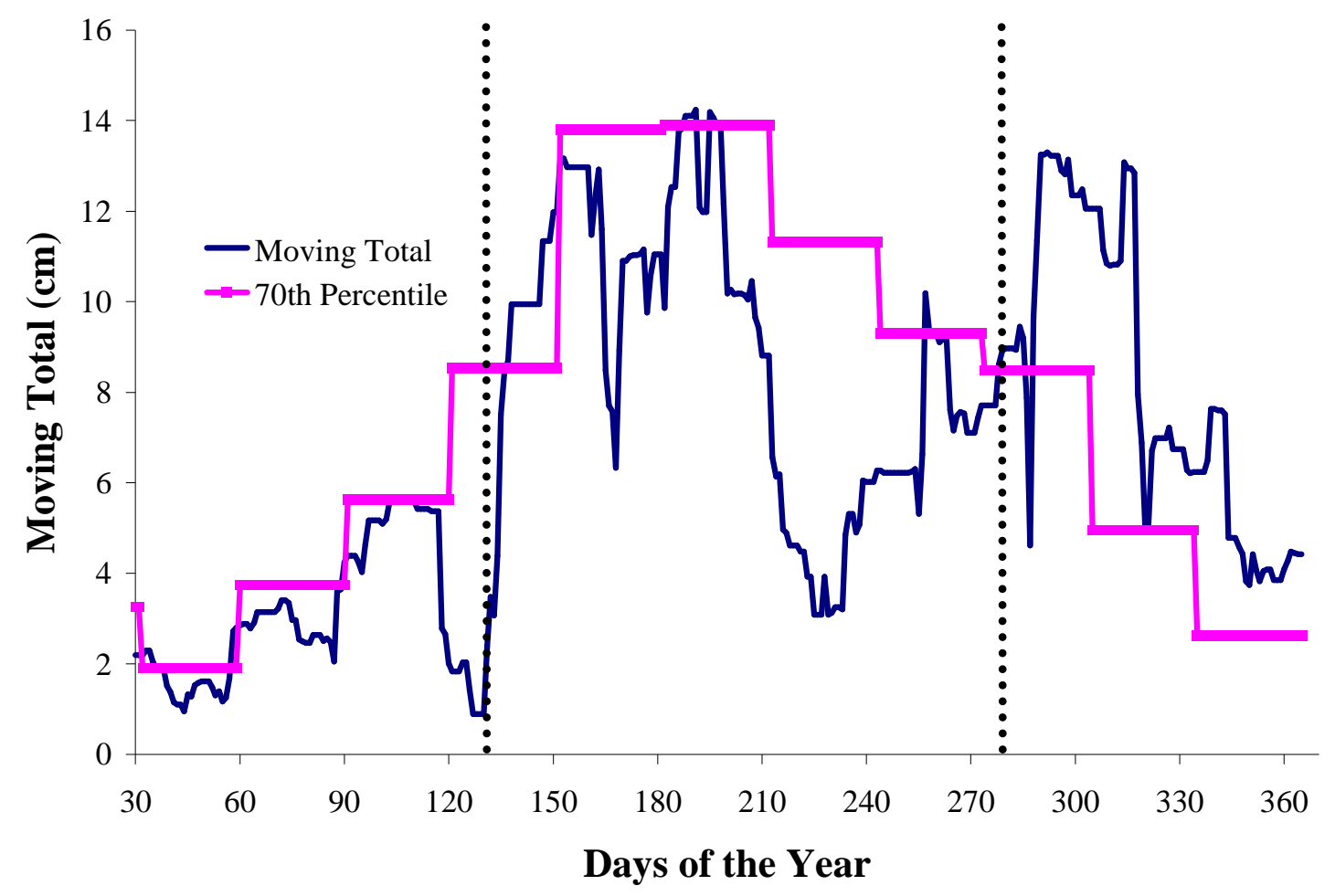

Figure D.123: Moving total graph for plots S1, S2, S3, and S6 at Marcell for year 1998.

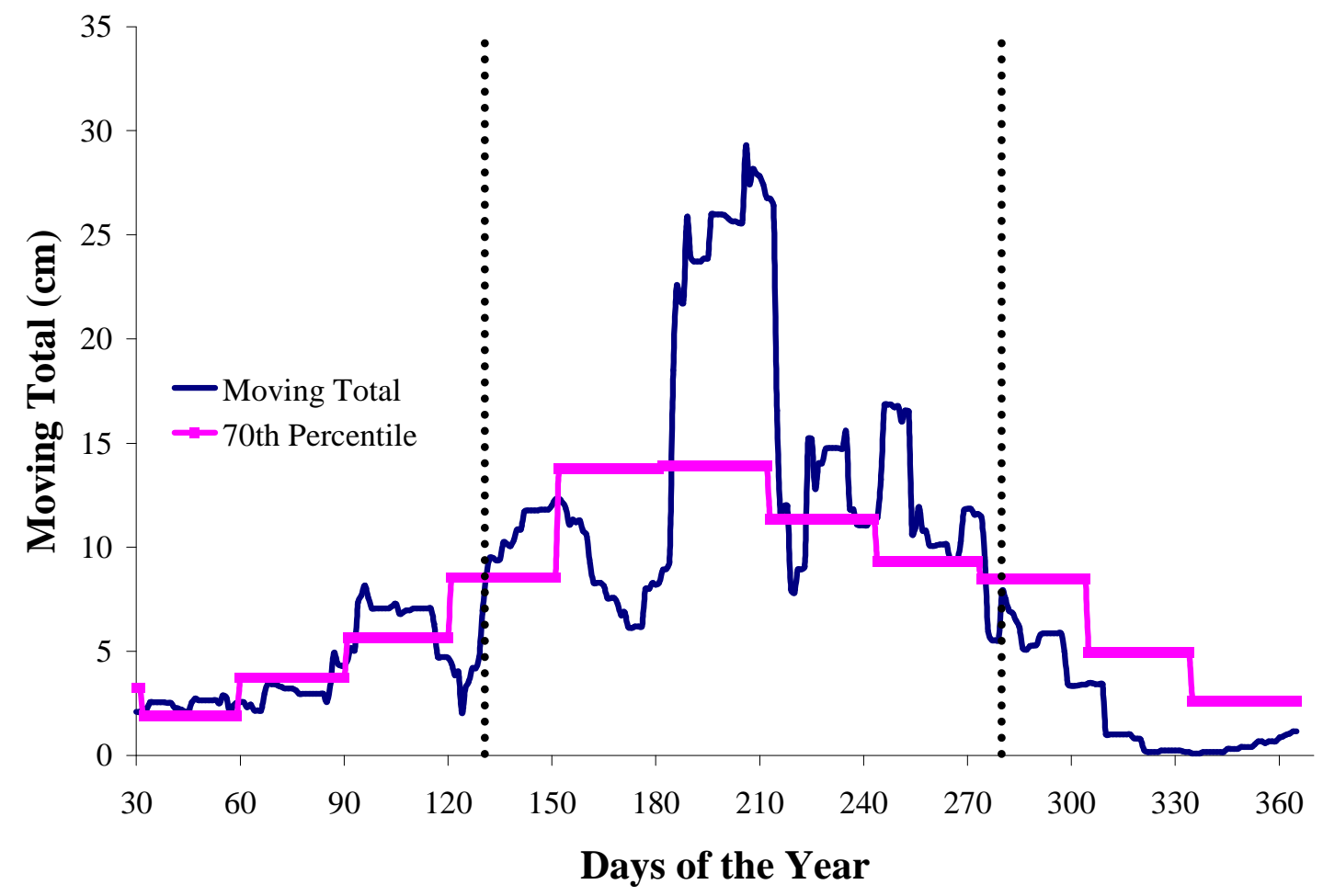

Figure D.124: Moving total graph for plots S1, S2, S3, and S6 at Marcell for year 1999. 


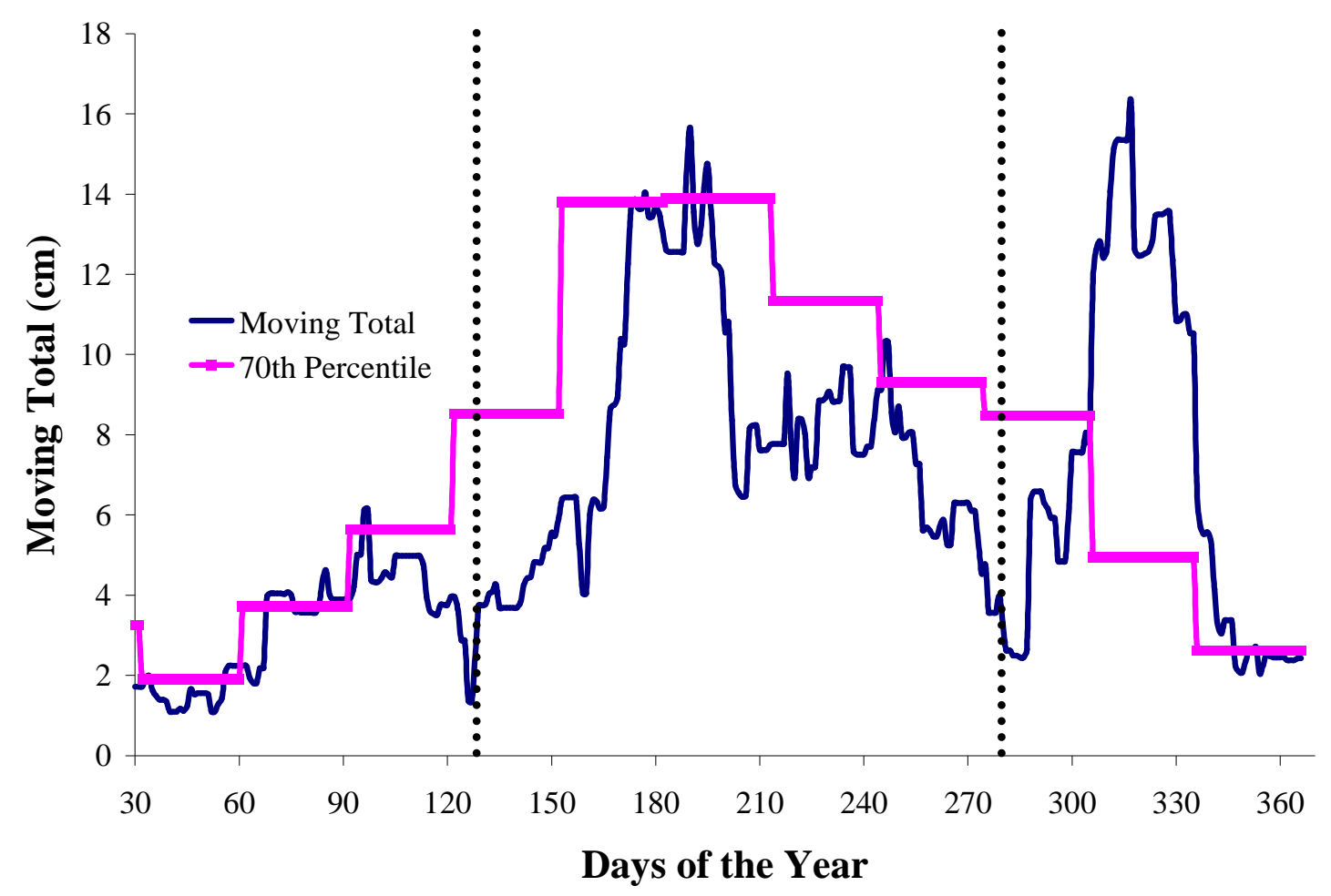

Figure D.125: Moving total graph for plots S1, S2, S3, and S6 at Marcell for year 2000.

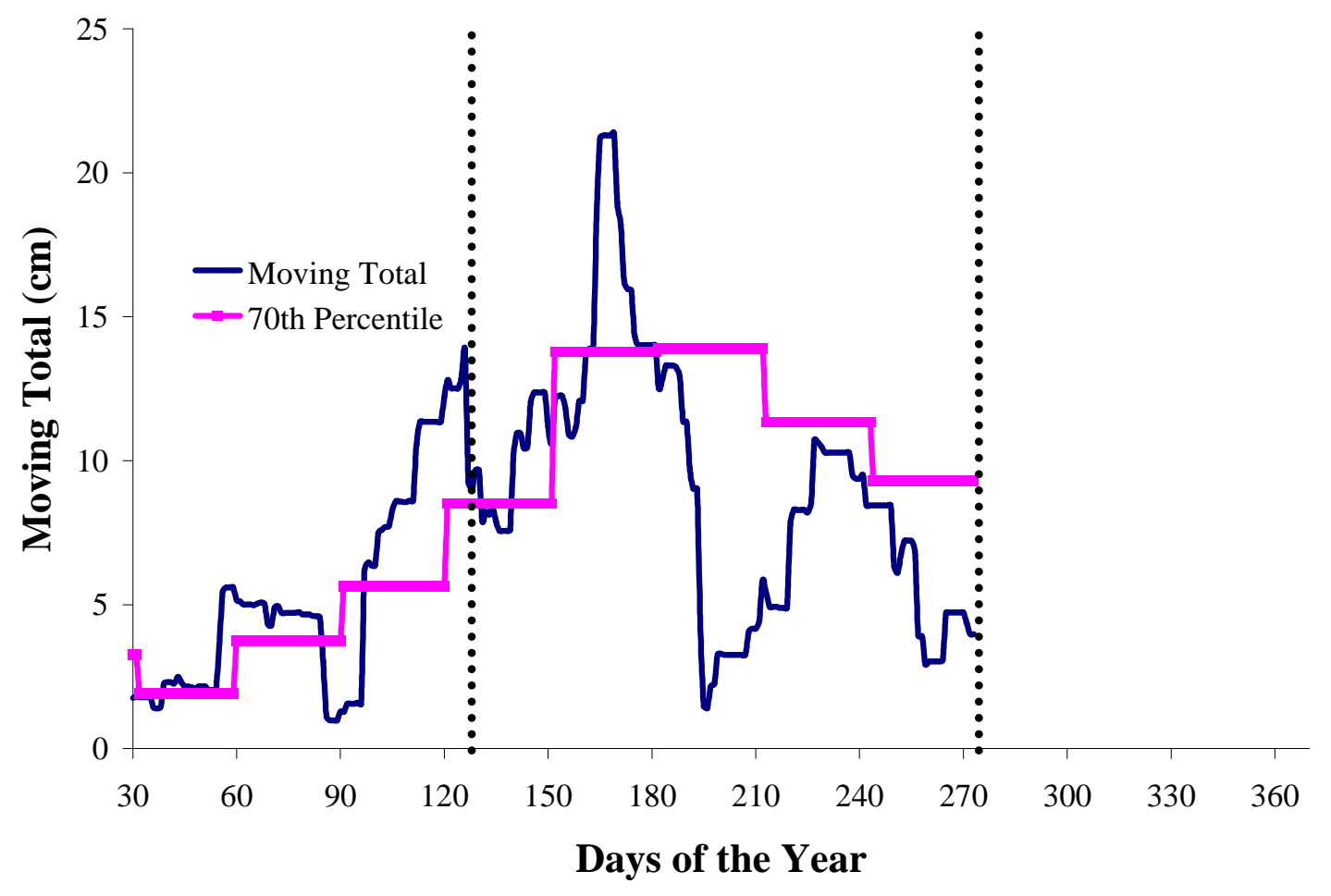

Figure D.126: Moving total graph for plots S1, S2, S3, and S6 at Marcell for year 2001. 


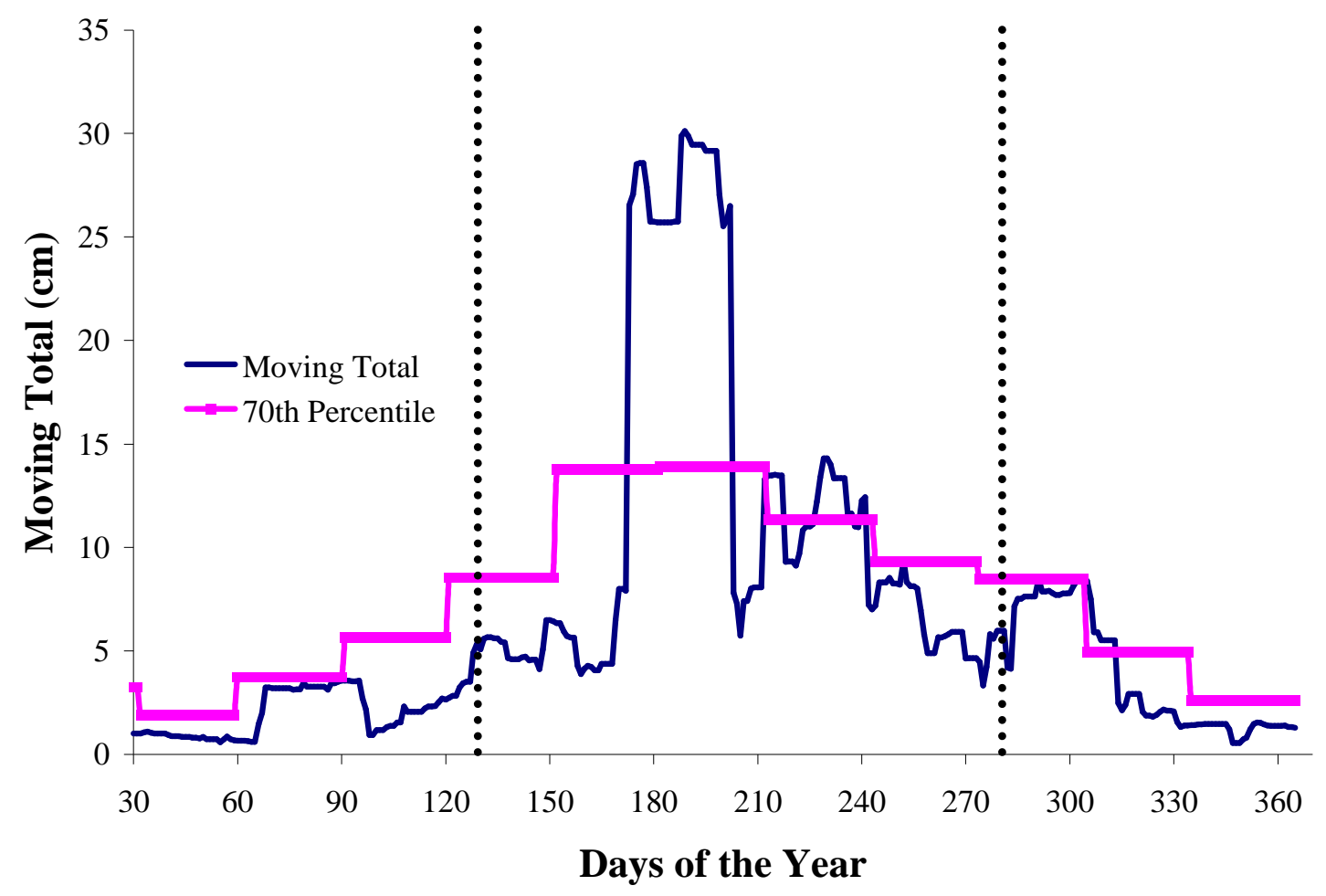

Figure D.127: Moving total graph for plots S1, S2, S3, and S6 at Marcell for year 2002.

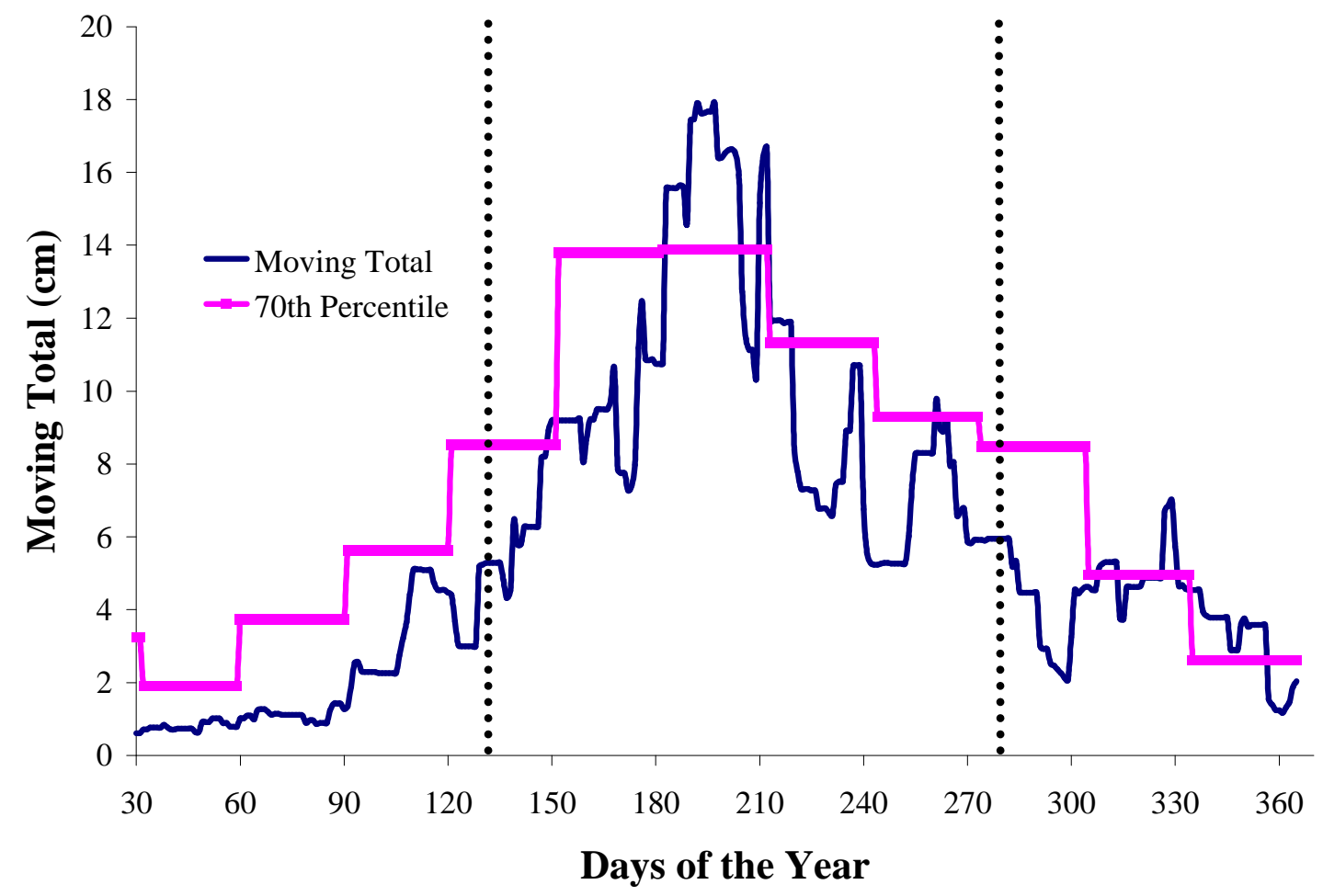

Figure D.128: Moving total graph for plots S1, S2, S3, and S6 at Marcell for year 2003. 


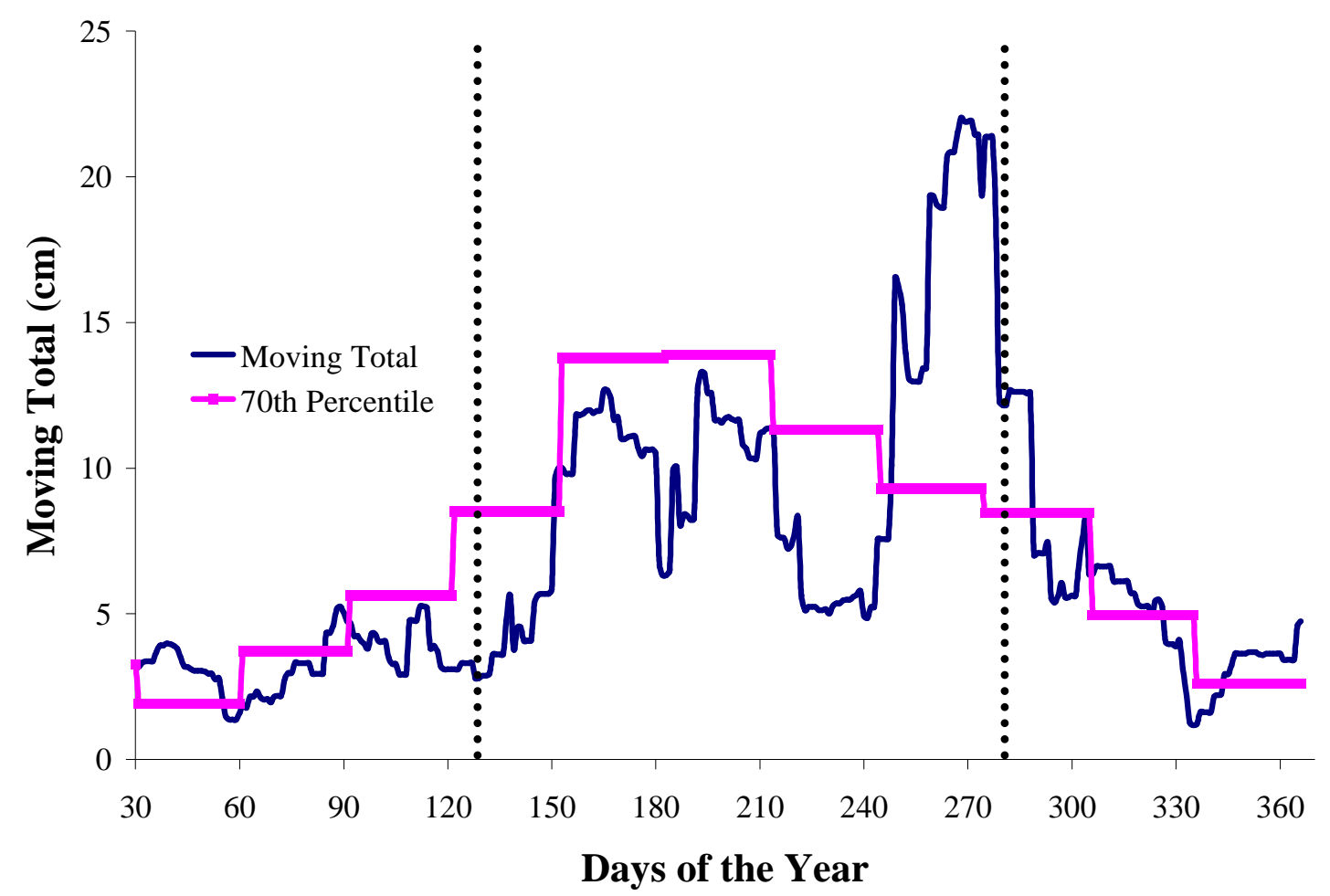

Figure D.129: Moving total graph for plots S1, S2, S3, and S6 at Marcell for year 2004.

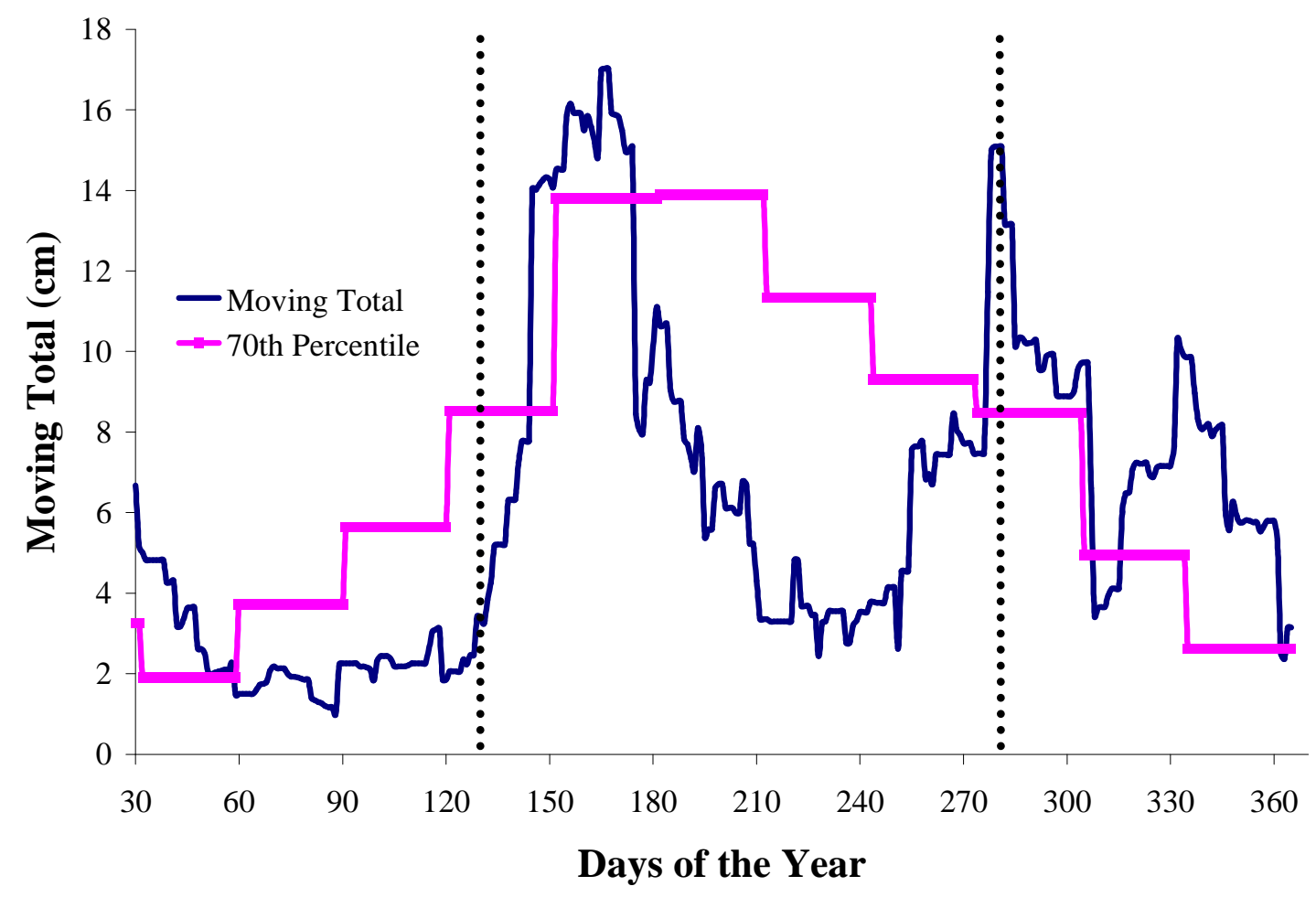

Figure D.130: Moving total graph for plots S1, S2, S3, and S6 at Marcell for year 2005. 


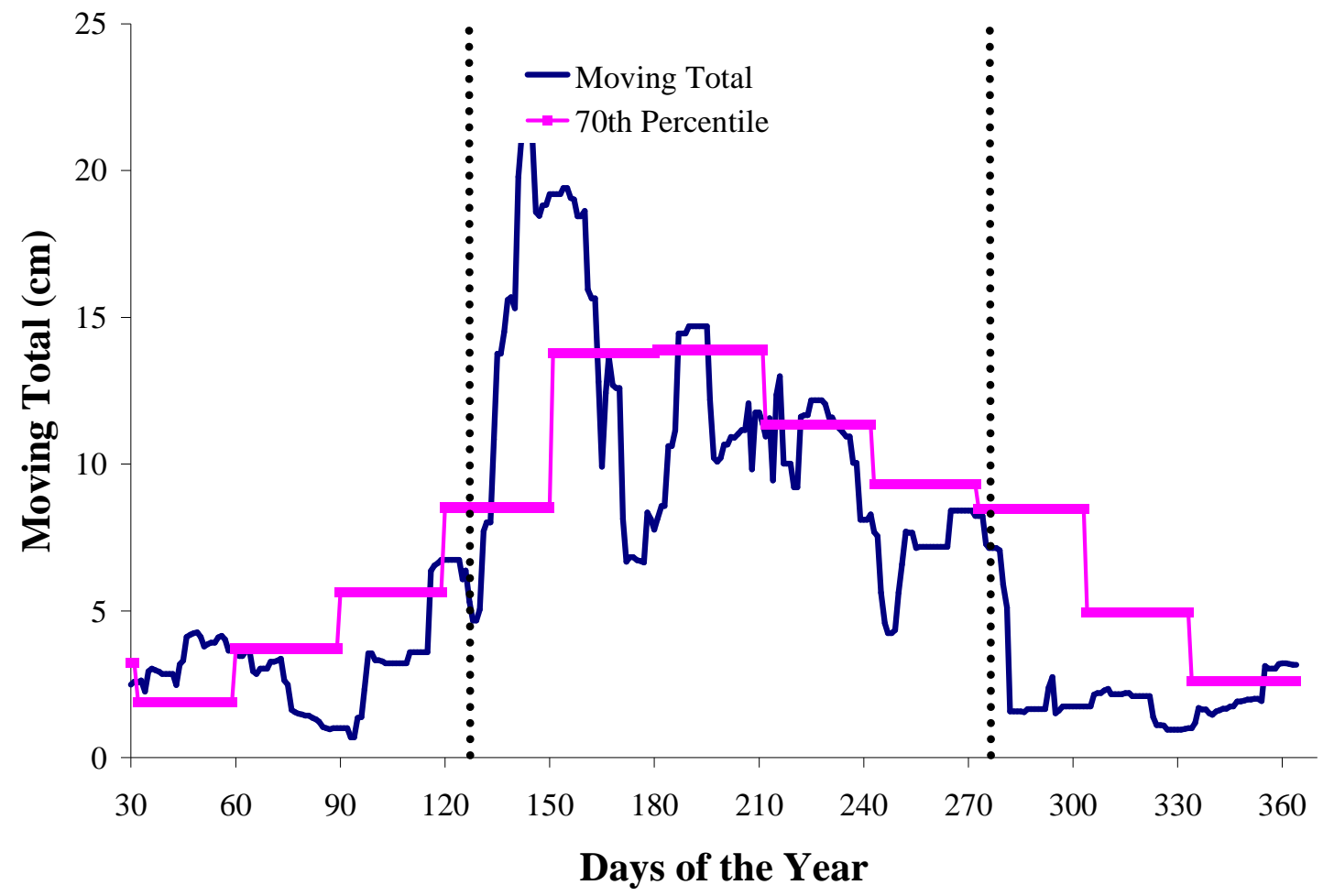

Figure D.131: Moving total graph for plots S4 and S5 at Marcell for year 1962.

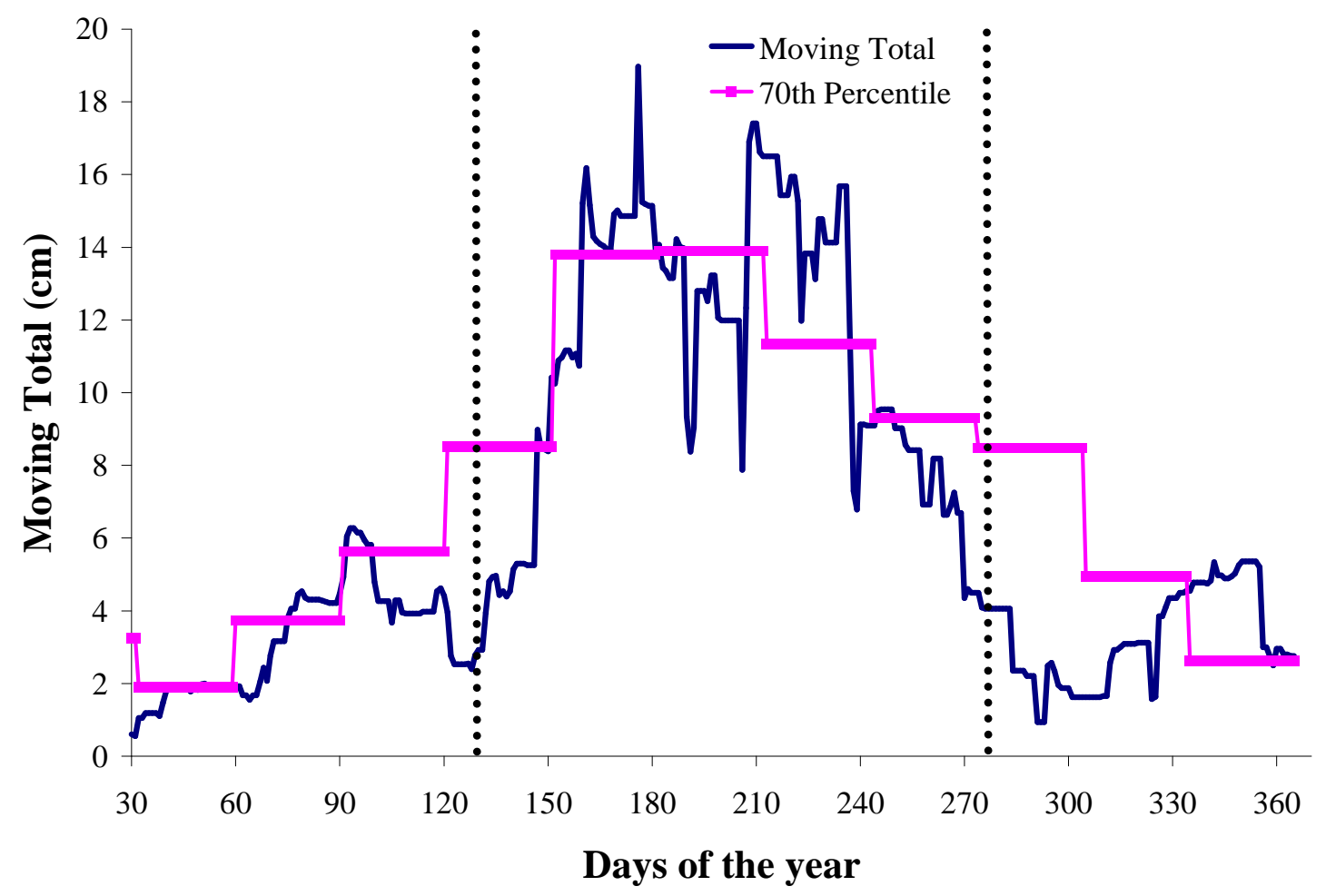

Figure D.132: Moving total graph for plots S4 and S5 at Marcell for year 1963. 


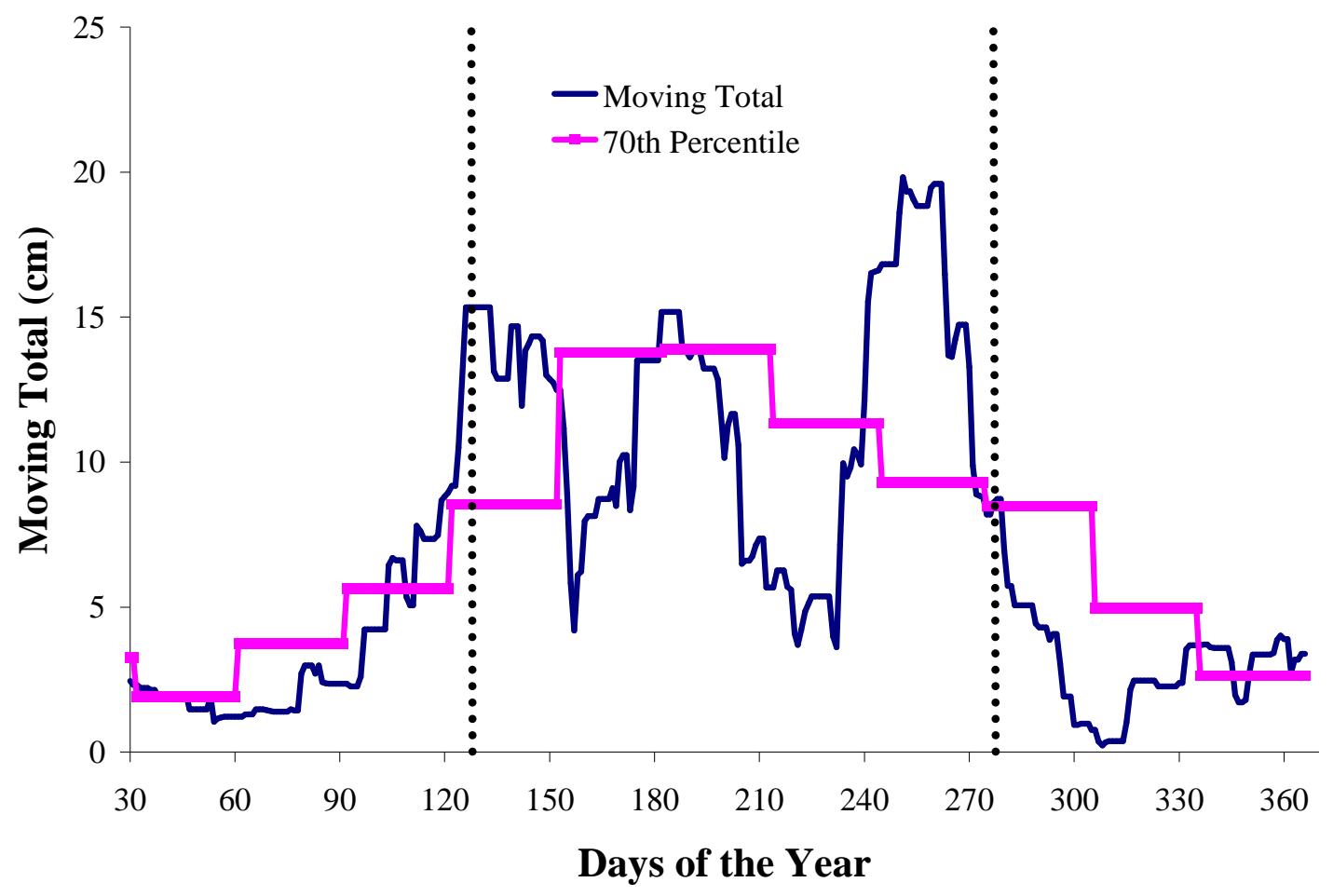

Figure D.133: Moving total graph for plots S4 and S5 at Marcell for year 1964.

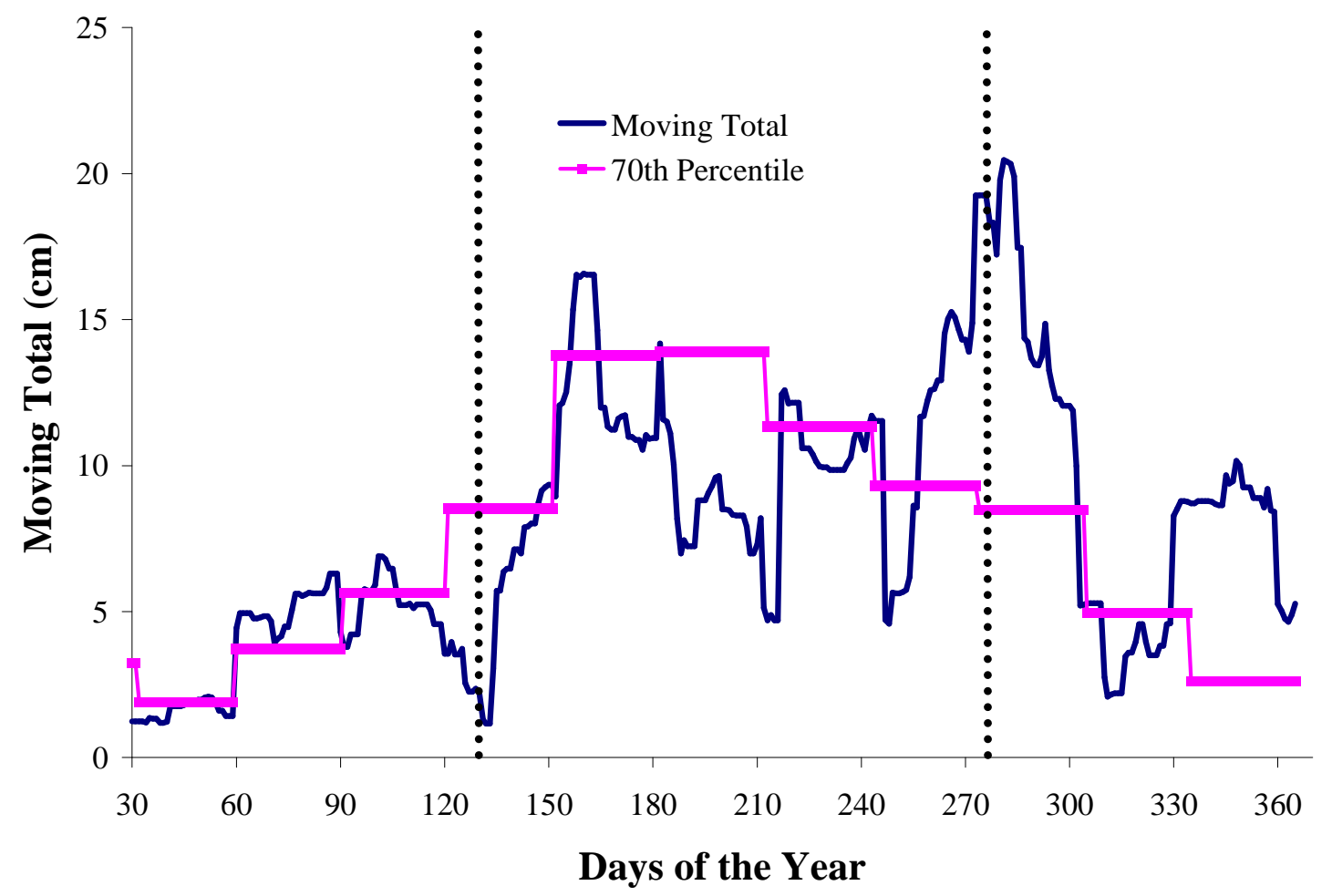

Figure D.134: Moving total graph for plots S4 and S5 at Marcell for year 1965. 


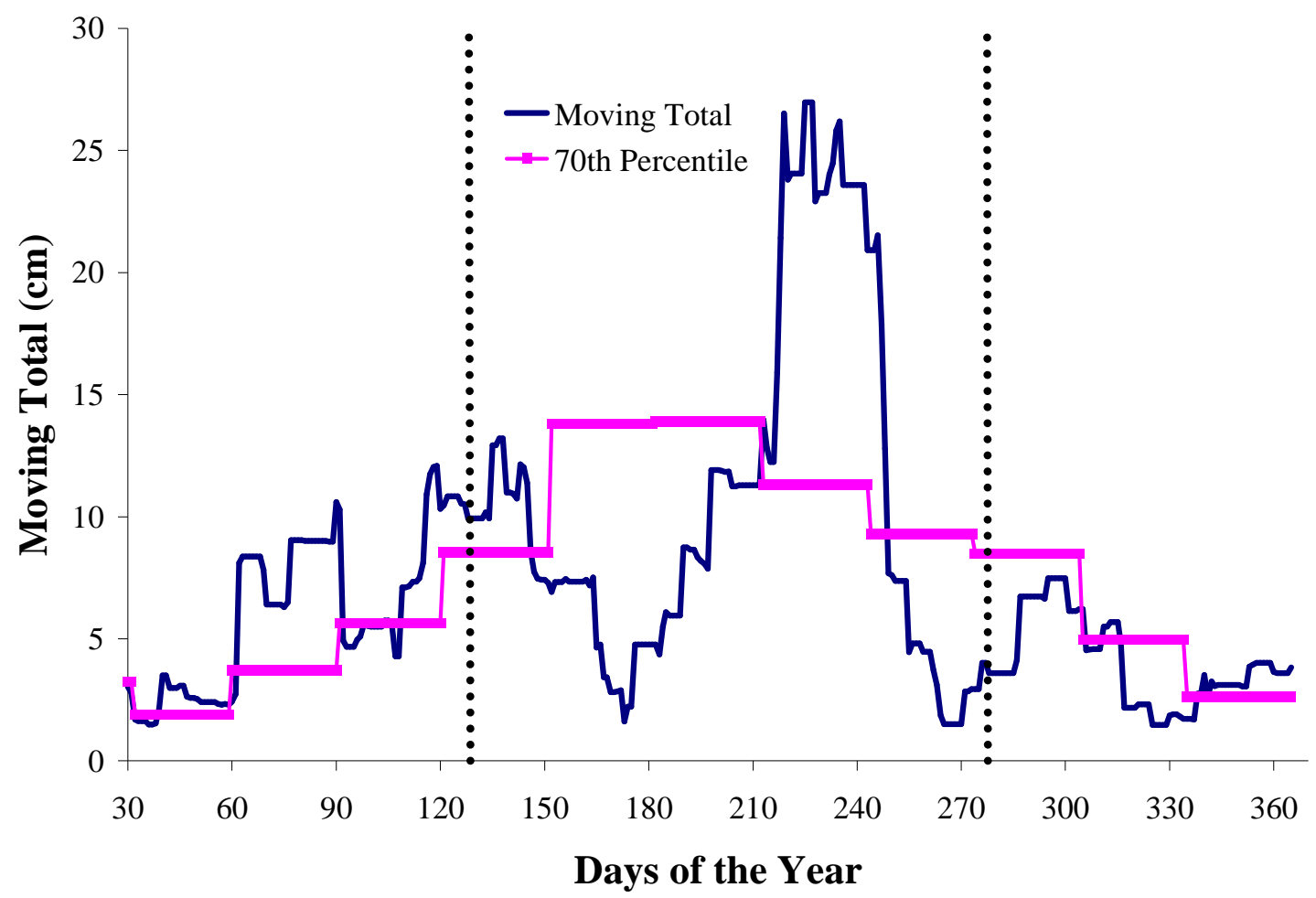

Figure D.135: Moving total graph for plots S4 and S5 at Marcell for year 1966.

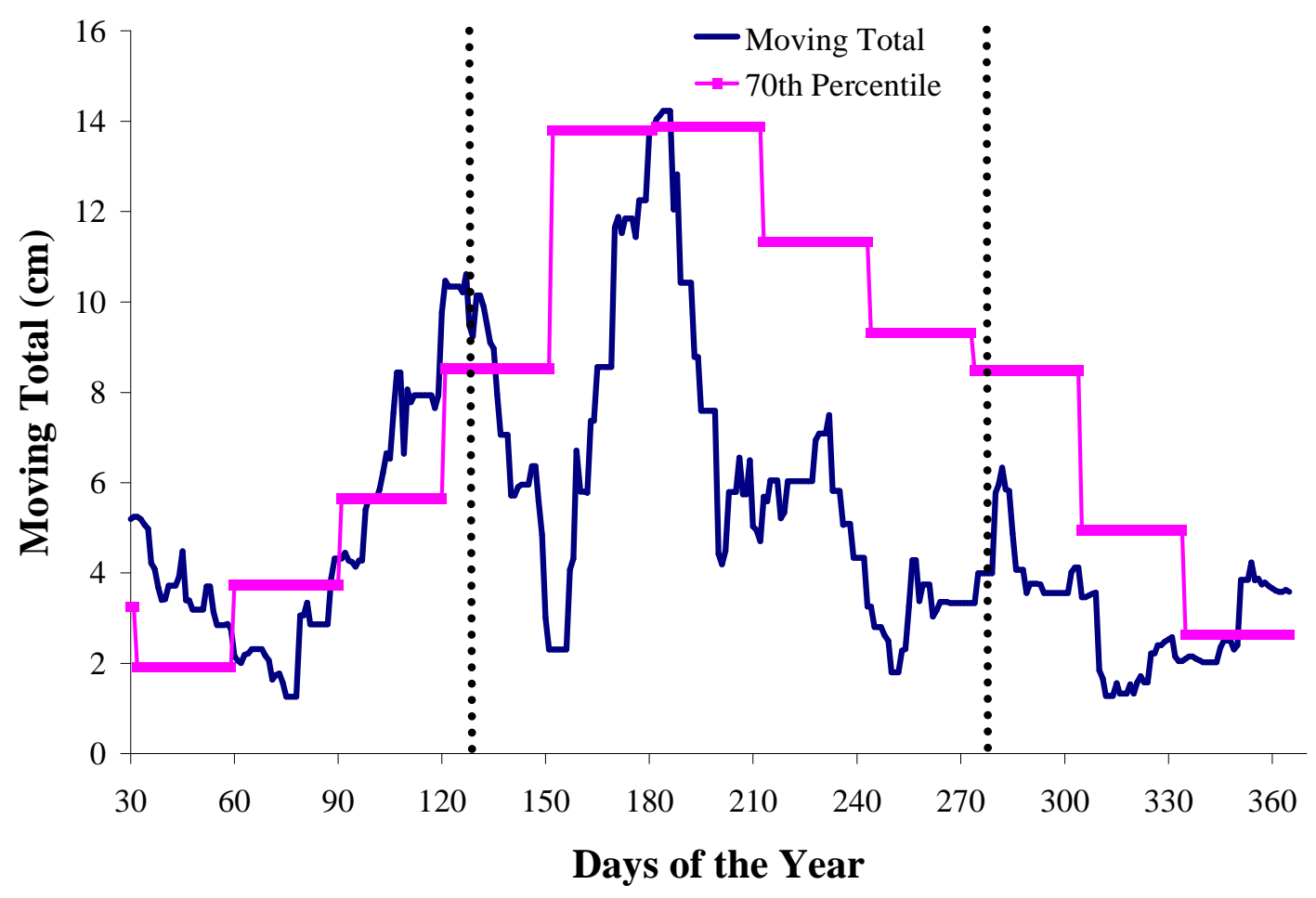

Figure D.136: Moving total graph for plots S4 and S5 at Marcell for year 1967. 


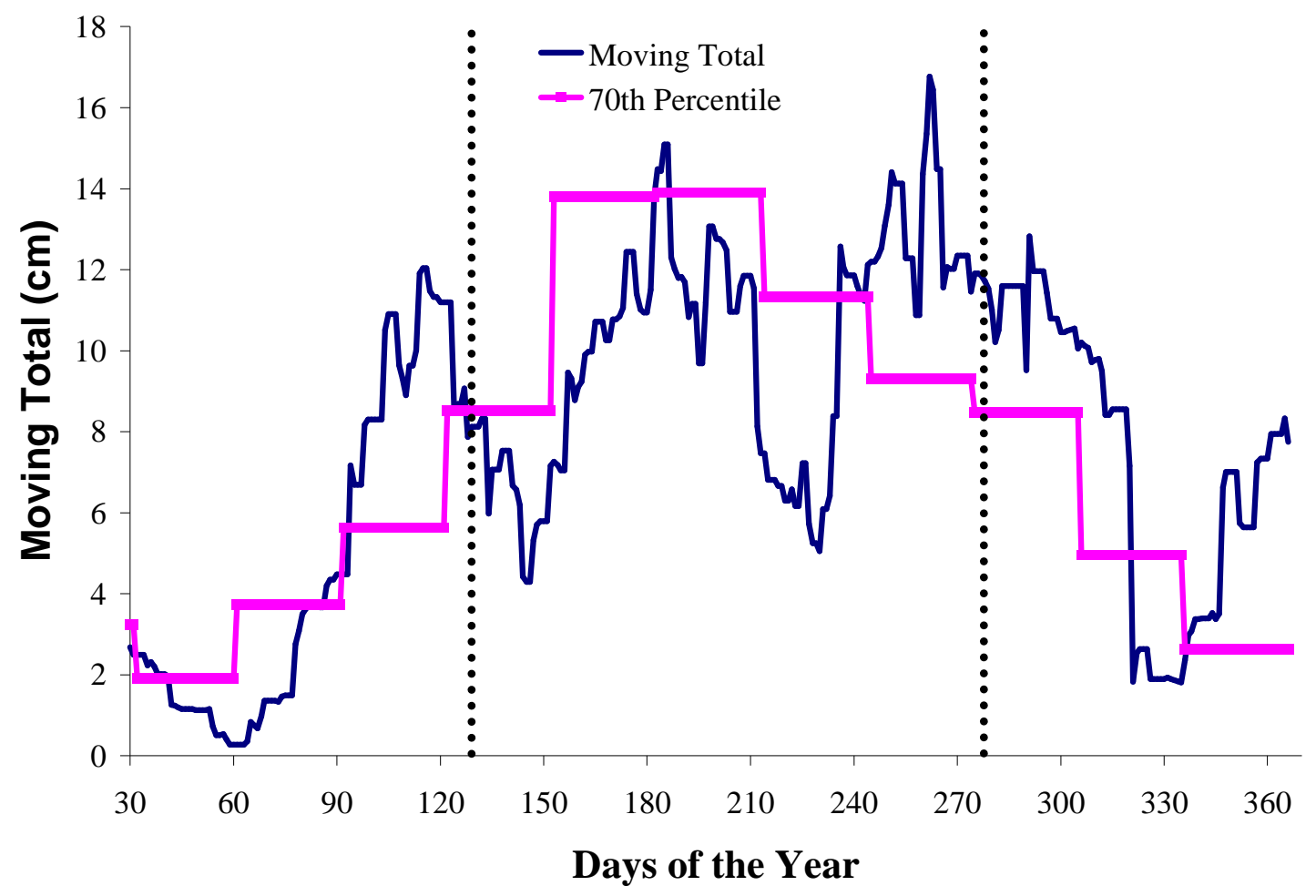

Figure D.137: Moving total graph for plots S4 and S5 at Marcell for year 1968.

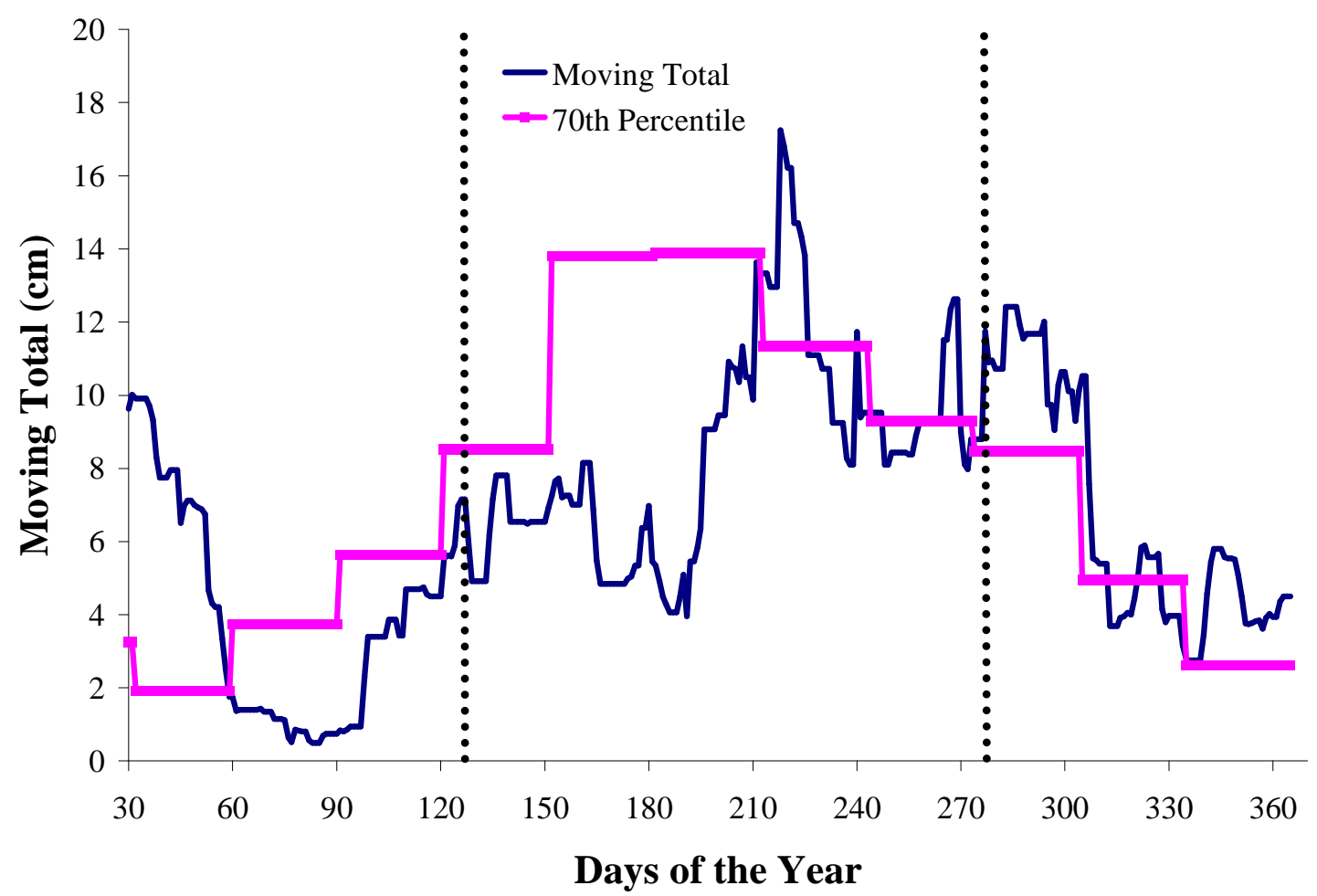

Figure D.138: Moving total graph for plots S4 and S5 at Marcell for year 1969. 


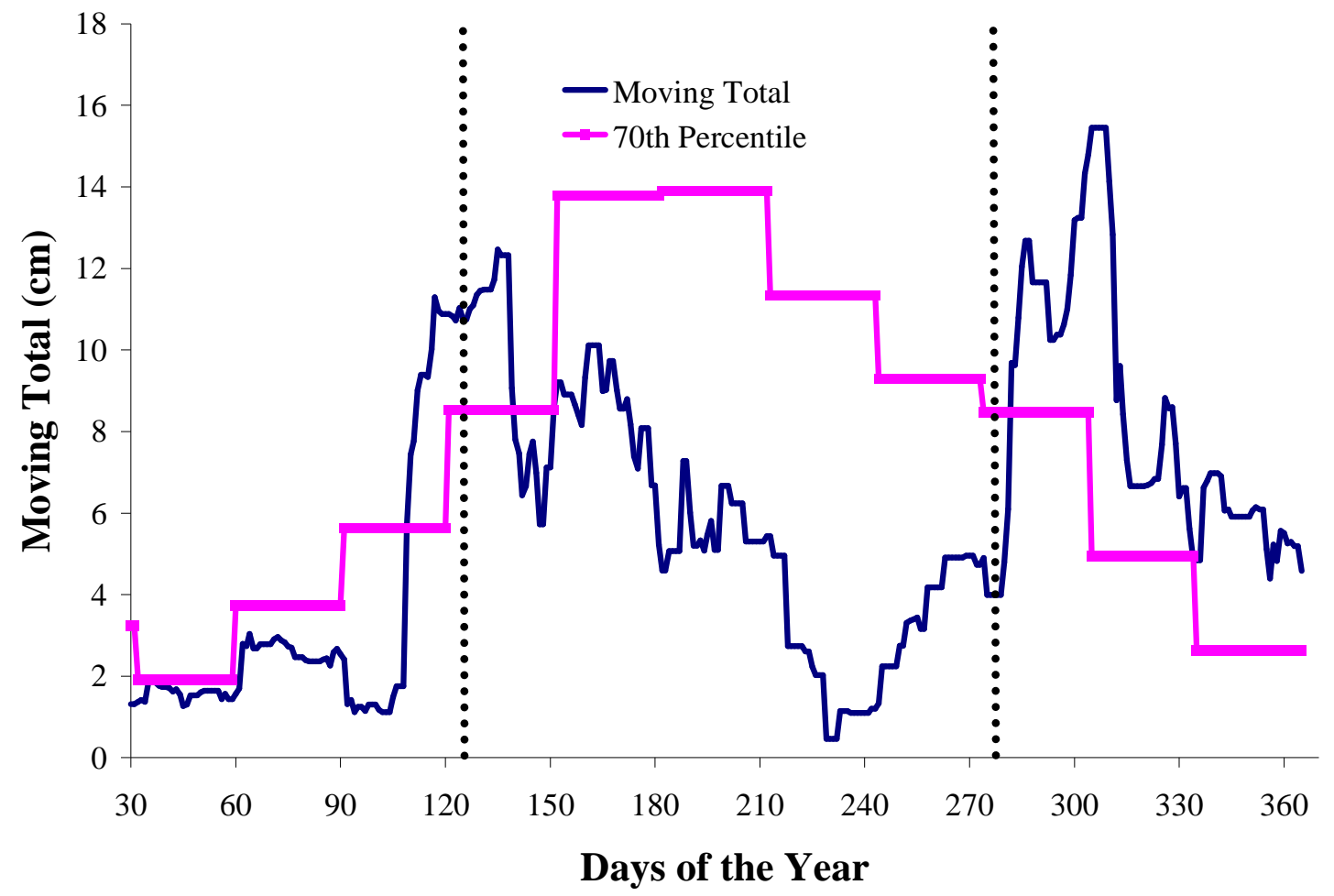

Figure D.139: Moving total graph for plots S4 and S5 at Marcell for year 1970.

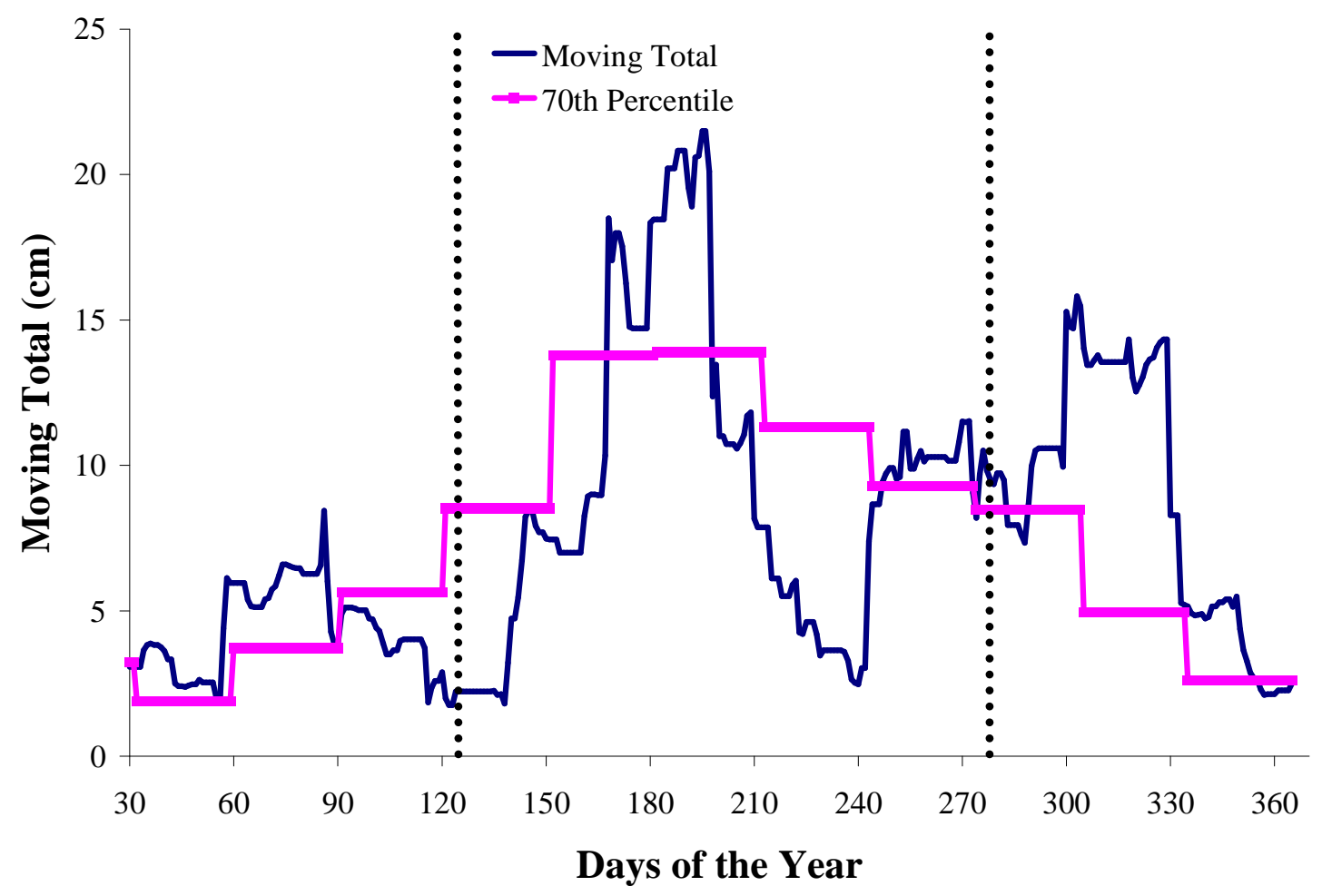

Figure D.140: Moving total graph for plots S4 and S5 at Marcell for year 1971. 


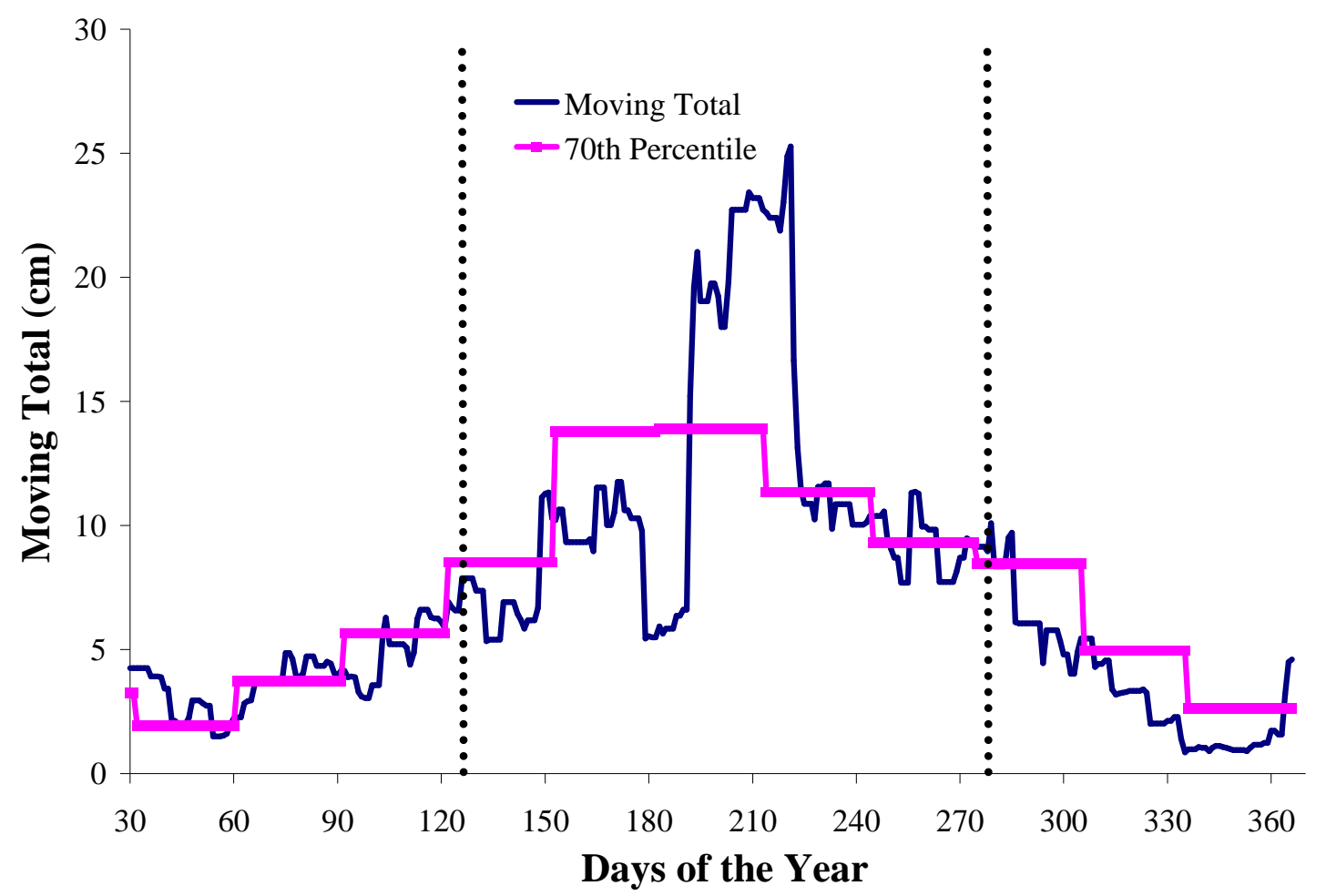

Figure D.141: Moving total graph for plots S4 and S5 at Marcell for year 1972.

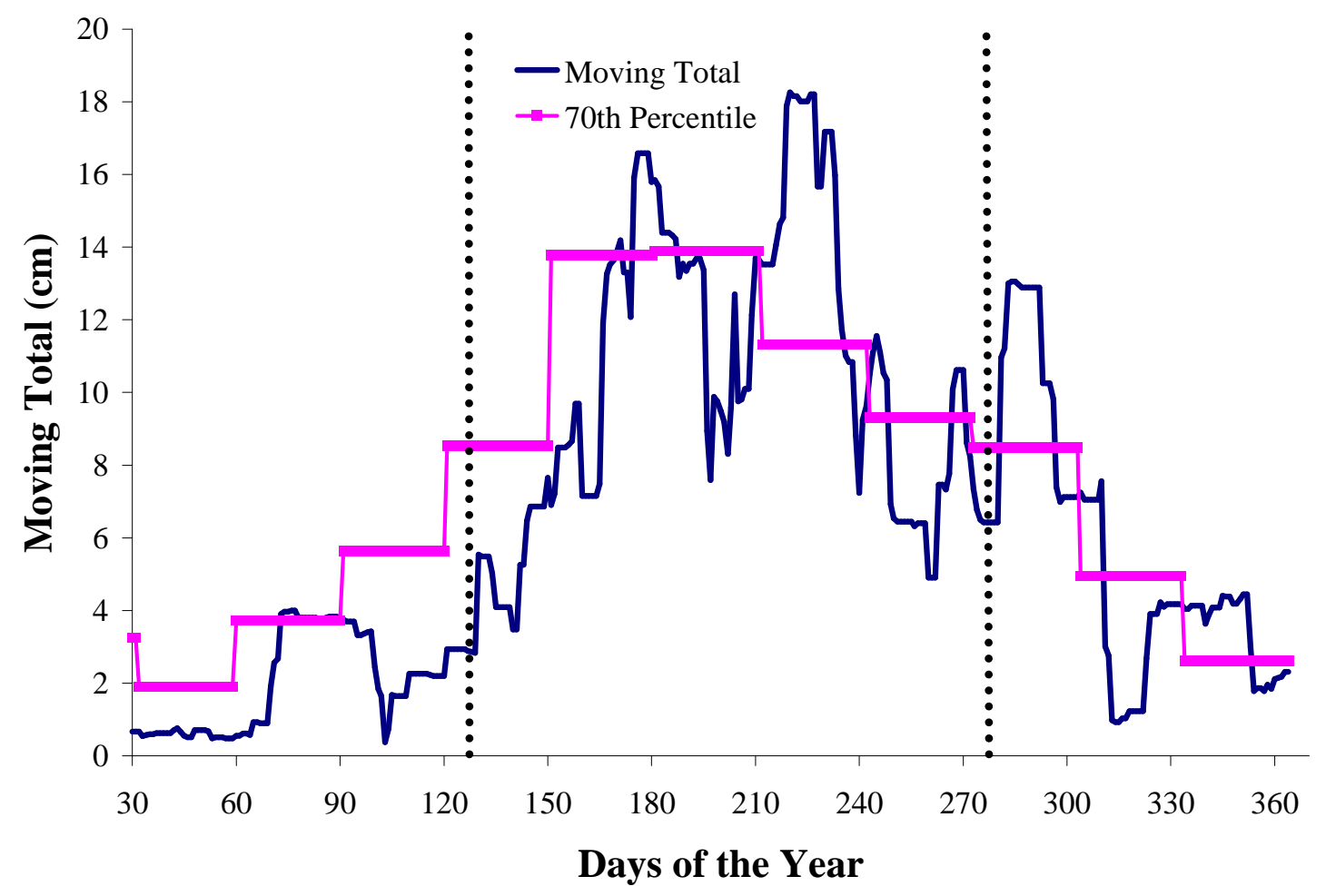

Figure D.142: Moving total graph for plots S4 and S5 at Marcell for year 1973. 


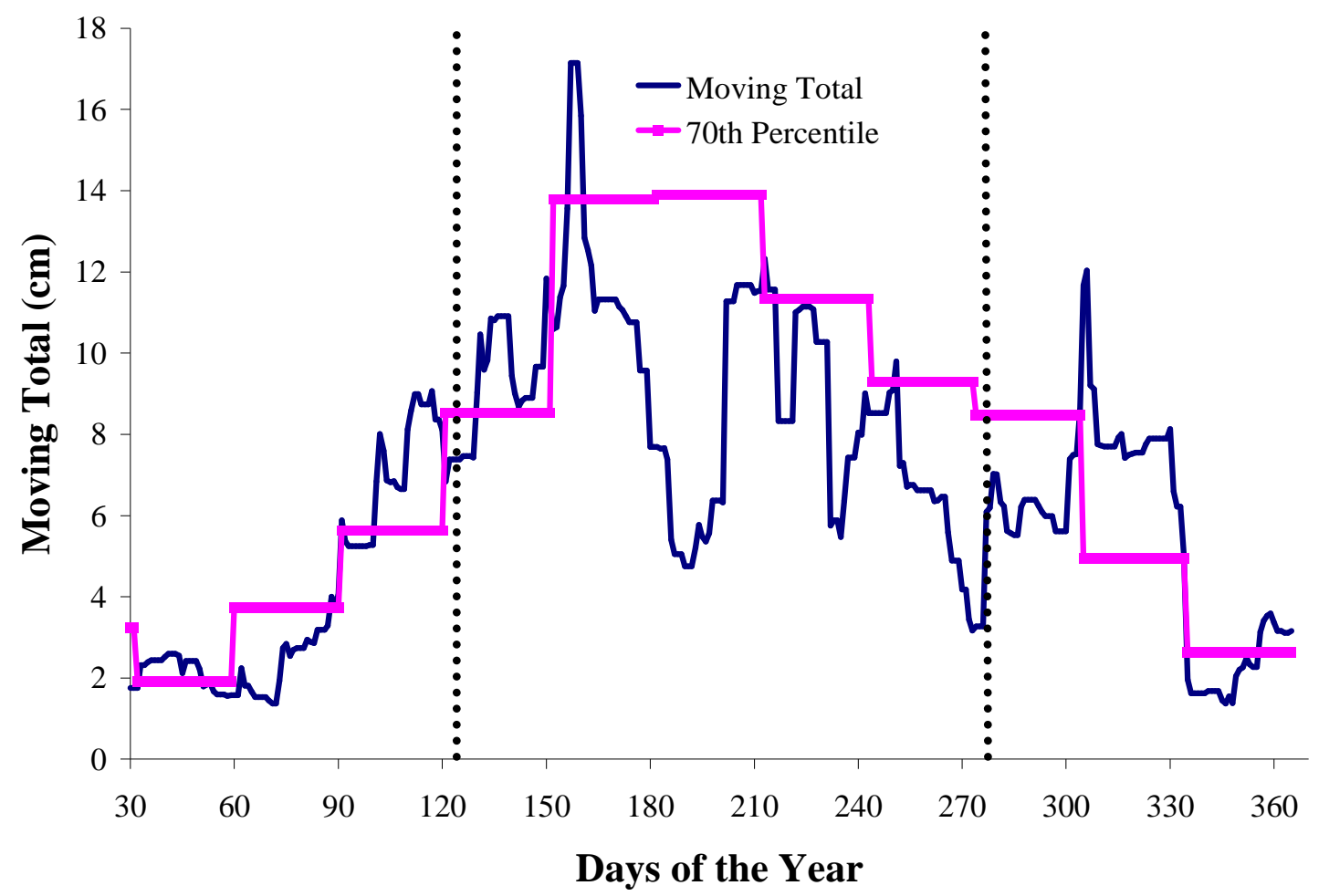

Figure D.143: Moving total graph for plots S4 and S5 at Marcell for year 1974.

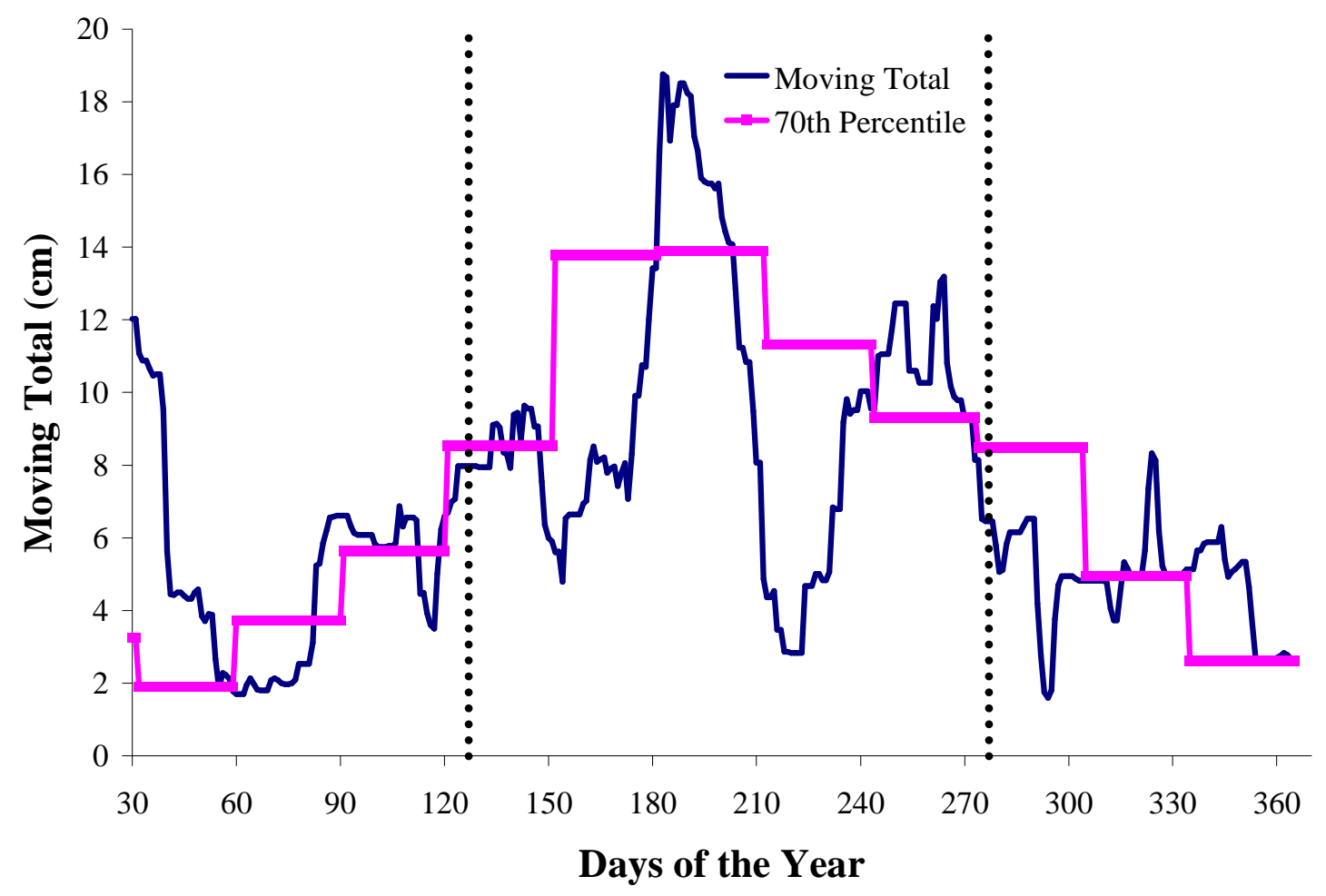

Figure D.144: Moving total graph for plots S4 and S5 at Marcell for year 1975. 


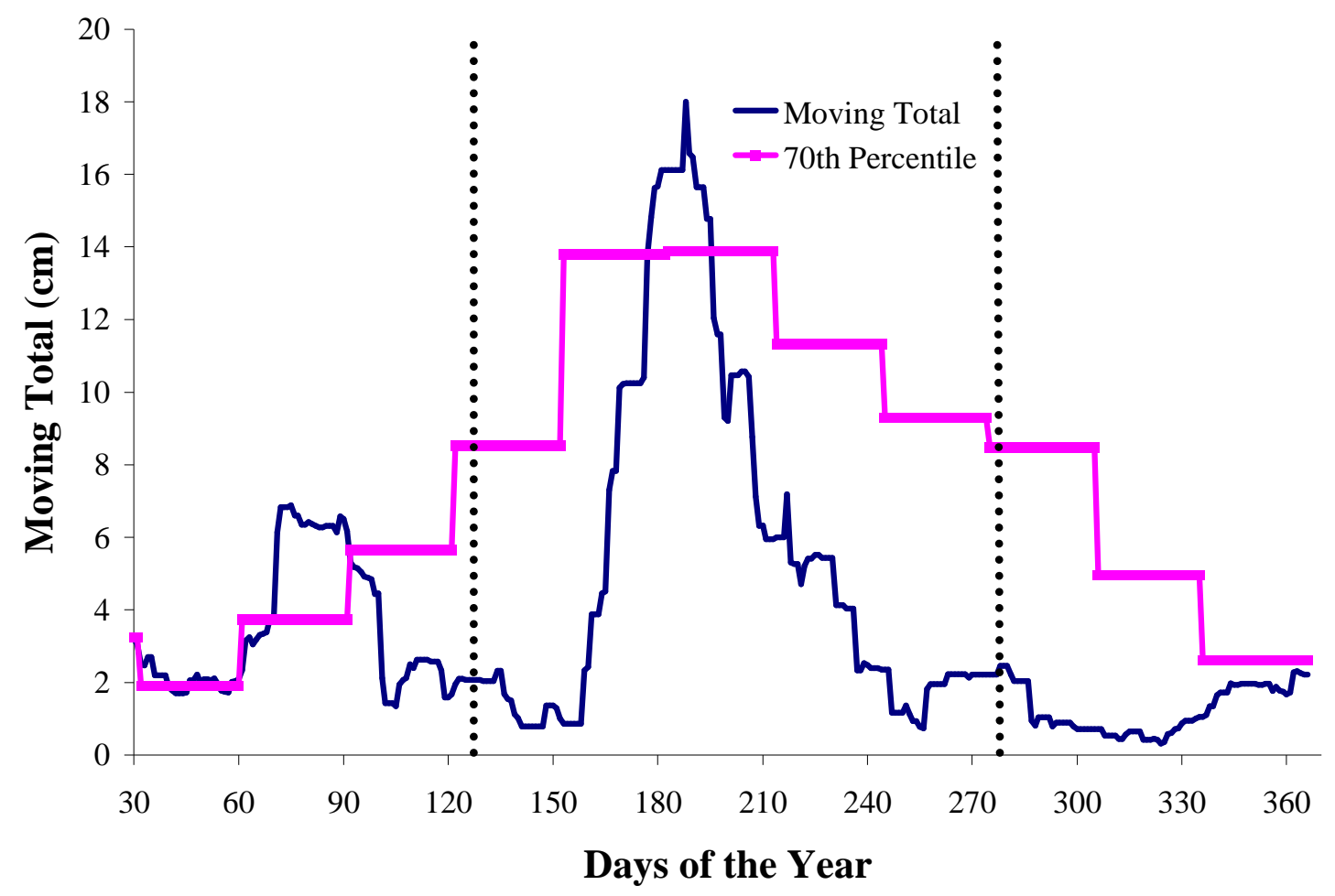

Figure D.145: Moving total graph for plots S4 and S5 at Marcell for year 1976.

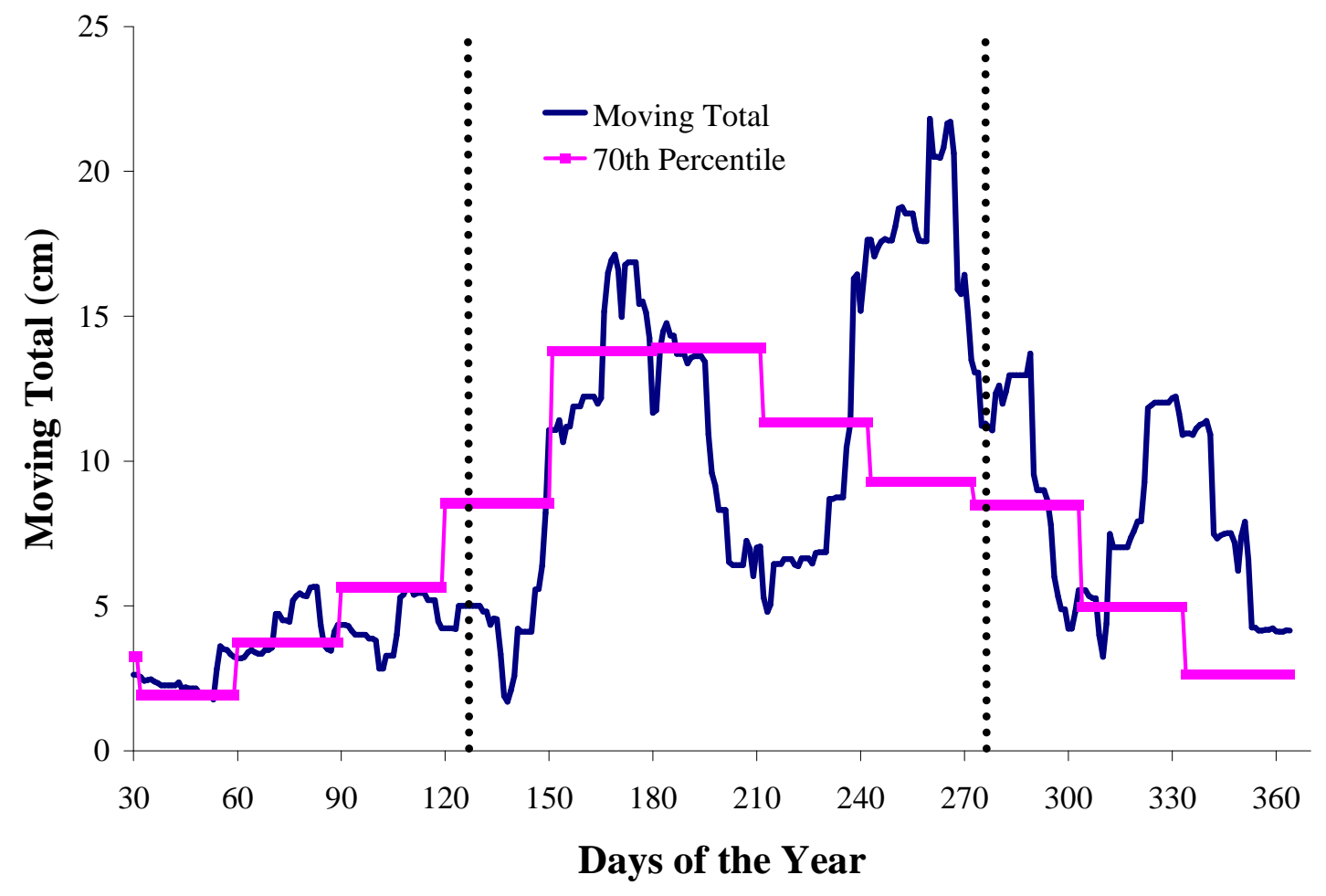

Figure D.146: Moving total graph for plots S4 and S5 at Marcell for year 1977. 


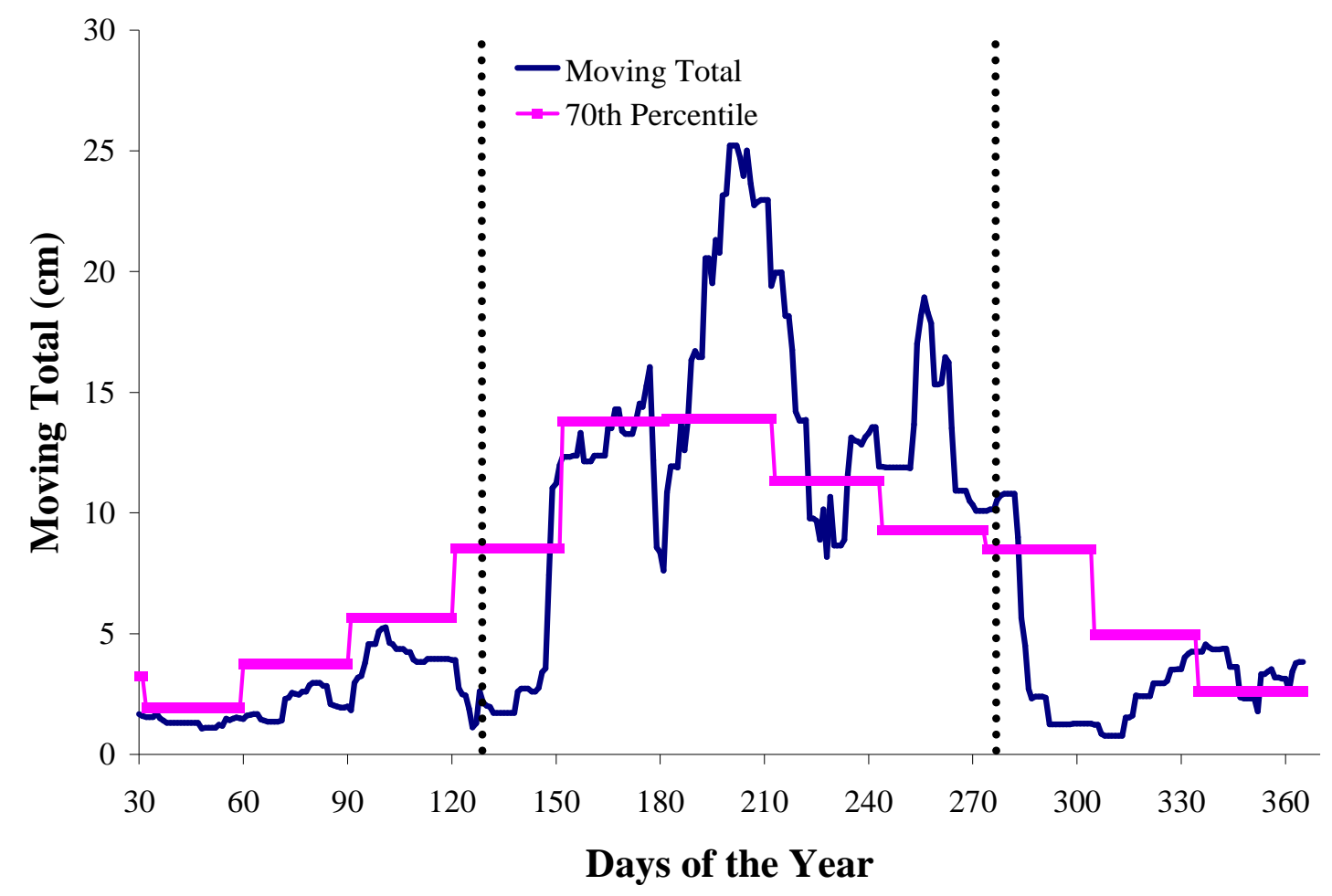

Figure D.147: Moving total graph for plots S4 and S5 at Marcell for year 1978.

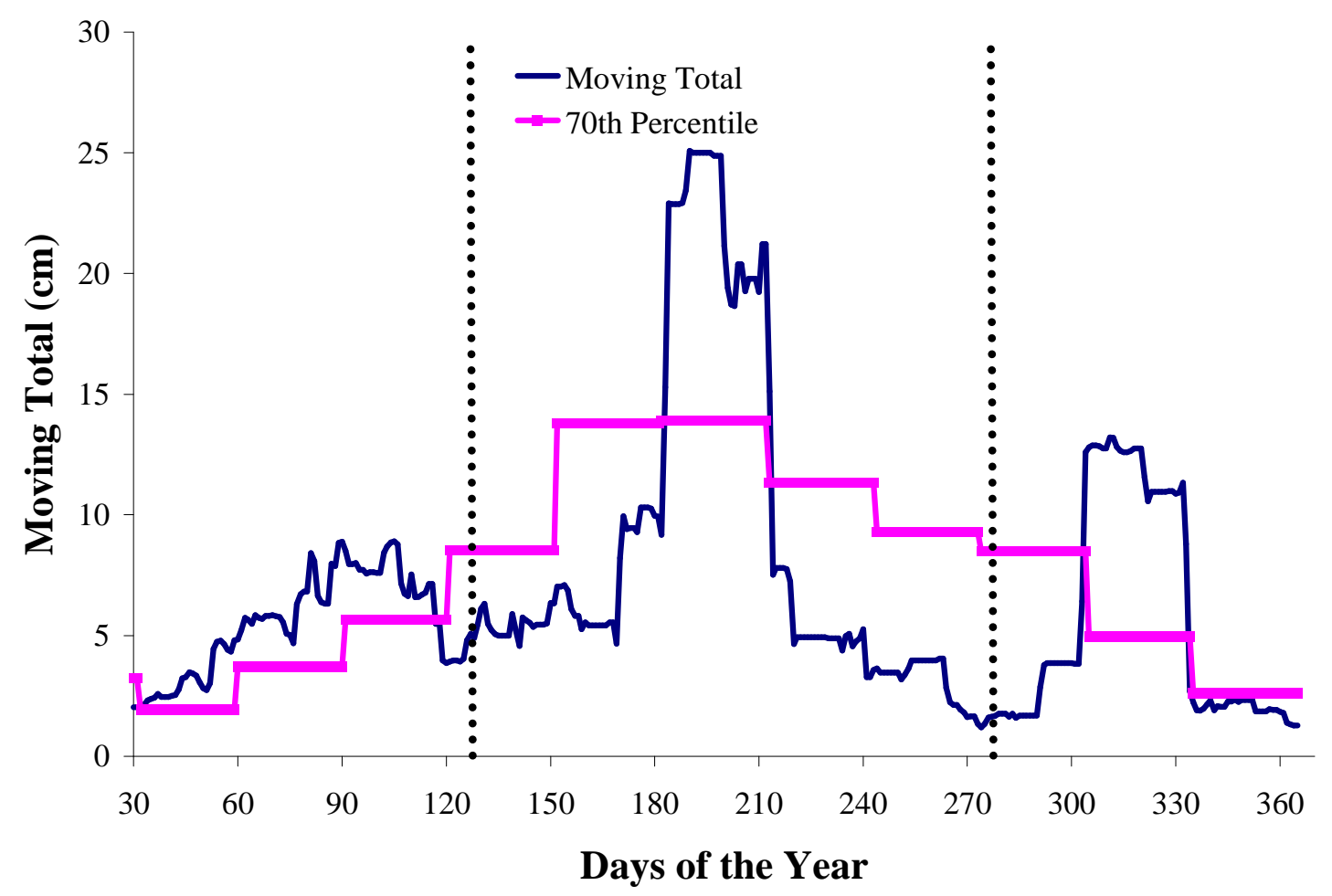

Figure D.148: Moving total graph for plots S4 and S5 at Marcell for year 1979. 


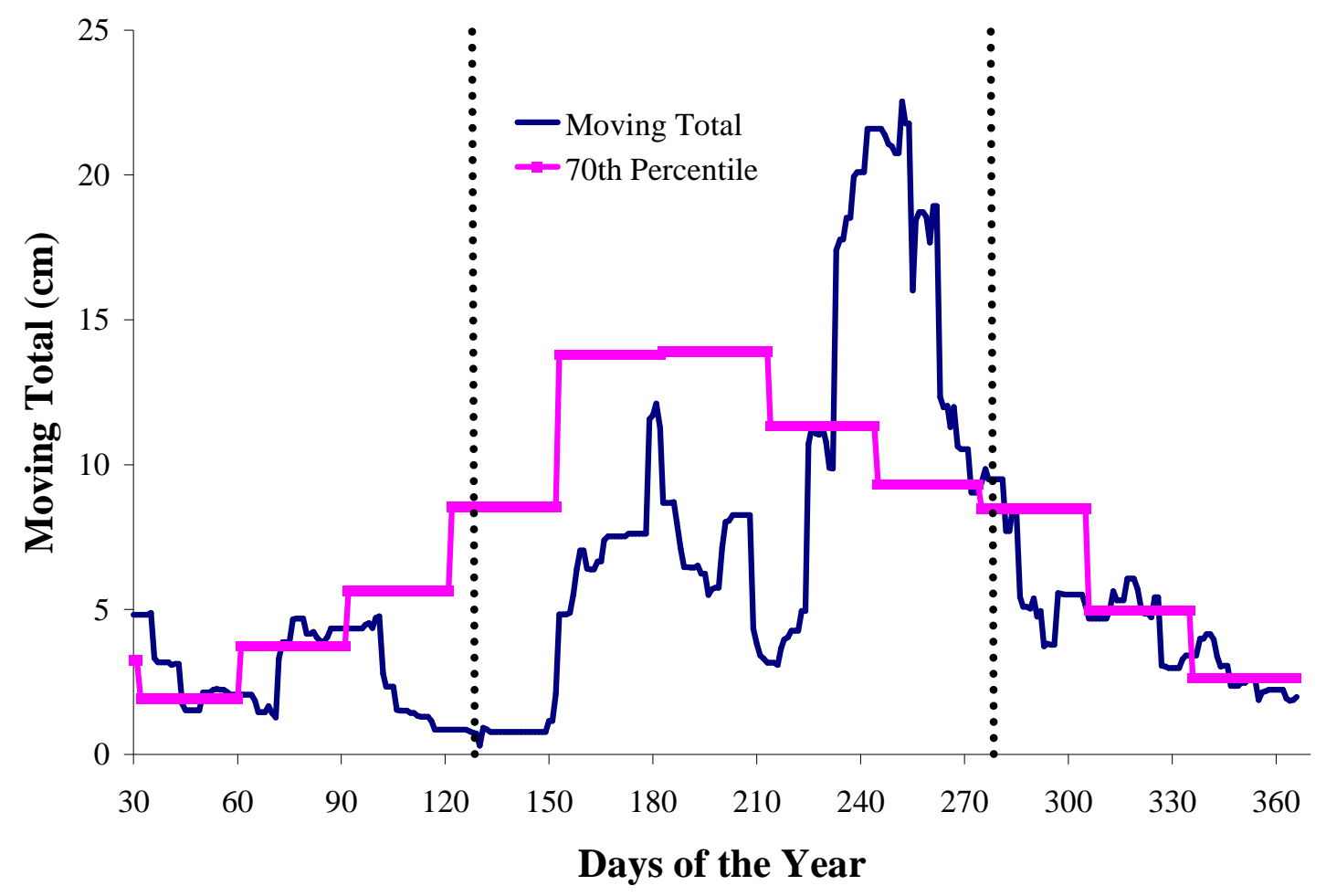

Figure D.149: Moving total graph for plots S4 and S5 at Marcell for year 1980.

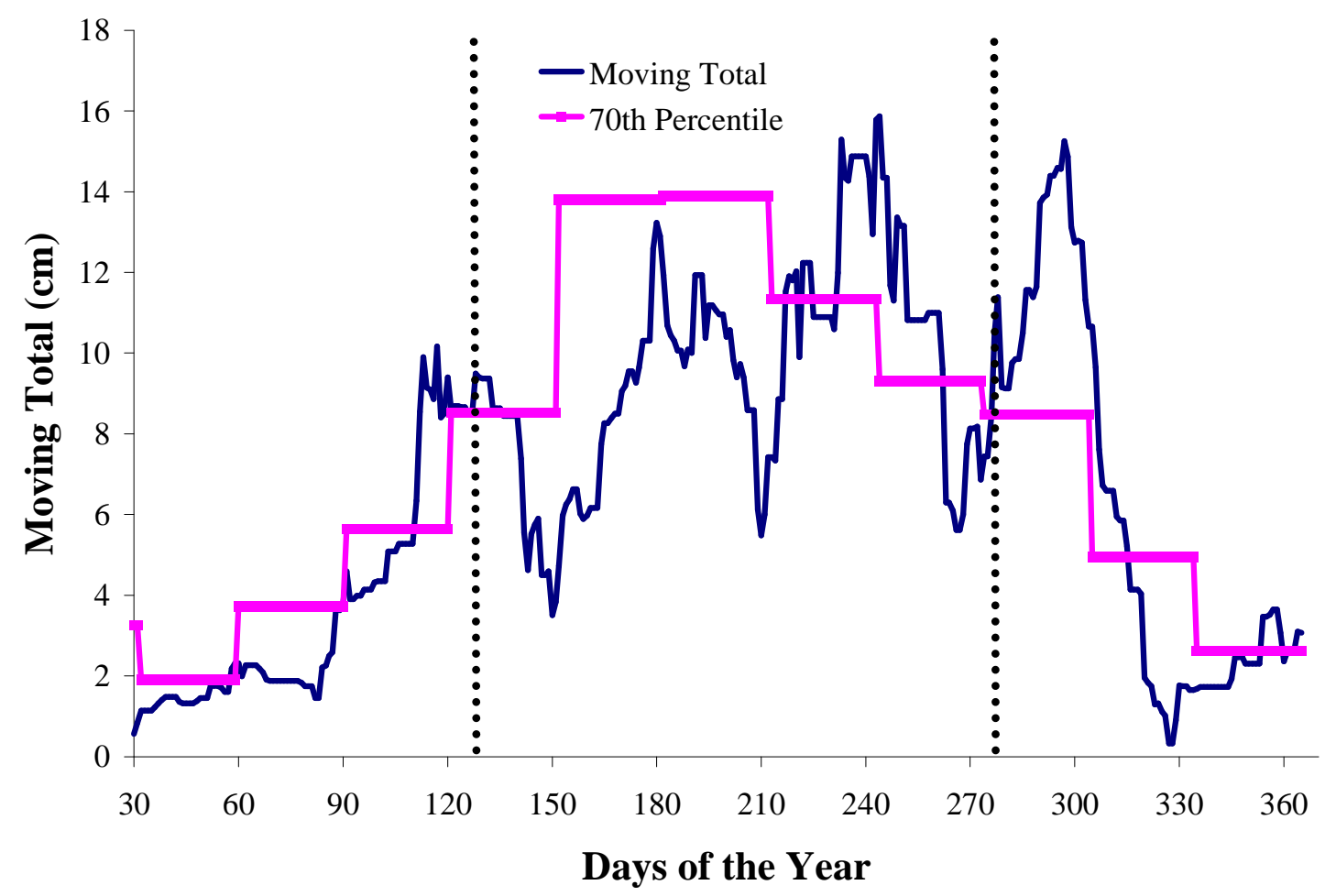

Figure D.150: Moving total graph for plots S4 and S5 at Marcell for year 1981. 


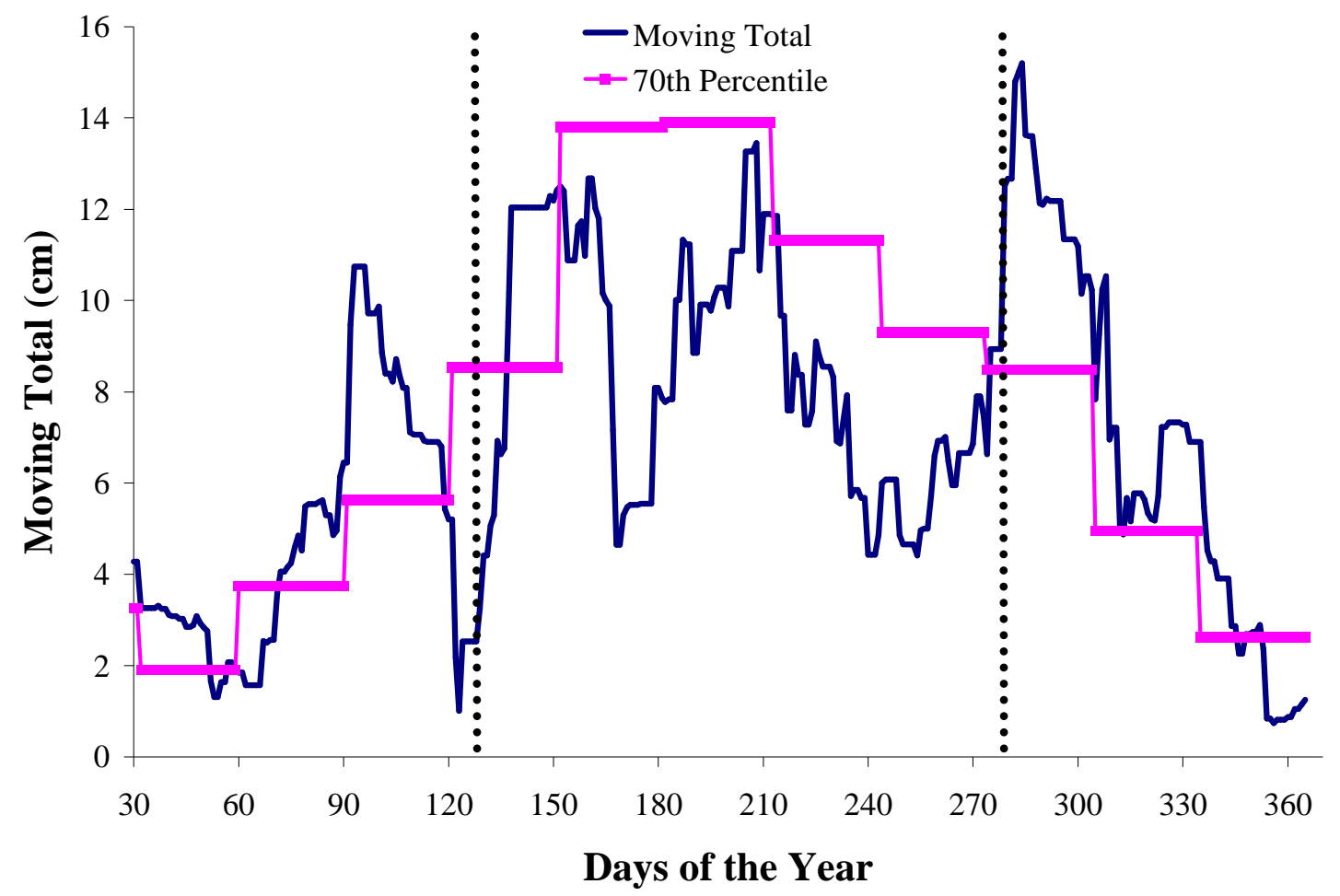

Figure D.151: Moving total graph for plots S4 and S5 at Marcell for year 1982.

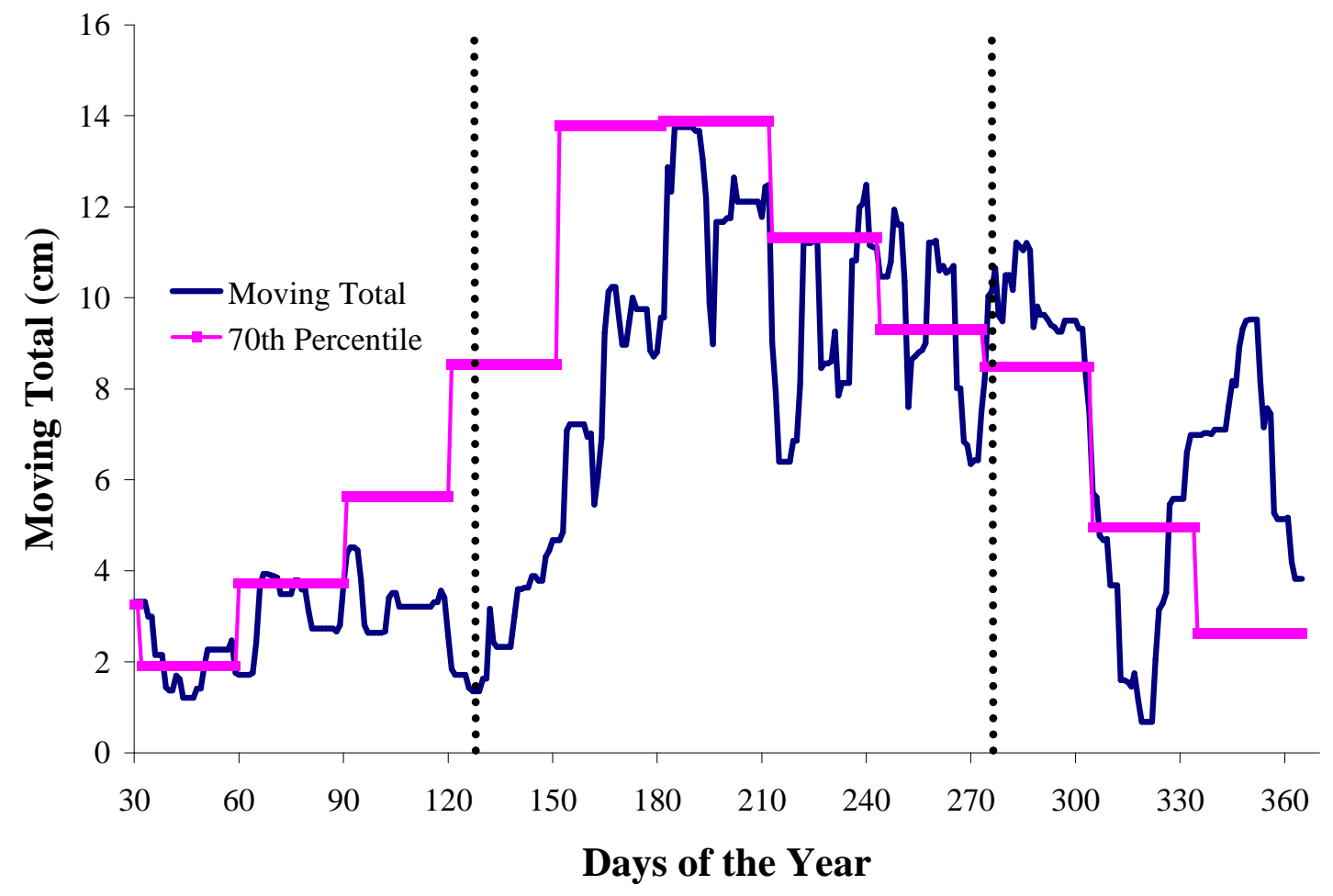

Figure D.152: Moving total graph for plots S4 and S5 at Marcell for year 1983. 


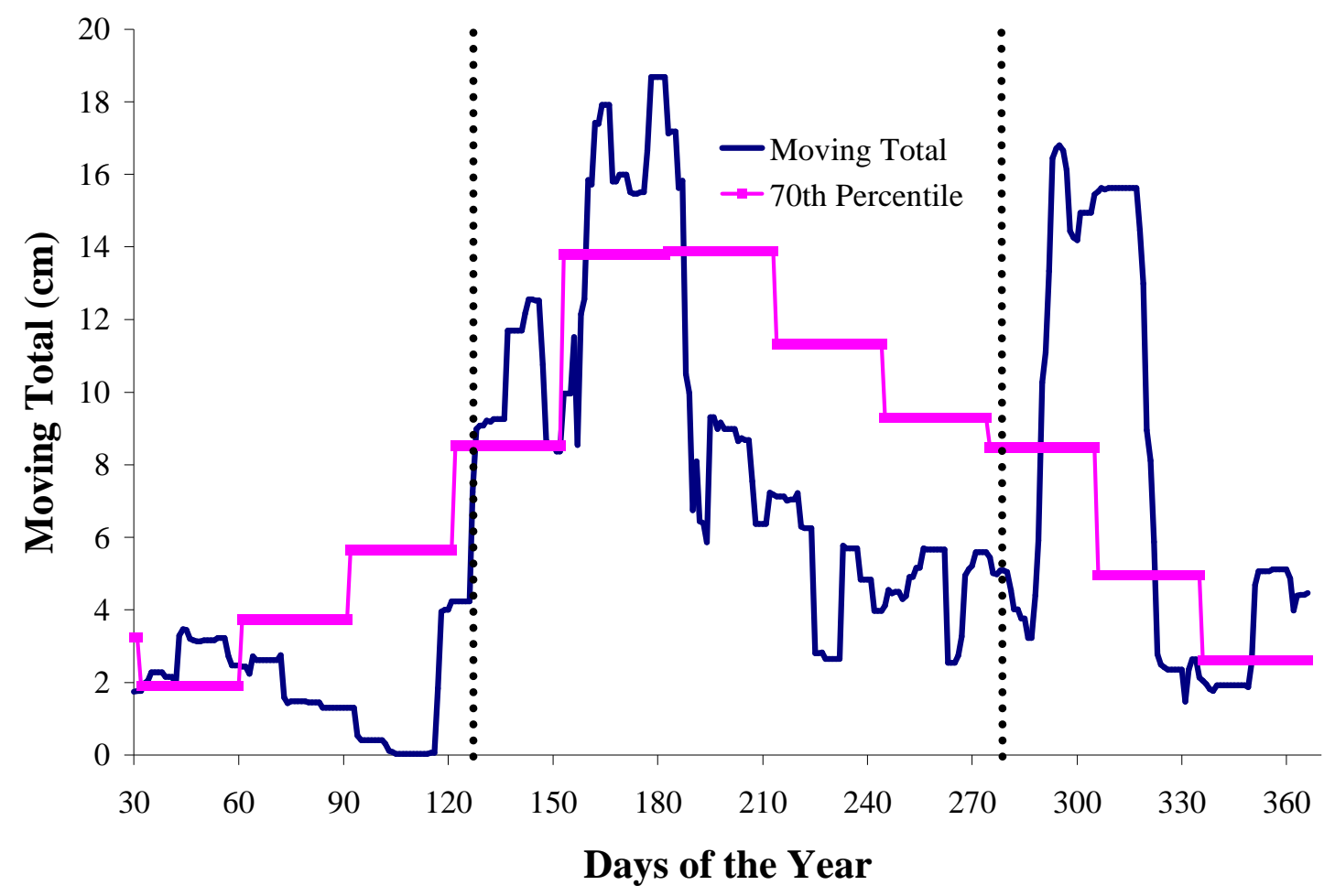

Figure D.153: Moving total graph for plots S4 and S5 at Marcell for year 1984.

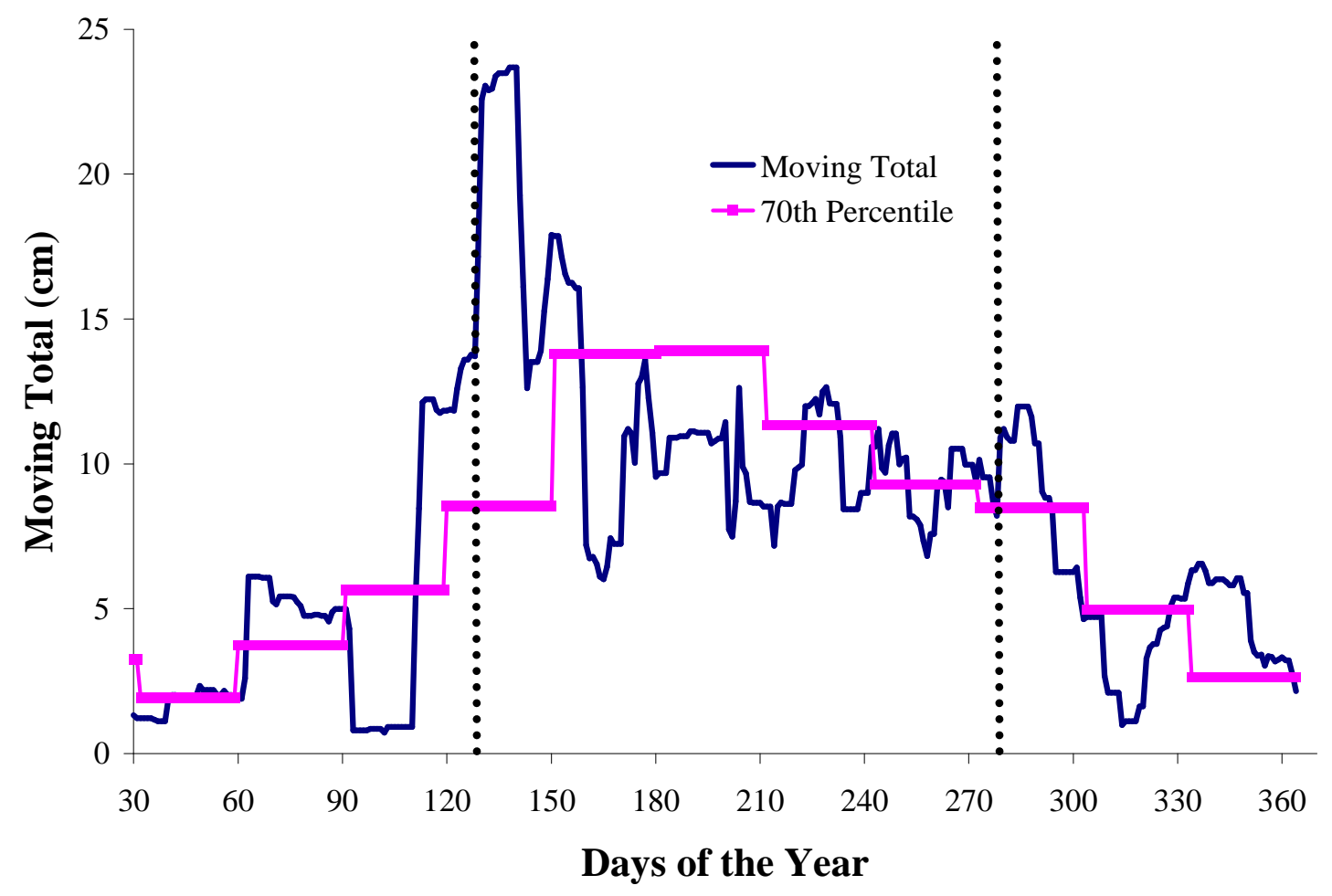

Figure D.154: Moving total graph for plots S4 and S5 at Marcell for year 1985. 


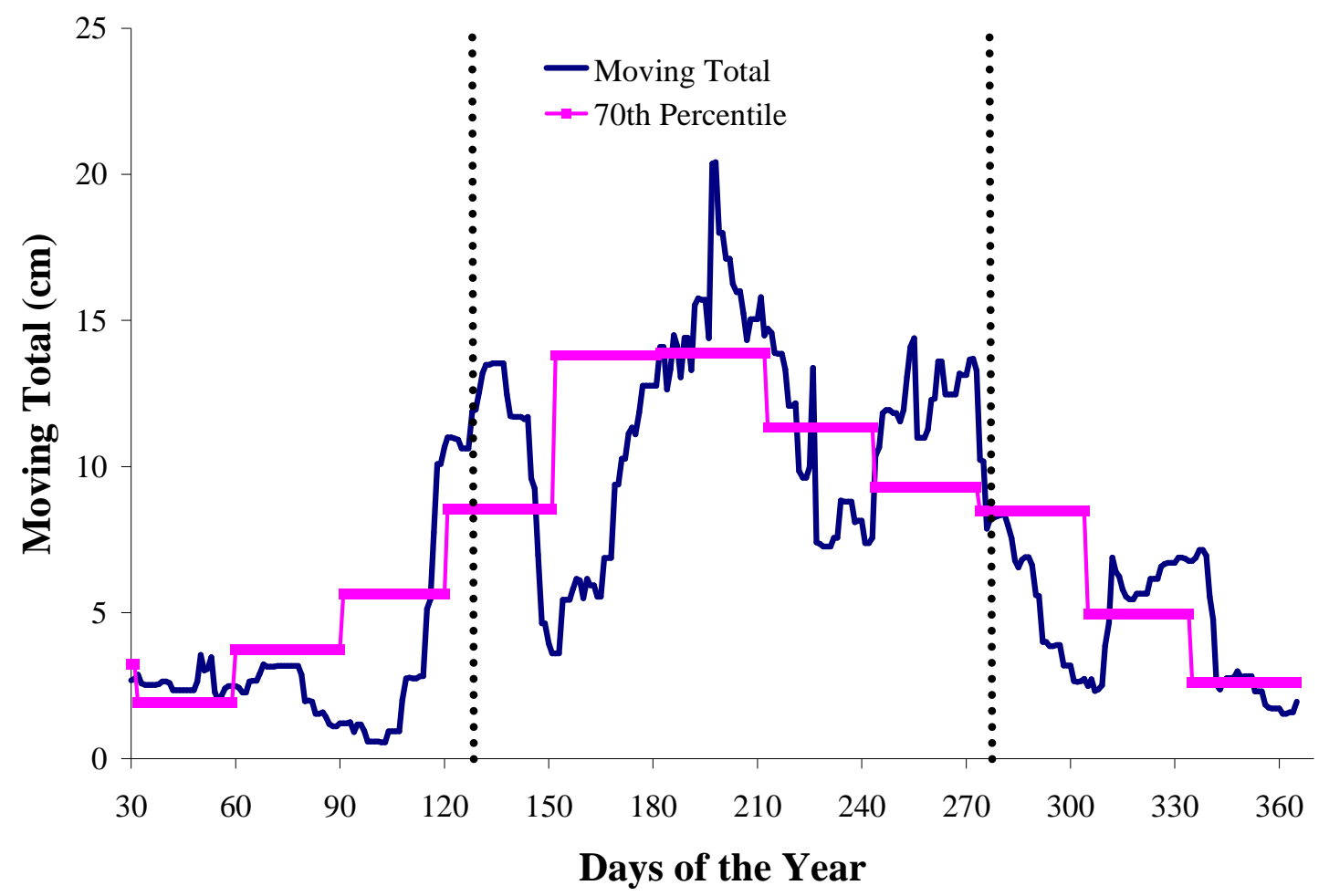

Figure D.155: Moving total graph for plots S4 and S5 at Marcell for year 1986.

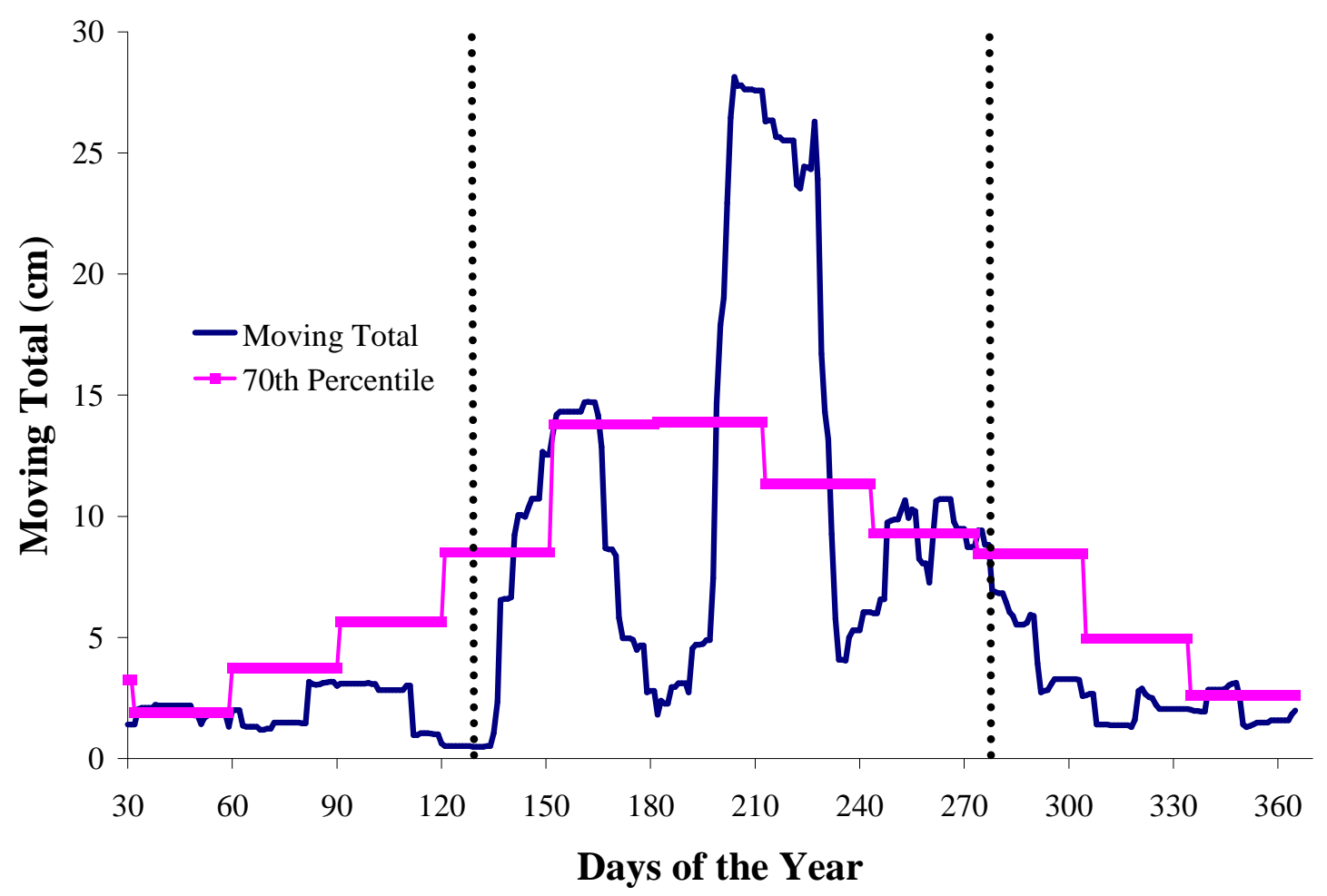

Figure D.156: Moving total graph for plots S4 and S5 at Marcell for year 1987. 


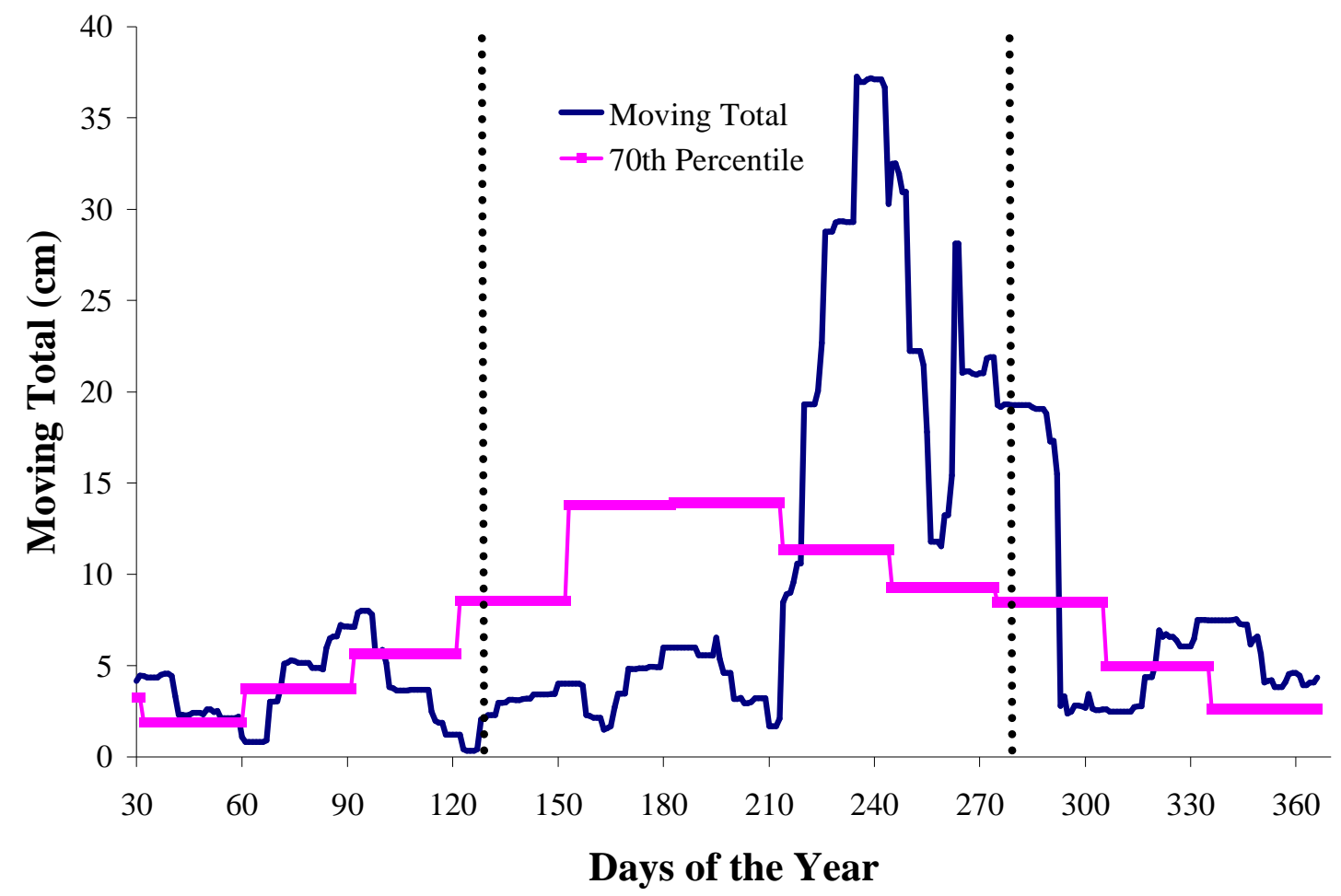

Figure D.157: Moving total graph for plots S4 and S5 at Marcell for year 1988.

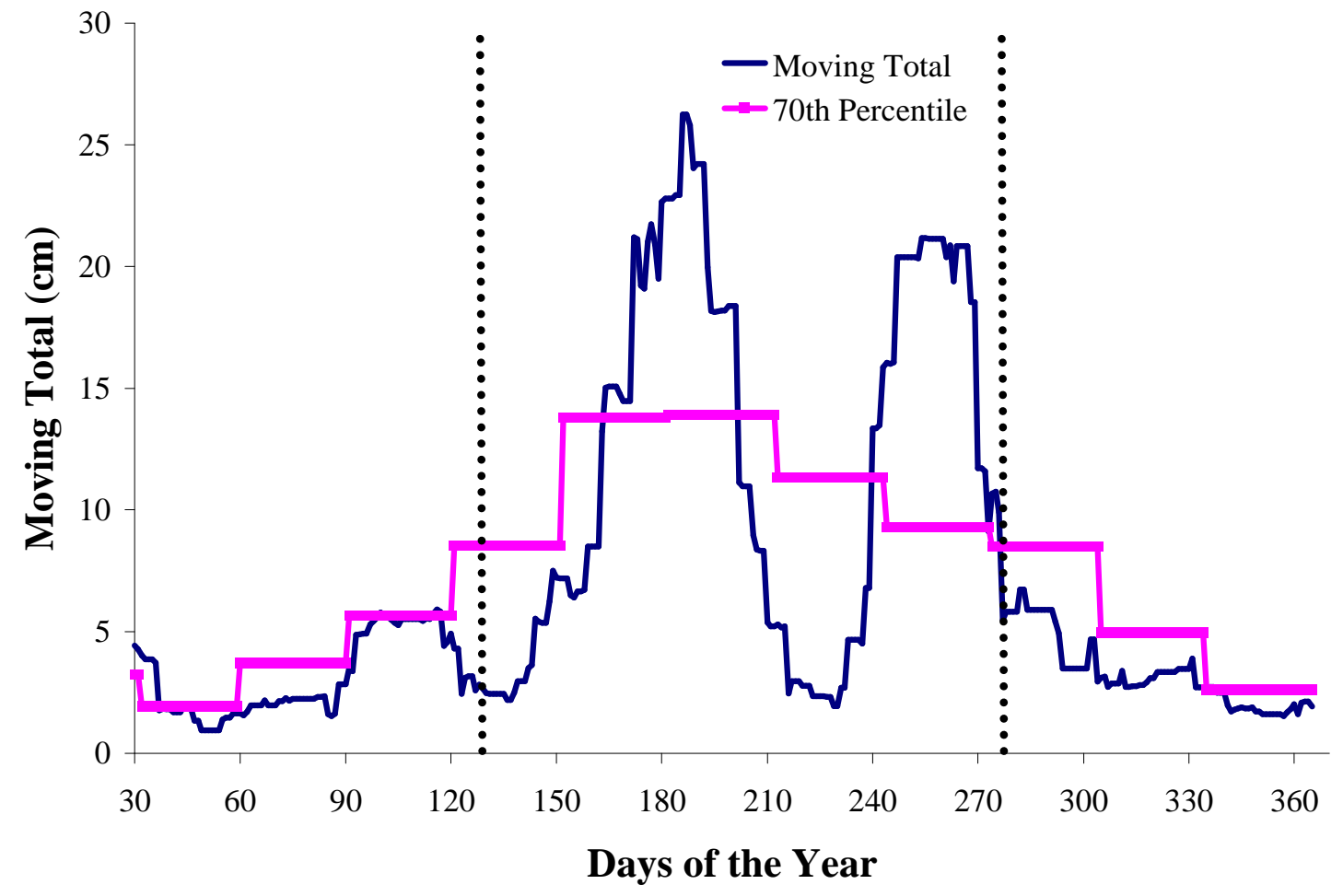

Figure D.158: Moving total graph for plots S4 and S5 at Marcell for year 1989. 


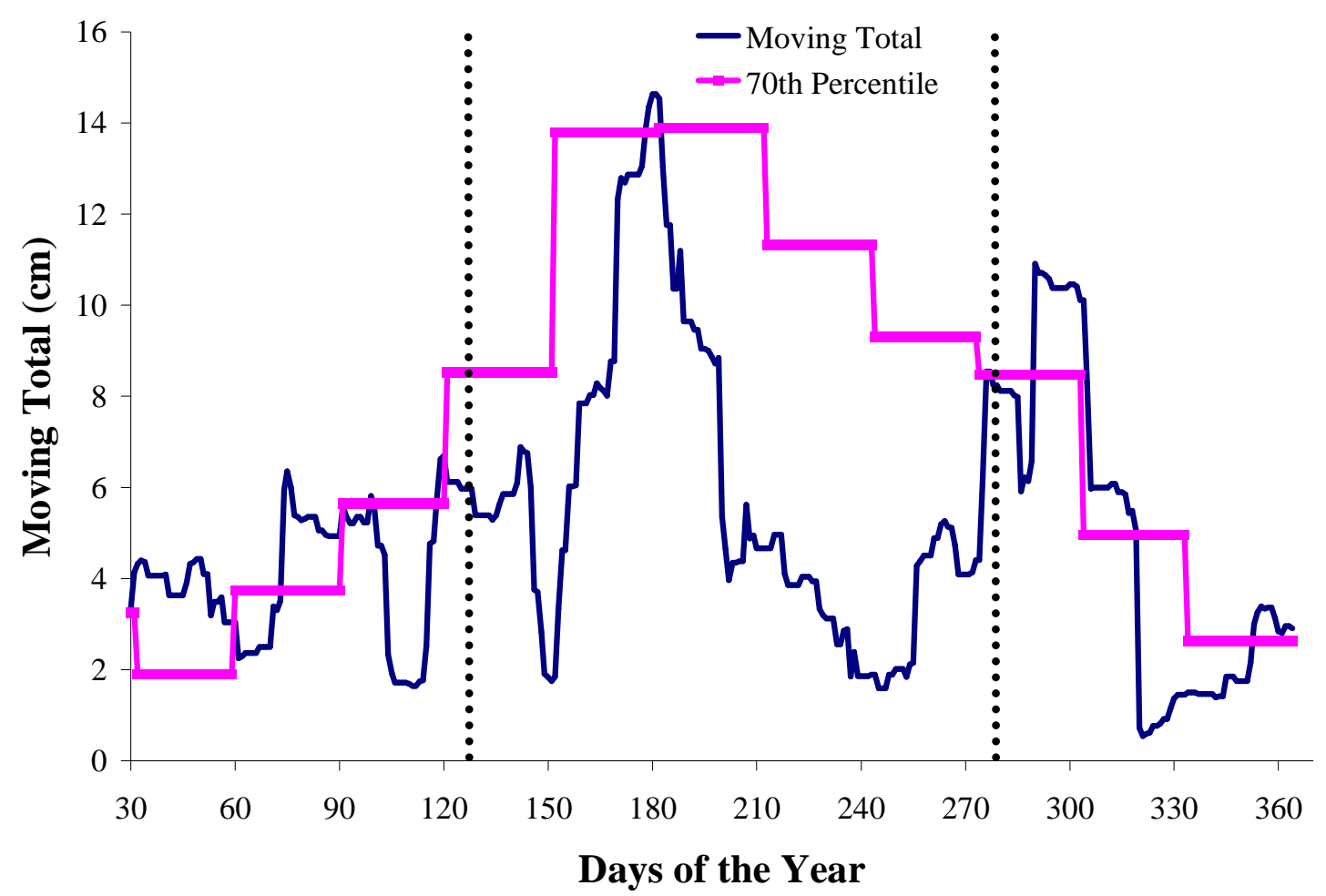

Figure D.159: Moving total graph for plots S4 and S5 at Marcell for year 1990.

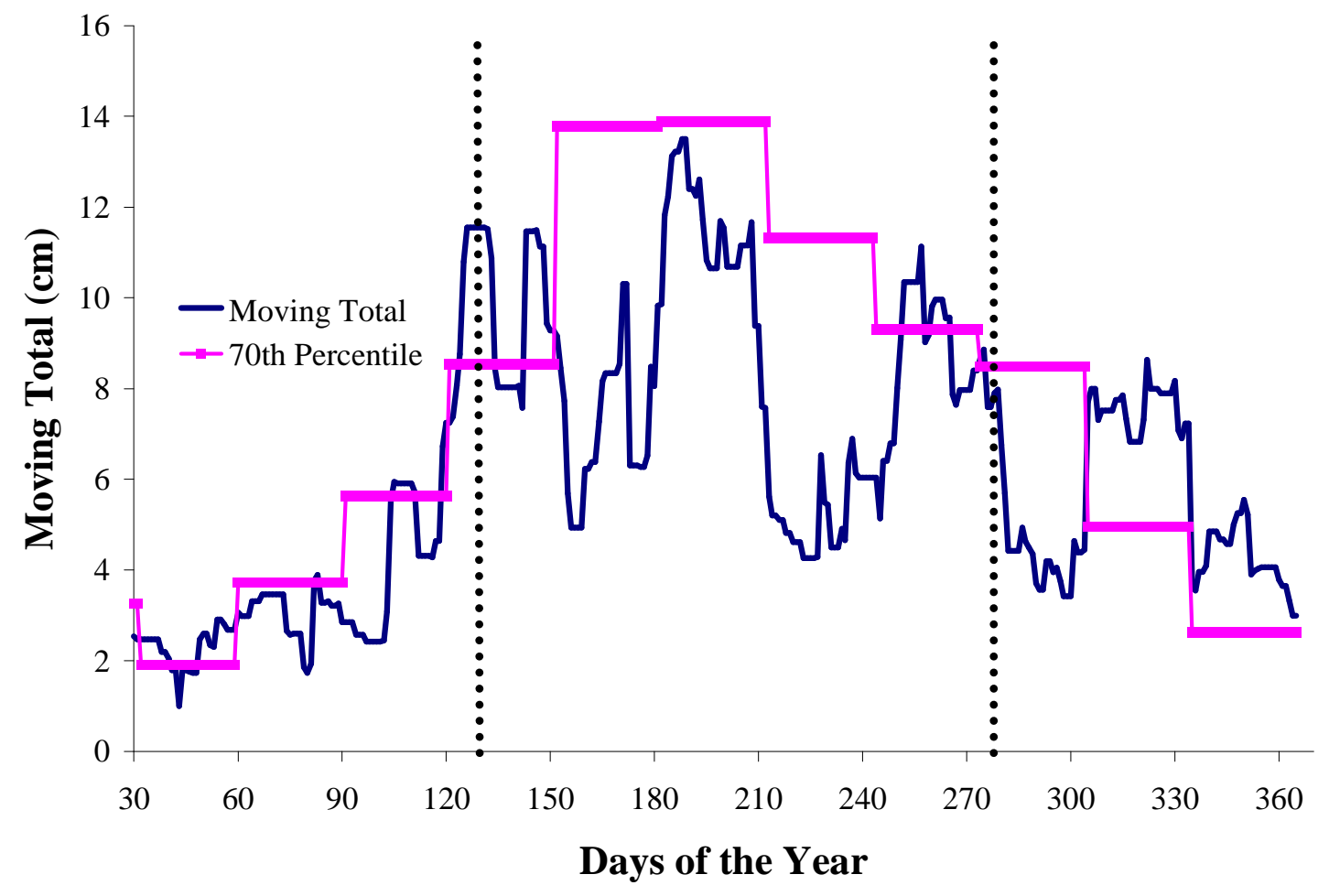

Figure D.160: Moving total graph for plots S4 and S5 at Marcell for year 1991. 


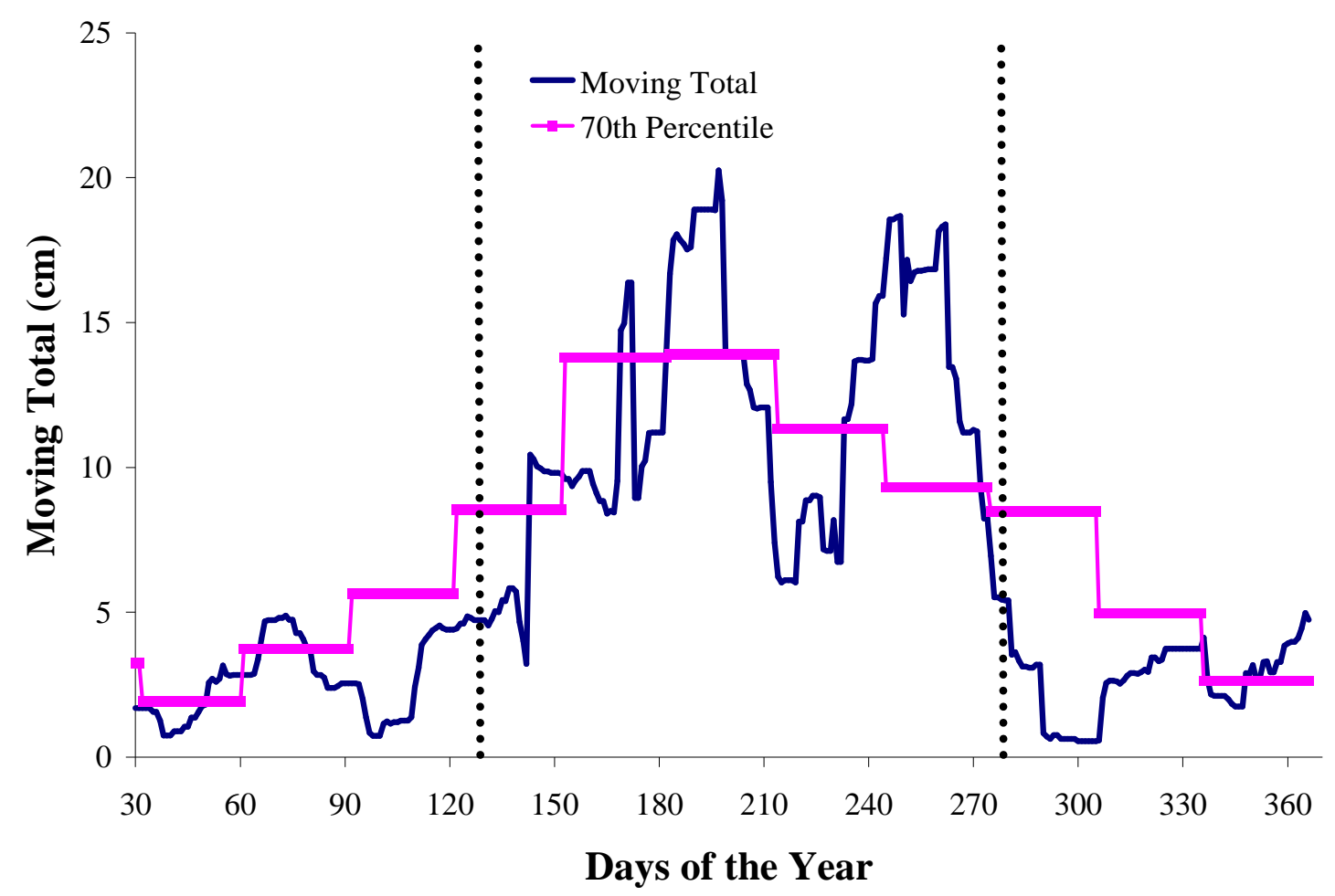

Figure D.161: Moving total graph for plots S4 and S5 at Marcell for year 1992.

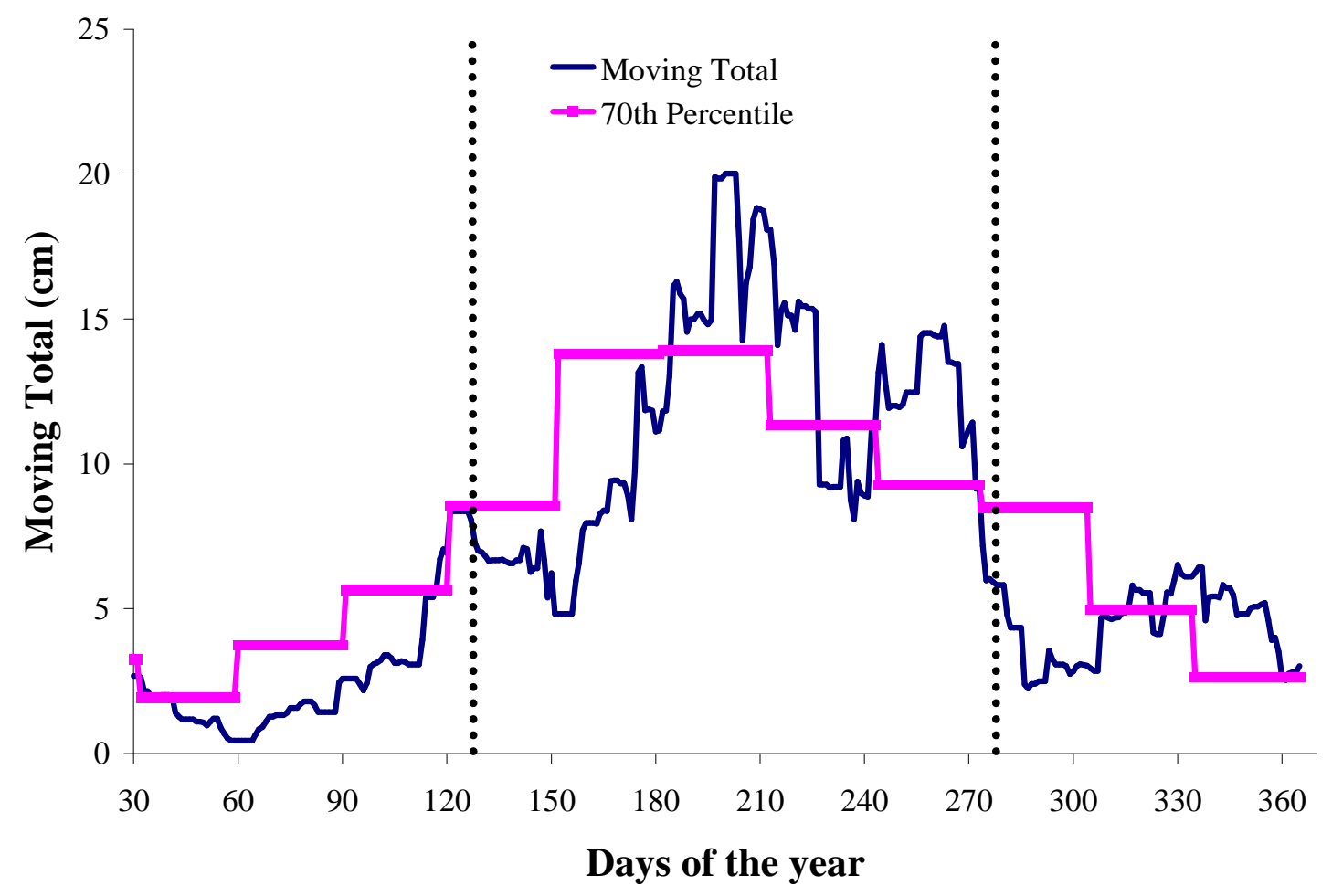

Figure D.162: Moving total graph for plots S4 and S5 at Marcell for year 1993. 


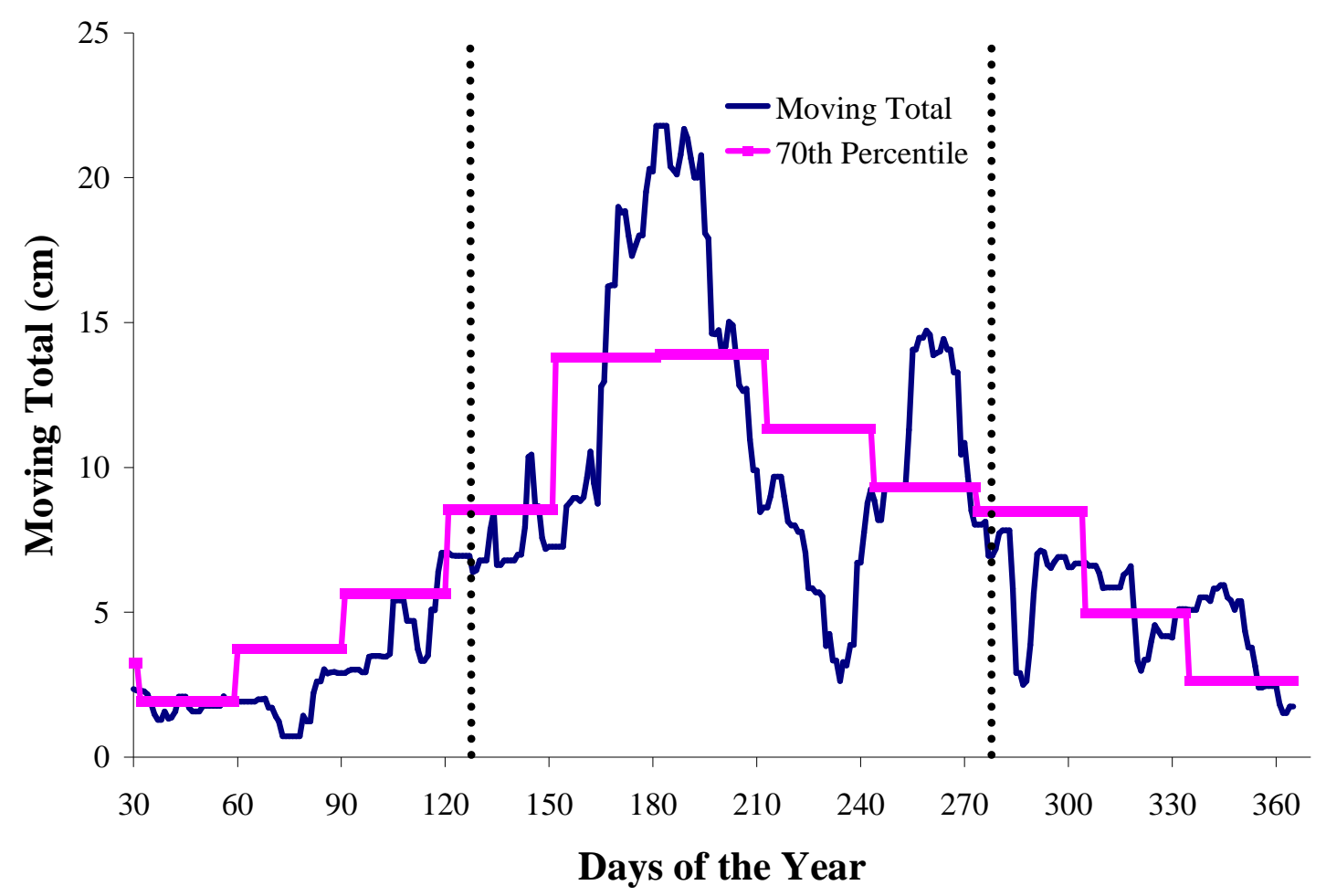

Figure D.163: Moving total graph for plots S4 and S5 at Marcell for year 1994.

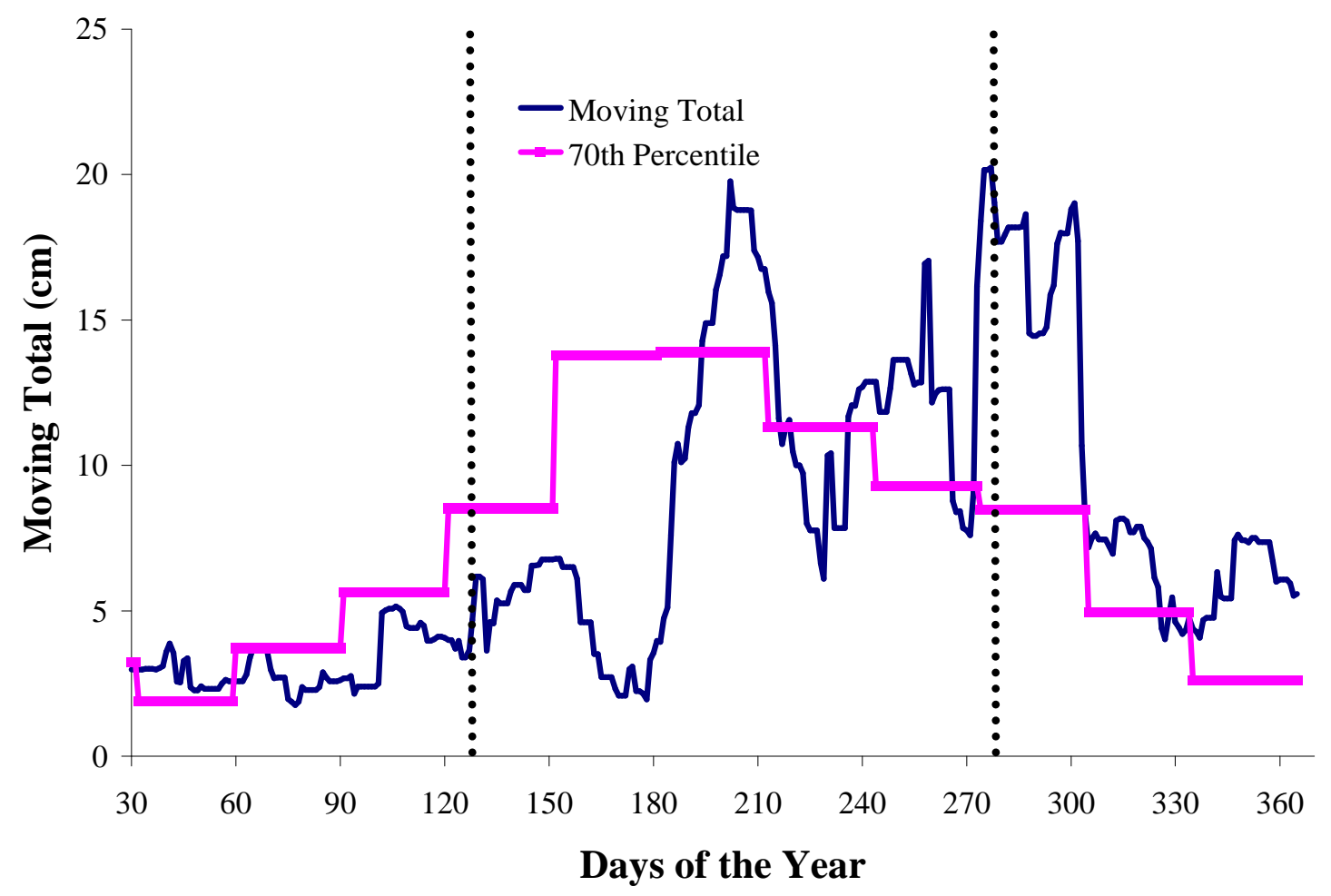

Figure D.164: Moving total graph for plots S4 and S5 at Marcell for year 1995. 


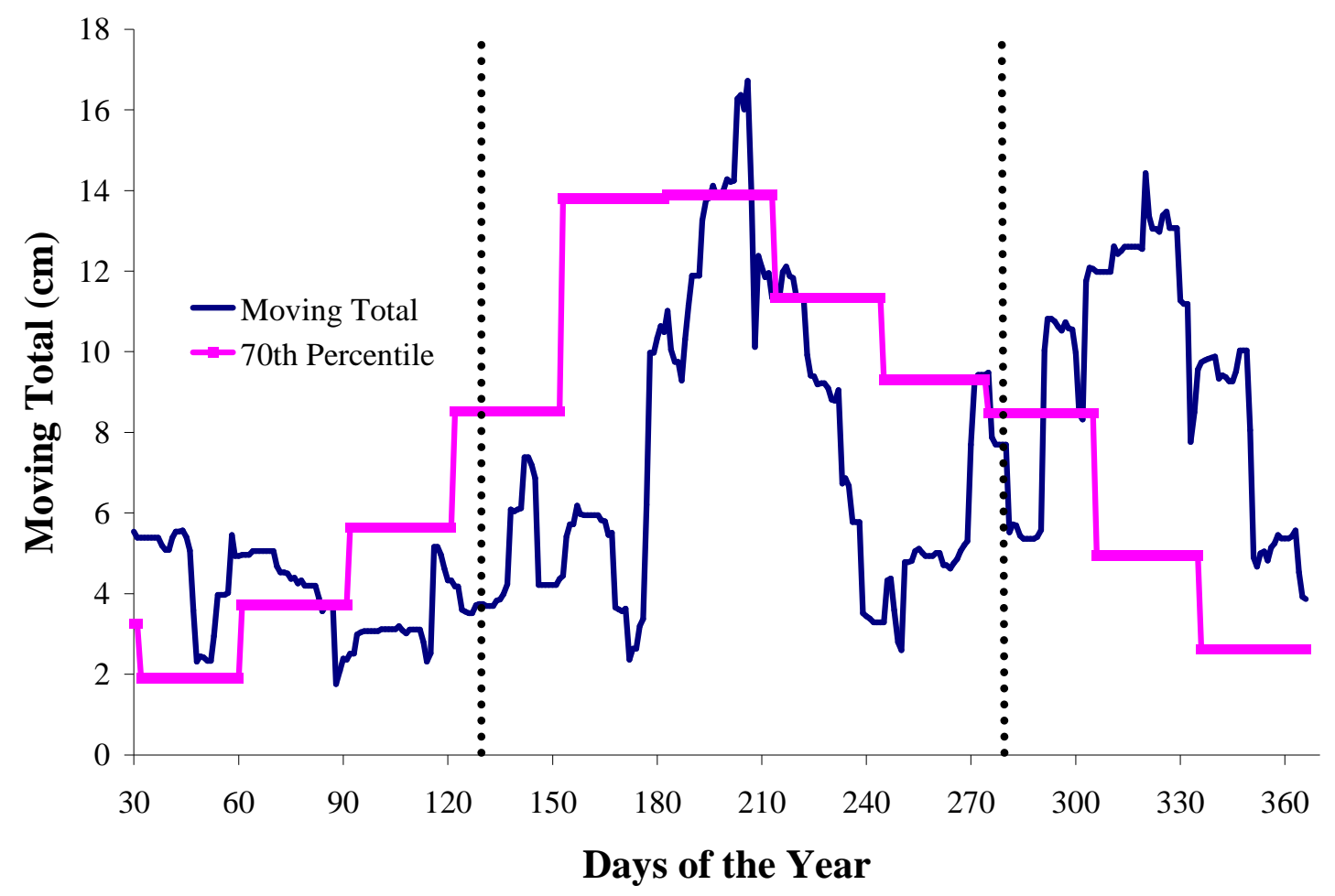

Figure D.165: Moving total graph for plots S4 and S5 at Marcell for year 1996.

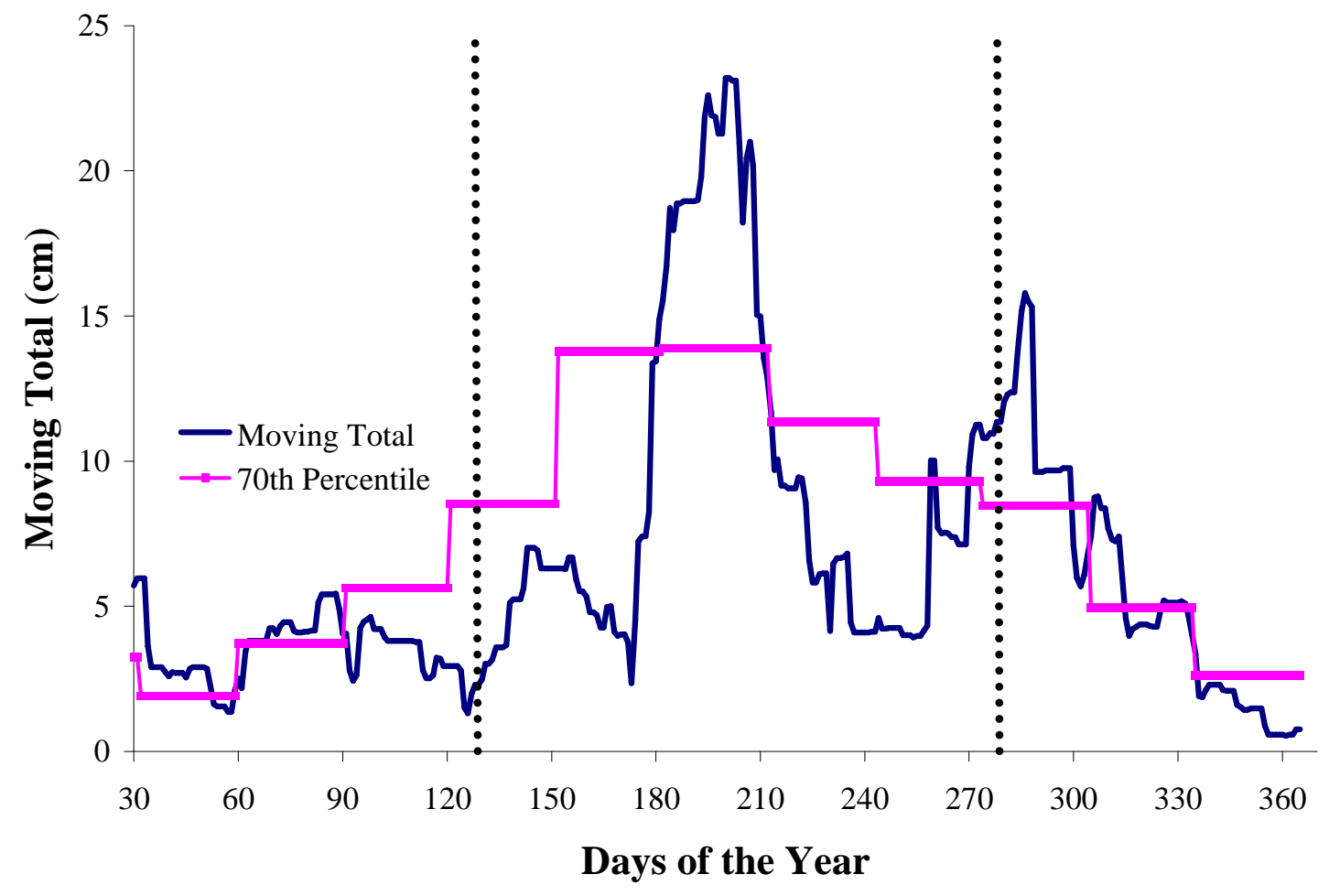

Figure D.166: Moving total graph for plots S4 and S5 at Marcell for year 1997. 


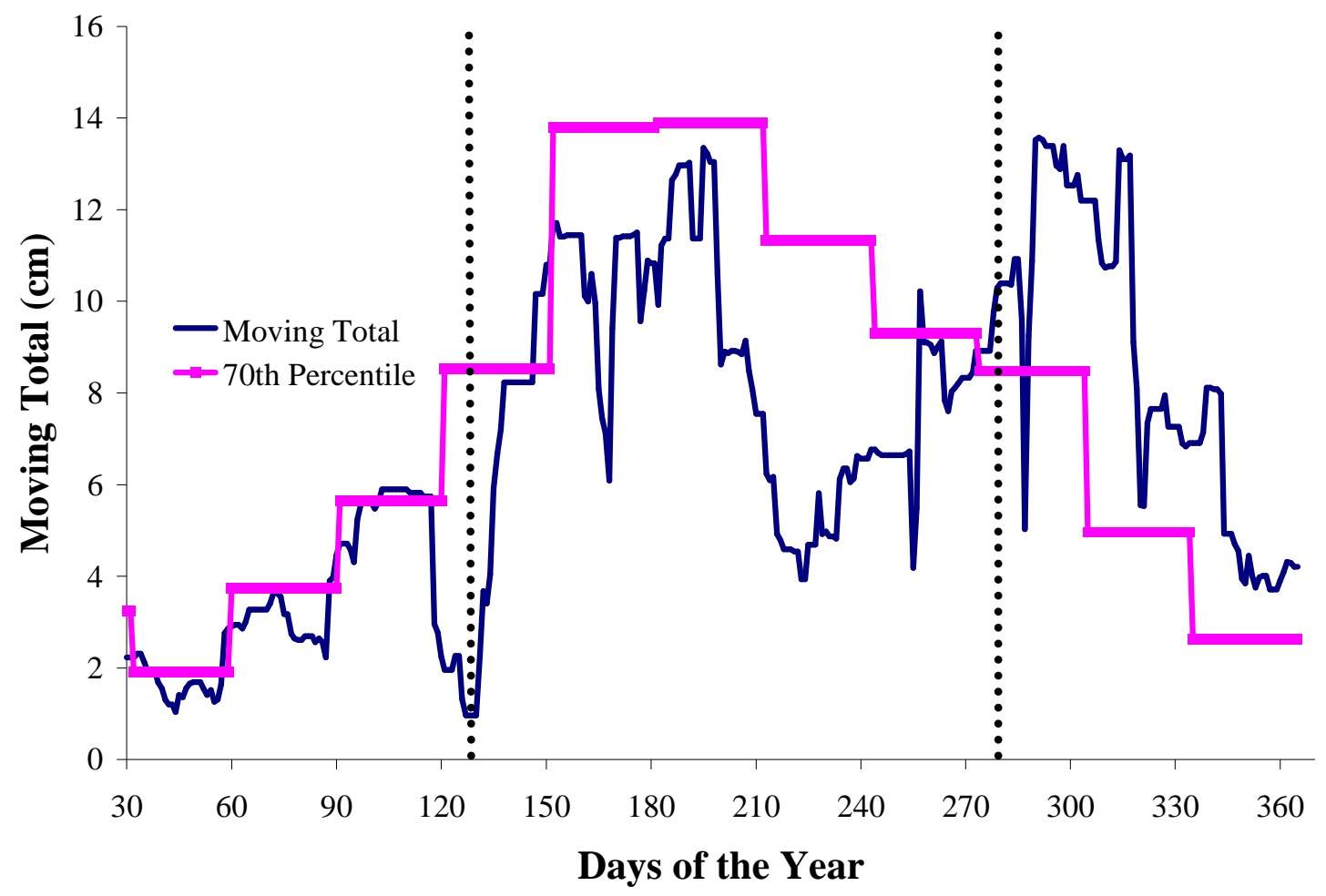

Figure D.167: Moving total graph for plots S4 and S5 at Marcell for year 1998.

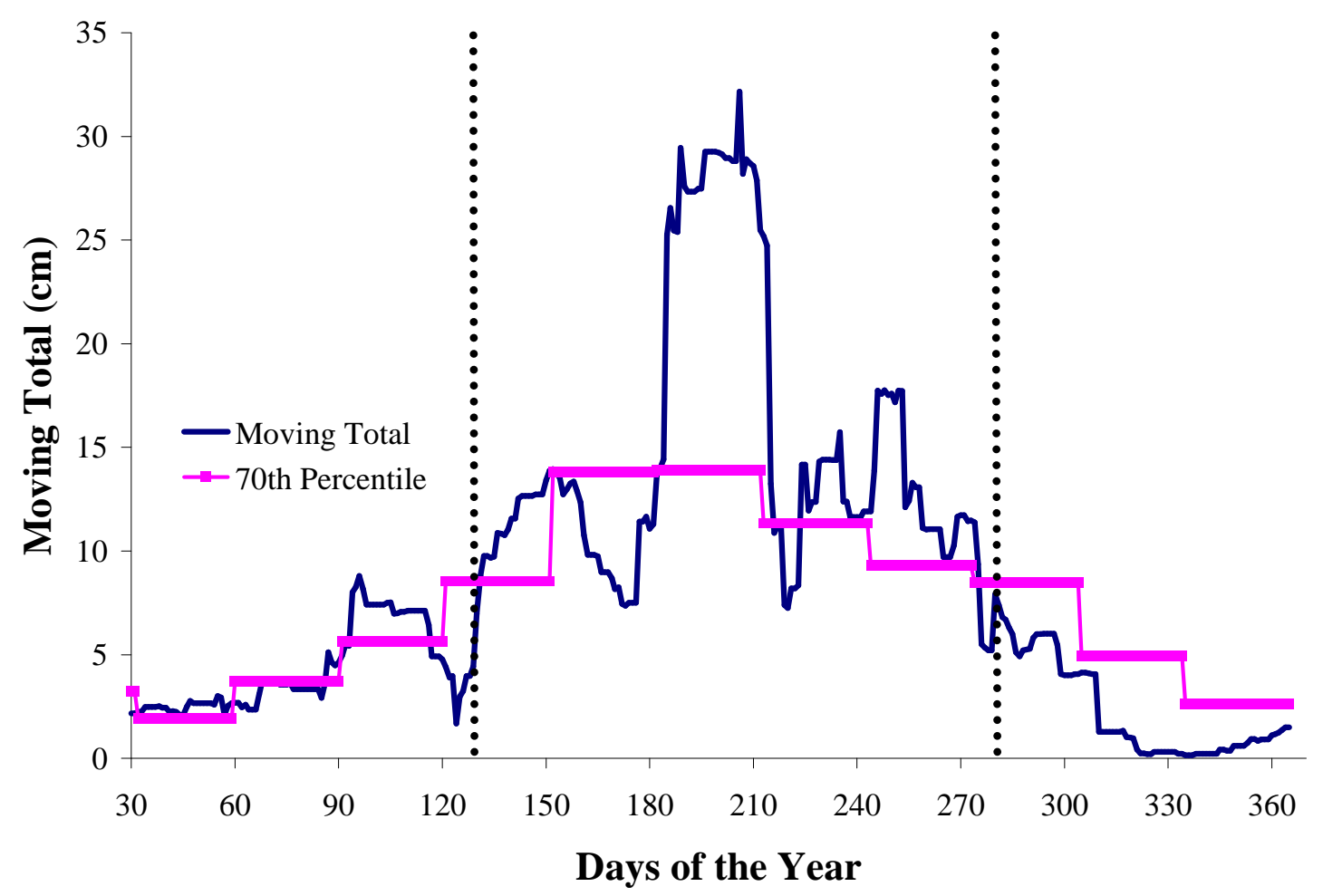

Figure D.168: Moving total graph for plots S4 and S5 at Marcell for year 1999. 


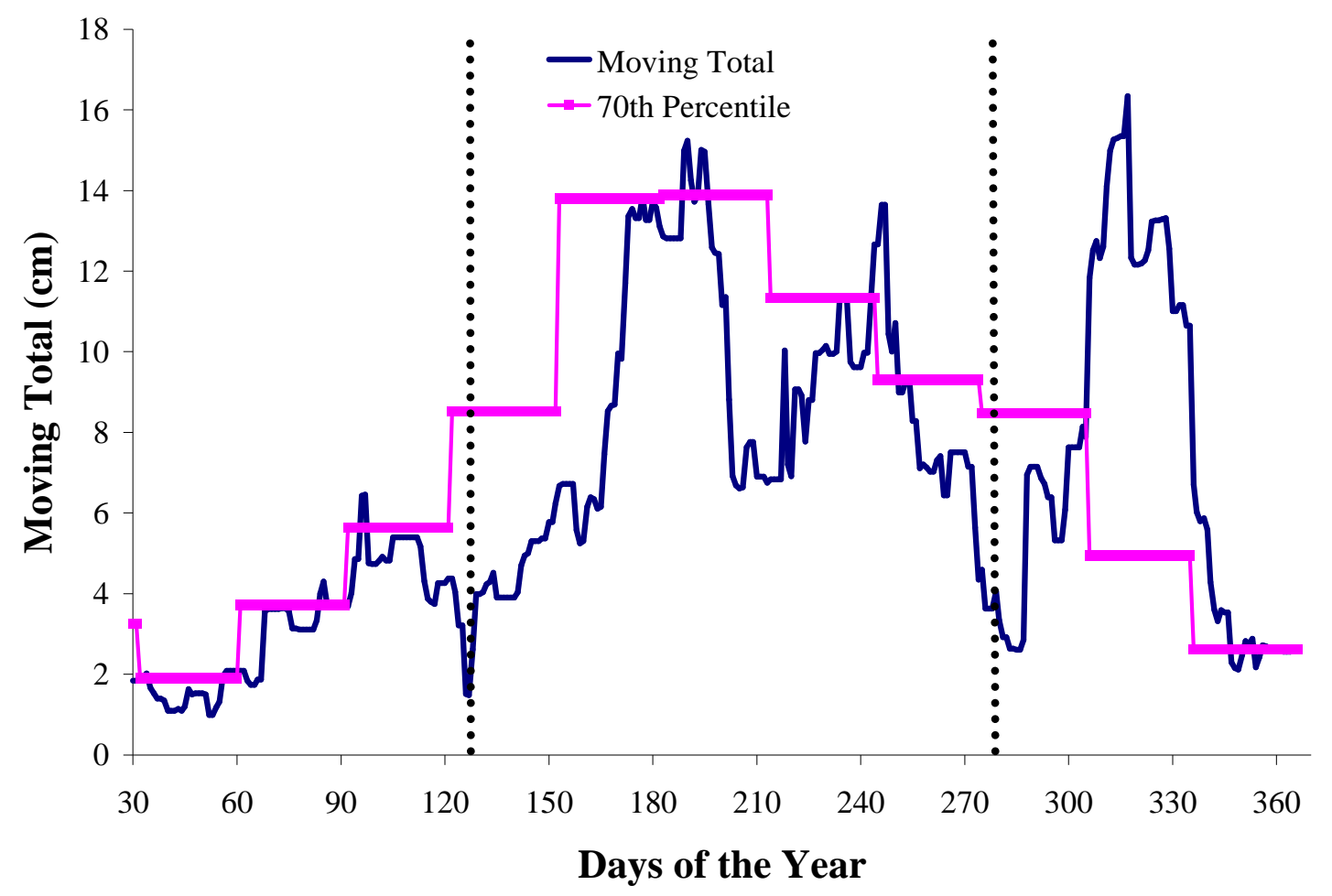

Figure D.169: Moving total graph for plots S4 and S5 at Marcell for year 2000.

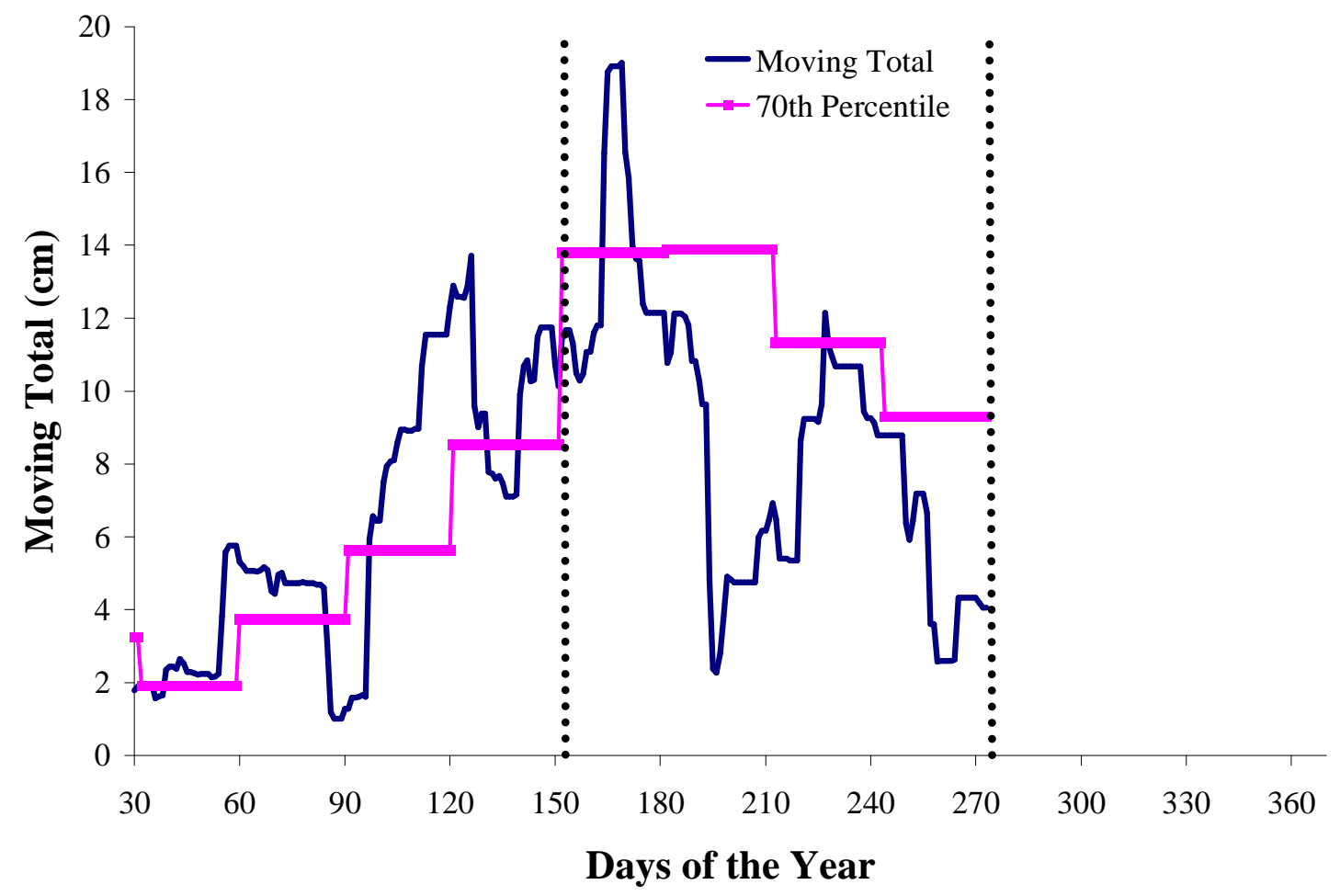

Figure D.170: Moving total graph for plots S4 and S5 at Marcell for year 2001. 


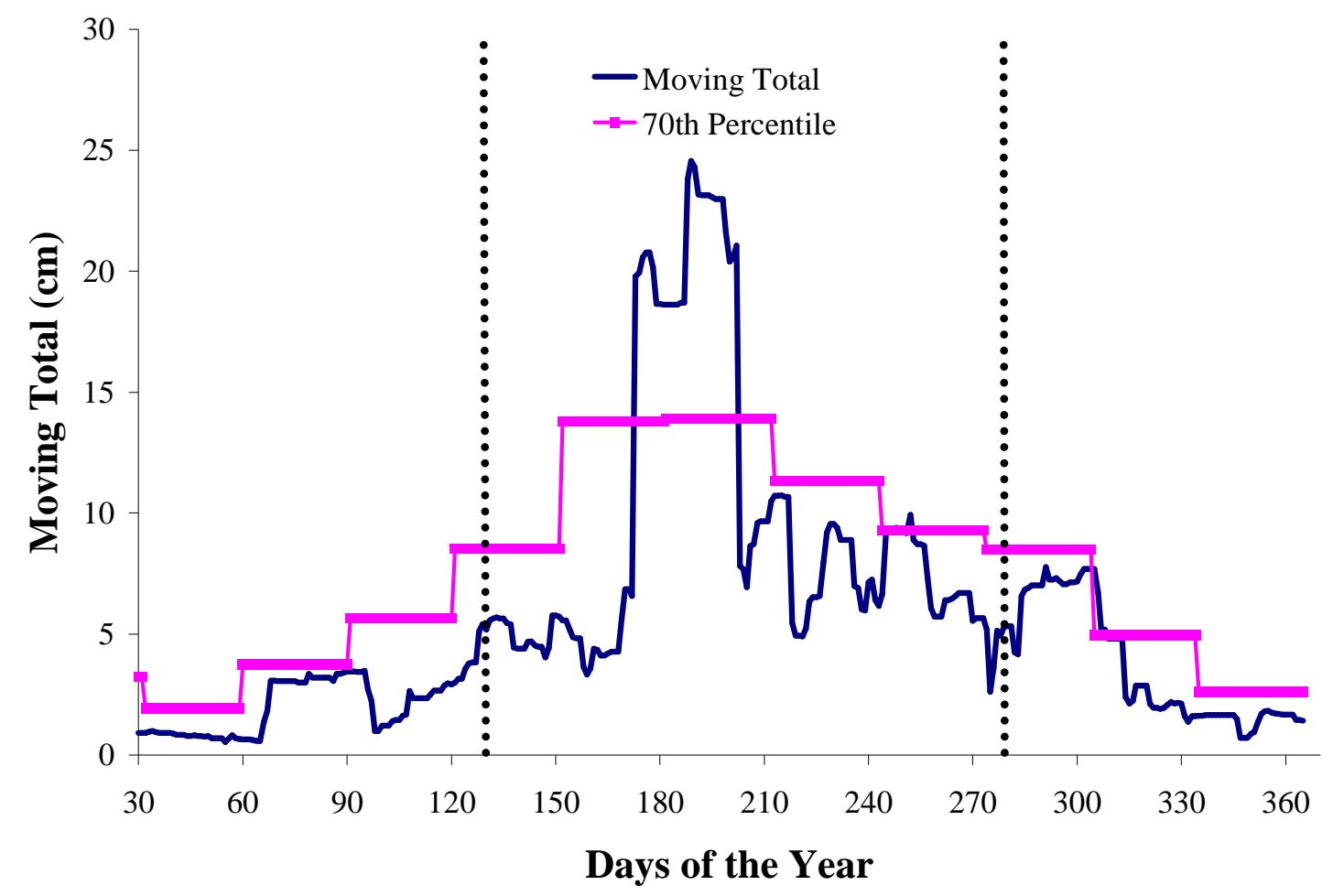

Figure D.171: Moving total graph for plots S4 and S5 at Marcell for year 2002.

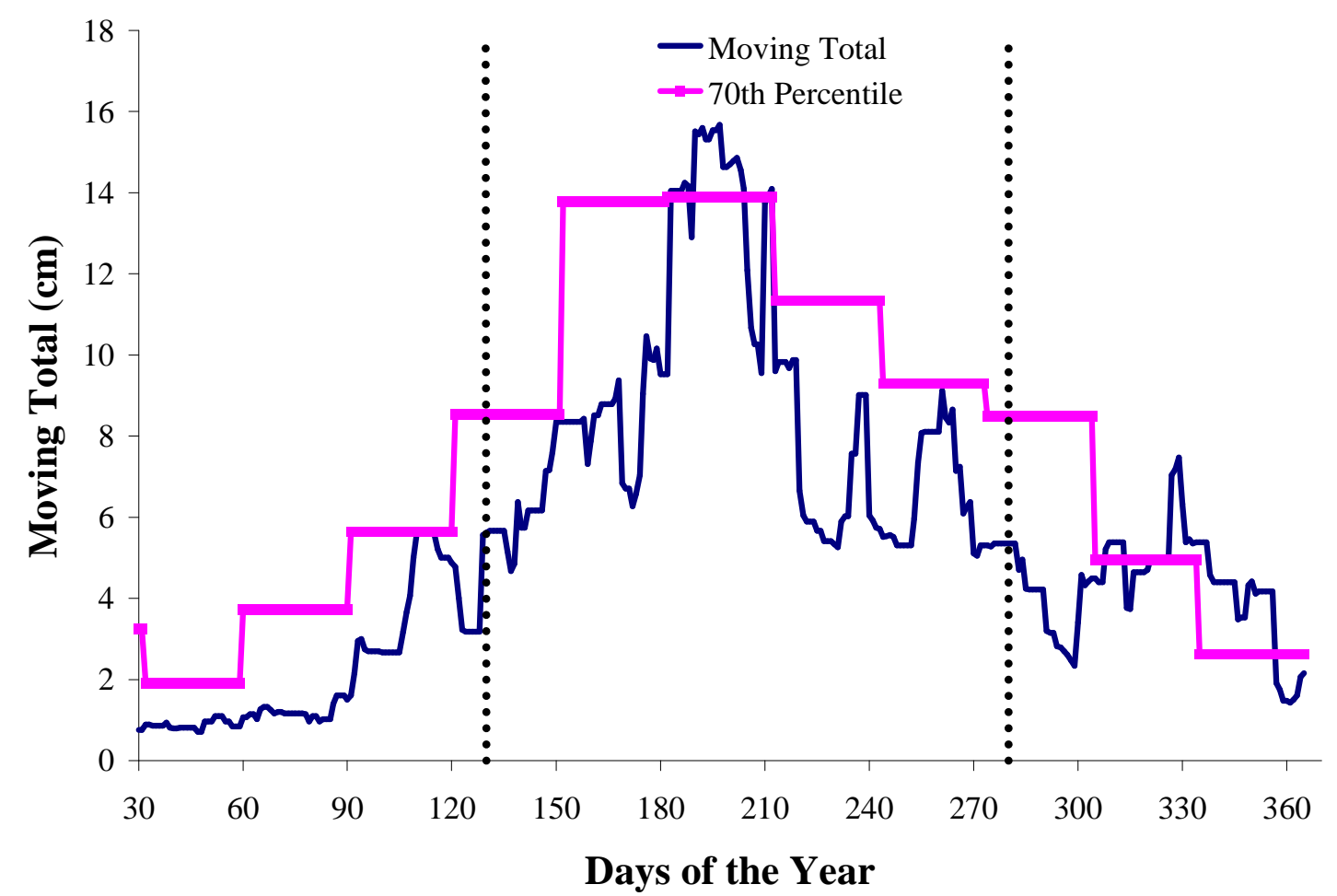

Figure D.172: Moving total graph for plots S4 and S5 at Marcell for year 2003. 


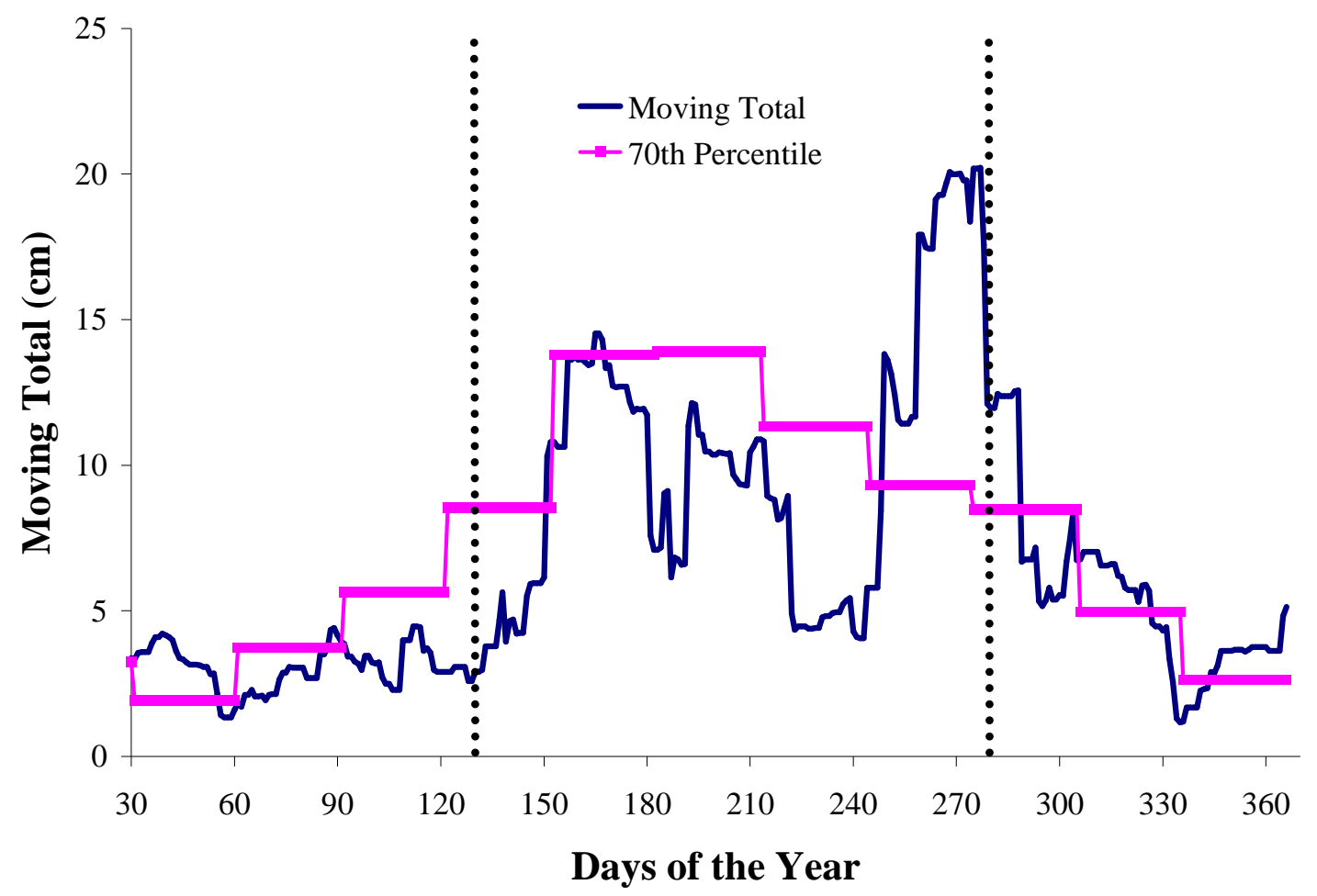

Figure D.173: Moving total graph for plots S4 and S5 at Marcell for year 2004.

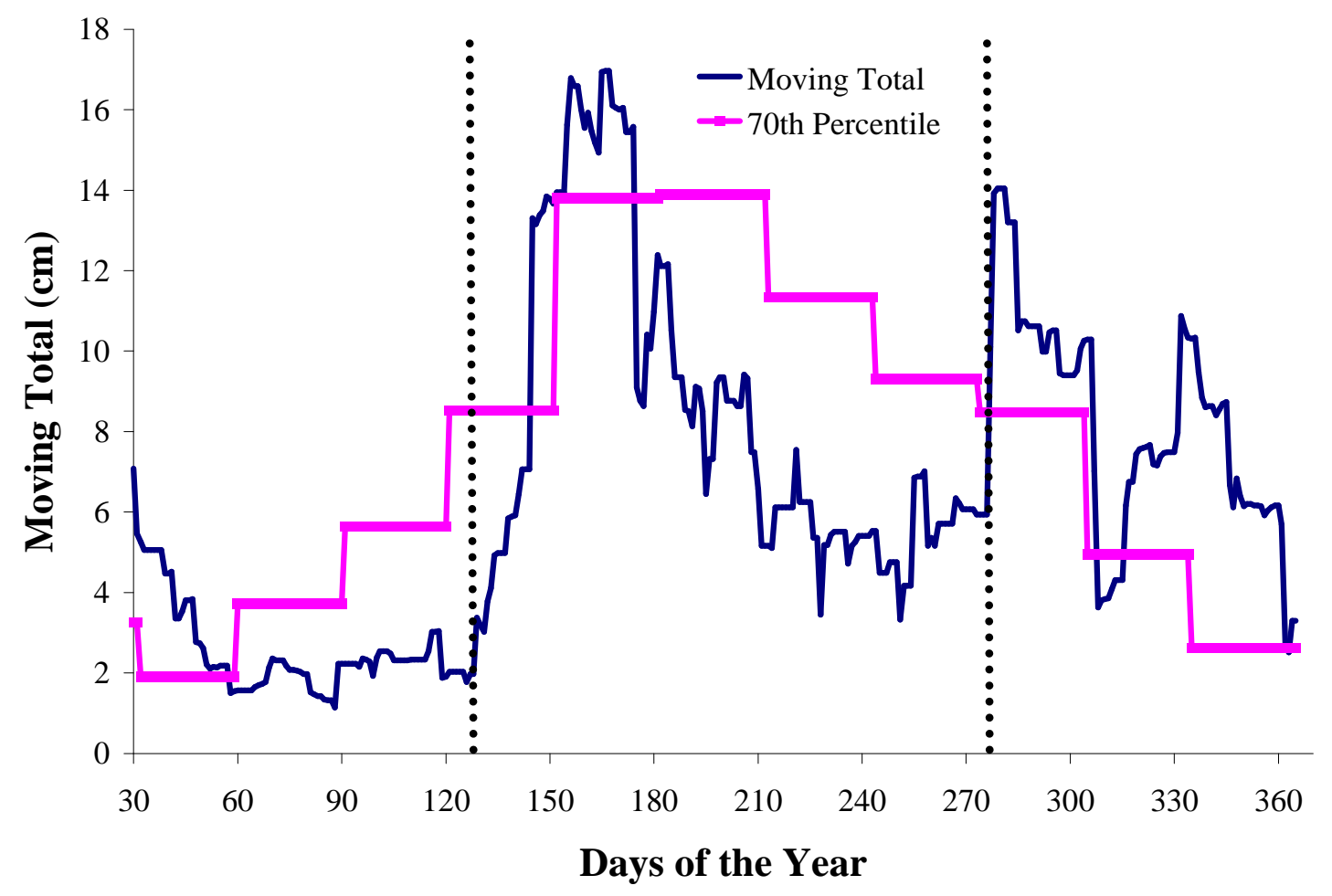

Figure D.174: Moving total graph for plots S4 and S5 at Marcell for year 2005. 